Departamento de Proyectos de Ingeniería

\title{
PROPUESTA METODOLÓGICA PARA LA EVALUACIÓN INTEGRAL DE PROYECTOS EN EL SECTOR ENERGÉTICO
}

\section{TESIS DOCTORAL}

Violeta Parodi de Camargo

DIRECTORES

Dr. Vicente A. Cloquell

Dr. Víctor A. Cloquell

Valencia, Marzo 2013 
A Dios

A María Eugenia, Gustavo y Carolina A María Daniela, Valentina, Sebastián y Catalina

A Tata y Popolo A mi querido hermano Franklin A toda mi familia 


\section{Agradecimientos}

A la Universidad Metropolitana por su soporte en la realización del Doctorado en Proyectos de Ingeniería de la Universidad Politécnica de Valencia, España.

A mi tutor, Dr. Vicente A. Cloquell por su guía y ayuda en los momentos más oportunos.

A mi hijo Gustavo cuyos valiosos consejos y apoyo en el uso de nuevas herramientas computacionales me simplificaron enormemente el trabajo. A Caro y Carlos siempre atentos a echarme una mano cuando la computadora no daba más; y a su amigo, Alfredo, listo a actualizar $\mathrm{mi}$ inventario con nuevos paquetes informáticos y a asistirme en su uso.

A Alicia, María Ángeles y María Blanca, amigas y profesoras de la Universidad Metropolitana, siempre dispuestas a apoyarme. A Geraldine Bustamante y Miguel Granell quienes gentilmente me orientaron en los últimos trámites administrativos en la Universidad Politécnica de Valencia.

A todos mis compañeros de trabajo en la Universidad Metropolitana, a los profesores de la Universidad Simón Bolívar y de la Universidad de Los Andes en Venezuela, a mis profesores de la Universidad Politécnica de Valencia en España, a los directivos de CORPOELEC, a los ejecutivos de la empresa privada y a todos los profesionales jóvenes y menos jóvenes que amablemente dedicaron parte de su tiempo a suministrarme información valiosa en las entrevistas y encuestas realizadas.

A todos los que de alguna forma me prestaron su apoyo para la realización de este trabajo.

A mis hijos, a mis hermanos, a toda mi familia por estar siempre a mi lado, alegres con mis logros y solidarios con mis fracasos, dándome siempre la fortaleza para seguir adelante.

A todos muchas gracias. 


\section{Resumen}

Este trabajo tuvo como objeto el desarrollo de una metodología para la evaluación integral de proyectos en el sector energético. La comparación de diversos métodos de análisis multicriterio permitió seleccionar al Proceso de Jerarquías Analíticas de Saaty como la plataforma metodológica de referencia para la realización del trabajo. Una investigación sobre el sector energético proporcionó una visión de conjunto del mismo y de las características de cada uno de diecinueve tipos de recursos energéticos estudiados. Tomando como punto de partida tales características fue posible seleccionar un grupo de 76 aspectos diferenciadores que podían afectar la priorización de proyectos en el área; éstos fueron reducidos progresivamente a 59, 44 y 24 aspectos principales que se agruparon de acuerdo a su naturaleza, en seis dimensiones: técnica, económica, ambiental, social, estratégica y de riesgo. La reducción se realizó en base a rondas de consulta a expertos, reflexión y al análisis estadístico de las opiniones recabadas. A cada aspecto se asignó un objetivo y un criterio que guiase la evaluación del grado de cumplimiento del primero por parte de un proyecto bajo estudio. Los criterios seleccionados fueron agrupados en una estructura jerárquica de tres niveles y se diseñó un sistema de 24 indicadores de naturaleza cuantitativa y cualitativa, acorde con la misma. Para cada indicador se creó una ficha resumen contentiva de su definición, sus unidades originales de medida, las posibles fuentes de información para su estimación y se creó una escala [1-5] para su medición. Todo el conjunto fue validado de nuevo por académicos y profesionales en una segunda ronda de entrevistas, donde se recogió además información sobre la importancia de cada criterio en comparaciones por pares entre criterios del mismo nivel. La información fue procesada con ayuda de la herramienta computacional Expert Choice ${ }^{\circledR}$ que además permitió verificar la consistencia de la data aportada por cada participante. El producto final de esta etapa del trabajo fue un modelo jerárquico de criterios para la evaluación de propuestas de inversión en el sector energético. En el modelo, la mayor importancia correspondió a la dimensión riesgo $(24,3 \%)$ seguida de las dimensiones ambiental $(20,5 \%)$ y económica (15,9\%). Las dimensiones técnica $(13.7 \%)$, estratégica $(13.5 \%)$ y social $(12.2 \%)$ tuvieron importancias relativas menores.

El modelo de valor diseñado se utilizó conjuntamente con técnicas de programación lineal en la evaluación de posibles soluciones al suministro de energía eléctrica en Venezuela, ante la crisis que vive el país y que tuvo su máxima expresión en el año 2010. El objetivo a cumplir se estableció como el diseño de una matriz eléctrica a implementar a lo largo del período 20112025, basada en los potenciales desarrollables de cada fuente energética que posee el país y en su demanda estimada; y sujeta a las limitaciones financieras de la nación y a los 
compromisos y convenios internacionales que la misma ha suscrito. Para su uso como insumo a la resolución del problema, se proyectó la demanda eléctrica del país al período señalado, en tres escenarios que difieren en el crecimiento económico esperado. Nueve opciones correspondientes respectivamente a la utilización de derivados de petróleo, gas, carbón, biomasa, energía nuclear y, potencial hidráulico, eólico, solar y geotérmico como insumo energético primario a la generación eléctrica, fueron evaluadas de acuerdo con el modelo de valor diseñado. La información de fuentes oficiales requerida para la estimación de los indicadores de índole cuantitativa para cada alternativa, resultó escasa y no consistente; de esta forma gran parte de la data utilizada fue obtenida de publicaciones internacionales y de expertos en el sector privado del país. Una tercera ronda de entrevistas a expertos en el sector público y privado, proporcionó la información necesaria para la estimación de los indicadores de índole cualitativa. La consolidación de la información en un coeficiente de robustez para cada alternativa permitió identificar a la opción eólica como la mejor opción, seguida de la generación hidráulica y de la generación basada en gas. La generación nuclear resultó por mucho, la peor opción.

Los coeficientes de robustez obtenidos fueron insumo a un modelo de programación lineal cuya resolución permitió identificar la 'mejor combinación' de las potenciales opciones de generación a instalar entre las evaluadas en el paso anterior, que se ajustase a las condiciones existentes en el país. Un análisis de sensibilidad de los resultados a cambios en las restricciones impuestas al modelo, rindió dos soluciones que difieren sólo en la participación o no, de la opción nuclear en ellas. Ambas, incluyen la opción hidráulica mayoritariamente ( $\geq$ $32 \%$ ) y una contribución de un $15 \%$ de energía eólica, además de las opciones de petróleo, gas y carbón. Cada una de ellas, de implementarse, es capaz de añadir 120.000 GWh al suministro eléctrico al país, para el año 2025. La capacidad de generación a instalar durante el período 2013-2025, se acerca a 28 GW; y el presupuesto necesario para ejecutarla, a 65 mil millones de US\$; y entre 1,5 y 2 veces esta cifra, si se incluye la adecuación de la red para distribuir la electricidad producida. La puesta en marcha de la matriz eléctrica total para el país producirá unos 260.000 GWh para el año 2025, tendrá una participación $\geq 45 \%$ de energía hidráulica y una contribución de un $6,9 \%$ de energía eólica. Se estima que se requiere un período de al menos 5 años para disponer de las primeras nuevas centrales eléctricas.

Finalmente, se propuso una metodología combinada para la evaluación multicriterio de alternativas de inversión institucional, técnica, económica y ambientalmente viables en el sector energético. Sí las alternativas son excluyentes, resultará suficiente para su evaluación y ordenamiento la aplicación del modelo jerárquico diseñado; si no es así, esta primera etapa debe completarse con el planteamiento de un modelo de programación lineal que maximice la robustez de la solución y la acerque más a las circunstancias propias del país sede. 


\section{Resum}

Este treball va tindre com a objecte el desenrotllament d'una metodologia per a l'avaluació integral de projectes en el sector energètic. La comparació de diversos mètodes d'anàlisi multicriteri va permetre seleccionar el Procés de Jerarquies Analítiques de Saaty com la plataforma metodològica de referència per a la realització del treball. Una investigació sobre el sector energètic va proporcionar una visió de conjunt del mateix i de les característiques de cada un dels dèneu tipus de recursos energètics estudiats. Prenent com a punt de partida tals característiques va ser possible seleccionar un grup de 76 aspectes diferenciadors que podien afectar la priorització de projectes en l'àrea; estos van ser reduïts progressivament a 59, 44 i 24 aspectes principals que es van agrupar d'acord amb la seua naturalesa, en sis dimensions: tècnica, econòmica, ambiental, social, estratègica i de risc. La reducció es va realitzar basantse en rondes de consulta a experts, reflexió i a l'anàlisi estadística de les opinions demanades. A cada aspecte es va assignar un objectiu i un criteri que guiara l'avaluació del grau de compliment del mateix per part d'un projecte baix estudi. Els criteris seleccionats van ser agrupats en una estructura jeràrquica de tres nivells i es va dissenyar un sistema de 24 indicadors de naturalesa quantitativa i qualitativa, d'acord amb la mateixa. Per a cada indicador es va crear una fitxa resum contentiva de la seua definició, les seues unitats originals de mesura, les possibles fonts d'informació per a la seua estimació i una escala [1-5] per al seu mesurament. Tot el conjunt va ser validat de nou per acadèmics i professionals en una segona ronda d'entrevistes, on es va arreplegar a més informació sobre la importància de cada criteri en comparacions per parelles entre criteris del mateix nivell. La informació va ser processada amb ajuda de la ferramenta computacional Expert Choice $\Re$ que a més va permetre verificar la consistència de la data aportada per cada participant. El producte final d'esta etapa del treball va ser un model jeràrquic de criteris per a l'avaluació de propostes d'inversió en el sector energètic. En el model, la major importància va correspondre a la dimensió risc $(24,3 \%)$ seguida de les dimensions ambiental $(20,5 \%)$ i econòmica $(15,9 \%)$. Les dimensions tècnica $(13.7 \%)$, estratègica $(13.5 \%)$ i social $(12.2 \%)$ van tindre importàncies relatives menors i semblants entre si.

El model de valor dissenyat es va utilitzar conjuntament amb tècniques de programació lineal en l'avaluació de possibles solucions al subministrament d'energia elèctrica a Veneçuela, davant de la crisi que viu el país i que va tindre la seua màxima expressió l'any 2010. L'objectiu a complir es va establir com el disseny d'una matriu elèctrica a implementar al llarg del període 2011-2025, basada en els potencials desenrotllables de cada font energètica que posseïx el país i en la seua demanda estimada; i subjecta a les limitacions financeres de la 
nació $\mathrm{i}$ als compromisos i convenis internacionals que la mateixa ha subscrit. Per al seu ús com insumo a la resolució del problema, es va projectar la demanda elèctrica del país al període assenyalat, en tres escenaris que diferixen en el creixement econòmic esperat. Nou opcions corresponents respectivament a la utilització de derivats de petroli, gas, carbó, biomassa, energia nuclear $i$, potencial hidràulic, eòlic, solar i geotèrmic com insumo energètic primari a la generació elèctrica van ser avaluades, d'acord amb el model de valor dissenyat. La informació de fonts oficials requerida per a l'estimació dels indicadors d'índole quantitativa per a cada alternativa, va resultar escassa i no consistent; d'esta manera gran part de la data utilitzada va ser obtinguda de publicacions internacionals i d'experts en el sector privat del país. Una tercera ronda d'entrevistes a experts en el sector públic i privat, va proporcionar la informació necessària per a l'estimació dels indicadors d'índole qualitativa. La consolidació de la informació en un coeficient de robustesa per a cada alternativa va permetre identificar a l'opció eòlica com la millor opció, seguida de la generació hidràulica i de la generació basada en gas. La generació nuclear va resultar per molt, la pitjor opció.

Els coeficients de robustesa obtinguts van ser insumo per a un model de programació lineal la resolució del qual va permetre identificar la 'millor combinació' de les potencials opcions de generació a instal-lar entre les avaluades en el pas anterior, que s'ajustara a les condicions existents en el país. Una anàlisi de sensibilitat dels resultats a canvis en les restriccions imposades al model, va rendir dos solucions que diferixen només en la participació o no, de l'opció nuclear en elles. Ambdós, inclouen l'opció hidràulica majoritàriament (> 32\%) i una contribució d'un 15\% d'energia eòlica, a més de les opcions de petroli, gas i carbó. Cada una d'elles, d'implementar-se, és capaç d'afegir $120.000 \mathrm{GWh}$ al subministrament elèctric al país, per a l'any 2025. La capacitat de generació a instal-lar durant el període 2013-2025, s'acosta a 28 GW; i el pressupost necessari per a executar-la, a 65 mil milions d'US\$; i entre 1,5 i 2 vegades esta xifra, si s'inclou l'adequació de la xarxa per a distribuir l'electricitat produïda. La posada en marxa de la matriu elèctrica total per al país produirà uns 260.000 GWh per a l'any 2025, tindrà una participació > 45\% d'energia hidràulica i una contribució d'un 6,9\% d'energia eòlica. S'estima que es requerix un període del menys 5 anys per a disposar de les primeres noves centrals elèctriques.

Finalment, es va proposar una metodologia combinada per a l'avaluació multicriteri d'alternatives d'inversió institucional, tècnica, econòmica i ambientalment viables en el sector energètic. Si les alternatives són excloents, resultarà suficient per a la seua avaluació i ordenament l'aplicació del model jeràrquic dissenyat; si no és així, esta primera etapa ha de completar-se amb el plantejament d'un model de programació lineal que maximitze la robustesa de la solució i l'acoste més a les circumstàncies pròpies del país seu. 


\section{Abstract}

This study was aimed at developing a methodology for comprehensive evaluation of projects in the energy sector. Comparison of different multicriteria analysis methods allowed to select the Saaty's Analytical Hierarchy Process as the methodological reference for the work. An investigation into the energy sector provided the characteristics of nineteen examined types of energy resources. This information was the basis to select a group of 76 distinctive aspects that could affect the prioritization of projects in the area. These were reduced progressively to 59, 44 and 24 main aspects that were grouped in six dimensions according to their nature: technical, economic, environmental, social, strategic and risk. Reflection and the statistical analysis of information collected in interviews with experts allowed this reduction.

An objective and a criteria were assigned to each selected aspect to evaluate the degree to which the project complies with said objective. The criteria were grouped into a three-level hierarchical structure arranged as a system of 24 qualitative/quantitative indicators. A summary sheet was created for each indicator containing the definition, the original measurement units, the possible sources of information for its estimation and a scale [1-5] for its measurement. The entire set was again validated by academics and professionals in a second series of interviews, which also collected information on the relative importance of each criterion. The data was processed using the Expert Choice ${ }^{\circledR}$ tool that also verified the consistency of the data provided by each participant. The final product of this phase was a hierarchical model of criteria for evaluating investment proposals in the energy sector. In the resulting model, the biggest importance corresponded to the risk $(24.3 \%)$ environmental $(20.5 \%)$ and cost $(15.9 \%)$ dimensions. The technical $(13.7 \%)$, strategic $(13.5 \%)$ and social $(12.2 \%)$ dimensions had lower relative importance.

The hierarchical model obtained was combined with linear programming techniques for the evaluation of possible solutions to Venezuela's electrical power crisis that had its peak in 2010. The objective was to find the best electrical grid to implement over the period 2011-2025, based on the potential of each energy source in the country and in its estimated demand, and subject to financial constraints and international commitments and agreements that the nation has signed. The electricity demand for the stated period was projected in three scenarios only differing by the expected country's economic growth. Oil, gas, coal, biomass, water resources, nuclear energy, wind and, solar and geothermal potentials were evaluated as primary energy input to electricity generation according to the designed value model. The information from 
official sources was poor and not consistent, in this way much of the data used to estimate the quantitative indicators was obtained from international publications and experts working in the private sector of the country. A third series of interviews with experts in the public and private sectors, provided the information needed for estimation of the qualitative indicators. The data obtained was integrated in a robustness coefficient for each alternative. The coefficients allowed to identify the wind option as the best choice, followed by hydro and gas based generation. Nuclear generation was by far the worst option.

The robustness coefficients obtained were input to a linear programming model to identify the 'best mix' of electrical generation options that would meet the conditions in the country. A sensitivity analysis of the results to changes in the restrictions on the model, yielded two solutions that differ only in the participation of the nuclear option in them. Both of them include hydraulic option mostly ( $\geq 32 \%$ ) and a $15 \%$ contribution from wind power. Oil, gas and coal options are also incorporated. Each of them, if implemented, is able to add 120,000 GWh to power the country for 2025. The generation capacity to install through the period 20132025 is approximately $28 \mathrm{GW}$, and the budget required ascends to 65 billion \$US. This figure increases by a factor of 1,5 to 2 if the adequacy of the electric network is included. The commissioning of the total electrical grid for the country would produce about 260,000 GWh in 2025 , would have a $\geq 45 \%$ hydro participation and a $6.9 \%$ contribution from wind energy. It is estimated that it would take at least five years to have the first new power plants.

Finally, it was proposed a combined methodology for the multicriteria evaluation of institutional, technical, economic and environmentally viable investment alternatives in the energy sector. If the alternatives are mutually exclusive, the application of the hierarchical model designed would be sufficient for their evaluation; if not, this first stage should be complemented with a linear programming model approach that maximizes the robustness of the solution and places it closer to the specific circumstances of the country. 


\section{Índice de materias}

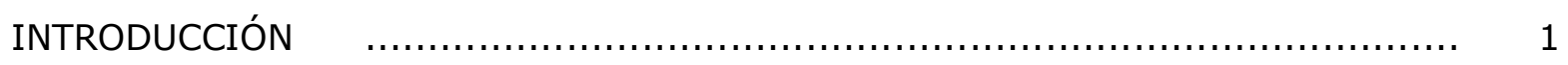

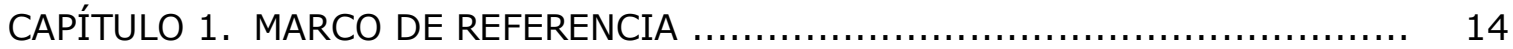

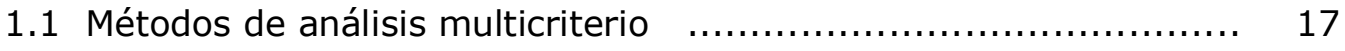

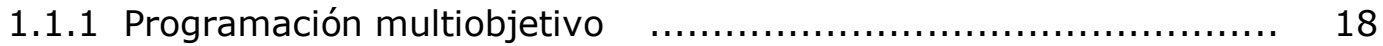

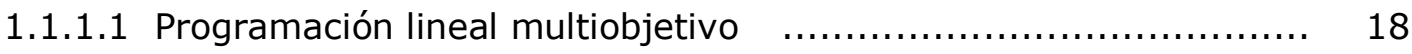

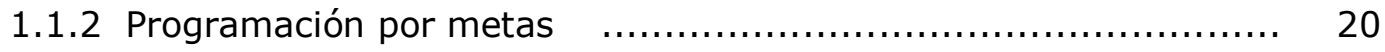

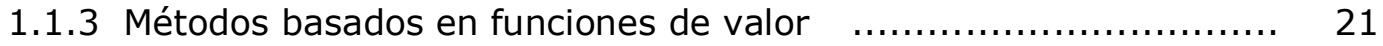

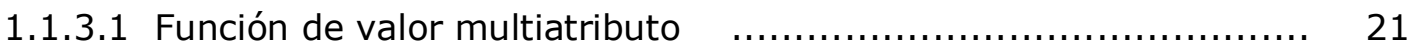

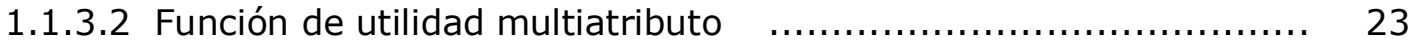

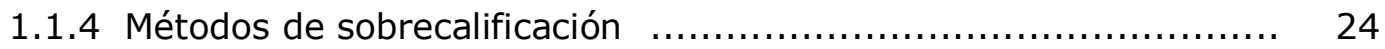

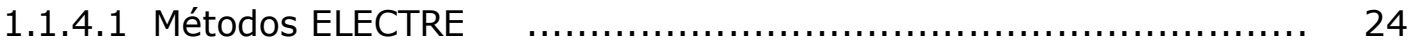

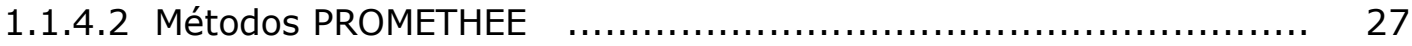

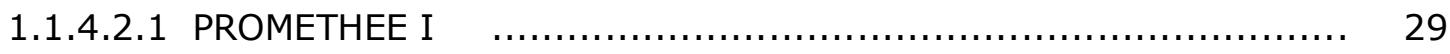

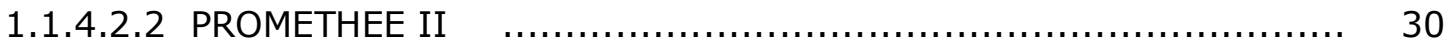

1.1.5 Métodos basados en jerarquías y redes analíticas $\quad \ldots \ldots \ldots \ldots \ldots \ldots . . . . . .31$

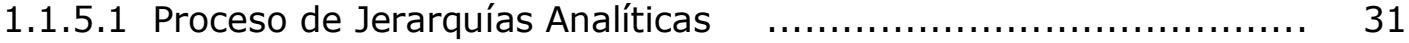

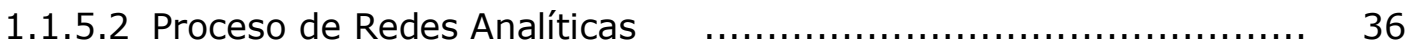

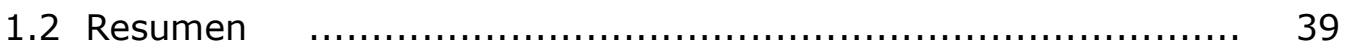

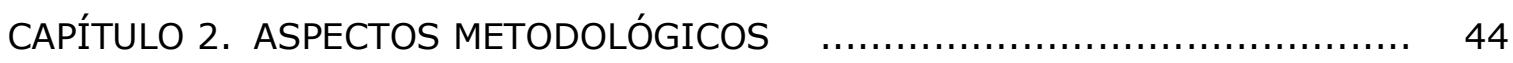

CAPÍTULO 3. CARACTERIZACIÓN DEL SECTOR ENERGÉTICO $\ldots \ldots \ldots \ldots \ldots \ldots \ldots . . . \ldots \ldots$

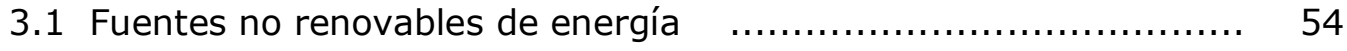

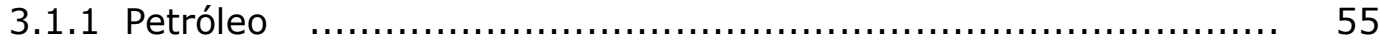




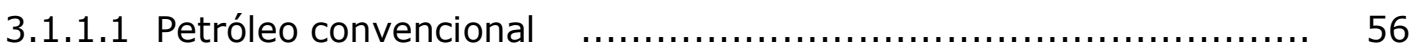

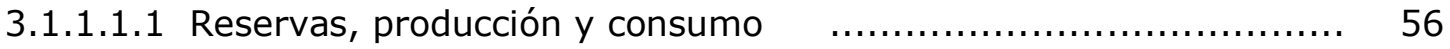

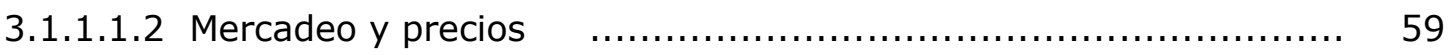

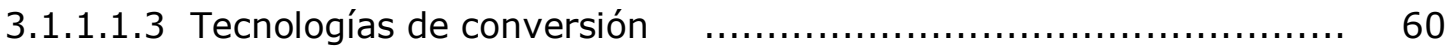

3.1.1.1.4 Efectos sobre el ambiente y consideraciones finales $\quad \ldots \ldots \ldots \ldots \ldots \ldots .61$

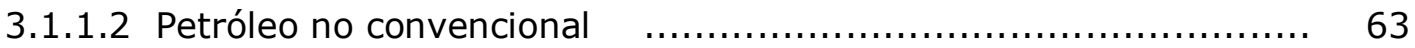

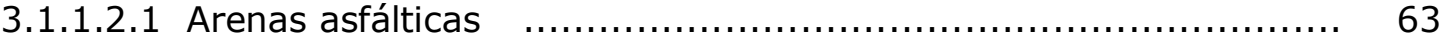

3.1.1.2.1.1 Tecnologías de extracción, transporte y conversión $\quad \ldots \ldots \ldots \ldots \ldots \ldots . . . \ldots 4$

3.1.1.2.1.2 Efectos sobre el ambiente y consideraciones finales $\quad \ldots \ldots \ldots \ldots \ldots \ldots . \ldots 5$

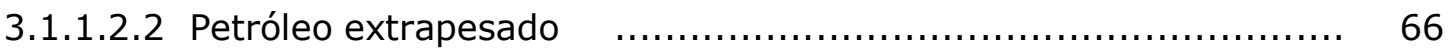

3.1.1.2.2.1 Tecnologías de extracción, transporte y conversión $\quad \ldots . . . \ldots \ldots \ldots \ldots . . . .67$

3.1.1.2.2.2 Efectos sobre el ambiente y consideraciones finales $\quad \ldots \ldots \ldots \ldots \ldots . . . . .68$

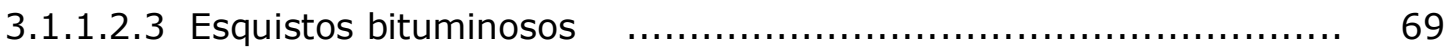

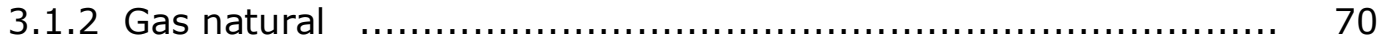

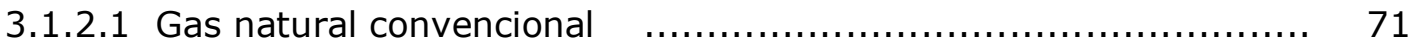

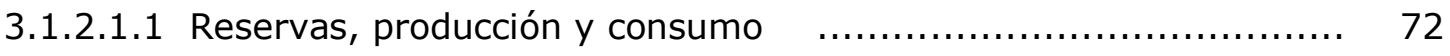

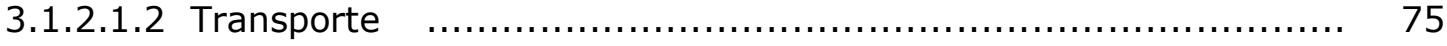

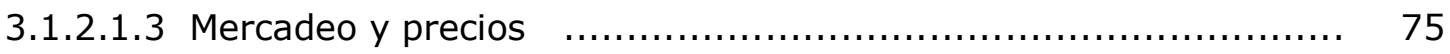

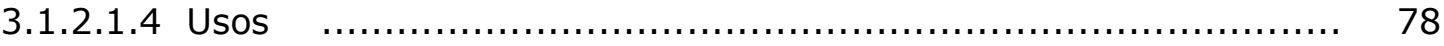

3.1.2.1.5 Efectos sobre el ambiente y consideraciones finales $\quad \ldots \ldots \ldots \ldots \ldots . . . . . \quad 80$

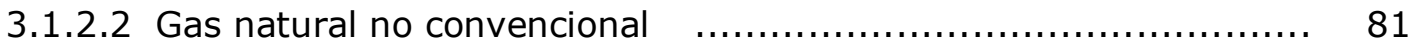

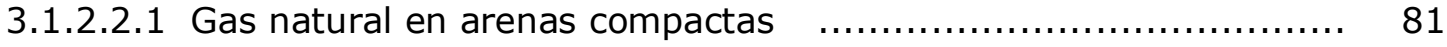

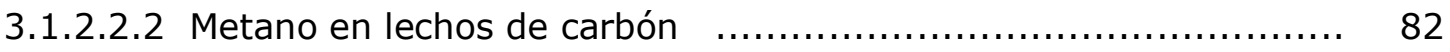

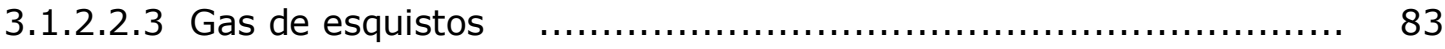

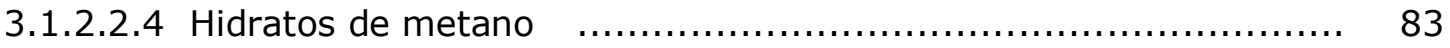

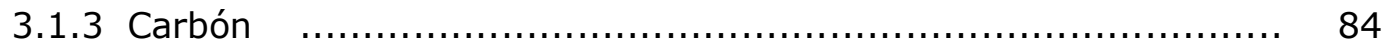

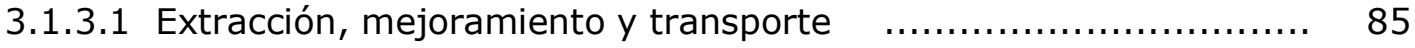

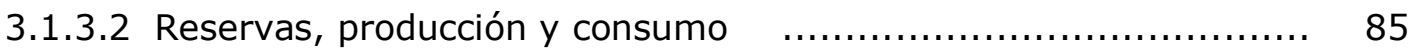

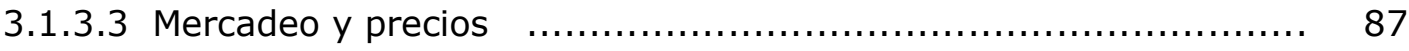

UNIVERSIDAD POLITÉCNICA DE VALENCIA. TESIS DOCTORAL. Violeta Parodi $\quad$ xi 
3.1.3.4 Efectos sobre el ambiente y nuevas tecnologías $\quad \ldots \ldots \ldots \ldots \ldots \ldots \ldots . . . \ldots 8$

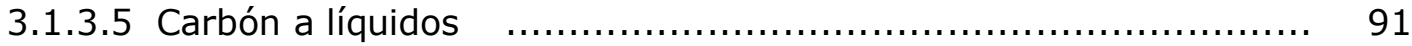

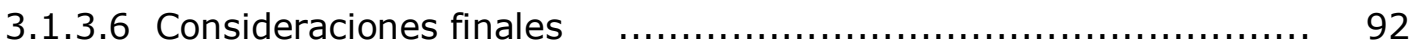

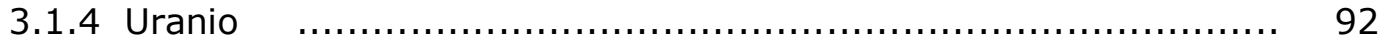

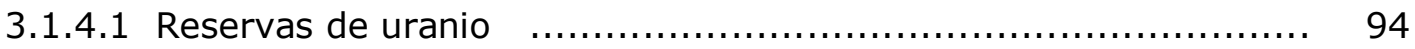

3.1.4.2 Tecnologías de extracción y conversión $\quad \ldots \ldots \ldots \ldots \ldots \ldots \ldots \ldots \ldots \ldots . \ldots \ldots$

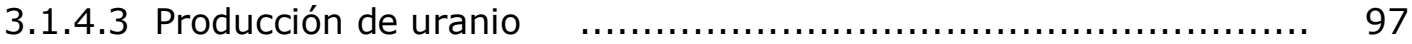

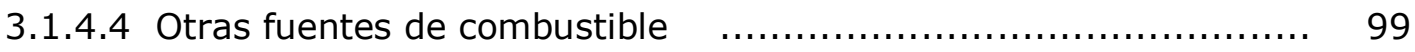

3.1.4.5 Reactores nucleares: tecnología y operación $\quad \ldots \ldots \ldots \ldots \ldots \ldots \ldots \ldots \ldots \ldots$

3.1.4.6 Capacidad nuclear de generación eléctrica $\quad \ldots \ldots \ldots \ldots \ldots \ldots \ldots \ldots \ldots . \ldots \ldots$

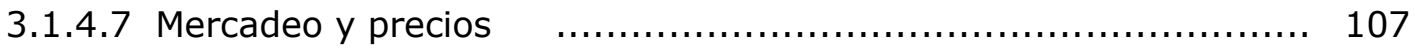

3.1.4.8 Efectos sobre el ambiente y consideraciones finales $\quad \ldots \ldots \ldots \ldots \ldots \ldots . .109$

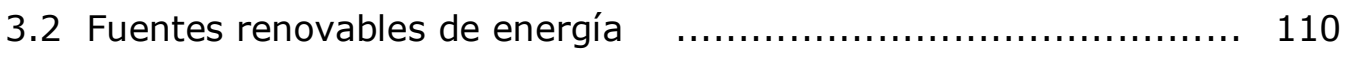

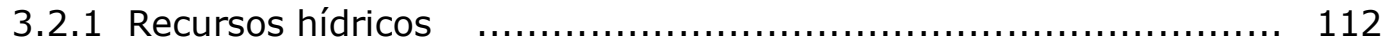

3.2.1.1 Potencial, capacidad instalada y producción $\quad \ldots \ldots \ldots \ldots \ldots \ldots \ldots \ldots . \ldots \ldots \ldots$

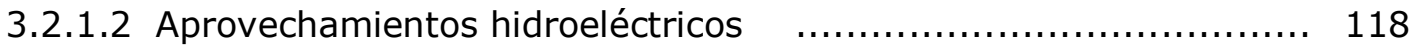

3.2.1.3 Efectos sobre el ambiente y consideraciones finales $\quad \ldots \ldots \ldots \ldots \ldots \ldots .118$

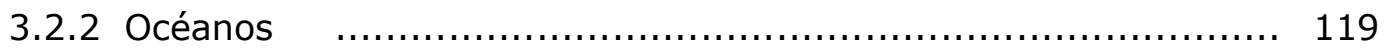

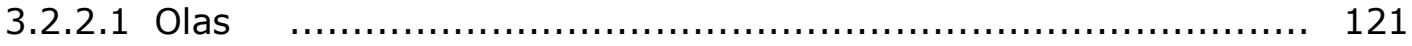

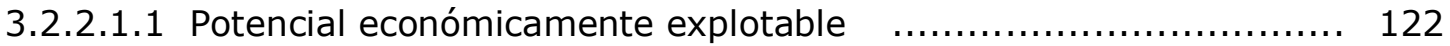

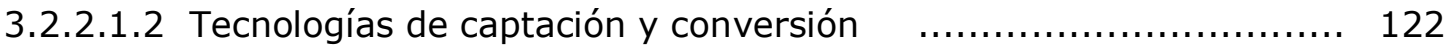

3.2.2.1.3 Impacto sobre el ambiente y consideraciones finales $\quad \ldots \ldots \ldots \ldots \ldots \ldots .123$

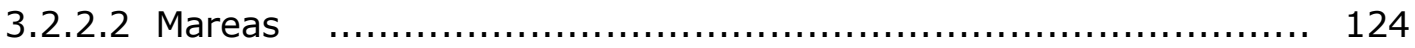

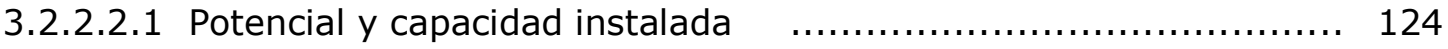

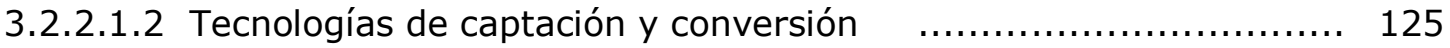

3.2.2.1.3 Impacto sobre el ambiente y consideraciones finales $\ldots \ldots \ldots \ldots \ldots . . . .126$

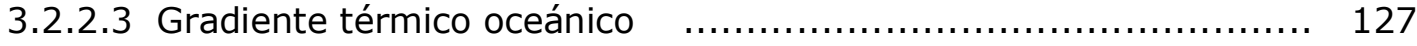

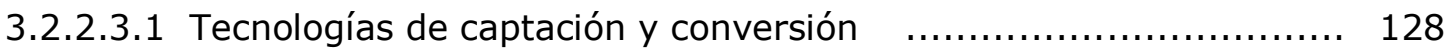

3.2.2.3.2 Impacto sobre el ambiente y consideraciones finales $\quad \ldots \ldots \ldots \ldots \ldots . . .129$ 


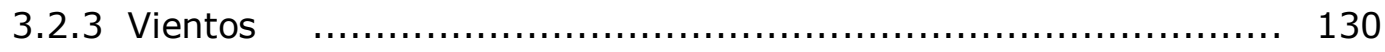

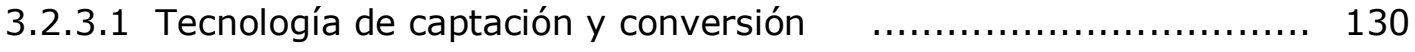

3.2.3.2 Potencial, capacidad instalada y producción $\quad$.......................... 131

3.2.3.3 Impacto sobre el ambiente y consideraciones finales $\ldots \ldots \ldots \ldots \ldots \ldots \ldots$

3.2.4 Radiación solar f...................................................... 136

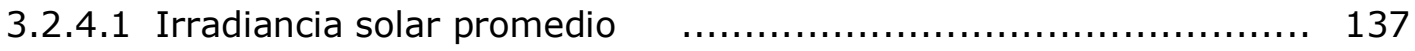

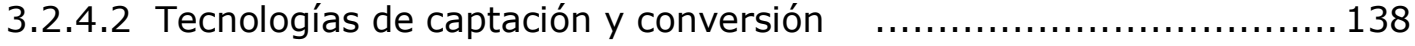

3.2.4.2.1 Tecnologías de calentamiento/enfriamiento $\quad \ldots \ldots \ldots \ldots \ldots \ldots \ldots \ldots \ldots . . . . . . . . . .138$

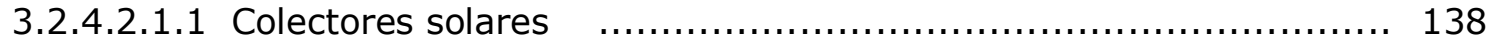

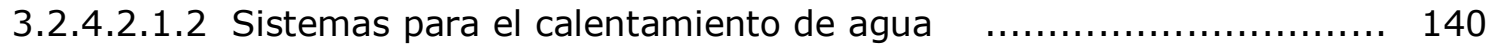

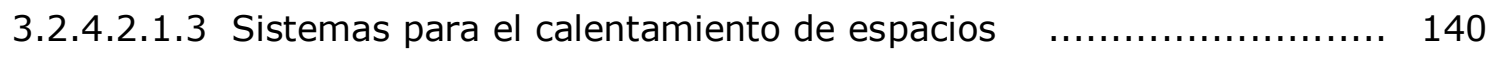

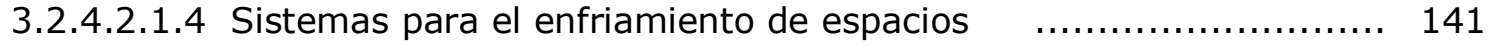

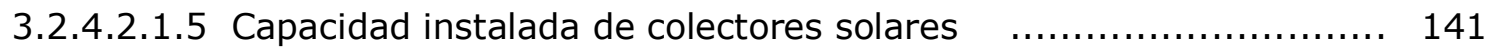

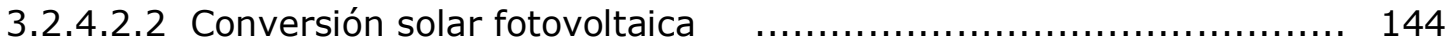

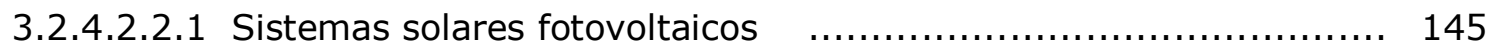

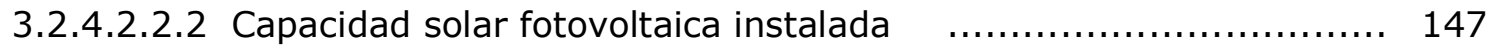

3.2.4.2.3 Tecnologías de concentración de energía solar $\quad$........................ 149

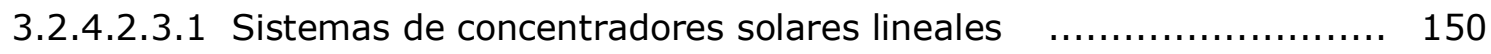

3.2.4.2.3.2 Sistemas de torre central de concentración solar $\quad \ldots \ldots \ldots \ldots \ldots \ldots \ldots \ldots 151$

3.2.4.2.3.3 Sistemas de disco parabólico /máquina $\quad$............................. 152

3.2.4.3 Mecanismos de almacenamiento/respaldo al sistema base $\quad$......... 154

3.2.4.4 Efectos sobre el ambiente y consideraciones finales $\ldots \ldots \ldots \ldots \ldots \ldots . . .156$

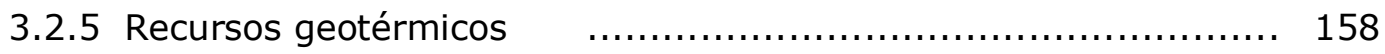

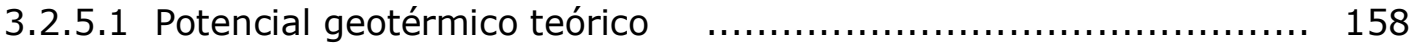

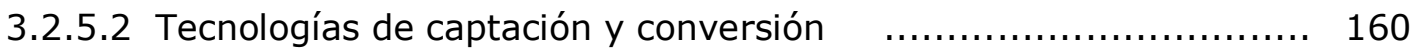

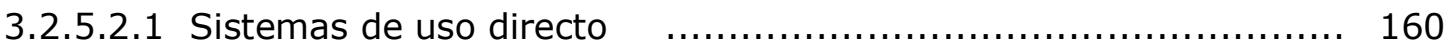

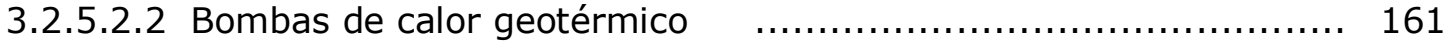

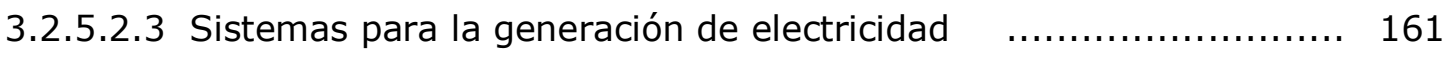

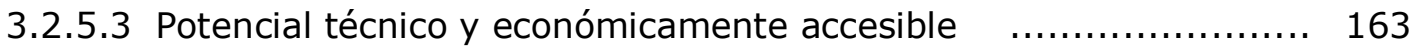




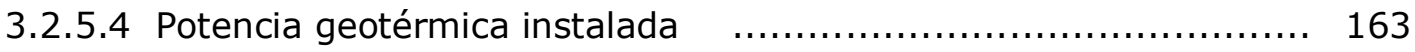

3.2.5.4.1 Capacidad instalada y producción de electricidad $\quad$.................... 164

3.2.5.4.2 Capacidad instalada y producción de uso directo $\quad \ldots \ldots \ldots \ldots \ldots \ldots . . . \ldots 6$

3.2.5.5 Efectos sobre el ambiente y consideraciones finales $\quad \ldots \ldots \ldots \ldots \ldots \ldots .167$

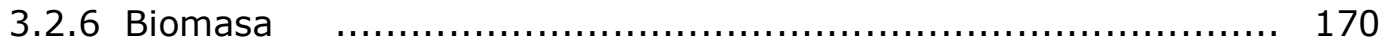

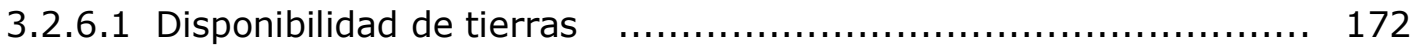

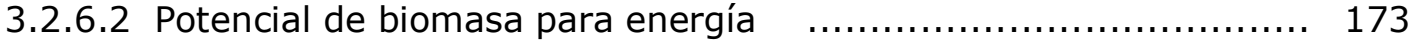

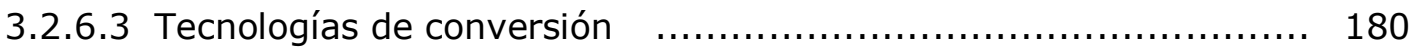

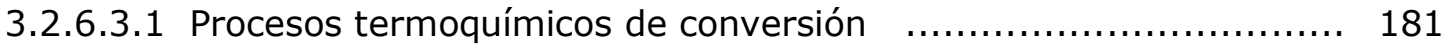

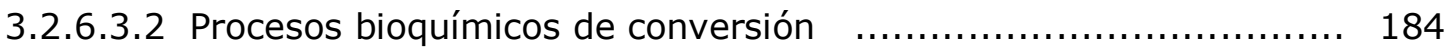

3.2.6.3.3. Tecnologías de primera, segunda y tercera generación $\quad \ldots . . . \ldots . . . .186$

3.2.6.4 Producción de calor, electricidad y combustibles $\ldots \ldots \ldots \ldots \ldots \ldots \ldots \ldots . .187$

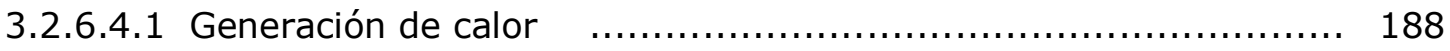

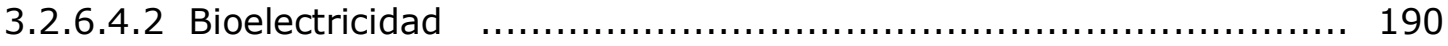

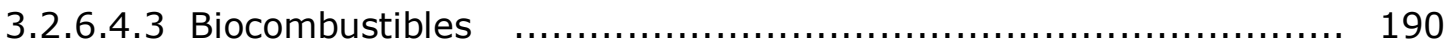

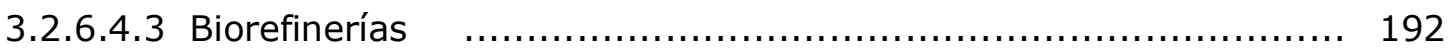

3.2.6.5 Intercambio comercial de biomasa y biocombustibles $\ldots \ldots \ldots \ldots \ldots .193$

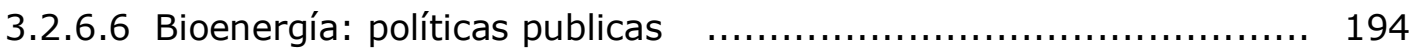

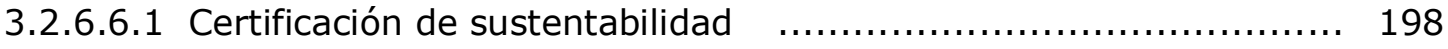

3.2.6.7 Efectos sobre el ambiente y consideraciones finales $\ldots \ldots \ldots \ldots \ldots \ldots . . \ldots 0$

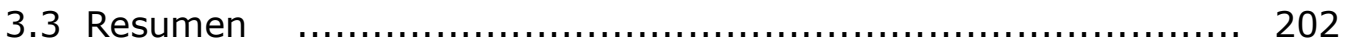

CAPÍTULO 4. ESTRUCTURACION DEL MODELO DE VALOR $\ldots \ldots \ldots \ldots \ldots \ldots \ldots \ldots \ldots \ldots \ldots \ldots \ldots$

4.1 Estructuración del modelo multicriterio de valor $\ldots \ldots \ldots \ldots \ldots \ldots . \ldots 226$

4.1.1 Selección de la plataforma de análisis multicriterio $\quad \ldots \ldots \ldots \ldots \ldots \ldots .227$

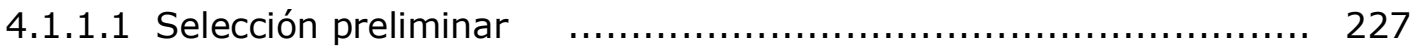

4.1.1.2 Tendencia histórica de uso y selección final $\quad \ldots \ldots \ldots \ldots \ldots \ldots \ldots \ldots . . \ldots . \ldots . \ldots 230$

4.1.2 Selección de criterios e indicadores para la evaluación $\quad \ldots \ldots \ldots \ldots \ldots .233$

4.1.2.1 Aspectos importantes para la evaluación. Sector energético $\quad \ldots \ldots . .234$

4.1.2.2 Validación de los criterios preseleccionados $\quad \ldots \ldots \ldots \ldots \ldots \ldots \ldots \ldots \ldots .240$

UNIVERSIDAD POLITÉCNICA DE VALENCIA. TESIS DOCTORAL. Violeta Parodi Xiv 
4.1.2.2.1 Selección de la muestra y levantamiento de la información $\quad \ldots . . . .240$

4.1.2.2.2 Procesamiento y análisis de la información recabada $\quad . . . \ldots \ldots \ldots \ldots . . . .242$

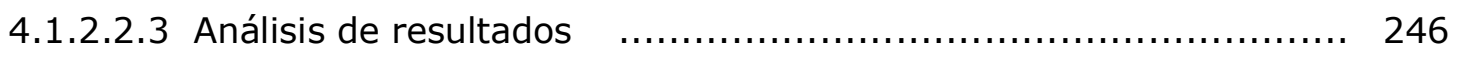

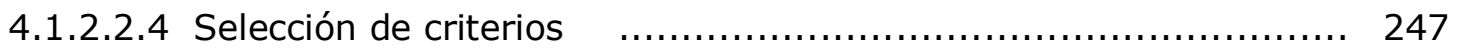

4.1.2.3 Propuesta de estructuración de criterios $\ldots \ldots \ldots \ldots \ldots \ldots \ldots \ldots \ldots . \ldots \ldots \ldots$

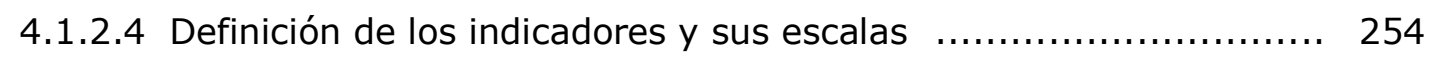

4.1.2.4.1 Indicadores de energía para el desarrollo sostenible $\ldots \ldots \ldots \ldots \ldots \ldots .254$

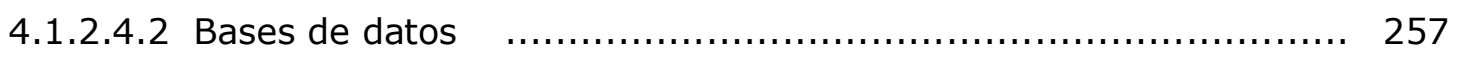

4.1.2.4.3 Indicadores propuestos para la evaluación $\quad \ldots \ldots \ldots \ldots \ldots \ldots \ldots \ldots . \ldots \ldots \ldots$

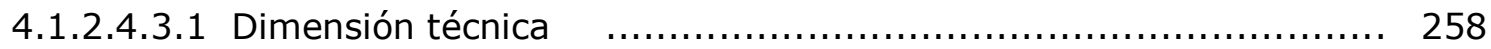

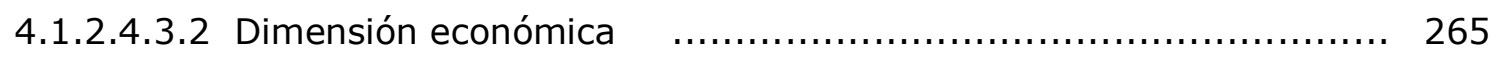

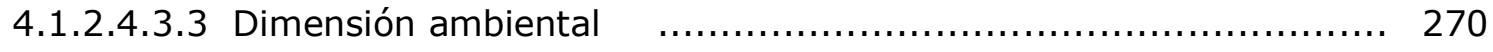

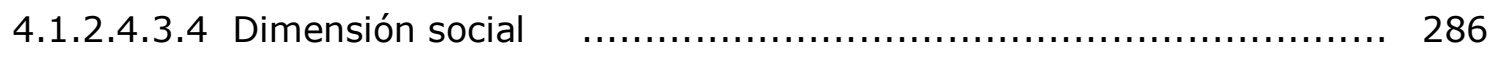

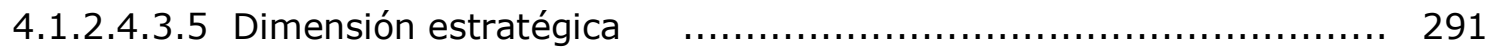

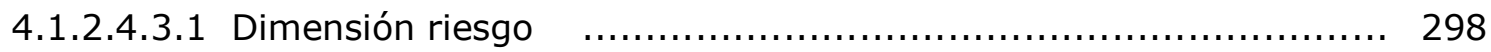

4.1.2.4.5 Sistema de indicadores para la evaluación

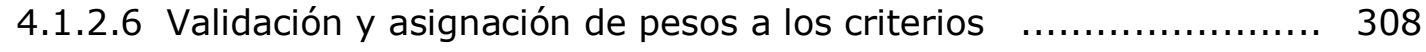

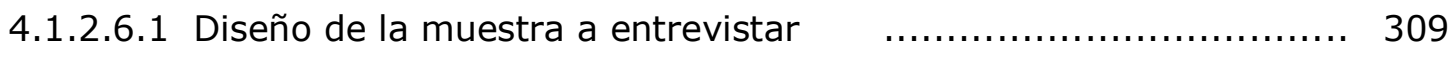

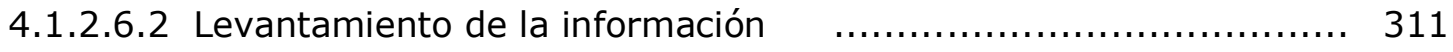

4.1.2.6.2.1 Información para validación final del modelo de valor $\quad \ldots \ldots \ldots \ldots \ldots . . . .311$

4.1.2.6.2.2 Información para la estimación de los pesos de los criterios $\quad \ldots . . .313$

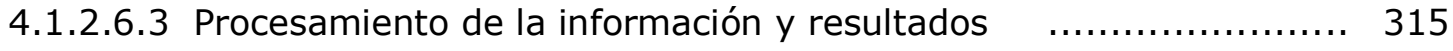

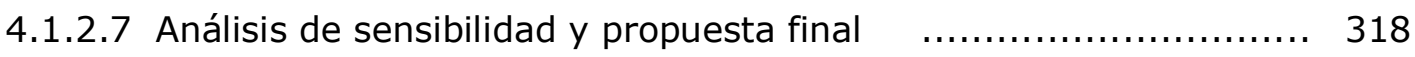

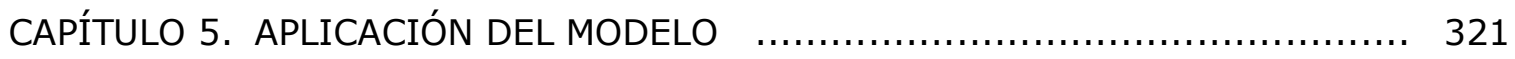

5.1 Caso: Crisis eléctrica en Venezuela $\quad$.............................. 321

5.1 .1 Potencial de recursos energéticos no renovables $\quad$.................... 322

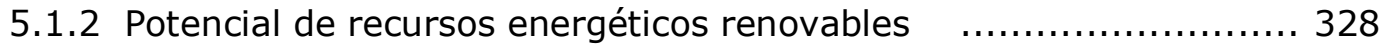

5,1,3 El problema: la crisis eléctrica en Venezuela $\quad$...................... 335

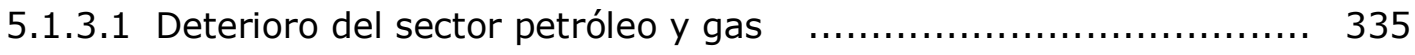




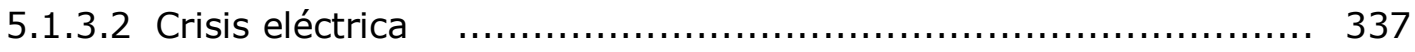

5.1.3.3 Aplicación del modelo de análisis multicriterio $\quad$........................ 343

5.1.3.3.1 Capacidad eléctrica a instalar para el período 2011-2025 ........... 344

5.1.3.3.1.1 Tendencia de crecimiento interanual de la población $\quad \ldots \ldots \ldots \ldots \ldots \ldots . . .345$

5.1.3.3.1.2 Tendencia del consumo de energía eléctrica, 2001-2010 ........... 346

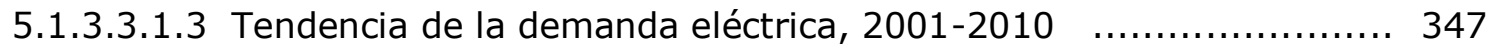

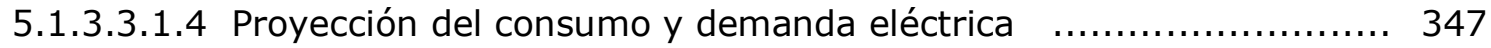

5.1.3.3.1.5 Distribución del consumo y demanda de energía eléctrica $\quad$.......... 352

5.1.3.3.2 Selección de las opciones de generación eléctrica a evaluar $\quad$........ 355

5.1.3.3.3 Evaluación de las alternativas preseleccionadas ...................... 358

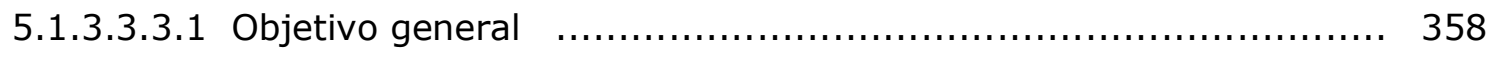

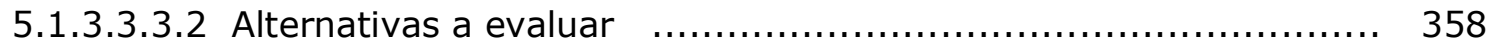

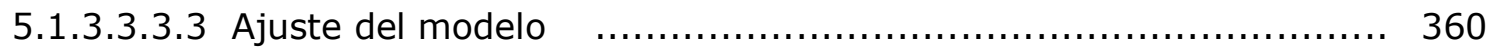

5.1.3.3.3.4 Estimación de los indicadores para la evaluación $\quad$.................... 362

5.1.3.3.3.5 Procesamiento de la información y resultados $\ldots . . . \ldots \ldots \ldots \ldots \ldots \ldots . . . . . . . . . .379$

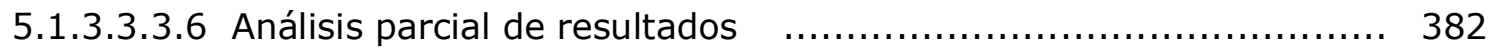

5.1.3.3.4 Incorporación de soluciones a la solución del problema $\quad \ldots \ldots \ldots \ldots . . . .384$

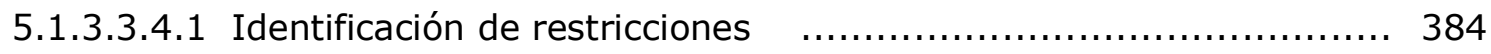

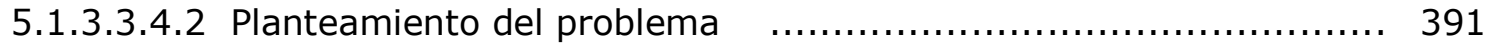

5.1.3.3.4.3 Parámetros del problema $\quad$............................................. 394

5.1.3.3.4.4 Procesamiento de la información y resultados ........................ 397

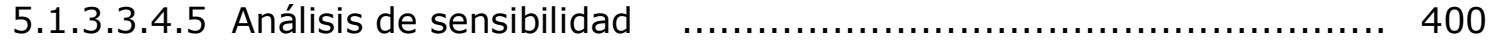

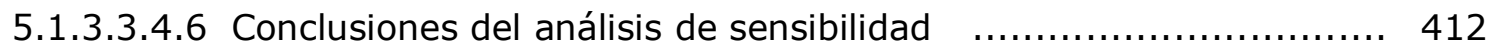

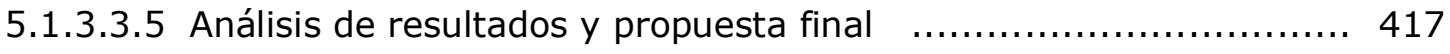

CAPÍTULO 6. PROPUESTA METODOLÓGICA DE EVALUACIÓN $\quad \ldots \ldots \ldots \ldots \ldots \ldots \ldots . \ldots . \ldots . \ldots 33$

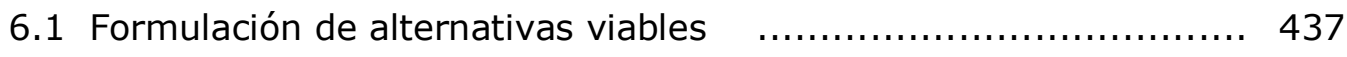

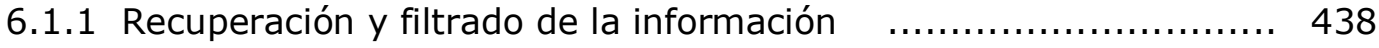

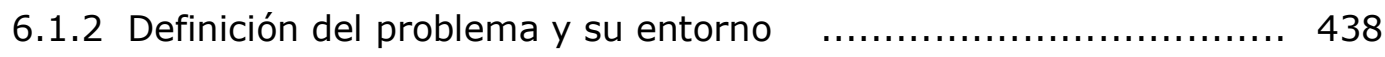

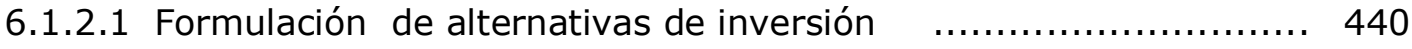




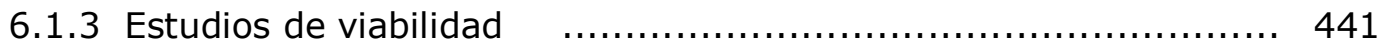

6.2 Evaluación multicriterio de alternativas viables $\quad . . \ldots \ldots \ldots \ldots \ldots . . \ldots 443$

6.2.1 Selección de alternativas viables a evaluar $\quad \ldots \ldots \ldots \ldots \ldots \ldots \ldots \ldots . \ldots 44$

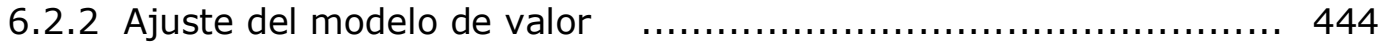

6.2.3 Estimación de los indicadores para la evaluación $\quad$.................. 445

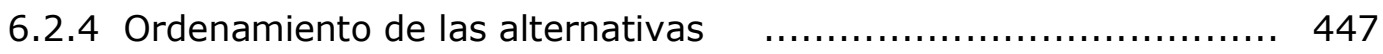

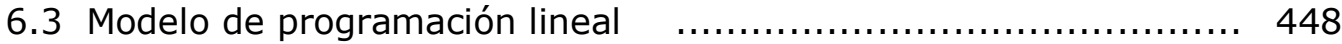

6.3.1 Planteamiento y solución del modelo $\ldots \ldots \ldots \ldots \ldots \ldots \ldots \ldots \ldots \ldots . \ldots \ldots 48$

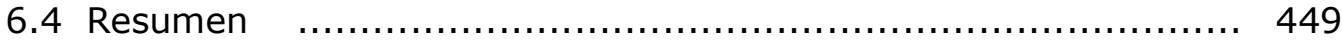

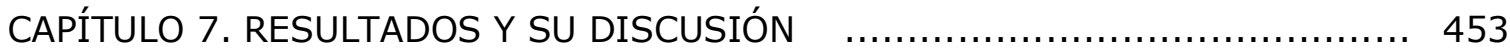

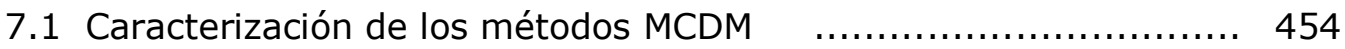

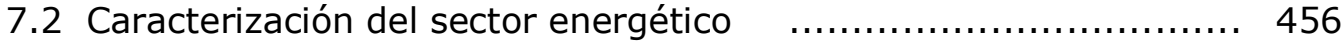

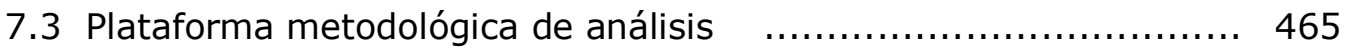

7.4 Estructuración del modelo de valor $\quad \ldots \ldots \ldots \ldots \ldots \ldots \ldots \ldots \ldots \ldots \ldots \ldots \ldots, 467$

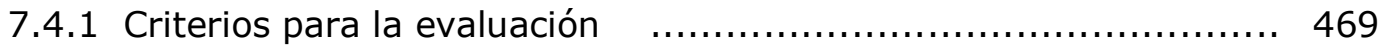

7.4.2 Indicadores para la evaluación y sus escalas $\quad \ldots \ldots \ldots \ldots \ldots \ldots \ldots . \ldots . \ldots 41$

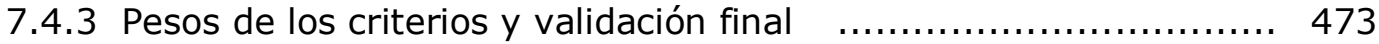

7.4.4 Análisis de sensibilidad y propuesta final $\quad \ldots \ldots \ldots \ldots \ldots \ldots \ldots \ldots . \ldots 44$

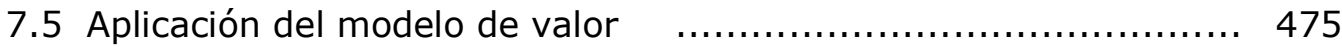

7.5.1 Definición del caso de estudio y su entorno $\quad \ldots \ldots \ldots \ldots \ldots \ldots \ldots \ldots . \ldots 46$

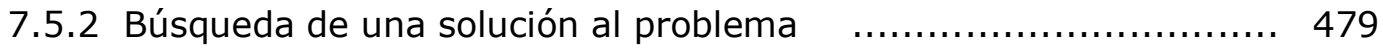

7.5.2.1 Proyección de la capacidad eléctrica a instalar $\quad \ldots \ldots \ldots \ldots \ldots \ldots \ldots \ldots . \ldots 1$

7.5.2.2 Selección de las alternativas a evaluar $\quad \ldots \ldots \ldots \ldots \ldots \ldots \ldots \ldots \ldots . \ldots . \ldots \ldots 2$

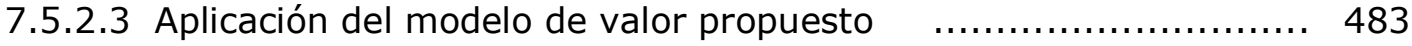

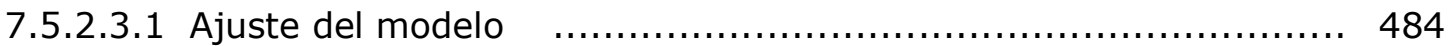

7.5.2.3.2 Obtención del valor de los indicadores para la evaluación $\quad \ldots . . . . . .484$

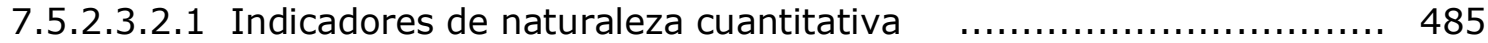

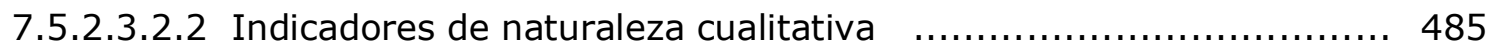

7.5.2.3.2.4 Obtención de los coeficientes de robustez $\quad \ldots \ldots \ldots \ldots \ldots \ldots \ldots \ldots \ldots \ldots \ldots \ldots$ 


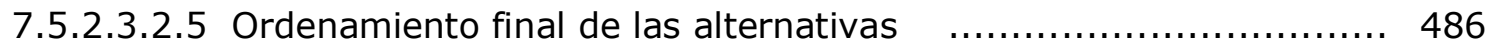

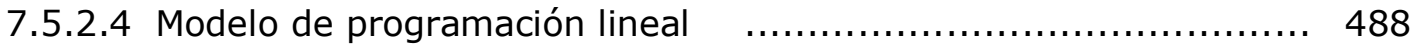

7.5.2.4.1 Identificación de limitaciones y modelo de solución $\quad$............... 489

7.5.2.4.2 Introducción de para metros al modelo y su resolución $\quad$............. 491

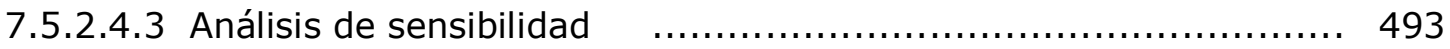

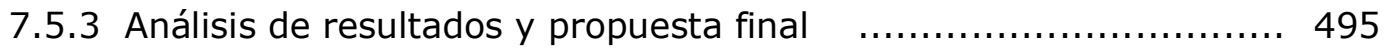

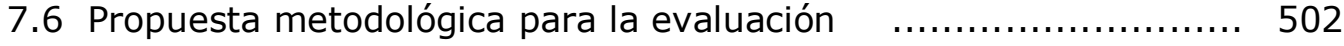

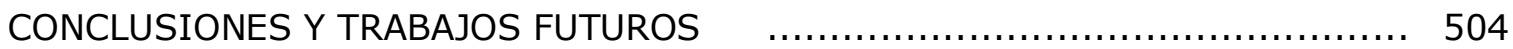

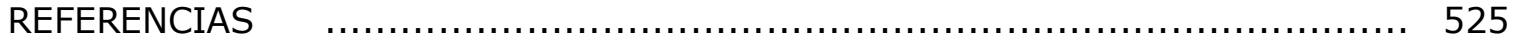

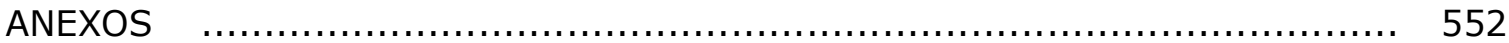




\section{Índice de tablas}

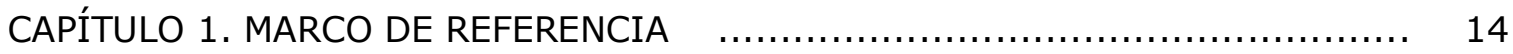

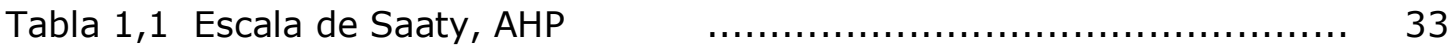

1.2.1 Cuadro comparativo de métodos de análisis multicriterio I $\quad . . . . . .40$

1.2.2 Cuadro comparativo de métodos de análisis multicriterio II $\quad \ldots . . .44$

CAPÍTULO 3. CARACTERIZACIÓN DEL SECTOR ENERGÉTICO $\ldots \ldots \ldots \ldots \ldots \ldots \ldots . . . \ldots \ldots$

Tabla 3.1 Potencial hidroeléctrico técnicamente explotable por regiones, 2009

3.2 Zonas de interés por la velocidad de sus vientos, por continente ... 132

3.3 Políticas públicas de apoyo al sector de renovables, $2010 \quad \ldots \ldots \ldots . . .197$

3.4 Caracterización del sector energético. Energías no renovables .... 203

3.5 Caracterización del sector energético. Energías renovables $\ldots \ldots \ldots 211$

CAPÍTULO 4. ESTRUCTURACIÓN DEL MODELO DE VALOR $\ldots \ldots \ldots \ldots \ldots \ldots \ldots \ldots \ldots \ldots \ldots \ldots \ldots \ldots \ldots$

Tabla 4.1 Algunas modalidades de clasificación de proyectos en el sector

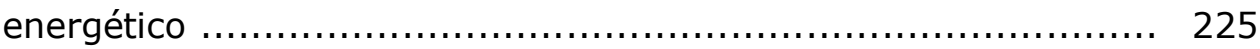

4.2 Tendencia histórica de uso, MCDA, Sector planificación energética 231

4.3 Aspectos a considerar en la evaluación de proyectos. Sector energético

4.4 Distribución de la muestra de expertos para validación de criterios. Encuesta preliminar

4.5 Validación de los criterios preseleccionados. Sector energético .... 244

4.6 Aspectos importantes a evaluar en estudios de viabilidad previos.. 249

4.7 Aspectos a consolidar por similitud o dependencia 251

4.8 Sistemas de indicadores para evaluación de sostenibilidad de planes de desarrollo en el sector energético. Referencias consultadas .... 256 
4.9 Accidentes nucleares más grandes en las últimas décadas

4.10 Sistema de indicadores para la evaluación multicriterio de proyectos en el sector energético 305

4.11 Distribución de la muestra de expertos para validación del modelo final y asignación de los pesos a los criterios de evaluación 310

4.12 Composición del grupo 1. Sectores público, privado y académico .. 312

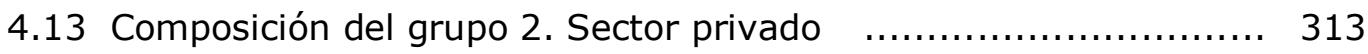

4.14 Pesos globales de los criterios de evaluación en el modelo propuesto

4.15 Dispersión de los resultados entre grupos de entrevistados 319

CAPÍTULO 5. APLICACIÓN DEL MODELO 321

Tabla 5.1 Posición energética de Venezuela. Recursos no renovables, 2010.. 323

5.2 Posición energética de Venezuela. Recursos renovables, 2010 ..... 329

5.3 Desarrollos eólicos en Venezuela. Planes 2009 .................... 332

5.4 Consumo de combustibles en el sector eléctrico 340

5.5a. Proyección del consumo, de la demanda máxima y de la capacidad de generación eléctrica necesaria. Escenario 1.

5.5b Idem 5.5a. Escenario 2, 2011-2025 350

5.5c Idem 5.5a. Escenario 3, 2011-2025 351

5.6 Resultados de proyección CORPOELEC de la demanda eléctrica, 2010-2030 354

5.7 Matriz de descarte de opciones de generación eléctrica, Venezuela 357

5.8 Alternativas de generación eléctrica a evaluar, Venezuela ......... 359

5.9 Modificación de indicadores del modelo de valor propuesto ........ 361

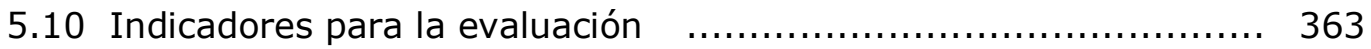

5.11 Información técnica sobre tecnologías de generación seleccionadas 365

5.12 Costo nivelado NREL2015 para diferentes opciones de generación U.S.A. 366

5.13 Estimación de costo nivelado para generación hidroeléctrica 368 
5.14 Efecto estimado sobre balanza de pagos por opción de generación 370

5.15 Promedio de emisiones no radioactivas para el ciclo de vida, por opción de generación eléctrica

5.16 Promedio de emisiones de gases tipo invernadero y de partículas para el ciclo de vida, por opción de generación eléctrica $\quad \ldots \ldots \ldots \ldots \ldots . . \ldots 372$

5.17 Promedio de emisiones acidas para el ciclo de vida, por opción de generación eléctrica

5.18 Promedio de emisiones de precursores de ozono para el ciclo de vida, por opción de generación eléctrica

5.19 Promedio de empleos generados por opción de generación eléctrica

5.20 Promedio de salarios creados por opción de generación eléctrica... 376

5.21 Muestra entrevistada para evaluación de opciones de generación... 377

5.22 Recolección de juicios de valor sobre indicadores de índole cuantitativa

5.23 Coeficientes de robustez y ordenamiento de las alternativas bajo estudio

5.24 Ordenamiento final de las alternativas de generación eléctrica $\ldots 382$

5.25 Inversión promedio para estimación de presupuesto $\quad$............... 387

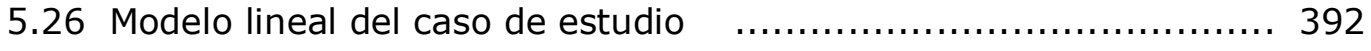

5,27 Suposiciones en el planteamiento del modelo $\quad$..................... 393

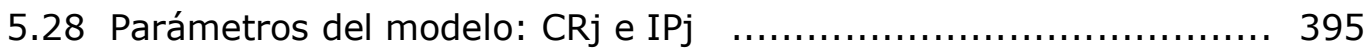

5.29 Parámetros del modelo: Capacidad a instalar $\quad \ldots \ldots \ldots \ldots \ldots \ldots \ldots \ldots . \ldots \ldots$

5.30 Parámetros del modelo: Presupuesto, CGT, CGHI, CGC1, CGC4, CGC5, POT5 y potenciales desarrollables de las energías renovables .... 396

5.31 Modelo lineal del caso de estudio. Caso base $\quad$...................... 398

5.32 Análisis de sensibilidad. Etapa 1. Caso base sin restricciones $[\geq]$. Variación en presupuesto, generación carboeléctrica y nuclear ... 401

5.33 Análisis de sensibilidad. Etapa 2. Caso base con restricciones $[\geq]$. 
Limitación en la generación basada en gas natural y petróleo ..... 404

5.34 Análisis de sensibilidad. Etapa 2. Caso 10 como base $\ldots . . . . . . . . .406$

5.35 Estimación del consumo de combustible. Casos 15, 17 y 18 ...... 409

5.36 Análisis de sensibilidad. Etapa 3. Casos 17 y 18 como base. Variación en la participación de anergias renovables $\quad \ldots \ldots \ldots \ldots \ldots \ldots \ldots \ldots, 411$

5.37 Índices de robustez y diversidad. Casos 18, 24, 25 y $26 \quad \ldots \ldots \ldots .419$

5.38 Capacidad estimada de generación eléctrica a instalar durante el período 2013-2015, por tipo de energía primaria. Dos propuestas 422

5.39 Estimación del consumo de combustible 2025, Casos 25 y $26 \quad \ldots . .423$

5.40 Una aproximación a la matriz eléctrica para Venezuela, 2025 ...... 427

CAPÍTULO 6. PROPUESTA METODOLÓGICA DE EVALUACIÓN $\quad \ldots \ldots \ldots \ldots \ldots \ldots \ldots \ldots . \ldots . \ldots . \ldots . \ldots 33$

Tabla 6.1 Fuentes de información para estimación de estimadores

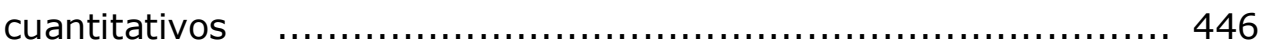

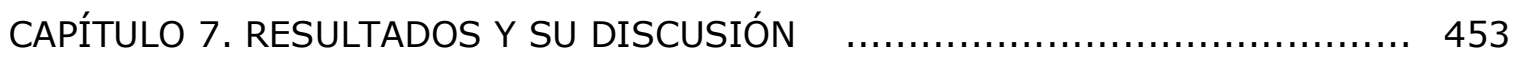

Tabla 7.1 División del trabajo realizado y resultados $\ldots \ldots \ldots \ldots \ldots \ldots \ldots \ldots \ldots 454$

7.2 Estructuración del modelo de valor: actividades y resultados ...... 468

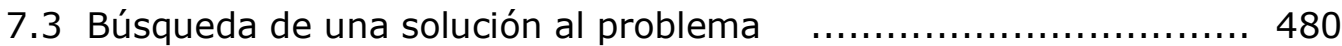

7.4 Capacidad eléctrica a incorporar. Período 2011-2025, con todas las restricciones planteadas en el modelo original $\quad \ldots \ldots \ldots \ldots \ldots \ldots \ldots \ldots 492$ 


\section{Índice de figuras}

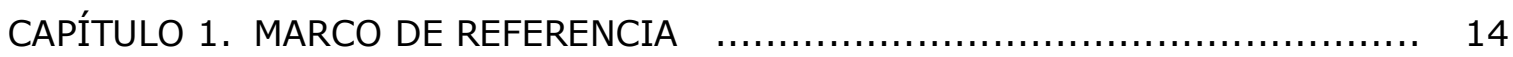

Figura 1.1 Funciones de preferencia, métodos PROMETHEE $\quad \ldots \ldots \ldots \ldots \ldots \ldots . . . . . .28$

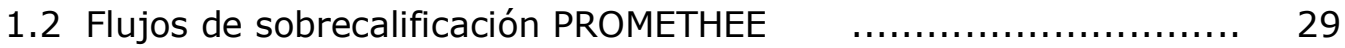

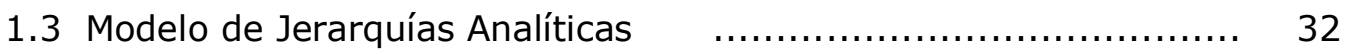

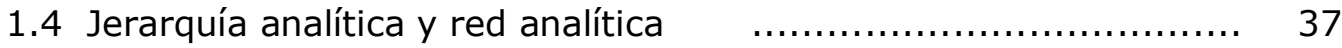

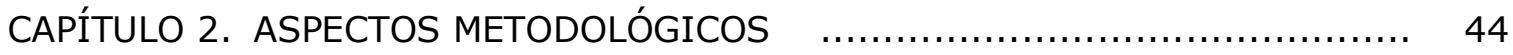

Figura 2.1 Plan de tareas, flujo de información y resultados $\quad$................. 45

CAPÍTULO 3. CARACTERIZACIÓN DEL SECTOR ENERGÉTICO

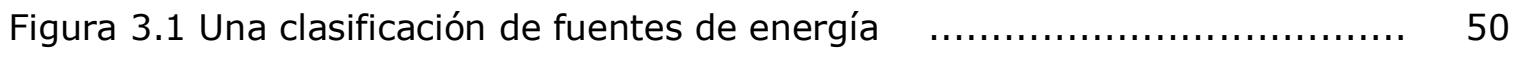

3.2a Suministro mundial de energías primarias por combustible, 2009 .. 52

3.2b Emisiones mundiales de CO2 por combustible, $2009 \quad \ldots \ldots \ldots \ldots \ldots . \ldots 2$

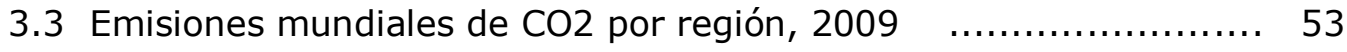

3.4 Reservas probadas, producción y consumo de petróleo convencional

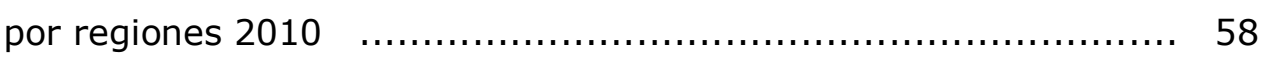

3.5 Precio promedio anual de crudos marcadores $\ldots \ldots \ldots \ldots \ldots \ldots \ldots \ldots \ldots \ldots \ldots$

3.6 Capacidad de refinación instalada y utilizada por regiones, 2010... 61

3.7 Principales depósitos de petróleo no convencional en el mundo ...... 63

3.8 Reservas probadas, producción comercializada y consumo de gas natural por regiones, 2010

3.9 Precios promedio de referencia para el gas natural y el gas natural

3.10 Reservas probadas, producción y consumo de carbón, 2010 ....... 86

3.11 Precios promedio anuales de referencia para el carbón $\quad \ldots \ldots \ldots \ldots . \quad 88$

3.12 Reservas de uranio en países seleccionados, 2009 ................. 95 
3.13a Producción primaria de uranio por país, 2011

3.13b Producción primaria y requerimiento global de uranio para el sector eléctrico, 2011

3.14 Número de reactores nucleares por país, 2012 104

3.15 Capacidad nuclear y requerimiento de uranio para generación eléctrica, 2012

3.16 Precios a corto y largo plazo del U3O8 108

3.17 Participación de las energías renovables en el consumo final de energía,2009

3.18a Capacidad instalada de generación hidroeléctrica, 2009 114

3.18b Grandes complejos hidroeléctricos, 2011

3.19a Composición de la producción eléctrica mundial, 2009 115

3.19b Distribución de la producción hidroeléctrica mundial, 2010 115

3.20a Producción hidroeléctrica de países seleccionados, 2009 116

3.20b Participación hidroeléctrica en el sector eléctrico por país, 2009 ... 116

3.21 Distribución del potencial teórico mundial de energía oceánica .... 120

3.22 Potencia energética media de olas para sitios seleccionados 121

3.23 Rango medio entre mareas alta y baja para sitios seleccionados ..

3.24 Zonas oceánicas con gradiente térmico $>20^{\circ} \mathrm{C}$ entre la superficie del mar y $1000 \mathrm{~m}$. de profundidad 127

3.25 Capacidad instalada de turbinas de viento, 2010

3.26 Capacidad instalada de turbinas de viento costa afuera, 2010 ... 134

3.27 Irradiancia solar promedio sobre la superficie terrestre

3.28 Capacidad instalada de colectores solares por tipo de colector, 2009

3.29 Capacidad instalada de colectores solares por países, 2009 143

3.30a Capacidad instalada fotovoltaica solar, 2006-2010 148

3.30b Capacidad fotovoltaica solar instalada por países, 2010 148

3.31 Capacidad instalada CSP, 2010 153 
3.32 Zonas con potencial geotérmico en el mundo $\quad \ldots \ldots \ldots \ldots \ldots \ldots \ldots \ldots . \ldots . \ldots . \ldots 159$

3.33 Potencia geotérmica instalada por continente,2009 ............... 164

3.34a Capacidad geotérmica instalada para generación de electricidad

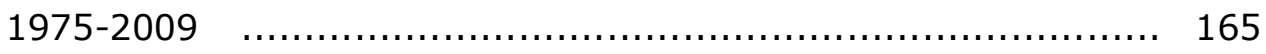

3.34b Capacidad geotérmica instalada para generación de electricidad,

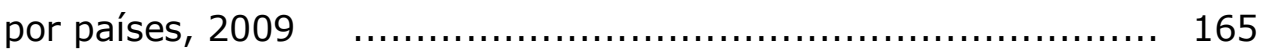

3.35a Producción de energía eléctrica geotérmica por países, $2009 \quad \ldots . . .166$

3.35b Energía geotérmica en la demanda eléctrica de cada país, 2009 .. 166

3.36a Uso directo de la energía geotérmica por países, $2009 \quad \ldots \ldots \ldots \ldots \ldots .166$

3.36b Uso directo de la energía geotérmica por aplicaciones, $2009 \quad \ldots \ldots . .166$

3.37 Promedio mundial de emisiones de $\mathrm{CO} 2$ en generación eléctrica y en calefacción, por tipo de recurso usado $\ldots \ldots \ldots \ldots \ldots \ldots \ldots \ldots \ldots . \ldots \ldots \ldots$

3.38 Costo nivelado de generación eléctrica, por tipo de recurso usado.. 169

3.39 Flujos de biomasa y algunos de sus potenciales usos $\ldots \ldots \ldots \ldots \ldots \ldots, 171$

3.40 Distribución de tierras por uso, a nivel mundial $\quad \ldots \ldots \ldots \ldots \ldots \ldots \ldots . \ldots . \ldots 172$

3.41 Distribución del potencial global de biomasa para producción de energía. Escenario de alto nivel tecnológico en cultivos, 2050 .... 177

3.42 Estimación del potencial global de biomasa para energía, 2050 ... 177

3.43 Distribución por fuente de energía del potencial global sostenible

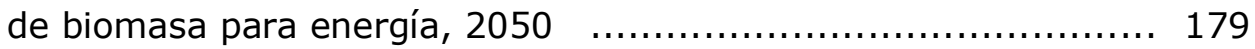

3.44 Algunas rutas de conversión [Biomasa $=>$ Calor, electricidad o

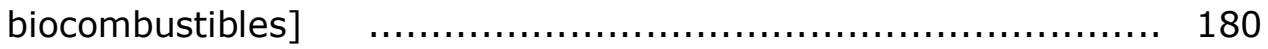

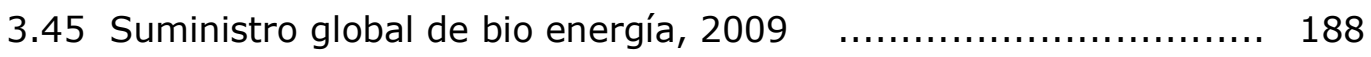

3.46a Capacidad instalada de generación eléctrica a partir de biomasa, 2010

3.46a Distribución de Capacidad instalada de generación eléctrica a partir

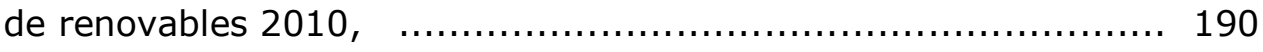

3.47a Producción de bioetanol y biodiesel, 2005-2010 ................. 191

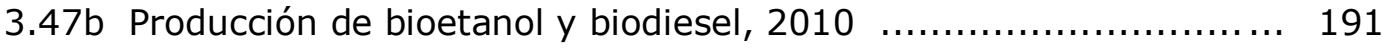


3.48 Esquema de rutas de comercio internacional de biomasa $\ldots . . . \ldots . .193$ CAPÍTULO 4. ESTRUCTURACIÓN DEL MODELO DE VALOR $\ldots \ldots \ldots \ldots \ldots \ldots \ldots \ldots \ldots \ldots \ldots \ldots \ldots \ldots \ldots \ldots$

Figura 4.1 Tendencia de uso por metodología MCDA, 2000-2010 ............ 231

4.2 Selección de criterios e indicadores para la evaluación $\ldots . . \ldots \ldots \ldots \ldots .233$

4.3 Histograma del coeficiente de variación de las medias de grupo para cada criterio (M) y la media de las medias (MM) ............. 246

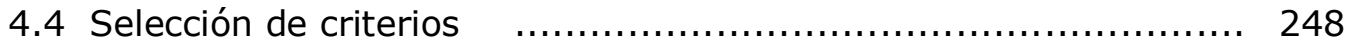

4.5 Jerarquía de criterios para la evaluación de proyectos. Sector

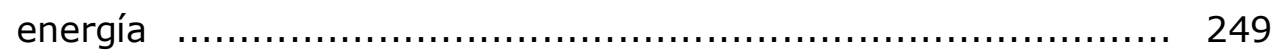

4.6 Curva de Gartner (Hype Cicle) para tecnologías emergentes ... 259

4.7 Balance de energía para procesos de aprovechamiento de los

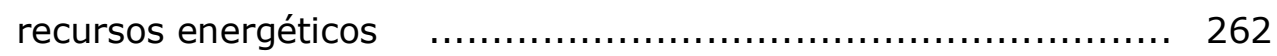

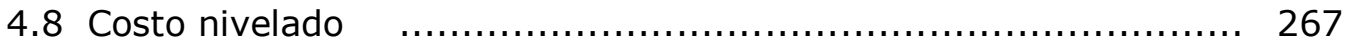

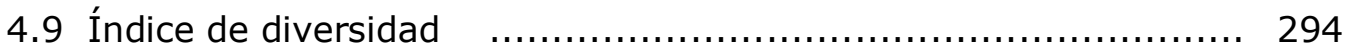

4.10 Matrices de juicios para levantamiento de la información $\quad \ldots \ldots \ldots \ldots .314$

4.11 Modelo de valor para la evaluación de proyectos en el sector

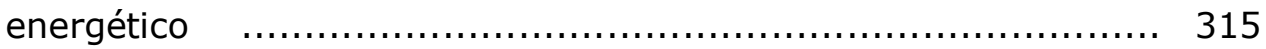

4.12 Modelo de valor. Importancia relativa de los criterios

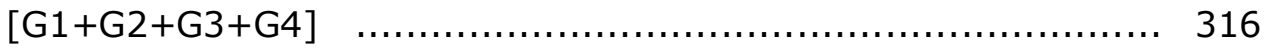

4.13 Pesos globales de los criterios propuestos, por grupos $\quad \ldots \ldots \ldots \ldots . . . .318$

4.14 Dispersión de los pesos globales de los criterios de evaluación .. 319

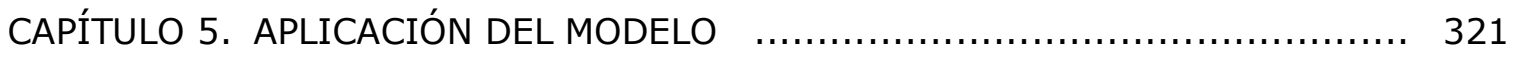

Figura 5.1 Ubicación geográfica de los recursos energéticos no renovables,

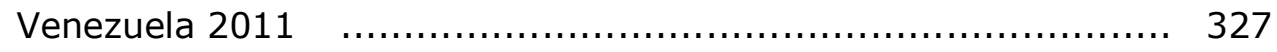

5.2 Potencial solar, eólico e hidráulico, zonas más favorables en

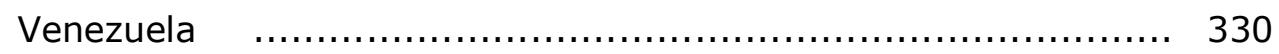

5.3 Ubicación geográfica del potencial geotérmico y bioenergético,

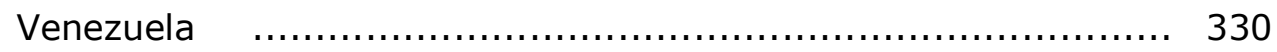

5.4 Aprovechamientos hidroeléctricos en Venezuela, $2009 \quad \ldots \ldots \ldots \ldots . . . .333$ 
5.5 Producción de petróleo e importaciones de gas, Venezuela 2000-2010

5.6 Consumo de gasolina y diesel frente a capacidad máxima de producción Venezuela 2009-2010

5.7 Capacidad de generación instalada, capacidad disponible y demanda máxima. Sector eléctrico venezolano 2000-2020 338

5.8 Comportamiento de las incorporaciones hasta mediados del 2010340

5.9 Procedimiento para la solución del caso de estudio $\quad \ldots \ldots \ldots \ldots \ldots . . . \ldots 343$

5.10 Crecimiento estimado de la población venezolana, 2011-2025 .... 345

5.11 Tendencia del consumo de energía eléctrica en Venezuela, ........ 346

5.12 Consumo, demanda máxima eléctrica y factor de carga $\quad$.......... 347

5.13 Proyección del consumo y de la capacidad de generación eléctrica

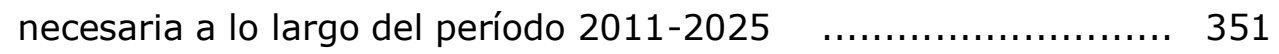

5.14 Zonas geoeléctricas a efectos del estudio CORPOELEC2010 sobre consumo de energía eléctrica en Venezuela

5.15 Proyección CORPOELEC2010 de consumo y de demanda máxima de energía eléctrica, clasificada por regiones geoeléctricas, 2030

5.16 Opciones de generación eléctrica a evaluar 356

5.17 Cambio en los pesos de los criterios por ajuste del modelo 361

5.18 Modelo de valor ajustado a las condiciones del caso de estudio $\quad$.. 362

5.19 Solución del caso base. Capacidades de generación a instalar para el período 2013-2025, por tipo de energía primaria base

5.20 Sensibilidad ante variaciones en el presupuesto en el caso base sin restricciones $[\geq]$

5.21 Efecto de variación en la participación de las opciones gas y petróleo

5.22 Soluciones posibles para un presupuesto de 65 mil millones de US\$

5.23 Una aproximación a la localización de nuevos desarrollos eléctricos 424 
5.24 Potencial evolución de la matriz de suministro de electricidad al país,

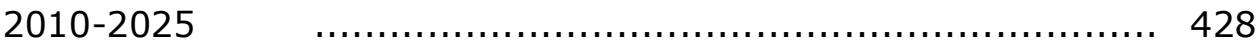

CAPÍTULO 6. PROPUESTA METODOLÓGICA DE EVALUACIÓN $\quad \ldots \ldots \ldots \ldots \ldots \ldots \ldots . \ldots . \ldots . \ldots 33$

Figura 6.1a Propuesta metodológica para la evaluación de proyectos en el sector energético. FASES PREVIA. Formulación de alternativas viables ... 435

Figura 6.1b Propuesta metodológica para la evaluación de proyectos en el sector energético. Evaluación (multicriterio+PL) de las alternativas viables 436 


\section{Índice de anexos}

ANEXO 1. ENCUESTA PRELIMINAR

552

1.1 Aspectos a considerar para la evaluación de proyectos. Sector energía

1.1 Formato para la recolección de la información 554

1.2 Hoja de cálculo y resultados 556

ANEXO 2. ENCUESTA 1. VALIDACION DEL MODELO Y PESOS DE LOS CRITERIOS ... 558

2.1 Encuesta 1. Matrices de juicios de los entrevistados 559

2.2 Pantallas Expert Choice ${ }^{\circledR}$. Grupos 1, [1+2] y [3+4] 563 ANEXO 3. ENCUESTA 2. APLICACION DEL MODELO 565

3.1 Hoja para el cálculo de los coeficiente de robustez por entrevistado y alternativa..... 566

3.2 Hoja para la consolidación de los coeficientes de robustez por alternativa 568

3.2 Hoja de cálculo para SOLVER. Casos 25 y 26 569

3.3 Hoja de cálculo para SOLVER. Caso base 570 


\section{Introducción}

Hoy día, uno de los desafíos más importantes de los gobiernos del mundo es asegurar a sus respectivos países, el suministro de energía necesario para su desarrollo económico y para el bienestar de sus pueblos. En los tiempos que corren, adicionalmente, esa energía debe ser de la más alta calidad posible.

El crecimiento sostenido de la economía mundial en las últimas décadas; especialmente el impresionante ritmo de desarrollo económico de China e India en los últimos años, ha sido impulsado por un incremento sin precedentes en el suministro global de energía. Si los gobiernos del mundo continúan con las mismas políticas energéticas que se han aplicado hasta el presente, sin una acción coordinada de todos los países dirigida a racionalizar el uso de los recursos energéticos, la demanda global de energía primaria para el año 2030 podría alcanzar 16.800 millones de toneladas de petróleo equivalente ${ }^{1}$ lo que representa un incremento aproximado de un $40 \%$ sobre el consumo del año 2009. Tal como sucede hoy en día, los combustibles fósiles seguirían representando alrededor de un $80 \%$ de la cesta mundial de la demanda de energía primaria; y de ella, el combustible dominante seguiría siendo el petróleo [IEA, 2009a]. Este patrón de consumo provocaría una excesiva dependencia de las importaciones de petróleo y gas por parte de los países consumidores sin los recursos energéticos necesarios para autoabastecerse; y un incremento sostenido de las emisiones de $\mathrm{CO}_{2}$ y otros óxidos gaseosos en la atmósfera, con influencia importante sobre el calentamiento global y cambios irreversibles en el clima de la tierra.

\footnotetext{
11 tonelada equivalente de petróleo $=1$ tep $=42 \mathrm{GJ}=42 \times 10^{9} \mathrm{~J}$
} 
A las tasas de consumo actual, el tiempo estimado de duración de las reservas mundiales probadas de petróleo convencional que alcanzan aproximadamente 1,4 billones $\left(1,4 \times 10^{12}\right)$ de barriles, se estima en unos 46 años [BP, 2011]. Si se incluyen en el cálculo, las reservas probables en campos descubiertos y los depósitos por descubrir, el potencial remanente recuperable de petróleo convencional se eleva a 2,4 billones de barriles [IEA, 2008]. Adicionalmente, a esta cifra debe añadirse las reservas de petróleo no convencional ${ }^{2}$ : arenas asfálticas y petróleo extrapesado localizadas principalmente en Alberta, Canadá y en la Faja del Orinoco en Venezuela, que se acercan a los tres billones de barriles de los cuales más de 400 mil millones de barriles son reservas probadas [Government of Alberta, 2012; PDVSA, 2010); y unos 1,5 billones de barriles de reservas de esquistos bituminosos [WEC, 2007] gran parte de las cuales se ubican en Utah, Estados Unidos.

Por su parte, las reservas probadas de gas natural convencional se sitúan en más de 180 billones de metros cúbicos estándar; y a la tasa de producción actual, su duración se estima en unos 60 años [BP, 2011]. Las reservas podrían subir a 400 billones de metros cúbicos y su duración a más de 130 años, si se incluyen las reservas probables y posibles en campos descubiertos y los yacimientos por descubrir [IEA, 2008]. Adicionalmente habría que añadir unos 900 billones de metros cúbicos de gas natural no convencional procedente de arenas de baja porosidad, lechos de carbón y esquistos que se encuentran mayoritariamente en Estados Unidos [IEA, 2008].

Aún cuando el agotamiento de los combustibles fósiles no parece ser el problema al menos a mediano plazo, la capacidad para extraerlos a la misma velocidad que el mercado los demanda, si lo es. En el caso de un campo petrolero, la tasa de producción crece exponencialmente hasta que se alcanza una tasa máxima de extracción del recurso, y luego declina en forma sostenida hasta que se agota el

2 Petróleo no convencional se refiere a petróleo con densidad menor a $10^{\circ} \mathrm{API}$, alta viscosidad, alto contenido de azufre y metales pesados. Su extracción, transporte y refinación debe efectuarse con tecnologías más avanzadas que requieren más agua, energía y disolventes que los métodos tradicionales. 
yacimiento ${ }^{3}$. La tasa de declinación post-pico varía de campo a campo en función de su tamaño, la intensidad con la cual haya sido explotado, su localización o no en tierra firme y las inversiones efectuadas para combatir la declinación natural en la producción del yacimiento. La tasa promedio global de declinación observada para aquellos campos que han pasado su pico de producción se estima en 6,7\% [IEA, 2008]; y en base a la declinación observada de la producción de los campos petroleros más importantes del mundo, se debate sobre el momento a partir del cual la producción mundial de petróleo convencional comenzará una declinación irreversible, con el consiguiente riesgo al suministro si no se efectúan cuantiosas inversiones no sólo en el mantenimiento de los campos existentes sino en exploración y desarrollo de nuevas alternativas de producción de petróleo y gas.

Sin embargo, los países con las mayores reservas de gas y petróleo en el mundo han asumido casi completamente el manejo de sus recursos energéticos, excluyendo - colocando severas restricciones a las compañías internacionales que tradicionalmente han dominado la industria y que disponen del capital, el conocimiento y la tecnología para desarrollar sus reservas. Las corporaciones nacionales pueden no tener la capacidad de efectuar las inversiones necesarias, muy cuantiosas especialmente en las etapas de exploración y desarrollo de nuevos yacimientos; ni tener acceso a las más nuevas tecnologías para el incremento de la producción. Otras inversiones importantes tienen que ver con la actualización y expansión de la capacidad de refinación que en estos momentos está prácticamente copada a nivel mundial [OPEC, 2011]. De esta forma, si se desea mantener el ritmo de inversiones necesario para expandir o al menos estabilizar la oferta de crudo y productos refinados, se impone, al menos en algunos casos, alianzas con el capital y la tecnología extranjera.

Por otra parte, el elevado consumo energético actual crea a los países que no pueden autoabastecerse, una excesiva dependencia de las importaciones procedentes de los pocos países donde se encuentran concentradas las reservas más importantes de petróleo y de gas en el mundo. Así, los miembros de la Organización

${ }^{3}$ Curva en forma de campana de Hubbert. 
de Países Exportadores de Petróleo y la Unión Soviética poseen en conjunto el 90\% de las reservas probadas de petróleo, el 80,4 \% de las reservas probadas de gas y son responsables por el $76,5 \%$ de las exportaciones de crudo en el mundo que dirigen mayoritariamente a China e India, Europa Occidental, Estados Unidos y Japón; y del $48 \%$ de las exportaciones de gas [OPEC, 2011]. Con tal cuota del mercado, es natural que estos países busquen obtener la mayor ventaja de la venta de sus recursos para lo cual periódicamente revisan sus cuotas de producción de forma de controlar, al menos parcialmente, el nivel de precios del combustible en el mercado. Adicionalmente, algunos de estos países son políticamente inestables y representan una fuente de riesgo de interrupciones del suministro, que ya han ocurrido en el pasado con un importante impacto sobre el precio de los combustibles. También pueden verse afectadas las rutas de suministro.

Ante una creciente demanda mundial de energía sin el correspondiente incremento y seguridad en el suministro de petróleo y gas, el mundo se viene enfrentando a una escalada de los precios a la cual son especialmente sensibles los países más pobres del mundo. A mitades del 2008, el precio del petróleo alcanzó un máximo de 145,31 US\$/bbl (WTI Cushing Oklahoma) para luego ante la crisis económica mundial bajar hasta unos 30 US\$/bbl a finales del mismo año, recuperarse y volver a bajar hasta 94 US $\$ / b b l$ a mediados del 2012 [U.S.EIA, 2012a] mostrando una extrema variabilidad. Los más grandes consumidores han reaccionado acumulando inventarios en época de precios más bajos; sin embargo, la seguridad de acceso a energía a precios accesibles, pasa por diversificar la cesta energética y las fuentes geográficas de suministro por parte de cada país; y naturalmente, por la normalización del funcionamiento del mercado.

Un segundo problema de importancia creciente, es el continuo incremento de los niveles de $\mathrm{CO}_{2}$ y otros óxidos gaseosos en la atmósfera como consecuencia en gran medida de la combustión de los combustibles fósiles y de sus productos derivados. Gases como el dióxido de carbono $\left(\mathrm{CO}_{2}\right)$, metano $\left(\mathrm{CH}_{4}\right)$, óxido nitroso $\left(\mathrm{N}_{2} \mathrm{O}\right)$ y otros gases o vapores $\left(\mathrm{O}_{3}, \mathrm{H}_{2} \mathrm{O}\right.$ y halo-carbonados) tienen la capacidad de absorber la radiación infrarroja emitida por la superficie de la Tierra y re-emitirla en todas las direcciones, especialmente de vuelta hacia la superficie terrestre evitando su continuo enfriamiento; el fenómeno se conoce como efecto invernadero. Cuando 
estos gases se acumulan en la atmósfera, el proceso se acentúa y se produce un incremento mayor en la temperatura terrestre lo que a su vez produce cambios importantes en el sistema climático como la fusión de las nieves y hielos del planeta y la elevación del nivel promedio de los mares [IPCC, 2008].

Para el año 2005, las concentraciones promedio de $\mathrm{CO}_{2}, \mathrm{CH}_{4}$ y $\mathrm{N}_{2} \mathrm{O}$ en la atmósfera alcanzaron $379 \mathrm{ppm}, 1.774 \times 10^{-3} \mathrm{ppm}$ y $319 \times 10^{-3} \mathrm{ppm}$ respectivamente ${ }^{4}$, cifras muy superiores a los valores de referencia prevalecientes antes de la revolución industrial [IPCC, 2008]. Como consecuencia, los registros instrumentales de las temperaturas terrestres muestran que su promedio mundial se elevó aproximadamente en $0,74{ }^{\circ} \mathrm{C}$ en el período [1906-2005] hasta alcanzar unos 14,5 ${ }^{0} \mathrm{C}$; los valores observados del nivel del mar indican que su promedio mundial se incrementó en 3,1 mm/año desde 1993; y datos satelitales obtenidos desde 1978 revelan que la extensión de los hielos marinos árticos ha disminuido en un 2,7\% por decenio. Otras observaciones evidencian el incremento de las precipitaciones en algunos lugares del mundo y de la superficie afectada por las sequias, en otros; y un aumento de la actividad ciclónica en el Atlántico Norte, todo aproximadamente desde el año 1970 [IPCC, 2008].

Las emisiones de dióxido de carbono provenientes de la combustión de recursos fósiles representan un $99,6 \%$ de las emisiones totales a la atmósfera y alcanzaron 29.000 millones de toneladas para el año 2009 [IEA, 2011a], siendo los principales emisores China, Estados Unidos, la Federación Rusa e India [IEA, 2011c]. Si se mantiene el predominio de los combustibles fósiles en el patrón de uso de la energía, un incremento en el suministro de energía primaria mundial del orden del $40 \%$ entre el 2009 y el 2030 podría disparar las emisiones de $\mathrm{CO}_{2}$ hasta alcanzar unas 40,2 Gt para el año 2030 con importantes cambios sobre el sistema climático mundial [IEA. 2009a].

Aún cuando sólo un 27,2\% del suministro de energía primaria mundial para el año 2009 provino del carbón, su participación en el total de las emisiones de $\mathrm{CO}_{2}$ a la

4 ppm: unidad de concentración, partes por millón en volumen 
atmósfera fue de $43 \%$ dado su elevado contenido de C por unidad de energía liberada ${ }^{5}$. Para el mismo año, el petróleo siguió siendo el combustible dominante con un $32,8 \%$ del suministro de energía primaria total aunque su aportación disminuyó a favor del gas, combustible menos contaminante cuya participación subió a un $20,9 \%$. Las emisiones de $\mathrm{CO}_{2}$ a la atmósfera por la utilización de estos combustibles fueron respectivamente del $36,7 \%$ y $19,9 \%$ del total de $\mathrm{CO}_{2}$. Otros tipos de energía como la solar, eólica, hidráulica, geotérmica, oceánica y biomasa participaron con $19,1 \%$ en el suministro mundial de energía y su contribución a las emisiones de $\mathrm{CO}_{2}$ fue prácticamente nula [IEA, 2011a].

Para el año 2009, los sectores de generación de electricidad y calor produjeron un $41 \%$ de las emisiones globales de $\mathrm{CO}_{2}$. Para el año 2035, se pronostica un incremento del 75\% sobre la demanda del año 2009 [IEA, 2011c] debido al rápido crecimiento de la población y la actividad económica en algunos de los países en vías de desarrollo y al incremento en el uso de la electricidad en hogares, comercios e industrias. Igualmente, se anticipa que el carbón suministre gran parte de los requerimientos de energía del sector, especialmente en países como China e India, con un desarrollo industrial acelerado y con grandes reservas de carbón pero limitados recursos de otras fuentes de combustible. En consecuencia, se producirá un aumento importante en las emisiones de $\mathrm{CO}_{2}$ derivadas del sector.

Sin embargo, la generación de electricidad y calor puede hacerse a partir de otras fuentes de energías menos contaminantes, como el gas, las energías no renovables y la energía nuclear. La evolución final de las emisiones dependerá en gran medida del incremento de la cuota de estas fuentes de energía alternativas en la generación y del uso generalizado de los procesos de captura y almacenamiento de $\mathrm{CO}_{2}$ que ya han comenzado a implementarse.

Para el año 2009, el sector transporte contribuyó con un 23\% de las emisiones globales de $\mathrm{CO}_{2}$. Sin medidas adicionales que racionalicen el uso de la energía, la demanda mundial de este sector se incrementará en un 40\% para el año 2035 [IEA,

5 IPCC factores de emisión: carbón : 25,8-29,1 tC/TJ ; petróleo : 27,5 tC/TJ ; Gas : 15,3 tC/TJ 
2011c]. Para limitar las emisiones en el sector, se requerirán políticas innovadoras y un marco regulatorio que fomente la inversión en el diseño de vehículos con mayor eficiencia en el uso del combustible; y más importante, la inversión en el desarrollo de tecnologías que permitan el desplazamiento hacia el uso de fuentes de energía menos contaminantes como la electricidad, el hidrógeno y el uso de biocombustibles en mezclas con gasolina y con diesel.

En resumen, el cambio climático, la dependencia creciente de los combustibles fósiles, la situación del mercado mundial de energía caracterizado por un gran incremento de la demanda, la falta de seguridad en el suministro motivado a conflictos en los pocos países que disponen de las mayores reservas, la necesidad de cuantiosas inversiones para mantener el nivel de suministro requerido y el incremento de las facturas energéticas como consecuencia de un aumento pronunciado en los precios del combustible han colocado a los países desarrollados o menos desarrollados en una situación de vulnerabilidad económica y de peligro al bienestar de su pueblos; ante lo cual se han visto obligados a implementar políticas fiscales y medidas regulatorias que favorezcan la búsqueda de alternativas de energía más limpias y el desarrollo de tecnologías más eficientes para su transformación y uso.

América es un continente conformado por países que en su gran mayoría no poseen las reservas de combustibles fósiles necesarias para su autoabastecimiento. Estados Unidos y Brasil son casos notables. Ambos han realizado importantes esfuerzos para garantizar su seguridad energética, aunque en diferentes direcciones. Estados Unidos ha tratado de asegurar sus fuentes de suministro externo ante el previsible deterioro de sus reservas; y ha iniciado el desarrollo de tecnologías para el aprovechamiento de energías no renovables; entre ellas, la producción de biocombustibles a partir de maíz. Sin embargo, el volumen y perfil de su consumo energético no ha variado significativamente. En tal sentido la Comisión de las Comunidades Europeas ha formulado un llamado a esta nación a implementar políticas que aceleren el crecimiento en el uso de energías renovables de forma tal que para el año 2020 su participación alcance un 20\% del consumo nacional. Por otra parte, el presidente de Estados Unidos ha asegurado que dará todo el apoyo necesario al desarrollo de tecnologías para el aprovechamiento de fuentes de energía 
renovables como complemento a las fuentes de energía convencionales de forma de asegurar su independencia energética.

Por su parte, Brasil ha hecho importantes avances en biocombustibles. En particular, ha dedicado esfuerzo y recursos al desarrollo de tecnología para la producción de etanol proveniente de la fermentación de la caña de azúcar, que hoy día es usado como mezclas gasolina-etanol (10\% y $85 \%$ ) por gran parte de su parque automotor. Para el año 2005, aplicó la experticia adquirida con el bioetanol en la producción de biodiesel a partir de aceite de ricino y aceite de palma. Para finales del 2006, el programa había producido más de 100.000 empleos en el noreste del país adicionales a los 500.000 empleos rurales mantenidos por el programa ProAlcool y los 500.000 empleos indirectos relacionados a la producción rural de etanol [Mathews J., 2007]. Hoy en día, Brasil exporta biocombustibles siendo China e India sus principales clientes, es productor de petróleo y recientemente ha realizado descubrimientos de importantes yacimientos de petróleo y gas que garantizan su autosuficiencia energética.

Otros países en Suramérica, Centroamérica y el Caribe mantienen el mismo patrón de dependencia de los combustibles fósiles. Venezuela es un país con grandes reservas de petróleo y gas natural cuya explotación permite su abastecimiento y la exportación especialmente de petróleo y sus derivados, lo cual constituye una principalísima fuente de ingresos al país. Hasta la fecha, no se perciben avances significativos en el desarrollo del sector de las energías renovables. México, Colombia, Ecuador, Perú y Bolivia producen petróleo y/o gas; entre ellos Colombia ha comenzado a producir etanol a partir de la caña de azúcar. Otros países en Centroamérica y el Caribe son importadores de combustibles fósiles; muchos de ellos son países poco desarrollados donde la factura por importación de petróleo con la situación actual de los precios, realmente constituye una carga no sostenible para sus respectivos presupuestos.

Cada país debe desarrollar los mejores planes energéticos de acuerdo a sus presupuestos, sus disponibilidades de fuentes de energía propias o importadas y a información actualizada sobre las tecnologías más eficientes a fin de de asegurar el bienestar de sus ciudadanos y de colaborar con la calidad de vida en el planeta. 
Latinoamérica es un continente casi virgen en tal sentido. Cualquier esfuerzo que facilite la evaluación formal y sistemática del impacto económico, ambiental y social de planes energéticos o proyectos que favorezcan el aprovechamiento eficiente de la energía, constituye un aporte al avance en la dirección correcta dentro del sector energía. Los resultados del análisis apoyarán la búsqueda de la mejor decisión en cada caso. La misma puede ser afectada por gran número y variedad de factores y debe apoyarse en la adecuada combinación de los criterios definidos por los agentes involucrados en el análisis.

Una investigación sobre el uso del análisis de decisión multicriterio (MCDA, por sus siglas en inglés) en el sector de planificación energética [Parodi, 2007] mostró el incremento significativo que han sufrido las aplicaciones de las metodologías MCDA durante la últimas décadas. Específicamente, el método de las Jerarquías Analíticas ha acaparado las preferencias de los usuarios, seguido de lejos por los métodos PROMETHEE, ELECTRE y el Proceso de Redes Analíticas (ANP). Cada uno de ellos presenta sus ventajas e inconvenientes frente a una problemática en particular, lo que hace pensar en la posibilidad de confrontar resultados obtenidos por vías diferentes, o en combinar metodologías de forma de aprovechar las fortalezas de cada una de ellas, si las características del problema lo permiten.

El trabajo de investigación que se propone tiene que ver, en primer lugar, con la identificación y validación de un conjunto común de factores, atributos o aspectos importantes en los cuales pueda basarse la evaluación de proyectos y la formulación de los mejores planes en el sector energético de un país. En segundo lugar, tiene que ver con la definición y validación de un conjunto común de indicadores que permita cuantificar el potencial impacto que en cada uno de los aspectos previamente identificados ocasionará cada proyecto bajo consideración. En tercer lugar, tiene que ver con la formulación de un modelo de valor que incorpore los atributos, indicadores y criterios validados, y que permita integrar en un único indicador el impacto económico, ambiental y social de los proyectos considerados. $Y$ finalmente, tiene que ver con la propuesta de una metodología que agrupe los procesos anteriores y que permita la evaluación integral de los proyectos de inversión, técnica y legalmente viables, en el sector energético. 
En virtud de lo anteriormente expuesto pueden plantearse como hipótesis del trabajo propuesto:

- Para el sector energético de cada país, es posible identificar y validar un conjunto común de objetivos, atributos y criterios relevantes, significativos, fácilmente entendibles y no redundantes que reflejen los aspectos importantes que pueden afectar la priorización de proyectos en el área.

- Para el sector energético de cada país, es posible definir y validar un conjunto común de indicadores que permitan la cuantificación de los atributos previamente identificados y validados.

- Para el sector energético de cada país, es posible formular un modelo de valor de apoyo a las decisiones en el área que incorpore los aspectos económicos, sociales y ambientales que puedan influir en la priorización de proyectos técnica y legalmente viables en el área.

- Dado que las decisiones sobre planes y proyectos en el sector energético competen a las autoridades locales, regionales o nacionales de un país, es deseable incorporarlas junto a otros expertos en el área, al proceso de validación de objetivos, atributos, criterios e indicadores previamente identificados. Si se cumple este paso, es posible formular una metodología para la evaluación integral de proyectos en el sector, que sea sencilla de aplicar, compatible con la información disponible, que provea el tipo de resultados requerido y que se perciba como confiable por parte del decisor.

El trabajo se realiza como requisito final para optar al Doctorado en Proyectos de Ingeniería que ofrece la Universidad Politécnica de Valencia en España y tiene como objetivos los que se copian a continuación.

\section{Objetivo general}

Proponer una metodología para la evaluación integral de proyectos de inversión técnica y legalmente viables en el sector energético de cada país. La propuesta debe integrar al análisis, los aspectos económicos, sociales y ambientales que puedan influir en la aceptación y ordenamiento de las opciones posibles en la formulación de los mejores planes en el sector. 


\section{Objetivos específicos}

- Obtener una visión sobre el estado del arte en el tema de decisión multicriterio; especialmente sobre las metodologías más utilizadas en la estructuración inicial del problema de decisión y en la formulación del modelo de valor de apoyo a la toma de decisiones.

- Seleccionar la metodología de decisión multicriterio base, en torno a la cual se iniciará el estudio.

- Obtener un panorama general de las características de las fuentes de energía disponibles en el mundo de hoy, las tecnologías para su extracción, captación o producción, y para su conversión en calor, electricidad y/o combustibles; el monto y distribución geográfica aproximada de sus reservas o su potencial energético, su nivel de producción y uso, el impacto ambiental derivado de su utilización; y finalmente, las ventajas y desventajas de su empleo.

- Identificar y clasificar los aspectos importantes que pueden influir en la priorización de proyectos en el sector energético.

- Identificar, estructurar y validar objetivos, atributos, criterios e indicadores para la evaluación integral de proyectos en el sector energético.

- Formular y validar un modelo de valor de apoyo a la decisión que incorpore los aspectos técnicos, económicos, sociales y ambientales que puedan influir en la evaluación de proyectos en el sector energético.

- Obtener la información necesaria para la estructuración del caso de estudio.

- Estructurar el caso de estudio.

- Resolver el caso de estudio con ayuda del modelo de valor propuesto.

- Proponer una metodología para la evaluación integral de proyectos en el sector energético, especialmente en países en vías de desarrollo como Venezuela.

El trabajo se divide para su exposición en siete capítulos. El capítulo 1 presenta una síntesis de los métodos de análisis multicriterio más citados en la bibliografía 
especializada, haciendo especial énfasis en las ventajas y desventajas de sus respectivos usos, y mención a los paquetes informáticos disponibles que permiten el procesamiento individual y en grupo de los juicios de valor de los expertos que participen en el proceso.

El capítulo 2 explica la metodología seguida para cumplir con cada uno de los objetivos de la investigación enunciados anteriormente. Se presenta el diagrama de flujo de las actividades a desarrollar señalando las fuentes de información a utilizar y el producto de cada una de ellas.

El capítulo 3 presenta las características del sector energético en el mundo actual. Ello incluye la caracterización de cada fuente de energía primaria disponible, el inventario y la ubicación geográfica aproximada de sus reservas; la descripción de las tecnologías modernas más utilizadas para su obtención y transformación en energías útiles al hombre y una indicación aproximada de los costos asociados; la reseña de las vías para su comercialización y sus precios; y finalmente, un resumen de los efectos ambientales y sociales que produce su aprovechamiento. El capítulo presenta como producto final una serie de cuadros donde se destacan las ventajas y desventajas derivadas del aprovechamiento de cada fuente de energía identificada; la información contenida en tales cuadros constituyen un insumo muy valioso a la etapa siguiente del trabajo de investigación a completar.

El capítulo 4 expone detalladamente el trabajo realizado en el diseño del modelo de valor para la evaluación multicriterio de proyectos en el sector energético, objetivo central del trabajo a desarrollar. El capítulo se divide en tres grandes secciones que describen respectivamente las actividades desarrolladas durante, (i) la escogencia de la plataforma de referencia para el análisis de proyectos, en base a la información resumida en el capítulo 1 y a estadísticas sobre aplicaciones de cada metodología identificada durante la última década; (ii) la selección, estructuración y validación de los criterios e indicadores para la evaluación, proceso iterativo realizado en base a la información obtenida en el capítulo 3 y a los juicios de los expertos seleccionados para la participación en el proceso; y (iii) la estructuración y validación del modelo final de evaluación multicriterio.

El capítulo 5 presenta la aplicación del modelo propuesto a un caso de estudio seleccionado y el análisis de sus resultados. 
Como producto final del trabajo realizado, el capítulo 6 resume la propuesta metodológica para la evaluación integral de proyectos en el sector energético. El capítulo 7 resume y discute los resultados obtenidos, en el contexto global del trabajo realizado.

Finalmente, se incluye en anexos las hojas de cálculo desarrolladas para su uso en el trabajo e información que sirvió de base al desarrollo del mismo. 


\section{Capítulo 1 Marco de referencia}

Un proyecto es un conjunto de ideas coherentes y organizadas sobre la forma de cumplir con uno o más objetivos fijados. Un proyecto de inversión es un plan de acción a futuro cuya preparación, ejecución, puesta en marcha y explotación implica la asignación de recursos a la generación de bienes y/o a la prestación de servicios con miras a obtener determinados beneficios económicos y sociales. La ruta tecnológica y logística para pasar de los recursos a los resultados es una alternativa de acción; y para la consecución de sus objetivos y en la búsqueda de la mejor solución, el proyecto puede plantear una o más potenciales vías de acción.

El análisis de la viabilidad de las acciones propuestas y el estudio comparativo de los resultados o efectos que se espera alcanzar frente a los recursos necesarios para lograrlo se conoce como evaluación del proyecto y sus conclusiones pueden servir de apoyo a la decisión de ejecutar o no el proyecto; o de incorporarlo, si éste es el caso, a los planes de desarrollo de una nación.

Tradicionalmente, el análisis de un proyecto de inversión se ha realizado desde los puntos de vista institucional, técnico, económico, financiero y administrativo. Una vez comprobada su viabilidad técnica y legal, la valuación del proyecto se realizaba casi exclusivamente en base a su rendimiento económico. Posteriormente, se comprobaba su viabilidad financiera y la idoneidad de los sistemas administrativos y logísticos propuestos para su ejecución y explotación; y finalmente, se reseñaban aquellos factores difícilmente cuantificables que podían afectar el éxito del proyecto [Naciones Unidas, 1958; Naciones Unidas, 1972; OCDE/CEMLA 1972, Allen, 1972; ILPES, 1974; ONUDI, 1987; Parodi, 1995; Sapag, 1998 y 2001; Baca G., 2001]. 
Más recientemente y debido a la creciente toma de conciencia frente al deterioro de los espacios del planeta y a la necesidad de mejorar la calidad de vida de millones de personas en el mundo, se han incorporado al análisis y adquirido una gran relevancia para su evaluación, los efectos ambientales y sociales que se estima producirá el proyecto una vez entre en funcionamiento. Bajo ese enfoque, un proyecto técnica e institucionalmente viable es tanto más valioso mientras mayor sea su rendimiento económico, menor su impacto ambiental y mayores los beneficios que produzca a la comunidad. Si estos valores pueden proyectarse al futuro, el proyecto será sostenible en el tiempo; esto es, será capaz de "cumplir las necesidades del presente sin comprometer la capacidad de las generaciones posteriores de cumplir sus propias necesidades" [Brundtland, 1987].

De esta forma, la complejidad del estudio se incrementa por el número de factores a considerar, porque el volumen y la variedad de la información a recabar crece y a menudo es incompleta; y porque la tendencia moderna es a incluir en el proceso de análisis no sólo a los expertos en las respectivas áreas sino a las personas o grupos de personas que pueden resultar afectadas por la puesta en marcha y explotación del proyecto. Todos ellos tienen expectativas, juicios de valor, preferencias e intereses diferentes los cuales deben conciliarse para identificar los criterios relevantes al análisis y lograr un adecuado equilibrio entre ellos. El estudio ya no se limita a evaluar la efectividad y la eficiencia técnica del proyecto, o su relación beneficio/costo sino que habrá que incorporar formalmente al análisis, los aspectos sociales y ambientales, que bajo la óptica de diferentes grupos de opinión, estén relacionados con el proyecto; todo dentro del marco legal, estratégico y/o político propio del país sede del proyecto.

En consecuencia, la evaluación de una propuesta de inversión deja de ser un análisis monocriterio cuyos resultados se basan en métodos de optimización de un objetivo único aplicados por un grupo de expertos en el área; para convertirse en un estudio que debe apoyarse en metodologías de análisis multicriterio (MCDA, por sus siglas en inglés), con la participación de múltiples actores que aportan diferentes puntos de vista cuya conciliación es un proceso iterativo que debe repetirse tantas veces como sea necesario para alcanzar un equilibrio entre los factores considerados que satisfaga a todos los participantes. 
El enfoque multicriterio de la evaluación de proyectos se ha visto fortalecido por el gran desarrollo de la informática y de las telecomunicaciones que viene experimentando el mundo desde hace unas pocas décadas. En efecto, por una parte se ha simplificado el acceso a una información que es cada vez más variada y extensa; y por la otra, la aparición de metodologías de apoyo al análisis multicriterio y de aplicaciones informáticas en el área, las altas velocidades de procesamiento de información de los computadores y las redes de comunicación han derrumbado las barreras para el modelado de proyectos con las exigencias del mundo moderno, de acuerdo a múltiples criterios que manejan factores de índole cuantitativa o cualitativa, y con la participación de múltiples actores localizados o no en la misma ubicación geográfica [Parodi, 2007].

Un gran número de trabajos publicados en el campo de la decisión multicriterio dan cuenta de la relevancia que el tema ha adquirido desde la última década del siglo pasado. Aplicaciones de las técnicas de análisis multicriterio se encuentran en los sectores militar, agrícola, industrial, energético, salud, turismo, educación, banca y servicios; en problemas de planificación estratégica, planificación de uso de tierras, planificación energética, sistemas de manufactura, localización, gestión de recursos, evaluación de energías renovables, control ambiental, selección de proyectos, finanzas y ética, entre otros [Chatzimouratidis, 2008; Diskoulaki et al., 2009;; Burton, 2007; Terrados, 2007; Hirschberg, 2006; Cavallaro, 2005; Brans y Mareschal, 2005; Figueira, Mousseau y Roy, 2005; Erdogmus Kapanoglu y Ekoc, 2006, Saaty 2005a, Pohekar y Ramachandran, 2004; Becalli, 2003].

Particularmente en el sector energético, el análisis multicriterio se ha utilizado en planificación energética [Kaya et al., 2010; Tsoutsos et al., 2009; Terrados et al., 2009; Diakoulaki et al. 2009; Ulutas, 2005]; selección entre alternativas energéticas [Kahraman et al., 2010; Wang et al., 2008]; evaluación de conveniencia de uso de energías renovables [Theodorou et al., 2010; Phalan, 2009; Papalaxandrau et al., 2008; planificación de uso de los recursos energéticos [Wang et al., 2010; Papadopoulos et al., 2006]; evaluación técnica, económica y sostenibilidad de sistemas de energía [Carrera et al, 2010; La Rovere et al., 2009; Chatzimouratidis et al., 2009; Wang el al., 2009; Cavallaro et al., 2005] y similares. 
La forma de incorporar al análisis los factores que pueden afectar la valoración del proyecto y el tipo de resultados obtenidos dependen de la metodología seleccionada para su evaluación. La elección en cada caso tiene que ver con la naturaleza de las variables del proyecto, con el tipo de información disponible, con la forma de plantear los objetivos que se desea alcanzar y con el tipo de resultados que se pretende obtener. Es conveniente que el método escogido sea sencillo de usar, fácil de entender, flexible y que se perciba como confiable por parte del decisor [Loken, 2007] y de todos los involucrados en el proceso de evaluación.

A continuación se presenta un resumen de los métodos de análisis multicriterio, que aparecen documentados con mayor frecuencia en las publicaciones especializadas de los últimos años. El énfasis de la revisión se coloca sobre las fortalezas y debilidades de cada metodología a fin de diferenciarlas, y de que la información recogida contribuya a la selección de la metodología más adecuada para la evaluación multicriterio de un proyecto de inversión. Un resumen de la información que se incluye fue parte importante del documento presentado ante la Universidad Politécnica de Valencia para optar al Diploma de Estudios Avanzados en Ingeniería de Proyectos [Parodi, 2007], requisito previo a la obtención del Doctorado en el área.

\subsection{Métodos de análisis multicriterio}

La descripción de un número importante de métodos de apoyo a la decisión multicriterio (MCDM, por sus siglas en inglés) se encuentra disponible en la literatura especializada. Su característica común es que buscan la valoración y el ordenamiento de múltiples alternativas de acción, en base a sus respectivos rendimientos frente a múltiples criterios, conflictivos entre sí; y que en general, se expresan en unidades no comparables. Los métodos MCDM pueden clasificarse en cinco grupos, a saber:

- Programación multiobjetivo

- Programación por metas

- Métodos basados en funciones de valor

- Métodos de sobreclasificación

- Métodos basados en jerarquías y redes analíticas 
Como es natural, la revisión que sigue no es exhaustiva.

\subsubsection{Programación multiobjetivo}

Los métodos de programación multiobjetivo se utilizan cuando se busca un conjunto de soluciones eficientes en un contexto definido por múltiples objetivos a optimizar que compiten entre sí y deben satisfacer un determinado conjunto de restricciones ; esto es,

sujeto a

$$
\operatorname{Eff} F(x)=[F 1(x), F 2(x), \ldots . . F n(x)]
$$

$$
\begin{aligned}
& x \in R \\
& x \geq 0
\end{aligned}
$$

donde $F j(x)$ es la expresión matemática del objetivo $j$ a optimizar; $x$, el vector de variables de decisión; y $R$, el conjunto de restricciones que definen el conjunto de soluciones posibles. A cada objetivo debe asignarse un atributo cuantificable que se busca maximizar o minimizar, de acuerdo a su naturaleza. El modelo no incorpora las preferencias del decisor.

Nótese que las alternativas de solución al problema no se definen a priori sino que son el resultado de la resolución matemática del problema planteado.

\subsubsection{Programación lineal multiobjetivo}

Cuando los objetivos y las restricciones pueden expresarse como funciones lineales de las variables del problema, se habla de programación lineal multiobjetivo y el problema se plantea como sigue:

$$
\begin{aligned}
& \text { Eff } F(x)=\{F 1(x), F 2(x), \ldots . F m(x)\} \\
& \qquad \begin{array}{l}
F j(x)=\sum_{i=1}^{n} c j i x i \quad \text { para } j=1,2, \ldots m \\
\text { sujeto a } \\
R k(x)=\sum_{i=1}^{n} \text { aki } x i \leq b k \quad \text { para } k=1,2, \ldots p \\
x i \geq 0
\end{array}
\end{aligned}
$$


Las técnicas más utilizadas para aproximarse al conjunto eficiente son el método de las ponderaciones, el método de las restricciones y el método Simplex multicriterio [Romero, 1996]. El método de las ponderaciones utiliza como función objetivo única a optimizar, la suma ponderada de los objetivos planteados. Para cada vector de pesos se obtiene una solución eficiente y la variación paramétrica del mismo permite aproximarse al conjunto eficiente. Nótese que los pesos no tienen que ver con juicios de valor del decisor.

Por su parte, con el método de las restricciones, se optimiza sólo uno de los objetivos mientras que los demás objetivos se incorporan al problema como restricciones paramétricas. Para cada vector de términos independientes (bk) en la formulación matemática de las nuevas restricciones, se obtiene una solución eficiente y la variación paramétrica del mismo permite aproximarse al conjunto eficiente.

En problemas de programación lineal con un objetivo y dos dimensiones, la solución óptima cae en una de los vértices de la región de las soluciones posibles [Bierman, Bonini y Hausman, 1991]. En problemas de programación lineal multiobjetivo el conjunto de soluciones eficientes cae sobre la frontera Pareto de las soluciones posibles. El SIMPLEX multicriterio es un algoritmo que genera todos los vértices eficientes de un problema multiobjetivo y verifica la eficiencia de cada punto obtenido. El algoritmo trabaja adecuadamente con no más de cinco objetivos y un número de variables y restricciones no superior a cien [Romero, 1996].

Tal como se ha presentado, la programación multiobjetivo puede considerarse como la primera etapa del análisis de decisión multicriterio [Romero, 1996]. En efecto, la aplicación del modelo permite obtener el subconjunto de alternativas de solución eficientes del conjunto de alternativas posibles, en base a atributos que pueden expresarse en forma cuantitativa, sin tener en cuenta las preferencias de los individuos participantes en el análisis del problema.

\subsubsection{Programación por metas}

La programación por metas [Belton y Stewart, 2003] se apoya en el modelo de satisfacción sugerido por Simon (1976), en el sentido de que coloca el énfasis en el 
logro de niveles satisfactorios para cada criterio u objetivo relevante a la decisión, ante la imposibilidad de optimizar todos los objetivos que compiten entre sí. Para ello, a cada criterio identificado como relevante a la decisión, debe asociarse un atributo cuantificable y una meta o nivel de aspiración; de forma que:

$$
F_{j}(x)+n_{j}-p_{j}=g_{j}
$$

donde, $\mathrm{Fj}(\mathrm{x})$ representa la expresión matemática del objetivo $\mathrm{j}$ al cual se asocia una meta $\mathrm{gj}_{\mathrm{j}}$. Las variables $\mathrm{nj}_{\mathrm{y}}$ y $\mathrm{pj}$ cuantifican respectivamente la desviación negativa (falta de logro) y positiva (exceso de logro) del objetivo con relación a la meta. Una variable de desviación es no deseada cuando al decidor le conviene minimizarla para alcanzar el objetivo planteado. Pueden distinguirse tres casos:

- Si el objetivo debe maximizarse, la variable no deseada es nj.

- Si el objetivo debe minimizarse, la variable no deseada es pj.

- Si se desea alcanzar exactamente el nivel de aspiración del objetivo, ambas variables de desviación son no deseadas.

El proceso de minimización de las variables de desviación no deseadas puede ejecutarse de forma diferente (Romero, 1996). En la programación por metas ponderadas se engloban convenientemente ponderadas todas las variables de desviación, en una sola función objetivo. Algebraicamente, el modelo puede expresarse como:

$$
\underset{1}{\operatorname{Min}} \sum(\alpha j n j+\beta j p j)
$$

sujeto a

$$
\begin{aligned}
& \text { Fj }(x)+n j-p j=g j \\
& x \in R \\
& x \geq 0 \quad n j \geq 0 \quad \text { pj } \geq 0 \quad \text { para } j=1,2, \ldots m
\end{aligned}
$$

donde $\alpha \mathrm{j}$ y $\beta \mathrm{j}$ son los pesos asociados a las variables de decisión negativa y positiva respectivamente $\mathrm{y} R$ es el conjunto de restricciones que definen el conjunto de soluciones posibles. Por otra parte, nj y pj deben expresarse en unidades homogéneas para lo cual puede trabajarse con desviaciones porcentuales dividiendo el valor en términos absolutos de la desviación entre su respectivo nivel de 
aspiración. Si el problema es lineal puede utilizarse el algoritmo SIMPLEX para su solución.

Un área de incertidumbre al aplicar la programación por metas es la fijación de de los niveles de aspiración por parte de los participantes. Las soluciones del problema son sensibles a las metas fijadas que pueden oscilar entre valores muy optimistas, no realistas y valores muy bajos. Los mejores resultados se obtienen cuando las metas seleccionadas son optimistas pero posibles [Belton y Stewart, 2003].

Por otra parte, el método requiere que los objetivos estén asociados a atributos cuantificables. De esta forma, el método se limita a problemas que puedan ser formulados en esos términos y excluye problemas que incorporan criterios que se evalúan subjetivamente. En este último caso, la programación por metas puede usarse como una fase previa al análisis MCDA propiamente dicho, para generar una lista más corta de alternativas que luego pueden ser analizadas de acuerdo a los aspectos no cuantificables [Belton y Stewart, 2003].

\subsubsection{Métodos basados en funciones de valor}

Cuando se usa este tipo de metodologías se asocia una puntuación numérica o valor V, a cada alternativa, de forma de producir un orden de preferencia, consistente con los juicios de valor expresados por los participantes, tal que "la alternativa a" sea preferida a la "alternativa b" ( $\mathrm{a}>\mathrm{b}$ ), sí y sólo sí, $\mathrm{V}(\mathrm{a})>\mathrm{V}(\mathrm{b})$; y "la alternativa a sea indiferente con la alternativa b" $(a \sim b)$, sí y sólo sí, $V(a) \sim V(b)$.

\subsubsection{Función de valor multiatributo}

La Teoría de Valor Multiatributo (MAVT, por sus siglas en inglés) utiliza comúnmente una función aditiva de valor definida como:

$$
V(a)=\sum_{j=1}^{m} w j V j(a)
$$

donde, $V(a)$ es el valor global de la alternativa $a, V j(a)$ es el valor que refleja el nivel de logro o rendimiento de la alternativa a con relación al criterio j, y wj es la importancia relativa que se asigna al criterio $j$, para $j=1,2$..m. Para que el modelo 
sea apropiado, los criterios deben satisfacer la condición de independencia preferencial [Benton y Stewart, 2003] que establece que el orden de preferencia en términos de un criterio no debe depender de los niveles de rendimiento asociados a ningún otro criterio.

La definición de una función de valor parcial $\mathrm{Vj}$ que refleje las preferencias o actitud del decisor con relación al desempeño de las alternativas identificadas frente al criterio $j$, requiere la identificación o construcción de una escala intervalo sobre la cual se "mida" el nivel de logro de cada alternativa con relación a dicho criterio. Para construir la escala es necesario definir dos puntos de referencia; típicamente, el peor y mejor desempeño mostrado por las alternativas planteadas con relación al criterio j; o más globalmente, el peor y mejor desempeño de las alternativas concebibles frente al criterio $j$, en un contexto similar. Es conveniente que las funciones de valor parcial sean normalizadas asignando la puntuación 100 al mejor rendimiento y la puntuación cero al peor rendimiento. Las alternativas restantes reciben puntuaciones intermedias que reflejan su rendimiento con relación a los dos puntos extremos [Benton y Stewart, 2003].

La aplicación de la ecuación (10) a cada una de las alternativas de solución planteadas rinde un conjunto de valores globales $\mathrm{V}(\mathrm{x}), \mathrm{x}=\mathrm{a}, \mathrm{b} .$. que permite el ordenamiento de las mismas. Naturalmente, la alternativa con la puntuación más alta es la preferida.

La simplicidad de modelo de agregación aditivo lo hace sencillo de usar y fácilmente entendible por los actores involucrados quienes en cooperación con los analistas sólo deben definir la importancia relativa de cada criterio y asignar puntuaciones a los rendimientos de las alternativas de solución planteadas frente a cada uno de ellos [Benton y Stewart, 2003; Loken, 2007]. El método es compensatorio, y sus resultados son dependientes de la asignación de los pesos a los criterios; por tanto, puede resultar manipulable.

\subsubsection{Función de utilidad multiatributo}

La Teoría de Utilidad Multiatributo (MAUT, por sus siglas en inglés) [Keeney y Raffia, 1976] puede considerarse una extensión de la teoría de valor multiatributo para comparar y ordenar alternativas en presencia de incertidumbre [Loken, 2007; 
Sthub, Bard y Globerson, 1994]. En este caso, el desempeño de cada alternativa con relación a un criterio en particular está descrita en términos de una distribución de probabilidad para el atributo $Z$ asociado a dicho criterio, el cual debe ser cuantitativo y medible en una escala intervalo [Benton y Stewart, 2003].

Cuando se usa esta metodología debe definirse para cada alternativa una función de utilidad multiatributo $\mathrm{U}(Z)$, de tal forma que "la alternativa a sea preferida a la alternativa b", sí y sólo sí, la esperanza matemática de $U\left(Z^{a}\right)$ para la alternativa a es mayor que la esperanza matemática de $U\left(Z^{b}\right)$ para la alternativa b; esto es, $E\left[U\left(Z^{a}\right)\right]$ $>\mathrm{E}\left[\mathrm{U}\left(Z^{\mathrm{b}}\right)\right]$; donde $Z^{\mathrm{a}}$ y $Z^{\mathrm{b}}$ son los vectores de valores aleatorios del atributo que corresponden a las alternativas a y b respectivamente [Benton y Stewart, 2003].

La esperanza matemática $\mathrm{E}\left[\mathrm{U}\left(Z^{\mathrm{a}}\right)\right]$ puede estimarse de acuerdo a la siguiente ecuación [Sthub, Bard y Globerson, 1994]:

$$
E\left[U\left(Z^{a}\right)\right]=\sum_{j=1}^{m}\left[k j \int U j\left(Z^{a}\right) f\left(Z^{a}\right) d(Z)\right.
$$

donde $\mathrm{Uj}(\mathrm{Za})$ es la función de utilidad parcial de la alternativa a, con relación al criterio $j ; f(Z a)$ es la función de probabilidad asociada a $Z^{a}$ y $K j$ el coeficiente de ponderación correspondiente al criterio j.

La aplicación de la ecuación (11) a cada una de las alternativas de solución planteadas rinde un conjunto de valores globales $\mathrm{E}\left[\mathrm{U}\left(\mathrm{Z}^{\mathrm{x})}\right], \mathrm{x}=\mathrm{a}, \mathrm{b}\right.$... que permite el ordenamiento de las mismas. Naturalmente, la alternativa con la puntuación más alta es la preferida.

MAUT es una metodología rigurosa que requiere un nivel de información elevado. La definición de las funciones de utilidad para cada criterio es una tarea engorrosa y complicada debido a que generalmente los involucrados no tienen una buena percepción de sus propias preferencias ante el riesgo [Loken, 2007]; sin embargo es uno de los pocos métodos que incluyen la incertidumbre y la actitud ante el riesgo del decisor. Desde el punto de vista del consenso, la metodología esconde las implicaciones de la data de entrada hasta los cálculos finales lo que dificulta las discusiones de grupo [Sthub, Bard y Globerson, 1994]. 


\subsubsection{Métodos de sobrecalificación}

Los métodos de sobrecalificación para el ordenamiento de un conjunto de alternativas de acuerdo a más de un criterio, se basan en las relaciones de sobrecalificación que pueden existir entre cada dos alternativas del grupo más que en la evaluación individual de cada una de ellas. Una alternativa 'a' se dice que sobrecalifica a otra alternativa ' $b$ ', sí "a es tan buena como b" en la mayoría de los criterios y no significativamente peor en el resto de ellos [Papadopoulos y Karagiannidis, 2006; Benton y Stewart, 2003]. El manejo posterior de las relaciones de sobrecalificación para el ordenamiento de las alternativas, varía con el método particular utilizado.

\subsubsection{Métodos ELECTRE}

La familia de métodos ELECTRE (por sus siglas en francés, ELimination Et Choix Traduisant la REalité) fue desarrollada por Bernard Roy y sus asociados a partir de la década de los años 60, cuando aparece la primera versión ELECTRE I (1968). Otras versiones (IS, II, III, IV, y TRI) [Figueira, Mosseau y Roy, 2005] difieren en la cantidad y variedad de la información requerida de acuerdo a la problemática que se intenta resolver.

La información inicial necesaria para la aplicación de los métodos es una matriz cuyas entradas corresponden al rendimiento, $\mathrm{zj}(\mathrm{i})$, de cada alternativa i, evaluada de acuerdo a cada criterio de decisión $j$. La solución 'a' es considerada mejor que la solución ' $b$ ' sólo cuando $\mathrm{zj}(\mathrm{a})>\mathrm{zj}(\mathrm{b})$. A cada criterio debe asignarse un coeficiente de importancia kj o "poder de voto" que depende del juicio de los participantes en el análisis. Mientras más alto el peso asignado mayor es la importancia del criterio.

El método ELECTRE III [Figueira, Mousseau y Roy, 2005] requiere para la construcción de la relación de sobrecalificación entre dos alternativas a y b del grupo: (i) la introducción al problema de los umbrales de indiferencia ( $\left.q_{j}\right)_{\text {, }}$ preferencia $\left(\mathrm{pj}_{\mathrm{j}}\right.$ y veto ( $\mathrm{Vj}$ ) para cada criterio $\mathrm{j}$; (ii) la definición del índice de concordancia $C_{j}(a, b)$ entre las alternativas a y $b$, para el criterio $j$, y del índice global de concordancia $\mathrm{C}(\mathrm{a}, \mathrm{b})$ entre $\mathrm{a}$ y $\mathrm{b}$; (iii) la definición del índice de discordancia 
$\operatorname{Dj}(a, b)$ entre $a$ y $b$, para el critero j; y (iv) la definición del índice de credibilidad $\mathrm{S}(\mathrm{a}, \mathrm{b})$ que caracteriza la credibilidad de la relación "a sobrecalifica a b", aSb.

El índice de concordancia $\mathrm{Cj}(\mathrm{a}, \mathrm{b})$ se expresa en función de los umbrales de indiferencia y de preferencia definidos para el criterio $\mathrm{j}$, como:

Cj $(a, b)=1 \quad$ si $\quad z j(a)+q j \geq z j(b)$

Cj $(a, b)=0 \quad$ si $\quad z j(a)+p j \leq z j(b)$

$C j(a, b)=[p j+z j(a)-z j(b)] /[p j-q j] \quad$ si $\quad z j(a)+q j<z j(b)<z j(a)+p j$

Y el índice global de concordancia $\mathrm{C}(\mathrm{a}, \mathrm{b})$ se define como:

$$
C(a, b)=\sum_{1}^{m} k j C j(a, b) / \sum k j
$$

A efectos prácticos, el índice anterior es la suma de las pesos normalizados de cada criterio $j$ para $j=1,2 . . m$, para el cual se cumpla la relación $z j(a)+q j \geq z j(b)$.

El índice de discordancia $\mathrm{Dj}(\mathrm{a}, \mathrm{b})$ es definido en función del umbral de veto definido para el criterio j, como:

$\operatorname{Dj}(a, b)=0 \quad$ si $\quad z j(b) \leq z j(a)+p j$

$\operatorname{Dj}(a, b)=1 \quad$ si $\quad z j(b) \geq z j(a)+v j$

$\operatorname{Dj}(a, b)=[z j(b)-z j(a)-p i] /[v j-p j] \quad$ si $\quad z j(a)+p j<z j(b)<z j(a)+v j$

Nótese que la sobrecalificación de la alternativa a sobre la alternativa b es "vetada" (índice 1) si el rendimiento de b excede al de a en una cantidad mayor o igual al umbral de veto.

Finalmente, el índice global de concordancia y los índices de discordancia son combinados en el índice de credibilidad $\mathrm{S}(\mathrm{a}, \mathrm{b})$ que se define como:

$$
S(a, b)=C(a, b) \prod[1-D j(a, b)] /[1-C(a, b)] \text { para } D j(a, b)>C(a, b)
$$

Pueden distinguirse tres casos: (i) si no hay criterio discordante, la credibilidad de la relación de clasificación es igual al índice global de concordancia; (ii) cuando un criterio discordante $\mathrm{j}$ activa su poder de veto, $\mathrm{Dj}(\mathrm{a}, \mathrm{b})=1$ y $\mathrm{S}(\mathrm{a}, \mathrm{b})=0$; en 
consecuencia la relación aSb no es creíble; y (iii) si el índice global de concordancia es estrictamente menor que el índice de discordancia sobre el criterio discordante, el índice de credibilidad es una fracción del índice global de concordancia [Figueira, Mousseau y Roy, 2005].

Finalmente, para el ordenamiento de las alternativas se define el concepto de $\lambda$-preferencia [Belton y Stewart, 2003] que es incorporada al procedimiento como:

"a es $\lambda$-preferida a b" si $(1-s) S(a, b)>S(b, a)$ y $S(a, b)>\lambda$ para $s=0.3-0.15 \lambda$ $\lambda$-fortaleza ' $a$ '= número de veces que ' $a$ ' es $\lambda$-preferida a otras alternativas del grupo $\lambda$-debilidad ' $a$ ' $=$ número de alternativas del grupo que son $\lambda$-preferidas a ' $a$ '.

El ordenamiento se produce por un proceso de "destilación" con $\lambda=\lambda \max -\mathrm{s}, \mathrm{y}$ $\lambda \max =\operatorname{maxS}(a, b)$ de todas las alternativas bajo consideración. Para cada alternativa se determina su calificación como la diferencia entre su $\lambda$-fortaleza y su $\lambda$-debilidad. La alternativa o subgrupo de alternativas con la más alta calificación constituyen el "primer destilado" D1. Si D1 tiene más de una alternativa se repite el proceso hasta que todas las alternativas en D1 hayan sido ordenadas; se continúa el proceso con el conjunto original menos D1. Se repite el proceso hasta que todas las alternativas hayan sido ordenadas.

El procesamiento de la información cuando se trabaja con los métodos ELECTRE puede realizarse con la ayuda de paquetes informáticos como ELECTRE IS, ELECTRE III-IV y TRI ${ }^{6}$ desarrollados por LAMSADE, Universidad de Paris, Francia.

Las diferentes versiones de los métodos ELECTRE fueron desarrollados para resolver problemas distintos y difieren en la sofisticación para modelar la problemática que intentan resolver. Así, ELECTRE I y ELECTRE IS se dirigen a la escogencia de una alternativa; ELECTRE II, III Y IV, a problemas de ordenamiento; y ELECTRE TRI, a la clasificación de las alternativas en categorías. ELECTRE III permite un manejo más sofisticado de los criterios que ELECTRE II, sin embargo; ello se traduce en un esfuerzo mayor para asignar valores a los umbrales de indiferencia,

6 LAMSADE, Université de Paris, Francia, mcda.software@lamsade.dauphine.fr 
preferencia y veto para cada criterio. Estos conceptos son difíciles de entender por parte de los participantes y su inadecuada asignación puede modificar significativamente los resultados. Adicionalmente, está el problema de asignación de los coeficientes de importancia de los criterios modelados.

Por otra parte, el procesamiento de la información se realiza de acuerdo a un algoritmo complicado, difícil de entender por parte de los participantes en el análisis y que no contribuye a mejorar el conocimiento del problema. Los resultados del proceso de destilación dependen del grupo de alternativas considerado y la adición o remoción de una alternativa puede alterar el orden entre las alternativas restantes [Belton y Stewart, 2003].

\subsubsection{Métodos PROMETHEE}

Los métodos PROMETHEE I y II (por sus siglas en inglés, PReference Ranking Organization Method for Enrichment Evaluation) fueron presentados por primera vez en 1982 por J.P. Brans en la Université Laval de Canadá. Posteriormente se han desarrollado las versiones III, IV, V y VI [Brans y Marechal, 2005]; en lo que sigue se resumen lo métodos PROMETHEE I y II.

Los métodos PROMETHEE utilizan el concepto de intensidad de preferencia de la alternativa ' $a$ ' sobre la alternativa ' $b$ ', $\operatorname{Pj}(a, b)$, descrita en función de la diferencia en los rendimientos de las alternativas $d=[z j(a)-z j(b)]$ con relación al criterio $j$. El valor que toma la función de preferencia oscila entre 0 y 1.

Brans [1986] propone los tipos de funciones que se muestran en la figura 1.1. El umbral de indiferencia ' $q$ ' representa la desviación más grande que el decisor considera despreciable mientras que el umbral de preferencia ' $p$ ' es el valor más pequeño que se considera suficiente para generar franca preferencia. La identificación de una función de preferencia en la figura 1.1 implica definir ninguno, uno o dos parámetros, de acuerdo al caso. En el caso de la curva de Gauss debe especificarse el parámetro ' $s$ ' que define el punto de inflexión de la función de preferencia. 


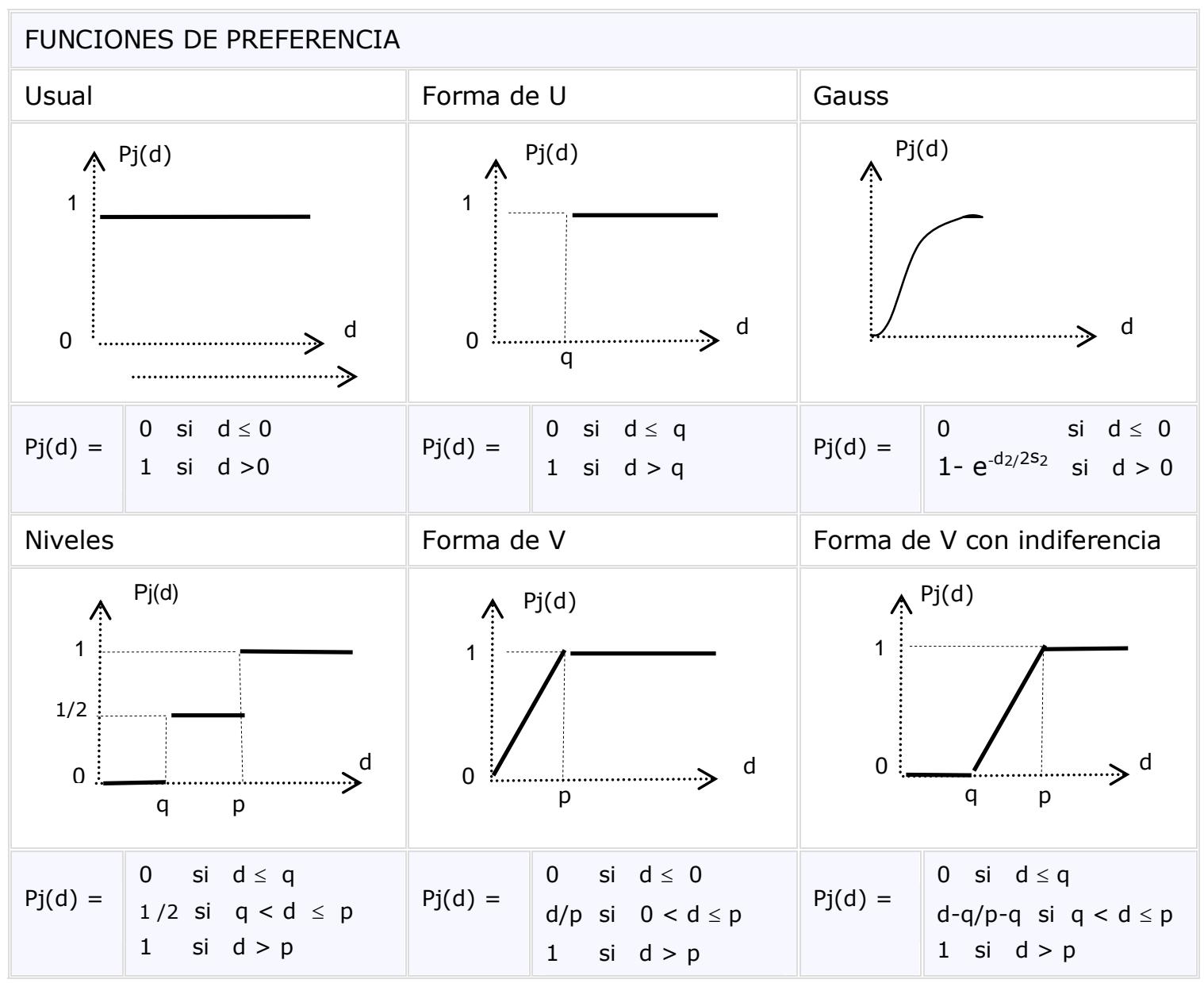

Figura 1.1. Funciones de preferencia, métodos PROMETHEE

Los métodos PROMETHEE se basan [Brans y Mareschal, 2005] en la comparación por pares de las alternativas planteadas, de acuerdo a cada criterio j. El índice de preferencia $\mathrm{P}(\mathrm{a}, \mathrm{b})$ expresa el grado de preferencia de la alternativa ' $a$ ' sobre la alterativa ' $b$ ', tomado sobre todos los criterios identificados, y se define como :

$$
\begin{gathered}
\mathrm{m}(\mathrm{a}, \mathrm{b})=\sum_{\mathrm{J}=1} \mathrm{Pj}(\mathrm{a}, \mathrm{b}) \mathrm{wj} \\
\mathrm{J}
\end{gathered}
$$

donde, $\operatorname{Pj}(a, b)$ es el valor que toma la función de preferencia asociada al criterio para la diferencia entre los rendimientos de las alternativas, $d=z(a)-z(b)$; y wj es la importancia relativa que se asigna al criterio $\mathrm{j}$. 
Los índices de preferencia, dos para cada par de alternativas, pueden utilizarse para su ordenamiento. Para ello se construye un gráfico donde cada alternativa se representa por un nodo. Entre dos nodos a y b puede haber dos líneas de flujo, una que sale del nodo $\mathrm{a}$, con un valor $\mathrm{P}(\mathrm{a}, \mathrm{b})$; y otra que entra al nodo $\mathrm{a}$, con un valor $P(b, a)$. Cada alternativa se compara con otras $(n-1)$ alternativas del grupo. Se definen las siguientes relaciones de flujo:

$$
\begin{array}{ll}
\text { Flujo positivo } \phi^{+}(a)=\left(1 /(n-1) \sum P(a, b)\right. & \text { para } b \neq a \\
\text { Flujo negativo } \phi^{-}(a)=\left(1 /(n-1) \sum P(b, a)\right. & \text { para } a \neq b
\end{array}
$$$$
\text { Flujo neto } \phi(a)=\phi^{+}(a)-\phi^{-}(a)
$$

El flujo positivo $\phi^{+}$(a) expresa como la alternativa a sobrecalifica al resto de las alternativas en el grupo; mientras más alto mejor. El flujo negativo $\phi^{-}(a)$ expresa como la alternativa a es sobrecalificada por el resto de las alternativas en el grupo; mientras más bajo mejor. El flujo neto $\phi(a)$ es el balance entre los flujos positivo y negativo para la alternativa a; mientras más alto es mejor la alternativa. La figura 1.2 muestra gráficamente los flujos de sobreclasificación de una alternativa con relación a las otras del conjunto [Brans y Mareschal, 2005].

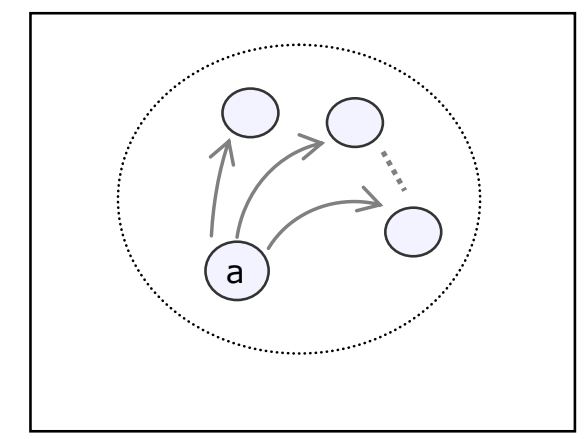

Flujo positivo $\phi^{+}(a)$

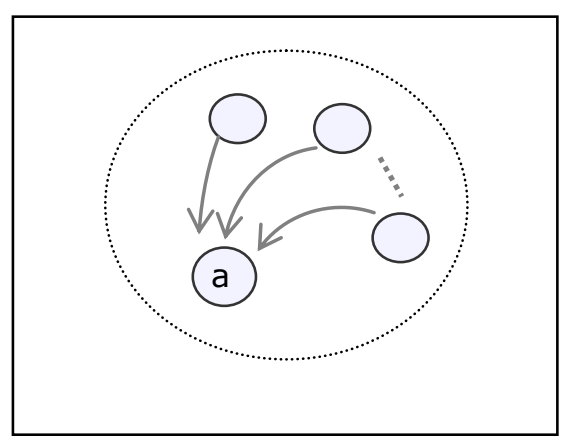

Flujo negativo $\phi^{-}(a)$

Figura 1.2. Flujos de sobrecalificación PROMETHEE

\subsection{PROMETHEE I}

El método PROMETHE I produce un ordenamiento preliminar de las alternativas identificadas, mediante la comparación de los flujos positivo y negativo para cada 
par posible de alternativas. Para ello utiliza las siguientes relaciones de sobrecalificacion $\left(a S^{\mathrm{I}} b\right)$, indiferencia $\left(\mathrm{aI}^{\mathrm{I}} \mathrm{b}\right)$ o incompatibilidad $\left(a \mathrm{R}^{\mathrm{I}} \mathrm{b}\right)$ entre ellas:

$$
\begin{aligned}
& \text { aS }{ }^{\mathrm{I} b} \text { sí y sólo sí } \phi^{+}(\mathrm{a}) \geq \phi^{+}(\mathrm{b}) \text { y } \phi^{-}(\mathrm{a})<\phi^{-}(\mathrm{b}) \text {, } \\
& \text { o } \phi^{+}(a) \geq \phi^{+}(\mathrm{b}) \text { y } \phi^{-}(\mathrm{a})<\phi^{-}(\mathrm{b}) \\
& \text { aI } \mathrm{I}^{\mathrm{b}} \text { sí y sólo sí } \phi^{+}(\mathrm{a})=\phi^{+}(\mathrm{b}) \text { y } \phi^{-}(\mathrm{a})=\phi^{-}(\mathrm{b}) \\
& \text { aR }{ }^{\mathrm{I} b} \text { sí y sólo sí } \phi^{+}(\mathrm{a})>\phi^{+}(\mathrm{b}) \text { y } \phi^{-}(\mathrm{a})>\phi^{-}(\mathrm{b}) \\
& \text { o } \quad \phi^{+}(a)<\phi^{+}\left(\text {b) } \text { y } \phi^{-}(a)<\phi^{-}(b)\right.
\end{aligned}
$$

El método PROMETHEE no produce ninguna recomendación sobre cuál es la mejor alternativa del grupo identificado, sólo produce un ordenamiento parcial del mismo.

\subsection{PROMETHEE II}

El método PROMETHE II utiliza el flujo neto de sobrecalificación definido anteriormente, para producir un ordenamiento completo de las alternativas identificadas. Para ello, usa las siguientes relaciones de sobrecalificacion ( $a S^{\mathrm{II}} \mathrm{b}$ ) e indiferencia $\left(\mathrm{aI}^{\mathrm{II}} \mathrm{b}\right)$ :

$$
\begin{array}{ll}
\text { aS }{ }^{\mathrm{II}} \mathrm{b} \text { sí y sólo sí } & \phi(\mathrm{a})>\phi(\mathrm{b}) \text { y } \phi^{-}(\mathrm{a})<\phi^{-}(\mathrm{b}) \\
\text { aII }{ }^{\mathrm{II} b} \text { sí y sólo sí } & \phi(\mathrm{a})=\phi(\mathrm{b}) \text { y } \phi^{-}(\mathrm{a})=\phi^{-}(\mathrm{b})
\end{array}
$$

El paquete informático DECISION $\mathrm{LAB}^{\circledR}{ }^{7}$ desarrollado por la empresa canadiense Visual Decision en cooperación con los autores, es un apoyo a los usuarios de los métodos PROMETHEE que permite la introducción de la información a través de pantallas amigables, efectúa las comparaciones entre alternativas y los cálculos inherentes al procedimiento, produce gráficos que muestran la relación entre las

\footnotetext{
${ }^{7}$ http://www.visualdecision.com/products.htm
} 
alternativas y permite un análisis de sensibilidad de los resultados obtenidos [Brans y Mareschal, 2005].

La principal ventaja de los métodos de sobrecalificación es que se basan en la comparación por pares de las alternativas identificadas para obtener el grado de preferencia de una sobre la otra; y finalmente, su ordenamiento. Este mecanismo, si se quiere, se asemeja a la forma natural como los individuos efectúan comparaciones cuando se trata de juzgar la alternativa preferida en un conjunto.

Sin embargo, los algoritmos utilizados para convertir las diferencias entre el rendimiento de cada dos alternativas del conjunto en valores que permitan el ordenamiento final de ellas, pueden resultar complicados para el usuario promedio. En el caso de los métodos PROMETHEE, se requiere introducir una función de preferencia con umbrales de indiferencia y preferencia; conceptos estos que pueden resultar de difícil comprensión y cuya inadecuada elección puede incidir significativamente en los resultados del proceso. [Benton y Stewart, 2003].

\subsubsection{Métodos basados en jerarquías y redes analíticas}

Estos métodos tienen en común que utilizan una estructura jerárquica o una red para describir el problema y las interacciones entre sus elementos. Los métodos permiten la incorporación al proceso de los juicios de los grupos que puedan resultar afectados por la decisión, sobre (i) la intensidad de la importancia de un criterio sobre otro, con relación a un tercero jerárquicamente superior, en rondas de comparaciones por pares entre los criterios y (ii) el grado de cumplimiento de cada alternativa con relación a cada criterio, expresado el primero como una medida relativa sobre otra alternativa del conjunto, en comparaciones por pares entre las alternativas. Los métodos han sido desarrollados por Thomas Saaty [1986] que argumenta que es ésta la forma natural como las personas enfrentadas a una decisión, expresan la intensidad de sus juicios; y por tanto, las metodologías de apoyo a su decisión deben adaptarse a ella.

\subsubsection{Proceso de Jerarquías Analíticas}

El Proceso de Jerarquías Analíticas (AHP, por sus siglas en inglés) es una metodología de apoyo a la decisión multicriterio que propone la evaluación y 
posterior ordenamiento de las alternativas de acción planteadas mediante la estructuración de un árbol jerárquico donde el nivel superior es ocupado por el objetivo fundamental en términos de su enunciado y el segundo nivel corresponde a los aspectos generales o criterios más importantes relevantes a la evaluación; subdividido cada uno de ellos en los criterios y subcriterios que se juzgue conveniente incluir para definir completamente el problema. Las alternativas de solución planteadas ocupan el último nivel.

A efectos de ilustración, la figura que sigue muestra un árbol jerárquico de cinco niveles donde el segundo nivel está ocupado por " $n$ " criterios cada uno de los cuales es subdividido en subcriterios de acuerdo al grado de detalle que se desee. El último nivel es ocupado por "s" alternativas.

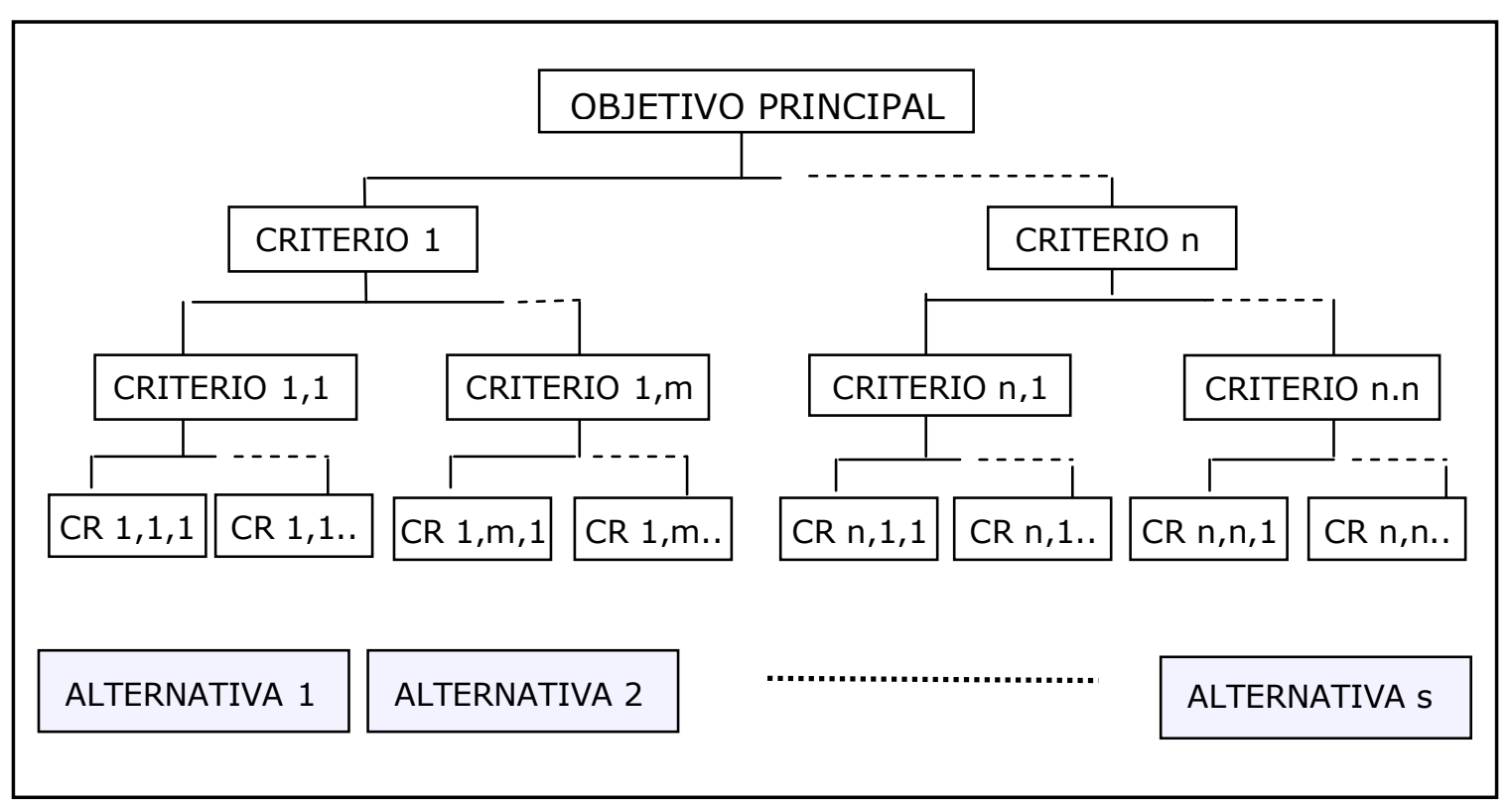

Figura 1.3. Modelo de Jerarquías Analíticas

Una vez que la jerarquía ha sido estructurada deben establecerse las prioridades locales o importancia relativa de cada criterio con relación al nivel jerárquicamente superior. Las comparaciones se hacen por pares, entre los criterios del mismo nivel (o entre las alternativas en el último nivel) cuyo peso se intenta determinar; preguntándose en cada caso, cuánto más importante es el criterio i que el criterio j, con relación al criterio superior al que están asociados. Las comparaciones se inician 
en el nivel de las alternativas, se continúan con el nivel inmediatamente superior; y así sucesivamente hasta alcanzar el nivel más alto. La Tabla 1.1 muestra la escala fundamental que utiliza el AHP para las comparaciones por pares [Saaty, 1986].

Tabla 1.1. Escala de Saaty, AHP

\begin{tabular}{|c|l|l|}
\hline wi/wj & \multicolumn{1}{|c|}{ DEFINICIÓN } & \multicolumn{1}{c|}{ EXPLICACIÓN } \\
\hline 1 & Igual & $\begin{array}{l}\text { Ambos criterios se consideran } \\
\text { igualmente importantes. }\end{array}$ \\
\hline 3 & Moderada & $\begin{array}{l}\text { El criterio i es ligeramente más } \\
\text { importante que el criterio j. }\end{array}$ \\
\hline 5 & Fuerte & $\begin{array}{l}\text { El criterio i es fuertemente más } \\
\text { importante que el criterio j. }\end{array}$ \\
\hline 7 & Muy fuerte o demostrada & $\begin{array}{l}\text { El criterio i es mucho más } \\
\text { importante que el criterio j. }\end{array}$ \\
\hline $2,4,6,8$ & Valores intermedios & $\begin{array}{l}\text { El criterio i es incuestionablemente } \\
\text { más importante que el criterio j. }\end{array}$ \\
\hline
\end{tabular}

Cada nivel en la escala de Saaty corresponde a la intensidad (wi/wj) de la importancia del criterio i sobre el criterio j, con relación al criterio superior. En caso de que el criterio j sea más importante que el criterio i, el valor a asignar es el inverso.

Los valores [aij $=$ wi/wj] obtenidos a través de las opiniones individuales expresadas por cada participante en el proceso, se acomodan en matrices de juicios; una para cada ronda de comparaciones binarias [Saaty, 2005a]. Si el decisor es consistente se genera una matriz $[\mathrm{A}]$ cuyas entradas, aij, satisfacen las siguientes condiciones [Saaty, 2005b]:

(i) $\quad$ Si aij $=$ a entonces $a j i=1 / a$

(ii) $\quad$ Si $j=\mathrm{i}$ entonces aij $=a j i=a i i=1$ para todo $\mathrm{i}$.

La matriz recíproca $[\mathrm{A}]$ cumple con la igualdad: $[\mathrm{A}][\mathrm{w}]=\mathrm{n}[\mathrm{w}]$, donde $[\mathrm{w}]$ es el vector de prioridades o pesos de los criterios $\left[w_{1}, w_{2} \ldots w_{n}\right]$ y $n$ la dimensión de la matriz; esto es, 


$$
\left(\begin{array}{cccc}
\mathrm{w}_{1} / \mathrm{w} 1 & \mathrm{w} 1 / \mathrm{w} 2 & \ldots & \mathrm{w} 1 / \mathrm{wn} \\
\mathrm{w} 2 / \mathrm{w}_{1} & \mathrm{w} 2 / \mathrm{w} 2 & \ldots & \mathrm{w} 2 / \mathrm{wn} \\
\vdots & \vdots & & \vdots \\
\mathrm{wn} / \mathrm{w} 1 & \mathrm{wn} / \mathrm{w} 2 & \ldots & \mathrm{wn} / \mathrm{wn}
\end{array}\right)\left(\begin{array}{c}
\mathrm{w}_{1} \\
\mathrm{w} 2 \\
\vdots \\
\mathrm{wn}
\end{array}\right)=\mathrm{n}\left(\begin{array}{c}
\mathrm{w} 1 \\
\mathrm{w} 2 \\
\vdots \\
\mathrm{wn}
\end{array}\right)
$$

Si el decisor es no consistente se genera una matriz [R] que es una perturbación de $[\mathrm{A}]$ y que cumple con la igualdad: $[\mathrm{R}][\mathrm{w}]=\lambda \max [\mathrm{W}]$, donde $\lambda \max$ es el autovalor dominante de la matriz de comparación y [w] su autovector. Puede demostrarse que $\lambda \max \geq n$, donde la igualdad significa consistencia perfecta [Stuhb et al., 1994].

Finalmente, se define el índice de consistencia, IC $=(\lambda \max -\mathrm{n}) /(\mathrm{n}-1)$ y la relación de consistencia, $\mathrm{RC}=\mathrm{IC} / \mathrm{RI}$; donde RI es un promedio de los índices de consistencia de una gran muestra de matrices cuyas entradas se escogen de forma aleatoria. Saaty [1986] obtuvo los siguientes resultados para RI,

\begin{tabular}{|l|cccccccccc|}
\hline $\mathrm{n}$ & 1 & 2 & 3 & 4 & 5 & 6 & 7 & 8 & 9 & 10 \\
\hline $\mathrm{RI}$ & 0.00 & 0.00 & 0.58 & 0.90 & 1.12 & 1.24 & 1.32 & 1.41 & 1.45 & 1.49 \\
\hline
\end{tabular}

La experiencia [Saaty, 2006a; Saaty, 2005a] sugiere que la relación de consistencia debe ser menor a 0.1 para que los resultados sean confiables.

Finalmente, el peso global asociado a cada criterio i (o alternativa, en el último nivel) se obtiene multiplicando su peso local $w_{i}$ por el peso global del criterio superior al que está relacionado. La suma de los pesos globales de cada alternativa con respecto a cada criterio proporciona la evaluación de cada alternativa.

Cuando el análisis se realiza en grupo deben combinarse los juicios de los participantes de forma que se cumpla la condición de reciprocidad; esto es, que se cumpla que el valor síntesis de los recíprocos de los juicios individuales sea igual al recíproco del valor síntesis de esos juicios; esto es, para un grupo de n participantes donde xi es el juicio del participante i,

$$
F(1 / x 1,1 / x 2, \ldots 1 / x n)=1 / F(x 1 . x 2, . . x n)
$$


Se ha comprobado que sólo la media geométrica de los valores satisface la condición anterior. De esta forma, en AHP para obtener el resultado consolidado para el grupo se toma la media geométrica de las prioridades globales obtenidas de las jerarquías individuales de cada individuo participante (Saaty, 2005a).

Expert Choice ${ }^{8}{ }^{8}$ es una aplicación informática muy usada, basada en el método de Jerarquías Analíticas, desarrollada en la Universidad George Washington (Forman E., 1983) y comercializada por Expertchoice ${ }^{\circledR}$ Decision Support Software Inc., Arligton, Va, USA., que facilita el procesamiento de los juicios de valor en problemas complejos con múltiples actores involucrados; consolida los resultados individuales, calcula la relaciones de consistencia individuales y del grupo, y permite el análisis de sensibilidad de los resultados finales a las variables del problema.

El método de Jerarquías Analíticas es simple de entender, flexible, intuitivo en su aplicación y es capaz de manejar criterios cuantitativos y cualitativos en el mismo marco de trabajo [Loken, 2007]. Otra de sus principales ventajas es que permite el cálculo de índices de consistencia de los juicios de cada participante [Pohekar y Ramachandran, 2004; Sthub, Bard y Globerson, 1994], y que a él se asocia un paquete informático amigable en su uso y ampliamente probado en el mundo ${ }^{3}$. Finalmente, la construcción de una jerarquía de criterios, atributos y alternativas facilita el entendimiento del problema por parte de los participantes en el análisis y la comunicación de las recomendaciones finales.

Sin embargo, el método ha originado un extenso debate sobre algunos de sus aspectos teóricos y prácticos, considerados no convenientes por algunos autores [Benton y Stewart, 2003; Pérez et al., 2004; Bana e Costa y Vansnick, 2007; entre otros]. Entre ellos, destaca el fenómeno de inversión del orden de la alternativas que se produce eventualmente [Saaty y Vargas, 1993] por la adición de una alternativa "irrelevante". Algebraicamente, el problema se produce porque la nueva alternativa afecta en forma diferente las preferencias relativas de las alternativas, para cada criterio. El autor del método no se ha mostrado conceptualmente de acuerdo con las

\footnotetext{
${ }^{8}$ http://www.expertchoice.com
} 
críticas; sin embargo, para solventar el asunto ha propuesto utilizar valores o "calificaciones absolutas" para las alternativas (una a la vez) con relación a cada criterio, en lugar de las relaciones obtenidas en las comparaciones por pares [Saaty, 1994; Saaty, 2006b; Saaty, 2005a; entre otros]. De esta forma cada alternativa se valúa con referencia a un "ideal" cuya puntuación es 1 , independientemente de la otra; y en consecuencia, una alternativa poco relevante que se adicione al conjunto quedará ubicada más abajo que las alternativas más relevantes y no podrá revertir su orden.

Cuando se utiliza el modo absoluto para evaluar a las alternativas, una vez establecidas las intensidades (p.e. excelente, muy bueno, bueno, regular, malo) posibles para cada criterio, (i) se obtienen sus prioridades mediante comparaciones por pares, (ii) las prioridades obtenidas se dividen por la mayor de ella para convertirlas en "prioridades idealizadas" o absolutas que correspondan a cada una de las intensidades antes definidas para el criterio. Posteriormente, a cada alternativa se asigna la prioridad idealizada que le corresponda de acuerdo a cada criterio. El proceso se repite para cada criterio identificado; y finalmente, el rendimiento total de cada alternativa es obtenido como la suma de las calificaciones obtenidas por los pesos de los respectivos criterios.

El uso de calificaciones absolutas puede ahorrar tiempo cuando se trata de asignar puntuación a cada alternativa en un grupo grande de ellas [Saaty, 1994].

\subsubsection{Proceso de Redes Analíticas}

El Proceso de Redes Analíticas (ANP, por sus siglas en inglés) es una generalización del Proceso de Jerarquías Analíticas que permite considerar la interacción entre los diferentes factores del proceso de evaluación. Para ello, utiliza redes en lugar de una jerarquía para la representación del problema. La figura 1.4 muestra la diferencia entre una jerarquía y una red. Como puede observarse una jerarquía es una estructuración unidireccional de los factores relevantes al problema, sin retroalimentación de los elementos en los niveles inferiores a los elementos en los niveles superiores. Por el contrario una red es una representación de las interacciones entre los componentes de un problema y entre los elementos de cada componente. 


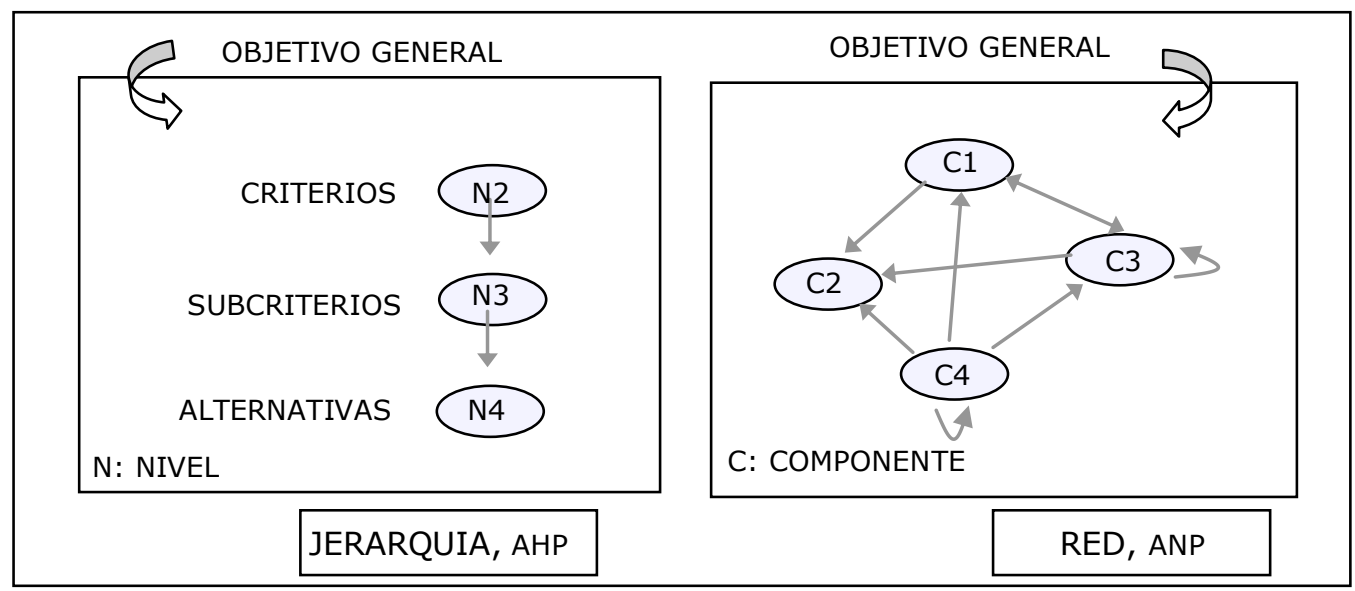

Figura 1.4. Jerarquía analítica y red analítica

Una jerarquía comprende un objetivo general, niveles de elementos relevantes al problema y conexiones entre niveles que van desde el tope a la base. Una red tiene grupos de elementos que pueden conectarse entre grupos o dentro de cada grupo. En la figura 1.4, los grupos C1, C2, C3 y C4 interactúan entre ellos, y los elementos en los grupos C3 y C4 respectivamente interactúan entre sí, dentro de cada grupo. Los niveles de elementos en una jerarquía corresponden a los grupos de elementos en una red. Una red puede generarse de una jerarquía aumentando las conexiones paulatinamente de forma de permitir la interacción entre y dentro de los componentes [Saaty, 2005a; Saty 2005b].

Los elementos ei 1, ei $2, .$. en un componente Ci de la red, interactúan, impactan o son impactados por los elementos del mismo componente $\mathrm{Ci}$ o de otro componente $\mathrm{Cj}$, con relación a un criterio de control. EL vector de prioridades derivado de las matrices de comparaciones por pares, representa la importancia del impacto de un grupo de elementos de un componente sobre otro elemento en la red. Cuando un elemento no tiene influencia sobre otro elemento en la red, la importancia de su influencia es cero. Las prioridades derivadas de esta forma se acomodan en una supermatriz [W] cuyas entradas representan la importancia del impacto de un elemento en la parte izquierda de la matriz sobre un elemento en el tope de la matriz.

Posteriormente deben obtenerse (i) la matriz de componentes cuyas columnas contienen el vector de intensidades de impacto de los componentes de la red sobre 
otro componente de la red, derivado de las matrices de las respectivas comparaciones en pares, con relación a cada componente, (ii) la supermatriz ponderada $\left[\mathrm{W}^{\prime}\right]$ donde cada elemento en la submatriz $\mathrm{Wij}^{\prime}$ es el producto de los correspondientes elementos de la submatriz Wij en [W] por el peso wij en la matriz de componentes. Finalmente, esta matriz es elevada a potencias sucesivas hasta que los valores en las filas converjan al mismo valor para cada columna de la matriz. (Saaty 2005a; Saaty, 2005b].

Todo el proceso debe repetirse para cada criterio de control; y los resultados obtenidos expresados en forma "idealizada", y ponderados por la importancia relativa de cada criterio de control, lo que proporciona finalmente el impacto de cada alternativa. Los criterios de control pueden estar agrupados en jerarquías de control correspondientes a los méritos: beneficios, costos, oportunidades y riesgos (BCOR). En ese caso; en lugar de uno, se obtienen cuatro vectores de resultados idealizados, uno para cada uno de los méritos planteados. Para consolidar los resultados, se requiere definir criterios estratégicos y sus prioridades para obtener los pesos de cada uno de los méritos y utilizarlos para obtener la síntesis global de los cuatro vectores. Para cada alternativa se sustrae la suma de los costos y riesgos ponderados de la suma de los beneficios y oportunidades ponderados, a ella asociados. La alternativa que obtenga el mayor valor es la preferida [Saaty 2005a; Saaty 2005b; Erdogmus, Kapanoglu y Ekoc, 2006; Konea y Bukeb, 2007].

El paquete informático Super Decisions $\AA^{9}$ desarrollado por Creative Decisions Foundation, Pittsburg, Pa, USA está basado en el Proceso de Redes Analíticas y sirve de apoyo en procesos de decisión multicriterio con dependencia y retroalimentación, en base a los juicios individuales de un grupo de trabajo.

El Proceso de Redes Analíticas produce modelos más complejos tratando de aproximarse a la forma como se toman las decisiones en el mundo real; de esta forma, maneja un mayor volumen de información cuya consistencia debe ser

\footnotetext{
${ }^{9}$ http://www.superdecisions.com
} 
controlada para obtener resultados confiables. Por lo demás, el método es intuitivo en su aplicación, fácil de entender y sencillo de aplicar.

\subsection{Resumen}

En las páginas precedentes se ha presentado una síntesis de los métodos de análisis multicriterio más citados en la bibliografía especializada reciente. Los métodos pueden utilizarse en la evaluación multicriterio de propuestas de inversión y en su ordenamiento; e incluso, si éste es el caso, en la conformación preliminar de planes de desarrollo. Los métodos evalúan las propuestas en base al grado de cumplimiento de objetivos previamente fijados que expresan la dirección de mejora de los aspectos importantes o atributos del problema que se busca resolver.

Los objetivos se asocian a criterios para la evaluación; y se definen con el concurso de los expertos en el área y de los afectados por la puesta en marcha de una u otra alternativa. Los criterios son estándares o reglas que permiten medir el grado de cumplimiento de los objetivos, pueden ser conflictivos entre sí; y cada uno, tener una importancia o peso diferente para cada actor en el proceso. Cada metodología introduce estos elementos al análisis de forma diferente. Así, el grupo de alternativas a considerar puede ser (i) un conjunto infinito donde cada alternativa se define en función de los valores que puedan tomar las variables del problema; o (ii) un conjunto finito, compuesto de alternativas eficientes definidas a priori. Por su parte, los criterios pueden estar asociados a atributos cuantitativos y cualitativos, o sólo a atributos cuantificables; y sus respectivas importancias ser asignadas por consenso o ser producto de rondas de comparaciones por pares de criterios, entre los involucrados en el proceso.

Las tablas 1.2.1 y 1.2.2 presentan en formato muy resumido las características que distinguen a cada método de apoyo a la decisión multicriterio descrito a lo largo de este capítulo. Las características se refieren al tipo de alternativas, criterios, información y resultados que manejan. Además se señalan las ventajas y desventajas de su uso y se citan las respectivas herramientas informáticas de apoyo. La información contenida en los cuadros se utilizará posteriormente para la selección de la metodología base de evaluación de proyectos, parte importante de la propuesta metodológica objeto de este trabajo. 
Tabla 1.2.1. Cuadro comparativo de métodos de apoyo a la decisión multicriterio I

\begin{tabular}{|c|c|c|c|c|}
\hline & \multirow{2}{*}{$\begin{array}{c}\text { PROGRAMACIÓN LINEAL } \\
\text { MULTIOBJETIVO }\end{array}$} & \multirow{2}{*}{$\begin{array}{l}\text { PROGRAMACIÓN } \\
\text { POR METAS }\end{array}$} & \multicolumn{2}{|c|}{ MÉTODOS BASADOS EN FUNCIONES DE VALOR } \\
\hline & & & MAVT & MAUT \\
\hline Modelo & Ecuaciones 1,2 a 5 del texto & Ecuaciones 1,6 a 9 del texto & Ecuación 10 del texto & Ecuación 11 del texto \\
\hline Alternativas & Conjunto infinito & Conjunto infinito & Conjunto finito eficiente & Conjunto finito eficiente \\
\hline $\begin{array}{l}\text { Objetivo y } \\
\text { resultados }\end{array}$ & $\begin{array}{l}\text { Conjunto de soluciones } \\
\text { eficientes. }\end{array}$ & $\begin{array}{l}\text { Conjunto de soluciones } \\
\text { eficientes. }\end{array}$ & $\begin{array}{l}\text { Conjunto ordenado en base a } \\
\mathrm{V}(\mathrm{a}) \text {. }\end{array}$ & $\begin{array}{l}\text { Conjunto ordenado en base a } \\
U(Z) \text {. }\end{array}$ \\
\hline Criterios & $\begin{array}{l}\text { Asociados a atributos } \\
\text { cuantificables. }\end{array}$ & $\begin{array}{l}\text { Asociados a atributos } \\
\text { cuantificables. }\end{array}$ & $\begin{array}{l}\text { Asociados a atributos } \\
\text { cuantitativos/cualitativos. }\end{array}$ & $\begin{array}{l}\text { Asociados a atributos } \\
\text { cuantificables. }\end{array}$ \\
\hline $\begin{array}{l}\text { Pesos de los } \\
\text { criterios }\end{array}$ & No aplica & No aplica & $\begin{array}{l}\text { Importancia relativa asignada } \\
\text { por consenso. }\end{array}$ & $\begin{array}{l}\text { Importancia relativa asignada } \\
\text { por consenso. }\end{array}$ \\
\hline $\begin{array}{l}\text { Información base } \\
\text { necesaria }\end{array}$ & $\begin{array}{l}\text { Fórmulas matemáticas de } \\
\text { objetivos y restricciones. }\end{array}$ & $\begin{array}{l}\mathrm{Fj}(\mathrm{xi}), \mathrm{Rk}(\mathrm{xi}) \text { y metas por } \\
\text { objetivo. }\end{array}$ & $\begin{array}{l}\text { Funciones de valor por } \\
\text { criterio. }\end{array}$ & $\begin{array}{l}\text { Funciones de utilidad por } \\
\text { criterio. }\end{array}$ \\
\hline $\begin{array}{l}\text { Información inicial } \\
\text { necesaria }\end{array}$ & No aplica & No aplica & $\begin{array}{l}\text { Matriz de rendimientos de las } \\
\text { alternativas y vector de } \\
\text { pesos de los criterios. }\end{array}$ & $\begin{array}{l}\text { Matriz de rendimientos de las } \\
\text { alternativas y vector de } \\
\text { pesos de los criterios. }\end{array}$ \\
\hline Software & SIMPLEX Internet. & SIMPLEX Internet & HIPRE +, Internet. & Internet \\
\hline $\begin{array}{l}\text { Ventajas y } \\
\text { desventajas }\end{array}$ & $\begin{array}{l}\text { - Limitación a problemas } \\
\text { términos de atributos cua } \\
\text { puede usarse como fase } \\
\text { subconjunto de soluciones } \\
\text { otras metodologías para } \\
\text { problema al análisis. } \\
\text { - Resultados sensibles a la } \\
\text { problema y/o a la fijación } \\
\text { por objetivo. }\end{array}$ & $\begin{array}{l}\text { que pueden plantearse en } \\
\text { antificables. En otros casos, } \\
\text { previa al MCDA para definir } \\
\text { eficientes o combinado con } \\
\text { introducir limitaciones del } \\
\text { adecuada formulación del } \\
\text { de los niveles de satisfacción }\end{array}$ & $\begin{array}{l}\text { - Sencillo de usar y fácil de } \\
\text { entender. } \\
\text { Método compensatorio y } \\
\text { dependiente de los pesos } \\
\text { de los criterios asignados; } \\
\text { por tanto manipulable. }\end{array}$ & $\begin{array}{l}\text { - Metodología rigurosa y } \\
\text { definición engorrosa de } \\
\text { funciones de utilidad. } \\
\text { - No transparente, difícil } \\
\text { de entender. } \\
\text { - Incluye incertidumbre y } \\
\text { actitud ante el riesgo del } \\
\text { participante. }\end{array}$ \\
\hline
\end{tabular}


Tabla 1.2.2. Cuadro comparativo de métodos de apoyo a la decisión muticriterio II

\begin{tabular}{|c|c|c|c|c|}
\hline & \multicolumn{2}{|c|}{ RELACIONES DE SOBRECALIFICACIÓN } & \multicolumn{2}{|c|}{ JERARQUÍAS Y REDES ANALÍTICAS } \\
\hline & ELECTRE III & PROMETHEE I,II & AHP & ANP \\
\hline Modelo & $\begin{array}{l}\text { Ecuaciones } 12 \text { a } 16 \text { del texto. } \\
\text { Comparación por pares }(a, b) \text {. }\end{array}$ & $\begin{array}{l}\text { Ecuaciones } 17 \text { a } 20 \text { del texto. } \\
\text { Comparación por pares }(a, b)\end{array}$ & $\begin{array}{l}\text { Ecuaciones } 21 \text { y } 23 \text { del texto. } \\
\text { Comparación por pares }(a, b) \text {. }\end{array}$ & $\begin{array}{l}\text { Ecuación } 23 \text { del texto. } \\
\text { Comparación por pares }(a, b) \text {. }\end{array}$ \\
\hline Alternativas & Conjunto finito eficiente & Conjunto finito eficiente & Conjunto finito eficiente & Conjunto finito eficiente \\
\hline $\begin{array}{l}\text { Objetivo y } \\
\text { resultados }\end{array}$ & $\begin{array}{l}\text { Conjunto ordenado en base } \\
\text { a } S(a, b) \text { y } \lambda \text {-preferencia. }\end{array}$ & $\begin{array}{l}\text { Conjunto ordenado en base a } \\
\phi+(a) \text {. }\end{array}$ & $\begin{array}{l}\text { Conjunto ordenado en base a } \\
\text { importancia relativa (a). }\end{array}$ & $\begin{array}{l}\text { Conjunto ordenado en base a } \\
\text { importancia relativa (a). }\end{array}$ \\
\hline Criterios & $\begin{array}{l}\text { Asociados a atributos } \\
\text { cuantitativos/cualitativos. }\end{array}$ & $\begin{array}{l}\text { Asociados a atributos } \\
\text { cuantitativos/cualitativos. }\end{array}$ & $\begin{array}{l}\text { Asociados a atributos } \\
\text { cuantitativos/cualitativos. }\end{array}$ & $\begin{array}{l}\text { Asociados a atributos } \\
\text { cuantitativos/cualitativos. }\end{array}$ \\
\hline $\begin{array}{l}\text { Pesos de los } \\
\text { criterios }\end{array}$ & $\begin{array}{l}\text { Coeficientes de importancia } \\
\text { asignados por consenso. }\end{array}$ & $\begin{array}{l}\text { Importancia relativa asignada } \\
\text { por consenso. }\end{array}$ & $\begin{array}{l}\text { Comparación por pares de } \\
\text { criterios a nivel individual }=> \\
\text { importancia relativa }\end{array}$ & $\begin{array}{l}\text { Comparación por pares de } \\
\text { criterios a nivel individual }=> \\
\text { importancia relativa }\end{array}$ \\
\hline $\begin{array}{l}\text { Información base } \\
\text { necesaria }\end{array}$ & $\begin{array}{l}\text { Umbrales de indiferencia, } \\
\text { preferencia y veto. }\end{array}$ & $\begin{array}{l}\text { Función de preferencia por } \\
\text { criterio. }\end{array}$ & Jerarquía analítica & Red analítica \\
\hline $\begin{array}{l}\text { Información inicial } \\
\text { necesaria }\end{array}$ & $\begin{array}{l}\text { Matriz de rendimientos de } \\
\text { alternativas, y vector de } \\
\text { coeficientes de importancia } \\
\text { de los criterios. }\end{array}$ & $\begin{array}{l}\text { Matriz de rendimientos de las } \\
\text { alternativas y vector de } \\
\text { pesos de los criterios. }\end{array}$ & \multicolumn{2}{|c|}{$\begin{array}{l}\text { Matrices de juicios sobre importancia de los criterios y los } \\
\text { rendimientos de las alternativas expresados en escala Saaty. } \\
\text { Volumen de información: ANP >>> AHP. }\end{array}$} \\
\hline Software & $\begin{array}{l}\text { ELECTRE III-IV } ® \text {, comercial } \\
\text { probado. }\end{array}$ & $\begin{array}{l}\text { DECISION }{ }^{\circledR} \text { LAB, comercial } \\
\text { probado. }\end{array}$ & $\begin{array}{l}\text { EXPERT CHOICE } ® \text {, comercial } \\
\text { probado. }\end{array}$ & $\begin{array}{l}\text { SUPER DECISIONS } ® \text {, } \\
\text { comercial probado. }\end{array}$ \\
\hline $\begin{array}{l}\text { Ventajas y } \\
\text { desventajas }\end{array}$ & \multicolumn{2}{|c|}{$\begin{array}{l}\text { - Algoritmo complicado de solución en el caso de ELECTRE. } \\
\text { Conceptos como concordancia, discordancia, umbrales de } \\
\text { indiferencia, preferencia y veto; y funciones de preferencia } \\
\text { (PROMETHEE) pueden confundir al participante. } \\
\text { - Resultados sensibles a los pesos de los criterios; a la } \\
\text { escogencia adecuada de umbrales (ELECTRE); o a la } \\
\text { escogencia de la función de preferencia (PROMETHEE) } \\
\text { - Incorpora las opiniones de los grupos afectados. }\end{array}$} & \multicolumn{2}{|c|}{$\begin{array}{l}\text { - Intuitivo en su aplicación y fácil de entender. La } \\
\text { construcción de una jerarquía o red para el problema, } \\
\text { facilita su entendimiento y la comunicación entre los } \\
\text { participantes en el análisis. ANP permite interacción entre } \\
\text { factores del proceso que resulta + complejo que en AHP. } \\
\text { - Incorpora al proceso a los grupos afectados y permite el } \\
\text { cálculo de índices de consistencia de juicios individuales y } \\
\text { de grupo. } \\
\text { - Problema de inversión del orden se presenta si se utilizan } \\
\text { preferencias relativas para alternativas. Se solventa con el } \\
\text { uso de preferencias absolutas. }\end{array}$} \\
\hline
\end{tabular}


La escogencia de un determinado método de evaluación y el tipo de resultados obtenidos de su aplicación depende de la información disponible o que se esté en disposición de buscar; o viceversa, la información requerida depende de la metodología seleccionada. Así, la aplicación de algunas métodos requiere la introducción de juicios sobre la importancia de los criterios y de matrices de rendimientos de las alternativas por criterio, medidos en escalas asociadas a una función de valor o a una función de utilidad por criterio; o a puntuaciones absolutas o relativas que los participantes asignan a las alternativas. En otros casos, se sustituye esta información por la formulación matemática de los objetivos identificados y sus restricciones.

Los métodos revisados difieren en la forma de plantear el problema, procesar la información de entrada y presentar los resultados. Algunos de ellos introducen conceptos adicionales, a veces poco claros, no fácilmente entendibles; y por tanto menos atractivos a sus posibles usuarios. Así, la definición de las funciones de utilidad requeridas por los métodos basados en la teoría de utilidad multiatributo (MAUT), es un procedimiento riguroso y complicado de llevar a cabo; aún cuando tiene la ventaja de que incorpora la incertidumbre asociada al problema y la actitud ante el riesgo de los participantes en el análisis. Los métodos basados en la teoría de valor multiatributo (MAVT) requieren la determinación de las funciones de valor para cada criterio cuya obtención resulta más sencilla. Ambos metodologías requieren la introducción del vector de pesos de los criterios, son compensatorias y sus resultados pueden ser afectados por el manejo que se haga de los mismos.

Por su parte, la principal ventaja de los métodos de sobrecalificación es que se basan en la comparación por pares de las alternativas para obtener el grado de preferencia de una sobre la otra, con relación a cada criterio; proceso que si se quiere, se asemeja a la forma en que se toman decisiones en la vida real. Sin embargo, los algoritmos utilizados para convertir tales diferencias en valores que permitan el ordenamiento final de las alternativas, son complicados, y requieren introducir conceptos como concordancia, discordancia, funciones de preferencia y umbrales de indiferencia, preferencia y veto; no fácilmente manejables por los 
participantes en el proceso y cuya elección inadecuada puede modificar sensiblemente los resultados obtenidos.

La aplicación de los métodos de jerarquías y redes analíticas requiere la estructuración del problema en un árbol jerárquico (AHP) o en una red (ANP) que muestre las interacciones entre los diferentes elementos del problema. En estos métodos, el mecanismo de comparación por pares se extiende también a los criterios; a fin de obtener los juicios individuales de los participantes sobre (i) la intensidad de la importancia de un criterio sobre el otro con relación al criterio jerárquicamente superior; y (ii) el rendimiento de una alternativa sobre la otra con relación a cada criterio identificado. Los métodos permiten estimar la consistencia en los juicios de valor expresados individualmente y en grupo; son sencillos de aplicar y la representación del problema en una jerarquía o red facilita la comunicación entre los participantes en el análisis.

Finalmente, los métodos de programación lineal multiobjetivo y la programación por metas requieren que los objetivos estén asociados a atributos cuantificables; y en consecuencia, su aplicación se limita a problemas que puedan ser formulados en esos términos. Sin embargo, los métodos siempre pueden usarse como una fase previa al análisis MCDA propiamente dicho, para generar un conjunto de soluciones eficientes con relación a las variables cuantitativas del problema; conjunto que posteriormente debe ser estudiado en un contexto que contemple la influencia que sobre la decisión pueden tener factores de índole cualitativa.

Hoy en día y en todos los casos incluidos en la revisión, los métodos son respaldados en su aplicación por paquetes informáticos que facilitan el procesamiento de la data necesaria. Algunas de estas herramientas pueden ser descargadas de Internet; otras son productos comercializados por empresas reconocidas (ELECTRE III-IV $®$, DECISION LAB $R$, EXPERT CHOICE $®$, SUPER DECISIONS $($ ) que permiten el manejo individual y en grupo, de los juicios de valor emitidos por los expertos, y que incorporan en algunos casos, el cálculo de la consistencia de los juicios de valor introducidos y facilidades para realizar un estudio de sensibilidad de los resultados ante variaciones en los aspectos críticos del problema. 


\section{Capítulo 2 Aspectos metodológicos}

Este capítulo presenta la metodología y el plan de tareas a seguir para cumplir con los objetivos específicos enunciados en la parte introductoria de este documento; y con su objetivo central; esto es, el planteamiento de una propuesta para la evaluación multicriterio de proyectos en el sector energético de un país.

El trabajo a desarrollar se ha dividido en las etapas que se listan a continuación:

- Elaboración del marco de referencia

- Caracterización del sector energético

- Estructuración del modelo multicriterio de valor

- Aplicación del modelo multicriterio de valor

- Propuesta metodológica para la evaluación multicriterio de proyectos en el sector energético.

La figura 2.1 es un diagrama de flujo que muestra la secuencia en que se ejecutarán las actividades y el flujo de información entre ellas. Cada etapa toma información de las etapas precedentes y suministra información revisada, clasificada y consolidada o procesada, a las etapas siguientes. En el diagrama, cada actividad se representa por un recuadro simple y la información producto de cada fase del trabajo, por un recuadro doble en color azul claro. Cada sector delimitado en la figura corresponde respectivamente a las etapas listadas anteriormente. 


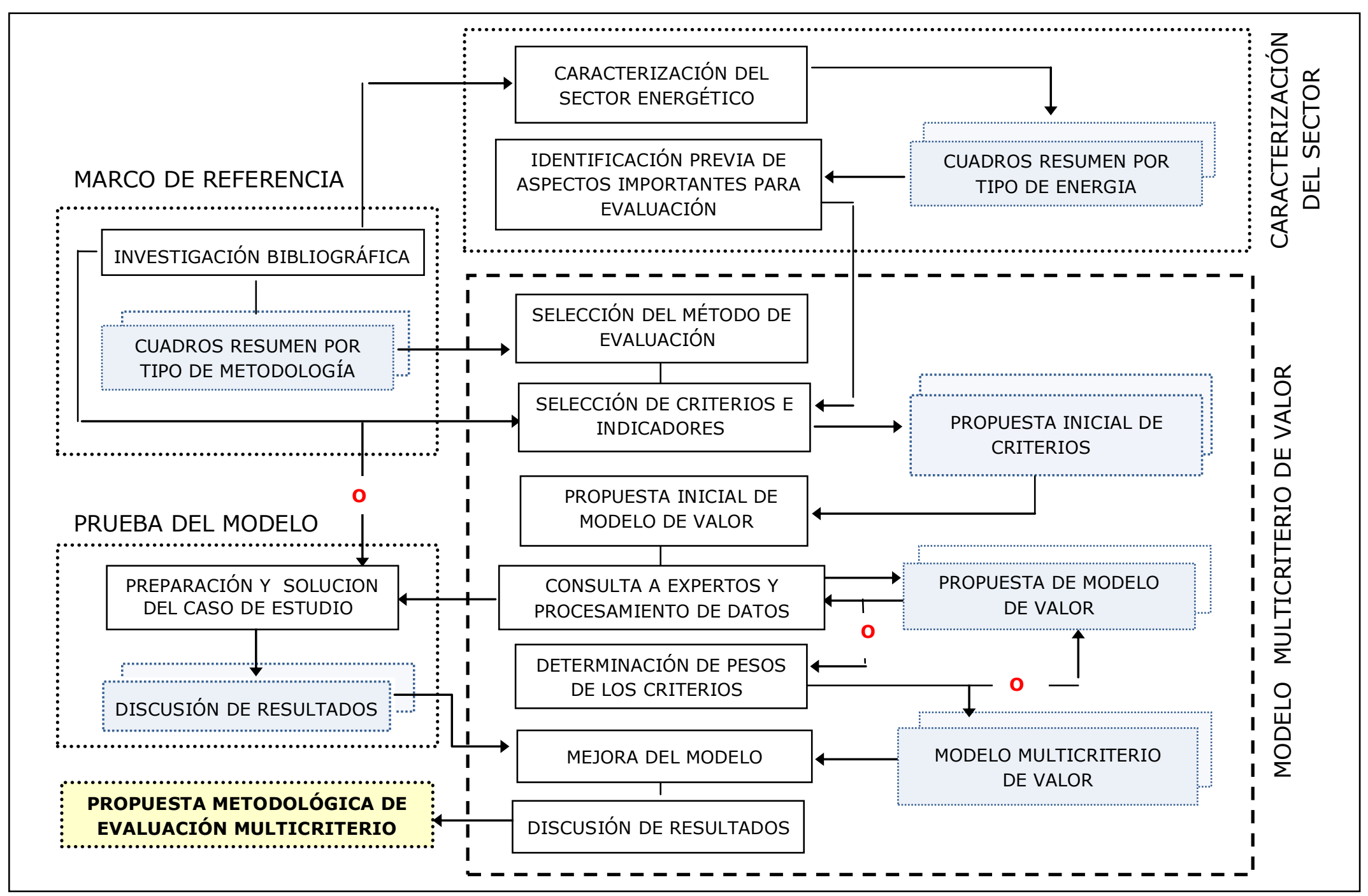

Figura 2.1. Plan de tareas, flujo de información y resultados 
A continuación una breve descripción cada fase en el diagrama anterior.

- Marco de referencia. Comprende la investigación bibliográfica sobre la situación actual en materia de evaluación multicriterio de proyectos y sobre las técnicas de análisis que pueden apoyar el proceso. La información revisada y clasificada será un insumo importante en la selección de la plataforma de análisis base para el desarrollo de la propuesta metodológica de evaluación de proyectos.

- Caracterización del sector energético. Abarca la investigación sobre el funcionamiento del sector energético en el mundo. El análisis de la información obtenida, resumida y clasificada, permitirá identificar aspectos diferenciadores entre las fuentes energéticas disponibles en el planeta; y los problemas y/o retos comunes del sector energético global.

- Modelo multicriterio de valor. Es la parte central del proceso y tiene como objetivo la formulación del modelo de valor para la evaluación multicriterio de proyectos en el sector energía. Las actividades a realizar comprenden la selección de la metodología de evaluación y la elección de los atributos, objetivos, criterios e indicadores que validados y determinadas sus importancias relativas, conformarán un modelo jerárquico para la evaluación

- Prueba y mejora del modelo. En esta etapa se prueba la aplicabilidad del modelo formulado. Las actividades contemplan la preparación de un caso de estudio, la aplicación del modelo de valor a su evaluación, la discusión de los resultados obtenidos; y en base a ellos, la complementación o mejora del modelo originalmente diseñado.

- Propuesta metodológica de evaluación multicriterio. En base al conocimiento adquirido y al trabajo realizado, en esta fase del proceso se elabora y presenta la propuesta metodológica para la evaluación multicriterio de proyectos en el sector energético, objetivo central de este trabajo de investigación.

La información requerida para cumplir con cada una las actividades señaladas en el diagrama anterior puede obtenerse de múltiples fuentes; entre ellas se cuentan: 
- BASE DE DATOS SCIENCE DIRECT. Artículos académicos y/o aplicaciones en materias seleccionadas como: metodologías de apoyo a la decisión multicriterio, evaluación ambiental y social de proyectos, sostenibilidad, planificación para el desarrollo, planificación energética, energías renovables; entre otras.

- INTERNET. Textos y artículos de opinión; informes anuales y estadísticas publicadas por agencias internacionales, regionales o nacionales para las diferentes fuentes de energía identificadas; publicaciones estadísticas periódicas de organizaciones gubernamentales que regulan y fiscalizan las operaciones en el sector, nacional o internacionalmente; publicaciones y estadísticas de empresas transnacionales, privadas o estadales, que operan en el sector energético; publicaciones universitarias; presentaciones en congresos y foros internacionales.

- TEXTOS, material de cursos y trabajos previos del autor.

- ENTREVISTAS PERSONALES Y GRUPOS DE OPINIÓN con expertos en energía y en materias relacionadas para apoyar el proceso de definición, validación y estructuración de posibles criterios e indicadores para la evaluación.

El desarrollo detallado de las actividades en el plan de trabajo se presenta en los capítulos siguientes de este documento. 


\section{Capítulo 3 Caracterización del sector energético}

En Física, energía se define como la capacidad de efectuar trabajo. En términos económicos, el vocablo se asocia a un recurso natural renovable o no, y a la tecnología utilizada para explotarlo y transformarlo de forma conveniente para su posterior utilización.

El sector energético agrupa las actividades relacionadas con el aprovechamiento de los recursos energéticos y el conjunto de individuos, empresas, y entidades públicas a cargo de realizarlas. Tales actividades incluyen la localización y cuantificación del potencial de producción del recurso; su recuperación, transporte y transformación en calor, electricidad, combustibles para el transporte; la distribución y mercadeo de los productos obtenidos; el trabajo de investigación y desarrollo sobre nuevas tecnologías y mejoramiento de eficiencias en el sector; la evaluación de nuevas alternativas energéticas y el diseño, construcción y puesta en marcha de los respectivos proyectos; la elaboración e implementación de políticas públicas y del marco regulatorio correspondiente; $y$ todas las actividades administrativas $y$ logísticas que permitan el buen funcionamiento de las operaciones en el sector.

Existe una gran variedad de recursos energéticos en el planeta; y atendiendo a lo que se considera su característica principal, diferentes modalidades para su clasificación. Así, puede diferenciarse entre fuentes de energía, renovables o no renovables, de acuerdo a la velocidad del agotamiento causado por su explotación frente a su velocidad de formación. Puede diferenciarse entre fuentes de energía convencionales o no convencionales, clasificación que más que al recurso 
corresponde a la complejidad de las tecnologías utilizadas para extraerlo y transformarlo, y a su costo. $Y$ finalmente, puede diferenciarse entre fuentes de energía tradicionales $o$ alternativas, en referencia al período de tiempo durante el cual se ha manejado su explotación; y por tanto, al conocimiento y pericia que se tenga sobre ella.

En las páginas siguientes, se presenta el producto de la investigación realizada sobre el funcionamiento del sector energético en el mundo. El conocimiento adquirido sobre la materia, resumido y estructurado, facilitará en mucho la próxima etapa en el trabajo a realizar; esto es, la identificación, selección y validación de un grupo de criterios e indicadores que sirvan como base para la evaluación integral de proyectos en el sector energético. La figura 3.1 que se incluye en la próxima página, muestra la clasificación de las energías y de los recursos energéticos que se adopta para la exposición de las materias, así como su relación con los otros esquemas de clasificación antes descritos. Para mayor claridad, las pequeñas cajas ubicadas en las zonas resaltadas en azul corresponden a los recursos respectivamente relacionados a los tipos de energía señalados en las cajas ubicadas en las zonas claras del esquema.

Para el año 2009, el suministro mundial de energía primaria ${ }^{10}$ a nivel mundial alcanzó 12.150 millones de toneladas de petróleo equivalente [IEA, 2011a] del cual una altísima fracción fue aportada por los combustibles fósiles; esto es, por petróleo, gas y carbón. La distribución de las reservas de este importante tipo de recursos no es uniforme en el planeta como tampoco lo es el consumo de los productos finales derivados de ellos. En efecto, las mayores reservas de combustibles fósiles, especialmente en el caso del petróleo, se localizan en un grupo muy limitado de países en vías de desarrollo que tienen una influencia muy importante sobre los volúmenes comercializados y sus precios; mientras tanto, el consumo se ubica mayoritariamente en un grupo distinto de países, técnica e industrialmente más avanzados; y en menor proporción, en el resto de los países del mundo.

\footnotetext{
${ }^{10}$ Energía primaria se refiere a energía en su forma inicial, después de su producción o importación [IEA, 2006.
} 


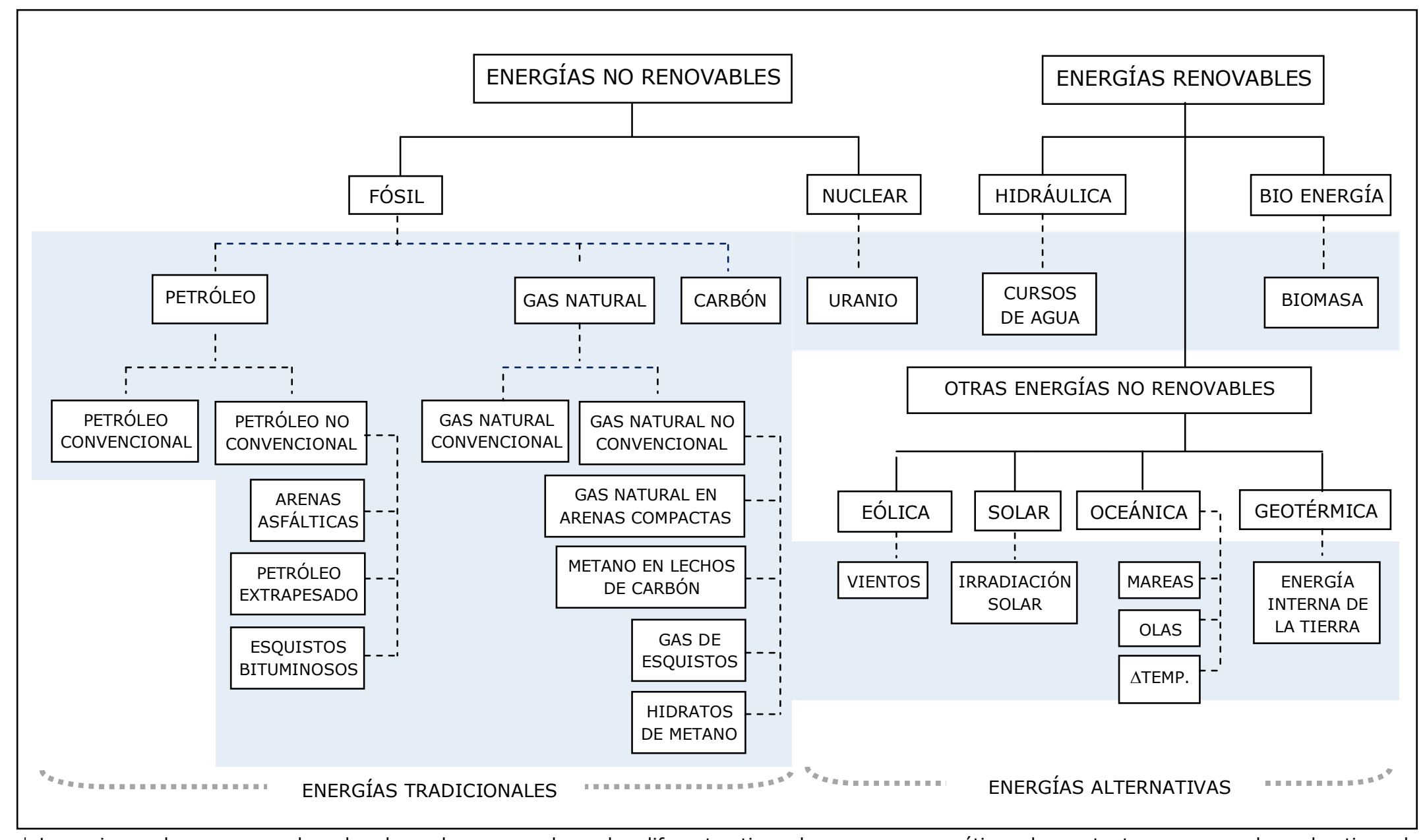

\# Las cajas en las zonas sombreadas de azul corresponden a los diferentes tipos de recursos energéticos, las restantes corresponden a los tipos de energía.

Figura 3.1. Una clasificación de fuentes de energía 
La no coincidencia de la distribución de las reservas y del consumo crea una dependencia energética por parte de los países que no pueden autoabastecerse hacia los países poseedores de las reservas con capacidad de exportar excedentes de producción. Esta dependencia se convierte en inseguridad energética cuando aparecen amenazas de interrupción en el suministro e incertidumbre en los precios.

Un segundo problema en el uso de los combustibles fósiles como proveedor de energía para los sectores industrial, doméstico y de transporte es que su combustión produce grandes cantidades de $\mathrm{CO}_{2}$ y otros gases invernadero que se emiten a la atmósfera con un efecto directo sobre el calentamiento global, tema principalísimo de discusión en los tiempos actuales.

Los problemas señalados anteriormente, han redirigido la investigación hacia tecnologías que permitan la explotación rentable de fuentes alternativas de energía. La radiación solar, los vientos, el desnivel de los ríos, las mareas, las olas, el calor interno de la tierra y los residuos de las cosechas de bosques y cultivos agrícolas son recursos energéticos renovables, ampliamente distribuidos en el mundo y ambientalmente muy poco contaminantes que potencialmente pueden sustituir con ventaja, a los combustibles fósiles. Hoy día, en Estados Unidos, China, España, Alemania y otros países de la Unión Europea; y en Latinoamérica, en Brasil y México; entre otros muchos, se han presentado un gran número de iniciativas tecnológicas en el área. Sin embargo, sólo algunas de ellas han logrado su paso a escala comercial debido fundamentalmente a las grandes inversiones necesarias que llevan el costo del producto final a precios no competitivos con productos similares derivados de los combustibles fósiles.

La energía nuclear se utiliza para generación de electricidad. El uso de esta fuente de energía alternativa no renovable no produce emisiones de $\mathrm{CO}_{2}$ ni de otros gases invernadero pero requiere una inversión inicial y costos de mantenimiento elevados. A finales del siglo pasado, Francia y otros países han construido y puesto en marcha un grupo importante de plantas nucleares con la oposición de algunas reconocidas organizaciones, ya que su operación se percibe como muy riesgosa. Por una parte, está la magnitud del daño a la población cercana que puede causar un accidente en la operación del reactor; y por la otra, está el problema del transporte y disposición 
final de los residuos radioactivos. Adicionalmente está el riesgo, considerado muy importante en los tiempos modernos, de que uranio enriquecido sea utilizado en la construcción de armas que puedan amenazar la supervivencia de la humanidad. Hoy día, el tema está en la agenda de algunos países en vía de desarrollo que esgrimen su derecho a utilizar la energía nuclear con fines pacíficos, en abierto desafío a países emblemáticos del primer mundo que se oponen a ello.

Las figura 3.2a muestra la importante participación de los combustibles fósiles en el suministro mundial de energía, la cual para el año 2009 alcanzó un $80.9 \%$ del total. El resto, un 19,1 \% correspondió a las energías alternativas; y entre ellas, un $13,3 \%$ a las energías renovables [IEA, 2011a].

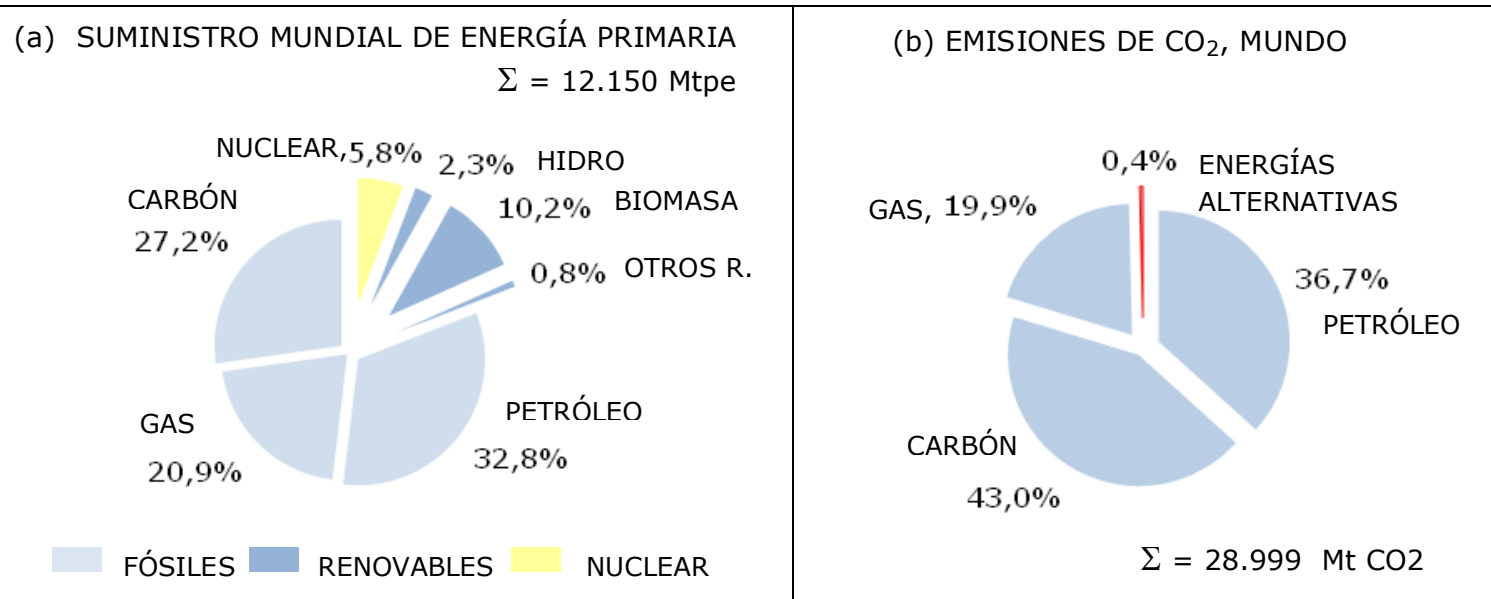

₹ OTROS: energía solar, eólica, geotérmica y oceánica entregada para generación de electricidad y calor. Fuente de datos: IEA, 2011a

Figuras 3.2 (a) Suministro mundial de energía primaria por combustible, 2009 (b) Emisión mundial de $\mathrm{CO}_{2}$ por combustible, 2009

Para el año 2009, la cantidad de $\mathrm{CO}_{2}$ emitida a la atmósfera como consecuencia de la explotación y uso de las fuentes energéticas fue de 28.999 millones de toneladas; de esta cifra apenas un 0,4\% correspondió a las energías alternativas, cifra insignificante si se compara con un 99,6\% aportado por las energías fósiles [IEA, 2011a]. Tal situación se puede observar en la figura 3.2b donde se evidencia claramente el porqué es necesario avanzar en la sustitución al menos parcial de los combustibles fósiles por alternativas 'limpias' como proveedores de energía. Para el 
mismo año, la figura 3.3 muestra la distribución de las emisiones de $\mathrm{CO}_{2}$ por región del mundo. Como es natural, el mayor aporte porcentual correspondió al grupo de naciones más industrializadas del planeta agrupadas en la Organización para la Cooperación y el Desarrollo Económico (OCDE, por sus siglas en francés) ${ }^{11}$ con un $41,5 \%$ del total. Siguen China $(23,7 \%)$ que se reporta separadamente en las fuentes especializadas [IEA, 2011] y Asia ${ }^{12}(10,9 \%)$. Latinoamérica $(3,4 \%)$ y África $(3,2 \%)$ son las regiones que arrojan menos $\mathrm{CO}_{2}$ a la atmósfera [IEA, 2011a].

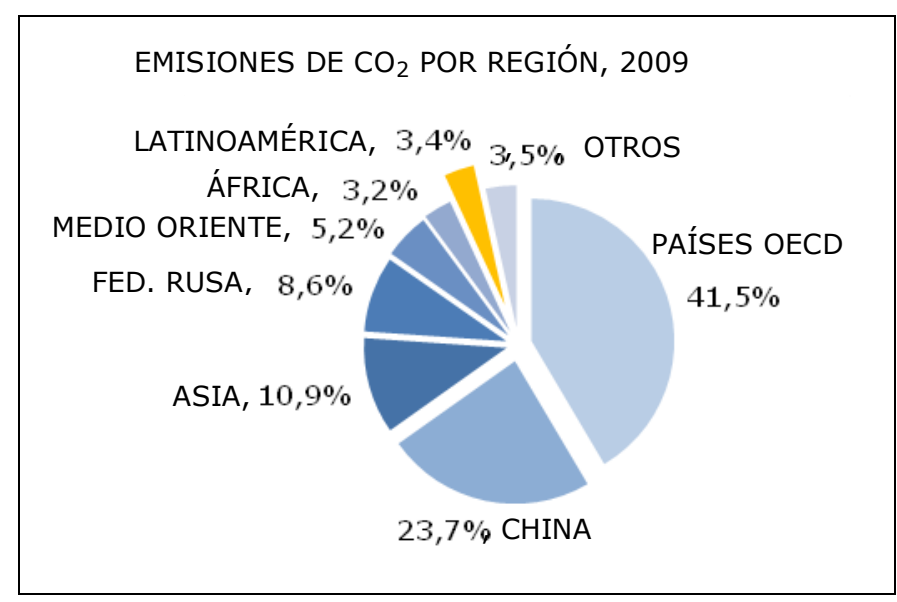

Fuente de datos: IEA, 2011a

Figura 3.3. Emisión de $\mathrm{CO}_{2}$ por región, 2009

En las páginas siguientes se presenta un resumen del funcionamiento del sector energético mundial. El orden de presentación coincide con la clasificación de fuentes de energía presentada en la figura 3.1 antes incluida. La información general, estadística y tecnológica asociada a la explotación de cada recurso fue recabada en artículos especializados; y primordialmente, en publicaciones e informes anuales de

11 OECD : Organización para la Cooperación y el Desarrollo Económico que agrupa 33 países: Alemania, Australia, Austria, Bélgica, Canadá, Corea, Chile, Dinamarca, Eslovenia, España, Estados Unidos, Finlandia, Francia, Grecia, Holanda, Hungría, Islandia, Israel, Irlanda, Italia, Japón, Luxemburgo, México, Nueva Zelanda, Noruega, Polonia, Portugal, República Checa, República Eslovaca, Reino Unido, Suecia, Suiza, Turquía. Chile, Eslovaquia e Israel se incorporaron a la Organización a mediados del año 2010; por tanto, no se incluyen en la estadística.

12 Asia excluye China. 
reconocidas organizaciones multinacionales, públicas y privadas, cuya misión es el seguimiento y análisis de las actividades en el sector energía. En el último caso, la referencia bibliográfica se hace al autor líder del proyecto de publicación y sus cercanos colaboradores, y como editor se coloca a la organización en cuestión; a menos que no se reporten los autores en cuestión. Al final del capítulo se presenta una síntesis del material desarrollado.

\subsection{Fuentes no renovables de energía}

El carbón, el petróleo y el gas natural son fuentes no renovables de energía fósil; esto es, su velocidad de explotación excede por mucho la tasa a la cual se forman, por lo cual su uso implica su desaparición. Su producción, transporte y procesamiento producen frecuentemente impactos ambientales no deseables; y su uso o la de sus derivados como combustible en el sector industrial, eléctrico, de transporte y doméstico arroja emisiones de $\mathrm{CO}_{2}$ y de otros óxidos a la atmósfera que afectan de forma irreversible la salud del planeta y de sus habitantes. Hoy día, los combustibles fósiles representan alrededor de un $81 \%$ de la demanda global de energía primaria; y en ella, el petróleo es el combustible dominante [IEA, 2011a] seguido del carbón y del gas.

La energía nuclear se produce a partir de uranio en reactores de fisión nuclear. La gran cantidad de energía liberada en la reacción se utiliza para la generación de electricidad. Esta fuente de energía no renovable, se asocia a una tecnología compleja, con alta inversión y costos de mantenimiento, que se percibe como riesgosa por el manejo de materiales radioactivos y su disposición final, y por la posibilidad de que uranio enriquecido pueda ser utilizado con propósitos peligrosos para la vida en el planeta. Sin embargo, el proceso de transformación de uranio para obtener finalmente electricidad no produce emisiones de gases invernadero a la atmósfera, lo que constituye una amplia ventaja en los tiempos donde se dicta academia; o simplemente, se conversa sobre cómo podrá sobrevivir el mundo al calentamiento global.

A continuación una breve descripción de cada una de las fuentes citadas de energía no renovable, su participación actual y futura en el panorama energético 
mundial, sus usos y los efectos ambientales que de ello derivan, las nuevas tecnologías para su explotación, sus costos y su eficiencia energética y ambiental.

\subsubsection{Petróleo}

El petróleo es la fuente de energía más importante en el mundo. Sus reservas probadas $^{13}$, sus reservas probables ${ }^{14}$ en yacimientos ya descubiertos, y las que se estima descubrir, aún son inmensas y no se prevé su agotamiento en muchos años [IEA, 2011b]. Para el año 2009, el suministro mundial de petróleo representó aproximadamente un 33\% de la demanda de energía primaria [IEA, 2011a] y se pronostica que seguirá siendo el combustible predominante en el consumo mundial de energía en las próximas décadas, aún cuando se anticipa una disminución de su participación en el mismo [IEA, 2011b].

Existen diferentes calidades de petróleo; de sus características y las de los reservorios que los contienen dependerá en gran medida su mayor o menor facilidad de extracción y la intensidad de los tratamientos para su conversión a productos refinados de alto valor como gas licuado, gasolina, kerosene, diesel, fueloil, aceites y asfalto; y en consecuencia, el costo por barril extraído y procesado. En tal sentido, resulta conveniente clasificar los crudos en petróleos convencionales y petróleos no convencionales; los primeros fáciles y baratos de extraer y los segundos, todo lo contrario [WEC, 2007].

13 Reservas probadas: cantidad del recursos en el reservorio que con razonable certeza puede ser recuperada comercialmente a futuro, con la tecnología disponible y las regulaciones gubernamentales vigentes. En términos probabilísticos, "razonable certeza" corresponde a una probabilidad de al menos $90 \%$ de que la cantidad recuperada sea igual o exceda al estimado [SPE, 2009].

14 Reservas probables: reservas adicionales con una probabilidad de al menos un $50 \%$ de que la cantidad recuperada sea igual o exceda el estimado de reservas probadas más reservas probables [SPE, 2009]. 


\subsubsection{Petróleo convencional}

El petróleo denominado convencional es una mezcla predominantemente de hidrocarburos que existen en fase líquida natural en reservorios bajo tierra y que son recuperables como líquidos a condiciones atmosféricas de presión y temperatura. Su viscosidad es inferior a 10.000 centipoises $^{15}$ [WEC, 2007], su densidad es superior a $10^{\circ}$ API $^{16}$ [Zitter y Schindler, 2007]; y en general, está acompañado de cantidades pequeñas de azufre y metales pesados.

En esta categoría se suelen incluir, especialmente cuando se suministran estadísticas de producción, los líquidos de gas natural (NGL, por sus siglas en inglés) denominación que agrupa aquellos hidrocarburos que existen en el reservorio como constituyentes del gas natural pero que luego de ser extraídos se recuperan como líquidos en separadores o plantas de procesamiento de gas [WEC, 2007]. Los líquidos de gas natural incluyen propano, butano, pentano, hexano y heptano pero no etano y metano.

\subsection{Reservas, producción y consumo}

Las reservas mundiales probadas de petróleo convencional se ubican entre 1,4 y $1,5 \times 10^{12}$ barriles [BP, 2011; OPEC, 2011], y a la tasa de consumo actual, su tiempo de duración se estima en unos 46 años. Si a esta cifra se suman las reservas probables en campos descubiertos y los depósitos que se estima descubrir, el potencial remanente recuperable de petróleo convencional se eleva a 2,4 billones de barriles [IEA, 2008]. Las reservas de petróleo convencional se concentran en los países miembros de la Organización de Países Exportadores de Petróleo ${ }^{17}$ que poseen

151 centipoise $=10^{-2} \mathrm{~g} /(\mathrm{cm} \mathrm{s})$, unidad de viscosidad dinámica

16 Gravedad API $=(141,5 / \mathrm{Ge})-131,5$ Ge: gravedad especifica a $60^{\circ} \mathrm{F}$

17 Organización de Países Exportadores de Petróleo con sede en Viena, Austria y conformada por Arabia Saudita, Emiratos Árabes Unidos, Irán, Iraq, Kuwait, Qatar (Medio Oriente), Argelia, Angola, Libia, Nigeria (África), Indonesia (Asia), Ecuador y Venezuela (Latinoamérica). 
aproximadamente el $77 \%$ de las reservas mundiales; y en la Federación Rusa con una participación del 9,1\% de las mismas [BP, 2011].

Aún cuando el agotamiento del petróleo no parece ser el problema al menos a mediano plazo, la capacidad para extraerlo a la misma velocidad que el mercado lo demanda, sí lo es. En el caso de un campo petrolero, la tasa de producción crece exponencialmente hasta que se alcanza una tasa máxima de extracción del recurso, y luego declina en forma sostenida hasta que se agota el yacimiento ${ }^{18}$. La tasa de declinación post-pico varía de campo a campo en función de su tamaño, la intensidad con la cual haya sido explotado, su localización o no en tierra firme y; las inversiones efectuadas para combatir la declinación natural en la producción del yacimiento. La tasa promedio global de declinación para aquellos campos que han pasado su pico de producción se estima en 6,7\% anual [IEA, 2008]; y en base a la declinación observada de la producción de los campos petroleros más importantes del mundo, se debate sobre el momento en el que la producción mundial de petróleo alcanzará su pico de producción después del cual iniciará un descenso irreversible, con el consiguiente riesgo al suministro si no se efectúan cuantiosas inversiones no sólo en el mantenimiento de los campos existentes, sino en exploración y desarrollo de nuevas alternativas de producción.

Para el año 2010, la producción de petróleo a nivel mundial alcanzó unos 82,1 millones de barriles por día lo que representó un incremento de sólo un 2,2\% con relación al año 2009; mientras que el consumo global que llegó a 87,4 millones de barriles diarios, aumentó en un 3,1\%. Los grandes productores de petróleo fueron los países miembros de la OPEP $(41,5 \%)$ especialmente los países del Medio Oriente $(30,3 \% \%)$, la Federación Rusa $(12,9 \%)$ y Estados Unidos $(8,7 \%)$; y los grandes consumidores fueron Estados Unidos (21,1\%), la Unión Europea (16,4\%), China, Japón e India, estos tres últimos con una participación de un $19.5 \%$ del consumo

${ }^{18}$ Teoría del pico de Hubbert. Afirma que la producción de petróleo en una determinada área geográfica, tiende a seguir una curva en forma de campana. Hubbert creó un método de modelar la curva de producción dado el volumen del recurso a recuperar. 
global. Los países del Medio Oriente fueron los más importantes exportadores, mientras que Estados Unidos, la Unión Europea y Japón debieron importar grandes cantidades de crudo y/o productos refinados para satisfacer su demanda de energía. [BP, 2011].

La figura 3.4 presenta gráficamente algunas estadísticas para el año 2010 sobre reservas probadas, producción y consumo de petróleo convencional clasificado por grandes regiones del mundo. Las cifras cambian de fuente a fuente de datos dependiendo de los renglones que se incluyan en los términos producción y consumo, y en cómo se realicen los cálculos.

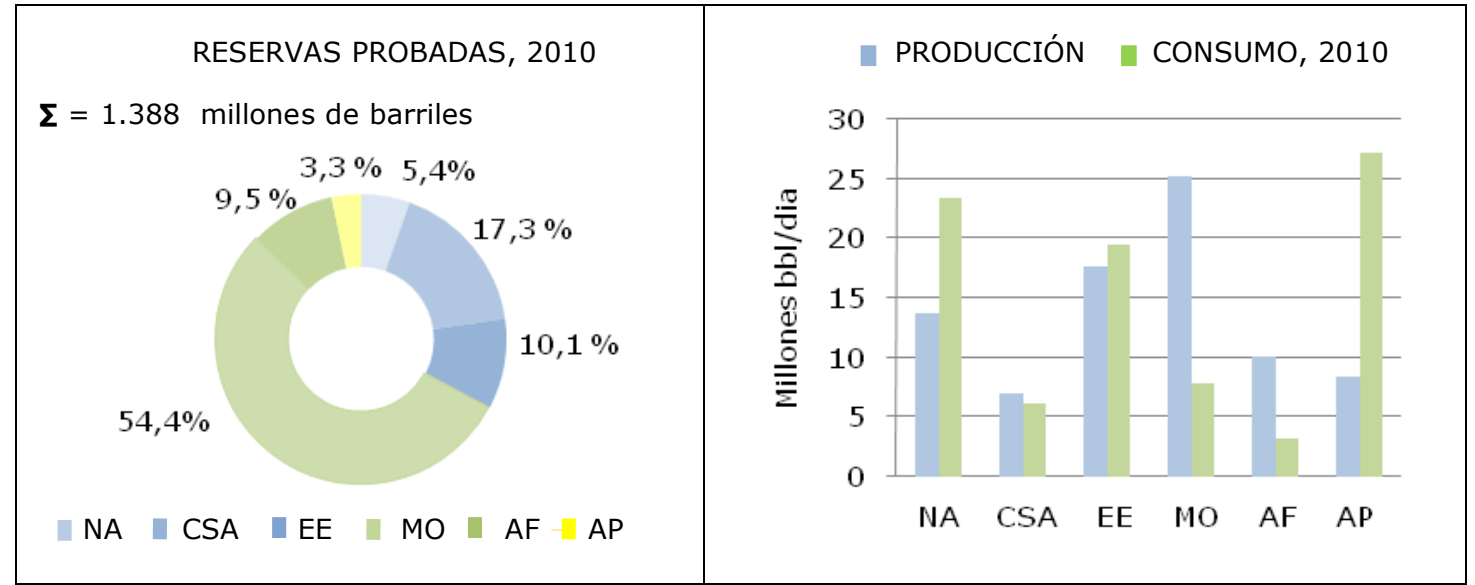

NA: Norteamérica; CSA: Centro y Suramérica; EE: Europa y Eurasia; MO: Medio Oriente; AF: África; AP: Asia-Pacifico ${ }^{19}$, Fuente de datos: BP, 2011.

Figura 3.4. Reservas probadas, producción y consumo de petróleo convencional, por regiones, 2010.

La diferencia entre los totales mundiales de producción y consumo de crudo es igual al cambio de los inventarios; y naturalmente, a las disparidades en la

19 Norteamérica : Canadá, Estados Unidos y México; Centro y Suramérica: Caribe, Centro y Suramérica; Europa y Eurasia: Europa y Antigua Unión Soviética; Medio Oriente: Península Arábiga, Irán, Iraq, Israel, Jordán, Libia y Siria; África: Mauritania a Angola, Cabo Verde, Chad, Sudan, República de Suráfrica, Botsuana, Madagascar, Malawi, Namibia, Uganda, Zambia y Zimbabue.; Asia-Pacífico: Australia, Brunei, China, India, Indonesia, Japón, Malasia, Tailandia, Vietnam, otros. 
definición, medida o conversión de los datos utilizados. En cada región, la diferencia entre la producción y el consumo debe ser importada, en el caso de las regiones netamente consumidoras (NA, EE y AP), o es exportada en el caso de las regiones netamente exportadoras (CSA, ME y AF).

\subsection{Mercadeo y precios}

La elevada demanda de energía frente a un suministro a veces irregular por parte de unos pocos países suplidores, poseedores de las más grandes reservas en el mundo y algunos de ellos localizados en zonas en conflicto permanente como el Medio Oriente; unido a la declinación observada de algunos importantes yacimientos en el mundo han contribuido a la elevación y volatilidad de los precios en los últimos años; esta última especialmente marcada a partir la crisis financiera del año 2008 y posterior recesión de la que se recupera lentamente el mundo. A mitades del 2008 el precio del petróleo alcanzó un máximo de 145,3 US\$/bbl (WTI Cushing Oklahoma) para luego bajar hasta unos $30 \mathrm{US} \$ / \mathrm{bbl}$ a finales del mismo año, recuperarse hasta unos 112 US\$ a mitades del año 2011 y volver a bajar hasta 94 US\$ a mitades del 2012 (15.5.2012, U.S.EIA, 2012a].

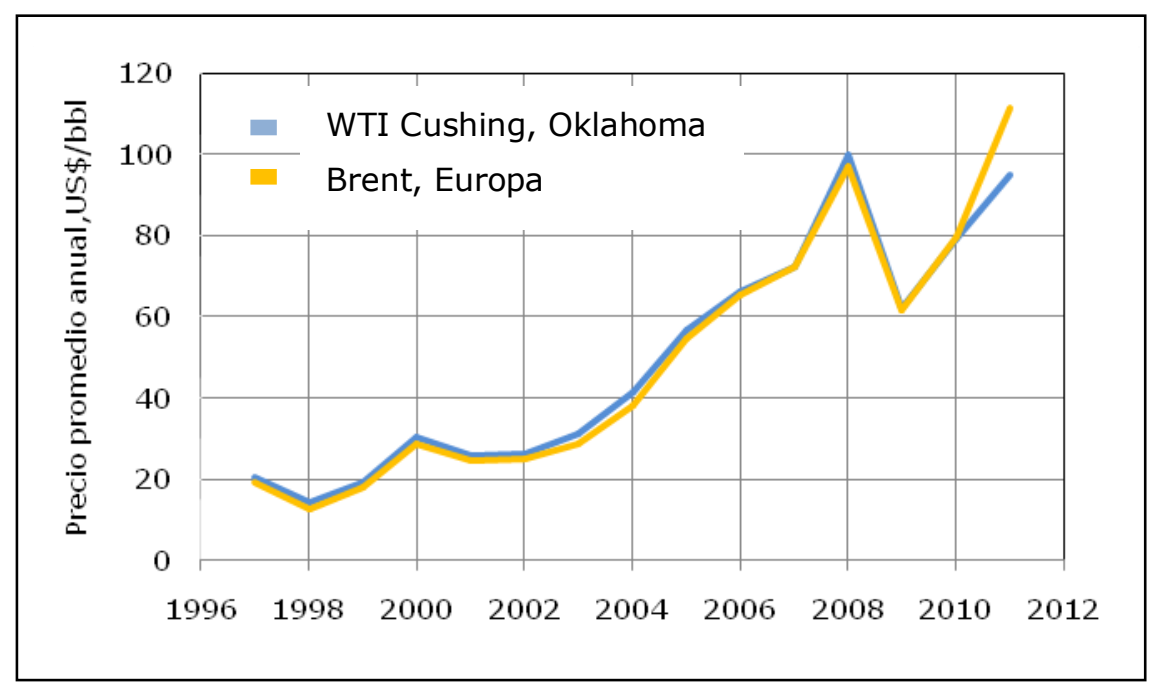

Fuente de datos: U.S.EIA, 2011

Figura 3.5. Precio promedio anual para crudos marcadores 
La gráfica anterior muestra la evolución del 'precio al contado' promedio anual del crudo marcador WTI-Cushing Oklahoma para la última década. Otros crudos como el Brent y la cesta OPEP siguen la misma tendencia pero ligeramente por debajo 20 .

\subsection{Tecnologías de conversión}

El petróleo es una mezcla de hidrocarburos con diferentes puntos de ebullición, propiedad ésta que se aprovecha para fraccionarla. Si la mezcla se somete a destilación atmosférica se obtienen gases, cortes livianos, cortes medianos y residuales; esta última fracción puede ser fraccionada de nuevo mediante una destilación al vacío para separar las fracciones más livianas y asfalto. Todas las fracciones líquidas obtenidas son típicamente procesadas mediante craqueo catalítico, hidrocraqueo, hidrotratamiento o una combinación de estos procesos, para tratar de recuperar y mejorar las fracciones más livianas que posteriormente van a constituir productos de alto valor en el mercado; entre otros, gasolinas para autos y aviones, kerosene utilizado para calefacción y en aviones de turbina, y diesel utilizado en calefacción, maquinas diesel y plantas de generación de potencia eléctrica. Adicionalmente, se obtiene fueloil utilizado en generación de potencia eléctrica y como combustible en procesos industriales; gas de refinería, gas licuado [LPG, por sus siglas en inglés], solventes, coque, lubricantes y similares. Como un subproducto puede obtenerse azufre resultado del proceso de desulfuración del crudo o sus fracciones; ello puede plantear un serio problema ambiental si las cantidades obtenidas son grandes. En general, los precios de los productos refinados en el mercado internacional siguen los movimientos del precio del crudo.

20

Los crudos marcadores son utilizados como crudos de referencia a efectos de realizar transacciones comerciales en una determinada zona del mundo. El West Texas intermedio es un crudo liviano y con poco contenido de azufre utilizado como marcador en los Estados Unidos. El marcador Brent es una mezcla de crudos de 15 campos en el Mar del Norte utilizado en Europa. La cesta OPEP es una mezcla de crudos tipo de cada uno de los 12 países miembros, utilizado en todo el mundo. 
La figura 3.6 muestra gráficamente, para el año 2010, la distribución de la capacidad de refinación instalada y la fracción de ella utilizada, todo clasificado por grandes regiones del mundo.

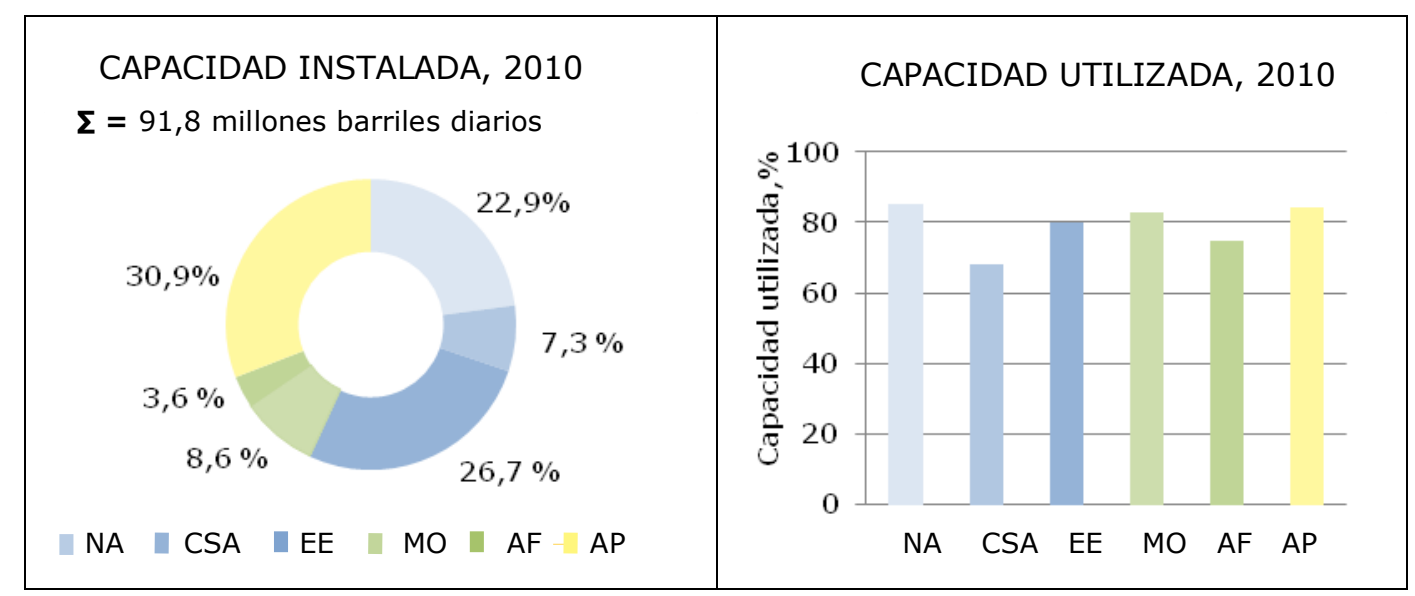

NA: Norteamérica; CSA: Centro y Suramérica; EE: Europa y Eurasia;

MO: Medio Oriente; AF: África; AP: Asia-Pacífico.

Fuente de datos: BP, 2011.

Figura 3.6. Capacidad de refinación instalada y utilizada por regiones, 2010.

Para el año 2010, la capacidad de refinación mundial medida en capacidad instalada de destilación atmosférica, alcanzó aproximadamente 91,8 millones de barriles por día. Los países con mayor capacidad de refinación fueron Estados Unidos con un 22,9\% del total, China, Japón e India que juntos totalizaron un 19,9\%, Italia, Francia, Alemania, el Reino Unido, España y Holanda en Europa, con un 11,7\%; y la Federación Rusa con un $6.1 \%$ del total. La capacidad utilizada promedio global de capacidad de refinación fue de $81,5 \%$. En general, los precios de los productos en el mercado internacional siguieron los movimientos del precio del crudo [BP, 2011].

\subsection{Efectos sobre el ambiente y consideraciones finales}

El impacto ambiental que produce la exploración, perforación, extracción, refinación, transporte y uso final del petróleo incluye el uso de la tierra, el manejo de los residuos, la contaminación de agua, las emisiones de gases invernadero a la atmósfera, y el potencial daño a la ecología del planeta por el riesgo de derrames en el proceso de producción y en el transporte del crudo y sus productos refinados, a través de tuberías y por tanqueros. 
Para el año 2009, el petróleo utilizado como combustible fue responsable por el $36,7 \%$ de un total de 29 Gt de emisiones de $\mathrm{CO}_{2}$ a la atmósfera [IEA, 2011a; IEA, 2011c]; y de allí, un 59\% aproximadamente correspondió a la participación del sector transporte, una de la causas más importante de la contaminación atmosférica en el mundo [IEA, 2011c]. En tal sentido, las oficinas nacionales de planificación deben considerar políticas que incentiven el desarrollo y la adopción de tecnologías más eficientes en la utilización del combustible en los vehículos, un empleo más intensivo del transporte público y un mayor uso de nuevos combustibles con menor contenido de carbón tales como el hidrógeno y los biocombustibles.

\subsubsection{Petróleo no convencional}

Los petróleos no convencionales se caracterizan por su elevada viscosidad, su alta densidad, y sus elevadas concentraciones de nitrógeno, oxígeno, azufre y metales pesados. Su extracción, transporte y mejoramiento para su posterior envío a refinación debe efectuarse con tecnologías más avanzadas que requieren más agua, energía y disolventes que los métodos tradicionales; y que por tanto, resultan más costosas.

Los depósitos reportados de petróleo no convencional en sitio son inmensos y distribuidos a lo largo y ancho del mundo [WEC, 2007]; sin embargo hasta la fecha sólo algunos de ellos tienen el tamaño suficiente para hacer su explotación comercial. La figura 3.7 que se presenta en la próxima página, muestra la ubicación de los principales depósitos de petróleo no convencional en el mundo; entre ellos se destacan, las arenas asfálticas de Alberta en Canadá y el petróleo extra pesado de la Faja del Orinoco en Venezuela que totalizan unos 3 billones de barriles en sitio, y de los cuales más de 400 mil millones de barriles son de reservas recuperables [Government of Alberta, 2012; PDVSA, 2010]; y los esquistos bituminosos ubicados en Colorado, Utah y Wyoming en Estados Unidos con 1,5 billones de barriles en sitio [WEC, 2007].

La necesidad de asegurar la independencia energética, el alto nivel de los precios del crudo y la casi certeza de que tal situación no se modificará; la existencia de grandes depósitos de petróleo no convencional en el mundo y la disponibilidad de 
tecnologías para su explotación aún a costos muy elevados, ha hecho pensar en la extracción y comercialización de este tipo de crudos. De esta forma, se han realizado inversiones cuantiosas para la explotación de grandes depósitos de bitumen y de petróleo extrapesado a fin de complementar el suministro de petróleo convencional. Naturalmente, la tecnología debe ser mejorada para incrementar los rendimientos y hacer el proceso de su explotación y suministro más económico y menos contaminante.

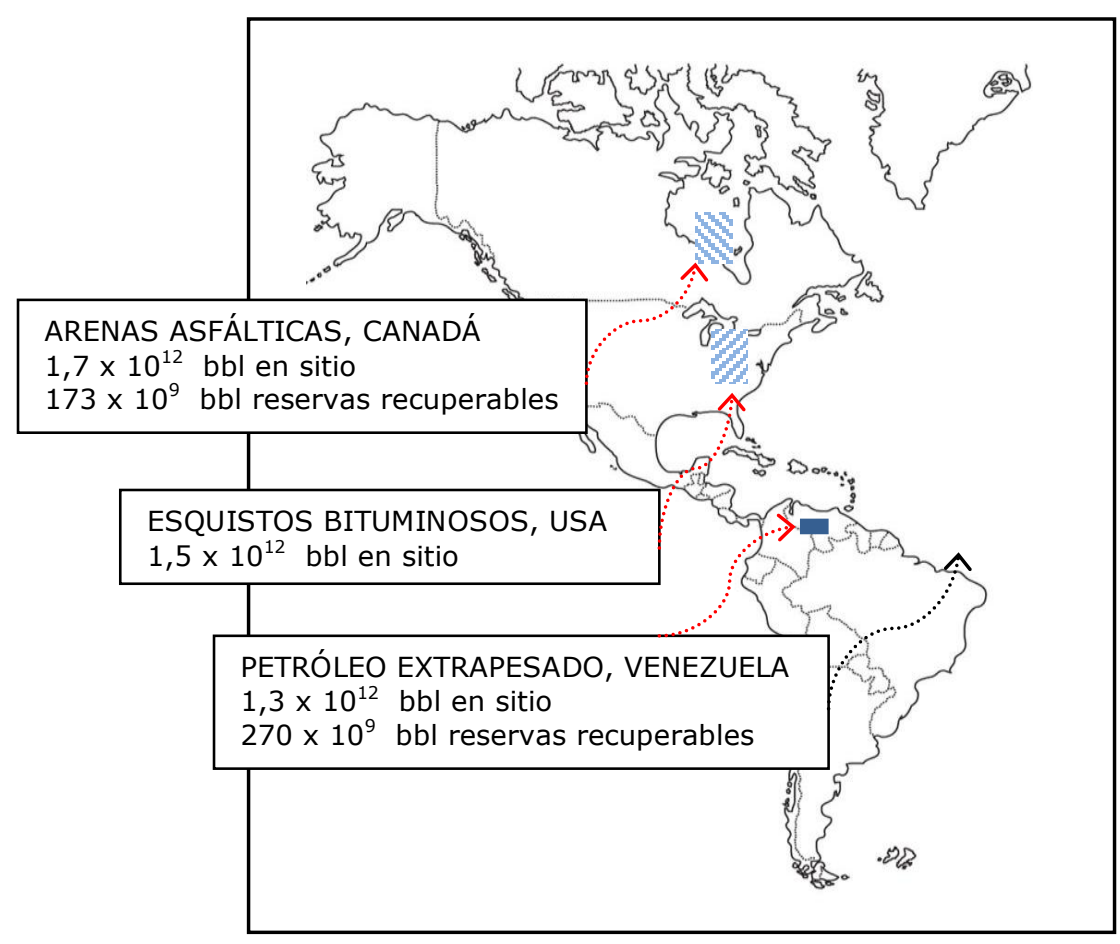

Fuente de datos: [Government of Alberta, 2012; PDVSA, 2010; WEC, 2007]

Figura 3.7. Principales depósitos de petróleo no convencional en el mundo

A continuación algunos comentarios sobre cada fuente de petróleo no convencional antes citada.

\subsection{Arenas asfálticas}

Las arenas asfálticas son mezclas de arena o arcilla, agua y una forma de petróleo extremadamente pesado (densidad < $10^{\circ}$ API) y viscoso (viscosidad en reservorio > 10.000 centipoises) que se conoce como bitumen, que se encuentran naturalmente 
en depósitos muy cercanos a la superficie de la tierra. Se han reportado descubrimientos de bitumen en 22 países [WEC, 2007]; sin embargo, los reservorios más grandes del mundo y los únicos explotados comercialmente hasta la fecha, son las arenas asfálticas de Athabasca, Peace River y Cold Lake en Canadá, Alberta con bitumen descubierto en sitio de aproximadamente 1,5 billones de barriles y reservas probadas de 169,3 mil millones de barriles [Government of Alberta, 2012; CAPP, 2012].

\subsection{Tecnologías de extracción, transporte y conversión}

Los depósitos de Alberta han sido comercialmente explotados desde 1967, utilizando la minería de superficie para los depósitos menos profundos o la recuperación in-situ para los más profundos. En el primer caso, el mineral extraído de la mina es triturado y tratado con agua caliente para formar una suspensión de la que es recuperado el bitumen por flotación. En el segundo caso, se inyecta vapor de agua al reservorio para elevar la temperatura y disminuir la viscosidad del bitumen que así puede ser bombeado a la superficie. La estimulación del yacimiento puede hacerse en forma cíclica (CSS, por sus siglas en inglés) donde el mismo pozo se utiliza alternativamente para inyectar vapor y luego recuperar el bitumen calentado hasta agotar el yacimiento; o utilizando una tecnología más eficiente conocida como Drenaje por Gravedad Asistido con Vapor (SAGD, por sus siglas en inglés) donde el vapor inyectado en forma continua a través de un pozo horizontal calienta el yacimiento permitiendo al bitumen fluir por gravedad a un pozo horizontal de producción ubicado unos metros más abajo; y de allí, ser bombeado a la superficie [Government of Alberta, 2012; Schlumberger, 2012b].

Una vez extraído, el bitumen debe ser calentado o mezclado con diluyentes para su transporte a un sitio con facilidades para su mejoramiento; o ser mejorado en el sitio. El mejoramiento produce un crudo sintético con características que dependen de los requisitos de las refinerías a las que posteriormente será enviado para su refinación, especialmente en lo que se refiere a densidad y contenido de azufre.

El proceso de mejoramiento se inicia con una destilación atmosférica o al vacío que recupera los disolventes para su reciclaje al campo original, y produce gasoil y 
residuos. El gasoil es sometido a hidrotratamiento catalítico o a hidrocraqueo, procedimientos en los cuales se trata con hidrógeno para reducir el contenido de azufre y nitrógeno. Mientras, el residuo es sujeto a un procedimiento previo de desasfaltaje con solventes, para la remoción de los materiales asfálticos; y posteriormente, convertido mediante tratamiento térmico, en una mezcla de fracciones más livianas y un residuo. Las tecnologías más utilizadas para este último paso son: (i) la viscoreducción que produce gasolina de baja calidad, gasoil y un alquitrán residual, (ii) la coquefacción que fragmenta los hidrocarburos más pesados presentes en el residuo, para producir fracciones más livianas y coque, y (iii) el hidrocraqueo en donde se adiciona hidrógeno al residuo a elevadas condiciones de temperatura y presión lo que incrementa la conversión a fracciones líquidas. El rendimiento de conversión a crudo sintético varía entre 0,8 y 0,9 barriles de crudo por barril de bitumen, de acuerdo con el proceso utilizado y el grado de mejoramiento deseado [WEC, 2007]; y se necesitan aproximadamente 2 toneladas de arenas por barril de crudo sintético obtenido [Government of Alberta, 2012].

Para el año 2010, la producción de bitumen fue de 1,6 millones de barriles diarios de los cuales un $47 \%$ correspondió a su extracción por minería y un 53\% a extracción in situ. Por su parte, la capacidad de refinación alcanzó 1,309 millones de barriles por día [Government of Alberta, 2012].

\subsection{Efectos sobre el ambiente y consideraciones finales}

La explotación de las arenas asfálticas causa un impacto ambiental importante sobre el terreno donde se localiza la extracción, especialmente si ésta se realiza por minería de superficie; y además consume gran cantidad de agua y energía. Adicionalmente, las emisiones de gases invernadero a la atmósfera son mayores que en la producción de petróleos convencionales. Todo ello, ha motivado una estricta regulación ambiental y el seguimiento detallado de toda la operación por parte del Gobierno de Canadá y ha focalizado la investigación en tecnologías que permitan la disminución de agua, energía y emisiones, y/o la captura y almacenamiento en el subsuelo del $\mathrm{CO}_{2}$ generado (CCS, por sus siglas en inglés). 
En tal sentido, dos nuevas tecnologías que han despertado especial interés son (i) la Extracción de Petróleo Asistida con Vapotalon (VAPEX, por sus siglas en inglés) que propone reducir la relación vapor/petróleo e inyectar una mezcla de hidrocarburos líquidos al reservorio para ayudar la reducción de la viscosidad del bitumen inducida por el vapor [Schlumberger, 2012a], y (ii) la tecnología de Inyección de Aire 'Punta a Talón' (THAI, por sus siglas en inglés), una variación de la combustión in-situ, que combina una inyección de aire vertical con un pozo horizontal de producción cuyo extremo está alineado con el pozo vertical. El proceso comienza con el calentamiento del reservorio con vapor hasta una temperatura a la cual el crudo en el sitio se encienda en presencia del aire inyectado. Alimentado por la inyección de aire, se forma un frente de combustión que se desplaza por el área que contiene el petróleo pesado en la dirección 'punta a talón' del pozo de producción horizontal; éste recoge el petróleo más liviano producto del proceso de craqueo del petróleo pesado que se produce cuando el frente avanza y que baja por gravedad al pozo de producción. Pruebas experimentales muestran que el proceso puede recuperar el $80 \%$ del petróleo en el sitio; y paralelamente, efectúa un mejoramiento parcial del mismo [Schlumberger, 2012b; ANL, 2008]. Ambas tecnologías permiten reducir el consumo de vapor; esto es, el consumo de agua y energía; y las emisiones de CO2 a la atmósfera.

En resumen, existen grandes depósitos de bitumen cuya extracción y mejoramiento son mucho más complicados que en el caso de los petróleos convencionales. Su desarrollo sostenible y su creciente participación en la cesta energética mundial dependerán de cómo se supere el reto tecnológico y ambiental que ello significa, a costos de inversión y operación que frente a los precios vigentes de su oferta en el mercado permitan la competitividad y supervivencia del negocio.

\subsection{Petróleo extrapesado}

Los petróleos extrapesados son crudos extremadamente viscosos (viscosidad en reservorio < $10.000 \mathrm{cP}$ ), con una densidad inferior a $10^{\circ}$ API y con un elevado contenido de azufre y metales pesados. Existen depósitos de petróleo extrapesado reportados en 22 países [WEC, 2007] siendo el más importante la Faja Petrolífera del Orinoco en Venezuela que alberga aproximadamente 1,36 billones de barriles en sitio 
de los cuales son recuperables unos 270 mil millones de barriles ${ }^{21}$. Las reservas probadas se estiman en 170 mil millones de barriles [PDVSA, 2010]. Para el año 2009, la producción en el área fue 898 mil barriles por día; aproximadamente un $30 \%$ de la producción petrolera venezolana para el mismo año [PDVSA, 2010].

\subsection{Tecnologías de extracción, transporte y conversión}

Los depósitos de crudo extrapesado venezolano difieren de las arenas asfálticas canadienses en que fluyen más fácilmente a temperatura ambiente debido a su menor viscosidad y a mejores características de permeabilidad y temperatura del reservorio; sin embargo siguen siendo muy viscosos y tienen un alto contenido de azufre, níquel y vanadio lo que hace complicada y costosa su extracción, transporte y mejoramiento previa a la refinación.

Aprovechando las características de movilidad del petróleo en la Faja, la producción se realiza en frío a través de pozos horizontales debidamente posicionados en arenas delgadas pero relativamente continuas, en combinación con bombas eléctricas sumergibles y bombas de cavidad progresiva. El factor de recuperación en la Faja oscila entre $8 \%$ y $12 \%$ del petróleo en sitio [WEC, 2007]; sin embargo, el año 2009 se ha puesto en marcha un nuevo proyecto basado en la metodología SAGD con cuya aplicación se pretende elevar la recuperación a niveles del 60\% [PDVSA, 2010] a un costo inferior al de operaciones comparables en las arenas asfálticas de Canadá [Dusseault, 2008].

Una vez extraído, el crudo se mezcla a boca de pozo con diluyentes para su transporte a las facilidades de mejoramiento ubicadas al norte del país y luego es exportado a refinerías cautivas en Estados Unidos y el Caribe. El grado de mejoramiento del crudo dependerá de las características del crudo extraído y de las características que debe tener el crudo sintético para ser procesado en la refinería destino. La integración vertical entre el productor del crudo, el mejoramiento y los

21 U.S. Geological Survey ha estimado el volumen de petróleo extrapesado recuperable en la Faja del Orinoco entre 380 y 652 mil millones de barriles [USGS, 2009]. 
refinadores disminuye el riesgo que significa competir con crudos de mejor calidad y el diferencial de precio entre éstos y el crudo sintético producido.

\subsection{Efectos sobre el ambiente y consideraciones finales}

La producción de petróleo extrapesado y su conversión a un crudo sintético más liviano en la Faja del Orinoco, produce además de las emisiones de gases, cantidades importantes de azufre y coque. Los derivados de azufre se exportan para su uso en fertilizantes, agroquímicos, cauchos vulcanizados y similares, mientras que el coque se vende internamente a la industria del acero; sin embargo, su almacenamiento y transporte al destino final incrementa los costos y tienen un impacto sobre el ambiente cuyo crecimiento es proporcional a la producción en la Faja.

En la búsqueda de una mejor productividad, de un menor impacto al ambiente y de la reducción de costos en la explotación, transporte y mejoramiento del crudo de la Faja, para una tercera etapa se han considerado las tecnologías THAI y CAPRI. La tecnología THAI es una variación de la combustión in-situ y fue brevemente descrita en la sección anterior. El método disminuye los requerimientos de vapor y las emisiones de $\mathrm{CO}_{2}$ a la atmósfera, reduce el contenido de azufre en el crudo entre un $20 \%$ y un $30 \%$ y elimina los metales pesados en aproximadamente un $90 \%$ que quedan como residuos inertes sobre la arena del reservorio. No requiere agua ni gas durante el proceso de producción y produce una disminución de la densidad. La tecnología THAI aún está en fase de prueba y se estima le falte algún tiempo para instalarse comercialmente [Schlumberger, 2012b; ANL, 2008].

La tecnología CAPRI es una variación de la tecnología THAI que añade un catalizador sólido rodeando en forma anular el pozo de producción horizontal. El petróleo térmicamente craqueado por THAI en su ruta hacia el pozo productor pasa a través del catalizador. Pruebas de laboratorio indican que la combinación THAICAPRI puede lograr un significativo mejoramiento in-situ convirtiendo prácticamente el petróleo pesado en un petróleo liviano de gravedad superior a $22^{\circ} \mathrm{API}$ que fluye sin necesidad de diluyente por tuberías [ANL, 2008] con el consiguiente ahorro en costos de transporte y en un posterior mejoramiento. 
La viscosidad de los crudos extrapesados en la Faja del Orinoco y la calidad de sus reservorios es superior a las de las arenas asfálticas de Canadá [WEC, 2007]. Sin embargo, en los tiempos que corren Canadá es un país políticamente más estable y con una tradición de investigación en el área muy superior a la de Venezuela. Recientemente, el país ha establecido convenios de explotación bajo la modalidad de empresas mixtas con una gran variedad de compañías extranjeras. Claramente, la adopción de nuevas tecnologías en el área y la inversión en proyectos para el uso de las mismas hará la diferencia que podría convertir a la Faja Petrolífera del Orinoco en el área productora más importante en el mundo.

\subsection{Esquistos bituminosos}

Los esquistos bituminosos son rocas sedimentarias de grano fino de muy baja permeabilidad y con un alto contenido de materia orgánica conocida como kerógeno de cuyo procesamiento pueden obtenerse hidrocarburos líquidos [WEC, 2007]. Aunque la información de la que se dispone es rudimentaria, se estima que el potencial mundial de esquistos bituminosos alcanza unos 2,8 billones de barriles; de ellos, unos 1,5 billones se encuentran depositados en la formación del Green River en la frontera común entre los Estados Colorado, Utah y Wyoming en el oeste de los Estados Unidos [WEC, 2007].

El proceso más común de producción ha sido la minería de superficie o bajo la tierra, seguida por el procesamiento en grandes retortas del material extraído donde es sometido a altas temperaturas en ausencia de oxígeno. A unos $350{ }^{\circ} \mathrm{C}$, el kerógeno comienza a licuarse y se separa de la roca fuente. La sustancia que emerge puede ser mejorada y convertida en un crudo sintético para su envío a refinación. Todo el proceso causa una serie de problemas ambientales tales como emisiones de gases invernadero, alteración del terreno donde se efectúa la minería, disposición de la roca agotada, uso de fuentes de agua e impactos sobre la calidad de la misma.

El Proceso de Conversión In Situ (ICP, por sus siglas en inglés) plantea el calentamiento de los esquistos bituminosos bajo tierra utilizando calentadores eléctricos colocados en pozos verticales perforados a través de la sección del 
depósito que se quiere explotar. Luego de un período de dos o tres años, se alcanza una temperatura de aproximadamente $350^{\circ} \mathrm{C}$, el aceite empieza a liberarse del esquisto, es colectado en pozos adecuadamente ubicados en la zona calentada y bombeado a la superficie. El escape de hidrocarburos y de metales pesados que puedan contaminar los acuíferos en el área y/o el ingreso de agua a la zona calentada se previene creando una barrera de frío en el perímetro de la zona de extracción, mediante el bombeo de fluido de refrigeración a través de una serie de pozos perforados alrededor de la zona de extracción.

El proceso ICP produce una mezcla de hidrocarburos que contiene propano, butano y una mezcla de fracciones livianas de hidrocarburos con bajo contenido de azufre y una densidad aproximada de 34\% API [Klainberg, 2007]; y elimina los problemas que ocasionan la minería y la disposición de grandes cantidades de esquistos agotados, disminuyendo significativamente los costos, aunque aún no ha sido comercialmente probada.

Los depósitos de esquistos bituminosos han sido escasamente explotados, simplemente por el hecho de que no pueden competir económicamente con el petróleo como recurso de energía fósil. En la medida en que el suministro de crudo disminuya y su precio aumente, la explotación de los esquistos bituminosos podría llegar a ser una alternativa energética, especialmente si la tecnología para lograrlo es perfeccionada.

\subsubsection{Gas natural}

El gas natural es una mezcla de hidrocarburos, primordialmente metano y etano, que existe en fase gaseosa, o disuelta en petróleo, en reservorios naturales bajo tierra, y que es gaseoso a condiciones atmosféricas de temperatura y presión. En general, los volúmenes de gas natural suelen expresarse en metros cúbicos en condiciones estándar medido seco, a $15^{\circ} \mathrm{C}$ y 1 atmósfera de presión [WEC, 2007]. Las cifras de volúmenes de gas natural que se presentan a lo largo de este capítulo corresponden a volúmenes en condiciones estándar aún cuando esta condición no se exprese explícitamente. 
El gran volumen de reservas de gas existente en el mundo, el aumento y volatilidad de los precios del petróleo así como la falta de seguridad en su suministro, los avances tecnológicos unidos a la reducción de los costos de extracción, licuefacción y transporte del gas, el crecimiento de la población mundial y de la actividad económica en algunos países en vía de desarrollo como China e India, el Medio Oriente, e incluso, Latinoamérica; y la cada vez mayor exigencia de utilizar combustibles menos emisores de $\mathrm{CO}_{2}$ a la atmósfera, han contribuido al incremento de la producción de gas natural a nivel mundial, por su bajo contenido de carbono en comparación con el carbón y el petróleo. Para el año 2010, la producción de gas contribuyó en un $20,9 \%$ al suministro de energía primaria en el mundo y contribuyó con un $19,9 \%$ de las emisiones globales de $\mathrm{CO}_{2}$ [BP, 2011].

Las características físicas de los reservorios afecta la dificultad y cuantía de la posible recuperación del gas localizado en ellos. De acuerdo a tales características, los depósitos de gas pueden clasificarse en convencionales y no convencionales. La extracción del gas en depósitos no convencionales con permeabilidades de roca muy baja, requiere tecnología más avanzada e inversiones más elevadas que la tecnología estándar que se requiere en los depósitos convencionales. La composición del gas en ambos tipos de depósitos es similar; esto es, primordialmente metano y etano, cantidades moderadas de otros hidrocarburos livianos y alguna cantidad de sustancias como $\mathrm{H} 2 \mathrm{~S}$ gaseoso, mercaptanos, $\mathrm{CO}_{2}$, agua, mercurio y otros contaminantes.

\subsubsection{Gas natural convencional}

La mayor parte de la producción mundial de gas natural proviene de reservorios bajo tierra con condiciones geológicas favorables para atrapar el gas natural en un depósito de tamaño y calidad comercial que no requiere procedimientos extensivos de recuperación para obtener elevados niveles de productividad y rentabilidad económica. Dentro del sector energético, tales reservorios se conocen como depósitos convencionales de gas natural; en ellos, el gas almacenado puede encontrarse como gas asociado disuelto en petróleo a las altas presiones existentes en el reservorio; o debido a su menor densidad, como una capa sobre el depósito de petróleo. También existen reservorios que contienen solamente gas no asociado. 


\subsection{Reservas, producción y consumo}

Las reservas probadas mundiales de gas natural convencional se ubican alrededor de 190 billones de metros cúbicos; reservas que a la tasa de producción actual, se estima duren poco menos de 60 años [BP, 2011; OPEC, 2011]. Para el año 2010, tales reservas se concentraban primordialmente en tres países, la Federación Rusa $(23,9 \%)$, Irán $(15,8 \%)$ y Qatar $(13,5 \%)$; dos de ellos miembros de la OPEP, que en su totalidad reúne más del 49\% de las reservas mundiales [OPEC, 2011]

De esta forma, los recursos de gas a nivel mundial son suficientes para hacer frente al incremento de la demanda que se estima alcance unos 4,3 billones de metros cúbicos para el año 2030, si las políticas energéticas actuales se mantienen sin ningún cambio [IEA, 2009a]. La capacidad y la inversión necesaria para responder a la demanda prevista dependen en gran medida de la tasa de agotamiento de la producción en los yacimientos de gas existentes tras alcanzar su techo de producción. Un análisis detallado de las tendencias históricas de la producción de gas en unos 600 yacimientos que representan más del $55 \%$ de la producción mundial, y las evaluaciones del tamaño y la distribución de edad de los yacimientos de gas en el mundo han permitido estimar la tasa media mundial de agotamiento ponderada por la producción, una vez alcanzado el máximo de producción, en un 7,5\% anual [IEA, 2009a]; un índice similar a la tasa de agotamiento de los yacimientos petroleros.

A nivel de prospección y extracción, el desarrollo tecnológico ha permitido el estudio de las capas inferiores de la corteza terrestre sin necesidad de perforaciones, permitiendo con ayuda de un ordenador, crear mapas tridimensionales que representan las distintas capas de roca presentes en el subsuelo. Una vez localizado un depósito de gas no asociado, es posible obtener gas del reservorio mediante la perforación de pozos en el área; la operación se detiene cuando la presión en la formación decline a un punto donde el valor de gas obtenido no cubra los costos de la misma. Dependiendo de la permeabilidad de la formación, el factor de recuperación de gas puede alcanzar entre un $75 \%$ y un $80 \%$ del gas original en sitio [Britannica, 2009]. La automatización de las plataformas de perforación y la perforación horizontal han permitido el monitoreo de los pozos durante la 
perforación, acceder a reservas que se encuentran a mayor profundidad y la reducción de los costos. El uso de nuevas tecnologías en las plataformas de perforación mar adentro ha permitido alcanzar profundidades superiores a los 3000 metros [Naturalgas.org, 2010a]. A diferencia del gas no asociado, el gas asociado es un subproducto de la producción de petróleo que puede ser separado en la superficie.

El gas producido puede ser reinyectado al yacimiento para mantener su presión y aumentar su productividad; puede ser quemado ${ }^{22}$ aun cuando esta práctica ha disminuido debido a las restricciones ambientales; o puede ser comercializado. Las dos primeras opciones constituyen alternativas especialmente para el gas asociado cuando no se dispone de un mercado cercano para su colocación rentable.

Antes de su comercialización, el gas natural debe ser acondicionado para obtener un producto menos contaminante, muy rico en metano, que demanda el mercado. Típicamente, ello incluye la remoción de impurezas como agua, $\mathrm{CO}_{2}, \mathrm{H}_{2} \mathrm{~S}$, azufre, nitrógeno, helio, agua y mercurio; y la extracción de los hidrocarburos más pesados en forma de líquidos del gas natural (NGL, por sus siglas en inglés) y de gas de petróleo licuado (LPG, por sus siglas en inglés); éste último constituido principalmente por propano y butano, puede ser licuado a presiones moderadas y vendido como combustible doméstico o industrial.

Para el año 2010, la producción comercializada de gas natural en el mundo alcanzó 3,2 billones de metros cúbicos estándar $\left(3,2 \times 10^{12} \mathrm{~m}^{3}\right)$ lo que representó un incremento del 7,3\% con relación a la producción del año 2009. Los más grandes productores fueron Estados Unidos con un 19,3\% de la producción mundial y la Federación Rusa con un $18,4 \%$ de la misma [BP, 2011]; y los principales consumidores fueron Estados Unidos con $21,7 \%$ del consumo mundial y la Federación Rusa con un 13\%. Brasil, Chile, Perú, China, India, indonesia, Sur Corea

22 Observación satelital de "mechurrios" en el mundo, http://www.ethanzuckerman.com/blog/wpcontent/2007/11/flares.jpg, 1/2010. 
y Taiwán, entre otros, mostraron incrementos superiores al $20 \%$ sobre el nivel de su consumo de gas en el año 2009 [BP, 2011].

La figura 3.8 presenta algunas cifras para el año 2010, sobre reservas probadas, producción comercializada y consumo de gas, clasificadas por grandes regiones del mundo. El volumen de producción reportado corresponde a la producción total de gas comercializado en el mundo, allí incluida la producción de gas no convencional de los Estados Unidos. Las cifras cambian de fuente a fuente de datos dependiendo de los renglones se incluyan en los términos producción y consumo, y en la forma como se realicen los cálculos.

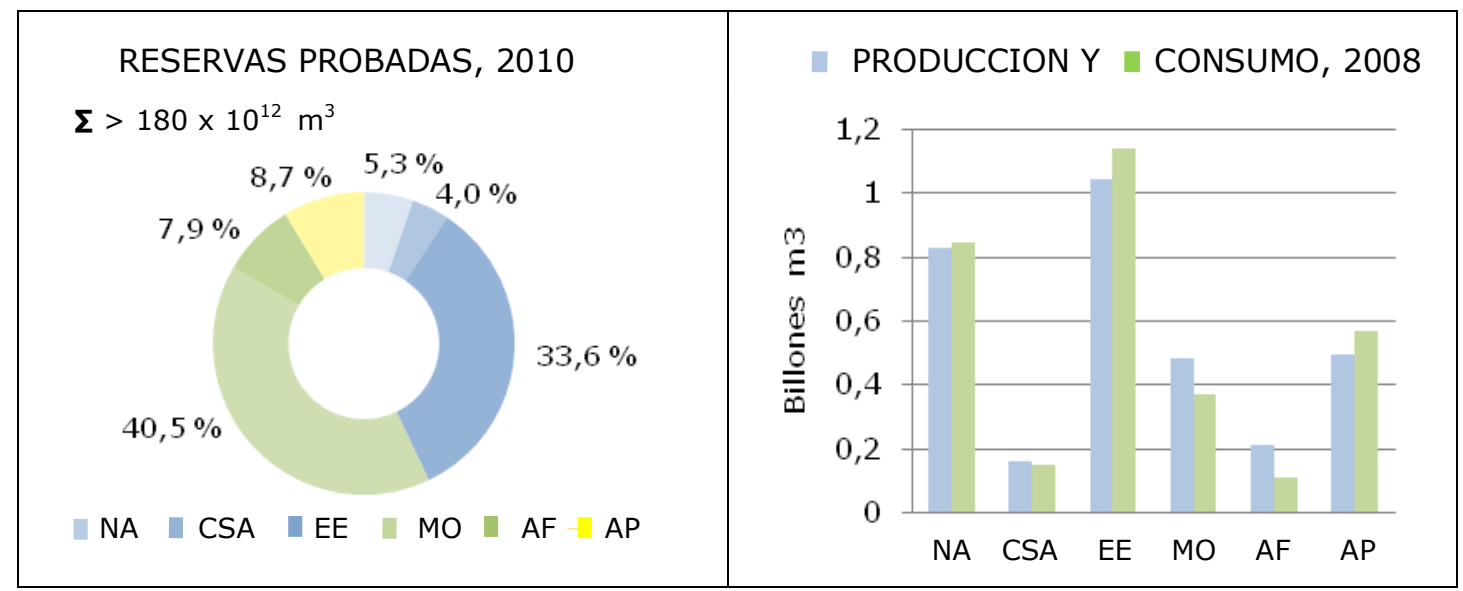

NA: Norteamérica; CSA: Centro y Suramérica; EE: Europa y Eurasia; MO: Medio Oriente; AF: África; AP: Asia-Pacifico, Fuente de datos: BP, 2011.

Figura 3.8. Reservas probadas, producción comercializada y consumo de gas natural, 2010.

Las diferencias entre los totales mundiales de producción y consumo de gas se deben al cambio de los inventarios por almacenamiento en los tanques de las plantas de licuefacción; y naturalmente, a las disparidades en la definición, medida o conversión de los datos utilizados. En cada región, la diferencia entre la producción y el consumo debe ser importada como es el caso de las regiones predominantemente consumidoras como Norteamérica, Europa, Eurasia y Asia; o es exportada, en el caso de las regiones exportadoras como Centro y Suramérica, el Medio Oriente y África. 


\subsection{Transporte}

Una vez acondicionado, el gas es transportado por tubería para su distribución, si la distancia a los mercados hace la operación técnica o económicamente posible. El transporte de grandes volúmenes de gas natural a través del océano o a través de grandes distancias, se realiza previa su conversión a gas natural licuado (LNG, por sus siglas en inglés) por disminución en etapas de la temperatura hasta aproximadamente $-162^{\circ} \mathrm{C}$, a presión cercana a la atmosférica. La reducción en volumen (1/600) permite almacenar y transportar grandes cantidades de gas haciendo la operación rentable a pesar del alto costo de la planta de licuefacción necesaria en el terminal de embarque y del equipo de regasificación requerido en el terminal receptor. El LNG es transportado mayoritariamente en tanqueros con envases criogénicos especialmente construidos para ello.

Una segunda alternativa es transportar gas natural comprimido (CNG, por sus siglas en inglés) aproximadamente a presiones de 200 bar $^{23}$, en cisternas sobre distancias más cortas, directamente a los usuarios finales o a centros de distribución. Esta opción permite la explotación de reservas de gas fuera de tierra firme donde no existen tuberías para su transporte o donde la opción LNG no es económicamente viable. Los equipos necesarios de compresión y descompresión son menos costosos que las plantas de licuefacción y regasificación; sin embargo la inversión y el costo de operación del transporte del CNG es elevado.

\subsection{Mercadeo y precios}

Para el año 2010, el comercio de gas en el mundo representó el $31 \%$ de la producción de gas. Los importadores de gas más importantes fueron Estados Unidos, Japón, Alemania, Italia y el Reino Unido; y los exportadores más notables la Federación Rusa, Canadá y Noruega [BP, 2011]. El comercio de gas por tubería representó un $69 \%$ del total y se incrementó en un 5,4\% sobre el nivel del año anterior, liderado por el crecimiento del intercambio entre Rusia, Europa y Eurasia, responsables por aproximadamente dos tercios del comercio global por esta vía. Las

231 atmósfera a nivel del mar $=1,01325$ bar $=101.325 \mathrm{~Pa}$ 
exportaciones de LNG crecieron en aproximadamente $22,6 \%$ sobre el nivel del año anterior y fueron dominadas por Qatar, Malasia e Indonesia. El principal importador de gas natural licuado fue Japón seguido de Sur Corea, España y Estados Unidos [BP, 2011].

El precio del gas natural se forma en un mercado competitivo influenciado por muchas variables como la oferta y la demanda, el nivel de inventarios, el tipo de consumidor $^{24}$ y las regulaciones gubernamentales, y la tendencia futura que se aprecie en esas u otras variables. La demanda depende a su vez del crecimiento económico, del precio de otras fuentes de energía y de las condiciones del tiempo, entre otros factores. La figura 3.9 que se incluye a continuación, muestra la evolución durante la última década de los promedios anuales de los precios Henry $H_{u b}{ }^{25}$ y National Balancing Point (NBP) ${ }^{26}$, referencias importantes en contratos de compra y venta de gas natural a futuro en los mercados norteamericano y europeo, respectivamente.

Los precios del gas natural siguieron los vaivenes del precio del petróleo frente a la crisis financiera y posterior recesión económica que se inició el año 2008. A mitades de ese año, el precio del gas natural alcanzó un máximo de 13,6 US\$/MM BTU (Henry Hub) para luego bajar hasta unos 6 US\$/MM BTU al final del año. La tendencia hacia la baja siguió en el 2009 y se mantuvo entre 3 y 4 US\$/MM BTU durante gran parte del año para recuperarse a 6 US\$/MM BTU, mediados del 2010 y

24 Ver http://www.eia.doe.gov/oil_gas/natural_gas/data_publications/natural_gas_monthly/ngm

25 Henry Hub es un punto sobre la red de gasoductos en Luisiana, U.S., donde se interconectan gran cantidad de tuberías que transportan el gas a diferentes mercados en los Estados Unidos. El precio para el gas entregado en el lugar es una referencia para los contratos a futuro que se transan a través del New York Mercantil Exchange con sede en New York, USA. El AECO Hub en Alberta, Canadá es un punto de referencia similar para la fijación del precio en contratos de compra-venta de gas en Norteamérica.

26 El National Balancing Point es una localización virtual de comercialización para la venta y compra de gas natural en el Reino Unido que se toma como referencia para la fijación de precios en los contratos a futuro que se transan a través del Intercontinental Exchange (ICE). El Zeebrugge Hub en Bélgica es otro punto de referencia para la fijación de precios en el mercado europeo. 
seguir bajando hasta llegar a 2,7 US\$/MM BTU a mitades del 2012 [22/5/2012, U.S.EIA, 2012b].

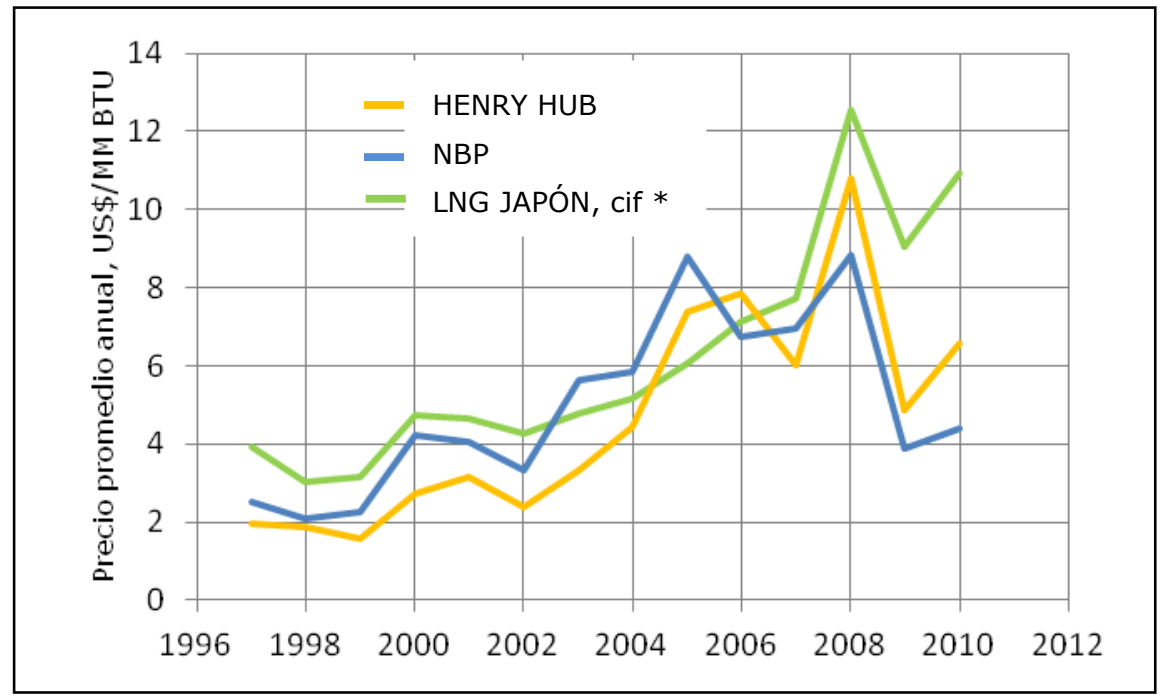

* cif, incluye costo, seguro y flete hasta el puerto de destino.

Fuente de datos: BP, 2011.

Figura 3.9. Precios promedio de referencia para el gas natural y el gas natural licuado.

Adicionalmente, la figura 3.9 muestra la evolución de los promedios anuales del precio del LNG (Japón, cif) para la última década. Los precios del gas natural licuado (LNG) toman como referencia los precios de los combustibles que compiten con él. Así, en Asia, el precio se relaciona al precio del petróleo importado ${ }^{27}$; en Estados Unidos se utiliza como referencia el 'precio al contado' Henry Hub para la compra y

27 El precio de paridad con el petróleo se determina en base a un barril de petróleo equivalente y es muy usado en Asia. En general, los contratos se firman a largo plazo con poca flexibilidad; por ello, la fórmula de precios contiene un término determinado por negociación que protege al vendedor o al comprador de un cambio abrupto de precios. En Japón, Korea y Taiwan el precio de la fórmula se relaciona con el precio promedio de los veinte crudos con importaciones más importantes a Japón denominada Japan Crude Coktail (JCC, por sus siglas en inglés). En Indonesia, la formula de precios en los contratos para la compra venta de LNG se referencia a los precios de mercado de cinco crudos mercadeados internacionalmente en Indonesia, Malasia, Australia, Dubai y Oman cuyo promedio constituye el Indonesian Crude Price (ICP, por sus siglas en inglés) [Zhang, Yoshikawa, Ishii y Shimoda, 2008]. 
venta de gas natural; y en Europa la fórmula de precios en cada contrato toma como elemento de referencia los precios del crudo Brent o un promedio de los precios del gasoil, y de los crudos de alto y bajo contenido de azufre. En general, los precios del LNG en Asia son superiores a los precios de este combustible en otras regiones [Zhang, Yoshikawa, Ishii y Shimoda, 2008] y a los precios del gas natural distribuido por gasoductos [BP, 2011].

Naturalmente, la calidad del gas es un asunto importante en la negociación y el vendedor está obligado a cumplir con las especificaciones del mismo en el contrato, bajo pena de indemnización al comprador. Las especificaciones se dirigen a garantizar que el gas sea no corrosivo, no tóxico y no sobrepase los límites máximos

de azufre, $\mathrm{H}_{2} \mathrm{~S}, \mathrm{CO}_{2}$ y mercurio; que no exceda los contenidos máximos de agua e hidrocarburos condensables de forma de prevenir la formación de agua o hidratos; y especialmente, que cumpla con el contenido calórico especificado.

\subsection{Usos}

El gas natural es la fuente de energía cuyo uso ha evolucionado más rápidamente en los últimos años. Su utilización en tiempos pasados estuvo limitada a los mercados locales o regionales, debido fundamentalmente a la dificultad y costo para transportarlo. La creciente toma de conciencia por parte de los diferentes sectores de la sociedad de la necesidad de mantener la calidad del aire y de no contribuir al incremento del problema del calentamiento global con excesivas emisiones de gases invernadero, el avance en las tecnologías de la cadena [prospección-extraccióntratamiento-transporte y utilización] del gas y la desregulación de los mercados han contribuido a que su uso se haya incrementado notablemente, especialmente como combustible en el sector de generación de potencia eléctrica y en el sector industrial.

Paralelamente, el gas natural se utiliza en la calefacción y enfriamiento de espacios y en la cocción de alimentos en los sectores residencial y comercial; como materia prima en la manufactura de pulpa y papel, vidrio, plásticos, fertilizantes y derivados petroquímicos, entre otros; y en mucha menor proporción, como sustituto de la gasolina en el sector vehicular. 
Las plantas generadoras de potencia eléctrica alimentadas con combustibles fósiles utilizan turbinas de gas de combustión o turbinas de vapor para proveer la energía mecánica insumo a los generadores eléctricos. En una turbina de vapor, el combustible es quemado en un hervidor para calentar agua y producir vapor a alta presión y temperatura, el cual se expande a través de la turbina acoplada a un generador que produce electricidad. Para grandes turbinas de vapor (>500 kW), la eficiencia de conversión a energía eléctrica oscila entre 33\% y 35\% de la energía térmica usada para generar el vapor [naturalgas.org, 2010a].

Por su parte, en una turbina de gas de combustión, en lugar de vapor son los gases calientes y a alta presión, producto de la combustión del combustible, los que se expanden a través de la turbina acoplada a un generador de electricidad. Típicamente, este tipo de turbinas es ligeramente menos eficiente que las grandes turbinas de vapor pero puede ser mejorada instalando en la corriente aún muy caliente que sale de la turbina, una unidad de recuperación de calor que se usa para producir vapor para la calefacción o para usos industriales. El proceso se conoce como cogeneración y puede aumentar la eficiencia global de conversión de energía a niveles del $80 \%$. Alternativamente, el vapor producido en la unidad de recuperación de calor puede ser utilizado en una turbina de vapor para generar electricidad. La combinación de una turbina de gas de combustión con una turbina de vapor para producir energía eléctrica se conoce como planta de ciclo combinado (CCGT, por sus siglas en inglés) y alcanza eficiencias térmicas que oscilan entre $50 \%$ y $60 \%$ [natural.org, 2010b].

Por sus características de combustible más limpio, la utilización del gas natural como sustituto de la gasolina en vehículos de uso intensivo como taxis, camiones, y autobuses públicos, ha despertado gran interés en los últimos años. La mayoría de los vehículos a gas opera con gas natural comprimido (CNG); una menor cantidad usa gas licuado (LNG) o son flexibles; esto es, pueden usar gasolina o gas natural como combustible. Sus costos de llenado del tanque y de mantenimiento son menores que los de los vehículos similares a gasolina; sin embargo, su costo inicial es mayor y no existe una infraestructura de estaciones expendedoras suficientemente extendida lo que ha frenado su masificación. 


\subsection{Efectos sobre el ambiente y consideraciones finales}

El gas natural es el menos contaminante de todos los combustibles fósiles. Su combustión produce cantidades menores de $\mathrm{CO}_{2}$ por unidad de energía liberada que la combustión de otros combustibles como los derivados del petróleo y el carbón que tienen una relación $\mathrm{C} / \mathrm{H}$ más elevada; además produce cantidades pequeñas de $\mathrm{SO}_{2}$ y óxidos de nitrógeno y prácticamente nada de cenizas y partículas sólidas.

Sin embargo, la exploración, producción, transporte y distribución del gas natural puede afectar el ambiente; de allí que la industria del gas haya desarrollado y adoptado tecnologías para (i) maximizar el gas natural obtenido por pozo y así reducir el impacto de la perforación sobre el ambiente, y (ii) minimizar los riesgos de emisiones y/o escapes de gas de los pozos, tanques de almacenamiento 0 gasoductos, toda vez que el metano, principal constituyente gas natural, es un gas invernadero unas 20 veces más potente que el dióxido de carbono en sus efectos cuando se libera a la atmósfera.

Además, es prioritario para la industria rebajar los volúmenes de gas asociado quemado o venteado a la atmósfera que se estiman en unos 150 mil millones de metros cúbicos por año los cuales producen una 400 millones de toneladas de emisiones de gases invernadero a la atmósfera [The World Bank, 2009]. Una reducción en el gas quemado contribuirá a rebajar las emisiones de $\mathrm{CO}_{2}$ a la atmósfera; y al mismo tiempo, a incrementar la disponibilidad de gas natural en el mundo.

En conclusión, el gas natural es un combustible ampliamente distribuido en el planeta, flexible en sus usos, más limpio que otros combustibles fósiles como el carbón y el petróleo; y competitivo, frente al incremento de los precios y a la reducción de costos lograda por una industria cada vez más innovadora y tecnificada. Tales características unidas a una estricta regulación ambiental y al avance tecnológico en el área, ofrece a la industria del gas nuevas oportunidades de crecimiento y una serie de retos que deberá superar para tener una participación importante a la cesta energética de este nuevo siglo. 


\subsubsection{Gas natural no convencional}

Parte de la producción mundial de gas natural proviene de depósitos no convencionales donde el recurso es de extracción técnicamente más difícil y más costosa que el gas en depósitos convencionales. Las reservas globales de gas natural no convencional son enormes y están ampliamente distribuidas alrededor del mundo; sin embargo no han sido suficientemente evaluadas y su producción es limitada. Los recursos recuperables de gas natural no convencional, primordialmente en arenas de baja porosidad, lechos de carbón y esquistos gasíferos alcanzan más de 900 billones de metros cúbicos, localizados mayoritariamente en Estados Unidos y Canadá [IEA, 2009a; NPC, 2007].

La explotación del gas no convencional es más costosa y contaminante que la del gas convencional. Sin embargo, la tecnología moderna ha permitido mejorar la eficiencia por pozo y rebajar los costos. Los principales obstáculos para su producción comercial son el difícil acceso físico a los reservorios, la necesidad de grandes cantidades de agua y el impacto ambiental que causa su explotación; y a veces, la distancia del sitio de explotación a la red de gasoductos existente.

El principal productor de gas no convencional en el mundo es Estados Unidos; la producción en otras regiones es relativamente pequeña. En Australia, China, India e Indonesia existen proyectos en desarrollo. El porcentaje de gas no convencional en la producción total comercializada estadounidense pasa hoy día del $60 \%$, independientemente de sus precios [IEA, 2011d].

\subsubsection{Gas natural en arenas compactas}

Este tipo de gas no convencional se forma en arenas muy compactas, no porosas, con permeabilidades inferiores a 0,1 milidarcy ${ }^{28}$. Tales reservorios albergan una gran cantidad de gas [NPC, 2007] cuya extracción demanda un considerable esfuerzo

\footnotetext{
28 La permeabilidad tiene que ver con la resistencia que opone un medio al paso de un fluido. Un lecho con una permeabilidad de 1 darcy deja pasar un fluido de viscosidad igual a 1 centipoise, a una velocidad de $1 \mathrm{~cm} / \mathrm{s}$ bajo un gradiente de presión de 1 atmósfera/cm. 1 darcy =9,867 X 10 ${ }^{-13} \mathrm{~m}^{2}$.
} 
debido a las pequeñas velocidades de flujo natural del gas a través de la formación; específicamente, requiere el bombeo de fluidos dentro de la roca para crear o expandir fracturas a través de las cuales pueda fluir el gas hasta un pozo productor. Un pozo de este tipo produce a una tasa más baja que un pozo convencional pero por un tiempo más largo.

Los recursos recuperables mundiales de gas natural en arenas compactas se estiman en más de 200 billones de metros cúbicos [NPC, 2007]; y para el año 2009, la producción de gas en arenas compactas fue de 256 mil millones de metros cúbicos de los cuales un 64\% correspondió a Estados Unidos, un 16\% a Canadá y un 20\% a otros países [Greenberg, 2009].

\subsection{Metano en lechos de carbón}

Generalmente, el carbón se encuentra en capas bajo tierra que son explotadas mediante excavación y remoción del carbón allí presente. Muchas de estas capas o la roca que los rodea contienen metano que es liberado a la atmósfera como un producto colateral del proceso de explotación, constituyendo una amenaza a la seguridad de los mineros. Por esta razón, el metano así producido era ventilado a la atmósfera contribuyendo como gas invernadero que es, a la contaminación del aire en los alrededores.

Actualmente, el metano en lechos de carbón puede ser extraído y transportado a través de tuberías para su uso en calefacción y generación de electricidad; y como materia prima en procesos industriales. El metano presente en los lechos de carbón se encuentra en las fracturas de las vetas de carbón y/o adsorbido sobre la superficie de los microporos del carbón mismo. Su producción comercial requiere reducir la presión en el reservorio bombeando fuera del mismo, el agua atrapada en las capas de carbón; ello permite que el gas se desprenda de las partículas de carbón y pueda fluir hacia las fracturas existentes en el reservorio. Los recursos recuperables globales de gas en lechos de carbón (CBM, por sus siglas en inglés) se estiman en más de 250 billones de metros cúbicos [NPC, 2007].

Hoy día, el gas en lechos de carbón constituye la segunda fuente de gas no convencional en el mundo. Para el año 2009, su producción fue de 70 mil millones de 
metros cúbicos de los cuales un $71 \%$ correspondió a Estados Unidos, un $10 \%$ a Canadá y un $13 \%$ a otros países entre los cuales se cuentan Australia, India, China y Colombia [Greenberg, 2009].

\subsection{Gas de esquistos}

Las formaciones de esquistos pueden actuar como una fuente de gas natural y como su reservorio. En efecto, una vez generado, el gas se adsorbe sobre la materia orgánica que contiene la roca o es retenido en los microporos o en las fracturas naturales de la misma. En general, su extracción requiere la utilización de fluidos hidráulicos para crear fracturas que permitan al gas fluir; y la aplicación de perforación horizontal y direccional. Con la tecnología actual, el promedio de la recuperación por pozo alcanza aproximadamente un $7 \%$ del gas en sitio [NPC, 2007]. Avances tecnológicos que permitan una mejor caracterización del yacimiento para lograr controlar el avance del proceso de fractura en tiempo real así como la adecuada colocación del pozo de perforación permitirán un incremento futuro de este factor de recuperación.

Los recursos recuperables a nivel mundial de gas de esquistos se estiman como mínimo en 450 billones de metros cúbicos [NPC, 2007]. Con la excepción de Estados Unidos y Canadá, el gas de esquisto ha sido poco estudiado, de esta forma las cifras sobre el potencial de este recurso se consideran inciertas. Para el año 2009, la producción mundial de gas de esquisto fue de 67 mil millones de metros cúbicos y provino casi en su totalidad (97\%) de los Estados Unidos; un 3\% correspondió a Canadá y el resto del mundo no tuvo ninguna producción [Greenberg, 2009].

\subsection{Hidratos de metano}

Los hidratos de metano son una clase de sustancia en la cual moléculas de agua forman una red sólida abierta que encierra, sin enlace químico, moléculas de metano. Tales combinaciones cristalinas de metano y agua se forman en ambientes con baja temperatura y elevada presión; específicamente, se han reportado descubrimientos en las regiones permafrost árticas y en aguas profundas de las plataformas continentales en todo el mundo. Investigaciones han mostrado que los hidratos de carbono pueden contener más carbono orgánico que el contenido en el 
conjunto de las reservas actuales de carbón, petróleo y gas convencional [NETL, 2010]; este enorme potencial ha incentivado la investigación sobre su posible uso como fuente de energía y sobre las implicaciones que sobre el ciclo natural del carbón, el ambiente y la estabilidad del fondo marino pueda tener su explotación. En la medida en que la tecnología avance y se desarrollen nuevos y rentables métodos para extraer y usar esta fuente de gas natural no convencional, el mundo podrá contar con el enorme potencial energético que ella representa.

\subsubsection{Carbón}

El carbón es una roca sedimentaria estratificada que contiene fundamentalmente carbono con alguna cantidad de hidrógeno, oxígeno, nitrógeno y azufre; y fases minerales que se transforman en ceniza que queda después de la combustión de la roca. El carbón es producto de una serie de transformaciones sufridas por deposiciones en zonas pantanosas de vegetación prehistórica que posteriormente fue siendo sepultada debajo de diferentes tipos de sedimentos. Durante el proceso, la materia orgánica es sometida a temperatura y presión elevadas, pierde el agua y los elementos volátiles, se enriquece en carbono y genera gases que permanecen atrapados en la roca debido a su baja permeabilidad. La edad del depósito determina el tipo de vegetación originalmente depositada y es uno de los factores que influye en las características finales del carbón; entre ellas, el rango o grado de madurez del carbón [IFP, 2008].

Los carbones de alto rango como la antracita y el carbón bituminoso contienen más carbono, tienen un menor contenido de humedad y producen más energía que los carbones de bajo rango como el carbón sub-bituminoso y la lignita. Entre todos, la antracita tiene el valor calórico más elevado (30 $\mathrm{MJ} / \mathrm{Kg})$; se utiliza en los sectores doméstico e industrial y su contribución a las reservas mundiales del recurso es sólo 1\%. Sigue en poder calórico, el carbón bituminoso $(18,8-29,3 \mathrm{MJ} / \mathrm{kg})$ que es el más abundante en la naturaleza con una contribución del 52\% a las reservas globales del recurso; se utiliza en la generación de electricidad, en la producción de coque para los altos hornos usados en la fabricación de hierro y acero, en la manufactura de cemento y en otros usos industriales. El carbón sub-bituminoso con un poder calórico que oscila entre $8,3 \mathrm{MJ} / \mathrm{kg}$ y $25 \mathrm{MJ} / \mathrm{kg}$ y una contribución del $30 \%$ a las reservas 
mundiales, se utiliza principalmente en generación de electricidad y en el sector industrial; y finalmente. La lignita con un poder calórico bajo $(5,5-14,3 \mathrm{MJ} / \mathrm{kg})$ contribuye con el $17 \%$ a las reservas mundiales de carbón y su uso está limitado a la producción de electricidad [IFP, 2008; WCI, 2012a].

\subsubsection{Extracción, mejoramiento y transporte}

El carbón es producido excavando en minas superficiales cuando el recurso está cerca de la superficie; o en minas subterráneas cuando no es así. Cuando la mina es superficial puede recuperarse $90 \%$ o más del carbón en el sitio. La explotación bajo tierra requiere de túneles donde se realiza la extracción del carbón que luego es transportado a la superficie mediante elevadores. Una vez extraído, el carbón es procesado para remover otras rocas, tierra, ceniza, azufre y otros materiales no deseados; y posteriormente trasladado en camiones, por tren o en chalanas; en barcos a través del mar; o como una suspensión en agua, a través de tuberías. Los costos de transporte suelen ser muy elevados por lo que algunas plantas generadoras de electricidad se ubican cerca de las minas de carbón, si ello rebaja los costos [WCI, 2012a].

\subsubsection{Reservas, producción y consumo}

El carbón es una de las mayores fuentes de energía en el mundo. A finales del año 2010, sus reservas probadas totalizaban 861.000 millones de toneladas presentes en más de 70 países y en cada continente del mundo. Estados Unidos $(27,6 \%)$, la Federación Rusa (18,2\%), China (13,3\%), Australia (8,9\%), India (7,0\%) y Alemania $(4,7 \%)$ disponen de las mayores reservas. A la tasa de consumo actual, se estima que las reservas durarán poco menos de 120 años [BP, 2011].

Para el año 2010, la producción mundial de carbón alcanzó aproximadamente 3.731 millones de toneladas de petróleo equivalente, lo que representó un poco más de la cuarta parte del suministro mundial de energía primaria [BP, 2011; IEA, 2011a]; sin embargo y debido a su alto contenido de C por unidad de energía liberada, su combustión produjo un $43 \%$ de de las emisiones mundiales de $\mathrm{CO}_{2}$ [IEA, 
2011a, 2011c]. Los principales productores fueron China $(48,3 \%)$ y los Estados Unidos $(14,8 \%)$ [BP, 2011].

La figura 3.10 presenta gráficamente algunas estadísticas para el año 2010 sobre reservas probadas, producción y consumo de carbón, clasificadas por grandes regiones del mundo. Como puede observarse, la región Asia-Pacífico (AP) lidera por mucho la producción de carbón con un $67,2 \%$ del total mundial, siguen Norteamérica (NA) y la región Europa-Euroasia (EE) con participaciones más modestas del 15,9\% y $11,5 \%$ respectivamente. Es notable la poca producción y consumo de Centro y Suramérica (CSA) y de los países del Medio Oriente (MO).

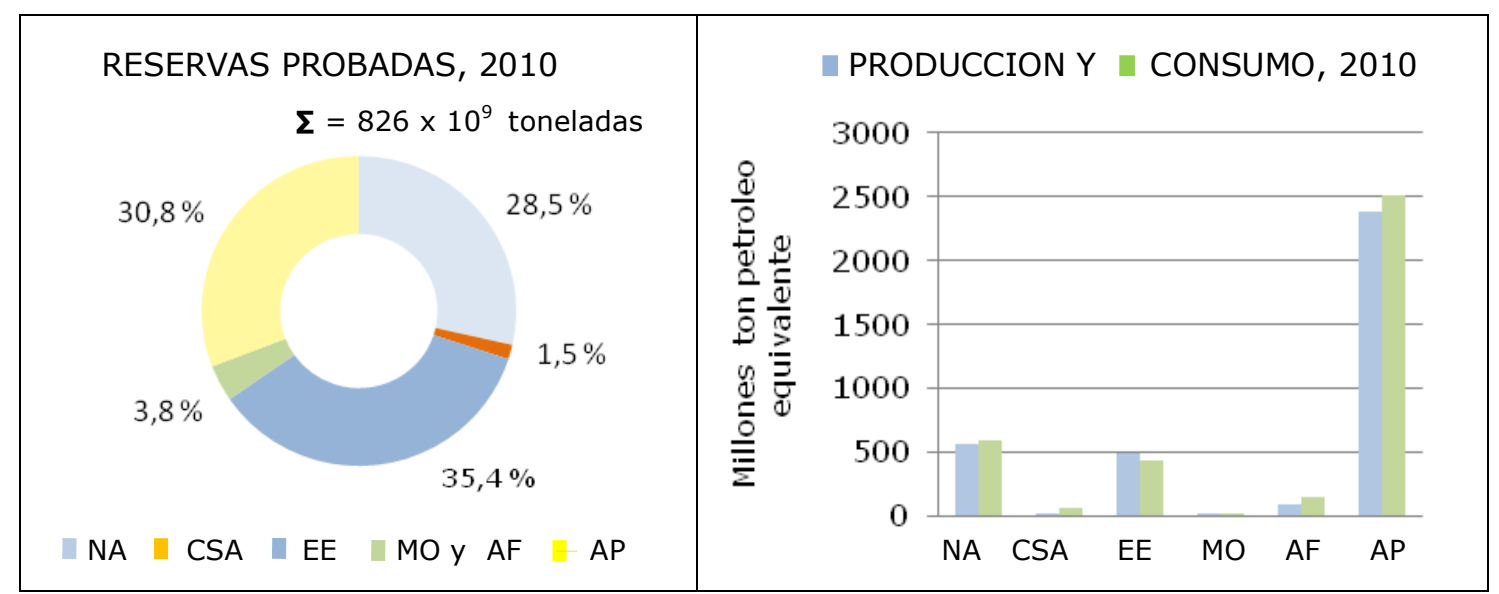

NA: Norteamérica; CSA: Centro y Suramérica; EE: Europa y Eurasia; MO: Medio Oriente; AF: África; AP: Asia-Pacífico, Fuente de datos: BP, 2011.

Figura 3.10. Reservas probadas, producción y consumo de carbón, 2010.

Los principales países consumidores de carbón son China, Estados Unidos. Australia e India con participaciones respectivas del $48,2 \%, 14,8 \%$ y $6,3 \%$ y $5,8 \%$ de la energía mundial consumida proveniente del carbón durante el año 2010 [BP, 2011].

El carbón se utiliza fundamentalmente para generación de electricidad, contribuyendo con 40,6\% del total generado para el año 2009 [IEA, 2011a]. Además es utilizado en la producción de acero, manufactura de acero y para obtener combustible líquido. Otros usuarios importantes son las industrias del aluminio, papel, química y farmacéutica; y los fabricantes de productos especializados como el 
carbón activado utilizado en filtros de agua, purificación de aire y máquinas de diálisis; y de fibra de carbón, material de refuerzo en construcción [WCI, 2012a].

\subsubsection{Mercadeo y precios}

Gran parte de la producción mundial de carbón se utiliza en el país donde es producida; de esta forma, la fracción comercializada del total mundial consumido durante el año 2010 fue sólo de un 16\% [WCI, 2010b]. Japón, Taiwán y Corea en el mercado del Pacifico; y Alemania, el Reino Unido y España, en el mercado del Atlántico son los importadores más importantes de carbón para generación de electricidad y de coque para la producción de acero. El exportador más importante de carbón es Australia el cual es simultáneamente el más grande suplidor de coque. Le siguen Indonesia, la Federación Rusa, Colombia y Suráfrica.

El carbón es un combustible abundante e históricamente su precio se ha mantenido relativamente estable y más bajo que el precio del petróleo y del gas, si se compara en una base de energía equivalente. La figura 3.11 muestra la evolución de los precios anuales promedio del carbón para la última década; específicamente, de los precios marcadores: (i) North West Europe (NWE, por sus siglas en inglés) que refleja el valor de mercado del carbón estándar bituminoso que es entregado en el Norte de Europa Occidental ${ }^{29}$, (ii) U.S. Central Appalachian que representa el promedio de los precios del carbón entregado cerca de la confluencia de los ríos Ohio y Big Sandy en la región de Appalachia Central que abarca parte de los estados Virginia Occidental, Virginia, Kentucky y Tennessee de los Estados Unidos y que es

29 El marcador NWE es un promedio de los precios de material bituminoso entregado en países del Norte de Europa como el Reino Unido, Francia, los Países Bajos, Alemania, Dinamarca y el norte de España. Los precios son ajustados al precio equivalente CIF Rotterdam, Holanda utilizando los diferenciales de flete entre éste y los respectivos puertos de descarga reportados por el intermediario y verificado por las mesas de flete de los mercados participantes. Se incluyen las transacciones de material bituminoso de todos los orígenes, en tanto y cuanto, cumpla con la norma europea; esto es, el carbón debe tener un contenido de azufre inferior a $1 \%$ y los precios se ajustan a un poder calórico de $6000 \mathrm{Kc} / \mathrm{Kg} \mathrm{NAR}$ (Neto As Received, por sus siglas en ingles, incluye humedad). Los principales suplidores son Suráfrica, Colombia, Polonia, Rusia, Asia y Estados Unidos [McCloskey, 2009]. 
utilizado como referencia en los contratos a futuro que se transan a través del New York Mercantil Exchange con sede en New York, USA ${ }^{30}$; y (iii) el promedio de los precios cif de coque (JCCM) y de carbón para generación de electricidad (JSCM) provenientes de Australia, China e Indonesia y entregados en Japón ${ }^{31}$.

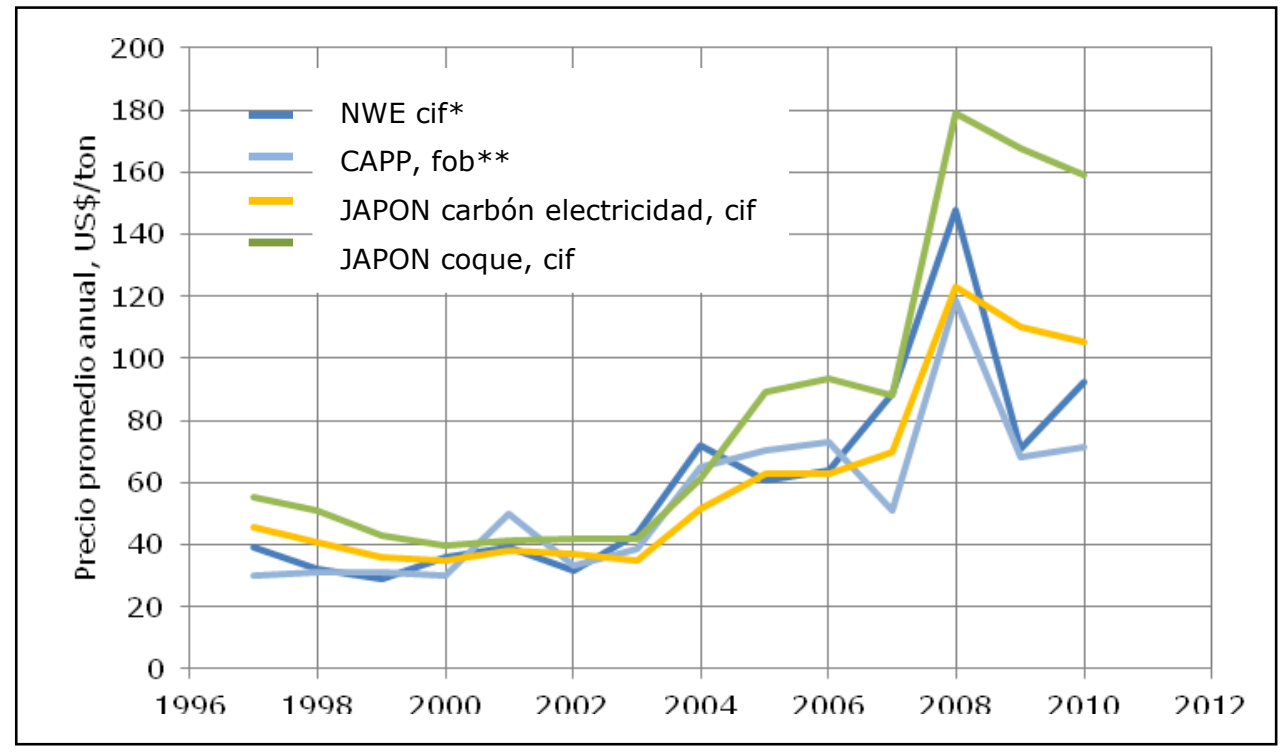

* cif, incluye costo, seguro y flete hasta el puerto de destino.

** fob, libre a bordo

Fuente de datos: BP, 2011.

Figura 3.11 Precios anuales promedio de referencia para el carbón

El marcador CAPP es el precio promedio del carbón en el mercado a corto plazo de la región Appalachia Central, Estados Unidos. El origen del carbón no está definido pero debe cumplir con una serie de especificaciones sobre valor calórico, contenido de azufre, contenido de humedad entre otras [EIA, 2010]. El marcador CAPP reportado en la figura 3.11 corresponde al precio 'fob' de material bituminoso con un valor calórico de 12.500 BTU/lb y un contenido de azufre de 1,2\% [BP, 2009].

31

Los marcadores Japan Coking Coal Marker (JCCM, por sus siglas en inglés) y Japan Steam Coal Marker (JSCM, por sus siglas en inglés) toman en cuenta los precios 'cif' de las respectivas entregas en Japón de coque y carbón para generación de electricidad, desde Australia, China e Indonesia. Todos los precios se ajustan a una base v.c. 6.080 kilocaloría/Kg NAR. El marcador se obtiene como un promedio de los precios individuales ponderados en base a la proporción en que contribuye cada origen en las importaciones de carbón a Japón, por un período móvil de tres meses. El promedio se basa en las estadísticas japonesas [McCloskey, 2009]. 1 kilocaloría = 4,187 ] 


\subsubsection{Efectos sobre el ambiente y nuevas tecnologías}

La combustión del carbón produce emisiones importantes de $\mathrm{CO}_{2}$, óxidos de nitrógeno, óxidos de azufre y partículas en suspensión; y su explotación es muy contaminante del ambiente. A futuro, se pronostica que el carbón forme parte importante de la cesta energética particularmente de países como China e India con un creciente desarrollo industrial, grandes reservas de carbón y limitadas reservas de otro tipo de combustible. Para tratar de mitigar el nivel de emisiones que esto puede significar, se ha dedicado un gran esfuerzo al desarrollo de tecnologías que permitan mejorar la eficiencia de combustión del carbón y de nuevas técnicas de captura y almacenamiento de $\mathrm{CO}_{2}$ producido en la generación de electricidad o en cualquier otra actividad industrial.

La tecnología de Gasificación Integrada con Ciclo Combinado (IGCC, por sus siglas en inglés) utiliza alta temperatura y presión para gasificar el carbón y convertirlo en gas de síntesis $\left(\mathrm{H}_{2}+\mathrm{CO}\right)$ el cual es tratado para eliminar contaminantes antes de ser enviado para su combustión a una turbina de gas; el calor en los gases que salen de esta primera turbina es aprovechado para producir vapor de agua que entra a una turbina de vapor; de esta forma, se produce electricidad en ambas turbinas. El proceso permite incrementar eficiencias y reducir significativamente el $\mathrm{CO}_{2}$, los óxidos de nitrógeno, los óxidos de azufre y las partículas emitidas a la atmósfera; sin embargo es costoso si se compara con la generación convencional de electricidad [U.S.DOE, 2011].

El $\mathrm{CO}_{2}$ producido en la generación de electricidad o en otros procesos industriales puede ser capturado de los gases de combustión y almacenado (CCS, por sus siglas en inglés) en formaciones geológicas como yacimientos ya explotados de gas y petróleo, minas no explotables de carbón o acuíferos salinos profundos. La inyección de $\mathrm{CO}_{2}$ en yacimientos de petróleo o gas contribuye a la recuperación mejorada de tales combustibles; es un proceso estudiado y utilizado hace varias décadas en la industria petrolera, y cuyos beneficios pueden ayudar a pagar todo el proceso de captura del $\mathrm{CO}_{2}$. De la misma forma, la inyección de $\mathrm{CO}_{2}$ en minas de carbón no explotables puede favorecer la recuperación del metano que se suele encontrar entre sus capas y costear el gasto de almacenamiento de $\mathrm{CO}_{2}$ [WCA, 2012a]. 
Finalmente, los acuíferos salinos son areniscas subterráneas que contienen agua salada y que ofrecen un gran potencial de almacenamiento; sin embargo, la geología de tales formaciones no está suficientemente estudiada y se necesita realizar un trabajo adicional de investigación para seleccionar las formaciones más adecuadas para el almacenamiento seguro de $\mathrm{CO}_{2}$ [WCA, 2012a].

Otra tecnología de interés es la Gasificación de Carbón Bajo Tierra [UCG, por sus siglas en inglés) que permite la explotación de depósitos de carbón que por razones económicas o geológicas no pueden explotarse por los métodos regulares de minería. El proceso requiere la perforación de dos pozos en el área del yacimiento, uno para la inyección de una mezcla oxidante (oxígeno o aire, y/o vapor); y otro a cierta distancia, para sacar el producto gaseoso a la superficie. El carbón en la base del primer pozo se calienta a temperaturas que se controlan mediante la regulación del flujo de oxidante de forma que el carbono pueda transformarse en gas de síntesis $\left(\mathrm{H}_{2}+\mathrm{CO}\right)$ que es retirado a través del segundo pozo. El $\mathrm{CO}_{2}$ que se forma en la reacción in situ puede ser devuelto a la capa de carbón gasificada evitándose así este tipo de las emisiones.

El proceso UCG elimina la excavación del carbón; y con ello, la descarga de residuos sólidos causando un menor impacto sobre el ambiente que la minería tradicional. Adicionalmente, reduce las emisiones de $\mathrm{SO}_{2}$ y óxidos de nitrógeno a la atmósfera; sin embargo, los materiales orgánicos tóxicos que quedan en la cavidad donde se produce la gasificación pueden contaminar acuíferos cercanos con el consiguiente peligro para la salud de la gente. Finalmente, la gasificación de carbón bajo tierra reduce los costos por unidad de energía producida al eliminar los costos de transporte del recurso al destino final.

La tecnología ha despertado gran interés y existen planes y proyectos a diferentes niveles de avance en países como China, India y Australia. En Suráfrica, han operado por algún tiempo plantas pilotos UCG; otros países como Estados Unidos, Europa Occidental y Oriental, Rusia, Japón, Indonesia y Vietnam efectúan investigaciones en el tema [WCI, 2012c]. 


\subsubsection{Carbón a líquido}

El alza en los precios de petróleo y la falta de seguridad en el acceso al recurso cuyas mayores reservas se encuentra en manos de unos pocos países políticamente inestables, ha planteado la posibilidad a algunas naciones de obtener parte de los combustibles líquidos necesarios para su crecimiento económico, a partir de la licuefacción del carbón.

La tecnología que permite la transformación de Carbón a Liquido (CTL, por sus siglas en inglés) puede producir combustibles de alta calidad para el transporte, el uso doméstico y la generación de electricidad. La conversión puede efectuarse hidrogenando el carbón, a temperatura y presión elevadas, y refinando posteriormente el liquido obtenido. Alternativamente, en una primera etapa se puede gasificar el carbón para obtener gas de síntesis $\left(\mathrm{H}_{2}+\mathrm{CO}\right)$ al cual se le elimina el azufre antes de introducirlo a una reacción catalítica Fischer-Tropsch ${ }^{32}$ que rinde combustibles líquidos. El combustible producido puede ser distribuido utilizando la infraestructura existente para los derivados del petróleo; y usado sin modificaciones en la flota vehicular actual. El proceso produce grandes cantidades de $\mathrm{CO}_{2}$ cuya emisión a la atmósfera puede minimizarse con el uso de procedimientos de captura y almacenamiento de carbón (CCS) [WCA, 2012b]

Las tecnologías CTL se convierten en una alternativa atractiva para la sustitución de petróleo en aquellos países que disponen de grandes reservas de carbón y mucha menor cantidad de reservas de petróleo. Australia ha venido produciendo líquidos del carbón desde 1955 y actualmente suple aproximadamente un $30 \%$ de las necesidades de gasolina y diesel a partir del carbón doméstico. Actualmente existen proyectos CTL alrededor del mundo en diferentes etapas de desarrollo; China, Estados Unidos y Australia tienen proyectos en operación y existe interés en el tema por parte de países como Alemania, Indonesia e India [WCA, 2012b]. La viabilidad económica de las plantas CTL depende en gran parte de los precios del petróleo con

32 Síntesis Fischer-Tropsch. Proceso químico para la producción de hidrocarburos líquidos (gasolina, kerosén, gasoil y lubricantes) a partir de gas de síntesis $\left(\mathrm{CO}+\mathrm{H}_{2}\right)$. 
los cuales debe competir. Si el precio del petróleo es alto la transformación de carbón a líquidos se vuelve más competitiva.

\subsubsection{Consideraciones finales}

En resumen, el carbón es un combustible fósil abundante, ampliamente distribuido en el mundo y su precio es más bajo y estable que los precios del petróleo y gas; sin embargo su combustión produce cantidades importantes de $\mathrm{CO}_{2}$ y otros óxidos contaminantes causantes del efecto invernadero. El Grupo Intergubernamental de Expertos en el Cambio Climático (IPCC, por sus siglas en inglés) ha estimado que existe una capacidad de almacenamiento de $\mathrm{CO}_{2}$ en estas formaciones de 2.000 mil millones de toneladas ${ }^{33}$ [WEC, 2007]. De esta forma, la captura y almacenamiento de millones de toneladas de $\mathrm{CO}_{2}$ producto de la generación de electricidad y de otros procesos industriales unido al desarrollo y propagación de tecnologías más limpias para la utilización del carbón, podría ser parte de la solución del problema de las emisiones.

\subsubsection{Uranio}

El uranio es un elemento radioactivo que se encuentra en muy bajas concentraciones en la corteza terrestre. Su forma de ocurrencia más común es como $\mathrm{U}_{3} \mathrm{O}_{8}$ ya que es oxidado rápidamente en presencia de aire. Su símbolo químico es $U$ y es el elemento más pesado de los que se encuentran en la naturaleza. Sus isótopos ${ }^{34}$ más comunes son el U-238 y el U-235, presentes en el uranio natural en proporciones de $99,284 \%$ y 0,711 \% respectivamente [NEA, 2005]. Entre ellos, el U-235 es fácilmente divisible en dos cuando su núcleo es bombardeado con un

33 El Grupo Intergubernamental de Expertos sobre el Cambio Climático fue constituido en 1988 conjuntamente por la Organización Meteorológica Mundial (OMM) y el Programa de las Naciones Unidas para el Medio Ambiente con el objeto de estudiar el problema del cambio climático y sus consecuencias [IPCC, 2007].

34 Isótopos son diferentes tipos de átomos del mismo elemento químico, cada uno de los cuales tiene un número diferente de neutrones. 
neutrón al que captura, liberando una gran cantidad de energía y expeliendo dos o tres neutrones. A su vez, estos neutrones expelidos pueden causar que otros átomos U-235 vecinos se dividan y liberen más neutrones, produciéndose así una reacción en cadena. El proceso se conoce como fisión nuclear y la energía desprendida durante la misma puede utilizarse para producir el vapor que alimenta a las turbinas en plantas nucleares de generación de electricidad. A fines de comparación, un kilogramo de uranio natural utilizado en un reactor nuclear tipo puede producir unas 20.000 veces la energía que produce la combustión de un kilogramo de carbón [NEA, 2005). En proporción mucho más baja, la energía obtenida en reactores nucleares de menor tamaño puede utilizarse para alimentar los motores de buques y submarinos nucleares.

Alternativamente, los neutrones liberados en la fisión del átomo de uranio pueden golpear los núcleos de átomos vecinos y rebotar sin interacción alguna, o pueden ser absorbidos por el núcleo en cuyo caso el átomo de uranio se transforma en otro elemento. Una cantidad importante de tales elementos de alta toxicidad y larga vida constituyen parte del residuo nuclear y deben ser aislados por períodos largos de tiempo. Otros, como el plutonio, pueden ser utilizados como combustible nuclear.

Hoy día, el uranio es una fuente importante de energía para el área de generación de electricidad donde compite con el carbón y el gas cuya combustión vierte más gases invernadero a la atmósfera. Sin embargo, la extracción del mineral de $\mathrm{U}_{3} \mathrm{O}_{8}$, su conversión hasta el uranio enriquecido necesario en las plantas nucleares para generación de electricidad; y la operación de estas últimas, produce residuos con efectos radioactivos de larga duración cuyo manejo es altamente peligroso a la salud humana.

Ello, ha generado un rechazo por parte de la sociedad que ha contribuido a frenar un poco la instalación de nuevas centrales nucleares, independientemente de la existencia de normas estrictas para una operación segura de la planta y para el manejo de sus residuos. Para el año 2011, la contribución de la energía nuclear al suministro mundial de electricidad fue de 2.518 TWh lo que representó alrededor de un $13,4 \%$ de la electricidad total generada ese año [IEA, 2011; WNA, 2012]. 


\subsubsection{Reservas de uranio}

El total mundial de los recursos identificados de uranio recuperables a un costo inferior a 130 US $\$ / \mathrm{kg} U$ se ubica alrededor de 5,5 millones de toneladas; de ellos, 3,3 millones de toneladas son clasificados como recursos razonablemente seguros ${ }^{35}$ (RAR, por sus siglas en inglés) y el resto como recursos inferidos ${ }^{36}$. La primera cifra aumenta a 16 millones de toneladas si se suman las reservas no descubiertas ${ }^{37}$ cuya monto se estima en unos 10,5 millones de toneladas de uranio [NEA/IAEA, 2008]. A la tasa actual de consumo que se aproxima a las 70 mil toneladas por año, los recursos identificados de uranio durarían unos 80 años mientras que las reservas totales se agotarían en unos 230 años. Este lapso se extiende a 60.000 años aproximadamente, si se avanza en tecnologías económicamente viables para la recuperación del uranio en el agua de mar cuyas reservas se estiman en unos 4.500 millones de toneladas [Fetter, 2009; WEC, 2007].

La figura 3.12 presenta la distribución de recursos identificados de uranio, recuperables a un costo menor a $130 \mathrm{US} \$ / \mathrm{Kg} U$ entre los países con mayor potencial de reservas (85\% del total mundial 2009); entre ellos destacan Australia y Kazajstán con $31 \%$ y $12 \%$ respectivamente; siguen la Federación Rusia y Canadá con participaciones del 9\% del total mundial, cada uno [WNA, 2011a]. Las reservas de uranio con costos de producción inferiores a $80 \mathrm{US} \$ / \mathrm{kgU}$ han disminuido

35 Recursos razonablemente seguros (RAR, por sus siglas en inglés) se refieren a uranio recuperable en depósitos bien conocidos cuyo tamaño, concentración de mineral y estructura permiten que la cantidad especificada pueda ser recuperada con las tecnologías de minería y procesamiento disponibles, en el rango de costo especificado. Se clasifican en tres niveles de costo de producción por $\mathrm{Kg}$ de uranio recuperado: $<40$ US $\$ / \mathrm{kg}$, $<80$ US $\$ / \mathrm{kg}$ y $<130$ US $\$ / \mathrm{kg}$. Corresponden a reservas probadas con una altísima probabilidad de ocurrencia [NEA/IAEA, 2008; WEC 2007].

36 Recursos inferidos corresponden a uranio recuperable adicional a las reservas probadas (RAR) que se infiere existen en depósitos bien estudiados y donde se ha establecido continuidad geológica pero donde la información disponible no es suficientemente confiable como para ser clasificadas como reservas probadas [NEA/IAEA, 2008; WEC 2007].

37 Reservas no descubiertas se refieren a reservas pronosticadas y reservas especulativas cuya estimación se basa sólo en evidencia indirecta [NEA/IAEA, 2008; WEC 2007]. 
drásticamente en Estados Unidos, Namibia y Nigeria; por el contrario, en Australia, Canadá, Kazajstán, Brasil y Suráfrica, el costo de recuperación de las reservas es mayoritariamente menor a $80 \mathrm{US} \$ / \mathrm{kgU}$.

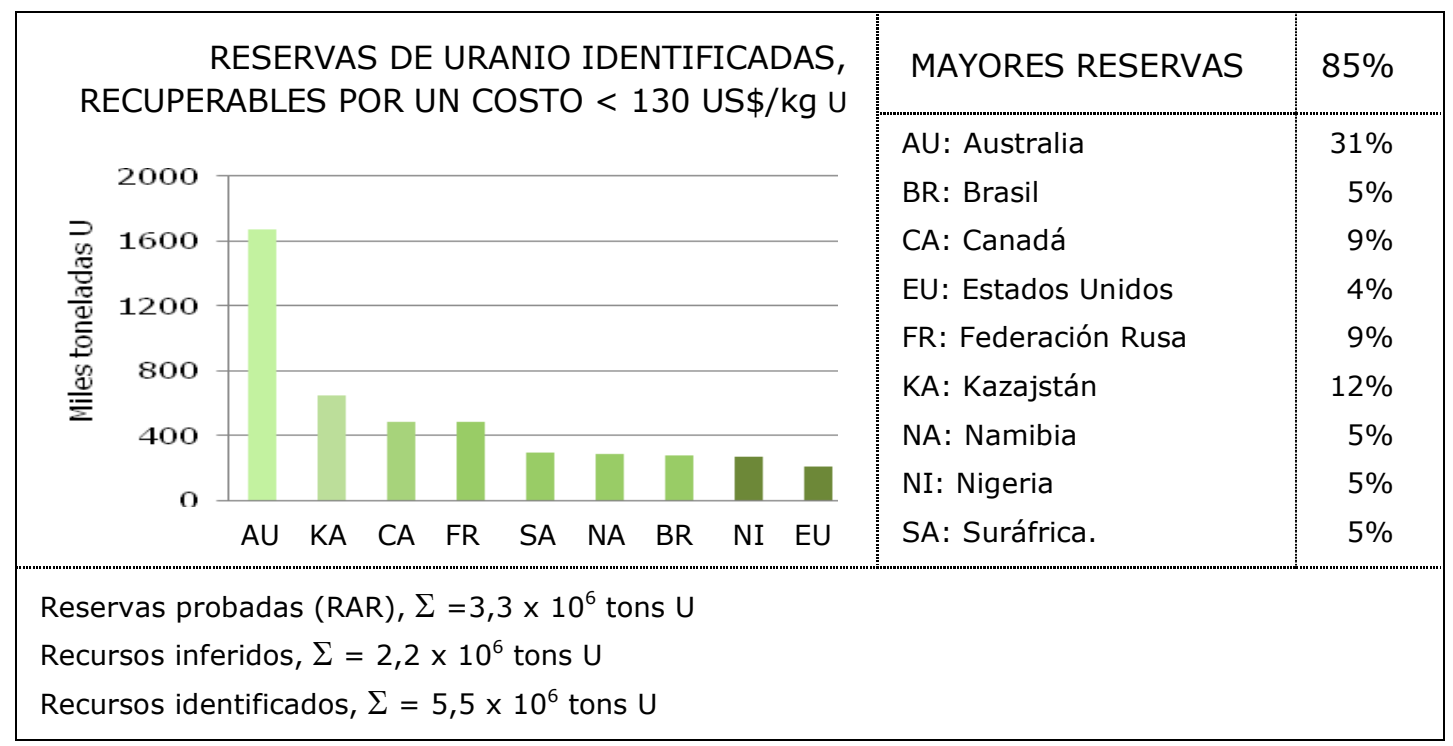

Fuente de datos: [WNA, 2011a].

Figuras 3.12. Reservas de uranio en países seleccionados, 2009.

\subsubsection{Tecnologías de extracción y conversión}

Aproximadamente un $47 \%$ de la producción mundial de uranio se extrae por minería convencional, a cielo abierto o bajo tierra. El mineral así obtenido es triturado y tratado para disolver el óxido de uranio presente, el cual es posteriormente precipitado de la solución resultante y secado hasta obtener una torta amarilla que contiene alrededor de un $85 \%$ de $\mathrm{U}_{3} \mathrm{O}_{8}$. Un método alternativo para la obtención del uranio es la lixiviación in situ (ISL, por sus siglas en inglés) donde una solución solvente se inyecta bajo tierra, disuelve el uranio y luego es recuperada por pozos para la extracción del uranio disuelto. Alrededor de un $45 \%$ de la producción mundial de uranio se extrae por este método; y el restante $7 \%$ se recupera por métodos más complejos, como un coproducto o subproducto cuando ocurre en asociación con minerales de oro, cobre y fosfatos [WNA, 2012b; WNA, 2011b]. 
Los procesos de minería, molienda y tratamiento del mineral obtenido generan residuos de difícil manejo por su gran volumen y su contenido de contaminantes químicos y radioactivos. Por su parte, la lixiviación in situ no produce residuos sólidos pero es aplicable sólo bajo condiciones geológicas específicas y debe ser manejada para preservar las corrientes de aguas subterráneas.

Las próximas etapas en el procesamiento del uranio para obtener el insumo adecuado a los reactores nucleares son (i) la conversión de la torta amarilla a $\mathrm{UF}_{6}$ gaseoso, y (ii) el enriquecimiento del uranio cuyo objetivo es la separación parcial del uranio en sus dos isótopos principales U-235 y U-238. Este proceso produce dos corrientes; una enriquecida, con una concentración de U-235 más elevada que su concentración natural $(0,711 \%)$; y otra correspondientemente empobrecida en este isótopo. La mayoría de los reactores comerciales instalados hoy día utilizan uranio enriquecido a menos de $5 \%$ de U-235. En contraste, el uranio utilizado en la construcción de armas nucleares debe ser enriquecido a niveles de $90 \%$; y algunos reactores dedicados a la investigación pueden utilizar uranio enriquecido a niveles superiores a 20\% en U-235 [WNA, 2012c; WNA, 2011b; NEA, 2005].

La difusión gaseosa y la centrifugación son los dos métodos más usados para el enriquecimiento del uranio. Ambos utilizan como insumo UF $_{6}$ gaseoso y aprovechan la pequeña diferencia en masa de los isótopos U-235 y U-238 para su separación. En el proceso de difusión gaseosa se pasa $\mathrm{UF}_{6}$ gaseoso a través de una cascada de membranas porosas o diafragmas; el U-235, más liviano, tiene una mayor probabilidad de pasar a través de los poros de las membranas que el U-238 y el UF 6 que se difunde a través de ellas termina siendo ligeramente más rico en U-235. En el proceso de centrifugación gaseosa se introduce el $\mathrm{UF}_{6}$ en baterías de tubos al vacío, cada uno de los cuales rota a razón de 50.000 a 70.000 revoluciones por minuto, facilitando la separación parcial de las moléculas de U-238 hacia la periferia de cada tubo e incrementando la concentración de U-235 hacia el eje del mismo. El gas enriquecido se alimenta a la etapa siguiente mientras que el gas empobrecido se recircula a la etapa previa. Ambas corrientes se separan al término de una cascada de centrífugas [WNA, 2012c]. 
Por su potencial riesgo, el uranio empobrecido producto de la etapa de enriquecimiento, es generalmente almacenado por largo tiempo, como UF $_{6}$ o como óxidos sólidos de uranio para su eventual uso en reactores que lo permitan; o puede ser re-enriquecido para recuperar el U-235 remanente en él [NEA, 2005]. El grado de enriquecimiento sobre una cantidad dada de material se mide en unidades de trabajo de separación (SWU, por sus siglas en inglés) y tiene que ver con la energía eléctrica consumida en el proceso. El proceso de difusión gaseosa consume alrededor de $2.500 \mathrm{kWh} / \mathrm{SWU}$ mientras que la centrifugación gaseosa requiere $50 \mathrm{kWh} / \mathrm{SWU}$ [WNA, 2012c].

Para el año 2010, un 65\% del enriquecimiento de uranio se realizó con plantas de centrifugación gaseosa, con un costo de enriquecimiento mucho menor debido fundamentalmente a la gran reducción del consumo de energía que ofrece el proceso sobre el enriquecimiento por difusión gaseosa que ocupó sólo un $25 \%$ del total. Grandes plantas de centrifugación gaseosa están en construcción en Francia y Estados Unidos; y ya existen en Rusia, Alemania, Holanda, y el Reino Unido. Plantas mucho más pequeñas existen en China, Japón, Brasil, Pakistán e Irán, Francia y Estados Unidos [WNA, 2012c]. Actualmente, sólo Estados Unidos y Francia poseen plantas de difusión gaseosa con una capacidad importante [WNA, 2012c].

La mayoría de los reactores nucleares utiliza dióxido de uranio como combustible; ello requiere la conversión del $\mathrm{UF}_{6}$ enriquecido a pequeños dados cilíndricos de $\mathrm{UO}_{2}$ los cuales se acomodan en tubos metálicos para formar barras de combustible que se arreglan en ensambles para su carga al reactor nuclear. Otros utilizan uranio o $\mathrm{UO}_{2}$ natural y las tecnologías más recientes utilizan una mezcla de óxidos, $\mathrm{PuO}_{2} / \mathrm{UO}_{2}$ (MOX, por sus siglas en inglés). El isótopo del plutonio PU-239 está presente en el combustible 'usado' producto de la fisión nuclear en el reactor y su utilización es una forma de disponer de los residuos radioactivos de la reacción [WNA, 2010f]

\subsubsection{Producción de uranio}

La producción mundial primaria de uranio para el año 2011 se originó en 19 países y alcanzó la suma de 53.494 toneladas o su equivalente 63.085 toneladas de $\mathrm{U}_{3} \mathrm{O}_{8}$. La figura 3.13 a presenta la distribución de la producción mundial de uranio 
para el año 2011. Los más grandes productores fueron Kazajstán con 19.451 toneladas de uranio y una participación del 27\% del total mundial, Canadá con 9.145 toneladas y una participación del $20 \%$ y Australia con 5.983 toneladas de uranio y una contribución del 16\% al total mundial producido [WNA, 2012b].

La figura 3.13b muestra las respectivas tendencias de la producción primaria de uranio y de los requerimientos relacionados con la producción nuclear de electricidad, para el período 2006-2011. Es notoria la diferencia entre las cifras anuales registradas. A inicios del período sólo un $63 \%$ de las necesidades fue cubierto por la producción de uranio en minas; sin embargo, la insuficiencia ha venido disminuyendo en el tiempo y para el año 2011, la producción primaria suplió un $85 \%$ de la demanda del sector de generación nuclear de electricidad que alcanzó 62.552 toneladas de uranio [WNA, 2012a; WNA, 2012b]. Esta mejoría se debe no sólo al incremento de las actividades de exploración-producción sino a un incremento en los factores de carga de la flota de reactores instalados.

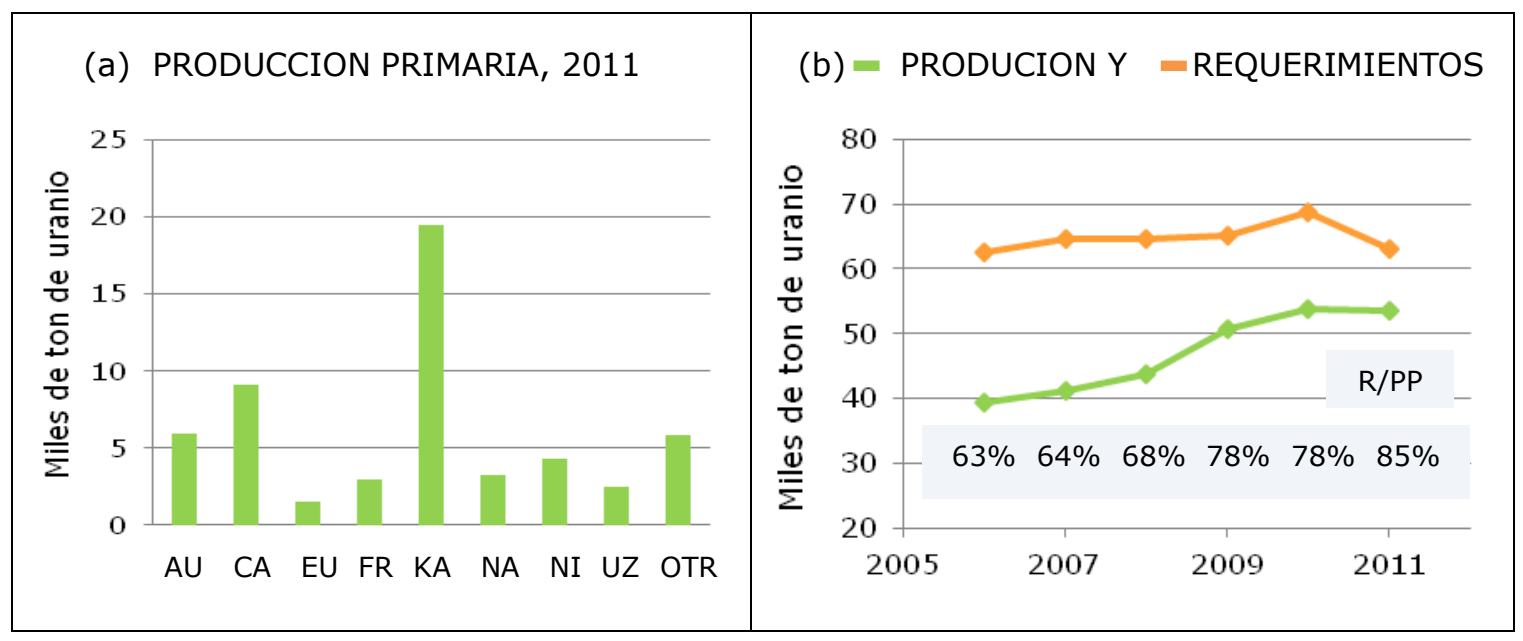

AU: Australia CA: Canadá EU: Estados Unidos FR: Federación Rusa KA: Kazajstán NA: Namibia NI: Nigeria UZ: Uzbekistán. R/PP: requerimiento/producción primaria. Fuente de datos: [WNA, 2012a, 2012b]]

Figura 3.13 (a) Producción primaria de uranio por país, 2011.

(b) Producción primaria y requerimiento global de uranio para el sector eléctrico, 2006-2011. 


\subsubsection{Otras fuentes de combustible nuclear}

En tanto, la diferencia ha sido suplida por fuentes secundarias como existencias de uranio natural o enriquecido del sector civil y militar, uranio 'usado' reprocesado y uranio empobrecido re-enriquecido. Existe incertidumbre sobre los inventarios de uranio que mantienen empresas productoras y distribuidoras de electricidad, productores de uranio y gobiernos; sin embargo, pueden estimarse como la diferencia entre la producción primaria y el consumo asociado respectivamente acumulados hasta la fecha. Para el año 2006, la cifra alcanzó unas 625 mil toneladas de uranio que fueron dirigidas al sector civil y, en una mayor proporción, al sector militar [NEA/IAEA 2008].

Otra fuente importante de combustible nuclear son los excedentes mundiales de armas nucleares de Rusia y Estados Unidos. Tales armas contienen una gran cantidad de uranio altamente enriquecido (HEU, por sus siglas en inglés), a niveles sobre $90 \%$ de U-235 que puede mezclarse con uranio empobrecido (LEU, por sus siglas en inglés, mayoritariamente $\mathrm{U}-238)$, uranio natural $(0,7 \%$ en $\mathrm{U}-235)$ o uranio parcialmente enriquecido para producir uranio enriquecido, típicamente a menos de $5 \%$ de U-235 que se usa como combustible en reactores comerciales. Otras armas contienen plutonio-239 con más de 90\% del isótopo el cual puede usarse en mezclas con óxido de uranio (MOX, por sus siglas en inglés) que se utilizan como combustible en reactores de tecnología más avanzada. El combustible nuclear después de usado en reactores nucleares no es adecuado para la manufactura de armas [WNA, 2011d] lo que resulta una ventaja para la humanidad.

La dilución de uranio altamente enriquecido proveniente de las existencias de armas nucleares ha desplazado alrededor de 10.600 toneladas por año de la producción primaria de $\mathrm{U}_{3} \mathrm{O}_{8}$ lo que representa alrededor de un $15 \%$ de los requerimientos de los reactores nucleares para producción de electricidad en el mundo que alcanzó unas 63.000 toneladas para el año 2011. Por su parte, se estima que los inventarios civiles de uranio de empresas y gobiernos alcanzan unas 154,000 toneladas de uranio [WNA, 2011d; WNA, 2011a]. 
De la misma forma, el uranio ya 'usado' que se descarga de un reactor comercial es potencialmente reciclable ya que contiene el plutonio producto del proceso de fisión y parte del uranio fisionable. El Pu-239 puede ser separado y utilizado para producir MOX; y el uranio reprocesado es, en general, almacenado para uso futuro. Se estima que el reciclaje de uranio 'usado' ahorra entre 1500 y 2000 toneladas por año de producción primaria de uranio [WNA, 2011a; WNA, 2011f].

Finalmente, el re-enriquecimiento de uranio empobrecido puede ser una fuente secundaria de combustible nuclear. Se estima que existen 1,5 millones de toneladas de uranio empobrecido con concentraciones que oscilan entre $0,25 \%$ y $0,35 \%$ de $\mathrm{U}$ 235 proveniente de las actividades de enriquecimiento en el sector civil y militar. Tales existencias pueden mezclarse con plutonio para obtener combustible MOX o puede utilizarse como combustible en reactores de neutrones rápidos [WNA, 2011a].

\subsubsection{Reactores nucleares: tecnología y operación}

Un reactor nuclear es la concreción de una tecnología que permite manejar la energía desprendida en la división de los núcleos de los átomos de determinados elementos. Un reactor nuclear comercial aprovecha la energía liberada en la fisión nuclear para formar vapor que se alimenta a turbogeneradores que producen electricidad. Aunque se utilizan diferentes diseños para su funcionamiento, todos tienen como elementos comunes: un combustible, un moderador, un refrigerante, barras de control de la reacción, un envase de reacción, un sistema para generar vapor y edificaciones de contención.

Un moderador es un elemento necesario para 'frenar' sin capturar los neutrones con alta energía creados en la fisión nuclear que tiene lugar en el reactor; de esta forma se incrementa la eficiencia de la reacción ${ }^{38}$. En general se utiliza agua común

38 Neutrones con una energía cinética relativamente baja $(<0,1 \mathrm{eV})$ se conocen como neutrones térmicos y son más eficientes para causar fisión en el uranio o plutonio. Todos los neutrones producto de una fisión nuclear son neutrones rápidos con una energía cinética en el rango de 10 millones de eV [NEA 2005]. 1 electronvoltio $=1 \mathrm{eV}=1 \times 10^{-19} \mathrm{~J}$. 
como elemento moderador; otras alternativas son el grafito y el agua pesada ${ }^{39}$. El agua también puede utilizarse como refrigerante para remover el calor producido en la fisión nuclear y mantener la temperatura del combustible dentro de los límites aconsejados. Otros refrigerantes usados son el agua pesada, gases como dióxido de carbono o helio, y metales fundidos como el sodio. Finalmente, las barras de control son hechas de materiales que absorben neutrones y pueden insertarse en el núcleo del reactor para frenar o parar la reacción si éste fuese el caso.

El combustible y la estructura metálica que lo mantiene en su sitio, conforman el núcleo del reactor que está rodeado de un material reflector que previene el escape de los neutrones producidos durante la fisión; y de este modo, maximiza su eficiencia. Todo ello va encerrado en un envase de acero dentro del cual circula el refrigerante durante la operación normal. Finalmente, todo se encierra en un edificio de concreto reforzado de gran espesor para contener los productos radioactivos si hubiese un escape de ellos y para proteger la estructura de ataques externos como fuegos, explosiones o misiles.

Alrededor de un $\mathbf{8 8 \%}$ de los reactores nucleares instalados a nivel mundial utilizan agua común como moderador y como refrigerante; por ello, se conocen como reactores de agua liviana (LWR, por sus siglas en inglés). Entre ellos, (i) los reactores de agua presurizada (PWR, por sus siglas en inglés) donde el refrigerante se somete a alta presión para mantenerlo liquido a temperaturas superiores a 300 ${ }^{0} \mathrm{C}$, circula en el envase de reacción y pasa al generador de vapor donde cede su energía para formar el vapor necesario que va a los turbogeneradores, y (ii) los reactores de agua en ebullición (BWR, por sus siglas en é) donde el refrigerante hierve al recibir el calor desprendido en la fisión; el vapor producido pasa directamente a las turbinas para la generación de electricidad. Los reactores LWR utilizan $\mathrm{UO}_{2}$ enriquecido como combustible [WNA, 2012d; WNA, 2011e; NEA, 2005].

Otros tipos de reactores nucleares que se utilizan actualmente son (i) el reactor de agua pesada presurizada (PDWR/CANDU, por sus siglas en inglés) que utiliza

39 Agua pesada es agua formada con deuterio, ${ }^{2} \mathrm{H} 2$, un isótopo del hidrogeno. 
agua pesada como refrigerante y moderador lo que le permite trabajar con $\mathrm{UO}_{2}$ natural como combustible; (ii) el reactor de grafito (moderador) y agua liviana (refrigerante) (LWGR, por sus siglas en inglés) que utiliza $\mathrm{UO}_{2}$ enriquecido como combustible (iii) los reactores enfriados con gases que utilizan grafito como moderador ( $A G R$, por sus siglas en inglés), $\mathrm{CO}_{2}$ como refrigerante y uranio natural o ligeramente enriquecido como combustible; y (iv) el reactor de neutrones rápidos (FBR, por sus siglas en inglés) que utiliza una mezcla de oxido de plutonio y oxido de uranio como combustible y no utiliza moderador. En este caso, el núcleo del reactor está rodeado por una capa de U-238' no fisible, que absorbe los neutrones que escapan de la fisión nuclear, convirtiéndose en plutonio-239 fisible, que puede ser separado y reutilizado como combustible posteriormente [WNA, 2012d; WNA, 2011e; NEA, 2005].

En general, un tercio del combustible es reemplazado cada 12 o 18 meses para mantener la planta en operación continua. El combustible 'usado' que se saca del reactor (SNF, por sus siglas en inglés] es almacenado inicialmente, un período que oscila entre 5 y 10 años, en piscinas de agua donde se enfría y pierde paulatinamente su alta radioactividad. Posteriormente, es transferido a un segundo almacenamiento por un período que oscila entre 30 y 50 años, antes de su descarte final en repositorios subterráneos con características técnicas que deben ser aprobadas por los gobiernos respectivos.

Alternativamente, el combustible 'usado' puede ser reprocesado para recuperar el plutonio formado en la fisión nuclear y el uranio no utilizado que se almacena para un eventual posterior uso. El residuo del proceso de reprocesamiento (1\%) es clasificado como de alta radioactividad [HLW, por sus siglas en inglés]. Las plantas de reprocesamiento constituyen una alternativa para reducir el volumen de los desechos de gran toxicidad que se descargan del reactor nuclear; sin embargo, son complicadas y costosas por lo que sólo han sido instaladas en unos algunos países de la Comunidad Europea, Rusia, China, India y Japón [NEA, 2005].

Una planta nuclear debe solicitar una licencia del gobierno del país donde pretende operar para su construcción y puesta en marcha. Una vez en operación, su vida se extiende por unos 30 a 40 años. Sin embargo, con inversiones importantes 
para la renovación de los sistemas de seguridad, estructuras y componentes de las plantas, sus vidas útiles pueden ser extendidas. Así, en algunos países se considera la renovación de las licencias basada en un riguroso análisis que utiliza los más modernos métodos, información y requerimientos de seguridad para la evaluación de una subsecuente operación segura [WNA, 2012d] después del monitoreo de la experiencia de operación, rendimiento y modernización de cada planta.

Una vez cancelada la licencia de operación y tomada la decisión de cerrar una planta nuclear permanentemente, está debe ser desmantelada, y las instalaciones y el sitio dejado en condiciones que no dañe a la gente ni al ambiente. En el caso de un reactor nuclear, el proceso comprende tres etapas: (i) la clausura del sitio después de la recuperación y disposición del combustible usado, el drenaje de los fluidos y la desconexión de los sistemas, (ii) la descontaminación, desmantelamiento y disposición de los equipos y edificios conectados con el proceso; y el posterior monitoreo de los restos y del medioambiente en el sitio y (iii) la demolición y limpieza del sitio. Todo el proceso puede durar mucho tiempo (> 100 años) para permitir que la radioactividad baje hasta que las personas puedan participar en forma segura en la disposición final de los residuos [NEA, 2005].

\subsubsection{Capacidad nuclear de generación eléctrica}

A mitades del año 2012, 433 reactores nucleares comerciales se encuentran en operación en 29 países, con una capacidad instalada de 371,4 mil MWe ${ }^{40}$, una producción alrededor de 2,5 billones de kWh (14\% de la electricidad producida a nivel mundial) y requerimientos del orden de 68 mil toneladas de uranio por año; 63 reactores se hallan en construcción, con una capacidad de generación de 62,2 mil MWe; 160 han sido ordenados o se incluyen en los planes energéticos ${ }^{41}$ de diferentes países, con una capacidad adicional estimada, a 8 o 10 años, de 179,7 mil MWe; y 329 han sido propuestos y se espera que entren en operación en unos 15 años, con

$40 \quad 1 \mathrm{MWe}=1 \mathrm{MW}$ eléctrico a diferencia del MW térmico (MWt).

41 Reactores planificados se refiere a reactores con las aprobaciones y el financiamiento para la construcción y cuya entrada en funcionamiento se estima en ocho o diez años [WNA, 2012a]. 
una capacidad de 376,3 MWe [WNA, 2012a]. Las nuevas plantas que han entrado en funcionamiento son aproximadamente balanceadas por plantas que han agotado su vida útil y deben ser retiradas. Se estima que al menos unas 60 plantas actualmente en operación, en su mayoría de pequeña capacidad, estarán cerradas para el año 2030 [WNA, 2012a].

En las figuras 3.14 y 3.15 se presenta información sobre el número de reactores nucleares en operación, en construcción o en planes; y sobre su capacidad de generación de electricidad, clasificada por países. Estados Unidos opera 104 reactores con una capacidad instalada de 101,6 mil MWe los cuales producen el $19,2 \%$ de la electricidad generada en el país; Francia posee 58 reactores con una capacidad instalada de 63,1 mil MWe los cuales contribuyen con un 77,7\% al sector de energía eléctrica en el país; y Japón, 50 reactores con una capacidad instalada de 44,4 mil MWe los cuales generan el $18,1 \%$ de la electricidad que se consume en el país. Un cuarto país importante en la lista es Rusia que opera 33 reactores con una capacidad instalada 24,2 mil MWe los cuales producen un $17,6 \%$ de la electricidad que se produce en el país [WNA, 2012a].

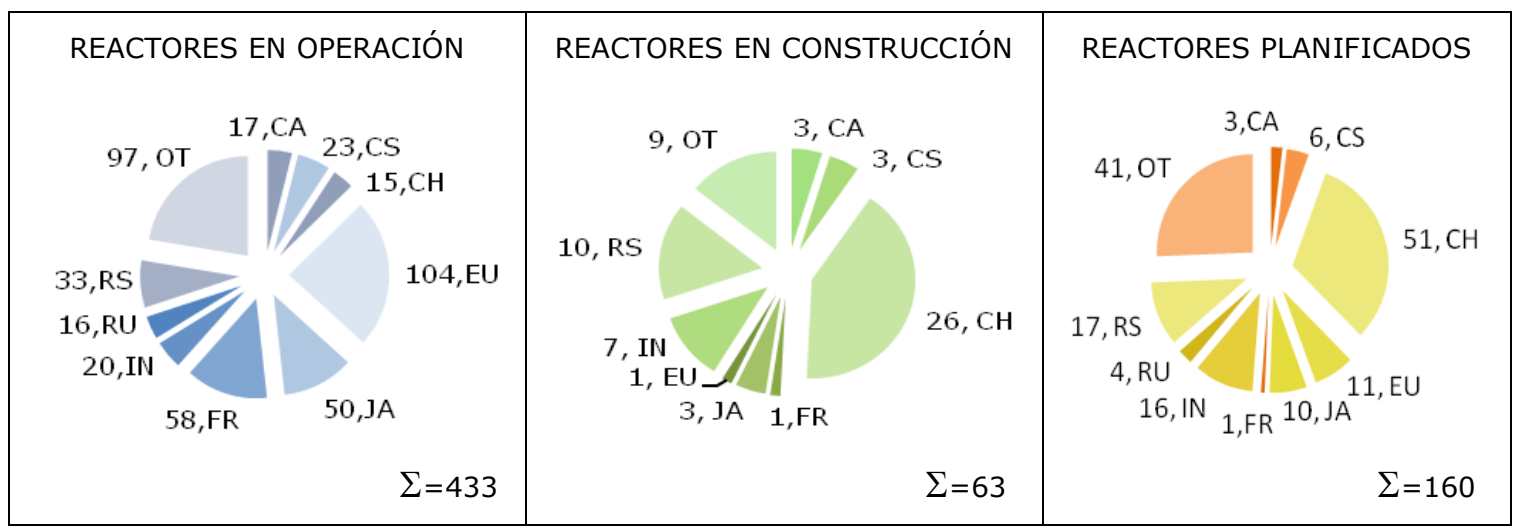

CA: Canadá CS: Corea del Sur CH: China EU: Estados Unidos JA: Japón FR: Francia IN: India RU: Reino Unido RS: Rusia OT: Otros. Fuente de datos [WNA. 2012a].

Figura 3.14. Número de reactores nucleares por país, 2012

Es notable el caso de China que opera 15 reactores con una capacidad instalada de aproximadamente 11,9 mil MWe, tiene 26 reactores en construcción (27,6 mil MWe) y otros 51 planificados (57,5 mil MWe); y el caso de India que opera 20 reactores $(4,4 \mathrm{mil} \mathrm{MWe})$, tiene en construcción 7 reactores $(5,3 \mathrm{mil} \mathrm{MWe})$ y 16 UNIVERSIDAD POLITÉCNICA DE VALENCIA. TESIS DOCTORAL. Violeta Parodi 104 
reactores planificados (14,3 mil MWe) [WNA, 2010a]. Si los planes se cumplen, China habrá multiplicado más de siete veces e India por más de cuatro veces su capacidad nuclear instalada para generación de electricidad, en un período de diez a quince años. Otros países como Corea del Sur, Japón, Rusia y Estados Unidos muestran incrementos porcentuales en plantas nuevas mucho más reducidos que pueden ser balanceados parcialmente por el retiro de plantas más viejas [WNA 2012a].

Adicionalmente, la figura 3.15 reporta los requerimientos de uranio para el funcionamiento de los reactores nucleares en operación hoy día. El gráfico muestra información para los más importantes consumidores: Estados Unidos, Francia, China, Japón, Rusia, Corea del Sur, el Reino Unido, Canadá e India que juntos requieren más de un $80 \%$ de un total estimado de uranio para la generación mundial de electricidad que alcanza a 67.990 toneladas [WNA, 2012a].

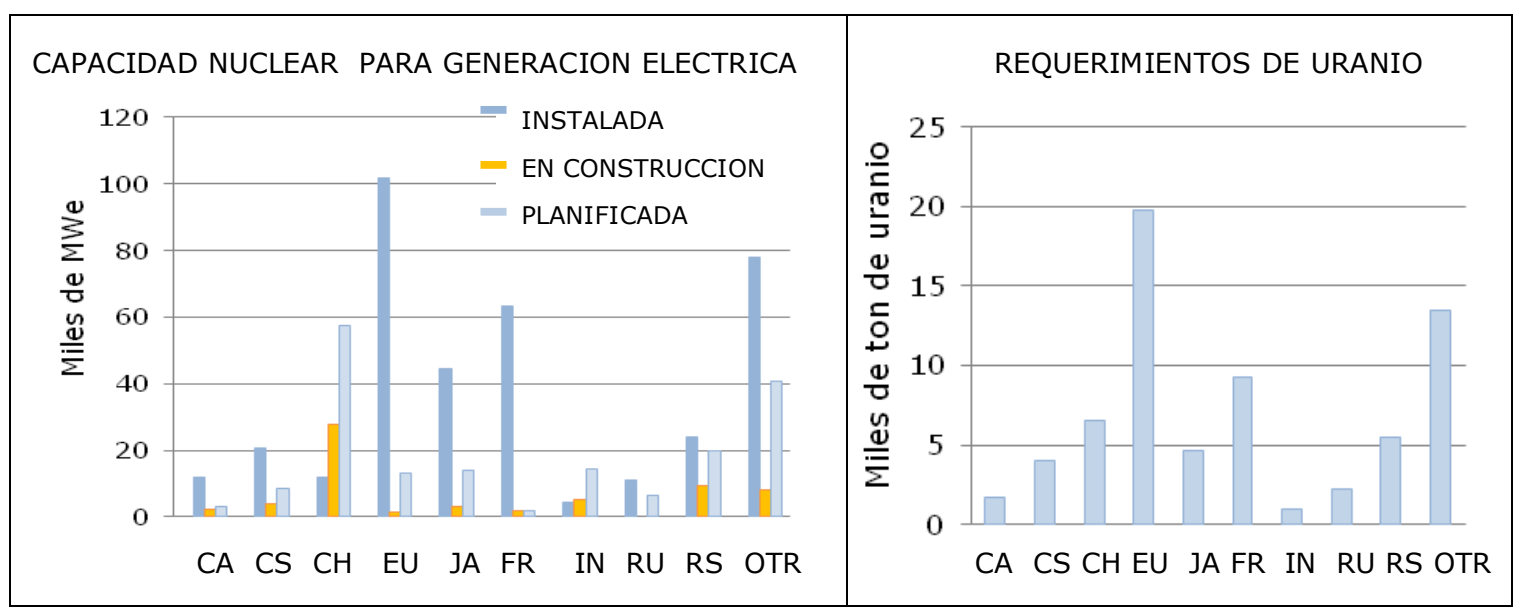

CA: Canadá CS: Corea del Sur CH: China EU: Estados Unidos JA: Japón FR: Francia IN: India RU: Reino Unido RS: Rusia OTR: Otros. Fuente de datos [WNA. 2012a].

Figura 3.15. Capacidad nuclear y requerimientos de uranio para generación eléctrica, 2012.

Entre los países citados, sólo Canadá se autoabastece. Estados Unidos requiere cerca de 20.000 toneladas de uranio y produce una cantidad muy inferior; Rusia exporta una cantidad muy cercana a su producción y no está claro como suple su consumo interno; en tanto que la producción de Francia, Japón, Corea del Sur, China y el Reino Unido es pequeña, insignificante o nula [WNA, 2012a; WNA, 2010c]. De 
esta forma, la dependencia de las importaciones de uranio en estos países es un hecho semejante a la dependencia de las importaciones de petróleo o gas [WNA 2012a].

Los grandes exportadores de uranio son Australia, Canadá, Rusia y Kazajstán [WNA, 2012b]. Los dos primeros, imponen estrictas condiciones (inspecciones y procedimientos de auditoría) para asegurar que el uranio exportado sea utilizado con propósitos pacíficos y no se derive a usos militares o que ayuden a la proliferación de armas nucleares. En tal sentido, se han establecido acuerdos bilaterales entre los gobiernos de Australia y Canadá y los países que deseen importar su uranio, adicionales a los controles de la Agencia Internacional de Energía Nuclear (IAEA sus siglas en inglés) administrados bajo el Tratado de No-proliferación de Armas Nucleares $^{42}$ [WNA, 2007].

Finalmente, existen 250 reactores nucleares de investigación instalados en 56 países y alrededor de unos 220 reactores que se utilizan en la propulsión de barcos y submarinos. El objetivo principal de los reactores de investigación es ser una fuente de haces de neutrones para investigación científica y para la producción de isótopos que se utilizan en medicina y en el sector industrial. Estos reactores son más simples que los reactores que se utilizan para generar electricidad, operan a temperaturas más bajas, requieren menos combustible, generan menos residuos de fisión pero requieren para su funcionamiento uranio altamente enriquecido, típicamente U-235 en concentraciones que oscilan entre $20 \%$ y $90 \%$. La capacidad total instalada de los reactores nucleares de investigación en el mundo alcanza unos 3.000 MW térmicos [WNA, 2011c].

42 El Tratado de No-proliferación de Armas Nucleares fue firmado en 1970 para evitar la proliferación de armas nucleares, favorecer el uso pacífico de la energía nuclear y aproximarse al objetivo del desarme. El tratado establece un sistema de controles bajo la responsabilidad de la Agencia Internacional de Energía Atómica (IAEA, por sus siglas en inglés). Actualmente 189 países son parte del tratado; de ellos, Estados Unidos, Rusia, Francia, el Reino Unido y China han reconocido poseer armas nucleares. Cuatro países no-participantes del tratado, India, Pakistán, Corea del Norte e Israel, se conoce o se cree disponen de armas nucleares [IAEA, 1970]. 


\subsubsection{Mercadeo y precios}

El uranio no se comercializa en un mercado abierto como otros productos básicos; en lugar de ello, los contratos se negocian directamente entre compradores y vendedores. Los precios promedio transados en las operaciones de compra-venta de los diferentes productos del ciclo del uranio $\left[\mathrm{U}_{3} \mathrm{O}_{8}\right.$ y $\left.\mathrm{UF}_{6}\right]$ y de los servicios de conversión, enriquecimiento y fabricación del combustible son publicados semanal y/o mensualmente por consultores independientes. El servicio de enriquecimiento se expresa en términos de unidades de trabajo de separación (SWU, por sus siglas en inglés), una medida compleja que es función de la cantidad de uranio procesado y el grado al cual se enriquece así como el nivel de empobrecimiento del material restante; y que indica la energía utilizada en el enriquecimiento cuando la alimentación y los productos se expresan en kilogramos. Como un ejemplo, se requieren 3,8 SWU para producir un kilogramo de uranio enriquecido 3\% U-235 si la planta se opera hasta que el uranio empobrecido alcance una concentración de 0,25\% en U-235 [WNA, 2012c]. Por su parte, los precios de servicios de conversión a $\mathrm{UF}_{6}$ se separan de acuerdo a su lugar de entrega, Norteamérica y Europa.

Las publicaciones incluyen los precios en el mercado a corto plazo, típicamente con entregas a menos de 1 año, y los precios en contratos a largo plazo con entregas multianuales. La participación de las transacciones a corto plazo alcanza sólo un $15 \%$ de las transacciones en el mercado global [ESA, 2010]. La figura 3.16 muestra la evolución del promedio mensual de precios del $\mathrm{U}_{3} \mathrm{O}_{8}$ en el mercado a corto plazo y en el mercado a largo plazo para el período 2005-2012. Las empresas consultoras más conocidas en el área son UxC y TradeTech ${ }^{43}$

Ux Consulting Company fundada en 1994 provee información sobre precios en el mercado del uranio y de los servicios de conversión, enriquecimiento y fabricación del combustible nuclear; incluyendo el soporte para los contratos de ventas futuras de uranio que se transan a través del New York Mercantil Exchange (NYMEX) [UxC, 2012]. TradeTech a través de su predecesor Nuclear Exchange Corporation (NUEXCO, por sus siglas en inglés) comenzó en 1968 a publicar precios de los productos y servicios que se ofrecen a lo largo de la cadena de producción del combustible nuclear (U308, UF6, conversión y SWU) para el mercado a corto y a largo plazo [TradeTech, 2012]. 


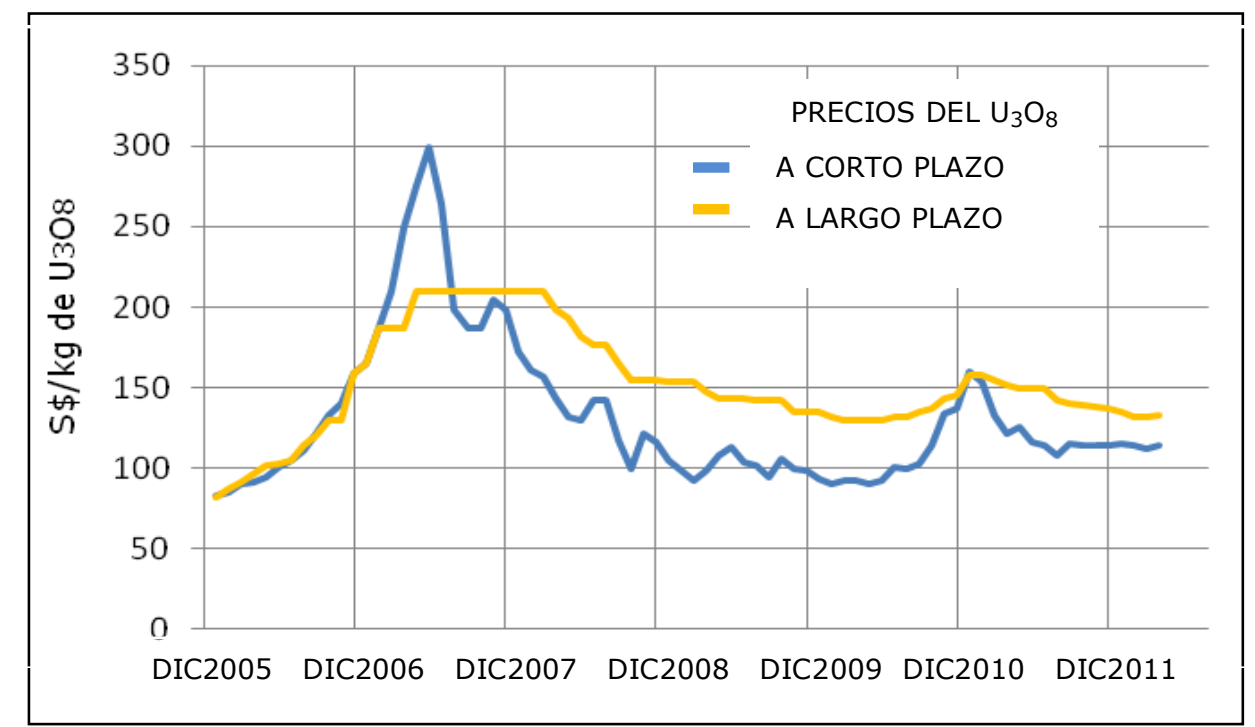

Fuente de datos: CAMECO, 2012. Precios originales expresados en US $\$ / \mathrm{Ib} \mathrm{U}_{3} \mathrm{O}_{8}$

Figura 3.16. Precios a corto y a largo plazo del $\mathrm{U}_{3} \mathrm{O}_{8}$.

El precio del uranio en el mercado a corto plazo creció sostenidamente desde niveles cercanos a $16 \mathrm{US} \$ / \mathrm{Kg} \mathrm{U}_{3} \mathrm{O}_{8}$ a inicios del año 2001, hasta alcanzar un máximo de 300 US $\$ / \mathrm{Kg} \mathrm{U}_{3} \mathrm{O}_{8}$ a mediados del año 2007. El incremento de precios tuvo que ver con la gran cantidad de recursos financieros disponibles para su colocación en 'papel uranio' como una forma de protegerse de la volatilidad de los precios en un contexto de especulación mundial en productos básicos; y en cierta medida, con la percepción de una insuficiencia de la producción primaria para cubrir el gran aumento de la capacidad de generación nuclear durante el período, especialmente por parte de China.

Posteriormente, la crisis financiera que ha afectado al mundo ha presionado los precios a la baja, por un aumento en los requerimientos de efectivo que ha frenado la inversión; de esta forma los precios a corto plazo han venido disminuyendo hasta llegar a mitades del año 2012, a 113,7 US\$/kg U $\mathrm{U}_{3} \mathrm{O}_{8}$ [Cameco, 2012]. Por su parte, los precios transados en los contratos a largo plazo sólo alcanzaron $209 \mathrm{US} \$ / \mathrm{Kg} \mathrm{U}_{3} \mathrm{O}_{8}$ a mediados del año 2007; y por su misma naturaleza, se mantuvieron en la misma cifra hasta mediados del 2008. Después de ello, siguieron la misma tendencia hacia la baja llegando hoy día a 133,3 US\$/ $\mathrm{Kg} \mathrm{U}_{3} \mathrm{O}_{8}$ [Cameco, 2012]. 
La tendencia en los precios promedio anuales del uranio a corto y a largo plazo, es también registrada y publicada por algunos gobiernos o autoridades internacionales como Australia (ABARE, 2008), Estados Unidos [U.S. EIA, 2010a] y las Comunidades Europeas [ESA, 2010]. Las cifras corresponden al precio promedio ponderado de las exportaciones efectuadas durante el año, en el caso de Australia; o al precio promedio ponderado pagado en las compras efectuadas en Estados Unidos o en la Comunidad Europea respectivamente durante el año, en el mercado a corto plazo o bajo contratos a largo plazo.

\subsubsection{Efectos sobre el ambiente y consideraciones finales}

El futuro de la energía nuclear dependerá del crecimiento de la demanda de electricidad; de los resultados de la investigación en temas como reactores avanzados y seguridad en el manejo de residuos altamente radioactivos y en su disposición final; de su competitividad económica y ambiental con otras fuentes energéticas; y de la percepción que tenga la gente y los gobiernos sobre los riesgos asociados a accidentes y al peligro de la proliferación de armas nucleares.

La fisión de una pequeña cantidad de uranio produce una enorme cantidad de energía lo que representa una ventaja si se quiere satisfacer la creciente demanda de energía eléctrica en el mundo. Por otra parte, su uso como combustible en la generación de electricidad no produce emisiones de gases tipo invernadero. Sin embargo, la extracción del mineral de uranio y su tratamiento genera un volumen importante de residuos con un alto contenido de contaminantes químicos y radioactivos. Las etapas siguientes en el ciclo del uranio, especialmente su utilización en un reactor nuclear, producen residuos radioactivos sumamente peligrosos cuyo manejo y disposición requiere rigurosas medidas de seguridad. Por ello y por el potencial riesgo de que el uranio enriquecido sea utilizado con fines no pacíficos, la actividad está estrictamente regulada por convenios y normativas internacionales [NEA, 2005]; y a menudo se percibe como muy riesgosa por la población en general.

Paralelamente, todo el proceso es técnicamente complejo y requiere personal muy capacitado lo que puede limitar su uso en países poco desarrollados. Se caracteriza por muy altos costos de inversión, bajos costos de operación y mantenimiento y 
bajos costos de combustible que incluyen la compra, conversión y enriquecimiento del uranio, fabricación del combustible, reprocesamiento y/o disposición del combustible usado y de los residuos altamente radioactivos producto del reprocesamiento del uranio; así como su transporte. Típicamente, los costos de combustible representan un $20 \%$ del costo total de producción; y de éste aproximadamente un 5\% corresponde al costo del uranio por lo que una variación en su precio afecta muy poco la economía del proceso. En contrapartida, el costo de inversión representa aproximadamente un $60 \%$ del costo total de producción e incluye además de la gran inversión inicial requerida para la construcción y puesta en marcha del reactor, las reinversiones necesarias para renovación de estructuras, equipos y sistemas de seguridad que así lo requieran y los desembolsos para la disposición segura de los residuos radioactivos al finalizar la vida del reactor. El 20\% restante corresponde a costos de operación y mantenimiento.

El negocio será rentable en la medida en que el precio de la energía eléctrica de origen nuclear supere el costo de producirla [NEA, 2005]; y naturalmente, deberá competir con otras alternativas de energía no renovable, más baratas, probadas tecnológica y comercialmente, pero más contaminantes; o con opciones de energía renovable, menos desarrolladas, hoy día más costosas, pero poco contaminantes de la atmósfera y del ambiente en general.

\subsection{Fuentes renovables de energía}

El sol, los vientos, las corrientes de agua, las mareas, las olas, el calor interno de la tierra y la biomasa son fuentes renovables de energía; esto es, su aprovechamiento no implica su extinción. Todas ellas tienen en común que su utilización no genera residuos de difícil eliminación y produce poca o ninguna contaminación por emisión de $\mathrm{CO} 2$ u otros óxidos gaseosos a la atmósfera. Por ello, son vistos como una alternativa frente a las fuentes fósiles de energía aún cuando en algunos casos las tecnologías para su explotación no estén completamente desarrolladas y sus costos puedan resultar más elevados que los costos de la energía convencional. 
Las fuentes renovables de energía pueden reemplazar a los combustibles tradicionales en los sectores de generación eléctrica, suministro de agua caliente y calefacción, calor para la industria y producción de combustibles para el transporte. Para el año 2009, la energía de fuentes renovables contribuyó en un 13,3\% al suministro de energía primaria global (Fig.3.2) y aproximadamente en un $16,2 \%$ al consumo final ${ }^{44}$ global de energía. La figura 3.17 muestra su participación por usos.

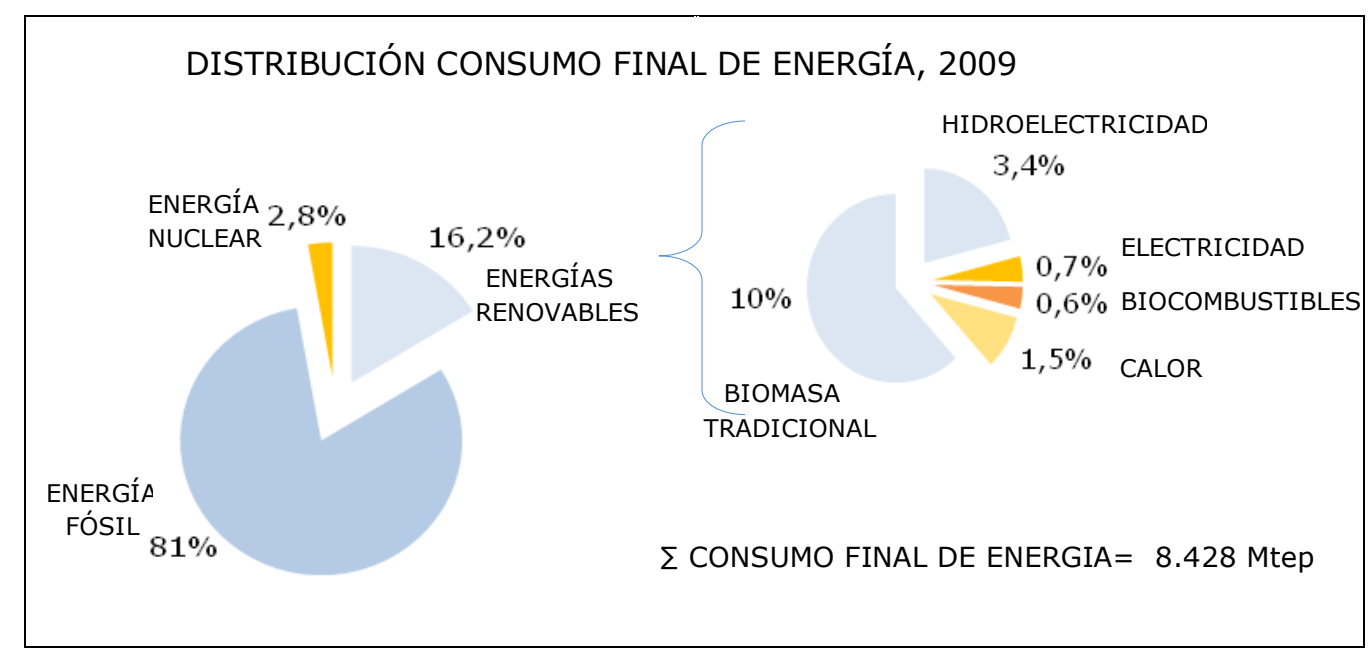

Fuente de datos: REN21, 2011; IEA, 2011a

Figura 3.17. Participación de las energías renovables en el consumo final de energía, 2009.

Las fuentes renovables de energía son endógenas y por tanto, su disponibilidad en cada país no depende del suministro por parte de otros países; ello hace a las sociedades menos vulnerables desde el punto de vista energético. Además, pueden explotarse en forma local y descentralizada de forma que cada comunidad de acuerdo a sus recursos puede potencialmente producir la energía que necesita donde la necesita, minimizando las pérdidas y el equipo necesario para transmitir la energía a través de largas distancias; creando empleos locales para la puesta en marcha, operación y mantenimiento de las instalaciones; y primordialmente, permitiendo el acceso a energía moderna a una multitud de hogares y pequeñas empresas rurales.

${ }^{44}$ Consumo final de energía se refiere al punto de uso final: electricidad, calor y combustibles vehiculares. 
A continuación una breve descripción de los más importantes tipos de energía renovable, su participación actual y futura en el panorama energético mundial, las tecnologías actuales para su aprovechamiento; sus costos y sus eficiencias energética y ambiental.

\subsubsection{Recursos hídricos}

La hidroenergía, o energía que existe en el agua en movimiento es una de las fuentes de energía renovable que ha sido más utilizada en el planeta. En efecto, la energía cinética y potencial de una corriente de agua puede ser convertida en energía eléctrica al salvar el desnivel existente entre dos puntos de su recorrido. El tipo más común de planta de generación hidroeléctrica utiliza una presa sobre un río para almacenar agua en un reservorio. El agua del reservorio se libera desde un nivel más alto a un nivel más bajo a través de un tubo inclinado, al salir del cual golpea y mueve las aspas de una turbina conectada a un generador que produce electricidad. El agua es devuelta al río aguas abajo y la electricidad generada pasa a un transformador, y de allí a la red de distribución que permite su transporte a las industrias, hogares y otros puntos de consumo que pueden estar localizados a cientos de kilómetros.

El proceso de generación de energía hidroeléctrica no es contaminante de la atmósfera ni produce residuos; y las tecnologías utilizadas están ampliamente probadas, son confiables y son accesibles. Sin embargo, es altamente dependiente de las precipitaciones en la cuenca donde se ubica el rio cuyo caudal se aprovecha.

El reservorio de agua formado por la presa puede dedicarse sólo a almacenar agua para producir energía eléctrica; o puede simultáneamente dedicarse a otros usos como irrigación, control de inundaciones, suministro de agua, navegación y recreación. En general, su desarrollo actúa como detonante de una serie de actividades económicas, genera oportunidades de trabajo y con ello una mejoría de la calidad de vida en la región de influencia. Dado su carácter endógeno, el aprovechamiento del potencial hidroeléctrico contribuye a la independencia energética del país que lo desarrolla. 


\subsubsection{Potencial, capacidad instalada y producción}

Los recursos hídricos naturales están ampliamente distribuidos en más de 150 países y se estima que dos tercios del potencial allí existente no ha sido aprovechado, especialmente en los países en vías de desarrollo.

Tabla 3.1. Potencial hidroeléctrico técnicamente explotable por regiones, 2010

\begin{tabular}{|l|c|c|}
\hline \multicolumn{1}{|c|}{ REGION } & $\begin{array}{c}\text { PHTE } \\
\text { (TWh/año) }\end{array}$ & $\begin{array}{c}\text { PHTEE no desarrollado } \\
\text { (\% sobre PHTEE regional) }\end{array}$ \\
\hline Norteamérica & 1659 & $61 \%$ \\
Latinoamérica & 2856 & $74 \%$ \\
Europa & 102 & $47 \%$ \\
África & 1174 & $92 \%$ \\
Asia & 7681 & $80 \%$ \\
Australasia/Oceanía & 185 & $80 \%$ \\
\hline Mundo & 14576 & $75 \%$ \\
\hline
\end{tabular}

PHTE: potencial hidroeléctrico técnicamente explotable

Fuente de datos:[ Kumar et al./IPCC, 2011].

El potencial hidroeléctrico bruto ${ }^{45}$ estimado a nivel mundial se acerca a los 40.000 TWh/año; de éste, el potencial técnicamente explotable es de unos 14.600 TWh/año y el potencial técnica $y$ económicamente explotable ${ }^{46}$ se ubica alrededor de 9000 TWh/año [Intpow, 2010]. El cuadro 3.1 que se incluye en la página anterior, presenta el potencial técnicamente explotable y la fracción no explotada del mismo

45 Potencial hidroeléctrico bruto $(P H B)$ es la cantidad de energía potencialmente disponible en cada país si todos los cursos de agua fueran turbinados con una eficiencia global del $100 \%$, hasta el nivel del mar o hasta el nivel del agua en la frontera del país si el curso de agua se extiende a otro país. Las cifras se estiman en base a las precipitaciones atmosféricas y a las escorrentías del agua desde el terreno a los cursos de agua [WEC, 2007].

46 Potencial técnicamente explotable (PHTE) es la cantidad del PHB que puede ser explotado con la tecnología disponible hasta la fecha [WEC, 2007].

Potencial técnica y económicamente explotable (PHTEE) es la cantidad del PHB que puede ser explotado con la tecnología disponible y las condiciones económicas esperadas a la fecha [WEC, 2007]. 
en una base regional [Kumar et al./IPCC, 2011]. África, Asia y Australasia tienen índices de aprovechamiento del potencial hidroeléctrico inferiores al nivel mundial que alcanza en promedio un 25\%. Los países con el mayor potencial hidroeléctrico en el mundo son China, Estados Unidos, Rusia, Brasil y Canadá [IEA, 2011a; IPC, 2011].

La figura 3.18a presenta la capacidad instalada de la planta hidroeléctrica en algunos países seleccionados, para el año 2009. De nuevo, destacan China con 168 GW instalados y Estados Unidos con 100 GW; Brasil con 78 GW y Canadá con 75 GW; y Japón y la Federación Rusa con 47 GW cada uno de potencia hidroeléctrica instalada. Por su parte, la figura 3.18b presenta información relativa a los complejos hidroeléctricos más grandes del mundo. Entre ellos, Three Gorges sobre el rio Yangtze en China, con 22,5 GW instalados; Itaipu sobre el rio Paraná en la frontera entre Brasil y Paraguay, con $14 \mathrm{GW}$ instalados; y Guri sobre el rio Caroní en Venezuela con 10,2 GW instalados [IEA 2011a; Green World Investor, 2011;].

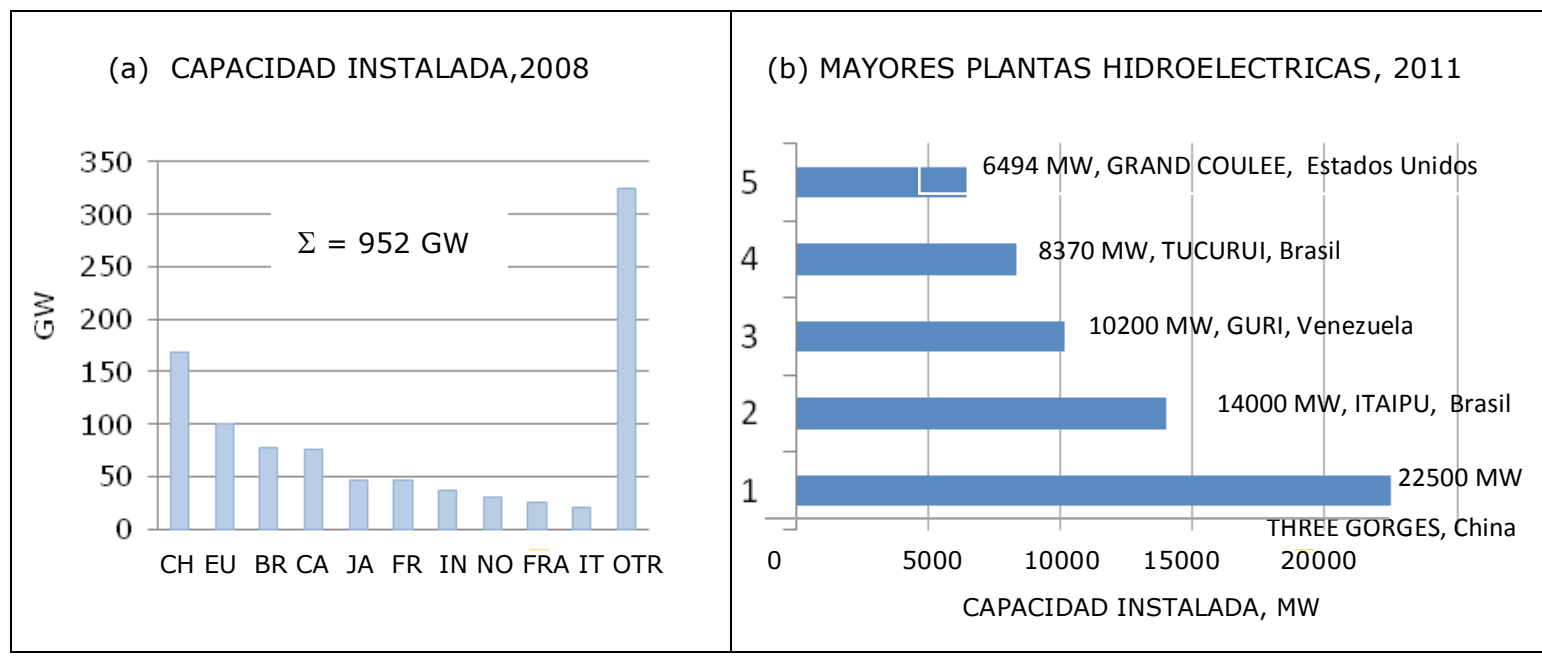

CH: China BR: Brasil CA: Canadá EU: Estados Unidos FR: Federación Rusa NO: Noruega IN: India JA: Japón FR: Francia IT: Italia OTR: Otros

Fuente de Datos: IEA, 2011a, Green World Investor, 2011

Figura 3.18 (a) Capacidad instalada de generación hidroeléctrica, 2009

(b) Grandes complejos hidroeléctricos, 2011.

Para el año 2009, la hidroelectricidad producida fue de 3.329 TWh lo que representó un $16,2 \%$ de la generación mundial de electricidad; la cifra es superior a 
la electricidad obtenida vía energía nuclear $(13,4 \%)$ pero muy inferior a la electricidad producida por la combustión de recursos fósiles $(67,1 \%)$ [IEA, 2011a,]. La figura 3.19a presenta la composición de la electricidad mundial producida para el año 2009, de acuerdo al origen de la fuente de energía usada para su producción. El renglón OTROS representa la contribución hecha por otras fuentes renovables a la producción mundial de energía.

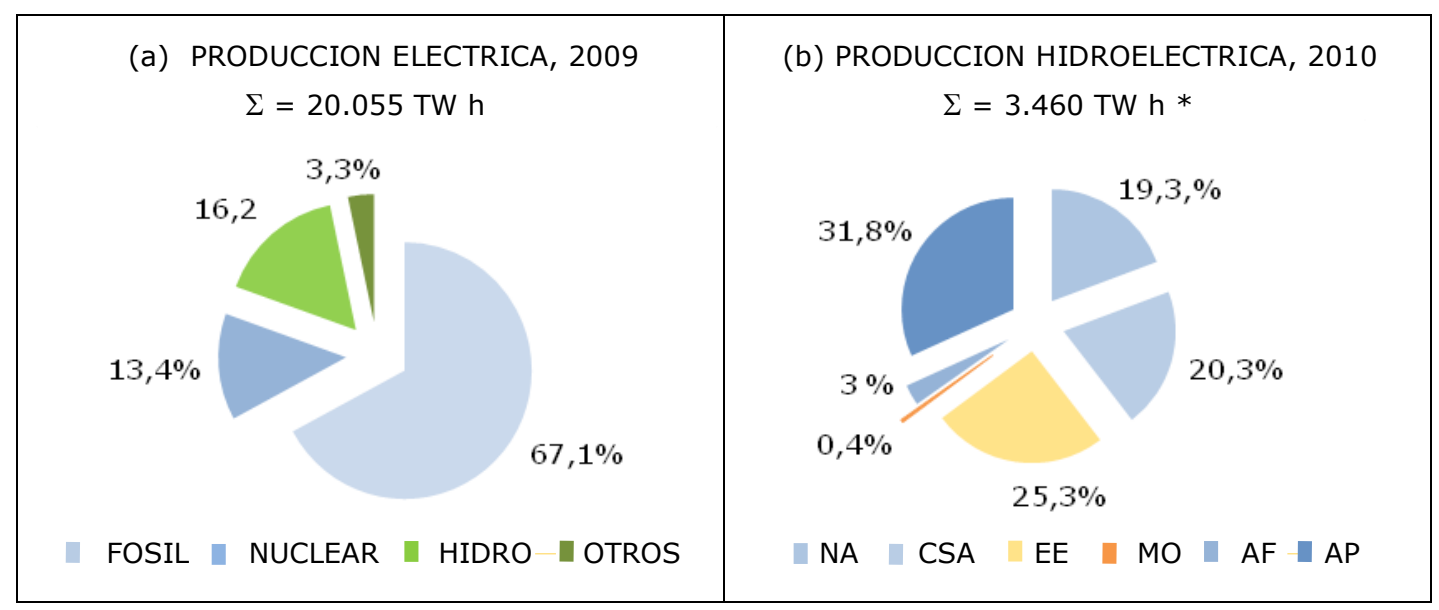

NA: Norteamérica; CSA: Centro y Suramérica; EE: Europa y Eurasia; MO: Medio Oriente; AF: África; AP: Asia-Pacífico, Fuente de datos: IEA, 2011a; BP, 2011. * estimado

Figura 3.19 (a) Composición de la producción eléctrica mundial, 2009

(b) Distribución de la producción hidroeléctrica mundial, 2010

La figura 3.19b muestra la distribución de la energía hidroeléctrica producida en el mundo para el año 2010. Nótese que la región Asia-Pacifico (AP) muestra la participación más importante en el total mundial debido primordialmente a la contribución de China (21\%), seguida de Europa y Euro-Asia (EE) con contribuciones importantes de la Federación Rusa (4,9\%) y Noruega (3,4\%). El continente americano (CCSA+NA) agrupa el $51,1 \%$ de la producción mundial con contribuciones notables de Brasil (11,6\%), Canadá $(10,4 \%)$, Estados Unidos $(7,6 \%)$ y Venezuela $(2,2 \%)$. Finalmente, la producción hidroeléctrica en África y los países del Medio Oriente contribuye sólo con un 3\% a la producción eléctrica mundial [BP, 2011].

La figura 3.20 presenta para los mayores productores, estadísticas sobre su producción hidroeléctrica y su importancia en el sector hidroeléctrico de cada país. 


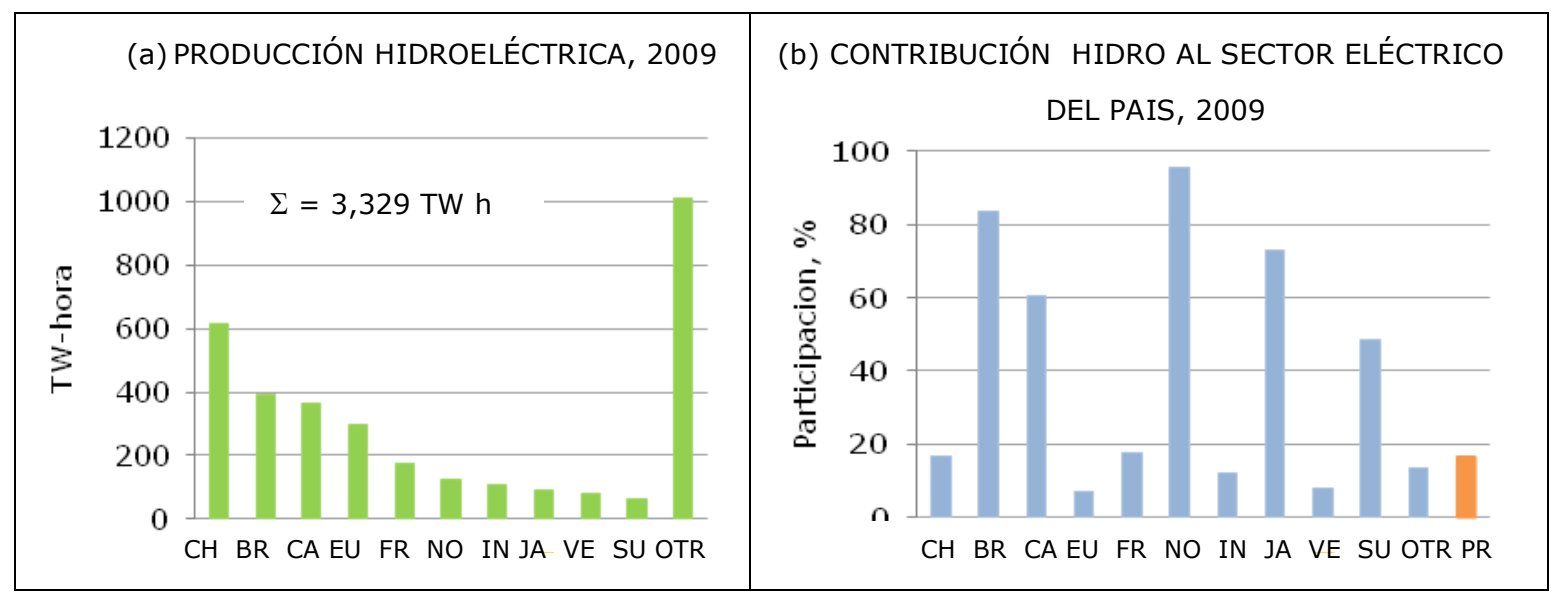

CH: China BR: Brasil CA: Canadá EU: Estados Unidos FR: Federación Rusa NO: Noruega IN: India JA: Japón VE: Venezuela SU: Suecia OTR: Otros PR: promedio mundial.

Fuente de Datos: IEA, 2011a

Figura 3.20 (a) Producción hidroeléctrica de países seleccionados, 2009

(b) Participación hidroeléctrica en el sector eléctrico por país, 2009

Cinco países, China, Brasil, Canadá, Estados Unidos y la Federación Rusa aportan más del $55,4 \%$ de la hidroelectricidad generada en el mundo. La producción hidroeléctrica en Noruega, Brasil, Venezuela y Canadá suple más del $50 \%$ del consumo propio de electricidad. Para el 2008, Noruega suplió la casi totalidad de su consumo eléctrico con su producción hidroeléctrica $(95,7 \%)$; y en Venezuela, un país exportador de petróleo, un $72,8 \%$ del consumo eléctrico fue suplido por la producción hidroeléctrica. El promedio mundial de participación hidroeléctrica en la producción eléctrica en el mundo fue de 16,5\% [IEA, 2011a].

\subsubsection{Aprovechamientos hidroeléctricos}

La construcción de un complejo hidroeléctrico es una tarea de envergadura que requiere en primer lugar la selección del sitio de presa, del tamaño y del tipo de la misma, en función de las condiciones geológicas del terreno, las características del caudal de agua en el sitio, el régimen de precipitaciones en la cuenca a la que pertenece el rio, la extensión del impacto que la inundación de una extensión de terreno pueda causar sobre el ambiente; y la evaluación económica de cada alternativa posible. La información requerida para realizar los estudios necesarios es extensa y de no hallarse a disposición, deberá levantarse o complementarse lo que 
representa un esfuerzo considerable en tiempo, recursos humanos y dinero necesario. Adicionalmente, la planificación, la obtención de permisos, el diseño y construcción de un aprovechamiento hidroeléctrico consumen mucho tiempo y la inversión inicial requerida es elevada. Es importante tomar en cuenta que la ruptura de una presa por efectos naturales 0 , eventualmente, por ataques terroristas o similares puede producir una catástrofe de grandes proporciones a la población que habita aguas abajo de la misma; y se discute la probabilidad de que el gran peso que representa el agua contenida en un embalse muy grande, pueda inducir la sismicidad en la zona.

En contrapartida, la vida estimada de un complejo hidroeléctrico es larga, típicamente entre 40 y 50 años, lapso que puede extenderse con costos de mantenimiento moderados y el cambio periódico de equipos o partes electromecánicas; y sus costos de operación son relativamente bajos.

La tecnología para la generación de eléctrica se ha probado por muchos años y aprovecha la rápida caída de caudales de agua que se envían desde su reservorio a un nivel más alto; a un nivel más bajo, aguas abajo del río. La generación de energía hidroeléctrica puede enfrentar las variaciones típicas de la demanda diaria de electricidad, simplemente regulando el caudal de agua liberado desde el embalse que la contiene; sin embargo, el nivel de mismo depende fuertemente de las lluvias en la cuenca del río objeto del aprovechamiento y del manejo que se haga del mismo.

Una alternativa para enfrentar la variación de la demanda es una planta de almacenamiento por bombeo que permite almacenar energía para utilizarla en las horas 'pico' o de alta demanda. Esto es, durante las horas de baja demanda de electricidad, el agua que normalmente sale de las turbinas a un reservorio localizado debajo del nivel de la presa, es bombeada y almacenada en un reservorio superior. La energía así almacenada se utiliza en períodos de alta demanda, cuando el agua es liberada del depósito superior y devuelta al rio o depósito inferior, moviendo las turbinas y activando los generadores para producir electricidad.

Sin embargo, no se necesita una gran presa para generar electricidad. Proyectos más pequeños, típicamente de capacidad inferior a $10 \mathrm{MW}$, constituyen en muchas 
regiones del mundo (Asia, Europa, Estados Unidos), alternativas menos costosas, mucho más rápidas de construir y que tienen un menor impacto ambiental. Las microcentrales hidroeléctricas con capacidades inferiores a $100 \mathrm{~kW}$, sólo usan un canal para desviar el agua directamente del rio hacia una turbina conectada a un generador de electricidad; ellas constituyen una alternativa de bajo costo, que puede utilizar mano de obra y materiales locales, para proporcionar electricidad a sitios rurales o montañosos alejados. La instalación de pequeñas plantas hidroeléctricas ha aumentado, en ocasiones considerablemente, el potencial hidroeléctrico del país donde se ubican.

\subsubsection{Efectos sobre el ambiente y consideraciones finales}

La construcción y puesta en marcha de grandes embalses ha causado grandes polémicas especialmente porque la necesaria inundación de grandes lotes de terreno implica el desplazamiento forzoso y relocalización de núcleos humanos; la pérdida de grandes extensiones de vegetación que además al quedar sumergidas, pueden empezar a descomponerse a medida que pasa el tiempo, y producir metano y otros gases dañinos a la salud; la desaparición de al menos parte de la fauna y de la herencia cultural en la zona inundada; y la modificación del hábitat de especies animales que viven en el rio represado.

Un embalse para generación hidroeléctrica o de cualquier otro tipo interrumpe el flujo natural del río represado y con ello el libre desplazamiento, hacia arriba y hacia abajo, de algunos especímenes de peces. Como una solución, se han introducido corrientes artificiales o 'escaleras para peces', donde especies como el salmón puedan nadar aguas arriba para desovar y reproducirse; la medida ha detenido la declinación de la población de estos peces en los últimos años [Kristoff, 2008] al noroeste de los Estados Unidos.

Adicionalmente, la operación diaria de las instalaciones puede causar que el nivel de las aguas debajo de la presa, suba o caiga drástica e intermitentemente afectando las formas de vida allí existentes; y eventualmente, disminuyendo su concentración. Por otra parte, una presa transforma a un río en un lago y la vegetación que queda bajo sus aguas puede descomponerse a medida que pasa el 
tiempo, y producir cantidades importantes de metano y otros gases nocivos al ambiente y a la salud, efecto que puede disminuirse con la deforestación previa de la zona a inundar.

La construcción de Three Gorges sobre el rio Yangtze en China, uno de los complejos hidroeléctricos más grandes del mundo, causó el desplazamiento y la relocalización de más de un millón de personas y la pérdida de activos culturales en el área inundada. En contrapartida, con capacidad instalada de 18.200 MW (22.500 MW en el año 2012), surte de electricidad limpia, confiable y a costo accesible a gran parte del territorio chino, reduciendo en una cantidad importante las emisiones de $\mathrm{CO}_{2}, \mathrm{SO}_{2}$ y óxidos de nitrógeno a la atmósfera, si se compara con la alternativa de generación con carbón; opera como un sistema de control de inundaciones para alrededor de $1,5 \mathrm{Km}^{2}$ de tierras agrícolas y ciudades y 15 millones de personas en el área; y permite la navegación de buques de 10 mil toneladas, aguas arriba de la presa y por una extensión de más de 600 Km [China TGCo, 2002].

De esta forma, el planteamiento para el aprovechamiento del potencial hidroeléctrico en cada región no sólo debe contemplar los aspectos técnicos y económicos de la generación propiamente dicha sino que debe incorporar a la discusión los efectos ambientales y sociales que produce su construcción y puesta en marcha; invitando a los actores que de una u otra forma resulten afectados; considerando la posibilidad de integraciones regionales; y pensando en el aprovechamiento múltiple de los embalses que optimice las inversiones y el uso que de ellas se hace.

\subsubsection{Océanos}

Los océanos cubren más del $70 \%$ de la superficie del globo terráqueo y sus aguas guardan un gran potencial de energía cuyo aprovechamiento podría contribuir a satisfacer de una forma 'limpia' las necesidades energéticas del mundo. La captación y transformación de la energía oceánica en energía utilizable por el hombre es una industria emergente. Algunos pocos gobiernos en el mundo han subsidiado la investigación en el área (Reino Unido, Estados Unidos, Portugal, entre otros) y el conocimiento sobre este tipo de energías ha mejorado especialmente en la última 
década y se han diseñado gran cantidad de dispositivos para su aprovechamiento; sin embargo, el costo de desarrollar y utilizar esas tecnologías a escala comercial sigue siendo prohibitivo. La investigación y las pruebas piloto realizadas se han dirigido primordialmente al estudio de la energía contenida en (i) las olas sobre y debajo de la superficie del mar, (ii) las mareas y (iii) el gradiente de temperatura entre las aguas en las profundidades del océano y su superficie.

La figura 3.21 muestra la distribución del potencial teórico de energía oceánica en el mundo por tipo de energía. Las cifras corresponden a la data de fecha más reciente encontrada en la bibliografía especializada [OES, 2011]. Los recursos oceánicos son vastos pero no están uniformemente distribuidos; la energía en las olas tiende a ser mayor en las latitudes más altas mientras que el gradiente térmico aprovechable se ubica alrededor del ecuador. En el renglón 'Otros' se incluye el gradiente salino entre la alta salinidad del agua de mar y el agua de los ríos, el cual puede ser usado para generar electricidad [OES, 2011].

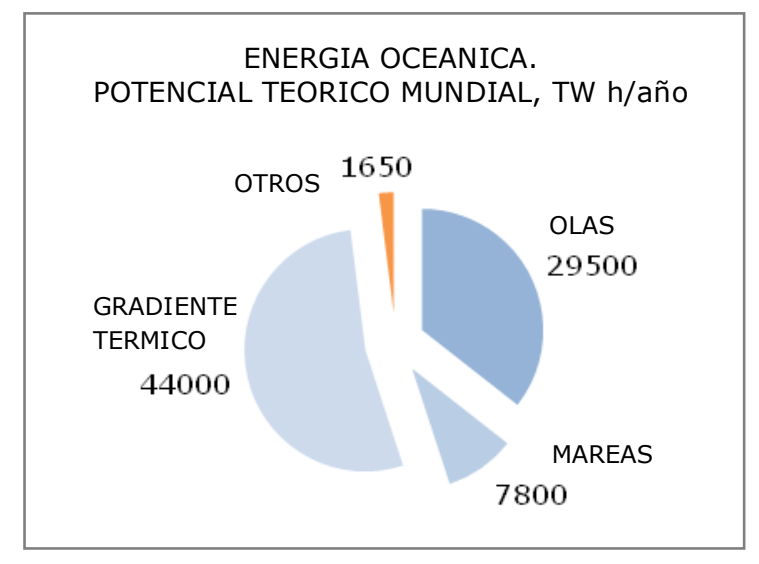

Fuente de datos: OES, 2011

Figura 3.21. Distribución del potencial teórico mundial de energía oceánica

Adicionalmente a los costos de instalación, desarrollo y puesta en marcha de los respectivos sistemas de aprovechamiento, debe solucionarse el problema del financiamiento de la infraestructura para la conexión de la energía producida en áreas costeras a la red de distribución principal; y todo lo referente a un marco regulatorio que establezca claramente normas para el aprovechamiento ambientalmente viable de las energías oceánicas. A continuación una breve 
descripción de los recursos oceánicos y de la tecnología actual para la captación y conversión de la energía en el área.

\subsubsection{Olas}

Las olas constantemente en movimiento en los océanos son producto de los vientos que soplan en su superficie. Una vez creadas, viajan grandes distancias, sobre la superficie del mar y bajo ella, sin pérdida importante de energía. Cerca de la costa, la intensidad de la energía disminuye; sin embargo, la topografía del fondo del mar puede dirigirlas y concentrarlas en zonas energéticas cercanas a la línea costera. Un aumento en la potencia energética de las olas $(\mathrm{kW} / \mathrm{m}$ de cresta) se detecta entre $30^{\circ}$ y $60^{\circ}$ de latitud, en ambos hemisferios; así, las costas noroccidentales de América y Europa, y las costas suroccidentales de Australia, Nueva Zelanda, Suramérica y Suráfrica son zonas con olas de alto contenido energético [WEC, 2010]. La figura 3.22 señala las zonas costeras en el mundo con mayor intensidad de potencia de olas medida en $\mathrm{kW} /$ metro de cresta. Adicionalmente presenta la localización de los valores más altos de potencia de olas, en el mundo.

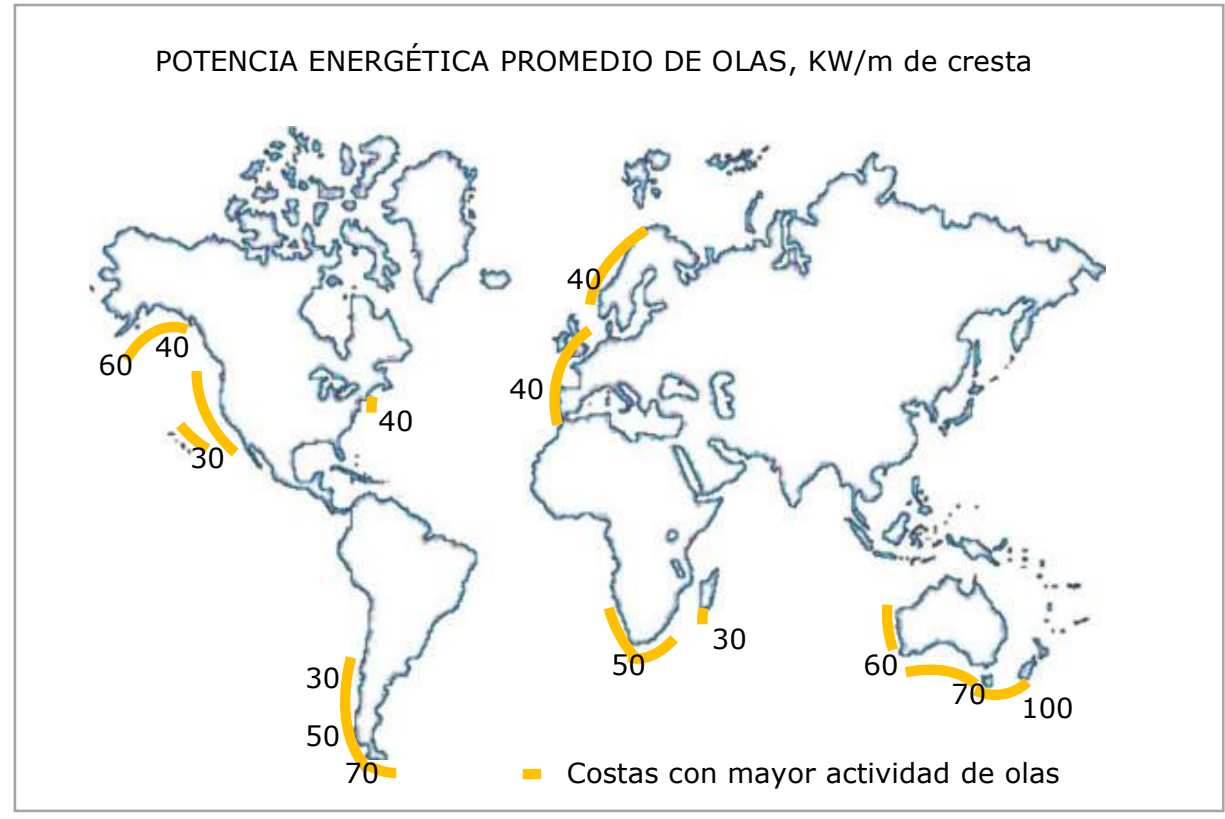

Fuente de datos: [Brito e Melo, 2009; Soerensen, 2008]

Figura 3.22. Potencia energética media de olas para sitios seleccionados 


\subsubsection{Potencial económicamente explotable}

El potencial teórico mundial de energía ${ }^{47}$ en las olas oceánicas se ha estimado entre 8000 y 80.000 TWh/año [Brito e Melo, 2009; OEC, 2011]; y el potencial económicamente explotable ${ }^{48}$ para las condiciones actuales de tecnología, entre 140 y 750 TWh/año. Esta última estimación puede elevarse a 2000 TWh/año si se concretan algunas potenciales mejoras a las tecnologías existentes [WEC, 2010].

\subsection{Tecnologías de captación y de conversión}

Hasta la fecha se han desarrollado una cantidad importante de dispositivos para el aprovechamiento de la energía contenida en las olas; sin embargo, sólo unos pocos se prueban actualmente a escala comercial. Los dispositivos pueden agruparse de acuerdo a los medios básicos que utilizan para conversión de energía [Soerensen, 2008; WEC, 2007], en:

- Dispositivos que utilizan una columna oscilante de agua (OWC, por sus siglas en inglés). En esencia, el sistema está conformado por una estructura hueca, parcialmente sumergida en el mar, con una apertura en su base la cual permite la entrada del agua; ésta forma una columna cuya superficie se eleva con la llegada de las olas, forzando al aire dentro de la estructura a escapar a través de un conducto y entrar a una turbina que activa a un generador de electricidad. Cuando las olas se retiran, la superficie de la columna de agua baja y el espacio sobre ella se llena de nuevo de aire. Plantas que utilizan este principio de conversión se han instalado en las islas de Pico, Portugal $(0,4 \mathrm{MW})$ y en el Reino Unido $(0,5 \mathrm{MW})$.

47 Potencial teórico de energía en el recurso es un enunciado del máximo de energía potencialmente disponible en la totalidad del recurso [Brito e Melo, 2009].

48 Potencial económicamente explotable de energía en el recurso es la fracción del recurso teórico que puede ser explotado con las tecnologías existentes y cuya explotación resulta comercialmente atractiva bajo las condiciones de mercado previstas [Brito e Melo, 2009]. 
- Dispositivos que permiten almacenar el agua de las olas entrantes en un reservorio sobre el nivel promedio del océano que lo rodea. Posteriormente, el agua es devuelta al océano a través de una turbina acoplada a un generador de electricidad. La plataforma puede ser flotante o ser construida sobre la costa. Un sistema con capacidad de generación de $7 \mathrm{MW}$, está completamente probado y disponible para ser instalado en la costa de Gales, si el financiamiento necesario se hace realidad.

- Dispositivos conformados por una boya cilíndrica flotante llena de aire que puede moverse dentro de una base cilíndrica fija al fondo del mar, cuando una ola pasa sobre el tope del dispositivo. Este movimiento relativo entre las partes es aprovechado para producir electricidad utilizando un generador lineal. Dispositivos de este tipo se han instalado $(0,2 \mathrm{MW})$ en la costa de Oregón, Estados Unidos.

- Estructuras flotantes conformadas por una serie de cilindros huecos de acero unidos con bisagras y orientados en la dirección en que se mueven las olas, de forma que ellas se desplazan a lo largo del dispositivo, causan flexión en las juntas de los segmentos; la cual es utilizada para bombear aceite a través de motores hidráulicos conectados a generadores eléctricos. Dispositivos que utilizan esta forma de conversión de la energía, con una capacidad de generación de 2,25 MW se han probado en la costa de Portugal.

Los dispositivos para la captación y conversión de la energía de las olas oceánicas se instalan en 'granjas', interconectados, a fin de alcanzar la capacidad deseada. La modularidad del sistema permite la incorporación gradual de los convertidores.

\subsubsection{Impacto sobre el ambiente y consideraciones finales}

La energía obtenida de las olas del mar es renovable y su conversión y uso evita las emisiones de gases de tipo invernadero a la atmósfera; sin embargo, para la ubicación de las granjas de dispositivos deben tomarse en cuenta potenciales impactos sobre el hábitat marino y sobre el paisaje de costas y océano si la altura de los dispositivos es elevada; el nivel de generación de ruido sobre y debajo de la superficie del mar; la posibilidad de derrames accidentales de líquidos tóxicos que se 
utilizan en sistemas hidráulicos; y finalmente, el conflicto con otros usuarios de los espacios del mar como botes de pesca y navegación comercial y recreacional, en general.

\subsubsection{Mareas}

La elevación y caída periódica del nivel de los océanos es causada por la interacción de los campos gravitacionales en el sistema planetario de la Tierra, el Sol y la Luna, y está influenciada por la posición relativa de los tres astros. Hay dos mareas altas y dos mareas bajas cada día y la diferencia de elevación entre ellas depende de la posición relativa de los tres astros. Cuando la Luna y el Sol están alineados, sus respectivas fuerzas de atracción por la Tierra, se sobreponen y la diferencia entre la marea alta y la baja es máxima; por el contrario, si las fuerzas de atracción de la Luna y el Sol por la Tierra actúan en ángulo recto, se contraponen y la diferencia entre la marea alta y baja es mínima. En algunas costas, especialmente en los estuarios, la diferencia se acentúa y puede ser aprovechada para producir electricidad; así como las corrientes asociadas al ir y venir del agua.

\subsubsection{Potencial y capacidad instalada}

Hay lugares en el mundo cuyas condiciones geográficas producen un rango elevado entre las mareas alta y baja. El potencial teórico mundial de energía en las mareas oceánicas se estima en 7.800 TWh/año [OES, 2011]. Sitios de especial interés se encuentran en la costa norte de Francia, el Reino Unido y Canadá con rangos medios entre 7 y 10 m [WEC, 2010]. La figura 3.23 presenta algunos lugares en el mundo con rangos de mareas excepcionales; entre ellos, sólo unos pocos sitios son explotados actualmente [OEC, 2012].

Una planta mareomotriz que opera en La Rance, Bretaña en Francia desde 1966, tiene una capacidad instalada de $240 \mathrm{MW}$ y produce aproximadamente $600 \mathrm{MWh} / \mathrm{año}$ [WEC, 2010; OEC, 2012]. Otras plantas de menor capacidad operan en Canadá (20 MW) y en China (5 MW) [OEC, 2012, WEC, 2007]. Estos sistemas de captación y conversión de la energía en las mareas están caracterizados por bajos factores de capacidad, generalmente entre $20 \%$ y $35 \%$ [OEC, 2012]. 


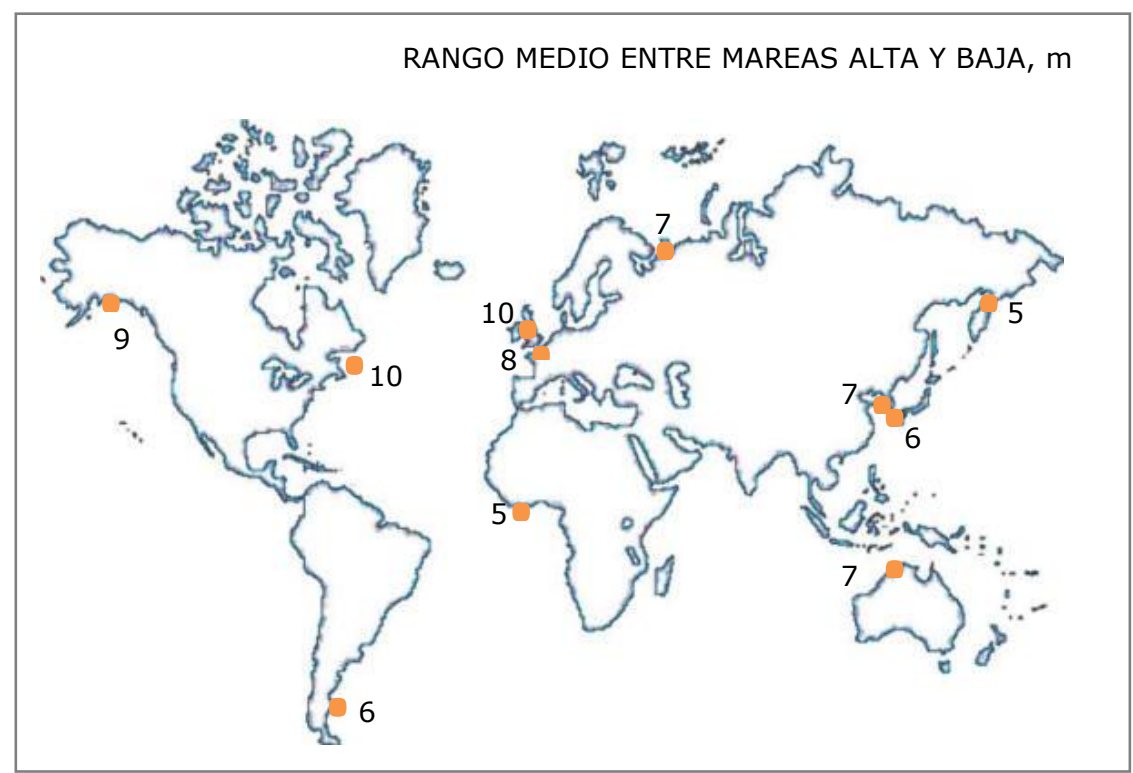

Fuente de datos: [Soerensen, 2008].

Figura 3.23. Rango medio entre mareas alta y baja para sitios seleccionados

\subsubsection{Tecnologías de captación y conversión}

Hay dos formas diferentes de abordar la explotación de la energía en las mareas oceánicas; la primera es aprovechar la energía potencial asociada a la diferencia de altura entre las mareas alta y baja, y la segunda, tiene que ver con el aprovechamiento de la energía cinética de las corrientes marinas producto del flujo de las mareas.

La tecnología utilizada para el aprovechamiento del desnivel entre las mareas baja y alta es similar a la tecnología usada en las plantas de energía hidroeléctrica. Esto es; una vez identificado un estuario con un rango de mareas importante, se cierra con una 'barrera' a fin de formar un reservorio del agua que llega a la playa con la marea alta; cuando la diferencia entre la elevación del agua en cada lado de la presa es la adecuada, se deja fluir el agua a través de una turbina de baja diferencia de nivel la cual activa un generador que produce electricidad. Típicamente, el flujo de agua hacia las turbinas se abre una vez que la carga alcanza aproximadamente la mitad del rango de la marea [WEC, 2007]. El sistema libera energía eléctrica sólo durante parte del ciclo de la marea y no puede ajustar el período de generación de 
forma de satisfacer los requerimientos de los consumidores. Por ello, se han propuesto sistemas con doble reservorio, uno de los cuales actuaría como un espacio de almacenamiento para asegurar que haya siempre una capacidad de generación. Se requiere al menos de un rango entre las mareas altas y baja de $7 \mathrm{~m}$ para una operación económicamente viable [OEC, 2010].

Por su parte, el aprovechamiento de la energía cinética en las corrientes asociadas al flujo de las mareas, puede efectuarse con una turbina sumergida vertical colocada de forma que sus aspas roten al ser golpeadas por la corriente. Un generador convierte la energía de rotación en electricidad que se transporta a la playa para su incorporación a la red eléctrica. Las turbinas se mantienen fijas mediante cables anclados al fondo del mar. La instalación, supervivencia y mantenimiento de tales equipos son complicados y han frenado su explotación comercial.

Localizaciones con corrientes particularmente intensas se encuentran alrededor de Inglaterra e Irlanda, las islas del Canal de la Mancha y Francia, los estrechos de Messina entre Italia y Sicilia, en algunos canales entre las islas griegas, al sureste de Asia, en las costas este y oeste de Canadá, entre otros [Soerensen et al., 2008].

\subsubsection{Impacto sobre el ambiente y consideraciones finales}

La energía en las mareas oceánicas es un recurso renovable cuyo aprovechamiento es poco contaminante. La construcción de presas para el aprovechamiento de la energía derivada del desnivel entre las mareas puede afectar negativamente los ecosistemas acuáticos y de la línea costera; y las aspas de las turbinas para el aprovechamiento de las corrientes oceánicas pueden provocar daños en las especies marinas.

Además, pueden afectarse las rutas de las embarcaciones comerciales y turísticas. En su lugar se han propuesto lagunas de mareas; esto es, cuerpos protegidos de agua de océano, semicerrados por una barrera rocosa o de otro tipo y localizados cerca a la costa pero sin afectar la línea costera ni interrumpir la circulación de embarcaciones. La electricidad se genera de forma similar que en las presas convencionales sobre los estuarios. 


\subsubsection{Gradiente térmico oceánico}

Como se ha señalado, los océanos cubren más de un $70 \%$ de la superficie del planeta lo que los convierte en un enorme sistema de colección y almacenamiento de la energía solar. Un proceso conocido como Conversión de la Energía Térmica Oceánica (OTEC, por sus siglas en inglés) convierte esta energía solar acumulada en energía eléctrica utilizando el gradiente de temperatura natural entre las capas del océano, específicamente entre el agua cálida de la superficie de los océanos en áreas tropicales y subtropicales y el agua muy fría a una profundidad aproximada de 1000 metros. Para que el proceso funcione bien, la diferencia de temperatura debe ser al menos de $20{ }^{\circ} \mathrm{C}$, condiciones que existen en áreas costeras entre $0^{\circ}$ y $20^{\circ}$ de latitud norte y sur respectivamente [NREL, 2012a]. Algunos países como Cuba, República Dominicana y otras islas del Caribe en América, algunos países del África, y del Pacífico llenan esta condición y además el recurso se encuentra a menos de $25 \mathrm{Km}$ de la costa [NREL, 2012a; WEC, 2007]. Se estima que el potencial teórico global del recurso es de 14.000 TWh/año [OES, 2012].

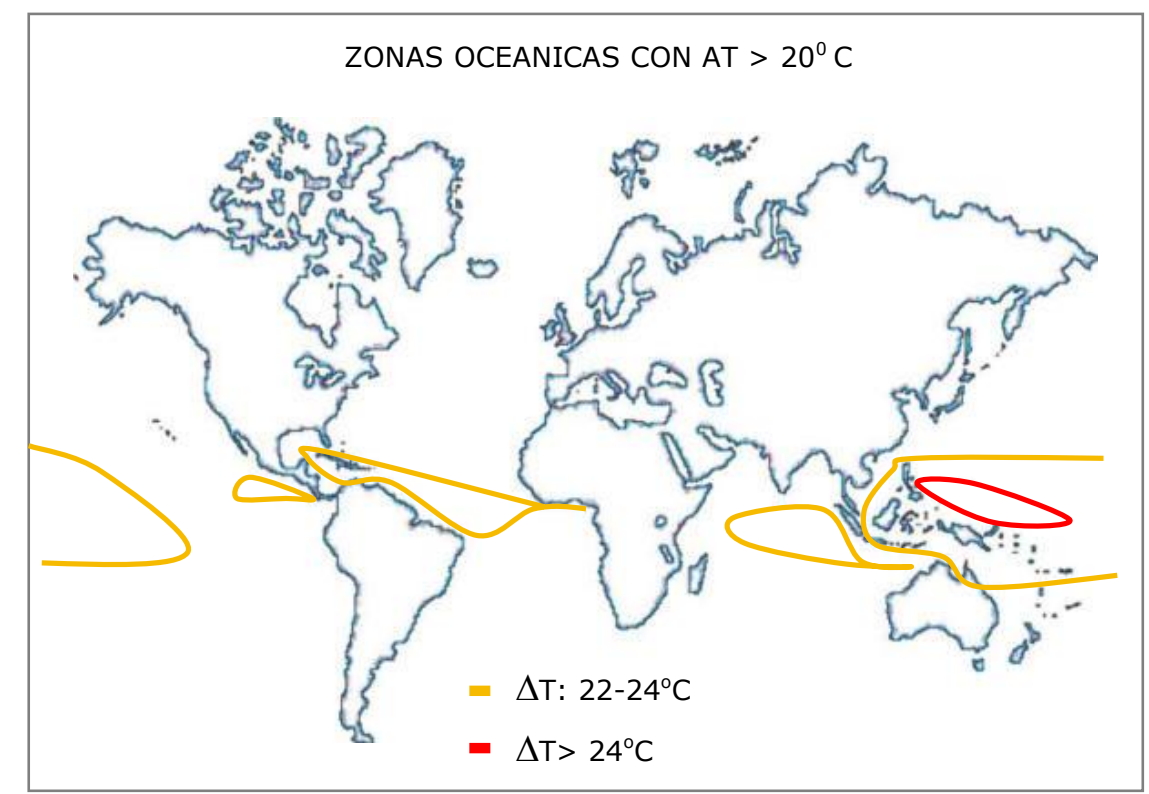

Fuente de datos: NREL, 2012a

Figura 3.24. Zonas oceánicas con gradiente térmico de temperatura $>20{ }^{\circ} \mathrm{C}$ entre la superficie del mar y $1000 \mathrm{~m}$. de profundidad. 
La figura 3.24 que se presenta en la página anterior, muestra aproximadamente las zonas oceánicas donde el gradiente térmico de temperatura entre la superficie del mar y una profundidad de 1000 metros supera los $20{ }^{\circ} \mathrm{C}$ necesarios para su potencial aprovechamiento como fuente de energía. Las zonas con $\Delta \mathrm{T}>20^{\circ} \mathrm{C}$ están encerradas en los contornos dibujados.

\subsection{Tecnologías de captación y conversión}

El sistema OTEC utiliza un ciclo vaporización-condensación de un fluido para producir electricidad. Pueden diferenciarse dos tipos de sistemas, a saber:

- OTEC de ciclo cerrado. En este tipo de ciclo, agua cálida de la superficie del mar se bombea a través de un intercambiador de calor cediendo su energía a un fluido de bajo punto de ebullición como el amoníaco, el cual se vaporiza. El vapor se expande, hace rotar un turbogenerador y se dirige a un segundo intercambiador al cual se bombea agua fría de las profundidades del mar que toma la energía del vapor que sale de la turbina el cual, una vez condensado, se recircula al sistema [NREL, 2012a].

- OTEC de ciclo abierto. Este tipo de sistema dirige el agua cálida de la superficie del mar a un recipiente al vacio donde se vaporiza. El vapor producido mueve una turbina unida a un generador eléctrico después de lo cual es condensado por intercambio de calor con el agua a muy baja temperatura de las profundidades del océano. El agua que entra al recipiente a baja presión deja su contenido de sal al evaporarse; por tanto, el vapor que sale de recipiente y luego se condensa, es agua casi pura [NREL, 2012a]. Se estima que un sistema de ciclo abierto de $1 \mathrm{MW}$ puede producir más de 2.000 metros cúbicos por día de agua fresca. Así, el aprovechamiento de la energía térmica contenida en los océanos constituye una alternativa viable para la producción de agua potable a partir del agua de mar. [Josey, 2008].

- OTEC híbrido. Este sistema combina las características de los ciclos cerrado y abierto descritos antes. El agua cálida de la superficie del mar entra a un recipiente al vacio donde se vaporiza; el vapor producido se condensa cediendo su calor para vaporizar el liquido de trabajo (contenido en un circuito cerrado) que 
entra a un turbogenerador para producir electricidad. El vapor condensado sale como agua desalinizada [NREL, 2012a].

En Hawái, se han probado con éxito sistemas OTEC de ciclo cerrado (1999, 250 kW) y de ciclo abierto (1993, 50 kW) pero la inversión inicial sigue siendo muy alta para su implementación a nivel comercial. Las instalaciones pueden construirse (i) en tierra firme, (ii) sobre plataformas costa afuera a no más de 100 metros de la costa y a profundidades que oscilen entre 10 y 30 metros de profundidad, (iii) mar afuera como instalaciones flotantes o como embarcaciones autopropulsadas que utilizan la energía generada en producción de productos como hidrógeno, metanol o amoníaco. El sistema requiere la instalación de una tubería de gran diámetro para la toma de agua fría de las profundidades del mar que debe extenderse una distancia de 1000 metros o más bajo el mar, hasta alcanzar una temperatura de aguas profundas suficientemente baja para obtener un gradiente con la temperatura de superficie de al menos $20{ }^{\circ} \mathrm{C}$. [NREL, 2012a]

De acuerdo a la localización de las instalaciones, los costos de instalación de la tubería pueden alcanzar un $75 \%$ del costo total del sistema. Las instalaciones costa afuera requieren menos trayecto de tubería pero son menos estables que los sistemas en tierra y se ven sometidas a condiciones ambientales que en eventos extremos puedan resultar en daños importantes o en su destrucción. Adicionalmente se requiere de cables sumergidos para la electricidad a tierra firme donde podrá enviarse a la red de distribución. Las instalaciones en tierra requieren una tubería más larga pero tienen una probabilidad menor de verse afectadas por temporales o mal tiempo y permiten operar en forma conjunta con industrias relacionadas como cultivos de especies marinas o aquellas que requieran agua desalinizada [NREL, 2012a; Josey, 2008].

\subsection{3. Impacto sobre el ambiente y consideraciones finales}

La diferencia de temperatura existente entre la superficie del mar y sus aguas profundas puede ser convertida en energía útil al hombre sin arrojar emisiones de gases a la atmósfera y sin contaminar con desechos al ambiente; sin embargo, la 
construcción de las plantas OTEC y el tendido de tuberías en aguas cercanas a la costa pueden causar daño localizado a arrecifes y los ecosistemas del sitio.

Plantas OTEC han sido probadas a muy pequeña escala y no se ha demostrado su viabilidad económica a escala comercial. Las plantas deben estar localizadas en sitios donde exista un gradiente de temperatura superior a $20^{\circ} \mathrm{C}$ que se mantenga a lo largo del año; y preferiblemente, las aguas profundas deben estar disponibles lo más cerca de la costa para una operación económica satisfactoria. Sin embargo, la conversión de la energía térmica oceánica constituye una fuente energética alternativa para el grupo de islas tropicales que reúnen las condiciones para la explotación del recurso y que dependen fuertemente del combustible importado. El desarrollo de esta alternativa puede proveer a las comunidades que allí habitan de la energía necesaria para sus actividades regulares así como de agua desalinizada y el comercio de especies marinas cultivadas en lagunas alimentadas con el agua rica en nutrientes de las profundidades del océano. Hoy día, se trabaja en la posibilidad de convertir el desarrollo tecnológico alcanzado en alternativas económicamente viables a escala comercial.

\subsubsection{Vientos}

Los vientos, producto de una serie de mecanismos como la rotación de la tierra, la energía térmica que viene del sol, los gradientes de temperatura entre la tierra y el mar, y los efectos físicos de montañas y otros obstáculos [WEC, 2007], constituyen una fuente doméstica, limpia e inagotable de energía que puede convertirse en otros tipos de energía útil para el hombre. El recurso es abundante y está ampliamente distribuido en el mundo, de tal manera que su aprovechamiento puede contribuir en forma significativa a suplir la demanda energética en cada país. Su utilización como fuente de energía no arroja gases invernadero a la atmósfera, y no contamina corrientes de agua ni produce desechos sólidos que afecten el ambiente; por ello, en estos tiempos de gran preocupación por el calentamiento global y por la conservación del ambiente en general, constituye una alternativa energética de interés para los países desarrollados y menos desarrollados del mundo.

\subsubsection{Tecnología de captación y conversión}


La conversión de la energía cinética del viento, en electricidad o en energía mecánica útil para molinos de granos, bombas y similares, es un proceso que requiere una turbina de viento, un generador y equipos de control e interconexión. Una turbina de viento dispone de dos o tres aspas y se coloca sobre una torre elevada tubular de acero; en la mayoría de los casos, con el eje de rotación del rotor paralelo a la dirección del viento. Cuando el viento circula entre las hojas de la turbina, las hace rotar y mueve un eje conectado a un generador de electricidad. Un sistema de control monitorea y ajusta la inclinación de las aspas para controlar su velocidad de rotación y regular la potencia de salida; o en el caso de rangos muy elevados de velocidad de viento (20-25 m/s), sacar las aspas de la influencia de este último, para evitar posibles daños [WEC, 2007].

Las turbinas de viento pueden utilizarse en forma independiente o pueden estar integradas formando una 'granja eólica' con decenas de plantas, conectada a la red de distribución y cuyo tamaño varía de acuerdo a las especificaciones requeridas. Hoy día, existen turbinas de viento instaladas en tierra firme con un diámetro de rotor que varía entre 60 y $80 \mathrm{~m}$ y una potencia de $3 \mathrm{MW}$. En el caso de turbinas de viento instaladas costa afuera, la potencia llega hasta $6 \mathrm{MW}$ y su diámetro de rotor es superior a 100 metros [WEC 2010].

El uso de los grandes equipos se ha incrementado porque liberan más energía y resultan relativamente menos costosos. Adicionalmente, la eficiencia de los equipos es un poco mayor, en parte, porque el rotor está más elevado sobre el terreno e intercepta vientos con una velocidad más elevada [WEC, 2010].

Los desarrollos pequeños, típicamente con capacidad menor a $10 \mathrm{~kW}$, se utilizan principalmente en áreas rurales donde pueden constituir una solución rápida y sencilla al problema energético de regiones apartadas con una gran carencia de electricidad.

\subsubsection{Potencial, capacidad instalada y producción}

La tabla 3.2 resume información, extraída de los mapas de Czisch (2001) y Archer (2005), sobre las zonas con los mayores potenciales energéticos del viento en tierra firme. 
Tabla 3.2. Zonas de interés por la intensidad de sus vientos, por continente.

\begin{tabular}{|l|l|}
\hline \multicolumn{1}{|c|}{ REGION } & \multicolumn{1}{c|}{ ZONAS } \\
\hline África & $\begin{array}{l}\text { Costas norte y suroeste, algunas } \\
\text { áreas en el norte del continente. } \\
\text { Costas del este, algunas áreas en el } \\
\text { centro del continente } \\
\text { Costas del norte especialmente a lo } \\
\text { largo del Mar del Norte, } \\
\text { Norteamérica } \\
\text { Costas del este y del oeste de } \\
\text { Canadá y Estados Unidos, región de } \\
\text { los Grandes Lagos. } \\
\text { Costas del sur, algunas áreas en el } \\
\text { sudeste del continente } \\
\text { Oceantas este y sur, isla de Tasmania, } \\
\text { gran parte de Australia. }\end{array}$ \\
\hline
\end{tabular}

Fuente de datos: Mapas 2000 Archer C. 2005 y Czisch, 2001

Las zonas costeras y algunas zonas montañosas de todos los continentes tienen las mayores intensidades de vientos. Adicionalmente, existe un potencial energético importante en los vientos que soplan sobre los océanos, especialmente en la franja entre los $40^{\circ}$ y $60^{\circ}$ de latitud aproximadamente, en ambos hemisferios [Czisch, 2001]. El aprovechamiento del viento oceánico es una alternativa preferida a otras formas de generación en zonas donde el terreno es un recurso escaso y los vientos costa afuera son fuertes, como es el caso de Dinamarca y otros países al norte de Europa. Su uso depende, entre otras cosas, de la profundidad del mar en las posibles localizaciones.

El potencial energético global del viento que puede ser interceptado y convertido en electricidad fue estimado por Lu y otros colaboradores [2009], en aproximadamente $870 \mathrm{PWh} /$ año $\left(870 \times 10^{15} \mathrm{Wh}\right)$; de esta cifra, aproximadamente un $82 \%$ corresponde al potencial del viento que sopla sobre tierra firme y el resto a vientos oceánicos. A efectos de la estimación efectuada por Lu, (i) el terreno disponible para el aprovechamiento de la energía eólica excluyó el espacio ocupado por ciudades, bosques y similares; y (ii) la localización de los desarrollos costa afuera, se limitó a una franja menor o igual $92,6 \mathrm{Km}$ de la línea costera, a profundidades iguales o inferiores a 200 metros. El estimado final incluye además UNIVERSIDAD POLITÉCNICA DE VALENCIA. TESIS DOCTORAL. Violeta Parodi 
pérdidas de $20 \%$ del potencial energético teórico para potenciales desarrollos en tierra firme; y del 10\% para desarrollos costa afuera [Lu et al., 2009].

Para el año 2010, la capacidad instalada en turbinas de viento alcanzó 196,6 GW lo que representó un $23,6, \%$ de crecimiento con relación a la capacidad instalada en el año 2009. Para el mismo año, la producción mundial de electricidad generada por turbinas de viento alcanzó 430 TWh lo que representó un 2,5\% de la demanda global de electricidad. Un total de 83 países usaron energía eólica para producir electricidad en una base comercial; en algunos de ellos, el viento constituyó una de las fuentes más importantes de electricidad, como en el caso de Dinamarca donde representó un $21 \%$ de la energía consumida por el país; en Portugal, España y Alemania, la misma fracción representó $18 \%, 16 \%$ y $9 \%$ respectivamente [WWEA, 2011].

La figura 3.25 muestra la capacidad global instalada de turbinas de viento para el año 2010 y su distribución por países. Estados Unidos, China, Alemania, España e India totalizaron alrededor del $74,2 \%$ de la capacidad mundial instalada [WWEA, 2011]. Por continentes, Europa lidera el sector con un $43,7 \%$ de la capacidad total instalada, seguida por Asia $(31,1 \%)$ y Norteamérica $(22,5 \%)$; sin embargo, es Asia quién encabeza las nuevas adquisiciones de turbinas de viento con un $54,6 \%$ del total instalado.

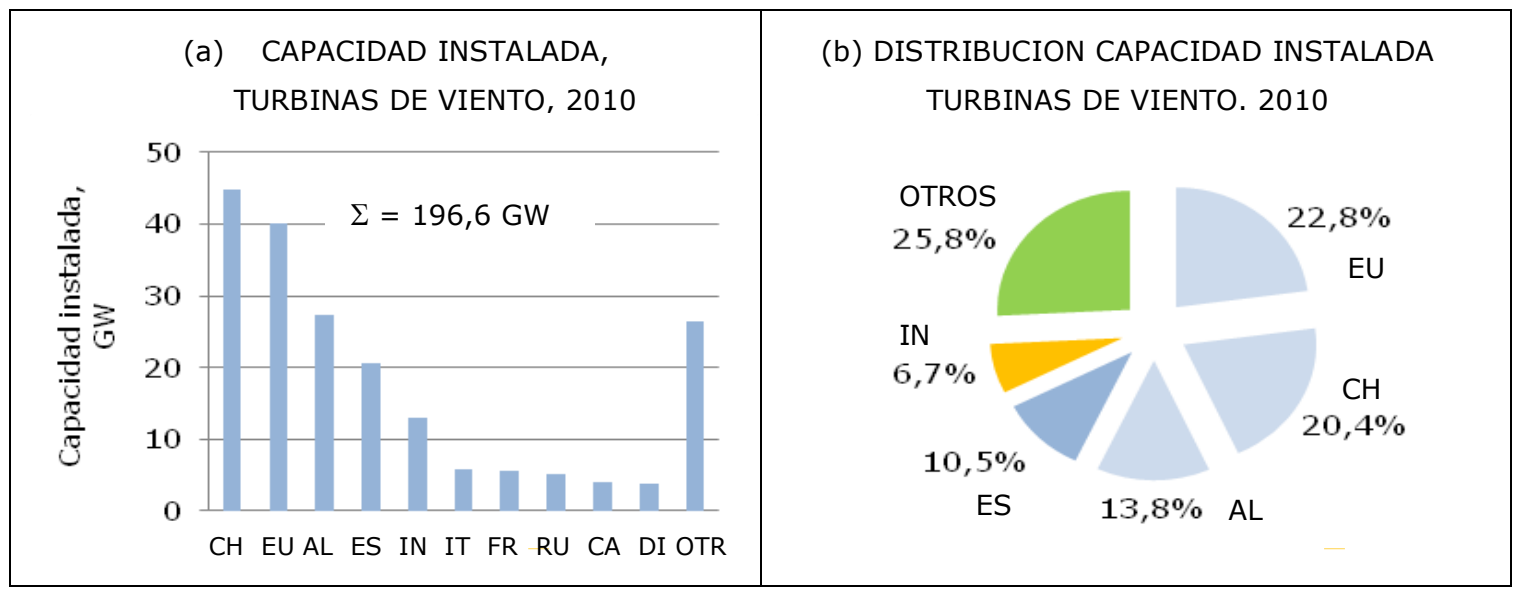

CH: China EU: Estados Unidos AL: Alemania ES: España IN: India IT: Italia FR: Francia RU: Reino Unido CA: Canadá DI: Dinamarca OTR: Otros 2011.

Figura 3.25. Capacidad instalada de turbinas de viento, 2010 
En Latinoamérica, con excepción de Brasil (320 MW) y México (105 MW), el aprovechamiento de la energía eólica es prácticamente nulo. Para el año 2010, la capacidad total instalada de turbinas de viento no llegó a 2 GW [WWEA, 2011].

Para el mismo año, la capacidad instalada mundial de turbinas de viento costa afuera alcanzó aproximadamente $3,1 \mathrm{GW}$ lo que representó un $1,6 \%$ de la capacidad mundial instalada para el mismo año [WWEA, 20101]. La figura 3.26 muestra su distribución por países, en valores absolutos y en valores porcentuales. Como puede observarse, el Reino Unido, Dinamarca, Holanda, Bélgica y Suecia totalizan aproximadamente el $90 \%$ de la capacidad mundial instalada de turbinas de viento costa afuera; y de ellos, los dos primeros representaron un 70,4\% de la capacidad total en turbinas de viento costa afuera. [WWEA, 2011].

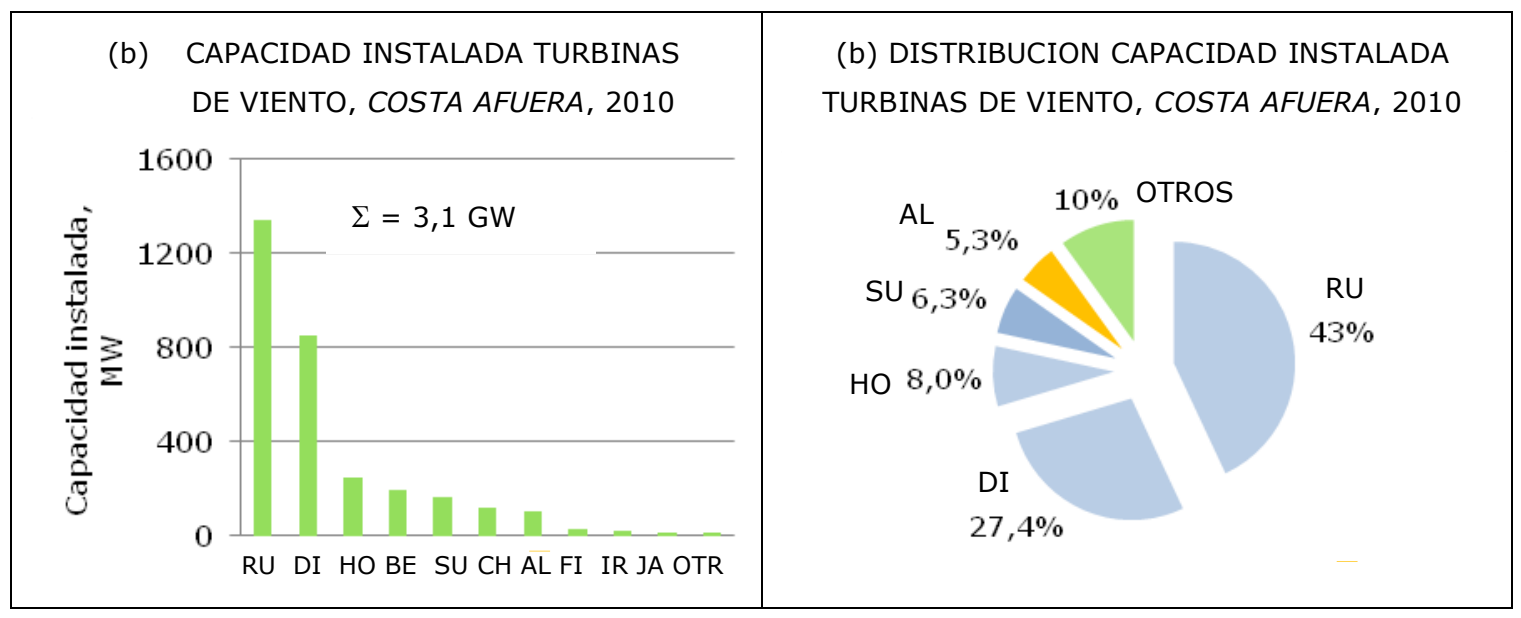

RU: Reino Unido DI: Dinamarca HO: Holanda BE: Bélgica SU: Suecia CH: China AL: Alemania

FI: Finlandia IR: Irlanda JA: China OTR: España y Noruega. Fuente de Datos: WWEA, 2011.

Figura 3.26. Capacidad instalada de turbinas de viento costa afuera, 2010.

\subsubsection{Impacto sobre el ambiente y consideraciones finales}

Los vientos son una fuente de energía variable. Su velocidad, su densidad y las características de la turbina envuelta en el proceso de su aprovechamiento influyen en la cantidad de electricidad producida. Si la velocidad del viento es baja, no se produce electricidad; y si es muy alta, la turbina se detiene para evitar daños. De esta forma, la salida de una sola turbina puede variar grandemente cuando la 
velocidad del viento varía; sin embargo, la potencia de salida se hace menos variable si se conectan mayor cantidad de turbinas a la red; ello requiere de extensiones de terreno importantes.

La cuidadosa elección del sitio donde instalar el grupo de turbinas de aire puede eliminar o atenuar la resistencia de la comunidad a su instalación, ante problemas de afectación del paisaje especialmente notable cerca de las playas o en zonas escénicas tierra adentro, el ruido que producen las aspas al rotar y los dispositivos de transmisión y control con la operación de las turbinas, las interferencias a las señales de comunicaciones, el posible daño a pájaros cuya ruta de migración se cruce con ellas y la ocupación de grandes lotes de terreno aún cuando estos puedan compartirse parcialmente con otros usos como la agricultura. El cumplimiento de las normas para la protección de la salud del ser humano y su hábitat; y la participación de la comunidad afectada en la elección, ayudarán a encontrar el balance más conveniente a todos.

El viento es una fuente de energía renovable, abundante, ampliamente distribuida; y si es necesario, explotable a pequeña escala para suplir las necesidades eléctricas de comunidades rurales sin acceso a la red principal de distribución; su uso no produce emisiones de gases tipo invernadero y sus efectos sobre el medio ambiente son tolerables si se comparan con los efectos de otras fuentes de energía.

En la última década, el uso del recurso eólico para la generación de electricidad ha crecido rápidamente. La continuidad de su desarrollo dependerá en gran medida del compromiso de los gobiernos por reducir las emisiones de dióxido de carbono a la atmósfera, del desarrollo de la tecnología para su uso a costos competitivos con el de otras fuentes de energía, de la confianza que genere como medio para incrementar la seguridad energética y de su aceptación sobre otras fuentes energéticas por parte de la comunidad internacional.

Estimados basados en las políticas que se han implementado en muchos países y en la tasa de crecimiento de instalación de turbinas de viento, ubican la participación 
de la energía eólica a nivel global, en aproximadamente $600 \mathrm{GW}$ para el año 2015 y en 1500 GW para el año 2020 [WWEA, 2011].

\subsubsection{Radiación solar}

La radiación solar es una fuente de energía limpia, inmensa, inagotable y sin costo alguno; sin embargo para poder utilizarla hay que recolectarla, transformarla y distribuirla lo que conlleva inversiones muy grandes; por ello entre otras causas, su modesta contribución al suministro energético mundial actual.

La radiación solar anual que recibe la superficie terrestre es aproximadamente igual a 3.400.000 EJ [WEC, 2007]; así, si sólo se aprovechase un 0,15\% de este total con una eficiencia de conversión y distribución del 10\%, podría cubrirse el suministro mundial de energía primaria que para el año 2008 alcanzó unos 500 EJ ${ }^{49}$ [IEA, 2011a].

El flujo de radiación solar por unidad de tiempo o irradiancia solar que entra a la capa exterior de la atmósfera es en promedio igual a $342 \mathrm{~W} / \mathrm{m}^{2}$ de superficie terrestre $^{50}$. Aproximadamente un $30 \%$ de este flujo es reflejado y devuelto al espacio por las nubes, aerosoles y otros gases en la atmósfera; y en menor proporción, por la superficies continental y oceánica del planeta. De esta forma, el promedio de flujo de energía solar que es absorbido por el planeta y su atmósfera está alrededor de $240 \mathrm{~W} / \mathrm{m}^{2}$; de ellos, unos $170 \mathrm{~W} / \mathrm{m} 2$ son absorbidos en promedio por la superficie terrestre. El resto es absorbido por la atmósfera terrestre [Uriarte 2010; IPCC, 2007].

Suministro mundial de energía primaria $2009=12.150$ Mtep; 1 Mtep = 41,868 T] [IEA. 2010a].

50 Irradiancia o densidad de flujo electromagnético solar es la cantidad de energía solar radiante que incide sobre una superficie por unidad de tiempo y por unidad de área. La irradiancia solar extraterrestre promedio a una distancia media entre el Sol y la Tierra, sobre una superficie normal (área $=\pi \mathrm{R}^{2}$, R: radio terrestre) al haz solar es de $1367 \mathrm{~W} / \mathrm{m}^{2}$ y se conoce como constante solar. Si este flujo de radiación solar se distribuye sobre la superficie de la esfera terrestre (área $=4 \pi R^{2}$ ), se reduce a una cuarta parte de su valor; esto es, a un promedio de $342 \mathrm{~W} / \mathrm{m}^{2}$ de superficie terrestre [WEC, 2007]. 


\subsubsection{Irradiancia solar promedio}

El flujo de energía solar que alcanza la superficie del planeta, lo hace en forma directa o en forma difusa. La radiación directa (DNI, por sus siglas en inglés) llega a la superficie terrestre en línea recta desde el Sol sin sufrir ningún tipo de desviación, mientras que la radiación difusa viene desde cualquier dirección después de haber sido reflejada varias veces en su paso a través de la atmósfera. La radiación directa excede en mucho a la radiación difusa en días claros y en localizaciones tropicales; o viceversa, la radiación difusa es mayor que la radiación directa en altas latitudes y en días nublados. Otras variables que pueden afectar la irradiancia solar son la estación del año y la hora del día en que se tome la medición.

La figura 3.27 muestra la irradiancia solar promedio recibida en algunas zonas del planeta. El valor oscila entre un máximo de $275 \mathrm{~W} / \mathrm{m} 2$ en el desierto del Sahara y la península Arábiga, y un mínimo de $75 \mathrm{~W} / \mathrm{m}^{2}$ en la zona Ártica. Otras zonas de alta incidencia solar son el Norte de África con una irradiancia promedio de $250 \mathrm{~W} / \mathrm{m}^{2}$; y el Sur de África, Australia, la región del Caribe, el suroeste de los Estados Unidos y el norte de México con irradiancias medias iguales a $225 \mathrm{~W} / \mathrm{m}^{2}$. Los datos fueron tomados de Uriarte [2010].

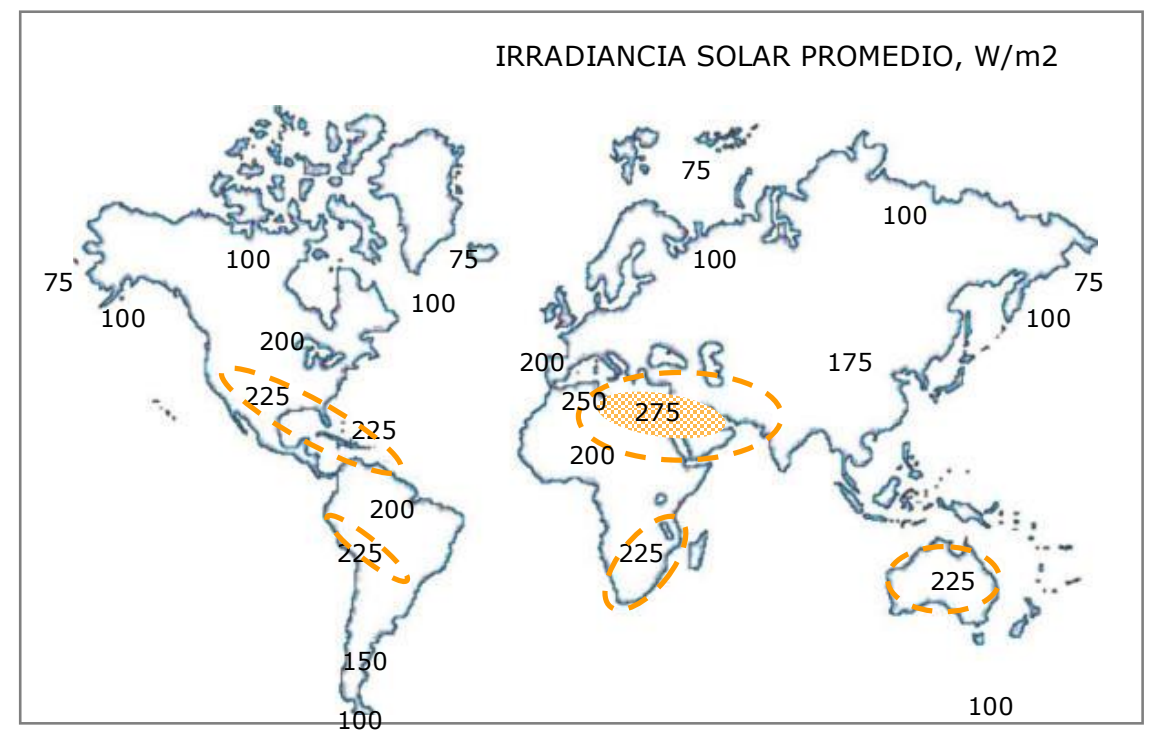

Fuente de datos: [Uriarte, 2010].

Figura 3.27. Irradiancia solar promedio sobre la superficie terrestre. 
El Centro Mundial de Datos de Radiación (WRDC, por sus siglas en inglés), con sede en San Petersburgo, Rusia posee series de mediciones de radiación solar recogidas por muchos años con la ayuda de una amplia red de estaciones en el mundo. El acceso a la información puede realizarse a través de una página web [WRDC, 2010] operada en conjunto con el Laboratorio Nacional de Energía Renovable (NREL, por sus siglas en inglés) del Departamento de Energía en los Estados Unidos. Por su parte, el Centro Aeroespacial Alemán (DLR, por sus siglas en alemán) presenta mapas globales y series de datos de la irradiancia global hemisférica (GHI, por sus siglas en inglés) o cantidad total de radiación solar por unidad de área recibida por una superficie horizontal y de la irradiancia solar directa [DNI, por sus siglas en inglés] o radiación recibida por unidad de área de una superficie que se mantiene en posición perpendicular a los rayos que vienen en línea recta desde el Sol. Para el período 1984-2004, el DNI mundial promedio fue de 145 $\mathrm{W} / \mathrm{m} 2$ y el GHI promedio mundial de $186 \mathrm{~W} / \mathrm{m} 2$ [DLIR-ISIS, 2010]. Los datos actualizados para un sitio seleccionado son muy importantes para el diseño e instalación de sistemas fotovoltaicos y sistemas de concentración de la energía solar cuya descripción se presenta en las páginas siguientes. En general, los países ubicados entre las latitudes $-/+35^{\circ}$, zona conocida como el 'cinturón del sol' se caracterizan por recibir una radiación solar elevada.

\subsubsection{Tecnologías de captación y conversión}

La energía en los rayos del sol puede ser (i) utilizada directamente para calentar agua y/o para calentar o enfriar espacios en hogares, edificios e industrias; (ii) concentrada en focos de alta intensidad para producir electricidad mediante plantas termoeléctricas solares o máquinas térmicas; o (iii) convertida en electricidad utilizando celdas fotovoltaicas. A continuación una breve descripción de las tecnologías dirigidas a satisfacer cada uno de los usos citados.

\subsection{Tecnologías de calentamiento/enfriamiento}

Las tecnologías solares de calentamiento/enfriamiento permiten capturar y utilizar la energía en los rayos del sol para calentar agua y espacios; o para sistemas de aire acondicionado. Los sistemas de calentamiento de agua o espacios para edificaciones 
tienen generalmente dos componentes primordiales, un colector solar y un tanque de almacenamiento.

\subsection{Colectores solares}

Los colectores solares son dispositivos para captar la radiación solar, transformarla en energía térmica y transferirla a un fluido que puede ser agua, un fluido de trabajo o aire. En general, pueden distinguirse dos tipos de dispositivos:

Colectores planos de placa. Este tipo de dispositivo consiste en una caja metálica aislada con una cubierta de vidrio o plástico dentro de la cual se encuentra una placa de color obscuro que absorbe la energía solar la cual se transfiere al fluido que circula dentro de tubos embutidos o adyacentes a la misma. Estos colectores calientan líquido o aire a temperaturas inferiores a $90^{\circ} \mathrm{C}$. Los colectores planos son muy utilizados en los hogares; dada la menor conductividad térmica del aire, los colectores que se utilizan para calentar líquidos son más eficientes que aquellos que se utilizan para calentar aire. Una modalidad alternativa son los colectores planos no vidriados, más económicos y que se utilizan primordialmente en el calentamiento de agua para piscinas [US. DOE, 2011b; Saversolar, 2011; REW, 2004].

Colectores de tubos al vacío. Este tipo de colector utiliza tubos sellados de vidrio con un segundo tubo en su interior sobre el cual se coloca una placa de absorción de energía solar. El aire es evacuado del espacio entre el tubo interno y el externo hasta crear un vacío que permite evitar las pérdidas por conducción o convección de calor. Los tubos se arreglan en filas paralelas y el fluido a calentar fluye por el tubo interno. Con el uso de este tipo de colectores se pueden alcanzar temperaturas entre $90{ }^{\circ} \mathrm{C}$ y $180{ }^{\circ} \mathrm{C}$, haciéndolos más apropiados para aplicaciones de enfriamiento de espacios en centros comerciales y plantas industriales; sin embargo pueden resultar más costosos que los colectores planos de placa [US. DOE, 2011b; Solarsaver, 2011; REW, 2004]. 


\subsection{Sistemas para calentamiento de agua}

Los sistemas solares para el calentamiento de agua pueden ser activos o pasivos. Los sistemas activos utilizan bombas eléctricas para la circulación del agua y son los más utilizados; se diferencian dos modalidades: (i) los sistemas directos o abiertos que bombean agua potable al colector solar donde se calienta y desde donde se envía a un tanque de almacenamiento para ser surtida a los ocupantes del inmueble; y (ii) los sistemas indirectos o de circuito cerrado que en lugar de agua bombean una solución anticongelante al colector solar; la solución caliente se envía a un intercambiador de calor donde cede su calor al agua contenida en un tanque de almacenamiento y es posteriormente devuelta al colector solar para reiniciar el ciclo, sin entrar en contacto con el agua que se utiliza en el inmueble. Esta última modalidad se utiliza en climas con temperaturas muy bajas con peligro de congelación de los fluidos dentro de las tuberías.

Alternativamente, los sistemas pasivos no utilizan bombas para la circulación del agua; los más usados disponen de un tanque del almacenamiento colocado más arriba que el nivel del colector solar en cuya base, procedente de la base del tanque, entra el agua fría; y desde donde se eleva el agua caliente, menos densa, hacia la parte superior del tanque. Otros sistemas disponen de uno o más tanques de almacenamiento colocados en una caja aislada con un lado vidriado de cara al sol que permite el paso de la radiación solar para el calentamiento del agua en ellos contenida [U.S. DOE, 2011b; REW, 2004]

En todos los casos, el tanque de almacenamiento del agua caliente debe estar bien aislado y disponer de un sistema convencional de calentamiento que sirva de respaldo en caso necesario.

\subsubsection{1 .3 . Sistemas para calentamiento de espacios}

Los sistemas solares para el calentamiento de espacios en las viviendas pueden ser pasivos, activos o una mezcla de ambas modalidades. Los sistemas pasivos incorporan en el diseño de la vivienda detalles como grandes ventanales orientados para que capten el calor del sol, y materiales de construcción en paredes y pisos que absorban el calor del sol durante el día y lo liberen en la noche. 
Por su parte, los sistemas activos constan de colectores solares, ventiladores y bombas eléctricas para transferir y distribuir el calor absorbido. El fluido que circula y absorbe calor en el colector puede ser agua, una solución anticongelante o aire. Los sistemas operan de forma similar a los sistemas indirectos para el calentamiento de agua pero tienen una mayor área de colectores, mayores unidades de almacenamiento y sistemas de control más complejos. Generalmente, los sistemas basados en aire emplean un intercambiador de calor aire-agua que permite la transferencia de calor a un sistema de calentamiento de agua que puede usarse paralelamente.

Los sistemas para el calentamiento de espacios absorben energía del sol; y lo transfieren a un espacio interior o a un sistema de almacenamiento desde el cual se distribuye el calor absorbido. Se configuran para suplir entre $40 \%$ y $80 \%$ de las necesidades de calefacción y/o calentamiento de agua de la vivienda. Un sistema de respaldo provee el calor necesario cuando es necesario [NREL, 2009a].

La inversión inicial de los sistemas para el calentamiento de agua y espacios es accesible y puede recuperarse a partir de las economías en la factura eléctrica en un período aproximado de 5 años. Su vida útil oscila entre 25 y 30 años y sus costos de mantenimiento no son elevados [NREL, 2009a].

\subsection{Sistemas para enfriamiento de espacios}

El enfriamiento de espacios puede llevarse a cabo con sistemas de enfriamiento térmicamente activados (TACS, por sus siglas en inglés) por energía solar. Hoy día, los sistemas disponibles incluyen (i) sistemas enfriadores de absorción que utilizan energía térmica para evaporar un fluido refrigerante que enfría el aire objeto del sistema $y$, (ii) sistemas desecantes que utilizan la energía térmica para regenerar desecantes que secan el aire enfriándolo. El costo inicial de este tipo de sistemas es muy elevado; por ello, no se utilizan actualmente [U.S. DOE, 2011a].

\subsection{Capacidad instalada de colectores solares}

A finales del año 2009, la capacidad instalada mundial en operación de colectores solares para el calentamiento de agua y espacios alcanzó un total de 172,4 GW 
térmicos ${ }^{51}$, o su equivalente, 276,2 millones de metros cuadrados ${ }^{52}$ de área de colectores [Weiss y Mauthner, 2011]. La figura 3.28 muestra la distribución de la capacidad mundial instalada de colectores solares para finales del año 2009.

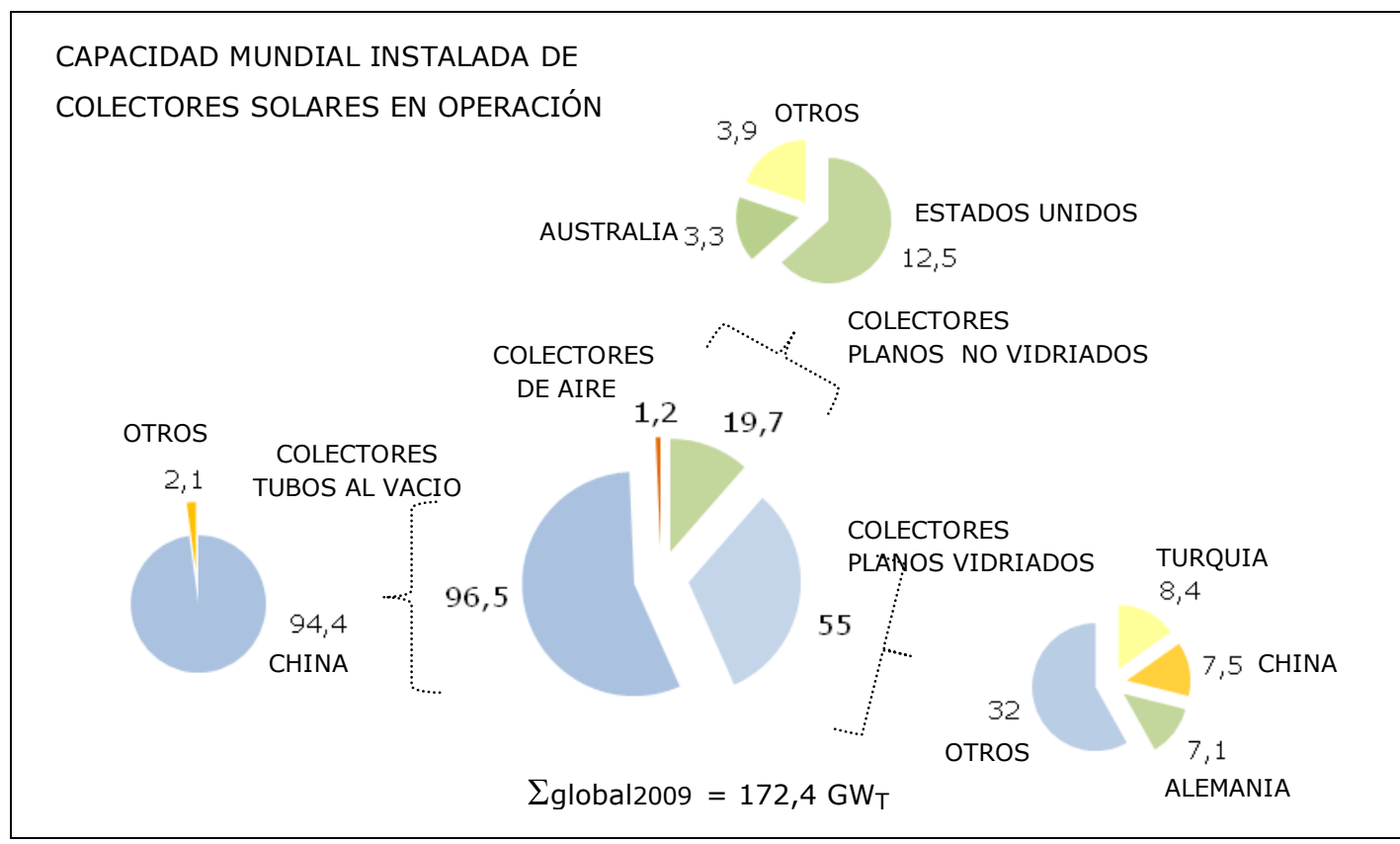

Fuente de datos: [Weiss y Mauthner, 2011]

Figura 3.28. Capacidad instalada de colectores solares en $\mathrm{GW}_{\mathrm{T}}$, por tipo de colector, 2009.

51 La cifra corresponde a la capacidad instalada en operación en 53 países registrados en el informe al que se hace referencia [Weiss y Mauthner, 2011] los cuales representan en conjunto, aproximadamente un $10 \%$ de la población mundial; y la capacidad en ellos instalada, más de o un $90 \%$ de la capacidad mundial instalada.

52 A fin de hacer comparables las cifras de capacidad instalada de los colectores solares, expresadas hasta la fecha en $\mathrm{m}^{2}$ de superficie instalada, y las de capacidad instalada de otras fuentes de energía, un grupo de expertos de Austria, Canadá, Alemania, Holanda y Estados Unidos así como la Federación Europea de la Industria Solar Térmica (ESTIF) y el Programa Calentamiento /Enfriamiento Solar de la Agencia Internacional de la Energía, acordaron en un encuentro conjunto en Gleisdorf, Austria (IEA, 2004), utilizar un factor de $0,7 \mathrm{KW} / \mathrm{m}^{2}$ para convertir la superficie instalada de los colectores solares a su capacidad nominal en $\mathrm{kW}_{\mathrm{T}}$. 
De la capacidad total instalada, $96,5 \mathrm{GW}_{\mathrm{T}}$ corresponde a colectores de tubos evacuados de los cuales un 98\% $\left(94,4 \mathrm{GW}_{\mathrm{T}}\right)$ se encuentran en China; 19,7 $\mathrm{GW}_{\mathrm{T}}$ corresponde a colectores planos no vidriados de los cuales un $62 \%\left(12,2 \mathrm{GW}_{\mathrm{T}}\right)$ se encuentra en Estados Unidos; $55 \mathrm{GW}_{\mathrm{T}}$ es la capacidad instalada global de colectores planos vidriados que están distribuidos en países de todo el mundo entre los cuales se destacan Turquía, China, Alemania, Japón, Grecia, Israel, Brasil y Austria; y la capacidad instalada de los colectores de aire sólo alcanzó $1,2 \mathrm{GW}_{\mathrm{T}}{ }^{53}$ [Weiss y Mauthner, 2011).

Las figuras 3.29 presentan la distribución de la capacidad instalada mundial de colectores solares, para los seis países líderes en el mercado, a finales del año 2009.

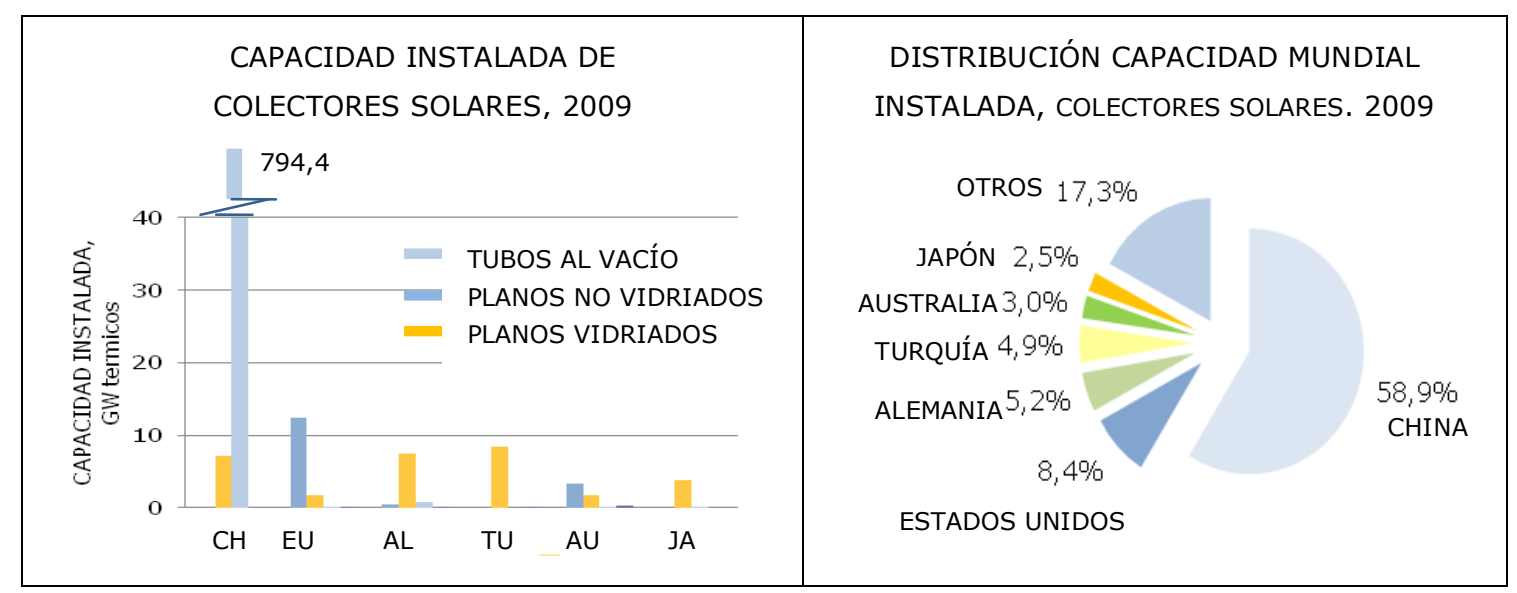

CH: China EU: Estados Unidos AL: Alemania TU: Turquía JA: Japón AU: Australia Fuente de Datos: Weiss y Mauthner, 2011

Figura 3.29. Capacidad instalada de colectores solares, por países, 2009.

Como puede observarse, China ocupa el primer lugar con un 58,9\% de la capacidad instalada global; o en cifras absolutas, 101,5 GW Tran parte de los cuales

53 Las cifras correspondientes a colectores planos no vidriados y a colectores de aire son registradas oficialmente por pocos países; de esta forma, las cifras suministradas son aproximadas. 
corresponden a colectores de tubos al vacío. Estados Unidos ocupa el segundo lugar a nivel mundial con un $8,4 \%$ de la capacidad instalada; o $14,4 \mathrm{GW}_{\mathrm{T}}$ conformados primordialmente por conductores planos no vidriados. La capacidad instalada restante está conformada principalmente por colectores planos vidriados, con excepción de Australia que posee una cantidad importante de colectores planos no vidriados.

Para el año 2009, la cantidad de energía obtenida de los colectores solares fue igual a 142,8 TWh equivalente a 14,4 millones de toneladas de petróleo; ello significó aproximadamente $1,2 \%$ de la demanda de energía primaria global en ese año [IEA, 2009d]. Para el año 2010, la capacidad instalada de colectores solares térmicos en el mundo alcanzó $196 \mathrm{GW}_{\mathrm{T}}$ que rindieron 162 TWh de energía calórica [Weiss y Muahtner, 2011]

Los sistemas solares para el calentamiento doméstico de agua son comunes en diferentes lugares del mundo, con penetración significativa en Australia, China, Europa, Israel, Turquía y Brasil. Por su parte, el número de sistemas solares combinados de calentamiento y calefacción doméstica ha mostrado un rápido crecimiento especialmente en Alemania y Austria; y la tasa de incremento de los sistemas solares de gran escala $\left(\geq 1 \mathrm{MW}_{\mathrm{T}}\right.$ ) para calefacción urbana, es importante en los países escandinavos, Alemania y Austria. Sin embargo, el almacenamiento eficiente del calor recuperado de la luz del sol aún representa un reto a superar [IEA, 2009b].

\subsubsection{Conversión solar fotovoltaica}

La conversión solar fotovoltaica (PV, por sus siglas en inglés) es un proceso de conversión directa de la energía solar a electricidad que aprovecha la propiedad que tienen los elementos semiconductores como el silicio de producir cargas eléctricas cuando rayos de luz inciden sobre él.

Una celda solar es el dispositivo semiconductor más pequeño que utiliza la tecnología fotovoltaica; las más utilizadas, se construyen con cristales de silicio puro al que se introducen impurezas para incrementar su conductividad. Las impurezas, átomos de fósforo en un lado de la celda (silicio tipo ' $n$ ') y átomos de boro en el lado 
opuesto (silicio tipo ' $\mathrm{p}$ '); permiten que se cree un campo eléctrico, positivo de un lado de la celda y negativo del otro. Cuando fotones ${ }^{54}$ de luz caen sobre la celda, golpean y ceden su energía a los electrones que salen de su posición normal en el material semiconductor. Si se conectan conductores eléctricos a los lados positivo y negativo del dispositivo formando un circuito eléctrico, los electrones pueden ser capturados en forma de una corriente eléctrica.

En la búsqueda de mayores eficiencias y menores costos, se utilizan diferentes materiales y diseños para la fabricación de dispositivos fotovoltaicos; sin embargo, más de un $90 \%$ de las celdas que se construyen actualmente están basadas en láminas muy delgadas de silicio mono o multicristalino (200 $\mu \mathrm{m})$ [EC, 2009, U.S. DOE 2011c]. Hoy día, gran parte de la investigación se dirige hacia el uso de arseniuro de galio como uno de los componentes para celdas con múltiples uniones; cuyo uso permite capturar 'en cascada' una mayor porción del espectro solar. Otro material que se investiga para este tipo de celdas es el diselenuro cobre-indio [U.S. DOE, 2011c].

Otra familia importante de celdas fotovoltaicas son las basadas en películas muy finas de silicio amorfo $(1-2 \mu \mathrm{m})$ que se deposita sobre un soporte de vidrio, metal o lámina de plástico. El proceso de fabricación es más rápido, consume menos energía y es menos costoso [EC, 2009; U.S. DOE, 2011c].

\subsubsection{2 . Sistemas solares fotovoltaicos}

Un conjunto de celdas solares conectadas unas con otras y montadas en un soporte o marco conforma un módulo fotovoltaico y se diseña para suplir electricidad a un determinado voltaje. La corriente producida por el módulo depende de la intensidad de luz que incida sobre él y de las características del dispositivo fotovoltaico. A su vez, un grupo de módulos pueden conectarse unos a otros para formar una matriz de módulos fotovoltaicos. Celdas, módulos y matrices de módulos fotovoltaicos producen corriente directa (DC) y pueden ser conectadas en serie o en

54 Un fotón es una partícula de luz que actúa como una unidad energética independiente. 
paralelo para producir la combinación [voltaje-intensidad] que se requiera. Los sistemas fotovoltaicos pueden conectarse a la red eléctrica previa la introducción de un inversor o dispositivo para la conversión de la corriente directa que producen en corriente alterna compatible con la red; o pueden manejarse como un sistema autónomo, fuera de la red. De esta forma, pueden identificarse los siguientes sectores de aplicaciones primarias para los sistemas PV [IEA, 2007; EC, 2009];

- Sistemas domésticos, fuera de la red. Típicamente de capacidad aproximada a 1 $\mathrm{kW}$, constituyen la alternativa más recomendable para satisfacer requerimientos de electricidad para iluminación, refrigeración y similares en hogares y comunidades rurales o alejadas del servicio de la red eléctrica.

- Sistemas no domésticos, fuera de la red. Son una alternativa para proveer energía eléctrica a aplicaciones en las que una pequeña cantidad de electricidad tiene un alto valor; ejemplos de ello se encuentran en las telecomunicaciones, en el bombeo de agua, ayudas de navegación como boyas, faros y similares.

- Sistemas distribuidos, conectados a la red. Se instalan para dar electricidad a un cliente conectado a la red; o directamente, para dar electricidad a la red eléctrica si ella está diseñada para dar servicio a un grupo de clientes más que al transporte masivo de electricidad. Los sistemas pueden estar integrados a las instalaciones del cliente, sobre edificios públicos o comerciales. Su capacidad es variable, así mientras un sistema con $1 \mathrm{MW}$ de capacidad puede ser grande para instalarlo sobre un techo; éste no es el caso, para otro tipo de edificación.

- Sistemas centralizados, conectados a la red. El suministro de energía eléctrica de estos sistemas no está asociado con un cliente en particular, ni localizado para cumplir con otra función más que el suministro masivo de electricidad a la red eléctrica.

Los sistemas fotovoltaicos autónomos representan una solución en áreas remotas donde conectarse a una red eléctrica es más costoso que comprar un sistema PV que opere de forma independiente. Típicamente, tales sistemas suplen las necesidades de electricidad de los hogares en comunidades rurales mediante grupos de paneles PV solares que se instalan en los techos de las viviendas. Los paneles captan la luz 
del sol y la convierten en electricidad DC, la cual a su vez, debe ser convertida a electricidad AC con la ayuda de un inversor, antes de ser enviada al panel de servicios de la vivienda y distribuida a los diferentes equipos eléctricos o al circuito de iluminación del inmueble. Cuando se genera más electricidad que la que se necesita, ella puede ser almacenada en un banco de baterías, como electricidad DC. Las baterías continuarán supliendo de electricidad a la vivienda en horas de la noche; o en general, cuando haya fallas en la energía solar. En general, estos sistemas no conectados a la red disponen de otros respaldos como pequeños sistemas de viento o generadores que utilizan combustibles fósiles, en caso de que las baterías no sean suficientes para suplir las necesidades del inmueble.

Alternativamente, el sistema PV puede conectarse a una red eléctrica de servicio para complementar su suministro de electricidad a la vivienda; y puede disponer o no de un banco de baterías. En cualquiera de los dos casos, el exceso de electricidad puede ser exportado a la red eléctrica; o por el contrario, la red puede proporcionar electricidad a la edificación cuando no haya suficiente energía solar para producir electricidad; por ejemplo, en días nublados o en las noches. La contabilidad del flujo de energía importado o exportado desde la vivienda, puede ser llevada por un medidor que opere en ambas direcciones, asegurando que la misma sólo pague por la energía adicional que obtenga de la red; o por el contrario, que reciba un crédito de la empresa que comercializa el servicio, si el balance es favorable a ella. El sistema se conoce como 'medición neta' y opera en algunos países; entre ellos, Estados Unidos y España.

En climas soleados, un sistema solar eléctrico autónomo se diseña para suplir entre $40 \%$ y $50 \%$ de la necesidad energética de una vivienda dependiendo de la orientación e inclinación del techo donde se colocan los paneles solares y de la eficiencia en el uso de la energía en el hogar, entre otras variables. Un sistema típico puede tener una capacidad que oscila entre 1-3 kW [NREL, 2009a].

\subsection{2 . 2. Capacidad fotovoltaica solar instalada}

Para el año 2010, la capacidad instalada mundial de sistemas fotovoltaicos solares alcanzó aproximadamente 40 GW [REN21, 2011]. La figura 3.30a muestra la 
evolución de la capacidad instalada PV para el período 2006-2010 que a nivel global se ha multiplicado por un poco menos de seis. El crecimiento se debió fundamentalmente a los grandes aportes de España (2,6 GW en el 2008) y de Alemania (7,1 GW en 2007-2009). Para el año 2010, la capacidad PV solar instalada aumentó en $17 \mathrm{GW}$ con Alemania (7,4 GW) como el líder en el mercado y hubo incrementos de capacidad importantes en Italia $(2,3 \mathrm{GW})$, República Checa $(1,5$ GW), Japón (1 GW) y los Estados Unidos (0,9 GW)) [REN21, 2011]. Con el apoyo adecuado al sector, se estima que este crecimiento puede continuar y convertir a las tecnologías PV en una opción importante para la generación de electricidad a futuro [EPIA, 2012].

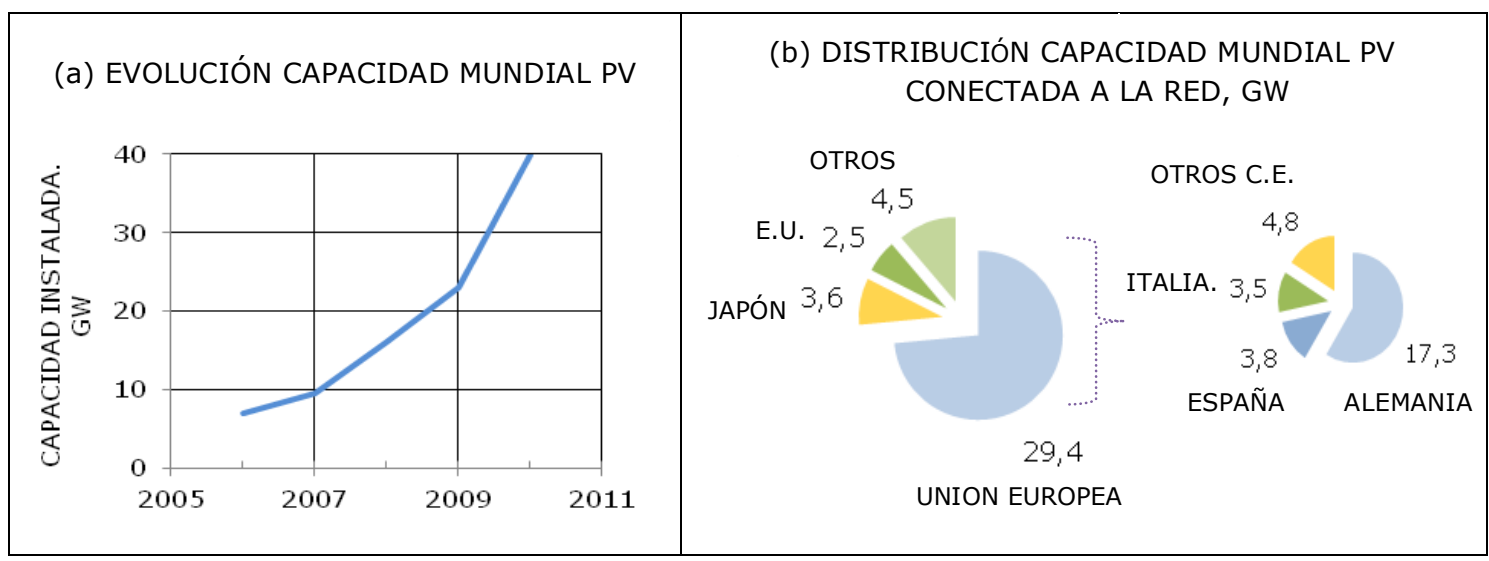

Fuente de datos: [REN21, 2011].

Figura 3.30 (a) Capacidad instalada fotovoltaica solar, 2006-2010.

(b) Capacidad fotovoltaica solar instalada por países, 2010.

La figura 3.30b muestra para el año 2010, la distribución de la capacidad PV instalada en el mundo. La Unión Europea alcanzó 29,4 GW de capacidad; esto es, un $73,5 \%$ de la capacidad global instalada. De esta cifra, un 58,8\% correspondió a instalaciones localizadas en Alemania (17,3 GW), un 12,9\% a España (3,8 GW), un $11,9 \%$ a Italia $(3,5 \mathrm{GW})$ y el restante $16,3 \%$ correspondió a otros países de la Unión Europea. La contribución de otras zonas en el mundo para el mismo año fue relativamente modesta [REN21, 2011].

Para el año 2011, se conectaron a la red 29,7 GW adicionales de los cuales 21,9 GW correspondieron a Europa con aportes significativos de Italia (9,3 GW) y 
Alemania (7,5 GW). De esta forma, la capacidad PV instalada para se aproximó a 70 GW lo que coloca a este tipo de recurso energético como la tercera fuente más importante de energía renovable, a nivel mundial, después de las energías hidráulica y eólica, en cuanto a capacidad instalada se refiere [EPIA, 2012).

La capacidad de las nuevas plantas solares PV se ha incrementado ( $>500 \mathrm{~kW}$ ) en virtud de su mayor eficiencia. En el año 2010, se finalizó la expansión de Sarnia en Ontario, Canadá hasta $97 \mathrm{MW}$, constituyéndose en la planta PV solar más grande del mundo con 1,3 millones de celdas solares de película fina y 950 acres de terreno [energyboom.com, 2010]. Plantas de gran tamaño se han completado en Italia (Monalto di Castro, 84MW y San Bellino, $71 \mathrm{MW}$ ), Alemania (Finsterwalde I, II y II, $80 \mathrm{MW}$ ) y España (Olmedilla, $60 \mathrm{MW}$ ); entre otras [Solarpraxis, 2012].

En el otro extremo, hay un interés creciente por plantas muy pequeñas, no conectadas a la red; entre otras cosas, porque representan una alternativa para los sectores rurales, especialmente en continentes como África, Asia y Latinoamérica.

\subsection{Tecnologías de concentración de energía solar}

Una forma alternativa de producir electricidad es mediante el uso de las tecnologías de concentración de energía solar (CSP, por sus siglas en inglés) que proponen el uso de espejos para reflejar y concentrar los rayos del sol en un foco de alta intensidad calórica que permita la generación del vapor necesario para mover una turbina conectada a un generador de electricidad. CSP es una tecnología probada y confiable pero, a diferencia de las celdas fotovoltaicas que pueden operar con radiación difusa, sólo funciona en lugares con cielos claros y luz solar directa que reciban al menos $2.000 \mathrm{kWh} / \mathrm{m}^{2}$ por año de radiación solar directa [Greenpeace International, SolarPACES y ESTELA, 2009]. Sitios adecuados para CSP incluyen estepas, sabanas, zonas semidesérticas y desiertos, localizados entre $15^{\circ}$ y $40^{\circ}$ de latitud norte o sur; entre ellos, el suroeste de los Estados Unidos, México, el norte de Chile, el norte y el sur de África, el Medio Oriente, España, los países del Mediterráneo, Australia y algunas zonas de Irán, India y Pakistán. Los mejores sitios reciben más de $2.800 \mathrm{kWh} / \mathrm{m}^{2}$ anualmente [Roselund 2010]. 
Los sistemas para la concentración de energía solar están conformados por un campo solar de cierta extensión donde se ubican los dispositivos para reflejar y concentrar la luz solar y por instalaciones para colectar la energía térmica y convertirla en el producto final que es la electricidad. De acuerdo a la forma que se utilice para colectar la energía solar, los sistemas térmico-solares pueden clasificarse en tres grandes grupos que se listan a continuación [U.S. DOE, 2010d; Roselund, 2010],

- Sistemas de concentradores solares lineales

- Sistemas de torre central de concentración solar

- Sistemas de disco parabólico/máquina térmica

A continuación una breve descripción de cada uno de los grupos citados.

\subsection{Sistemas de concentradores solares lineales}

Los sistemas que utilizan concentradores lineales de energía solar (LCSP, por sus siglas en inglés) capturan la energía solar mediante grandes espejos que reflejan y concentran la luz del sol sobre un tubo receptor lineal. A través del receptor circula un aceite sintético especial que se calienta y sale del campo de espejos solares para ser utilizado en la generación de vapor sobrecalentado que alimenta al subsistema turbina-generador que produce electricidad. La intensidad de la luz del sol que incide sobre los espejos y es reflejada, se concentra entre 70 y 100 veces y el fluido dentro del receptor alcanza temperaturas tan altas como $400{ }^{\circ} \mathrm{C}$ [Roselund, 2010]. Cuando el fluido cede su calor para generar el vapor, se enfría y es recirculado al campo solar para ser reutilizado. Alternativamente, puede utilizarse agua como fluido dentro del tubo receptor; en este caso, el vapor se genera directamente en el campo solar eliminando la necesidad de costosos intercambiadores de calor.

El campo solar de un sistema LSCP está conformado por un gran número de colectores instalados en filas paralelas que están típicamente alineados en un eje norte-sur para maximizar la recolección de energía anual. Los colectores están montados sobre un sistema de un único eje que permite que los espejos sigan al sol de este a oeste durante el día, de forma de asegurar que el sol se refleje constantemente sobre los tubos receptores. 
Pueden diferenciarse dos tipos de sistemas LSCP, a saber

Sistemas de colectores cilindro-parabólicos. En este caso, el campo solar está conformado por espejos en forma de parábola arreglados en filas y columnas que concentran la luz solar sobre un tubo receptor el cual se inserta a lo largo de la línea focal de cada espejo, se extiende a todos los colectores en una fila y se une con los receptores de otras filas para salir del campo conduciendo el fluido caliente que se alimentará al sistema de generación de electricidad [U.S. DOE, 2011e].

Sistemas de reflexión lineal Fresnel. En este caso, el campo solar está conformado por espejos planos o ligeramente curvos montados sobre estructuras configuradas de forma tal que reflejen la luz del sol sobre un sistema de tubos receptores colocados en el espacio sobre los espejos. Como en el caso anterior, el sistema receptor se extiende a lo largo de la fila de espejos y se une con los receptores de otras filas para conducir fuera del campo al fluido caliente necesario para el sistema de generación de electricidad. La inversión inicial y la eficiencia de este tipo de sistemas son menores [Roselund, 2010; U.S. DOE, 2010e].

\subsection{Sistemas de torre central de concentración solar}

Los sistemas con torre de concentración central utilizan un campo solar de heliostatos o grandes espejos planos con capacidad de seguir el movimiento del sol para concentrar su luz sobre un receptor localizado en el tope de una torre central. Un fluido de trabajo se calienta en el receptor por efecto del haz solar concentrado y posteriormente se utiliza para producir el vapor requerido por una turbina acoplada a un generador de electricidad.

Los sistemas de torre concentran la luz del sol de 600 a 1000 veces y el fluido de trabajo puede alcanzar temperaturas que oscilan entre $800{ }^{\circ} \mathrm{C}$ y $1000{ }^{\circ} \mathrm{C}$. En general, el fluido de trabajo es agua/vapor; sin embargo, también puede utilizarse aire, otros gases, o sales fundidas. Si se utiliza el aire o un gas presurizado como medio de transferencia, él puede reemplazar al gas natural en las turbinas convencionales de ciclo combinado para producir electricidad. Por su parte, las sales fundidas se utilizan 
en diseños avanzados debido a su capacidad para almacenar energía [Roselund, 2010; U.S. DOE, 2011f]

\subsection{Sistemas de disco parabólico/máquina}

Otros sistemas de concentración de energía solar utilizan un grupo de espejos arreglados en forma de disco parabólico que dirigen y enfocan la luz solar a un receptor localizado en el punto focal del disco. El receptor térmico puede ser un banco de tubos con un fluido, típicamente hidrógeno o helio, que absorbe la energía solar y la transfiere como calor a un sistema máquina/generador que produce electricidad. La máquina de Stirling es el equipo más usado en sistemas CSP de disco parabólico; la máquina usa el fluido de trabajo caliente para mover pistones y obtener energía mecánica que a través de un cigüeñal se convierte en un movimiento de rotación y de allí en energía eléctrica.

Los sistemas disco/máquina térmica producen relativamente poca electricidad, típicamente entre $3 \mathrm{~kW}$ y $25 \mathrm{~kW}$, comparados a otros sistemas de generación de electricidad a partir de energía solar. Pueden operar individualmente en lugares remotos, o combinados en grupo para producir energía eléctrica a mayor escala. Debido a la alta relación de concentración solar que se alcanza con un disco parabólico y al pequeño tamaño del receptor, típicamente el fluido de transferencia puede calentarse hasta $750{ }^{\circ} \mathrm{C}$. Pruebas de sistemas prototipos han mostrado que pueden conseguirse eficiencias de conversión energía solar-energía eléctrica superiores a $30 \%$ que es un valor significativamente más alto que el obtenido con cualquier otra tecnología de conversión solar [U.S. DOE, 2011g].

\subsection{Capacidad instalada CSP}

Las mayores plantas de concentración solar en el mundo utilizan colectores cilíndrico-parabólicos; entre ellas, destacan: el grupo de nueve unidades Solar Energy Generating Systems (SEGS, por sus siglas en inglés) que suman 354 MW, localizadas en el desierto de Mojave, California, U.S; Solnova (150 MW, Sevilla), y Andasol (150 MW, Granada) en España; y Nevada Solar One con 64 MW, Nevada), en Estados Unidos. Ejemplos de aplicación de otras tecnologías de concentración solar son, PS10 (11 MW) y PS20 (20 MW) en Sevilla, España que utilizan el sistema 
de torre de concentración central y Maricopa (1,5 MW) en Arizona, U.S. que utiliza el sistema disco/máquina de Stirling [Hering, 2009].

Estados Unidos y España lideran el sector en cuanto a capacidad instalada se refiere. Para el año 2010, la capacidad instalada mundial alcanzó 1.1 GW cifra de la que un 54,5\% (632 MW) correspondió a España y 45,5\% (509 MW) a Estados Unidos. La capacidad CSP en el resto de los países fue prácticamente nula [REN21, 2011].

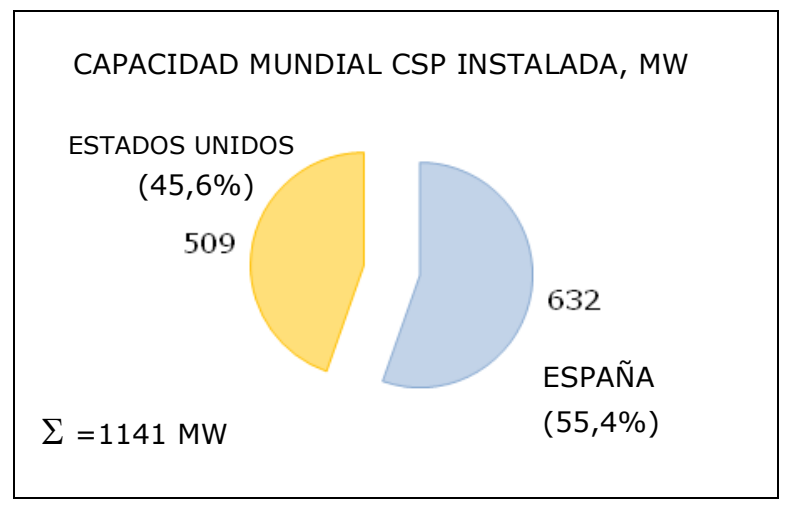

Fuente de datos: [REN21, 2011].

Figura 3.31. Capacidad instalada CSP, 2010.

A nivel mundial, aproximadamente 2,6 GW de capacidad CSP estaban en construcción a finales del año 2010 y se espera entren en operación a finales del año 2014 [REN21, 2011]. Las plantas solares térmicas más grandes en construcción son: el proyecto Ivanpah con 370 MW en el desierto de Mojave en California, Solana (280 MW) en Arizona y Mojave Solar Park (280 MW) en California.

Hay un número importante de proyectos importantes en construcción y/o desarrollo en España [Hering, 2009]; y en menor número en países en vía de desarrollo como Argelia, Egipto, Moroco, Australia, China, India, Israel, México, Suráfrica y los Emiratos Árabes Unidos. Se estima que si todos los proyectos planificados y/o en desarrollo se construyen, la capacidad instalada CSP excederá los 7.4 GW en el año 2016 [IEA, 2011e]. Por otra parte está, la Iniciativa DESERTEC, un plan muy ambicioso para generar electricidad en el desierto de Sahara utilizando CSP, PV y granjas eólicas; y transmitir gran parte de la potencia generada a Europa 
contribuyendo con un estimado de un $15 \%$ a $20 \%$ de las necesidades de ese continente [Roselund, 2010]. El proyecto será una realidad si se establece un marco legal estable que regule la operación entre potenciales exportadores e importadores [IEA, 2011e].

En cuanto a la tecnología más utilizada, el sistema de colectores cilíndricoparabólicos dominó el mercado con aproximadamente un $90 \%$ de la capacidad instalada para finales del año 2010 [REN21, 2011]. La misma característica se mantiene en los sistemas en construcción y/o en desarrollo [IEA, 2011e].

Políticas de apoyo en España y Estados Unidos han incentivado la preparación y desarrollo de nuevos proyectos CSP. Sin embargo, la significativa reducción en los costos de generación con las tecnologías PV harán difícil la presencia significativa de la generación CSP en el mercado [IEA, 2011e].

\subsubsection{Mecanismos de almacenamiento/respaldo al sistema base}

Aunque el sol provee energía limpia, abundante e inagotable, lo hace de forma intermitente y la cantidad y calidad de la radiación que llega a una planta solar está limitada por la hora del día, por la estación del año y por cambios en las condiciones del tiempo. Así para garantizar la salida continua de electricidad, la planta es en general complementada con instalaciones de respaldo que utilizan fuentes alternativas de energía como el viento, el agua o combustibles fósiles; o alternativamente, con un sistema de almacenamiento de la energía excedente durante la jornada, que permita su utilización en el momento que sea necesario.

Los sistemas fotovoltaicos fuera de red utilizan tradicionalmente baterías recargables donde se almacena el exceso de electricidad para utilizarse en períodos donde hay poca o ninguna energía solar. En los sistemas fotovoltaicos que suplen a uno o más clientes, el exceso de electricidad puede ser enviado a la red de transmisión que la devuelve en el momento en que el sistema no pueda cubrir la demanda. Medidores que miden la electricidad que fluye en uno y otro sentido permiten estimar la cantidad neta de electricidad que recibe el cliente. De esta forma, se utiliza la red como un mecanismo para almacenar energía. 
En el caso de sistemas CSP, la energía en exceso puede almacenarse en forma de energía térmica utilizando fluidos de almacenamiento con capacidad calórica elevada como aceite o sales fundidas. El fluido de almacenamiento es almacenado en dos tanques; uno a temperatura baja desde el cual puede dirigirse al colector solar donde adquiere la energía térmica del sol, y desde donde fluye a un tanque de temperatura elevada para su almacenamiento. El fluido en el tanque de temperatura elevada va a un intercambiador de calor donde cede energía para generar el vapor necesario al sistema turbina-generador. El fluido a baja temperatura que sale de los intercambiadores se dirige de nuevo al tanque de baja temperatura para repetir el ciclo [U.S. DOE, 2011h].

Alternativamente, el fluido de almacenamiento puede diferir del fluido utilizado para la generación de vapor. En este caso, hay dos circuitos; uno, a través del cual circula el fluido de almacenamiento que sale del tanque de elevada temperatura, pasa a través de un intercambiador de calor donde se produce vapor para el sistema turbogenerador y regresa al tanque de baja temperatura. El segundo circuito, a través del cual circula el fluido de trabajo que toma energía en el colector solar y luego la cede, en un intercambiador de calor adicional, al fluido de almacenamiento que sale del tanque de baja temperatura y va hacia el tanque de alta temperatura. El uso de este sistema o el descrito en el párrafo anterior es una decisión económica [U.S. DOE, 2011h].

Una tercera opción son los sistemas que almacenan la energía térmica en un medio sólido, comúnmente arena colocada en un tanque único. Durante la operación, una parte del medio se encuentra a temperatura alta; y la otra, a temperatura baja; y entre ellas, existe un gradiente de temperatura. Si el fluido de trabajo entra a temperatura elevada en la zona de alta temperatura, se desplaza a través del medio y sale en la base a baja temperatura. El proceso desplaza la zona de gradiente de temperatura hacia abajo y añade energía al sistema para su almacenamiento. Si por el contrario, entra en la base un fluido frío, se mueve la zona de gradiente hacia arriba y se recupera energía térmica del sistema para su posterior transformación en electricidad. Utilizando un medio sólido para almacenar energía, se necesita sólo un 
tanque lo que disminuye los costos si se compara con el sistema de dos tanques [U.S. DOE, 2011h].

A fin de disponer de ese almacenamiento de energía térmica, los sistemas CSP, y más específicamente los sistemas que usan colectores cilíndricos parabólicos, pueden sobre-diseñarse de forma de captar y almacenar la energía excedente para ser utilizada durante la noche o en climas nublados. También pueden diseñarse de manera que operen en forma híbrida; esto es, respaldados por un sistema que utilice combustibles fósiles; o por el contrario, que un campo solar relativamente pequeño se integre a una gran planta de ciclo combinado alimentada con gas natural. En este último caso, la planta solar aumenta la producción de vapor del ciclo combinado.

Una última alternativa es utilizar el exceso de energía captada para bombear agua desde una elevación inferior a una superior. La energía se recupera cuando sea necesario, liberando el agua a través del sistema bomba-motor que actúa como un sistema turbina-generador cuyo producto es potencia hidroeléctrica.

\subsubsection{Efectos sobre el ambiente y consideraciones finales}

La energía solar puede ser captada y transformada en calor o en electricidad sin emisiones a la atmósfera de gases de tipo invernadero y de otros contaminantes como óxidos de azufre, óxidos de nitrógeno, y partículas. Sin embargo, todas las facilidades solares cuando se usan para generar electricidad a escala comercial requieren superficies relativamente grandes, donde se instalan grandes matrices de colectores solares que pueden interferir con la luz del sol, la lluvia y el drenaje del terreno lo que podría tener efectos sobre la flora y la fauna del lugar; y afectar los usos habituales de las tierras. Adicionalmente, las numerosas filas de superficies altamente reflexivas pueden causar impacto visual; pero no producen ruido. La cuidadosa selección del sitio donde se ubicará el desarrollo solar puede minimizar los impactos sobre el terreno, el ecosistema y el paisaje.

Los paneles fotovoltaicos pueden contener materiales peligrosos como arsénico y cadmio que representan un riesgo potencial para los trabajadores y el ambiente, durante los procesos de construcción y desmantelamiento de los mismos, si ellos no son bien manejados. De la misma forma, los sistemas CSP pueden emplear líquidos 
como sales fundidas o aceites sintéticos que pueden ser peligrosos y presentan riesgos de derrame; igualmente, el manejo de fluidos hidráulicos, refrigerantes y lubricantes. El planeamiento adecuado y buenas prácticas de mantenimiento reducirán los riesgos de contaminación del ambiente por tal causa.

Los sistemas de colectores cilíndricos parabólicos y los sistemas de torre requieren agua de enfriamiento para el ciclo de vapor y para la limpieza de los espejos; tal requerimiento puede representar un problema si la planta se localiza en zonas desérticas. Sistemas de enfriamiento con aire reducen significativamente las necesidades de agua pero resultan más costosos.

Adicionalmente, los sistemas de concentración solar potencialmente pueden producir interferencia con las operaciones aéreas si los haces de luz reflejada son mal dirigidas hacia las rutas de los aviones. Las altas temperaturas envueltas en el proceso pueden significar un riesgo para el ambiente y para la vida en la zona; y como en todas las grandes instalaciones eléctricas pueden producirse campos magnéticos.

Finalmente, la construcción y posterior desmantelamiento de grandes instalaciones industriales y el tendido de nuevas líneas de transmisión, puede causar impactos diversos sobre el ambiente.

La radiación solar es una fuente de energía renovable, inmensa, sin costo alguno y está presente en cada rincón del planeta, aunque es intermitente y no se recibe uniformemente sobre la superficie del globo terrestre. La inversión inicial para la construcción de grandes sistemas de aprovechamiento de la energía solar es muy elevada; sin embargo el sistema es escalable; esto es, puede iniciarse a escala pequeña y expandirse en la medida en que sea necesario. Los sistemas autónomos de menor tamaño constituyen una forma excelente de suministrar energía a lugares aislados donde el costo de instalar nuevas líneas de distribución resultan muy elevados. El aprovechamiento de la energía solar disminuye el consumo de combustibles fósiles; ello contribuye a una mayor independencia energética en cada país y a mejorar el problema del calentamiento global que tanto preocupa al mundo. 
Por las razones expuestas, en los últimos años se ha visto un considerable adelanto en el desarrollo de tecnologías para la conversión de la energía solar en electricidad o en calor directamente aprovechables por el hombre. En la medida en que se mejoren las eficiencias, se reduzcan los costos de inversión y los gobiernos den incentivos para su desarrollo y comercialización, el negocio se hará más atractivo; en la medida en que los materiales y sistemas de almacenamiento se perfeccionen, se expandan las redes de transmisión eléctrica hasta donde sea necesario y el costo de la energía al consumidor se haga competitivo con el de la energía procedente de otras fuentes, el suministro se volverá respectivamente más confiable, más accesible y más aceptado por parte de la población para beneficio de las generaciones futuras.

\subsubsection{Recursos geotérmicos}

La energía geotérmica se origina en el interior de la Tierra como consecuencia del decaimiento radioactivo de algunos isótopos de uranio, torio y potasio; y originalmente, del calor producido en su formación. La Tierra está formada por el núcleo, con temperaturas muy elevadas y cuya capa externa es roca fundida o magma; el manto formado por magma y rocas; y la corteza terrestre que forma los continentes y el fondo del mar. Inmensas cantidades de energía térmica se generan y almacenan en el núcleo, en el manto y en la corteza terrestre. Se estima que las temperaturas en el núcleo de la tierra se encuentran entre $3.500{ }^{\circ} \mathrm{C}$ y $4.000{ }^{\circ} \mathrm{C}$; y en la base de la corteza terrestre, oscilan entre $200{ }^{\circ} \mathrm{C}$ y $1.000{ }^{\circ} \mathrm{C}$ [WEC, 2007].

\subsubsection{Potencial geotérmico teórico}

Los gradientes de temperatura entre las zonas más profundas muy calientes, y las zonas más superficiales menos calientes, generan un flujo de calor desde el núcleo hacia la corteza terrestre que viaja primordialmente por conducción y convección, no uniformemente distribuido; que en promedio se estima equivalente a 42 TW de potencia y que se espera se mantenga por miles de millones de años, asegurando un suministro inagotable de energía [Dickson y Fanelli, 2004; Hulen y Wright, 2001]. 
Eventualmente, el calor que fluye continuamente desde el núcleo de la Tierra hacia afuera, alcanza la superficie; sin embargo, puede permanecer bajo tierra, calentando rocas y agua cercanas, a temperaturas que pueden ser muy elevadas. El agua caliente $\mathrm{y} / \mathrm{o}$ vapor puede permanecer atrapado en rocas porosas bajo una capa de roca impermeable formando un reservorio geotérmico. Manifestaciones de la energía térmica interna que alcanza la superficie de la Tierra son los volcanes, las fuentes termales y los géiseres.

La corteza terrestre se encuentra dividida en placas cuyos bordes son zonas muy fracturadas caracterizadas por una intensa actividad sísmica, por la existencia de un gran número de volcanes debido al ascenso a través de las grietas de materiales muy calientes hacia la superficie, y por un flujo de calor asociado mucho más alto que el valor promedio para la Tierra. Por ello, las áreas geotérmicas más importantes están localizadas alrededor de los límites de tales placas. La figura 3.32 muestra las zonas de potencial geotérmico en el planeta. Las líneas rojas en el diagrama delimitan lo que se conoce como "anillo de fuego", conformado por las regiones con la mayor actividad sísmica en el planeta.

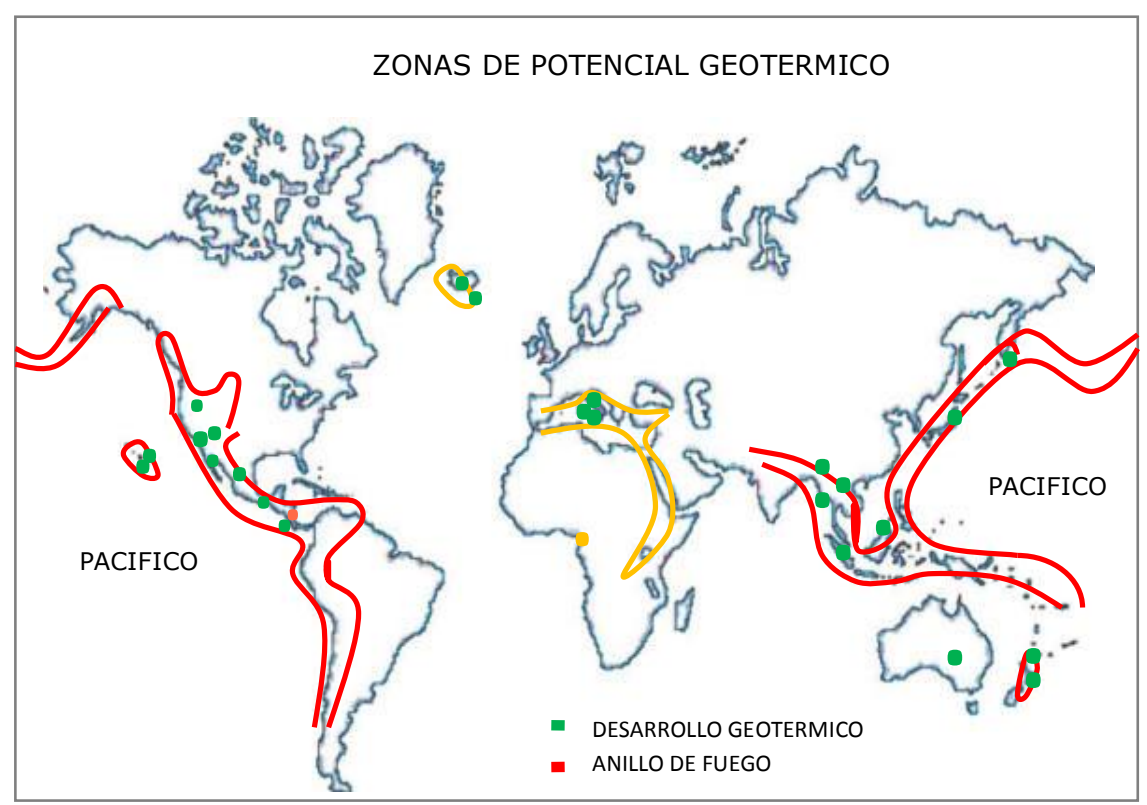

Fuente de datos: Dickson y Fanelli, 2004; Hulen y Wright, 2001

Figura 3.32. Zonas con potencial geotérmico en el mundo 


\subsubsection{Tecnologías de captación y conversión}

Las tecnologías para el aprovechamiento de los recursos geotérmicos varían de acuerdo a la profundidad y temperatura de los mismos. En tal sentido, pueden diferenciarse (i) recursos hidrotérmicos; esto es, una combinación de agua caliente y vapor localizados en rocas porosas bajo la superficie de la tierra a temperatura y profundidad variables y a los cuales se accede por perforación, (ii) recursos en reservorios geotérmicos localizados cerca de la superficie terrestre y (iii) suelos pocos profundos muy cerca de la superficie de la tierra con estabilidad de temperatura a lo largo del año. Aún no se explotan comercialmente, otros recursos geotérmicos existentes en rocas porosas a una presión mucho más elevada que su presión hidrostática; o recursos constituidos por formaciones rocosas secas de alta temperatura.

En correspondencia con la clasificación previamente citada, los sistemas tecnológicos para la explotación de los recursos geotérmicos pueden agruparse en i) sistemas de uso directo del recurso, (iii) sistemas que utilizan bombas de calor geotérmico y (iii) (i) sistemas para la producción de electricidad. A continuación una breve descripción de los mismos [WEC, 2010].

\subsection{Sistemas de uso directo}

Los sistemas de uso directo utilizan recursos geotérmicos localizados cerca de la superficie terrestre o que han aflorado a ella. Así, desde tiempos antiguos y aún hoy en día, las aguas termales se utilizan en los baños públicos; o en su versión actual, los spas. Modernamente, las aplicaciones han crecido en variedad y tamaño e incluyen la calefacción urbana o a viviendas individuales, agua caliente para criaderos de peces e invernaderos de plantas, secado de cosechas y algunos usos industriales.

El acceso al recurso localizado bajo tierra, se realiza mediante la perforación de un pozo hasta el reservorio que sirve como conducto de extracción de la corriente de agua caliente que posteriormente cederá su energía a un uso determinado. Una vez que se ha enfriado, el agua es inyectada bajo tierra o dispuesta sobre su superficie. 
La temperatura de las aguas termales depende de la profundidad a la cual se encuentren y del gradiente geotérmico en la zona. Es común un rango entre $50{ }^{\circ} \mathrm{C}$ y $100{ }^{\circ} \mathrm{C}$ en pozos de profundidad menor a $3 \mathrm{~km}$. Radiadores convencionales o sistemas bajo el piso del inmueble son los dispositivos más utilizados para aprovechar el calor del agua extraída del reservorio geotérmico. Un caso de utilización a gran escala de este tipo de recurso está en la ciudad de Reykjavik, Islandia donde aproximadamente un $90 \%$ de los hogares utiliza agua geotérmica para su calefacción [WEC, 2010].

\subsubsection{Bombas de calor geotérmico}

Los suelos poco profundos, hasta 3 metros desde la superficie, mantienen una temperatura constante entre $10{ }^{\circ} \mathrm{C}$ y $16{ }^{\circ} \mathrm{C}$. De esta forma, la temperatura del suelo es mayor que la temperatura del aire cuando el clima es frío y menor que la temperatura del aire cuando el clima es caliente; y si se utiliza una bomba de calor geotérmico puede transferirse calor de un ambiente a otro permitiendo la calefacción y enfriamiento de espacios.

Una bomba de calor geotérmico está conformada por un grupo de tuberías enterradas en el subsuelo adyacente a la edificación cuyo ambiente se desea acondicionar, la bomba misma y un sistema para la circulación del aire desde o hacia la bomba. A través de las tuberías circula agua o un fluido anticongelante que absorbe calor del suelo y lo transfiere a través de un intercambiador de calor y un sistema de circulación de aire, al ambiente interno del inmueble. En verano, el proceso se invierte y la bomba de calor mueve el calor del aire en el interior del inmueble hacia el fluido en el intercambiador de calor, fluido que luego va al subsuelo. Alternativamente, el calor removido puede ser utilizado para el calentamiento de agua requerido por la edificación.

La bomba de calor geotérmico es una de las tecnologías más limpias y eficientes para la calefacción o enfriamiento de espacios, disponibles hoy en día. Sin embargo, su costo inicial es muy elevado, debido primordialmente al costo de perforación e instalación de las tuberías requeridas en el subsuelo adyacente a la edificación objetivo [NREL, 2012c] 


\subsubsection{2 . Sistemas para la generación de electricidad}

Los recursos hidrotérmicos localizados a profundidades que oscilan entre $1,5 \mathrm{~km}$ y $3,5 \mathrm{~km}$ y temperaturas superiores a $100{ }^{\circ} \mathrm{C}$ pueden utilizarse para la generación de electricidad. El recurso, vapor o agua muy caliente se recupera a través de pozos perforados hasta el reservorio. Las plantas para la producción eléctrica utilizan vapor obtenido de los reservorios para mover las aspas de una turbina que activa un generador de electricidad. De acuerdo al tipo de vapor que utilicen, pueden diferenciarse tres tipos de plantas geotérmicas para la generación de electricidad, a saber:

- Plantas que utilizan vapor seco que sale del reservorio y va directamente a la unidad turbina/generador. The Geysers en el norte de California, U.S. es un ejemplo de reservorio de este tipo que se explota a escala comercial [NREL, 2012b].

- Plantas que utilizan evaporación instantánea de agua muy caliente que sube bajo su propia presión, a través de un pozo perforado hasta un reservorio de elevada temperatura $\left(>180{ }^{\circ} \mathrm{C}\right.$ ) y presión. En la superficie, la presión se reduce y parte del agua se convierte a vapor el cual es alimentado a la unidad turbina/generador. El agua no evaporada y el agua condensada del vapor son devueltas al reservorio. Hoy en día, estas plantas son el tipo más común en operación [NREL, 2012b].

- Plantas de ciclo binario operan con agua de reservorios a temperaturas que oscilan entre $100{ }^{\circ} \mathrm{C}$ y $180{ }^{\circ} \mathrm{C}$. La energía térmica del agua del reservorio es transferida a otro líquido, generalmente un compuesto orgánico con un punto de ebullición más bajo, que es vaporizado y usado para alimentar la unidad turbina/generador. El agua es devuelta al reservorio para ser recalentada e iniciar de nuevo el ciclo. El agua y el fluido de trabajo circulan en circuitos separados cerrados, nunca entran en contacto durante el proceso y no hay emisiones [NREL, 2012b].

La eficiencia de uso de los recursos geotérmicos mejora considerablemente cuando se emplean plantas de cogeneración más que plantas convencionales; esto es, plantas que produzcan electricidad y agua caliente que pueda utilizarse para 
calefacción urbana u otro uso directo. En Islandia operan tres plantas de cogeneración cuya distancia a las ciudades respectivamente más cercanas oscila entre 10 y $25 \mathrm{Km}$, lo que garantiza un mercado grande para el agua caliente [WEC, 2007] y la viabilidad económica de las plantas.

Por otra parte, se ha invertido un considerable esfuerzo en el desarrollo de Sistemas Geotérmicos Mejorados (EGS, por sus siglas en inglés), especialmente en Estados Unidos y Australia. La tecnología contempla inyectar agua a través de uno o más pozos perforados hasta la base de rocas calientes técnicamente accesibles pero de muy baja permeabilidad y contenido de líquido. El agua se inyecta a una presión suficientemente elevada para asegurar la fractura de la roca y/o su extensión dentro del reservorio que se intenta desarrollar. Luego, se perforan pozos de producción que interceptan la zona mejorada con las fracturas, se hace circular agua que extrae el calor de la roca caliente con mejor permeabilidad y luego se sube a la superficie a través de los pozos de producción. Se estima que con la inversión adecuada en investigación y desarrollo, EGS podría incrementar en 100 GW $\mathrm{E}$ la capacidad de generación de los Estados Unidos, en los próximos 50 años [NREL, 2012b;WEC, 2007].

Plantas pequeñas de energía geotérmica ( $<5 \mathrm{MW}$ ) pueden operar en zonas rurales o pueden respaldar la operación del sistema de distribución de electricidad [NREL, 2012b].

\subsubsection{Potencial técnico y económicamente accesible}

El potencial geotérmico técnicamente accesible que aloja la tierra; esto es, el potencial que se estima pueda ser desarrollado en las próximas décadas, con tecnología actual o futura, es de $5.000 \mathrm{GW}_{\mathrm{T}}$ para usos directos y $1.200 \mathrm{GW}_{\mathrm{E}}$, allí incluida la posibilidad de añadir $1.000 \mathrm{GW}_{\mathrm{E}}$ por el desarrollo y uso de técnicas EGS [Bertani, 2010]. Para el año 2050, el potencial geotérmico técnica y económicamente accesible; esto es, aquél que puede ser explotado en condiciones económicamente competitivas, se estima en $800 \mathrm{GW}_{\mathrm{T}}$ para uso directo y en $140 \mathrm{GW}_{\mathrm{E}}$ para producción de electricidad [Bertani, 2010]. 


\subsubsection{Potencia geotérmica instalada}

La figura 3.33 presenta la capacidad instalada para generación de electricidad y para uso directo de los recursos geotérmicos, clasificada por continentes. Para el año 2010, la capacidad mundial instalada en plantas geotérmicas para la generación de electricidad fue de $10,7 \mathrm{GW}_{\mathrm{E}}$ y la de uso directo del recurso, primordialmente calefacción, fue de 50,6 GW [Bertani, 2010].

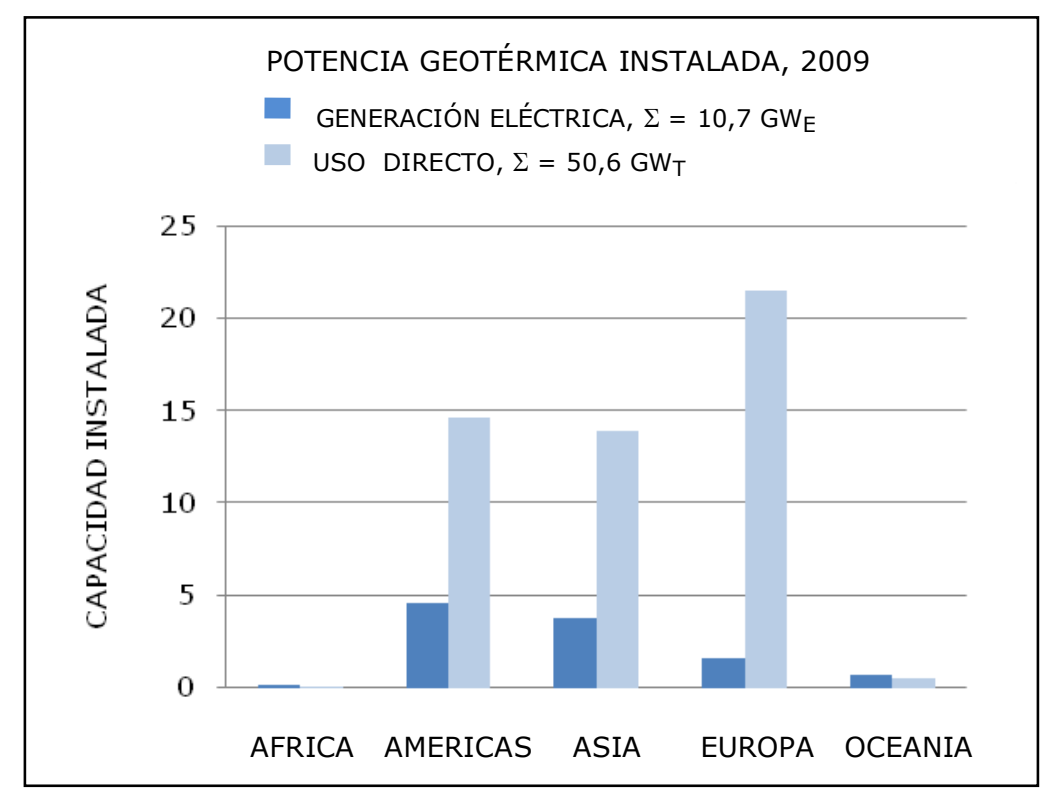

Fuente de datos: [Bertani, 2010]

Figura 3.33. Potencia geotérmica instalada por continente, 2009

Para el año 2010, Norte, Centro y Suramérica muestran el desarrollo de plantas geotérmicas eléctricas más elevado con 4,6 GW $\mathrm{GW}_{\mathrm{E}}$ seguida por Asia $\left(3,7 \mathrm{GW}_{\mathrm{E}}\right)$ y Europa $\left(1,6 \mathrm{GW}_{\mathrm{E}}\right)$. Por la otra parte, la proporción de uso directo del recurso es más elevada en Europa con 21,5 GW Te capacidad instalada que en América $\left(14,6 \mathrm{GW}_{\mathrm{T}}\right.$ ) y Asia $\left(13,9 \mathrm{GW}_{\mathrm{T}}\right)$. La utilización del recurso geotérmico en Oceanía y África es mucho más pequeña [Bertani, 2010].

\subsubsection{Capacidad instalada y producción de electricidad}

La figura 3.34a presenta la evolución para el período [1975-2009] de la potencia geotérmica mundial instalada para producción de electricidad. En el lapso señalado, 
la capacidad instalada se ha multiplicado por ocho alcanzando $10,7 \mathrm{GW}_{\mathrm{E}}$ a finales del año 2009 [Bertani, 2010].

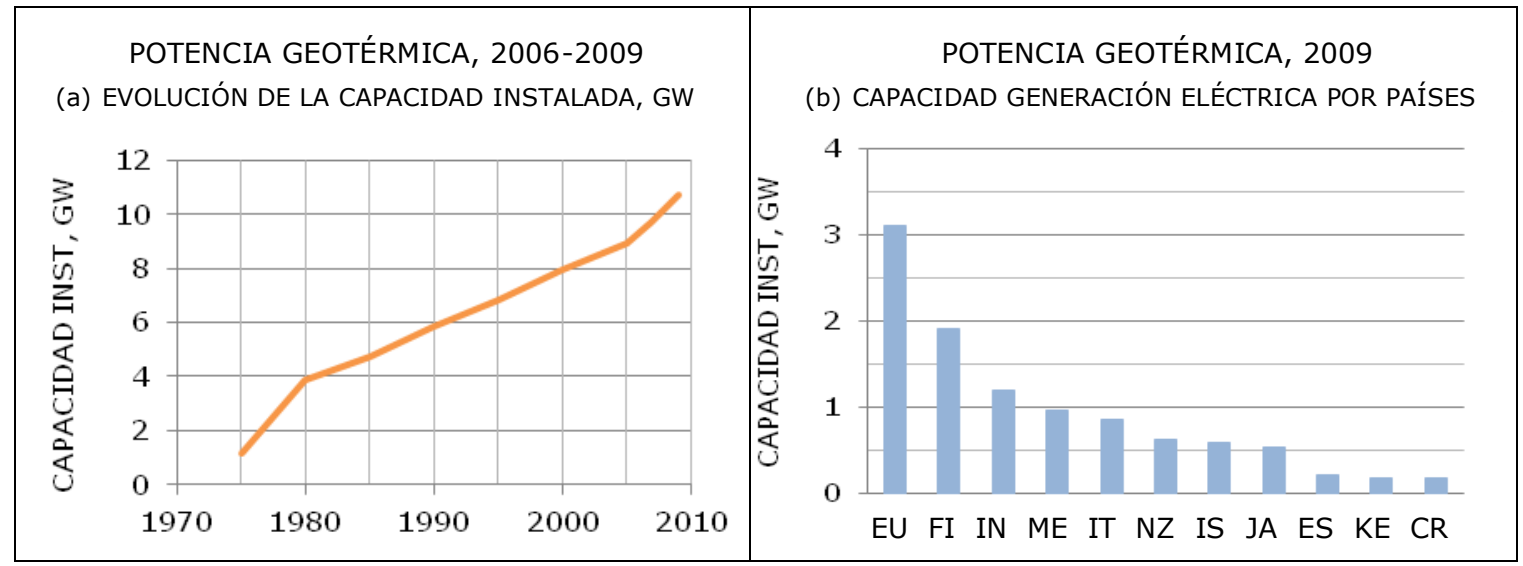

EU: Estados Unidos FI: Filipinas IN: Indonesia ME: México IT: Italia NZ Nueva Zelanda IS: Islandia JA: Japón ES: El Salvador KE: Kenia CR: Costa Rica.

Fuente de Datos: Bertani, 2010

Figura 3.34 (a) Evolución de la capacidad geotérmica instalada para generación de electricidad, 1975-2009.

(b) Capacidad geotérmica instalada para generación de electricidad, por países, 2009.

La figura 3.34b presenta para finales del año 2009, las cifras de capacidad instalada para los países líderes en generación eléctrica de origen geotérmico. Encabezan la lista Estados Unidos (3,1 $\left.\mathrm{GW}_{\mathrm{E}}\right)$, Filipinas $\left(1,9 \mathrm{GW}_{\mathrm{E}}\right)$, Indonesia $(1,2$ $\left.\mathrm{GW}_{\mathrm{E}}\right)$, México $\left(0,96 \mathrm{GW}_{\mathrm{E}}\right)$ e Italia $\left(0,84 \mathrm{GW}_{\mathrm{E}}\right)$. En Centroamérica destacan El Salvador (204 MWE ) y Costa Rica (166 MWE [Bertani, 2010].

Para el año 2009, la producción de energía eléctrica de origen geotérmico alcanzó 67,2 TWh/año [Bertani, 2010]. La figura 3.35a presenta la participación de los países líderes en el total mundial de electricidad producida de origen geotérmico; entre ellos, Estados Unidos ocupó el primer lugar con 16,6 GW $\mathrm{G}_{\mathrm{T}}$.

La importancia que la electricidad geotérmica ha alcanzado en el sector eléctrico de algunos países se muestra en la figura 3.35b. Destacan Islandia (25\%), El Salvador (22\%), Finlandia y Kenia (17\% cada uno), Costa Rica (13\%) y Nueva Zelanda (10\%) [IEA, 2010b; Georgsson y Fridleifsson, 2010]. 


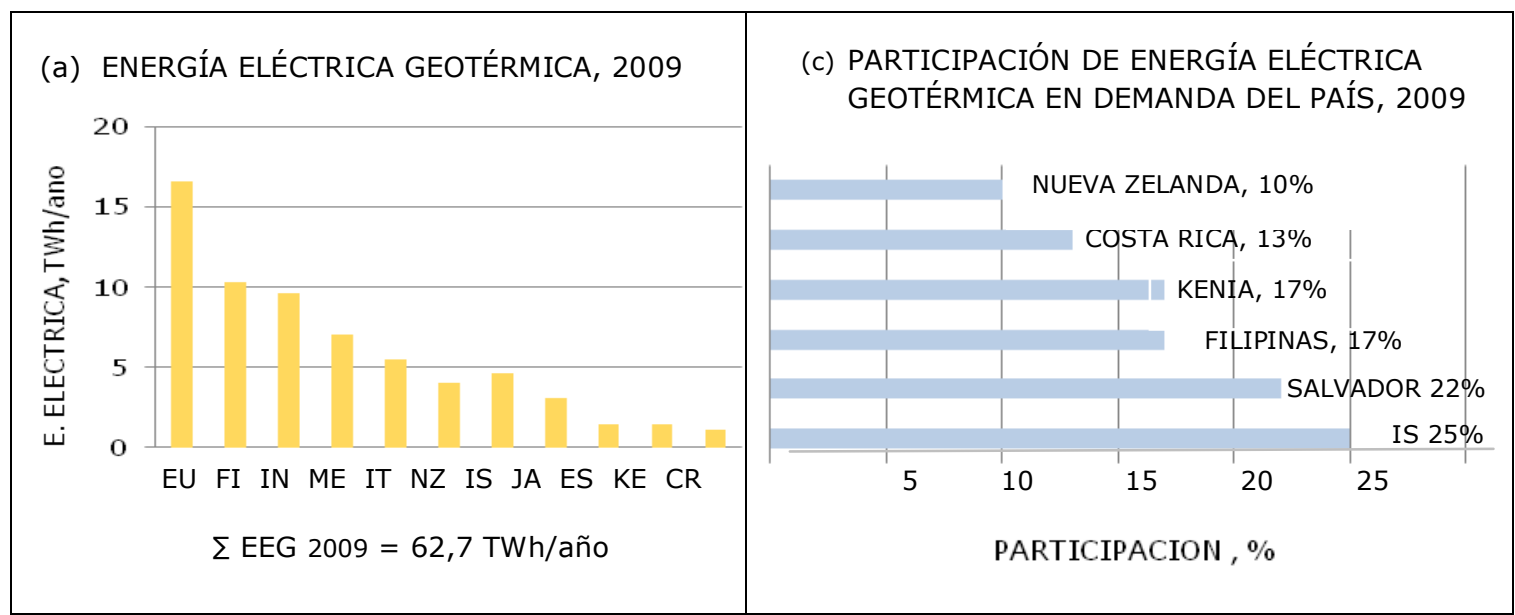

IS: Islandia. Fuente de datos:[IEA, 2010b; Georgsson y Fridleifsson, 2010]

Figura 3.35 (a) Producción de energía eléctrica geotérmica por países, 2009

(b) Energía geotérmica en la demanda eléctrica de cada país, 2009

\subsection{Capacidad instalada y producción de uso directo}

Las figuras 3.37 muestran algunas estadísticas sobre el uso directo de la energía geotérmica durante el año 2009, a nivel mundial.

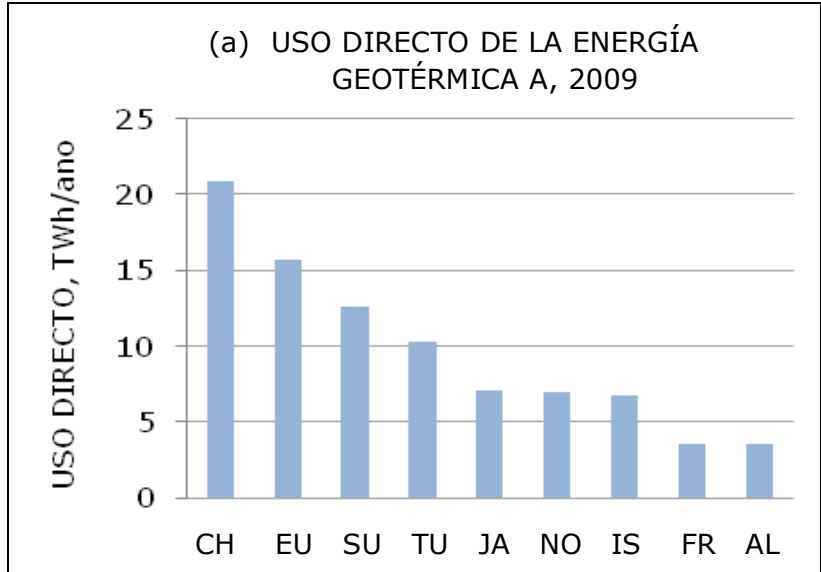

(b) DISTRIBUCIÓN USO DIRECTO DE LA ENERGÍA GEOTÉRMICA, 2009

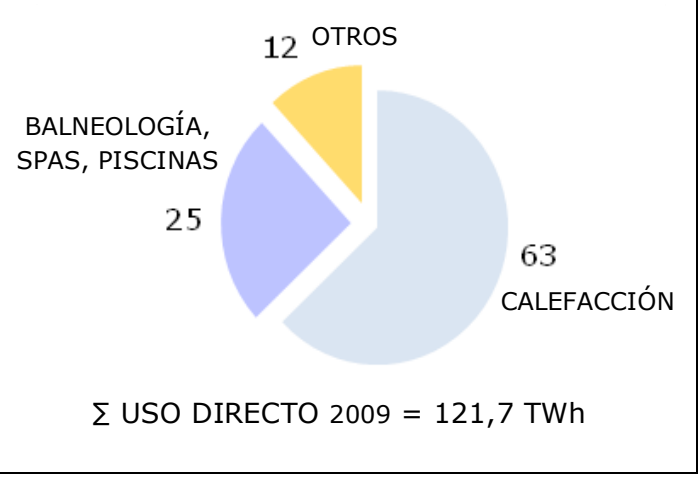

CH: China EU: Estados Unidos SU: Suecia TU: Turquía JA: Japón NO: Noruega IS: Islandia FR: Francia AL: Alemania

Fuente de Datos: [IEA, 2010b, Goldstein et al./IPCC, 2011]

Figura 3.36 (a) Uso directo de la energía geotérmica por países, 2010

(b) Uso directo de la energía geotérmica por aplicaciones, 2010. 
El uso directo de los recursos geotérmicos incluyen primordialmente la calefacción y enfriamiento de ambientes; la balneología o uso de aguas termales ricas en minerales con propósitos medicinales y el uso de aguas superficiales cálidas en spas y piscinas; el calentamiento de viveros (cultivos de vegetales y frutas) y de cultivos de truchas, salmón y otras especies, su aprovechamiento en procesos industriales y secado de productos agrícolas; y finalmente, su aprovechamiento en el fundido de la nieve para mantener limpias las carreteras. Entre ellas, tienen la mayor importancia las dos primeras categorías como se muestra en la figura 3.36b. [Goldstein et al./IPCC, 2011].

Para el año 2009, el uso directo del recurso geotérmico alcanzó 121,7 TWh y la capacidad instalada en 50,6 MWT [Goldstein et al./IPCC, 2011] . Los países líderes en el uso directo del recurso geotérmico fueron China (20,9 TWh/año), Estados Unidos $(15,7$ TWh/año), Suecia (12,6 TWh/año), Turquía (10,3 TWh/año) y Japón $(7,1$ TWh/año) un 55\% del uso directo global anual.

\subsubsection{Efectos sobre el ambiente y consideraciones finales}

La energía geotérmica es una de las alternativas para generar electricidad y para la calefacción de espacios, más amigable con el ambiente, tal como puede leerse en la figura 3.37 que se presenta a continuación.

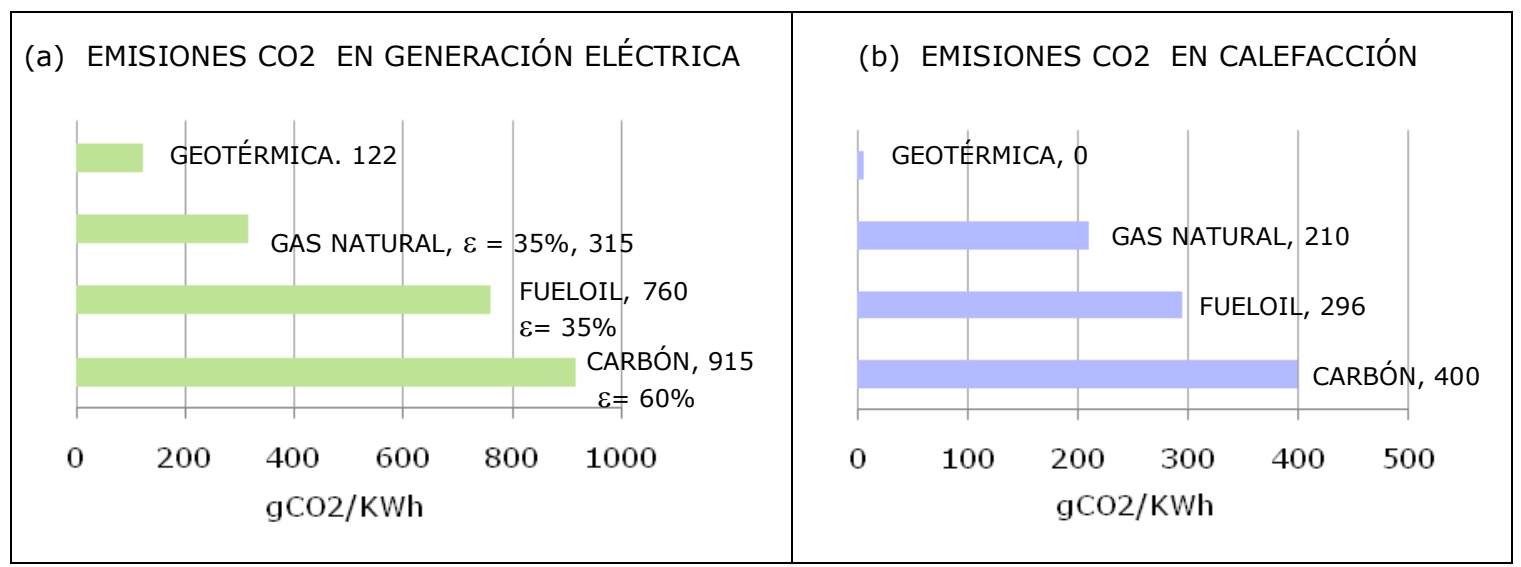

Fuente de datos: Björnsson, 2009

Figura 3.37. Promedio mundial de emisiones de $\mathrm{CO} 2$ en generación de electricidad y en calefacción, por tipo de recurso usado. 
La figura anterior reseña el nivel promedio de $\mathrm{CO} 2$ emitido por kWh producido de energía eléctrica o utilizado en la calefacción de espacios, en base a recursos geotérmicos frente al producido utilizando combustibles fósiles. El valor registrado para la calefacción de espacios utilizando bombas geotérmicas corresponde a la situación en que la energía para su desempeño provenga de fuentes renovables; si no es así, las emisiones se reducen al menos en 50\% comparadas con las emisiones de hervidores operados con combustibles fósiles [Björnsson, 2009].

Adicionalmente, la explotación de reservorios a elevada temperatura puede provocar la emisión de pequeñas cantidades de $\mathrm{NH}_{3}, \mathrm{H}_{2} \mathrm{~S}$ y metano en concentraciones no tóxicas. Por otra parte, los fluidos geotérmicos contienen trazas de sustancias tóxicas como amoníaco, mercurio, radón y boro que son concentradas en el agua residual la cual es rutinariamente reinyectada al reservorio para evitar su vertido al ambiente. Un problema adicional es que los fluidos geotérmicos a elevadas temperaturas pueden ocasionar corrosión sobre las tuberías que los conducen [Björnsson, 2009].

La energía geotérmica es una energía renovable, endógena, potencialmente sostenible y cuya utilización puede contribuir a la mitigación del cambio climático. Sin embargo, la localización geográfica de sitios con las condiciones geológicas y térmicas adecuadas no es simple. La inversión en exploración y perforación de pozos es parte importante del costo inicial y conlleva un riesgo significativo. Recursos geotérmicos de elevada temperatura requeridos para la generación de electricidad están restringidos primordialmente a los bordes de las placas terrestres con alta actividad sísmica o volcánica; actividad ésta que puede acrecentarse por la perforación y/o inyección de aguas (EGS).

En general, las instalaciones para la captación y conversión de la energía geotérmica requieren una extensión de terreno mucho menor que las instalaciones para el aprovechamiento de otras fuentes de energía renovable como el viento y la radiación solar; y el terreno es recuperable en caso de que cesaran las operaciones sobre él [Björnsson, 2009]. En el caso de su aprovechamiento para generación de electricidad, su factor de capacidad promedio esta alrededor de $72 \%$ y puntualmente 
puede llegar a más del 90\%, mucho más elevado que los factores de capacidad para la generación de potencia eléctrica a partir de otras fuentes de energía renovable [Björnsson, 2009]. Ello debido a que el suministro de energía geotérmica no depende de las condiciones del tiempo; o lo que es lo mismo, su suministro es continuo y no intermitente como en el caso de otras fuentes renovables como el viento y la radiación solar a las que puede complementar en caso necesario.

La energía geotérmica es la opción menos costosa para producir electricidad. Así lo concluyen dos estudios realizados por Crédito Suizo (2009) y el Banco Mundial (2007). A modo de referencia, el gráfico que sigue presenta los costos nivelados ${ }^{55}$ por MWh de electricidad producida publicadas por Crédito Suizo al respecto [Björnsson, 2009].

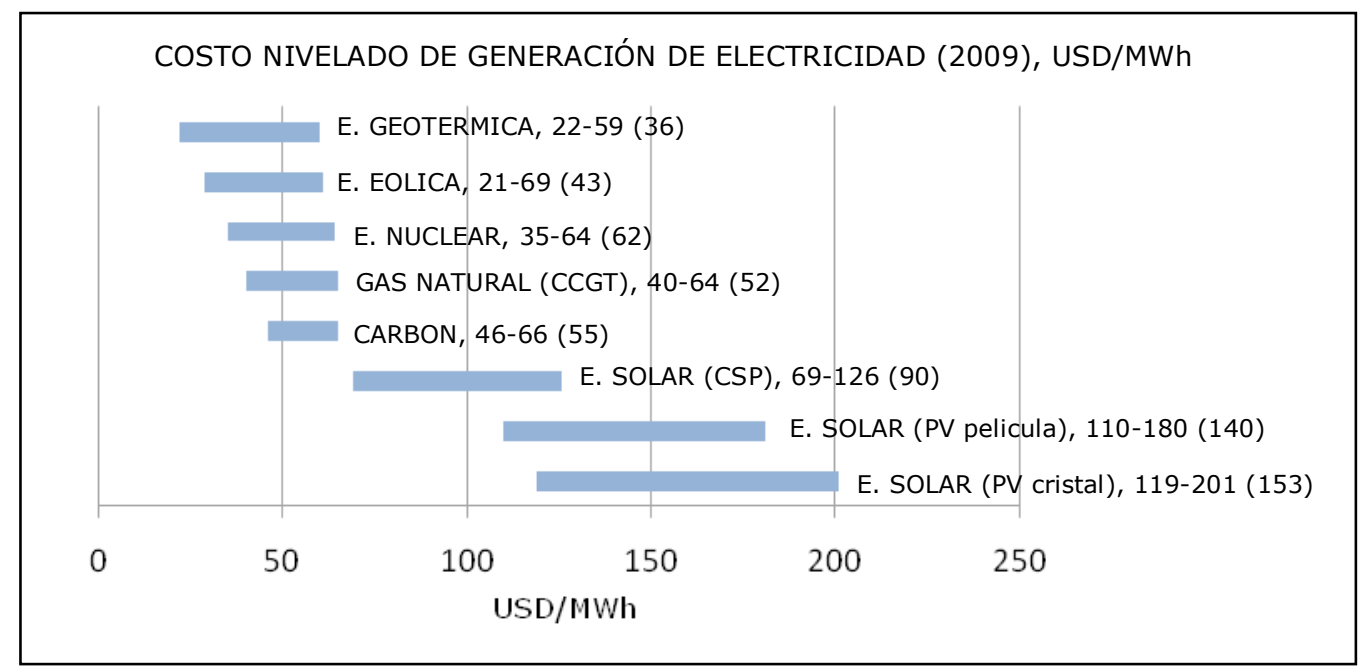

CCGT: ciclo combinado turbina de gas, CSP: concentración de energía solar

PV: energía fotovoltaica Fuente de datos: Björnsson, 2009; Mins, 2009

Figura 3.38. Costo nivelado de generación de electricidad, por recurso usado, 2009

55 Costo nivelado. Valor presente del costo total de construir y operar una planta generadora sobre su vida económica, por unidad de energía producida. 
En cualquier caso, la captación y conversión de la energía geotérmica en energía útil al hombre requiere un amplio conocimiento de las propiedades y conducta de los reservorios así como experiencia en perforación de pozos e instalación y manejo de equipos. Si ello se cumple, el resultado final será una instalación geotérmica con un alto factor de capacidad que contribuirá al suministro de energía limpia al mundo.

\subsubsection{Biomasa}

La bioenergía se puede definir como energía química acumulada mediante procesos recientes de fotosíntesis [BNDES y CGEE, 2008]. Los recursos naturales que poseen bioenergía se denominan biomasa y pueden procesarse para obtener energía útil al hombre. Entre otras, son fuentes de bioenergía, la leña y el carbón vegetal; los residuos y excedentes forestales y agrícolas; los desechos orgánicos municipales; y las cosechas agrícolas como la caña de azúcar, la remolacha, los granos y los cultivos oleaginosos.

La biomasa está ampliamente distribuida en el mundo; constituye la mayor fuente energética después del carbón, el petróleo y el gas natural; y es la opción de energía renovable más importante. Su transformación puede producir calor, bioelectricidad y biocombustibles como el bioetanol y el biodiesel que en algunos países complementan el suministro de gasolina al sector automotor.

El aprovechamiento de la biomasa puede hacerse en la forma tradicional, de baja eficiencia, que desde hace muchos años se utiliza en los medios rurales para satisfacer las necesidades básicas residenciales e industriales. Ejemplos son la utilización de la leña para la cocción de alimentos y la calefacción en el medio rural; y la producción de carbón vegetal obtenido de la tala de árboles y carbonización de la madera obtenida. Esta forma de utilización del recurso puede contribuir a la degradación de la tierra así como a desmejorar la calidad del aire puertas adentro; sin embargo, constituye la fuente principal de energía para algunas regiones del mundo como África y Asia [Hoogwijk et al., 2005].

Por el contrario, los sistemas modernos de elevada eficiencia incluso desde el punto de vista ambiental, utilizan tecnologías probadas comercialmente para atender las necesidades de energía de los sectores eléctrico, industrial y de transporte. 
Ejemplos de ellos son la producción de bioetanol de caña de azúcar en Brasil, los programas urbanos combinados de calefacción-potencia ( $\mathrm{CHP}$, por sus siglas en inglés) en Austria y los países escandinavos; y la co-combustión de biomasa en plantas eléctricas basadas en carbón, en Holanda [Hoogwijk et al., 2005].

La figura 3.39 muestra los diferentes flujos de biomasa terrestre que existen en la actualidad. Ellos pueden clasificarse en dos grandes grupos; el primero, los residuos forestales y agrícolas resultantes de los procesos de cosecha y procesamiento de los recursos así como del uso de los productos derivados (líneas azules); y el segundo, los cultivos dedicados a la producción de insumos para la producción de biocombustibles (línea amarilla). Para la biomasa primaria se señala en cada caso, la opción más importante de uso alternativo a la opción energética. Para la biomasa residual proveniente de procesos como la cosecha, procesamiento y consumo, sólo se señala su uso como fuente energética.

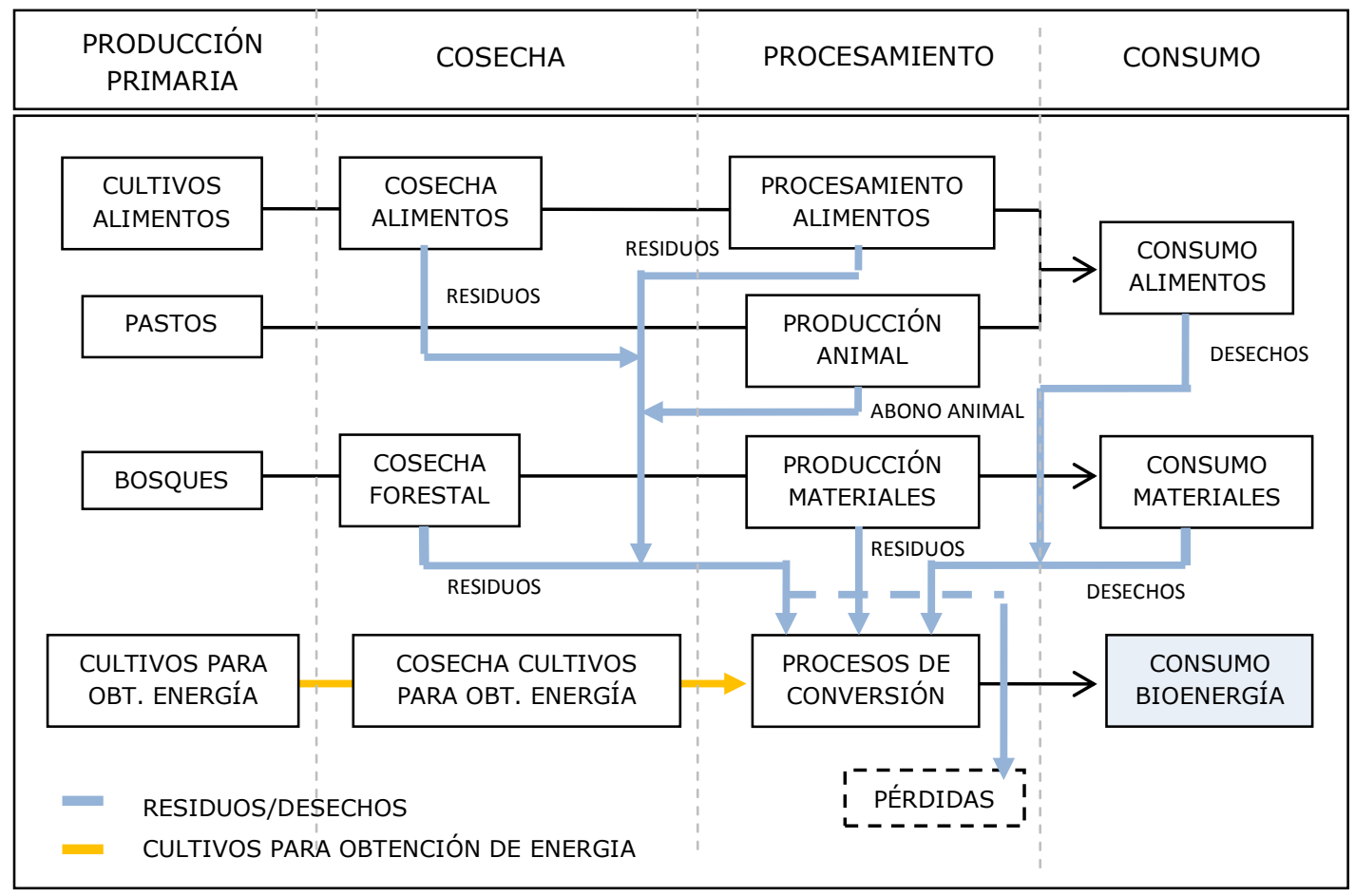

Adaptado de [Hoogwijk et al., 2005].

Figura 3.39. Flujos de biomasa y algunos de sus potenciales usos. 
Hoy en día, la biomasa suple aproximadamente $50 \mathrm{EJ}\left(50 \times 10^{18} \mathrm{~J}\right) /$ año lo que equivale a un $10 \%$ del suministro global de energía primaria [IEA, 2011a]. La biomasa usada de forma tradicional para la cocción de alimentos y calefacción representa la casi totalidad de esta cifra y sólo una fracción muy pequeña de las cosechas de caña de azúcar, granos y especies para obtener aceite vegetal se utilizan como insumos para la producción de biocombustibles líquidos. Por su parte, los residuos forestales y agrícolas, y los desechos municipales son los principales insumos para la generación de calor y electricidad a partir de biomasa. Los cultivos para la generación de energía compiten con las cosechas de alimentos, los pastos y los bosques por los terrenos potencialmente cultivables. Claramente, la prioridad debe ser la producción de alimentos.

\subsubsection{Disponibilidad de tierras}

La figura 3.40 muestra la distribución de la tierra disponible por usos, a nivel global, a finales del siglo XX. Como puede observarse, del total de área disponible que alcanza aproximadamente 13.400 millones de hectáreas, sólo un $11 \%$ son tierras agrícolas $\left(1.534 \times 10^{6}\right.$ has $)$ y un $26 \%$ (3.442 $\times 10^{6}$ has) está ocupado por pastos dedicados a la alimentación de la población animal [Bustamante et al. 2009; Holgrem-FAO, 2006]; de allí excluidos los animales domésticos cuya alimentación se deriva principalmente de cereales cultivados [Bustamante et al., 2009].

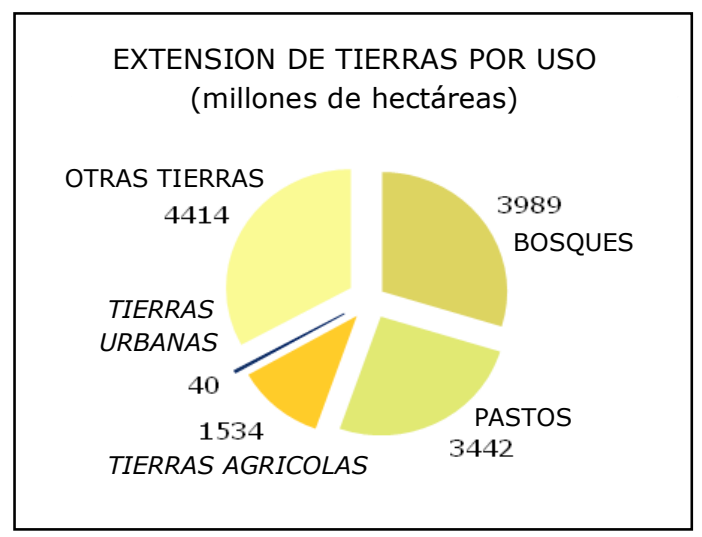

Fuente de datos: Bustamante et al. 2009

Figura 3.40. Distribución de tierras por uso, a nivel mundial, 2000 
El área utilizada en la producción de insumos para la generación actual de biocombustibles se incluye dentro de las tierras agrícolas reportadas en el gráfico anterior, y alcanza aproximadamente unos 27 millones de hectáreas o menos del 2\% del área total agrícola [Ravindranath et al., 2009]. La categoría 'Otras tierras' incluye sábanas, tundras, desiertos, áreas cubiertas de hielo y áreas debajo de ríos y lagos; y en general, las áreas que no corresponden a ninguna de las clasificaciones anteriores.

En las próximas décadas la demanda de terrenos adecuados para la producción de alimentos se incrementará como consecuencia del natural incremento en la demanda de alimentos. En los países subdesarrollados donde se espera el mayor crecimiento en el suministro de alimentos, la cantidad de terrenos adecuados para la producción de alimentos es muy limitada y a menudo, las tierras cultivables se ubican en la selva tropical o en otras áreas marginales [Bustamante et al., 2009]. Por otra parte, el incremento en la producción de biocombustibles que se espera se produzca, si se desea cumplir con las metas para la reducción de emisiones de gases invernadero a la atmósfera, demandará terrenos adicionales para el cultivo de la biomasa necesaria.

Todo ello deberá enfrentarse con la adecuada gestión de las tierras, privilegiando la producción de alimentos y de bienes necesarios al desarrollo del hombre sin menoscabar la reserva vegetal del planeta y favoreciendo la aplicación de las mejores técnicas a fin de aumentar la productividad de las cosechas y aumentar el área de tierras cultivables.

\subsubsection{Potencial de biomasa para energía}

La futura contribución de la biomasa en el suministro de energía ha sido estudiada por diferentes autores. Los estudios llegan a conclusiones muy diferentes debido primordialmente a que difieren en las suposiciones hechas por cada autor sobre la disponibilidad de la tierra y la evolución de los rendimientos de los cultivos energéticos; y naturalmente, en las respectivas metodologías utilizadas [Berndes et al., 2002]. 
Hoogwijk y otros colaboradores [2003] estudiaron el potencial de la biomasa para energía basándose en la disponibilidad de la tierra y en un rango de productividad de la biomasa de 10-20 toneladas por hectárea por año. Los autores analizan seis categorías de fuentes bioenergéticas: el excedente de tierras agrícolas y las tierras degradadas, los residuos agrícolas y forestales, el abono animal y los desechos orgánicos ${ }^{56}$; en múltiples escenarios futuros con diferentes proyecciones de población, patrones de consumo y sistemas de producción e intensidad de manejo de las tierras. El estudio concluye que el consumo de bioenergía primaria depende de factores como la cantidad y calidad de la demanda de alimentos que a su vez es función de la población mundial y su dieta, el sistema de producción que se adopte en el mundo de acuerdo a la disponibilidad de agua y de nutrientes, la productividad de bosques y cosechas agrícolas, la demanda de biomateriales y la existencia de otras opciones que compitan por el uso de la tierra. Los resultados obtenidos señalan que para el año 2050, el potencial global de biomasa para producción de energía oscilará entre 33 y 1.135 EJ/año, siendo el renglón de los cultivos energéticos en la tierra agrícola excedente, el principal contribuyente (0-988 EJ/año) a este monto [Hoogwijk et al., 2003].

Un estudio muy detallado llevado a cabo por el Instituto Copernicus de la Universidad de Utrecht en Holanda [Smeets et al., 2004] estima el potencial de biomasa para energía bajo cuatro escenarios que difieren entre sí por el valor asignado a variables como crecimiento de la población, patrones de consumo, rendimiento de cosechas y el nivel de tecnología aplicado en los cultivos. Cuatro tipos de biomasa se consideran en el estudio: cosechas especializadas dirigidas a la producción de energía, residuos agrícolas y forestales, abono animal y desechos municipales orgánicos. Los resultados ubican el potencial global de biomasa para generación de energía en el año 2050, entre 273 EJ/año para el escenario menos

Excedente de tierras agrícolas son tierras en exceso a las requeridas para la producción de alimentos para humanos y para animales. Tierras degradadas son áreas donde la actividad humana ha inducido degradación de los suelos y/o de la vegetación, potencialmente disponibles para reforestación; 0 alternativamente, para el cultivo de cosechas bioenergéticas. 
favorable y 1.471 EJ/año para el escenario que incluye la aplicación de las mejores prácticas de los sistemas agrícolas y tecnologías. Las regiones más prometedoras para un aumento importante de suministro de energía resultaron ser el África Subsahariana, Latinoamérica, el Caribe, y el Asia Oriental debido principalmente a grandes extensiones de tierra adecuadas para cultivos y al potencial de mejora de las bajas productividades existentes hoy en día y de aplicación de las mejores tecnologías para el año 2050.

Hoogwijk y otros colaboradores [2005] han publicado un trabajo donde analizan el potencial geográfico y técnico ${ }^{57}$ de los cultivos cuyo objetivo es la producción de energía para los años 2050 y 2100. Los investigadores realizan el estudio para cuatro escenarios que varían de acuerdo a los valores asignados a la población y al crecimiento económico, al cambio tecnológico, a la conducta social, a los aspectos ambientales y al nivel de globalización; y estiman el potencial geográfico de la biomasa para energía en tres categorías de tierras potencialmente disponibles para cultivos para la producción de energía: terrenos agrícolas abandonados, terrenos de baja productividad y terrenos residuales no requeridos para alimentos, bosques, pastos o bioreservas. El potencial geográfico se obtiene como el producto del área

57

Potencial teórico o productividad neta primaria de biomasa es el límite teórico superior de biomasa primaria que puede producirse por el proceso de fotosíntesis sobre el total de la superficie terrestre (EJ/año) [Hoogwjik et al., 2005].

Potencial geográfico de biomasa para la obtención de energía es la cantidad de biomasa primaria que puede ser producida para la generación de energía sobre las tierras disponibles después de satisfacer las necesidades de terrenos para cubrir la demanda regular de alimentos y productos derivados de los bosques, para los pastos de alimento a los animales, para el desarrollo de la naturaleza; corregida por perdidas de biodiversidad o físicamente no aptas para el desarrollo de cultivos; todo ello está incluido en lo que se denomina el factor de exclusión. Adicionalmente, la cifra obtenida debe ser corregida por el rendimiento estimado del cultivo y por el factor de manejo de la cosecha [Hoogwjik et al., 2005].

Potencial técnico de biomasa es igual al potencial geográfico corregido con la eficiencia de conversión del proceso de transformación de biomasa primaria a portadores secundarios de energía [Hoogwjik et al., 2005].

Potencial económico de biomasa para energía es el potencial técnico que puede producirse en forma económicamente rentable [Hoogwjik et al., 2005].

Potencial sustentable de biomasa es el potencial que cumple con los criterios económicos, ambientales y sociales de sustentabilidad como p.e. no deforestación, no competencia entre producción bioenergética y producción de alimentos, protección de la bioversidad y conservación de la naturaleza [Van Dam et el., 2008; Smeets y Faaij, 2010; Smeets et al. 2004]. 
disponible para el cultivo energético por su productividad. Los resultados indican que el potencial geográfico global de los cultivos para generación de energía para el año 2050 puede oscilar entre 310-660 EJ; y de allí, el sector más importante será la biomasa cultivada en tierra agrícola abandonada que puede variar entre $130 \mathrm{EJ}$ y $410 \mathrm{EJ}$, seguido por el potencial de biomasa en los terrenos residuales que oscila entre 35 EJ y 245 EJ [Hoogwijk et al., 2005]. El potencial técnico global de los cultivos para generación de electricidad o de biocombustibles se estima multiplicando el potencial geográfico por las respectivas eficiencias de conversión promedio de las tecnologías en tales sectores, estimadas para el año 2050. De esta forma, se

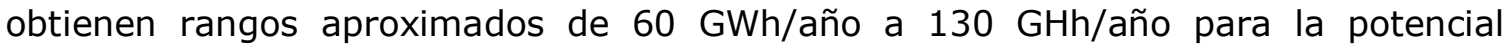

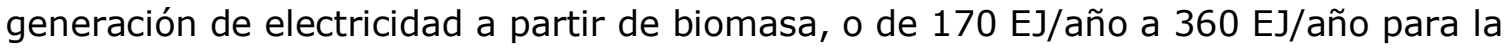
potencial producción de biocombustibles, ambas en el año 2050 [Hoogwijk et al., 2005].

Smeets, Faaij y otros investigadores [2006] estudiaron el potencial energético que puede derivarse de tres fuentes de biomasa: cultivos para obtención de energía; residuos forestales y agrícolas, y desechos municipales; y excedentes de los bosques. En el estudio se da especial atención a la posibilidad de reducir el área necesaria para la producción de alimentos si se incrementa la eficiencia del proceso; por ello, se prueban cuatro niveles de avance en las tecnologías agrícolas para el año 2050. Los resultados muestran que la aplicación de sistemas agrícolas muy eficientes combinados con la optimización del patrón de uso de la tierra puede reducir el área necesaria para cubrir la demanda mundial de alimentos para el 2050 a aproximadamente un $72 \%$ del área actualmente utilizada. Además de la demanda de alimentos, el modelo toma en cuenta los requerimientos de madera del sector industrial y de leña del sector tradicional, los requerimientos de pasto para la alimentación animal y su eficiencia de producción, y la necesidad de mantener los bosques existentes para la protección de la biodiversidad.

Para el año 2050, los resultados muestran un potencial global que oscila entre 367 EJ/año y 1.548 EJ/año. La figura 3.41 refleja la distribución geográfica del potencial hallado en el mejor de los escenarios de aplicación de tecnologías a la alimentación de animales y producción y rendimiento de cosechas agrícolas. Una 
gran parte de este potencial se encuentra en el África Subsahariana (49-347 EJ/año), Suramérica y el Caribe (89-281 EJ/año), los Países Bálticos y la Comunidad de Países Independientes (CIS, por sus siglas en inglés) (83-267 EJ/año).

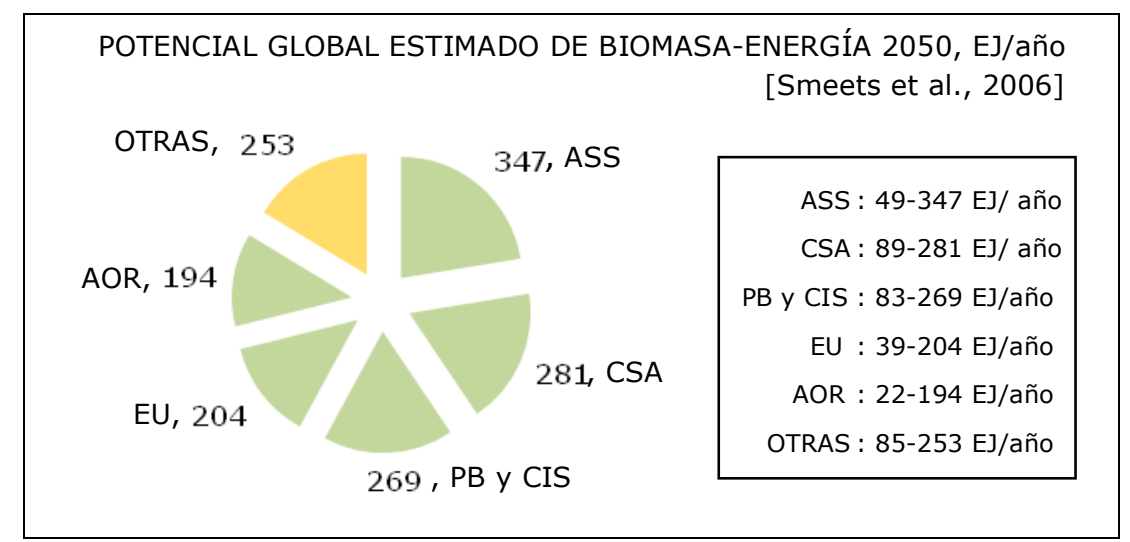

ASS: Africa Subsahariana CSA: Centro y Suramérica EU: Estados Unidos AOR: Asia Oriental PB Y CIS: Países Bálticos y Comunidad de Países Independientes ${ }^{58}$ OTRAS: Otras regiones. Fuente de datos: Smeets et al., 2006

Figura 3.41. Distribución del potencial global de biomasa para la producción de energía. Escenario de alto nivel tecnológico en cultivos, 2050.

Estudios del escenario actual de tecnologías y rendimientos de cultivos agrícolas muestran que los valores supuestos en el escenario optimista propuesto por Smeets y colaboradores pueden ser no realistas [Smeets et al., 2006].

Como era de esperarse, los resultados obtenidos para el potencial global de biomasa para producción de energía muestran gran variabilidad de autor a autor, debido primordialmente a las suposiciones hechas en cada estudio y a las diferentes metodologías empleadas. La figura 3.42 presenta las proyecciones del potencial de naciones independientes, antes parte de la Unión Soviética, formada por Belarus, Ucrania, Armenia, Azerbaiyan, Kazakhstan, Kyrgyzstan, Muldova, Tajikistan, Turkmenistan, Uzbekistan y Georgia.

Países Bálticos: Estonia, Latvia y Lituania, países independientes antes pertenecientes a la Unión Soviética. 
biomasa para el año 2050 si se cumple el mejor de los escenarios de dos de los estudios antes señalados. Los estimados se contrastan con el uso actual (2009) de biomasa para producción de energía, y los suministros actual (2009) y proyectado (2050) de energía primaria total.

Las estimaciones del potencial bioenergético son elevadas, sin embargo disminuyen aproximadamente a unos 510 EJ/año para el año 2050 [Bauen et al., 2010] cuando en el escenario de suministro se toman en cuenta restricciones económicas y sociales. Aún así, la biomasa podría contribuir de manera sostenible con al menos un 25\% con la mezcla energética para el año 2050 [Bauen et al., 2010].

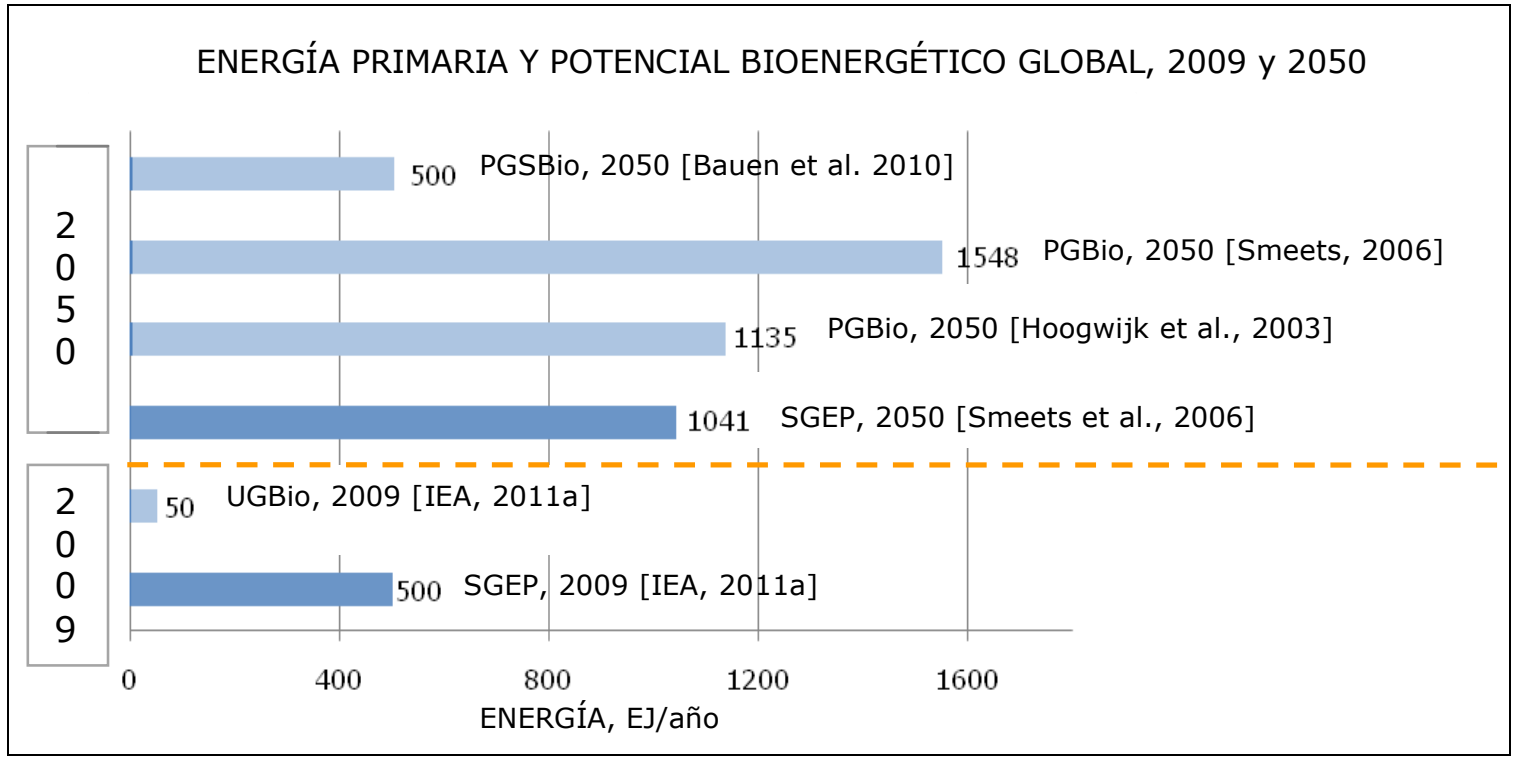

SGEP: Suministro global de energía primaria PGBio: Potencial global de biomasa para energía UGBio: Uso global de bioenergía primaria PGSBio: Potencial global sostenible de bio para energía

Fuente de datos : Bauen et al., 2010; IEA, 2011;, Smeets et al., 2006 y Hoogwijk et al., 2003

Figura 3.42. Estimación de potencial global de biomasa para energía, 2050.

Las fuentes de bioenergía y su contribución parcial al potencial sostenible señalado en el grafico anterior son primordialmente, (i) los residuos agrícolas y forestales, los residuos municipales y otros desechos orgánicos con una contribución del orden $100 \mathrm{EJ} / \mathrm{año}$, (ii) los excedentes forestales definidos como la diferencia entre el incremento neto anual de bosques menos las respectivas cosechas, con una UNIVERSIDAD POLITÉCNICA DE VALENCIA. TESIS DOCTORAL. Violeta Parodi 
contribución aproximada de $80 \mathrm{EJ} / a n ̃ o$, (iii) los cultivos de biomasa para la obtención de energía excluyendo áreas con suelos moderadamente degradados y/o moderada escasez de agua, con un aporte aproximado de $120 \mathrm{EJ} / \mathrm{año}$, (iv) los cultivos de biomasa para la obtención de energía en suelos moderadamente degradados $\mathrm{y} / \mathrm{o}$ moderada escasez de agua, con una contribución del orden de 70 EJ/año; y (v) el incremento en la productividad agrícola lo que hace que se produzcan más alimentos en igual o menor área, con una contribución estimada de 140 EJ/año [Bauen et al., 2010). La figura 3.43 muestra la distribución del potencial sustentable de biomasa para la obtención de energía, por fuente.

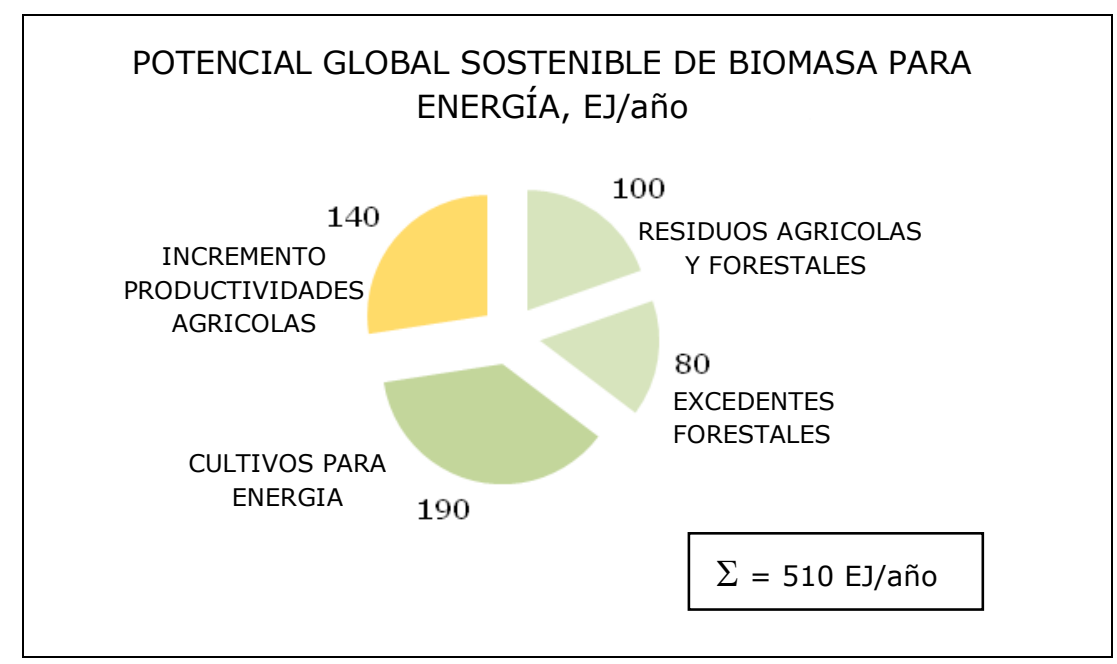

Fuente de datos: Bauen et al., 2010

Figura 3.43. Distribución por fuente de energía del potencial global sostenible de biomasa para energía, 2050.

La extensión en que realmente contribuirá la biomasa al suministro de energía en el futuro dependerá además de la disponibilidad de los terrenos necesarios para la producción de la biomasa; de la disponibilidad de agua, de limitaciones ambientales y logísticas; de los esfuerzos gubernamentales e industriales dirigidos a modernizar y difundir las técnicas agrícolas en regiones como África, Asia y Latinoamérica; de su productividad y costo de producción; del desarrollo e implementación de nuevas tecnologías de conversión y del costo del producto final, la aceptación por parte de la sociedad de los productos bioenergéticos y el costo de otras fuentes de energía; y finalmente, del apoyo gubernamental. 
A las cifras suministradas debe añadirse el potencial aún no definido que se almacena en las algas marinas y el gas que proviene de los rellenos sanitarios

\subsubsection{Tecnologías de conversión}

La conversión de la biomasa en energía útil al hombre puede realizarse por diferentes rutas. Las tecnologías de conversión se han adaptado a la amplia variedad de características físicas y químicas de la materia prima, y al producto final requerido; y se utilizan tecnologías de mejoramiento (aglomeración, torrefacción, pirólisis) para convertir la biomasa en bruto en materia prima más densa, con menor humedad y volumen, cuyo transporte, almacenamiento y uso subsiguiente en procesos de conversión resulte más fácil y menos costoso [Bauen et al., 2010]. La ruta de conversión seleccionada en cada caso, dependerá además del tipo de biomasa a convertir y del producto final a obtener, de la seguridad de suministro de la materia prima y de las limitaciones ambientales y económicas asociadas al proyecto.

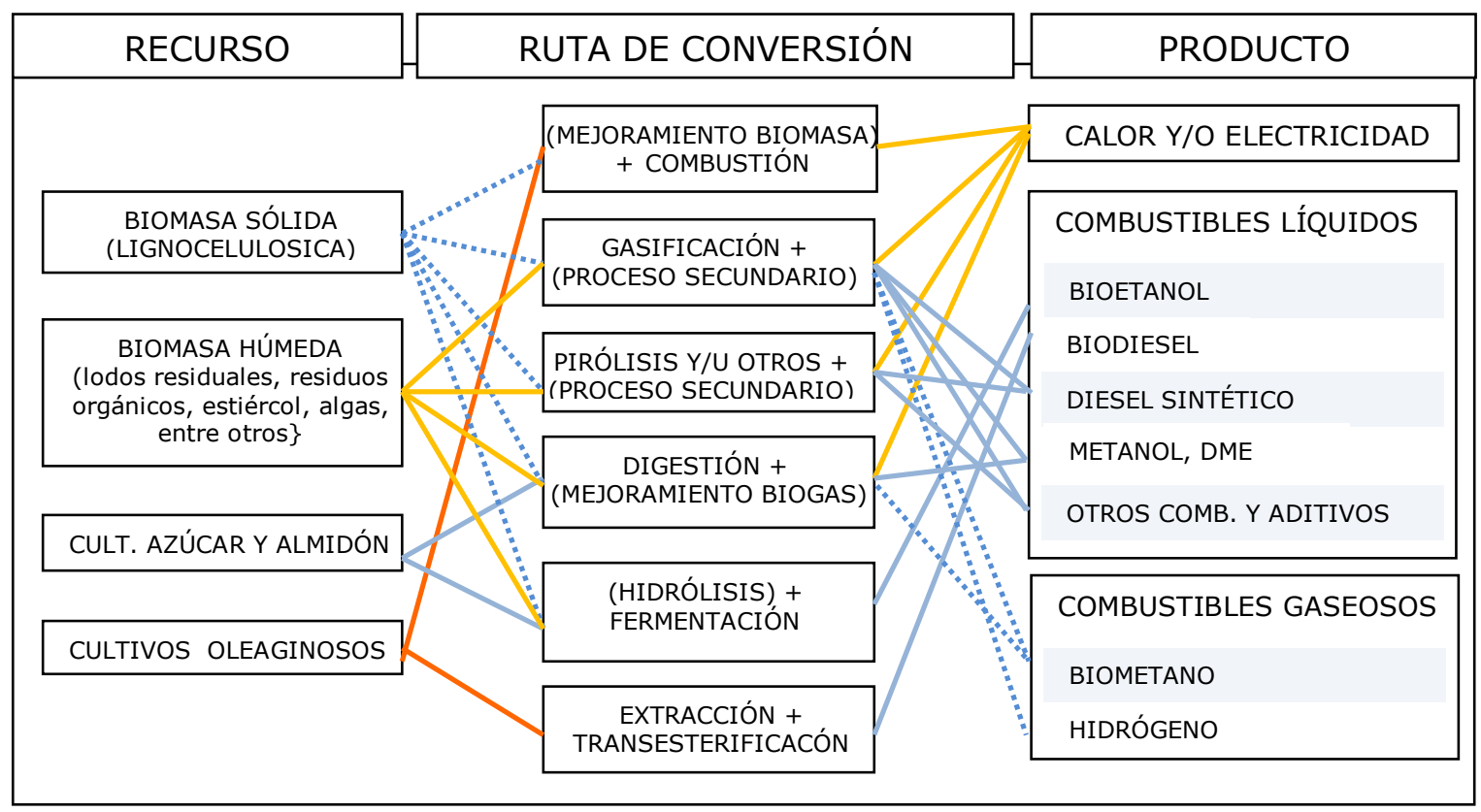

Fuente de información: Bauen et al., 2010.

Figura 3.44. Algunas rutas de conversión [Biomasa $=>$ Calor, electricidad o biocombustibles]. 
La figura 3.44 presenta algunas rutas para la conversión de biomasa en calor, electricidad o biocombustibles. Actualmente, los residuos forestales (ramas y cortezas de árboles) y agrícolas (p.e., restos de las cosechas de trigo, maíz y caña de azúcar) y municipales (p.e., embalajes, materiales de construcción y/o demolición, lodos residuales); y los residuos o desechos provenientes de actividades industriales o post-consumo de biomasa (p.e., aserrín, licor de la producción de papel, estiércol de animales) constituyen la principal fuente de materia prima para la generación de electricidad y calor a partir de la biomasa. En una menor proporción, los cultivos ricos en azúcar o almidón (p.e., caña de azúcar, remolacha y maíz) y los cultivos oleaginosos (p.e., canola, girasol y palma africana) se utilizan para la producción de biocombustibles líquidos como el bioetanol, el aceite vegetal y el biodiesel. A largo plazo, la biomasa acuática (algas) podría tener una participación en la canasta energética mundial. A la izquierda de la figura 3.44 se registran las fuentes de biomasa citadas.

En cuanto a las tecnologías de conversión, pueden diferenciarse procesos termoquímicos y procesos bioquímicos. A continuación, un breve resumen de los grupos de procesos citados.

\subsection{Procesos termoquímicos de conversión}

Entre los procesos termoquímicos para la conversión de la biomasa en energía útil al hombre, se cuentan la combustión y sus variantes, la gasificación, la pirólisis y otros procedimientos similares menos desarrollados.

- Combustión. La obtención de calor y electricidad por combustión directa de biomasa se realiza utilizando procesos similares a los aplicados con combustibles fósiles; y constituye, hoy día, la principal forma de aprovechamiento de la biomasa [Bauen et al., 2010]. La producción de calor para aplicaciones domésticas constituye un renglón importante en zonas rurales de Austria, Francia, Alemania y Suecia en Europa, y en los países menos desarrollados del mundo donde aún se quema leña en chimeneas o pequeños hornos con eficiencias cercanas al $10 \%$ y considerables emisiones de hollín. Paralelamente, se han realizado avances tecnológicos importantes en el sector, y hoy en día se dispone 
de sistemas de calefacción automáticos típicamente con capacidades que varían entre $1 \mathrm{MW}_{\mathrm{T}}$ y $5 \mathrm{MW}_{\mathrm{T}}$ que utilizan biomasa aglomerada y cuya eficiencia oscila entre $70 \%$ y $90 \%$, con significativa reducción en las emisiones si se compara a los sistemas tradicionales [Faaij, 2006, IEA, 2012a].

Por su parte, los sistemas termoeléctricos utilizan el calor generado en la combustión de la biomasa para producir vapor de alta presión que se introduce a una turbina de vapor conectada a un generador eléctrico. Capacidades típicas para plantas de combustión que utilizan residuos forestales como combustible varían entre $20 \mathrm{MW}_{\mathrm{E}}$ a $50 \mathrm{MW}_{\mathrm{E}}$; y sus eficiencias eléctricas, entre $25 \%$ y $30 \%$. La utilización de tecnologías de lecho fluidizado ha permitido elevar las eficiencias eléctricas a valores que oscilan entre $30 \%$ y $40 \%$ para escalas entre $50 \mathrm{MW}_{\mathrm{E}}$ y 80 $\mathrm{MW}_{\mathrm{E}}$ [Faaij, 2006].

- Ciclos combinados potencia-calor. Para incrementar la eficiencia global energética del proceso, a menudo se utilizan ciclos combinados que permiten la obtención consecutiva de electricidad y de calor utilizando el mismo combustible ( $\mathrm{CHP}$, por sus siglas en inglés). El proceso también se conoce como cogeneración y se diseña para recuperar el calor en los gases que salen de la turbinas de vapor, el cual se pierde en las estaciones termoeléctricas convencionales. En efecto, las instalaciones termoeléctricas alimentadas con biomasa deben garantizar su operación ubicándose en zonas industriales que tengan un suministro confiable de biomasa (p.e, fábricas de azúcar y/o bioetanol, plantas de pulpa y papel); en esos sitios, el calor recuperado del vapor que sale de las turbinas puede dirigirse a satisfacer las necesidades de calor de las plantas industriales allí ubicadas, incrementando la eficiencia energética global del proceso a valores superiores al $80 \%$ en sistemas con capacidad entre $1 \mathrm{MW}_{\mathrm{E}}$ y $10 \mathrm{MW}_{\mathrm{E}}$ [Faaij, 2006].

- Co-combustión. La combustión simultánea de diferentes tipos de combustible constituye otra alternativa para la utilización de biomasa, en particular en plantas de generación eléctrica alimentadas con carbón. En este caso, el carbón puede ser parcialmente reemplazado por residuos forestales, agrícolas o municipales con la consiguiente disminución en las emisiones dañinas a la atmósfera. Adicionalmente, el reemplazo de carbón con biomasa produce una reducción en 
los costos y una disminución en el riesgo del suministro de materia prima, especialmente cuando la planta de generación eléctrica está ubicada en las cercanías de complejos agroindustriales o plantas procesadoras de madera que generan una gran cantidad de los mismos.

Si estas plantas desean hacer un mejor uso de sus residuos generando electricidad, pero tienen un alto componente estacional, la co-combustión con combustibles fósiles puede permitirles la generación durante todo el año; ello representa una ventaja en términos de comercialización de la energía eléctrica producida, se incrementa la eficiencia global y permite mantener los equipos funcionando. En contrapartida, la adopción de la tecnología requiere modificaciones en el diseño de los hervidores y un mayor control en la operación de los mismos en lo referente a control del manejo y mezcla de los combustibles. Plantas capaces de quemar gas natural, carbón y diferentes tipos de biomasa se han probado con éxito en Europa (Avedore, Dinamarca) [Faaij, 2006] y otras partes del mundo.

- Gasificación. Es un proceso de conversión de la biomasa en una mezcla gaseosa combustible por oxidación parcial de la biomasa a temperaturas que oscilan entre $800{ }^{\circ} \mathrm{C}$ y $900{ }^{\circ} \mathrm{C}$. El gas producido está formado por $\mathrm{CO}, \mathrm{H}_{2}$ y trazas de metano y puede ser quemado directamente; o ser tratado y filtrado para eliminar compuestos químicos no deseados, y luego utilizado como combustible en motores y turbinas de gas o como materia prima en la producción de hidrocarburos líquidos o diesel sintético por la vía Fisher-Tropsch [Faaij, 2006].

Hoy día, existen pocos ejemplos de plantas de gasificación comerciales debido a la complejidad del sistema y a su elevado costo [Bauen et al., 2010]. La gasificación de biomasa integrada con turbinas de gas de ciclo combinado (BIG/CC, por sus siglas en inglés) ha mostrado una elevada eficiencia eléctrica que varía entre $40 \%$ y $50 \%$ para capacidades entre $30 \mathrm{MW}_{\mathrm{E}}$ y $60 \mathrm{MW}_{\mathrm{E}}$ [Faaij, 2006]; sin embargo, su desarrollo comercial sólo se producirá si adicionalmente se demuestra su viabilidad operativa y económica. 
- Pirólisis. Es un proceso de conversión de biomasa en fracciones líquida (biocrudo), sólida (carbón vegetal) y gaseosa, mediante su calentamiento en ausencia de aire y a temperaturas aproximadas a $500{ }^{\circ} \mathrm{C}$. La pirolisis instantánea produce primordialmente biocrudo con un rendimiento de hasta $70 \%$, basado en el contenido calórico de la fracción frente al de la biomasa de entrada [Faaij, 2006]. El biocrudo puede ser utilizado como combustible en motores y turbinas; sin embargo, algunos problemas con el proceso de conversión y el subsiguiente uso del biocrudo (corrosión, estabilidad) deben ser superados en forma económicamente rentable antes de que la tecnología sea implementada comercialmente [Faaij, 2006; McKendry, 2002]. Hoy en día, el procedimiento se utiliza como una alternativa de tratamiento previo de la biomasa cuando ésta debe ser transportada largas distancias [Faaij, 2006].

Otras vías para obtener líquidos intermedios a partir de biomasa son la licuefacción o conversión a alta presión de hidrógeno y el mejoramiento hidrotérmico (HTU, por sus siglas en inglés) o conversión en un ambiente húmedo a alta presión. Ambos procesos están poco desarrollados [Faaij, 2006].

\subsection{Procesos bioquímicos de conversión}

Entre los procesos bioquímicos para la conversión de la biomasa se cuentan la digestión anaeróbica, la fermentación y la esterificación precedida de la extracción mecánica de aceites de las semillas oleaginosas. A continuación un breve resumen de los procedimientos citados.

- Digestión anaeróbica. Es la descomposición de material orgánico por acción bacteriana en un ambiente anaeróbico, con la producción de una mezcla gaseosa o biogás formada por metano $(\approx 60 \%$ ), dióxido de carbono ( $\approx 40 \%$ ) y pequeñas cantidades de otros gases como sulfuro de hidrógeno. La tecnología de digestión anaeróbica ( $A D$, por sus siglas en inglés) está comercialmente probada y es ampliamente utilizada para el tratamiento de residuos orgánicos húmedos como desechos domésticos e industriales, desechos humanos y animales, lodos residuales y similares. El gas producido, después de un adecuado tratamiento, puede ser quemado directamente para calefacción o utilizado en motores de 
combustión interna para producir electricidad o trabajo [Kimble et al., 2008]. La eficiencia global de conversión de biomasa a electricidad varía entre $10 \%$ y $15 \%$ [Faaij, 2006; McKendry, 2002]. Adicionalmente el lodo que sale del digestor tiene un alto contenido en nitrógeno y otros nutrientes y puede ser usado como fertilizante [Kimble et al., 2008].

Una fuente de emisiones importantes de biogás son los rellenos sanitarios. El biogás allí desprendido es rico en metano, un gas invernadero que es unas 22 veces más potente que el $\mathrm{CO}_{2}$ en atrapar el calor en la atmósfera. De esta forma, colectar, tratar y usar este gas en la generación de electricidad resulta además de una alternativa rentable en muchos casos, favorable a la reducción de las emisiones de gases invernadero a la atmósfera [Faaij, 2006].

Procedimientos a gran escala para tratar residuos industriales húmedos se han aplicado en muchos países; entre ellos, Dinamarca y Holanda poseen sistemas avanzados para el tratamiento de varios tipos de desechos orgánicos húmedos [Faaij, 2006]. Digestores a pequeña escala se han utilizado mucho en países en vías de desarrollo como China, India, Nepal, Sur Corea, Brasil y Tailandia [Kimble et al., 2008].

- Hidrólisis y fermentación. La fermentación es una ruta de conversión clásica que se utiliza para transformar azúcares en bioetanol el cual puede ser utilizado como combustible, puro o mezclado en proporciones bajas con gasolina; en éste último caso, sin necesidad de adaptaciones importantes en el diseño de la flota automotor [Mckendry, 2002].

El proceso se aplica comercialmente a gran escala a los cultivos de caña de azúcar, remolacha, maíz y cereales especialmente en Brasil, Estados Unidos y Francia. En el caso de la caña de azúcar, la biomasa es cosechada, molida y los azúcares extraídos con agua y posteriormente sometidos a fermentación para obtener bioetanol. El residuo sólido o bagazo que sale del proceso de fermentación puede ser usado como combustible en hervidores o ser sujeto a una subsiguiente gasificación [Kimble et al. 2008]. 
En el caso del maíz, el proceso es similar con la excepción de que el cereal molido debe ser sometido a hidrólisis para convertir el almidón en él contenido, en azúcares que luego son transformados en bioetanol. El residuo procedente del proceso puede ser utilizado como alimento para ganado. En ambos casos, el etanol obtenido de la fermentación debe ser destilado, operación que consume una cantidad importante de energía [Kimble et al., 2008, McKendry, 2002].

- Extracción mecánica y transesterificación. La extracción mecánica es un procedimiento que se utiliza para producir aceite a partir de cultivos como canola, algodón, palma africana, girasol, entre otros. El aceite producido puede ser utilizado en motores diesel, para la preparación de alimentos o en generadores diesel para la producción de electricidad. Paralelamente, el proceso produce una torta residual que puede utilizarse para la alimentación de animales o como fertilizante [Kimble et al., 2008].

El aceite en bruto obtenido de las plantas oleaginosas puede ser filtrado y mezclado con metanol para iniciar una reacción de transesterificación cuyo producto después de refinado produce biodiesel y glicerina. El biodiesel puede ser utilizado en forma pura o mezclado con biodiesel derivado de petróleo en motores diesel; y la glicerina puede ser utilizada para producir jabón. La estandarización del biodiesel y su producción industrial hace que tenga un uso más amplio que el aceite que sale de la etapa de extracción [Kimble et al., 2008].

\subsection{Tecnologías de primera, segunda y tercera generación}

El bioetanol, el aceite vegetal y el biodiesel son biocombustibles líquidos de primera generación cuya producción se apoya en tecnologías bien conocidas como las descritas en las dos secciones anteriores; y su futuro desarrollo descansa más que en los aspectos técnicos, en la disponibilidad de tierras aptas para el cultivo de la biomasa necesaria, en sus costos de producción frente al precio de los combustibles fósiles y en el soporte que puedan brindarle las políticas del Estado.

Sin embargo, en los últimos años se ha abierto un debate sobre la conveniencia o no, de dedicar parte de las tierras agrícolas disponibles a la siembra de cultivos con fines energéticos, compitiendo con los cultivos de alimentos necesarios para suplir la 
creciente demanda global de alimentos. Por otra parte, el cultivo, transporte y procesamiento de la biomasa consume energía que generalmente proviene de combustibles fósiles lo que produce emisiones de gases a la atmósfera y disminuye el rendimiento neto de energía por hectárea cultivada haciendo menos atractiva esta opción para la obtención de energía. Finalmente, la sustracción de una parte importante de la cosecha de productos específicos básicos de la dieta humana para dirigirla a la producción de bioetanol ha sido señalada como causa principal del elevado incremento sufrido por los precios de estos renglones (maíz, en Estados Unidos) y del decremento de accesibilidad de estos productos a la población.

Las tecnologías de segunda generación permiten procesar un rango amplio de materias primas; especialmente, la biomasa lignocelulósica (residuos forestales y herbáceas) para obtener bioetanol, biodiesel, combustibles sintéticos e hidrógeno. El uso de este tipo de materia prima disminuiría significativamente la presión sobre el uso de la tierra, los requerimientos de energía para la producción de la biomasa y las emisiones de gases invernadero a la atmósfera comparado con algunos biocombustibles de primera generación.

Las tecnologías de segunda generación incluyen el hidrotratamiento, la hidrólisis y fermentación avanzadas, la gasificación y la síntesis química. Los nuevos procesos de conversión son mucho más complejos y muchos de ellos aún se encuentran en etapas de investigación y desarrollo. Una vez se demuestre su viabilidad técnica y económica, se estima que den un rendimiento energético, económico y ambiental superior a la primera generación de tecnologías [Kimble et al., 2008].

Una tercera generación de biocombustibles tales como aceites producidos a partir de algas están en la etapa de investigación y desarrollo, y necesitan cierto tiempo para llegar a ser competitivos en el mercado global de energía [Kimble et al., 2008].

\subsubsection{Producción de calor, electricidad y combustibles}

Hoy en día, el suministro de energía primaria al mundo está alrededor de 500 EJ o 12.150 millones de toneladas equivalentes de petróleo; de allí, un 10\% representa el aporte de la biomasa [IEA, 2011a]. Esta contribución varía ampliamente de país a país; así, mientras la bioenergía suple un promedio de un $22 \%$ del consumo de 
energía primaria en los países con menor desarrollo, y de hasta un $90 \%$ en zonas rurales como Nepal; su contraparte en la cesta energética primaria de los países más desarrollados ésta alrededor de un 3,4\% [Bauen et al. 2010]. En el primer caso, la utilización de la biomasa se dirige mayoritariamente a aplicaciones no comerciales de una baja eficiencia mientras que en los países más industrializados, la biomasa se dedica primordialmente a la obtención de calor, energía para el sector industrial y de biocombustibles para el sector transporte.

La figura 3.45 muestra la contribución de la bioenergía a la canasta energética mundial y su distribución por fuente para el año 2009. Para el año 2008, el aporte de bioenergía estuvo compuesto mayoritariamente por la quema de leña (67\%) y el uso de carbón vegetal (7\%) en los países menos desarrollados y en los medios rurales; le sigue el uso de residuos sólidos forestales, agrícolas, industriales y procedentes de la cría de animales que contribuyen aproximadamente con un $20 \%$ del total de bioenergía en el mundo, y los residuos municipales y rellenos sanitarios con un $3 \%$. Por su parte, los cultivos dedicados a la obtención de biocombustibles líquidos sólo contribuyen con un 3\% al suministro global de bioenergía [Bauen et al., 2010].

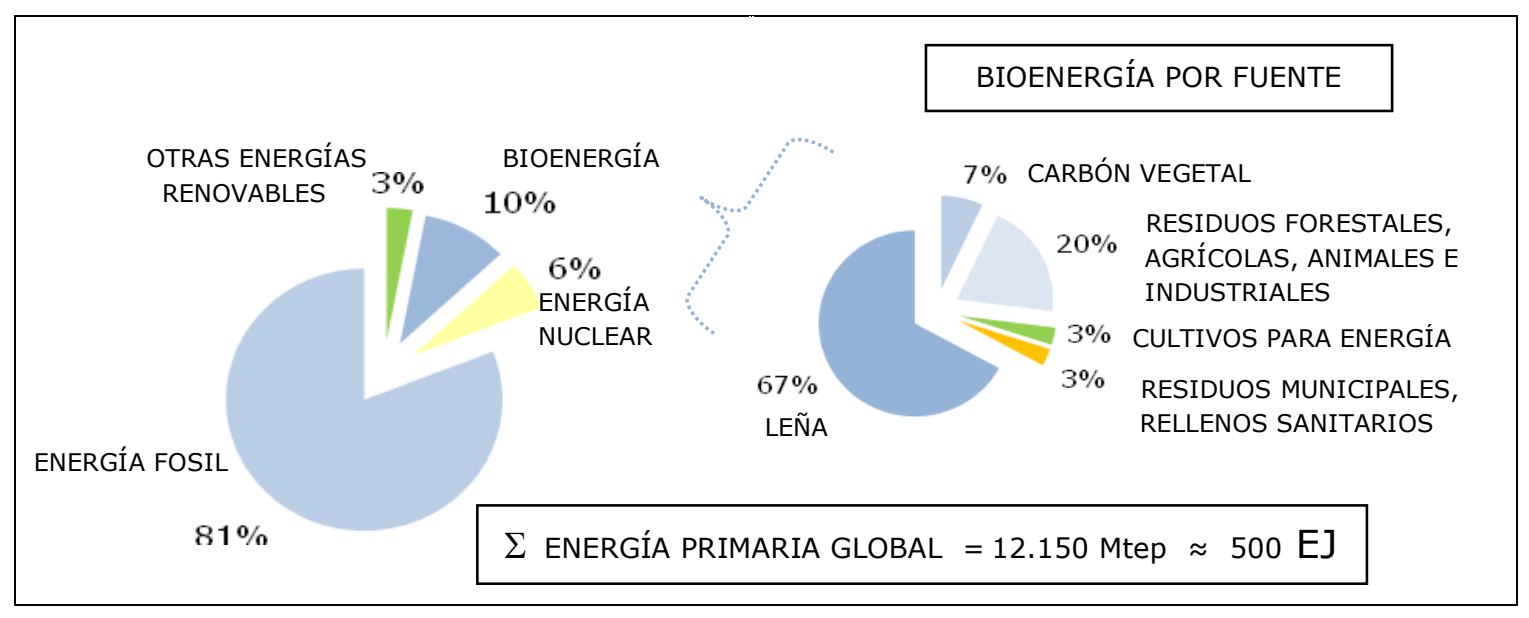

Fuente de datos: Bauen et al. 2010; IEA, 2011a

Figura 3.45. Suministro global de bioenergía, 2009. 


\subsection{Generación de calor}

A nivel mundial, la biomasa es el principal proveedor de calor producido a partir de fuentes renovables. El suministro de calor proviene de la combustión de biomasa sólida, líquida y gaseosa para propósitos que van desde la cocción de alimentos a hasta el calentamiento de agua y de espacios. De igual forma, las aplicaciones van desde unidades individuales a nivel residencial a grandes sistemas de calefacción municipal, y plantas combinadas calor-potencia (CHP).

Para el año 2010, la capacidad instalada para producción de calor a partir de biomasa alcanzó 280 GWT aproximadamente. Suecia, Finlandia y Dinamarca lideraron el mercado europeo de calor por biomasa produciendo más del $70 \%$ del consumo del sector en Europa. En promedio, el calor se produjo como una combinación de plantas CHP (64\%) y plantas sólo para producción de calor (36\%). La calefacción doméstica a través de pequeños equipos o de calefacción directa consumió la mayor cantidad de la biomasa sólida vendida en Europa [REN21, 2011].

El consumo de la biomasa compactada en pequeños trozos ('pellets', en inglés) como combustible para generación de electricidad, en plantas CHP y para calefacción doméstica y municipal, alcanzó alrededor de 11 millones de toneladas en Europa, para el año 2010; de ellos, Canadá y Estados Unidos suplieron 1,6 millones de toneladas. Suecia y Alemania fueron los más grandes consumidores. Se estima que en los Estados Unidos entre 2.1 millones y 2.6 millones de hogares utilizan madera como su fuente primaria de energía [REN21, 2011].

En cuanto a los países en vías de desarrollo, es común el uso de residuos agrícolas como las cáscaras de arroz y barbas de coco, y el bagazo que resta luego de la extracción del jugo de la caña de azúcar, para la producción de electricidad y/o calor. El uso del bagazo es significativo en países que poseen una industria azucarera como Brasil, Argentina, Australia, China, Colombia, Cuba, Guatemala, India, Kenia, Filipinas, Tanzania, Tailandia, y Uganda [REN21, 2011].

Para el año 2010, se utilizó biogás en millones de hogares en China e India para el cocimiento de sus alimentos; y para suplir necesidades de calor en pequeñas y medianas empresas. 


\subsection{Bioelectricidad}

A finales del año 2010, la capacidad global instalada de generación de electricidad procedente de la biomasa fue de 62 GW [REN21, 2011] y la producción alcanzó 280 TWh. Los principales productores fueron Estados Unidos (48 TWh), y la Unión Europea liderada por Alemania (28,7 TWh), Suecia y el Reino Unido [IEA, 2012, REN21, 2011]. Otros productores importantes fueron Brasil y China gracias a programas estadales de soporte para generación de electricidad en base a residuos agrícolas. La figura 3.46 presenta cifras relativas a capacidad instalada para algunos países o grupos de países seleccionados y la distribución de la capacidad instalada para generación de energía eléctrica a partir de fuentes renovables. Nótese la importancia de la participación bioenergética.

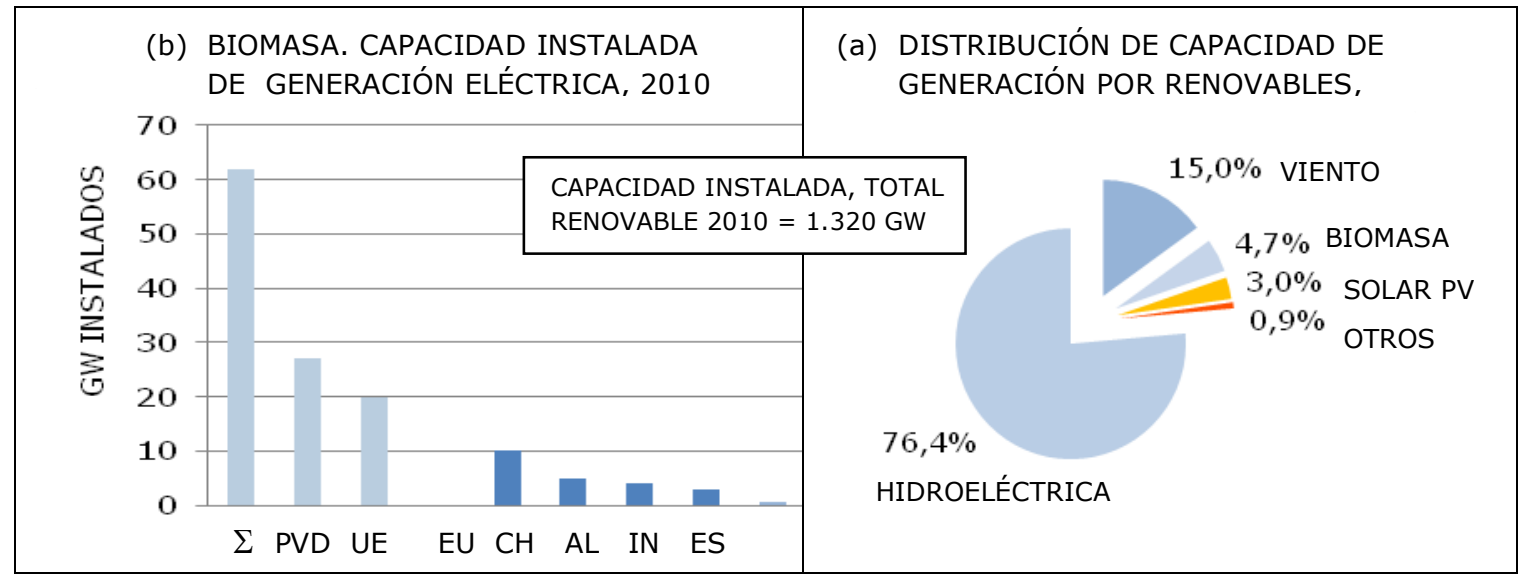

PDV: Países en vías de desarrollo UE: Unión Europea EU: Estados Unidos CH: China AL: Alemania IN: India ES: España.

Fuente de datos: (a) REN21, 2011; IEA, 2012

Figura 3.46 (a) Capacidad instalada de generación eléctrica a partir de biomasa, 2010.

(b) Distribución de capacidad instalada de generación eléctrica a partir de renovables, 2010.

\subsection{Biocombustibles}

Las industrias de bioetanol y biodiesel han venido creciendo sostenidamente durante las últimas décadas, particularmente en Latinoamérica y Estados Unidos; y en menor escala en Europa. Las figuras 3.47a y 3.47b muestran respectivamente la 
evolución de la producción de bioetanol y de biodiesel durante el período 2005-2010 y la distribución de tal producción por países al final de dicho lapso.

Para el año 2010, el volumen de bioetanol producido fue de 86.000 millones de litros casi triplicando la producción del combustible en el año 2005. Estados Unidos y Brasil encabezan la lista de productores de bioetanol con un $90 \%$ de la producción a nivel mundial. Estados Unidos produjo 49.000 millones de litros de bioetanol y se convirtió en exportador neto enviando 1.300 millones de litros principalmente a Canadá, Jamaica, Holanda, los Emiratos Árabes Unidos y Brasil [REN21, 2011]. La distribución interna del bioetanol producido se realiza a través de estaciones de E85, una mezcla de gasolina y bioetanol con un contenido de $15 \%$ del alcohol.

Para el mismo año, Brasil produjo 28.000 millones de litros de bioetanol [REN21, 2011]. En el país, más de un $95 \%$ de las ventas de vehículos nuevos son unidades flexibles; esto es, pueden usar etanol, gasolina o una mezcla de ambos; y las estaciones de servicio venden etanol puro y gasohol, una mezcla $25 \%$ en etanol y $75 \%$ de gasolina. China fue el principal productor en Asia con 2.000 millones de litros. En mucha menor proporción, otros países productores de bioetanol fueron Alemania, Francia, España, Canadá y Colombia [REN21, 2011].

(b) PRODUCCIÓN DE BIOETANOL Y BIODIESEL, 2005-2010

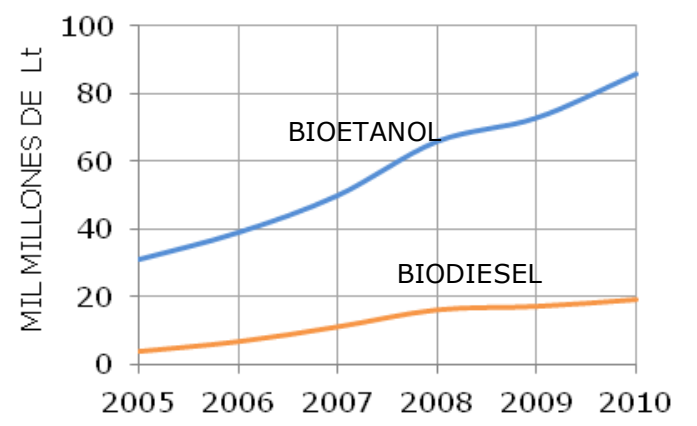

Fuente de datos: REN21, 2011 (a) PRODUCCIÓN DE BIOETANOL Y BIODIESEL, 2010.

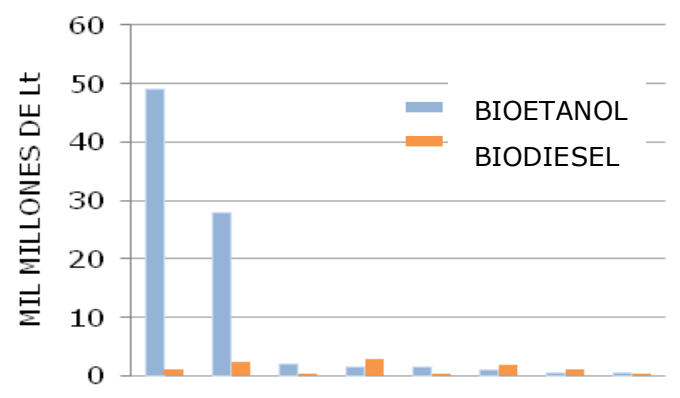

EU BR CH FR CA AL ES AR

Figura 3.47 (a) Producción de bioetanol y biodiesel, 2005-2010.

(b) Producción de bioetanol y biodiesel, 2010 
La producción de biodiesel se quintuplicó en el período 2005-2010 alcanzando 19.000 millones de litros para el el año 2010; sin embargo, aún es mucho menor que la producción de bioetanol. La Unión Europea es líder en la producción mundial de biodiesel con más de 10 mil millones de litros producidos durante el año 2010. Individualmente, Alemania lidera la lista de mayores productores de biodisel con 2.900 millones de litros producidos, seguido de Brasil, Francia y los Estados Unidos [REN21, 2011].

\subsection{Biorefinerías}

Una biorefinería es un conjunto de procesos de conversión para transformar biomasa en combustibles, potencia eléctrica, calor, químicos, alimentos y materiales diversos. El concepto es análogo al de una refinería de petróleo; así, podría producir combustibles líquidos en volúmenes que permitan cumplir con las necesidades del país sede y/o menor cantidad productos de alto valor agregado, mientras genera electricidad y calor para su propio uso o para su venta. Para ello, puede emplear una amplia variedad de procesos de conversión: térmicos, químicos y biológicos; y los tamaños adecuados de instalaciones. La optimización en el uso de los recursos y una alta eficiencia contribuirán a la consolidación de una industria basada en la biomasa rentable desde el punto de vista económico y sostenible en el tiempo [King et al, 2010; NREL, 2009b].

El Laboratorio Nacional para Energías Renovables (NREL, por sus siglas en inglés) ha venido desarrollando investigaciones sobre dos plataformas diferentes; una, basada en procesos de conversión bioquímicos con foco en la fermentación de azúcares contenidos en la biomasa; y otra basada en procesos termoquímicos de conversión con foco en la gasificación de biomasa y subproductos de procesos de conversión [NREL, 2009b]. Plantas de segunda generación para procesar material celulósico están siendo probadas a escala pre-comercial para la producción de biocombustibles a escala industrial [King et al. 2010, IEA, IEA, 2011f]. Recientemente se ha conformado un grupo de trabajo con participación de Estados Unidos, Canadá y algunos países europeos para el estudio de opciones futuras en el área [IEA, 2012b]. 


\subsubsection{Intercambio comercial de biomasa y biocombustibles}

El intercambio comercial de residuos forestales y agrícolas, y de biocombustibles como aceite vegetal, bioetanol y biodiesel se ha incrementado en los últimos años. Algunos de los países en vías de desarrollo poseen un elevado potencial de biomasa y costos de tierra y mano de obra relativamente bajos, pero su demanda no es suficiente para agotar el potencial que poseen; en consecuencia, la exportación de los excedentes constituye una oportunidad para el incremento de su ingreso y de puestos de trabajo. Por su parte, el país importador tiene la posibilidad de obtener a precios convenientes una fuente renovable de energía que contribuirá con sus metas de reducción de emisiones a atmósfera y con su seguridad energética.

La figura 3.48 muestra de manera esquemática las principales rutas de comercio de las materias bioenergéticas de mayor importancia hoy día, desde el punto de vista de su mercadeo internacional. No se muestran los flujos entre países de la misma región.

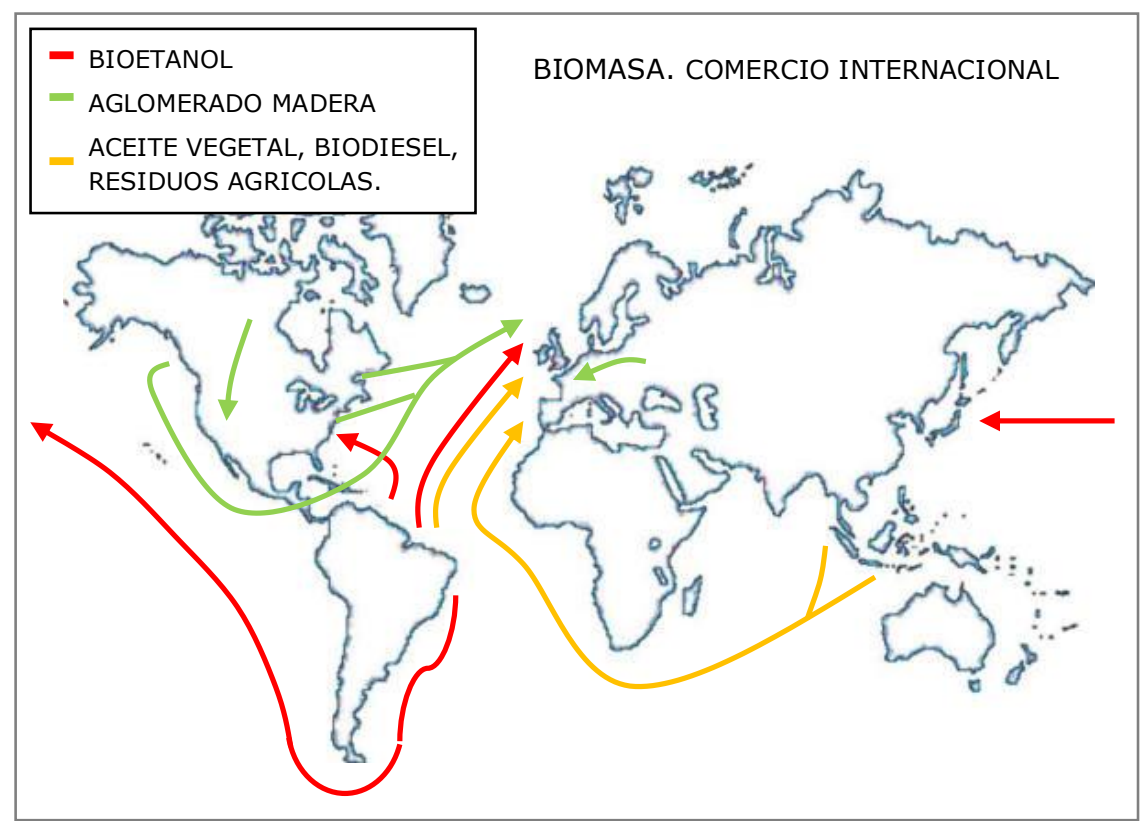

Fuente de datos: [Bauen et al., 2010]

Figura 3.48. Esquema de rutas de comercio internacional de biomasa 
El intercambio comercial de biomasa constituye sólo un $2 \%$ del consumo actual de bioenergía; esto es, aproximadamente $1 \mathrm{EJ} / a n ̃ o$. El mayor exportador de bioetanol es Brasil que aporta alrededor de la mitad del volumen total exportado; y los principales importadores son Japón, Suecia, Bélgica, Holanda y el Reino Unido [Juginger et al., 2008]. Por su parte, los residuos forestales aglomerados o en briquetas son exportados primordialmente por Canadá y Finlandia, y en menor proporción por Brasil y Noruega; y son importados por Suecia, Bélgica, Holanda y el Reino Unido donde contribuyen con una fracción importante de la generación de electricidad a partir de fuentes renovables [Juginger et al., 2008]. Finalmente, los aceites vegetales y el biodiesel son exportados principalmente desde el Sureste de Asia y Latinoamérica hacia Estados Unidos y Europa [Bauen et al., 2010].

A más largo plazo, se estima que podrán ser comercializados volúmenes mayores de biomasa entre Latinoamérica y el África Subsahariana como exportadores netos y, Norteamérica, Europa y Asia como importadores netos [Bauen et al., 2010]. Para ello, el precio de la biomasa debe competir con el precio de los combustibles fósiles y su consumo ser favorecido por incentivos en los países importadores. Adicionalmente, la infraestructura logística en países exportadores e importadores debe ser modernizada para poder manejar eficientemente mayores volúmenes de biomasa y deben ser desarrollados estándares de calidad y un sistema de certificación de producción sostenible.

\subsubsection{Bioenergía: políticas públicas}

El apoyo que los gobiernos pueden dar al desarrollo del sector de las energías renovables y en particular al sector de la bioenergía es esencial, al menos en el corto y mediano plazo. Actualmente, unos 118 países han implementado algún tipo de políticas que favorecen el desarrollo de las energías renovables. En líneas generales, las mismas pueden agruparse en tres grandes grupos:

- Políticas de cuotas de participación en el mercado a plazos determinados. Aproximadamente 96 países incluyendo los 27 miembros de la Unión Europea, han establecido objetivos o metas de participación de energías renovables en sus respectivas mezclas energéticas, a fechas determinadas. Los objetivos se 
expresan como fracciones de renovables en el consumo de energía primaria o de energía final, a nivel regional, nacional o estadal, en subsectores como la generación eléctrica, la producción de calor y la fabricación de biocombustibles. En la Comunidad Europea, doce países han fijado metas $\geq 20 \%$ de participación de energías renovables en su consumo de energía final, para el año 2020. [REN21, 2011] y la meta promedio es igual a un $20 \%$ de participación. Otros países que han fijado metas de participación de renovables en sus planes nacionales son Brasil, China e India; entre otros [REN21, 2011].

Un caso particular de la política de cuotas es el Estándar de Portafolio de Renovables (RPS, por sus siglas en inglés) de acuerdo al cual se exige a las empresas comercializadoras de electricidad tener un cierto porcentaje de potencia derivada de fuentes renovables en la mezcla ofertada, a un plazo determinado. Las políticas RPS pueden relacionarse con esquemas de "Certificados Verdes" o "Créditos de Energía Renovable" (REC, por sus siglas en é) para añadir flexibilidad y permitir a las empresas suplidoras de electricidad cumplir con su cuota a través de la negociación de los créditos. A inicios del año 2011, existían políticas RPS en 10 países y unas 50 jurisdicciones a nivel estadal/provincial [REN21, 2012]

- Tarifas de alimentación a la red de distribución eléctrica (FIT, por sus siglas en inglés). Este tipo de instrumento obliga a las empresas que suplen electricidad a comprar toda la electricidad inyectada a la red procedente de fuentes renovables a precios mínimos establecidos por las autoridades. Los precios son fijos, están garantizados por un período de tiempo determinado; y en general, son más altos que el precio regular de mercado. Adicionalmente, se establece la obligación por parte de las empresas distribuidoras de garantizar el acceso a las redes eléctricas de las centrales productoras. [Sawin, 2004]. A principios del año 2001, Al menos 61 países y 26 estados o provincias (Estados Unidos, Canadá, y Australia) habían implementado este tipo de instrumento normativo [REN21, 2011].

Una variación de las políticas de fijación de precios es el sistema de medición neta descrito anteriormente en este documento. El sistema permite a consumidores propietarios de pequeños sistemas de generación eléctrica basados en fuentes 
renovables, vender su excedente de electricidad a las empresas de servicio eléctrico. El exceso es vendido a los precios vigentes al por mayor. Actualmente, el sistema existe en 14 países y gran parte del territorio de los Estados Unidos [REN21, 2011].

- Oferta de subsidios a la inversión, descuentos en las tasas de importación, créditos en el pago de impuestos, fondos especiales para préstamos a bajo interés y similares son incentivos que se ofrecen a menudo, en forma individual o combinada, como un apoyo al desarrollo del sector de energías renovables [REN21, 2011].

La implementación de una u otra política de apoyo, o de una combinación de ellas, debe tomar en cuenta las fortalezas del país sede y las características de las tecnologías bajo consideración, de forma de favorecer la competitividad económica de la explotación de los recursos disponibles y de aumentar su atractivo a los inversionistas. Las políticas implementadas serán tanto más exitosas en tanto formen parte de un claro plan a largo plazo para el país que tenga en cuenta además de los elementos técnicos y económicos, los aspectos de disponibilidad o potencialidad de la materia prima, el acceso al mercado de los productos finales, los aspectos ambientales y sociales relacionados; y el marco legal, administrativo y logístico de ejecución.

La tabla 3.3 muestra los instrumentos más importantes de políticas públicas utilizados para apoyar el desarrollo y aprovechamiento de la biomasa en los sectores de producción de calor, electricidad y combustibles para el transporte, en algunos de los países industrializados y en vías de desarrollo en el mundo.

Particularmente en el sector de generación eléctrica, el establecimiento de precios especiales a toda la electricidad derivada de la biomasa que es inyectada a las redes (FIT) y el acceso prioritario a las mismas se ha convertido gradualmente en el mayor incentivo para la introducción y desarrollo de nuevas tecnologías en el área. Además son importantes los elementos técnicos y económicos, los aspectos de disponibilidad o potencialidad de la materia prima, el acceso al mercado de los productos finales, 
los aspectos ambientales y sociales relacionados; y el marco legal, administrativo y logístico de ejecución.

El éxito en el diseño y aplicación de las tarifas radica en que permitan atraer al inversionista ante la expectativa de una rentabilidad económica adecuada. Las políticas FIT se aplican de manera satisfactoria en Estados Unidos, Francia, Alemania, Italia, el Reino Unido, China e India; y el acceso prioritario a la red está establecido en los mismos países con excepción de Francia.

Tabla 3.3. Políticas públicas de apoyo al sector de renovables, 2010

\begin{tabular}{|c|c|c|c|c|c|c|c|}
\hline \multirow{3}{*}{ PAÍS } & \multicolumn{6}{|c|}{ POLÍTICAS REGULATORIAS } & \multirow{3}{*}{$\begin{array}{c}\text { SUBSIDIOS } \\
\text { FINANCIEROS } \\
\text { MEDIDAS } \\
\text { FISCALES, etc }\end{array}$} \\
\hline & \multirow{2}{*}{$\begin{array}{l}\text { POLÍTICAS } \\
\text { FIT }\end{array}$} & \multirow{2}{*}{$\begin{array}{c}\text { POLÍTICAS } \\
\text { RPS }\end{array}$} & \multirow{2}{*}{$\begin{array}{l}\text { MEDICIÓN } \\
\text { NETA }\end{array}$} & \multicolumn{2}{|c|}{ OBLIGACIÓN/MANDATO } & \multirow{2}{*}{$\begin{array}{c}\text { POLÍTICAS } \\
\text { REC }\end{array}$} & \\
\hline & & & & BIOCOMB & CALOR & & \\
\hline Estados Unidos & $\sqrt{ }(1)$ & $\sqrt{ }(1)$ & $\sqrt{ }(1)$ & $\sqrt{ }$ & $\sqrt{ }(1)$ & $\sqrt{ }(1)$ & $\sqrt{ }$ \\
\hline Canadá & $\sqrt{ }(1)$ & $\sqrt{ }(1)$ & $\sqrt{ }$ & $\sqrt{ }$ & & & $\sqrt{ }$ \\
\hline Francia & $\sqrt{ }$ & & & & & $\sqrt{ }$ & $\sqrt{ }$ \\
\hline Alemania & $\sqrt{ }$ & & & $\sqrt{ }$ & $\sqrt{ }$ & & $\sqrt{ }$ \\
\hline Italia & $\sqrt{ }$ & $\sqrt{ }$ & $\sqrt{ }$ & $\sqrt{ }$ & $\sqrt{ }$ & $\sqrt{ }$ & $\sqrt{ }$ \\
\hline Reino Unido & $\sqrt{ }$ & $\sqrt{ }$ & & $\sqrt{ }$ & & & $\sqrt{ }$ \\
\hline España & $\sqrt{ }$ & & & $\sqrt{ }$ & $\sqrt{ }$ & & $\sqrt{ }$ \\
\hline Japón & $\sqrt{ }$ & $\sqrt{ }$ & $\sqrt{ }$ & & & $\sqrt{ }$ & $\sqrt{ }$ \\
\hline
\end{tabular}

\begin{tabular}{|l|c|c|c|c|c|c|c|}
\hline Brasil & $\sqrt{ }$ & & & $\sqrt{ }$ & & & $\sqrt{ }$ \\
\hline China & $\sqrt{ }$ & $\sqrt{ }$ & & $\sqrt{ }$ & & $\sqrt{ }$ & $\sqrt{ }$ \\
\hline India & $\sqrt{ }$ & $\sqrt{ }$ & & & & & $\sqrt{ }$ \\
\hline México & & & $\sqrt{ }$ & & & & $\sqrt{ }$ \\
\hline Suráfrica & $\sqrt{ }$ & & & & & $\sqrt{ }$ & $\sqrt{ }$ \\
\hline
\end{tabular}

(1) Sólo en algunos estados/provincias.

Adaptado de REN21, 2011

Bajo el programa ProAlcool, Brasil ha sido el líder mundial en el uso de mezclas bioetanol-gasolina como una alternativa de combustible para vehículos automotores. Por mandato legal, la proporción de bioetanol en las mezclas se ha mantenido entre $20 \%$ y $25 \%$ en volumen. La medida se ha acompañado del requerimiento de venta 
de gasohol (E25) y etanol puro (E100) a la red de estaciones de servicio, y de incentivos fiscales para la producción o adquisición de vehículos flexibles que puedan funcionar con mezclas o con etanol puro. En el año 2008, Brasil inició además la mezcla de biodiesel en proporciones de $2 \%$ (B2) y 3\% (B3) y diesel; y en el 2010, un nuevo mandato incrementó la proporción de biodiesel a 5\% (B5).

Otros mandatos para mezclar biocombustibles líquidos con combustible para vehículos han sido promulgados a nivel estadal o provincial en Estados Unidos, Canadá, China e India; y en unos 14 países a nivel nacional. Las proporciones oscilan entre $10 \%$ y $15 \%$ de bioetanol en mezclas con gasolina, y de $2 \%$ a $5 \%$ de biodiesel en mezclas con diesel [REN21, 2011].

Paralelamente a los instrumentos señalados, los gobiernos aprueban con mucha frecuencia subsidios a la inversión y a la producción de calor, electricidad y combustibles derivados de la biomasa; y diferenciación fiscal con relación al uso de combustibles fósiles en las mismas actividades. El cuadro 3.3 refleja la extensión de este tipo de instrumentos como apoyo al desarrollo del sector de la bioenergía.

Los gobiernos pueden adelantar políticas de apoyo a los sectores relacionados con la cadena de suministro y con la comercialización de los productos derivados de ella; y políticas de información dirigidas a captar su aceptación por parte de la sociedad. Así, el soporte financiero a la investigación para identificar nuevos cultivos y mejorar los rendimientos en el sector agrícola; la evaluación de las tierras disponibles, la planificación de su uso y el mejoramiento de sus condiciones físicas y de la infraestructura necesaria para su explotación; y el apoyo al desarrollo de mejores técnicas de producción y manejo de las cultivos y bosques, influirán sin duda en su productividad y por tanto en la disponibilidad de la biomasa necesaria para la generación de calor, electricidad o biocombustibles. De manera similar, el mejoramiento de la infraestructura necesaria para facilitar el acceso a la materia prima o a las redes de distribución eléctrica, y políticas como la estandarización de las características de productos y materias primas fortalecerían la fluidez y transparencia en su comercio; y conjuntamente con políticas de información oportunas ayudarían a construir la confianza pública en el sector 


\subsection{Certificación de sustentabilidad}

Como ya se ha señalado, el creciente uso y producción de la biomasa como fuente renovable de energía ha creado un mercado internacional donde se comercian diferentes tipos de biomasa y de biocombustibles procedentes de la remoción de residuos de bosques y sistemas agrícolas, y del cultivo y procesamiento de biomasa dedicada a la producción de energía. Tales actividades, si no son manejadas adecuadamente pueden afectar negativamente el medio ambiente, el volumen de gases invernadero emitidos a la atmósfera, el patrón de usos de las tierras agrícolas disponibles y las condiciones socio-económicas de las poblaciones locales involucradas. Ante esta situación, la sostenibilidad de la producción de biomasa y de los procesos utilizados para su transformación en productos energéticos se ha convertido en un tema de discusión [REN21, 2010; Bauen et al., 2010; Van Dam et al., 2008; Buchholtz et al., 2009; Lewandowski y Faaij, 2006]; y actualmente, una certificación de sostenibilidad se considera como un posible requisito para el acceso a los mercados.

La certificación es un mecanismo mediante el cual un actor independiente evalúa el cumplimiento de un grupo predeterminado de requerimientos que en general, se formulan como criterios que deben ser aprobados por el producto o por el proceso de producción a certificar. Por su parte, La sostenibilidad tiene que ver con el cumplimiento de mínimos estándares económicos, sociales y ambientales.

Sólo pocos países han tomado la iniciativa de trabajar en el desarrollo de un sistema de certificación de sostenibilidad de los procesos y/o productos relacionados a las cadenas de suministro, transformación, generación de productos y distribución de la biomasa. Bélgica, Holanda, el Reino Unido, se encuentran entre ellos; y con una menor participación, Brasil, Alemania, Canadá y los Estados Unidos. [Van Dam et al., 2008]. El problema es complejo; sin embargo varias iniciativas dirigidas a la certificación de la bioenergía se han elaborado dentro de un marco de principios básicos [Van Dam et al., 2008; Bauen et al., 2010], entre los cuales se cuentan: 
- El balance de gases invernadero procedentes de la cadena de explotación y uso de la biomasa debe ser positivo; esto es, deben reducirse las emisiones de gases invernadero comparadas con su alternativa de referencia de energía fósil.

- El balance de energía de la cadena de explotación de la biomasa debe ser positivo; esto es, debe producir más energía que la que se consume en la producción, transporte y conversión de la biomasa y en la distribución de los productos derivados.

- La producción de biomasa para la obtención de energía no debe comprometer el suministro de alimentos y/o de materiales para diferentes usos.

- La producción de biomasa no debe vulnerar la biodiversidad; por el contrario, si es posible debe fortalecerla.

- En la producción y conversión de biomasa debe mantenerse o mejorarse la calidad del suelo, de las aguas subterráneas y superficiales, y del aire.

- La producción de la biomasa debe contribuir a la prosperidad local y al bienestar de los trabajadores y de las poblaciones involucradas.

Organizaciones públicas y privadas a nivel nacional trabajan en el diseño de criterios, indicadores y en la obtención de estándares mínimos para la certificación. A nivel supranacional, la Unión Europea trabaja en un sistema de certificación de biomasa sustentable para la región [Van Dam et al., 2008]. Sin embargo, hay diferencias mutuas en la extensión, rigurosidad y nivel de detalle de tales criterios e indicadores, y en la metodología para la estimación de los últimos. Es necesaria una mejor coordinación internacional para mejorar la coherencia y eficacia de las iniciativas nacionales o locales; ello dará un rumbo a las actividades a desarrollar y evitará la proliferación de sistemas de certificación independientes.

La certificación no es un objetivo en sí mismo sino uno de los medios para garantizar la sostenibilidad de la biomasa como fuente energética alternativa. Su combinación con otras políticas gubernamentales, el incremento en las eficiencias y el uso de las mejores prácticas en todas las etapas de la cadena de producción y uso de la biomasa, indudablemente redundarán en el aseguramiento de su participación en el consumo energético mundial. 


\subsubsection{Efectos sobre el ambiente y comentarios finales}

Hoy día, la biomasa es el mayor contribuyente de energía renovable al suministro de energía primaria a nivel mundial y se estima que tiene el potencial para colaborar de manera sostenible en la satisfacción de la demanda de energía de los próximos años. Sin embargo, su participación en los mercados futuros de energía dependerá de factores como la disponibilidad de los terrenos necesarios para la producción de la biomasa, su acceso al agua, su productividad y su costo de producción; el desarrollo e implementación de nuevas tecnologías de conversión energética y económicamente competitivas frente a otras opciones de fuentes renovables o no; la presencia de la infraestructura adecuada y de sistemas modernos y eficientes de apoyo logístico de acopio, transporte y conversión de la materia prima, la posibilidad de acceso a los mercados y a las redes de distribución del producto final, la existencia de políticas gubernamentales que favorezcan su incorporación a la mezcla energética mundial; y finalmente, la aceptación por parte de la sociedad de los productos derivados de la biomasa y de su precio frente a los precios de los combustibles fósiles y de otras opciones energéticas renovables.

Un plan estratégico a largo plazo para el desarrollo de la bioenergía deberá tomar en cuenta los aspectos económicos, los efectos ambientales y las repercusiones sociales sobre las comunidades involucradas. Sin la consideración de los impactos ambientales, el aumento de la producción de biomasa podría disminuir la biodiversidad y desmejorar la calidad del suelo, del agua, del aire y del hábitat. Si los aspectos sociales no se incluyen en el análisis, el incremento en la producción de biomasa colocaría una presión adicional sobre otros usos de la tierra comprometiendo la seguridad alimentaria. Y si el incremento en la producción y uso de biomasa no se coordina con objetivos más amplios de conservación del ambiente, incremento de eficiencias y reducción del consumo global de energía en el planeta, es probable que la bioenergía tenga un impacto menos importante que el esperado sobre el consumo global de energía.

Si por el contrario, los elementos antes enumerados concurren y el manejo de todo el proceso se realiza de forma eficaz, el sector bioenergía puede incrementar su participación en la mezcla energética mundial y hacerlo en forma sostenible, 


\subsection{Resumen}

Desde siempre, la disponibilidad de recursos energéticos en sus múltiples formas y la capacidad de transformarlos de forma eficiente en electricidad, calor y/o combustibles útiles al hombre, ha sido un factor clave en el desarrollo económico de los pueblos y en el mejoramiento de su calidad de vida.

En las páginas anteriores se han resumido los resultados de una investigación sobre el sector energético en el mundo. Además de los artículos especializados en el área fueron consultados publicaciones de organismos, empresas e instituciones reconocidos internacionalmente, entre las cuales destacan:

- British Petroleum (BP), Reino Unido

- Intergovernmental Panel for the Climate Change (IPCC), Suiza

- International Atomic Energy Agency (IEAA), Austria

- International Energy Agency (IEA), Francia

- Natural Renewable Energy Laboratory (NREL), Estados Unidos

- Nuclear Energy Agency (NEA), Francia

- Organization of Petroleum Exporting Countries (OPEC), Suiza

- Renewable Energy Policy Network for the 21th Century (REN21), Francia

- Petróleos de Venezuela (PDVSA), Venezuela

- The World Bank, Estados Unidos

- U.S. Department of Energy (U.S. DOE), Estados Unidos

- U.S. Energy Information Association (U.S. EIA), Estados Unidos

- World Coal Association (WCA), Reino Unido

- World Energy Council (WEC), Reino Unido

- World Wind Energy Association (WWEA), Alemania

- World Nuclear Association (WNA), Alemania

Las tablas 3.4 y 3.5 resumen el conocimiento adquirido en la investigación realizada y servirán de insumo a la próxima etapa en el trabajo objeto de este documento; esto es, la identificación, selección y validación de un grupo de criterios e indicadores que sirvan como base para la evaluación integral de proyectos en el sector energético. 
Tabla 3.4. Caracterización del sector energético - Energías no renovables (1)

\begin{tabular}{|c|c|c|c|}
\hline FUENTE & INFORMACIÓN GENERAL & VENTAJAS & DESVENTAJAS \\
\hline $\begin{array}{c}\text { PETRÓLEO } \\
\text { CONVENCIONAL }\end{array}$ & $\begin{array}{l}\text { - Mezcla viscosa de hidrocarburos, líquida } \\
\text { a condiciones P y T del yacimiento. } \\
\text { - Reservas probadas: } 1,4-1,5 \text { bill. bbls. } \\
\text { - R. [probadas+ posibles]: 2,4 bill.bbls. } \\
\text { - Producción 2010: } 82,1 \text { millones bbls/dia } \\
\text { (Países OPEP, } 41,5 \% \text { ). } \\
\text { - Tecnología de extracción: perforación } \\
\text { en tierra o costa afuera, extracción } \\
\text { natural o asistida. } \\
\text { - Tecnología de conversión: } \\
\text { mejoramiento de crudo, destilación, } \\
\text { craqueo catalítico, hidrocraqueo, otros } \\
\text { procesos. } \\
\text { Capacidad de refinación instalada } 2008 \text { : } \\
88,6 \text { millones bbls/día. } \\
\text { - Productos: gas, gasolina, diesel, fueloil, } \\
\text { aceites, asfalto y otros. } \\
\text { - Transporte: por tuberías, camiones y } \\
\text { tanqueros. }\end{array}$ & $\begin{array}{l}\text { - Mercado consolidado. } \\
\text { - Ingresos importantes para países } \\
\text { exportadores. } \\
\text { - Tecnologías de extracción y conversión } \\
\text { probadas. } \\
\text { - Industria consolidada con profesionales } \\
\text { capacitados. } \\
\text { - Fuente de empleos. } \\
\text { - Bajos costos en comparación con otras } \\
\text { fuentes de energía. } \\
\text { - Usos múltiples en diferentes sectores: } \\
\text { como combustible en el sector } \\
\text { doméstico, comercial, industrial (calor, } \\
\text { electricidad) y en el sector transporte; y } \\
\text { como materia prima en el sector } \\
\text { petroquímico. }\end{array}$ & $\begin{array}{l}\text { - Distribución no uniforme de las } \\
\text { reservas => falta de seguridad } \\
\text { energética para importadores. } \\
\text { - Agotamiento de yacimientos a una tasa } \\
\text { media mundial de } 6,7 \% \text {, una vez } \\
\text { alcanzado el pico de producción. } \\
\text { - Puede contener } \mathrm{S} \text { y metales pesados } \\
=>\text { tratamiento previo del crudo. } \\
\text { - Precios volátiles hacia el alza. } \\
\text { - La combustión de sus productos } \\
\text { derivados provoca emisiones elevadas } \\
\text { de } \mathrm{CO}_{2} \text { y otros gases invernadero a la } \\
\text { atmósfera. } \\
\text { - Riesgo de derrames que provocan alta } \\
\text { contaminación ambiental, en la } \\
\text { extracción y transporte del crudo. } \\
\text { - Difícil disposición de subproductos (S) } \\
\text { en mejoramiento del crudo. }\end{array}$ \\
\hline $\begin{array}{l}\text { ESQUISTOS } \\
\text { BITUMINOSOS }\end{array}$ & $\begin{array}{l}\text { - Roca sedimentaria con alto contenido } \\
\text { de kerógeno. } \\
\text { - Potencial mundial aproximado: } 2,8 \\
\text { billones bbls, de los cuales } 1,5 \text { billones } \\
\text { bbls en USA. } \\
\text { - Escasamente explotados. } \\
\text { - Tecnología de extracción: minería de } \\
\text { superficie o bajo tierra. } \\
\text { - Tecnología de conversión: tratamiento } \\
\text { térmico a temperaturas altas en } \\
\text { ausencia de } \mathrm{O}_{2} \text {. Posterior mejoramiento } \\
\text { hasta crudo sintético. }\end{array}$ & $\begin{array}{l}\text { - Gran volumen de reservas. } \\
\text { - Puede ser una opción energética si se } \\
\text { dispone de reservas, se mejora la } \\
\text { tecnología disponible y los costos llegan } \\
\text { a competir con el precio de petróleo en } \\
\text { el mercado. } \\
\text { - Se experimenta con una tecnología de } \\
\text { conversión in situ (ICP) que produce } \\
\text { una mezcla de hidrocarburos de } 34^{0} \mathrm{API} \\
\text { aproximadamente y bajo contenido de } \\
\text { azufre. Disminuye los problemas que } \\
\text { ocasiona la minería y reduce costos. }\end{array}$ & $\begin{array}{l}\text { - Su explotación causa alteración del } \\
\text { terreno donde se efectúa la minería. } \\
\text { - Problemas de disponibilidad de la roca } \\
\text { agotada. } \\
\text { - Uso de fuentes de agua e impactos } \\
\text { sobre la calidad de la misma. } \\
\text { - Cada etapa en la explotación del } \\
\text { esquisto y la combustión de los } \\
\text { productos derivados arrojan emisiones } \\
\text { elevadas de } \mathrm{CO}_{2} \text { a la atmósfera. } \\
\text { - Difícil disposición de subproductos del } \\
\text { mejoramiento: } \mathrm{S} \text { y coque. }\end{array}$ \\
\hline
\end{tabular}


Tabla 3.4. Caracterización del sector energético - Energías no renovables (2)

\begin{tabular}{|c|c|c|c|}
\hline FUENTE & INFORMACIÓN GENERAL & VENTAJAS & DESVENTAJAS \\
\hline $\begin{array}{c}\text { ARENAS } \\
\text { ASFÁLTICAS }\end{array}$ & $\begin{array}{l}\text { - Arena, agua y bitumen en depósitos } \\
\text { cercanos a la superficie, presencia de } \mathrm{S} \text {, } \\
\mathrm{N} \text { y metales pesados, densidad < } 10^{\circ} \\
\text { API, viscosidad }>10000 \mathrm{cp} \text {. } \\
\text { - Localización mayoritaria en Alberta, } \\
\text { Canadá. Bitumen original en sitio: } 1,7 \\
\text { billones bbls, } 10 \% \text { recuperable. } \\
\text { - Producción } 2010: 1,6 \times 10^{6} \text { bbls/día, } \\
\text { Canadá } \\
\text { - Tecnología de extracción: explotación } \\
\text { superficial o in situ con estimulación de } \\
\text { vapor. Transporte hacia mejoramiento: } \\
\text { por tuberías previo calentamiento y/o } \\
\text { mezcla con diluyente. } \\
\text { - Mejoramiento: reducción de } \mathrm{N}, \mathrm{S} \text { y } \\
\text { metales pesados, reducción de } \\
\text { viscosidad y densidad. } \\
\text { - Capacidad refinación } 2010: 1,3 \text { millones } \\
\text { bbls/dia. Producto: crudo sintético } \\
\text { procesable en refinerías ad-hoc. }\end{array}$ & $\begin{array}{l}\text { - Gran volumen de reservas. } \\
\text { - Opción energética si los costos } \\
\text { compiten con precios de petróleo } \\
\text { - Ingresos para países exportadores. } \\
\text { - Tecnologías de extracción y transporte } \\
\text { probadas. } \\
\text { - Investigación y desarrollo dinámicos, } \\
\text { (i) Nuevas tecnologías de extracción a } \\
\text { escala comercial (CSS y SAGD). } \\
\text { (ii) Nuevas tecnologías en fase } \\
\text { experimental (THAI) con recuperación } \\
\text { hasta } 80 \% \text { del bitumen en sitio y } \\
\text { disminución en el consumo de energía, } \\
\text { agua y emisiones a la atmósfera } \\
\text { - Tecnologías de mejoramiento probadas } \\
\text { con rendimientos entre } 0,8-0,9 \text { bbl } \\
\text { crudo sintético/bbl de bitumen. } \\
\text { - Industria en marcha, e empleos. }\end{array}$ & $\begin{array}{l}\text { - Viscosidad y densidad del bitumen muy } \\
\text { - Alevadas. } \\
\text { - Alto contenido de S, N y metales } \\
\text { - Tecnologías de extracción y transporte } \\
\text { complejos. Costos muy elevados. } \\
\text { - Minería superficial causa daños muy } \\
\text { importantes al terreno. } \\
\text { - Problemas de disponibilidad del } \\
\text { material residual en proceso de } \\
\text { explotación superficial. } \\
\text { - Elevado consumo de agua y energía, } \\
\text { especialmente en la explotación de las } \\
\text { arenas in situ. } \\
\text { - Su extracción, conversión y uso } \\
\text { provocan emisiones elevadas de } \mathrm{CO}_{2} \text { y } \\
\text { otros gases invernadero a la } \\
\text { atmósfera. } \\
\text { - Difícil disposición de subproductos (S) } \\
\text { en proceso de mejoramiento }\end{array}$ \\
\hline $\begin{array}{c}\text { PETRÓLEO } \\
\text { EXTRAPESADO }\end{array}$ & $\begin{array}{l}\text { - Crudos extremadamente, viscosos y } \\
\text { pesados, con S, N y metales pesados. } \\
\text { densidad < } 10^{\circ} \text { API, viscosidad } \leq \\
10000 \mathrm{cp} \text {. } \\
\text { - Predominantemente ubicados en la Faja } \\
\text { del Orinoco, Venezuela. Petróleo } \\
\text { original en sitio: 1,3 billones bbls, } \\
\text { Reservas probadas: } 170 \text { mil millones de } \\
\text { bbls. } \\
\text { - Producción 2009: } 898 \text { mil bbls/día }\end{array}$ & $\begin{array}{l}\text { - Gran volumen de reservas. } \\
\text { - Opción energética si costos compiten } \\
\text { con precios de petróleo convencional. } \\
\text { - Existe integración entre el productor del } \\
\text { crudo sintético, el mejoramiento y el } \\
\text { refinador }=>\text { disminuye el riesgo de } \\
\text { competir con crudo de mejor calidad. } \\
\text { - Ingresos adicionales por exportación }\end{array}$ & $\begin{array}{l}\text { - Viscosidad y densidad del petróleo muy } \\
\text { elevadas lo que dificulta y encarece su } \\
\text { extracción, manejo y envío a través de } \\
\text { tuberías. } \\
\text { - Alto contenido de S y metales pesados } \\
\text { => mejoramiento del crudo } \\
\text { - Procesos de extracción y } \\
\text { mejoramiento más complejos, } \\
\text { contaminantes del ambiente y } \\
\text { costosos. }\end{array}$ \\
\hline
\end{tabular}


Tabla 3.4. Caracterización del sector energético - Energías no renovables (3)

\begin{tabular}{|c|c|c|c|}
\hline FUENTE & INFORMACION GENERAL & VENTAJAS & DESVENTAJAS \\
\hline $\begin{array}{c}\text { PETRÓLEO } \\
\text { EXTRAPESADO }\end{array}$ & $\begin{array}{l}\text { - Tecnología de extracción: perforación } \\
\text { horizontal + bombas de cavidad } \\
\text { progresiva + bombas sumergibles. } \\
\text { - Transporte hacia mejoramiento: por } \\
\text { tuberías, previa mezcla con diluyente a } \\
\text { boca de pozo. } \\
\text { - Tecnología mejoramiento: recuperación } \\
\text { del diluyente, reducción de } \mathrm{N}, \mathrm{S} \text { y } \\
\text { metales pesados, reducción de } \\
\text { viscosidad y densidad. Capacidad } \\
\text { instalada: } 600 \text { mil bbls/d crudo sintético } \\
\text { - Producto: crudo sintético procesable en } \\
\text { refinerías ad-hoc. }\end{array}$ & $\begin{array}{l}\text { - Movilidad del petróleo a temperaturas } \\
\text { del yacimiento por lo que puede } \\
\text { extraerse en frio con menores costos y } \\
\text { recuperación entre } 8-12 \text {. } \\
\text { - Investigación y desarrollo dinámicos, } \\
\text { Nuevas tecnologías en fase } \\
\text { experimental con disminución en los } \\
\text { costos y, en el consumo de energía, } \\
\text { agua y emisiones a (THAI/CAPRI); } \\
\text { mejoramiento del petróleo in situ. } \\
\text { - Tecnologías de mejoramiento probadas } \\
\text { - Industria en marcha, fuente de } \\
\text { empleos. }\end{array}$ & $\begin{array}{l}\text { - Consumo de agua y energía. } \\
\text { - Difícil disposición de subproductos (S) } \\
\text { en proceso de mejoramiento. } \\
\text { - La combustión de sus productos } \\
\text { derivados produce emisiones elevadas } \\
\text { de } \mathrm{CO}_{2} \text { y otros gases invernadero a la } \\
\text { atmósfera. }\end{array}$ \\
\hline $\begin{array}{l}\text { GAS NATURAL } \\
\text { CONVENCIONAL }\end{array}$ & $\begin{array}{l}\text { - Mezcla primordialmente de metano y } \\
\text { etano que existe en reservorios bajo } \\
\text { tierra como gas asociado al petróleo o } \\
\text { gas no asociado. } \\
\text { - Reservas probadas: > } 180 \text { billones de } \\
\text { metros cúbicos. } \\
\text { - Reservas posibles: > } 400 \text { billones de } \\
\text { metros cúbicos } \\
\text { - Producción comercializada 2010: } 3,2 \\
\text { billones metros cúbicos estándar. } \\
\text { - Principales productores: Federación } \\
\text { Rusa ( } 19,6 \% \text { y USA (19,3\% ). } \\
\text { - Tecnología de extracción: perforación } \\
\text { en tierra o costa afuera, extracción } \\
\text { hasta declinación de la presión. } \\
\text { Recuperación en entre } 75-80 \% \text { del gas } \\
\text { original en sitio. }\end{array}$ & $\begin{array}{l}\text { - Volumen importante de reservas. } \\
\text { - Mercado consolidado. } \\
\text { - Ingresos adicionales para países } \\
\text { exportadores. } \\
\text { - No requiere procedimientos extensivos } \\
\text { de recuperación. Tecnologías probadas } \\
\text { y bajo costo relativo. } \\
\text { - Tecnologías de conversión y transporte } \\
\text { probadas. } \\
\text { - Usos múltiples en diferentes sectores: } \\
\text { como combustible en el sector } \\
\text { doméstico, comercial, industrial (calor, } \\
\text { electricidad), como materia prima en el } \\
\text { sector químico; y eventualmente, como } \\
\text { sustituto de la gasolina en el sector } \\
\text { vehicular (CNG y en menor proporción } \\
\text { LNG). }\end{array}$ & $\begin{array}{l}\text { - Agotamiento de yacimientos a una tasa } \\
\text { media mundial 7,5\%, una vez } \\
\text { alcanzado el pico de producción. } \\
\text { - El transporte de grandes volúmenes de } \\
\text { gas a través del océano o de grandes } \\
\text { distancias, es complejo y costoso. } \\
\text { Requiere (i) su conversión a gas } \\
\text { natural licuado (LNG) en el terminal de } \\
\text { embarque y regasificación del gas en } \\
\text { el terminal destino. Se traslada como } \\
\text { LNG en buques con tanques } \\
\text { criogénicos especialmente diseñados o } \\
\text { (ii) la compresión del gas (CNG) en el } \\
\text { terminal de embarque y la } \\
\text { despresurización en el terminal } \\
\text { destino. Se traslada como CNG en } \\
\text { buques especialmente diseñados. }\end{array}$ \\
\hline
\end{tabular}


Tabla 3.4 Caracterización del sector energético - Energías no renovables (4)

\begin{tabular}{|c|c|c|c|}
\hline FUENTE & INFORMACIÓN GENERAL & VENTAJAS & DESVENTAJAS \\
\hline $\begin{array}{l}\text { GAS NATURAL } \\
\text { CONVENCIONAL }\end{array}$ & $\begin{array}{l}\text { - Tecnología de mejoramiento: remoción } \\
\text { de impurezas y extracción de fracciones } \\
\text { más pesadas: líquidos de gas natural } \\
\text { (NGL) y gas de petróleo licuado (LPG). } \\
\text { - Productos: gas natural, NGL, LPG (gas } \\
\text { doméstico e industrial). } \\
\text { - Distribución del gas: por gasoductos, si } \\
\text { la distancia a los mercados hace la } \\
\text { operación técnica y económicamente } \\
\text { posible. } \\
\text { - Transporte gas natural a través de } \\
\text { océanos o largas distancias se realiza } \\
\text { como (i) gas licuado (LNG) en buques } \\
\text { con tanques criogénicos, o (ii) gas } \\
\text { comprimido (CNG) en cisternas } \\
\text { especiales. } \\
\text { - Usos: calor, generación de electricidad, } \\
\text { transporte e insumo al sector químico. }\end{array}$ & $\begin{array}{l}\text { - Posibilidad de cogeneración de } \\
\text { electricidad y calor que puede elevar la } \\
\text { eficiencia global de energía a niveles de } \\
80 \%, . \\
\text { - Posibilidad de utilizar un ciclo } \\
\text { combinado de una turbina de gas y una } \\
\text { turbina de vapor para producir energía } \\
\text { eléctrica. El sistema aprovecha el calor } \\
\text { en los gases de salida de la turbina de } \\
\text { gas para generar vapor que entra a la } \\
\text { turbina de vapor. Alcanza eficiencias } \\
\text { que oscilan entre } 50-60 \% \text {. } \\
\text { - El gas natural es el menos } \\
\text { contaminante (CO de todos los } \\
\text { combustibles fósiles. Su combustión } \\
\text { produce cantidades pequeñas de SO2 y } \\
\text { óxidos de nitrógeno y prácticamente } \\
\text { nada de cenizas y partículas sólidas. } \\
\text { - Industria consolidada, fuente de } \\
\text { empleos }\end{array}$ & $\begin{array}{l}\text { - Riesgo de escapes de gas de los pozos, } \\
\text { tanques de almacenamiento o } \\
\text { gasoductos. El principal componente } \\
\text { del gas natural es el metano, gas } \\
\text { invernadero mucho más potente en } \\
\text { sus efectos que el } \mathrm{CO}_{2} \text {. }\end{array}$ \\
\hline $\begin{array}{l}\text { GAS NATURAL } \\
\text { EN ARENAS } \\
\text { COMPACTAS }\end{array}$ & $\begin{array}{l}\text { - Gas no convencional en arenas muy } \\
\text { compactas, no porosas con } \\
\text { permeabilidades < a 0,1 x } 10^{-3} \text { darcy. } \\
\text { - Recursos recuperables: > } 200 \text { bill. } \mathrm{m}^{3} \text {. } \\
\text { - Producción 2009: } 256 \text { mil millones m3 } \\
\text { (64\% USA). } \\
\text { - Extracción: requiere el bombeo de } \\
\text { fluidos dentro la roca para fracturar la } \\
\text { roca lo que permite que el gas fluya } \\
\text { hacia el pozo productor. }\end{array}$ & $\begin{array}{l}\text { - Gran volumen de reservas. } \\
\text { - Opción energética si los costos } \\
\text { compiten con el precio de fósiles en el } \\
\text { mercado. } \\
\text { - Ingresos adicionales o ahorro de } \\
\text { egresos por factura energética. } \\
\text { - Oferta adicional en el mercado que } \\
\text { presiona los precios a la baja. } \\
\text { - Constante investigación para mejorar } \\
\text { eficiencias. Fuente de empleos. }\end{array}$ & $\begin{array}{l}\text { - Su extracción demanda un esfuerzo } \\
\text { considerable. } \\
\text { - Costos elevados. } \\
\text { - Su explotación causa contaminación } \\
\text { ambiental. } \\
\text { - Necesidad de grandes cantidades de } \\
\text { agua. } \\
\text { - A veces difícil acceso al sitio. } \\
\text { - Distancia del sitio de explotación a la } \\
\text { red de gasoductos existentes. }\end{array}$ \\
\hline
\end{tabular}


Tabla 3.4. Caracterización del sector energético - Energías no renovables (5)

\begin{tabular}{|c|c|c|c|}
\hline FUENTE & INFORMACIÓN GENERAL & VENTAJAS & DESVENTAJAS \\
\hline $\begin{array}{c}\text { METANO EN } \\
\text { LECHOS DE } \\
\text { CARBÓN }\end{array}$ & $\begin{array}{l}\text { - Metano presente en las fracturas entre } \\
\text { capas de carbón y/o adsorbido por el } \\
\text { mismo, en yacimientos carboníferos. } \\
\text { - Recursos recuperables: > } 250 \text { bill. m }{ }^{3} \text {. } \\
\text { - Producción 2009: } 70 \text { mil millones m3 } \\
\text { ( } 71 \% \text { USA). } \\
\text { - Extracción: requiere reducir la presión } \\
\text { del yacimiento bombeando el agua } \\
\text { atrapada en las capas del carbón, fuera } \\
\text { del mismo. } \\
\text { - Usos: calefacción, electricidad y materia } \\
\text { prima en procesos industriales. }\end{array}$ & $\begin{array}{l}\text { - Gran volumen de reservas. } \\
\text { - Opción energética si se dispone de } \\
\text { reservas y los costos compiten con } \\
\text { precios de fósiles en el mercado. } \\
\text { - Ingresos adicionales o ahorro de } \\
\text { egresos por factura energética. } \\
\text { - Sustracción de metano que puede } \\
\text { constituir una amenaza a la seguridad } \\
\text { de en minas de carbón, y un gas } \\
\text { invernadero } 20 \text { veces más poderoso en } \\
\text { su efectos que el CO2. }\end{array}$ & $\begin{array}{l}\text { - Explotación demanda un esfuerzo } \\
\text { mayor que el necesario para explotar } \\
\text { gas convencional. } \\
\text { - Costos elevados } \\
\text { - Su explotación causa contaminación } \\
\text { ambiental. } \\
\text { - A veces difícil acceso al sitio. } \\
\text { - Distancia del sitio de explotación a la } \\
\text { red de gasoductos existentes. }\end{array}$ \\
\hline $\begin{array}{c}\text { GAS DE } \\
\text { ESQUISTOS }\end{array}$ & $\begin{array}{l}\text { - Gas no convencional formado y retenido } \\
\text { en esquistos. } \\
\text { - Recursos recuperables: > } 450 \text { bill. } \mathrm{m}^{3} \text {. } \\
\text { - Producción 2009: } 67 \text { mil millones m3 } \\
\text { ( } 97 \% \text { USA). } \\
\text { - Extracción: requiere el bombeo de } \\
\text { fluidos para fracturar la roca que } \\
\text { permitan fluir al gas. Perforación } \\
\text { horizontal y direccional. }\end{array}$ & $\begin{array}{l}\text { - Gran volumen de reservas. } \\
\text { - Opción energética si se dispone de } \\
\text { reservas y los costos compiten con } \\
\text { precios de fósiles en el mercado. } \\
\text { - Ingresos adicionales o ahorro de } \\
\text { egresos por factura energética. } \\
\text { - Investigación para mejorar eficiencias. }\end{array}$ & $\begin{array}{l}\text { - Explotación demanda un esfuerzo } \\
\text { mayor que el necesario para explotar } \\
\text { gas convencional. } \\
\text { - Costos elevados. } \\
\text { - Su explotación causa contaminación } \\
\text { ambiental. } \\
\text { - A veces difícil acceso al sitio. } \\
\text { - Distancia del sitio de explotación a la } \\
\text { red de gasoductos existentes. }\end{array}$ \\
\hline $\begin{array}{l}\text { HIDRATOS DE } \\
\text { METANO }\end{array}$ & $\begin{array}{l}\text { - Clase de sustancia en la cual moléculas } \\
\text { de agua forman una red sólida que } \\
\text { encierra, sin enlace químico, moléculas } \\
\text { de metano. } \\
\text { - Presente en regiones permafrost árticas } \\
\text { y en aguas profundas de las } \\
\text { plataformas continentales en todo el } \\
\text { mundo. }\end{array}$ & $\begin{array}{l}\text { - Los hidratos de carbono pueden } \\
\text { contener mas carbono orgánico que el } \\
\text { contenido en las reservas actuales de } \\
\text { carbón, petróleo y gas convencional. } \\
\text { - Investigaciones sobre tecnologías para } \\
\text { la explotación ambientalmente segura } \\
\text { del recurso. Estudios sobre estabilidad } \\
\text { del fondo submarino. }\end{array}$ & $\begin{array}{l}\text { - Poco explotadas, poco conocida su } \\
\text { explotación. }\end{array}$ \\
\hline
\end{tabular}


Tabla 3.4. Caracterización del sector energético - Energías no renovables (6)

\begin{tabular}{|c|c|c|c|}
\hline FUENTE & INFORMACIÓN GENERAL & VENTAJAS & DESVENTAJAS \\
\hline CARBÓN & $\begin{array}{l}\text { - Roca sedimentaria estratificada que } \\
\text { contiene carbono con alguna cantidad } \\
\text { de azufre, hidrógeno, oxigeno, } \\
\text { nitrógeno y material que se transforma } \\
\text { en ceniza después de su combustión. } \\
\text { - Reservas probadas: } 861 \text { mil mill. ton. } \\
\text { presentes en más de } 70 \text { países. } \\
\text { - Producción 2010: } 3.731 \text { millones de } \\
\text { toneladas de petróleo equivalente. } \\
\text { - Extracción por minería superficial (90\% } \\
\text { recuperación del carbón en el sitio) o } \\
\text { bajo tierra. } \\
\text { - Mejoramiento: remoción de rocas, } \\
\text { tierra, ceniza, azufre y otros materiales. } \\
\text { - Transporte: en camiones, tren, } \\
\text { chalanas, barcos o como una } \\
\text { suspensión a través de tuberías. } \\
\text { - Usos: electricidad y calor. }\end{array}$ & $\begin{array}{l}\text { - Fuente de energía abundante y } \\
\text { ampliamente distribuida en el mundo. } \\
\text { - Precio del carbón < precio del petróleo } \\
\text { Precio del carbón < precio del gas } \\
\text { - Costos de explotación moderados. } \\
\text { - Avances tecnológicos para incrementar } \\
\text { eficiencias y/o minimizar impacto } \\
\text { ambiental en generación de electricidad } \\
\text { o calor I: captura y almacenamiento de } \\
\text { CO2 (CCS), gasificación integrada con } \\
\text { ciclo combinado (IGCC), gasificación de } \\
\text { carbón bajo tierra (UCG) y otros } \\
\text { (SCPC). Costos elevados. } \\
\text { - La tecnología para la conversión de } \\
\text { carbón a líquidos (CTL) permite obtener } \\
\text { combustibles de alta calidad para el } \\
\text { transporte, el sector doméstico y la } \\
\text { generación de electricidad. }\end{array}$ & $\begin{array}{l}\text { - Su combustión produce emisiones } \\
\text { importantes de CO2, óxidos de } \\
\text { nitrógeno, óxidos de azufre y partículas } \\
\text { en suspensión. } \\
\text { - Su explotación es muy contaminante } \\
\text { del ambiente. }\end{array}$ \\
\hline URANIO & $\begin{array}{l}\text { - Elemento radioactivo que se encuentra } \\
\text { como U3 O8 en concentraciones muy } \\
\text { bajas en la corteza terrestre. Su isótopo } \\
\mathrm{U}^{235} \text { puede dividirse en dos si su núcleo } \\
\text { es bombardeado con un neutrón, } \\
\text { liberándose una gran cantidad de } \\
\text { energía y dos o tres neutrones; se inicia } \\
\text { así una reacción en cadena conocida } \\
\text { como fisión nuclear. } \\
\text { - Recursos identificados recuperables a } \\
\text { un costo <130 US } \$ / \mathrm{kg} \mathrm{U}: 5,5 \text { mill.ton. }\end{array}$ & $\begin{array}{l}\text { - Amplias reservas de mineral de uranio, } \\
\text { distribuidas en todo el planeta. } \\
\text { - Enorme cantidad de energía producida, } \\
\text { por unidad de material utilizado. } \\
\text { - Energía 'limpia'. La utilización de uranio } \\
\text { para generación de electricidad no } \\
\text { arroja } \mathrm{CO}_{2} \text { ni otros gases invernadero a } \\
\text { la atmósfera. } \\
\text { - Opción energética para países con } \\
\text { acceso a uranio y a la tecnología } \\
\text { necesaria. }\end{array}$ & $\begin{array}{l}\text { - Consecuencias catastróficas en caso de } \\
\text { ocurrencia de un accidente nuclear. } \\
\text { - Rechazo al uso de energía nuclear por } \\
\text { una fracción importante de la } \\
\text { sociedad. } \\
\text { - Dependencia de los países } \\
\text { importadores de combustible nuclear } \\
\text { en sus diversas modalidades hacia los } \\
\text { exportadores. Sólo Canadá se } \\
\text { autoabastece. } \\
\text { - Difícil acceso a la tecnología, vigilancia } \\
\text { de la comunidad internacional. }\end{array}$ \\
\hline
\end{tabular}


Tabla 3.4. Caracterización del sector energético - Energías no renovables (7)

\begin{tabular}{|c|c|c|c|}
\hline FUENTE & INFORMACIÓN GENERAL & VENTAJAS & DESVENTAJAS \\
\hline URA & 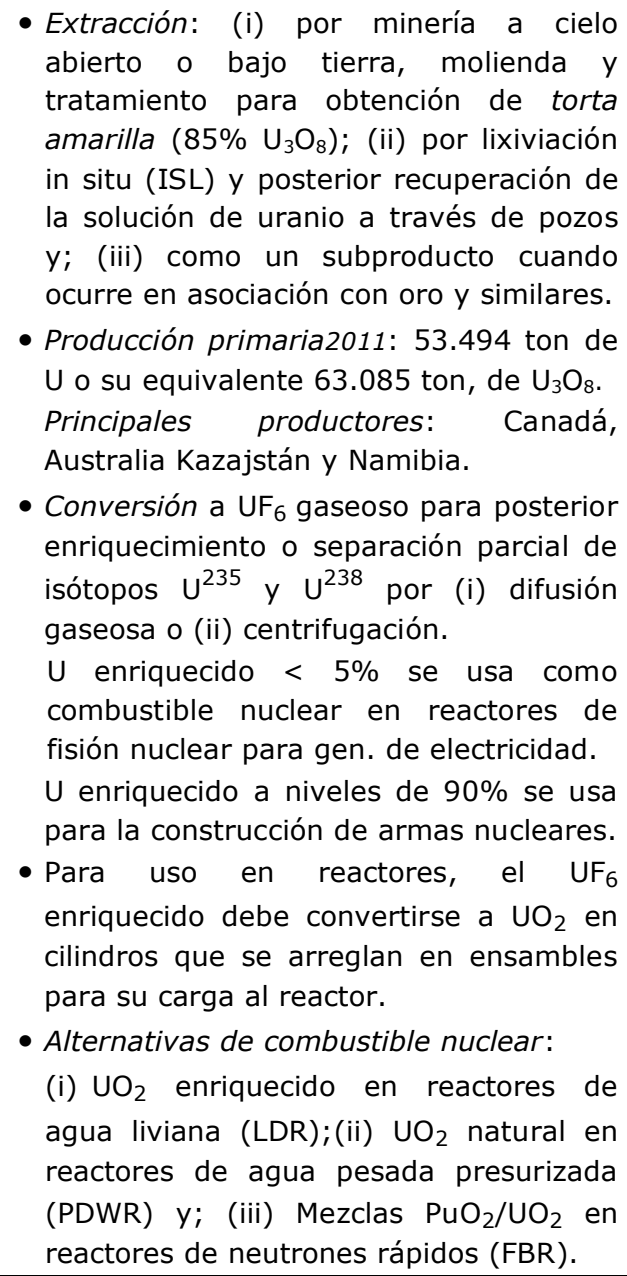 & $\begin{array}{l}\text { - Tecnología probada, variedad de } \\
\text { tecnologías y tipos de combustible } \\
\text { nuclear a utilizar. } \\
\text { - Poca influencia del precio del uranio } \\
\text { (5\%) en el costo total de generación } \\
\text { de electricidad en reactores nucleares; } \\
\text { así, una variación en los precios afecta } \\
\text { muy poco la economía del proceso. } \\
\text { - Existencia de normativa y de } \\
\text { protocolos muy estrictos de seguridad } \\
\text { para la construcción de una planta } \\
\text { nuclear y su posterior operación lo que } \\
\text { reduce significativamente la } \\
\text { probabilidad de ocurrencia de un } \\
\text { accidente. de convenios bilaterales } \\
\text { - Existencia de contre países } \\
\text { (inspecciones y auditorías) entre de la de } \\
\text { exportadores y países importadores de } \\
\text { uranio adicionales a los controles de la } \\
\text { Agencia Internacional de Energía } \\
\text { Atómica para asegurar que el uranio } \\
\text { exportado sea utilizado con propósitos } \\
\text { pacíficos y no se derive a la } \\
\text { proliferación de armas nucleares. } \\
\text { - Industria consolidada, fuente de } \\
\text { empleos. }\end{array}$ & $\begin{array}{l}\text { - Tecnología asociada al ciclo del uranio } \\
\text { desde la extracción del } \mathrm{U}_{3} \mathrm{O}_{8} \text { hasta su } \\
\text { conversión a uranio enriquecido (5\% } \\
\mathrm{U} \text {, materia prima a reactores nucleares } \\
\text { para generación de electricidad) es } \\
\text { compleja y su instalación exige altos } \\
\text { costos de inversión. } \\
\text { - Su puesta en marcha y explotación } \\
\text { regular requiere profesionales muy } \\
\text { capaces y entrenados lo que puede } \\
\text { limitar su uso en países poco } \\
\text { desarrollados. } \\
\text { - Minería, molienda y producción de } \\
\text { torta amarilla genera gran volumen de } \\
\text { residuos radioactivos de difícil } \\
\text { manipulación y disposición. } \\
\text { - Lixiviación in situ no produce residuos } \\
\text { sólidos pero puede contaminar aguas } \\
\text { subterráneas. } \\
\text { - A través de todo el ciclo del uranio, } \\
\text { manejo de materiales radioactivos } \\
\text { altamente peligrosos y de difícil } \\
\text { disposición. } \\
\text { - Una vez finalizada la vida útil de las } \\
\text { instalaciones nucleares, y decidido su } \\
\text { cierre, toma un período de tiempo muy } \\
\text { largo(> } 100 \text { años) la descontaminación } \\
\text { del lugar de modo que los trabajadores } \\
\text { puedan realizar el desmantelamiento, } \\
\text { demolición y clausura segura del sitio. }\end{array}$ \\
\hline
\end{tabular}


Tabla 3.4. Caracterización del sector energético - Energías no renovables (8)

\begin{tabular}{|c|c|c|c|}
\hline FUENTE & INFORMACION GENERAL & VENTAJAS & DESVENTAJAS \\
\hline URANIO & 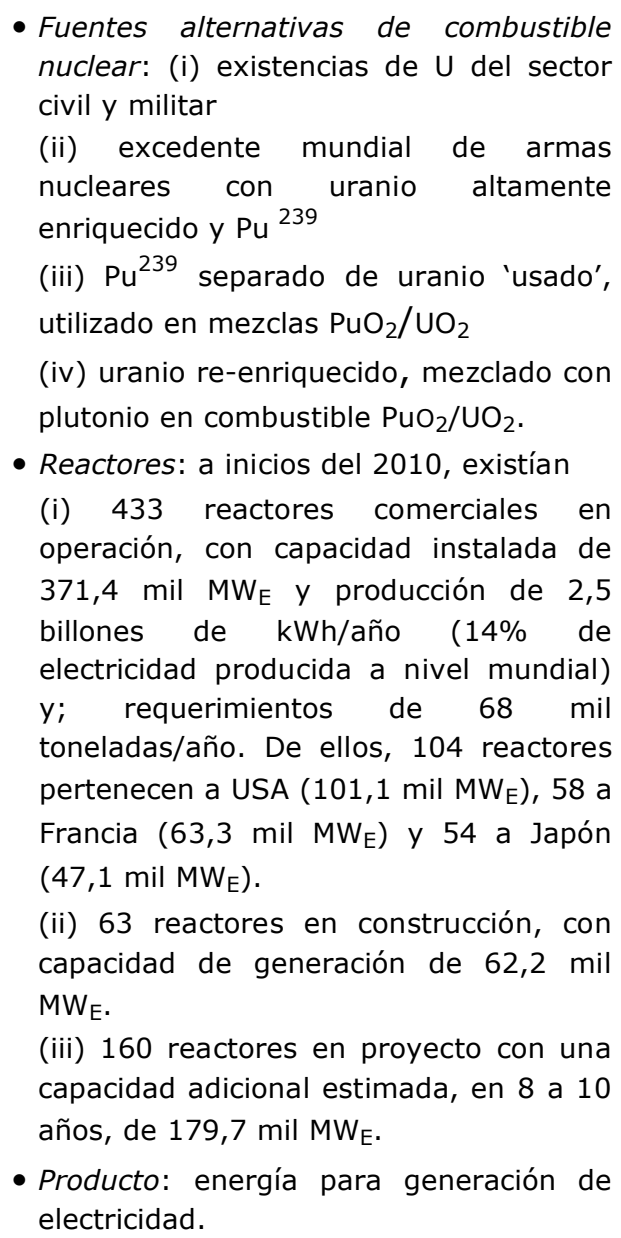 & & \\
\hline
\end{tabular}


Tabla 3.5. Caracterización del sector energético - Energías renovables (1)

\begin{tabular}{|c|c|c|c|}
\hline FUENTE & INFORMACIÓN GENERAL & VENTAJAS & DESVENTAJAS \\
\hline $\begin{array}{c}\text { RECURSOS } \\
\text { HÍDRICOS }\end{array}$ & $\begin{array}{l}\text { - Caídas de agua en movimiento } \\
\text { - Potencial técnicamente explotable: } \approx \\
14.700 \text { TWh/año. } \\
\text { Potencial hidroeléctrico técnica y } \\
\text { económicamente explotable: } \approx 9,000 \\
\text { TWh/año, gran parte no desarrollado. } \\
\text { - Capacidad instalada 2009: } 952 \mathrm{GW} \\
\text { - Producción energía hidroeléctrica 2009: } \\
\text { 3330 TWh/año (16\% de la producción } \\
\text { mundial). } \\
\text { - Principales productores: China, Estados } \\
\text { Unidos, Canadá, Brasil y Rusia. } \\
\text { - Tecnología de aprovechamiento: } \\
\text { (i) Embalse sobre el río cuyo caudal se } \\
\text { aprovecha. El agua represada se libera } \\
\text { desde un nivel más alto a un nivel más } \\
\text { bajo a través de un tubo inclinado, al } \\
\text { salir del cual golpea y mueve las aspas } \\
\text { de una turbina conectada a un } \\
\text { generador de electricidad, } \\
\text { (ii) Para enfrentar la variación de la } \\
\text { demanda eléctrica, puede instalarse } \\
\text { una planta de almacenamiento por } \\
\text { bombeo que almacena agua en un } \\
\text { reservorio superior para utilizarla en } \\
\text { las horas 'pico' o de alta demanda. } \\
\text { (iii) Micro y pico centrales (<100 MW) } \\
\text { sólo usan un canal para desviar el } \\
\text { agua desde el rio a una turbina } \\
\text { conectada a un generador de } \\
\text { electricidad. }\end{array}$ & $\begin{array}{l}\text { - Fuente energética endógena. Elimina el } \\
\text { costo de combustible y contribuye a la } \\
\text { independencia de fuentes exógenas. } \\
\text { - Fuente de energía 'limpia'. El proceso } \\
\text { de conversión en electricidad no } \\
\text { produce emisiones de cO2, SO2 u } \\
\text { óxidos de nitrógeno ni residuos. } \\
\text { - Tecnología de conversión conocida, } \\
\text { accesible, confiable y probada y los } \\
\text { equipos modernos producen altas } \\
\text { eficiencias de conversión energética. } \\
\text { - Vida útil de un aprovechamiento } \\
\text { hidroeléctrico entre } 40 \text { y } 50 \text { años } \\
\text { extensibles con el mantenimiento } \\
\text { adecuado. } \\
\text { - Costos de operación bajos. } \\
\text { - Posibilidad de uso múltiple del embalse } \\
\text { de agua: irrigación, control de } \\
\text { inundaciones, suministro de agua, } \\
\text { navegación y recreación, adicional a } \\
\text { reservorio de agua para generación de } \\
\text { electricidad. En este caso, actúa como } \\
\text { un detonante de la actividad } \\
\text { económica en la región, generando } \\
\text { oportunidad de trabajo y mejor calidad } \\
\text { de vida en la región de influencia. } \\
\text { - Micro y pico centrales constituyen } \\
\text { una alternativa de bajo costo, que } \\
\text { puede utilizar mano de material y } \\
\text { mano de obra locales, para dar } \\
\text { electricidad a sitios rurales, }\end{array}$ & $\begin{array}{l}\text { - Selección del sitio de una presa } \\
\text { requiere extensos y costosos estudios } \\
\text { del sitio: geológicos, pluviométricos y } \\
\text { de impacto ambiental. } \\
\text { - Tiempo de diseño y construcción de la } \\
\text { requieren un largo período de tiempo y } \\
\text { una inversión inicial elevada. } \\
\text { - La puesta en marcha de grandes } \\
\text { complejos hidroeléctricos requiere la } \\
\text { inundación de extensos lotes de } \\
\text { terreno, con: (i) el desplazamiento } \\
\text { forzoso y relocalización de núcleos } \\
\text { humanos, (ii) la desaparición de al } \\
\text { menos parte de la fauna y de la } \\
\text { herencia cultural en la zona inundada, } \\
\text { (iii)modificación del hábitat de especies } \\
\text { animales que viven en el rio represado. } \\
\text { (ii) vegetación sumergida puede } \\
\text { descomponerse con el tiempo y } \\
\text { producir metano y otros gases tóxicos. } \\
\text { Naturalmente, los efectos señalados } \\
\text { son menores en la medida en que } \\
\text { disminuye el área inundada. } \\
\text { - Generación de energía hidroeléctrica } \\
\text { depende de las lluvias en la cuenca del } \\
\text { rio cuyo caudal se aprovecha. } \\
\text { - Fractura natural o por acto terrorista } \\
\text { puede producir inundación severa } \\
\text { aguas abajo. Posibilidad de sismicidad inducida por } \\
\text { presas muy grandes. }\end{array}$ \\
\hline
\end{tabular}


Tabla 3.5. Caracterización del sector energético - Energías renovables (2)

\begin{tabular}{|c|c|c|c|}
\hline FUENTE & INFORMACIÓN GENERAL & VENTAJAS & DESVENTAJAS \\
\hline OLAS & $\begin{array}{l}\text { - Producto de los vientos que soplan } \\
\text { sobre la superficie del océano, contienen } \\
\text { energía que puede convertirse en } \\
\text { electricidad. } \\
\text { - Potencial mundial:8000-80000 TWh/año } \\
\text { - Potencial económicamente explotable: } \\
\text { 140-2000 TWh/año. } \\
\text { - Zonas con potencia energética de olas } \\
\text { elevada (kWh/m cresta) entre } 30^{\circ} \text { y } 60^{\circ} \\
\text { de latitud N y S: costas noroccidentales } \\
\text { de América y Europa y costas } \\
\text { suroccidentales de Australia, Nueva } \\
\text { Zelanda, Suramérica y Suráfrica. } \\
\text { - Tecnología de captación y conversión: } \\
\text { se prueban a escala comercial: (i) } \\
\text { Columna oscilante de agua (OWC), (ii) } \\
\text { Reservorio sobre el nivel promedio del } \\
\text { mar que lo rodea, } 7 \mathrm{MW} \mathrm{(Gales),} \mathrm{(iv)} \\
\text { Boya cilíndrica flotante con base fija, (v) } \\
\text { Cilindros huecos de acero unidos con } \\
\text { bisagras, instalados } 2 \mathrm{MW} \text { (Portugal) }\end{array}$ & $\begin{array}{l}\text { - Energía renovable explotable para los } \\
\text { países que dispongan de zonas } \\
\text { cercanas a la línea costera con } \\
\text { potencia de olas elevada (kW/m } \\
\text { cresta). } \\
\text { - Su aprovechamiento puede rendir una } \\
\text { cantidad significativa de energía. } \\
\text { - Elimina parcialmente dependencia y } \\
\text { costos de combustible exógeno. } \\
\text { - Su captación, conversión y uso evita } \\
\text { emisiones de gases tipo invernadero a } \\
\text { la atmósfera. } \\
\text { - Costos de operación y mantenimiento } \\
\text { relativamente bajos. } \\
\text { - Investigación activa en el área, } \\
\text { desarrollo de una gran cantidad de } \\
\text { dispositivos para la captación de la } \\
\text { energía oceánica (no probados a } \\
\text { escala comercial). }\end{array}$ & $\begin{array}{l}\text { - Tecnología poco probada, sólo } \\
\text { pequeños desarrollos aislados se } \\
\text { prueban a escala comercial, en } \\
\text { Escocia, Gales, Estados Unidos y } \\
\text { Portugal. } \\
\text { - Suministro de energía variable. } \\
\text { Depende de la intensidad y frecuencia } \\
\text { de las olas. } \\
\text { - 'Granjas' de dispositivos pueden } \\
\text { ocasionar: (i) impacto sobre el hábitat } \\
\text { marino (ii) modificación del paisaje de } \\
\text { costas y océano si la altura de los } \\
\text { dispositivos de captación es elevada } \\
\text { (iii) ruido sobre y debajo de la } \\
\text { superficie del mar (iv) posibilidad de } \\
\text { derrames accidentales de líquidos } \\
\text { tóxicos de sistemas hidráulicos. } \\
\text { - Posibilidad de conflicto con barcos de } \\
\text { pesca, navegación comercial y } \\
\text { recreacional. }\end{array}$ \\
\hline MAREAS & $\begin{array}{l}\text { - Elevación y caída periódica del nivel del } \\
\text { mar causado principalmente por la } \\
\text { interacción de campos gravitacionales } \\
\text { en el sistema planetario de la Tierra, el } \\
\text { Sol y la Luna. } \\
\text { - Potencial teórico mundial: } 7.800 \mathrm{TW} / \mathrm{a} \text {, } \\
\text { - Zonas con potencia energética de } \\
\text { elevada: Francia, Reino Unido y Canadá. } \\
\text { - Principal productor: Francia (La Race, } \\
\text { Bretaña, } 240 \mathrm{MW}, 600 \mathrm{MWh} / \mathrm{año} \text { ). }\end{array}$ & $\begin{array}{l}\text { - Energía renovable explotable para los } \\
\text { países que dispongan de áreas con un } \\
\text { rango de mareas superior a } 7 \text { metros. } \\
\text { - Elimina parcialmente dependencia y } \\
\text { costos de combustible exógeno. } \\
\text { - Fuente de energía confiable y } \\
\text { completamente predecible. } \\
\text { - Su captación, conversión y uso evita } \\
\text { emisiones de gases tipo invernadero a } \\
\text { la atmósfera. }\end{array}$ & $\begin{array}{l}\text { - Tecnología bien establecida pero es } \\
\text { costosa. } \\
\text { - Pocos desarrollos a nivel comercial: } \\
\text { Francia }(240 \mathrm{GW}) \text {, Canadá ( } 20 \mathrm{MW}) \text { y } \\
\text { China ( } 5 \mathrm{MW}) \text {. } \\
\text { - Tecnologías de bajos rendimientos, } \\
\text { típicamente entre } 20 \text { y } 35 \% \text {. } \\
\text { - La instalación, y mantenimiento de las } \\
\text { turbinas sumergidas es complicada y } \\
\text { ha frenado su explotación comercial }\end{array}$ \\
\hline
\end{tabular}


Tabla 3.5. Caracterización del sector energético - Energías renovables (3)

\begin{tabular}{|c|c|c|c|}
\hline FUENTE & INFORMACIÓN GENERAL & VENTAJAS & DESVENTAJAS \\
\hline MAREAS & $\begin{array}{l}\text { - Tecnología de captación y conversión: } \\
\text { (i) Cerramiento de un estuario con una } \\
\text { 'barrera' a fin de formar un reservorio } \\
\text { del agua que llega con la marea alta. } \\
\text { Cuando el } \Delta \text { de alturas del agua en } \\
\text { cada lado de la presa es la adecuada, } \\
\text { se deja fluir el agua a través de una } \\
\text { turbina la cual activa un generador que } \\
\text { produce electricidad. (ii) Turbinas } \\
\text { sumergidas para aprovechar corrientes } \\
\text { asociadas a las mareas. }\end{array}$ & & $\begin{array}{l}\text { - Suministro de energía variable. Se han } \\
\text { propuesto sistemas de } \\
\text { almacenamiento para continuidad en } \\
\text { generación. } \\
\text { - Impactos negativos sobre los } \\
\text { ecosistemas náuticos y de las costas. } \\
\text { - Modificación del paisaje de costas y } \\
\text { océano si la altura de los dispositivos } \\
\text { de captación es elevada. } \\
\text { - Posibilidad de interrupción de rutas de } \\
\text { naves comerciales y turísticas. }\end{array}$ \\
\hline $\begin{array}{l}\text { GRADIENTE } \\
\text { TÉRMICO } \\
\text { OCEANICO }\end{array}$ & $\begin{array}{l}\text { - Diferencia de temperatura entre la } \\
\text { superficie del mar y sus aguas } \\
\text { profundas. Puede usarse para producir } \\
\text { electricidad, si } \Delta \text { temperatura es } \geq 20^{\circ} \mathrm{C} \text {. } \\
\text { - Potencial teórico mundial del recurso: } \\
10000 \text { TWh/año. } \\
\text { - Zonas con gradiente de temperatura } \\
\text { adecuado para su explotación entre } 0^{\circ} \\
\text { y } 23,5^{\circ} \text { de latitud } \mathrm{N} \text { y } \mathrm{S} \text { Cuba, Rep. } \\
\text { Dominicana, islas del Caribe algunos } \\
\text { países del África, y del Pacifico. } \\
\text { - Tecnología de captación y conversión: } \\
\text { (i) Ciclo OTEC abierto vaporiza el agua } \\
\text { de la superficie del mar dirigiéndola a un } \\
\text { recipiente a baja presión; el vapor } \\
\text { mueve un turbogenerador y luego se } \\
\text { condensa con agua fría del fondo del } \\
\text { mar. El sistema puede producir agua } \\
\text { fresca ( } \approx 2000 \mathrm{~m}^{3} \text { agua fresca/MW). }\end{array}$ & $\begin{array}{l}\text { - Energía renovable explotable para los } \\
\text { países que dispongan en sus mares de } \\
\text { gradientes térmicos }>20{ }^{0} \mathrm{C} \text { entre la } \\
\text { superficie y aguas a } 1000 \mathrm{~m} \text { de } \\
\text { profundidad } \\
\text { - Es una energía renovable, 'limpia', de } \\
\text { fuente natural. Su uso evita emisiones } \\
\text { de gases tipo invernadero a la } \\
\text { atmósfera y no genera desechos. } \\
\text { - Fuente de energía endógena. Si se } \\
\text { explota, puede contribuir a disminuir } \\
\text { la dependencia y los costos de } \\
\text { combustibles fósiles exógenos. } \\
\text { - Tecnología disponible (OTEC), } \\
\text { investigación para subir rendimientos. } \\
\text { - Flexibilidad del ciclo OTEC: cerrado, } \\
\text { abierto o híbrido. Instalaciones } \\
\text { pueden localizarse en tierra o costa } \\
\text { afuera. }\end{array}$ & $\begin{array}{l}\text { - Tecnología se ha probado sólo a } \\
\text { pequeña escala en Hawái: OTEC ciclo } \\
\text { abierto ( } 250 \mathrm{~kW}) \text { y de ciclo abierto } \\
\text { (50 kW) para producir electricidad, sin } \\
\text { embargo su costo es muy elevado para } \\
\text { implementación a nivel comercial. } \\
\text { - Condiciones para funcionamiento de la } \\
\text { tecnología disponible reduce el número } \\
\text { de sitios para operación } \\
\text { económicamente viable. } \\
\text { - El sistema requiere la instalación de } \\
\text { una tubería de gran diámetro para la } \\
\text { toma de agua fría de de profundidades } \\
\text { superiores a } 1000 \text { m lo que significa } \\
\text { una inversión inicial muy elevada. } \\
\text { - Mantenimiento y reparación de } \\
\text { anclajes, tuberías y cables de } \\
\text { transmisión submarinos complicado y } \\
\text { costoso, en instalaciones costa afuera. }\end{array}$ \\
\hline
\end{tabular}


Tabla 3.5. Caracterización del sector energético - Energías renovables (4)

\begin{tabular}{|c|c|c|c|}
\hline FUENTE & INFORMACIÓN GENERAL & VENTAJAS & DESVENTAJAS \\
\hline $\begin{array}{l}\text { GRADIENTE } \\
\text { TÉRMICO } \\
\text { OCEÁNICO }\end{array}$ & $\begin{array}{l}\text { (ii) Ciclo OTEC cerrado utiliza el ciclo } \\
\text { vaporización-condensación de un fluido } \\
\text { de trabajo de bajo punto de ebullición.. } \\
\text { El fluido se vaporiza con el calor que } \\
\text { obtiene del agua a la temperatura de } \\
\text { superficie, se expande y mueve un } \\
\text { turbogenerador, luego se condensa con } \\
\text { al agua fría del fondo del mar ( } \approx 1000 \\
\text { m de profundidad) y reinicia el ciclo. } \\
\text { (iii) Ciclo OTEC híbrido combina las } \\
\text { características de ciclos anteriores }\end{array}$ & $\begin{array}{l}\text { - Los sistemas OTEC de ciclo abierto } \\
\text { pueden producir agua fresca además } \\
\text { de electricidad. Esto es una ventaja } \\
\text { importante en islas donde el agua } \\
\text { dulce es limitada. } \\
\text { - Los sistemas instalados en tierra firme } \\
\text { permiten la operación conjunta con } \\
\text { industrias relacionadas como cultivos } \\
\text { y comercialización de especies } \\
\text { marinas o aquellas que requieran } \\
\text { agua desalinizada. }\end{array}$ & $\begin{array}{l}\text { - La construcción de plantas OTEC y el } \\
\text { tendido de tuberías en zonas costeras } \\
\text { puede causar daño localizado en } \\
\text { arrecifes y ecosistemas del sitio. } \\
\text { - Los sistemas instalados sobre la línea } \\
\text { costera o costa afuera están sujetos a } \\
\text { las condiciones del clima marino, con } \\
\text { la posibilidad de daños importantes a } \\
\text { las instalaciones y tuberías o incluso la } \\
\text { destrucción por temporales } \\
\text { - Falta de marco regulatorio de la }\end{array}$ \\
\hline VIENTOS & $\begin{array}{l}\text { - Fuente inagotable de energía producto } \\
\text { de la rotación de la tierra, la energía } \\
\text { térmica que viene del sol, los gradientes } \\
\text { de temperatura entre la tierra y el mar, } \\
\text { y los efectos físicos de montañas y otros } \\
\text { - Potencial energético global del viento } \\
\text { que puede ser interceptado y convertido } \\
\text { en electricidad: } 870 \text { PWh/año. } \\
\text { Aproximadamente un } 82 \% \text { corresponde } \\
\text { a potencial del viento que sopla sobre } \\
\text { tierra firme, el resto a vientos } \\
\text { oceánicos. } \\
\text { - Tecnología de captación y conversión: } \\
\text { Turbina de viento colocada sobre una } \\
\text { torre elevada tubular de acero; dispone } \\
\text { de dos o tres aspas que rotan moviendo } \\
\text { un eje conectado a un generador, } \\
\text { cuando el viento circula entre ellas. Un } \\
\text { sistema de control ajusta la velocidad de } \\
\text { rotación regulando la potencia de salida. }\end{array}$ & $\begin{array}{l}\text { - Fuente de energía doméstica y } \\
\text { abundante. Su explotación como } \\
\text { fuente de energía disminuye la } \\
\text { dependencia y los costos de } \\
\text { combustibles fósiles exógenos. } \\
\text { - Su utilización no arroja } \mathrm{CO}_{2} \text { a la } \\
\text { atmósfera y no contamina fuentes de } \\
\text { agua ni arroja desechos al ambiente. } \\
\text { - Tecnología probada cuya aplicación ha } \\
\text { crecido rápidamente en la última } \\
\text { década } \\
\text { - Investigación activa para mejorar } \\
\text { eficiencias, disminuir costos y } \\
\text { mantener su competitividad } \\
\text { - Desarrollos pequeños (<10 kW) son } \\
\text { una alternativa sencilla energética } \\
\text { para comunidades rurales con gran } \\
\text { carencia de electricidad. }\end{array}$ & $\begin{array}{l}\text { - Suministro de energía variable. } \\
\text { - Granjas 'eólicas' ocupan grandes lotes } \\
\text { de terrenos aun cuando estos puedan } \\
\text { compartirse parcialmente con usos } \\
\text { como la agricultura. } \\
\text { - Pueden presentarse (i) problemas de } \\
\text { afectación del paisaje especialmente } \\
\text { notable cerca de las playas o en zonas } \\
\text { escénicas tierra adentro. } \\
\text { (ii) Problemas de ruido que producen } \\
\text { las aspas al rotar y los dispositivos de } \\
\text { transmisión y control de las turbinas. } \\
\text { (iii) Posibles interferencias con señales } \\
\text { de comunicaciones. } \\
\text { (iv) Posibles daños a pájaros cuya ruta } \\
\text { de migración se cruce con ellas. } \\
\text { - Problemas de falta de aceptación por } \\
\text { parte de la comunidad. }\end{array}$ \\
\hline
\end{tabular}


Tabla 3.5. Caracterización del sector energético - Energías renovables (5)

\begin{tabular}{|c|c|c|c|}
\hline FUENTE & INFORMACION GENERAL & VENTAJAS & DESVENTAJAS \\
\hline VIENTOS & $\begin{array}{l}\text { Las turbinas pueden utilizarse en forma } \\
\text { independiente o en 'granjas eólicas' con } \\
\text { decenas de plantas conectadas a la red } \\
\text { de distribución. } \\
\text { Turbinas muy grandes: } \varphi \text { tierra firme = } \\
93 \mathrm{~m} \text { y P }=2,6 \mathrm{MW} \text {; costa afuera = } \\
93 \mathrm{~m} \text { y P }=3,5 \mathrm{MW} \text { (tamaño máximo). } \\
\text { Un poco más eficientes. } \\
\text { Turbinas muy pequeñas: P = } 10 \mathrm{~kW} \text {; } \\
\text { desarrollos rurales. } \\
\text { - Producción mundial 2010: } 430 \text { TWh/año } \\
\text { (2,5\% demanda de electricidad). } \\
\text { - Capacidad instalada } 2010: 196,6 \mathrm{GW} \\
\text { Mayor capacidad en Estados Unidos, } \\
\text { China, Alemania y España. } \\
\text { Capac. inst. costa afuera 2010:3.1 GW } \\
\text { Mayor capacidad en Reino Unido, } \\
\text { Dinamarca, Holanda y Holanda. }\end{array}$ & & \\
\hline $\begin{array}{l}\text { RADIACION } \\
\text { SOLAR }\end{array}$ & $\begin{array}{l}\text { - Fuente primaria de energía para los } \\
\text { habitantes del planeta. Irradiancia solar } \\
\text { directa, DNI: oscila entre } 75-275 \mathrm{~W} / \mathrm{m}^{2} \text {. } \\
\text { - Tecnologías de captación y conversión : } \\
\text { (i) Calentamiento/enfriamiento. } \\
\text { - Paneles de colectores de placa o } \\
\text { colectores de tubos al vacío para } \\
\text { calentamiento de agua y espacios. } \\
\text { - Sistemas enfriamiento térmicamente } \\
\text { activados (TACS) para ambientes. } \\
\text { Usos: doméstico, comercial, industrial } \\
\text { Producción CS } 2009=142,8 \text { TWh/año }\end{array}$ & $\begin{array}{l}\text { - Fuente de energía inmensa, inagotable } \\
\text { y sin costo alguno; presente en cada } \\
\text { rincón del planeta. } \\
\text { - Su uso disminuye la dependencia de los } \\
\text { combustibles fósiles. } \\
\text { - La radiación solar es una fuente de } \\
\text { energía limpia. Su proceso de captación } \\
\text { y transformación en calor o electricidad } \\
\text { no produce CO2 ni otros contaminantes } \\
\text { como óxidos de azufre, óxidos de } \\
\text { nitrógeno, y partículas. } \\
\text { - Múltiples tecnologías: } \\
\text { solares, colectores } \\
\end{array}$ & $\begin{array}{l}\text { - La energía solar es intermitente y } \\
\text { variable. Son necesarios sistemas de } \\
\text { almacenamiento o respaldo para } \\
\text { garantizar el suministro continuo de } \\
\text { energía eléctrica. El almacenamiento } \\
\text { eficaz de la energía es aún un reto. } \\
\text { - La recolección de la energía solar y su } \\
\text { transformación y distribución implican } \\
\text { inversiones muy elevadas. } \\
\text { - Baja eficiencia de aplicaciones con } \\
\text { colectores solares que requieren alta } \\
\text { temperatura. como refrigeración y } \\
\text { generación de calor industrial. }\end{array}$ \\
\hline
\end{tabular}


Tabla 3.5. Caracterización del sector energético - Energías renovables (6)

\begin{tabular}{|c|c|c|c|}
\hline FUENTE & INFORMACION GENERAL & VENTAJAS & DESVENTAJAS \\
\hline $\begin{array}{l}\text { RADIACIÓN } \\
\text { SOLAR }\end{array}$ & $\begin{array}{l}\text { Capacidad inst. CS } 2009 \text { : } 172 \text { GWT } \\
\text { Países líderes: China y Estados Unidos } \\
\text { (ii) Conversión solar fotovoltaica: } \\
\text { - Celdas solares fotovoltaicas } \\
\text { convierten energía solar en } \\
\text { electricidad. Se agrupan en módulos y } \\
\text { éstos en paneles de celdas solares PV. } \\
\text { - Usos: Un sistema PV puede usarse ( } \\
\text { en forma autónoma para suplir } \\
\text { energía a comunidades aisladas u } \\
\text { hogares o ( a gran escala, conectado a } \\
\text { una red de distribución eléctrica. } \\
\text { - Capacidad inst. PV } 2011=70 \text { GW. } \\
\text { Países líderes: Alemania e Italia } \\
\text { (iii ) Concentración de energía solar: } \\
\text { - Colectores cilindro-parabólicos: } \\
\text { campo solar conformado por espejos } \\
\text { en forma de parábola que concentran } \\
\text { la energía en un tubo insertado a lo } \\
\text { largo del eje focal del espejo. El tubo } \\
\text { contiene un fluido que absorbe la } \\
\text { energía solar que se concentra en él; } \\
\text { y posteriormente, se dirige al sistema } \\
\text { de generación eléctrica. } \\
\text { - Capacidad instalada } 2010=1,1 \text { GW. } \\
\text { Países líderes: España y U.S.A. } \\
\text { Concentración lineal Fresnel: campo } \\
\text { solar conformado por espejos planos } \\
\text { que concentran la energía solar en un } \\
\text { sistema de tubos receptores colocados } \\
\text { en el espacio sobre los espejos. }\end{array}$ & $\begin{array}{l}\text { - Tecnologías probadas y con aplicaciones } \\
\text { en rápido crecimiento. } \\
\text { - Escalas múltiples: Grandes o medianos } \\
\text { desarrollos y proyectos a nivel de } \\
\text { vivienda. } \\
\text { - Proyectos escalables: puede iniciarse la } \\
\text { construcción con una tamaño accesible } \\
\text { al presupuesto y luego expandir según } \\
\text { necesidades. } \\
\text { - Operación flexible. (i) autónoma para } \\
\text { proyectos individuales o pequeños } \\
\text { desarrollos a nivel rural que no tienen } \\
\text { acceso a la red, (ii) conectada a la red. } \\
\text { La electricidad producida se envía total } \\
\text { o parcialmente a la red de distribución. } \\
\text { Posibilidad en algunos países de } \\
\text { "medición neta". } \\
\text { - Investigación activa para mejorar } \\
\text { eficiencias, perfeccionar materiales y } \\
\text { para almacenamiento de la energía } \\
\text { excedente y reducción de los costos de } \\
\text { inversión. } \\
\text { - Inversión accesible para paneles solares } \\
\text { a escala doméstica, con vida útil entre } \\
25-30 \text { años, corto período de instalación } \\
\text { y corto período de recuperación, por } \\
\text { economías en la factura eléctrica. } \\
\text { - Una forma excelente (colectores } \\
\text { solares, celdas PV o disco/máquina) } \\
\text { para suplir energía a lugares aislados } \\
\text { donde el costo de instalación de líneas } \\
\text { de distribución es elevado.. }\end{array}$ & $\begin{array}{l}\text { - Tecnologías PV y CSP requieren una } \\
\text { extensión grande de terrenos, donde } \\
\text { se instalan grandes matrices de } \\
\text { colectores solares que pueden } \\
\text { interferir con la luz del sol, la lluvia y } \\
\text { el drenaje del terreno lo que podría } \\
\text { tener efectos sobre la flora y fauna del } \\
\text { lugar; y afectar los usos habituales de } \\
\text { las tierras. } \\
\text { - Las numerosas filas de espejos (CSP, } \\
\text { PV) pueden causar impacto visual. La } \\
\text { cuidadosa selección del sitio donde se } \\
\text { ubicará el desarrollo solar puede } \\
\text { minimizar los impactos sobre el } \\
\text { terreno, el ecosistema y el paisaje. } \\
\text { - Los paneles fotovoltaicos pueden } \\
\text { contener materiales peligrosos como } \\
\text { arsénico y cadmio que representan un } \\
\text { riesgo potencial para los trabajadores } \\
\text { y el ambiente durante los procesos de } \\
\text { construcción y desmantelamiento de } \\
\text { los mismos, si no son bien manejados. } \\
\text { - Los sistemas cSP pueden emplear } \\
\text { líquidos como sales fundidas o aceites } \\
\text { sintéticos que pueden ser peligrosos y } \\
\text { presentan riesgos de derrame; } \\
\text { igualmente, el manejo de fluidos } \\
\text { hidráulicos, refrigerantes y lubricantes. } \\
\text { El planeamiento adecuado y buenas } \\
\text { prácticas de mantenimiento reducirán } \\
\text { los riesgos de contaminación del } \\
\text { ambiente por tal causa. }\end{array}$ \\
\hline
\end{tabular}


Tabla 3.5. Caracterización del sector energético - Energías renovables (7)

\begin{tabular}{|c|c|c|c|}
\hline FUENTE & INFORMACIÓN GENERAL & VENTAJAS & DESVENTAJAS \\
\hline $\begin{array}{l}\text { RADIACIÓN } \\
\text { SOLAR }\end{array}$ & $\begin{array}{l}\text { - Torre de concentración central: campo } \\
\text { solar conformado por grandes espejos } \\
\text { planos que pueden seguir el movimiento } \\
\text { del Sol para concentrar su energía en un } \\
\text { tanque colocado en el tope de una torre } \\
\text { central con un fluido de trabajo que } \\
\text { absorbe la energía en él concentrada y } \\
\text { la transfiere para generación eléctrica } \\
\text { - Disco/ máquina: un grupo de espejos } \\
\text { arreglados en forma de disco parabólico } \\
\text { que enfocan la luz solar a un receptor } \\
\text { localizado en el punto focal del disco. El } \\
\text { receptor térmico transfiere calor a un } \\
\text { sistema máquina/generador eléctrico. } \\
\text { - Almacenamiento y/o respaldo: } \\
\text { baterías recargables (PV); aceite, sales } \\
\text { fundidas (CSP); la red como destino de } \\
\text { la energía eléctrica excedente; agua } \\
\text { almacenada a un nivel más alto y } \\
\text { sistemas complementarios operados con } \\
\text { viento, agua o fósiles. } \\
\text { Usos. Generación eléctrica a pequeña y } \\
\text { mediana escala con excepción. }\end{array}$ & $\begin{array}{l}\text { - Aplicaciones de colectores solares a } \\
\text { baja temperatura tienen eficiencias } \\
\text { elevadas } \\
\text { - Operación no ruidosa a diferencia } \\
\text { de otras tecnologías para } \\
\text { aprovechamiento de energías } \\
\text { renovables. }\end{array}$ & $\begin{array}{l}\text { - Los sistemas de colectores cilíndricos } \\
\text { parabólicos y los sistemas de tore } \\
\text { requieren agua de enfriamiento para el } \\
\text { ciclo de vapor y para la limpieza de los } \\
\text { espejos; => un problema si la planta se } \\
\text { localiza en zonas desérticas. Sistemas de } \\
\text { enfriamiento con aire reducen las } \\
\text { necesidades de agua pero resultan más } \\
\text { costosos. } \\
\text { - Los sistemas CSP potencialmente (i) } \\
\text { pueden producir interferencia con las } \\
\text { operaciones aéreas, si los haces de luz } \\
\text { reflejada son mal dirigidas hacia las rutas } \\
\text { de los aviones, (ii) pueden significar un } \\
\text { riesgo para el ambiente y para la vida en } \\
\text { la zona debido a las altas temperaturas } \\
\text { envueltas en el proceso y(iii) pueden } \\
\text { producir campos magnéticos. } \\
\text { - La construcción y desmantelamiento } \\
\text { posterior de grandes instalaciones } \\
\text { industriales y el tendido de nuevas líneas } \\
\text { de transmisión, pueden causar impacto } \\
\text { sobre el ambiente. }\end{array}$ \\
\hline $\begin{array}{c}\text { RECURSOS } \\
\text { GEOTÉRMICOS }\end{array}$ & $\begin{array}{l}\text { - La energía geotérmica se origina en el } \\
\text { interior de la Tierra como consecuencia } \\
\text { del decaimiento radioactivo de algunos } \\
\text { isótopos de uranio, torio y potasio } \\
\text { - Zonas potencial geotérmico importante: } \\
\text { Anillo de fuego en Nueva Zelanda, } \\
\text { Indonesia, Filipinas, Japón, California } \\
\text { México, Centroamérica y Los Andes }\end{array}$ & $\begin{array}{l}\text { - La energía geotérmica es renovable } \\
\text { y endógena. Su uso disminuye la } \\
\text { dependencia de los combustibles } \\
\text { fósiles. } \\
\text { - La energía geotérmica se considera } \\
\text { sostenible porque cualquier } \\
\text { extracción es pequeña comparada } \\
\text { con la energía interna de la Tierra. }\end{array}$ & $\begin{array}{l}\text { - Zonas de recursos geotérmicos a elevada } \\
\text { temperatura }\left(>150^{\circ} \mathrm{C}\right) \text { está limitada a las } \\
\text { cercanías de los bordes de las placas } \\
\text { terrestres con intensa actividad sísmica } \\
\text { y/o volcánica. } \\
\text { - Otros recursos geotérmicos a } \\
\text { temperaturas menos elevadas pueden } \\
\text { hallarse en sitios diversos. }\end{array}$ \\
\hline
\end{tabular}


Tabla 3.5. Caracterización del sector energético - Energías renovables (8)

\begin{tabular}{|c|c|c|c|}
\hline FUENTE & INFORMACION GENERAL & VENTAJAS & DESVENTAJAS \\
\hline $\begin{array}{c}\text { RECURSOS } \\
\text { GEOTÉRMICOS }\end{array}$ & $\begin{array}{l}\text { - Los recursos geotérmicos varían de } \\
\text { acuerdo a su profundidad y temperatura } \\
\text { - Recursos hidrotérmicos (agua caliente } \\
+ \text { vapor) a profundidad y temperatura } \\
\text { variable, (ii) recursos localizados cerca } \\
\text { de la superficie o que afloran a ella, (iii) } \\
\text { suelos muy cerca de la superficie (< } 3 \\
\text { m) con temperatura entre } 10-16^{\circ} \mathrm{C} \text { todo } \\
\text { el año, (iv) recursos en rocas porosas a } \\
\text { presión muy elevada o rocas secas a alta } \\
\text { temperatura. Hoy en día no se explotan. } \\
\text { - Tecnologías de captación y conversión: } \\
\text { (i) Sistemas de uso directo de la } \\
\text { energía calórica contenida en aguas } \\
\text { cercanas a la superficie y temperatura } \\
\text { entre } 50 \text { y } 100{ }^{0} \mathrm{C} \text {. Usos: balneología, } \\
\text { spas, piscinas, calentamiento de } \\
\text { espacios. } \\
\text { (ii) Bombas de calor geotérmico que } \\
\text { aprovechan la constancia en el tiempo } \\
\text { de la temperatura de suelos muy } \\
\text { cercanos a la superficie (< } 3 \text { m), para } \\
\text { calentamiento-enfriamiento } \\
\text { espacios. } \\
\text { (iii) Sistemas para generación electrica } \\
\text { - Plantas que utilizan vapor seco que } \\
\text { sale del reservorio. } \\
\text { - Plantas que utilizan la evaporación } \\
\text { instantánea de agua muy caliente que } \\
\text { sale del reservorio ( }>180^{\circ} \mathrm{C} \text { ) y llega a } \\
\text { la superficie. }\end{array}$ & $\begin{array}{l}\text { - Energía limpia. Su proceso de captación y } \\
\text { transformación en calor o electricidad } \\
\text { produce una cantidad muy pequeña o nula } \\
\text { de gases invernadero. } \\
\text { - Es la opción energética menos costosa } \\
\text { para producir electricidad. } \\
\text { - Puede obtenerse electricidad de origen } \\
\text { geotérmico en forma continua, } \\
\text { independientemente de las condiciones } \\
\text { del tiempo. } \\
\text { - Factor de carga promedio para plantas de } \\
\text { generación eléctrica de origen geotérmico } \\
\text { elevado, = 72\% y puede ser > 95\% en } \\
\text { forma puntual (Islandia). } \\
\text { - En general, las instalaciones para la } \\
\text { captación y conversión de la energía } \\
\text { geotérmica requieren una extensión de } \\
\text { terreno menor que las instalaciones para } \\
\text { el uso de otras energías renovables. } \\
\text { - El calentamiento de espacios y de agua } \\
\text { son actividades obligadas en grandes } \\
\text { zonas del mundo; de esta forma, el } \\
\text { potencial uso directo de la energía } \\
\text { geotérmica es muy grande. } \\
\text { - Uso directo de la energía geotérmica tiene } \\
\text { múltiples aplicaciones en calentamiento y } \\
\text { enfriamiento de espacios (bombas de } \\
\text { calor), en calefacción municipal, } \\
\text { balneología, spas, piscinas, secado de } \\
\text { cosechas, calentamiento de agua, en } \\
\text { cultivos de peces e invernaderos. }\end{array}$ & $\begin{array}{l}\text { - La estabilidad geológica de los } \\
\text { potenciales ditios de } \\
\text { aprovechamiento de la energía } \\
\text { geotérmica puede verse afectada } \\
\text { (eventos sísmicos) por la } \\
\text { perforación de pozos e inyección de } \\
\text { agua (EGS). } \\
\text { - La inversión en exploración y } \\
\text { perforación conlleva riesgos } \\
\text { significativos. el conocimiento } \\
\text { - Es necesario el del } \\
\text { adecuado de las condiciones del } \\
\text { reservorio geotérmico y } \\
\text { cuidadoso seguimiento; si no es } \\
\text { así, después de un tiempo de } \\
\text { operación puede ocurrir el } \\
\text { agotamiento localizado del sitio. } \\
\text { - Problemas de corrosión en tuberías } \\
\text { causados por el contacto con } \\
\text { fluidos geotérmicos a elevadas } \\
\text { temperaturas. } \\
\text { - Los fluidos geotérmicos contienen } \\
\text { trazas de sustancias toxicas como } \\
\text { mercurio, boro y arsénico que se } \\
\text { concentran en el agua residual y } \\
\text { que constituyen un peligro para el } \\
\text { ambiente si no es reinyectada al } \\
\text { reservorio. }\end{array}$ \\
\hline
\end{tabular}


Tabla 3.5. Caracterización del sector energético - Energías renovables (9)

\begin{tabular}{|c|c|c|c|}
\hline FUENTE & INFORMACIÓN GENERAL & VENTAJAS & DESVENTAJAS \\
\hline $\begin{array}{c}\text { RECURSOS } \\
\text { GEOTÉRMICOS }\end{array}$ & $\begin{array}{l}\text { - Plantas binarias que utilizan un fluido de } \\
\text { trabajo el cual vaporiza utilizando la } \\
\text { energía que cede el agua del reservorio. } \\
\text { - Sistemas geotérmicos mejorados (EGS) } \\
\text { que contemplan la fractura con agua a } \\
\text { presión de rocas accesibles pero con } \\
\text { muy baja permeabilidad; la inyección de } \\
\text { agua para extraer la energía calórica de } \\
\text { la roca y la posterior extracción del agua } \\
\text { caliente a la superficie. } \\
\text { - Potencial técnicamente accesible: (i) } \\
\text { 5.000 GW usos directos y (ii) } 1.200 \mathrm{GW} \\
\text { para generación eléctrica. } \\
\text { - Capacidad mundial instalada } 2009 \text { para: } \\
\text { (i) Generación electricidad }=10,7 \mathrm{GW} \\
\text { Producción electricidad }=62,7 \mathrm{TWh} \\
\text { Países líderes: Estados Unidos, Filipinas. } \\
\text { (ii) Uso directo de energía }=50,6 \mathrm{GW} \\
\text { Producción uso directo }=121,7 \mathrm{TWh} \\
\text { Países líderes: China y Estados Unidos }\end{array}$ & $\begin{array}{l}\text { - Sistemas de cogeneración que } \\
\text { producen electricidad y agua } \\
\text { caliente, incrementan la eficiencia } \\
\text { del sistema. } \\
\text { - Plantas pequeñas de energía } \\
\text { geotérmica (< } 5 \mathrm{MW} \text { ) pueden operar } \\
\text { en zonas rurales o pueden respaldar la } \\
\text { operación del sistema de distribución } \\
\text { de electricidad. } \\
\text { - Su desarrollo beneficia las economías } \\
\text { locales. }\end{array}$ & \\
\hline BIOMASA & 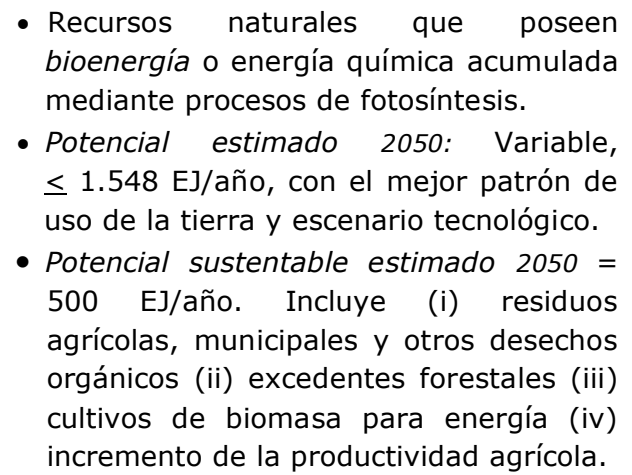 & $\begin{array}{l}\text { - Fuente de energía renovable, muy } \\
\text { abundante, particularmente en zonas } \\
\text { con actividad agrícola, bosques, } \\
\text { pantanos y en zonas urbanas donde se } \\
\text { producen desechos biodegradables. } \\
\text { - La electricidad, calor o biocombustibles } \\
\text { de origen en la biomasa puede } \\
\text { suministrarse sin interrupción en tanto } \\
\text { se disponga de un flujo continuo de } \\
\text { biomasa. No depende de las } \\
\text { condiciones del tiempo como otras } \\
\text { fuentes de energía renovable }\end{array}$ & $\begin{array}{l}\text { - El cultivo de la biomasa dirigida a la } \\
\text { producción de energía compite por } \\
\text { tierras con cultivos de alimentos. } \\
\text { - El cultivo de la biomasa para producir } \\
\text { energía requiere agua en cantidades } \\
\text { importantes. } \\
\text { - El cultivo, transporte y procesamiento } \\
\text { de la biomasa consume energía que } \\
\text { en general proviene de fósiles; ello } \\
\text { disminuye el rendimiento neto de } \\
\text { energía por área cultivada. }\end{array}$ \\
\hline
\end{tabular}


Cuadro 3.5. Caracterización del sector energético - Energías renovables (10)

\begin{tabular}{|c|c|c|c|}
\hline FUENTE & INFORMACION GENERAL & VENTAJAS & DESVENTAJAS \\
\hline BIOMASA & $\begin{array}{l}\text { - Producción bioenergía primaria } 2009 \\
\text { = } 50 \text { EJ/año, } \approx 10 \% \text { de TPES. } \\
\text { - Usos: producción de calor, } \\
\text { electricidad y biocombustibles. } \\
\text { - Primera generación procesos } \\
\text { conversión } \\
\text { (i) Pre-tratamiento: aglomeración, } \\
\text { torrefacción, pirólisis => material } \\
\text { aglomerado y menos húmedo. } \\
\text { (ii) Procesos termoquímicos: } \\
\text { - Combustión para generación } \\
\text { eléctrica o de calor, a nivel } \\
\text { doméstico e industrial. } \\
\text { - CHP o cogeneración de electricidad } \\
\text { y calor a nivel industrial. } \\
\text { - Co-combustión o combustión } \\
\text { compartida con fósiles. } \\
\text { - Gasificación o conversión a biogás } \\
\text { (CO, metano e H2) combustible. } \\
\text { (iii) Pirólisis o conversión a } \\
\text { fracciones líquida (70\%), sólida y } \\
\text { gaseosa. } \\
\text { (iV) Procesos bioquímicos: } \\
\text { - Digestión anaeróbica de desechos } \\
\text { húmedos. Hidrólisis seguida de fermentación } \\
\text { - >bioetanol Extracción mecánica seguida de } \\
\text { transesterificación => aceites } \\
\text { vegetales y biodiesel. }\end{array}$ & $\begin{array}{l}\text { - Su combustión produce menor cantidad } \\
\text { de emisiones de gases invernadero a la } \\
\text { atmósfera que los combustibles fósiles. } \\
\text { - El procesamiento de residuos sólidos } \\
\text { municipales contribuye a la solución del } \\
\text { problema de transporte y disposición de } \\
\text { dichos residuos en rellenos sanitarios. } \\
\text { - La remoción de residuos forestales de } \\
\text { la cosecha en bosques y de la poda de } \\
\text { árboles y arbustos, mejora las } \\
\text { condiciones del sitio para su posterior } \\
\text { utilización; y el retiro de la biomasa en } \\
\text { exceso reduce el peligro de incendios. } \\
\text { - La biomasa puede transportarse y } \\
\text { almacenarse a diferencia de otras } \\
\text { fuentes de energía. } \\
\text { - Existen múltiples rutas de conversión } \\
\text { de biomasa a energía, en base a } \\
\text { tecnologías sencillas y probadas. } \\
\text { - Las tecnologías son flexibles: } \\
\text { aplicaciones a pequeña escala en } \\
\text { comunidades rurales, o de mayor } \\
\text { tamaño en plantas industriales. } \\
\text { - Variados insumos y productos } \\
\text { intermedios que se utilizan en los } \\
\text { sectores de transporte, calefacción, } \\
\text { calentamiento de agua y electricidad. } \\
\text { - Cosechas dedicadas de biomasa pueden } \\
\text { convertirse a biocombustibles líquidos, } \\
\text { la mejor opción posible a la fecha para } \\
\text { sustituir parcialmente la gasolina. }\end{array}$ & $\begin{array}{l}\text { - La sustracción de parte de la cosecha } \\
\text { de productos básicos de la dieta } \\
\text { humana para dirigirla a la producción } \\
\text { de bioetanol puede causar un } \\
\text { incremento en los precios de estos } \\
\text { renglones y tener un efecto negativo } \\
\text { sobre el acceso de los productos. } \\
\text { - Altos costos de transporte y } \\
\text { almacenamiento. Para su reducción, } \\
\text { la biomasa puede ser sometida a } \\
\text { tratamiento previo (aglomeración, } \\
\text { torrefacción, pirólisis) para disminuir } \\
\text { su volumen y su humedad. } \\
\text { - En algunas regiones del mundo no se } \\
\text { practican las mejores prácticas para } \\
\text { el cultivo y recolección de la } \\
\text { biomasa. En consecuencia, deben } \\
\text { mejorarse las tecnologías a utilizar y } \\
\text { los rendimientos de los cultivos de } \\
\text { biomasa para que la actividad resulte } \\
\text { económicamente competitiva frente } \\
\text { al uso de otras fuentes de energía. } \\
\text { - Hace falta convenios internacionales } \\
\text { de estandarización que garanticen la } \\
\text { calidad de la biomasa y sus productos } \\
\text { derivados mercadeados; y que éstos } \\
\text { se obtengan de forma sustentable. } \\
\text { - Hace falta información sobre la } \\
\text { biomasa y sus ventajas; ello puede } \\
\text { causar falta de confianza en sus } \\
\text { productos derivados. }\end{array}$ \\
\hline
\end{tabular}


Tabla 3.5. Caracterización del sector energético - Energías renovables (11)

\begin{tabular}{|c|c|c|}
\hline FUENTE & INFORMACION GENERAL & VENTAJAS \\
\hline BIOMASA & 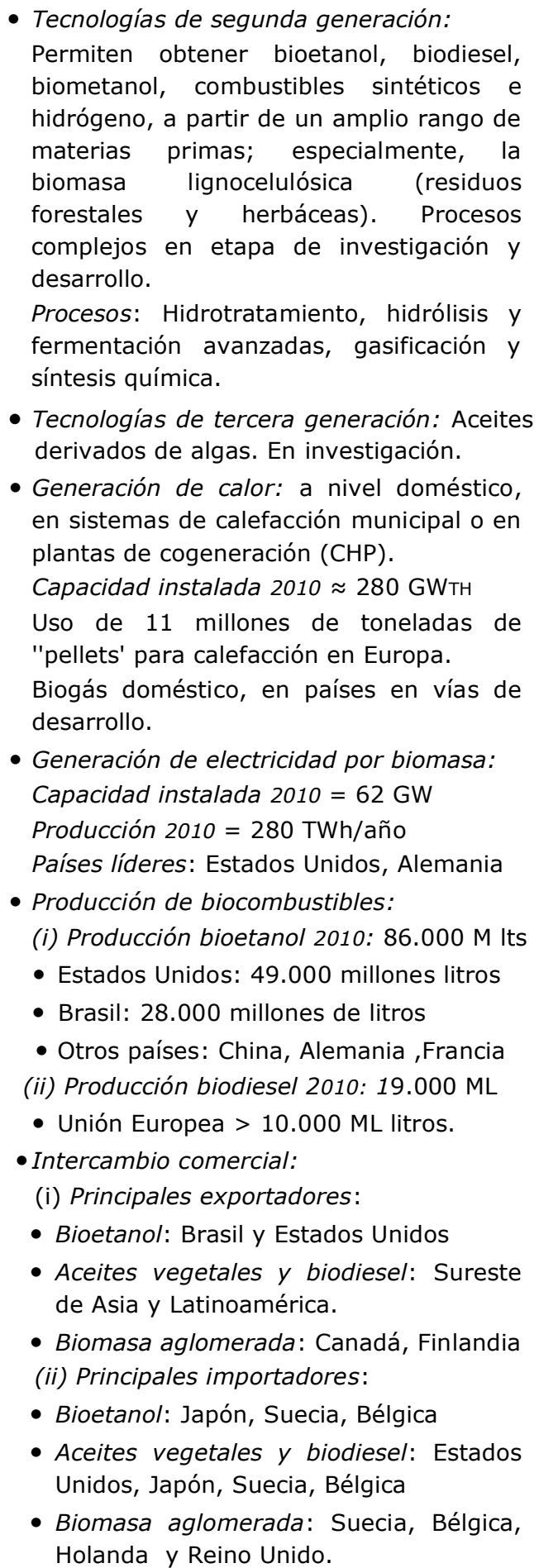 & $\begin{array}{l}\text { - La biomasa es endógena. Su uso como } \\
\text { fuente de energía contribuye a la } \\
\text { diversificación de la cesta energética y al } \\
\text { incremento de la seguridad energética } \\
\text { cuando se sustituye combustibles fósiles } \\
\text { importados por biomasa. } \\
\text { - Investigación activa de nuevas tecnologías } \\
\text { que puedan procesar en forma técnica, } \\
\text { ambiental y económicamente eficiente, } \\
\text { materiales que no constituyan alimento } \\
\text { para la población. Con su aplicación, se } \\
\text { reducirían la presión sobre el uso de las } \\
\text { tierras, los requerimientos de energía para } \\
\text { la producción de biomasa y las emisiones } \\
\text { de gases invernadero comparados con } \\
\text { tecnologías de primera generación. } \\
\text { - La cadena de producción, acopio, } \\
\text { transporte, conversión y distribución de } \\
\text { biomasa y productos derivados abren } \\
\text { nuevos empleos especialmente para las } \\
\text { comunidades rurales; y en general, } \\
\text { favorecen su desarrollo social y económico. } \\
\text { - Un gran número de países favorecen el uso } \\
\text { de la biomasa como fuente de energía y } \\
\text { han adoptado políticas de apoyo al sector; } \\
\text { entre ellas: } \\
\text { - Tarifas preferenciales y preferencia en } \\
\text { acceso a la red de distribución. } \\
\text { - Cuotas de participación a cierto plazo } \\
\text { - Mandatos de mezcla bioetanol-gasolina } \\
\text { y biodiesel-diesel. } \\
\text { - Incentivos y/o créditos fiscales a la } \\
\text { producción o a la inversión. } \\
\text { - Hoy día, se trabaja en acuerdos sobre } \\
\text { indicadores y estándares mínimos para } \\
\text { derivados y procedencia de la biomasa. Ello } \\
\text { crecimeto el comercio internacional y el } \\
\text { antoctor. }\end{array}$ \\
\hline
\end{tabular}


El trabajo de investigación realizado y el análisis de la información recabada ha permitido presentar de forma estructurada las características más resaltantes de las fuentes de energía disponibles en el planeta y de las tecnologías existentes para su transformación en electricidad, calor, combustibles y otros productos derivados insumo a todos los sectores de la actividad humana. Se han resaltado las ventajas y desventajas de cada tipo de energía estudiado; en un intento por identificar los aspectos diferenciadores más importantes que pueden convertirse en criterios e indicadores para la valoración integral de un proyecto en el sector energético.

Para el año 2009, el suministro mundial de energía primaria a nivel mundial alcanzó 12.150 millones de toneladas equivalentes de petróleo del cual aproximadamente un $80,9 \%$ fue aportado por combustibles fósiles; esto es, por petróleo, gas y carbón. El resto correspondió a energías alternativas; y entre ellas, aproximadamente un $13,3 \%$ a energías renovables. Para el mismo año 2009, el volumen de $\mathrm{CO}_{2}$ emitido a la atmósfera como consecuencia de la explotación y uso de las fuentes energéticas fue de $\mathbf{2 9 . 0 0 0 ~ m i l l o n e s ~ d e ~ t o n e l a d a s ; ~ d e ~ e s t a ~ c i f r a ~ a p e n a s ~}$ un $0,4 \%$ correspondió a las energías alternativas, cifra insignificante si se compara con un 99,6\% aportado por las energías fósiles [IEA, 2011a].

La magnitud de las cifras anteriores y su tendencia al alza, el agotamiento de los yacimientos de recursos energéticos no renovables y la concentración de sus reservas en manos de países políticamente inestables, ha traído a la discusión pública dos temas (i) la diversificación energética como medida para apuntalar la seguridad energética de cada país; esto es, el acceso seguro y costeable a los recursos energéticos necesarios para su desarrollo económico y social y (ii) la necesidad urgente de reducir las emisiones de $\mathrm{CO}_{2}$ y de otros gases invernadero provenientes de la quema de combustibles fósiles, causantes principales del calentamiento global, La forma como cada país supla sus necesidades energéticas contribuirá o no, a la solución de estos problemas. 


\section{Capítulo 4 Estructuración del modelo de valor}

La evaluación multicriterio de un proyecto de inversión es un proceso de análisis que busca su valoración, tomando como referencia para ello no un único, sino múltiples criterios que suelen competir entre sí.

Los proyectos de inversión pueden clasificarse atendiendo a los objetivos que pretenden alcanzar o a las características que lo identifican. En el sector energético, la clasificación puede basarse en el tipo de recurso energético cuyo aprovechamiento se propone; en el tipo de producto final que se plantea producir y/o comercializar, en la opción tecnológica que se sugiere utilizar, en la actividad que se proyecta realizar, o en el sector de la economía con el cual contribuirá una vez en operación. Los proyectos pueden pertenecer al sector público, al sector privado, o a ambos; tener fines de desarrollo social y económico o fines estrictamente comerciales; pueden ser proyectos grandes medianos o pequeños de acuerdo a la inversión o a la fuerza laboral que será necesaria para su ejecución y/o explotación; pueden ser proyectos de investigación y desarrollo de nuevas tecnologías o productos; de construcción, montaje y puesta en marcha de la infraestructura física, logística o administrativa necesaria para la explotación de un determinado recurso energético; o proyectos para la producción y/o comercialización de bienes y servicios.

La tabla 4.1 que se incluye en la próxima página presenta algunas de las modalidades de clasificación de proyectos en el sector energético. Naturalmente, el cuadro no agota todas las posibilidades y algunas formas de clasificación pueden aplicarse a todo tipo de proyectos. 
Tabla 4.1. Algunas modalidades de clasificación de proyectos en el sector energético

\begin{tabular}{|c|c|c|c|}
\hline \multicolumn{4}{|c|}{ PROPIAS DEL SECTOR ENERGÉTICO } \\
\hline POR TIPO DE ENERGÍA & $\begin{array}{l}\text { POR SECTOR } \\
\text { ECONÓMICO }\end{array}$ & POR ACTIVIDAD & $\begin{array}{c}\text { POR PRODUCTO } \\
\text { FINAL }\end{array}$ \\
\hline $\begin{array}{l}\text { Fósil convencional } \\
\text { - } \text { Petróleo } \\
\text { - Gas } \\
\text { - Carbón } \\
\text { - Fósil no convencional } \\
\text { - } \text { Petróleo } \\
\text { - Nus } \\
\text { - Hidráulica } \\
\text { - Oceánica } \\
\text { - Eólica } \\
\text { - Solar } \\
\text { - Geotérmica } \\
\text { - Bioenergía }\end{array}$ & $\begin{array}{l}\text { - Industrial } \\
\text { - Servicios } \\
\text { - Transporte } \\
\text { - Doméstico } \\
\text { - Mixtos }\end{array}$ & $\begin{array}{l}\text { - Investigación y desarrollo } \\
\text { - Exploración } \\
\text { - Extracción/Captación } \\
\text { - Cultivo y recolección de } \\
\text { biomasa } \\
\text { - Mejoramiento } \\
\text { - Transformación } \\
\text { - Distribución } \\
\text { - Comercialización } \\
\text { - Más de una de las anteriores. } \\
\text { - Otros }\end{array}$ & $\begin{array}{l}\text { - Electricidad } \\
\text { - Calor } \\
\text { - Calor y electricidad } \\
\text { - Combustibles } \\
\text { - Otros }\end{array}$ \\
\hline
\end{tabular}

\begin{tabular}{|l|l|l|}
\hline \multicolumn{3}{|c|}{ GENERALES } \\
\hline \multicolumn{2}{|c|}{ POR ORGANIZACIONES PARTICIPANTES } & \multicolumn{1}{c|}{ POR ÁMBITO DEL PROYECTO } \\
\hline $\begin{array}{l}\text { Organismos y organizaciones nacionales o } \\
\text { multinacionales en el sector gubernamental. } \\
\text { - Empresas y organizaciones nacionales o } \\
\text { multinacionales en el sector privado. }\end{array}$ & $\begin{array}{l}\text { - Diseño y desarrollo de nuevos productos. } \\
\text { - Construcción y montaje de infraestructura física, } \\
\text { logica y/o administrativa. }\end{array}$ \\
\hline
\end{tabular}

Naturalmente, cada tipo de proyectos muestra una especificidad en cuanto a los requerimientos, tratamiento y estructuración de la información necesaria para su formulación y evaluación; sin embargo, para todos ellos puede proponerse una metodología común de evaluación multicriterio basada en un modelo de valor cuya aplicación brinde resultados que apoyen su selección sobre otras opciones energéticas y/o la decisión sobre su inclusión o no, en los planes de desarrollo social y económico de la nación sede.

Este capítulo tiene como objetivo fundamental presentar el trabajo realizado para la estructuración de un modelo multicriterio de valor útil a la evaluación de proyectos en el sector energético. 
La estructuración del modelo se basó en: (i) la información recabada, clasificada y resumida en las tablas 1.2.1 y 1.2.2 sobre métodos de apoyo a la decisión multicriterio, (ii) la información recabada, clasificada y resumida en las tablas 3.4 (1-9) y 3.5 (1-11) sobre las características diferenciadoras más resaltantes de cada tipo de recurso energético identificado en el capítulo anterior de este documento y de su proceso de transformación en energías útiles al hombre, (iii) el conocimiento adquirido en entrevistas personales con expertos en materia energética, ambiental, económica y social en el país, (iv) el intercambio de información entre los participantes de grupos de opinión conformados por académicos de la Universidad Metropolitana en Caracas, Venezuela, ( $v$ ) la información recabada en sesiones de trabajo con grupos de estudiantes cursantes del último año de Ingeniería de la misma Universidad; y (vi) en información recogida en encuestas devueltas a través de Internet por expertos en el área de las energías renovables. A continuación una descripción del trabajo realizado.

\subsection{Estructuración del modelo multicriterio de valor}

La etapa central en el diseño de una metodología para la evaluación multicriterio de proyectos de inversión es la formulación del modelo que servirá de referencia para la valoración de sus posibles alternativas de solución. El modelo debe incorporar los aspectos o atributos que se consideren críticos para la evaluación, expresados como objetivos, criterios e indicadores cuya agregación, concertada entre los participantes en el proceso, permita obtener un índice de la robustez de cada propuesta de inversión a evaluar.

Las tareas a cumplir para lograr el objetivo señalado en el párrafo anterior, se pueden clasificar bajo tres grandes títulos,

- Selección de la plataforma de análisis multicriterio

- Selección y validación de los criterios e indicadores para la evaluación

- Estructuración del modelo multicriterio de evaluación

A continuación se describen en forma detallada, estos tres grupos de actividades. 


\subsubsection{Selección de la plataforma de análisis multicriterio}

El Capítulo 1 de este documento hace referencia al gran número de métodos de apoyo a la decisión multicriterio cuyas aplicaciones se han reseñado ampliamente en la literatura especializada. Allí, se presentan las características de algunos de estos métodos, no sólo en cuanto a los basamentos matemáticos y/o lógicos en los cuales respectivamente se fundamentan sino en cuanto al tipo, fuente y forma de procesamiento de la información de entrada y a la presentación de los resultados que se producen. En las tablas 1.2.1 y 1.2.2 se resumen tales características, se cita la herramienta informática más utilizada de apoyo a la aplicación de cada método considerado y se resaltan las fortalezas y debilidades que a criterio del autor están respectivamente asociadas a su uso.

\subsubsection{Selección preliminar}

La naturaleza de las variables del problema de evaluación, el tipo de información disponible o a la que se puede acceder, la forma de plantear los objetivos que se desea alcanzar y el tipo de resultados que se pretende obtener son factores que frente a las bondades específicas de cada método de apoyo a la decisión multicriterio, orientan la escogencia de la metodología de análisis adecuada para tratar una problemática en particular. Es muy importante que la metodología a seleccionar sea fácil de entender y sencilla de aplicar; ello redundará en una mayor confianza en el método y en su aceptación por parte de todos los participantes en el problema de la evaluación [Parodi, 2007].

En el sector energético, los proyectos de inversión presentan características muy diversas. En efecto, las combinaciones [recurso energético, producto derivado, tamaño, tecnología y equipos a utilizar, localización, distribución] posibles suelen ser muchas y definen un extenso y variado conjunto discreto de potenciales proyectos; al que además deben añadirse todos los proyectos relacionados de investigación y desarrollo de nuevas tecnologías, infraestructura, instalación de equipos, operación, logística y administración. 
De esta forma, la elección de un método base para la evaluación de proyectos en el sector energético debe contemplar la posibilidad de incorporar y consolidar de forma adecuada, información muy variada en su naturaleza y formato. El gran desarrollo de las telecomunicaciones y de las redes de información que caracterizan los tiempos modernos no sólo ha facilitado el acceso a tal información sino que la ha ampliado permitiendo la incorporación de los juicios de valor e intereses de múltiples actores localizados o no, en la misma ubicación geográfica, al proceso de análisis. En ambos casos, la información obtenida puede ser de índole cuantitativa o cualitativa.

Por otra parte, debe buscarse que la metodología seleccionada contemple la posibilidad de verificar la consistencia de la información de entrada y que produzca resultados que representen en la mejor forma posible el valor de las propuestas de las opciones consideradas; y de ésta forma puedan ser usados como apoyo en la decisión de modificar, ejecutar, incluir en un plan de desarrollo o rechazar, una o más de una, de las opciones estudiadas.

Finalmente, es muy recomendable que el método seleccionado esté respaldado para su aplicación por un paquete informático sencillo de usar y accesible en costo; que produzca los resultados que se espera produzca, permita agregar los juicios de los participantes e incorpore rutinas para verificar la consistencia de la información de entrada y la sensibilidad de los resultados obtenidos [Parodi, 2007].

Con estas características en mente, una revisión de las tablas 1.2 .1 y 1.2.2, permite llegar a las siguientes conclusiones:

- Los métodos de programación lineal multiobjetivo y de programación por metas requieren que sus objetivos estén asociados a atributos cuantificables; y en consecuencia, su aplicación se limita a problemas que puedan ser formulados en esos términos. Sin embargo los métodos pueden usarse como un complemento de los métodos MCDA, en problemas de planificación energética donde existan limitantes políticas, presupuestarias, físicas o de otra índole.

Por otra parte, este tipo de métodos no permiten la incorporación en forma sistemática de las opiniones y juicios de valor de múltiples actores en el proceso de la evaluación del proyecto. 
- Los métodos basados en funciones de valor requieren la determinación de las funciones de utilidad (MAUT) o de las funciones de valor (MAVT) para cada criterio de evaluación elegido. La tarea puede resultar complicada en el primer caso; sin embargo resulta sencilla, en el segundo caso. A criterio del autor, su principal debilidad radica en que son métodos compensatorios, y sus resultados pueden ser afectados por el manejo que se haga de los pesos. Como en el caso anterior, la participación de múltiples actores en el proceso de evaluación es limitada.

- Los métodos de sobrecalificación utilizan algoritmos complejos que requieren el manejo de conceptos como concordancia, discordancia (ELECTRE), funciones de preferencia (PROMETHEE) y umbrales de preferencia, indiferencia y veto (PROMETHEE, ELECTRE); no fácilmente manejables por los participantes en el proceso y cuya elección inadecuada puede modificar sensiblemente los resultados obtenidos. A criterio del autor, su principal ventaja es que permiten la participación activa de múltiples participantes en el proceso de evaluación a través de la expresión de sus preferencias, en comparaciones entre pares de alternativas para cada criterio de evaluación identificado.

- Los métodos de jerarquías o redes analíticas requieren la construcción de un árbol jerárquico de objetivos a cumplir (AHP) o de una red que muestre las interacciones entre ellos (ANP) lo que facilita el entendimiento del problema y propicia la comunicación entre los participantes en el análisis. Los métodos son de fácil aplicación y permiten la incorporación activa de múltiples actores a través de sus juicios de valor sobre la importancia relativa de los criterios para la evaluación y el grado de cumplimiento con relación a cada uno de ellos, de las alternativas objeto del estudio. Adicionalmente, los métodos ofrecen la posibilidad de verificar la consistencia de la información de entrada.

- Hoy en día, los métodos mencionados son respaldados en su aplicación por paquetes informáticos que facilitan el procesamiento de la data disponible.

Si se reconoce que excepción hecha de los problemas técnicos de diseño, la toma de una decisión en la vida real se realiza de acuerdo a criterios de índole cualitativa y cuantitativa, el universo de las alternativas a considerar en la escogencia del método 
más adecuado para la evaluación de proyectos, se reduce en forma importante [Parodi, 2007].

Si además se tiene en cuenta el hecho de que el éxito de un proyecto depende en cierto grado del apoyo que reciba de las comunidades que serán afectadas por su ejecución; y por tanto, se le da primera importancia a la posibilidad de que el método seleccionado permita la incorporación de los juicios y preferencias no sólo de los expertos sino de autoridades y líderes de las comunidades involucradas; la elección parece ubicarse entre los métodos de sobrecalificación y los métodos de jerarquías o redes analíticas. Entre ellos, son los últimos, los más sencillos de entender y utilizar; y están respaldados por sendos paquetes informáticos ${ }^{59}$ que permiten verificar la consistencia de la información de entrada y estudiar la sensibilidad de los resultados obtenidos; son muy sencillos de usar y ofrecen una interfaz muy amigable con el usuario.

Para confirmar las apreciaciones del autor en el párrafo anterior, a continuación se analiza la tendencia de uso en los últimos años de los métodos PROMETHEE, ELECTRA, AHP y ANP en el sector de planificación energética. Diferencias significativas entre la utilización de los métodos en aplicaciones en el sector, serán un índice de la apreciación de los usuarios en relación a las respectivas bondades de los mismos.

\subsubsection{Tendencia histórica de uso y selección final}

La tendencia histórica de uso de los métodos MCDA puede considerarse un indicador de la mayor o menor confianza que los usuarios han depositado en cada metodología. La tabla 4.2 presenta el número de artículos publicados anualmente para el período 2000-2011 en la base de datos Science Direct $^{60}$ bajo las palabras clave: planificación energética, siglas de la metodología MCDA cuya aceptación se

59

http://www.expertchoice.com. Ver Proceso de Jerarquías Analíticas, Capítulo 2

http://www.superdecisions.com. Ver Proceso de Redes Analíticas Capítulo 2

60 http://www.sciencedirect.com, 3/2011. 
pretende investigar. La figura 4.1 es la representación gráfica de los resultados obtenidos.

Tabla 4.2. Tendencia histórica de uso, MCDA. Sector: planificación energética

\begin{tabular}{|l|c|c|c|c|c|c|c|c|}
\cline { 2 - 9 } \multicolumn{1}{c|}{} & \multicolumn{2}{c|}{ ELECTRE } & \multicolumn{2}{c|}{ PROMETHEE } & \multicolumn{2}{c|}{ AHP } & \multicolumn{2}{c|}{ ANP } \\
\hline Año & Número & $\Sigma$ & Número & $\Sigma$ & Número & $\Sigma$ & Número & $\Sigma$ \\
\hline $3 / 2011$ & 26 & 306 & 19 & 218 & 99 & 1118 & 32 & 490 \\
\hline 2010 & 46 & 280 & 33 & 199 & 200 & 1019 & 76 & 458 \\
\hline 2009 & 40 & 234 & 31 & 166 & 133 & 819 & 57 & 382 \\
\hline 2008 & 38 & 194 & 28 & 135 & 121 & 686 & 46 & 325 \\
\hline 2007 & 38 & 156 & 32 & 107 & 104 & 565 & 43 & 279 \\
\hline 2006 & 19 & 118 & 13 & 75 & 64 & 461 & 47 & 236 \\
\hline 2005 & 5 & 99 & 5 & 62 & 41 & 397 & 21 & 189 \\
\hline 2004 & 16 & 94 & 10 & 57 & 39 & 356 & 17 & 168 \\
\hline 2003 & 13 & 78 & 5 & 47 & 33 & 317 & 11 & 151 \\
\hline 2002 & 2 & 65 & 3 & 42 & 25 & 284 & 6 & 140 \\
\hline 2001 & 3 & 63 & 2 & 39 & 20 & 259 & 18 & 134 \\
\hline 2000 & 2 & 60 & 3 & 37 & 13 & 239 & 15 & 116 \\
\hline$<2000$ & 58 & 58 & 34 & 34 & 226 & 226 & 101 & 101 \\
\hline
\end{tabular}

Fuente: Science Direct ${ }^{66}$. Palabras claves: planificación energética, siglas método MCDA

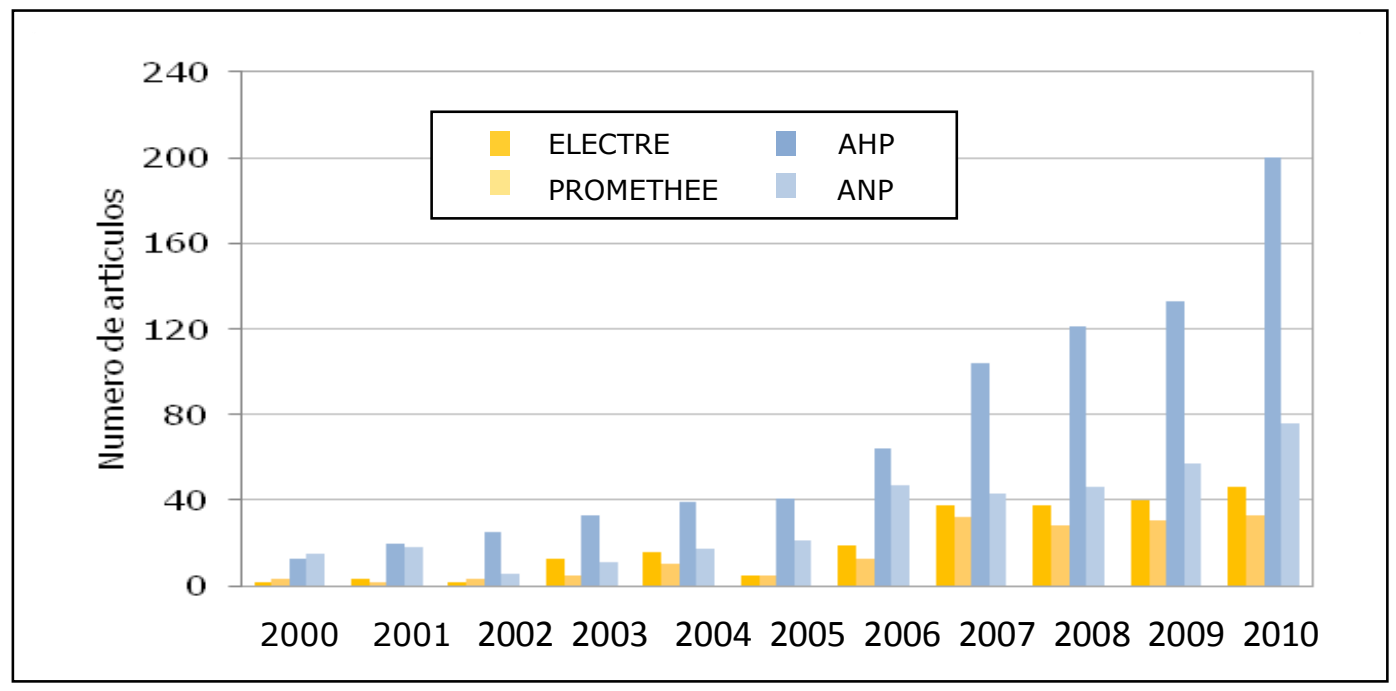

Figura 4.1. Tendencia de uso por metodología MCDA, 2000-2010 
Las cifras en el cuadro anterior fueron recuperadas a inicios del mes de marzo del año 2011; y específicamente se refieren a aplicaciones de cada uno de los métodos de apoyo MCDA en planes con energías renovables, energía nuclear, gas natural, energía eléctrica, desarrollo sostenible, manejo de residuos, impacto ambiental, localización de recursos, gestión de proyectos, entre otras.

La lectura de la Tabla 4.2 y de la figura 4.1 evidencia que para el sector y el período de tiempo considerado:

- Existe un importante crecimiento del uso de los métodos multicriterio de apoyo a la decisión.

- En la última década, el método de Jerarquías Analíticas (AHP) prevalece en las preferencias de los usuarios sobre la de otros métodos MCDA, año tras año. Para el año 2010, el número de publicaciones con aplicaciones del AHP más que duplicó al número de publicaciones en ANP; más que cuadriplicó el número de publicaciones en ELECTRE y más que sextuplicó el mismo indicador en PROMETHEE.

- A partir del año 2006, se inicia un fuerte incremento en las publicaciones sobre aplicaciones del AHP, frente a incrementos moderados en artículos sobre ANP y los métodos MCDA de sobrecalificación. Para el año 2010, alrededor de un 56\% del total de publicaciones sobre los cuatro métodos MCDA considerados, correspondió a publicaciones en AHP.

- El número total de artículos sobre aplicaciones del AHP registrados en Science Direct bajo la palabra clave "planificación energética" hasta la fecha de la investigación (3/2011), fue igual a 1.118 del cual un total de 892 se publicaron a partir del año 2000. La cifra equivale a un 52\% del total de publicaciones para los cuatro métodos MCDA a partir del año 2000.

Las consideraciones anteriores indican claramente que el método de Jerarquías Analíticas ha sido ampliamente preferido por los usuarios como herramienta de análisis de problemas de decisión multicriterio en el sector de planificación energética, durante la última década. 
Lo anterior, unido a las otras bondades del Proceso de Jerarquías Analíticas y al

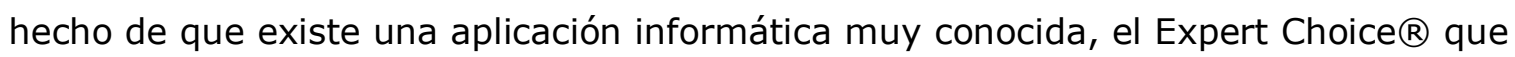
permite el rápido procesamiento de la información, verifica su consistencia y permite el análisis de sensibilidad de los resultados consolidados para el grupo de participantes el proceso; fundamentan la elección del AHP como la plataforma de análisis de la metodología para la evaluación multicriterio de proyectos en el sector energético, objetivo central de este trabajo de investigación.

\subsubsection{Selección de criterios e indicadores para la evaluación}

Una vez escogida la metodología básica de análisis para la evaluación multicriterio de proyectos, la próxima etapa es la elección de los atributos, criterios e indicadores que le darán forma y contenido al modelo para la valoración de proyectos en el sector energético. La figura 4.2 es un diagrama de flujo de las actividades a realizar. La figura destaca en color amarillo los puntos de entrada de información al sistema y su procedencia.

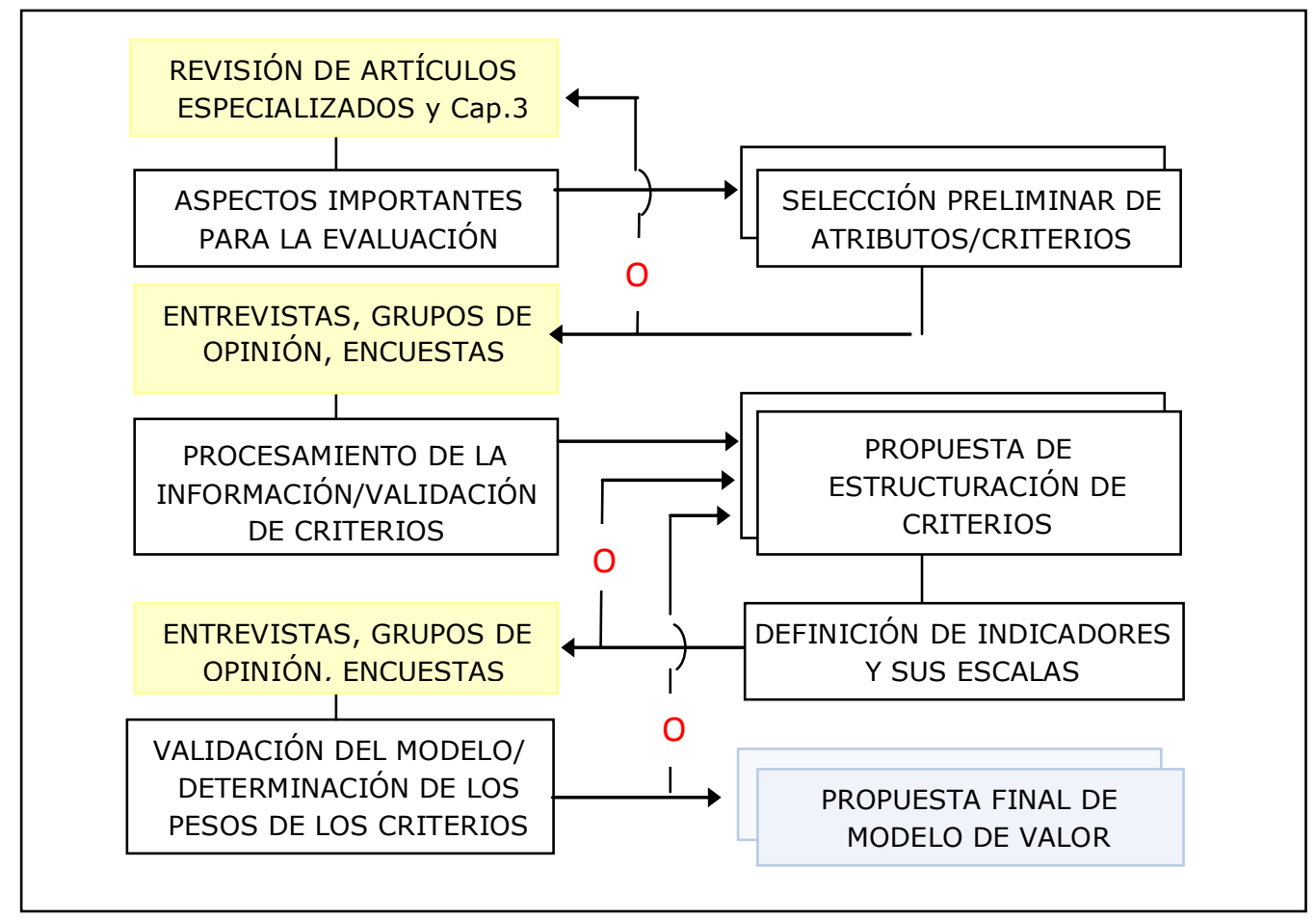

Figura 4.2. Selección de criterios e indicadores para la evaluación 
A continuación se describe el trabajo realizado hasta obtener el producto final de esta etapa. Para el diseño y validación del modelo de valor, las actividades se organizaron en la forma siguiente:

- Identificación y clasificación de los aspectos diferenciadores importantes para la evaluación de proyectos en el sector energético.

- Validación o eliminación de los criterios preseleccionados

- Propuesta de estructuración de criterios

- Definición de indicadores y sus escalas, y rediseño del modelo jerárquico

- Validación del modelo y determinación de las importancias relativas de cada criterio.

- Propuesta final.

Cada actividad es iterativa en sí; y por tanto se repite el número de veces que sea necesario para obtener el mejor producto posible.

\subsubsection{Aspectos importantes para la evaluación. Sector energético}

El examen detallado de la información presentada en el Capítulo 3 de este documento; y más específicamente, de las características, fortalezas y debilidades resumidas respectivamente en las tablas 3.4 y 3.5 para cada recurso energético investigado, permitió la identificación de aspectos diferenciadores importantes que constituyen la base para la selección de los atributos, objetivos, criterios e indicadores que conformarán el modelo de valor.

Una primera inspección de las tablas antes citadas arrojó un total de 76 aspectos importantes a considerar o atributos los cuales se listan en el anexo 1-1 al final de este documento. La consideración detallada de cada atributo y de su importancia relativa aproximada para la evaluación de proyectos relacionados con un recurso energético en particular, frente a la importancia de dicho recurso para el sector energético en general, permitió la eliminación, consolidación y ajuste de algunos de los aspectos previamente identificados. La lista fue contrastada con indicadores de sostenibilidad sugeridos en artículos especializados en el área [Gallegos el al., 2010;; Wang et al., 2009; Kruyt et al., 2009; Lebre et al, 2009; Terrados et al., 2009; Buchholz et al., 2009; Wang et al., 2008; Hirschberg et al., 2007; y otros] y por 
organizaciones internacionales (IAEA y otras, 2005); y consultada con expertos en las diferentes áreas de conocimiento involucradas. Después de varios intentos, la selección original quedó reducida a 44 atributos que se listan en la tabla 4.3.

Tabla 4.3. Aspectos a considerar en la evaluación de proyectos. Sector energético

\begin{tabular}{|c|c|c|c|c|c|c|c|c|c|c|c|c|c|c|c|c|}
\hline \multicolumn{4}{|r|}{ ATRIBUTOS A CONSIDERAR } & $\mathrm{C}$ & $\mathrm{PC}$ & PNC & GC & GNC & $\mathrm{N}$ & $\mathrm{H}$ & $E$ & $\mathrm{~S}$ & M & $\mathrm{O}$ & G & B \\
\hline 1 & $P$ & & $\Delta$ Diversificación en importaciones & & & $\sqrt{ }$ & $\sqrt{ }$ & $\sqrt{ }$ & $\sqrt{ }$ & $\sqrt{ }$ & $\sqrt{ }$ & $\sqrt{ }$ & $\sqrt{ }$ & $\sqrt{ }$ & $\sqrt{ }$ & $\sqrt{ }$ \\
\hline 2 & $P$ & $E$ & Volatilidad en precios suministros & & $\sqrt{ }$ & $\sqrt{ }$ & $\sqrt{ }$ & $\sqrt{ }$ & $\sqrt{ }$ & & & & & & & \\
\hline 3 & $P$ & $\mathrm{~T}$ & Relación reservas/producción & $\sqrt{ }$ & $\sqrt{ }$ & $\sqrt{ }$ & $\sqrt{ }$ & $\sqrt{ }$ & $\sqrt{ }$ & & & & & & & \\
\hline 4 & $P$ & $\mathrm{~T}$ & Continuidad de suministro & & $\sqrt{ }$ & & $\sqrt{ }$ & & & $\sqrt{ }$ & $\sqrt{ }$ & $\sqrt{ }$ & $\sqrt{ }$ & $\sqrt{ }$ & $\sqrt{ }$ & $\sqrt{ }$ \\
\hline 5 & $P$ & & Acceso a tecnologías & $\sqrt{ }$ & $\sqrt{ }$ & $\sqrt{ }$ & $\sqrt{ }$ & $\sqrt{ }$ & $\mathrm{L}$ & $\sqrt{ }$ & $\sqrt{ }$ & $\sqrt{ }$ & $\sqrt{ }$ & $\sqrt{ }$ & $\sqrt{ }$ & $\sqrt{ }$ \\
\hline 6 & $P$ & $\mathrm{~T}$ & Investigación en el área & & & & & & & $\sqrt{ }$ & $\sqrt{ }$ & $\sqrt{ }$ & $\sqrt{ }$ & $\sqrt{ }$ & $\sqrt{ }$ & $\sqrt{ }$ \\
\hline 7 & $P$ & & Disponibilidad personal entrenado & $\sqrt{ }$ & $\sqrt{ }$ & $\sqrt{ }$ & $\sqrt{ }$ & $\sqrt{ }$ & $\mathrm{L}$ & $\sqrt{ }$ & $\sqrt{ }$ & $\sqrt{ }$ & $\sqrt{ }$ & $\sqrt{ }$ & $\sqrt{ }$ & $\sqrt{ }$ \\
\hline 8 & $P$ & & Oportunidad de entrenamiento & $\sqrt{ }$ & $\sqrt{ }$ & $\sqrt{ }$ & $\sqrt{ }$ & $\sqrt{ }$ & $\mathrm{L}$ & $\sqrt{ }$ & $\sqrt{ }$ & $\sqrt{ }$ & $\sqrt{ }$ & $\sqrt{ }$ & $\sqrt{ }$ & $\sqrt{ }$ \\
\hline 9 & $P$ & & Acceso a financiamiento & $\mathrm{L}$ & $\mathrm{L}$ & $\mathrm{L}$ & $\mathrm{L}$ & $\mathrm{L}$ & $\mathrm{L}$ & $\mathrm{L}$ & $\mathrm{L}$ & $\mathrm{L}$ & $\mathrm{L}$ & $\mathrm{L}$ & $\mathrm{L}$ & $\mathrm{L}$ \\
\hline 10 & $P$ & & $\Delta$ Terrenos para cultivo alimentos & & & & & & & & & & & & & $\mathrm{L}$ \\
\hline 11 & $\mathrm{P}$ & & $\Delta$ Precio alimentos & & & & & & & & & & & & & $\sqrt{ }$ \\
\hline 12 & $P$ & & Desplazamiento poblacional & & & & & & & $\sqrt{ }$ & & & & & & \\
\hline 13 & $\mathrm{R}$ & $\mathrm{S}$ & Oposición de la comunidad & $\sqrt{ }$ & $\sqrt{ }$ & $\sqrt{ }$ & $\sqrt{ }$ & $\sqrt{ }$ & $\sqrt{ }$ & $\sqrt{ }$ & $\sqrt{ }$ & $\sqrt{ }$ & $\sqrt{ }$ & $\sqrt{ }$ & $\sqrt{ }$ & $\sqrt{ }$ \\
\hline 14 & & & Conflicto por uso de áreas & & & & & & & $\sqrt{ }$ & & & $\sqrt{ }$ & $\sqrt{ }$ & & $\sqrt{ }$ \\
\hline 15 & $\mathrm{R}$ & & Vulnerabilidad a eventos extremos & & & & & & $\sqrt{ }$ & $\sqrt{ }$ & & & $\sqrt{ }$ & $\sqrt{ }$ & $\sqrt{ }$ & \\
\hline 16 & $\mathrm{R}$ & & Peligro radioactivo & & & & & & $\sqrt{ }$ & & & & & & & \\
\hline 17 & $\mathrm{R}$ & & $\begin{array}{l}\text { Acceso no autorizado a material } \\
\text { radioactivo. }\end{array}$ & & & & & & $\sqrt{ }$ & & & & & & & \\
\hline 18 & A & $\mathrm{R}$ & $\mathrm{CO}_{2}$ a la atmósfera & $\sqrt{ }$ & $\sqrt{ }$ & $\sqrt{ }$ & $\sqrt{ }$ & $\sqrt{ }$ & & & & & & & & $\sqrt{ }$ \\
\hline 19 & A & $\mathrm{R}$ & Otros gases a la atmósfera & $\sqrt{ }$ & $\sqrt{ }$ & $\sqrt{ }$ & $\sqrt{ }$ & $\sqrt{ }$ & & & & & & & & \\
\hline 20 & A & $\mathrm{R}$ & Vertidos al ambiente & $\sqrt{ }$ & $\sqrt{ }$ & $\sqrt{ }$ & $\sqrt{ }$ & $\sqrt{ }$ & $\sqrt{ }$ & & & & & & & \\
\hline 21 & A & $\mathrm{S}$ & Desechos sólidos & $\sqrt{ }$ & & $\sqrt{ }$ & & & & & & & & & & \\
\hline 22 & A & $\mathrm{R}$ & Desechos radioactivos & & & & & & $\sqrt{ }$ & & & & & & & \\
\hline 23 & A & $\mathrm{R}$ & Efectos sobre biodiversidad & & & & & & & $\sqrt{ }$ & & & & & & $\sqrt{ }$ \\
\hline 24 & A & $\mathrm{S}$ & Efectos acústicos & & & & & & & & $\sqrt{ }$ & & & & & \\
\hline 25 & A & $\mathrm{S}$ & Afectación del paisaje & $\sqrt{ }$ & $\sqrt{ }$ & $\sqrt{ }$ & $\sqrt{ }$ & $\sqrt{ }$ & $\sqrt{ }$ & $\sqrt{ }$ & $\sqrt{ }$ & $\sqrt{ }$ & $\sqrt{ }$ & $\sqrt{ }$ & $\sqrt{ }$ & $\sqrt{ }$ \\
\hline 26 & $E$ & & Monto de la inversión & $\mathrm{L}$ & $\mathrm{L}$ & $\mathrm{L}$ & $\mathrm{L}$ & $\mathrm{L}$ & $\mathrm{L}$ & $\mathrm{L}$ & $\mathrm{L}$ & $\mathrm{L}$ & $\mathrm{L}$ & $\mathrm{L}$ & $\mathrm{L}$ & $\mathrm{L}$ \\
\hline 27 & $E$ & & Anualidad Equivalente & $\sqrt{ }$ & $\sqrt{ }$ & $\sqrt{ }$ & $\sqrt{ }$ & $\sqrt{ }$ & $\sqrt{ }$ & $\sqrt{ }$ & $\sqrt{ }$ & $\sqrt{ }$ & $\sqrt{ }$ & $\sqrt{ }$ & $\sqrt{ }$ & $\sqrt{ }$ \\
\hline 28 & $E$ & & Subsidios & & $\sqrt{ }$ & $\sqrt{ }$ & & $\sqrt{ }$ & & & $\sqrt{ }$ & $\sqrt{ }$ & $\sqrt{ }$ & $\sqrt{ }$ & $\sqrt{ }$ & $\sqrt{ }$ \\
\hline 29 & $E$ & $\mathrm{~S}$ & Contribución al PIB regional & $\sqrt{ }$ & $\sqrt{ }$ & $\sqrt{ }$ & $\sqrt{ }$ & $\sqrt{ }$ & $\sqrt{ }$ & $\sqrt{ }$ & $\sqrt{ }$ & $\sqrt{ }$ & $\sqrt{ }$ & $\sqrt{ }$ & $\sqrt{ }$ & $\sqrt{ }$ \\
\hline 30 & $E$ & & $\Delta($ EXP-IMP) & $\sqrt{ }$ & $\sqrt{ }$ & $\sqrt{ }$ & $\sqrt{ }$ & $\sqrt{ }$ & $\sqrt{ }$ & $\sqrt{ }$ & $\sqrt{ }$ & $\sqrt{ }$ & $\sqrt{ }$ & $\sqrt{ }$ & $\sqrt{ }$ & $\sqrt{ }$ \\
\hline 31 & $\mathrm{~T}$ & $\mathrm{P}$ & Existencia de infraestructura apoyo & $\sqrt{ }$ & $\sqrt{ }$ & $\sqrt{ }$ & $\sqrt{ }$ & $\sqrt{ }$ & $\sqrt{ }$ & $\sqrt{ }$ & $\sqrt{ }$ & $\sqrt{ }$ & $\sqrt{ }$ & $\sqrt{ }$ & $\sqrt{ }$ & $\sqrt{ }$ \\
\hline 32 & $\mathrm{~T}$ & & Balance energético & $\mathrm{L}$ & $\mathrm{L}$ & $\mathrm{L}$ & $\mathrm{L}$ & $\mathrm{L}$ & $\mathrm{L}$ & $\mathrm{L}$ & $\mathrm{L}$ & $\mathrm{L}$ & $\mathrm{L}$ & $\mathrm{L}$ & $\mathrm{L}$ & $\mathrm{L}$ \\
\hline 33 & $\mathrm{~T}$ & $\mathrm{P}$ & Disponibilidad de tierras & $\mathrm{L}$ & $\mathrm{L}$ & $\mathrm{L}$ & $\mathrm{L}$ & $\mathrm{L}$ & $\mathrm{L}$ & $\mathrm{L}$ & $\mathrm{L}$ & $\mathrm{L}$ & $\mathrm{L}$ & $\mathrm{L}$ & $\mathrm{L}$ & $\mathrm{L}$ \\
\hline 34 & $\mathrm{~T}$ & $\mathrm{P}$ & Disponibilidad de agua & $\mathrm{L}$ & $\mathrm{L}$ & $\mathrm{L}$ & $\mathrm{L}$ & $\mathrm{L}$ & $\mathrm{L}$ & $\mathrm{L}$ & $\mathrm{L}$ & $\mathrm{L}$ & $\mathrm{L}$ & $\mathrm{L}$ & $\mathrm{L}$ & $\mathrm{L}$ \\
\hline 35 & $\mathrm{~T}$ & $\mathrm{E}$ & Rendimientos & $\sqrt{ }$ & $\sqrt{ }$ & $\sqrt{ }$ & $\sqrt{ }$ & $\sqrt{ }$ & $\sqrt{ }$ & $\sqrt{ }$ & $\sqrt{ }$ & $\sqrt{ }$ & $\sqrt{ }$ & $\sqrt{ }$ & $\sqrt{ }$ & $\sqrt{ }$ \\
\hline
\end{tabular}

Continúa en la página siguiente 
Tabla 4.3 (C) Aspectos a considerar en la evaluación de proyectos. Sector energético

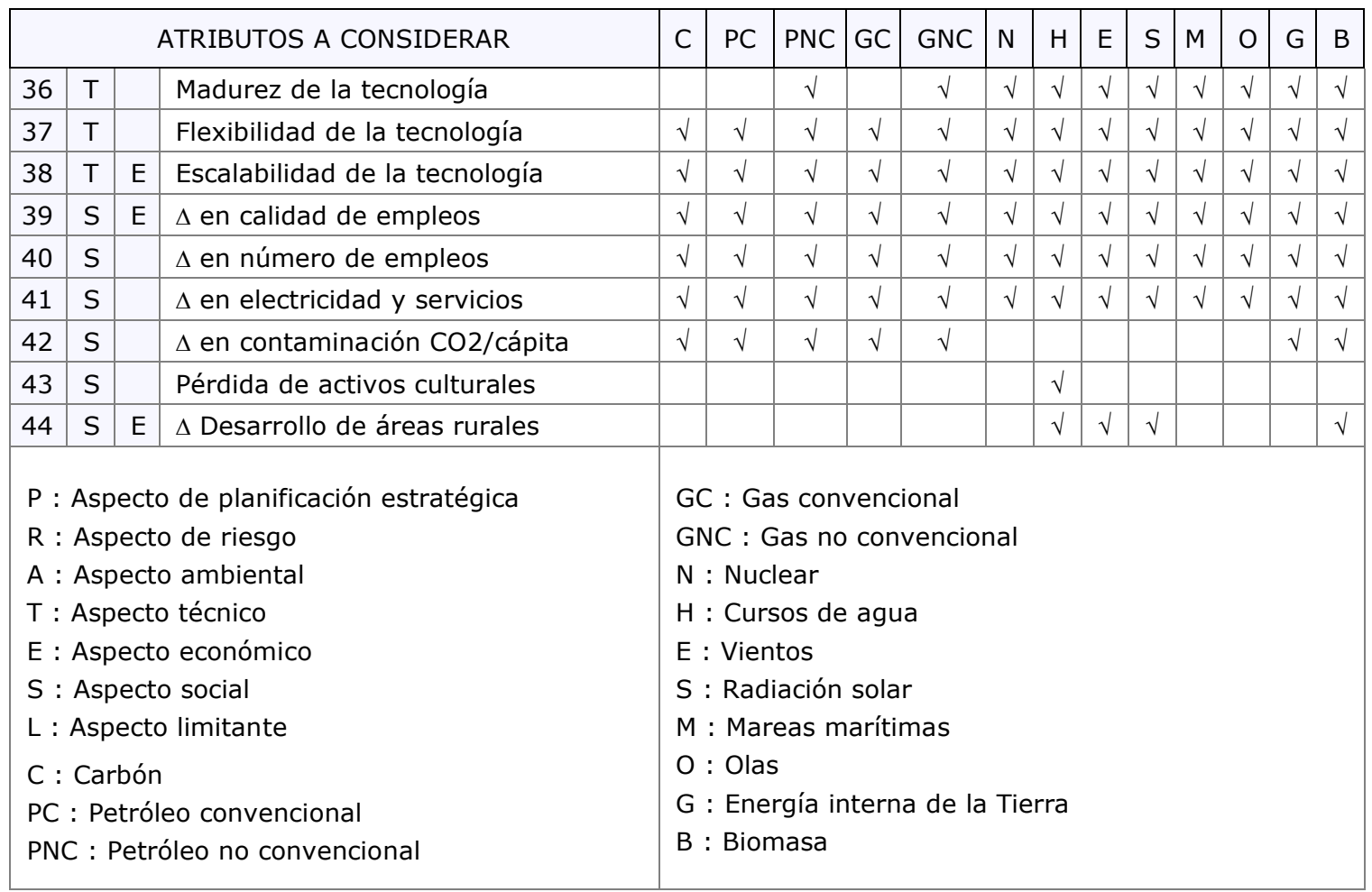

El signo $\sqrt{ }$ señala los aspectos importantes para la evaluación de proyectos que respectivamente utilicen como insumo los recursos energéticos reseñados.

Como puede observarse, la lista de atributos incluidos en el cuadro anterior no sólo tiene en cuenta las dimensiones ambiental, económica y social señalados reiteradamente en los artículos especializados sobre sostenibilidad, sino que introduce las dimensiones técnica, de riesgo y de planificación estratégica. La primera de ellas tiene que ver con algunos aspectos sobre las características de las tecnologías utilizadas, sus requerimientos y sus rendimientos; temas de gran actualidad especialmente en el campo de las energías renovables.

La dimensión riesgo, como su nombre lo indica, tiene que ver con la importancia de los daños a la población, al ambiente o a las instalaciones del proyecto por la probabilidad de ocurrencia de accidentes, una vez que éste entre en funcionamiento. 
El tema ha retomado su vigencia ante el accidente ocurrido en la planta de Fukushima en Japón que ha sido catalogado como "accidente grave", categoría $7^{61}$ en la escala Internacional de Accidentes Nucleares (INES, por sus siglas en inglés) de la Organización Internacional de Energía Atómica.

Por su parte, la dimensión estratégica intenta introducir en el análisis la compatibilidad del proyecto con los planes energéticos nacionales o regionales, y su capacidad de contribuir al alivio de problemas relacionados con el suministro y uso de la energía, que hoy día preocupan a la humanidad; entre ellos:

- El elevado y creciente consumo de energía en el mundo, mayoritariamente suplido por los combustibles fósiles y particularmente por el petróleo. Tan elevado consumo produce entre otras consecuencias:

(i) La emisión de grandes cantidades de $\mathrm{CO}_{2}$ y otros gases de tipo invernadero con un efecto directo sobre el calentamiento global, preocupación principalísima en todos los sectores y a todos los niveles de la población por las graves implicaciones que sobre el clima y el nivel de los mares, entre otras cosas, prevén los expertos en la materia.

(ii) La dependencia energética de los países que no disponen de petróleo, gas o carbón en cantidad suficiente para satisfacer sus necesidades, hacia los países con capacidad de exportar excedentes de producción.

La situación se complica por el hecho de que las mayores reservas de petróleo en el mundo se encuentran en manos de un grupo muy limitado de países en desarrollo, algunos de ellos políticamente inestables, que tienen una considerable influencia sobre los volúmenes comercializados y sus precios en el mercado. Como un ejemplo, los recientes sucesos en el Norte de África, especialmente en Libia generaron alarma ante una posible interrupción del

61 Greenpeace, USA, http://www.greenpeace.org/usa/en/media-center/reports/Fukushima--INES-scalerating/, 29/03/11. 
suministro. Hoy día, los precios de petróleo se ubican alrededor de los 100 $\$ / \mathrm{bbl}^{62}$.

En el caso del suministro de gas, la situación es menos crítica pero también compleja. A inicios del año 2009, Europa sufrió la interrupción del suministro de gas ruso a causa del conflicto entre Rusia y Ucrania. Y más recientemente, los graves disturbios que se han desarrollado en algunos países árabes hicieron temer una posible interrupción del suministro de gas libio a Italia y España ${ }^{63}$

Los problemas señalados configuran una situación de amenaza a la seguridad energética de los países debido al potencial recorte del suministro de los recursos energéticos necesarios ya sea por interrupción física del mismo; o en el caso de los países más pobres, por la imposibilidad de hacer frente a la elevación de la ya cuantiosa factura por importación de combustibles.

(iii) El agotamiento de las reservas mundiales de petróleo y gas convencional, a mediano plazo. A la tasa de consumo actual, la duración de las reservas de petróleo convencional es de unos 46 años [BP, 2011] mientras que la de gas natural convencional se acerca a unos 60 años [BP, 2011].

Adicionalmente, y como es natural, muchos de los países propietarios de las reservas han nacionalizado sus recursos y las instalaciones existentes para su explotación; sin embargo, a veces no disponen de las tecnologías modernas y del elevado capital necesario para hacer frente a la búsqueda de nuevos yacimientos y para un eficaz manejo y desarrollo de los que se encuentran bajo explotación, con la consecuente disminución en la producción y su oferta al mercado.

62 A mitades del 2008 el precio del petróleo alcanzó un máximo de 145,3 US\$/bbl (WTI Cushing Oklahoma) para luego bajar hasta unos $30 \mathrm{US} \$ / \mathrm{bbl}$ a finales del mismo año, recuperarse hasta unos 112 US\$ a mitades del año 2011 y volver a bajar hasta 94 US\$ a mitades del 2012 (15.5.2012, EIA, 2012a].

63 http://www.heraldo.es/noticias/espana_podria_hacer_frente_posible_corte-gas-libia.html, 2/11 
- El desigual acceso a los servicios básicos energéticos a lo ancho y largo del planeta. Hoy día, existen en el mundo más de 1.400 millones de personas sin acceso a electricidad y unos 2.700 millones que dependen de la biomasa tradicional para la cocción de sus alimentos; mayoritariamente localizados en el África Subsahariana, India y algunos países del sur de Asia [IEA, 2009a]. A modo de contraste, mientras el consumo de energía en Kuwait para el año 2009 sobrepasó los 17.000 kWh/cápita; en Haití, el mismo indicador no superó los 36 kWh/cápita [WB, 2009]. En Centro y Suramérica existe un aproximado de 31 millones de personas sin acceso a electricidad, ubicadas en su gran mayoría en aéreas rurales [IEA, UNDP y UNIDO, 2010c].

El acceso a los modernos servicios energéticos es importante para la superación de las condiciones de vida de las población en cuanto a provisión de agua limpia, saneamiento y salud a la población, iluminación, calefacción, medios eficientes para el cocimiento de alimentos, potencia mecánica, transporte y servicios de telecomunicaciones [IEA, UNDP y UNIDO, 2010c].

- El potencial desplazamiento de cultivos de alimentos por cultivos dirigidos a la producción de biocombustibles. El tema ha causado una amplia polémica en los Estados Unidos donde las cosechas de maíz fueron dirigidas a la producción de biocombustibles causando una disminución de su oferta al mercado de alimentos y causando, entre otros factores, el aumento de los precios. En Venezuela, el presidente Chávez vetó públicamente el desarrollo de cualquier plan de producción de biocombustibles a partir del cultivo de biomasa en terrenos que puedan ser dedicados a la producción de alimentos.

La consideración de los elementos señalados sumados a los aspectos económicos, relacionados a la optimización del uso de los recursos disponibles; a los aspectos ambientales asociados a los efectos de vertidos y desechos que las operaciones de explotación y transformación de los recursos energéticos y/o uso de sus productos derivados, pueden producir sobre la atmósfera, la tierra y las aguas del planeta; y finalmente, a los aspectos sociales que tienen que ver con el mejoramiento de las condiciones de vida de la población; sirvieron de estructura a seguir en la elección de los atributos recogidos en la tabla 4.3, incluida anteriormente. 


\subsubsection{Validación de los criterios preseleccionados}

A los aspectos importantes para la evaluación o atributos preliminares seleccionados en la etapa anterior, deben asociarse respectivamente objetivos a cumplir y un grupo de criterios que guiarán la evaluación. Todo el conjunto debe ser validado posteriormente con las opiniones que expertos en el área aporten individualmente o como parte de un grupo de discusión, en una o más rondas de entrevistas y toma de encuestas a los participantes seleccionados al efecto.

El grupo de atributos y criterios seleccionados debe contribuir a conformar un modelo de valor preliminar para la evaluación de proyectos en el sector energético que represente de forma lo más completa posible pero a la vez concisa y sencilla en su aplicación, lo esencial de un problema extenso y complejo. Los atributos y criterios incluidos en el grupo deben ser relevantes, significativos, fácilmente entendibles, no redundantes y medibles objetiva o subjetivamente. Si los atributos no cumplen con estas condiciones deben ser redefinidos, agrupados o subdivididos hasta que se alcance una situación satisfactoria.

Con las características antes expresadas en mente, la validación de los criterios preseleccionados se realizó de acuerdo al siguiente plan de actividades:

- Selección de la muestra a entrevistar y levantamiento de la información

- Procesamiento y análisis de la información recabada

- Elección de criterios

A continuación, un resumen de las tareas realizadas.

\subsubsection{1 . Selección de la muestra y levantamiento de la información}

Para ésta primera aproximación al resultado buscado, la muestra de personas a entrevistar o convocar a grupos de opinión, se seleccionó en base a dos criterios concurrentes, (i) el conocimiento, experticia y/o afinidad sobre uno o más de uno de los diferentes aspectos del problema bajo estudio, por parte de cada candidato a entrevistar, y (ii) la disponibilidad del candidato para la entrevista. 
La tabla 4.4 muestra la distribución de una muestra de 53 personas entrevistadas, individualmente o en grupos de opinión.

Tabla 4.4. Distribución de la muestra de expertos para validación de criterios. Encuesta preliminar.

\begin{tabular}{|c|c|c|c|c|}
\hline \multirow{2}{*}{ GRUPO } & \multirow{2}{*}{$\begin{array}{l}\text { ÁREA DE } \\
\text { CONOCIMIENTO/EXPERTICIA } \\
\text { O AFINIDAD }\end{array}$} & \multicolumn{2}{|c|}{ CANTIDAD } & \multirow{2}{*}{ ENCUESTA } \\
\hline & & IND & GRUP & \\
\hline \multirow{6}{*}{ ACADÉMICOS } & Economía/Planificación & 1 & - & 1 \\
\hline & Ingeniería/Ambiente/MCDM & 2 & - & 2 \\
\hline & Ingeniería/Energía & 3 & - & 3 \\
\hline & Ingeniería/Energía/MCDM & 3 & - & 3 \\
\hline & Políticas públicas & 1 & - & NO \\
\hline & Ingeniería/MCDM & & 7 & 7 \\
\hline $\begin{array}{l}\text { ESTUDIANTES ÚLTIMO } \\
\text { AÑO INGENIERÍA, GRUPO } 1\end{array}$ & Energía & - & 18 & 18 \\
\hline $\begin{array}{l}\text { ESTUDIANTES ÚLTIMO } \\
\text { AÑO INGENIERÍA, GRUPO } 2\end{array}$ & Ingeniería Económica & - & 18 & 18 \\
\hline \multicolumn{2}{|r|}{ TOTAL } & 10 & 43 & 52 \\
\hline \multicolumn{2}{|c|}{$\begin{array}{r}\text { ESTUDIANTES GRUPO } 1, \\
18 \text { ENCUESTAS } \\
14 \%\end{array}$} & \multicolumn{2}{|c|}{$\begin{array}{l}\text { ACADÉMICO } \\
17 \text { ENTREVIs } \\
16 \text { ENCUEST }\end{array}$} & $\begin{array}{l}\text { AS, } \\
\text { S. }\end{array}$ \\
\hline
\end{tabular}

Esta primera ronda de consultas se realizó entre:

- Profesores de la Universidad Metropolitana y de la Universidad Simón Bolívar, ambas localizadas en Caracas, Venezuela, con experiencia académica promedio estimada $\geq 15$ años.

- Dos grupos de estudiantes cursando materias relacionadas con proyectos y/o energía, en el último año de Ingeniería en la Universidad Metropolitana.

Dado el gran número de criterios a validar y a fin de dar algún sentido a su utilización en la evaluación de un proyecto en el sector energético, los mismos se 
agruparon en torno a siete objetivos relacionados con los problemas señalados en el aparte 4.1.2.1 y al contenido de las tablas 3.4 y 3.5, Capítulo 3, de este documento. Los objetivos fueron los siguientes:

- Maximizar seguridad energética

- Maximizar apoyo gubernamental

- Minimizar impacto ambiental

- Minimizar el riesgo para la población y el proyecto

- Maximizar bienestar de la comunidad

- Maximizar conveniencia técnica

- Maximizar conveniencia económica

Previa la exposición del problema y su discusión, el registro de las opiniones de cada participante se realizó objetivo a objetivo. En cada caso, se solicitó contestar la pregunta ¿Cuán pertinente es el criterio sometido a validación para medir el cumplimiento del objetivo al cual está asociado y cuál su importancia? y que la respuesta se expresase en una escala del 1 al 5, donde 1 correspondía a la menor importancia y 5 a la mayor.

Se realizaron 53 entrevistas, individualmente o en grupos, y se recogieron 52 encuestas. El experto en Políticas Públicas dio su opinión general sobre la estructura planteada e hizo observaciones sobre la importancia de la participación de la comunidad en los planes de implantación de proyectos en general; sin embargo, se manifestó no apto en otros aspectos de la encuesta.

\subsubsection{Procesamiento y análisis de la información recabada}

En el anexo 1 al final de este documento, se presenta el instrumento utilizado para la realización de las consultas y la hoja EXCEL diseñada para el procesamiento de la información levantada en la etapa anterior.

Como puede observarse, cada criterio se ubicó en la dimensión a cual fue originalmente asignado en la tabla 4.3, sección 4.1.2.1 de este documento. Las valuaciones sobre la pertinencia e importancia de cada criterio a validar, suministradas por los participantes en las entrevistas, se clasificaron para su 
procesamiento, de acuerdo a tres grupos de procedencia: académicos, estudiantesG1 o estudiantes-G2. Sobre la información así revisada y clasificada, se efectuaron las siguientes operaciones:

- Estimación de la media aritmética de las mediciones de preferencia (M), la desviación estándar $(\sigma)$ y el coeficiente de variación para cada grupo y criterio $(\sigma / M)$.

- Estimación de la media aritmética de las medias por grupo para cada criterio $(M M)$, la desviación estándar $(\sigma M)$ y el coeficiente de variación ( $\sigma M / M M)$ correspondientes a la población de medias.

La desviación estándar y el coeficiente de variación permiten medir la dispersión de las mediciones de la media de la muestra, en forma absoluta o relativa respectivamente. Ciertamente, la mejor combinación para seleccionar un criterio de acuerdo a las valoraciones que de su importancia hagan los entrevistados es una valuación alta y un coeficiente de variación bajo. Si se estiman estos parámetros para la población de las medias de los grupos para cada criterio (MM), el respectivo coeficiente de variación ( $\sigma M / M M)$ puede servir como un indicador de la mayor o menor diferencia entre las medias de los diferentes grupos.

- Estimación de la media aritmética por dimensión de las medias de los criterios para cada grupo y para toda la muestra (MD); y de la desviación estándar $(\sigma D)$ y el coeficiente de variación ( $\sigma D / M D$ ) correspondientes a la población de medias por criterio para la totalidad de la muestra.

La estimación de la media aritmética de los criterios asignados a una dimensión es una forma de obtener un límite inferior para la selección de criterios; y el respectivo coeficiente de variación es un indicador de la dispersión de la población de las medias MM con relación a su media (MD).

La tabla 4.5 que se presenta en la página siguiente muestra los resultados obtenidos. Su análisis y las acciones derivadas fueron la base para la estructuración del modelo de valor objetivo primordial de este trabajo de investigación. 
Tabla 4.5. Validación de los criterios preseleccionados. Sector energético

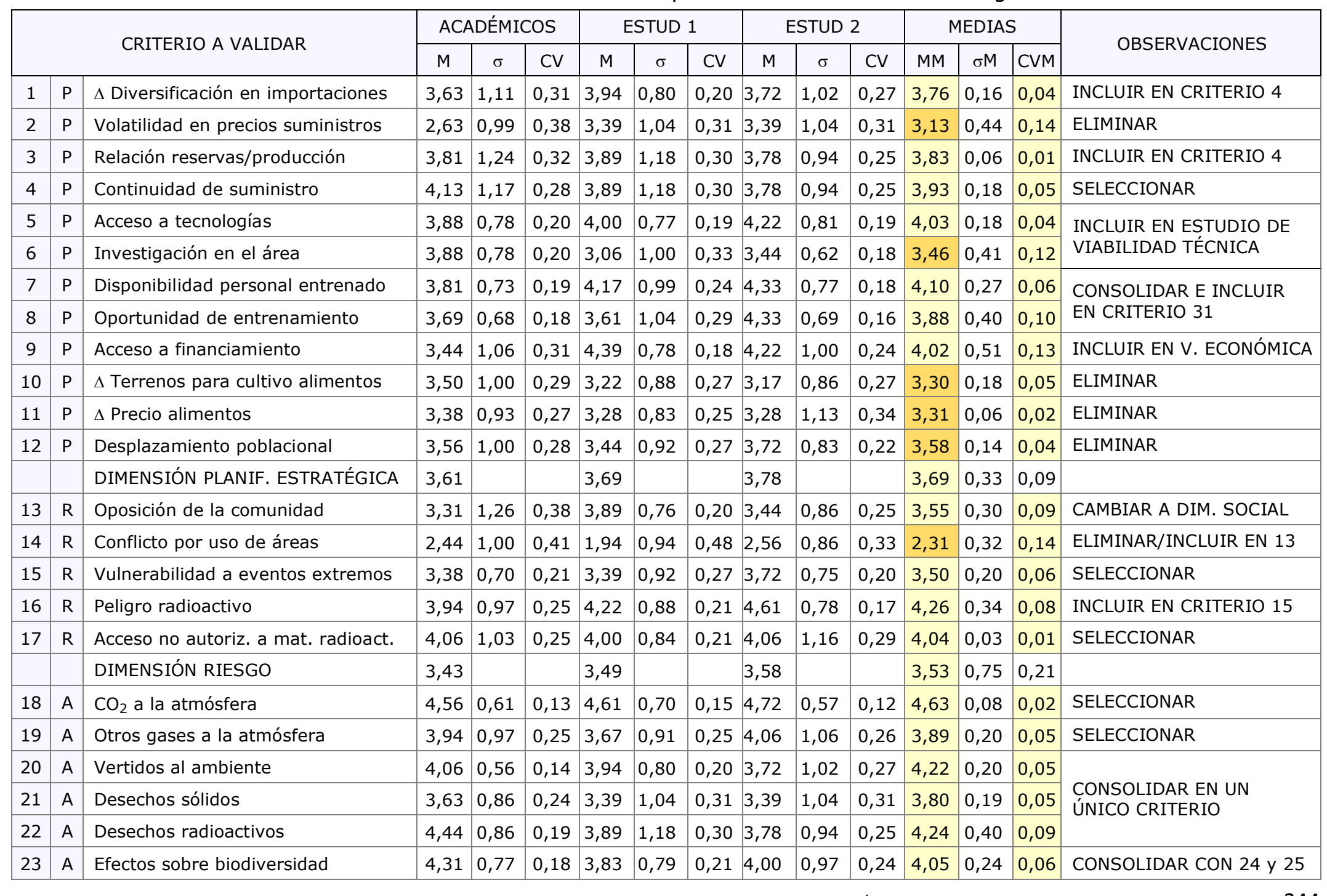


Tabla 4.5 (C). Validación de los criterios preseleccionados. Sector energético

\begin{tabular}{|c|c|c|c|c|c|c|c|c|c|c|c|c|c|c|c|}
\hline \multirow{2}{*}{\multicolumn{3}{|c|}{ CRITERIO A VALIDAR }} & \multirow{2}{*}{\multicolumn{3}{|c|}{ ESTUD 1}} & \multirow{2}{*}{\multicolumn{3}{|c|}{ ESTUD 2}} & \multirow{2}{*}{\multicolumn{3}{|c|}{ ACADÉMICOS }} & \multirow{2}{*}{\multicolumn{3}{|c|}{ TOTALIDAD }} & \multirow{3}{*}{ OBSERVACIONES } \\
\hline & & & & & & & & & & & & & & & \\
\hline & & & \multirow{2}{*}{\begin{tabular}{|c|}
$M$ \\
2,69 \\
\end{tabular}} & \multirow{2}{*}{\begin{tabular}{|c|}
$\sigma$ \\
0,58 \\
\end{tabular}} & \multirow{2}{*}{$\frac{\mathrm{CV}}{\mathrm{C}, 22}$} & \multirow{2}{*}{\begin{tabular}{|c|}
$M$ \\
2,44 \\
\end{tabular}} & \multirow{2}{*}{\begin{tabular}{|c|}
$\sigma$ \\
0,86 \\
\end{tabular}} & \multirow{2}{*}{\begin{tabular}{|c|} 
CV \\
0,35
\end{tabular}} & \multirow{2}{*}{$\begin{array}{c}M \\
2,89\end{array}$} & \multirow{2}{*}{\begin{tabular}{|c|}
$\sigma$ \\
1,08 \\
\end{tabular}} & \multirow{2}{*}{\begin{tabular}{|c|} 
CV \\
0,37 \\
\end{tabular}} & \multirow{2}{*}{\begin{tabular}{|c|} 
MM \\
2,67 \\
\end{tabular}} & \multirow{2}{*}{\begin{tabular}{|c|}
$\sigma$ \\
0,22
\end{tabular}} & \multirow{2}{*}{\begin{tabular}{|c|} 
CV \\
0,08
\end{tabular}} & \\
\hline 24 & A & Efectos & & & & & & & & & & & & & \multirow{2}{*}{$\begin{array}{l}\text { CONSOLIDAR CON } \\
\text { CRITERIO } 23\end{array}$} \\
\hline \multirow[t]{2}{*}{25} & A & Afectación del paisaje & 2,44 & 0,50 & 0,20 & 2,33 & 1,03 & 0,44 & 2,72 & 1,23 & 0,45 & 2,50 & 0,20 & 0,08 & \\
\hline & & DIMENSIÓN AMBIENTAL & 3,76 & & & 3,58 & & & 3,92 & & & 3,75 & 0,76 & 0,20 & \\
\hline 26 & $\mathrm{E}$ & Monto de la inversión & 3,44 & 1,06 & 0,31 & 4,39 & 0,78 & 0,18 & 4,28 & 0,96 & 0,22 & 4,03 & 0,52 & 0,13 & INCLUIR EN V. ECONÓMICA \\
\hline 27 & $\mathrm{E}$ & Anualidad equivalente s/subsidios & 4,50 & 0,61 & 0,14 & 4,39 & 0,70 & 0,16 & 4,06 & 0,73 & 0,18 & 4,31 & 0,23 & 0,05 & \multirow{2}{*}{$\begin{array}{l}\text { CONSOLIDAR EN UN } \\
\text { ÚNICO CRITERIO }\end{array}$} \\
\hline 28 & $\mathrm{E}$ & Anualidad equivalente c/subsidios & 4,69 & 0,58 & 0,12 & 4,28 & 0,75 & 0,18 & 3,83 & 0,86 & 0,22 & 4,27 & 0,43 & 0,10 & \\
\hline 29 & $\mathrm{E}$ & Contribución al PIB regional & 4,38 & 0,70 & 0,16 & 4,67 & 0,69 & 0,15 & 4,11 & 0,68 & 0,16 & 4,38 & 0,28 & 0,06 & SELECCIONAR \\
\hline \multirow[t]{2}{*}{30} & $\mathrm{E}$ & $\Delta($ EXP-IMP) & 4,13 & 0,86 & 0,21 & 4,17 & 0,92 & 0,22 & 4,11 & 0,96 & 0,23 & 4,13 & 0,03 & 0,01 & SELECCIONAR \\
\hline & & DIMENSIÓN ECONÓMICA & 4,23 & & & 4,38 & & & 4,08 & & & 4,23 & 0,14 & 0,03 & \\
\hline 31 & $\mathrm{~T}$ & Existencia de infraestructura apoyo & 3,88 & 0,99 & 0,26 & 4,00 & 0,91 & 0,23 & 4,06 & 0,80 & 0,20 & 3,98 & 0,09 & 0,02 & SELECCIONAR \\
\hline 32 & $\mathrm{~T}$ & Balance energético & 4,38 & 0,70 & 0,16 & 4,56 & 0,70 & 0,15 & 4,39 & 0,61 & 0,14 & 4,44 & 0,10 & 0,02 & \multirow{3}{*}{$\begin{array}{l}\text { INCLUIR EN ESTUDIO DE } \\
\text { VIABILIDAD TÉCNICA }\end{array}$} \\
\hline 33 & $\mathrm{~T}$ & Disponibilidad de tierras & 4,69 & 0,98 & 0,21 & 3,78 & 0,81 & 0,21 & 4,00 & 1,03 & 0,26 & 4,16 & 0,47 & 0,11 & \\
\hline 34 & $\mathrm{~T}$ & Disponibilidad de agua & 4,69 & 0,98 & 0,21 & 4,11 & 0,68 & 0,16 & 4,33 & 0,84 & 0,19 & 4,38 & 0,29 & 0,07 & \\
\hline 35 & $\mathrm{~T}$ & Rendimientos & 4,06 & 0,75 & 0,18 & 4,33 & 0,69 & 0,16 & 4,06 & 0,73 & 0,18 & 4,15 & 0,16 & 0,04 & SELECCIONAR \\
\hline 36 & $\mathrm{~T}$ & Madurez de la tecnología & 3,94 & 0,75 & 0,19 & 4,11 & 1,13 & 0,28 & 4,28 & 0,67 & 0,16 & 4,11 & 0,17 & 0,04 & SELECCIONAR \\
\hline 37 & $\mathrm{~T}$ & Flexibilidad de la tecnología & 4,06 & 0,83 & 0,20 & 4,17 & 0,71 & 0,17 & 4,00 & 0,84 & 0,21 & 4,08 & 0,08 & 0,02 & SELECCIONAR \\
\hline \multirow[t]{2}{*}{38} & $\mathrm{~T}$ & Escalabilidad de la tecnología & 3,63 & 0,99 & 0,27 & 3,56 & 1,25 & 0,35 & 4,00 & 0,84 & 0,21 & 3,73 & 0,24 & 0,06 & ELIMINAR \\
\hline & & DIMENSIÓN TÉCNICA & 16 & & & 4,08 & & & 4,14 & & & 4,13 & 0,22 & 0,05 & \\
\hline 39 & $\mathrm{~S}$ & $\Delta$ en calidad de empleos & 4,13 & 0,86 & 0,21 & 4,33 & 0,69 & 0,16 & 4,22 & 1,00 & 0,24 & 4,23 & 0,10 & 0,02 & \multirow{3}{*}{$\begin{array}{l}\text { CONSOLIDAR EN UN } \\
\text { ÚNICO CRITERIO }\end{array}$} \\
\hline 40 & $\mathrm{~S}$ & $\Delta$ en número de empleos & 4,00 & 0,79 & 0,20 & 4,33 & 0,69 & 0,16 & 4,44 & 0,92 & 0,21 & 4,26 & 0,23 & 0,05 & \\
\hline 41 & $\mathrm{~s}$ & $\Delta$ en electricidad y servicios & 4,38 & 0,60 & 0,14 & 4,11 & 0,83 & 0,20 & 3,89 & 0,58 & 0,15 & 4,13 & 0,24 & 0,06 & \\
\hline 42 & $\mathrm{~S}$ & $\Delta$ en contaminación $\mathrm{CO} 2 /$ cápita & 3,94 & 0,75 & 0,19 & 4,22 & 0,65 & 0,15 & 4,06 & 0,73 & 0,18 & 4,07 & 0,14 & 0,04 & \multirow{3}{*}{ INCLUIR EN CRITERIO 13} \\
\hline 43 & $\mathrm{~S}$ & Pérdida de activos culturales & 3,25 & 1,03 & 0,32 & 3,00 & 1,14 & 0,38 & 2,89 & 0,96 & 0,33 & 3,05 & 0,18 & 0,06 & \\
\hline \multirow[t]{2}{*}{44} & $\mathrm{~S}$ & $\Delta$ Desarrollo de áreas rurales & 4,19 & 0,63 & 0,15 & 4,17 & 0,86 & 0,21 & 4,17 & 0,79 & 0,19 & 4,17 & 0,01 & 0,00 & \\
\hline & & DIMENSIÓN. SOCIAL & 3,98 & & & 4,03 & & & 3,94 & & & 3,98 & 0,46 & 0,12 & \\
\hline
\end{tabular}




\subsection{Análisis de resultados}

La lectura de los resultados presentados en la tabla 4.5, permitió identificar algunos criterios potencialmente descartables de la lista propuesta en la tabla 4.3, sección 4.1.2.1 de este documento. El análisis de las cifras sirvió de base para una serie de modificaciones sobre el contenido restante de la misma, a fin de articular a partir de ella, un modelo para la valuación de proyectos que resultase confiable, no redundante en sus criterios y sencillo en su manejo. Las observaciones en la última columna de la tabla 4.5 corresponden a la acción final tomada con el atributo listado en su tercera columna.

El análisis de las cifras obtenidas en la investigación de campo y resumidas en el cuadro anterior, permitió llegar a las siguientes conclusiones:

(i) El coeficiente de variación entre las medias para cada criterio y cada grupo (M) y la media de las medias (MM) es mayor a 0,07, sólo en menos del $20 \%$ de los casos. Esta situación se refleja en la figura 4.3 y revela que no hay diferencia importante entre las opiniones promedio por grupo.

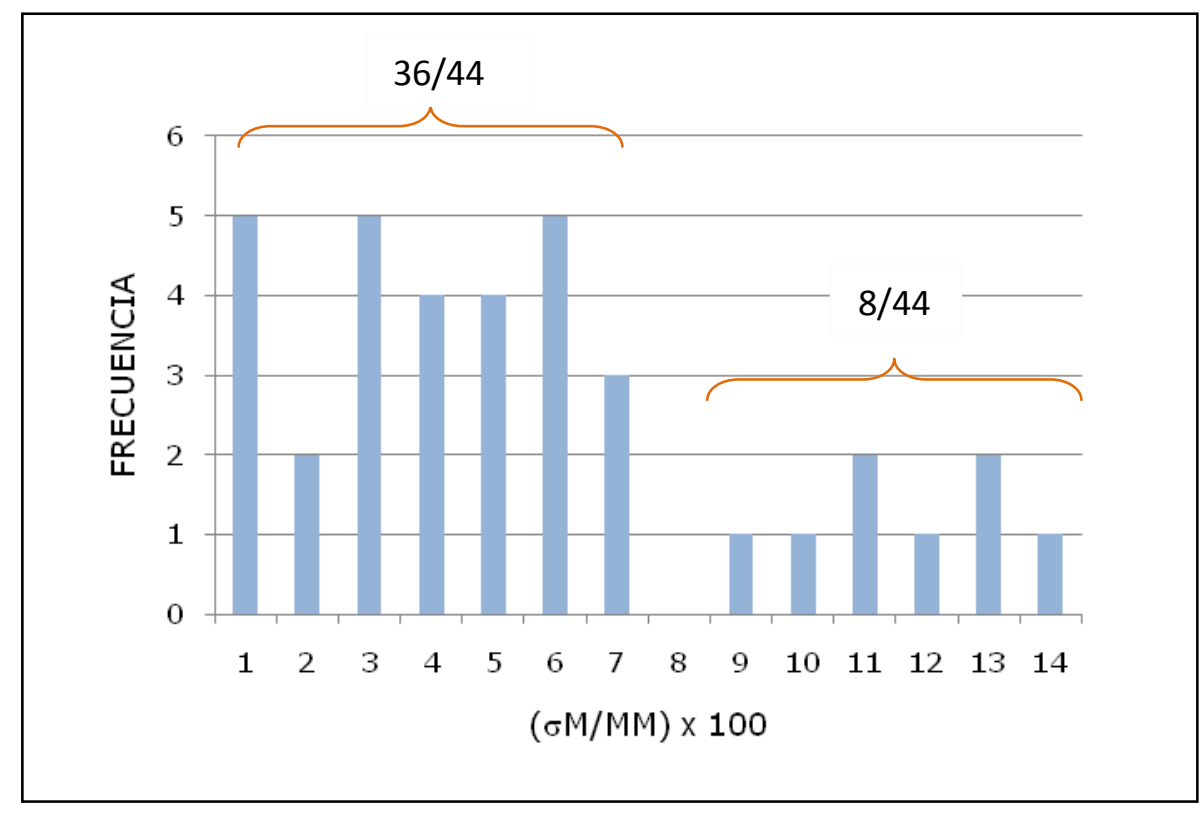

Figura 4.3. Histograma del coeficiente de variación de las medias de grupo para cada criterio (M) y la media de las medias (MM). 
En base a lo anteriormente expresado, se consideró adecuado tomar la media de las medias de cada criterio por grupo, como su valuación promedio; o lo que es equivalente, la media de la totalidad de las valuaciones para dicho criterio (MM).

(ii) Las medias de las mediciones de las preferencias por criterio son en su gran mayoría cercanas o mayores a 4 sobre un máximo de 5 , y los respectivos coeficientes de variación oscilan entre 0,12 y 0,48; sin embargo la mayor parte de ellos se encuentran alrededor de 0,2. Si se elige como condición para el descarte de un criterio que su media sea inferior a la media de los criterios para la dimensión y que su coeficiente de variación sea alto, pueden eliminarse para cada dimensión, los criterios que cumplan con esta condición.

La situación se señala en la tabla 4.5 y puede observarse gráficamente en la figura 4.4 que se presenta en la próxima página. Un examen de la tabla 4.5 muestra que si se aplica la condición expresada en el párrafo anterior, el número a considerar de criterios para la evaluación se reduce a 36; cifra aún elevada si se quiere configurar una estructura jerárquica sencilla que sirva a la evaluación multicriterio de proyectos.

En consecuencia, se hace necesario un análisis más detallado de la información recogida a fin de seleccionar el número necesario y suficiente; y no más, de aspectos importantes para la evaluación. La tarea realizada en tal sentido se describe en la próxima sección.

\subsection{Selección de criterios}

La figura 4.4 muestra gráficamente los resultados consolidados para la muestra entrevistada en su totalidad, clasificados por dimensión. Las líneas punteadas rojas representan la media de las preferencias de los criterios en cada dimensión y sirven como límite de referencia para la eliminación de los criterios que captaron la preferencia más baja dentro de sus respectivas dimensiones, por parte de los expertos entrevistados. Las barras que sobrepasan tal límite representan los aspectos finalmente seleccionados para su inclusión como criterios de evaluación en el modelo de valor; el proceso de su selección se explica a continuación. 


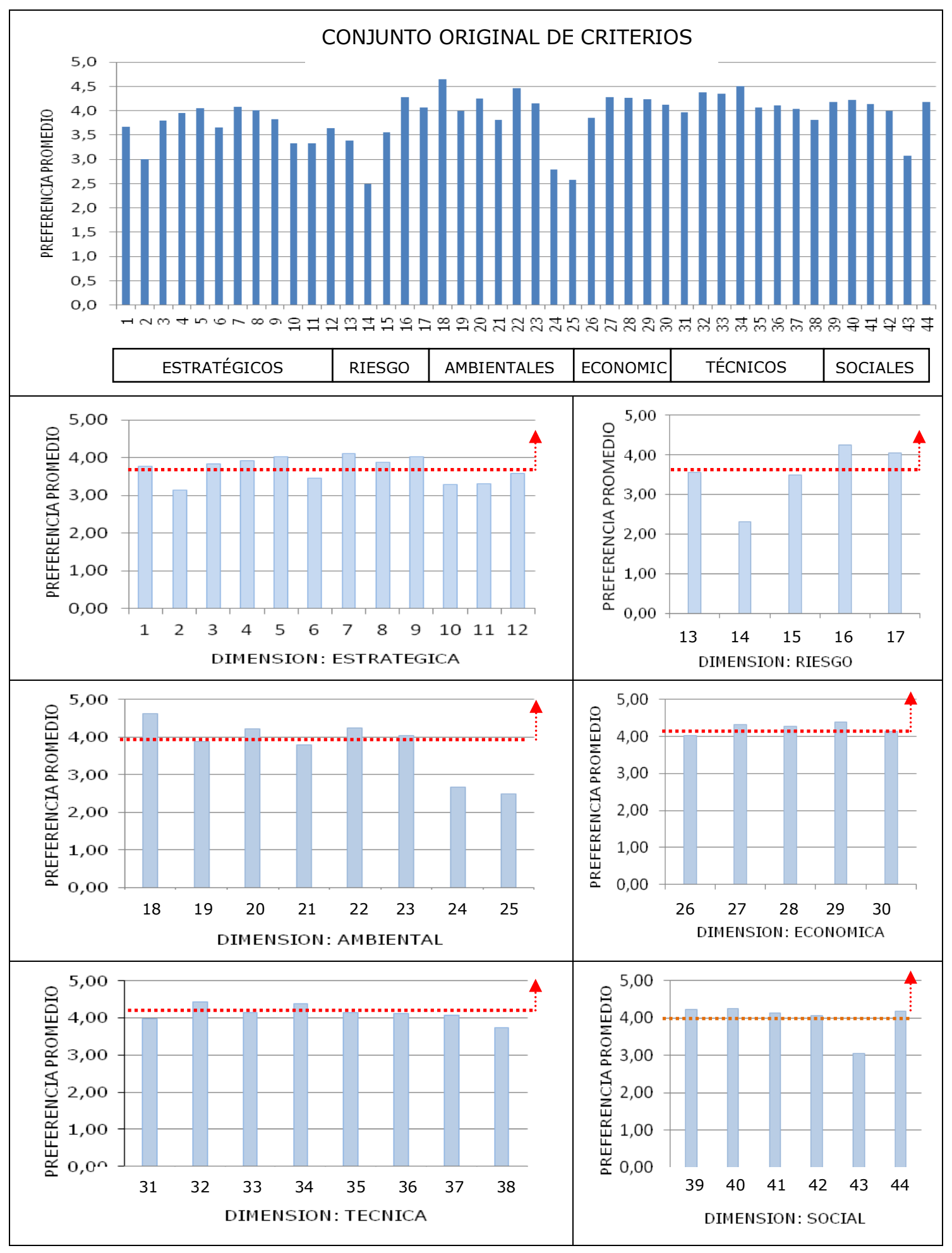

Figura 4.4. Selección de criterios 
Tomando como base la información reflejada por la figura anterior; y en un intento por sistematizar la selección de criterios para conformar un modelo de evaluación integral de proyectos en el sector energético, se siguió el siguiente procedimiento:

- La lista de criterios originalmente propuesta se clasificó en seis dimensiones: planificación estratégica, riesgo, ambiente, tecnología, economía y bienestar social. Se consideró conveniente asignar a cada dimensión entre dos y cuatro criterios, a menos que otras consideraciones aconsejasen lo contrario.

La bibliografía consultada al respecto [Gallegos el al., 2010; Kahraman et al., 2010; Kaya et al., 2010; Wang et al., 2010; Wang et al., 2009; Kruyt et al., 2009; Lebre et al, 2009; Terrados et al., 2009; Buchholz et al., 2009; Wang et al., 2008; Hirschberg et al., 2007 y otros; IAEA y otras; 2005; OECD, 2008], arroja una amplia variabilidad no sólo en cuanto a tipo de indicadores sino al número de ellos considerado. En general, se refieren a indicadores de sostenibilidad en las áreas ambiental, social y económica.

- Los aspectos limitantes para la ejecución del proyecto no son negociables; y por tanto, se eliminaron de la estructura jerárquica a proponer. A criterio del autor, los criterios con esta condición y que los entrevistados consideraron deben permanecer en el análisis, pueden evaluarse en estudios previos de viabilidad del proyecto. La tabla 4.6 lista los aspectos eliminados del modelo de valor por este concepto y los parámetros estadísticos a ellos respectivamente asociados.

Tabla 4.6. Aspectos importantes a evaluar en estudios de viabilidad previos

\begin{tabular}{|c|c|c|c|c|c|c|}
\hline ESTUDIO & DIM & CRITERIO & MM & $\sigma \mathrm{M} / \mathrm{MM}$ & MD & $\sigma D / M D$ \\
\hline \multirow{5}{*}{$\begin{array}{l}\text { VIABILIDAD } \\
\text { TÉCNICA }\end{array}$} & $\mathrm{P}$ & Acceso a tecnologías & 4,03 & 0,04 & \multirow{2}{*}{3,69} & \multirow{2}{*}{0,69} \\
\hline & $P$ & Investigación en el área* & 3,46 & 0,12 & & \\
\hline & $T$ & Disponibilidad de terrenos & 4,16 & 0,11 & \multirow{3}{*}{4,13} & \multirow{3}{*}{0,05} \\
\hline & $\mathrm{T}$ & Disponibilidad de agua & 4,38 & 0,07 & & \\
\hline & $\mathrm{T}$ & Balance energético & 4,44 & 0,02 & & \\
\hline \multirow{2}{*}{$\begin{array}{l}\text { VIABILIDAD } \\
\text { ECONÓMICA }\end{array}$} & $E$ & Monto de la inversión & 4,02 & 0,13 & 4,23 & 0,03 \\
\hline & $P$ & Acceso a financiamiento & 4,03 & 0,13 & 3,69 & 0,09 \\
\hline
\end{tabular}

* No limitante 
La primera columna del cuadro anterior indica el tipo de estudio donde respectivamente se deben incluir los aspectos señalados en la tercera columna del mismo cuadro. Nótese que con sólo una excepción, estos criterios son limitantes para la ejecución del proyecto; y por tanto, debe verificarse cuidadosamente el cumplimiento de tales limites previo a cualquier evaluación.

El criterio 'Investigación en el área' tiene que ver con la potencialidad de mejoras en la tecnología sugerida por el proyecto y con su capacidad para incorporarlas en el momento oportuno. El aspecto es no limitante y obtuvo una preferencia inferior a la media de su dimensión, por parte de los expertos; sin embargo, por su importancia debe incorporarse a los estudios previos especialmente si se trabaja en el área de recursos renovables y reflejarse posteriormente en los criterios que tienen que ver con la madurez y la flexibilidad de la tecnología.

Por su parte, el aspecto 'Monto de la inversión. es limitante especialmente si no se tiene acceso a financiamiento; y su preferencia promedio es ligeramente inferior a la media de los criterios en su dimensión pero aún mayor a 4 . Por ambas causas, no se eliminó sino que se creyó conveniente incluirlo en un estudio previo de viabilidad económica, junto con el resto de los indicadores en la tabla 4.6.

- Los criterios afines, interdependientes o derivados se consolidaron en un único criterio o se incluyeron en el criterio con la preferencia más alta. La tabla 4.7 presenta los criterios con esta condición, los parámetros estadísticos relativos a cada uno de ellos y la acción a tomar en cada caso.

Algunos aspectos con baja preferencia entre los encuestados fueron incluidos en la definición del respectivo criterio consolidado, en lugar de ser eliminados. Los casos específicos se señalan en la tabla 4.7. La decisión se tomó en base a la frecuencia con que aparecen citados en la bibliografía especializada; y en último instancia, en base al análisis cuidadoso previo a su eliminación.

La consolidación de criterios se efectuó en todas las dimensiones y logró reducir significativamente el número de aspectos/criterios. 
Tabla 4.7. Atributos a consolidar por similitud o dependencia

\begin{tabular}{|c|c|c|c|c|c|c|c|}
\hline DIM & & CRITERIO & MM & $\sigma \mathrm{M} / \mathrm{MM}$ & MD & $\sigma \mathrm{D} / \mathrm{MD}$ & ACCIÓN \\
\hline$P$ & 1 & $\Delta$ Diversificación de importaciones & 3,76 & 0,04 & \multirow{3}{*}{3,69} & \multirow{3}{*}{0,09} & \multirow{3}{*}{$\begin{array}{l}\text { Afines }=> \\
\text { CONSOLIDAR en } \\
\text { nuevo criterio }\end{array}$} \\
\hline$P$ & 3 & Relación reservas/producción & 3,83 & 0,01 & & & \\
\hline$P$ & 4 & Continuidad de suministro & 3,93 & 0,05 & & & \\
\hline$P$ & 7 & Disponibilidad de personal entrenado & 4,1 & 0,06 & \multirow{2}{*}{3,69} & \multirow[t]{2}{*}{0,09} & \multirow{3}{*}{$\begin{array}{l}\text { Criterios } 7 \text { y } 8 \\
=>\text { a criterio } 31\end{array}$} \\
\hline$P$ & 8 & Oportunidad de entrenamiento & 3,88 & 0,10 & & & \\
\hline $\mathrm{T}$ & 31 & Infraestructura de apoyo & $(3,98)$ & 0,02 & 4,13 & 0,05 & \\
\hline $\mathrm{R}$ & 15 & Vulnerabilidad a eventos extremos & 3,50 & 0,06 & \multirow{2}{*}{3,53} & \multirow{2}{*}{0,21} & \multirow{2}{*}{$\begin{array}{l}\text { Criterio } 16=> \\
\text { a criterio } 15 .\end{array}$} \\
\hline $\mathrm{R}$ & 16 & Peligro radiactivo & 4,26 & 0,08 & & & \\
\hline A & 20 & Vertidos al ambiente & 4,22 & 0,05 & \multirow{3}{*}{3,75} & \multirow{3}{*}{0,02} & \multirow{3}{*}{$\begin{array}{l}\text { Afines }=> \\
\text { CONSOLIDAR en } \\
\text { nuevo criterio }\end{array}$} \\
\hline A & 21 & Desechos solidos & 3,80 & 0,05 & & & \\
\hline$A$ & 22 & Desechos radioactivos & 4,24 & 0,09 & & & \\
\hline A & 23 & Efecto sobre biodiversidad & 3,80 & 0,05 & \multirow{3}{*}{3,75} & \multirow{3}{*}{0,20} & \multirow{3}{*}{$\begin{array}{l}\text { Afines }=> \\
\text { CONSOLIDAR en } \\
\text { nuevo criterio }\end{array}$} \\
\hline$A$ & 24 & Efectos acústicos & 2,67 & 0,08 & & & \\
\hline A & 25 & Afectación del paisaje & 2,50 & 0,08 & & & \\
\hline$E$ & 27 & Anualidad equivalente s/subsidios & 4,31 & 0,05 & \multirow{2}{*}{4,23} & \multirow{2}{*}{0,03} & \multirow{2}{*}{$\begin{array}{l}\text { Afines }=> \\
\text { CONSOLIDAR en } \\
\text { nuevo criterio }\end{array}$} \\
\hline $\mathrm{E}$ & 28 & Anualidad equivalente c/subsidios & 4,27 & 0,10 & & & \\
\hline $\mathrm{R}$ & 13 & Oposición de la comunidad & 3,55 & 0,09 & 3,53 & 0,21 & \multirow{4}{*}{$\begin{array}{l}\text { Afines }=> \\
\text { CONSOLIDAR en } \\
\text { nuevo criterio }\end{array}$} \\
\hline $\mathrm{S}$ & 42 & $\Delta$ contaminación $\mathrm{CO} 2 /$ cápita & 4,07 & 0,04 & \multirow{3}{*}{3,98} & \multirow{3}{*}{0,12} & \\
\hline $\mathrm{S}$ & 43 & Pérdida de activos culturales & 3,05 & 0,06 & & & \\
\hline S & 44 & $\Delta$ Desarrollo de áreas rurales & 4,17 & 0,00 & & & \\
\hline S & 39 & $\Delta$ Número de empleos & 4,26 & 0,05 & \multirow{3}{*}{3,98} & \multirow{3}{*}{0,12} & \multirow{3}{*}{$\begin{array}{l}\text { Afines }=> \\
\text { CONSOLIDAR en } \\
\text { nuevo criterio }\end{array}$} \\
\hline S & 40 & $\Delta$ Calidad de empleo & 4,23 & 0,02 & & & \\
\hline $\mathrm{S}$ & 41 & $\Delta$ Electricidad y servicios & 4,13 & 0,06 & & & \\
\hline
\end{tabular}

- La lista de criterios preseleccionados en los pasos anteriores, fue ampliada por la incorporación de algunos criterios que debieron ser validados en etapas posteriores. De esta forma,

(i) Se incorporó al esquema preliminar, el criterio 'Compatibilidad con planesregión', a fin de tener en cuenta la ventaja que representa para la aprobación de un proyecto, el hecho de estar ubicado en un área prioritaria de desarrollo para el gobierno del país sede.

(ii) El criterio principal 'Continuidad de suministro' pasó a ser criterio subalterno del criterio más amplio, 'Seguridad energética', que contempla no sólo la 
parte cuantitativa sino la parte cualitativa del suministro de energía mediante la incorporación del criterio subalterno 'Diversidad de la cesta energética'.

(iii) El criterio 'Rendimientos' perteneciente a la dimensión técnica, fue sustituido por dos criterios 'Eficiencia térmica' y 'Factor de capacidad' para incorporar al análisis los aspectos de eficiencia térmica de conversión de la tecnología de transformación del recurso energético objeto del proyecto a evaluar; y de la disponibilidad promedio de las respectivas instalaciones para lograrlo.

- Cada nuevo criterio se definió en función de criterios subalternos asociados, cuando ello contribuía a su mejor medición. La definición de subcriterios en la dimensión ambiental fue específicamente consultada con expertos en el área, por su alto grado de especialización.

- Finalmente y a fin de simplificar la aplicación del modelo para la evaluación, vía la reducción de la información poco accesible requerida para la misma, se eliminó el criterio 'Contribución al Producto Interno Bruto local'.

Como es bien sabido, la contribución al PIB puede estimarse como el valor a precios de mercado de los bienes y servicios generados directa e indirectamente como consecuencia de la entrada en operación de las nuevas instalaciones propuestas. Los efectos indirectos pueden ser importantes y su estimación requiere de la participación de expertos lo que complicaría y encarecería innecesariamente el proceso de evaluación.

En resumen, el análisis de la información suministrada por los entrevistados permitió refinar la propuesta original de aspectos importantes a considerar en el problema de la evaluación multicriterio de proyectos en el sector energético introducida en la sección 4.1.2.1 de este documento.

El proceso permitió la reducción de aproximadamente un $50 \%$ del número de atributos/criterios de la lista original que pasó de contener 44 aspectos principales a contener 17 criterios principales y 12 criterios subordinados; e incrementó la calidad de los criterios en su conjunto, en cuanto a su simplicidad, facilidad de medición, independencia y cualidades diferenciadoras para la evaluación. 


\subsubsection{Propuesta de estructuración de criterios}

La figura 4.5 presenta una propuesta de estructuración jerárquica en tres niveles de los criterios seleccionados en la etapa anterior para evaluar la conveniencia de un proyecto en el sector energético.

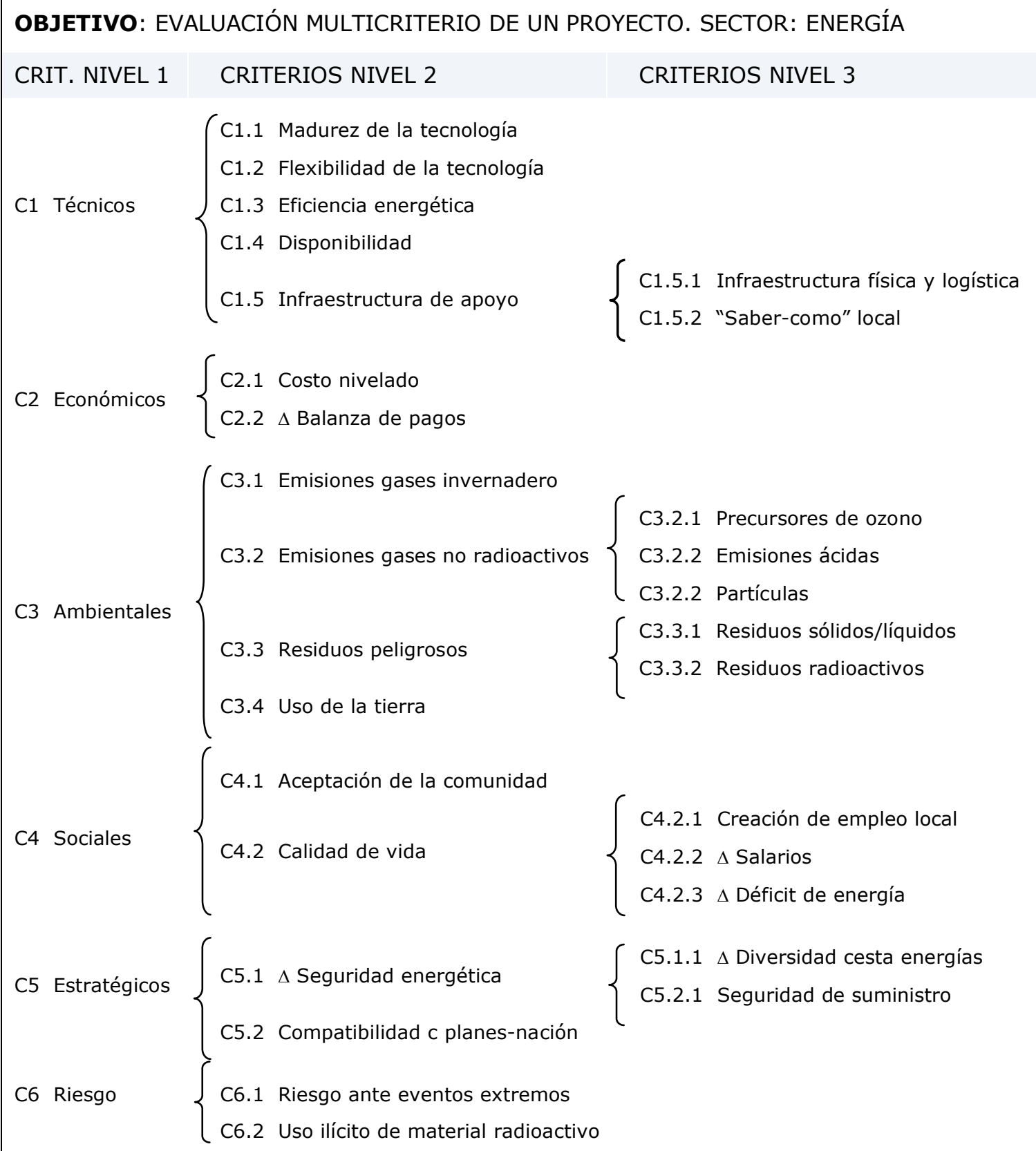

Figura 4.5. Jerarquía de criterios para la evaluación de proyectos. Sector energía 
Los criterios en la estructura jerárquica planteada se distribuyen en tres niveles. El nivel 1 es el superior y en él se ubican las seis dimensiones planteadas. Bajo cada dimensión se localizan entre dos y cinco criterios principales; todos ellos corresponden al nivel 2. Finalmente, en el nivel 3 se ubican doce criterios subalternos correspondientes a algunos de los criterios del nivel anterior. Cada criterio está identificado por la combinación de la letra $\mathrm{C}$ y uno o más números, que indican su posición en el diagrama.

Una vez estructurados los criterios en un esquema jerárquico, el próximo paso hacia la concreción del modelo de valor, es definir los indicadores y las escalas respectivamente correspondientes a los criterios seleccionados, problema que se aborda en la próxima sección.

\subsubsection{Definición de los indicadores y sus escalas}

Un indicador es un instrumento que sintetiza información sobre una situación en particular. Los indicadores son tanto más útiles en cuanto midan lo que efectivamente se desea conocer, sean fácilmente entendibles y estén basados en información confiable que exista o que se pueda recabar oportunamente al menor costo posible.

En el sector energético, profesionales, estadísticos y académicos utilizan indicadores para evaluar y monitorear el cumplimiento de metas prefijadas de planes y proyectos. El trabajo realizado en el área es una referencia obligatoria a revisar antes de proponer un sistema de indicadores que se ajuste a la estructura jerárquica de criterios de evaluación presentada en la tabla 4.9. A continuación algunas observaciones al respecto.

\subsection{Indicadores de energía para el desarrollo sostenible}

A partir de la introducción del concepto de 'desarrollo sostenible' por el informe Brundtland [UN/WECD, 1987]; y especialmente, a partir de 1995, organizaciones nacionales e internacionales han venido trabajando en sistemas de indicadores que fuesen una guía para evaluar uno o más aspectos de la sostenibilidad de proyectos y planes de desarrollo en las diferentes regiones del mundo. En la última década, la 
Agencia Internacional de Energía Atómica (IAEA), el Departamento de Asuntos Económicos y Sociales de las Naciones Unidas (UNDESA), la Agencia Internacional de Energía (IEA), la Oficina Europea de Estadística (Eurostat) y la Agencia Europea para el Ambiente (EEA) han realizado un notable esfuerzo conjunto en la conformación de un sistema de indicadores capaz de suministrar información de apoyo para la evaluación de la sostenibilidad de programas y planes desarrollo en el sector energético (2001-2005). El sistema que se conoce como 'Indicadores de energía para el desarrollo sostenible' (EISD, por sus siglas en inglés) está conformado por 30 indicadores clasificados en tres dimensiones: social, económica y ambiental $^{64}$ [IAEA y otros, 2005]. En una segunda fase, la IAEA coordinó un esfuerzo por implementar el sistema en Brasil, Cuba, Lituania, México, la Federación Rusa, Eslovaquia y Tailandia. Cada país en la lista seleccionó los indicadores más relevantes a las prioridades energéticas para el análisis de sus políticas y planes futuros [IAEA y UNDESA, 2007].

El tema de la energía relacionada al desarrollo sostenible ha sido objeto no sólo de documentos de trabajo e informes de organizaciones internacionales sino de publicaciones en el sector académico. En general, las propuestas de indicadores para evaluar la sostenibilidad de planes en uno o más subsectores del sector energético plantean la convergencia de condiciones mínimas en los ámbitos económico, ambiental y social como requisito de sostenibilidad. Eventualmente, se contemplan aspectos en las dimensiones técnica e institucional del plan o proyecto. La tabla 4.8 refiere el contenido de algunas publicaciones en el área durante la última década. Cada renglón en el cuadro incluye el objeto de la publicación, el número de indicadores propuestos para cumplir con el mismo y las dimensiones de sostenibilidad contempladas en el análisis

Desarrollo sostenible: "Desarrollo que satisface las necesidades del presente sin comprometer la habilidad de las generaciones futuras de satisfacer sus propias necesidades', Our Common Future, [UN/WCED, 1987]. 
Tabla 4.8. Sistemas de indicadores para evaluación de sostenibilidad de planes de desarrollo en el sector energético. Referencias consultadas.

\begin{tabular}{|c|c|c|c|c|c|c|c|}
\hline \multirow{2}{*}{ REFERENCIA } & \multicolumn{5}{|c|}{ DIMENSIÓN } & \multirow{2}{*}{ NI } & \multirow{2}{*}{ OBJETO DE LA PUBLICACIÓN } \\
\hline & $E$ & $A$ & $\mathrm{~S}$ & $\mathrm{~T}$ & $\mathrm{P}$ & & \\
\hline OECD, 2008 & & $\sqrt{ }$ & & & & 10 & Energía y ambiente \\
\hline IAEA y otros, 2005 & $\sqrt{ }$ & $\sqrt{ }$ & $\sqrt{ }$ & & & 30 & Energía y desarrollo sostenible \\
\hline Beccalli et al., 2003 & $\sqrt{ }$ & $\sqrt{ }$ & $\sqrt{ }$ & $\sqrt{ }$ & & 12 & Planificación energética sostenible \\
\hline Cavallaro et al., 2005 & $\sqrt{ }$ & $\sqrt{ }$ & $\sqrt{ }$ & $\sqrt{ }$ & & 11 & $\begin{array}{l}\text { Energía renovable sostenible, } \\
\text { Italia }\end{array}$ \\
\hline Chatzimouratidis et al., 2008 & & $\sqrt{ }$ & $\sqrt{ }$ & & & 11 & Energía e impacto socioambiental \\
\hline Chatzimouratidis et al., 2007 & & $\sqrt{ }$ & & & & 5 & Energía y emisiones al ambiente \\
\hline Hirschberg et al., 2007 & $\sqrt{ }$ & $\sqrt{ }$ & $\sqrt{ }$ & & & 18 & Energía y desarrollo sostenible \\
\hline Burton et al., 2007 & $\sqrt{ }$ & $\sqrt{ }$ & $\sqrt{ }$ & $\sqrt{ }$ & & 8 & Energías renovables \\
\hline Vera et al., 2007 & $\sqrt{ }$ & $\sqrt{ }$ & $\sqrt{ }$ & & & 30 & Energía y desarrollo sostenible \\
\hline Athanasios et al., 2008 & & $\sqrt{ }$ & $\sqrt{ }$ & & & 11 & Energía e impacto socioambiental \\
\hline Wang et al., 2008 & $\sqrt{ }$ & $\sqrt{ }$ & $\sqrt{ }$ & $\sqrt{ }$ & & 16 & Energía, MCDA, China \\
\hline Diakoulaki et al., 2009 & $\sqrt{ }$ & $\sqrt{ }$ & & $\sqrt{ }$ & & 8 & Plan. energética sostenible, Grecia \\
\hline Lebre La Rovere et al., 2009 & $\sqrt{ }$ & $\sqrt{ }$ & $\sqrt{ }$ & $\sqrt{ }$ & & 14 & Planificación energética sostenible \\
\hline Terrados et al., 2009 & $\sqrt{ }$ & $\sqrt{ }$ & $\sqrt{ }$ & $\sqrt{ }$ & & 11 & Planes energéticos sostenibles \\
\hline Wang et al., 2009 & $\sqrt{ }$ & $\sqrt{ }$ & $\sqrt{ }$ & $\sqrt{ }$ & & 29 & Planificación energética sostenible \\
\hline Carrera et al., 2010 & & & $\sqrt{ }$ & $\sqrt{ }$ & $\sqrt{ }$ & 9 & Energía y efectos sociales \\
\hline Kahraman et al., 2010 & $\sqrt{ }$ & $\sqrt{ }$ & $\sqrt{ }$ & $\sqrt{ }$ & $\sqrt{ }$ & 17 & Planificación energética sostenible \\
\hline Kaya et al., 2010 & $\sqrt{ }$ & $\sqrt{ }$ & $\sqrt{ }$ & $\sqrt{ }$ & & 29 & Planificación energética sostenible \\
\hline Kruyt et al., 2009 & & & & & $\sqrt{ }$ & 21 & Revisión seguridad energética \\
\hline Wang et al., 2010 & $\sqrt{ }$ & $\sqrt{ }$ & $\sqrt{ }$ & & & 17 & Planificación energética. China \\
\hline
\end{tabular}

E : Económica A: Ambiental S: Social T: Técnica P: Política/ institucional

NI: número de indicadores

Las propuestas presentan una gran variabilidad en contenido y número de indicadores. En algunos casos, se trata el tema de forma general y se proponen sistemas de indicadores que permiten evaluar y monitorear el desarrollo sostenible para un país o región [IAEA, 2005; OECD, 2008; Vera, 2007]; sin embargo, en la mayoría de los casos, el tratamiento se limita a planes o alternativas de inversión en un subsector de los muchos que componen el sector energético, y se proponen grupos de indicadores que se adapten a cada situación en particular. En ninguno de los casos referidos en la tabla 4.8, el problema de la evaluación de proyectos en el sector energético se trata de forma integral. 


\subsection{Bases estadísticas de datos}

Adicionalmente, se encuentran las bases estadísticas de datos, actualizadas periódicamente y publicadas a través de Internet, por las organizaciones internacionales y nacionales relacionadas con el sector energético [The World Bank, 2012; BP; 2011; IEA, 2012a; IEA, 2010c; EEA, 2008]. De ellas puede obtenerse información básica para la estimación de los indicadores que se crea conveniente incorporar a la evaluación; o indicadores más elaborados que a veces, pueden usarse directamente en el análisis sobre aspectos técnicos, económicos y ambientales de las distintas fuentes de energía que se explotan, transforman y utilizan en el mundo actual. Las cifras generalmente se clasifican por fuente energética, región o país del mundo.

\subsubsection{Indicadores propuestos para la evaluación}

El diseño de un sistema de indicadores soporte para la evaluación multicriterio de proyectos en el sector energético, tomó como referencia el modelo jerárquico de valor planteado en la figura 4.5. Las características y la potencial facilidad en la obtención de la información necesaria para la estimación de los indicadores fueron factores importantes en la escogencia de cada indicador. El procedimiento de elección contempló la asignación inicial de un indicador a cada criterio en la figura 4.5 , seguido de un proceso interactivo que permitió ajustar el indicador al criterio o redefinir el criterio en función de la información disponible para la estimación del indicador. A cada indicador seleccionado se asignó una escala de medición o conjunto ordenado de los posibles valores estimados que el indicador puede tomar. Cada elemento en el conjunto representa un grado o puntuación de la escala y puede estar caracterizado por un número o una frase [Parodi, 2007].

Como resultado del proceso anterior se refinó el modelo jerárquico propuesto en la figura 4.5. El sistema de indicadores alcanzado guarda correspondencia con ese modelo y está conformado por 24 indicadores ubicados en seis dimensiones, 17 criterios y 12 subcriterios.

En el diseño del sistema se trató de asegurar: (i) la simplicidad de cada indicador sin que perdiera la esencia de lo que se quiere evaluar, (ii) la disponibilidad efectiva 
de la información para su cálculo, (iii) la inclusión de las condiciones, prioridades y capacidades del país sede del proyecto y (iv) un número manejable de indicadores. Todo el sistema fue inicialmente validado con la literatura especializada listada en la tabla 4.8; y posteriormente, en entrevistas con expertos en el área conjuntamente con la determinación de las importancias relativas de cada criterio en la evaluación, proceso que se explica en la próxima sección de este documento.

A continuación la descripción de cada indicador en el sistema diseñado. La exposición se ha organizado siguiendo el modelo final establecido en la figura 4.5. Para cada indicador se presenta una ficha con el resumen de la información que a él concierne; esto es, la dimensión donde se ubica, el objetivo o dirección de mejora del atributo al cual se asocia y su criterio asociado; su definición, las fuentes de información para su cálculo y su escala de medición.

\subsection{Dimensión técnica}

Los criterios técnicos pretenden incorporar explícitamente a la evaluación multicriterio aspectos que tienen que ver con la conveniencia de utilización de la tecnología propuesta por el proyecto. Para ello se han incorporado cinco indicadores asociados respectivamente a los criterios técnicos de evaluación propuestos en el nivel 2 del modelo de valor propuesto. Ellos son:

C1.1. Nivel de madurez de la tecnología

C1.2. Flexibilidad de la tecnología

C1.3. Eficiencia energética

C1.4. Factor de capacidad

C1.5. Infraestructura de apoyo local

El estudio formal de la viabilidad técnica del proyecto debe realizarse en etapa previa. Los indicadores arriba señalados sólo buscan poner de manifiesto aspectos que a criterio del autor pueden influir en el rendimiento técnico del proyecto una vez esté instalado. A continuación se presenta la descripción de cada indicador.

C1.1. Nivel de madurez de la tecnología. Se refiere a la etapa de desarrollo de la tecnología en cuanto a su desempeño técnico, operacional y comercial. En 
relación a las tecnologías emergentes puede ser útil la curva de bombo (Hype Cycle, por su nomenclatura original)) de Gartner, una representación gráfica de la madurez y adopción de la tecnología y sus aplicaciones en el tiempo [Gartner, 2011]. La figura 4.6 muestra el aspecto general de una curva de Gartner.

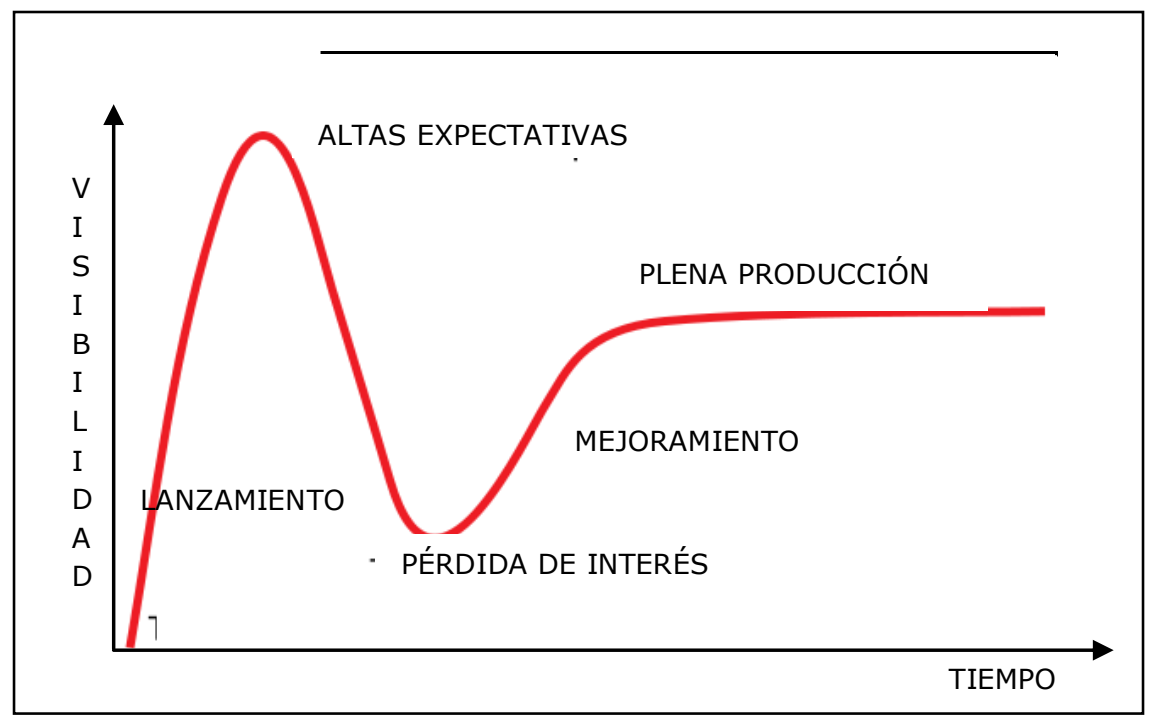

Figura 4.6. Curva de Gartner (Hype Cicle) para tecnologías emergentes

En general, la curva de Gartner diferencia las siguientes fases en la evolución de una tecnología emergente (i) el lanzamiento, con expectativas crecientes sobre las posibilidades de la tecnología pero con viabilidad comercial no comprobada, (ii) un período de altas expectativas seguido de algunos fracasos y pérdida de interés de los inversores, (iii) un período de mejoramiento de la tecnología y (iv) una etapa de productividad plena donde se han superado las fallas iniciales y la tecnología se vuelve rentable. Después de un lapso de tiempo variable, la tecnología se hará obsoleta y será reemplazada por una nueva tecnología. Previo a su lanzamiento, la tecnología debe ser evaluada a diferentes niveles y comprobada su viabilidad técnica y operacional.

Tomando en cuenta, lo anteriormente expuesto se diseñó la escala de medición del indicador correspondiente. A continuación se presenta su ficha resumen. 


\begin{tabular}{|c|c|}
\hline \multicolumn{2}{|c|}{ DIMENSIÓN : TÉCNICA } \\
\hline \multicolumn{2}{|r|}{ ATRIBUTO/CRITERIO: C1.1 Madurez de la tecnología } \\
\hline \multicolumn{2}{|r|}{ OBJETIVO ASOCIADO: MAX [madurez de la tecnología] } \\
\hline \multicolumn{2}{|r|}{ INDICADOR: Nivel de madurez de la tecnología } \\
\hline \multicolumn{2}{|c|}{$\begin{array}{l}\text { DEFINICIÓN: Etapa de desarrollo de la tecnología propuesta. Una tecnología } \\
\text { ha alcanzado la madurez cuando se ha usado por un tiempo tal que sus fallas } \\
\text { iniciales y problemas técnicos, operacionales y comerciales hayan sido } \\
\text { superados o reducidos significativamente. }\end{array}$} \\
\hline \multicolumn{2}{|r|}{$\begin{array}{l}\text { FUENTE DE INFORMACIÓN: Curva probable de Gartner. Estudio de viabilida } \\
\text { técnica del proyecto. }\end{array}$} \\
\hline \multicolumn{2}{|c|}{ UNIDADES: Apreciación cualitativa } \\
\hline \multicolumn{2}{|c|}{ ESCALA } \\
\hline 1 & Tecnología obsoleta \\
\hline 2 & Tecnología sólo probada a nivel de laboratorio \\
\hline 3 & Tecnología técnica y operacionalmente probada en una planta piloto \\
\hline 4 & Tecnología probada en fase de mejoramiento \\
\hline 5 & Tecnología que ha alcanzado su madurez \\
\hline
\end{tabular}

C1.2. Flexibilidad de la tecnología. Se refiere a la facilidad que tiene la tecnología propuesta de (i) incorporar innovaciones tecnológicas (ii) poder instalarse de acuerdo a las necesidades de tamaño y localización requeridas y (iii) adaptarse a variaciones en las especificaciones de los insumos al proceso y de los productos que demanda el mercado.

En general, las tecnologías maduras tienen poca necesidad de innovaciones; sin embargo, las nuevas tecnologías deben incorporar constantemente cambios técnicos para su mejoramiento y permanencia en el mercado. Por otra parte, las tecnologías para el aprovechamiento de la energía solar, eólica e hidráulica pueden instalarse a pequeña escala de forma descentralizada, en zonas rurales; no así, las tecnologías de transformación de combustibles fósiles y las tecnologías para la generación eléctrica térmica, nuclear o hidroeléctrica que requieren grandes complejos que aprovechan la economía de escala para cumplir de forma rentable con la demanda de la región a la que suplen energía. 
En aras de la simplificación del sistema se adoptó sólo un indicador de carácter cualitativo cuya valor crece en la medida que se incrementa la intensidad y número de las flexibilidades tecnológicas importantes para el proyecto. A continuación se presenta su ficha resumen.

\begin{tabular}{|c|c|}
\hline & ENSIÓN : TÉCNICA \\
\hline & BUUTO/CRITERIO: C1.2 Flexibilidad \\
\hline & ETIVO ASOCIADO: MAX [flexibilidac \\
\hline & CADOR: Flexibilidad de la tecnologí \\
\hline & $\begin{array}{l}\text { NICIÓN: Facilidad de la tecr } \\
\text { vaciones, ser instalable en difer } \\
\text { tarse a variaciones de la calidad } \\
\text { uctos demandados. } \\
\text { rado de flexibilidad es una aprec } \\
\text { entan en intensidad y número las } f \\
\text { el proyecto. }\end{array}$ \\
\hline & $\begin{array}{l}\text { VTE DE INFORMACIÓN: Suplidores } \\
\text { ica del proyecto. }\end{array}$ \\
\hline & DADES: Apreciación cualitativa \\
\hline & ALA \\
\hline 1 & Tecnología muy poco flexible \\
\hline 2 & Tecnología poco flexible \\
\hline 3 & Tecnología medianamente flexible \\
\hline 4 & Tecnología flexible \\
\hline 5 & Tecnología muy flexible \\
\hline
\end{tabular}

C1.3. Eficiencia térmica. Se refiere a la relación entre el contenido de energía de productos de un proceso o cadena de procesos para el aprovechamiento de un recurso energético y la energía fósil necesaria para producirlos (EP/EFE). Un valor del indicador superior a 1 muestra que el balance energético asociado al sistema en estudio es positivo, condición indispensable para su aceptación. Un valor elevado del indicador es signo de una mayor eficiencia en el sistema.

La figura 4.6 muestra esquemáticamente las corrientes involucradas en el balance de energía del sistema delimitado por la línea punteada. El sistema 
puede comprender uno, más de uno o toda la cadena de procedimientos para la obtención y transformación del recurso energético en el producto requerido. El indicador que se propone es la relación expresada en unidades de energía entre la corriente 3 y la suma de de las corrientes 1 y 2 , en la figura 4.7.

Un indicador alternativo para incorporar al análisis. la eficiencia térmica de conversión, es la relación inversa; esto es, la relación entre la energía calórica proveniente de los combustibles fósiles en la entrada al sistema y la energía de salida del sistema. El indicador es comúnmente utilizado en el sector eléctrico para estimar el combustible necesario por unidad de potencia eléctrica a producir. Nótese que en el caso de las energías renovables con excepción de la bioenergía, el primer indicador toma un valor igual a infinito y el indicador inverso es cero.

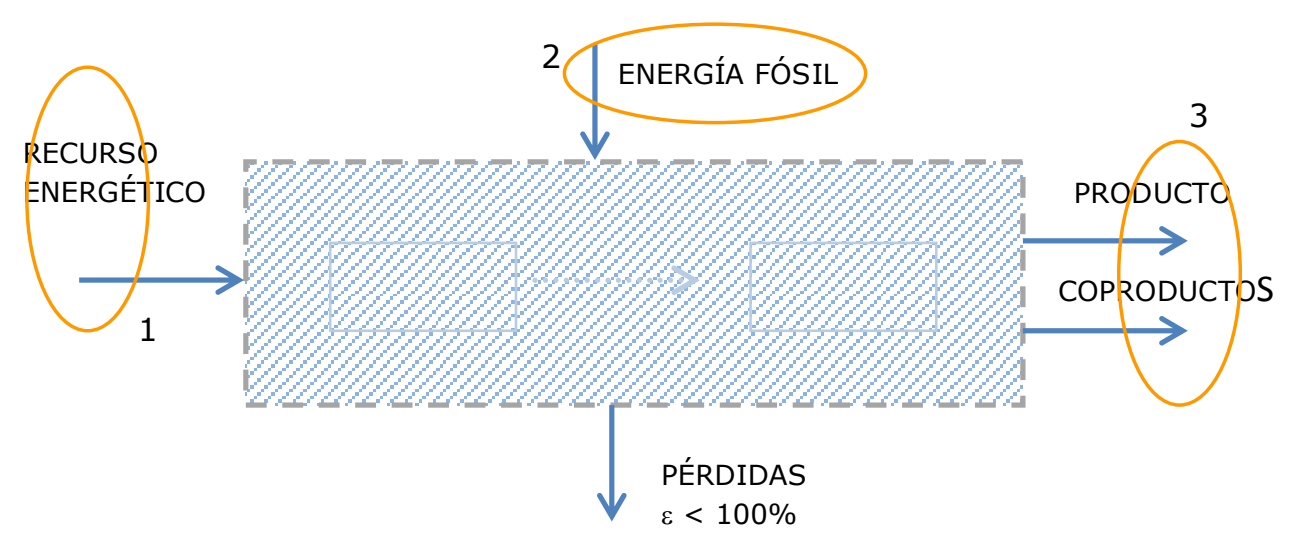

EFICIENCIA ENERGÉTICA = ENERGÍA EN 3/ENERGÍA EN [1+2]

RELACIÓN INVERSA = ENERGÍA CALÓRICA EN [1+2]/POTENCIA ELÉCTRICA en 3

Figura 4.7. Balance de energía para procesos de aprovechamiento de los recursos energéticos.

El tema de un balance energético positivo ha adquirido especial relevancia cuando se relaciona con el sistema que comprende el cultivo, recolección, transporte, transformación de biomasa en biocombustibles, y con su distribución y uso final. En el caso de la producción de bioetanol a partir de maíz, el balance energético puede resultar desfavorable si se compara la cantidad de energía fósil necesaria 
para obtener bioetanol versus la energía que éste puede contener. Actualmente su relación EP/EFE se ha elevado aproximadamente a 1,3 pero hace pocos años era inferior a 1; ello ha motivado la investigación dirigida a aumentar las eficiencias en los diferentes etapas de la cadena productiva y a buscar tecnologías alternativas con un balance energético más favorable [Bourne, 2007].

A continuación, la ficha resumen del indicador que se propone para incluir este aspecto en la evaluación.

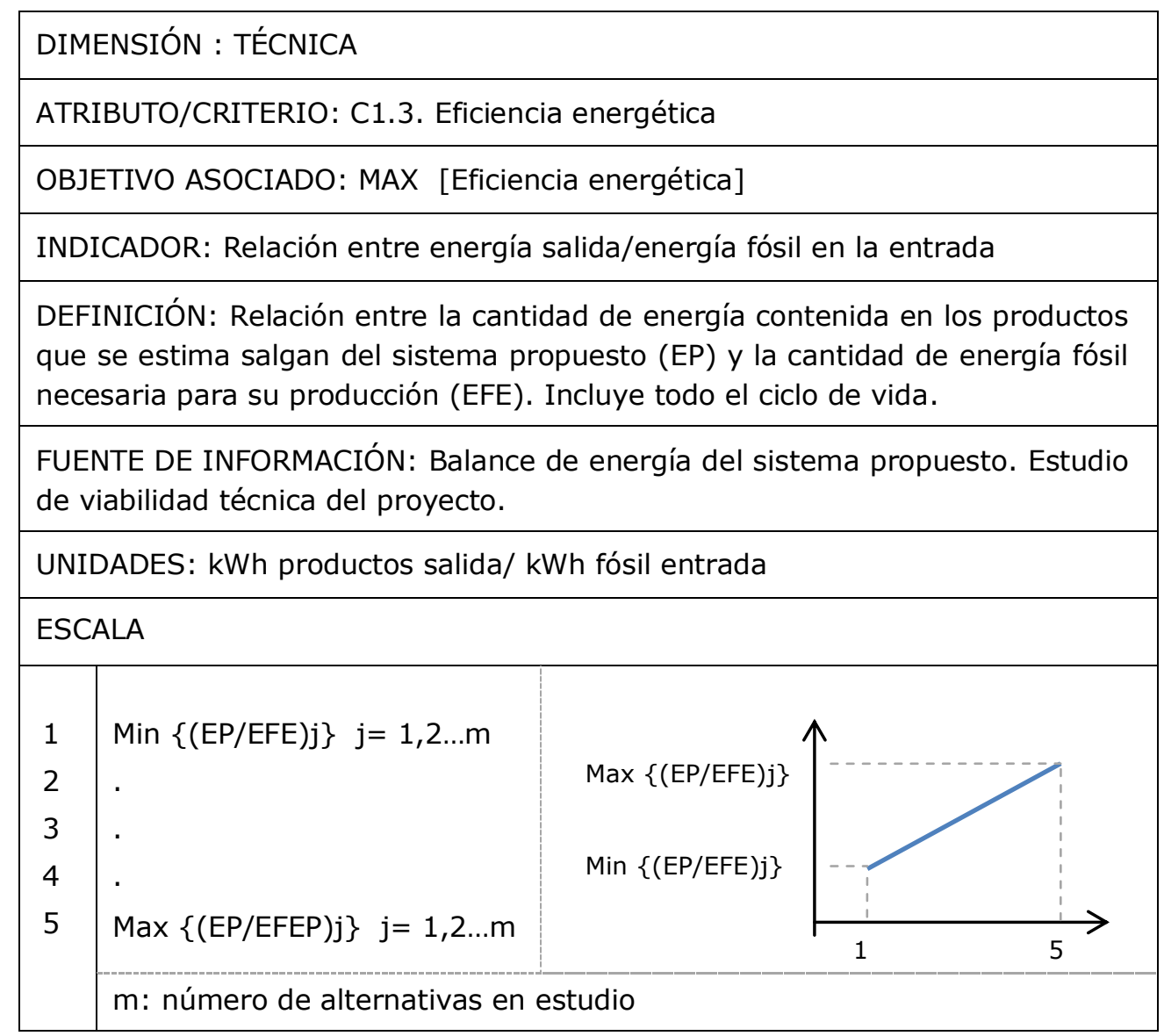

C1.4. Disponibilidad. El factor de capacidad es la relación entre la cantidad de energía útil producida en un período determinado de tiempo y la cantidad que se hubiese podido producir si hubiese operado a la capacidad nominal de las instalaciones. El índice corresponde a la disponibilidad máxima de las instalaciones las cuales pueden estar fuera de servicio por mantenimiento, reparaciones; o en 
el caso de las energías renovables como la eólica y la solar, por efecto de las condiciones climáticas [Chatzimouratidis y Pivalaci, 2009].

El diseño de la planta, su régimen de operación, la calidad del equipo, su mantenimiento y el tipo de combustible utilizado tienen una gran incidencia en la capacidad real de las instalaciones [Chatzimouratidis y Pivalaci, 2009]. A continuación la ficha resumen del indicador que se sugiere para incluir este aspecto en el análisis.

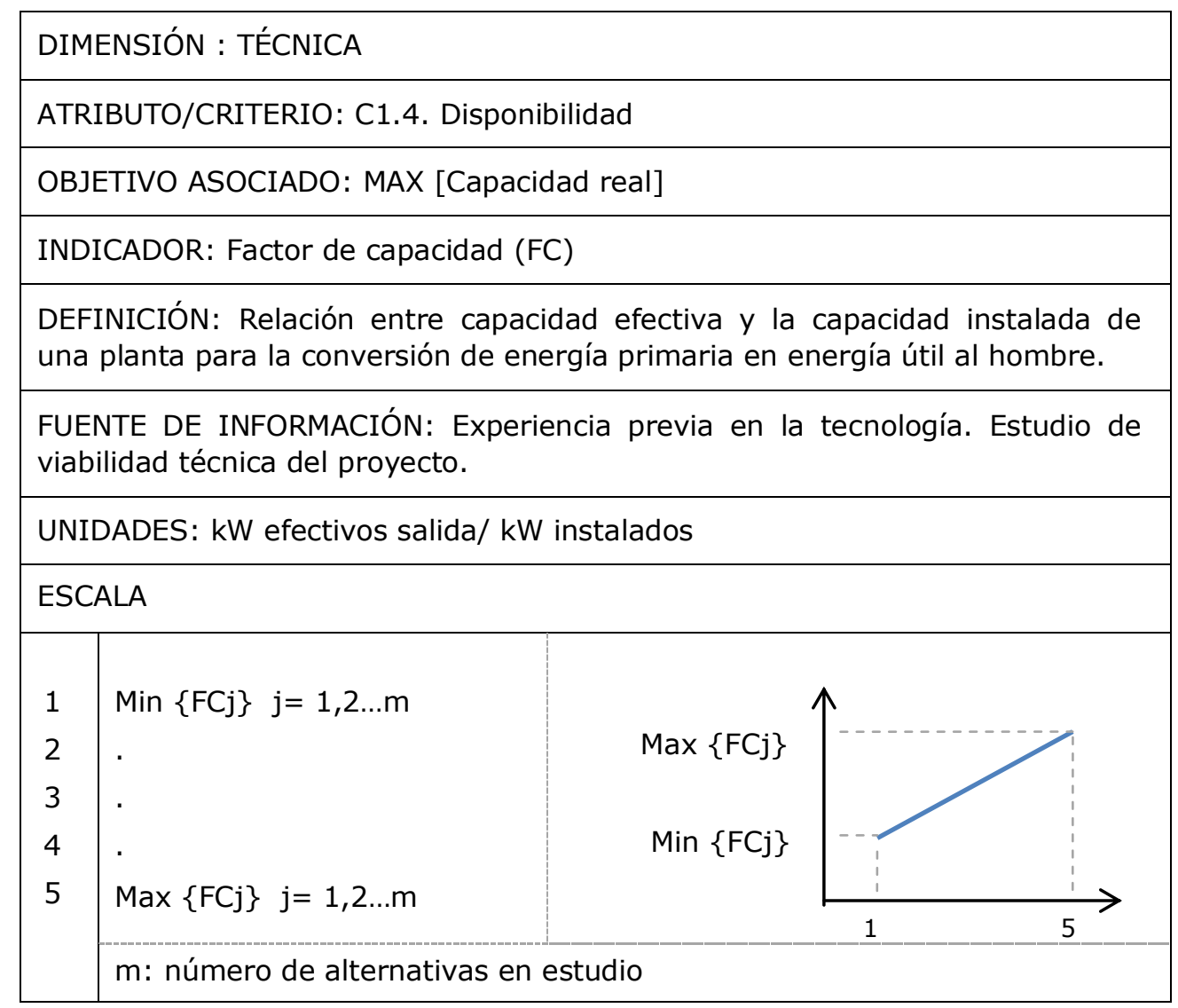

C.1.5. Infraestructura de apoyo local. Se refiere a la disponibilidad de infraestructura física y de capital humano local para asegurar la construcción y buen funcionamiento de las instalaciones del proyecto. Se subdivide en:

C1.4.1. Infraestructura física y logística

C1.4.2. "Saber-como" local 
C1.5.1. Infraestructura física y logística. El indicador trata de incorporar al análisis, la ventaja que representa para un proyecto (i) pertenecer a un sector energético consolidado, con infraestructura que puede servir de apoyo a la instalación y funcionamiento del proyecto bajo estudio, y (ii) tener acceso a redes de distribución para los productos energéticos derivados. A continuación se presenta su ficha resumen.

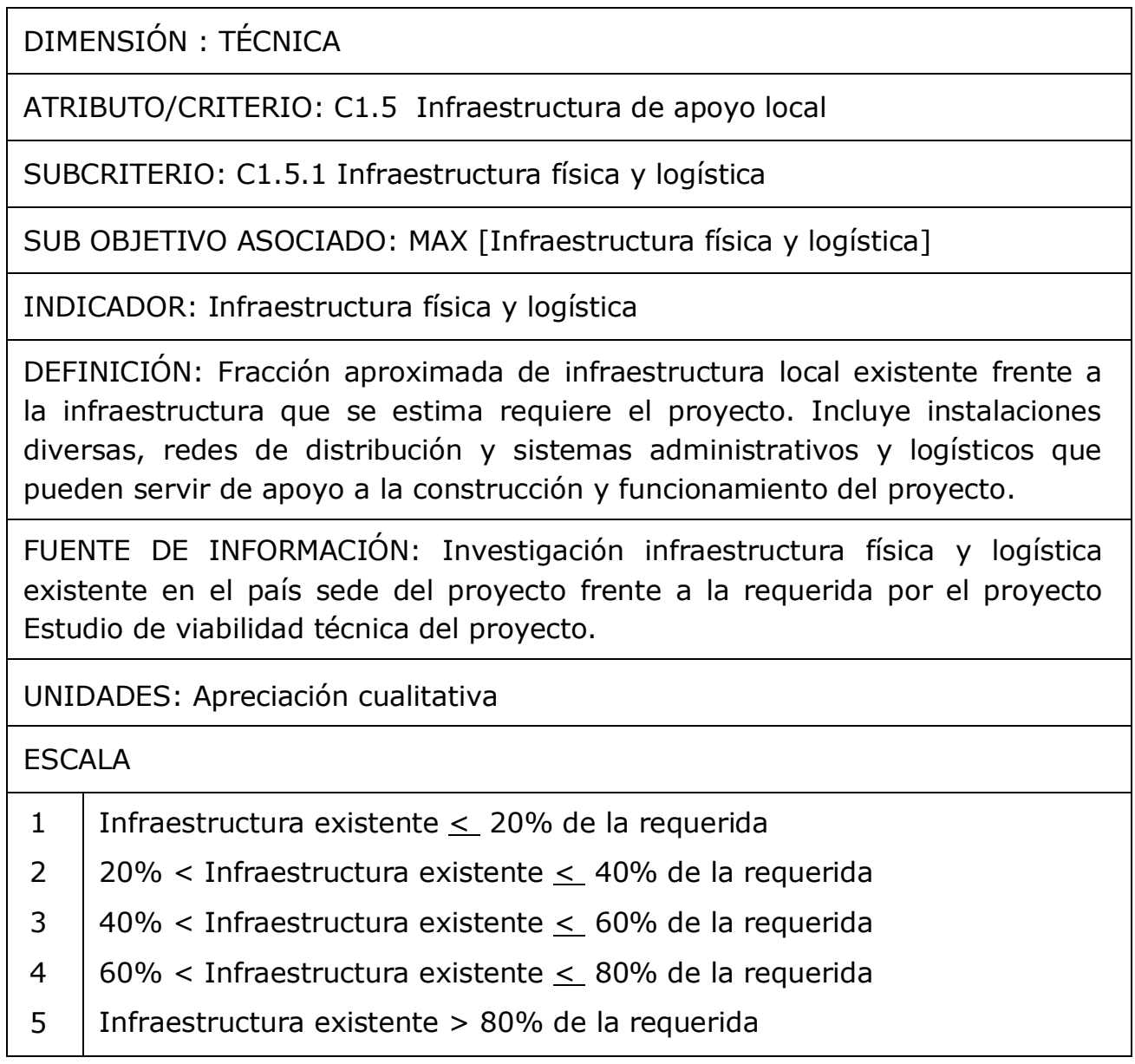

El nivel de apoyo que puede brindar la infraestructura física y logística existente en la localidad sede del proyecto puede expresarse como una fracción aproximada de las necesidades estimadas para la construcción, puesta en marcha y operación del proyecto sobre las facilidades existentes.

C1.5.2. "Saber-como" local. Apreciación cualitativa sobre la formación y entrenamiento que tiene el personal local disponible para garantizar la UNIVERSIDAD POLITÉCNICA DE VALENCIA. TESIS DOCTORAL. Violeta Parodi 
construcción, puesta en marcha y adecuado funcionamiento de la nueva unidad productora, frente a la complejidad de la tecnología propuesta. A continuación se presenta su ficha resumen.

\begin{tabular}{|c|c|}
\hline \multicolumn{2}{|c|}{ DIMENSIÓN : TÉCNICA } \\
\hline \multicolumn{2}{|r|}{ ATRIBUTO/CRITERIO: C1.5 Infraestructura de apoyo } \\
\hline \multicolumn{2}{|c|}{ SUBCRITERIO: C1.5.2. "Saber-como" } \\
\hline \multicolumn{2}{|r|}{ SUBOBJETIVO ASOCIADO: MAX ["Saber-como"] } \\
\hline \multicolumn{2}{|c|}{ INDICADOR: "Saber-como" disponible } \\
\hline \multicolumn{2}{|r|}{$\begin{array}{l}\text { DEFINICIÓN: Capacidad que tiene el personal local disponible para garantiza } \\
\text { la instalación y adecuado funcionamiento de la nueva unidad productora } \\
\text { frente a la complejidad de la tecnología propuesta. }\end{array}$} \\
\hline \multicolumn{2}{|r|}{ FUENTE DE INFORMACIÓN: Estudio de viabilidad técnica del proyecto. } \\
\hline \multicolumn{2}{|c|}{ UNIDADES: Apreciación cualitativa } \\
\hline \multicolumn{2}{|c|}{ ESCALA } \\
\hline 1 & Personal poco calificado sin entrenamiento, necesidad asesoría externa \\
\hline 2 & Personal medianamente calificado sin entrenamiento, asesoría externa \\
\hline 3 & Personal bien calificado sin entrenamiento, asesoría externa \\
\hline 4 & Personal bien calificado en entrenamiento \\
\hline 5 & Personal bien calificado y entrenado \\
\hline
\end{tabular}

En la próxima sección se describen los indicadores económicos.

\subsection{Dimensión económica}

Los criterios económicos de evaluación permiten introducir al análisis multicriterio del proyecto, los beneficios que desde el punto de vista privado o social es capaz de generar la alternativa energética propuesta. Para valorar el proyecto en este aspecto, se propone un grupo de dos indicadores, a saber:

C2.1. Costo nivelado

C2.2. $\triangle$ Balanza de pagos

A continuación se presenta la descripción de cada indicador propuesto. 
C2.1. Costo nivelado (CN). Valor presente (VP) del costo total de construcción y operación $\left(\mathrm{C}_{k}\right)$ de la nueva unidad de explotación propuesta, sobre la vida económica del proyecto $(n)$, expresado en unidades monetarias reales por unidad de energía anual que se espera obtener. Los costos citados incluyen el valor inicial de la inversión más los intereses para el financiamiento de la misma, los costos de operación y mantenimiento y los costos de combustible [U.S. EAI, 2012c]. El costo pueden incluir o no los créditos fiscales por inversión y/o por producción que pueden otorgar las autoridades fiscales de cada país como un incentivo para el desarrollo de uno más tipos de energía. Si se consideran los subsidios, los mismos se deducen de los costos antes citados. La figura 4.8 ilustra la situación.

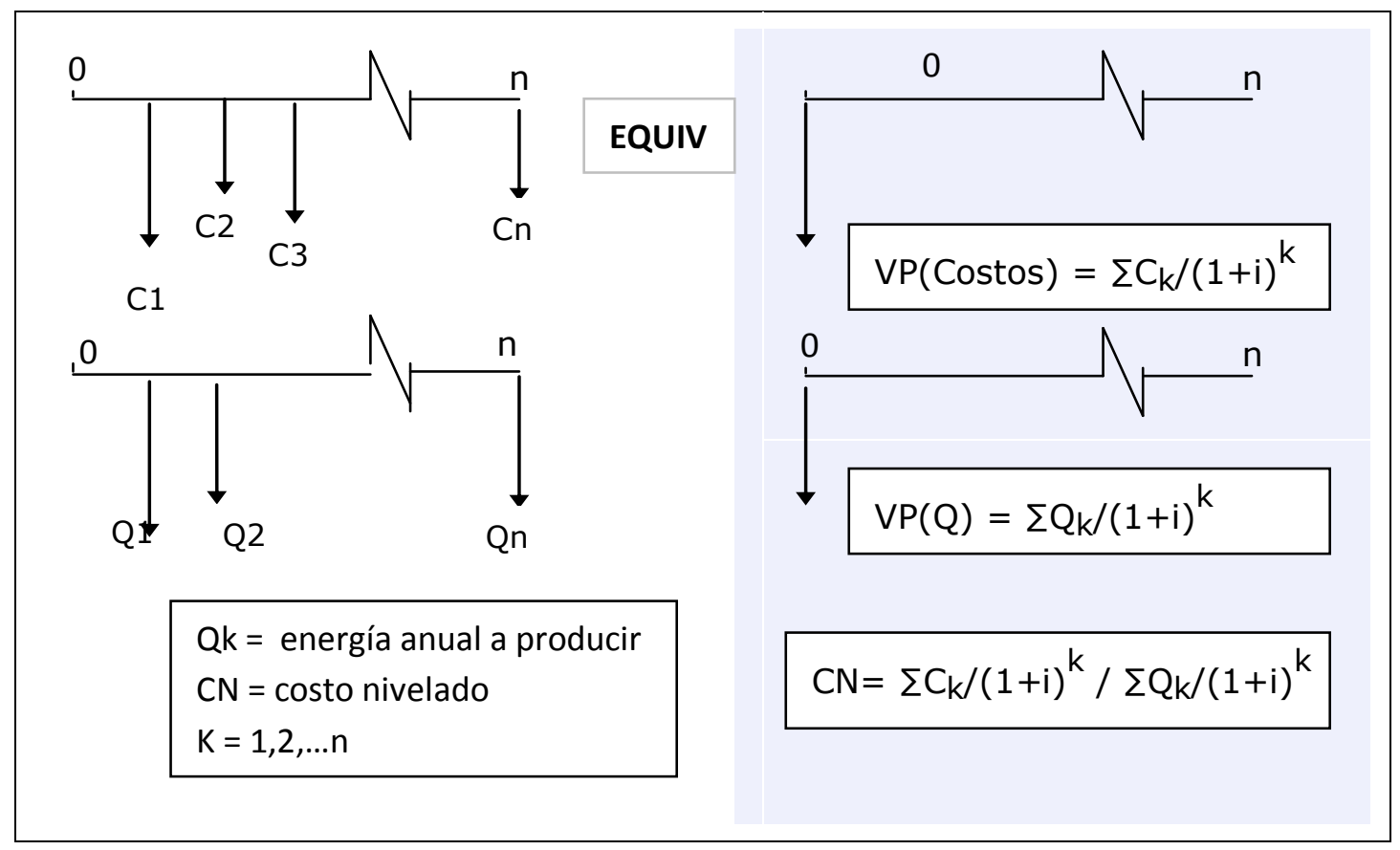

Figura 4.8. Costo nivelado

Los costos totales cada año se descuentan a una tasa de interés i que varia con las circunstancias del país sede del proyecto [Parodi, 1995]. El cálculo detallado del costo nivelado asociado a un proyecto en el sector energía, puede encontrarse en Lazard [2009].

Como condición límite, el costo nivelado con subsidios debe ser al menos igual al precio del producto energético (PP) a obtener para que el proyecto sea 
comercialmente sostenible. Si bajo las mismas condiciones de costo, no existiesen subsidios o si las autoridades fiscales deciden retirarlos, el proyecto se vuelve comercialmente no operable. La ficha resumen del indicador se presenta a continuación.

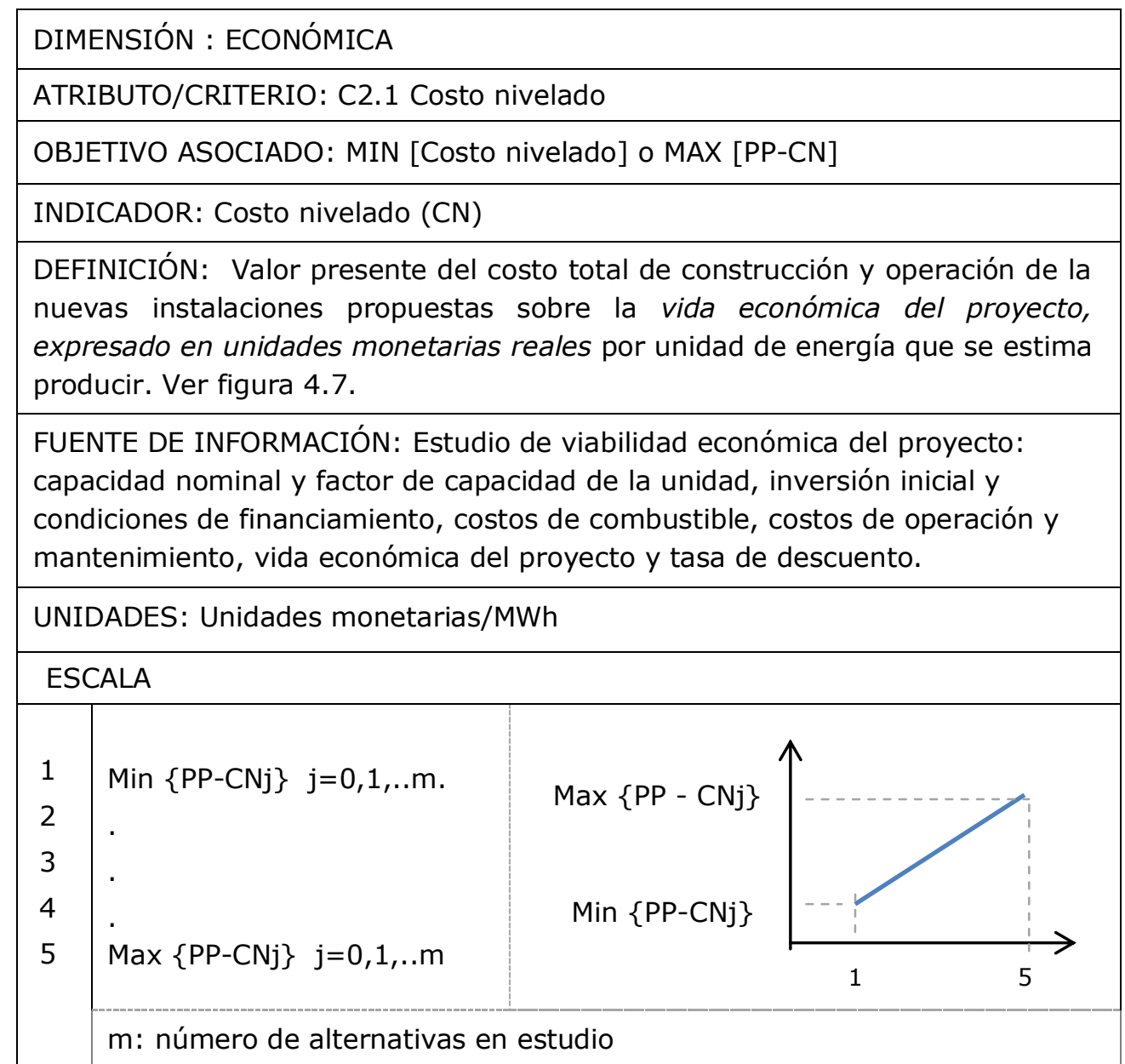

En el cuadro anterior se establece una variación lineal del valor de la diferencia entre el precio del producto energético a obtener y su costo nivelado, donde el extremo superior corresponde a la máxima diferencia entre ambas cifras para cada una de las alternativas a evaluar. Nótese que si el precio del producto es muy volátil y esta condición desea introducirse en el análisis podría utilizarse el valor 'nivelado' de las diferencias $[P P-C] j$ para $k=1,2, \ldots n$; y verificar que éste sea positivo para la sostenibilidad comercial del proyecto. Ello equivale a efectuar la evaluación en función del Valor Presente Neto 'nivelado' del proyecto. 
Por otra parte, si el producto a obtener es el mismo para los proyectos a evaluar; o si se toma PP igual al precio del producto que se pretende sustituir, el precio deja de ser relevante a la comparación y la estimación del indicador en la escala [1-5] se haría en función del costo nivelado en cada caso, donde 5 corresponde al mínimo costo nivelado.

C2.2. $\Delta$ Balanza de pagos $^{65}$. La ejecución de un proyecto de obtención y/o transformación de energía incrementa la capacidad de producción de un país; y por tanto incide sobre su balanza de pagos (BP) vía la sustitución de importaciones o el incremento de las exportaciones del país.

Una variación positiva de la balanza de pagos representa una adición al ingreso del país. Para que ello suceda, es necesario que los efectos de una ampliación de la capacidad de producción ( $\mathrm{ACP}$ ) más que compensen la importación de insumos materiales o intangibles componentes de la inversión requerida o necesarios para la fase de producción. De esta forma, el valor de la capacidad anual añadida de producción debe ser corregida con la depreciación de los bienes de capital importados (DBCI) y con el valor de los insumos importados para la producción (VIP) asociados al incremento de producción que cause la implementación y operación del proyecto; esto es, para el año k de la vida del proyecto,

$$
\Delta\left(\mathrm{BP}_{\mathrm{k}}\right)=\operatorname{Valor}(\mathrm{ACP})_{\mathrm{k}}-(\mathrm{DBCI}+\mathrm{VIP}) \mathrm{k} \quad \mathrm{k}=1,2, \ldots . \mathrm{n}
$$

Y para el proyecto, puede utilizarse como indicador el valor presente de las variaciones anuales en la balanza de pago causadas por la adición de la capacidad de producción del proyecto a lo largo de su vida (n), expresado en unidades monetarias constantes por unidad de energía a obtener. Las variaciones anuales en la balanza de pagos por unidad de energía obtenida se descuentan a una tasa de interés i, que varía con las condiciones de cada país. Así, el indicador puede calcularse con la siguiente expresión:

65 Balanza nacional de pagos es la diferencia entre el valor de las exportaciones y el de las importaciones de un país. [Dernburg y McDougall, 1968]. 


$$
\Delta(\mathrm{BP})=\left[\Sigma\left(\mathrm{BP}_{\mathrm{k}} / \mathrm{Q}_{\mathrm{k}}\right) /(1+\mathrm{i})^{\mathrm{k}}\right] \quad \mathrm{k}=1,2 \ldots \mathrm{n}
$$

El indicador propuesto no incluye los efectos indirectos que pueda tener el proyecto sobre otras áreas de producción de la economía nacional.

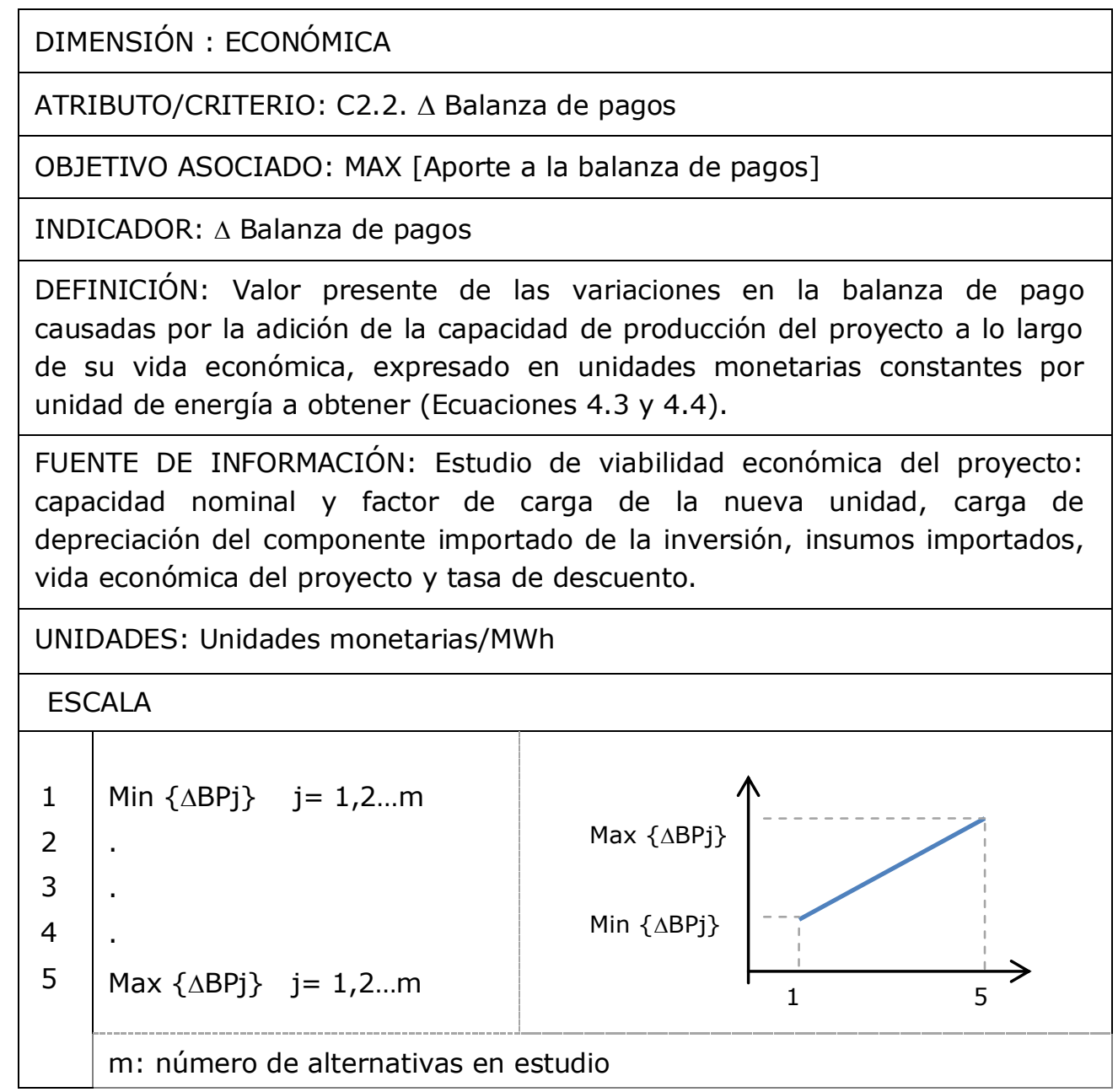

\subsection{Dimensión ambiental}

Los criterios ambientales incorporan a la evaluación multicriterio aspectos que tienen que ver con la potencial incidencia sobre el ambiente que tendría la ejecución y explotación del proyecto en estudio. Los indicadores asociados respectivamente a los criterios ambientales del modelo final de valor propuesto, son:

C3.1. Emisiones de gases tipo invernadero 


\section{C3.2. Otras emisiones no radioactivas}

\section{C3.3. Residuos}

\section{C3.4. Uso de la tierra}

La obtención, transformación, transporte y uso de la energía causan importantes presiones antropogénicas sobre el ambiente las cuales se traducen en cambios ambientales, deforestación, y polución sobre aire, agua y tierra. Los impactos ambientales de tales actividades son función del tipo y calidad de recurso energético elegido y del sistema propuesto para su transformación y uso. Un análisis de ciclo de vida que incluya todas las etapas de la cadena energética relacionadas con el sistema cuya utilización se propone puede proporcionar los valores de uno o más de los indicadores señalados [Meier, 2005]. La estimación requiere experticia, información y detalle por lo que el cálculo puede convertirse en un cuello de botella especialmente si no se dispone de la data específica que se requiera. A continuación se presenta la descripción de cada indicador antes señalado.

C3.1. Emisiones de gases tipo invernadero. Los gases tipo invernadero incluyen $\mathrm{CO}_{2}$, metano $\left(\mathrm{CH}_{4}\right)$, oxido nitroso $\left(\mathrm{N}_{2} \mathrm{O}\right)$ y gases hidrofluorocarbonados (HFC's), perfluorocarbonados (PFC's) y hexafluoruro de azufre $\left(\mathrm{SF}_{6}\right)$. Las emisiones de gases invernadero se expresan en toneladas de $\mathrm{CO}_{2}$ equivalente utilizando los potenciales de calentamiento global con un horizonte de tiempo de 100 años, especificados en el Protocolo de Kyoto; esto es, 1 ton de $\mathrm{CH}_{4}=21$ ton. de $\mathrm{CO}_{2}$ equivalente; 1 ton de $\mathrm{N}_{2} \mathrm{O}=310$ ton de $\mathrm{CO}_{2}$ equivalente; 1 ton SF6 = 23.900 ton de $\mathrm{CO}_{2}$ equivalente y los gases fluorocarbonados tienen potenciales de calentamiento global muy variados dependiendo del gas del cual se trate [EEA, 2008; U.S. EPA, 2006].

El dióxido de carbono $\left(\mathrm{CO}_{2}\right)$ es uno de los gases que contribuyen en mayor proporción con el efecto invernadero. El gas se produce fundamentalmente en la combustión de carbón, gas, petróleo y sus derivados en el sector transporte o para la producción de energía eléctrica; y en la producción de calor para las industrias, comercios y hogares. 
Por su parte, el metano $\left(\mathrm{CH}_{4}\right)$ es el principal componente del gas natural y puede ser emitido a la atmósfera en los procesos de producción, procesamiento, transmisión y distribución del gas. La producción y procesamiento de petróleo puede también emitir metano puesto que a menudo existe gas natural en los yacimientos. En ambos casos, el metano se escapa de los equipos de procesamiento y almacenaje, de las líneas de distribución de gas, de la quema deliberada de gas en mechurrios y de los sistemas de ventilación en los campos de producción [U.S.EPA, 2006].

Otra fuente importante de emisiones de metano es la minería de carbón, especialmente la que se efectúa bajo tierra. Debido a que el metano es explosivo en concentraciones entre el $5 \%$ y el $15 \%$, se suele remover por ventilación o desgasificación como medida de seguridad. El carbón puede continuar emitiendo metano después de su extracción dependiendo de sus características y los procedimientos utilizados para su manejo, especialmente en las operaciones de triturado, reducción de tamaño y secado para su uso industrial [U.S.EPA, 2006].

El óxido nitroso $\left(\mathrm{N}_{2} \mathrm{O}\right)$ es un producto de la reacción entre el nitrógeno y el oxígeno en la combustión de combustibles fósiles o de biomasa. Está presente en mayor o menor cantidad en los gases de escape de los motores de vehículos y aviones, dependiendo de las mezclas aire-combustible utilizadas, los equipos de control de polución empleados, las distancias viajadas, la edad de de los equipos entre otras cosas [U.S.EPA, 2006].

Los compuestos fluorocarbonados llegan a la atmósfera por fugas de los sistemas de enfriamiento y aire acondicionado; y por aplicaciones de aerosoles, solventes para limpieza, extintores de incendios, entre otros usos [U.S.EPA, 2006]. En general, están poco relacionados con el sector energía y por ello no se incluirán en el indicador cuya ficha resumen se presenta en la próxima página.

En cada caso, las tecnologías envueltas y la calidad del combustible pueden significar una diferencia significativa en el volumen y calidad de las emisiones. A continuación se presenta una ficha resumen para este indicador que incluye las emisiones referidas para todo el ciclo de vida asociado al proyecto. 


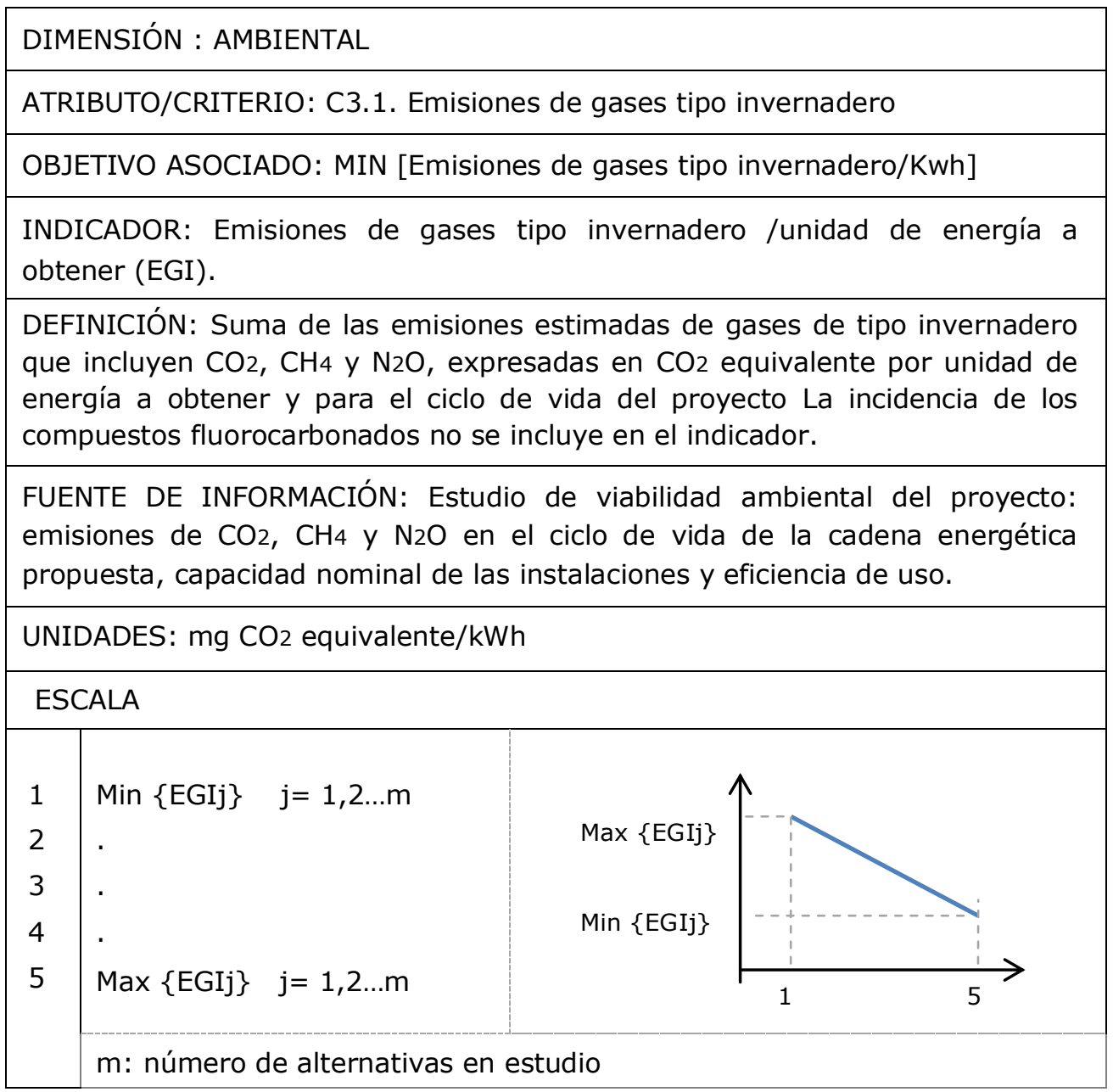

C3.2. Otras emisiones no radioactivas. Los principales emisiones no radioactivas relacionadas con el sector energía, comprenden además de los gases tipo invernadero, compuestos orgánicos volátiles diferentes de metano (NMVOCs, por sus siglas en inglés), óxidos de nitrógeno ( $\mathrm{NOx}$ ), dióxido de azufre $\left(\mathrm{SO}_{2}\right)$ y partículas emitidas directamente a la atmósfera. Su efecto sobre el ambiente y la salud de las personas es proporcional a su concentración en el aire. Para incluir en el análisis del proyecto, el efecto que sobre la salud de la personas tienen tales gases, se proponen tres indicadores, a saber,

C.3.2.1. Precursores de ozono

C.3.2.2. Emisiones ácidas

C.3.2.3. Partículas 
C3.2.1. Precursores de ozono. Los compuestos precursores de ozono reaccionan en presencia de la luz solar para producir ozono troposférico uno de los componentes del "smog" que cubre algunas regiones del mundo y cuya inhalación puede afectar el bien funcionamiento de las vías respiratorias. Entre estos gases se encuentran los NMVOCs, los óxidos de nitrógeno, y en mucha menor proporción, el $\mathrm{CO}$ y el $\mathrm{CH}_{4}$. Los NMVOCs se producen en procesos industriales mientras que los óxidos de nitrógeno se producen en la combustión de recursos fósiles y de biomasa [Chatzimouratidis y Pilavachi, 2008].

El indicador que se propone sólo contempla emisiones de los NMVOCs y los NOx cuya presencia en al aire puede expresarse en NMVOC equivalente utilizando sus respectivos potenciales de formación de ozono troposférico cuyo valor es igual a 1 para los NMVOCs, e igual a 1,22 para los NOx [EEA, 2008]. A continuación, la ficha resumen del indicador propuesto.

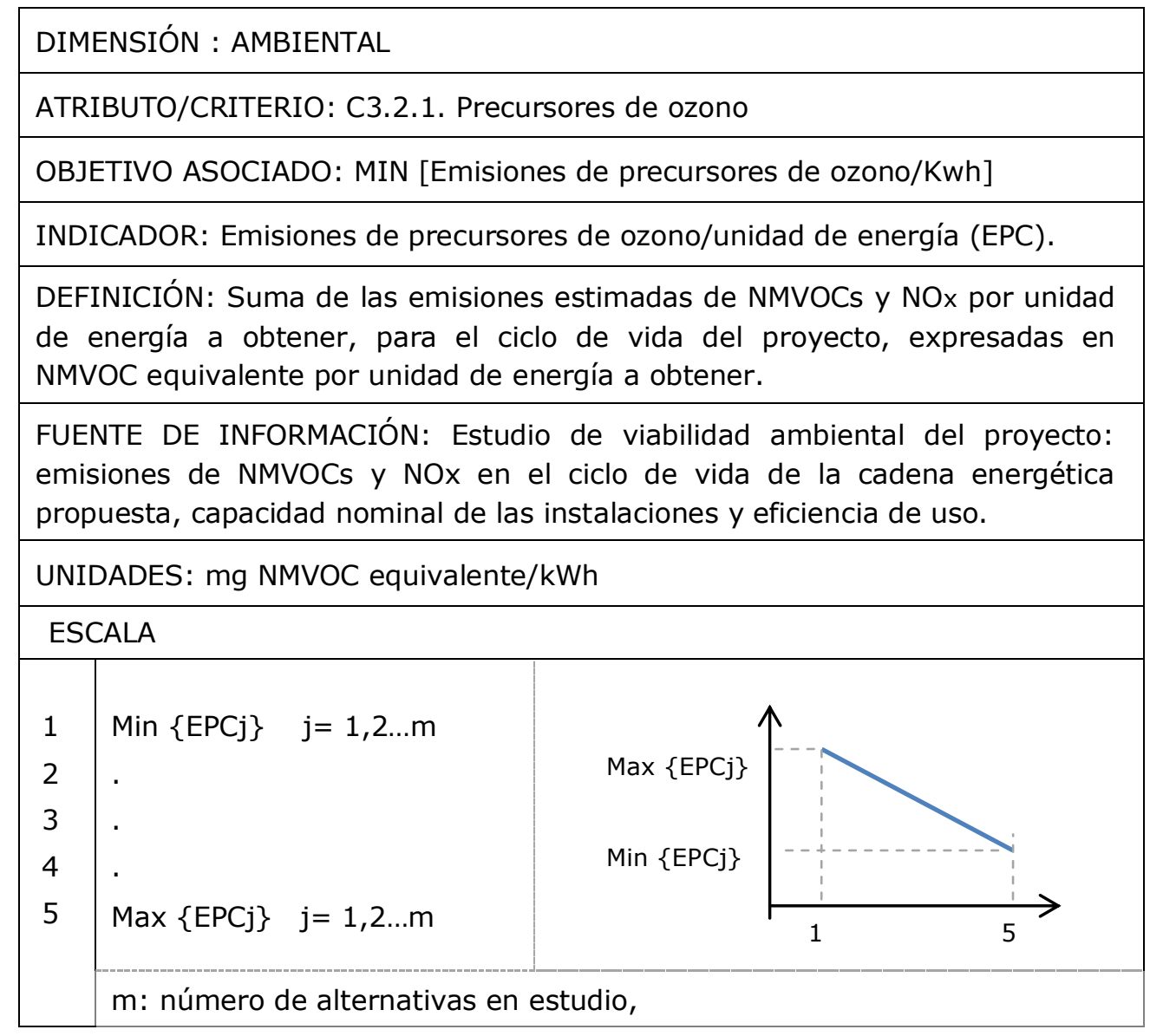


C3.2. 2. Emisiones ácidas. Entre estas emisiones se encuentran principalmente los óxidos de nitrógeno y el $\mathrm{SO}_{2}$ procedente de la combustión de carbón, petróleo y/o gas. Estos gases al contacto con agua se convierten en ácidos y son responsables de la 'lluvia ácida' que puede causar daños en las cosechas, corrosión en las construcciones e introducir sustancias tóxicas en la cadena alimenticia [Chatzimouratidis y Pilavachi, 2008]. Su presencia en la atmósfera puede expresarse en función de sus respectivos potenciales de acidificación; cuyo valores son para el $\mathrm{SO}_{2}=(2 / 64) \mathrm{g}$-ácido equivalente/g, y para el $\mathrm{NO}=(1 / 46) \mathrm{g}$ ácido equivalente/g [EEA, 2008]. A continuación se presenta la ficha resumen del indicador asociado.

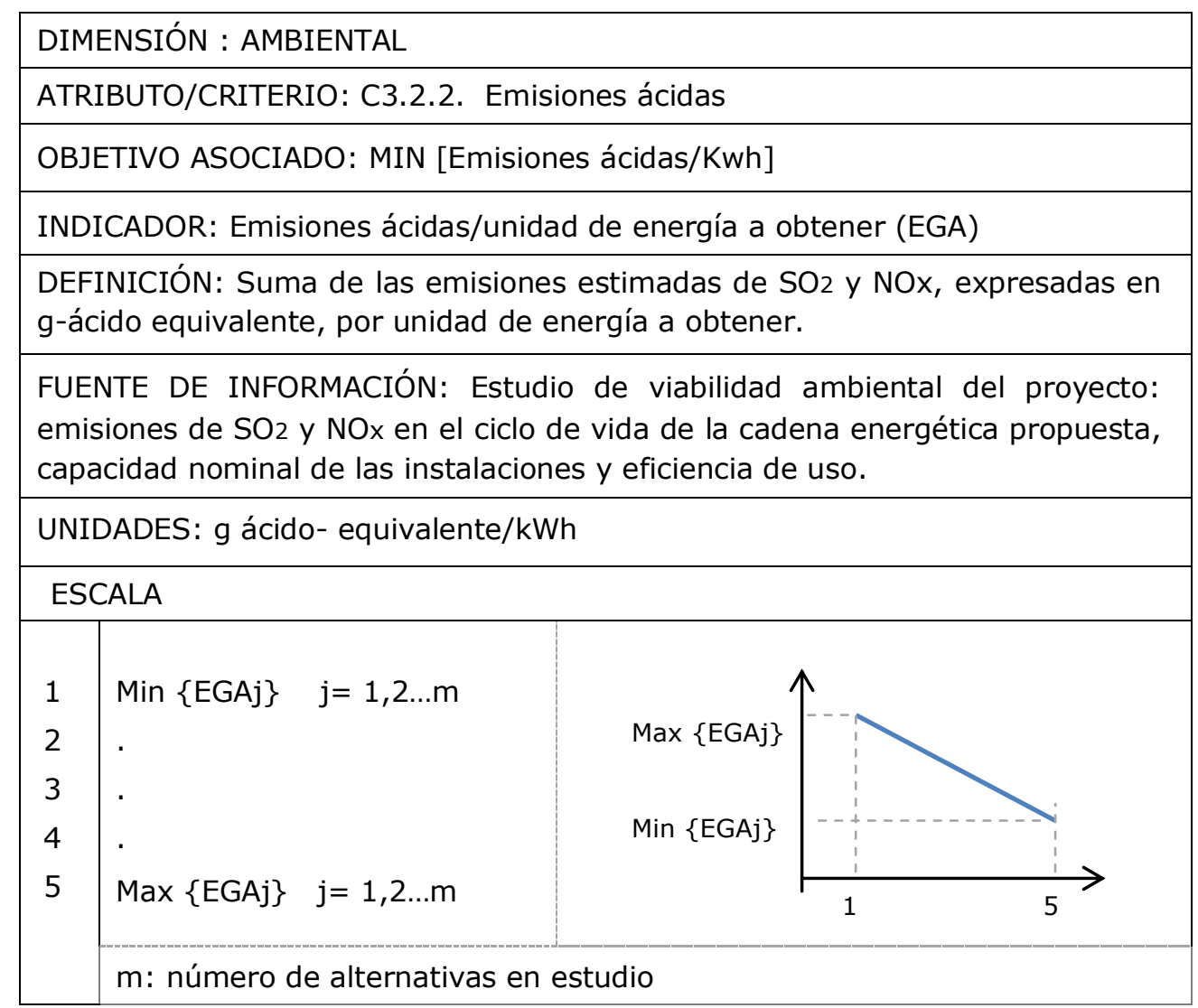

C3.2.3. Emisiones de partículas. El material particulado es una mezcla de partículas extremadamente pequeñas y gotas de líquido cuyo diámetro oscila entre $10 \mathrm{~nm}$ y $100 \mu \mathrm{m}$ [Chatzimouratidis y Pilavachi, 2008] y está conformada por compuestos orgánicos, metales y partículas de polvo, entre otras cosas. La 
combustión de carbón, de petróleo o de biomasa así como la construcción de celdas fotovoltaicas, producen un volumen importante de partículas.

El material particulado fino con partículas cuyo diámetro es igual o inferior a 2,5 $\mu \mathrm{m}$ produce depósitos en las arterias de las personas que respiran tales emisiones, con los consiguientes problemas cardiovasculares [Chatzimouratidis y Pilavachi, 2007]. A continuación se presenta la ficha resumen del indicador que se propone para incorporar este aspecto al análisis.

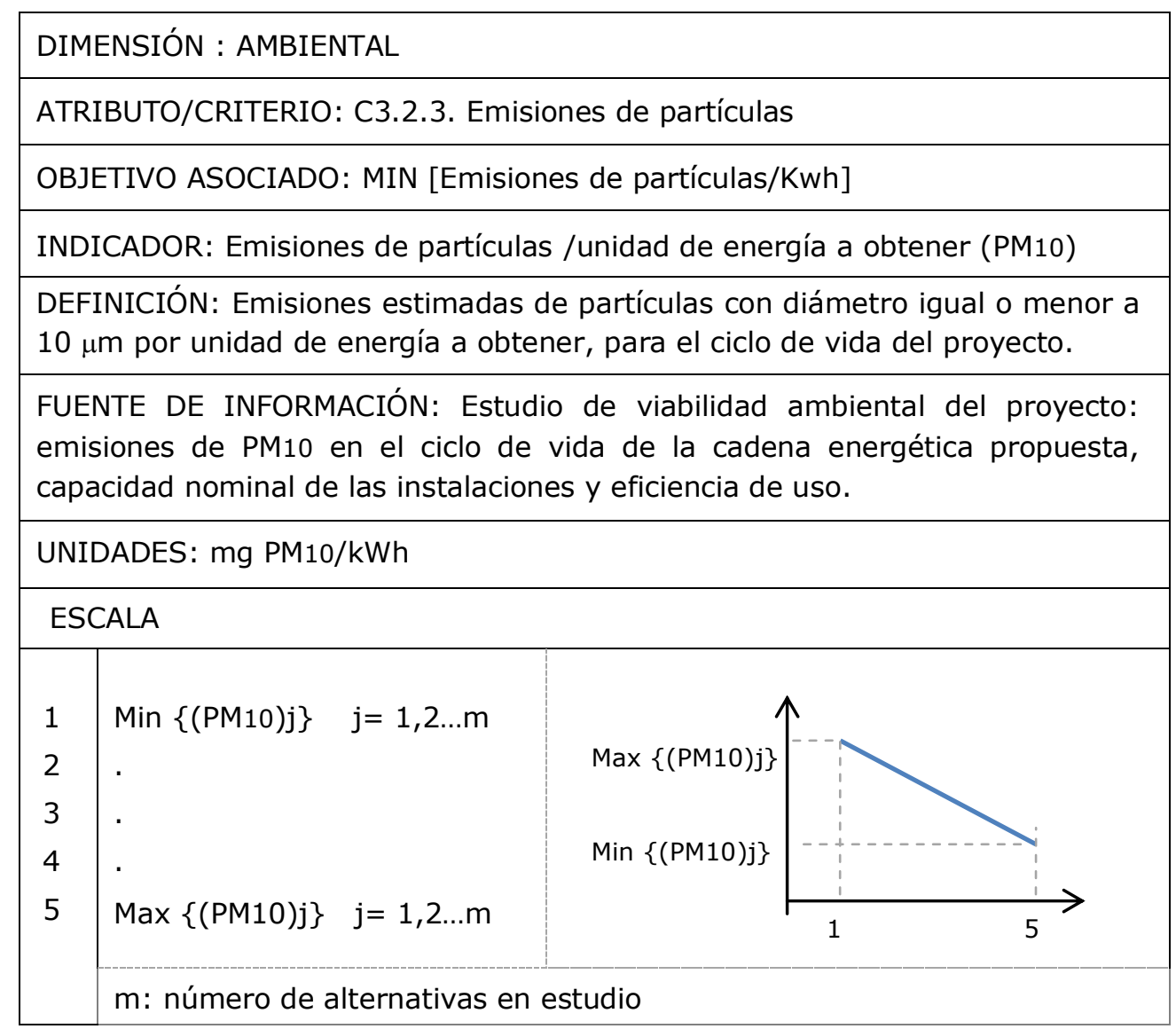

La obtención de información específica sobre emisiones de gases no radioactivos a la atmósfera es una tarea de expertos y puede resultar difícil y costosa. Una aproximación al problema, si se dispone de las relaciones adecuadas, puede ser utilizar valores globales o sectoriales y luego prorratearlos a los sectores energéticos de interés para el análisis del proyecto en consideración. 
C3.3. Residuos peligrosos. A lo largo de la cadena de obtención y transformación del recurso energético en energía útil al hombre se producen efluentes líquidos, sólidos y gaseosos, que impactan el ambiente y pueden afectar la salud de la comunidad.

En la sección anterior, se introdujo un indicador que toma en cuenta los efectos que las emisiones gaseosas pueden tener sobre el ambiente y la salud del hombre. Los efectos que pueden causar los efluentes líquidos y sólidos se tratan de recoger, en forma cualitativa, en dos subindicadores, a saber:

\section{C3.3.1. Residuos sólidos y líquidos}

\section{C3.3.2. Residuos radioactivos}

A continuación, algunos comentarios sobre cada uno de ellos.

C3.3.1. Residuos sólidos y líquidos. En general, el término se refiere a material de desecho resultante de actividades industriales, comerciales, mineras, agrícolas o municipales y cuyo estado físico puede ser "sólido, semisólido, líquido o contener material gaseoso" [U.S.EPA, 1999]. Un residuo es catalogado como peligroso si posee una o más de las siguientes características: es fácilmente inflamable, es corrosivo, es inestable y contiene compuestos tóxicos [U.S. EPA, 1999]; y será tanto más peligroso mientras mayor sea su volumen, continuidad de flujo, toxicidad; y primordialmente, mientras su manejo, tratamiento, almacenamiento y disposición final no sean los adecuados para proteger la salud humana y el ambiente.

El tratamiento, almacenamiento temporal y disposición permanente de los residuos peligrosos se realiza en facilidades diseñadas para ello que permiten prevenir la liberación de contaminantes peligrosos al ambiente. Entre tales sistemas, se encuentran los rellenos sanitarios, los embalses o lagunas superficiales, los pozos de reinyección y las unidades de tratamiento en las cuales se mezcla el residuo con tierra del sitio en la cual se ha comprobado la existencia natural de microbios que pueden degradar, transformar o inmovilizar los constituyentes peligrosos [U.S. EPA, 2012]. 
En el caso del sector energético merecen especial atención por su potencial emisión de residuos, las actividades de:

- Exploración y explotación de petróleo o gas. Estas actividades generan tres tipos de residuos: (i) agua que acompaña al crudo y/o gas extraído, y que viene mezclada con productos químicos añadidos para mejorar las operaciones, (ii) los fluidos de perforación constituidos por fragmentos de rocas y lodos de perforación, y (iii) pequeñas cantidades de sedimentos y agua que provienen de los tanques de separación en los que se estaciona el recurso extraído antes de ser enviado a las respectivas tuberías; residuos aceitosos, suelos contaminados y arenas extraídas [U.S, Congress 1992].

Las aguas producidas conjuntamente con petróleo y gas, pueden tratarse o no, y ser reinyectadas entre capas impermeables de rocas para evitar la contaminación de otras aguas subterráneas; pueden ser sometidas a evaporación o percolación en embalses superficiales; o ser vertidas en aguas superficiales.

Por su parte, los fluidos de perforación pueden ser dispuestos en fosas construidas al efecto, colocadas en el espacio anular de los pozos de perforación o ser vertidos en aguas superficiales previo el tratamiento adecuado. El resto de los residuos asociados a las operaciones de producción de petróleo y gas pueden ser almacenados, tratados, dispuestos en rellenos sanitarios, mezclados con tierra en unidades de tratamiento, descargados en aguas superficiales y eventualmente, recirculados o reinyectados.

El manejo no adecuado de los residuos señalados puede ocasionar, entre otras cosas; (i) daños a tierras agrícolas, cosechas, corrientes de agua y ecosistemas acuático, por descargas de las aguas residuales y lodos de perforación, (ii) degradación del suelo y de aguas subterráneas, por escorrentías y filtraciones de unidades de tratamiento o disposición de residuos y, (iii) contaminación de aguas subterráneas por mal funcionamiento de los pozos de reinyección [U.S. Congress, 1992]. 
- Minería de carbón y de arenas bituminosas. La minería de superficie para la extracción de carbón o arenas bituminosas puede producir alteraciones importantes en grandes extensiones de terrenos y en las aguas superficiales y subterráneas asociadas. Los residuos producidos incluyen, (i) rocas 0 materiales que se han desplazado para acceder al material y (ii) residuales del proceso de beneficio para remover material no combustible y azufre inorgánico del carbón; o para recuperar el bitumen presente en las arenas extraídas y trituradas. En minas de carbón subterráneas, la afectación de la superficie es mucho menor pero el fenómeno de subsidencia puede ser importante.

En el caso de la explotación de carbón, puede producirse el fenómeno de drenaje ácido de la mina o escurrimiento del ácido sulfúrico formado al ponerse en contacto las superficies de carbón con agua y aire. El ácido drenado se mueve hacia los cauces de agua causando impactos que pueden ser importantes sobre las tierras y la vida acuática involucrados. El fenómeno puede continuar aún si la mina cesa su operación. Otros problemas relacionados con la explotación de carbón incluyen la generación de grandes cantidades de polvo y la existencia de metales pesados y compuestos radioactivos en los desechos de la mina.

- Combustión de carbón en plantas generadoras de electricidad. En este caso, los residuos comprenden: (i) cenizas en el gas de combustión de salida que son generalmente atrapadas por dispositivos de control de polución del aire, (ii) partículas de mayor tamaño que sedimentan en la base de la caldera, (iii) lodos generadas por la remoción de $\mathrm{SO}_{2}$ de otros gases y (iv) residuos de menor volumen que incluyen purgas de la caldera y de las torres de enfriamiento, escorrentías de carbón apilado, de-mineralizadores y limpiadores de la caldera, entre otros [U.S Congress, 1992].

En general, este tipo de residuos pueden ser tratados y dispuestos en rellenos sanitarios o en embalses superficiales donde los sólidos sedimentan dejando agua relativamente clara en la superficie; ésta es posteriormente descargada a aguas superficiales o recirculada al proceso, previo su tratamiento o no. Los sólidos se acumulan en el fondo del embalse hasta que esté lleno; o pueden ser 
dragados periódicamente y llevados a un relleno sanitario [U.S. Congress, 1992].

- Refinación de petróleo. La refinación de petróleo genera una cantidad importante de residuos que contienen altos niveles de sulfuros, amoníaco, fenoles, hidrocarburos policíclicos y otros tóxicos orgánicos que pueden afectar de forma importante la salud de las comunidades. Gran parte de estos residuos son suspensiones acuosas, el resto incluye suelos contaminados, lodos aceitosos, catalizadores usados y compuestos químicos. La disposición de los residuos puede realizarse en embalses superficiales, rellenos sanitarios, por inyección bajo tierra, reciclo, incineración o tratamiento en tanques. También pueden ser enviados para su disposición en rellenos sanitarios fuera del sitio [U.S. Congress, 1992].

- Aplicación de fertilizantes en el cultivo de biomasa. La escorrentía del agua de lluvias sobre cultivos donde se han aplicado fertilizantes para mejorar el rendimiento, puede aportar un nivel muy alto de nutrientes a sistemas acuáticos con poco movimiento del agua. El fenómeno se conoce como eutrofización o enriquecimiento masivo de nutrientes de un ecosistema $y$ provoca la proliferación de algas verdes que impiden el paso de la luz al fondo del medio receptor con consecuencias importantes sobre la subsistencia de las especies previamente existentes. El nitrógeno y el fósforo son los elementos primordiales en el enriquecimiento de nutrientes; en general su contribución se expresa en términos de $\left(\mathrm{PO}_{4}\right)^{-3}$ equivalentes [Hermmann et al., 2007].

Las líneas precedentes ofrecen un breve resumen sobre las posibles fuentes de residuos y sobre su potencial impacto sobre los ecosistemas involucrados y sobre la salud humana. Como ya se ha señalado, este impacto tiene que ver con el volumen, continuidad de flujo y toxicidad de los materiales que se vierten o filtran al ambiente; y éstos últimos, con la existencia de buenos sistemas para su tratamiento y disposición.

La materia es muy amplia y debe ser tratada en detalle por expertos. Por ello, en lo anteriormente expuesto sólo se pretende suministrar información a fin de de 
orientar una apreciación cualitativa del indicador cuya ficha resumen se propone a continuación.

\begin{tabular}{|c|c|}
\hline \multicolumn{2}{|c|}{ DIMENSIÓN : AMBIENTAL } \\
\hline \multicolumn{2}{|r|}{ ATRIBUTO/CRITERIO: C3.3.1. Residuos sólidos y líquidos } \\
\hline \multicolumn{2}{|r|}{ OBJETIVO ASOCIADO: MIN [Efecto de residuos sólidos y líquidos] } \\
\hline \multicolumn{2}{|r|}{ INDICADOR: Residuos sólidos y líquidos } \\
\hline \multicolumn{2}{|r|}{$\begin{array}{l}\text { DEFINICIÓN: Apreciación cualitativa de los potenciales efectos que sobre el } \\
\text { ambiente y la salud de la comunidad se estima tengan los residuos asociados } \\
\text { a la cadena energética bajo estudio. Los residuos pueden ser sólidos, } \\
\text { semisólidos, líquidos o contener material gaseoso [U.S.EPA, 1999]. No incluye } \\
\text { los residuos radioactivos. }\end{array}$} \\
\hline \multicolumn{2}{|r|}{$\begin{array}{l}\text { FUENTE DE INFORMACIÓN: Estudio de viabilidad ambiental del proyecto: } \\
\text { volumen, continuidad de fluencia, toxicidad y sistemas propuestos para el } \\
\text { tratamiento y disposición de los residuos relacionados. }\end{array}$} \\
\hline \multicolumn{2}{|r|}{$\begin{array}{l}\text { UNIDADES: Apreciación cualitativa, combinación de la información arriba } \\
\text { descrita. }\end{array}$} \\
\hline \multicolumn{2}{|c|}{ ESCALA } \\
\hline 1 & Muy alto impacto \\
\hline 2 & Alto impacto \\
\hline 3 & Mediano impacto \\
\hline 4 & Bajo impacto \\
\hline 5 & Muy bajo impacto \\
\hline
\end{tabular}

C3.3.2. Residuos radioactivos. El problema más importante relacionado con la generación de electricidad a partir de combustible nuclear es el manejo y disposición de los residuos de alto nivel de radioactividad (HLW, por sus siglas en inglés). Aunque relativamente de poco volumen, son de altísima peligrosidad para la supervivencia y/o para la salud de las personas que resulten expuestas a ellos. Entre tales residuos se diferencian,

- El combustible nuclear 'gastado' (SNF, por su siglas en inglés) que se extrae del reactor cuando la mayor parte del uranio ha sido fisionado. Contiene los productos de alto nivel radioactivo de la fisión y algunos elementos transuránicos (número atómico $>$ NA uranio $=92$ ) producidos a partir del UNIVERSIDAD POLITÉCNICA DE VALENCIA. TESIS DOCTORAL. Violeta Parodi 
uranio y el plutonio durante la operación del reactor. El material puede almacenarse en piscinas de agua en el sitio donde se ubica el reactor hasta tanto se disponga de facilidades para su almacenamiento permanente; o puede ser reprocesado para recuperar el uranio y el plutonio no fisionado, presente en él [U.S.EPA, 2011, WNA, 2011].

- El residuo de alto nivel radioactivo del proceso de reprocesamiento del SNF. El uranio y plutonio recuperados del proceso de reprocesamiento son usados para producir nuevo combustible (MOX) el cual es recirculado al reactor. El material residual con los productos de la fisión y algunas actinidas ${ }^{66}$ es un líquido de alto nivel radioactivo que debe ser solidificado para su disposición final.

Otros residuos de baja o mediana radioactividad ( $L L W$ e ILW, por sus siglas en inglés) se producen a lo largo de la secuencia de operaciones que conducen a la producción de energía de origen nuclear. Son considerados residuos de bajo nivel radioactivo, los residuos arenosos procedentes de la minería y molienda del mineral de uranio original. Su disposición se realiza en estanques y luego se recubren con arcilla, roca y vegetación [Tilman, 2009] para prevenir la fuga de gas radón desde los residuos y asegurar la estabilidad del relleno. Por otra parte, el tratamiento posterior para transformar el uranio extraído en la "torta amarilla" consume cantidades importantes de agua y químicos que luego deben ser dispuestos adecuadamente [Tilman, 2009].

Los residuos de mediana radioactividad incluyen resinas, lodos químicos, revestimientos metálicos y los materiales contaminados provenientes del desmantelamiento del reactor. En general, los residuos de mediana radioactividad son dispuestos bajo tierra a una profundidad que depende de la vida radioactiva del residuo [WNA, 2011].

66 Actinidas: Grupo de 14 elementos radioactivos con números atómicos entre 90 y 103. 
Por la alta peligrosidad de los residuos radioactivos, su transporte, almacenamiento provisional y disposición definitiva están estrictamente normados, licenciados y supervisados por las autoridades en cada país y por organismos internacionales que generalmente asesoran sobre la materia. De esta forma, es una condición limitante para la aceptación de un proyecto nuclear que el mismo incluya el diseño adecuado de las facilidades y equipos; y la incorporación del personal capacitado para cumplir con la normativa vigente.

A continuación la ficha resumen del indicador propuesto para incorporar la materia a la evaluación.

\begin{tabular}{|c|c|}
\hline \multicolumn{2}{|c|}{ DIMENSIÓN : AMBIENTAL } \\
\hline \multicolumn{2}{|r|}{ ATRIBUTO/CRITERIO: C3.3.2. Residuos radioactivos } \\
\hline \multicolumn{2}{|r|}{ OBJETIVO ASOCIADO: MIN [Efecto de residuos radioactivos] } \\
\hline \multicolumn{2}{|c|}{ INDICADOR: Residuos radioactivos } \\
\hline \multicolumn{2}{|r|}{$\begin{array}{l}\text { DEFINICIÓN: Apreciación cualitativa sobre el nivel de peligrosidad que puede } \\
\text { representar el transporte, almacenamiento provisional y disposición final de los } \\
\text { residuos radioactivos generados en todas las operaciones del ciclo de vida del } \\
\text { proyecto bajo estudio, una vez entre en operación. Incluye residuos de bajo, } \\
\text { intermedio y alto nivel radioactivo (LLW, ILW y HLW). }\end{array}$} \\
\hline \multicolumn{2}{|r|}{$\begin{array}{l}\text { FUENTE DE INFORMACIÓN: Estudio de viabilidad técnica y ambiental del } \\
\text { proyecto: volumen y nivel radioactivo de los residuos generados en todas las } \\
\text { operaciones contempladas en el ciclo de vida asociado al proyecto y sistema de } \\
\text { seguridad para el manejo de los mismos. }\end{array}$} \\
\hline \multicolumn{2}{|r|}{$\begin{array}{l}\text { UNIDADES: Apreciación cualitativa en función del volumen, nivel radioactivo de } \\
\text { los residuos generados y apego a la normativa vigente del sistema de seguridad } \\
\text { para el manejo de los mismos. }\end{array}$} \\
\hline \multicolumn{2}{|c|}{ ESCALA } \\
\hline 1 & $\begin{array}{l}\text { HLW, volumen bajo, apego a la normativa de manejo y disposición vigente, } \\
\text { sin consideraciones sobre sitio de disposición permanente. }\end{array}$ \\
\hline 2 & $\begin{array}{l}\text { HLW, volumen bajo, apego a la normativa de manejo y disposición vigente, } \\
\text { con consideraciones sobre sitio de disposición permanente. }\end{array}$ \\
\hline 3 & $\begin{array}{l}\text { Sólo LLW y ILW, volumen bajo/mediano y apego a la normativa de manejo } \\
\text { y disposición vigente. }\end{array}$ \\
\hline 4 & Sólo LLW, volumen bajo y apego a la norma de manejo y disposición vigente \\
\hline 5 & No existen residuos radioactivos \\
\hline
\end{tabular}


Es particularmente importante y aún un problema no solucionado en gran parte de los países que operan reactores nucleares, la selección y diseño del sitio para la disposición permanente de los residuos de alto nivel radioactivo y el diseño de sus instalaciones para que no represente una amenaza a la humanidad aún en presencia de eventos catastróficos; por ello, esta consideración se incluye en la escala para la medición del indicador.

C3.4. Uso de la tierra. El efecto sobre la flora, la fauna y el ecosistema en general, que tiene la instalación y operación de un proyecto para la obtención, transporte y/o transformación de energía; así como la afectación visual y acústica que el mismo produce, son aspectos importantes que deben incorporarse a la evaluación del proyecto.

Los efectos sobre el ecosistema derivados de la ocupación de una extensión de tierra que cambia su estado original a terreno inundado u ocupado con cultivos o construcciones, se incrementan primordialmente con la cantidad de tierra requerida y con la intensidad de intervención en la misma ${ }^{67}$. Así, la instalación de un desarrollo hidroeléctrico requiere la inundación de grandes extensiones de terreno con pérdida o afectación de las especies y activos originalmente existentes y el desplazamiento de los habitantes de la zona que en el caso de los grandes complejos hidroeléctricos es considerable ${ }^{68}$.

De forma similar, la producción de biocombustibles requiere extensas superficies cultivadas $^{76}$ de biomasa (maíz. caña de azúcar u otros) que antes pudieron ser bosques, praderas o similares. En estos casos, la búsqueda de una alta

67 Requerimiento promedio de tierras ( $\mathrm{km} 2 / 1000 \mathrm{MW}$ a producir) para plantas generadoras de electricidad que utilizan: biomasa (5000), energía hidráulica (750), viento (100), energía solar fotovoltaica (35), energía geotérmica (18), carbón, petróleo, gas natural o energía nuclear (25) [Chatzimouratidis y Pilavachi, 2008].

68 Como un ejemplo, la construcción del complejo hidroeléctrico "Tres Gargantas" en China desplazo más de un millón de personas [China TG Co, 2002]. 
productividad requiere de cantidades importantes de agua y fertilizantes que afectan el equilibrio del ecosistema existente antes de la intervención.

Las instalaciones de turbinas de viento para la generación de electricidad producen ruidos que pueden causar pérdida del oído y afectar la salud psicológica de las personas, afectar el paisaje de zonas extensas y causar incidentes aislados como la colisión de aves con las aspas de las turbinas. Por su parte, las grandes matrices de colectores que se instalan para la captación de la energía solar pueden interferir con la luz del sol, la lluvia y el drenaje zonas vastas de terreno lo que puede afectar la flora y fauna de las mismas.

La explotación de minas de carbón o de arenas bituminosas puede deteriorar grandes extensiones de terreno y contaminar las aguas superficiales $y$ subterráneas asociadas, afectando de forma importante la fauna, flora y el paisaje sobre el terreno intervenido. La extracción, el transporte y la transformación de otros hidrocarburos fósiles pueden generar residuos muy contaminantes y ser origen de derrames que causan graves daños al ecosistema afectado.

Otros sistemas para obtención y transformación de la energía requieren áreas pequeñas para su funcionamiento, con intensidad de impacto variable. Así, el terreno que ocupa una planta nuclear es relativamente pequeño pero una vez que finaliza su operación y se toma la decisión de cerrar la planta de forma permanente, no es apto siquiera para el tránsito humano dado los niveles de radiación existentes los cuales pueden durar más de 100 años [NEA. 2005]. En el otro extremo, los paneles solares que se instalan sobre los techos de los inmuebles para proporcionar calor o energía a sus habitantes, no requieren ningún terreno adicional y su impacto por este concepto es muy pequeño o nulo.

El estudio detallado de los aspectos señalados es materia de expertos y objeto de un estudio ambiental del proyecto. El indicador cuya ficha resumen se presenta a continuación, sólo pretende incorporar a la evaluación del proyecto, el efecto en términos cualitativos, que ocasionará el cambio de uso de la tierra sobre la demanda de agua, la biodiversidad, el paisaje, el nivel de ruido y similares. 
La extensión de tierra requerida para la instalación y funcionamiento del proyecto, y la magnitud de los cambios sobre el ambiente que se estima tengan lugar, pueden servir como una guía para la calificación a otorgar. Información adicional resumida puede tomarse de las tablas 3.4 y 3.5, Capítulo 3, de este documento.

\begin{tabular}{|c|c|}
\hline \multicolumn{2}{|c|}{ DIMENSIÓN : AMBIENTAL } \\
\hline \multicolumn{2}{|r|}{ ATRIBUTO/CRITERIO: C3.2.3. Uso de la tierra } \\
\hline \multicolumn{2}{|r|}{$\begin{array}{l}\text { OBJETIVO ASOCIADO: MIN [Otros efectos ambientales por cambio de uso de la } \\
\text { tierra). }\end{array}$} \\
\hline \multicolumn{2}{|c|}{ INDICADOR: Uso de la tierra } \\
\hline \multicolumn{2}{|r|}{$\begin{array}{l}\text { DEFINICIÓN: Apreciación cualitativa que combina los efectos sobre la } \\
\text { biodiversidad, la afectación del paisaje y el nivel de ruido que se estima tendrá } \\
\text { la instalación y operación de las instalaciones del proyecto, en función de la } \\
\text { extensión de tierra ocupada y la intensidad de su uso. }\end{array}$} \\
\hline \multicolumn{2}{|r|}{$\begin{array}{l}\text { FUENTE DE INFORMACIÓN: Estudio de viabilidad ambiental del proyecto: } \\
\text { extensión de terreno requerida para la instalación y funcionamiento de las } \\
\text { instalaciones del proyecto e impacto estimado que tendrá su cambio de uso. }\end{array}$} \\
\hline \multicolumn{2}{|r|}{$\begin{array}{l}\text { UNIDADES: Apreciación cualitativa, combinación de la extensión de tierra } \\
\text { requerida y el número e I intensidad de los cambios sobre ella. }\end{array}$} \\
\hline \multicolumn{2}{|c|}{ ESCALA } \\
\hline 1 & Muy alta intensidad de impacto sobre dos o más de los elementos citados \\
\hline 2 & Alta intensidad de impacto sobre dos o más de los elementos citados \\
\hline 3 & Mediana intensidad de impacto sobre uno o más de los elementos citados \\
\hline 4 & Baja intensidad de impacto sobre uno o más de los elementos citados \\
\hline 5 & Intensidad de impacto nula o muy baja \\
\hline
\end{tabular}

En la próxima sección se hace referencia a los indicadores asociados a cada uno de los criterios propuestos para la evaluación del proyecto en su dimensión social.

\subsection{Dimensión social}

Los criterios sociales tienen que ver con los beneficios que recibe o los perjuicios que sufre la población como consecuencia de la instalación del proyecto bajo estudio; y con la percepción que de ellos tenga la comunidad. Para evaluar estos aspectos se proponen dos indicadores; ellos son: 
C4.1. Aceptación de la comunidad

C4.2. Calidad de vida

A continuación se presenta la descripción de cada indicador.

C4.1. Aceptación de la comunidad. Este criterio incluye en el proceso de evaluación, la predisposición que la población local tiene en relación a la instalación y operación del proyecto bajo estudio. La estimación del indicador instrumento del criterio es resultado de la percepción que las personas involucradas tengan sobre temas como, (i) las consecuencias que sobre la salud y el ambiente puedan tener emisiones y residuos generados regularmente por las instalaciones; o eventualmente, por accidentes de operación y eventos catastróficos, (ii) la afectación estética, funcional y acústica, del terreno que ocuparán las instalaciones, y (iii) el desarrollo económico y mejoría en la calidad de vida que puede generar la implementación y puesta en marcha del proyecto.

A continuación se presenta la ficha resumen del indicador propuesto..

\begin{tabular}{|c|c|}
\hline \multicolumn{2}{|c|}{ DIMENSIÓN : AMBIENTAL } \\
\hline \multicolumn{2}{|c|}{ ATRIBUTO/CRITERIO: C4.1. Aceptación de la comunidad } \\
\hline \multicolumn{2}{|c|}{ OBJETIVO ASOCIADO: MAX [Aceptación de la comunidad] } \\
\hline \multicolumn{2}{|c|}{ INDICADOR: Aceptación de la comunidad } \\
\hline \multicolumn{2}{|c|}{$\begin{array}{l}\text { DEFINICIÓN: Nivel de aceptación de la comunidad sobre la instalación y } \\
\text { funcionamiento del proyecto que tiene la comunidad sede del proyecto. }\end{array}$} \\
\hline \multicolumn{2}{|c|}{$\begin{array}{l}\text { FUENTE DE INFORMACIÓN: Encuesta en la comunidad u opinión de sus } \\
\text { representantes en el análisis y discusión del proyecto. }\end{array}$} \\
\hline \multicolumn{2}{|c|}{ UNIDADES: Apreciación cualitativa } \\
\hline \multicolumn{2}{|c|}{ ESCALA } \\
\hline 1 & Muy baja aceptación \\
\hline 2 & Baja aceptación \\
\hline 3 & Mediana aceptación \\
\hline 4 & Alta aceptación \\
\hline 5 & Muy alta aceptación \\
\hline
\end{tabular}


La aceptación del proyecto por parte de la comunidad es limitante y debe ser obtenida o negociada antes de adelantar otros etapas del proyecto; de no ser así, la opinión de grupos de presión dentro de la localidad pueden obstaculizar su construcción o alargar el tiempo necesario para el inicio de misma.

C4.2. Calidad de vida. Este segundo criterio pretende incluir en el proceso de evaluación, el efecto que sobre la calidad de vida de la localidad sede del proyecto, se estima tendrá su ejecución y funcionamiento. El indicador que se propone es un promedio ponderado de tres subindicadores respectivamente correspondientes con los criterios de evaluación propuestos en la tabla 4.9, nivel 3 de este documento. Los indicadores son:

\section{C4.2.1. Creación de empleo}

\section{C4.2.2. $\Delta$ Salarios}

\section{C4.2.3. $\Delta$ Déficit de energía}

A continuación se presentan algunos comentarios y las fichas resumen de cada indicador propuesto.

C4.2.1. Creación de empleo. La creación estimada de nuevos empleos relacionados directa e indirectamente con el proyecto bajo estudio, es uno de los indicadores importantes cuando se trata de estimar los efectos que sobre la calidad de vida de la localidad puede tener el mismo.

Las actividades relacionadas con la obtención, transformación y distribución de energía hasta el usuario final generan toda clase de ocupaciones. Entre otras muchas, se encuentran las labores relacionadas con el diseño, la construcción y puesta en marcha de las instalaciones, la operación y el mantenimiento de las mismas, el transporte y almacenamiento de los recursos energéticos y de los productos finales, si es el caso; el manejo de las redes de distribución, las operaciones comerciales, administrativas y logísticas relacionadas; y finalmente, el desmantelamiento de las instalaciones. Además, deben añadirse todas las actividades de investigación, comerciales, de transporte y de apoyo dirigidas a suplir, por una parte, los recursos energéticos, tecnologías, equipos y servicios 
necesarios para el buen funcionamiento de las instalaciones; y por la otra, los productos al consumidor.

A continuación se presenta la ficha resumen del indicador que se propone para incorporar este aspecto de índole social a la evaluación de un proyecto.

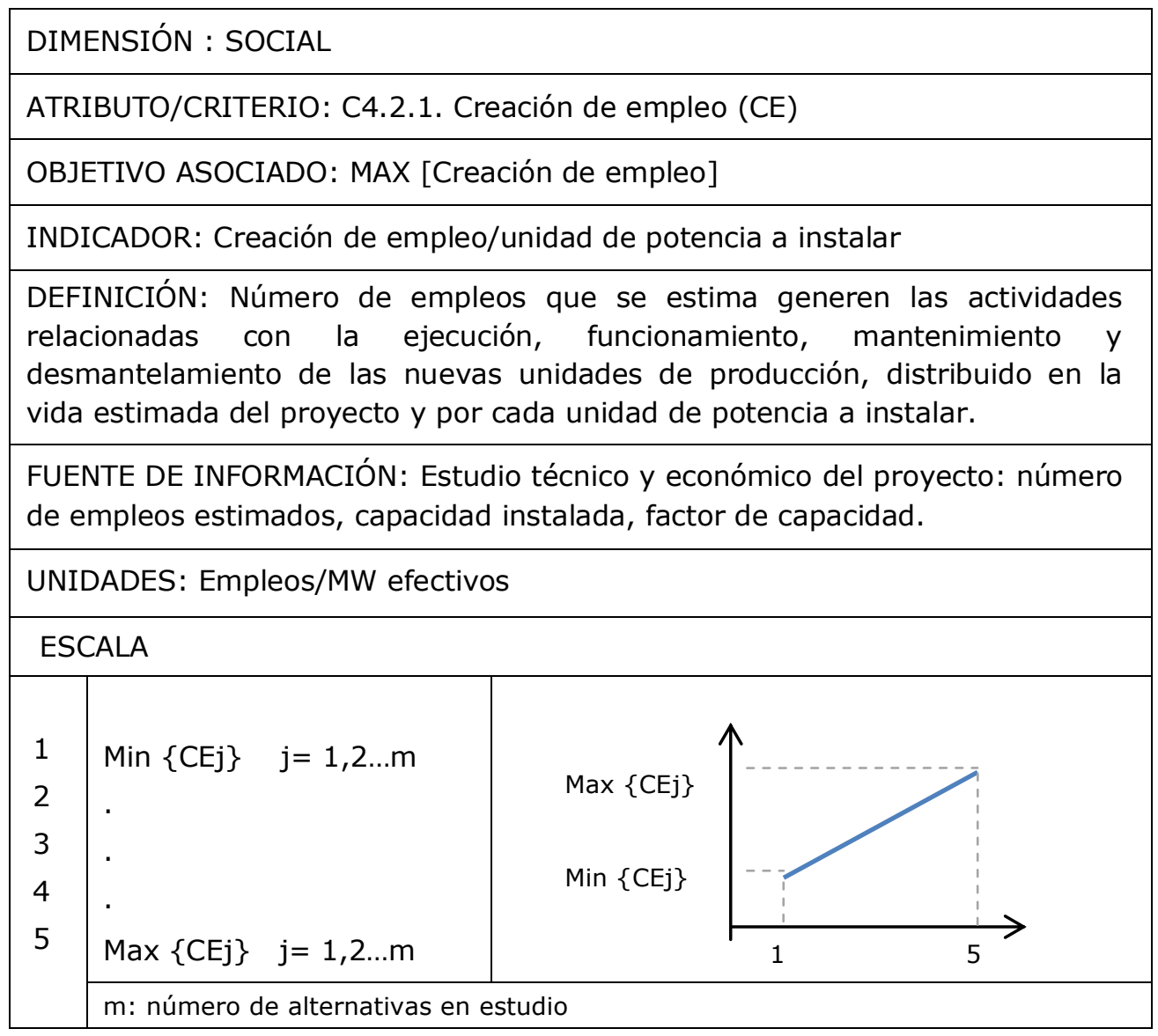

C4.2.2. $\Delta$ Salarios. Adicionalmente a la consideración del número de empleos directos e indirectos que es capaz de generar el proceso de obtención del recurso energético, su transformación y su distribución como energía útil al hombre; es importante incorporar al proceso de evaluación, el aspecto de la calidad del empleo. Un mayor número de empleos bien remunerados es sin duda uno de los factores que más influyen en la calidad de vida de una localidad.

Un indicador para incluir este efecto en el análisis puede basarse en el valor presente del costo de mano de obra relacionada al proyecto bajo estudio (CMO). 
Así, si CMOk es el costo de mano de obra para el año k y Qk la cantidad de energía que se estima producir para el mismo año, el índice puede calcularse de acuerdo a la siguiente ecuación:

$$
\mathrm{CMO}=\left[\Sigma\left(\mathrm{CMO}_{\mathrm{k}} / \mathrm{Q}_{\mathrm{k}}\right) /(1+\mathrm{i})^{\mathrm{k}}\right] \quad \mathrm{k}=1,2 \ldots \mathrm{n}
$$

A continuación se presenta la ficha resumen del indicador sugerido.

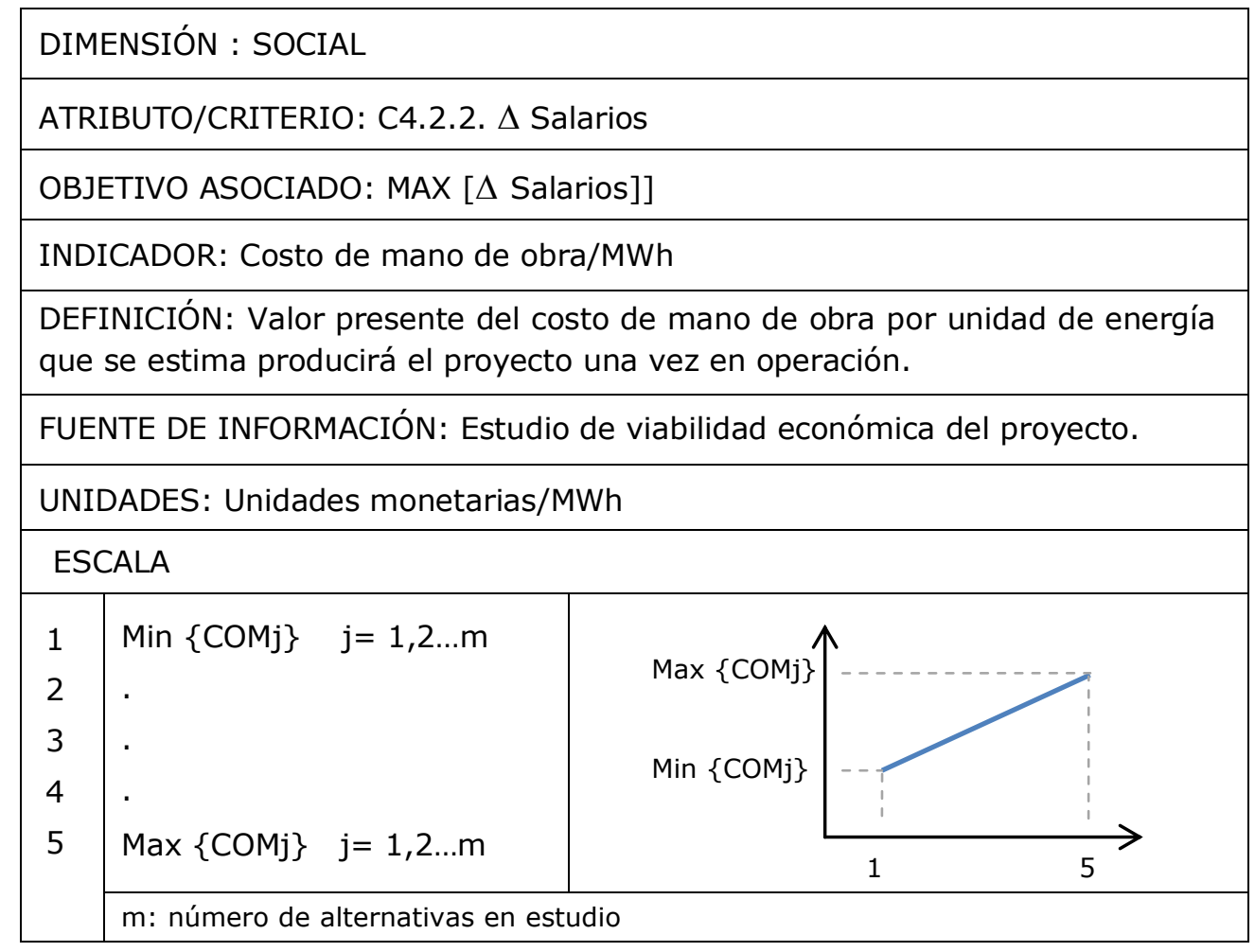

C4.2.3. $\Delta$ Déficit de energía. El acceso a la electricidad, calor y combustibles ayuda a la superación de las condiciones de vida en términos de saneamiento y salud, educación, iluminación, calefacción, medios para el cocimiento de los alimentos, comunicación y distracción; especialmente de la población más marginada como comunidades rurales e indígenas. Adicionalmente, potencia las perspectivas de aumento del ingreso familiar si se utiliza en actividades productivas.

A continuación se presenta la ficha resumen del indicador que se propone para incorporar este aspecto a la evaluación del proyecto bajo estudio. 


\begin{tabular}{|l|l|}
\hline \multicolumn{2}{|l|}{ DIMENSIÓN : SOCIAL } \\
\hline ATRIBUTO/CRITERIO: C4.2.3. Déficit de energía \\
\hline OBJETIVO ASOCIADO: MAX [Disminución en déficit de energía] \\
\hline INDICADOR: $\triangle$ Déficit de energía (DDE) \\
\hline $\begin{array}{l}\text { DEFINICIÓN: Fracción del déficit de energía local (regional) que se estima } \\
\text { puede suplir el proyecto. }\end{array}$ \\
\hline $\begin{array}{l}\text { FUENTE DE INFORMACIÓN: Estudio de viabilidad económica del proyecto: } \\
\text { capacidad instalada del proyecto, factor de capacidad, déficit de energía en la } \\
\text { región de influencia del proyecto. }\end{array}$ \\
\hline UNIDADES: \% \\
\hline ESCALA
\end{tabular}

En la próxima sección se presentan los indicadores para la valuación del proyecto en aspectos que tienen que ver con consideraciones estratégicas del país sede del proyecto.

\subsection{Dimensión estratégica}

La planificación estratégica es el proceso de desarrollo de planes coordinados a corto, mediano y largo plazo que orienten los programas futuros de inversión en determinadas áreas, a nivel de una empresa, localidad, región, nación o grupo de naciones. En general, los planes buscan optimizar el uso de los recursos energéticos, técnicos, humanos, financieros, institucionales. administrativos y logísticos con los que se cuenta para cumplir con los requerimientos de la población.

Un proyecto tendrá una mayor oportunidad de aprobación en tanto sus objetivos coincidan, contribuyan; o al menos no colidan con los planes que en el área tenga la empresa patrocinadora o los organismos planificadores en la región sede del 
proyecto. En el sector de las energías renovables, podrá incluso conseguir algún soporte de los gobiernos regionales o nacionales como créditos preferenciales, incentivos a la producción y excepciones al impuesto sobre la renta, hasta tanto sus productos puedan competir en precio con sus similares en el mercado.

En el sector energético, el alivio de problemas como la emisión de grandes cantidades de $\mathrm{CO}_{2}$ y otros gases invernadero a la atmósfera, con su importante efecto sobre el calentamiento global; la seguridad energética de los países desarrollados y no desarrollados, el agotamiento de las reservas mundiales de petróleo y gas convencional a mediano plazo, el desigual acceso a los servicios básicos energéticos a lo ancho del planeta; y en menor proporción, el desplazamiento de cultivos de alimentos por cultivos dirigidos a la producción de energía, conforman la agenda prioritaria de los gobiernos del mundo.

A continuación se proponen y definen indicadores para valorar la compatibilidad del proyecto bajo estudio con los objetivos antes señalados. Algunos de ellos ya han sido incluidos en indicadores ambientales o sociales específicos definidos en apartes anteriores. Otros, como la seguridad energética, el agotamiento de las reservas de combustibles fósiles convencionales y el desplazamiento ocasional de cultivos de alimentos por cultivos para la producción de energía se incluyen en el análisis mediante los indicadores que se definen a continuación. Los indicadores se asocian respectivamente a los criterios estratégicos de evaluación propuestos en los niveles 2 y 3 del modelo final de valor planteado en la figura 4.8 , sección 4.1.2.4.5 de este documento. Los indicadores son,

\section{C5.1. Seguridad energética}

C5.2. Compatibilidad con planes-nación

A continuación se presenta un breve resumen de cada uno de ellos.

C5.1. Seguridad energética. Un suministro de energía confiable y accesible en su costo es indispensable para el buen desarrollo económico de las naciones y el mejoramiento de la calidad de vida de sus poblaciones. El acceso a la energía se complica por su elevada demanda actual, la alta participación de los combustibles fósiles en ella, el gradual agotamiento de sus yacimientos y la concentración de 
las reservas mundiales de petróleo convencional en manos de un grupo muy limitado de países, algunos de ellos con explosivas situaciones políticas que son capaces de causar la interrupción del suministro a los mercados y la elevación de los precios. La situación del gas convencional es similar.

Las amenazas al suministro seguro de los combustibles fósiles y la presión creciente de todos los sectores de la sociedad por una disminución significativa en la emisión de gases de tipo invernadero a la atmósfera, han desviado la atención hacia el desarrollo de tecnologías que permitan el aprovechamiento de las energías renovables y su incorporación a la canasta energética de los países del mundo. En la medida en que la cesta energética se diversifique por la incorporación de nuevos tipos de energía, especialmente de energía renovable, el país aumentará su independencia energética. En la medida en que un país importador de energía diversifique la procedencia de sus embarques y mantenga inventarios estratégicos que puedan utilizarse en escenarios de crisis, el país aumentará su seguridad energética.

Con el mismo objetivo, los países productores de recursos energéticos no renovables buscan conservar o incrementar la relación reservas a producción $(R / P)$. Tal es el caso de los propuestas de exploración y desarrollo de nuevos yacimientos. Para las energías renovables, la relación $R / P$ es infinita pero en general el recurso está limitado a localizaciones geográficas con determinadas características y el tiempo de acceso a ella no es continuo (sol, viento, caudal de los ríos, mareas) a menos que el sistema para la captación y aprovechamiento de la energía disponga del almacenamiento necesario o de fuentes auxiliares de energía alterna para suplir la falta periódica de energía.

En base a lo anteriormente expresado, el indicador que se propone puede expresarse como un promedio ponderado de dos subindicadores, a saber:

C5.1.1. Diversidad de la matriz energética

\section{C5.1.2. Seguridad de suministro}

A continuación se presenta una breve descripción de los indicadores propuestos. 
C5.1.1 Índice de diversidad de la cesta energética. Como ya se ha señalado, una mayor variedad en el tipo de los recursos que utiliza un país para proveer energía a sus habitantes incrementa su seguridad energética. En general, el índice Herfindhal-Hirschman [Kruyt et al., 2009] es uno de los indicadores más usados para medir diversidad. Si xi es la fracción del combustible i, en la mezcla energética, y $\mathrm{n}$, el número de combustibles en ella; el índice de diversidad HHI, se expresa como:

$$
\mathrm{HHI}=\sum x \mathrm{i}^{2} \quad \mathrm{i}=1,2 \ldots \mathrm{n}
$$

A modo de ilustración, la figura 4.9 muestra el índice de diversidad HHI para una cesta de tres componentes. La fracción de uno de los componentes se muestra en el eje de abscisas; la fracción restante se reparte a partes iguales entre los otros dos componentes. En el eje de ordenadas se llevan los correspondientes índices de diversidad para cada distribución de la cesta. Como puede observarse, el mínimo de la curva resultante se presenta cuando la mezcla se distribuye a partes iguales entre los tres componente. El mayor valor del índice ocurre cuando la mezcla está conformada por sólo un componente; y toma un valor intermedio cuando está conformada por dos componentes. De esta forma, un menor valor del índice representa una mayor diversidad en la cesta.

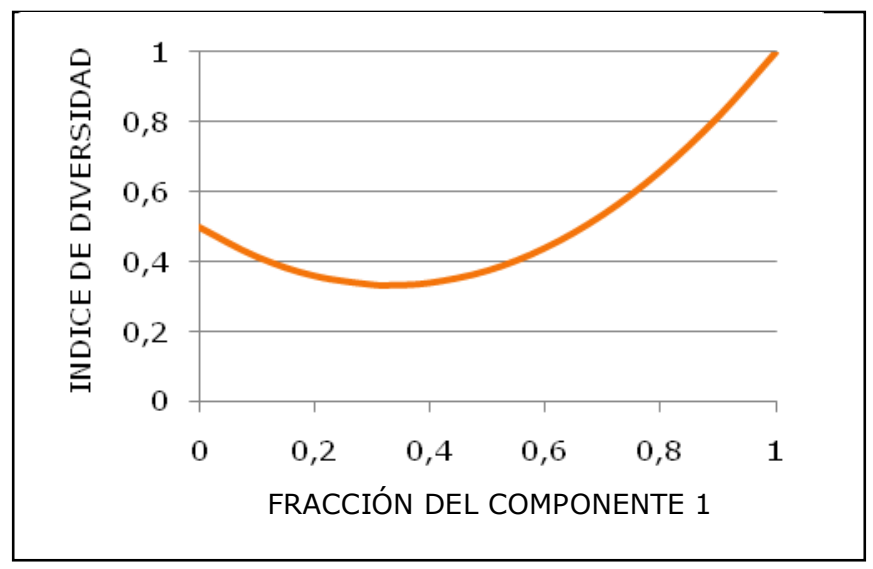

Figura 4.9. Índice de diversidad [Kruyt et al., 2009]

Si el índice de diversidad de la cesta energética (IDCE) se estima, antes y después de la puesta en marcha del proyecto bajo estudio, la diferencia obtenida puede 
utilizarse como un indicador del efecto que dicho proyecto tiene sobre su diversidad energética. A continuación se presenta su ficha resumen.

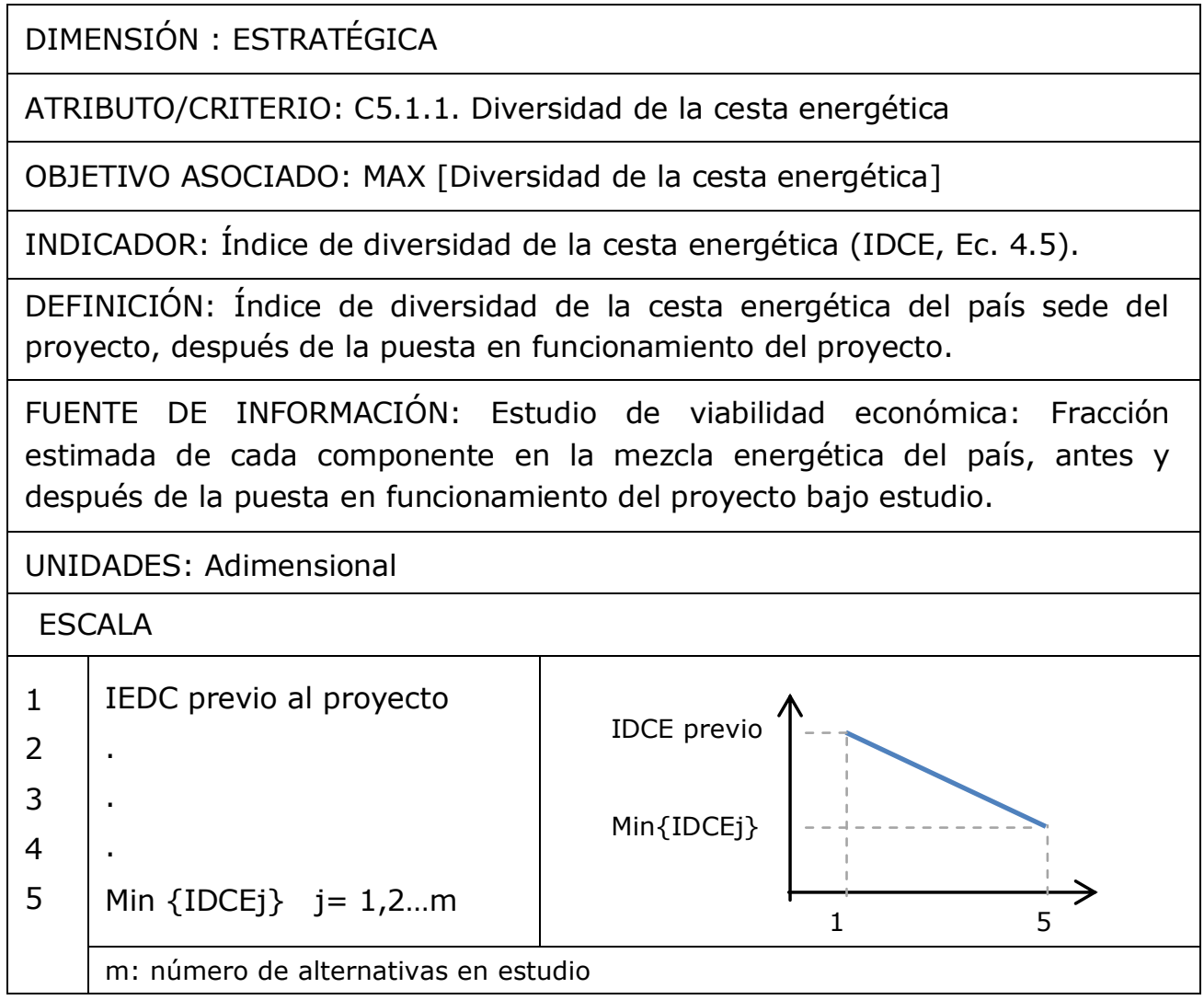

C5.1.2. Seguridad de suministro. La fuente de los recursos energéticos requeridos para el normal funcionamiento de las futuras instalaciones asociadas a un proyecto en el sector, puede ser endógena o exógena al país sede. Mientras mayor sea la fracción del componente endógeno en el total de recursos que se estima requerirá el proyecto una vez entre en operación, mayor será la probabilidad de su suministro oportuno y menor la vulnerabilidad de su continuidad operativa. $Y$ en el caso del componente importado, mientras mayor sea el número y confiabilidad de los suplidores, y mientras mayores inventarios estratégicos se mantengan; mayor será su seguridad de suministro.

Nótese que en el caso del aprovechamiento de los recursos energéticos renovables, la totalidad de los recursos energéticos que se estima requerirá el proyecto se encuentra en el territorio sede del mismo. Sin embargo, debe 
tomarse en cuenta que la continuidad e intensidad de su suministro se ve afectada por su potencial en la región, por la hora del día, por la época del año y/o por las condiciones del tiempo (vientos, radiación solar, lluvias).

\begin{tabular}{|c|c|}
\hline \multicolumn{2}{|c|}{ DIMENSIÓN : ESTRATEGICA } \\
\hline \multicolumn{2}{|r|}{ ATRIBUTO/CRITERIO: C5.1.2. Seguridad de suministro } \\
\hline \multicolumn{2}{|r|}{ OBJETIVO ASOCIADO: MAX [Seguridad de suministro] } \\
\hline \multicolumn{2}{|r|}{$\begin{array}{l}\text { INDICADOR: Relación de insumos energéticos nacionales a insumos energéticos } \\
\text { importados. }\end{array}$} \\
\hline \multicolumn{2}{|r|}{$\begin{array}{l}\text { DEFINICIÓN: Relación entre el componente nacional y el componente importado } \\
\text { del suministro energético requerido por el proceso bajo estudio. }\end{array}$} \\
\hline \multicolumn{2}{|r|}{ FUENTE DE INFORMACIÓN: Estudio de viabilidad técnica y económica. } \\
\hline \multicolumn{2}{|c|}{ UNIDADES: Apreciación cualitativa. } \\
\hline \multicolumn{2}{|c|}{ ESCALA } \\
\hline 1 & Suministro nacional < Suministro importado, diversidad de suplidores baja \\
\hline 2 & Suministro nacional < Suministro importado, diversidad de suplidores alta \\
\hline 3 & Suministro nacional $>>$ Suministro importado \\
\hline 4 & Suministro nacional, disponibilidad $<80 \%$ \\
\hline 5 & Suministro nacional, disponibilidad $\geq 80 \%$ \\
\hline
\end{tabular}

La calificación en la seguridad de suministro del componente importado puede realizarse en base a un 'Índice de diversidad de suplidores' definido con ayuda de la ecuación 4.5; y donde xi representaría la fracción del total importado que es suministrado por el suplidor $i$.

C5.2. Compatibilidad con planes-nación. En general, las políticas y planes de desarrollo de una nación van acordes con sus necesidades más urgentes. Así, son planes usuales de desarrollo aquellos que buscan el bienestar y mayores oportunidades para los sectores más marginados de la población. Además, los países pueden desarrollar planes que respondan a políticas regionales 0 a convenios internacionales. Específicamente, en el sector energético, algunas políticas y/o planes comunes son: 
- La ampliación, modernización y/o diversificación de los sistemas de generación y distribución eléctrica de forma de dar acceso seguro a toda su población, especialmente a aquellos que viven en zonas rurales apartadas.

- La ampliación y modernización de la planta de refinación a fin de cumplir con la demanda interna y los compromisos de exportación que tenga el país.

- El desarrollo de sistemas para el aprovechamiento de las energías renovables con el doble propósito de avanzar en su independencia energética y de disminuir las emisiones de gases a la atmósfera.

- El apoyo a la investigación sobre nuevas tecnologías para la producción de biocombustibles.

- La exploración y desarrollo de nuevos yacimientos de combustibles fósiles convencionales o no convencionales, con el propósito de ampliar las reservas del país y sus posibilidades de ingresos futuros adicionales.

- El fomento de la seguridad alimentaria; lo que a veces implica, la no utilización de terrenos que pueden dedicarse al cultivo de cosechas de alimentos a cultivos con fines energéticos.

- El desarrollo de proyectos en las áreas rurales a fin de favorecer su desarrollo económico, la aparición de nuevos puestos de trabajos, y en general, un mejor nivel de vida a sus habitantes.

- El desarrollo de un programa nuclear con fines pacíficos; o viceversa, la sustitución de reactores nucleares con muchos años de uso y/o sin los estrictos controles de operación y manejo de emergencias necesarios, por sistemas que infundan en la población mayor sensación de seguridad.

Naturalmente, un proyecto que sea compatible con los planes del país sede tendrá una mayor posibilidad de aprobación, ejecución y funcionamiento adecuado; ello debe ser considerado una ventaja cuando de evaluar el proyecto se trata.

A continuación se presenta la ficha resumen de un indicador que incorpora esta materia al análisis multicriterio. 


\begin{tabular}{|c|c|}
\hline \multicolumn{2}{|c|}{ DIMENSIÓN : ESTRATEGICA } \\
\hline \multicolumn{2}{|r|}{ ATRIBUTO/CRITERIO: C5.2. Compatibilidad con otros planes-nación } \\
\hline \multicolumn{2}{|r|}{ OBJETIVO ASOCIADO: MAX [Compatibilidad con otros planes-nación] } \\
\hline \multicolumn{2}{|r|}{ INDICADOR: Compatibilidad con otros planes-nación } \\
\hline \multicolumn{2}{|r|}{$\begin{array}{l}\text { DEFINICIÓN: Apreciación cualitativa sobre la compatibilidad del proyecto bajo } \\
\text { estudio con los planes de desarrollo de la localidad, región o país. }\end{array}$} \\
\hline \multicolumn{2}{|r|}{$\begin{array}{l}\text { FUENTE DE INFORMACIÓN: Estudio de viabilidad económica: justificación del } \\
\text { proyecto. }\end{array}$} \\
\hline \multicolumn{2}{|c|}{ UNIDADES: Apreciación cualitativa } \\
\hline \multicolumn{2}{|c|}{ ESCALA } \\
\hline 1 & Poca o ninguna compatibilidad con planes de desarrollo del país. \\
\hline 2 & $\begin{array}{l}\text { Compatibilidad con planes de menor importancia para el país. Con } \\
\text { regulación en fase preliminar o sin existencia de ella. }\end{array}$ \\
\hline 3 & $\begin{array}{l}\text { Compatibilidad con planes de mediana importancia para el país. } \\
\text { Regulación existente. }\end{array}$ \\
\hline 4 & Compatibilidad con planes prioritarios para el país. Regulación existente. \\
\hline 5 & $\begin{array}{l}\text { Compatibilidad con planes prioritarios para el país. Regulación, políticas } \\
\text { de incentivos y subsidios existentes. }\end{array}$ \\
\hline
\end{tabular}

\subsection{Dimensión riesgo}

La puesta en marcha y funcionamiento de un proyecto para el aprovechamiento de los recursos energéticos existentes en el planeta, lleva consigo una serie de riesgos sobre el ambiente y sobre la salud de la población en su región de influencia. Tales riesgos pueden asociarse (i) a la operación normal de las instalaciones (ii) a eventos extremos con una probabilidad de ocurrencia muy baja pero con daños potenciales de gran magnitud y generalmente irreversibles (iii) a otros eventos.

El primer tipo de riesgos se refiere a posibles efectos nocivos a la salud de la población por emisiones y otros efluentes peligrosos de las operaciones; así como a los daños a la integridad física o eventual pérdida de vida de los trabajadores en accidentes ocurridos durante el funcionamiento normal de las instalaciones. El primer subgrupo de efectos fue incluido indirectamente en los indicadores de la dimensión ambiente. El segundo subgrupo es función de la experiencia en el manejo de la 
tecnología en cuestión, del buen mantenimiento de las instalaciones, de la existencia de normas y protocolos de operación y de seguridad, y de su estricta observancia en la operación regular $\mathrm{y} / \mathrm{o}$ en situaciones de emergencia. En general, si estas condiciones se cumplen, la incidencia de estos accidentes es muy baja; y depende más de las condiciones de operación del proceso que del proyecto planteado.

De esta forma, sólo se incorporan al modelo de valor para la evaluación, aquellos indicadores que permiten estimar los riesgos que se perciben como críticos por la magnitud de los potenciales daños asociados. Para lograr este objetivo se proponen dos indicadores, a saber:

\section{C6.1. Riesgo ante eventos extremos}

C6.2. Uso ilícito de material radioactivo

A continuación se presenta la descripción de cada indicador antes citado.

C6.1 Riesgo ante eventos extremos. Los eventos extremos pueden definirse como accidentes que traen consigo daños de magnitud muy importante a personas, al ambiente y a las propiedades. Accidentes serios pueden ser causados por eventos naturales como terremotos, tsunamis, inundaciones y tormentas; por fallas en el diseño de las instalaciones y /o por errores humanos en el manejo y en el seguimiento de los protocolos de seguridad de las instalaciones. En los últimos tiempos se ha añadido el terrorismo como causal de eventos catastróficos.

Grandes inundaciones causadas por el colapso de presas asociadas a desarrollos hidroeléctricos han causado ${ }^{69}$ pérdidas humanas en número importante, inundación de grandes extensiones de terreno, pérdida de activos y el desplazamiento de grandes masas de población que pierden sus hogares y sus fuentes de trabajo [Kirschberg et al., 2003].

En el año 1975, presas en Bianqiao y Shimantan en China se desbordaron causando la inundación de un millón de hectáreas de terreno, el desplazamiento de millones de personas que perdieron sus hogares y la pérdida de unas 26,000 vidas en el momento de la inundación, y otras 145,000, poco tiempo después por epidemias y hambre [Hirschberg, 2003]. 
Explosiones por acumulación de metano en minas de carbón han producido centenas de muertes; e incendios causados por la ignición del polvo de carbón o de vetas en la mina son muy difíciles de apagar y pueden causar víctimas y el cierre permanente de la misma. También pueden producirse derrumbes en las galerías de minas bajo tierra cerrando los canales de ventilación y produciendo daños a personas no sólo por la caída de rocas sino por la acumulación de gases tóxicos que pueden ser letales [Kirschberg et al, 2003].

Derrames en actividades de perforación de pozos y en el transporte de petróleo o en la distribución de sus productos derivados pueden afectar el equilibrio ecológico del área afectada que puede ser muy grande. En el año 2010, la explosión de una plataforma petrolera de perforación causó la muerte de 11 trabajadores, provocando una fuga de petróleo del pozo perforado que se ha estimado en unos 4,9 millones de barriles de petróleo arrojados al Golfo de México, a razón de unos 53,000 bbls/día durante tres meses. El vertido afectó el ecosistema de unos $11,000 \mathrm{~km}^{2}$ alrededor del pozo y de miles de kilómetros de las costas sur de los Estados Unidos, catalogándose como el mayor desastre de este tipo nunca ocurrido [Campbell y Krauss, 2010].

Por otra parte, derrames de importancia sobre el océano se producen con frecuencia por la colisión de tanqueros que transportan petróleo o sus derivados; o desde tuberías que transportan crudos o distribuyen productos derivados. El peligro de incendios y explosiones está presente en toda la cadena de actividades de exploración, explotación, transformación y transporte de la industria de petróleo y de gas.

Sin embargo, son los accidentes nucleares los más temidos por la población debido a sus graves consecuencias sobre la vida o salud de los trabajadores y de la población vecina al sitio del evento. La tabla 4.9 presenta información muy breve sobre tres de los accidentes más importantes ocurridos en las últimas décadas. 
Tabla 4.9. Accidentes nucleares más graves en las últimas décadas

\begin{tabular}{|c|c|c|}
\hline CENTRAL & INES & CARACTERÍSTICAS/EFECTOS \\
\hline $\begin{array}{l}\text { Three Miles Island, } \\
\text { USA, } 1979 \text { (a) }\end{array}$ & 5 & $\begin{array}{l}\text { Fusión parcial del núcleo de un reactor. Emisión de gases } \\
\text { radioactivos a la atmósfera. Evento controlado. Máxima } \\
\text { radiación por persona } \leq 1 \mathrm{mSv}\end{array}$ \\
\hline $\begin{array}{l}\text { Chernóbil, URSS, } \\
1986^{(\text {b) }}\end{array}$ & 7 & $\begin{array}{l}\text { Explosión de un reactor que liberó aproximadamente un } \\
5 \% \text { del núcleo radioactivo a la atmósfera. } 31 \text { personas } \\
\text { murieron en el momento o en pocas semanas por } \\
\text { exposición a una alta radiación. Se incrementó la } \\
\text { incidencia de cáncer de tiroides en los niños de la zona. } \\
600,000 \text { personas participaron en labores de limpieza de } \\
\text { las cuales unas } 200,000 \text { fueron sometidas a dosis de } \\
\text { radiación entre } 100 \text { y } 500 \mathrm{mSv} \text {. La zona de exclusión } \\
\text { alcanzó } 4300 \mathrm{~km} 2 \text { y más de } 300,000 \text { personas fueron } \\
\text { evacuadas de ella. La radiación se extendió a algunos } \\
\text { países de Europa. }\end{array}$ \\
\hline $\begin{array}{l}\text { Fukushima, Japón, } \\
2011^{(c)}\end{array}$ & 7 & $\begin{array}{l}\text { Desperfectos en un reactor tras un terremoto de grado } 8,9 \\
\text { en la escala de Richter y un tsumani. Fallas en el sistema } \\
\text { de refrigeración, posterior fusión parcial de los núcleos de } \\
\text { dos reactores. Emisiones de gases radioactivos y fugas de } \\
\text { agua contaminada al mar. Se estima que unas } 160 \\
\text { personas quedaron expuestas a la radiación y otras } \\
200,000 \text { fueron evacuadas en un radio de unos } 30 \mathrm{~km} \text {. }\end{array}$ \\
\hline
\end{tabular}

(a) WNA (2010), http://www.world-nuclear.org/info/inf36.html,

(b) WNA (2011), http://www.world-nuclear.org/info/chernobyl/inf07.html, 5/2011

(c) http://www.elpais.com/aarticulo/internacional/Fukushima/vive/peor/accidente/nuclear/Chernobil /elpepuint/20110312elpepuint_2/Tes, 5/2011.

La segunda columna en al cuadro anterior muestra el nivel de gravedad del accidente de acuerdo a la Escala Internacional de Eventos Nucleares (INES, por sus siglas en inglés). La categoría 7 corresponde a un 'accidente grave' y la categoría 5 a un 'accidente con consecuencias mayores' Dependiendo de su severidad, las consecuencias de un accidente nuclear incluyen la muerte inmediata o a corto plazo, la tendencia de las personas sometidas a elevadas dosis de radiación a desarrollar cáncer, la evacuación de grandes masas de población residente en las áreas afectadas para evitar su exposición a emisiones o efluentes radioactivos y la grave afectación del ambiente en las áreas que rodean al sitio del evento y cuya recuperación requiere esfuerzo y tiempo. 
A continuación se presenta la ficha resumen de un indicador que se basa en la percepción que sobre el riesgo del proyecto tiene el evaluador.

\begin{tabular}{|c|c|}
\hline \multicolumn{2}{|c|}{ DIMENSIÓN : RIESGO } \\
\hline \multicolumn{2}{|r|}{ ATRIBUTO/CRITERIO: C6.1. Riesgo ante eventos extremos } \\
\hline \multicolumn{2}{|r|}{ OBJETIVO ASOCIADO: MIN [Riesgo ente eventos extremos] } \\
\hline \multicolumn{2}{|r|}{ INDICADOR: Riesgo ante eventos extremos } \\
\hline \multicolumn{2}{|r|}{$\begin{array}{l}\text { DEFINICIÓN: Riesgo percibido en la instalación y operación de las futuras } \\
\text { instalaciones, en función de los potenciales daños a las personas, al ambiente } \\
\text { y a las propiedades que puedan producirse ante eventos severos. }\end{array}$} \\
\hline \multicolumn{2}{|r|}{$\begin{array}{l}\text { FUENTE DE INFORMACIÓN: Encuestas en la comunidad o en el grupo de } \\
\text { involucrados con el proyecto. }\end{array}$} \\
\hline \multicolumn{2}{|c|}{ UNIDADES: Apreciación cualitativa } \\
\hline \multicolumn{2}{|c|}{ ESCALA } \\
\hline 1 & $\begin{array}{l}\text { Localización en zona sísmica. Riesgo de exposición a dosis elevadas de } \\
\text { radiación, emisiones. efluentes y desechos radioactivos, ante eventos } \\
\text { severos. Posible desplazamiento de residentes en zona de exclusión. } \\
\text { Daño severo al ambiente e interrupción de actividades. Permanencia de } \\
\text { radioactividad en el tiempo. }\end{array}$ \\
\hline 2 & $\begin{array}{l}\text { Localización en zona sísmica o de lluvias intensas. Riesgo de inundaciones } \\
\text { mayores con pérdidas de vidas, daños severos al ambiente y pérdidas de } \\
\text { activos. Posible desplazamiento de residentes y cierre de actividades }\end{array}$ \\
\hline 3 & $\begin{array}{l}\text { Localización en zona sísmica. Riesgo de derrames, incendios, explosiones } \\
\text { con daños a personas, al ambiente y a las instalaciones. }\end{array}$ \\
\hline 4 & Riesgo moderado de daños a las personas, ambiente e instalaciones. \\
\hline 5 & Poco o ningún riesgo \\
\hline
\end{tabular}

El análisis de la información suministrada por las personas encuestadas al inicio de esta etapa del trabajo, llevó a la conclusión de que en la percepción de riesgo ante eventos extremos, cuenta mucho más la magnitud de los potenciales daños que su probabilidad de ocurrencia; especialmente cuando la población está sensibilizada ante una muy reciente catástrofe como la ocurrida en Japón. En base a ello, se configuró la escala [1-5] del indicador anterior donde las condiciones intermedias entre dos niveles de riesgo pueden calificarse con puntuaciones intermedias. 
C.6.2 Uso ilícito de material radioactivo. El enorme poder destructivo de un arma nuclear ha llevado a la comunidad internacional a tratar de frenar su proliferación. En tal sentido, un marco de leyes nacionales basadas en principios reflejados en acuerdos internacionales regulan prácticamente todos los aspectos del uso de la energía nuclear. Entre ellos, es de especial importancia el Tratado de

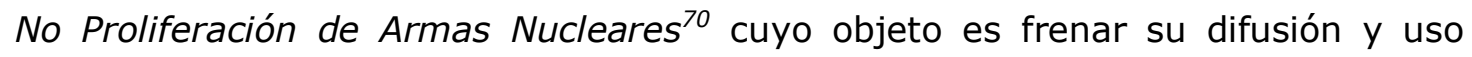
indiscriminado, asunto que es causa de gran preocupación entre los habitantes del planeta. Paralelamente, la Agencia Internacional de Energía Atómica ha producido una serie de medidas de salvaguarda que implican la declaración del material nuclear y la inspección acordada con los países para verificar el diseño de las instalaciones, su operación y el control de calidad del material producido [NEA, 2005].

Acuerdos regionales y medidas de seguridad nacional complementan en muchos casos la supervisión necesaria para prevenir el desvío de materiales y tecnologías nucleares. Tales medidas contemplan vigilancia de las instalaciones, códigos de acceso y acceso limitado a información sensible. Adicionalmente, los suplidores internacionales reconocidos de material, tecnología y equipos nucleares han incrementado las normas de seguridad en cuanto al transporte del material y a sus destinos finales. Más recientemente, se ha creado la preocupación adicional del desvío de material nuclear para la fabricación de bombas sucias por parte de organizaciones terroristas; esto es, bombas que utilizan explosivos convencionales para dispersar material radioactivo [NEA, 2005].

Es pues, responsabilidad de los gobiernos el establecimiento de una regulación y su estricto cumplimiento para colaborar con la no proliferación de armas nucleares en el mundo o el desvío de materiales nucleares con fines ilícitos. El riesgo que la población percibe en relación a la materia depende en mucho de la confianza que

El Tratado de No Proliferación de Armas Nucleares (1970) fue suscrito por 188 países y compromete a los países que poseían armas nucleares antes de su puesta en vigencia (China, Francia, Rusia, Reino Unido y los Estados Unidos) a no transferirlas ni ayudar a desarrollarlas a ningún país no-nuclear. India, Israel y Pakistán se negaron a firmar el Tratado \{NEA, 2005]. 
tengan en sus autoridades. A continuación, la ficha resumen de un indicador cuya escala de medición toma en cuenta lo anteriormente señalado.

\begin{tabular}{|c|c|}
\hline \multicolumn{2}{|c|}{ DIMENSIÓN : RIESGO } \\
\hline \multicolumn{2}{|r|}{ ATRIBUTO/CRITERIO: C6.2. Uso ilícito de material radioactivo } \\
\hline \multicolumn{2}{|r|}{ OBJETIVO ASOCIADO: MIN [Uso ilícito de material radioactivo] } \\
\hline \multicolumn{2}{|c|}{ INDICADOR: Uso ilícito de material radioactivo } \\
\hline \multicolumn{2}{|r|}{$\begin{array}{l}\text { DEFINICIÓN: Apreciación cualitativa sobre la posibilidad de que material } \\
\text { radioactivo a lo largo de la cadena energética propuesta sea desviado a usos } \\
\text { ilícitos, una vez que entre en operación el proyecto bajo estudio. }\end{array}$} \\
\hline \multicolumn{2}{|r|}{$\begin{array}{l}\text { FUENTE DE INFORMACIÓN: Elementos regulatorios, protocolares y de control } \\
\text { sobre el manejo de materiales radioactivos incluidos en el proyecto. Encuesta } \\
\text { entre la población involucrada. }\end{array}$} \\
\hline \multicolumn{2}{|c|}{ UNIDADES: Apreciación cualitativa } \\
\hline \multicolumn{2}{|c|}{ ESCALA } \\
\hline 1 & $\begin{array}{l}\text { Manejo y control del destino de material nuclear no sujeto a normativa y } \\
\text { protocolos internacionales. País sede políticamente conflictivo. }\end{array}$ \\
\hline 2 & $\begin{array}{l}\text { Manejo y control del destino de material nuclear de acuerdo a normativa } \\
\text { y protocolos internacionales. Poca confianza en regulación y controles del } \\
\text { país sede. }\end{array}$ \\
\hline 3 & $\begin{array}{l}\text { Manejo y control del destino de material nuclear de acuerdo a normativa } \\
\text { y protocolos internacionales. Mediana confianza en regulación y controles } \\
\text { del país sede. }\end{array}$ \\
\hline 4 & $\begin{array}{l}\text { Manejo y control del destino de material nuclear de acuerdo a normativa } \\
\text { y protocolos internacionales. Existencia de regulación y controles estrictos } \\
\text { en país sede. }\end{array}$ \\
\hline 5 & $\begin{array}{l}\text { Inexistencia de materiales radioactivos en la cadena de energia para el } \\
\text { proyecto. }\end{array}$ \\
\hline
\end{tabular}

En la próxima sección se presenta un resumen del sistema de indicadores propuesto en las páginas anteriores.

\subsubsection{Propuesta de indicadores para la evaluación}

Las tablas 4.10.1 que se presentan en las páginas siguientes, contienen un resumen del sistema de indicadores que se propone para la evaluación multicriterio de proyectos en el sector energético. Como ya se ha señalado, el sistema contempla 
seis dimensiones de evaluación, diecisiete indicadores principales y doce indicadores subalternos que se corresponden respectivamente con los criterios y subcriterios del modelo final de valor propuesto en la figura 4.5, sección 4.1.2.4. de este documento.

Tabla 4.10. Sistema de indicadores para la evaluación multicriterio de proyectos en el sector energético (1).

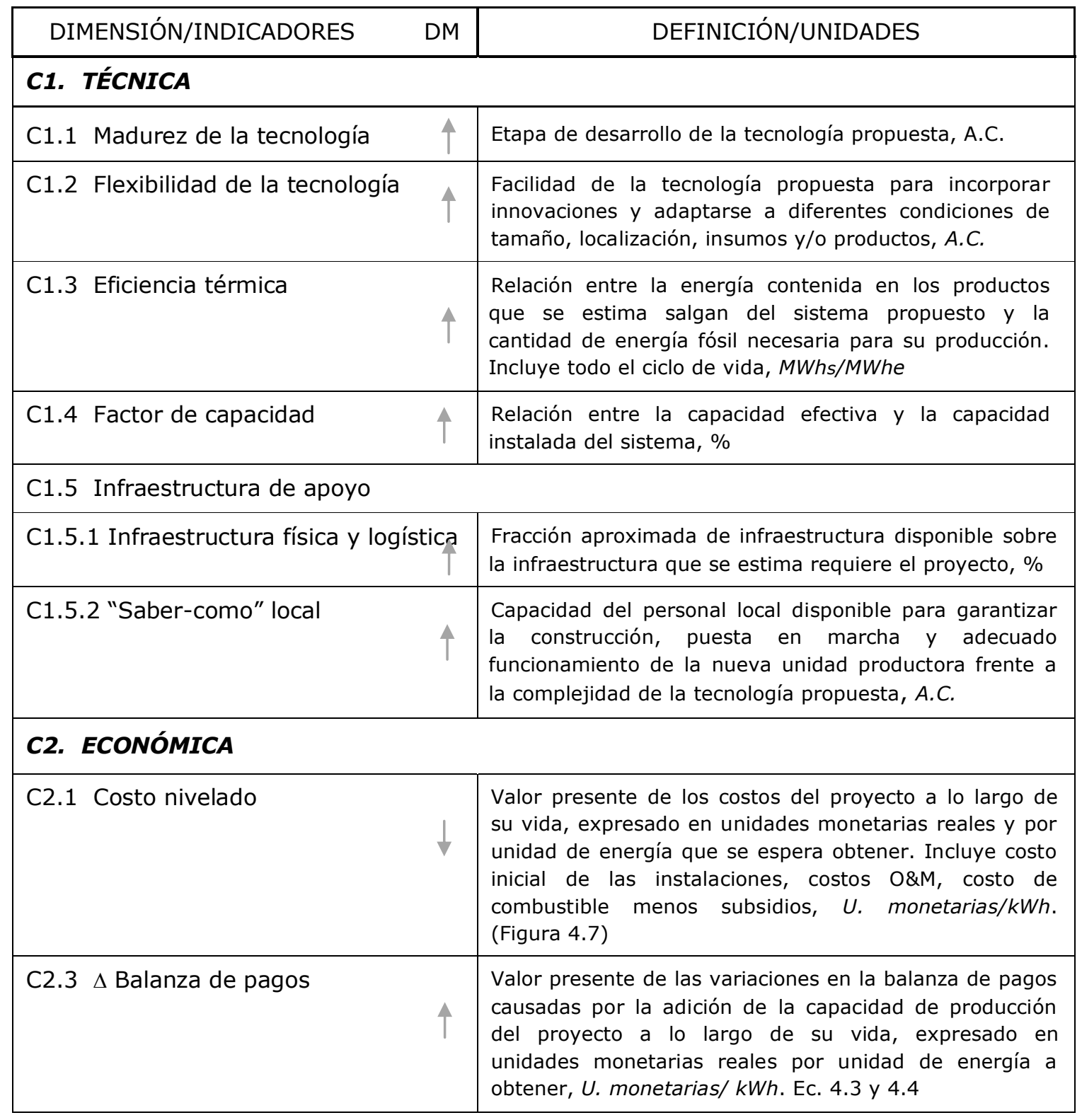

A.C., apreciación cualitativa 
Tabla 4.10. Sistema de indicadores para la evaluación multicriterio de proyectos en el sector energético (2).

\begin{tabular}{|c|c|c|}
\hline DIMENSIÓN/INDICADORES & DM & DEFINICIÓN/UNIDADES \\
\hline \multicolumn{2}{|l|}{ C3. AMBIENTAL } & UMBRAL : Normativa regulatoria \\
\hline \multicolumn{2}{|c|}{ C3.1 Emisiones de gases invernadero } & $\begin{array}{l}\text { Suma de las emisiones de gases de tipo invernadero, } \\
\text { expresadas en } \mathrm{CO} 2 \text { equivalente por unidad de energía a } \\
\text { obtener. Incluye } \mathrm{CO} 2, \mathrm{CH} 4 \text { y } \mathrm{N} 2 \mathrm{O} \text { para el ciclo de vida } \\
\text { del proyecto, mg } \mathrm{CO} 2 \text { eq./ } \mathrm{kWh}\end{array}$ \\
\hline \multicolumn{3}{|c|}{ C3.2 Otras emisiones no radioactivas } \\
\hline \multicolumn{2}{|c|}{ C3.2.1. Precursores de ozono } & $\begin{array}{l}\text { Suma de las emisiones de NMVOCs y NOx para el ciclo } \\
\text { de vida del proyecto, expresadas en NMVOC } \\
\text { equivalente por unidad de energía a obtener, } \\
\text { mg NMVOC equivalente/kWh }\end{array}$ \\
\hline \multicolumn{2}{|l|}{ C3.2.2. Emisiones ácidas } & $\begin{array}{l}\text { Suma de las emisiones de } \mathrm{SO} 2 \text { y NOx, para el ciclo de } \\
\text { vida del proyecto, expresadas en ácido equivalente, por } \\
\text { unidad de energía a obtener, mg acido-equivalente/kWh }\end{array}$ \\
\hline \multicolumn{2}{|l|}{ C3.2.3. Partículas } & $\begin{array}{l}\text { Emisiones de partículas con diámetro igual o menor a } \\
10 \mu \mathrm{m} \text { para el ciclo de vida del proyecto, por unidad de } \\
\text { energía a obtener, mg } P M 10 / \mathrm{kWh}\end{array}$ \\
\hline \multicolumn{3}{|l|}{ C3.3 Residuos peligrosos } \\
\hline \multicolumn{2}{|c|}{ C3.3.1. Residuos sólidos y líquidos } & $\begin{array}{l}\text { Apreciación cualitativa de los potenciales efectos que } \\
\text { sobre el ambiente y la salud de la comunidad se estima } \\
\text { tengan los residuos asociados a la cadena energética } \\
\text { bajo estudio, Los residuos pueden ser sólidos, } \\
\text { semisólidos, líquidos o contener material gaseoso. No } \\
\text { incluye los residuos radioactivos, A.C. }\end{array}$ \\
\hline \multicolumn{2}{|c|}{ C3.3.2. Residuos radioactivos } & $\begin{array}{l}\text { Apreciación cualitativa sobre el nivel de peligrosidad } \\
\text { que puede representar el transporte, almacenamiento } \\
\text { provisional y disposición final de los residuos } \\
\text { radioactivos que se estima se generen en todas las } \\
\text { operaciones del ciclo de vida del proyecto bajo estudio. } \\
\text { Incluye residuos de bajo, intermedio y alto nivel } \\
\text { radioactivo (LLW, ILW y HLW), A.C. }\end{array}$ \\
\hline \multicolumn{2}{|l|}{ C3.4 Uso de la tierra } & $\begin{array}{l}\text { Apreciación cualitativa que combina los efectos sobre la } \\
\text { biodiversidad, la afectación del paisaje y el nivel de } \\
\text { ruido que se estima tendrá la construcción y operación } \\
\text { de las instalaciones del proyecto, en función de la } \\
\text { extensión de tierra ocupada y la intensidad de su uso, } \\
\text { A.C. }\end{array}$ \\
\hline \multicolumn{3}{|l|}{ C4. SOCIAL } \\
\hline \multicolumn{2}{|c|}{ C4.1 Aceptación de la comunidad } & $\begin{array}{l}\text { Nivel de aceptación que sobre la instalación y } \\
\text { funcionamiento del proyecto tiene la comunidad sede } \\
\text { del proyecto, A.C. }\end{array}$ \\
\hline
\end{tabular}


Tabla 4.10. Sistema de indicadores para la evaluación multicriterio de proyectos en el sector energético (3).

\begin{tabular}{|c|c|c|}
\hline DIMENSIÓN/INDICADORES & $\mathrm{DM}$ & DEFINICIÓN/UNIDADES \\
\hline \multicolumn{3}{|l|}{ C4. SOCIAL } \\
\hline \multicolumn{3}{|l|}{ C4.2 Calidad de vida } \\
\hline C4.2.1 Creación de empleo local & $\uparrow$ & $\begin{array}{l}\text { Número de empleos locales que se estima generen las } \\
\text { actividades relacionadas con la construcción, operación, } \\
\text { mantenimiento y desmantelamiento de las nuevas } \\
\text { unidades de producción, distribuido en la vida del } \\
\text { proyecto, por cada unidad de energía a obtener, número } \\
\text { de empleos/MWh. }\end{array}$ \\
\hline C4.2.2 $\Delta$ Salarios & $\uparrow$ & $\begin{array}{l}\text { Valor presente del costo de mano de obra a lo largo de } \\
\text { la vida del proyecto expresado en unidades monetarias } \\
\text { reales y por unidad de energía a obtener, Unidades } \\
\text { monetarias/MWh }\end{array}$ \\
\hline C4.2.3 $\Delta$ Déficit de energía & $\uparrow$ & $\begin{array}{l}\text { Fracción del déficit de energía local (regional) que se } \\
\text { estima puede suplir el proyecto, } \%\end{array}$ \\
\hline \multicolumn{3}{|l|}{ C5. ESTRATÉGICA } \\
\hline \multicolumn{3}{|l|}{ C5.1 $\Delta$ Seguridad energética } \\
\hline $\begin{array}{l}\text { C5.1.1 Índice de diversidad de la } \\
\text { cesta energética. }\end{array}$ & $\downarrow$ & $\begin{array}{l}\text { Índice de diversidad de la cesta energética del país } \\
\text { sede, después de la puesta en funcionamiento del } \\
\text { proyecto, adimensional }\end{array}$ \\
\hline C5.1.2 Seguridad de suministro & $\uparrow$ & $\begin{array}{l}\text { Relación entre el componente nacional y el componente } \\
\text { importado del suministro energético requerido por el } \\
\text { proceso bajo estudio, A.C. }\end{array}$ \\
\hline C5.2 Compatibilidad con planes- $n$ & ación & $\begin{array}{l}\text { Compatibilidad del proyecto bajo estudio con los planes } \\
\text { de desarrollo de la localidad, región o país sede del } \\
\text { proyecto, A.C. }\end{array}$ \\
\hline \multicolumn{3}{|l|}{ C6. RIESGO } \\
\hline \multicolumn{2}{|c|}{ C6.2 Riesgo ante eventos extremos $\downarrow$} & $\begin{array}{l}\text { Riesgo percibido en puesta en marcha del proyecto, por } \\
\text { potenciales daños ante eventos severos, A.C. }\end{array}$ \\
\hline C6.3 Uso ilícito de material radioa & $\stackrel{\operatorname{ctivo}}{\downarrow}$ & $\begin{array}{l}\text { Apreciación cualitativa sobre la posibilidad de que } \\
\text { material radioactivo sea desviado a usos ilícitos, a lo } \\
\text { largo de la cadena energética bajo estudio, A.C }\end{array}$ \\
\hline
\end{tabular}

A.C., apreciación cualitativa

El cuadro anterior incluye la definición de cada indicador sugerido, su unidad original de medida y su dirección de mejora (DM). Los índices definidos son de naturaleza cuantitativa o cualitativa; en ambos casos, el valor de cada indicador se ubica o se convierte a una escala [1-5] donde el 1 corresponde a la peor calificación 
y el 5 a la calificación máxima. En el caso de que el indicador sea cualitativo, cada paso en la escala corresponde a la condición señalada a su lado en la respectiva ficha resumen. Si el indicador es cuantitativo, su valor en las unidades de medida originales, se convierte a la escala [1-5] utilizando una transformación lineal entre los valores mínimo y máximo que puede tomar el indicador de acuerdo a como se indica en la respectiva ficha resumen.

Las pequeñas flechas en la primera columna del cuadro anterior, muestran la dirección de mejora del atributo; así una flecha dirigida hacia arriba significa que el efecto sobre la valoración del proyecto bajo estudio será tanto mejor en cuanto sea más elevado sea su valor y en consecuencia el nivel 5 de la escala corresponderá al valor máximo que pueda tomar el indicador. Este es el caso típico de los indicadores que miden ventajas o beneficios del proyecto. Por el contrario, si la flecha se dirige hacia abajo, su efecto sobre la valoración de la propuesta bajo estudio será tanto mejor en cuanto sea más pequeño sea su valor y en consecuencia el nivel 5 de la escala corresponderá al valor mínimo que pueda tomar el indicador. Este es el caso típico de los indicadores que miden desventajas o costos del proyecto.

Las características y la potencial disponibilidad de la información necesaria para la evaluación fueron factores importantes en la definición de los indicadores y en la simplificación de la estructura jerárquica de criterios presentada en la figura 4.5. Como ya se ha señalado, para la definición de cada indicador se siguió un proceso iterativo que permitió ajustar el indicador al criterio o redefinir el criterio en función de la información disponible para la estimación del indicador. Como resultado se obtuvo un modelo jerárquico simplificado, sin perder contenido ni calidad, no redundante y sencillo en su aplicación.

El nuevo modelo debió ser validado por expertos y asignadas las importancias relativas de los criterios de evaluación en él incluidos. La próxima sección trata esta materia.

\subsubsection{Validación final y asignación de pesos a los criterios}

La validación de los criterios de evaluación en el modelo jerárquico diseñado y la asignación de sus respectivas importancias relativas, es un proceso donde deben 
participar no sólo los analistas y expertos sino los representantes de las comunidades afectadas por la ejecución del mismo. La conservación de todos los criterios en el modelo depende de las diferencias entre las opciones energéticas que se comparen, de las características del país sede del proyecto; y en última instancia, de las preferencias que al respecto tengan los individuos participantes en el análisis. Por su parte, el peso relativo de los criterios del modelo dependerá de los juicios de valor que sobre la importancia de uno u otro criterio en comparaciones por pares, sean emitidos por la muestra consultada.

Habiendo señalado lo anterior, esta sección describe el procedimiento para la validación final y obtención de la importancia relativa de cada criterio en el modelo jerárquico de evaluación propuesto, tomando como base las opiniones de una muestra de expertos, profesionales y estudiantes. relacionados con el área de la energía y/o materias afines. El proceso completo contempló los siguientes pasos:

- Diseño de la muestra a entrevistar

- Levantamiento de la información

- Procesamiento de la información obtenida

- Propuesta final del modelo multicriterio de valor para la evaluación

A continuación un resumen de las tareas realizadas.

\subsection{Diseño de la muestra a entrevistar}

Para cumplir con los objetivos enunciados; esto es, la validación del modelo final de valor y la asignación de los pesos de los criterios en él incluidos, se efectuó una segunda ronda de entrevistas. El levantamiento de la nueva información se realizó por comunicación directa, personal o en grupos de opinión; o a través de Internet.

La tabla 4.11 muestra la configuración de la muestra de expertos entrevistada, conformada casi en su totalidad, por personas no consultadas en la primera ronda de entrevistas. En esta oportunidad, se consideró conveniente tomar opinión de académicos, de profesionales en el sector público y privado, y de estudiantes cursando el último año de Ingeniería. El área de experticia de los integrantes de cada 
grupo, la forma de recoger la información en cada caso y la participación de cada grupo en la muestra total se detallan en la misma tabla.

Tabla 4.11. Distribución de la muestra de expertos para validación del modelo final y asignación de los pesos a los criterios de evaluación.

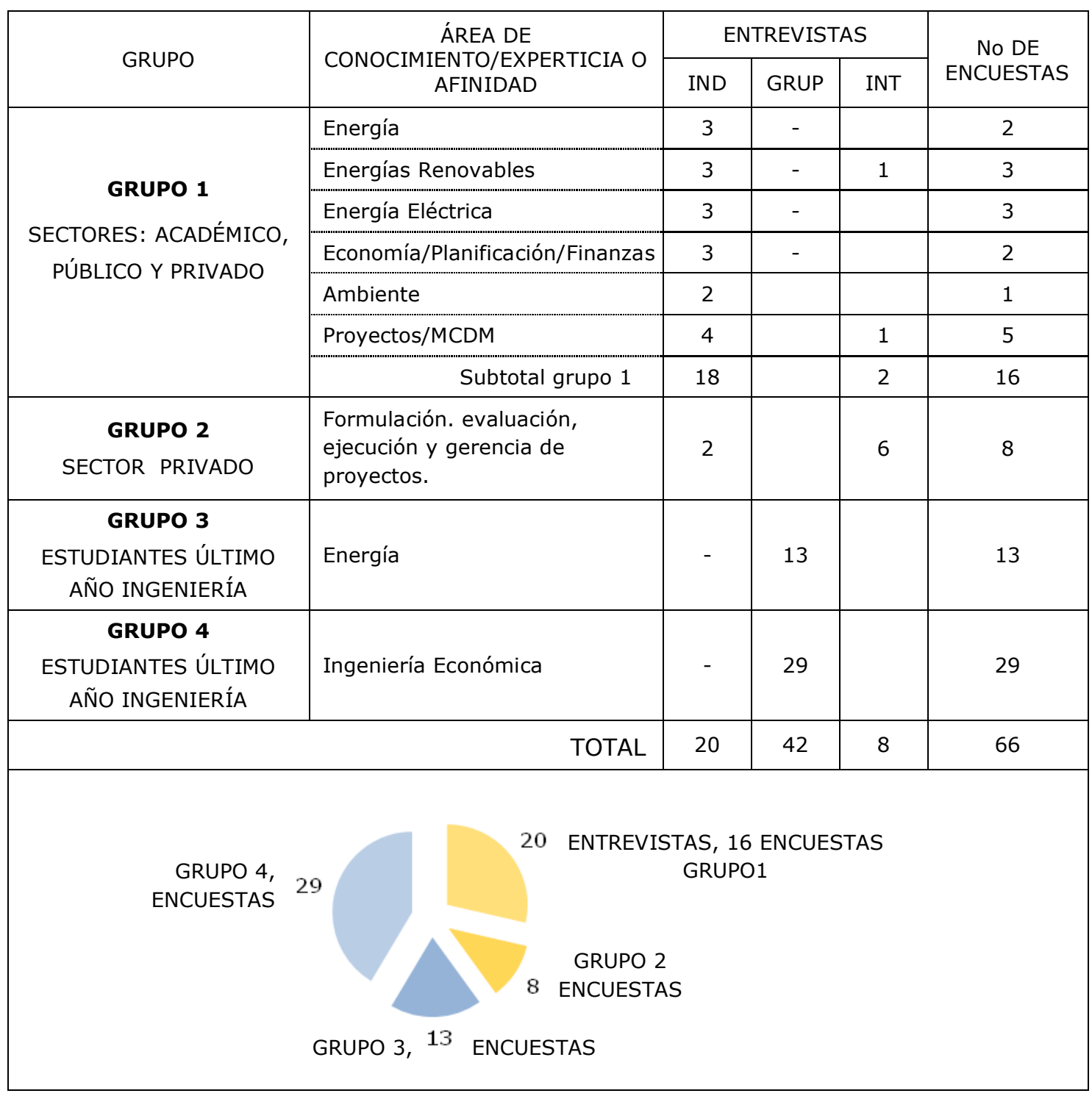

Como puede observarse, la muestra de personas a entrevistar se dividió en :

- Grupo 1. Conformado por profesionales cuidadosamente seleccionados, de amplia trayectoria profesional y/o académica en el país, con experiencia laboral en el sector público y/o privado, expertos en una o más de una de las siguientes áreas: 
energía, energías renovables, generación y distribución de energía eléctrica, economía, finanzas, planificación y políticas públicas, ambiente, proyectos y métodos de análisis multicriterio.

- Grupo 2. Conformado por profesionales con estudios de postgrado, trabajando en el sector privado nacional o internacional, actualizados tecnológicamente, con experiencia laboral que oscila entre 7 y 12 años, expertos o afines en el área de formulación, evaluación, control de ejecución, procura y/o gerencia de proyectos en sus respectivas áreas de desempeño.

- Grupos 3 y 4 . Dos grupos de estudiantes del último año de Ingeniería en la Universidad Metropolitana, Caracas, Venezuela respectivamente relacionados con las áreas de energía y evaluación de proyectos.

Las opiniones recogidas en los grupos 1 y 2 fueron particularmente importantes para la validación del modelo final de valor propuesto. La información recabada en todos los grupos fue utilizada para la asignación de las importancias relativas de los criterios incluidos en el modelo. Todos los grupos aportaron su sentido crítico.

\subsection{Levantamiento de la información}

La recolección de la información necesaria para cumplir con los objetivos enunciados se realizó con ayuda de un instrumento especialmente diseñado a los efectos. A cada persona y grupo de opinión directamente consultado, se explicó detalladamente el alcance y estructuración del modelo de valor; y paralelamente a la entrega de material escrito con breves definiciones de cada uno de los criterios de evaluación incluidos, se contestaron preguntas y aclararon dudas sobre su significado, características de medición, escala y justificación.

\subsubsection{6.}

Las tablas 4.12 y 4.13 presentan la composición y la descripción de los integrantes de los grupos 1 y 2 de entrevistados para validar el modelo final. La consulta fue realizada en Caracas, Venezuela (2011) a profesionales venezolanos y extranjeros, radicados dentro o fuera del país. 
Tabla 4.12. Composición del Grupo 1. Sectores público, privado y académico.

\begin{tabular}{|c|c|}
\hline $\begin{array}{c}\text { POSICIÓN DEL ENTREVISTADO EN SECTOR } \\
\text { ENERGÍA Y AFINES }\end{array}$ & SECTOR/ÁREA \\
\hline $\begin{array}{l}\text { Ex Presidente de Petroquímica de Venezuela } \\
\text { Ex Miembro del Directorio de Petróleos de Venezuela } \\
\text { Asesor internacional en materia energética }\end{array}$ & $\begin{array}{l}\text { PÚBLICO/PRIVADO } \\
\text { Energía }\end{array}$ \\
\hline $\begin{array}{l}\text { Ex Rector, Universidad Simón Bolívar, Venezuela } \\
\text { Ex Vice Rector Académico, Universidad Metropolitana } \\
\text { Director de la Oficina de Iniciativas Emprendedoras, } \\
\text { Universidad Metropolitana, Venezuela. }\end{array}$ & $\begin{array}{l}\text { ACADÉMICO } \\
\text { Proyectos de Innovación }\end{array}$ \\
\hline $\begin{array}{l}\text { Ex Rector, Universidad Simón Bolívar, Venezuela } \\
\text { Ex Vice Rector Académico, Universidad Metropolitana } \\
\text { Rector de la Universidad Metropolitana }\end{array}$ & $\begin{array}{l}\text { ACADÉMICO Energías } \\
\text { Renovables }\end{array}$ \\
\hline $\begin{array}{l}\text { Ex Miembro Consejo Nacional de Economía, Venezuela } \\
\text { Director de Estudios de Posgrado en Economía y Estudios } \\
\text { Sociales, UNIMET, Venezuela. }\end{array}$ & $\begin{array}{l}\text { PÚBLICO/ACADÉMICO } \\
\text { Economía/Planificación }\end{array}$ \\
\hline $\begin{array}{l}\text { Ex Miembro Permanente del Directorio del Fondo de } \\
\text { Inversiones de Venezuela } \\
\text { Ex Miembro del Directorio de la Corporación Andina de } \\
\text { Fomento } \\
\text { Asesor en materia económica (sector privado) }\end{array}$ & $\begin{array}{l}\text { PÚBLICO/PRIVADO } \\
\text { Economía/Planificación } \\
\text { Proyectos }\end{array}$ \\
\hline $\begin{array}{l}\text { Ex Vicepresidente Banco Hipotecario Falcón, Venezuela } \\
\text { Ex Presidente del Banco Hipotecario de la Vivienda, } \\
\text { Venezuela. } \\
\text { Asesor en materia financiera (sector privado). }\end{array}$ & $\begin{array}{l}\text { PRIVADO } \\
\text { Economía/Finanzas }\end{array}$ \\
\hline $\begin{array}{l}\text { Ex Vicepresidente del Instituto Nacional de Obras } \\
\text { Sanitarias, MARNR } \\
\text { Ex Director de la Oficina del Inventario Nacional del } \\
\text { Potencial Hidroeléctrico, MARNR }\end{array}$ & $\begin{array}{l}\text { ACADÉMICO/PRIVADO } \\
\text { Planificación/Proyectos } \\
\text { hidroeléctricos. }\end{array}$ \\
\hline $\begin{array}{l}\text { Director Nacional de Proyectos, Ministerio para la } \\
\text { Energía Eléctrica, MPPEE, Venezuela }\end{array}$ & $\begin{array}{l}\text { PÚBLICO/ACADÉMICO } \\
\text { Energía Eléctrica/ MCDM }\end{array}$ \\
\hline $\begin{array}{l}\text { Coordinador del Dpto. de Uso Eficiente de la Energía, } \\
\text { CORPOELEC, Venezuela }\end{array}$ & $\begin{array}{l}\text { PÚBLICO } \\
\text { Ambiente }\end{array}$ \\
\hline $\begin{array}{l}\text { Jefe del Dpto. de Ambiente, Universidad Metropolitana } \\
\text { Presidente de VITALIS, Organización No Gubernamental } \\
\text { en el área ambiental, Venezuela. }\end{array}$ & $\begin{array}{l}\text { ACADÉMICO/PRIVADO } \\
\text { Ambiente }\end{array}$ \\
\hline $\begin{array}{l}\text { Director del Instituto de Energía, Universidad Simón } \\
\text { Bolívar, Venezuela }\end{array}$ & $\begin{array}{l}\text { ACADÉMICO } \\
\text { Energía }\end{array}$ \\
\hline $\begin{array}{l}\text { Jefe del Instituto de Recursos Naturales Renovables, } \\
\text { Universidad Simón Bolívar, Venezuela }\end{array}$ & $\begin{array}{l}\text { ACADÉMICO } \\
\text { Recursos Renovables }\end{array}$ \\
\hline $\begin{array}{l}\text { Profesores UNIMET Y USB en Caracas, Venezuela (7) y } \\
\text { UPV, en Valencia, España (1). }\end{array}$ & $\begin{array}{l}\text { ACADÉMICO } \\
\text { Proyectos/MCDM } \\
\text { Energía, Ambiente }\end{array}$ \\
\hline
\end{tabular}


A cada entrevistado, en los grupos 1 y 2 , se le solicitó opinión sobre la calidad del modelo. Juicios sobre su relevancia, alcance, no redundancia, simplicidad de uso y/o posibilidad de medición objetiva o subjetiva de los criterios/indicadores en él incluidos, fueron expresados por los entrevistados y registrados en las encuestas. En general, las opiniones fueron favorables; sin embargo hubo observaciones sobre la nomenclatura de algunos de los criterios ambientales, por parte de dos expertos en el área. Luego de la revisión bibliográfica respectiva, las sugerencias fueron incorporadas. A continuación, la composición del grupo 2 de entrevistados. Las encuestas fueron llenadas a título personal.

Tabla 4.13. Composición del Grupo 2. Sector privado

\begin{tabular}{|l|l|l|}
\hline \multicolumn{1}{|c|}{ GRUPO } & \multicolumn{1}{|c|}{ EMPRESA } & \multicolumn{1}{c|}{ ÁREA } \\
\hline Ingenieros mecánicos & $\begin{array}{l}\text { Procter \& Gamble, U.S.A. } \\
\text { Technix Machinery, U.S.A. }\end{array}$ & $\begin{array}{l}\text { Gerencia de proyectos } \\
\text { Gerencia de proyectos }\end{array}$ \\
\hline \multirow{3}{*}{ Ingenieros químicos } & $\begin{array}{l}\text { Procter \& Gamble, Panamá } \\
\text { Procter \& Gamble, Bélgica } \\
\text { Procter \$ Gamble, Bélgica } \\
\text { Empresas Polar, Venezuela }\end{array}$ & $\begin{array}{l}\text { Proyectos/MCDM } \\
\text { Proyectos } \\
\text { Proyectos }\end{array}$ \\
\hline \multirow{2}{*}{ Ingenieros de sistemas } & $\begin{array}{l}\text { CANTV, Venezuela } \\
\text { Procter \& Gamble, Panamá }\end{array}$ & $\begin{array}{l}\text { Gerencia de proyectos } \\
\text { Soporte informático a proyectos }\end{array}$ \\
\hline
\end{tabular}

En esta segunda ronda de entrevistas se realizaron 70 entrevistas y 66 encuestas fueron llenadas y devueltas; entre ellas, 16 correspondieron al grupo 1, 8 al grupo 2, 13 al grupo 3 y 29 al grupo 4.

\subsection{Información para la estimación de los pesos de los criterios}

A cada entrevistado de los grupos $1,2,3$ y 4 se le solicitó opinión sobre la importancia relativa de los criterios de evaluación en el modelo. La información fue registrada en una encuesta estructurada como un grupo de matrices de juicios de valor. A cada grupo de criterios o subcriterios en los niveles 1,2 y 3 del modelo propuesto correspondió una matriz para el registro de los resultados de la comparación por pares de los criterios del grupo. La figura 4.10 que se presenta en la próxima página, muestra tres matrices tipo correspondientes respectivamente a grupos seleccionados de criterios en el nivel 1, 2 y 3 . Los criterios en cada grupo 
encabezan las filas (con sus nombres y códigos) y las columnas de la matriz (con sus códigos). La encuesta completa se presenta en el anexo 2 de este documento.

En las celdas en blanco sobre la diagonal de cada matriz, se colocan las respuestas, $\mathrm{Cij}$, a la pregunta: ¿Con relación al criterio inmediatamente superior, cuanto más importante es el criterio i que el criterio j? La respuesta se expresa en la escala de Saaty incluida en la sección 1.1.5.1, Capítulo 1, de este documento; y se copia en la celda de la matriz que corresponde a la fila i y a la columna j. Si el criterio i es más importante que el criterio $j$, la respuesta es un número $n>1$. Si el criterio $\mathrm{j}$ es más importante que el criterio i, la respuesta es $1 / \mathrm{n}$. Si ambos criterios son igualmente importantes, la respuesta es 1 .

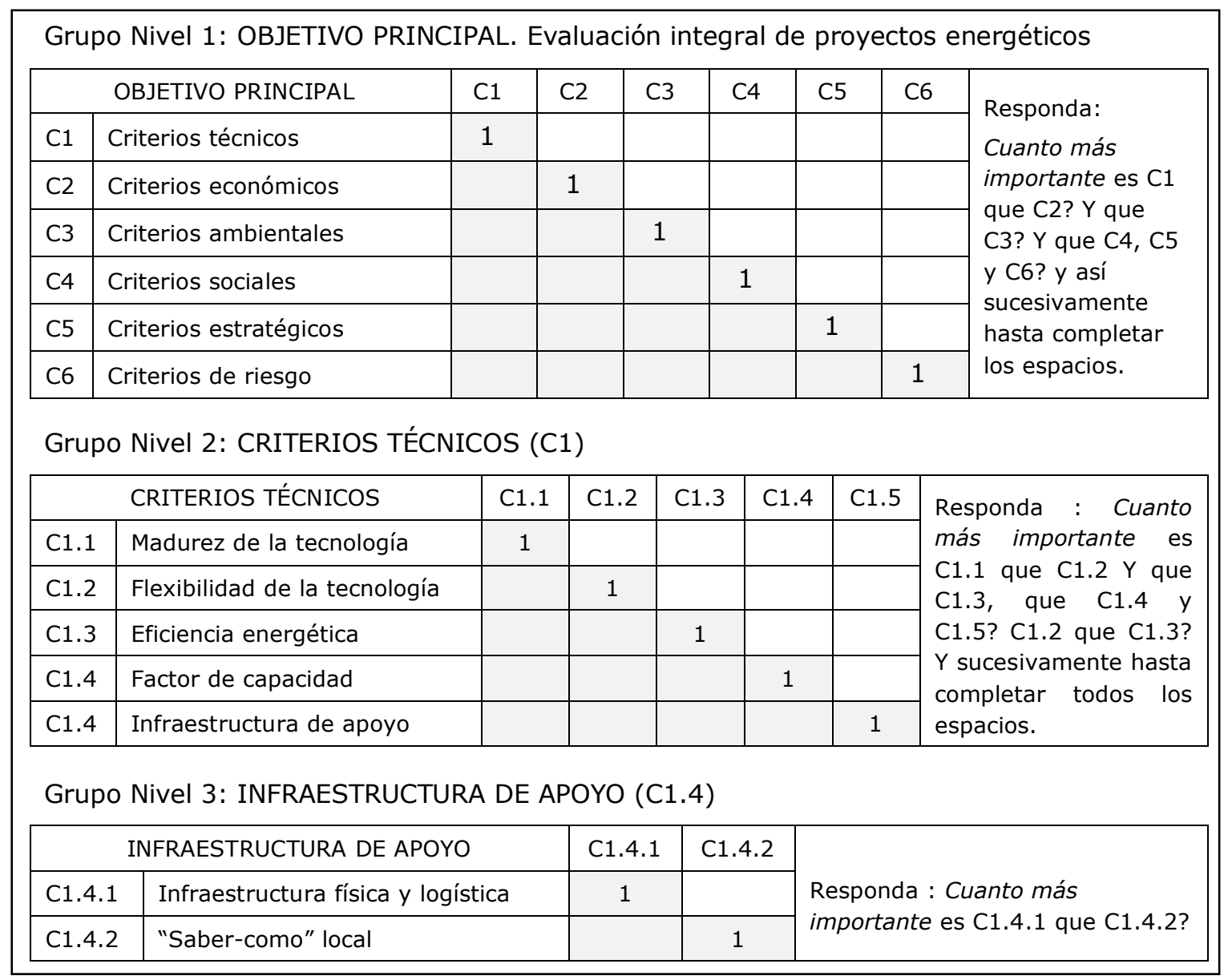

Figura 4.10. Matrices de juicios para levantamiento de la información 


\subsection{Procesamiento de la información y resultados}

La información recogida fue revisada, clasificada por tipo de encuestados e introducida a la aplicación informática Expert Choice ${ }^{\circledR}$ que como ya ha sido señalado, facilita el procesamiento de los juicios de valor aportados por múltiples actores; consolida los resultados individuales, calcula las relaciones de consistencia individuales y del grupo; y finalmente, proporciona los pesos de los criterios.

La información fue procesada por grupos; y para toda la muestra. Los coeficientes de consistencia individuales y para cada uno de los grupos conformados, fueron constantemente supervisados. La figura 4.11 muestra la pantalla suministradas por el Expert Choice ${ }^{\circledR}$ cuando se consolidan las opiniones de todos los entrevistados. Pantallas similares que muestran resultados consolidados por cada grupo, se incluyen en el anexo 2 al final del documento.

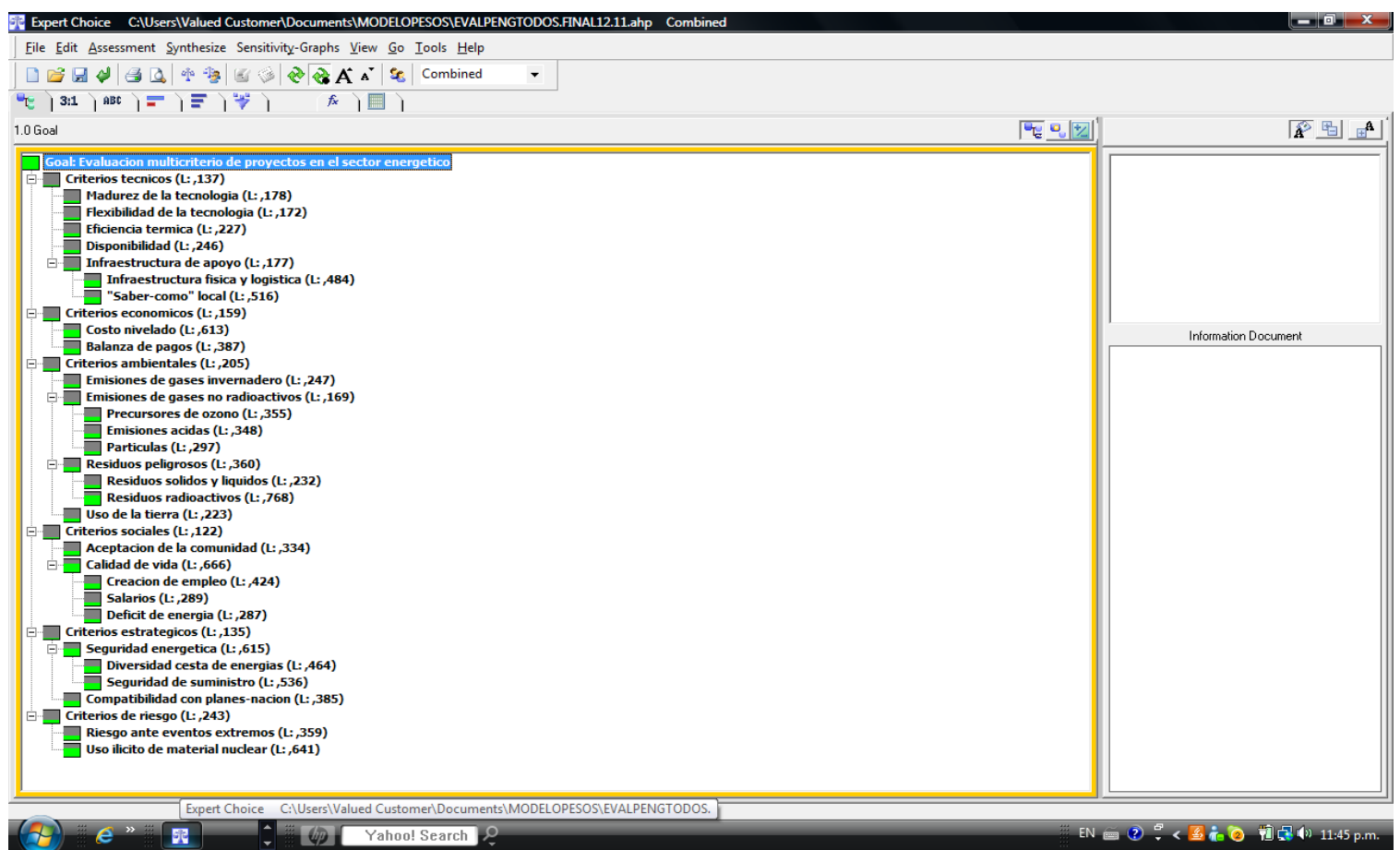

Figura 4.11. Modelo de valor para la evaluación de proyectos en el sector energético Grupos 1, 2, 3 y 4.

La figura 4.12 que se incluye a continuación, lista los pesos locales y los pesos globales de los criterios en la estructura jerárquica mostrada en la figura anterior. 


\begin{tabular}{|c|c|c|c|c|c|}
\hline IMPORTANCIA RELATIVA & LOCAL & GLOBAL & & \begin{tabular}{|l|l} 
LOCAL \\
\end{tabular} & GLOBAL \\
\hline CRITERIOS TÉCNICOS & 0,137 & 0,137 & & & \\
\hline Madurez & 0,178 & 0,024 & & & \\
\hline Flexibilidad & 0,172 & 0,024 & & & \\
\hline Eficiencia térmica & 0,227 & 0,031 & & & \\
\hline Disponibilidad & 0,246 & 0,034 & Física y logística & 0,484 & 0,012 \\
\hline Infraestructura & 0,177 & 0,024 & Saber-como & 0,516 & 0,013 \\
\hline CRITERIOS ECONÓMICOS & 0,159 & 0,159 & & & \\
\hline Costo nivelado & 0,613 & 0,097 & & & \\
\hline Balanza de pagos & 0,387 & 0,062 & & & \\
\hline CRITERIOS AMBIENTALES & 0,205 & 0,205 & & & \\
\hline Gases invernadero & 0,247 & 0,051 & Precursores ozono & 0,355 & 0,012 \\
\hline Otros gases no radioactivos & 0,169 & 0,035 & Emisiones ácidas & 0,348 & 0,012 \\
\hline & & & Partículas & 0,297 & 0,010 \\
\hline Residuos peligrosos & 0,360 & 0,074 & R. sólidos y líquidos & 0,232 & 0,017 \\
\hline Uso de la tierra & 0,223 & 0,046 & R. radioactivos & 0,768 & 0,057 \\
\hline CRITERIOS SOCIALES & 0,122 & 0,122 & & & \\
\hline Aceptación comunidad & 0,334 & 0,041 & Creación de empleo & 0,424 & 0,034 \\
\hline Calidad de vida & 0,666 & 0,081 & $\Delta$ Salarios & 0,289 & 0,024 \\
\hline & & & $\Delta$ Déficit energía & 0,287 & 0,023 \\
\hline CRITERIOS ESTRATÉGICOS & 0,135 & 0,135 & & & \\
\hline Seguridad energética & 0,615 & 0,083 & Diversidad energética & 0,464 & 0,039 \\
\hline Compatibilidad planes-país & 0,385 & 0,052 & Seguridad suministro & 0,536 & 0,044 \\
\hline CRITERIOS DE RIESGO & 0,243 & 0,243 & & & \\
\hline Eventos extremos & 0,359 & 0,087 & & & \\
\hline Uso material radioactivo & 0,641 & 0,156 & & & \\
\hline
\end{tabular}

Figura 4.12. Modelo de valor. Importancia relativa de los criterios, [G1+G2+G3+G4]

El cuadro anterior presenta los resultados de la consolidación de los juicios emitidos por la totalidad del grupo de expertos encuestados. Para cada criterio, el 
cuadro anterior reseña (i) su peso local; esto es, con relación al indicador en el nivel inmediatamente anterior y (ii) su peso global dentro de la jerarquía completa de criterios. El cuadro que sigue resume los resultados obtenidos cuando las opiniones obtenidas se consolidan como se indica en los respectivos encabezamientos.

Tabla 4.14. Pesos globales de los criterios de evaluación en el modelo propuesto

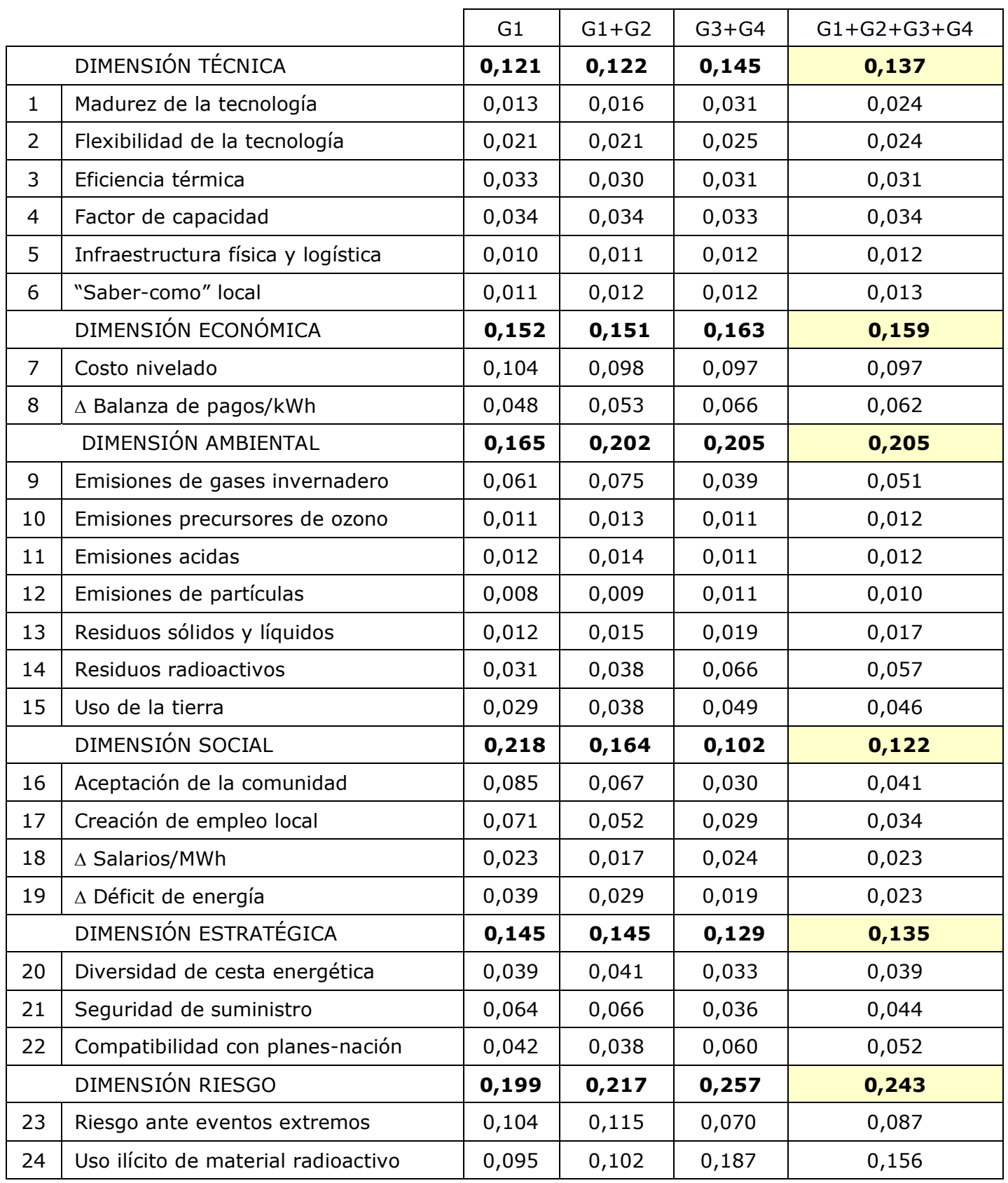




\subsubsection{Análisis de sensibilidad y propuesta final}

En un intento por visualizar mejor la dispersión de los resultados, la figura 4.13 presenta los pesos globales obtenidos por indicador y grupo de entrevistados. Para su análisis, se consideró conveniente comparar los siguientes grupos:

(i) Grupo [G1+G2], profesionales y académicos, en el sector público y privado, nacional o internacional.

(ii) Grupo [G3+G4], estudiantes cursando el último año de Ingeniería en la Universidad Metropolitana, Venezuela.

(iii) Grupo [G1+G2+G3+G4], la totalidad de los entrevistados.

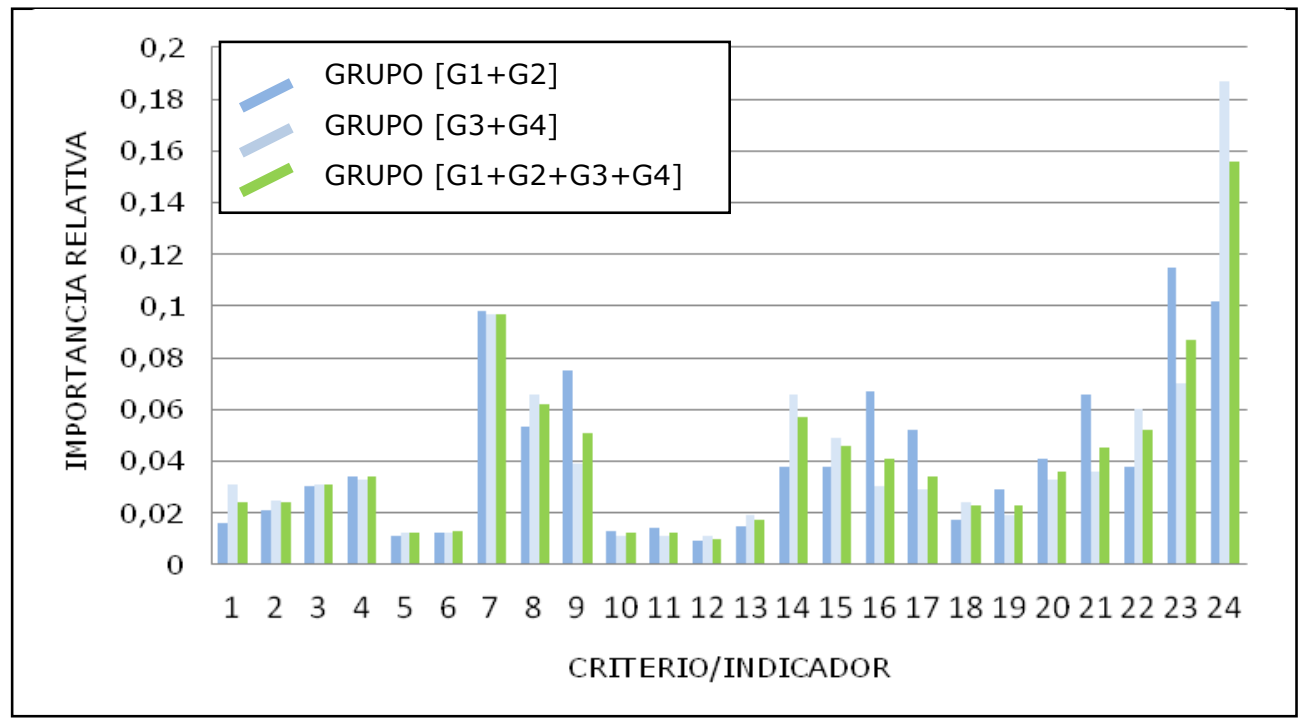

Figura 4.13. Pesos globales de los criterioss propuestos, por grupos

Como puede observarse, la diferencia entre los pesos globales respectivamente estimados en base a la consolidación de las opiniones de los grupos [G1+G2] y [G3+G4] es notoria ( $\triangle \mathrm{PG}>4 \%$ de su contribución en el total) sólo en el caso de los criterios de riesgo ( 23 y 24 ). La situación completa se detalla en el cuadro que sigue.

Tabla 15. Dispersión de los resultados entre grupos de entrevistados

\begin{tabular}{|c|c|c|c|c|}
\hline$\Delta \mathrm{PG} \leq 1 \%$ & $1 \%<\Delta \mathrm{PG} \leq 2 \%$ & $2 \%<\Delta \mathrm{PG} \leq 3 \%$ & $3 \%<\Delta \mathrm{PG}<4 \%$ & $\Delta \mathrm{PG} \geq 4 \%$ \\
\hline 13 criterios & 4 criterios & 3 criterios & 2 criterios & 2 criterios \\
\hline
\end{tabular}


La apreciación para las estimaciones de los pesos globales de los criterios a nivel de dimensión es similar, tal como refleja la figura 4.14 que se incluye a continuación.

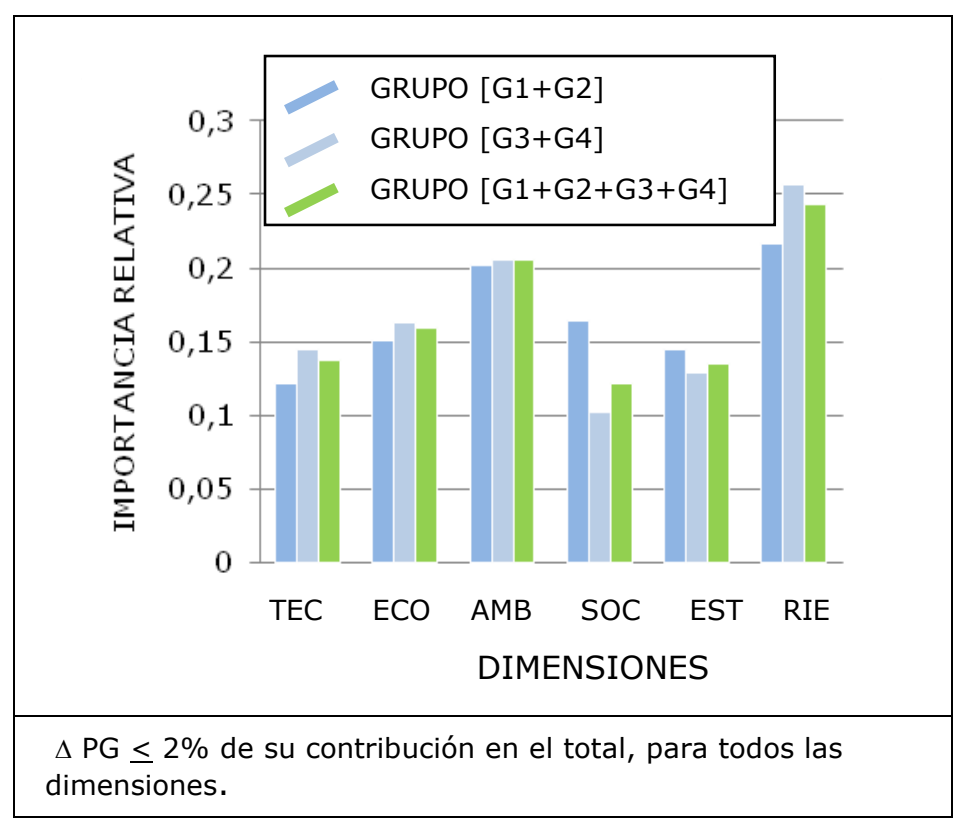

Figura 4.14. Dispersión de los pesos globales de los criterios de evaluación, nivel 1.

En vista de la poca diferencia entre los pesos globales producto de diversos agrupamientos de la información disponible, se propone como modelo de valor para la evaluación multicriterio de proyectos en el sector energético, el resultante de la consolidación de las opiniones de todos los entrevistados. La estructura jerárquica de criterios y sus respectivos pesos están reflejados en las figuras 4.11 y 4.12 incluidas en la sección anterior de este documento.

En el modelo propuesto, la mayor importancia corresponde a la dimensión riesgo $(24,3 \%)$ lo que refleja la preocupación que existe por la gravedad de los daños que una potencial falla en las instalaciones podría causar a los trabajadores, a la población aledaña y al ambiente, especialmente si ellas manejan material radioactivo. Las dimensiones ambiental $(20,5 \%)$ y económica $(15,3 \%)$ la siguen en importancia; resultado si se quiere esperado dado; por una parte, la relevancia que ha adquirido la protección ambiental y el tema del calentamiento global en el mundo; y por la otra, la preferencia que siempre ha tenido la rentabilidad económica como elemento en el cual basar la decisión sobre invertir o no, en un determinado 
proyecto. Finalmente se ubican las dimensiones técnica, estratégica y social con importancias que oscilan entre un 12,2\% para los aspectos sociales y un $13,7 \%$ para los aspectos técnicos.

En el segundo nivel de la jerarquía de criterios destacan en importancia los criterios de riesgo, el costo nivelado, el manejo de residuos peligrosos y la emisión de gases invernadero, la calidad de vida y la seguridad energética.

Los pesos globales obtenidos son producto de las opiniones que sobre cada materia expresaron una selección de expertos de experiencia variable, opiniones emitidas en las circunstancias presentes que vive Venezuela y el mundo. En consecuencia, su potencial aplicación en la evaluación multicriterio de proyectos en el sector energético debe considerar un ajuste previo del modelo de acuerdo a las condiciones específicas del problema a resolver, su localización geográfica y las circunstancias que dominen el momento en el tiempo en que se haga la evaluación. En cualquier caso, el modelo propuesto pretende servir sólo como una referencia en el proceso de evaluación.

Finalmente, es conveniente recordar que la estructura jerárquica propuesta sólo permite valorar alternativas de inversión en el sector energético y ordenarlas de acuerdo a tal evaluación. Sin embargo, si se desea elaborar y/o evaluar planes donde puedan participar más de un tipo de proyecto, es necesario maximizar o minimizar la función que se considere pertinente, expresada como una combinación de las respectivas participaciones; e incorporar al problema las limitaciones que pueda haber para su ejecución. Si la función a optimizar es lineal; se sugiere complementar el modelo con las técnicas de programación lineal explicadas en la sección 1.1.1.1, capítulo 1 de este documento. 


\section{Capítulo 5 Aplicación del modelo}

La disponibilidad de energía es un elemento fundamental en el desarrollo económico y en el bienestar de los pueblos. La elección de las fuentes energéticas a utilizar depende no sólo de las consideraciones técnicas y ambientales relacionadas con las tecnologías disponibles sino de las características de índole legal, económica, social y política propias de la región o país donde se toma la decisión.

En este capítulo se ilustra la aplicabilidad del modelo de valor formulado en las páginas anteriores. Inicialmente se describe un problema en el sector energético y algunas de las alternativas de solución al mismo. Seguidamente se utiliza el modelo propuesto para la evaluación multicriterio de las opciones planteadas; y finalmente, se discuten los resultados obtenidos los cuales pueden servir como una referencia a los responsables de las decisiones que deban tomarse.

\subsection{Caso: Crisis eléctrica en Venezuela}

Venezuela es un país situado al norte de Suramérica y tiene un considerable potencial energético. En efecto, posee las reservas de petróleo más grandes del mundo, reservas de gas y carbón; yacimientos de uranio; un importante potencial hidroeléctrico; y en zonas seleccionadas del territorio, la posibilidad de aprovechar los vientos, la radiación solar, la energía geotérmica y las mareas que son características de cada región.

La industria de petróleo, gas, carbón y energía eléctrica están nacionalizadas. Las actividades de explotación, transformación, distribución y comercialización de 
petróleo y gas son manejadas por la empresa Petróleos de Venezuela, PDVSA; el carbón es extraído por empresas estatales filiales de CORPOZULIA, y recientemente fue creada La Corporación Eléctrica Nacional, CORPOELEC que está a cargo de la generación, transmisión, distribución y comercialización de la energía eléctrica.

\subsubsection{Potencial de recursos energéticos no renovables}

La tabla 5.1 que se presenta en la próxima página, muestra las reservas de recursos no renovables $(R)$, su producción $(P)$ y la respectiva relación $R / P$ del país a finales del año 2010. Las cifras se expresan en las unidades comúnmente usadas en cada caso y en toneladas equivalentes de petróleo. La unidad comúnmente usada para expresar volúmenes de gas es el metro cúbico en condiciones estándar medido seco a $15^{\circ} \mathrm{C}$ y 1 atmósfera de presión. Para el petróleo y el gas también se incluyen otras cifras de interés.

Las reservas de los recursos energéticos no renovables en el país totalizan 36,2 mil millones de toneladas equivalentes de petróleo, de las cuales la casi totalidad corresponde a las reservas de gas y petróleo. A continuación algunos comentarios al respecto.

- Petróleo. Venezuela es un país muy rico en reservas petroleras. A inicios del año 2011, las autoridades gubernamentales del sector elevaron las reservas probadas y certificadas ${ }^{71}$ a 297 mil millones de barriles de petróleo, lo que coloca al país en el primer lugar mundial en cuanto a reservas de crudo se refiere, y su duración en una cifra superior a 200 años, si se mantiene la tasa de producción actual. Del monto de reservas probadas, 220 mil millones de barriles corresponden a petróleo extrapesado con gravedad inferior a $10^{\circ}$ API ubicado en la Faja Petrolífera del Orinoco (FPO), un área de $55.314 \mathrm{~km}^{2}$ ubicada al oriente de Venezuela y cuya explotación requiere de altas inversiones y de tecnologías de extracción,

\footnotetext{
71 Noticias24 (2011), "Petróleo. Venezuela asegura registrar las mayores reservas de petróleo del mundo", http://economia.noticias24.com/noticia/48459/venezuela-dice-certificar-mayores-reservas-de-petroleodel-mundo, 19/01/2011. Otras fuentes [BP, 2011; U.S. EIA, 2011] ubican las reservas de Venezuela en 211 mil millones de barriles de petróleo, lo que colocaría al país en un segundo lugar a nivel mundial.
} 
transporte y refinación no convencionales. Para la exploración, cuantificación de las reservas y la explotación del crudo FPO, el gobierno nacional se ha asociado con firmas extranjeras, en empresas mixtas donde mantiene una participación mayoritaria. Yacimientos de petróleo liviano, mediano y pesado se encuentran en el occidente y en el nororiente del país.

Tabla 5.1. Posición energética de Venezuela. Recursos no renovables, 2010

\begin{tabular}{|c|c|c|c|}
\hline & UNIDADES & MONTO & TEP \\
\hline \multicolumn{4}{|l|}{ PETRÓLEO } \\
\hline $\begin{array}{l}\text { Reservas probadas } \\
\text { Producción } \\
\text { Consumo interno } \\
\text { Capacidad refinación } \\
\text { Relación R/P }\end{array}$ & $\begin{array}{l}\text { barriles } \\
\text { bbls/día } \\
\text { bbls/día } \\
\text { bbls/día } \\
\text { años }\end{array}$ & $\begin{array}{l}296,5 \times 10^{9 \neq} \\
2,47 \times 10^{6} \\
765 \times 10^{3} \\
981,2 \times 10^{3 *} \\
>200\end{array}$ & $\begin{array}{r}40,4 \times 10^{9} \\
126,6 \times 10^{6} \\
35,2 \times 10^{6}\end{array}$ \\
\hline \multicolumn{4}{|l|}{ GAS } \\
\hline $\begin{array}{l}\text { Reservas probadas } \\
\text { Producción bruta } \\
\text { Producción neta } \\
\text { Consumo interno } \\
\text { Relación R/P }\end{array}$ & $\begin{array}{l}\text { m³ estándar }^{3} \\
\mathrm{~m}^{3} \text { estándar } \\
\mathrm{m}^{3} \text { estándar } \\
\mathrm{m}^{3} \text { estándar } \\
\text { años }\end{array}$ & $\begin{array}{l}5,5 \times 10^{12} \\
71,1 \times 10^{9} \\
28,5 \times 10^{9} \\
30,7 \times 10^{9} \\
>100\end{array}$ & $\begin{array}{c}5 \times 10^{9} \\
25,7 \times 10^{6} \\
27,6 \times 10^{6}\end{array}$ \\
\hline \multicolumn{4}{|l|}{ CARBÓN } \\
\hline $\begin{array}{l}\text { Reservas probadas } \\
\text { Producción } \\
\text { Relación R/P }\end{array}$ & $\begin{array}{l}\text { toneladas } \\
\text { TPE } \\
\text { años }\end{array}$ & $\begin{array}{l}479 \times 10^{6} \\
2,9 \times 10^{6} \\
>100\end{array}$ & $\begin{array}{l}300 \times 10^{6} \\
2,9 \times 10^{6}\end{array}$ \\
\hline \multicolumn{4}{|l|}{ URANIO } \\
\hline Reservas* & toneladas & $50 \times 10^{3 * *}$ & $460 \times 10^{6}$ \\
\hline TOTAL RESERVAS & & & $46,2 \times 10^{9}$ \\
\hline
\end{tabular}

Fuente: BP, 2011; *OPEC, 2011;**Hernández 2009

72 El petróleo FPO en sitio totaliza más de $1.2 \times 10^{12}$ barriles con un factor de recuperación aproximado de 20\%, Ramírez R., en http://economia.noticias24.com/noticia/71495/ramirez-venezuela-tiene-lasprimeras-reservas-de-crudo-gracias-a-la-vision-politica-de-chavez/, 07/2011.

73 Producción neta de gas = producción bruta - reinyección - gas quemado - líquidos que acompañan al gas natural (NGL, por sus siglas en ingles) - consumo propio en planta y pérdidas. 
Para el año 2010, la producción de petróleo en Venezuela ascendió aproximadamente a 2,5 millones de bbls/día y su consumo fue de 765 miles bbls/día $[B P, 2011]^{74}$. Su capacidad de refinación es de 981,2 miles de bbls/día [OPEC, 2011] distribuida en cuatro refinerías con una disponibilidad operativa promedio un poco mayor al 60\% [Hernández, 2011a]. La capacidad nominal máxima de producción de gasolina es de 325 mil bbls/día y el consumo interno para el año 2010 fue de 290 mil bbls/día [Hernández, 2011a, OPEC 2011]. La venta de los excedentes de petróleo y productos derivados constituyen una fuente principalísima de ingresos para Venezuela, representando más del $90 \%$ de las divisas que recibe el país [Hernández, 2011a].

Venezuela posee una red de distribución nacional de petróleo y productos refinados y las instalaciones necesarias para su exportación desde puertos de aguas profundas. Adicionalmente, acumula la experiencia de muchos años de exploración, extracción y transformación de crudos livianos y pesados; sin embargo, no posee las nuevas tecnologías, experticia y capacidad de financiamiento necesarias para la explotación de crudos extrapesados por lo que ha requerido la participación de compañías extranjeras. Hoy día, empresas de Estados Unidos (CHEVRON), Noruega (STATOIL), el Reino Unido (BP), Francia (TOTAL) China (CNCP), Brasil (PETROBRAS), España (REPSOL), Italia (ENI), y consorcios de India, Rusia, Malasia, Japón y Vietnam operan y/o han firmado convenios bilaterales para la exploración y potencial explotación de tres de los cuatro bloques en que se ha dividido el área. En todas las asociaciones participa PDVSA como socio mayoritario [U.S EIA, 2011].

Por otra parte, la falta de inversiones oportunas y de mantenimiento adecuado y continuo de las instalaciones existentes; la distracción de fondos y fuerza de trabajo a labores no propias de la industria, la politización de la empresa, el incremento de la demanda incentivado por el precio de la gasolina $(0,1 \mathrm{Bs} / \mathrm{litro})$

Otras fuentes sitúan la producción de petróleo de Venezuela para el año 2010 en 2,1 millones de barriles diarios [Hernández, 2011b] y Petrofinanzas, Núñez J. (2010), "Cae PDVSA a 2,07 MM b/d" en http://www.petrofinanzas.com/?p=1612, 4/7/2011. 
muy inferior a su costo de producción, el cese de los programas de investigación y la pérdida de los conocimientos y experiencia acumulados a lo largo de 15 años, en promedio, de alrededor de 18.000 trabajadores despedidos de la empresa estatal Petróleos de Venezuela a raíz de la huelga general en el país en el año 2002, han provocado la caída de la producción nacional, la disminución del ingreso de divisas y han contribuido a la actual crisis energética del país.

- Gas natural. A finales del año 2010, las reservas de gas natural en Venezuela totalizaron $5,5 \times 10^{12} \mathrm{~m}^{3}$ estándar [BP, 2011] de las cuales alrededor de un $90 \%$ correspondió a gas asociado y el resto a gas libre [U.S. EIA, 2011]. Para el mismo año, la producción total de gas alcanzó $71,1 \times 10^{9} \mathrm{~m}^{3}$ medidos en condiciones estándar; de allí, aproximadamente un $43 \%$ fue reinyectado para ayudar a la extracción de petróleo [OPEC, 2011]. La producción neta después de descontar pérdidas y el gas venteado a la atmósfera y quemado, sólo alcanzó $28,5 \times 10^{9} \mathrm{~m}^{3}$ estándar y el consumo interno fue de 30,7 $\times 10^{9} \mathrm{~m}^{3}$ estándar; la diferencia, unos $2,2 \times 10^{9} \mathrm{~m}^{3}$, se importó de Colombia [BP, 2011]. La duración de las reservas se estima superior a 100 años, si se mantiene la misma tasa de producción.

Venezuela posee una red de gasoductos con una capacidad de transmisión de 105 millones de $\mathrm{m}^{3}$ /día que suple a tres refinerías, tres complejos petroquímicos, el complejo siderúrgico y de aluminio de Guayana, 4 plantas de cemento, 20 plantas eléctricas, 650 clientes industriales y 500 mil clientes domésticos Al igual que la infraestructura para la distribución de petróleo y productos derivados desde los lugares de producción a los centros de transformación o consumo, el sistema de gasoductos requiere de adecuación y ampliación, lo que se ha planificado pero aún está en una etapa incipiente [Hernández, 2011a].

Alrededor de un $95 \%$ de los hogares venezolanos utiliza gas licuado (LPG, por sus siglas en inglés) en bombonas y tanques el cual es distribuido y comercializado por la empresa estatal PDVSA Gas Comunal, S.A. La disminución de la producción de gas asociado, el incremento natural de la demanda, compromisos de envío de LPG con los países del ALBA y la politización de las actividades ha incidido en la eficiencia de entrega de la empresa, ocasionando un desplazamiento hacia las cocinas eléctricas y el incremento del consumo de este tipo de energía. 
PDVSA produce la mayor cantidad de gas natural en Venezuela y es también su más grande distribuidor. Como ya se ha señalado, se estima que un $90 \%$ del gas producido está asociado a la producción de petróleo. Como es natural, Venezuela desea aumentar la producción de gas no asociado a partir de sus reservas costa afuera por lo que ha asignado bloques de exploración en la Plataforma Deltana, en la región nororiental del país y en el Golfo de Venezuela. Los resultados de la exploración realizada por empresas como REPSOL y ENI han elevado las reservas del país en unos 170-230 mil millones de metros cúbicos de gas natural recuperable [U.S. EIA, 2011]. Sin embargo, la producción de gas libre permanece baja, el país no dispone de la experiencia necesaria para su explotación costa afuera; y seguramente deberá recurrir a tecnología, experiencia y financiamiento extranjero si quiere hacerlo.

- Carbón. Las reservas carboníferas de Venezuela totalizan 479 millones toneladas métricas; sin embargo, la producción sólo alcanzó el equivalente a 2,9 millones de toneladas de petróleo en el año 2010 [BP, 2011]. Si esta producción se mantiene, la duración de las reservas se estima superior a 100 años. El consumo interno es insignificante $[\mathrm{BP}, 2011]$ y prácticamente todo el carbón producido se exporta a Norteamérica, Europa y Latinoamérica.

Geográficamente, el carbón se encuentra ubicado en el nororiente y occidente del país. La mayor concentración de reservas se encuentra en la cuenca del Guasare en el estado Zulia; su explotación y comercialización está a cargo de Carbones del Guasare dependiente de Carbozulia, filial de PDVSA.

Por otra parte, el "coque de petróleo", subproducto del proceso de refinación del petróleo puede utilizarse como combustible en la generación de energía eléctrica. Hoy día, Venezuela produce unas 8 millones de toneladas por año y el Gobierno Nacional ha suscrito un convenio con China para el desarrollo de plantas de generación eléctrica que utilicen como combustible tal material. Se estima que su oferta puede triplicarse a finales de la década, dependiendo, entre otras cosas, de la expansión de la producción y de la entrada en funcionamiento de unidades de mejoramiento del petróleo de la Faja del Orinoco [CORPOELEC, 2010]. 
- Uranio. Estudios realizados en la década de los años 70 permitieron determinar la presencia de uranio en la formación Úrico en la confluencia de los ríos úrico y Chicharán en el estado Bolívar, y en otras formaciones del Macizo Guayanés. Una prospección realizada en la misma época mostró reservas de unas 50.000 toneladas métricas en el país [Hernández, 2010]. Sin embargo, aunque el Gobierno Nacional ha mostrado interés en desarrollar la energía nuclear con fines pacíficos $y$, se ha hablado mucho de su relación con Irán y de una posible extracción de uranio a cambio de tecnología, no se reporta ninguna actividad oficial de explotación de esas reservas.

La figura 5.1 muestra de forma aproximada la ubicación geográfica de los recursos no renovables en Venezuela. No se incluye el uranio.

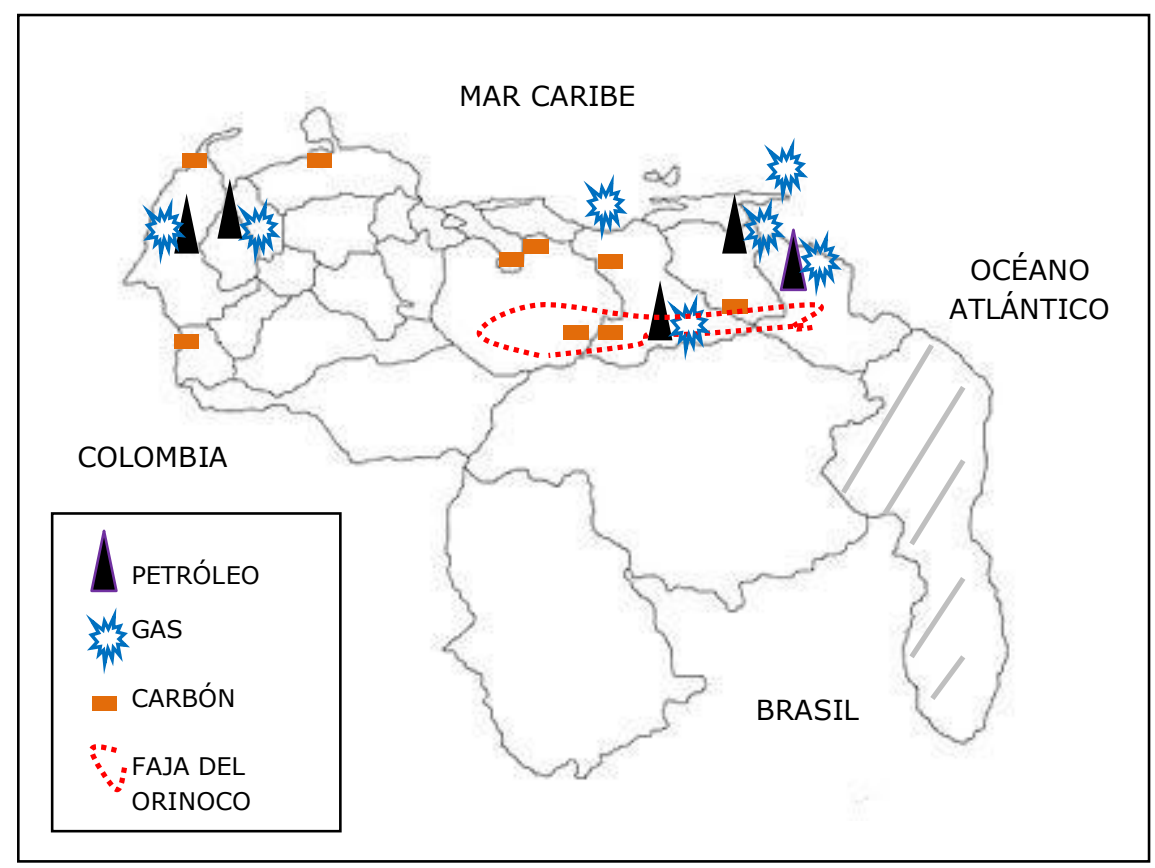

Fuente: [Hernández, 2011a]

Figura 5.1. Ubicación geográfica de los recursos energéticos no renovables, Venezuela 2011.

La explotación de petróleo en Venezuela comenzó a gran escala a inicios del siglo pasado; y hoy día, su extracción, refinación y comercialización conjuntamente con la del gas natural, constituye la principal actividad económica del país y su medio de subsistencia. El gran volumen de reservas disponible de estos recursos es causal de 
la exclusión del aprovechamiento en forma significativa de otros recursos energéticos como el carbón y la energía nuclear. Hoy más que nunca, Venezuela es un país que depende casi exclusivamente de las ventas de sus excedentes petroleros al extranjero los cuales han venido disminuyendo. El consumo de productos derivados como la gasolina, el gasoil y el fueloil se acerca peligrosamente a su capacidad máxima de producción; no produce el gas suficiente para satisfacer su consumo interno y honrar sus compromisos con otros países; y la explotación del carbón es muy pequeña.

A finales del año 2010, el gobierno nacional suscribió un acuerdo de cooperación con Rusia para el aprovechamiento pacífico de la energía nuclear en el país. Los planes se congelaron a raíz del accidente nuclear de Fukushima ocurrido poco después. Sin embargo, recientemente se han retomado y se contempla la instalación y puesta en marcha en suelo venezolano de entre dos y cuatro reactores nucleares con capacidad nominal de $1.200 \mathrm{MW}$ cada uno. No se contempla la explotación del uranio existente en Venezuela. Por lo complejo de las operaciones para obtener el combustible nuclear enriquecido insumo a los reactores, el mismo será suplido por Rusia quien también se encargará del manejo de los residuos radioactivos. El plan es disponer de aproximadamente 4.000 MW adicionales en un período de 10 años, con una inversión que se acerca a los 20.000 mil millones de US $\${ }^{75}$.

\subsubsection{Potencial de recursos energéticos renovables}

Con motivo de la Cumbre Mundial para el Desarrollo Sostenible realizada en Johannesburgo, Sudáfrica en el año 2002, los países de Latinoamérica y del Caribe propusieron [PNUMA, 2002] como meta a cumplir para el año 2010, la incorporación de al menos $10 \%$ de uso de energías renovables del insumo total de energía a sus respectivas economías. Si la cifra se interpreta como un compromiso promedio adquirido por la región y se incluyen en su estimación los grandes desarrollos hidroeléctricos que operan en Latinoamérica y el crecimiento de la industria de

75 Guia.com.ve (2012), http://www.guia.com.ve/noti/68336/reactores-nucleares-que-construira-rusiaen-venezuela-son-un-prototipo, 1/2012. 
biocombustibles en el Brasil, la meta propuesta se había cumplido de antemano; sin embargo si ésta se aplica a cada país en la región, la situación difiere.

La tabla 5.2 presenta el potencial energético de Venezuela en cuanto a recursos energéticos renovables se refiere. Como puede leerse, el país posee un potencial de energías renovables que alcanza el equivalente a 9 millones de barriles diarios de petróleo donde destaca la energía solar que contribuye aproximadamente con la mitad del monto total, seguida de la energía hidráulica y de la energía eólica. Otras energías como la geotérmica, la mareomotriz y la bioenergía contribuyen en menor proporción.

Tabla 5.2. Potencial energético de Venezuela. Recursos renovables, 2010

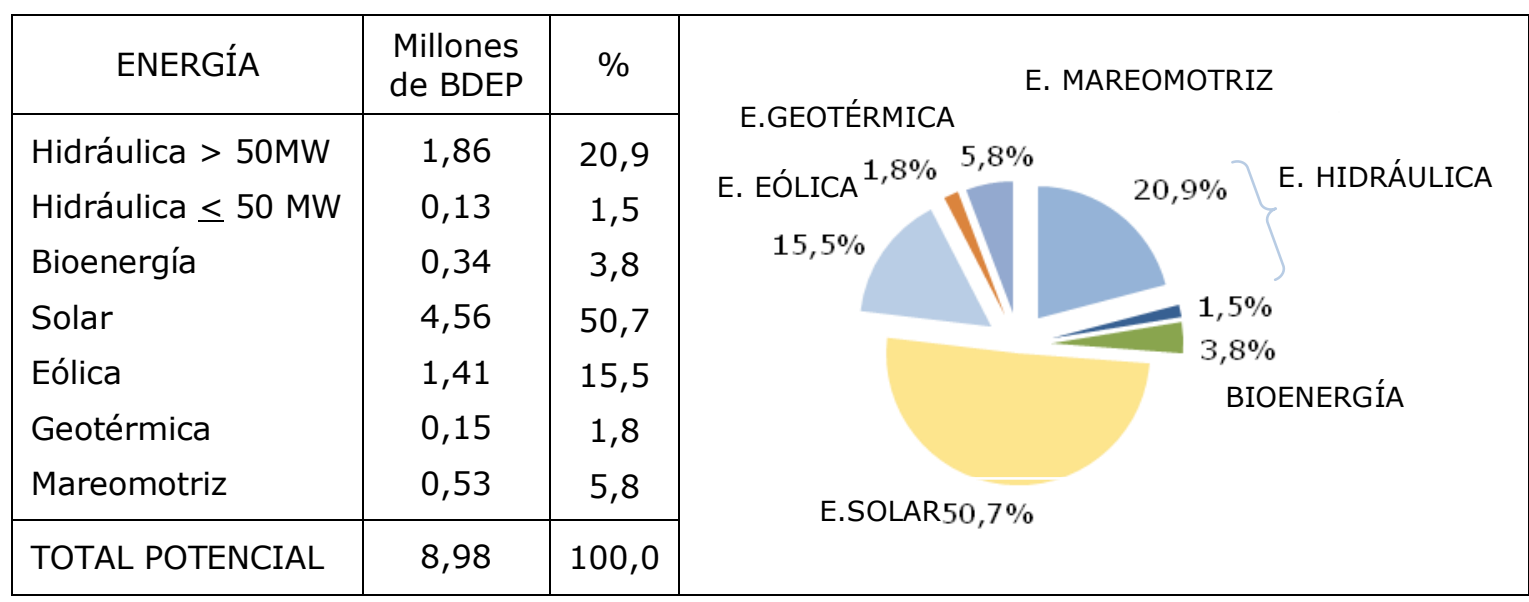

Fuente: [Hernández, 2009] BDEP: barriles equivalentes de petróleo/día

El Proyecto Nacional Simón Bolívar 2007-2013, en el aparte VI.3. Estrategias y Políticas del Capítulo VI. Venezuela: Potencia Energética Mundial, reza textualmente en el punto VI.3.3. "Propiciar el uso de fuentes de energía alternas, renovables y ambientalmente sostenibles"; sin embargo, con excepción de los grandes desarrollos hidroeléctricos que comenzaron a construirse en el país desde los años 70, el uso que Venezuela ha dado a su potencial energético en recursos renovables puede calificarse de muy modesto o prácticamente nulo.

La figura 5.2 y 5.3 que se presentan en la próxima página, muestran de forma aproximada las regiones geográficas de Venezuela donde las condiciones resultan más favorables para la explotación de su potencial de energías renovables. 


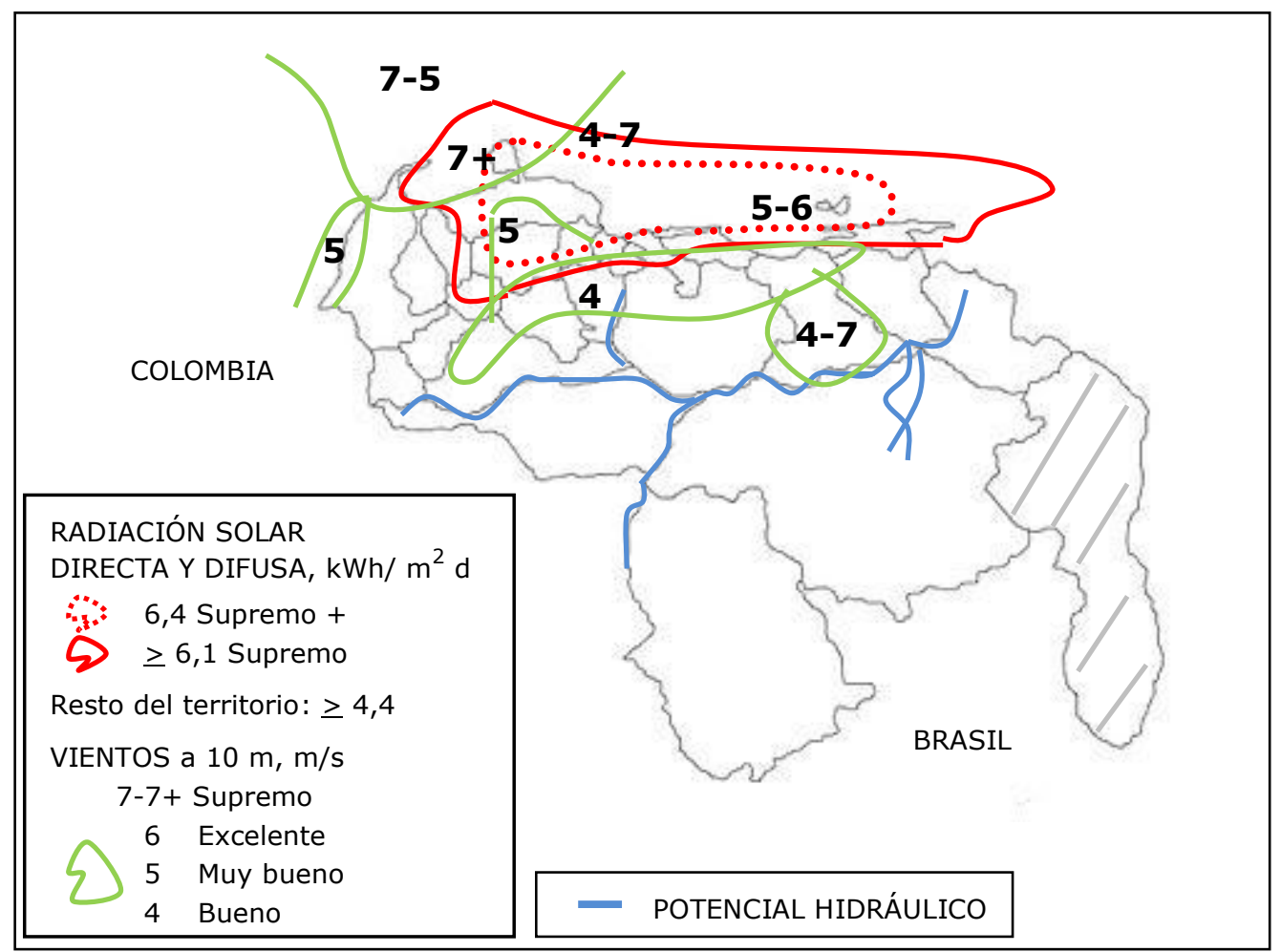

Fuente: [Hernández 2010b; Durán, 2009]

Figura 5.2. Potencial solar, eólico e hidráulico, zonas más favorables en Venezuela

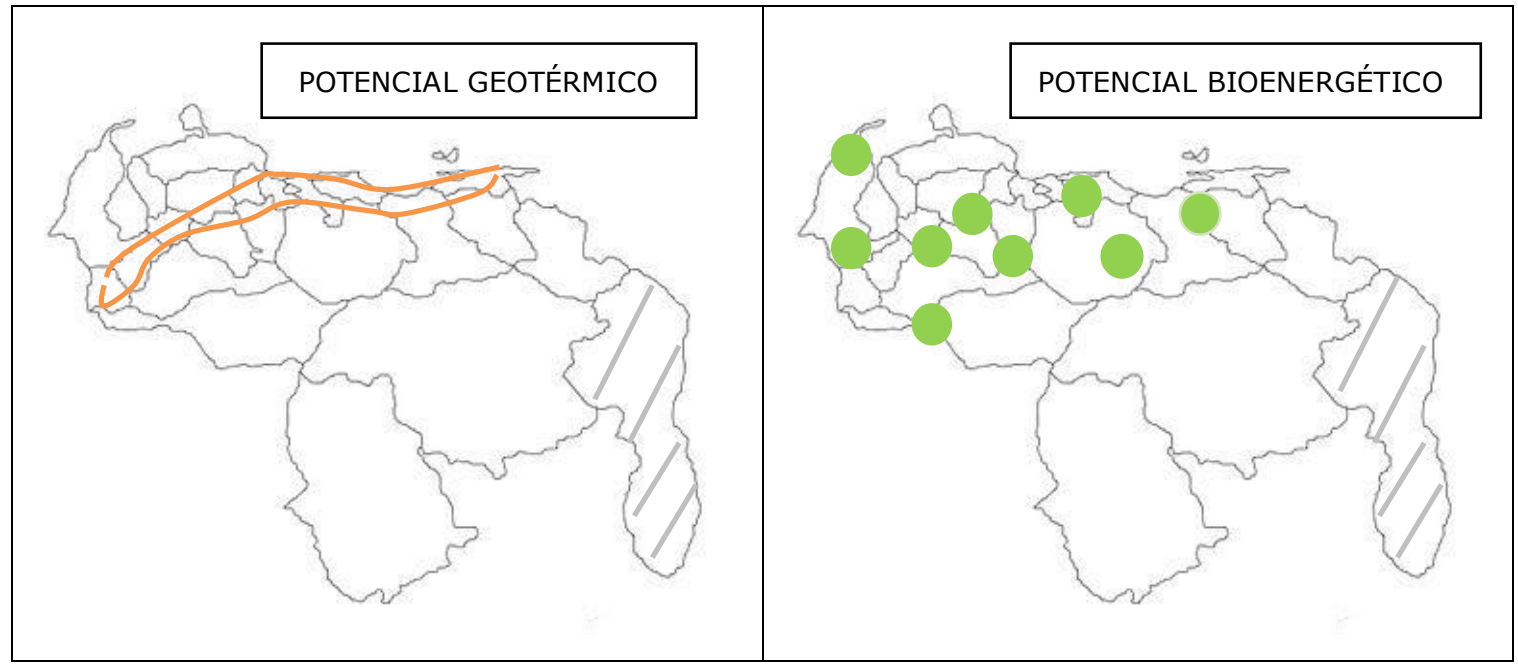

Fuente: [Hernández, 2010b]

Fuente: [Durán, 2009]

Figura 5.3. Ubicación geográfica del potencial geotérmico y bioenergético, Venezuela 
A continuación algunos comentarios sobre la posibilidad de desarrollo de cada tipo de energía renovable en el país.

- Radiación solar. Venezuela es un país situado en el extremo norte de América del Sur, entre $1^{0} \mathrm{~N}$ y $12^{\circ} \mathrm{N}$ de latitud, por lo que está incluido en lo que se conoce como cinturón del sol, zona que recibe una alta radiación solar durante todo el año. La línea roja continua sobre la figura 5.2, delimita el área que recibe una irradiación solar mayor o igual a $6,1 \mathrm{kWh} / \mathrm{m}^{2}$ día; dentro de ella, la línea roja punteada encierra la zona con mayor irradiación solar en Venezuela, unos 6,4 $\mathrm{kWh} / \mathrm{m}^{2}$ día. El área se extiende a lo largo de la costa norte del país destacándose en ella, el estado Falcón y la isla de Margarita. El resto del territorio venezolano recibe una irradiación solar superior a $4,4 \mathrm{kWh} / \mathrm{m}^{2}$ día y en muchos lugares superior o igual a $5,5 \mathrm{kWh} / \mathrm{m}^{2}$ día, condición buena o muy buena para la instalación de sistemas solares. Otra ventaja importante es que no existen variaciones extremas del clima en el país.

A pesar del gran potencial de energía solar en el país, su aprovechamiento se ha realizado a escala muy pequeña. El gobierno nacional ha instalado paneles fotovoltaicos para proveer electricidad a plantas potabilizadores de agua en comunidades indígenas al sur del país o para dotar de energía eléctrica a comunidades aisladas. Existe un grupo de pequeñas firmas asesoras en el sector y planes para la fabricación de celdas fotovoltaicas en el país.

- Vientos. Las líneas verdes sobre la figura 5.2 antes incluida, delimitan áreas con diferente intensidad de vientos sobre el territorio venezolano. Las regiones insulares y la región norte costera del territorio destacan por la velocidad de sus vientos y resultan muy atractivas para el desarrollo de sistemas eólicos.

Se han identificado cuatro zonas con velocidades de viento $\geq$ a $8 \mathrm{~m} / \mathrm{s}$ y existen planes para la instalación de 172 MW distribuidos en la península de Paraguaná (100 MW), en la Goajira venezolana (24 MW) y en los estados Nueva Esparta (24 MW) y Sucre (24 MW) [Durán, 2009]. La tabla 5.3 lista los sitios identificados, su velocidad promedio y la altura a la cual fue realizada la medición. El gráfico a la derecha muestra su ubicación aproximada sobre el territorio nacional. 
Tabla 5.3. Desarrollos eólicos en Venezuela. Planes, 2009

\begin{tabular}{|l|l|c|c|}
\hline \multicolumn{1}{|c|}{ ESTADO } & \multicolumn{1}{|c|}{ SITIO } & $\begin{array}{c}\text { VELOCIDAD } \\
\text { PROMEDIO } \\
(\mathrm{m} / \mathrm{s})\end{array}$ & $\begin{array}{c}\text { ALTURA DE } \\
\text { MEDICIÓN } \\
(\mathrm{m})\end{array}$ \\
\hline ZULIA & La Goajira & 8,8 & 10 \\
\hline FALCÓN & Los Taques & 8,5 & 67 \\
\hline SUCRE & Araya & 8 & 10 \\
\hline $\begin{array}{l}\text { NUEVA } \\
\text { ESPARTA }\end{array}$ & Margarita & 8 & 10 \\
\cline { 2 - 6 } & Coche & 8,2 & 10 \\
\hline
\end{tabular}

Fuente: [Ravelo y Sepúlveda, 2009]

Fuente: [Durán, 2009]

Recientemente se han iniciado los trabajos en el estado Falcón. No se conocen otros planes al respecto.

- Recursos hidroenergéticos. Entre los recursos energéticos renovables, la energía hidráulica ha sido por mucho la más estudiada y explotada en Venezuela. Para el año 2010, el potencial hidroeléctrico desarrollable del país se estimaba en 46.640 MW; de ellos, la capacidad instalada de generación hidroeléctrica alcanzaba 15.300 MW en la cuenca del Caroní y 645 MW en el suroccidente del país, que si se suman a unos 2.931 MW en construcción, dejan un margen de 27.584 MW potencialmente desarrollables [CORPOELEC 2010].

Como dato de interés, vale mencionar que la Central Simón Bolívar (Guri) ubicada sobre el Bajo Caroní, es el tercer desarrollo hidroeléctrico más grande del mundo con una capacidad instalada de 10.270 MW [Aguilar, 2011]. Su ubicación aproximada y la de otras grandes centrales hidroeléctricas que operan en el país se identifica con pequeños círculos azules, en la figura 5.4 que se incluye a continuación. Los pequeños círculos amarillos en la misma figura muestran la ubicación de las centrales en construcción para el año 2009.

Adicionalmente, se han desarrollado y operan con éxito una serie de microcentrales ( $<1 \mathrm{MW}$ ) en sitios muy apartados de La Gran Sabana y del Estado Amazonas contribuyendo a la mejora de la calidad de vida de grupos indígenas y de pequeñas comunidades. En la figura 5.4 se señala con pequeños triángulos, la situación aproximada de tales microcentrales; así como la de sitios bajo estudio. 


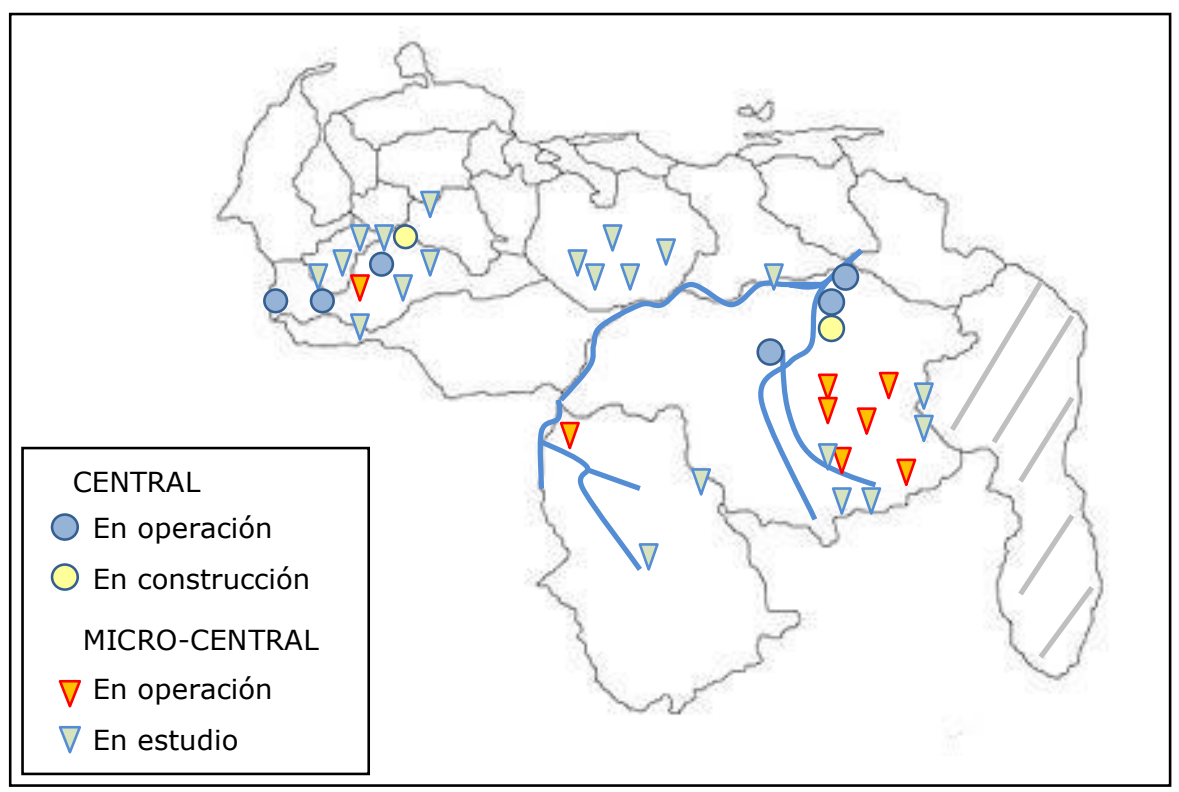

Fuente: [Durán, 2009]

Figura 5.4. Aprovechamientos hidroeléctricos en Venezuela, 2009

La minería ilegal en la cuenca del Alto Caroní ha erosionado de forma importante la región disminuyendo su potencialidad; ello ha motivado al Gobierno Nacional a explorar otras fuentes de energía para la futura generación de electricidad en el país.

- Recursos geotérmicos, biomasa y mareas. Una revisión de la tabla 5.1 muestra que el potencial geotérmico y el potencial bioenergético en Venezuela, aunque importantes, son bastante más pequeños que el de los otros recursos renovables. Las figuras 5.3 incluidas anteriormente, muestran su localización geográfica. En cuanto al potencial mareomotriz, éste se ubica lo largo de kilómetros de costa al norte del territorio nacional.

Las tecnologías para la explotación de la energía mareomotriz y geotérmica son poco conocidas en el país; y en general, se tiene poca experiencia en su manejo en el mundo. Hoy día, no existe ningún proyecto para el aprovechamiento de su potencial en Venezuela.

En cuanto a la bioenergía, la primera generación de tecnologías para la transformación de biomasa en biocombustibles ha sido cuestionada por su bajo 
rendimiento para el ciclo de vida, con la excepción del aprovechamiento de la caña de azúcar en Brasil; y aún en este caso, se objeta que se dediquen grandes extensiones de terreno al cultivo de la biomasa insumo al proceso. Hoy en el mundo, se trabaja en una nueva generación de tecnologías más eficientes, menos costosas y que pueda utilizar variados tipos de insumos.

Venezuela es un país productor de petróleo, donde la agricultura está muy disminuida, sino casi ausente. El presidente Chávez ha expresado públicamente en varias oportunidades, su oposición a dedicar tierras que podrían dedicarse al cultivo de alimentos, a la producción de biomasa para su transformación en biocombustibles, especialmente disponiendo de otras alternativas energéticas. De esta forma, sólo existen planes muy modestos de quema del bagazo de caña de azúcar para suplir la energía requerida en las plantas productoras de azúcar, y algunas aproximaciones al aprovechamiento de residuos agrícolas y urbanos.

En conclusión, Venezuela por su ubicación y características geográficas dispone de un potencial de recursos energéticos renovables importante, entre los que destacan el sol, los vientos, los caudales y desniveles de sus corrientes de agua, y las mareas al norte del país. Sin embargo y a pesar de compromisos internacionales adquiridos, no los ha desarrollado en forma apreciable, con excepción hecha del recurso hidráulico a gran escala. Causas de ello, pueden encontrarse, (i) en la existencia de una infraestructura, experiencia y tradición acumulada por muchos años en la extracción, transformación y comercialización de la gran cantidad de recursos fósiles de los cuales dispone el país, frente a la poca experiencia de manejo o desconocimiento de las tecnologías para la explotación de recursos renovables y (ii) en la gran dependencia que tiene el país de los ingresos por la venta de sus excedentes petroleros, fuente principalísima de sustento de la nación.

En los últimos años y motivado por una parte, a la inquietud de algunos profesionales de avanzar hacia una Venezuela en sintonía con la preocupación mundial hacia la conservación del planeta; y más recientemente, por la necesidad de añadir posibles soluciones a la crisis energética que vive el país, éste se ha ido moviendo en la dirección de lograr una mayor participación de los recursos energéticos renovables en la vida de sus pobladores. 


\subsubsection{El problema: la crisis eléctrica en Venezuela}

A pesar de su gran potencial energético, Venezuela vive hoy una situación complicada que tiene como expresión, (i) el deterioro de la industria del petróleo y del gas y (ii) la crisis del sector eléctrico.

\subsubsection{Deterioro del sector petróleo y gas}

La falta de inversiones oportunas para la ampliación, mejoramiento y mantenimiento de las instalaciones existentes en el sector petrolero y del gas, la politización excesiva de las actividades de la empresa estatal PDVSA responsable final por toda la actividad en la industria, la pérdida de un gran grupo de profesionales e investigadores capaces, formados en las mejores universidades con una experiencia acumulada promedio de 15 años en la industria; el agotamiento natural de algunos yacimientos, la escasez de planificación, el no cumplimiento de las metas, o a veces, el abandono de proyectos en sus fases iniciales de ejecución; y el incremento de la demanda interna incentivada por los bajos precios de la gasolina y del gas al consumidor final han causado el deterioro de la industria. Son síntomas notorios de tal deterioro, los siguientes hechos:

- La producción petrolera ha bajado alrededor de $1 \times 10^{6}$ bbls/día si se compara con

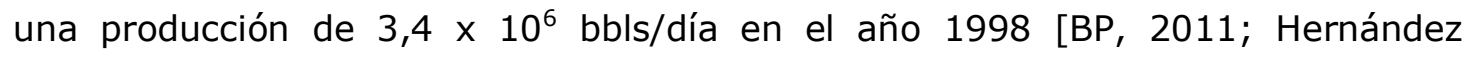
2011a].

- La producción de gas asociado a la producción petrolera que representa un 90\% del gas producido en Venezuela, viene disminuyendo desde el año 2007. Para el año 2010 el déficit para completar el consumo interno fue de 2,2 millones $\mathrm{m}^{3}$ de gas el cual debió importarse desde Colombia. La deficiencia de gas ha obligado a la jerarquización del consumo de gas y a su sustitución por combustibles líquidos en ciertos sectores productivos, especialmente en el sector eléctrico lo que ha aumentado considerablemente el consumo de diesel [Hernández, 2011a]. La figura 5.5 ilustra la evolución de la producción de petróleo para el período 20002010 y de las importaciones de gas a partir del año 2007. 


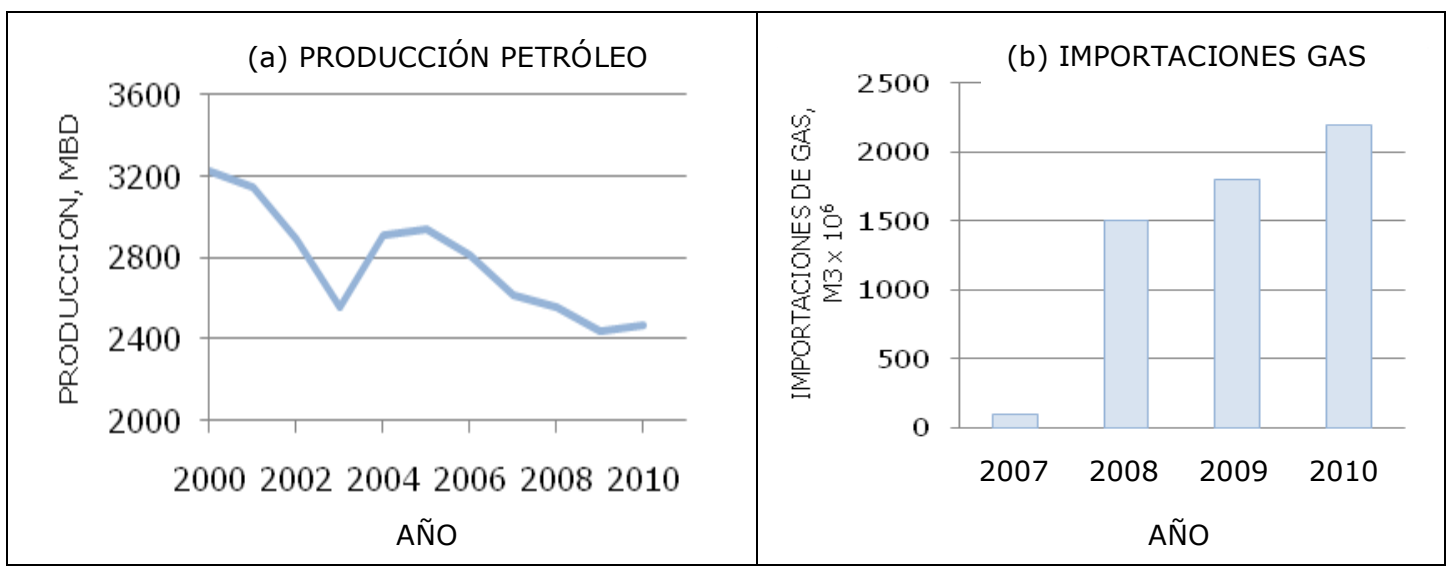

Fuente: [BP, 2011]

Fuente: [OPEC, 2011; BP, 2011]

Figura 5.5. Producción de petróleo e importaciones de gas, Venezuela 2000-2010

- La capacidad de refinación ha disminuido su holgura con relación al consumo interno de productos derivados. Actualmente, las refinerías tienen una disponibilidad del $60 \%$ de su capacidad instalada. La capacidad máxima de producción de gasolinas es de 325 mil bbls/día y el consumo para el año 2010 fue de 290 mil bbls/día. La situación para el diesel es menos ajustada; la capacidad máxima de producción es de 241 mil bbls/día frente a un consumo de 170 mil bbls/día; sin embargo se prevé un incremento importante del consumo a corto plazo [Hernández, 2011a]. La gráfica 5.6 ilustra la situación.

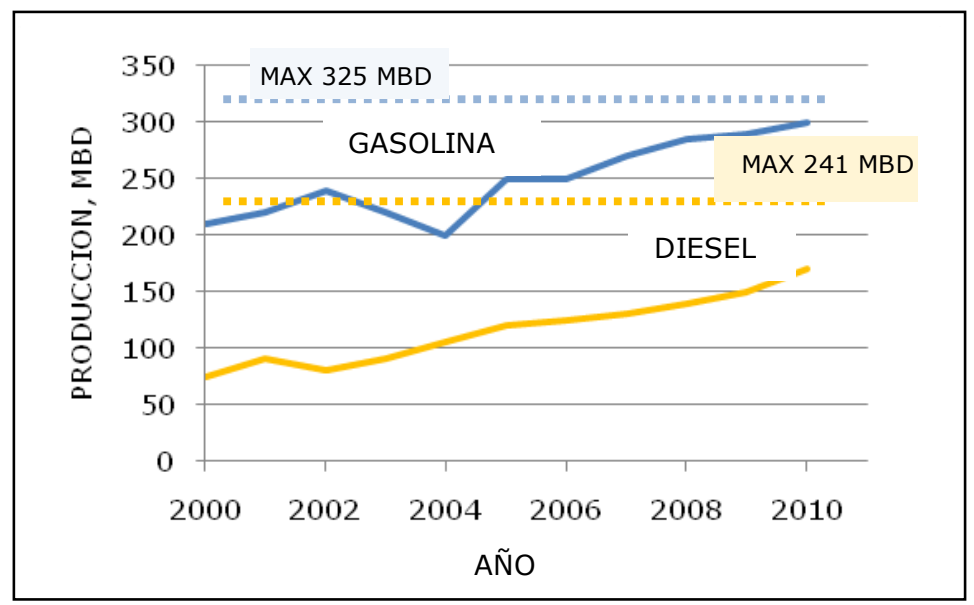

Fuente: [Hernández, 2011b]

Figura 5.6. Consumo de gasolina y diesel frente a capacidad máxima de producción, Venezuela 2000-2010. 
Petróleos de Venezuela había anunciado la construcción de tres nuevas refinerías para el período 2006-2012, ninguna de ellas se ha iniciado [Hernández, 2011a].

- La vulnerabilidad de Venezuela en cuanto a los ingresos por venta de excedentes petroleros al exterior, se ha incrementado. Aún cuando el precio de la cesta de exportación ha subido considerablemente, y hoy día oscila alrededor de los 100 US\$/bbl de petróleo, una disminución en el volumen exportado sumado a una baja en los precios del petróleo puede colocar al país en una situación incómoda y limitar, entre otras cosas, las inversiones para el desarrollo de nuevos proyectos de incremento del potencial energético del país.

Paralelamente a la crisis en el sector del petróleo y del gas; la situación en la generación y suministro de electricidad en el país se ha venido agravando desde mitades de esta década hasta hacer explosión el año 2010. Desde entonces se han implementado medidas de emergencia pero aún no se logra salir de la crítica situación. A continuación algunos comentarios al respecto.

\subsubsection{Crisis eléctrica}

El Sistema Eléctrico Nacional (SEN) suple de electricidad al 98,8 \% [Hernández, 2009] de la población venezolana que alcanza unos 29 millones de habitantes. La generación de electricidad se realiza a partir de dos fuentes principales: las grandes centrales hidroeléctricas que para el año 2010 suministraron un 65,8\% del total generado de $116.702 \mathrm{GWh}$, y las centrales termoeléctricas que aportaron el 34,2\% restante [Hernández, 2011a]; esto es, es fuertemente dependiente de la fuente hidroeléctrica.

El parque termoeléctrico comprende plantas con turbinas de vapor, con turbinas de gas, de ciclo combinado y plantas de generación distribuida ${ }^{76}$ recientemente

76 Las plantas de generación distribuida son centrales eléctricas de pequeño tamaño (en general de capacidad $\leq 15 \mathrm{MW}$ ); sólo pueden operar entre 6 a 8 horas por día y su vida útil no llega a 10 años. Su tamaño puede resultar muy grande para poblaciones aisladas; o muy pequeño, para poblaciones interconectadas. [Matas A., en http://www.soberania.org/Articulos/articulo_4425.htm]. 
añadidas al sistema eléctrico. De acuerdo a su tipo, las plantas utilizan gas, fueloil o diesel como combustible [CNG, 2010]. Algunas plantas pueden trabajar con gas o con combustible líquido; en este último caso, se incrementa significativamente su costo de mantenimiento y su vida física puede ser menor [Aguilar, 2011b].

Las grandes plantas termoeléctricas se ubican al norte de Venezuela y los desarrollos hidroeléctricos se ubican al sur del país y en la región de Los Andes como se ha señalado en la figura 5.4 antes incluida. Todo el sistema esta interconectado con $13.037 \mathrm{Km}$ de líneas de transmisión que comprenden líneas de 765 kV, 400 kV y 230 kV; y con 311 km de líneas de distribución de 115 kV [Hernández, 2011a]. Algunas comunidades indígenas y otras comunidades aisladas obtienen electricidad con la ayuda de micro-centrales hidroeléctricas o plantas termoeléctricas de baja capacidad; otras no tienen acceso a la electricidad.

A partir del año 2007, el gobierno nacional estatizó todas las empresas privadas que suministraban el servicio y fundó la Corporación Eléctrica Nacional (CORPOELEC) que hoy día es responsable por toda la actividad en el sector y opera a través de filiales en regiones delimitadas del territorio venezolano.

La figura 5.7 presenta la evolución de la capacidad instalada, la capacidad disponible para generación de energía eléctrica y la demanda eléctrica en Venezuela.

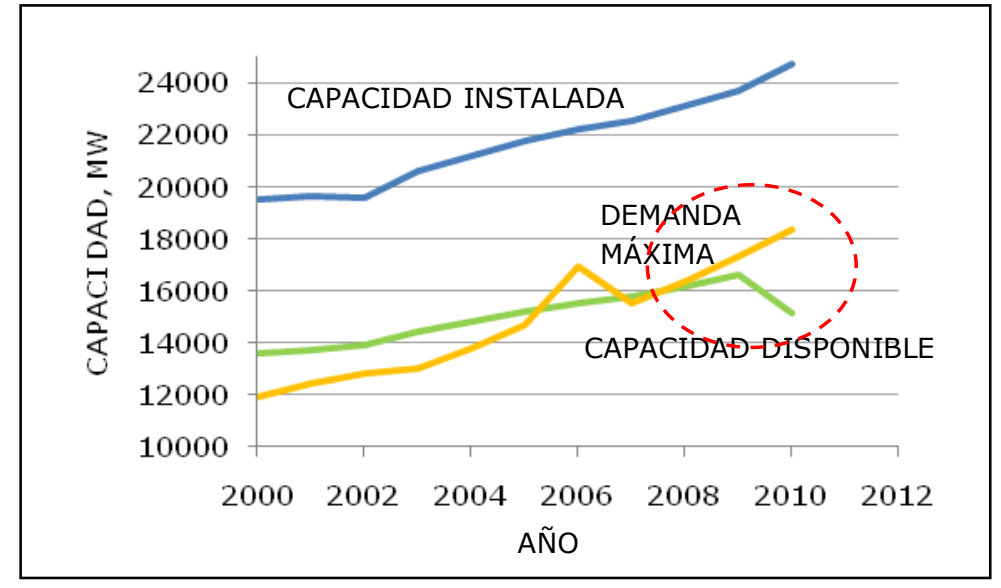

Fuente: [Aguilar, 2011b]

Figura 5.7. Capacidad de generación instalada, capacidad disponible y demanda máxima. Sector eléctrico venezolano, 2000-2010. 
Como puede observarse, a finales del año 2008, la capacidad disponible fue ligeramente inferior a la demanda máxima del mismo año. En los años siguientes la situación empeoró y se hizo particularmente grave para el año 2010 cuando se produce una sequía que se extiende por varios meses y el nivel del embalse de Guri, la planta hidroeléctrica más grande del país, se acerca peligrosamente a la cota crítica. Paralelamente se suceden los siguientes hechos que configuran una situación de crisis energética en el país [Aguilar, 2011; Hernández, 2011a; Lara et al., 2010; Hernández, 2010a; Hernández, 2010c; Hernández 2009b; AIPOP, 2010; CORPOELEC/EDELCA, 2009],

- Las plantas termoeléctricas han perdido su capacidad para incrementar su suministro, debido a la falta de mantenimiento y obsolescencia de algunos de sus equipos instalados hace más de dos décadas.

- La producción de gas se ha hecho deficitaria frente a las necesidades del país; en consecuencia, muchas de las plantas termoeléctricas con flexibilidad en cuanto al tipo de combustible a usar y que operaban regularmente con gas, deben operarse con fueloil o diesel, elevándose los costos de mantenimiento.

- El gobierno nacional apresura la recuperación de algunos equipos y la adquisición e instalación de un grupo de plantas termoeléctricas de baja capacidad que funcionan con diesel. Las plantas, en su gran mayoría, con capacidad $\leq 15 \mathrm{MW}$, [CNG, 2010] con baja inversión inicial y un corto tiempo de instalación, se distribuyen a lo largo y ancho del país para tratar de paliar la crisis eléctrica en desarrollo (generación distribuida). Gran parte de los equipos, sino todos provienen de Cuba.

La figura 5.8 muestra el comportamiento de las incorporaciones hasta mediados del 2010. Para esa fecha, de un total de $1660,5 \mathrm{MW}$ de potencia nueva añadida o recuperada, 449,2 MW se encuentran de nuevo fuera de operación; ubicándose la operatividad de las incorporaciones en un $73 \%$. Es notable que incluso algunos de los equipos de generación distribuida recientemente adquiridos (en azul claro), no se encuentran operativos (en verde oscuro) como puede observarse si se comparan los dos gráficos inferiores en la figura 5.8. 


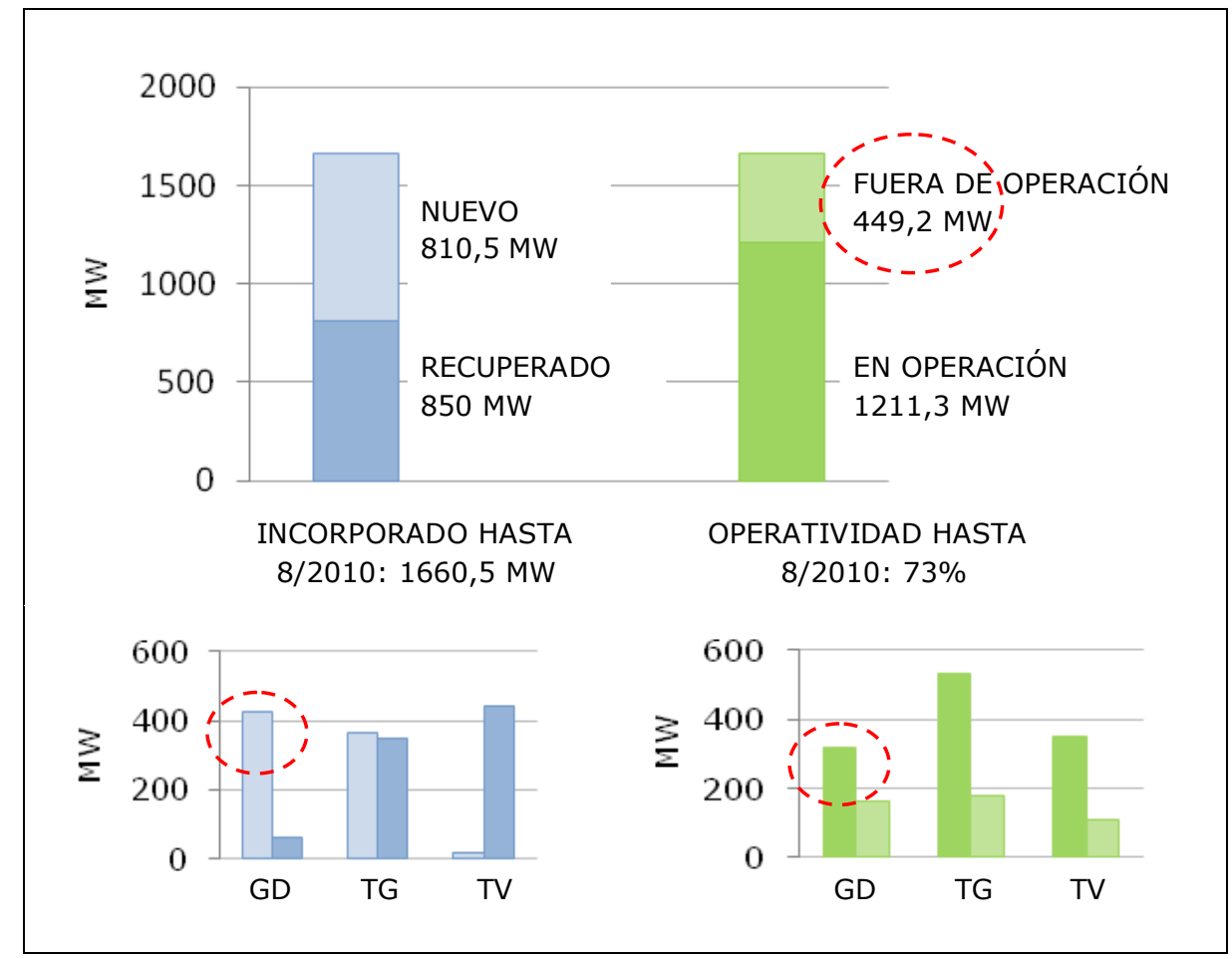

GD: Generación distribuida TG: Turbinas de gas TV: Turbinas de vapor Fuente de datos: [Hernández, 2010a].

Figura 5.8. Comportamiento de las incorporaciones hasta mediados del 2010.

- Las grandes empresas privadas deben garantizar su operatividad y adquieren plantas termoeléctricas, añadiendo presión adicional al consumo de diesel, combustible que se acerca a su máxima capacidad de producción en las refinerías del país. La tabla 5.4 que se incluye en la próxima página, muestra el incremento en el consumo de diesel para suplir deficiencias de gas y otros consumos para el período $8 / 2009-8 / 2010$.

Tabla 5.4. Consumo de combustibles en el sector eléctrico, 2009-2010

\begin{tabular}{|l|c|c|c|}
\hline \multicolumn{1}{|c|}{ COMBUSTIBLE } & MBDEP 2009 & MBDEP 2010 & $\Delta$ MBDEP \\
\hline Diesel & 51,2 & 63 & $(1,8)$ \\
\hline Fueloil & 56,2 & 56 & $-0,2$ \\
\hline Gas natural & 99,6 & 94 & $-5,6$ \\
\hline TOTAL & 207 & 213 & 6,0 \\
\hline
\end{tabular}

Fuente de datos: [Hernández, 2010a] 
El exceso de diesel consumido se deja de exportar con la consiguiente baja en los ingresos de la nación y una menor disponibilidad de los fondos necesarios para la adecuación y expansión del sistema eléctrico.

- La falta de agua en Guri y de disponibilidad de una fracción importante de equipos en la planta hidroeléctrica y térmica del país, provocan apagones, se raciona el suministro en algunas ciudades del interior y se informa sobre la emergencia de la situación.

- Después de unos meses termina la sequía, el embalse de Guri se llena completamente y se debe liberar agua porque no hay capacidad disponible de generación ni de transmisión. Algunas turbinas en Guri están fuera de operación por la sobreexplotación y falta de mantenimiento durante el período 2006-2009 [CORPOELEC/EDELCA, 2009].

- El gobierno sigue realizando inversiones importantes para elevar la capacidad instalada; sin embargo la crisis continúa, se establecen límites de consumo y penalizaciones a las industrias y hogares que los excedan. Para el año 2011, la situación parece mejorar, se levantan algunas restricciones al consumo; sin embargo a mediados del año 2011, Venezuela debe importar energía eléctrica de Colombia. A inicios del 2012, la crisis aún está vigente [Núñez J., 2012].

El considerable rezago en la ejecución de proyectos que soportasen el incremento en la demanda eléctrica del país, la falta de inversiones y del mantenimiento adecuado y oportuno en instalaciones para la generación y transmisión de la energía eléctrica agravado por la sobre explotación del embalse de Guri durante el período 2006-2009 [CORPOELEC/EDELCA, 2009], la politización de las actividades y la desprofesionalización del sector, la falta de planificación para poder manejar adecuadamente los recursos hídricos disponibles, y la improvisación en la toma de decisiones, son causas de la minusvalía eléctrica que aún hoy amenaza el desarrollo económico del país y la calidad de vida de sus pobladores.

Ante la crisis y como ya se ha señalado, el gobierno nacional ha venido implementando una serie de medidas de emergencia; entre ellas, una reducción importante del suministro a las empresas siderúrgica y del aluminio en Guayana, la 
sustitución parcial de bombillos de filamento por bombillos ahorradores de energía, el recorte de los horarios de trabajo de los centros comerciales y de las oficinas públicas, la reducción de ventas de electricidad a Brasil y el incremento de generación térmica hasta su límite máximo.

Adicionalmente, se planifica la incorporación de $4.420 \mathrm{MW}$ de plantas térmicas (3.920 MW) e hidroeléctricas (500 MW) de pequeña capacidad entre el año 2010 y 2012 [CORPOELEC, 2010]. Los planes prevén la incorporación de 3.910 MW hasta el año 2011 y de 510 MW para el año 2012 [Hernández, 2010c].

Por otra parte, se apresura la construcción de un pequeño desarrollo eólico al norte del país y se suscriben convenios (i) con China para el desarrollo de plantas eléctricas que utilice el coque de petróleo producido en Venezuela y (ii) con Rusia, para el potencial desarrollo en el país de generación nuclear con fines pacíficos.

Sin embargo, paralelamente a estas medidas de naturaleza reactiva ante la crisis, deben formularse políticas, planes, programas y proyectos a mediano y largo plazo con base en la demanda futura para el período de estudio seleccionado, los recursos energéticos que posee en gran abundancia el país, las características de las mejores tecnologías y equipos disponibles en el mercado para su explotación, las condiciones técnicas y geofísicas mínimas requeridas para su aplicación, sus eficiencias energéticas y rendimientos económicos, la afectación ambiental que la explotación pueda causar y los potenciales riesgos para la población; las inversiones necesarias frente al presupuesto que a ello destine la nación, las características políticas, sociales y económicas del país, su marco regulatorio y los compromisos internacionales adquiridos. $Y$ naturalmente, debe captarse al personal técnico idóneo para su ejecución oportuna.

Planteado de esta forma, la planificación en el sector eléctrico para el país es un problema de análisis multicriterio que como objetivo principal debe tener el diseño de la mejor matriz energética para el período que se juzgue de interés. En el cumplimiento de tal tarea, el modelo de evaluación multicriterio de alternativas propuesto en el capítulo anterior puede servir como una herramienta de apoyo a la toma de decisiones que deba efectuarse. 


\subsubsection{Aplicación del modelo de análisis multicriterio}

A continuación se muestra como puede contribuir el modelo de valor propuesto en el capítulo anterior, a la búsqueda de una solución parcial al problema eléctrico en Venezuela. Dada la escasez de estadísticas precisas por parte de los organismos públicos en el país, se trabaja salvo algunas excepciones, en base a valores promedio tomados de publicaciones internacionales en el sector, en publicaciones del sector privado y académico del país, y en algunas publicaciones de la prensa electrónica nacional. En consecuencia, los resultados obtenidos constituyen una solución aproximada al problema propuesto.

El objetivo final a lograr es una propuesta de matriz eléctrica para Venezuela cuya implementación a lo largo del período 2011-2025 permita cumplir con los requerimientos de potencia eléctrica de la nación. La figura 5.9 muestra el procedimiento a seguir.

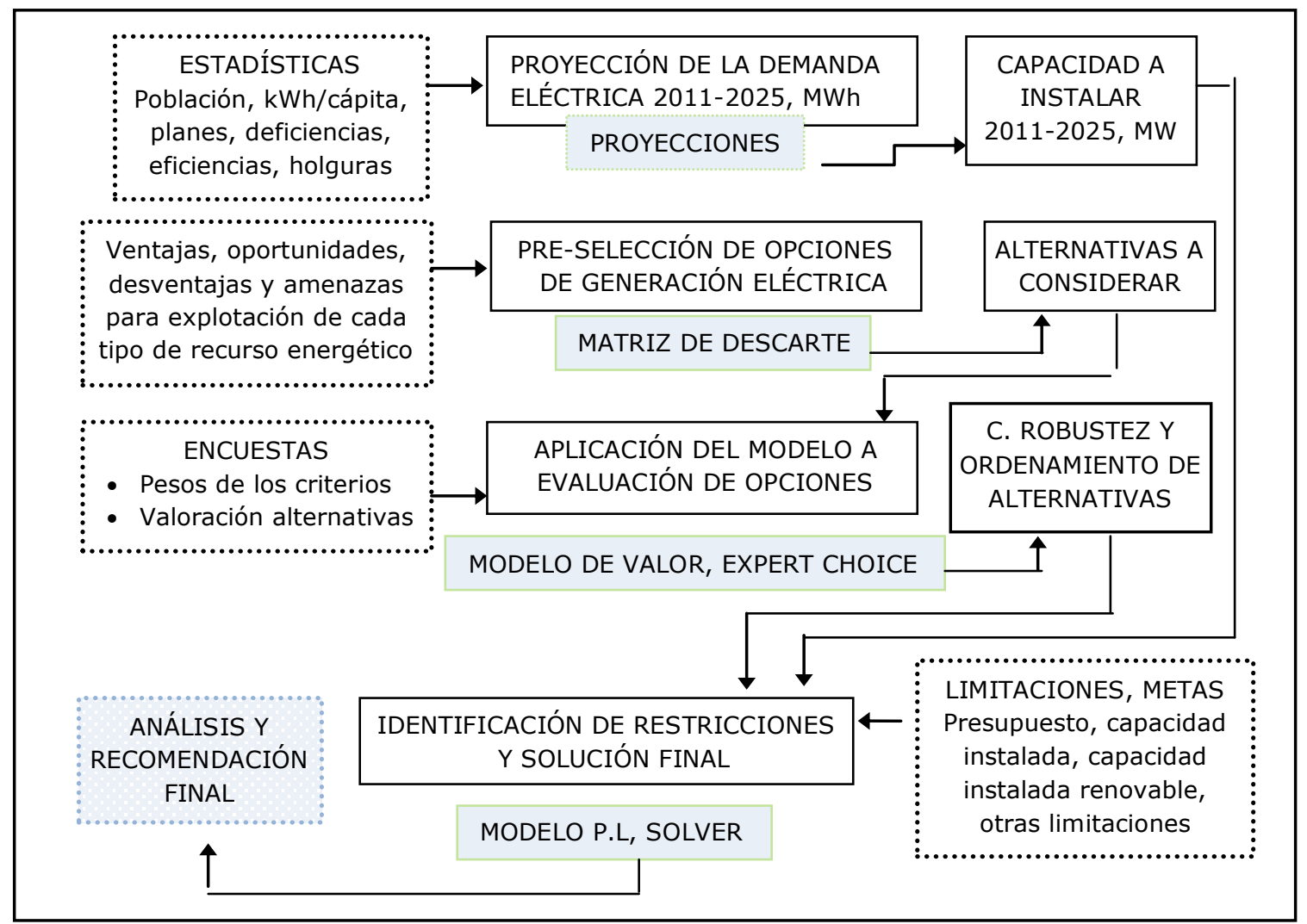

Figura 5.9. Procedimiento para la solución del caso de estudio 
Se consideró conveniente tomar un período de estudio de al menos 15 años, contados a partir del año 2011, de forma de abarcar los extensos períodos de construcción de algunas instalaciones para la generación de energía eléctrica. El proceso de solución contempla los pasos que se listan a continuación:

- Estimación de la capacidad eléctrica a instalar para el período 2011-2025

- Preselección de las opciones de generación eléctrica a evaluar

- Aplicación del modelo a la evaluación de las alternativas preseleccionadas

- Identificación de las restricciones a la solución del problema

- Planteamiento de un modelo que incorpore las restricciones identificadas

- Análisis de resultados y recomendaciones finales.

A continuación la descripción de los cálculos efectuados en cada etapa listada.

\subsection{Capacidad eléctrica a instalar para el período 2011-2025}

La posición oficial sobre la situación actual de la crisis eléctrica en Venezuela y sobre los planes para enfrentarla no es transparente; la información es suministrada de forma puntual por voceros de los organismos creados para el manejo del sector ${ }^{77}$; las estadísticas que existen son incompletas; y a veces, no compatibles entre las fuentes; y los anuncios sobre ejecución de planes sólo se cumplen parcialmente.

Dada la gran incertidumbre que se percibe en el futuro del sector, se hace necesario plantear varios escenarios para la proyección del consumo y la demanda eléctrica en el país. La estructuración de los escenarios se basa (i) en la data oficial más actualizada y completa de la cual se dispone, contrastada y/o complementada con información privada divulgada en artículos, conferencias y prensa electrónica por expertos en el área y con data puntual suministrada en ruedas de prensa de las autoridades en el sector y (ii) en la percepción que el autor tiene sobre la materia.

77 (i) CORPOELEC, (ii) Ministerio del Poder Popular para la Energía Eléctrica (MPPEE) creado con motivo de la crisis, (iii) Oficina para la Operación del Sistema Interconectado (OPSIS ahora CNG) cuya página web ha sido cerrada por incompatibilidad de información con el MPPEE y (iv) Ministerio de Energía y Petróleo (MENPET). 
La capacidad eléctrica a instalar es función de la demanda estimada de la población; y ésta a su vez, del crecimiento y requerimientos estimados del sector doméstico y del sector económico productivo de la nación; de los planes del sector público y de los montos para inversión disponibles; de la capacidad instalada o recuperada a la fecha y de las deficiencias acumuladas hasta la misma; de los recursos energéticos y de las tecnologías disponibles para su transformación, de las eficiencias en cada parte del proceso de generación y distribución de la energía; y de las holguras requeridas. A continuación, alguna información recabada al respecto.

\subsection{Tendencia de crecimiento de la población}

Las figuras $5.10 \mathrm{a}$ y $5.10 \mathrm{~b}$ muestran la tendencia estimada de crecimiento de la población venezolana para el período 2011-2025, expresada respectivamente en cifras absolutas y en tasas de incremento interanual. Se utilizaron las cifras del período 2001-2015 publicadas por el Instituto Nacional de Estadística, Venezuela [INE, 2011] para: (i) calcular el crecimiento porcentual de la población cada año durante el período 2001-2015 y proyectarlo al período 2016-2025, (ii) estimar la población anual para el período 2016-2025, y (iii) calcular la tasa interanual de crecimiento de la población (TIC) para el período 2011-2025, de acuerdo a la siguiente expresión:

$$
\operatorname{TIC}_{2011-2025}=\left(P_{2025} / P_{2010}\right)^{1 / 15}-1=0,0134
$$

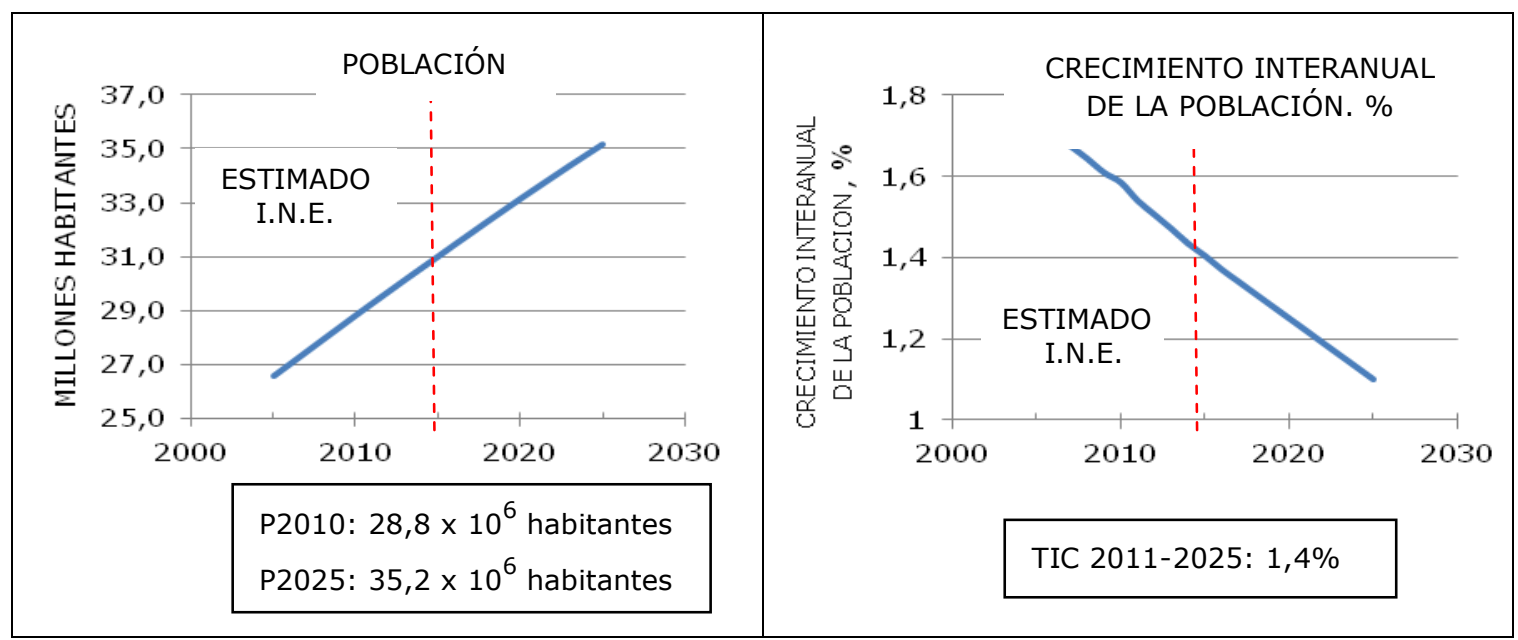

Fuente de datos: INE, 2011

Figura 5.10. Crecimiento estimado de la población venezolana, 2011-2025 
Para el período 2011-2025, la tasa de crecimiento interanual de la población venezolana se estimó en $1,4 \%$.

\subsection{Tendencia del consumo de energía eléctrica, 2001-2010}

El consumo de energía eléctrica por habitante en Venezuela es el más alto en América Latina. La aplicación reciente de una serie de medidas de ahorro, racionamiento y penalidades económicas a la población y a las grandes empresas que excedan un límite prefijado de consumo eléctrico, logró bajar el consumo a 3.900 kWh/cápita; cifra que representó una reducción del $9 \%$ sobre el mismo indicador del año 2009 y que aún resulta un $14 \%$ más elevada que el correspondiente promedio latinoamericano ${ }^{78}$. En cuanto al consumo total, su reducción Ilegó a un 7,5\% [MENPET, 2010; INE, 2011].

La figura 5.11 muestra claramente la tendencia al crecimiento del consumo eléctrico para el período 2000-2009. La tasa interanual de crecimiento del consumo para dicho lapso fue de $4,3 \%$.

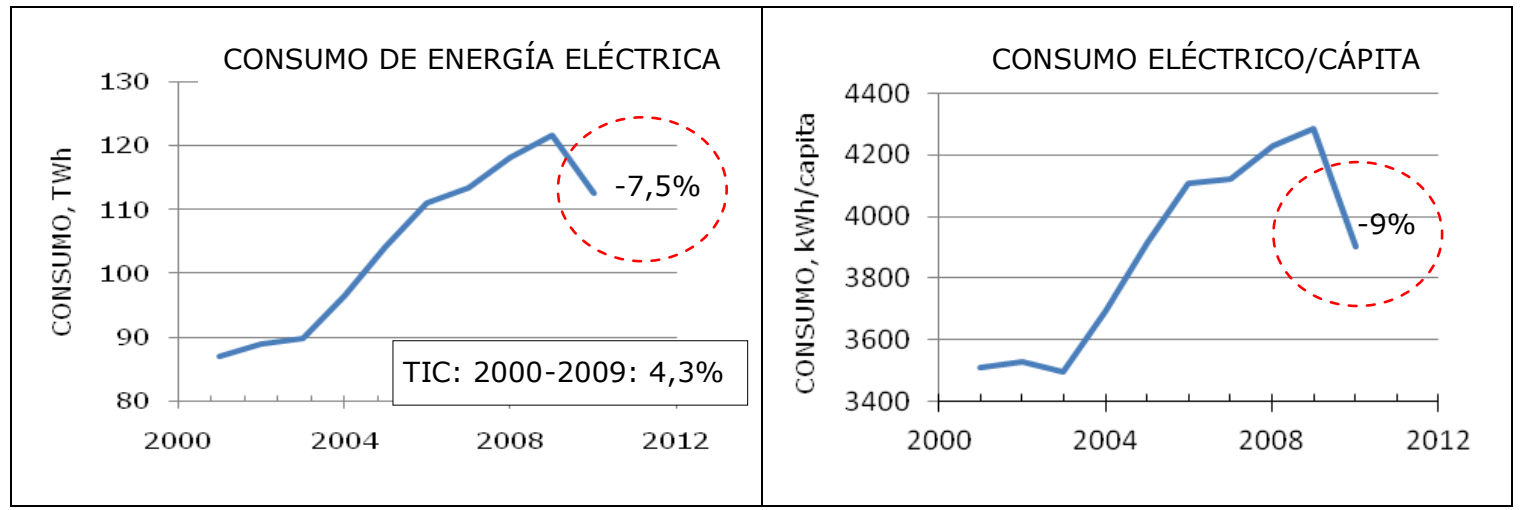

Fuente de datos: [MENPET, 2010; INE, 2011]

Figura 5.11. Tendencia del consumo de energía eléctrica en Venezuela, 2001-2010

Araque A. (16/6/2011), "Venezuela consume el 14\% más de energía que el promedio por habitante en América Latina", Noticias24.com, en http://www.noticias24.com/actualidad/noticia/268643/venezuelaconsume-14-mas-energia-que-el-promedio-por-habitante-en-america-latina/, 8/ 2011. 
La reducción en el consumo que se observa para el año 2010 es la primera vez que se presenta en muchos años y es consecuencia de las medidas oficiales para enfrentar la crisis. Adicionalmente, expertos gubernamentales han propuesto iniciar un programa de uso racional y eficiente de la energía (UREE) que tiene como meta una reducción de un 10\% acumulado del consumo eléctrico para el período 20112015 y de un $30 \%$ hasta el año 2030 [CORPOELEC, 2010].

\subsection{Tendencia de la demanda de energía eléctrica, 2001-2010}

La figura 5.12 muestra el consumo y la demanda de energía eléctrica (MW) en Venezuela para el período 2001-2010; así como la relación anual entre ambos renglones para un determinado período, o factor de carga [CORPOELEC, 2010].

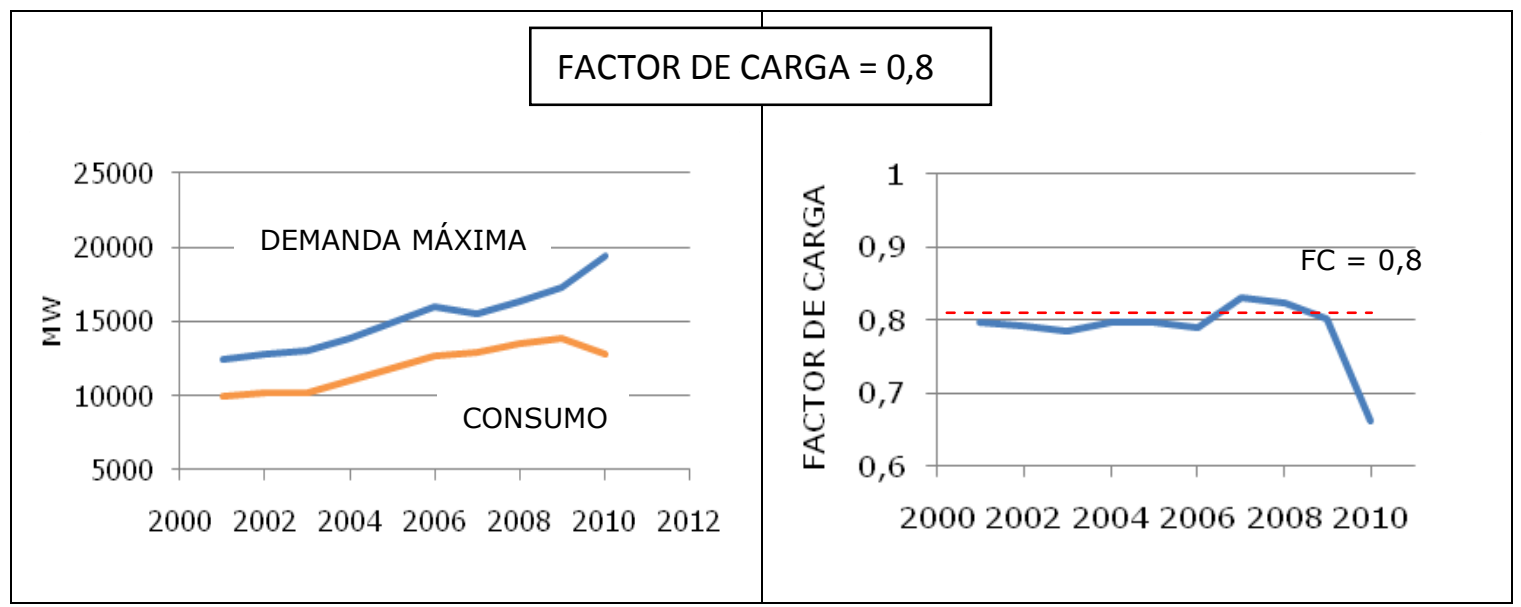

Fuente de datos: [Aguilar,2010]

Figura 5.12. Consumo, demanda máxima de energía eléctrica y factor de carga, Venezuela, 2001-2010.

Como puede observarse el factor de carga se ubica en promedio, alrededor de 0,8 para el período 2001-2009. En la cifra no se incluye el año 2010 durante el cual se forzó el consumo a la baja.

\subsection{Proyección del consumo y demanda de energía eléctrica}

El Fondo Monetario Internacional proyecta un crecimiento económico para Venezuela de 2,8\% para el año 2011 que se eleva a 3,6\% en el año 2012 frente a promedios estimados de $4,7 \%$ y $4 \%$ respectivamente para las economías más 
grandes de América Latina ${ }^{79}$ [FMI, 2011]. Si se toman estas cifras como una referencia y se tienen en cuenta (i) las tendencias observadas de crecimiento de la población venezolana, del consumo eléctrico y de la demanda eléctrica máxima de la nación, (ii) los planes de ahorro y racionamiento que viene aplicando el gobierno nacional desde al año 2010 y (iii) el programa de inversiones y recuperaciones que añadiría 4.420 MW [CORPOELEC 2010]; la proyección del consumo eléctrico en Venezuela puede realizarse bajo las siguientes suposiciones:

(i) Hasta el año 2012 se mantendrá el consumo de 3.900 kWh por habitante logrado en el año 2010; esto es equivalente a suponer que el consumo en GWh crecerá a una tasa interanual igual al crecimiento poblacional de 1,4\%, señalado en la figura 5.10. A juicio del autor, colocar un número más bajo no sería realista en un país con tendencia histórica tal como se indica en la figura 5.11, con poca eficiencia en uso de la electricidad y con las autoridades responsables tratando de suplir el déficit en un año de elecciones. De acuerdo a los planes de las autoridades nacionales en el sector, se añadirá un total de $4.420 \mathrm{MW}$ hasta el año 2012 distribuidos como se señaló en el aparte 5.1.3.2.1. La operatividad de tales incorporaciones se tomará igual a $73 \%$ tal como se señaló en la figura 5.8 .

(ii) Para el resto del período, se contemplan tres escenarios de crecimiento del consumo, a saber:

ESCENARIO 1. Para el período 2013-2025, se asume una tasa interanual de crecimiento del consumo igual a su crecimiento histórico del 4,3\%, señalado en la figura 5.11. Es un escenario optimista donde se supone que el país deberá realizar un esfuerzo adicional para acercarse al crecimiento promedio estimado por el Fondo Monetario Internacional para las economías grandes de América Latina durante el año 2012 [FMI, 2011].

79 Incluye Argentina, Brasil, Chile, Colombia, México, Perú y Venezuela 
ESCENARIO 2. Para el período 2013-2025, se asume un crecimiento moderado del consumo, con una tasa intermedia del 3,6\% interanual, igual a la estimada por el FMI para el país durante el año 2012.

ESCENARIO 3. Para el período 2013-2025 se asume un crecimiento bajo del consumo con una tasa igual a $3 \%$ de crecimiento interanual, superior al crecimiento poblacional pero inferior a la cifra estimada por el FMI para el país durante el año 2012.

La demanda eléctrica puede estimarse en base los resultados obtenidos y el factor de carga estimado para el país (figura 5.12). Adicionalmente, y de acuerdo a las mejores prácticas en el área [Hernández, 2010c] debe añadirse un 30\% de holgura para estimar la capacidad instalada necesaria de generación. Las tablas 5.5 y las figuras 5.13 muestran los resultados obtenidos para los escenarios 1 a 3 descritos en la página anterior.

Tabla 5.5a. Proyección del consumo, de la demanda máxima y de la capacidad de generación eléctrica necesaria, Venezuela 2011-2025. Escenario 1.

\begin{tabular}{|c|c|c|c|c|}
\hline \multirow{3}{*}{ AÑO } & \multicolumn{4}{|c|}{ ESCENARIO 1} \\
\hline & \multicolumn{2}{|c|}{ CONSUMO } & \multirow{2}{*}{$\begin{array}{l}\text { DEMANDA } \\
\text { FC=0,8 } \\
(\mathrm{MW})\end{array}$} & \multirow{2}{*}{$\begin{array}{l}\text { CAPACIDAD DE } \\
\text { GENERACIÓN } \\
(\mathrm{MW})\end{array}$} \\
\hline & (GWh) & $\begin{array}{l}\text { CRECIMIENTO } \\
\text { INTERANUAL }\end{array}$ & & \\
\hline 2010 & 116.702 & Base: datos reales ${ }^{a}$ & 18.377 & 15.129 \\
\hline 2011 & 118.336 & $1,4 \%$ & NA & $17.883^{C}$ \\
\hline 2012 & 119.993 & $1,4 \%$ & ND & $18.356^{c}$ \\
\hline 2015 & 136.147 & \multirow{3}{*}{$\begin{array}{c}\text { TIC 2013-2025 }= \\
4,3 \%\end{array}$} & 19.427 & $25.256 *$ \\
\hline 2020 & 168.046 & & 23.979 & 31.173* \\
\hline 2025 & 207.420 & & 29.598 & $38.477 *$ \\
\hline \multicolumn{4}{|c|}{ DEMANDA $=$ CONSUMO $* 1000 /(365 * 24 * 0,8)$} & $\mathrm{CG}=\mathrm{DEM} * 1,3$ \\
\hline
\end{tabular}

a Valores reales para el año 2010, Aguilar (2010) * Capacidad instalada, holgura $=30 \%$ c CG disponible $2011=15129+3910 * 0,73 ;$ CG disponible $2012=$ CG $_{2011}+510 * 0,73$

Las cifras en la primera línea del cuadro anterior corresponden respectivamente a valores reales del consumo, de la demanda máxima y de la capacidad de generación disponible para el año 2010. El consumo para los años 2011 y 2012 se estima 
suponiendo un crecimiento interanual 1,4\%; y la capacidad de generación disponible para los mismos años, se estima tomando en cuenta los planes de incorporación de 4.420 MW, con un factor de operatividad de 73\%; todo ello establecido en las suposiciones comunes para todos los escenarios. Su cálculo se ilustra al pie del cuadro. Las cifras para el resto del período son estimadas de acuerdo a las suposiciones del escenario 1 ; entre ellas, las cifras en la última columna corresponden a capacidad de generación instalada necesaria hasta el año que se indica en la primera columna.

Para el escenario que supone un crecimiento económico más elevado, el consumo se estima respectivamente en 136,2 TWh, 168,1 TWh y 207,4 TWh para los años 2015, 2020 y 2025 para suplir los cuales, la capacidad de generación necesaria se ubica en 25.256 MW hasta el año 2015, 31.173 MW hasta el año 2020 y 38.477 MW hasta el año 2025.

Tabla 5.5b. Proyección del consumo, de la máxima demanda y de la capacidad de generación eléctrica necesaria, Venezuela 2010-2025. Escenario 2.

\begin{tabular}{|c|c|c|c|c|}
\hline \multirow{3}{*}{ AÑO } & \multicolumn{4}{|c|}{ ESCENARIO 2} \\
\hline & \multicolumn{2}{|c|}{ CONSUMO } & \multirow{2}{*}{$\begin{array}{c}\text { DEMANDA } \\
\mathrm{FC}=0,8 \\
(\mathrm{MW})\end{array}$} & \multirow{2}{*}{$\begin{array}{c}\text { CAPACIDAD DE } \\
\text { GENERACIÓN* } \\
(\mathrm{MW})\end{array}$} \\
\hline & $(G W h)$ & $\begin{array}{l}\text { CRECIMIENTO } \\
\text { INTERANUAL (\%) }\end{array}$ & & \\
\hline 2010 & 116.702 & Base: datos reales ${ }^{a}$ & 18.377 & 15.129 \\
\hline 2011 & 118.336 & $1,4 \%$ & NA & $17.883^{c}$ \\
\hline 2012 & 119.993 & $1,4 \%$ & NA & $18.356^{c}$ \\
\hline 2015 & 133.424 & \multirow{3}{*}{$\begin{array}{c}\text { TIC } 2012-2025= \\
3,6 \%\end{array}$} & 19.039 & 24.750* \\
\hline 2020 & 159.233 & & 22.722 & 29.538* \\
\hline 2025 & 190.034 & & 27.117 & $35.252 *$ \\
\hline \multicolumn{4}{|c|}{ DEMANDA $=$ CONSUMO $* 1000 /(365 * 24 * 0,8)$} & $C G=D E M * 1,3$ \\
\hline
\end{tabular}

a Valores reales para el año 2010, Aguilar (2010) * Capacidad instalada, holgura $=30 \%$ c CG disponible $2011=15129+3910 * 0,73 ;$ CG disponible $2012=$ CG $_{2011}+510 * 0,73$

Para un escenario de crecimiento económico moderado, la capacidad de generación necesaria se ubica en 24.750 MW hasta el año 2015, 29.538 MW hasta el año 2020 y 35.252 MW hasta el año 2025. 
Tabla 5.5c. Proyección del consumo, de la máxima demanda y de la capacidad de generación eléctrica necesaria, Venezuela 2010-2025. Escenario 3.

\begin{tabular}{|c|c|c|c|c|}
\hline \multirow{3}{*}{ AÑO } & \multicolumn{4}{|c|}{ ESCENARIO 3} \\
\hline & \multicolumn{2}{|r|}{ CONSUMO } & \multirow{2}{*}{$\begin{array}{c}\text { DEMANDA } \\
\mathrm{FC}=0,8 \\
(\mathrm{MW})\end{array}$} & \multirow{2}{*}{$\begin{array}{c}\text { CAPACIDAD DE } \\
\text { GENERACIÓN* } \\
(\mathrm{MW})\end{array}$} \\
\hline & (GWh) & $\begin{array}{l}\text { CRECIMIENTO } \\
\text { INTERANUAL }\end{array}$ & & \\
\hline $2010 \neq$ & 116.702 & Base: datos reales ${ }^{a}$ & 18.377 & 15.129 \\
\hline 2011 & 118.336 & $1,4 \%$ & NA & $17883^{c}$ \\
\hline 2012 & 119.993 & $1,4 \%$ & NA & $18356^{c}$ \\
\hline 2015 & 131.119 & \multirow{3}{*}{$\begin{array}{c}\text { TIC } 2012-2025= \\
3 \%\end{array}$} & 18.710 & 24.323* \\
\hline 2020 & 152.003 & & 21.690 & 28.197* \\
\hline 2025 & 176,213 & & 25.145 & $32.688^{*}$ \\
\hline \multicolumn{4}{|c|}{ DEMANDA $=$ CONSUMO $* 1000 /(365 * 24 * 0,8)$} & $C G=D E M * 1,3$ \\
\hline
\end{tabular}

a Valores reales para el año 2010, Aguilar (2010) * Capacidad instalada, holgura $=30 \%$ c CG disponible $2011=15129+3910 * 0,73 ;$ CG disponible $2012=\mathrm{CG}_{2011}+510 * 0,73$

Para un escenario de crecimiento económico bajo, la capacidad necesaria se ubica en 24.323 MW hasta el año 2015, 28.197 MW hasta el año 2020 y 32.688 MW hasta el año 2025.

La figura 5.13 es un grafico de los resultados para los escenarios supuestos.

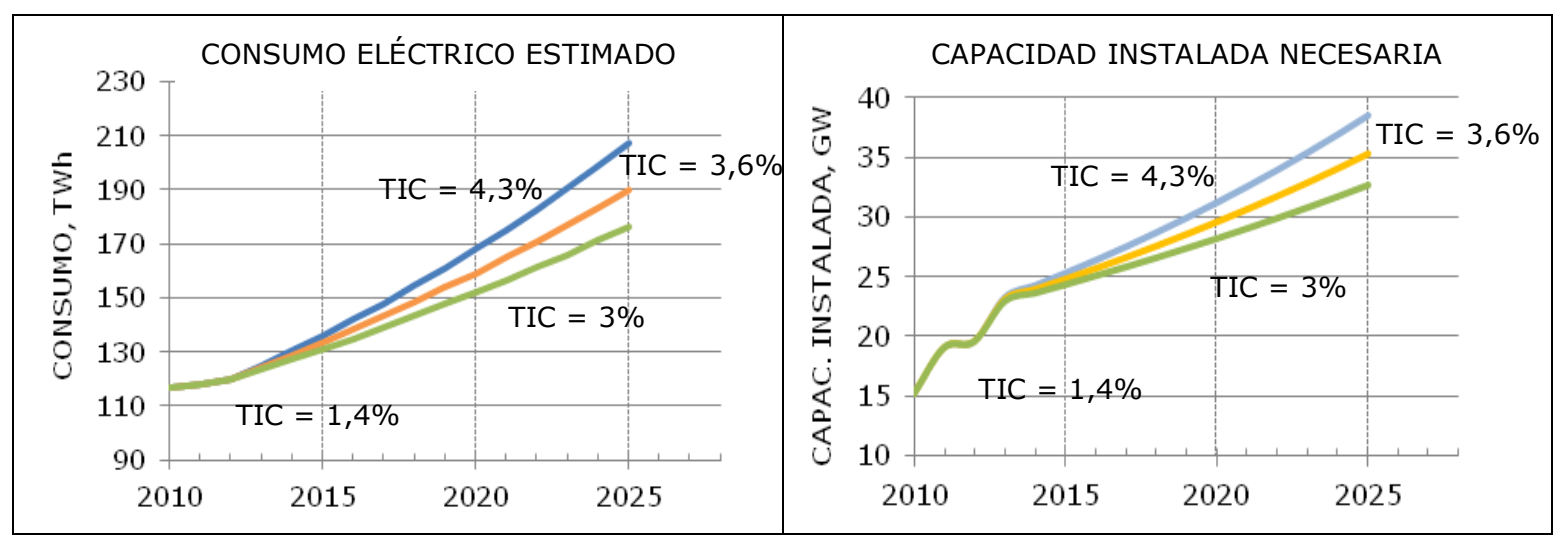

Figura 5.13. Proyección del consumo y de la capacidad de generación eléctrica necesaria a lo largo del período 2011-2025. 
La diferencia entre la capacidad de generación necesaria para cumplir con los requerimientos del país durante el período de estudio y la capacidad disponible al inicio del mismo es igual a la capacidad a instalar. Si la capacidad disponible a esa fecha es de 15.129 MW [Aguilar, 2010] deberán instalarse y/o recuperarse entre $17,6 \mathrm{GW}$ y $23,3 \mathrm{GW}$, durante el período 2011-2025. Adicionalmente, la capacidad que por una u otra razón salga de operación debe ser restituida. En tal sentido, la operatividad de las incorporaciones hasta mediados del año 2010 fue de un 73\% tal como se refleja en la figura 5.7 incluida anteriormente. Si se toma en cuenta esta cifra y se desea mantener la holgura, la capacidad a instalar se ubica entre $24,1 \mathrm{GW}$ y 31,9 GW para el mismo el período.

Sin embargo, el gobierno nacional ya ha comenzado la incorporación de un estimado de 4.420 MW para el período 2010-2012. Si los planes se cumplen, la capacidad a instalar se ubica entre 19,7 GW y 27,5 GW para el período 2013-2025; esto es, un promedio que oscila entre $1,5 \mathrm{GW} /$ año y $2,1 \mathrm{GW} /$ año para dicho período.

\subsection{Distribución del consumo y demanda de energía eléctrica}

La Corporación Eléctrica Nacional en su documento Plan Maestro Socialista para el Rescate y Desarrollo del Sistema Eléctrico 2010-2030 [CORPOELEC, 2010] presenta los resultados de un estudio prospectivo sobre el consumo y la demanda eléctrica venezolana para el período señalado. La proyección del consumo de energía eléctrica se realiza para cada una de nueve zonas geoeléctricas definidas a efectos del estudio; y dentro de cada zona, para los sectores doméstico, industrial, comercial y otros. La figura 5.14 que se presenta en la próxima página, muestra esquemáticamente, la división del país en regiones geoeléctricas.

Series estadísticas para el período 2001-2009 sobre consumo eléctrico facturado, nivel de actividad económica expresada en función del crecimiento del Producto Interno Bruto (PIB) y del crecimiento estimado de la población sirvieron de insumo al modelo utilizado para las proyecciones. Adicionalmente, se añadió de manera explícita, la carga requerida por los proyectos contemplados en el Plan Nacional de Desarrollo Simón Bolívar [RBV Presidencia, 2007], las pérdidas de energía y la demanda represada definida como la energía demandada por los usuarios que no ha 
sido completamente atendida por problemas de sobrecarga en subestaciones y circuitos de distribución, de caídas de tensión, o por estar ubicada en zonas remotas [CORPOELEC, 2010].

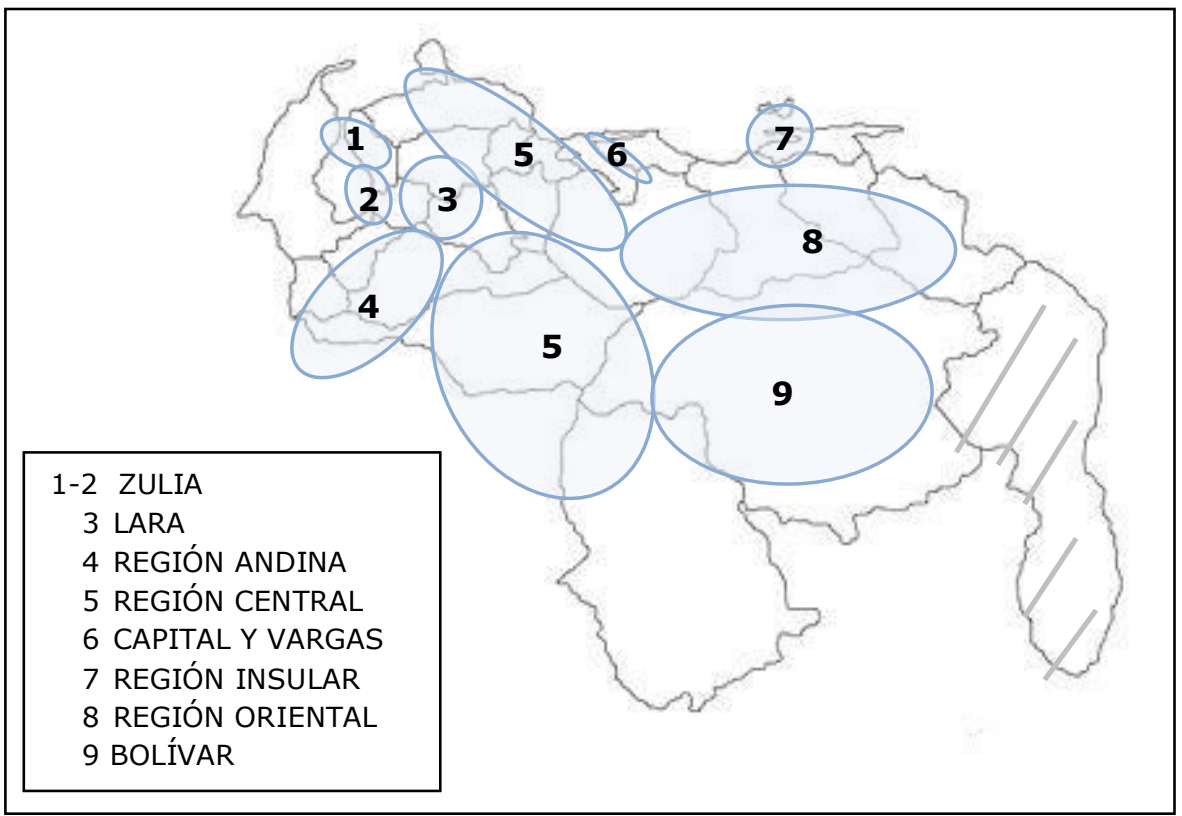

Fuente: Tomado de [CORPOELEC, 2010]

Figura 5.14. Zonas geoeléctricas a efectos del estudio CORPOELEC 2010 sobre consumo de energía eléctrica en Venezuela.

Se consideraron dos escenarios de partida y dos escenarios alternativos modificación de los anteriores, a saber:

ESCENARIO 1. Se asume crecimiento moderado de la economía relacionado con el crecimiento de la población económicamente activa (1,4\%). Se añade de forma explícita, la carga requerida por los proyectos asociados al Plan Simón Bolívar pero se desplaza su ejecución y puesta en operación de acuerdo a información suministrada por el Ministerio de Planificación y Finanzas por un período de tres años.

ESCENARIO 2. Se asume un mayor crecimiento del PIB (2,5\%) asociado al efecto multiplicador que se supone tendrá la aplicación del plan de desarrollo de la nación. Se añade de forma explícita, la carga requerida por los proyectos asociados al Plan Simón Bolívar en la fecha original planificada para su ejecución y 
puesta en operación de acuerdo a información suministrada por el Ministerio de Planificación y Finanzas.

ESCENARIOS ALTERNATIVOS 3 y 4 . Se añade a los escenarios 1 y 2 , el efecto que se estima producirá la aplicación de las medidas contempladas en el programa de uso racional y eficiente de la energía (UREE), citado en la sección 5.1.3.3.1.2.

Las cifras obtenidas y el factor de carga estimado para cada región geoeléctrica definida, sirvieron de base para la estimación de la demanda eléctrica a nivel regional. Los factores de carga estimados se ubican entre $75 \%$ y $86 \%$ para las regiones. Los resultados obtenidos se copian en la Tabla 5.6 que se incluye a continuación.

Tabla 5.6. Resultados proyección de la demanda eléctrica CORPOELEC, 2010-2030

\begin{tabular}{|c|l|c|c|c|}
\hline \multicolumn{2}{|c|}{ ESCENARIO } & \multirow{2}{*}{ CONSUMO } & \multicolumn{2}{c|}{ TASA INTERANUAL CRECIMIENTO } \\
\cline { 5 - 5 } CÓDIGO & DESCRIPCIÓN & $2030(\mathrm{GWh})$ & CONSUMO & DEMANDA MÁXIMA \\
\hline E1 & Moderado & 293.162 & $4,4 \%$ & $4.2 \%$ \\
\hline E2 & Desarrollo & 350.597 & $5,0 \%$ & $4,8 \%$ \\
\hline E3 & Moderado + UREE & ND & $3,5 \%$ & $3,4 \%$ \\
\hline E4 & Desarrollo + UREE & ND & $4,0 \%$ & $3,9 \%$ \\
\hline
\end{tabular}

Fuente: [CORPOELEC, 2010]

La tasa interanual de crecimiento del consumo eléctrico que arroja el estudio realizado por CORPOELEC para el período 2010-2030 oscila entre 3,5\% y 5\%, tal como se refleja en el cuadro anterior. El resultado es más elevado que el rango para la misma variable $(3 \%-4,6 \%)$ dentro del cual se ubicaron los escenarios menos favorable y más favorable de crecimiento del consumo, en el estudio para estimar la capacidad de generación necesaria para el período [2011-2025] realizado por el autor y recogido en las páginas anteriores de este documento.

Para el año 2030 el estudio CORPOVEN diagnostica un consumo total de 293.162 GWh en el escenario moderado y de 350.597 GWh en el escenario base de desarrollo económico. Para los escenarios moderado y de desarrollo económico con uso eficiente de la energía no se dispone de cifras, que probablemente se acercarán más a las obtenidas anteriormente por el autor. 
Para el mismo año, las figura 5.15 muestran la distribución estimada por zona geoeléctrica del consumo y de la demanda de energía máxima.

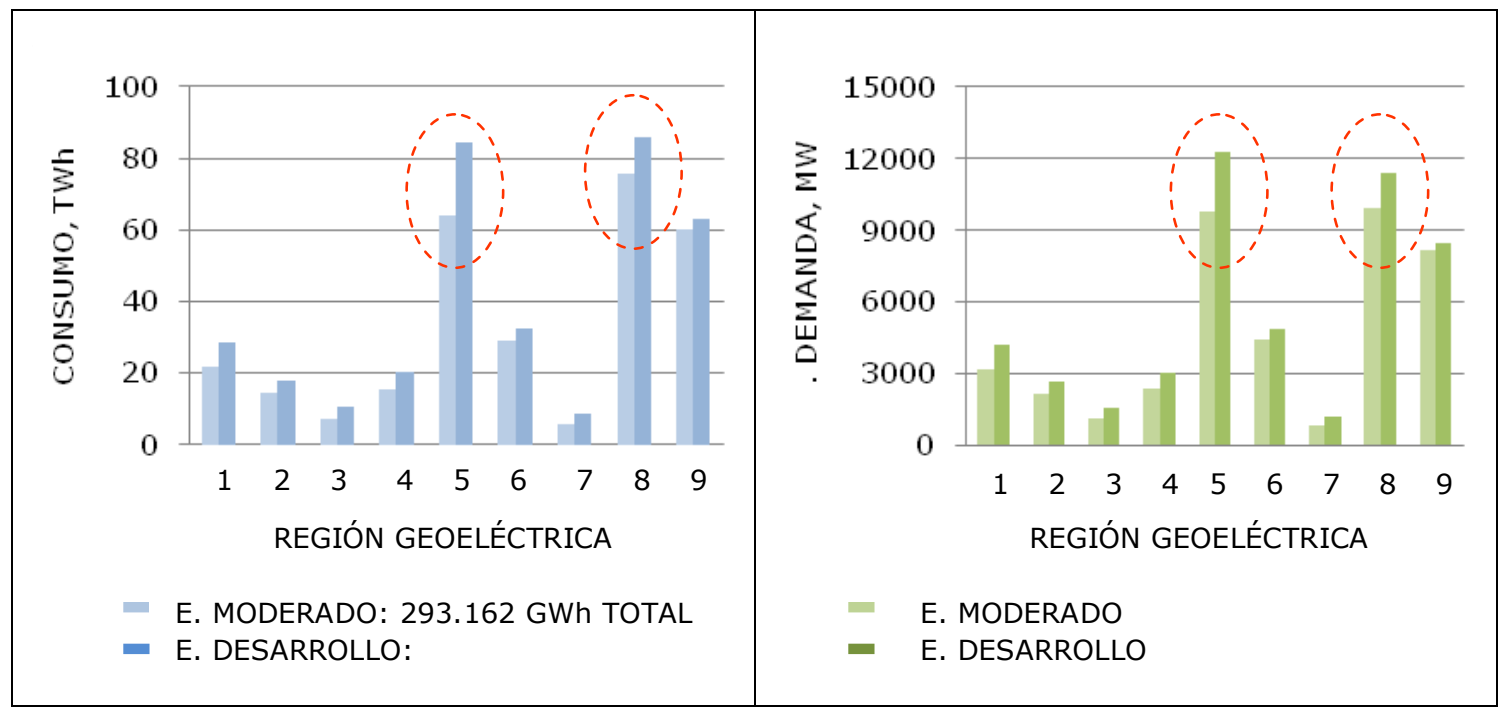

Fuente: [CORPOELEC, 2010]

Figura 5.15. Proyección CORPOELEC2010 de consumo y de demanda máxima de energía eléctrica, clasificada por regiones geoeléctricas, 2030.

Como puede observarse, el mayor consumo y demanda eléctrica corresponde a los estados centrales (zona 5) y a la región oriental del país (zona 8). La capacidad necesaria de generación para el mismo año, se estima en 40.174 MW en el escenario moderado. Los resultados mostrados en el gráfico pueden servir de referencia para la distribución espacial de la capacidad eléctrica que los planes recomienden instalar.

\subsection{Selección de las opciones de generación eléctrica a evaluar}

Una vez obtenidos el rango donde se estima oscilará la capacidad de generación eléctrica necesaria para el período 2011-2025 en Venezuela, y su distribución temporal y geográfica aproximada; el paso que sigue es construir la matriz eléctrica más conveniente a los intereses del país tomando en cuenta los requerimientos, las opciones y las restricciones del problema. La figura 5.16 muestra las posibles opciones con un símbolo de chequeo en color rojo. Las opciones se asocian respectivamente a los recursos energéticos con un potencial identificable en el país. Los cuadros rayados en azul corresponden a los recursos energéticos que 
actualmente se utilizan para la generación de electricidad en Venezuela; otras opciones de energía se utilizan muy poco o nada.

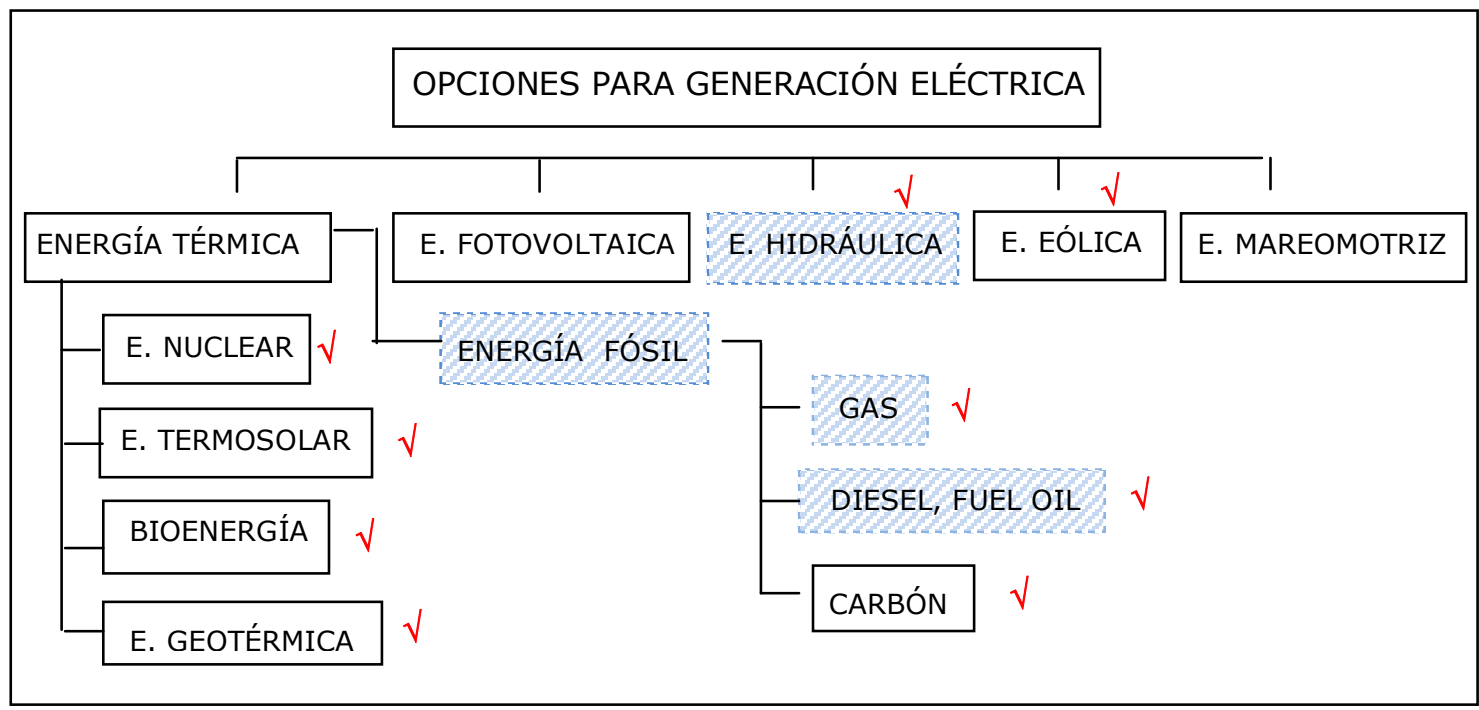

Figura 5.16. Opciones de generación eléctrica a evaluar $(\sqrt{ })$

Como un paso preliminar y a objeto de reducir el tamaño del problema, se elaboró la matriz de descarte que se presenta en la próxima página. La matriz consolida las opiniones del autor, dos directores de CORPOELEC y dos académicos especialistas sobre cuales serían los elementos esenciales a tomar en cuenta para la elaboración del plan de generación 2011-2025 en las circunstancias actuales del país, cuál su importancia y cuál el grado de cumplimiento por parte de cada una de las opciones presentadas en la figura 5.15. Las opiniones se expresaron de forma aproximada utilizando una escala 1-3 donde 1 representó el nivel más bajo de satisfacción.

Nótese que la tabla 5.7 es una matriz de descarte y no de selección. Los criterios utilizados y su dirección de mejoramiento se copian en la primera columna; y la importancia que respectivamente se le da a cada uno de ellos ( $\mathrm{Pi}$ ), se copia en la segunda columna. De esta forma, la calificación $(\mathrm{Cj}$ ) para la opción energética $\mathrm{j}$, se obtiene como un promedio ponderado del grado de cumplimiento de la opción con relación a cada criterio i $(\mathrm{Ci}, \mathrm{j})$; esto es,

$$
\mathrm{Cj}=\Sigma \mathrm{Pi} \times \mathrm{Ci}, \mathrm{j}
$$


Los criterios utilizados se refieren a aspectos que se consideran muy importantes ante la circunstancia de crisis eléctrica que vive Venezuela, y ellas apuntan a favorecer a aquellas alternativas que permitan la instalación de la capacidad faltante a un precio conveniente y en el menor tiempo posible. Menor importancia se le da a factores ambientales y de riesgo; y a la consulta a la comunidad.

Tabla 5.7. Matriz de descarte de opciones de generación eléctrica, Venezuela

\begin{tabular}{|c|c|c|c|c|c|c|c|c|c|c|c|c|}
\hline \multirow{2}{*}{ CONDICIÓN } & \multirow{2}{*}{ PESO } & \multicolumn{11}{|c|}{ OPCIONES DE GENERACIÓN } \\
\hline & & $P$ & GN & C & $\mathrm{N}$ & $\mathrm{H}$ & $\mathrm{E}$ & FV & TS & G & $M$ & $B$ \\
\hline Disponibilidad del recurso $(+)$ & 0,15 & 3 & 2 & 3 & 1 & 3 & 3 & 3 & 3 & 3 & 3 & 2 \\
\hline $\begin{array}{l}\text { Capacidad posible de generación } \\
\text { con el uso de la tecnología } \\
\text { asociada (+) }\end{array}$ & 0,15 & 3 & 3 & 3 & 3 & 3 & 2 & 1 & 2 & 2 & 1 & 2 \\
\hline Inversión inicial accesible/Mw(-) & 0,15 & 3 & 3 & 2 & 1 & 1 & 3 & 1 & 1 & 2 & 2 & 1 \\
\hline $\begin{array}{l}\text { Conocimiento y experiencia en el } \\
\text { manejo de la tecnología }(+)\end{array}$ & 0,08 & 3 & 3 & 3 & 1 & 3 & 1 & 1 & 1 & 1 & 1 & 2 \\
\hline $\begin{array}{l}\text { Disponibilidad de personal } \\
\text { entrenado }(+)\end{array}$ & 0,08 & 3 & 3 & 3 & 1 & 3 & 2 & 1 & 1 & 1 & 1 & 2 \\
\hline $\begin{array}{l}\text { Período de construcción y puesta } \\
\text { en marcha }(-)\end{array}$ & 0,10 & 3 & 3 & 3 & 1 & 1 & 3 & 2 & 2 & 1 & 1 & 2 \\
\hline $\begin{array}{l}\text { Posibilidad de generación } \\
\text { distribuida }(+)\end{array}$ & 0,05 & 3 & 1 & 1 & 1 & 2 & 3 & 3 & 2 & 1 & 1 & 2 \\
\hline Residuos radioactivos (-) & 0,03 & 3 & 3 & 3 & 1 & 3 & 3 & 3 & 3 & 3 & 3 & 3 \\
\hline Energía limpia $(+)$ & 0,05 & 1 & 2 & 1 & 3 & 3 & 3 & 2 & 3 & 3 & 3 & 2 \\
\hline $\begin{array}{l}\text { Riesgo puntual elevado para la } \\
\text { población o el ambiente }(-)\end{array}$ & 0,03 & 2 & 2 & 2 & 1 & 2 & 3 & 3 & 3 & 3 & 3 & 3 \\
\hline $\begin{array}{l}\text { Potencial aprobación de la } \\
\text { comunidad afectada }(+)\end{array}$ & 0,05 & 3 & 3 & 2 & 1 & 2 & 3 & 3 & 2 & 2 & 2 & 3 \\
\hline $\begin{array}{l}\text { Inclusión en planes inmediatos } \\
\text { del Gobierno Nacional }(+)\end{array}$ & 0,08 & 3 & 3 & 3 & 3 & 2 & 3 & 1 & 1 & 1 & 1 & 1 \\
\hline$C_{j}$ & 1,00 & 2,9 & 2,7 & 2,6 & 1,6 & 2,5 & 2,7 & 1,8 & 1,8 & 1,8 & 1,7 & 2,0 \\
\hline $\begin{array}{l}\text { P: Fueloil, gasoil G: Gas C: Carbc } \\
\text { FV : Solar fotovoltaica TS: Termosc }\end{array}$ & ar & $M: M$ & areas $r$ & maríti & & & Geoté & érmica & B : & : Biom & nasa & \\
\hline
\end{tabular}

En el cuadro anterior, las alternativas con la mayor puntuación tienen la mayor opción a formar parte de la matriz energética buscada. El descarte de las alternativas con menor puntuación simplificará el problema de selección aunque 
existe la posibilidad de dejar por fuera alguna alternativa en cuyo desarrollo se tenga particular interés; en ese caso, siempre se la puede incluir en la evaluación.

De acuerdo con lo anteriormente señalado, el examen del cuadro anterior aconseja concentrar el esfuerzo de evaluación en las opciones termoeléctricas que utilizan derivados líquidos del petróleo, gas o carbón como combustible; y en las opciones de aprovechamiento de energía hidráulica y energía eólica. Sin embargo, el gobierno nacional ha firmado un convenio con Rusia para la instalación de reactores nucleares; y por otra parte, estudia la utilización a mediano plazo y a pequeña escala de la biomasa, la energía solar y la energía geotérmica [CORPOELEC, 2010]. Por ello, estas opciones también se incluirán en la evaluación.

\subsection{Evaluación de las alternativas preseleccionadas}

La evaluación de las alternativas preseleccionadas se realizó con la ayuda del modelo de análisis multicriterio presentado en la tabla 4.8 del capítulo anterior. El problema se planteó en los términos que se explican a continuación.

\subsection{Objetivo general}

El objetivo general del proceso es la evaluación del uso de las fuentes de energía seleccionadas para la generación de energía eléctrica en Venezuela, en un marco de crisis energética como el que se ha detallado anteriormente.

\subsection{Alternativas a evaluar}

Las alternativas a evaluar son las opciones de generación de potencia eléctrica preseleccionadas en la sección anterior. Cada una ellas se diferencia por la fuente de energía primaria que propone utilizar para suplir los requerimientos de energía eléctrica del país y por la tecnología básica necesaria para hacerlo; por su rendimiento técnico y económico, por las implicaciones ambientales y sociales de su entrada en operación; por los potenciales riesgos para la población, y finalmente, por su capacidad para contribuir a solucionar el déficit de energía eléctrica en el país con una inversión razonable y sin afectar otros planes de la nación. 
Es conveniente señalar que en esta etapa del problema, sólo se trata de evaluar la potencialidad de cada fuente de energía primaria como insumo para la generación de energía en el contexto del país, y las principales tecnologías asociadas a su explotación. Otros aspectos como la distribución de la capacidad a instalar entre las fuentes energéticas frente a los requerimientos de la nación y las limitaciones en los recursos monetarios necesarios para hacerlo, no son variables en esta parte de la resolución del problema; su inclusión en la misma se realizará en la próxima sección.

La tabla 5.8 lista las opciones a evaluar. A cada fuente de energía listada se asocian alternativas tecnológicas utilizadas para generación eléctrica a gran escala, en centrales eléctricas ubicadas geográficamente cerca de la fuente de energía, conectadas a la red de transmisión para llevar la energía a los consumidores. En el caso de las fuentes fósiles, existe la posibilidad de trabajar con turbinas de combustión, turbinas de vapor o con una planta de ciclo combinado, un sistema que como se señaló en el capítulo 3 de este documento, permite incrementar la eficiencia energética frente a sistemas que utilizan sólo una turbina de gas o una turbina de vapor. El combustible de entrada al sistema puede ser diesel, gas o, carbón pulverizado o gasificado.

Tabla 5.8. Alternativas de generación eléctrica a evaluar, Venezuela

\begin{tabular}{|c|c|c|c|c|}
\hline \multicolumn{2}{|c|}{ ALTERNATIVA } & \multicolumn{2}{|c|}{ PROCESO DE CONVERSIÓN A POTENCIA ELÉCTRICA } & \multirow[b]{2}{*}{ GD } \\
\hline ID & $\begin{array}{c}\text { FUENTE DE } \\
\text { ENERGÍA }\end{array}$ & TECNOLOGÍA & REFERENCIA & \\
\hline $\mathrm{C} 1-\mathrm{C} 2$ & Carbón & $\begin{array}{l}\text { Carbón pulverizado } \\
\text { IGCC }\end{array}$ & Cap. 3, Sección 1.1.3.4 & \\
\hline G1-G2 & Gas & Turbina de combustión & Can 3 Secrión 11214 & $\sqrt{ }$ \\
\hline $\mathrm{P} 1-\mathrm{P} 2$ & Petróleo & Ciclo combinado & Cap. 0, sectom 1.1 .2 .1 .4 & $\sqrt{ }$ \\
\hline $\mathrm{N}$ & Nuclear & Reactor nuclear & Cap. 3, Sección 1.1.4.4 & \\
\hline $\mathrm{H}$ & Hidráulica & Turbina hidráulica & Cap. 3, Sección 1.2.1 & $\sqrt{ }$ \\
\hline $\mathrm{E}$ & Eólica & Turbinas eólicas (en tierra) & Cap. 3, Sección 1.2.2.1 & $\sqrt{ }$ \\
\hline S & Solar & Solar fotovoltaica & Cap. 3, Sección 1.2.3.2.2 & $\sqrt{ }$ \\
\hline B & Biomasa & Gasificación biomasa & Cap. 3, Sección 1.2.3.5.1 & $\sqrt{ }$ \\
\hline G & Geotérmica & Hidrotérmica & Cap. 3, Sección 1.2.4.2.3 & \\
\hline
\end{tabular}


Adicionalmente, para cada alternativa a evaluar se señala la posibilidad de generación distribuida o in situ, a pequeña escala ( $<10 \mathrm{~kW}$ ) conectada a la red de distribución ( $<145 \mathrm{kv}$ ) en un punto muy cercano a la ubicación del consumidor. El uso de esta opción es más común en el caso de aprovechamientos de energías renovables como el viento, el sol, los desniveles de agua y la biomasa. El indicador se basa fundamentalmente en la disponibilidad de la fuente de energía primaria en el sitio escogido o en la posibilidad de su acceso a través de medios de transporte económicamente convenientes.

Estrictamente hablando, la posibilidad de utilización de cada recurso para la generación distribuida de electricidad representa una opción diferente de inversión. Sin embargo, a efectos de la resolución de este caso de estudio, sólo se considerará como una ventaja adicional para el recurso y no como una opción diferente.

\subsection{Ajuste del modelo}

El modelo de valor para la evaluación multicriterio de proyectos propuesto en el capítulo 4 de documento, es producto de la investigación sobre las ventajas y desventajas técnicas, económicas, ambientales, y sociales asociadas al uso de cada tipo de recurso energético disponible en un mundo conflictivo por el desigual acceso a la alimentación, los servicios básicos y las oportunidades de progreso; gravemente amenazado por el deterioro climático y profundamente interdependiente. Como tal, su planteamiento es necesariamente general, organizado en una estructura jerárquica que trata de incluir en la forma más sencilla posible, muy variados aspectos que a criterio del autor y de expertos seleccionados, deben tenerse en cuenta en el proceso de evaluación de alternativas en el sector energético.

Naturalmente, el modelo puede ajustarse de acuerdo a las características del problema que se intenta resolver, a la disponibilidad de información confiable y al nivel de aproximación requerida en las estimaciones. Específicamente, los ajustes se refieren a la eliminación de criterios que pueden volverse redundantes o no relevantes en la evaluación de alternativas similares, a la consolidación de criterios, a la inclusión de nuevos criterios; y en el caso de falta o escasez de información, a la modificación del proceso sugerido para la estimación de algunos indicadores. Con la 
excepción de este último tipo de ajuste, la ejecución de una o más de las acciones citadas requiere el ajuste de los pesos relacionados.

La tabla 5.9 muestra los ajustes realizados al modelo de valor propuesto en el capítulo anterior, a efectos de su utilización en la evaluación de las alternativas energéticas listadas en la tabla 5.7. El cuadro reporta los cambios efectuados, su causa y la acción tomada para el ajuste del modelo.

Tabla 5.9. Modificación en indicadores del modelo de valor propuesto

\begin{tabular}{|c|c|l|l|}
\hline INDICADOR & CAMBIO & \multicolumn{1}{|c|}{ CAUSA } & \multicolumn{1}{|c|}{ ACCIÓN } \\
\hline $\begin{array}{c}\Delta \text { Déficit de } \\
\text { energía }\end{array}$ & ELIMINADO & $\begin{array}{l}\text { Por definición del } \\
\text { problema, la base de la } \\
\text { evaluación es una unidad } \\
\text { de energía generada }=> \\
\text { el índice no es relevante. }\end{array}$ & $\begin{array}{l}\text { Se redistribuyen los } \\
\text { pesos del criterio entre } \\
\text { los criterios restantes } \\
\text { del mismo grupo y } \\
\text { nivel. }\end{array}$ \\
\hline $\begin{array}{c}\text { Diversidad de la } \\
\text { cesta energética }\end{array}$ & CUALITATIVO & $\begin{array}{l}\text { Por definición del } \\
\text { problema, no se dispone } \\
\text { del volumen que puede } \\
\text { producir cada opción, a } \\
\text { priori. }\end{array}$ & $\begin{array}{l}\text { Se estima en una } \\
\text { escala [1-5] en función } \\
\text { de la naturaleza de la } \\
\text { opción de energía } \\
\text { primaria considerada. }\end{array}$ \\
\hline
\end{tabular}

La eliminación del indicador 'A Déficit de energía' del modelo, hace necesario la distribución del peso del criterio eliminado entre los criterios restantes en el mismo grupo y nivel. La modificación se realizó con ayuda de Expert Choice $\Re$, sobre el modelo de valor reflejado en las figuras 4.11 y 4.12 del capítulo anterior. La figura 5.17 muestra el cambio en los pesos de los indicadores afectados.

\begin{tabular}{|c|c|c|c|c|c|c|}
\hline & PL & PG & \multirow{2}{*}{\multicolumn{3}{|c|}{ PL }} & \multirow[b]{2}{*}{ PG } \\
\hline CRITERIOS SOCIALES & 0,122 & 0,122 & & & & \\
\hline Aceptación comunidad & 0,334 & 0,041 & & Creación de empleo & 0,424 & 0,034 \\
\hline Calidad de vida & 0,666 & 0,081 & & & 0,289 & 0,024 \\
\hline & & & \multicolumn{2}{|c|}{$\Delta$ Déficit energía } & 0,287 & 0,023 \\
\hline CRITERIOS SOCIALES & 0,122 & 0,122 & & & & \\
\hline Aceptación comunidad & 0,334 & 0,041 & & Creación de empleo & 0,580 & 0,047 \\
\hline Calidad de vida & 0,666 & 0,081 & & $\Delta$ Salarios & 0,420 & 0,034 \\
\hline
\end{tabular}

Figura 5.17. Cambio en los pesos de los indicadores por ajuste del modelo 
La figura 5.18 que se incluye a continuación, presenta el modelo ajustado que se utilizó posteriormente para la evaluación de las opciones definidas en la tabla 5.7.

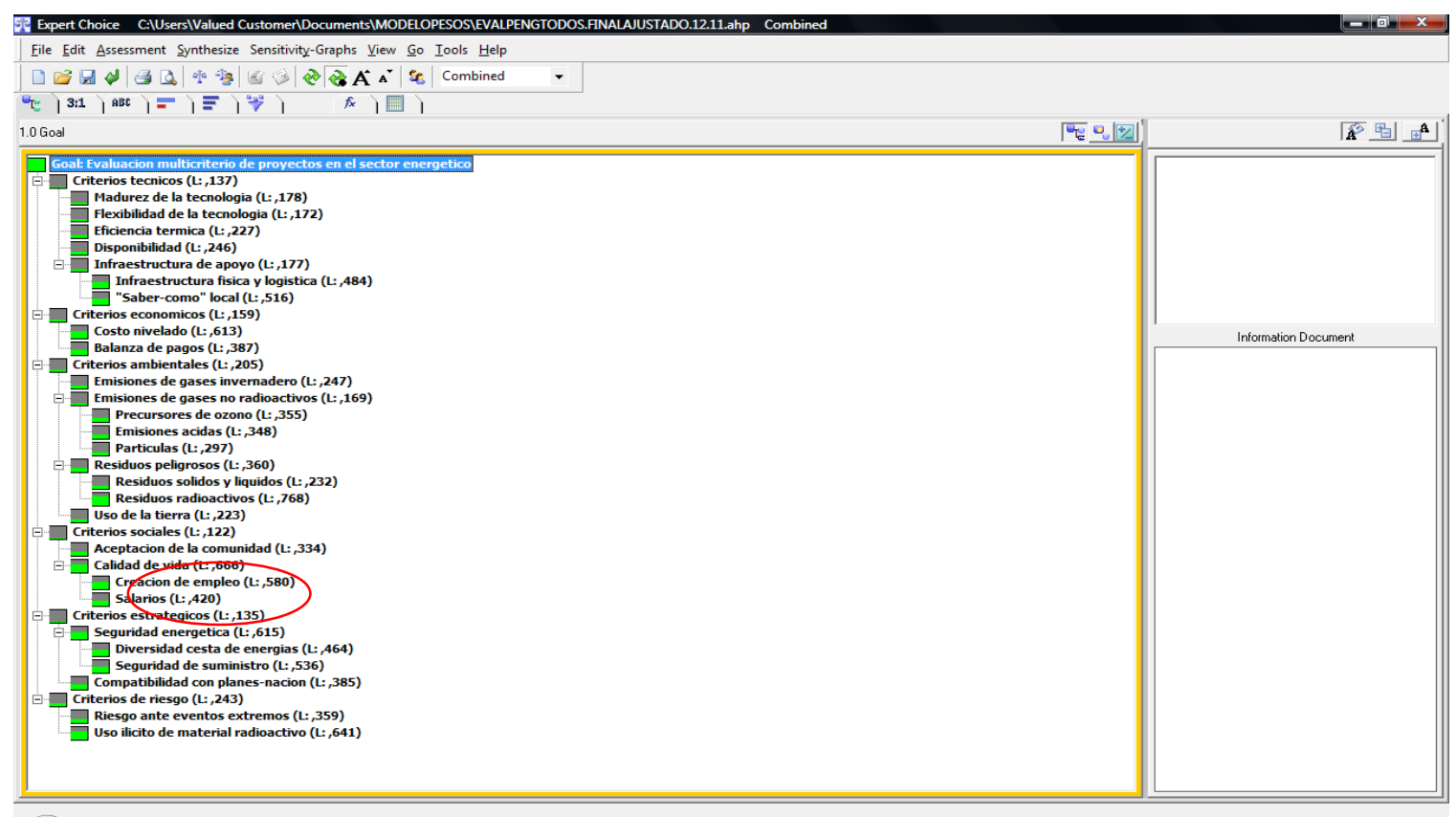

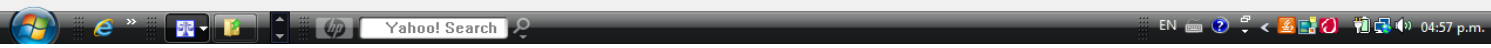

Figura 5.18. Modelo de valor ajustado a las condiciones del caso de estudio

Una vez ajustado el modelo de valor, el próximo paso en el procedimiento es la estimación de los indicadores que permiten instrumentalizar la evaluación de las alternativas bajo estudio.

\subsection{Estimación de los indicadores para la evaluación}

A efectos de la recopilación de la información necesaria para la evaluación, los indicadores en el modelo de valor propuesto pueden clasificarse en dos grupos:

- Indicadores de índole cuantitativa

- Indicadores de índole cualitativa

La segunda columna de la tabla 5.10 refleja la naturaleza de cada indicador considerado; esto es, si el indicador es cualitativo o cuantitativo. La última columna del mismo cuadro cita la fuente de información para la estimación del indicador en cada caso. 
Tabla 5.10. Indicadores para la evaluación

\begin{tabular}{|c|c|c|}
\hline INDICADOR & UNIDAD & FUENTE DE DATOS \\
\hline \multicolumn{3}{|l|}{ DIMENSIÓN TÉCNICA } \\
\hline Madurez de la tecnología & CUALITATIVO & Consulta a expertos \\
\hline Flexibilidad de la tecnología & CUALITATIVO & Consulta a expertos \\
\hline Eficiencia térmica & UE/MWh & U.S.EIA, 2009; NREL, 2010 \\
\hline Factor de capacidad & $\%$ & U.S.EIA, 2009; NREL, 2010 \\
\hline Infraestructura física y logística & CUALITATIVO & Consulta a expertos \\
\hline "Saber-como" local & CUALITATIVO & Consulta a expertos \\
\hline \multicolumn{3}{|l|}{ DIMENSIÓN ECONÓMICA } \\
\hline Costo nivelado & US\$/MWh & NREL, 2010; Tabla 5.12 \\
\hline$\Delta$ Balanza de pagos & US\$/MWh & NREL, 2010, Tabla 5.13 \\
\hline \multicolumn{3}{|l|}{ DIMENSIÓN AMBIENTAL } \\
\hline Emisiones de gases invernadero & $\mathrm{g} \mathrm{CO} 2 \mathrm{eq} / \mathrm{kWh}$ & Chatzimouratidis et al, 2008 \\
\hline Emisiones precursores de ozono & mg NMVOCs/kWh & Chatzimouratidis et al, 2008 \\
\hline Emisiones ácidas & $\mathrm{g}$ ácido-eq/kWh & Chatzimouratidis et al, 2008 \\
\hline Emisiones de partículas & $\mathrm{mg}$ PM10/kWh & Chatzimouratidis et al, 2008 \\
\hline Residuos sólidos y líquidos & CUALITATIVO & Consulta a expertos \\
\hline Residuos radioactivos & CUALITATIVO & Consulta a expertos \\
\hline Uso de la tierra & CUALITATIVO & Consulta a expertos \\
\hline \multicolumn{3}{|l|}{ DIMENSIÓN SOCIAL } \\
\hline Aceptación de la comunidad & CUALITATIVO & Consulta a expertos \\
\hline Creación de empleo local & Empl/MWh & Wei et al., 2010 \\
\hline$\Delta$ Salarios & US\$/MWh & NREL 2010; Wei et al. 2010 \\
\hline \multicolumn{3}{|l|}{ DIMENSIÓN ESTRATÉGICA } \\
\hline$\Delta$ Diversidad de cesta energética & CUALITATIVO & Consulta a expertos \\
\hline Seguridad de suministro & CUALITATIVO & Consulta a expertos \\
\hline Compatibilidad con planes-nación & CUALITATIVO & Consulta a expertos \\
\hline \multicolumn{3}{|l|}{ DIMENSIÓN RIESGO } \\
\hline Riesgo ante eventos extremos & CUALITATIVO & Consulta a expertos \\
\hline Uso ilícito de material radioactivo & CUALITATIVO & Consulta a expertos \\
\hline
\end{tabular}


En el caso de los indicadores de naturaleza cuantitativa, la segunda columna del cuadro 5.9 muestra su unidad original de medida. A continuación, algunas particularidades sobre la recolección y procesamiento de la información en cada uno de los casos señalados.

- Indicadores de naturaleza cuantitativa. Dada la poca consistencia y confiabilidad de la escasa data disponible ${ }^{80}$ relativa a procesos de generación eléctrica basados en las fuentes de energía primaria existentes en Venezuela; la información técnica, económica y ambiental necesaria para la evaluación debió obtenerse de publicaciones internacionales especializadas. En cada caso, la información fue contrastada en varias fuentes y seleccionada la que a criterio del autor resultó con la mejor combinación posible de atributos: bien respaldada, completa, actualizada y mejor adaptada a las condiciones venezolanas.

Toda la data obtenida fue posteriormente convertida de sus unidades originales a una escala [1-5] para hacerla compatible con la escala en la cual se expresa el valor de los indicadores cualitativos. La transformación de escala se efectuó de acuerdo a los procedimientos respectivamente sugeridos en las fichas de los indicadores incluidas en el capítulo anterior. La fuente de datos seleccionada en cada caso, se copia en la última columna de la tabla 5.10 .

DIMENSIÓN TÉCNICA. La tabla 5.11 reúne la información técnica que se consideró relevante para cada una de las opciones tecnológicas enumeradas en la tabla 5.7. Las columnas 2,3 y 4 presentan valores tipo para cada tecnología y constituyen data de entrada para la estimación del costo anual respectivo que se explica en la próxima sección. Entre ellas, la columna 'puesta en marcha' se refiere al lapso promedio en años desde que se inicia la construcción del proyecto hasta que puede ser puesto en marcha. Las últimas columnas del cuadro presentan para cada tecnología, los valores en su unidad original y en la escala

80 Entrevistas personales en la Universidad Simón Bolívar, Universidad Metropolitana y en CORPOELEC. Estadísticas oficiales en el área en fuentes electrónicas casi inexistentes. 
[1-5] para los indicadores 'Factor de capacidad' y 'Eficiencia térmica' incluidos en el modelo de valor propuesto en el capítulo anterior.

La información se tomó de la base de datos preparada por U.S. EIA [2010] para la elaboración de su informe anual sobre energía 2010 (AEO 2010). Como ya se señaló, la transformación a la escala [1-5] se realizó de acuerdo al procedimiento sugerido en las respectivas fichas de los indicadores incluidas en el capítulo anterior. A continuación algunos comentarios relativos a los indicadores señalados.

(i) Factor de capacidad. Es una medida de disponibilidad de las instalaciones asociadas a la tecnología de generación y se define como la relación entre potencia eléctrica efectivamente producida y potencia instalada.

(ii) Eficiencia térmica. Es una medida de la eficiencia térmica de conversión de la tecnología de generación. En este caso, se toma como la relación entre la energía de origen térmico necesaria en la entrada al proceso de conversión y la energía eléctrica salida del mismo (BTU/kWh).

Tabla 5.11. Información técnica sobre tecnologías seleccionadas de generación

\begin{tabular}{|l|c|c|c|c|c|c|}
\hline \multirow{2}{*}{ TECNOLOGÍA } & \multirow{2}{*}{$\begin{array}{c}\text { TAMAÑO } \\
(\mathrm{MW})\end{array}$} & $\begin{array}{c}\text { PUESTA EN } \\
\text { MARCHA } \\
(\mathrm{años})\end{array}$ & \multicolumn{2}{c|}{$\begin{array}{c}\text { FACTOR DE } \\
\text { CAPACIDAD }\end{array}$} & \multicolumn{2}{|c|}{ ETE/EES 2008* } \\
\cline { 5 - 8 } & & 4 & $\begin{array}{c}\text { Escala } \\
{[1-5]}\end{array}$ & (BTU/kWh) & $\begin{array}{c}\text { Escala } \\
{[1-5]}\end{array}$ \\
\hline Carbón pulverizado & 600 & 4 & 5 & 5 & 9200 & 4 \\
\hline Carbon - IGCC & 550 & 4 & 85 & 5 & 8765 & 4 \\
\hline P/G Turbina combustión & 230 & 2 & 92 & 5 & 9289 & 4 \\
\hline P/G Ciclo combinado & 400 & 3 & 87 & 5 & 6752 & 4 \\
\hline Nuclear & 1350 & 6 & 90 & 5 & 10488 & 4 \\
\hline Hidráulica & 500 & 4 & 65 & 3 & - & 5 \\
\hline Eólica & 50 & 3 & 44 & 2 & - & 5 \\
\hline Solar térmica- CSP & 100 & 3 & 31 & 1 & - & 5 \\
\hline Biomasa & 80 & 4 & 83 & 5 & 9451 & 4 \\
\hline Geotérmica & 50 & 4 & 90 & 5 & 32969 & 1 \\
\hline
\end{tabular}

* ETE/EES: Eficiencia térmica de conversión (energía térmica en la entrada/energía eléctrica salida) Fuente de datos: [U.S. EIA, 2010; NREL 2010] 
El conocimiento del valor de la eficiencia térmica de una tecnología permite en cada caso, estimar el volumen de combustible con un contenido calórico conocido, requerido por unidad de potencia eléctrica generada. Naturalmente, en el caso de las tecnologías basadas en recursos naturales renovables no existe requerimiento de combustibles y la relación es cero.

DIMENSIÓN ECONÓMICA. En esta dimensión, se definieron dos indicadores de naturaleza cuantitativa, a saber:

- Costo nivelado

- $\Delta$ Balanza de pagos/kWh

(i) Costo nivelado. La tabla 5.12 que se presenta a continuación recoge los costos nivelados de energía ( $L C O E$, por sus siglas en é) estimados por Tidball y colaboradores [NREL, 2010] para 11 tecnologías de generación de electricidad, en base al grupo de datos reunido por la EIA para la elaboración de su reporte anual sobre energía AEO2010 [U.S. EIA, 2010]. La última columna del cuadro muestra el indicador expresado en una escala [1-5], donde 5 corresponde al costo nivelado más bajo.

Tabla 5.12. Costo nivelado NREL2015 para diferentes tipos de generación, U.S.A.

\begin{tabular}{|c|c|c|c|c|c|}
\hline \multirow{2}{*}{ TECNOLOGÍA } & \multicolumn{3}{|c|}{ COSTO (US $\$ 2007 / M W h)$} & \multicolumn{2}{|c|}{ COSTO NIVELADO } \\
\hline & CAPITAL & O\&M & COMBUSTIBLE & $(\$ 2007 / M W h)$ & $\begin{array}{c}\text { Escala } \\
{[1-5]}\end{array}$ \\
\hline Carbón pulverizado & 23 & 8 & 19 & 50 & 5 \\
\hline Carbón - IGCC & 28 & 8 & 17 & 53 & 5 \\
\hline P/G Turbina de combustión & 7 & 4 & 50 & 61 & 5 \\
\hline P/G Ciclo combinado & 11 & 3 & 37 & 51 & 5 \\
\hline Nuclear & 42 & 12 & 10 & 64 & 5 \\
\hline Hidráulica $^{1}$ & 35 & 4 & 0 & 39 & 5 \\
\hline Eólica & 58 & 8 & 0 & 66 & 5 \\
\hline Solar térmica - CSP & 154 & 20 & 0 & 174 & 1 \\
\hline Biomasa & 40 & 15 & 18 & 73 & 4 \\
\hline Geotérmica & 61 & 20 & 0 & 81 & 4 \\
\hline
\end{tabular}

Fuente de datos: [NREL, 2010, p. 196-198]

${ }^{1}$ Valores estimados 
En cada caso, el costo nivelado se estima como el valor presente de los costos de capital y de los costos anuales de operación, mantenimiento y combustible pero no incluye costos de financiamiento ni ningún tipo de incentivo fiscal. Los costos se estiman a precios del año 2007 colocados en el 2015; año para cuya selección se argumenta que el período más largo de construcción y puesta en marcha de los sistemas de generación bajo estudio es de 6 años (nuclear, tabla 5.10) contados a partir del año 2009, lo que ubica su fecha de arranque mínima en el año 2015 [NREL, 2010].

El costo nivelado CN para cada tecnología se calcula de acuerdo a la siguiente ecuación [NREl, 2010, p.184]:

$$
\mathrm{CN}=\frac{\left.\mathrm{CC} * \mathrm{FP} * \mathrm{~T}+\sum\left(\mathrm{CCOM}+\mathrm{CFOM} * \mathrm{~T}+\mathrm{CVOM}^{*} \mathrm{~T}^{*} \mathrm{FC} * 8760 *(1-\mathrm{D})^{\mathrm{k}}\right) \mathrm{k}\right) /(1+\mathrm{i})^{\mathrm{k}}}{\sum\left(\left[\mathrm{T}^{*} \mathrm{FC} * 8760 *(1-\mathrm{D})^{\mathrm{k}}\right]_{\mathrm{k}} /(1+\mathrm{i})^{\mathrm{k}}\right.}
$$

Para $\mathrm{k}=1$, 2. . 15 y donde, CC $=$ Costo capital, US $\$ 2007 / \mathrm{kW}$

CCOMk = Costo de combustible para el año k, US $\$ 2007$

CFOMk = Costo fijo de operación y mantenimiento para el año k, US\$2007/kW

CVOMk = Costo variable de operación y mantenimiento del año k, US $\$ 2007 / \mathrm{kWh}$

$\mathrm{T}=$ tamaño de las instalaciones, $\mathrm{kW}$ instalados

$\mathrm{FP}=$ multiplicador para el período de construcción

$\mathrm{FC}=$ factor de capacidad de las instalaciones, fracción decimal

$\mathrm{D}=$ tasa de deflación interanual del volumen de electricidad, fracción decimal

$\mathrm{i}=$ tasa de descuento anual, fracción decimal

$\mathrm{n}=$ vida o período de estudio (2030-2015), años

CC representa el costo de capital ajustado con dos factores que dependen de la tecnología considerada y de su grado de madurez: (i) un factor de contingencia que oscila entre 1,05 y 1,1 y (ii) un factor de optimismo para tener en cuenta la posibilidad de subestimación del costo para tecnologías emergentes o nuevos diseños no probados. Para tecnologías maduras el factor es igual a 1 ; en otros casos, el factor es superior a 1. Por otra parte, FP es un multiplicador para el período de construcción que se aplica al costo de capital [NREL, 2010, p.190]. 
CCOM es el costo anual de combustible que se estima en función de la eficiencia térmica de conversión de la tecnología (tabla 5.10), del contenido calórico promedio para el tipo de combustible utilizado y del precio del mismo que puede variar en el tiempo. Naturalmente, el costo de combustible es cero para las tecnologías basadas en la utilización de recursos renovables [NREL, 2010, p.197].

D es la tasa de deflación interanual de la electricidad producida y se estima en base al comportamiento de cada tecnología. Para las tecnologías objeto del estudio, D es igual a 0\% [NREL, 2010, p.191]. El período de estudio se extiende entre el año 2015 y el año 2030; y la tasa de descuento i, se toma igual a 7\% anual [NREL, 2010, p. 59).

El costo nivelado de la energía obtenida por generación hidráulica no aparece reportado en la referencia citada [NREL, 2010]. En consecuencia. se procedió a estimarlo en base a los costos de capital y de operación y mantenimiento registrados por la U.S.EIA [2009]. Las ecuaciones utilizadas fueron:

$$
\begin{gathered}
C N(C C) \$ 2007 / M W h=C C * F P * 1000 /\left(365 * 24 * F C *\left(\left((1+i)^{n}-1\right) /\left(i(1+i)^{n}\right)\right)\right) \\
C N(O \& M) \$ 2007 / M W h=C V O M+C F O M /(8760 * F C)
\end{gathered}
$$

Los datos y parámetros utilizados en el cálculo se resumen en la tabla que sigue.

\begin{tabular}{|c|c|c|c|c|}
\hline \multirow[b]{2}{*}{ TECNOLOGÍA } & \multicolumn{3}{|c|}{ COSTOS } & \multirow{2}{*}{$\begin{array}{l}\text { FC } \\
(\%)\end{array}$} \\
\hline & $\begin{array}{c}C C \\
(\$ 2007 / \mathrm{kW})\end{array}$ & $\begin{array}{c}\text { CFOM } \\
(\$ 2007 / \mathrm{kW})\end{array}$ & $\begin{array}{c}\text { CVOM } \\
(\$ 2007 / M W h)\end{array}$ & \\
\hline Generación hidráulica & 2242 & 13,63 & 2,43 & 65 \\
\hline \multicolumn{2}{|c|}{ Fuente de datos: [U.S EIA, 2009] } & \multicolumn{3}{|c|}{$\mathrm{FP}=0,8 \quad \mathrm{i}=7 \% \quad \mathrm{n}=15$ años } \\
\hline
\end{tabular}

Tabla 5.13. Estimación del costo nivelado para generación hidroeléctrica

Las cifras presentadas en la tabla 5.12 corresponden a condiciones promedio en el territorio de los Estados Unidos de América y varían de fuente a fuente dependiendo de los renglones y parámetros que se incluyan en el cálculo [U.S. EIA, 2012c; Lazard, 2009]. Algunos autores reportan valores aislados de costos nivelados en Venezuela [Hernández, 2009b] mucho más elevados que los mostrados en el cuadro 5.12; sin embargo, no se dispone de su procedimiento de 
estimación ni de datos para todas las fuentes de energía primaria. Por ello, se escogió trabajar con los resultados presentados en la tabla 5.12, teniendo claro que las cifras suministradas sólo sirven como una referencia para la comparación y el ordenamiento de las alternativas de generación bajo estudio.

(ii) $\Delta$ Balanza de pagos/kWh. El efecto sobre la balanza de pagos ( $\triangle \mathrm{BP} / \mathrm{kWh}$ ) que tiene la implantación de cada tecnología a evaluar puede estimarse en función del valor presente (2015) de la variación (+/-) en las exportaciones y en las importaciones. Así, para cada año de la vida del proyecto, se cumple:

$$
\Delta \mathrm{BP} / \mathrm{kWh}=\Delta(\text { Exportaciones }- \text { Importaciones }) / \mathrm{kWh}
$$

En efecto, Venezuela no posee ni fabrica tecnología propia para la generación eléctrica y en consecuencia debe importarla. Por el contrario produce combustibles fósiles (gasoil, fueloil, gas) que puede dedicar a la generación o puede exportar. Si lo utiliza para la generación de electricidad, lo deja de exportar y debe rebajarse el monto respectivo $(\$ / \mathrm{kWh})$ del componente positivo (exportaciones) en la ecuación de 5.2; y si lo exporta debe importar el combustible y el respectivo monto (Bs/kWh) se refleja en el costo del componente importado. En el caso de la producción de electricidad con base nuclear, deberá importarse el combustible y su costo deberá reflejarse en el componente importado. De esta forma, el efecto sobre la balanza de pagos puede expresarse en función del costo anual de los equipos (CE) y de la factura de combustible (CCOM), de la forma siguiente:

$\Delta$ Balanza de pagos $/ \mathrm{kWh}=-($ Valor presente $(\mathrm{CE}+\mathrm{CCOM}) / \mathrm{kWh}))$

Y si se conocen las participaciones, (i) del costo de capital (CAP/CN) y del costo de combustible (CCOM/CN) en el costo nivelado; y (ii) del costo de equipos en el costo de capital (CE/CAP), el efecto que sobre la balanza de pagos tiene la tecnología a evaluar, puede expresarse en la forma siguiente

$$
\Delta \mathrm{BP} 2015=-\mathrm{CN}([\mathrm{CE} / \mathrm{CAP}][\mathrm{CAP} / \mathrm{CN}]+[\mathrm{CCOM} / \mathrm{CN}])
$$

La tabla 5.14 muestra para cada tecnología de generación considerada, la distribución en equipos y mano de obra, del costo de capital 2015 incluido en la 
tabla 5.12. Los datos fueron tomados del trabajo de Tidball [NREL, 2010, p. 199201]. Tomando como base estas cifras y los resultados sobre costos de la tabla anterior, puede estimarse $\triangle \mathrm{BP} 2015$, de acuerdo con la ecuación 5.8.

Tabla 5.14. Efecto estimado sobre balanza de pagos por tecnología de generación

\begin{tabular}{|l|c|c|c|c|c|c|c|}
\hline \multirow{2}{*}{ TECNOLOGÍA } & \multicolumn{3}{c|}{$\begin{array}{c}\text { COSTOS } \\
(\$ 2007 / M W h)\end{array}$} & \multicolumn{2}{c|}{$\begin{array}{c}\text { DISTRIBUCION } \\
\text { COSTO CAP }\end{array}$} & \multicolumn{2}{c|}{$\begin{array}{c}\text { COSTO EQUIPO + } \\
\text { C. COMBUSTIBLE }\end{array}$} \\
\cline { 2 - 9 } & CAP & COMB & EQ & $\begin{array}{c}\text { EQ } \\
(\%)\end{array}$ & $\begin{array}{c}\text { MO } \\
(\%)\end{array}$ & $\$ 2007 /$ MWh & $\begin{array}{c}\text { Escala } \\
{[1-5]}\end{array}$ \\
\hline Carbón pulverizado & 23 & 19 & 12 & 50 & 30 & 31 & 4 \\
\hline Carbón - IGCC & 28 & 17 & 14 & 50 & 20 & 31 & 4 \\
\hline P/G Turbina de combustión & 7 & 50 & 5 & 75 & 10 & 55 & 2 \\
\hline P/G Ciclo combinado & 11 & 37 & 7 & 60 & 15 & 44 & 3 \\
\hline Nuclear & 42 & 10 & 21 & 50 & 30 & 31 & 4 \\
\hline Hidráulica & 42 & 0 & 21 & 50 & SD & 21 & 5 \\
\hline Eólica & 58 & 0 & 41 & 70 & 10 & 41 & 3 \\
\hline Solar térmica -CSP & 154 & 0 & 77 & 50 & 30 & 77 & 1 \\
\hline Biomasa & 40 & 18 & 20 & 50 & 30 & 38 & 4 \\
\hline Geotérmica & 61 & 0 & 12 & 20 & 40 & 12 & 5 \\
\hline
\end{tabular}

Fuente de datos: NREL, 2010, p.196-197

Naturalmente, los resultados reportados en la tabla 5.14 son aproximados ya que por una parte, la data base para el cálculo corresponde a promedios en los Estados Unidos de América y no a Venezuela; y por la otra, se desprecian los efectos indirectos sobre la economía de la región donde se instala la tecnología de generación. Sin embargo, pueden servir como una referencia para el ordenamiento de las opciones a evaluar de acuerdo al respectivo criterio.

DIMENSIÓN AMBIENTAL. En esta dimensión se incluye un número importante de indicadores cuya cuantificación resulta de ayuda para la comparación de las alternativas en relación al volumen de emisiones a la atmósfera, dañinas al ambiente y a la salud del ser humano. La definición de cada indicador y su unidad de medida, así como el procedimiento para transformar su valor a una escala [1 - 5] se incluyen en el capítulo anterior. Los indicadores definidos fueron: 
- Emisiones de gases invernadero

- Emisiones de partículas

- Emisiones ácidas

- Precursores de ozono

La información para la valoración de los indicadores listados se tomó mayoritariamente de Chatzimouratidis y Pilavachi [2008] y se presenta para cada opción de generación considerada, en la tabla 5.15. En el caso de plantas operadas con carbón o petróleo sólo se reporta un valor relacionado a la fuente de energía primaria utilizada.

Tabla 5.15. Promedio de emisiones no radiactivas para el ciclo de vida, por opción de generación eléctrica.

\begin{tabular}{|l|r|r|r|r|r|}
\hline \multirow{2}{*}{\multicolumn{1}{|c|}{ TECNOLOGÍA }} & \multicolumn{5}{c|}{ Emisiones (mg/kWh) } \\
\cline { 2 - 6 } & NMVOCs & \multicolumn{1}{c|}{ CO2 eq. } & \multicolumn{1}{c|}{ NOx } & \multicolumn{1}{c|}{$\mathrm{SO}_{2}$} & PM10 \\
\hline Carbón & 24 & 986.000 & 2.986 & 16.511 & 347 \\
\hline Petróleo & 18 & 1.131 .178 & 5.253 & 81.590 & 128 \\
\hline Turbina gas combustión & 118 & 560.000 & 1.477 & 152 & 34 \\
\hline Turbina Ciclo Combinado & 118 & 450.000 & 756 & 152 & 6 \\
\hline Nuclear & 0 & 21.435 & 51 & 27 & 2 \\
\hline Hidráulica & 0 & 22.696 & 23 & 33 & 5 \\
\hline Eólica & 0 & 17.652 & 32 & 54 & 20 \\
\hline Solar - CSP ${ }^{1}$ & 0 & 17.000 & $\sim 0$ & $\sim 0$ & 0 \\
\hline Biomasa & 80 & 58.000 & 1325 & 76 & 268 \\
\hline Geotérmica & 0 & 18.913 & 280 & 20 & 0 \\
\hline
\end{tabular}

Tomado de Chatzimouratidis y Pilavachi, 2008

${ }^{1}$ Tomado de IEA, 2009c

A continuación, algunos comentarios sobre la estimación de los indicadores listados.

(i) Emisiones de gases tipo invernadero. Como ya se ha señalado, las emisiones de gases tipo invernadero incluyen $\mathrm{CO}_{2}$, metano $(\mathrm{CH} 4)$, oxido nitroso $\left(\mathrm{N}_{2} \mathrm{O}\right)$, gases fluorocarbonados y $\mathrm{SF}_{6}$ y pueden expresarse como gramos equivalentes de $\mathrm{CO}_{2}$. Las columnas 2 y 3 de la tabla 5.16 que se presenta a UNIVERSIDAD POLITÉCNICA DE VALENCIA. TESIS DOCTORAL. Violeta Parodi 
continuación, muestran respectivamente los valores que toma el indicador para cada opción considerada, en sus unidades originales y en una escala [1-5].

(ii) Emisiones de partículas. Este indicador se refiere a las partículas de diámetro inferior a $10 \mathrm{~nm}$ que se producen primordialmente en la combustión de combustibles fósiles y de biomasa. Las columnas 2 y 3 de la tabla 5.16 que sigue muestran respectivamente los valores que toma el indicador para cada opción considerada, en sus unidades originales y en una escala [1-5].

Tabla 5.16. Promedio de emisiones de gases tipo invernadero y de partículas, para el ciclo de vida y por opción de generación eléctrica.

\begin{tabular}{|l|c|c|c|c|}
\hline \multirow{2}{*}{ TECNOLOGÍA } & \multicolumn{2}{|c|}{ GASES INVERNADERO } & \multicolumn{2}{c|}{ PARTÍCULAS } \\
\cline { 2 - 5 } & $\mathrm{g}$ CO2 eq/kWh & Escala 1-5 & $\mathrm{mg}$ PM10/kWh & Escala 1-5) \\
\hline Carbón & 986 & 1 & 347 & 1 \\
\hline Petróleo & 1.131 & 1 & 128 & 4 \\
\hline Turbina gas combustión & 560 & 3 & 34 & 5 \\
\hline Turbina Ciclo Combinado & 450 & 4 & 6 & 5 \\
\hline Nuclear & 21 & 5 & 2 & 5 \\
\hline Hidráulica & 23 & 5 & 5 & 5 \\
\hline Eólica & 18 & 5 & 20 & 5 \\
\hline Solar - CSP & 17 & 5 & 0 & 5 \\
\hline Biomasa & 58 & 5 & 76 & 4 \\
\hline Geotérmica & 19 & 5 & 20 & 5 \\
\hline
\end{tabular}

Fuente de datos: Tabla 5.15

(iii) Emisiones ácidas. El indicador se refiere a las emisiones a la atmósfera de óxidos de nitrógeno (NOx) y de $\mathrm{SO}_{2}$ procedentes de los procesos para la generación de potencia eléctrica por cada uno de las tecnologías a evaluar. Su presencia en el aire se expresa en gramos de ácido equivalente utilizando los potenciales de acidificación para estos gases; ellos son, para el $\mathrm{SO}_{2}=(2 / 64) \mathrm{g}$ acido equivalente/g, y para el $\mathrm{NOx}=(1 / 46) \mathrm{g}$ ácido equivalente/g [EEA, 2008]. De esta forma, el valor del indicador para cada tecnología de generación puede estimarse de acuerdo a la siguiente ecuación:

Emisiones ácidas ( $\mathrm{mg}$ ácido equivalente/kWh $)(\mathrm{NOx}) *(1 / 46)+\left(\mathrm{SO}_{2}\right) * 2 / 64$ 
Donde, las cantidades de ( $\mathrm{NOx}$ ) y de $\left(\mathrm{SO}_{2}\right)$ se miden en $\mathrm{mg} / \mathrm{kWh}$ y los respectivos potenciales de acidificación en ( $\mathrm{mg}$ ácido equivalente/mg).

La tabla 5.17 que se incluye a continuación, presenta la información concerniente al cálculo de este indicador y sus resultados expresados en su unidad original y en la escala [1-5].

Tabla 5.17. Promedio de emisiones ácidas para el ciclo de vida, por opción de generación eléctrica.

\begin{tabular}{|l|r|r|r|r|r|r|}
\hline \multirow{2}{*}{ TECNOLOGÍA } & \multicolumn{2}{|c|}{$\mathrm{mg} / \mathrm{kWh}$} & \multicolumn{2}{c|}{$\mathrm{mg}$ ácido equivalente/kWh } & \multirow{2}{*}{ Escala 1-5 } \\
\cline { 2 - 8 } & \multicolumn{1}{|c|}{$\mathrm{NOx}$} & \multicolumn{1}{c|}{$\mathrm{SO}_{2}$} & \multicolumn{1}{c|}{$\mathrm{NOx}$} & \multicolumn{1}{c|}{$\mathrm{SO}_{2}$} & \multicolumn{1}{c|}{$\Sigma$} & \\
\hline Carbón & 2.986 & 16.511 & 64,9 & 516,0 & 580,9 & 4 \\
\hline Petróleo & 5.253 & 81.590 & 114,2 & 2549,7 & 2663,9 & 1 \\
\hline Turbina gas combustión & 1.477 & 152 & 32,1 & 4,8 & 36,9 & 5 \\
\hline Turbina Ciclo Combinado & 756 & 152 & 16,4 & 4,8 & 21,2 & 5 \\
\hline Nuclear & 51 & 27 & 1,1 & 0,8 & 2,0 & 5 \\
\hline Hidráulica & 23 & 33 & 0,5 & 1,0 & 1,5 & 5 \\
\hline Eólica & 32 & 54 & 0,7 & 1,7 & 2,4 & 5 \\
\hline Solar - CSP & $\sim 0$ & $\sim 0$ & 0,0 & 0,0 & 0,0 & 5 \\
\hline Biomasa & 1325 & 76 & 28,8 & 2,4 & 31,2 & 5 \\
\hline Geotérmica & 280 & 20 & 6,1 & 0,6 & 6,7 & 5 \\
\hline
\end{tabular}

Fuente de datos: Tabla 5.15

(iii) Precursores de ozono. El indicador se refiere a las emisiones de NMVOCs y NOx asociadas a cada opción tecnológica bajo estudio. Su presencia en al aire puede expresarse en NMVOC equivalente utilizando sus respectivos potenciales de formación de ozono troposférico cuyo valor es igual a 1 para los NMVOCs, e igual a 1,22 para los NOx [EEA, 2008]. Así, si las cantidades de (NOx) y de (NMVOCs) se miden en $\mathrm{mg} / \mathrm{kWh}$, el valor del indicador para cada tecnología de generación puede estimarse de acuerdo a la siguiente ecuación:

Precursores de ozono (mg NMVOC eq/kWh) $=(\mathrm{NOx}) * 1,22+($ NMVOCs $)$

La tabla 5.18 presenta la información concerniente al cálculo de este indicador y sus resultados expresados en su unidad original y en la escala [1-5]. 
Tabla 5.18. Promedio de emisiones de precursores de ozono para el ciclo de vida, por opción de generación eléctrica.

\begin{tabular}{|c|c|c|c|c|c|c|}
\hline \multirow{2}{*}{ TECNOLOGÍA } & \multicolumn{2}{|c|}{$\mathrm{mg} / \mathrm{kWh}$} & \multicolumn{3}{|c|}{$\begin{array}{c}\text { mg NMVOC } \\
\text { equivalente/kWh }\end{array}$} & \multirow{2}{*}{ ( Escala } \\
\hline & NOx & NMVOCs & NOx & NMVOC & $\Sigma$ & \\
\hline Carbón & 2.986 & 16.511 & 3643 & 16.511 & 20.154 & 2 \\
\hline Petróleo & 5.253 & 81.590 & 6409 & 81.590 & 87.999 & 1 \\
\hline Turbina gas combustión & 1.477 & 152 & 1802 & 152 & 1.954 & 5 \\
\hline Turbina Ciclo Combinado & 756 & 152 & 922 & 152 & 1.074 & 5 \\
\hline Nuclear & 51 & 27 & 62 & 27 & 89 & 5 \\
\hline Hidráulica & 23 & 33 & 28 & 33 & 61 & 5 \\
\hline Eólica & 32 & 54 & 39 & 54 & 93 & 5 \\
\hline Solar - CSP & $\sim 0$ & $\sim 0$ & 0 & $\sim 0$ & 0 & 5 \\
\hline Biomasa & 1325 & 76 & 1617 & 76 & 1.693 & 5 \\
\hline Geotérmica & 280 & 20 & 342 & 20 & 362 & 5 \\
\hline
\end{tabular}

Fuente de datos: Tabla 5.15

Como ya se señalado, la información y resultados en las tablas 5.15 a 5.18 se basan en información promedio tomada de la bibliografía especializada [Chatzimouratidis y Pilavachi, 2008; IEA, 2009e]; y como tales, son aproximados.

DIMENSIÓN SOCIAL. Esta dimensión contempla dos indicadores de índole cuantitativa; ellos son:

- Creación de empleo/MWh

- $\Delta$ Salarios/MWh

A continuación, se explica el procedimiento para la estimación de estos indicadores.

(i) Creación de empleo. La creación de nuevos empleos directa o indirectamente relacionados con la construcción de una planta de generación eléctrica, su operación y mantenimiento; así como con su desmantelamiento, constituye un indicador de su influencia sobre la calidad de vida de la comunidad sede del proyecto. 
Las cifras en la tabla 5.19 representan el promedio de las sumatorias del número de empleos en labores de construcción/instalación, obtención de los insumos, operación y mantenimiento relacionado con plantas de generación eléctrica publicadas por investigadores en el área durante el lapso 2001-2009. Los resultados de los estudios fueron analizados, transformados a la misma base de tiempo y distribuidos en la vida estimada del proyecto por Wei y colaboradores [2010]. En el caso de plantas hidroeléctricas y de plantas termoeléctricas que utilizan derivados del petróleo, las cifras correspondientes se estimaron por analogía, en base a datos publicados por Chatzimouratidis y Pivalachi [2008].

Tabla 5.19. Promedio de empleos generados por opción de generación eléctrica

\begin{tabular}{|c|c|c|c|c|c|c|}
\hline \multirow{2}{*}{ TECNOLOGÍA } & \multirow{2}{*}{$\begin{array}{l}\text { VIDA } \\
\text { (años) }\end{array}$} & \multirow{2}{*}{$\begin{array}{l}\text { FC } \\
(\%)\end{array}$} & \multicolumn{3}{|c|}{ EMPLEOS-año/GWh } & \multirow{2}{*}{$\begin{array}{c}\text { Escala } \\
{[1-5]}\end{array}$} \\
\hline & & & CONSTRUCCIÓN & $O \& M$ & TOTAL & \\
\hline Carbón & 40 & 80 & 0,03 & 0.08 & 0,11 & 1 \\
\hline Petróleo ${ }^{1}$ & 40 & 80 & 0,03 & 0,08 & 0,11 & 1 \\
\hline Gas natural & 40 & 85 & 0.01 & 0,10 & 0,11 & 1 \\
\hline Nuclear & 40 & 90 & 0,05 & 0,09 & 0,14 & 2 \\
\hline Hidráulica ${ }^{1}$ & SD & SD & SD & SD & 0,14 & 2 \\
\hline Eólica & 25 & 35 & 0,09 & 0,08 & 0,17 & 3 \\
\hline Solar - CSP & 25 & 40 & 0,08 & 0,15 & 0,23 & 5 \\
\hline Biomasa & 40 & 85 & 0,02 & 0,19 & 0,21 & 5 \\
\hline Geotérmica & 40 & 90 & 0,03 & 0,22 & 0,25 & 5 \\
\hline
\end{tabular}

Fuente de datos: Wei et al., 2010; 1 Estimado en base a Chatzimouratidis y Pivalachi, 2008

Las dos últimas columnas del cuadro anterior presentan el valor del indicador expresado respectivamente en empleos-año/GWh y en una escala [1-5].

(ii) $\Delta$ Salarios. Este indicador se incluye en el modelo de valor para cuantificar de alguna manera, la incidencia que la construcción y entrada en funcionamiento de una planta de generación eléctrica tiene sobre los ingresos y por tanto sobre la calidad de vida de los pobladores sede del proyecto. La estimación de este índice se realiza con la ayuda de la ecuación 5.11 que se copia inmediatamente. 
$\Delta$ Salarios $/$ GWh $=$ Costo de capital $*(\mathrm{MO} / 100) *(\mathrm{TE} / \mathrm{CO})$

donde,

MO = Participación de la mano de obra en los costos de capital del proyecto (\%). Tomado de la tabla 5.15 incluida anteriormente.

$\mathrm{CO}=$ Número de empleos-año/GWh en la fase de construcción e instalación y desmantelamiento asociado al proyecto bajo estudio (tabla 5.16\}

$\mathrm{TE}=$ Total de empleos-año/GWh asociados al proyecto bajo estudio (tabla 5.16)

La información insumo al cálculo fue tomada de NREL [2010], Wei y colaboradores [2008] y Chatzimourtidis y Pivalachi [2008] y fue resumida en las tablas 5.12 y 5.19 incluidas anteriormente. La tabla 5.20 recoge la data recopilada y los resultados obtenidos; estos últimos expresados en su unidad original y en una escala [1-5].

Tabla 5.20. Promedio de salarios generados por opción de generación eléctrica

\begin{tabular}{|c|c|c|c|c|c|c|c|c|}
\hline \multirow{3}{*}{ TECNOLOGÍA } & \multicolumn{3}{|c|}{ COSTO DE CAPITAL } & \multicolumn{2}{|c|}{ Empleos-año/GWh } & \multirow{3}{*}{$\mathrm{TE} / \mathrm{CO}$} & \multirow{3}{*}{$\begin{array}{c}\text { SALARIOS } \\
(\$ 2007 / G W h)\end{array}$} & \multirow{3}{*}{$\begin{array}{r}\text { Escala } \\
{[1-5]}\end{array}$} \\
\hline & \multicolumn{2}{|c|}{$(\$ 2007 / G W h)$} & \multirow{2}{*}{\begin{tabular}{|c|}
$\%$ \\
$\mathrm{MO}$
\end{tabular}} & \multirow{2}{*}{ CONSTR } & \multirow{2}{*}{$\begin{array}{c}\text { TOTAL } \\
\text { EMPLEOS }\end{array}$} & & & \\
\hline & TOTAL & MO & & & & & & \\
\hline Carbón & 23 & 6,9 & 30 & 0,03 & 0,11 & 2,7 & 18,4 & 1 \\
\hline Petróleo & 28 & 6,9 & 30 & 0,03 & 0,11 & 2,7 & 18,4 & 1 \\
\hline T. gas comb. & 7 & 0,7 & 10 & 0,01 & 0,11 & 10,0 & 7,0 & 1 \\
\hline Turbina CC & 11 & 1,7 & 15 & 0,01 & 0,14 & 10,0 & 16,5 & 1 \\
\hline Nuclear & 42 & 12,6 & 30 & 0,05 & 0,14 & 1,8 & 22,7 & 1 \\
\hline Hidráulica & 42 & 12,6 & $30 *$ & 0,05 & 0,14 & 1,8 & 18,9 & 1 \\
\hline Eólica & 58 & 5,8 & 10 & 0,09 & 0,17 & 0,9 & 5,2 & 1 \\
\hline Solar - CSP & 154 & 46,2 & 30 & 0,08 & 0,23 & 1,9 & 86,6 & 3 \\
\hline Biomasa & 40 & 12,0 & 30 & 0,02 & 0,21 & 9,5 & 114,0 & 4 \\
\hline Geotérmica & 61 & 24,4 & 40 & 0,03 & 0,25 & 7,3 & 178,9 & 5 \\
\hline
\end{tabular}

Fuente de datos: Tablas 5.12 y 5.19

Para finalizar esta sección, debe insistirse en que los resultados obtenidos en la estimación de los indicadores están basados en cifras promedio recogidas en publicaciones especializadas internacionales en el sector energético; y por ello, 
son necesariamente aproximadas. Cifras semejantes, confiables y consistentes, no se encontraron para el caso específico de Venezuela, a pesar de un gran esfuerzo invertido en su búsqueda.

- Indicadores de naturaleza cualitativa. La valoración de los indicadores de índole cualitativa se realizó en base a entrevistas individuales, personales o a distancia, con expertos venezolanos seleccionados en los sectores público y académico de Venezuela, y con profesionales a cargo de proyectos de diversa índole en Venezuela, Panamá y Estados Unidos. La tabla 5.21 muestra la conformación del grupo de expertos entrevistado.

Tabla 5.21. Muestra entrevistada para evaluación de opciones de generación

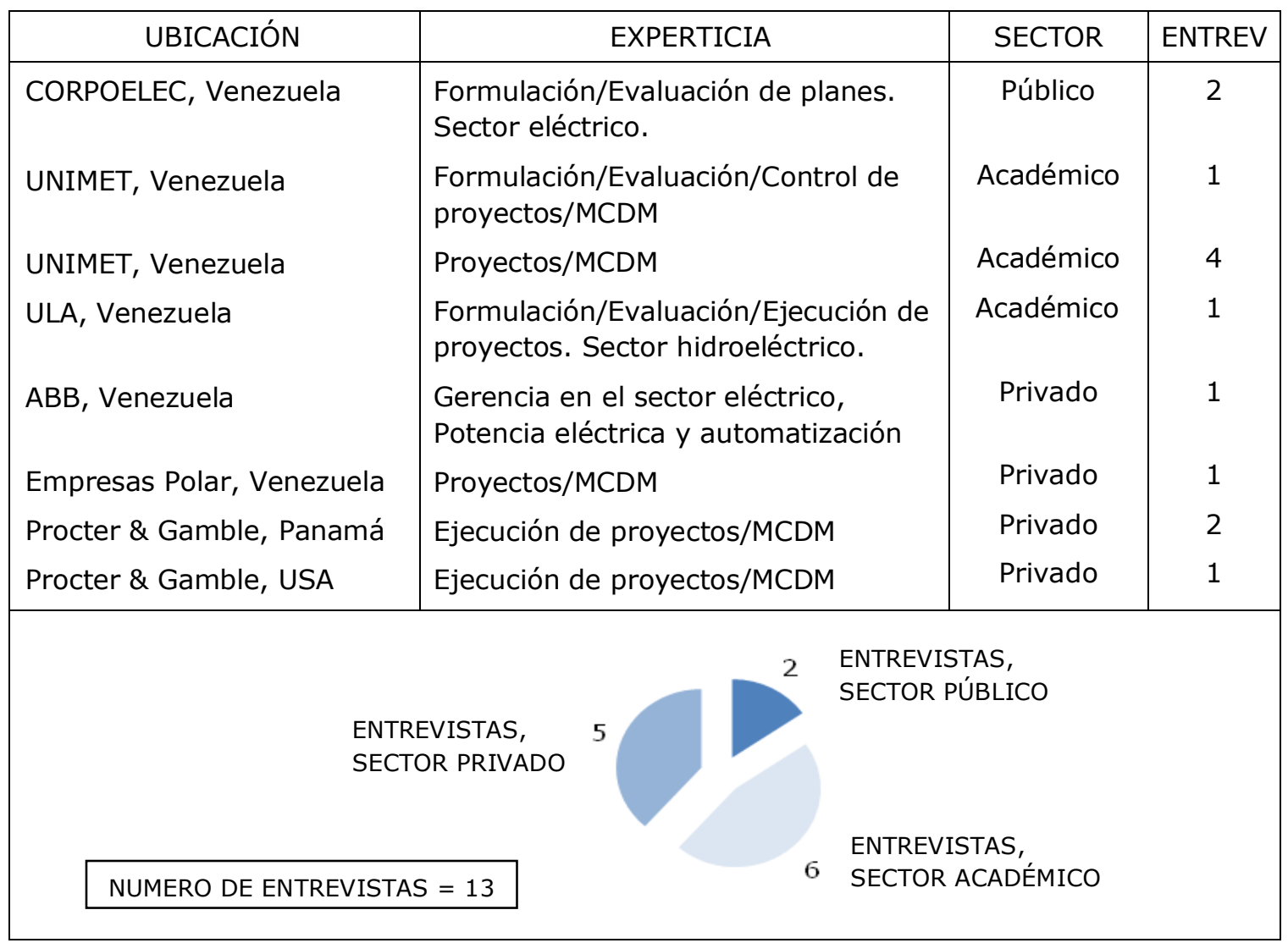

La información se recogió en el formato que se presenta en la tabla 5.22. 
Tabla 5.22. Recolección de juicios de valor sobre indicadores de índole cualitativa

\begin{tabular}{|c|c|c|c|c|c|c|c|c|c|}
\hline \multirow{2}{*}{ INDICADOR } & \multicolumn{9}{|c|}{ FUENTE DE ENERGÍA PRIMARIA } \\
\hline & $\mathrm{C}$ & $P$ & GN & $\mathrm{N}$ & $\mathrm{H}$ & $\mathrm{E}$ & $\mathrm{S}$ & B & G \\
\hline \multicolumn{10}{|l|}{ DIMENSIÓN TÉCNICA } \\
\hline \multicolumn{10}{|l|}{ Madurez de la tecnología } \\
\hline \multicolumn{10}{|l|}{ Flexibilidad de la tecnología } \\
\hline Factor de capacidad & 5 & 5 & 5 & 5 & 3 & 2 & 5 & 5 & 5 \\
\hline Eficiencia térmica & 4 & 4 & 4 & 4 & 5 & 5 & 5 & 4 & 1 \\
\hline \multicolumn{10}{|l|}{ Infraestructura física y logística } \\
\hline \multicolumn{10}{|l|}{ "Saber-como" local } \\
\hline \multicolumn{10}{|l|}{ DIMENSIÓN ECONÓMICA } \\
\hline Costo nivelado & 5 & 5 & 5 & 5 & 5 & 5 & 1 & 4 & 4 \\
\hline$\Delta$ Balanza de pagos/kWh & 4 & 3 & 3 & 4 & 5 & 3 & 1 & 4 & 5 \\
\hline \multicolumn{10}{|l|}{ DIMENSIÓN AMBIENTAL } \\
\hline Emisiones de gases invernadero & 1 & 1 & 4 & 5 & 5 & 5 & 5 & 5 & 5 \\
\hline Emisiones precursores de ozono & 2 & 1 & 5 & 5 & 5 & 5 & 5 & 5 & 5 \\
\hline Emisiones ácidas & 4 & 1 & 5 & 5 & 5 & 5 & 5 & 5 & 5 \\
\hline Emisiones de partículas & 1 & 4 & 5 & 5 & 5 & 5 & 5 & 5 & 5 \\
\hline \multicolumn{10}{|l|}{ Residuos sólidos y líquidos } \\
\hline \multicolumn{10}{|l|}{ Residuos radioactivos } \\
\hline \multicolumn{10}{|l|}{ Uso de la tierra } \\
\hline \multicolumn{10}{|l|}{ DIMENSIÓN SOCIAL } \\
\hline \multicolumn{10}{|l|}{ Aceptación de la comunidad } \\
\hline Creación de empleo local & 1 & 1 & 1 & 2 & 2 & 3 & 5 & 5 & 5 \\
\hline Salarios/MWh & 1 & 1 & 1 & 1 & 1 & 1 & 3 & 4 & 5 \\
\hline \multicolumn{10}{|l|}{ DIMENSIÓN ESTRATÉGICA } \\
\hline \multicolumn{10}{|l|}{ Diversidad de cesta energética } \\
\hline \multicolumn{10}{|l|}{ Seguridad de suministro } \\
\hline \multicolumn{10}{|l|}{ Compatibilidad con planes-nación } \\
\hline \multicolumn{10}{|l|}{ DIMENSIÓN RIESGO } \\
\hline \multicolumn{10}{|l|}{ Riesgo ante eventos extremos } \\
\hline Uso ilícito de material radioactivo & & & & & & & & & \\
\hline
\end{tabular}

C: carbón P: petróleo GN: gas natural N: nuclear H: hidráulica E:eólica S: solar B: biomasa G: geotérmica 
En el cuadro anterior, las casillas que corresponden a los indicadores de índole cuantitativa se rellenaron con los valores correspondientes a cada opción bajo estudio, estimados en la sección anterior. Las celdas restantes corresponden a los indicadores de índole cualitativa; y para su llenado se requirió a cada entrevistado expresar su opinión sobre el potencial desempeño de cada opción a evaluar, con relación a cada indicador incluido en el formato. Para ello, se solicitó asignar una calificación en una escala entre 1 y 5 , donde 5 correspondía a la mejor puntuación. En cada caso, se estableció un diálogo personal o telefónico, para aclarar dudas sobre la materia.

A objeto de reducir el volumen de información cualitativa a recabar, los valores de los indicadores para las tecnologías de carbón, petróleo y gas natural consideradas se consolidaron respectivamente en base a lo siguiente:

- Carbón. Los valores de los indicadores cuantitativos expresados en escala [1-5] coinciden para la tecnología que utiliza carbón pulverizado y la tecnología de gasificación integrada con ciclo combinado (IGCC, por sus siglas en inglés); en consecuencia, se consolidaron bajo la opción de energía primaria, 'Carbón'.

- Petróleo y Gas. Algunos de los valores de los indicadores cuantitativos estimados para la tecnología 'Turbina gas de combustión' y para la tecnología 'Turbina Ciclo Combinado' difieren. En este caso, se seleccionó el grupo de valores de la tecnología 'Turbina $\mathrm{CC}^{\prime}$, más eficiente, para representar las opciones 'Petróleo' y 'Gas Natural'.

\subsection{Procesamiento de la información y resultados}

Una vez reunida toda la información, su procesamiento se realizó con ayuda de una hoja de cálculo EXCEL especialmente diseñada al efecto. La utilización de la herramienta automatiza el cálculo del coeficiente de robustez para cada alternativa bajo evaluación. El índice expresa en forma consolidada el grado de cumplimiento de cada alternativa en relación a los criterios técnicos, ambientales, económicos, sociales, estratégicos y de riesgo propuestos en el modelo de valor. La hoja de cálculo diseñada incorpora las siguientes funciones, las cuales se cumplen en el mismo orden que se listan: 
(i) Estimación del coeficiente de robustez $\mathrm{CR}_{\mathrm{j}, \mathrm{k}}$ para cada alternativa j y para cada entrevistado $k$, a partir de sus juicios de valor y de acuerdo a la siguiente ecuación,

$$
\begin{gathered}
i=n \\
\mathrm{CR}_{\mathrm{j}, \mathrm{k}}=\sum_{\mathrm{i}}=1 \\
\hline \mathrm{PG} \\
\mathrm{i}
\end{gathered}
$$

donde, $n$ = número de indicadores para la evaluación, y j = C, P, GN, N. . . G $P G i=$ peso global del criterio $o$ indicador $i$.

$X_{i, j, k}=$ grado de cumplimiento [1-5] del criterio i por parte de la alternativa $j$, acuerdo al juicio del entrevistado $\mathrm{k}$.

(ii) Estimación del coeficiente de robustez consolidado CRCj para cada alternativa j, como la media geométrica de los coeficientes $C R j, k$ [Saaty, 2005a] ; de acuerdo con la siguiente expresión,

$$
\begin{gathered}
\mathrm{k}=\mathrm{m} \\
\mathrm{CRCj}=\left[\pi \mathrm{CR}_{\mathrm{j}, \mathrm{k}}\right]^{1 / \mathrm{m}} \\
\mathrm{k}=1
\end{gathered}
$$

donde, $\mathrm{m}$ es el número de entrevistados.

(iii) Normalización de los coeficientes de robustez CRj para cada alternativa, de acuerdo con la siguiente expresión,

$$
\mathrm{CR}_{\mathrm{j}}=\mathrm{CRCj} / \Sigma \mathrm{CRC}_{\mathrm{j}} \quad \mathrm{j}=\mathrm{C}, \mathrm{P}, \mathrm{GN}, \mathrm{N} . . \mathrm{G}
$$

El cálculo del coeficiente de robustez es una vía para valorar cada alternativa de generación eléctrica bajo estudio y para su posterior ordenamiento. Mientras más elevado resulte el índice mayor será la robustez de la alternativa bajo estudio.

La tabla 5.23 presenta los resultados obtenidos una vez procesada la información. Los valores en la matriz corresponden a los respectivos coeficientes de robustez CRj.k para cada alternativa y cada entrevistado. En esta base, en su última columna se muestran las preferencias de los entrevistados en cuanto a las opciones de 
generación eléctrica bajo estudio se refiere. La última línea en el cuadro presenta los coeficientes de robustez consolidados para cada alternativa; y en base a ellos, el ordenamiento para el grupo.

Tabla 5.23. Coeficientes de robustez y ordenamiento de las alternativas bajo estudio.

\begin{tabular}{|c|c|c|c|c|c|c|c|c|c|c|}
\hline & C & $P$ & GN & $\mathrm{N}$ & $\mathrm{H}$ & $E$ & S & B & G & ORDENAMIENTO \\
\hline E1 & 3,44 & 3,86 & 4,05 & 2,66 & 4,19 & 3,97 & 3,67 & 3,93 & 3,81 & $\begin{array}{l}\mathrm{H}>\mathrm{GN}>\mathrm{E}>\mathrm{B}>\mathrm{P} \\
>\mathrm{G}>\mathrm{S}>\mathrm{C}>\mathrm{N}\end{array}$ \\
\hline E2 & 3,44 & 3,55 & 3,84 & 2,56 & 4,25 & 4,03 & 3,72 & 3,77 & 3,50 & $\begin{array}{l}\mathrm{H}>\mathrm{E}>\mathrm{GN}>\mathrm{B}>\mathrm{S} \\
>\mathrm{P}>\mathrm{G}>\mathrm{C}>\mathrm{N}\end{array}$ \\
\hline E3 & 3,73 & 3,74 & 4,00 & 2,59 & 4,03 & 4,18 & 3,74 & 4,13 & 3,88 & $\begin{array}{l}E>B>H>G N>G \\
>S=P>C>N\end{array}$ \\
\hline E4 & 3,59 & 3,66 & 3,98 & 2,54 & 3,92 & 4,40 & 4,14 & 3,89 & 3,62 & $\begin{array}{l}E>S>G N>H>B \\
>P>G>C>N\end{array}$ \\
\hline E5 & 3,58 & 3,74 & 3,97 & 2,53 & 4,04 & 4,00 & 3,72 & 3,91 & 3,59 & $\begin{array}{l}\mathrm{H}>\mathrm{E}>\mathrm{GN}>\mathrm{B}>\mathrm{P} \\
>\mathrm{S}>\mathrm{G}>\mathrm{C}>\mathrm{N}\end{array}$ \\
\hline E6 & 3,44 & 3,73 & 4,04 & 2,56 & 3,97 & 4,12 & 3,64 & 3,96 & 3,58 & $\begin{array}{l}E>G N>H>B>P \\
>S>G>C>N\end{array}$ \\
\hline E7 & 3,30 & 3,65 & 4,00 & 2,56 & 3,84 & 4,16 & 3,69 & 4,14 & 3,82 & $\begin{array}{l}\mathrm{E}>\mathrm{B}>\mathrm{GN}>\mathrm{H}>\mathrm{G} \\
>\mathrm{S}>\mathrm{P}>\mathrm{C}>\mathrm{N}\end{array}$ \\
\hline E8 & 3,45 & 3,55 & 4,03 & 2,49 & 3,82 & 4,24 & 3,87 & 4,07 & 3,70 & $\begin{array}{l}E>B>G N>S>H \\
>G>P>C>N\end{array}$ \\
\hline E9 & 3,15 & 3,56 & 3,82 & 2,91 & 3,88 & 4,18 & 3,75 & 4,16 & 3,74 & $\begin{array}{l}E>B>H>G N>S \\
>G>P>C>N\end{array}$ \\
\hline $\mathrm{E} 10$ & 3,61 & 4,01 & 4,09 & 2,96 & 4,13 & 4,21 & 4,00 & 4,04 & 3,77 & $\begin{array}{l}E>H>G N>B>P \\
>S>G>C>N\end{array}$ \\
\hline $\mathrm{E} 11$ & 3,61 & 3,74 & 4,04 & 2,47 & 4,07 & 4,10 & 3,75 & 3,97 & 3,93 & $\begin{array}{l}\mathrm{E}>\mathrm{H}>\mathrm{GN}>\mathrm{B}>\mathrm{G} \\
>\mathrm{S}>\mathrm{P}>\mathrm{C}>\mathrm{N}\end{array}$ \\
\hline $\mathrm{E} 12$ & 3,61 & 3,82 & 4,15 & 2,71 & 4,03 & 4,32 & 3,93 & 4,03 & 3,89 & $\begin{array}{l}E>G N>H=B>S \\
>G>P>C>N\end{array}$ \\
\hline E13 & 3,45 & 3,69 & 4,01 & 2,56 & 3,97 & 4,12 & 3,64 & 3,96 & 3,58 & $\begin{array}{l}E>G N>H>B>P \\
>G>C>N\end{array}$ \\
\hline CRCj & 3,49 & 3,72 & 4,00 & 2,62 & 4,01 & 4,16 & 3,80 & 4,00 & 3,73 & $\begin{array}{l}E>H>G N=B>S \\
>G>P>C>N\end{array}$ \\
\hline
\end{tabular}

C: carbón P: petróleo GN: gas natural N: nuclear H: hidráulica E:eólica S: solar B: biomasa G:geotérmica 
La tabla 5.24 que se presenta a continuación, es una lista de las opciones de generación eléctrica bajo estudio, ordenadas en forma descendente de robustez. La última columna del cuadro muestra los coeficientes normalizados.

Tabla 5.24. Ordenamiento final de las alternativas de generación eléctrica

\begin{tabular}{|l|c|c|}
\hline \multicolumn{1}{|c|}{$\begin{array}{c}\text { ENERGÍA PRIMARIA/ } \\
\text { TECNOLOGÍA }\end{array}$} & $\begin{array}{c}\text { COEFICIENTE DE } \\
\text { ROBUSTEZ } \\
\text { Escala [1-5] }\end{array}$ & $\begin{array}{c}\text { COEFICIENTE DE } \\
\text { ROBUSTEZ } \\
\text { NORMALIZADO }\end{array}$ \\
\hline Eólica & 4,16 & 0,124 \\
\hline Hidráulica & 4,01 & 0,120 \\
\hline Gas (Ciclo Combinado) & 4,00 & 0,119 \\
\hline Biomasa & 4,00 & 0,119 \\
\hline Solar térmica & 3,80 & 0,113 \\
\hline Geotérmica & 3.73 & 0,111 \\
\hline Petróleo (Ciclo Combinado) & 3,72 & 0,111 \\
\hline Carbón (IGCC) & 3.49 & 0,104 \\
\hline Nuclear & 2,62 & 0,078 \\
\hline
\end{tabular}

El anexo 3 al final de este documento presenta la hoja de cálculo diseñada y los resultados obtenidos. A continuación algunos comentarios al respecto.

\subsection{Análisis parcial de resultados}

En una escala [1-5], los coeficientes de robustez obtenidos se ubican entre 2,62 para la opción nuclear y 4,16 para la opción eólica. En el rango de valores obtenidos, resalta el hecho de que la alternativa de generación de origen nuclear tiene un coeficiente de robustez muy inferior al resto de las opciones, tanto en las preferencias a nivel de cada entrevistado como en el ordenamiento consolidado para todo el grupo.

La generación de electricidad a partir de una fuente nuclear tiene el gran atractivo de la gran cantidad de calor que puede producirse con una cantidad muy pequeña de material nuclear. Sin embargo, Venezuela no dispone actualmente ni de la tecnología ni del personal entrenado para participar en la instalación, operación y 
mantenimiento de instalaciones que por su naturaleza deben ser estrictamente controladas y reguladas. Tampoco se dispone de un marco legal que norme tales actuaciones, y la disposición de desechos radioactivos producto de las operaciones. La percepción de la gente común es que el gobierno nacional maneja en forma poco clara, la posibilidad de la instalación de un reactor nuclear con fines pacíficos y tecnología no probada. Todo ello genera zozobra ante las potenciales terribles consecuencias de un accidente nuclear como el ocurrido recientemente en Fukushima, Japón. Por otra parte, aunque Venezuela dispone de reservas de uranio no explotadas, el material debe ser sometido a una serie de operaciones muy especializadas para convertirlo en material apto para el reactor; ello pondría al país en situación de dependencia de los centros que poseen la tecnología, los equipos y la experiencia para realizar tales transformaciones. Todo ello, se ha reflejado en las opiniones de los expertos para dar a la alternativa nuclear la última opción.

Por el contrario, las opciones eólica e hidráulica para generación de electricidad encabezan los ordenamientos a nivel individual y grupal. Su bajo impacto ambiental frente a opciones como la combustión de carbón o de derivados líquidos del petróleo, ambos altamente contaminantes; la existencia de un alto potencial hidráulico al sur del país, sólo parcialmente desarrollado; la disponibilidad de la experiencia en la construcción y operación de plantas hidroeléctricas, y de al menos parte de la red de distribución requerida para la transmisión de la potencial electricidad a generar; el potencial eólico estimado en la zona noroccidental y nororiental de Venezuela; la naturaleza renovable de esos recursos; la percepción de la poca complejidad de equipos, operación y logística de la opción eólica frente a la opción nuclear, geotérmica y bioenergética; y finalmente su menor costo comparado a la alternativa solar incidieron en la buena calificación obtenida.

Otras opciones oscilan entre los dos extremos citados. La alternativa de generación eléctrica con turbinas de gas se destaca por su mayor robustez frente a otras opciones de recursos fósiles que se perciben como menos 'limpias' y con inversión inicial más elevada. Por su parte, el aprovechamiento de la biomasa para la generación de energía eléctrica muestra elevada preferencia por parte de algunos de los entrevistados. Relacionado con este último punto, es conveniente recordar que los coeficientes de robustez estimados se basan parcialmente en información 
promedio obtenida en publicaciones internacionales especializadas y como tales son aproximados. A criterio del autor, esto es particularmente relevante en el caso de las tecnologías para el aprovechamiento de la bioenergía, en continua evolución y con una gran diversidad de insumos y de procesos posibles.

Para finalizar, nótese que en el proceso de evaluación y ordenamiento de las opciones de generación bajo estudio, no se ha considerado de forma explícita, la importante materia de la limitación de los recursos monetarios y físicos, y de los potenciales efectivamente desarrollables en el país, durante un período de tiempo razonablemente seleccionado y para cada fuente energética. Ni tampoco, los compromisos adquiridos por la nación. Este tipo de restricciones se incorporan a la solución del problema de evaluación planteado en la próxima sección.

\subsection{Incorporación de limitaciones a la solución del problema}

La existencia de restricciones en cuanto a presupuesto, potenciales efectivamente desarrollables de las fuentes de energía primaria a utilizar en la generación, disponibilidad de requerimientos de insumos físicos como agua y tierras, tamaño de los equipos comerciales accesibles; unida a la exigencia de la capacidad mínima que sería aconsejable instalar en un período seleccionado; y eventualmente, a las políticas del Estado en la materia, acotan las soluciones del problema a un espacio mucho más reducido que el considerado en el aparte anterior, donde implícitamente se supone la completa disponibilidad de todos los recursos necesarios.

De esta forma, los coeficientes de robustez obtenidos en la sección se convierten sólo en un valioso insumo al problema el cual se transforma del simple ordenamiento de las alternativas planteadas a la búsqueda de la mejor combinación de los recursos energéticos que puede explotar el país para enfrentar la demanda eléctrica nacional durante un período de tiempo dado, sujeta a las restricciones existentes.

\subsection{Identificación de restricciones}

Las limitaciones monetarias y físicas, los objetivos que se persigan en la realización de los planes, la disponibilidad de información y su confiabilidad, moldearán el problema. Específicamente, para la resolución del caso de estudio 
planteado, deberán efectuarse algunas sencillas suposiciones que luego se traducirán en las restricciones que acotarán el problema. Las suposiciones y su justificación, se listan a continuación.

(1) Para el período 2011-2025, el consumo eléctrico en Venezuela se realizará de acuerdo a los supuestos realizados en la sección 5.1.3.3.1.3 de este documento. De esta forma, la demanda máxima para finales del año 2025 se ubicará aproximadamente entre $(176.241 / 0,8)$ y $(207.241 / 0,8) \mathrm{GWh} / a n ̃ o$. La diferencia entre estas cifras y el consumo registrado para el año 2010, permitirá obtener el rango en el cual se estima oscile la capacidad de generación efectiva a incorporar al sistema durante el período 2011-2025.

De la cifra anterior hay que deducir el aporte de 4.420 MW cuya instalación urgente ha comenzado a ejecutar el gobierno nacional [Hernández, 2010c]. El objetivo señalado debe cumplirse durante el período 2010-2012 y hasta mediados del año 2010, se habían incorporado unos 1.660 MW de generación termoeléctrica distribuida, tal como se señala en la figura 5.8, sección 5.1.3.2 de este documento. Los cálculos se muestran en la tabla 5.29 incluida más adelante.

(2) Los planes del gobierno nacional incluyen disminuir significativamente la participación de la hidroelectricidad en la capacidad de generación eléctrica del país y basar su necesaria expansión en generación termoeléctrica que utilice derivados líquidos del petróleo, gas, carbón y combustible nuclear como fuente de energía primaria.

Para el año 2010, la generación de energía hidroeléctrica alcanzó un 65,8\% de la generación eléctrica nacional; de esta forma, la participación máxima de este tipo de energía en la matriz energética del país, debe ser menor a tal cifra.

(3) Para el período 2013-2025, se estima que el presupuesto de inversiones en sistemas de generación que garanticen un suministro de electricidad confiable a la nación se ubica alrededor de unos 55 mil millones de US\$, distribuidos a lo largo de dicho período. La cifra se obtuvo en base a las siguientes consideraciones: 
- Expertos venezolanos [CPTEDELCA, 2011c] coinciden en que se necesita una inversión inicial de 52 mil millones de dólares distribuidos en seis años, para recuperar el sistema eléctrico nacional y hacer frente a la futura demanda. De esta cifra, un 50\% corresponde a inversiones en nuevas instalaciones termoeléctricas, recuperación y terminación de plantas hidroeléctricas no concluidas para un gran total de $14.500 \mathrm{MW}$; y el resto a transmisión, distribución y apoyo logístico; lo que equivale a un promedio aproximado de 3.600 US\$/MW instalado, del cual unos 1.800 US\$/MW corresponden a inversión en sistemas de generación.

- El promedio anterior puede variar si el plan de incorporación de nuevas instalaciones incluye una fracción de energías alternativas. Como ya se ha señalado, Venezuela es un país donde la contribución de las energías renovables a la generación de electricidad es prácticamente nula; sin embargo, los diferentes sectores de la sociedad coinciden en señalar la conveniencia de su incorporación a la cesta energética del país. Si a ello se suma la intención del gobierno nacional de instalar al menos dos reactores nucleares y de aprovechar las reservas de carbón y la producción de coque de petróleo para elevar la generación de energía eléctrica en el país; la inversión promedio en generación debe estimarse como un promedio ponderado donde se asigne un peso tentativo al costo inicial de la generación a partir de energías alternativas.

La tabla 5.25 recoge información sobre costos promedio de inversión para los sistemas de generación eléctrica bajo estudio [U.S. EIA, 2010]. La información se arregla en dos grupos, energías convencionales y energías alternativas; y para cada uno de ellos, se estima la inversión promedio en generación actualizada al año 2010 y ponderada de acuerdo a las fracciones de participación que se anotan en la tercera columna.

Finalmente, la inversión promedio ponderada en generación expresada en US\$ 2010, se estima en base a la ecuación que sigue,

$$
\text { IPP GENERACIÓN, US } \$ 2010=\left(\operatorname{IPC0} * 0,90+\operatorname{IPEA}^{*} 0,10\right) *(1+\mathrm{t})^{2}
$$

donde, 
IPP GENERACIÓN = inversión promedio ponderada en generación, US\$/kW IPCO = inversión promedio en generación, energías convencionales, US $\$ / \mathrm{kW}$ IPEA = inversión promedio en generación, energías alternativas, US $\$ / \mathrm{kW}$ $\mathrm{t}=$ tasa de inflación promedio para los años 2009 y 2010 en USA. A efectos del cálculo se asigna un valor igual a $2,1 \%$ interanual ${ }^{81}$.

Nótese que en la expresión anterior se ha supuesto una relación 90/10 entre las participaciones respectivas de las energías convencionales y las energías alternativas en la generación eléctrica del país. La relación así como las fracciones de participación utilizadas en la estimación de los promedios por grupo, son producto de un proceso iterativo que se inicia en base a las suposiciones (5), (7) y (9) incluidas un poco más adelante y se comprueba con los resultados del modelo de programación lineal que se plantea en el cuadro 5.26 .

Tabla 5.25. Inversión promedio para estimación de presupuesto

\begin{tabular}{|c|c|c|c|}
\hline $\begin{array}{c}\text { ENERGÍA PRIMARIA/ } \\
\text { TECNOLOGÍA }\end{array}$ & $\begin{array}{l}\text { GENERACIÓN } \\
\text { (US\$2008/kW) }\end{array}$ & $\begin{array}{c}\text { PARTICIPACIÓN } \\
(\%)\end{array}$ & $\begin{array}{c}\text { PROMEDIO } \\
\text { (US } \$ 2010 / \mathrm{kW})\end{array}$ \\
\hline Carbón (IGCC) & 2569 & 30 & \multirow{4}{*}{1786} \\
\hline Petróleo (Ciclo Combinado) & 968 & \multirow{2}{*}{50} & \\
\hline Gas (Ciclo Combinado) & 968 & & \\
\hline Hidráulica & 2294 & 20 & \\
\hline N̂clear & 3820 & 50 & \multirow{5}{*}{3645} \\
\hline Eólica & 1966 & \multirow{4}{*}{50} & \\
\hline Solar térmica & 5132 & & \\
\hline Biomasa & 3849 & & \\
\hline Geotérmica & 1749 & & \\
\hline \multicolumn{3}{|l|}{ ÎPP GENERACIÓN } & 1972 \\
\hline
\end{tabular}

Fuente de datos: [U.S. EIA, 2010] $1,495 \%$ y $2,727 \%$ respectivamente [http://www.datosmacro.com/ipc-paises/usa, 2/2012]. La tasa de inflación promedio t se obtiene de la siguiente expresión: $(1+t)^{\wedge} 2=(1+0,01495)(1+0,02727)$. 
La última línea en el cuadro anterior registra la inversión promedio en generación para los sistemas bajo estudio, actualizada al año 2010 y en el supuesto de que se cumpla la ponderación señalada. Nótese que el promedio registrado no incluye la inversión en transmisión y distribución de la energía eléctrica producida. Según fuentes especializadas, el monto de esta partida expresada como un porcentaje de la inversión en generación asociada varía entre 50\% [Hernández, 2009b] y alrededor de 100\% [CPTEDELCA, 2011; Rousse, 2010]. Consulta muy reciente a un alto ejecutivo de ABB, Venezuela ${ }^{82}$ calificó esta cifra como muy variable y se inclinó por un máximo de $50 \%$ sobre la inversión en generación en el caso de instalaciones nuevas.

Ante la significativa diferencia entre las apreciaciones anteriores, y toda vez que la inversión en transmisión y distribución está asociada más que a las características del sistema de generación eléctrica que se utilice, a su ubicación relativa al mercado demandante y a las características y estado de la líneas existentes si las hay; la estimación del orden de magnitud del presupuesto requerido para la satisfacción de la demanda eléctrica en el país, durante el período bajo estudio, se basa en la inversión promedio en generación. Así, a objeto de la resolución del caso de estudio y para el período 2011-2025, se tiene,

$1970 * 24,1 * 10^{6} \leq$ PRESUPUESTO $2010-2025 \leq 1970 * 31,9 * 10^{6}$

47,5 mil millones US\$ $\leq$ PRESUPUESTO 2010-2025 $\leq 62,8$ mil millones US\$

Y si se descuenta la capacidad de generación en proceso de instalación citada en la suposición (1), la inversión en generación requerida para el período 2013-2025 se ajusta a,

$$
1970 * 19,7 * 10^{6} \leq \text { PRESUPUESTO } 2013-2025 \leq 1970 * 27,5 * 10^{6}
$$

38,8 mil millones US\$ $\leq$ PRESUPUESTO $2013-2025 \leq 54,2$ mil millones US $\$$

82 Mantilla X., Gerente, ABB Venezuela, 2/2012 
La cifra anterior es enorme, aún para un país con los ingresos de Venezuela pero que simultáneamente tiene otras muchas necesidades. Las autoridades gubernamentales han anunciado (2010) una primera asignación de 50 mil millones US\$ para la recuperación y fortalecimiento del sector, allí incluida la inversión en transmisión. Este último número y lo anteriormente expuesto, pueden servir como referencia para seleccionar el rango de presupuesto a utilizar en la solución del caso de estudio planteado.

(4) No existirá problema en el suministro de derivados de petróleo y gas a las plantas eléctricas que así lo requieran [CORPOELEC 2010]. Venezuela posee grandes reservas de petróleo y de gas; su relación R/P en el primer caso es superior a 300 años; y en el caso del gas natural, superior a 200 años.

Sin embargo, el país ha venido sufriendo una crisis energética que tiene entre sus características que a corto plazo, la disponibilidad efectiva de su capacidad de refinación no será suficiente para suplir los volúmenes de diesel que demanda el país, tal como se señala en la figura 5.6 incluida al inicio de este capítulo. El gobierno nacional ha informado sobre sus planes para la expansión de la capacidad de las refinerías de manera sustantiva; no obstante, tales planes aún no se enrumban de forma efectiva [Hernández, 2010a]. Las exportaciones de diesel han venido disminuyendo; y se prevé lo seguirán haciendo, para poder cumplir con la demanda futura de los sectores agrícola, industrial, de transporte y eléctrico del país; especialmente si como ya lo ha asomado el gobierno, el componente termoeléctrico en la generación de electricidad se incrementa. Peor aún, de no incrementarse la capacidad de producción de diesel en las refinerías del país, Venezuela deberá importar diesel con el consiguiente efecto sobre los ingresos, la balanza de pagos y la seguridad de suministro de la nación.

Por otra parte, en el país existe un déficit de gas que para el año 2010 alcanzó $2,2 \times 10^{6} \mathrm{~m}^{3}$ de gas [BP, 2011] y debió importarse desde Colombia. De nuevo, el gobierno nacional ha informado sobre planes para incrementar la explotación de gas no asociado, costa afuera; sin embargo tales planes han sufrido un considerable retraso. 
Dada su reciente historia, la actuación del gobierno nacional es impredecible. Existen planes para la ampliación de las capacidades que permitirán operar sin contratiempo la expansión del parque termoeléctrico en Venezuela. A efectos de la resolución del caso de estudio planteado, esa es la mejor información de la cual se dispone; y el gobierno ya trabaja en la instalación de 4.420 MW de plantas termoeléctricas de generación distribuida.

(5) Para el año 2025, la cuota de participación de las energías renovables excluyendo la energía hidroeléctrica, se acercará a un $10 \%$ del suministro total de electricidad a la nación, meta ambiciosa para un país latinoamericano; y a la vez modesta, si se compara con los niveles de aprovechamiento de energías renovables que ya han alcanzado algunos países europeos, y con los potenciales desarrollables de energía eólica y solar en el país tal como señala en la tabla 5.2 incluida al inicio del capítulo [Hernández, 2010; CORPOELEC, 2010].

(6) El potencial desarrollable de la energía eólica en el país se estima en unos 18.000 GWh/año [CORPOELEC, 2010]. A falta de información similar para otros recursos renovables, se supone que el potencial desarrollable de estos últimos se relaciona con sus respectivos potenciales estimados registrados en la tabla 5.2, como lo hace la energía eólica. Los cálculos se muestran en la tabla 5.30 incluida más adelante.

(7) Venezuela cuenta con un elevado potencial de carbón y coque de petróleo que puede alimentar plantas de generación eléctrica. Actualmente, el país produce unos 8 millones de toneladas de coque de petróleo resultado de los procesos de refinación existentes. El desarrollo de la Faja Petrolífera del Orinoco se estima incrementará paulatinamente este volumen a unos 25 millones de toneladas para el año 2020 y garantizará el insumo al menos a tres plantas de generación termoeléctrica con capacidad instalada de $2.700 \mathrm{MW}, 900 \mathrm{MW}$ y $1.800 \mathrm{MW}$ respectivamente, que el gobierno nacional ha planeado instalar en la zona [CORPOELEC, 2010].

Adicionalmente, el país tiene una producción anual de 8 millones de toneladas de carbón del cual un 83\% corresponde al estado Zulia. En base a ello, se ha planificado el desarrollo de una planta termoeléctrica de $2.000 \mathrm{MW}$ en la región 
[CORPOELEC, 2010]. Esta cifra, sumada a 5.400 MW que operarían en base a coque de petróleo en la Faja del Orinoco, totalizan 7.400 MW de plantas carboeléctricas a instalar, al menos en los planes del gobierno nacional.

(8) Para el año 2025, la generación nuclear contribuirá al suministro de energía eléctrica al país. En efecto, el gobierno nacional ha firmado convenios con Rusia para el estudio del potencial establecimiento de al menos 2 plantas nucleares de $1.200 \mathrm{MW}$ cada una ${ }^{83}$ y la autoridad en el sector ha confirmado tal posibilidad.

(9) A lo largo del período 2011-2025, la participación del componente hidroeléctrico en el suministro de electricidad a la nación bajará significativamente. Aún cuando el potencial hidroeléctrico no desarrollado ni en construcción es de 27.584 MW instalables [CORPOELEC, 2010], el gobierno nacional ha paralizado los planes de desarrollo hidroeléctrico del Alto Caroní y sólo se planea finalizar los desarrollos en construcción que alcanzan 2.931 MW [CORPOELEC, 2010] y recuperar algunas instalaciones no operativas.

De acuerdo con las suposiciones anteriores, el problema puede plantearse y resolverse con ayuda de las técnicas de programación lineal citadas en la sección 1.1.1.1 de este documento; tal como se plantea en la próxima sección.

\subsection{Planteamiento del problema}

La tabla 5.26 contiene el planteamiento del modelo base de programación lineal que se propone como apoyo a la solución del caso de estudio. Los resultados que se obtengan de su aplicación a la data reunida a lo largo de este capítulo, pretenden ser una contribución en la búsqueda de la mejor combinación de uso de las fuentes energéticas primarias para generación de potencia eléctrica en el país. Se entiende por 'mejor combinación', aquella que produce la máxima robustez al sistema global de generación, todo sujeto a las limitantes energéticas, económicas, y políticas de la nación; así como a los compromisos y a los convenios suscritos por la misma.

83

http://www.guia.com.ve/noti/68336/reactores-nucleares-que-construira-rusia-en-venezuela-son-un prototipo, 12/2011. 
La ecuación 5.16 en el modelo planteado refleja el objetivo a maximizar como una función de las capacidades de generación a instalar correspondientes a cada alternativa bajo estudio y a sus respectivos coeficientes de robustez. Las desigualdades 5.16 a 5.26 son expresión de las restricciones del problema las cuales se corresponden con las suposiciones efectuadas en la sección anterior.

Tabla 5.26. Modelo lineal del caso de estudio

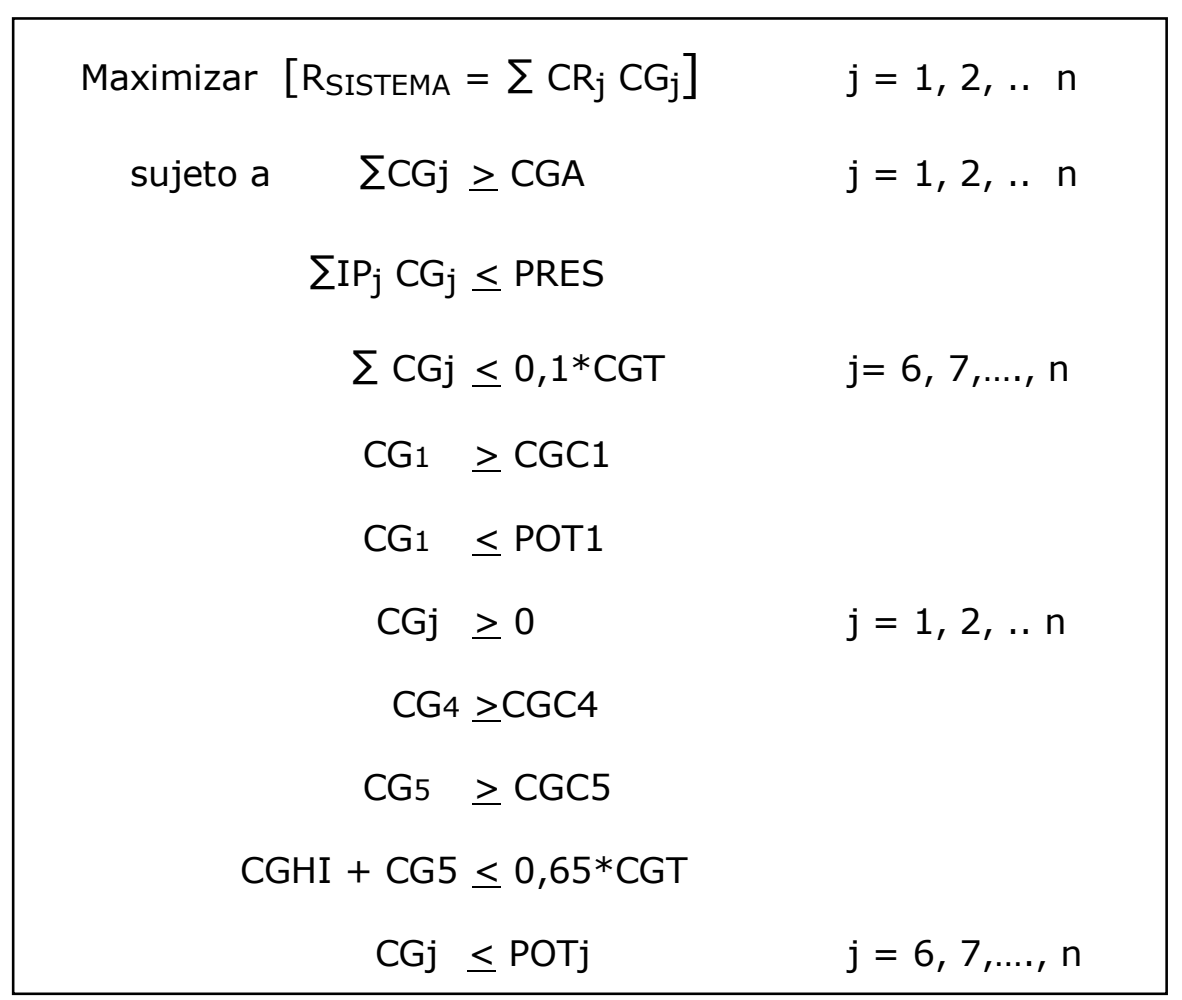

donde,

RSISTEMA $=$ Robustez del sistema, es la función a maximizar.

$\mathrm{CRj}=$ Coeficiente de robustez de la alternativa de generación $\mathrm{j}$

$\mathrm{CGj}=$ Capacidad de generación eléctrica a incorporar al sistema durante el período 2013-2025, correspondiente a la alternativa j, GWh/año

IPj = Inversión promedio para la alternativa de generación j, USD/(GWh/año)

CGA = Capacidad mínima de generación eléctrica a incorporar al sistema durante el período 2013-2025, GWh/año.

CGT = Capacidad total de generación eléctrica necesaria para el año 2025, GWh/año. 
PRES = Presupuesto asignado para la incorporación de la capacidad de generación eléctrica necesaria durante el período 2013-2025, US\$.

CGC1 = Capacidad de generación a desarrollar por convenios, basada en carbón y coque de petróleo, Gwh/año.

CGC4 = Capacidad de generación nuclear a desarrollar por convenios, GWh/año

CGC5 = Capacidad de generación hidroeléctrica en construcción, GWh/año

CGHI = Capacidad de generación hidroeléctrica disponible a inicio del período, GWh/año.

POTj = Potencial desarrollable del recurso energético usado por la alternativa $j$, GWh/año.

$\mathrm{n}$ = número de alternativas de generación bajo estudio, $\mathrm{n}=9$. A efectos de la aplicación del modelo, las alternativas de generación se identifican en la forma siguiente, $j=(1)$ térmica-carbón y coque (2) térmica-derivados líquidos de petróleo (3) térmica-gas natural (4) nuclear (5) hidráulica (6) eólica (7) térmica solar (8) biomasa (9) geotérmica.

Las restricciones 5.16 a 5.26 en el modelo planteado tratan de reflejar las limitantes impuestas al problema y se corresponden con las suposiciones efectuadas en la sección anterior, tal como se indica en el cuadro que sigue.

Tabla 5.27. Suposiciones en el planteamiento del modelo

\begin{tabular}{|c|c|l|}
\hline RESTRICCIÓN & SUPOSICIÓN & \multicolumn{1}{|c|}{ REFERENTE A (2013-2025) } \\
\hline 5.17 & 1 & Demanda capacidad eléctrica efectiva \\
\hline 5.18 & 3 & Presupuesto potencial a asignar \\
\hline 5.19 & 5 & Generación energías renovables \\
\hline 5.20 & 7 & Potencial desarrollable carbón y coque \\
\hline 5.21 & 7 & Generación carbón y coque \\
\hline 5.22 & 4 & Generación derivados de petróleo o gas \\
\hline 5.23 & 8 & Generación nuclear \\
\hline 5.24 & 9 & Generación hidroeléctrica \\
\hline 5.25 & 2 & Generación hidroeléctrica \\
\hline 5.26 & 6 & Potencial desarrollable de energías renovables. \\
\hline
\end{tabular}


La definición completa del modelo finaliza con la asignación de valores a los parámetros en función de los cuales se realizó su planteamiento. La materia se trata en la sección que sigue.

\subsection{Parámetros del problema}

La completa definición y resolución del problema requiere la introducción de la siguiente información al modelo planteado:

(i) Coeficientes de robustez $(\mathrm{CRj})$ e inversión promedio de nuevas instalaciones de generación de energía eléctrica (IPj), US\$/(GWh/año), para cada alternativa bajo estudio.

(ii) Presupuesto asignado para la incorporación de capacidad de generación eléctrica a incorporar durante el período 2013-2025 (PRES), US\$.

(iii) CGA, CGT, CGC1, CGC4, CGC5 y CGHI; todos definidos en la página anterior, GWh/año.

(iv) Los potenciales desarrollables para generación eléctrica en base a carbón y coque de petróleo (POT1), energía eólica (POT6), energía solar (POT7), biomasa (POT8) y energía geotérmica (POT9).

La tabla 5.28 que se incluye en la próxima página, presenta la información referente al punto (i). La segunda columna en el cuadro recoge los coeficientes normalizados de robustez obtenidos en la sección 5.1.3.3.3 y resumidos en la tabla 5.24, para cada alternativa de generación bajo estudio. Las cifras correspondientes a la inversión promedio en generación para cada opción (IPj) se presentan en su última columna. Los valores se expresan en US\$2010/(GWh/año) y su cálculo se efectúa en base a los respectivos promedios de inversión en generación en US\$ 2008/kW [U.S. EIA 2010], una tasa de inflación promedio igual a 2,1\% interanual (USA), los factores de carga promedio (FC)[NREL, 2010] y un factor de operatividad igual a 0,73 [Figura 5.8], tal como se expresa en las siguientes relaciones.

$$
\begin{aligned}
\text { IPG, US } \$ 2010 / \mathrm{kW} & =(\text { IP GENERACION, US } \$ 2008 / \mathrm{kW}) *(1,021)^{2} \\
\text { IP, US } \$ 2010 /(\mathrm{GWh} / \mathrm{año}) & =\text { IPG, US } \$ 2010 / \mathrm{kW} * 10^{6} /(365 * 24 * \text { FC } * 0,73)
\end{aligned}
$$


Tabla 5.28. Parámetros del modelo: CRj e IPj

\begin{tabular}{|l|c|c|c|c|c|}
\hline $\begin{array}{c}\text { ALTERNATIVA DE } \\
\text { GENERACIÓN }\end{array}$ & CRj & $\begin{array}{c}\text { IPGj } \\
(\text { US } \$ 2008 / \mathrm{kW})\end{array}$ & $\begin{array}{c}\text { IPGj } \\
(\text { US } \$ 2010 / \mathrm{kW})\end{array}$ & $\begin{array}{c}\text { FC } \\
(\%)\end{array}$ & $\begin{array}{c}\text { IPj } \\
(\text { US } \$ 2010 /(\mathrm{GWh} / \mathrm{año})\end{array}$ \\
\hline Carbón (IGCC) & 0,104 & 2569 & 2678 & 85 & $493 \times 10^{3}$ \\
\hline Petróleo (CC) & 0,111 & 968 & 1009 & 87 & $181 \times 10^{3}$ \\
\hline Gas (CC) & 0,119 & 968 & 1009 & 87 & $181 \times 10^{3}$ \\
\hline Nuclear & 0,078 & 3820 & 3982 & 90 & $692 \times 10^{3}$ \\
\hline Hidráulica & 0,120 & 2294 & 2391 & 65 & $575 \times 10^{3}$ \\
\hline Eólica & 0,124 & 1966 & 2049 & 44 & $728 \times 10^{3}$ \\
\hline Solar térmica & 0,113 & 5132 & 5350 & 31 & $2699 \times 10^{3}$ \\
\hline Biomasa & 0,119 & 3849 & 4012 & 83 & $756 \times 10^{3}$ \\
\hline Geotérmica & 0,111 & 1749 & 1823 & 90 & $317 \times 10^{3}$ \\
\hline
\end{tabular}

Fuente de datos: Tablas 5.24 y 5.11, [U.S, EIA, 2010; NREL, 2010]

La información insumo al modelo y referida en los puntos (ii), (iii) y (iv) se deriva de las suposiciones que sirvieron de base al modelo, recogidas en la tabla 5.27. Las tablas 5.29 y 5.30 resumen los cálculos efectuados y la fuente de los datos insumo a los mismos.

Tabla 5.29. Parámetros del modelo: Capacidad a instalar 2013-2025

\begin{tabular}{|c|c|c|}
\hline PARÁMETRO & CÁLCULOS & FUENTE \\
\hline $\begin{array}{c}\text { CGA } \\
\text { (GWh/año) }\end{array}$ & $\begin{array}{l}\mathrm{CGA}=(\mathrm{CONSUMO} 2025 / 0,8)-\mathrm{CONSUMO} 2010-\mathrm{MW} 2010-2012 \\
\mathrm{MW} 2010-2012=(3.920 * \mathrm{FCT}+500 * \mathrm{FCH}) * 365 * 24 * \mathrm{FO} / 1000 \\
\mathrm{FCT}=\text { Factor capacidad termo }=0,87 \\
\mathrm{FCH}=\text { Factor de capacidad hidro }=0,65 \\
\mathrm{FO}=\text { Factor operatividad promedio }=0,73 \\
\mathrm{MW} 2010-2012=(3.920 * 0,87+500 * 0,65) * 365 * 24 * 0,73 / 1000 \\
\text { MW } 2010-2012=23.887 \mathrm{GWh} / \text { año } \\
(207.420 / 0,8)-116.702-23.887 \geq \mathrm{CGA} \\
(176.213 / 0,8)-116.702-23.887 \leq \mathrm{CGA} \\
118.686 \geq \mathrm{CGA} \geq 79.677=>\quad \mathrm{CGA}=120.000 \mathrm{GWh} / \text { año }\end{array}$ & $\begin{array}{l}\text { Tablas } 5.5 \\
\text { Tabla } 5.28 \\
\text { Figura } 5.8 \\
\text { Suposición } 1\end{array}$ \\
\hline
\end{tabular}

(1) Durante el período 2010-2012 se instalan 3.920 MW de generación termoeléctrica y 500 MW de generación hidroeléctrica (suposición 1). 
Tabla 5.30. Parámetros del modelo: Presupuesto, CGT, CGHI, CGC1, CGC4, CGC5. POT5 y potenciales desarrollables de las energías renovables.

\begin{tabular}{|c|c|c|}
\hline $\begin{array}{l}\text { PRES } \\
(\text { MM US } \$)\end{array}$ & $\begin{array}{r}40.000 \text { MM US } \$ 2010<\text { PRES2013-2025 }<55.000 \text { MM US } \$ 2010 \\
=>\quad \text { PRES }=55.000 \text { MM US } \$\end{array}$ & $\begin{array}{l}\text { Tabla } 5.25 \\
\text { Suposición } 3\end{array}$ \\
\hline $\begin{array}{c}\text { CGT } \\
\text { (GWh/año) }\end{array}$ & $\begin{array}{l}\mathrm{CGT}=\left(\mathrm{CONSUMO}_{2025} / 0,8\right) \\
(207.241 / 0,8) \geq \mathrm{CGT} \geq(176.214 / 0,8) \\
259.275 \geq \mathrm{CGT} \geq 220.266=>\quad \text { CGT }=259.000 \mathrm{GWh} / \mathrm{año}\end{array}$ & Tablas 5.5 \\
\hline $\begin{array}{c}\text { CGHI } \\
(\text { GWh/año) }\end{array}$ & $\begin{array}{l}\mathrm{CGHI}=116.702 * 0,658=76.790 \mathrm{GWh} / \mathrm{año} \\
\quad=>\mathrm{CGHI}=76.800 \mathrm{GWh} / \text { año }\end{array}$ & $\begin{array}{l}\text { Sección } \\
5.1 .3 .2 .1\end{array}$ \\
\hline $\begin{array}{c}\text { CGC1 } \\
\text { (GWh/año) }\end{array}$ & $\begin{array}{l}\mathrm{CGC} 1=7.400 * 365 * 24 * \mathrm{FC} * \mathrm{FO} / 1000 ; \mathrm{FC}=0,85 \mathrm{FO}=0,73 \\
\mathrm{CGC} 1=7.400 * 365 * 24 * 0,85 * 0,73 / 1000 \\
\mathrm{CGC} 1=40.767 \mathrm{GWh} / \mathrm{año}=>\quad \mathrm{CGC} 1=40.000 \mathrm{GWh} / \text { año }\end{array}$ & $\begin{array}{l}\text { Tabla } 5.11 \\
\text { Suposición } 5\end{array}$ \\
\hline $\begin{array}{c}\text { CGC4 } \\
\text { (GWh/año) }\end{array}$ & $\begin{array}{l}\mathrm{CGC} 4=2.400 * 365 * 24 * \mathrm{FC} * \mathrm{FO} / 1000 ; \mathrm{FC}=0,90 \mathrm{FO}=0,73 \\
\mathrm{CGC} 4=2.400 * 365 * 24 * 0,9 * 0,73 / 1000 \\
\mathrm{CGC} 4=13.813 \mathrm{GWh} / \mathrm{año}=>\quad \mathrm{CGC} 2=13.800 \mathrm{GWh} / \text { año }\end{array}$ & $\begin{array}{c}\text { Tabla } 5.11 \\
\text { Suposición } 4\end{array}$ \\
\hline $\begin{array}{c}\text { CGC5 } \\
\text { (GWh/año) }\end{array}$ & $\begin{array}{l}\mathrm{CGC5}=2.931 * 365 * 24 * \mathrm{FC} * \mathrm{FO} / 1000) ; \mathrm{FC}=0,65 \mathrm{FO}=0,73 \\
\mathrm{CGC5}=14.418 \mathrm{GWh} \quad=>\quad \mathrm{CGC} 5=14.420 \mathrm{GWh} / \text { año }\end{array}$ & $\begin{array}{l}\text { Sección5.1.2 } \\
\text { Suposición } 9\end{array}$ \\
\hline $\begin{array}{c}\text { POT1 } \\
\text { (GWh/año) }\end{array}$ & 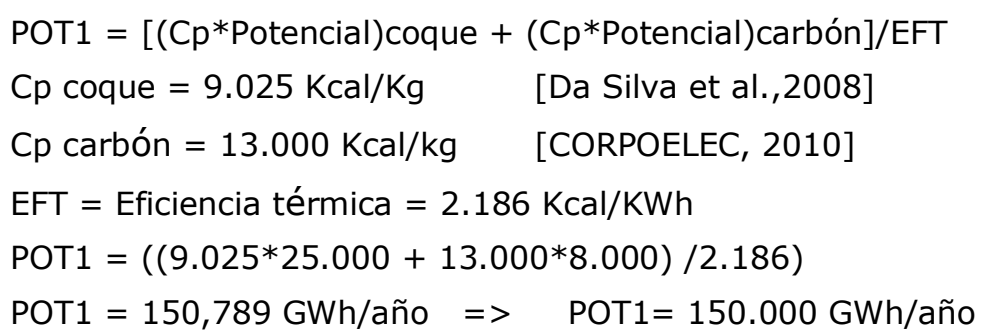 & $\begin{array}{l}\text { Tabla } 5.11 \\
\text { Suposición } 5\end{array}$ \\
\hline $\begin{array}{c}\text { POT5 } \\
\text { (GWh/año) }\end{array}$ & $\begin{array}{l}\text { POT5 }=(27.584+2.931) * 365 * 24 / 1000 \\
\text { POT5 }=267.311 \mathrm{GWh} / \text { año }=>\quad \text { POT5 }=267.000 \mathrm{GWh} / \text { año }\end{array}$ & Sección5.1.2 \\
\hline $\begin{array}{c}\text { POT6 } \\
\text { (GWh/año) }\end{array}$ & POT6 = $18.000 \mathrm{GWh} /$ año & Suposición 7 \\
\hline $\begin{array}{l}\text { POT7 } \\
\text { (GWh/año }\end{array}$ & $\begin{aligned} & \text { POT7 }=18.000 * 4,56 / 1,41= 58.213 \mathrm{GWh} / \text { año } \\
&=>\quad \text { POT7 }=58.200 \mathrm{GWh} / \text { año }\end{aligned}$ & \\
\hline $\begin{array}{l}\text { POT8 } \\
\text { (GWh/año }\end{array}$ & $\begin{aligned} & \text { POT8 }=18.000 * 0,34 / 1,41= 4.340 \mathrm{GWh} / \text { año } \\
&=>\quad \text { POT8 }=4.300 \mathrm{GWh} / \text { año }\end{aligned}$ & $\begin{array}{c}\text { Tabla } 5.2 \\
\text { Suposición } 7\end{array}$ \\
\hline $\begin{array}{c}\text { POT9 } \\
\text { (GWh/año }\end{array}$ & $\begin{aligned} \text { POT9 }=18.000 * 0,15 / 1,41 & =1.915 \mathrm{GWh} / \text { año } \\
& =>\quad \text { РОT9 }=1.900 \mathrm{GWh} / \text { año }\end{aligned}$ & \\
\hline
\end{tabular}


A falta de información más exacta, la asignación de valores a los potenciales desarrollables de energía solar (POT7), bioenergía (POT8) y energía geotérmica (POT9) se realizó bajo la suposición de que se mantiene la misma proporcionalidad entre los potenciales desarrollables que entre los potenciales energéticos estimados para las energías renovables en el país (tabla 5.2). Así, tomando como base al potencial desarrollable de la energía eólica en Venezuela (POT6) [CORPOELEC, 2010], puede escribirse,

$$
\text { POT }_{j}=\text { POT6* }^{*}(\text { POTENCIAL ENERGÉTICO })_{\mathrm{j}} / \text { POTENCIAL ENERGÍA EÓLICA }
$$

En tal sentido, el autor está consciente de que la suposición efectuada tiene una alta probabilidad de que no sea cierta; por ello, los valores asignados deben tomarse como lo que son, una referencia para acotar el valor de la variable correspondiente. En caso, de que los resultados del modelo se vean afectados significativamente por tales cifras es conveniente obtener valores más exactos; o en caso de no disponer de ellos, eliminar las restricciones correspondientes.

A continuación algunos comentarios sobre el procesamiento de la información disponible con el modelo de programación lineal planteado y sobre los resultados obtenidos.

\subsection{Procesamiento de la información y resultados}

La información reunida y transformada a las unidades convenientes fue procesada con ayuda de una hoja de cálculo diseñada para la utilización de la herramienta Microsoft Office Excel SOLVER la cual permite maximizar o minimizar el valor de una función de $n$ variables sujeta a restricciones que limitan los valores que pueden tomar las variables en la solución del problema. Si la función es lineal la herramienta utiliza el método Simplex en su solución.

El procesamiento de la información se convirtió en un proceso iterativo con el objetivo de mejorar el modelo originalmente planteado. Se replantearon, eliminaron y/o adicionaron restricciones; y en consecuencia, se redefinieron, eliminaron o definieron los parámetros respectivamente asociados a ellas; a fin de obtener un modelo cuya solución se aproximase lo más posible a la realidad del país. 
El planteamiento general finalmente obtenido y los valores de los parámetros asociados, están contenidos en las tablas 5.26 y 5.28 a 5.30 respectivamente. A modo de ilustración, el cuadro que sigue muestra el planteamiento del problema con todas las restricciones incluidas. El anexo 3 al final del documento presenta la hoja de cálculo diseñada y utilizada en su resolución y los resultados obtenidos.

Tabla 5.31. Modelo lineal del caso de estudio. Caso base

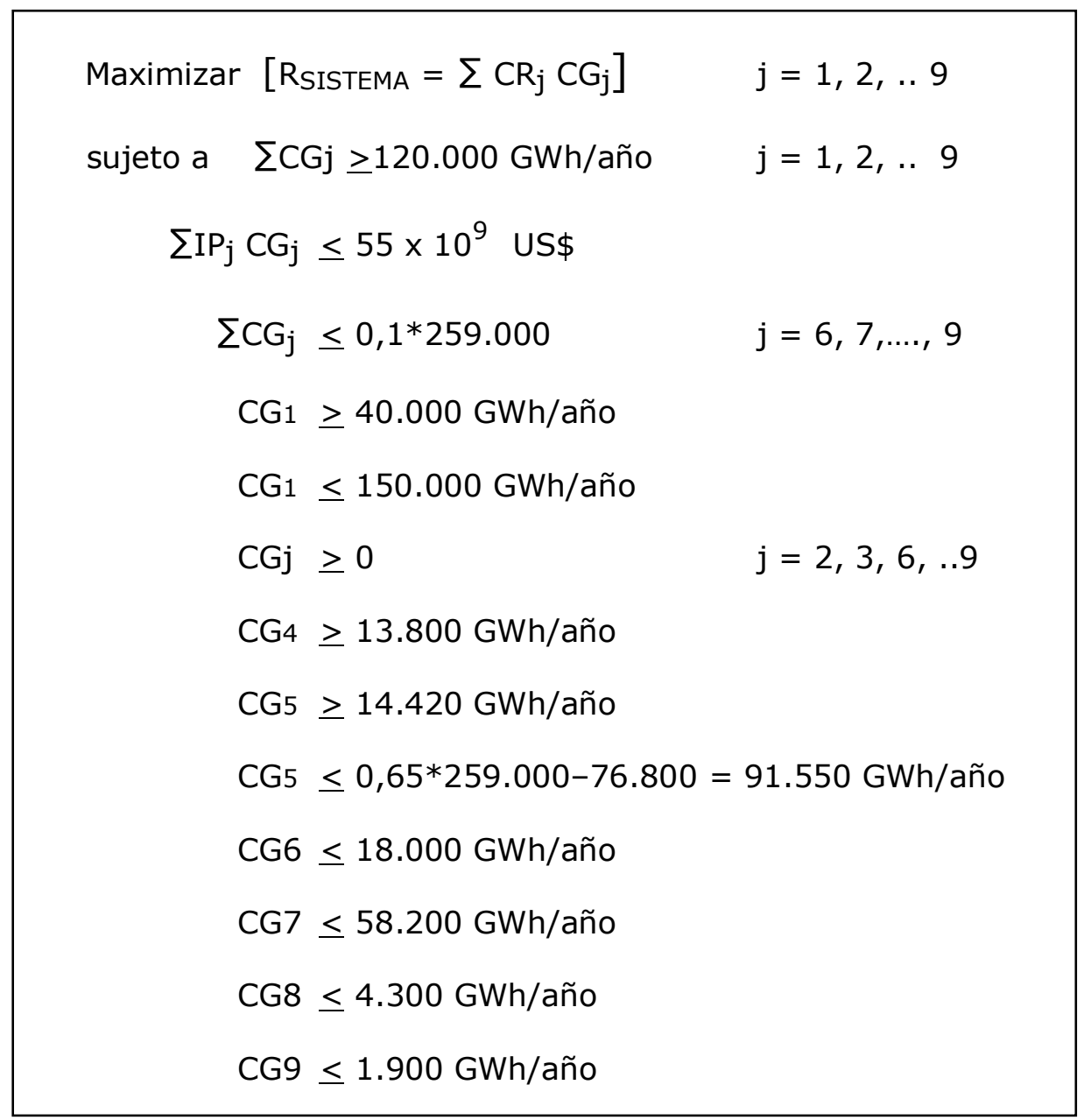

Las condiciones $[\leq]$ para CG1 y CG6 a CG9 corresponden a los potenciales desarrollables de generación eléctrica estimados para carbón y coque de petróleo, y para energía eólica, energía solar, biomasa y energía geotérmica respectivamente. No se incluye ninguna restricción correspondiente al potencial desarrollable de energía hidráulica (POT5 $=267.000 \mathrm{GWh} / \mathrm{año}$ ) toda vez que esa cifra es mucho 
mayor que la resultante ( $\leq 91.550 \mathrm{GWh} / \mathrm{año}$ ) al interpretar la estrategia del gobierno nacional de reducir en lo posible la participación de la generación hidroeléctrica en el suministro al país. Tampoco se consideran restricciones relacionadas con la generación termoeléctrica basada en petróleo y en gas natural $(\mathrm{CG} 2, \mathrm{CG} 3 \geq 0)$ ante la expectativa de ampliación de la capacidad de refinación en el país y de desarrollo de sus grandes reservas gasíferas, todo planteado en la suposición (2) incluida en la sección 5.1.3.3.4.1 de este documento.

Por su parte, las condiciones $[\geq]$ incorporan al modelo las capacidades de generación en estudio bajo convenios suscritos por el gobierno nacional (CG1 y CG4) y ya en construcción o recuperación (CG5).

Los resultados al caso planteado se recogen en la última columna de la tabla 5.32 incluida más adelante. La figura que sigue es la representación gráfica de los resultados correspondientes al caso planteado en el cuadro 5.31.

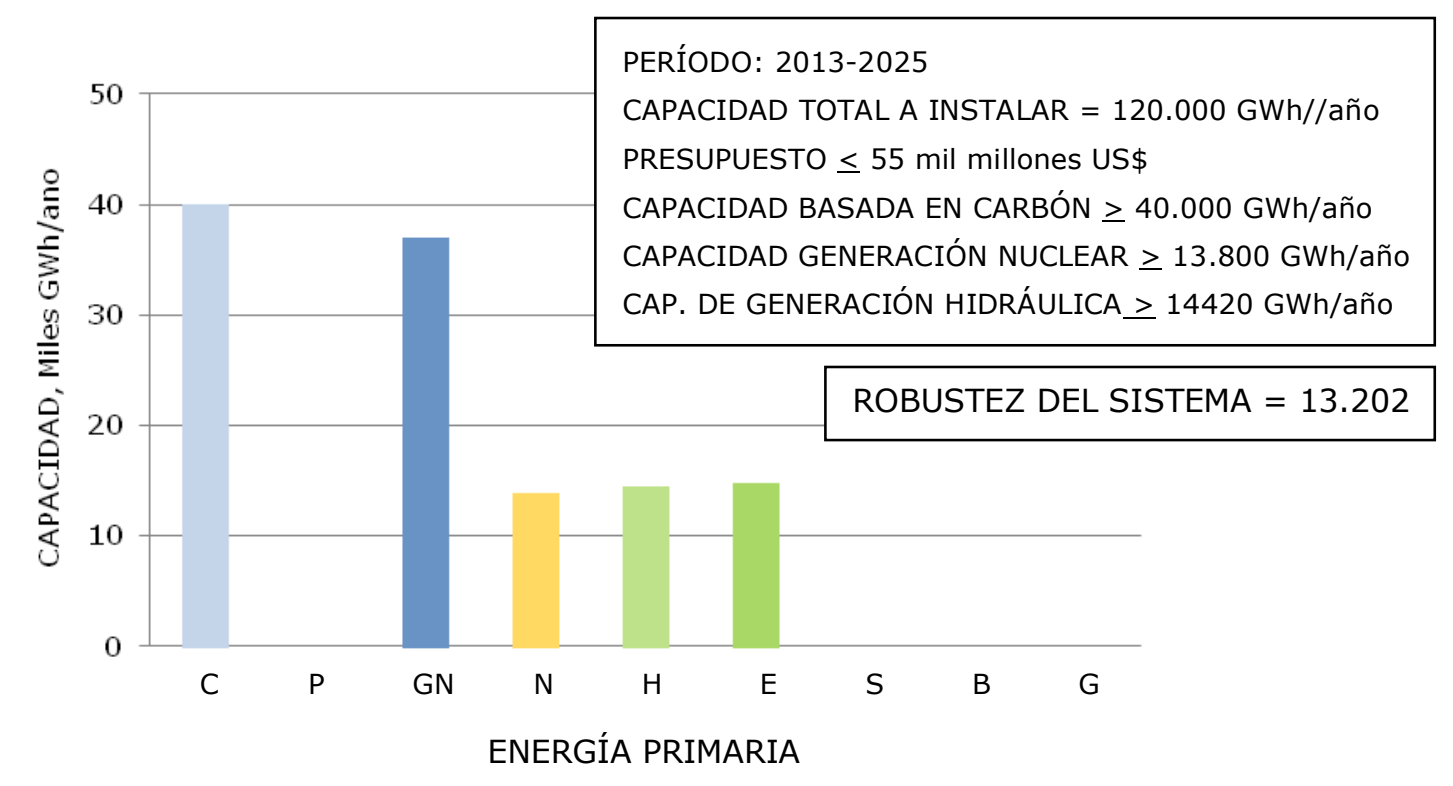

C: carbón, P: petróleo, GN: gas natural, N: energía nuclear, H: energía hidráulica, E: eólica, S: solar, B: biomasa, G: energía geotérmica.

Figura 5.19. Solución al caso base. Capacidades de generación a instalar para el período 2013-2025, por tipo de energía primaria base. 
Nótese que la solución anterior recomienda sólo la instalación de las capacidades mínimas de generación exigidas para tecnologías basadas en carbón, reactores nucleares y potencial hidráulico. Resulta por tanto interesante, modificar dentro de rangos razonables, el valor de tales parámetros y analizar su efecto sobre los resultados. La próxima sección trata esta materia.

\subsection{Análisis de sensibilidad}

El monto del presupuesto disponible (PRES) y la apreciación sobre los respectivos grados de cumplimiento de las metas gubernamentales relativas a la participación de renovables en la generación total de electricidad (CGC6 a CGC9] y a la instalación de generación nuclear (GGC4) y/o carboeléctrica (GG1) para el período de estudio, puede variar. Por otra parte y de acuerdo a lo explicado en la suposición (4), sección 5.1.3.3.4.1 de este documento, en el modelo planteado no se colocaron restricciones a las respectivas participaciones de sistemas basados en gas natural o en derivados líquidos de petróleo como combustible; sin embargo y como en la misma suposición se señala, todo el gas natural que produce el país ya está comprometido y la disponibilidad de diesel puede encontrarse en la misma situación a muy corto plazo, De esta forma, el estudio debe completarse con un análisis de sensibilidad de los resultados ante variaciones en el valor de los parámetros citados.

En tal sentido y dado el elevado número de combinaciones posibles de los valores de los parámetros del modelo, se creyó conveniente dividir el análisis en tres etapas, como se indica a continuación,

Etapa 1. Cambios en el presupuesto y en participación carboeléctrica y nuclear. Se parte de un caso base sin restricciones [ $>$ ]; esto es, sin limitaciones relativas a las capacidades mínimas a instalar; con excepción de la capacidad hidráulica ya en construcción o recuperación. El resto de las condiciones permanece idéntico. Se estudia el efecto que sobre la solución y su robustez tiene (i) una variación en el presupuesto de inversión en generación, en el rango de [55-70] mil millones de US\$, (ii) una variación de la capacidad mínima de generación carboeléctrica a instalar, en el rango de [0-100] \% de la meta gubernamental y (iii) una variación adicional en el número de reactores para generación nuclear a instalar entre 0,1 o 2 reactores de 1.200 MW de capacidad instalada cada uno. 
La mitad superior de la tabla 5.32 muestra el valor de los parámetros con el que se inicia el proceso y la variación progresiva de las restricciones al modelo hasta finalizar en el caso planteado y resuelto en la sección anterior. La mitad inferior de la misma tabla muestra los resultados obtenidos. La última fila en la tabla muestra el valor que toma la función objetivo ante las variaciones planteadas.

Tabla 5.32. Análisis de sensibilidad. Etapa 1. Caso base sin restricciones $[\geq]$. Variaciones en presupuesto, generación carboeléctrica y nuclear.

\begin{tabular}{|c|c|c|c|c|c|c|c|c|c|}
\hline \multicolumn{3}{|c|}{ PARÁMETRO CRITICO } & \multirow{2}{*}{$\begin{array}{l}\text { CASO } \\
\text { BASE }\end{array}$} & \multicolumn{6}{|c|}{ VARIACIÓN AL CASO BASE } \\
\hline RESTRICCIÓN & UNIDAD & $\mathrm{R}$ & & 1 & 2 & 3 & 4 & 5 & 6 \\
\hline Presupuesto & US\$ $\times 10^{9}$ & $\leq$ & 55 & 60 & 68 & 55 & 55 & 55 & 55 \\
\hline Carbón & GWh/año & $\geq$ & 0 & 0 & 0 & 30000 & 40000 & 40000 & 40000 \\
\hline Nuclear & GWh/año & $\geq$ & 0 & 0 & 0 & 0 & 0 & 6900 & 13800 \\
\hline Hidráulica & GWh/año & $\geq$ & 14420 & \multicolumn{6}{|c|}{ En recuperación o construcción } \\
\hline Renovables & GWh/año & $\leq$ & 25900 & \multicolumn{6}{|c|}{$\begin{array}{c}\Sigma \text { REN } \leq 10 \% \text { del total generado, convenios } \\
\text { internacionales }\end{array}$} \\
\hline \multicolumn{10}{|c|}{$\begin{array}{l}\text { Capacidad de generación MÁXIMA a instalar basada en: } \\
\text { (1) Petróleo, gas natural y nuclear: sin máximo } \\
\text { (2) Carbón y renovables: sus respectivos potenciales desarrollables estimados } \\
\text { (3) Hidráulica: } \leq 65 \% \text { de la capacidad total generación }\end{array}$} \\
\hline
\end{tabular}

\begin{tabular}{|l|c|c|c|c|c|c|c|}
\hline \multicolumn{1}{|c|}{ OPCIÓN DE GENERACIÓN } & \multicolumn{7}{c|}{ RESULTADOS (GWh/año) } \\
\hline Carbón (IGCC) & 0 & 0 & 0 & 30000 & 40000 & 40000 & 40000 \\
\hline Petróleo (Ciclo Combinado) & 0 & 0 & 0 & 0 & 0 & 0 & 0 \\
\hline Gas (Ciclo Combinado) & 42523 & 29832 & 10450 & 36279 & 34198 & 36247 & 37033 \\
\hline Nuclear & 0 & 0 & 0 & 0 & 0 & 6900 & 13800 \\
\hline Hidráulica & 59477 & 72168 & 91550 & 35721 & 27802 & 18853 & 14420 \\
\hline Eólica & 18000 & 18000 & 18000 & 18000 & 18000 & 18000 & 14747 \\
\hline Solar Térmica & 0 & 0 & 0 & 0 & 0 & 0 & 0 \\
\hline Biomasa & 0 & 0 & 0 & 0 & 0 & 0 & 0 \\
\hline Geotérmica & 0 & 0 & 0 & 0 & 0 & 0 & 0 \\
\hline RELACIÓN H/G & 1,40 & 2,42 & 8,76 & 0,98 & 0,81 & 0,52 & 0,39 \\
\hline ROBUSTEZ DEL SISTEMA & 14430 & 14442 & 14462 & 13956 & 13798 & 13506 & 13202 \\
\hline
\end{tabular}


El análisis de las cifras en el cuadro anterior permite establecer lo siguiente:

- La solución del caso base sin restricciones $[>]$ sólo incluye tecnologías de generación basadas en la combustión de gas natural, en energía hidráulica y en energía eólica. Alternativas que utilizan carbón o derivados líquidos del petróleo como combustible; o generación nuclear, no aparecen a pesar de no tener limitación alguna para hacerlo $(\geq 0)$. Naturalmente, todo ello se explica en los coeficientes de robustez obtenidos en la sección anterior para cada tipo de generación y en las respectivas inversiones promedio requeridas. El caso más notable es el de la generación eólica cuya capacidad asignada alcanza su potencial desarrollable de $18.000 \mathrm{GWh}$ /año [CORPOELEC, 2010] a pesar de su costo inicial más elevado. Otras energías renovables no forman parte de la solución aunque tienen margen para hacerlo ( $\leq 7.900 \mathrm{GWh} / \mathrm{año}$ ).

- Un incremento en el presupuesto de inversión sin variar la capacidad total necesaria ni otras restricciones, favorece la opción hidráulica como lo muestra la relación H/G en el cuadro anterior; y aumenta la robustez del sistema hasta llegar a un tope donde se alcanza la capacidad hidráulica máxima a desarrollar (91.150 MWh/año); esta solución corresponde a un valor de presupuesto de 68 mil millones USD.

- La inclusión de mínimos de capacidad de generación carboeléctrica y de generación nuclear sin variar la capacidad total necesaria ni otras restricciones, reduce la participación en la solución de las otras alternativas de generación consideradas; y disminuye la robustez del sistema. La relación H/G que se presenta en la tabla para cada caso considerado evidencia que la opción más afectada es la generación hidráulica, tal como muestran los cambios sobre de relación $H / G$ que pasa de 1,40 en el caso base sin restricciones $[\geq]$ a 0,39 en al caso 6 o caso base con restricciones $[>]$ resuelto en la sección anterior.

Entre los casos estudiados, el mejor valor de la función objetivo corresponde a la solución del caso 2 , donde las capacidades de generación a instalar por tipo de energía primaria base se obtienen en función de los respectivos coeficientes de robustez e inversiones promedio, sujetas sólo a sus respectivos potenciales 
desarrollables y a un presupuesto de 68 mil millones US\$, sin forzar ningún tipo de participación mínima. Esto es, si no existiesen planes de emergencia, convenios de desarrollo con otros países; o simplemente, líneas políticoestratégicas del gobierno nacional, la mejor solución sería basar los planes de expansión de generación eléctrica durante el período 2013-2025 en tecnologías que utilizan como fuente de energía primaria el recurso hidráulico, el gas natural o los vientos, todos con gran potencial de desarrollo en el país y con bajo o ningún poder contaminante del ambiente.

En cuanto al valor de presupuesto que se introduce al modelo, el mismo va a depender de la disponibilidad financiera del país para acometer los proyectos respectivos; y de acuerdo con el análisis realizado no debe sobrepasar los 68 mil millones de US\$ para esta solución; un nivel más alto no produce ningún cambio en ella. La figura 5.20 ilustra la situación.

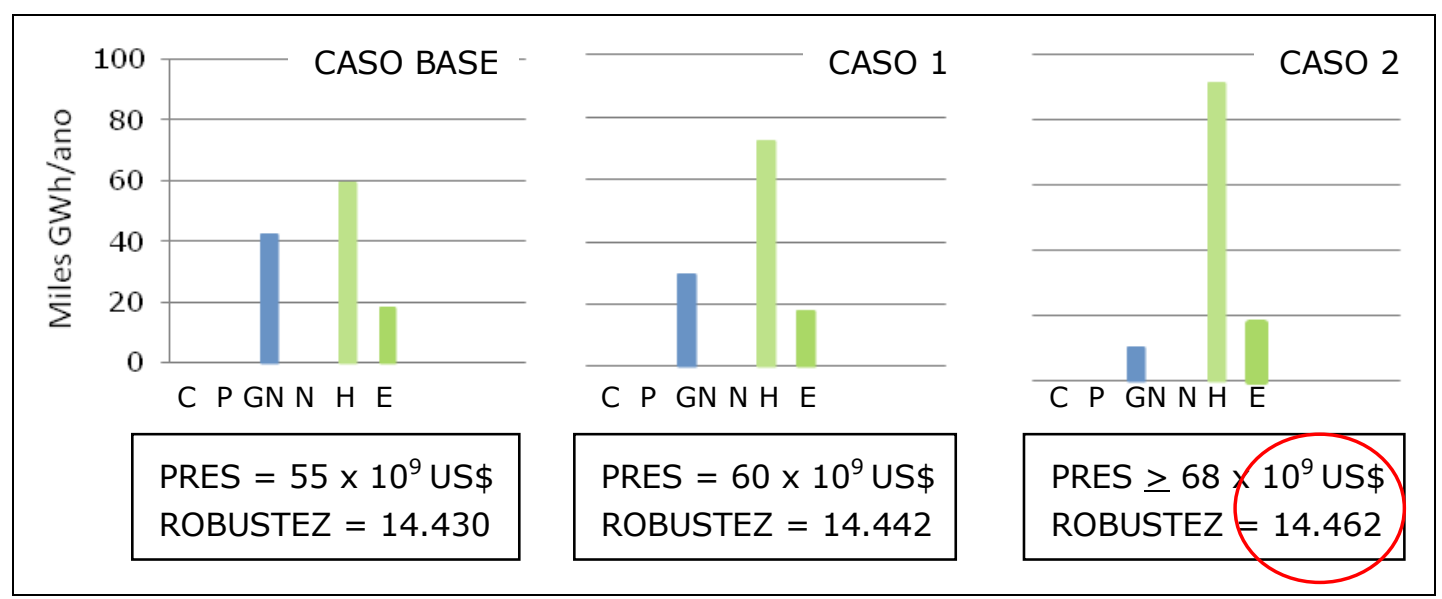

GN: Generación en base a gas natural H: Generación hidráulica E : Generación eólica

Figura 5.20. Sensibilidad ante variaciones en el presupuesto sobre el caso base sin restricciones $[\geq]$.

Sin embargo, para aproximarse a la realidad venezolana en el sector eléctrico, deben incorporarse todas las limitaciones impuestas en el modelo planteado en el cuadro 5.31. El contraste entre las figuras 5.19 y 5.20 , da cuenta de la diferencia entre las dos soluciones.

Etapa 2. Gas natural y derivados de petróleo. Para el año 2010, Venezuela ya importa 2.200 millones de metros cúbicos de gas natural/año [BP, 2011] y su UNIVERSIDAD POLITÉCNICA DE VALENCIA. TESIS DOCTORAL. Violeta Parodi 
consumo de diesel se ubica en unos 170 mil barriles por día como se ha señalado en la sección 5.1.3.1 de este documento [Hernández, 2011a]. Si a esta última cifra se añade el consumo correspondiente a unos 3,910 MW de generación distribuida en base a diesel cuya instalación está prevista para el período 20102012, el consumo de gasoil excedería la capacidad de refinación nacional de este combustible y el país debería importar diesel [Hernández, 2011c]. De esta forma, a menos que se acometan con éxito los planes de desarrollo de las reservas gasíferas de Venezuela y la expansión de la capacidad de refinación en el país, el suministro de combustible a nuevas plantas de generación termoeléctrica sólo podrá ser suplido por importaciones, especialmente en el caso del gas.

Ante la situación planteada, resulta interesante estudiar el efecto que sobre la solución del problema tiene la inclusión de limitaciones en la participación de generación termoeléctrica basada en gas o derivados de petróleo, de acuerdo a la disponibilidad efectiva del combustible a utilizar. Para ello, se parte del caso 6 planteado en el cuadro 5.32. Los resultados se presentan a continuación.

Tabla 5.33. Análisis de sensibilidad. Etapa 2. Caso base con restricciones $[\geq]$. Limitación en la generación basada en gas natural y petróleo.

\begin{tabular}{|c|c|c|c|c|c|c|c|c|c|}
\hline \multicolumn{3}{|c|}{ PARÁMETRO CRITICO } & CASO & \multicolumn{6}{|c|}{ VARIACIÓN AL CASO BASE } \\
\hline RESTRICCIÓN & UNIDAD & $\mathrm{R}$ & $(6)$ & 7 & 8 & 9 & 10 & 11 & 12 \\
\hline Presupuesto & US $\$ \times 10^{9}$ & $\leq$ & 55 & 55 & 55 & 55 & 55 & 55 & 55 \\
\hline Carbón & GWh/año & $\geq$ & 40000 & 40000 & 40000 & 40000 & 40000 & 40000 & 40000 \\
\hline Petróleo & GWh/año & $\mathrm{V}$ & $\geq 0$ & $\geq 0$ & $\geq 0$ & $\geq 0$ & 0 & $<20000$ & $\leq 25000$ \\
\hline Gas natural & GWh/año & $\mathrm{V}$ & $\geq 0$ & $\leq 20000$ & $\leq 10000$ & 0 & 0 & 0 & 0 \\
\hline Nuclear & GWh/año & $\geq$ & 13800 & 13800 & 13800 & 13800 & 13800 & 13800 & 13800 \\
\hline Hidráulica & GWh/año & $\geq$ & 14420 & \multicolumn{6}{|c|}{ En recuperación o construcción } \\
\hline Renovables & GWh/año & $\leq$ & 25900 & \multicolumn{6}{|c|}{$\begin{array}{c}\Sigma \mathrm{REN} \leq 10 \% \text { del total generado, convenios } \\
\text { internacionales }\end{array}$} \\
\hline
\end{tabular}

Capacidad de generación MÁXIMA a instalar basada en:

(1) Petróleo y gas natural: variable

(2) Generación nuclear : sin máximo

(3) Carbón y renovables: sus respectivos potenciales desarrollables estimados

(4) Hidráulica: $\leq 65 \%$ de la capacidad total generación 
Tabla 5.33. Análisis de sensibilidad. Etapa 2. Caso base con restricciones $[\geq]$. Cont.

\begin{tabular}{|l|c|c|c|c|c|c|c|}
\hline \multicolumn{1}{|c|}{ OPCIÓN DE GENERACIÓN } & \multicolumn{7}{|c|}{ RESULTADOS (GWh/año) } \\
\hline Carbón (IGCC) & 40000 & 40000 & 40000 & 40000 & $\mathrm{X}$ & $\mathrm{X}$ & 64322 \\
\hline Petróleo (Ciclo Combinado) & 0 & 17033 & 27033 & 37033 & $\mathrm{X}$ & $\mathrm{X}$ & 25000 \\
\hline Gas (Ciclo Combinado) & 37033 & 20000 & 10000 & 0 & $\mathrm{X}$ & $\mathrm{X}$ & 0 \\
\hline Nuclear & 13800 & 13800 & 13800 & 13800 & $\mathrm{X}$ & $\mathrm{X}$ & 13800 \\
\hline Hidráulica & 14420 & 14420 & 14420 & 14420 & $\mathrm{X}$ & $\mathrm{X}$ & 14978 \\
\hline Eólica & 14747 & 14747 & 14747 & 14747 & $\mathrm{X}$ & $\mathrm{X}$ & 0 \\
\hline Solar Térmica & 0 & 0 & 0 & 0 & $\mathrm{X}$ & $\mathrm{X}$ & 0 \\
\hline Biomasa & 0 & 0 & 0 & 0 & $\mathrm{X}$ & $\mathrm{X}$ & 0 \\
\hline Geotérmica & 0 & 0 & 0 & 0 & $\mathrm{X}$ & $\mathrm{X}$ & 1900 \\
\hline ROBUSTEZ DEL SISTEMA & 13202 & 13066 & 12986 & 12906 & $\mathrm{X}$ & $\mathrm{X}$ & 12549 \\
\hline
\end{tabular}

X: No se pudo encontrar una solución factible.

El análisis de las cifras en el cuadro anterior permite establecer lo siguiente:

- La disminución de la participación de la opción de gas natural en la solución al problema sin variar ninguna otra restricción, favorece la opción basada en derivados líquidos del petróleo y disminuye la robustez de la misma. En los casos estudiados, la participación de otras opciones de generación no se afecta.

- Si en la expansión de capacidad de generación eléctrica para el período 20132025 se decide no incluir la opción basada en gas natural y si todas las restricciones restantes permanecen sin cambio, la capacidad de generación basada en petróleo debe ser al menos de $25.000 \mathrm{GWh}$ /año para exista una solución que cumpla con todas las limitaciones planteadas.

La situación cambia, si se modifica el presupuesto disponible para la ejecución de la solución arrojada por el modelo, tal como puede apreciarse en la tabla 5.34 que se presenta en la próxima página, Allí, se estudia el efecto de variaciones en el presupuesto sobre el caso 10, sin solución para un presupuesto de 55 mil millones US\$. 
Tabla 5.34. Análisis de sensibilidad. Etapa 2. Caso 10 como base.

\begin{tabular}{|c|c|c|c|c|c|c|c|c|c|}
\hline \multicolumn{3}{|c|}{ PARÁMETRO CRITICO } & \multirow{2}{*}{$\begin{array}{c}\text { CASO } \\
\text { BASE } \\
(10)\end{array}$} & \multicolumn{6}{|c|}{ VARIACIÓN AL CASO BASE } \\
\hline RESTRICCIÓN & UNIDAD & $\mathrm{R}$ & & 13 & 14 & 15 & 16 & 17 & 18 \\
\hline Presupuesto & US $\$ \times 10^{9}$ & $\leq$ & 55 & 65 & 70 & 65 & 70 & 65 & 65 \\
\hline Carbón & GWh/año & $\geq$ & 40000 & \multicolumn{6}{|c|}{ Potencial capacidad a instalar. convenios } \\
\hline Petróleo & GWh/año & $\mathrm{V}$ & 0 & 0 & 0 & $\leq 20000$ & $\leq 20000$ & $\leq 20000$ & $\leq 20000$ \\
\hline Gas natural & GWh/año & V & 0 & 0 & 0 & 0 & 0 & $\leq 20000$ & $\leq 10000$ \\
\hline Nuclear & GWh/año & $\geq$ & 13800 & \multicolumn{6}{|c|}{ Capacidad a instalar en estudio, convenios } \\
\hline Hidráulica & GWh/año & $\geq$ & 14420 & \multicolumn{6}{|c|}{ En recuperación o construcción } \\
\hline Renovables & GWh/año & $\leq$ & 25900 & \multicolumn{6}{|c|}{$\begin{array}{c}\sum \mathrm{REN} \leq 10 \% \text { del total generado, convenios } \\
\text { internacionales }\end{array}$} \\
\hline \multicolumn{10}{|c|}{$\begin{array}{l}\text { Capacidad de generación MÁXIMA a instalar basada en: } \\
\text { (1) Petróleo y gas natural : variable } \\
\text { (2) Generación nuclear : sin máximo } \\
\text { (3) Carbón y renovables: sus respectivos potenciales desarrollables estimados } \\
\text { (4) Hidráulica: } \leq 65 \% \text { de la capacidad total generación }\end{array}$} \\
\hline
\end{tabular}

\begin{tabular}{|l|c|c|c|c|c|c|c|}
\hline \multicolumn{1}{|c|}{ OPCIÓN DE GENERACIÓN } & \multicolumn{7}{|c|}{ RESULTADOS (GWh/año) } \\
\hline Carbón (IGCC) & X & 62493 & 40000 & 40000 & 40000 & 40000 & 40000 \\
\hline Petróleo (Ciclo Combinado) & $X$ & 0 & 0 & 12915 & 225 & 0 & 2915 \\
\hline Gas (Ciclo Combinado) & $X$ & 0 & 0 & 0 & 0 & 12915 & 10000 \\
\hline Nuclear & $X$ & 13800 & 13800 & 13800 & 13800 & 13800 & 13800 \\
\hline Hidráulica & $X$ & 41807 & 48779 & 35285 & 47975 & 35285 & 35285 \\
\hline Eólica & $X$ & 0 & 17421 & 18000 & 18000 & 18000 & 18000 \\
\hline Solar Térmica & $X$ & 0 & 0 & 0 & 0 & 0 & 0 \\
\hline Biomasa & $X$ & 0 & 0 & 0 & 0 & 0 & 0 \\
\hline Geotérmica & $X$ & 1900 & 0 & 0 & 0 & 0 & 0 \\
\hline ROBUSTEZ DEL SISTEMA & $X$ & 12803 & 13250 & 13136 & 13250 & 13240 & 13216 \\
\hline
\end{tabular}

El análisis de las cifras en el cuadro anterior permite afirmar que un incremento en el presupuesto favorece significativamente la opción hidráulica. Entre las situaciones estudiadas, la solución que produce la mayor robustez corresponde a UNIVERSIDAD POLITÉCNICA DE VALENCIA. TESIS DOCTORAL. Violeta Parodi 
los casos 14 y 16, ambas con un presupuesto asignado de 70 mil millones US\$. En el caso 14, se eliminan de la solución, las opciones de generación basadas en gas natural o derivados líquidos de petróleo. Aunque no se registra explícitamente en el cuadro, más allá de un presupuesto de 71 mil millones US\$, la solución permanece inalterable. En el caso 16, se elimina el gas natural de la solución y se limita la generación basada en petróleo a 20.000 GWh; sin embargo, la solución producida es muy similar a la anterior.

Adicionalmente se estudiaron otros niveles de participación para las opciones basadas en gas natural y petróleo. La figura 5.21 muestra aquellas soluciones que para un presupuesto de 65 mil millones US\$, lucen más interesantes.

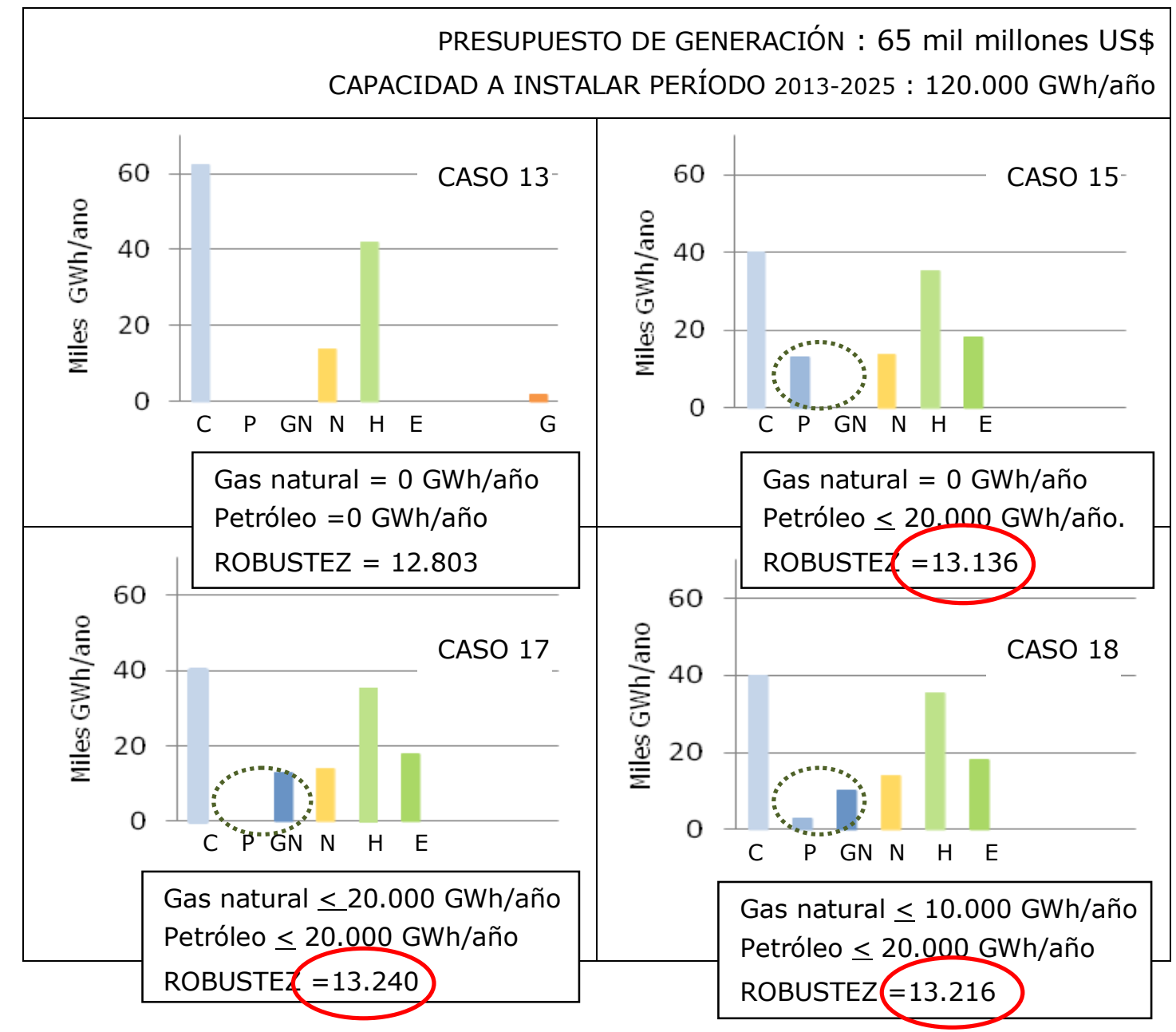

Figura 5.21. Efecto de variación en la participación de las opciones gas y petróleo 
La secuencia de gráficos en la figura 5.21 reproduce la incorporación sucesiva de las opciones gas y petróleo en la solución del problema. El recuadro izquierdo de la parte superior del cuadro, muestra la solución arrojada por el modelo si se excluyen las opciones de gas y petróleo, y se mantienen constantes todas las restricciones que se imponen en el caso base. Nótese que la capacidad a instalar que se asigna a estas dos opciones, se traslada mayoritariamente a la opción carbón lo que disminuye en forma importante la robustez del sistema. Otros efectos sobre el caso base son la desaparición de la opción eólica y la aparición poco significativa de la opción geotérmica.

Los recuadros que siguen presentan las soluciones obtenidas del modelo cuando:

(a) Se excluye de la solución sólo la opción gas y se limita la participación de la generación basada en derivados líquidos del petróleo a 20.000 GWh/año. Es notable que este límite no se alcance; aparece la opción eólica con una participación igual a su potencial desarrollable y el coeficiente de robustez mejora en forma importante en relación al caso anterior.

(b) Se limitan la participaciones de las opciones gas y petróleo a 20.000 GWh/año, cada una. La solución no incorpora la opción petróleo y no se alcanza el límite máximo impuesto a la generación con gas. Se mantiene la participación de la energía eólica. Se obtiene la mayor robustez para este nivel de presupuesto.

(c) Se limita la participación para la opción gas a 10.000 GWh/año y para la opción petróleo a 20.000 GWh/año. La solución lleva la generación basada en gas natural al máximo impuesto mientras que la cuota de petróleo se hace mucho menor; la participación de la opción eólica alcanza su máximo potencial desarrollable y la robustez del sistema disminuye ligeramente.

Claramente, existen muchas opciones posibles. Las soluciones correspondientes a los casos 15, 17 y 18 con participación de una amplia gama de tipos de energía en la generación y con los mejores coeficientes de robustez, lucen como una buena aproximación a las circunstancias que hoy vive Venezuela y a su proyección para el período 2013-2025. La tabla 5.35 que se incluye a continuación presenta 
los volúmenes estimados de combustible necesario asociado a cada uno de estos casos. La estimación se realiza en base a cifras promedio publicadas por Hernández [2011a] y de acuerdo a las expresiones que se incluyen en la parte inferior del cuadro.

Tabla 5.35. Estimación del consumo de combustible. Casos 15, 17 y 18

\begin{tabular}{|c|c|c|c|c|}
\hline \multirow[b]{2}{*}{ CASO } & \multicolumn{2}{|c|}{ GENERACIÓN ELÉCTRICA } & \multicolumn{2}{|c|}{ CONSUMO DE COMBUSTIBLE } \\
\hline & $\begin{array}{c}\text { GAS NATURAL } \\
\text { (CGN, GWh/año) }\end{array}$ & $\begin{array}{l}\text { DIESEL/FUELOIL } \\
\text { (CDF, GWh/año) }\end{array}$ & $\begin{array}{l}\text { GAS NATURAL } \\
\text { (millones } \mathrm{m}^{3} / \mathrm{año} \text { ) }\end{array}$ & $\begin{array}{l}\text { DIESEL/FUELOIL } \\
\text { (miles bbls/día) }\end{array}$ \\
\hline 15 & 0 & 12.915 & 0 & 41.9 \\
\hline 17 & 12.915 & 0 & 2.715 & 0 \\
\hline 18 & 10.000 & 2.915 & 2.090 & 10.2 \\
\hline $\begin{array}{l}\text { CONSUI } \\
\text { GAS I } \\
\text { DIESE } \\
\text { FUELC }\end{array}$ & $\begin{array}{l}\text { O PROMEDIO DE CON } \\
\text { ATURAL (millones } \mathrm{m}^{3} / \\
\text { (bbls/GWh) }=30,9 * \\
\text { L (bbls/GWh) }=20,1\end{array}$ & $\begin{array}{l}\text { STIBLE, VENEZUELA } \\
h)=0,177^{*}\left(0,305^{\wedge}\right. \\
0 / 24=1287,5 \\
00 / 24=1212,5\end{array}$ & ${ }^{k} 1000 / 24=0,209$ & \\
\hline $\begin{array}{r}\text { RELACI } \\
\text { CONS } \\
\text { CONSUI } \\
\text { GAS I } \\
\text { DIESE }\end{array}$ & $\begin{array}{l}\text { N DIESEL/FUELOIL, } \\
\text { MO PROMEDIO DE CC } \\
\text { O DE COMBUSTIBLE, } \\
\text { ATURAL (millones } \mathrm{m}^{3} \\
\text { (miles bbls/día) = C }\end{array}$ & $\begin{array}{l}\text { SUMO SECTOR } 2010 \\
\text { SUSTIBLE DIESEL/FU } \\
\text { SOS } 15,17 \text { y } 18 \\
\text { ) CGN*0,209 } \\
1255,4 /(365 * 1000)\end{array}$ & $\begin{array}{l}64 / 48 \\
=(1287,5 * 64+1212\end{array}$ & $48) / 112=1255,4$ \\
\hline
\end{tabular}

(1) Relación entre consumos expresados en barriles equivalentes de petróleo Fuente de datos: [Hernández, 2011a] .

Los resultados obtenidos en el cuadro anterior muestran que para generar entre 10.000 y $12.915 \mathrm{GWh}$ de energía eléctrica, se requieren entre 2.100 y 2.700 millones de metros cúbicos de gas natural. De esta forma, si tal capacidad de generación se incorpora al parque eléctrico nacional, el país deberá incrementar sus importaciones de gas. A más largo plazo, el gas puede ser obtenido de los

De acuerdo a cifras publicadas por Hernández [2011a], para una eficiencia térmica de 30\%, un factor de carga de $80 \%$ y un factor de operación de $80 \%$, el consumo promedio de combustible para generacion eléctrica basada en (i) gas natural es igual a 0,177 pie3/día MW efectivo, (ii) en diesel es igual a 30,9 bbls/dia MW efectivo y (iii) en fueloil es igual a 29,1 bbls/día MW efectivo. 
yacimientos gasíferos del país, si se emprenden lo más pronto posible y de forma eficaz los planes para su explotación y desarrollo.

La situación del diesel es similar. Las cifras en la tabla anterior muestran que hacen falta entre 10.000 y 42.000 barriles diarios de combustibles líquidos

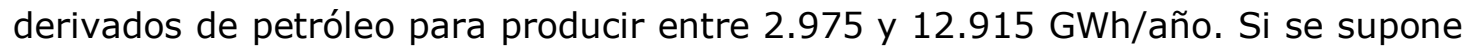
que la relación entre el consumo de diesel y el de fueloil en el sector se mantiene igual a la obtenida para el año 2010 [Hernández, 2011a] y que las capacidades calóricas del diesel y del fuel son semejantes, un $58 \%$ del combustible líquido requerido corresponderá a diesel; esto es, el consumo de diesel para un nivel de generación de 12.915 GWh/año se ubica entre 24.400 bbls/día y 42.000 bbls/día, en el caso de que la capacidad adicional se manejase sólo con diesel. De nuevo, si la capacidad de este tipo de generación se incorpora al parque eléctrico nacional será necesario importar diesel y/o acometer los planes para la ampliación de la capacidad de refinación y el incremento de la producción de petróleo que se dirige a ella.

Etapa 3. Cambios en la participación de las energías renovables. El cumplimiento de compromisos internacionales o simplemente el deseo de contribuir a una menor emisión de gases contaminantes en beneficio de la salud del planeta, puede llevar a los gobiernos a privilegiar los planes de aprovechamiento de la energía renovable en la generación eléctrica de los respectivos países. En Venezuela es casi nula la utilización de los vientos, la radiación solar, la biomasa y la energía geotérmica en la generación de electricidad. Sin embargo, se ha venido adquiriendo conciencia en la importancia que ello tiene; y hoy día, operan microcentrales hidroeléctricas y aprovechamientos experimentales que utilizan biomasa y energía solar, y se construyen pequeños campos eólicos en el país.

Dicho lo anterior, parece interesante estudiar el efecto que sobre las soluciones obtenidas en el punto anterior y su robustez, tiene la incorporación al modelo de una capacidad mínima de generación eléctrica basada en energías renovables. No se incluye la energía hidráulica en el grupo.

Para el análisis, se impone una participación mínima $[\geq]$ de energías renovables en la generación eléctrica total, a los casos 17 y 18 producto del análisis anterior. 
Específicamente, se prueba con cuotas mínimas de 5\%, 8\% y $10 \%$ de la generación eléctrica total. Los resultados del análisis se presentan en la tabla 5.36. La nueva restricción sustituye la desigualdad $[\leq]$ con la cual se imponía una participación máxima de un $10 \%$ de energías renovables.

Tabla 5.36. Análisis de sensibilidad. Etapa 3. Casos 17 y 18 como base. Variación en la participación de energías renovables.

\begin{tabular}{|c|c|c|c|c|c|c|c|c|}
\hline \multicolumn{3}{|c|}{ PARÁMETRO CRITICO } & \multirow{2}{*}{$\begin{array}{c}\text { CASO } \\
\text { BASE } \\
(17)\end{array}$} & \multicolumn{5}{|c|}{ VARIACIÓN AL CASO BASE } \\
\hline RESTRICCIÓN & UNIDAD & $\mathrm{R}$ & & 19 & 20 & 21 & 22 & 23 \\
\hline Presupuesto & US $\$ \times 10^{9}$ & $\leq$ & 65 & 65 & 65 & 65 & 65 & 65 \\
\hline Carbón & GWh/año & $\geq$ & 40000 & \multicolumn{5}{|c|}{ Potencial capacidad a instalar. convenios } \\
\hline Petróleo & GWh/año & $\leq$ & 20000 & \multicolumn{5}{|c|}{ Capacidad máxima asignada para el análisis } \\
\hline Gas natural & GWh/año & $\leq$ & 20000 & 20000 & 20000 & 20000 & 10000 & 10000 \\
\hline$\Sigma$ Renovables & GWh/año & $\mathrm{V}$ & $\leq 25900$ & $\geq 12950$ & $\geq 20720$ & $\geq 25900$ & $\geq 20720$ & $\geq 25900$ \\
\hline Nuclear & GWh/año & $\geq$ & 13800 & \multicolumn{5}{|c|}{ Capacidad a instalar en estudio, convenios } \\
\hline Hidráulica & GWh/año & $\geq$ & 14420 & \multicolumn{5}{|c|}{ En recuperación o construcción } \\
\hline \multicolumn{9}{|c|}{$\begin{array}{l}\text { Capacidad de generación MÁXIMA a instalar basada en: } \\
\text { (1) Gas natural : variable } \\
\text { (2) Generación nuclear : sin máximo } \\
\text { (3) Carbón y renovables: sus respectivos potenciales desarrollables estimados } \\
\text { (4) Hidráulica: } \leq 65 \% \text { de la capacidad total generación }\end{array}$} \\
\hline
\end{tabular}

\begin{tabular}{|l|c|c|c|c|c|c|}
\hline \multicolumn{1}{|c|}{ OPCIÓN DE GENERACIÓN } & \multicolumn{7}{|c|}{ RESULTADOS (GWh/año) } \\
\hline Carbón (IGCC) & 40000 & 40000 & 40000 & 40000 & 40000 & 40000 \\
\hline Petróleo (Ciclo Combinado) & 0 & 0 & 0 & 2811 & 2048 & 12811 \\
\hline Gas (Ciclo Combinado) & 12915 & 12915 & 14165 & 20000 & 10000 & 10000 \\
\hline Nuclear & 13800 & 13800 & 13800 & 13800 & 13800 & 13800 \\
\hline Hidráulica & 35285 & 35285 & 31315 & 17489 & 33432 & 17489 \\
\hline Eólica & 18000 & 18000 & 17421 & 18000 & 18000 & 18000 \\
\hline Solar Térmica & 0 & 0 & 0 & 1700 & 0 & 1700 \\
\hline Biomasa & 0 & 0 & 2720 & 4300 & 820 & 4300 \\
\hline Geotérmica & 0 & 0 & 0 & 1900 & 1900 & 1900 \\
\hline ROBUSTEZ DEL SISTEMA & 13240 & 13240 & 13236 & 13174 & 13206 & 13094 \\
\hline
\end{tabular}


La lectura del cuadro anterior permite anotar lo siguiente:

(i) La imposición de una participación mínima de energías renovables en la generación total eléctrica menor o igual a 18,000 GWh/año $(6,9 \%)$ no produce ningún cambio en la solución del caso base. La participación de la energía eólica alcanza su potencial desarrollable como en la mayoría de los casos anteriores estudiados.

(ii) La imposición de una participación mínima de energías renovables en la generación total eléctrica mayor a 18,000 GWh/año ( $8 \%$ y 10\%) introduce nuevos tipos de energías renovables en la solución, además de algunos ajustes en la participación de otro tipo de energías. La bioenergía es la primera que se hace presente, seguida de la energía geotérmica; y finalmente de la energía solar la cual parece menos atractiva por su alto costo de inversión inicial. La robustez baja en la medida en que la participación mínima impuesta sea más alta, si ésta es mayor al potencial desarrollable de la energía eólica.

Venezuela no dispone ni de la experiencia ni del personal entrenado para el aprovechamiento de las energías renovables en la generación de potencia eléctrica, a una escala que contribuya significativamente en la solución de la emergencia eléctrica que vive actualmente el país. Los resultados obtenidos en el análisis anterior y la necesidad de minimizar el riesgo de fracasos o retardos en la implementación y puesta en marcha de soluciones a corto y mediano plazo, que estabilicen la situación en el sector, hacen pensar en incluir sólo la energía eólica como energía básica primaria en los planes de generación eléctrica.

\subsection{Conclusiones del análisis de sensibilidad}

El estudio de sensibilidad de la solución al problema ante la inclusión o cambios en los parámetros del modelo planteado permite tener una idea más elaborada de lo que puede ser una aproximación a una matriz energética para la generación de potencia eléctrica en el país. En efecto, el análisis ha evidenciado que para el período 2013-2025,

(i) Para un presupuesto de generación igual a 55 mil millones US\$, la solución con mayor robustez $(R=14.430)$ incluye sólo la utilización del gas natural, energía 
hidráulica y energía eólica como fuentes de energía primaria para la generación. La solución es producto de un modelo donde la participación de cada tipo de energía primaria sólo se limita a su respectivo potencial desarrollable. En el caso de la energía hidráulica, este potencial se ve significativamente reducido por razones de protección a las cuencas importantes del país, algunas de las cuales se encuentran fuertemente erosionadas.

Adicionalmente, para las energías renovables se coloca como segunda limitación que la suma de sus respectivas participaciones no exceda un $10 \%$ de la generación eléctrica total [PNUMA, 2002]. No se incluyen máximos de participación para las alternativas de generación basadas en gas natural, petróleo y generación nuclear. La única participación mínima $[\geq]$ que se impone en el planteamiento del modelo corresponde a la capacidad de generación hidráulica en ejecución.

Alternativas que utilizan carbón, derivados de petróleo o la fisión nuclear como fuente de energía primaria para la generación, no aparecen en la solución a pesar de tener un amplio margen o no tener restricción alguna para hacerlo. La capacidad de generación asignada a la opción eólica alcanza su potencial desarrollable de $18.000 \mathrm{GWh}$ /año lo que resulta un indicio de una alta preferencia por este tipo de fuente energética. Sin embargo y a excepción de la energía hidráulica, ninguna otra fuente energética renovable aparece en la solución.

Incrementos en el presupuesto, sin modificar la capacidad necesaria de generación para finales de período ni la estructura de restricciones impuesta en este modelo inicial, favorecen la participación de la energía hidráulica y aumentan la robustez de la solución hasta alcanzar un máximo de 14.462 cuando el presupuesto de generación es igual a 68 mil millones US\$. Incrementos posteriores de presupuesto dejan la solución y su robustez inalterable.

(ii) La adición al modelo inicial de participaciones mínimas de generación carboeléctrica y/o nuclear reduce significativamente la robustez de la solución. En el caso extremo en el cual se obliga a incluir en la solución del problema, mínimos de participación iguales a 40.000 GWh/año para generación basada en carbón, y a 13.800 GWh/año para generación nuclear, la robustez del sistema baja a 13.202. 
Los resultados anteriores muestran la influencia no favorable de este tipo de recurso energético en la robustez del sistema energético resultante; sin embargo, estas restricciones deben incorporarse al modelo ya que como ya se ha señalado, son el producto de convenios de cooperación con otros países firmados por el gobierno nacional.

(iii) La inclusión de restricciones adicionales que tienen que ver con las limitaciones en el suministro de gas natural y de diesel a plantas de generación eléctrica que operan en base a dichos combustibles, reduce la robustez de la solución. En efecto, en la medida en que se restringe [ $<$ ] la participación del gas natural y se incrementa $[\geq]$ la participación de derivados de petróleo en la generación, el coeficiente de robustez disminuye.

En el caso extremo donde se excluyen de la solución ambas alternativas, manteniendo el resto de las restricciones constante, la rutina SOLVER no encuentra solución posible al problema. La capacidad de generación excluida debe llenarse con alternativas más costosas y se excede el presupuesto impuesto; o viceversa, si se cumple con el presupuesto asignado no se cumple con la generación necesaria estimada. La condición se mantiene hasta forzar la participación de petróleo en la generación a 25.000 GWh/año; en este último caso la robustez del sistema cae a un valor de 12.549 .

La situación cambia si se incrementa el presupuesto de generación. Así, cuando el valor de este parámetro se incrementa a 65 mil millones US\$, existe una solución posible a pesar de que se excluyan las opciones de generación a base de gas natural o petróleo. Para este nivel de presupuesto, se incrementa la robustez del sistema en la medida en que se aumenta la participación de la alternativa gas, elevándose a 13.136, 13.216 y 13.240 cuando limitándose [ < ] la participación de petróleo a $20.000 \mathrm{GWh} / a n ̃ o$, se restringe la participación de gas en la generación eléctrica a 0, 10.000 y 20.000 Gwh/año respectivamente. No se incrementa la participación de la opción nuclear ni la de la opción basada en carbón a pesar de tener margen para hacerlo. Incrementos posteriores del presupuesto más allá de 71 mil millones US\$ no modifican la solución ni su robustez. 
Hoy día, la producción de gas en Venezuela está comprometida y debe importarse para suplir el consumo nacional. Por ello, el gobierno nacional ha basado su estrategia a inmediato plazo para superar la crisis eléctrica, en la instalación distribuida en todo el territorio nacional de una serie de plantas termoeléctricas de pequeño tamaño que funcionan con diesel. Ello ha incrementado el volumen demandado de este combustible que se acerca rápidamente a la capacidad de refinación existente en el país, hecho que puede comprometer su suministro a las plantas termoeléctricas adicionales.

Sin embargo, Venezuela es un país productor y exportador de petróleo y sus derivados, y posee importantes reservas de petróleo y de gas ${ }^{85}$. De manera que resulta improbable que no se recurra a estos recursos para obtener el combustible necesario para la generación eléctrica. Ello, requerirá la activación y puesta en marcha de los planes de desarrollo de las reservas gasíferas, la expansión de la capacidad de refinación y el incremento de la producción petrolera insumo a las mismas. Tareas por cierto, que requieren una elevada inversión, experiencia en su ejecución y constancia para obtener los resultados deseados. Una segunda alternativa, al menos a corto plazo, es importar y/o disminuir la exportación del volumen y tipo de combustibles que se requiera.

En base a lo anteriormente expuesto, se creyó conveniente seleccionar como solución a recomendar aquélla que incluya la participación de opciones basadas en gas natural o en derivados líquidos de petróleo, previo la verificación de los niveles de combustible a utilizar. La utilización de la rutina SOLVER permitió el procesamiento de modelos con variados grupos de restricciones; los resultados obtenidos llevaron a la selección de tres casos en los cuales manteniéndose la

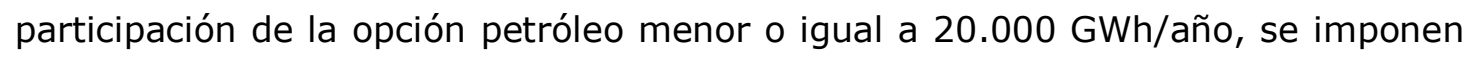
restricciones que limitan la participación de la opción gas a $0, \leq 10.000$ y $\leq$ 20.000 GWh/año, respectivamente. Para el período 2013-2025, las soluciones

85 A partir del año 2009, las reservas se han venido incrementando hasta alcanzar unos $190 \times 10^{12}$ pies cúbicos medidos en condiciones normales principalmente por nuevos descubrimientos costa afuera realizados por ENI (Italia) y REPSOL (España). 
correspondientes asignan un $10,7 \%$ de la generación eléctrica a instalar (12.915 GWh/año) a la suma de las participaciones de las dos opciones. Si la generación se basa exclusivamente en gas, requeriría un suministro adicional de 2.700 millones de metros cúbicos de gas natural por año; si se basa exclusivamente en diesel requeriría unos 42.000 barriles diarios adicionales de este combustible; y si se comparte, limitando por ejemplo, la participación de la opción gas a 10.000 GWh/año, se requerirían unos 2.100 millones de metros cúbicos de gas por año y unos 10.000 barriles diarios de diesel; cifras si se quiere, modestas frente a las grandes reservas de petróleo y gas del país.

(iv) Las alternativas basadas en energía eólica y en energía hidráulica aparecen en todas las soluciones; entre ellas, la opción eólica alcanza su máximo potencial desarrollable (18.000 GWh/año) en la gran mayoría de los casos estudiados. Otras energías renovables no lo hacen a menos que se incluyan restricciones que obliguen a una participación mínima de las mismas.

La adición al modelo de un mínimo de participación $[\geq]$ de energías renovables, sin variación en otras limitaciones, modifica la solución y disminuye su robustez siempre y cuando tal mínimo sea superior a $7 \%$ (18.000 GWh) de la capacidad de generación eléctrica necesaria para el año 2025. Si la participación mínima exigida es menor o igual a ese valor, la solución sólo incluye energía eólica y la solución al problema y su robustez no se modifican.

Ante incrementos progresivamente crecientes de la participación mínima exigida más allá de un 7\%, aparecen en la solución las opciones bioenergética, geotérmica y solar en el mismo orden. En el caso de que la suma de las participaciones de las opciones basadas en energía renovable (se excluye energía hidráulica) sea igual o mayor a un $10 \%$ de la generación eléctrica total a instalar, y el presupuesto asignado sea igual a 65 mil millones US\$, la solución al problema incluye todas las energías bajo estudio, y la robustez del sistema disminuye a 13.092 .

Venezuela no dispone ni de la experiencia ni del personal entrenado para el aprovechamiento de las energías renovables en la generación de potencia eléctrica, a una escala que contribuya significativamente con la solución de la 
emergencia eléctrica que vive actualmente el país; y la investigación en el área es casi nula. Ello, los resultados obtenidos en el análisis y la necesidad de minimizar el riesgo de fracasos o retardos en la implementación y puesta en marcha de soluciones a corto y mediano plazo, que estabilicen la situación en el sector, hacen pensar en excluir de la solución del problema las propuestas basadas en biomasa, energía geotérmica y energía solar. Con ello, no sólo se incrementa la robustez de la matriz energética resultante, sino que el país focalizaría sus esfuerzos en proyectos con una mayor posibilidad de éxito.

Nótese que lo dicho no implica que no se deba avanzar en el conocimiento y manejo de las nuevas tecnologías de generación eléctrica basadas en energías renovables. Al contrario, hay que favorecer la investigación y experimentación programada en plantas pilotos que demuestren la viabilidad técnica y económica de los respectivos proyectos; y posteriormente, pasar a la fase de su implementación y puesta en marcha a mayor escala. En tanto, pueden utilizarse recursos energéticos renovables como el sol, el viento, la biomasa y pequeños o medianos cursos de agua como una alternativa y/o complemento a la generación eléctrica en medios rurales o industriales.

\subsection{Análisis de resultados y propuesta final}

En resumen, existen múltiples soluciones al problema. Para las circunstancias que vive actualmente Venezuela y que se proyectarán con menor intensidad hacia el futuro, debe diferenciarse entre planes a inmediato plazo y, planes a mediano y más largo plazo.

El gobierno nacional ha escogido la vía más rápida y sencilla para llevar electricidad puntualmente a los sitios del país donde la falta de ella era cada vez más evidente, y ha instalado pequeñas plantas a diesel a lo largo y ancho del territorio nacional. Paralelamente intenta recuperar parte de la capacidad termoeléctrica e hidroeléctrica fuera de operación por mal manejo de las instalaciones y falta de mantenimiento, y de finalizar obras con retardo en su ejecución. Este plan de inmediato plazo se ha pautado para el período 2010-2012 y sus metas fueron incorporadas al estudio realizado como participaciones mínimas a lograr; o 
simplemente, deduciendo de los requerimientos estimados para el período 20102025, la capacidad ya instalada o en vías de instalación inminente, corregida por un factor de operatividad de las instalaciones. Adicionalmente, se han firmado convenios con China y Rusia para estudiar el potencial desarrollo de otras fuentes de energía.

Las soluciones que han surgido del análisis realizado a lo largo de este capítulo, tienen más que ver con planes a mediano y largo plazo que puestos en marcha a lo largo del período 2013-2025, y sumados a la base eléctrica existente en el país, podrían satisfacer la demanda estimada de potencia eléctrica para el mismo período.

En principio, la elección debe recaer en aquella solución que cumpliendo con todas las limitaciones reales o estimadas que definen el problema, maximice la robustez de la matriz eléctrica a instalar para el período bajo estudio sin descuidar el importante aspecto de la diversidad de fuentes energéticas que la misma ofrece. En tal sentido, los estudios realizados indican que para un presupuesto de 65 mil millones US\$ de inversiones en nuevas o recuperadas instalaciones de generación para el período 2013-2025, la alternativa que preliminarmente resulta la más conveniente entre las posibilidades estudiadas, es la solución obtenida para el caso 18. Nótese que la solución no presenta el mayor índice de robustez; sin embargo tiene a su favor que sustituye parcialmente los requerimientos de gas natural con diesel, ante la escasez del primero que por un tiempo sufrirá el país; focaliza el esfuerzo hacia aquellos proyectos con una mayor posibilidad de éxito y contempla un número importante de diferentes fuentes primarias de energía para la generación.

Sin embargo, es criterio del autor que la incorporación de la opción nuclear al sistema, a pesar de existir convenios firmados en tal sentido, debe verse con extremo cuidado por las implicaciones de índole internacional que se derivan; y especialmente, por los inmensos daños que puede causar a la población, la instalación de tecnologías no probadas y la falta de un adecuado control en el manejo de las instalaciones y en la disposición de los residuos radioactivos asociados, en un país sin personal especializado y sin ninguna experiencia en el manejo de este tipo de fuente energética.

De acuerdo con lo dicho, la figura 5.22 que se incluye más adelante, presenta cinco soluciones posibles para un presupuesto de 65 mil millones US\$: 
- La solución a un caso de referencia, sólo sujeto a las limitaciones de potencial desarrollable de cada fuente de energía, a las capacidades de generación hidráulica ya en ejecución y a un porcentaje de participación de energías renovables en el sistema.

- La solución al caso 18, con todas las restricciones citadas a lo largo del análisis.

- La solución a un nuevo caso (24) que excluye la participación de la opción nuclear manteniendo el resto de las restricciones sin alteración.

- La solución a un nuevo caso (25) que excluye la participación nuclear, rebaja la participación mínima de la opción carbón e incluye mínimos de participación para las opciones petróleo y gas.

- La solución a un nuevo caso (26) semejante al caso 25, excepto que incluye participación nuclear.

Adicionalmente, se incorpora el índice de diversidad explícitamente al análisis. La estimación del índice de diversidad en cada caso, se realiza de acuerdo a la fórmula de Herfindhal-Hirschman [Kruyt et al., 2009] expresada en la ecuación 4.5 del capítulo 4, sección 4.1.2.4.3.5 de este documento; y los resultados obtenidos para las soluciones propuestas se grafican versus los respectivos coeficientes de robustez y se presentan en el recuadro inferior derecho de la figura 5.22. Como se ha señalado, mientras más pequeño sea el valor del índice mayor es la diversidad de la solución que se estudia; y en consecuencia, mayor la seguridad energética que de implementarse puede proporcionar al país. La tabla que sigue presenta cifras utilizadas en la construcción del gráfico.

Tabla 5.37. Índices de robustez y diversidad. Casos 18, 24, 25 y 26

\begin{tabular}{|l|c|c|c|c|c|}
\cline { 2 - 6 } \multicolumn{1}{c|}{} & REFERENCIA & CASO 18 & CASO 26 & CASO 24 & CASO 25 \\
\hline ROBUSTEZ & 14.455 & 13.216 & 13.312 & 13.823 & 13.892 \\
\hline ÍNDICE DE DIVERSIDAD & 0,54 & 0,24 & 0,21 & 0,34 & 0,29 \\
\hline
\end{tabular}

Con relación al último punto es conveniente recordar que el índice de diversidad fue incluido de forma cualitativa. en el modelo multicriterio de valor utilizado para la estimación del coeficiente de robustez de cada una de las alternativas consideradas 
para la generación eléctrica en el país. Sin embargo, por su importancia como indicador de la seguridad energética de un país, su consideración explicita en el análisis puede ayudar a realizar una mejor elección final.

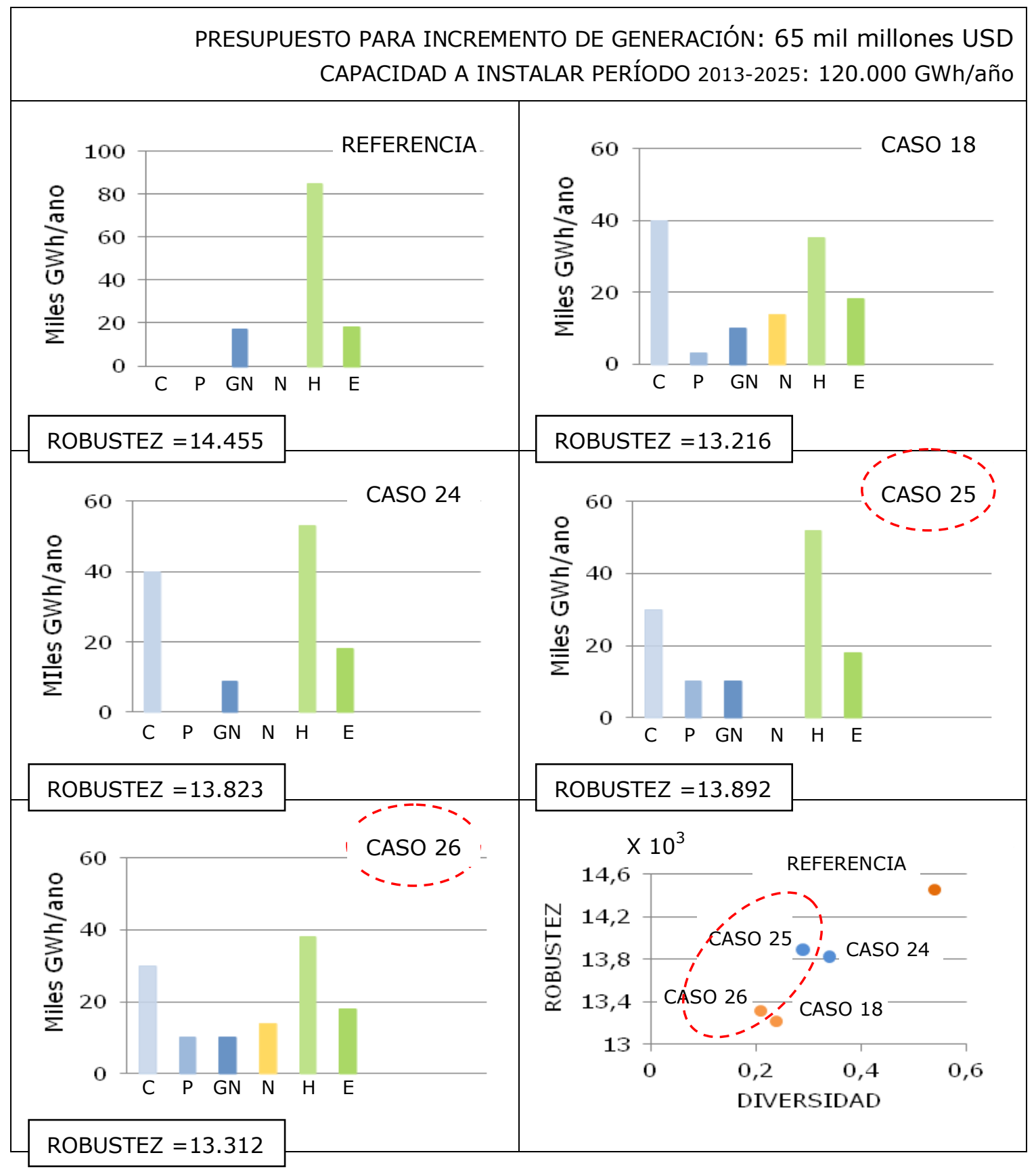

Figura 5.22. Soluciones posibles para un presupuesto de 65 mil millones US\$ 
En el gráfico anterior, puede observarse como mejora la robustez de la solución cuando se excluye la generación nuclear de ella (casos 24 y 25); y/o se disminuye la participación mínima de generación basada en carbón (caso 25 y 26). Entre los casos estudiados, es el caso 18 el que más se acerca a las limitaciones que se han identificado para el país; y por tanto, es la mejor aproximación preliminar a la solución del problema.

Una solución similar pero con un mejor coeficiente de robustez es la correspondiente al caso 26 representado en el recuadro inferior izquierdo de la figura 5.20 ; en él, se reduce la participación mínima de tecnologías basadas en carbón y coque de petróleo, y se introducen mínimos de participación para las opciones basadas en gas natural y derivados líquidos del petróleo. El coeficiente de robustez obtenido es 13.312, ligeramente superior al del caso 18 y mucho menor que el obtenido para el caso 25 que tiene las mismas limitaciones pero que no incluye generación nuclear.

La situación se aclara, si se analiza el gráfico incluido en el recuadro inferior derecho de la figura 5.21. Allí, los círculos azules representan las soluciones correspondientes a los casos 24 y 25, sin participación de la opción nuclear; y los círculos naranja, las soluciones correspondientes a los casos 18 y 26 donde se incluye una participación mínima de $13.600 \mathrm{GWh}$ /año para generación nuclear. Entre ellos, las soluciones que no incluyen generación nuclear presentan una robustez más alta y una menor diversidad que las soluciones que si la incluyen.

Por otra parte, la solución del caso 25 presenta mayor robustez y mayor diversidad que la del caso 24; y la misma situación se presenta entre los casos 26 y 18. De esta forma, la decisión se ubica entre las soluciones 25 y 26 las cuales ostentan los mejores indicadores entre los casos estudiados. La selección del mejor plan a implementar dependerá, entre otras cosas, de la importancia que se dé a una u otra condición.

La tabla 5.38 muestra la conformación de la capacidad eléctrica a instalar a lo largo del período 2013-2025, si se eligiese e implementase la solución al caso 26. Como una referencia, el cuadro muestra además la conformación de la capacidad a instalar si la selección recayese en la solución del caso 25. 
Tabla 5.38. Capacidad estimada de generación eléctrica a instalar durante el período 2013-2025, por tipo de energía primaria. Dos propuestas.

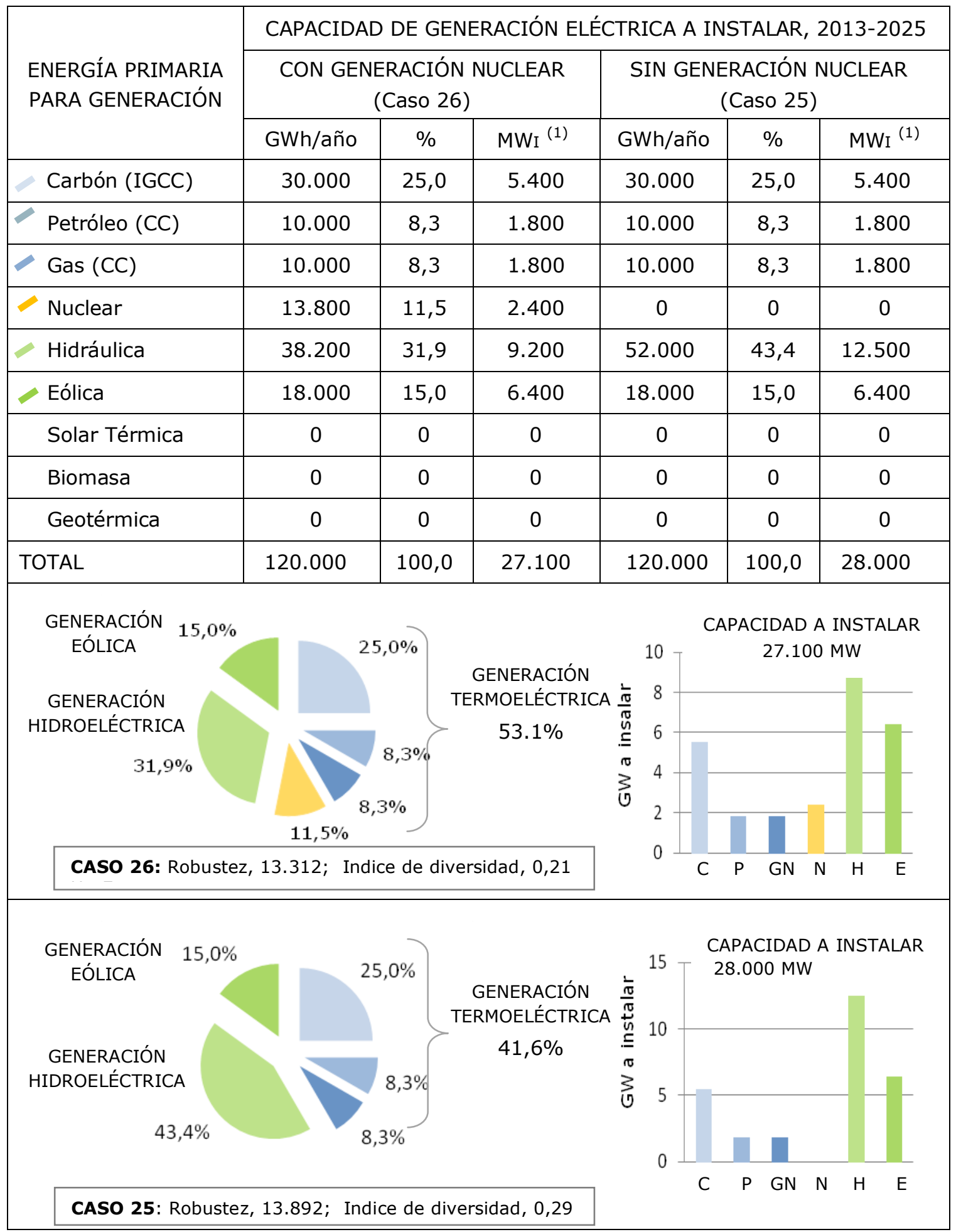

UNIVERSIDAD POLITÉCNICA DE VALENCIA. TESIS DOCTORAL. Violeta Parodi 
La mitad inferior del cuadro 5.38 muestra para los casos 25 y 26: (i) la estructuración porcentual del potencial suministro adicional de electricidad (GWh/año) para el año 2025 y (ii) la capacidad a instalar (MW) durante el período 2013-2025, todo clasificado por tipo de energía primaria. La relación para el caso 25 entre la generación termoeléctrica y la hidroeléctrica es ligeramente inferior a 1 , mientras que para el caso 26, la misma relación alcanza el valor de 1,7.

Requerimientos de combustible. En este punto, es conveniente referirse al importante aspecto de las cantidades de gas natural y de derivados líquidos del petróleo que se requerirán en caso de implementarse una u otra de las alternativas propuestas. En tal sentido, la tabla 5.39 muestra tales requerimientos, en base a los consumos promedio estimados en la tabla 5.35, incluida anteriormente.

Tabla 5.39. Estimación del consumo adicional de combustible, 2025. Casos 25 y 26

\begin{tabular}{|c|c|c|c|c|}
\hline \multirow[b]{2}{*}{ CASO } & \multicolumn{2}{|c|}{ GENERACIÓN ELÉCTRICA } & \multicolumn{2}{|c|}{ CONSUMO DE COMBUSTIBLE } \\
\hline & $\begin{array}{l}\text { GAS NATURAL } \\
\text { (CGN, GWh/año) }\end{array}$ & $\begin{array}{l}\text { DIESEL/FUELOIL } \\
\text { (CDF, GWh/año) }\end{array}$ & $\begin{array}{c}\text { GAS NATURAL } \\
\text { (millones } \mathrm{m}^{3} / \mathrm{año} \text { ) }\end{array}$ & $\begin{array}{l}\text { DIESEL/FUELOIL } \\
\text { (miles bbls/día) }\end{array}$ \\
\hline 25 & 10.000 & 10.000 & 2.090 & 34,4 \\
\hline 26 & 10.000 & 10.000 & 2.090 & 34,4 \\
\hline $\begin{array}{l}\text { CONs } \\
\text { GAS } \\
\text { CONs } \\
\text { CONs } \\
\text { GAS } \\
\text { DIES }\end{array}$ & $\begin{array}{l}\text { JMO PROMEDIO DE C } \\
\text { ATURAL : 0,209 (mill } \\
\text { JMO PROMEDIO DE C } \\
\text { JMO DE COMBUSTIBL } \\
\text { ATURAL (millones } \mathrm{m}^{3} \\
\text { - (miles bbls/día) }=C\end{array}$ & $\begin{array}{l}\text { IBUSTIBLE, VENEZUE } \\
\left.\mathrm{m}^{3} / \mathrm{GWh}\right) \\
\text { IBUSTIBLE DIESEL/F } \\
\text { CASOS } 25 \text { y } 26 \\
\text { (o) }=\text { CGN*0,209 } \\
* 1255,4 /(365 * 1000\end{array}$ & $1255,4 \mathrm{bbls} / \mathrm{GWh}$ & \\
\hline
\end{tabular}

Fuente de datos: Tabla 5.34, Sección 5.1.3.3.4.5.

Como puede observarse en el cuadro anterior, la operación de uno u otro de los planes propuestos una vez completamente instalados (2025), requerirán unos 2.100 millones de metros cúbicos estándar de gas natural/año y 34,4 miles bbls/día de derivados líquidos de petróleo. Como ya se ha señalado anteriormente, los volúmenes necesarios deberán ser importados hasta tanto se desarrolle capacidad adicional de producción en los yacimientos de gas y capacidad adicional de refinación en las refinerías del país. 
Distribución de la capacidad a instalar sobre la geografía nacional. La distribución en el territorio nacional de las soluciones sugeridas para el suministro de nueva potencia eléctrica en Venezuela debe tomar en cuenta; por una parte, la evolución estimada de la demanda para cada zona del país durante el período considerado; y por la otra, la ubicación de las fuentes de energía primaria. En principio, la mejor solución será la que minimice el costo de conectar la fuente de energía primaria con las instalaciones de generación de potencia eléctrica; y éstas a su vez con las regiones demandantes, a través de una red de distribución eléctrica confiable.

La materia no es fácil y debe ser resuelta en base a proyectos específicos que suministren no sólo la necesaria información de carácter técnico, económico y de impacto ambiental sino los detalles sobre requerimientos de tierras, agua, accesos e infraestructura requerida; y sobre la aceptación que la comunidad afectada muestre por cada proyecto. Todos ellos pueden resultar limitantes en la decisión final.

La figura 5.23 muestra en forma aproximada una posible distribución geográfica para los nuevos desarrollos eléctricos en el país.

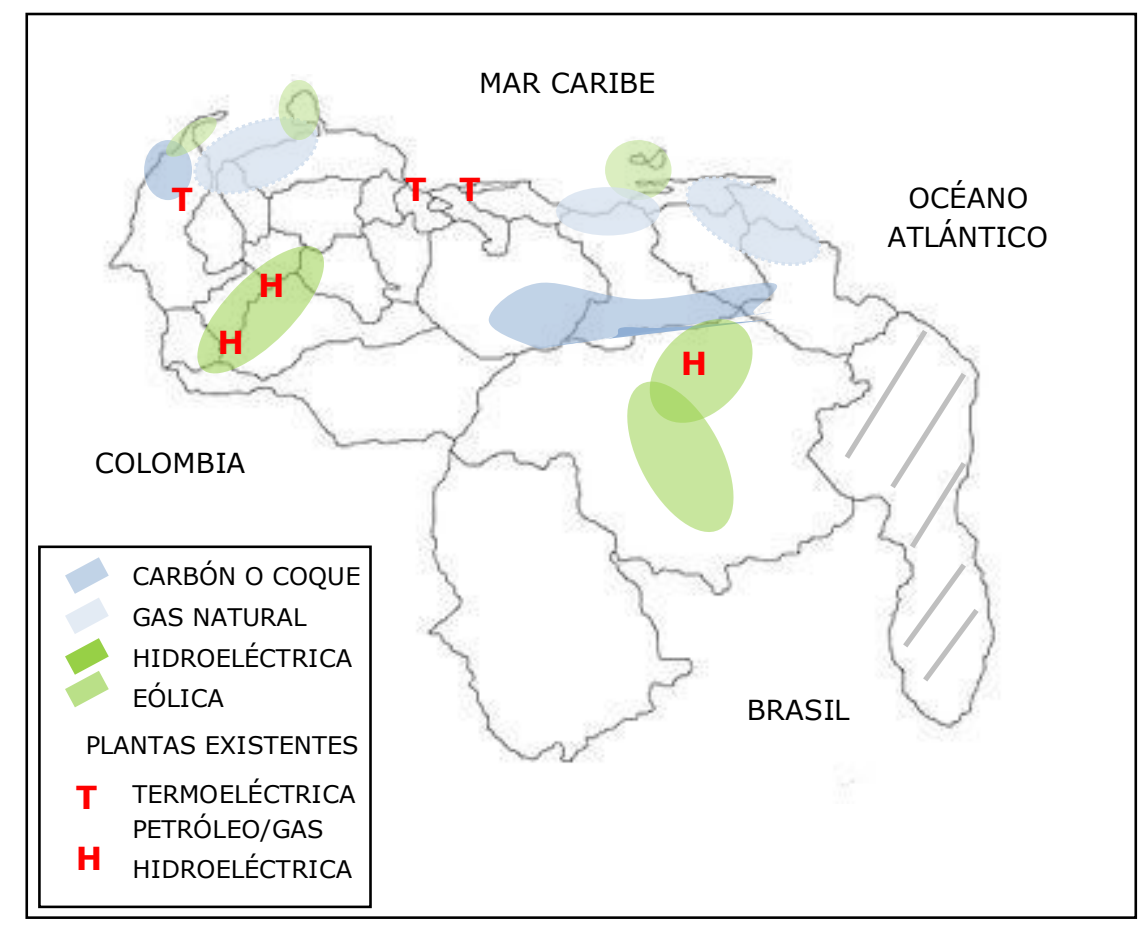

Figura 5.23. Una aproximación a la localización de nuevos desarrollos eléctricos 
El gráfico anterior es producto de la consideración de las figuras $5.1,5.2$ y 5.14 incluidas anteriormente en este capítulo, y de la revisión de los planes en el sector eléctrico esbozados por el gobierno nacional [CORPOELEC, 2011]; y sólo constituye un ejercicio del autor sobre una posible distribución sobre el territorio nacional de la nueva capacidad de generación a añadir durante el período estudiado, si se adoptase una u otra de las soluciones sugeridas en la sección anterior.

Como una referencia, sobre el mismo gráfico se indica la ubicación de los principales complejos termoeléctricos a gas natural, diesel y/o fueloil (T) e hidroeléctricos $(\mathrm{H})$ que hoy día suplen la demanda de energía eléctrica de la nación. Por falta de información precisa, no se delimita ninguna zona para la ubicación de reactores nucleares ni para nueva capacidad de generación basada en derivados líquidos de petróleo. En este último caso, y especialmente, si se considera la expansión del parque termoeléctrico en base a pequeñas plantas que funcionan con gasoil, los lugares para su ubicación deben contar con medios o vías de acceso que aseguren la disponibilidad oportuna del combustible.

Cronograma de ejecución. La instalación e implementación de las soluciones sugeridas para el suministro de potencia eléctrica en Venezuela durante los próximos trece años, debe ajustarse a la evolución estimada de la demanda para dicho período, a la urgencia de instalación en cada zona del país, a la disponibilidad de equipos en el mercado, a la inversión requerida frente a los recursos financieros disponibles y a los lapsos de construcción y puesta en marcha de las instalaciones asociadas a cada tipo de tecnología.

En la tabla 5.11, sección 5.1.3.3.3.4 de este documento, se registran los lapsos promedio de construcción de instalaciones de un tamaño estándar también reportado, asociadas a cada una a las opciones de generación bajo estudio. Los lapsos presuponen que existe disponibilidad inmediata de los equipos involucrados.

Ahora bien, Venezuela tiene una historia reciente de baja efectividad en la ejecución de los proyectos que se acometen; consecuencia entre otras cosas, de la demora en los trámites administrativos, de la escasez de algunos materiales y de la poca disponibilidad de personal calificado especialmente en los niveles gerenciales. De esta forma y para ser realistas, los lapsos registrados en la tabla 5.11 deben 
multiplicarse al menos por un factor estimado de construcción y puesta en marcha de 1,5. A ello, debe añadirse un período de uno o dos años para disponer de los proyectos respectivos. En consecuencia, dependiendo de la velocidad con la cual se acometan los planes y de la disponibilidad financiera para ejecutarlos, se necesitarán al menos unos cinco años para contar con las nuevas instalaciones con períodos de construcción más cortos; esto es, aquellas que basan su operación en la combustión de gas natural o derivados líquidos del petróleo, o en la energía eólica. Por su parte, las instalaciones de generación asociadas a tecnologías basadas en la combustión de carbón o coque de petróleo, las plantas hidroeléctricas y las plantas nucleares tienen lapsos de construcción y puesta en marcha bastante más largos.

Así en el plazo inmediato sólo queda recuperar y/o actualizar las instalaciones existentes, la instalación de pequeñas plantas termoeléctricas a diesel o gas; y paralelamente, la elaboración de un plan estratégico para el desarrollo e incorporación progresiva de centrales a mayor escala que son las que finalmente resolverán el problema del suministro de energía eléctrica.

La implementación con éxito de cualquier plan de mediano y largo plazo que contemple el aprovechamiento de las reservas de petróleo, gas y del gran potencial hidráulico que posee el país, demandará la activación urgente de planes de desarrollo de sus reservas gasíferas, la expansión de su capacidad de refinación, el incremento de su producción petrolera; y finalmente, las acciones que lleven a la progresiva recuperación de las cuencas hidrológicas al sur del país. Todo ello, requerirá de voluntad política, una fuerte inversión y de la experiencia y determinación de sus mejores profesionales y técnicos en las respectivas áreas.

Presupuesto. Como ya se ha señalado, los recursos financieros necesarios para la construcción e implementación de las instalaciones para generación eléctrica sugeridas en las soluciones 25 y 26, suman unos 65 mil millones US\$. A este monto debe añadirse una cantidad de dinero importante dirigida a la construcción y/o adecuación del sistema de transmisión y distribución de la energía producida hasta las zonas que la demandan.

En Venezuela no se han realizado ni las inversiones ni el mantenimiento necesario para mantener la red de distribución existente en condiciones adecuadas y el sistema UNIVERSIDAD POLITÉCNICA DE VALENCIA. TESIS DOCTORAL. Violeta Parodi 
presenta fallas frecuentes [Hernández, 2011a]. En consecuencia, los expertos estiman un monto total para la generación y distribución de la energía eléctrica producida en el país, que oscila entre 1,5 veces y 2 veces [CPTEDELCA, 2011; Rousse, 2010] la inversión inicial requerida para generación; esto es, se requerirían aproximadamente entre 100 y 130 mil millones US\$ distribuidos a lo largo del período 2013-2025 para llevar adelante cualquiera de los planes sugeridos.

Matriz global de suministro para generación eléctrica. La tabla 5.40 y la figura 5.24 que se incluyen a continuación, muestran la conformación de las matrices energéticas que para el sector eléctrico nacional tendría el país para el año 2025, en caso de implementarse una u otra de las soluciones alternativas presentadas en la tabla 5.38. Como una referencia se incluye la situación para los años 2010 y 2012; ésta última estimada en base a los planes que el gobierno viene implementando con urgencia desde el año 2010.

Tabla 5.40. Una aproximación a la matriz eléctrica para Venezuela, 2025

\begin{tabular}{|c|c|c|c|c|c|c|c|}
\hline \multirow{3}{*}{$\begin{array}{c}\text { ENERGÍA } \\
\text { PRIMARIA DE } \\
\text { GENERACIÓN }\end{array}$} & \multicolumn{7}{|c|}{ CAPACIDAD DE GENERACIÓN ELÉCTRICA (GWh/año) } \\
\hline & \multirow{2}{*}{$\begin{array}{c}\text { INSTALADA } \\
2010\end{array}$} & \multirow{2}{*}{$\begin{array}{c}\text { EN } \\
\text { EJECUCIÓN } \\
2010-2012\end{array}$} & \multirow{2}{*}{$\begin{array}{c}\text { TOTAL } \\
2012\end{array}$} & \multicolumn{2}{|c|}{$\begin{array}{l}\text { A INSTALAR } \\
2013-2025\end{array}$} & \multicolumn{2}{|c|}{ TOTAL 2025} \\
\hline & & & & CASO 25 & CASO 26 & CASO 25 & CASO 26 \\
\hline Carbón (IGCC) & 0 & 0 & 0 & 30.000 & 30.000 & 30000 & 30000 \\
\hline Petróleo (CC) & 21.712 & 21.809 & 43.521 & 10.000 & 10.000 & 53.521 & 53.521 \\
\hline Gas (CC) & 18.200 & 0 & 18.200 & 10.000 & 10.000 & 28.200 & 28.200 \\
\hline Nuclear & 0 & 0 & 0 & 0 & 13.800 & 0 & 13.800 \\
\hline Hidráulica & 76.790 & 2.078 & 78.868 & 52.000 & 38.200 & 130.868 & 117.068 \\
\hline Eólica & 0 & 0 & 0 & 18.000 & 18.000 & 18000 & 18000 \\
\hline Solar Térmica & 0 & 0 & 0 & 0 & 0 & 0 & 0 \\
\hline Biomasa & 0 & 0 & 0 & 0 & 0 & 0 & 0 \\
\hline Geotérmica & 0 & 0 & 0 & 0 & 0 & 0 & 0 \\
\hline TOTAL & 116.702 & 23.887 & 140.589 & 120.000 & 120.000 & 260.589 & 260.589 \\
\hline Robustez/GWh & 0,118 & - & 0,117 & - & - & 0,116 & 0,114 \\
\hline Diversidad & 0,49 & - & 0,43 & - & - & 0,32 & 0,28 \\
\hline
\end{tabular}




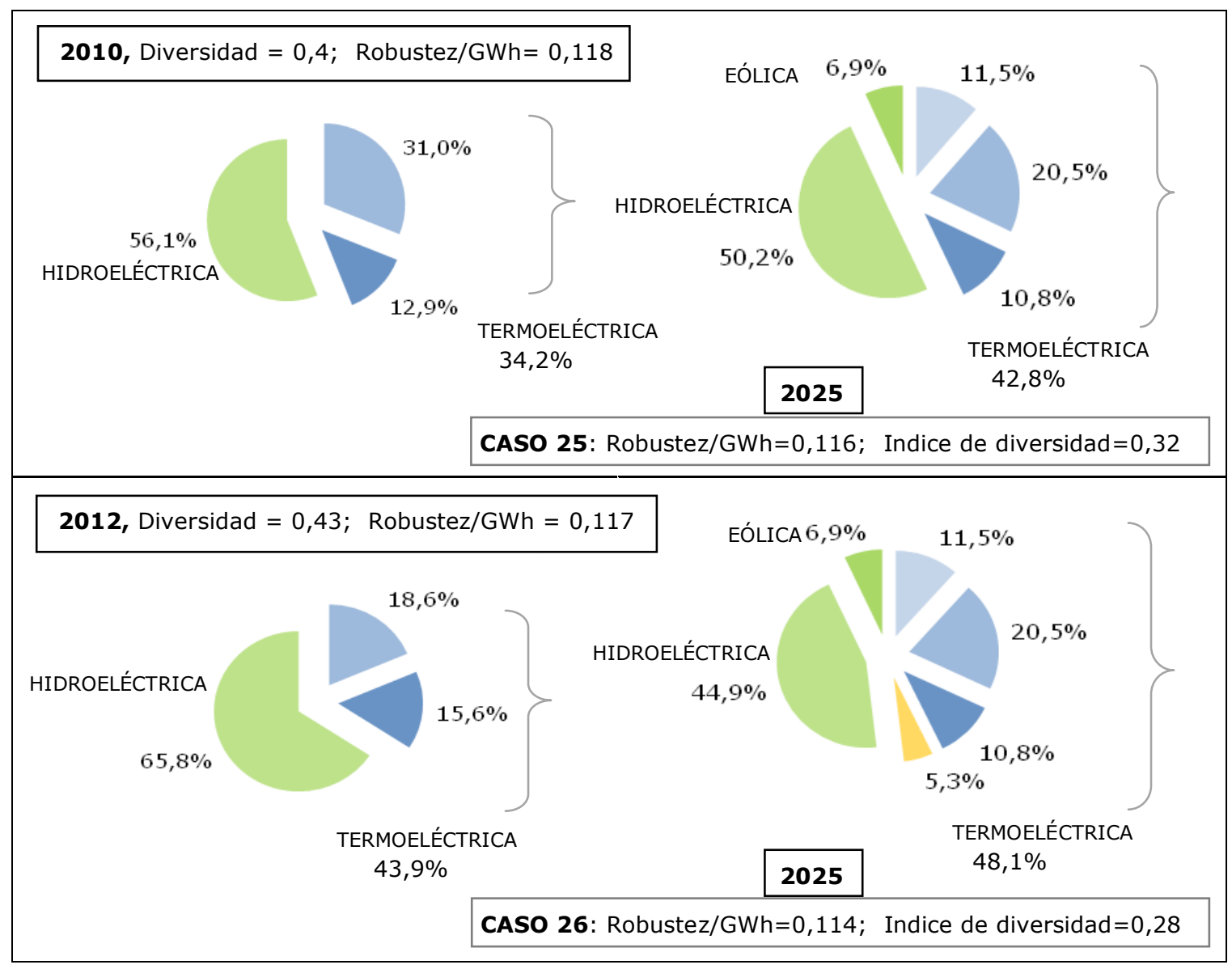

Figura 5.24. Potencial evolución de la matriz de suministro de electricidad al país, 2010-2025.

La lectura del cuadro anterior y de su gráfico derivado permite efectuar las siguientes observaciones;

- La robustez/GWh de la matriz eléctrica global para el país desmejora en la medida en que se incrementa la participación de tecnologías basadas en energía nuclear, carbón o coque de petróleo y derivados líquidos de petróleo; y se disminuye la participación de la energía hidráulica y del gas natural. De esta forma, las potenciales matrices eléctricas para el año 2025 tienen menor robustez que la correspondiente al año 2012; y ésta es menos robusta que la del año 2010. Tal resultado no puede evitarse si se incluyen las restricciones existentes en el país, en la solución buscada. 
- La diversidad de la matriz eléctrica para el país mejora en la medida en que se incluye un mayor número de fuentes energéticas en el mismo. De esta forma, las potenciales matrices energéticas para el año 2025 tienen mayor diversidad que la correspondiente al año 2012; y ésta es más diversa que la del año 2010. La condición es de interés para la planificación pública en el sector.

- La participación de la energía hidroeléctrica en la matriz eléctrica para el año 2025 disminuye con relación a la del año 2012; y su participación en ésta es menor que la del año 2010. Ello se corresponde a la estrategia del gobierno de sustentar su ampliación de capacidad de generación en fuentes termoeléctricas a fin de proteger las cuencas hidrográficas del sur del país y de obtener una mayor diversidad en el grupo de fuentes de energía primaria que alimentan al sistema eléctrico nacional.

Naturalmente, tales lineamientos estratégicos fueron incorporados al modelo como restricciones y se reflejan en los resultados obtenidos. En efecto, la relación entre las contribuciones de energía hidroeléctrica y energía termoeléctrica se mueve desde 1,9 en el año 2010 a relaciones estimadas de 1,3 en el año 2012, si se cumplen los planes anunciados por el gobierno para el período; y de 1,2 0 0,9 para el año 2025, si se implantasen respectivamente las soluciones a los casos 25 026.

- La participación de las energías renovables en la matriz energética para el sector eléctrico se mueve desde cero en el año 2010 a una participación estimada de $6,9 \%$ para el año 2025 . Esta meta recomendada por la solución al problema es difícil de obtener dada el modesto conocimiento y poquísima experiencia en la materia de la cual dispone el país frente a la existencia de un gran potencial de otras fuentes energéticas cuyo manejo es bien conocido de las cuales dispone el país.

Para concluir es necesario recordar que la propuesta final realizada sólo constituye una aproximación al problema del suministro eléctrico en Venezuela. Ante la falta de información completa, confiable y consistente por parte de los organismos oficiales del país, la resolución del caso se basó en promedios publicados por organismos internacionales en el sector y en información suministrada en conferencias, UNIVERSIDAD POLITÉCNICA DE VALENCIA. TESIS DOCTORAL. Violeta Parodi 
publicaciones y entrevistas de expertos mayoritariamente ubicados en universidades y en el sector privado del país. En lo posible, toda la información fue validada en diferentes fuentes. Alguna información, especialmente la referente a planes gubernamentales, fue obtenida de la empresa pública responsable del sector eléctrico en el territorio nacional. Cuando fue necesario, se realizaron encuestas entre estudiantes y profesionales relacionados con la materia, en el sector público y privado de la nación.

El problema es complejo no sólo por el número de factores involucrados, muchos de ellos impredecibles; sino por su estrecha relación con otras materias dentro del sector eléctrico y con otros sectores de la vida del país. La solución alcanzada progresivamente a lo largo de este capítulo, se refiere sólo a la necesidad de capacidad adicional de generación eléctrica para suplir la demanda estimada del país durante el período 2013-2025. Otros aspectos están fuera del alcance de este trabajo y aunque son en parte mencionados a lo largo del capítulo, no entran en el análisis formal del caso.

Claramente, las decisiones finales a tomar por las instancias a las que corresponda hacerlo, deben apoyarse en proyectos específicos que suministren información completa y confiable sobre los requerimientos físicos, tecnológicos y financieros de las alternativas de solución al problema, sus rendimientos, sus riesgos, su impacto ambiental, los beneficios sociales derivados de su ejecución y puesta en marcha; y la aceptación o no, que puedan tener en el seno de la comunidad afectada. Paralelamente es necesario tener un amplio conocimiento de la realidad nacional.

Con las limitaciones señaladas, la solución alcanzada puede contribuir a orientar los planes que en el sector se efectúan y a focalizar el esfuerzo que implica un mayor detalle en la información, en las alternativas energéticas que efectivamente pueden hacer más robusto el sector eléctrico en el país.

\subsection{Resumen}

En las páginas precedentes se ha demostrado la aplicabilidad del modelo multicriterio de valor desarrollado en el capítulo 4 de este documento, a la resolución 
de un problema de elección entre alternativas en el sector energético. Específicamente, se trabajó sobre un caso real y actual: la crisis eléctrica en Venezuela que presentó su mayor dificultad en el año 2010, cuando en algunas zonas del país se presentaron repetidos apagones y el gobierno nacional se vio forzado a racionar severamente el fluido eléctrico.

Una vez estudiada la información respectiva, el problema se planteó como la búsqueda de la mejor combinación de fuentes primarias de energía para su conversión en potencia eléctrica y de las tecnologías asociadas, capaz de suplir la demanda estimada faltante en el país para el período 2013-2025; todo ello sujeto a un presupuesto de ejecución disponible y a las limitaciones propias de la nación.

Una aproximación a la solución del problema se logró con la aplicación combinada del modelo multicriterio de valor propuesto en el Capítulo 4 y de métodos de programación lineal. La aplicación del modelo multicriterio permitió obtener índices de robustez para nueve tipos de energía básica potencialmente desarrollables en el país. Los resultados favorecieron a las opciones de generación eólica, hidráulica y combustión de gas natural. La alternativa menos favorecida fue la generación nuclear seguida de las opciones de generación basadas en carbón y en derivados líquidos del petróleo. Otras opciones basadas en recursos energéticos renovables no aparecieron en las soluciones recomendadas.

La aplicación de técnicas de programación lineal tuvo como objeto seleccionar entre las múltiples alternativas posibles, la combinación más robusta sujeta a las restricciones identificadas para el país. Un estudio de sensibilidad posterior analizó el efecto que sobre la solución inicial obtenida tenían cambios en el presupuesto y en las participaciones mínimas de energías renovables y no renovables. El análisis progresivo de los resultados permitió identificar dos aproximaciones a la solución del problema ; una de ellas, incluye generación nuclear; y la otra, no lo hace. Como un indicador complementario importante, se calculó el índice de diversidad de cada solución estudiada.

Para las dos mejores soluciones identificadas, se elaboraron las correspondientes matrices eléctricas para el año 2025, en el supuesto de que las propuestas fuesen implementadas. Se realizaron aproximaciones a su distribución en el territorio UNIVERSIDAD POLITÉCNICA DE VALENCIA. TESIS DOCTORAL. Violeta Parodi 
nacional, su cronograma de ejecución y el presupuesto requerido para su implementación y puesta en marcha. La escogencia de la más conveniente entre ellas dependerá de los tipos y tamaños de los equipos disponibles en el mercado y de las condiciones para su adquisición, de los plazos de instalación necesarios para la puesta en marcha de los proyectos asociados, de la accesibilidad y facilidad en la procura de los recursos energéticos necesarios, de la disponibilidad efectiva de personal entrenado, de limitaciones financieras, de las urgencias relativas de potencia eléctrica en cada región del país, de los compromisos nacionales o internacionales que adquiera la nación por razones ambientales, estratégicas o políticas; y finalmente de la seguridad energética que potencialmente puedan brindar al país. 


\section{Capítulo 6 Propuesta metodológica para la evaluación}

A medida que aumenta la complejidad de un proyecto de inversión se incrementa la necesidad de un análisis formal y sistemático de todos los factores que puedan afectar su futuro funcionamiento. El análisis permitirá evaluar los posibles cursos de acción para la solución del problema identificado o para la consecución de los objetivos propuestos; y fundamentará la selección de la mejor opción, entendiéndose como tal la que proporciona el mayor bienestar a las comunidades involucradas, cumpliendo con las limitaciones propias del país sede del proyecto.

La calidad de los resultados del análisis dependerá como siempre de las cualidades de la información insumo al proceso y de la habilidad de los evaluadores para seleccionar los métodos o combinación de métodos que mejor se adapten a la data disponible y al tipo de resultados que se pretende obtener.

Hoy día, Internet ha puesto un gran y variado volumen de información al alcance de todos. Así puede accederse a las publicaciones en revistas especializadas reunidas en bancos de datos; a la información obtenida en libros, estadísticas y publicaciones gubernamentales, informes anuales o puntuales de reconocidos organismos, agencias o grandes empresas internacionales y nacionales; a resúmenes de congresos y conferencias; a estudios contratados, encuestas y entrevistas personales; o simplemente, a artículos y opiniones de carácter privado vertidos en prensa y televisión. La información requerida debe ser seleccionada, clasificada, complementada y transformada a formatos que permitan su utilización en el análisis. 
Adicionalmente está la información que aportan los individuos o comunidades de individuos que pueden resultar afectados por la puesta en marcha y explotación del proyecto. La tendencia moderna por lo enriquecedor que resulta, es incorporar al proceso no sólo a los expertos en las respectivas áreas sino a los representantes de tales comunidades, con sus diversas motivaciones, opiniones, intereses y juicios de valor sobre los diversos aspectos del proyecto. La participación de todos los involucrados es una ocasión para mejorar el conocimiento del proyecto; la negociación entre las diferentes opiniones hasta encontrar un consenso, abre un espacio para incrementar la posibilidad de que el proyecto si se ejecuta, sea apoyado por las comunidades afectadas.

El proceso descrito puede llevarse a cabo con los actores en la misma localización geográfica o no. Efectivamente, los avances en las tecnologías de telecomunicaciones, las redes, la capacidad y velocidad de procesamiento de los computadores y el desarrollo de potentes aplicaciones informáticas permiten la transmisión, recuperación, clasificación y procesamiento de la información de diversa índole y procedencia, en diferentes formatos y a velocidades cada vez mayores.

Todo ello, ha abierto la inventiva de investigadores y evaluadores; y hoy día, además de un sinnúmero de facilidades para obtener y procesar la información, se dispone de un volumen creciente de métodos que permiten ampliar el alcance del análisis. La habilidad del analista para hacer uso de tales recursos y para combinar, particularizar y aplicar eficazmente los métodos de análisis disponibles, hará la diferencia en cuanto a la calidad de los resultados entregados; y a que la decisión a la cual sirven de soporte, sea efectivamente la mejor.

En base a todo el trabajo realizado, a continuación se propone una metodología para la evaluación y selección de proyectos en el sector energético. La metodología plantea la combinación o no, del Proceso de Jerarquías Analíticas y de métodos de programación lineal. Las figuras $6.1 \mathrm{a}$ y $6.1 \mathrm{~b}$ presentan un diagrama de flujo del proceso, el cual se divide en tres fases, a saber:

- Formulación de alternativas viables

- Evaluación multicriterio de las alternativas viables

- Modelo de programación lineal para la solución 


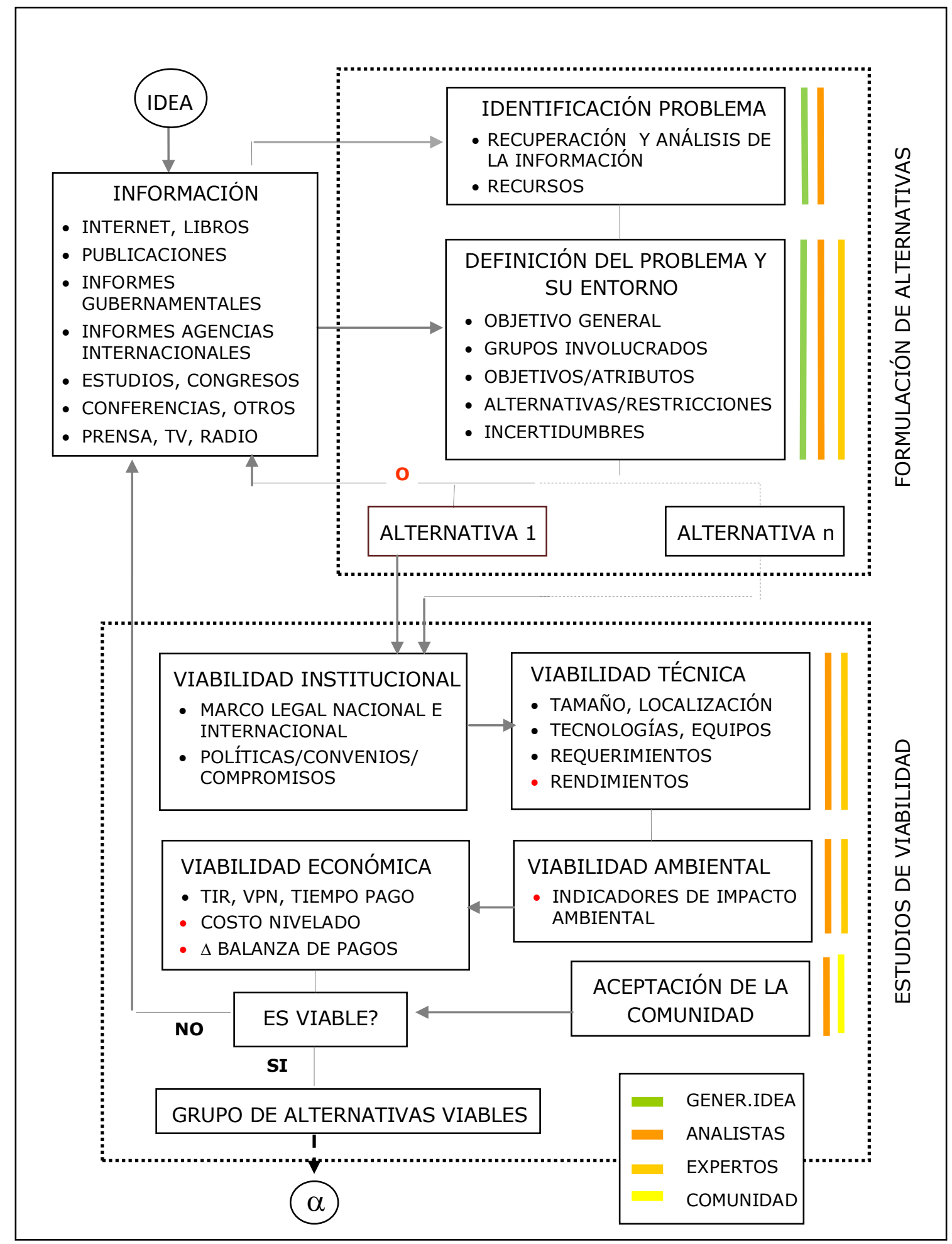

Figura 6.1a. Propuesta metodológica para la evaluación de proyectos en el sector energético. FASE PREVIA. Formulación de alternativas viables 


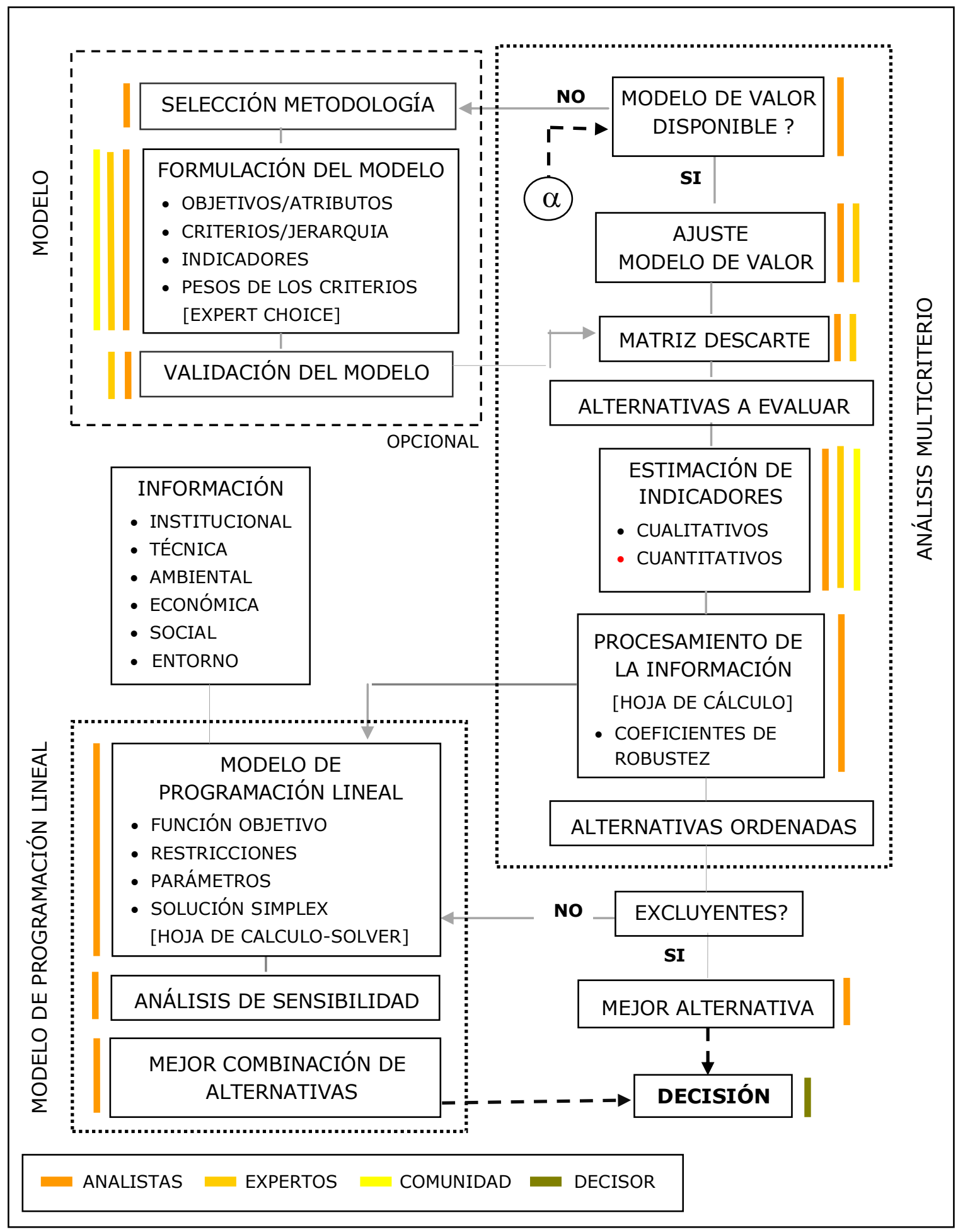

Figura 6.1b. Propuesta metodológica para la evaluación de proyectos en el sector energético. Evaluación [multicriterio $+\mathrm{PL}$ ] de las alternativas viables. 
Las líneas de colores en los diagramas anteriores señalan en forma simbólica, el tipo de actores participantes en la ejecución cada etapa del proceso, de acuerdo a la leyenda incluida en el borde inferior de los diagramas. Entre ellos se cuentan, el grupo generador de la idea, los analistas y expertos convocados para su estudio, y los representantes de las comunidades afectadas.

Inicialmente, el grupo generador de la idea puede interactuar con el grupo de trabajo para definir el problema; éste último es el responsable de conducir el análisis y de obtener resultados que apoyen la correspondiente decisión. Adicionalmente, es siempre conveniente conformar grupos de consulta con expertos y representantes de las empresas, institutos de investigación y universidades, y/o instituciones gubernamentales y no gubernamentales; e incorporar al proceso a líderes de las comunidades afectadas que aporten sus juicios de valor en la estructuración y evaluación de las alternativas de solución que deban compararse.

\subsection{Formulación de alternativas viables}

El ciclo de un proyecto desde su concepción hasta su puesta en funcionamiento, se inicia con una idea de una o más personas, con cuya ejecución se pretende (i) solucionar un problema, (ii) incrementar la eficiencia, eficacia o capacidad de una empresa, institución o sector de la sociedad, o (iii) innovar; todo con el objetivo de contribuir al incremento de la satisfacción de la comunidad afectada.

La idea puede originarse en los niveles gerenciales encargados de la toma de decisiones en las empresas, instituciones, instancias gubernamentales o instancias comunales; o viceversa y más frecuentemente, en niveles jerárquicos más bajos por grupos que identifican una oportunidad de mejora en sus intereses o en los de la organización o comunidad a la cual pertenecen y la plantean a los niveles de decisión que corresponda. Si la idea prospera, se asigna a su estudio, un grupo de analistas expertos en el área cuyo primer paso es la búsqueda de información sobre el tema.

En esta primera fase pueden identificarse tres etapas, a saber :

- Recuperación y filtrado de la información

- Definición del problema y su entorno 
- Estudios de viabilidad

A continuación algunos comentarios al respecto.

\subsubsection{Recuperación y filtrado de la información}

La recuperación de información en la cantidad y con la calidad necesarias requiere un mayor o menor esfuerzo en hombres, tiempo y dinero de acuerdo al grado de maduración de la idea, a la importancia que se asigne a su implementación y a la complejidad del problema a resolver. Paralelamente a las fuentes tradicionales, Internet ha puesto al alcance de todos, un volumen inmenso de información muy variada en contenido, formato y origen. En ella se cuentan publicaciones especializadas, informes periódicos o puntuales de reconocidas empresas y agencias internacionales o nacionales, estadísticas, trabajos presentados en congresos, conferencias y artículos de opinión. Dado su gran volumen y diferente procedencia, la información debe ser seleccionada, clasificada, contrastada, verificada su consistencia, complementada y consolidada en formatos útiles para el análisis.

Por otra parte, puede obtenerse información de interés en estudios contratados sobre tópicos seleccionados; y a través de entrevistas, encuestas o grupos de discusión, presencialmente o a distancia, utilizando las modernas redes y herramientas informáticas disponibles actualmente. La disponibilidad de recursos financieros decidirá hasta que punto detallar la investigación sin perjudicar la calidad de la información requerida.

Adicionalmente, debe adquirirse una idea clara de las circunstancias económicas y políticas del país o región sede del potencial proyecto; de su disponibilidad de recursos energéticos renovables y no renovables; del acceso a las tecnologías para su aprovechamiento; de la posibilidad de suplir el personal entrenado necesario para su respectiva utilización; del estado de la infraestructura de apoyo existente; y de los compromisos y/o convenios firmados por la nación en el sector bajo estudio.

\subsubsection{Definición del problema y su entorno}

Con base en la información recabada, el paso inicial del proceso es la conformación del grupo de analistas que estará a cargo del proyecto, de los expertos 
que brindarán su aporte en las respectivas áreas y de los representantes de las comunidades que puedan resultar afectadas con su ejecución. Ellos contribuirán en la medida de sus capacidades, conocimiento, intereses y experiencia en las diferentes fases del proceso.

En esta etapa, el esfuerzo debe dirigirse a la captura de nuevas ideas, a su registro y a su estructuración a fin de obtener una percepción clara del problema objeto del análisis Específicamente, se deben identificar los objetivos a cumplir, los recursos disponibles, las variables críticas del proyecto; y como un producto de las combinaciones de los valores que pueden tomar estas últimas, las potenciales alternativas de acción para lograr el cumplimiento de los objetivos planteados.

En general, la información que se maneja para la definición del problema y especialmente del entorno donde se inserta lleva asociada un grado de incertidumbre [Matos, 2007] o riesgo. Por una parte, la incertidumbre asociada a los juicios de valor aportados por los diferentes participantes en el mismo puede disminuirse con la necesaria retroalimentación del conocimiento adquirido de y hacia las diferentes etapas del proceso a fin de mejorar los procedimientos y controlar desde el punto de vista estadístico la consistencia y calidad de la información que entra al proceso de análisis.

Por otra parte, la incertidumbre relacionada con la falta de conocimiento sobre el entorno que rodea al problema y el impacto que sobre él pueda tener una escogencia en particular, no puede ser controlada por el grupo de análisis. Su incorporación al análisis multicriterio de decisión puede, entre otras formas, realizarse con el uso de escenarios o "futuros" relevantes al contexto del análisis.

En general, es conveniente definir al menos tres escenarios (p.e. pesimista, más probable, y optimista). La tarea puede requerir incrementar significativamente el tiempo que se dedique e la estructuración del problema [Belton y Stewart, 2003] y a su análisis. Si se dispone de la información estadística necesaria es posible asignar probabilidades de ocurrencia a cada escenario en cuyo caso se obtendrán resultados [valor, probabilidad] que pueden ser sustituidos por su valor esperado para cada alternativa. Si no es así, se obtendrá un rango donde se ubican los valores obtenidos para cada alternativa o para el proyecto. 


\subsubsection{Formulación de alternativas de inversión}

La presentación ordenada de las ideas para lograr los objetivos trazados se conoce como formulación del proyecto y es un proceso de aproximaciones sucesivas donde en cada iteración se buscan y se estudian nuevas alternativas de solución al problema, de acuerdo a: (i) nuevo conocimiento añadido al proceso por expertos a lo largo del proceso de análisis, (ii) la visión particular que tenga del problema cada actor involucrado, (iii) la necesaria discusión y negociación entre los participantes en el análisis y (iv) la flexibilización de las limitaciones.

La creatividad, la capacidad para escuchar y aceptar opiniones distintas a la propia, el conocimiento sobre la materia; y sobre todo, la experiencia en el tema son cualidades altamente apreciadas en ésta y en las etapas subsiguientes del problema.

Para cada alternativa posible, debe identificarse claramente: la tecnología requerida y el "saber-como" asociado, su vida esperada y sus rendimientos, los recursos energéticos insumo al proceso. las limitantes en cuanto a terrenos, agua y servicios para su instalación y posterior operación, las necesidades de personal entrenado y el potencial impacto que sobre el ambiente causará su construcción y puesta en operación.. En base al tamaño propuesto de proyecto, deben estimarse las inversiones requeridas, el presupuesto de ingresos y costos asociados; y tener una percepción inicial de la aceptación de la comunidad directamente afectada ante la instalación, operación y riesgos del proyecto. Finalmente, debe definirse el marco legal e institucional que aplica y señalarse las limitaciones técnicas, presupuestarias, ambientales, sociales, políticas o de cualquier otra índole que puedan afectar la ejecución del proyecto.

Las alternativas pueden ser excluyentes; esto es, la ejecución de una de ellas presupone la no ejecución de ninguna de las restantes; o pueden ser independientes en cuyo caso el objetivo final del análisis es encontrar la mejor combinación de ellas, sujeta a las restricciones identificadas.

El producto final de la etapa es un conjunto de posibles opciones de inversión para cumplir con los objetivos planteados, completamente definidas desde el punto de vista legal, técnico, ambiental y económico. Las alternativas deben demostrar su 
viabilidad en cada una de esos aspectos para competir frente a alternativas similares. Esta materia se trata en la próxima sección.

\subsubsection{Estudios de viabilidad}

La viabilidad de una alternativa de inversión se refiere al cumplimiento de condiciones mínimas en materia institucional, tecnológica, ambiental y económica que garanticen la ejecución y funcionamiento adecuado de las futuras instalaciones.

La viabilidad institucional tiene que ver con el respeto del marco legal nacional vigente y de los convenios internacionales que haya suscrito el país. También tiene que ver con aquellos elementos de política general, económica, ambiental y social de la región sede del proyecto, que puedan favorecer o contraponerse a la ejecución y explotación de la alternativa de acción en cuestión.

Por su parte, la viabilidad tecnológica se relaciona con la disponibilidad en el mercado de la tecnología propuesta y de los equipos con el tamaño y especificaciones requeridas; con el acceso al "saber como" asociado a su instalación y operación; con su aceptación en el sector energético internacional; con la existencia de la infraestructura física, de servicios y de distribución necesaria en la región sede del proyecto, o con la capacidad de construirla; con la seguridad de suministro de los recursos energéticos necesarios y el acceso a los recursos mínimos requeridos de tierra, agua, lluvias, intensidad de vientos y/o radiación solar; con la posibilidad de contratación de la mano de obra necesaria requerida; con un balance energético positivo para el proceso propuesto y con alcanzar una eficiencia mínima exigida; entre otras cosas.

La viabilidad ambiental tiene que ver con el cumplimiento de la normativa ambiental vigente, especialmente, en cuanto a las medidas de diseño para que la operación de las futuras instalaciones no represente un riesgo para la salud de las comunidades y/o del ambiente. En el sector energético, tiene especial importancia la emisión de gases como el $\mathrm{CO}_{2}$ y otros gases del tipo invernadero emitidos a la atmósfera, por su conocido efecto sobre el calentamiento global del planeta. Los gases son producto de la combustión de recursos fósiles especialmente en el sector transporte y en el sector eléctrico. Otros gases como los compuestos orgánicos, las 
emisiones ácidas y las partículas producidos en los ambientes industriales pueden resultar altamente dañinos a la salud de la población y al ambiente.

Por otra parte, el manejo, tratamiento, almacenamiento y disposición final de los residuos sólidos y líquidos deben ser los adecuados para evitar la contaminación de los suelos y de las corrientes de agua subterráneas y superficiales; y en general, para proteger ecosistemas que puedan resultar afectados.

Por su elevada peligrosidad, los residuos radioactivos resultan de especial interés. Su transporte, almacenamiento provisional y disposición definitiva están estrictamente normados y son, licenciados y supervisados, por las autoridades en cada país y por organismos internacionales que generalmente asesoran sobre la materia. De esta forma, debe ser una condición limitante para la aceptación de un proyecto en el sector energético basado en el aprovechamiento de la energía nuclear que el mismo incluya el diseño adecuado de las facilidades y equipos necesarios, y un plan de operaciones seguro con la incorporación del personal capacitado para cumplir con la normativa vigente. La sección 4.1.2.4.3.3, capítulo 4 de este documento presenta consideraciones más detalladas sobre esta importante materia; y en general, sobre el tema ambiental.

Finalmente, la viabilidad económica se refiere a la exigencia de un rendimiento económico mínimo estimado en base a los flujos de efectivo positivos y negativos asociados al proyecto para un período de servicio esperado o un período de estudio fijado. En general, el valor del rendimiento mínimo exigido en proyectos del sector publico es muy inferior a aquel exigido en proyectos del sector privado; sin embargo, cualquier tipo de proyecto debe cubrir al menos sus costos de inversión, operación y mantenimiento para su normal funcionamiento, a menos que por razones estratégicas se le otorguen subsidios o excepciones de impuesto que permitan ofrecer su producto a un precio inferior o igual al precio del producto energético que pretenden sustituir. Este tipo de prácticas es común en muchos países para incentivar el uso de las energías renovables y tratar de sustituir parcialmente la utilización de combustibles fósiles; y con ello, reducir las emisiones de $\mathrm{CO}_{2}$ y gases invernadero a la atmósfera. 
La formulación y comprobación de la viabilidad de las alternativas de acción para cumplir con el objeto del proyecto es un proceso de aproximaciones donde en cada iteración se mejoran o eliminan las opciones que no cumplan con las exigencias mínimas requeridas, o se añaden nuevas alternativas. El proceso finalmente rinde un conjunto de alternativas institucional, técnica, ambiental y económicamente viables que en fase posterior deben ser evaluadas con la ayuda de un modelo multicriterio de valor que se adapte lo más fielmente a la situación específica planteada. A continuación, algunas consideraciones sobre la materia.

\subsection{Evaluación multicriterio de alternativas viables}

Una vez comprobada la viabilidad de las posibles opciones de solución al problema; la búsqueda de la mejor entre ellas, debe sustentarse en un análisis formal y sistemático de la situación que incorpore las complejidades de la misma y cuyos resultados sirvan de apoyo a la decisión que sobre su ejecución o no, deben tomar las instancias correspondientes.

A efectos de este trabajo, se entiende como la "mejor solución", aquella que proporciona el mayor bienestar a las comunidades afectadas, sujeta a las limitaciones existentes en el país sede del proyecto. A continuación, una breve descripción de los pasos que deben seguirse en esta fase de la metodología.

\subsubsection{Selección de alternativas viables a evaluar}

Como un paso preliminar y a objeto de reducir el tamaño del problema, se recomienda elaborar una matriz de descarte con ayuda de la cual se puede reducir la lista original de alternativas a un número razonablemente más pequeño, de acuerdo con los juicios expresados por un grupo reducido de expertos con amplio conocimiento y experiencia en el sector; y con ello racionalizar el tiempo y costo de la etapa del análisis.

La sección 5.1.3.3.2 del capítulo anterior muestra detalladamente la construcción de una matriz de descarte y su utilización conjuntamente con la ecuación 5.2 incluida en la misma sección, en la escogencia del grupo de alternativas viables a evaluar. Si el número de alternativas en la lista inicial no es muy elevado, los cálculos pueden 
efectuarse en forma manual; si no es así, deberá diseñarse una hoja de cálculo a los efectos.

\subsubsection{Ajuste del modelo multicriterio de valor}

La figura 4.5 en el capítulo 4 de este documento muestra la estructura jerárquica de criterios que se propone para la evaluación multicriterio de proyectos en el sector energético. La jerarquía es el producto de un detallado estudio de las características de cada uno de diecinueve tipos de recursos energéticos y de sus tecnologías de transformación en calor, electricidad, combustibles u otros productos derivados. EL capítulo 3 de este documento resume el trabajo realizado para la recuperación, clasificación, verificación en varias fuentes y consolidación de la información. El capítulo 4 de este documento detalla paso a paso el camino seguido para la validación de los criterios incluidos en el modelo y para la determinación de sus importancias relativas dentro del esquema, en base a la información recabada entre un grupo de expertos en el sector académico, privado y/o público de la nación.

El procesamiento de la información se realizó con ayuda de la herramienta informática Expert Choice ${ }^{\circledR}$; y un análisis de sensibilidad de los resultados frente a cambios en la composición de los grupos entrevistados fundamentó la propuesta final del modelo de valor multicriterio para la evaluación; la misma se presenta en las figuras 4.11 y 4.12 del capítulo 4 del este documento.

Los criterios en la estructura jerárquica planteada se distribuyen en tres niveles. En el nivel superior se ubican seis dimensiones que agrupan respectivamente los criterios técnicos, económicos, ambientales, sociales, estratégicos y de riesgo. Bajo cada dimensión se localizan entre dos y cinco de diecisiete criterios principales que conforman el segundo nivel de la estructura. Finalmente, en el nivel 3 se ubican doce criterios subalternos correspondientes a algunos de los criterios del nivel anterior.

Los criterios y los pesos globales incluidos en el modelo son producto de las opiniones que en las circunstancias presentes que vive Venezuela y el mundo, expresó una selección de expertos de experiencia variable. Por ello, cada futura aplicación del modelo en la evaluación multicriterio de proyectos en el sector 
energético debe considerar un ajuste a las condiciones específicas que predominen en el momento que se realice la evaluación; así como a las características propias del problema a resolver, a su localización geográfica, y a la disponibilidad de información confiable.

Como ha sido señalado, los ajustes contemplan la eliminación de criterios que pueden volverse redundantes o no relevantes en la evaluación de alternativas similares, la consolidación de criterios, a la inclusión de nuevos criterios; y en el caso de falta o escasez de información, a la modificación del proceso sugerido para la estimación de algunos indicadores. Con la excepción de este último tipo de ajuste, la ejecución de una o más de una, de las acciones citadas requiere el ajuste de los pesos relacionados.

Opcionalmente, el grupo de analistas puede estructurar su propio modelo de valor siguiendo un proceso similar al reseñado en los capítulos 3 y 4 de este documento y que se muestra esquemáticamente en la esquina superior izquierda de la figura 6.2 incluida anteriormente.

\subsubsection{Estimación de los indicadores para la evaluación}

En correspondencia con los criterios y subcriterios en el modelo de valor propuesto se diseñó un sistema de indicadores que agrupados en seis dimensiones de evaluación, contempla diecisiete indicadores principales y doce indicadores subaltermos. Los indicadores permiten medir respectivamente el grado de cumplimento de cada alternativa bajo estudio con relación a cada criterio en el modelo.

La descripción detallada de cada indicador en el sistema diseñado se presenta en la sección 4.1.2.4.3, capítulo 4 de este documento. Para cada indicador se presenta una ficha con el resumen de la información que a él concierne; esto es, la dimensión donde se ubica, el objetivo o dirección de mejora del atributo al cual se asocia y su criterio asociado; su definición, sus unidades originales, las fuentes de información para su cálculo y su escala de medición. 
Los índices definidos son de naturaleza cuantitativa o cualitativa; en uno u otro caso, el valor de cada indicador se ubica o se convierte a una escala [1-5] donde el 1 corresponde a la peor calificación y el 5 a la calificación máxima. En el caso de que el indicador sea cualitativo, cada paso en la escala corresponde a la condición señalada a su lado en la respectiva ficha resumen. Si el indicador es cuantitativo, su valor en las unidades de medida originales, se convierte a la escala [1-5] utilizando una transformación lineal entre los valores mínimo y máximo que puede tomar el indicador de acuerdo a las indicaciones en la respectiva ficha resumen.

El valor que toman los indicadores de índole cuantitativa para cada opción a evaluar puede obtenerse de los estudios de viabilidad realizados en la fase previa del proceso de evaluación. La tabla 6.1 es un resumen de las fuentes de información comunes para la estimación u obtención de los indicadores cuantitativos propuestos en el modelo original.

Tabla 6.1. Fuentes de información para la estimación de los indicadores cuantitativos

\begin{tabular}{|c|c|c|}
\hline INDICADORES CUANTITATIVOS & UNIDADES & FUENTE DE INFORMACIÓN \\
\hline \multicolumn{3}{|l|}{ DIMENSIÓN TÉCNICA } \\
\hline Eficiencia térmica & UE/kWh & \multirow{2}{*}{$\begin{array}{c}\text { Informe de } \\
\text { viabilidad técnica }\end{array}$} \\
\hline Factor de capacidad & $\%$ & \\
\hline \multicolumn{3}{|l|}{ DIMENSIÓN ECONÓMICA } \\
\hline Costo nivelado & US\$/MWh & \multirow{2}{*}{$\begin{array}{c}\text { Informe de } \\
\text { viabilidad económica }\end{array}$} \\
\hline$\Delta$ Balanza de pagos & US\$/MWh & \\
\hline \multicolumn{3}{|l|}{ DIMENSIÓN AMBIENTAL } \\
\hline Emisiones de gases invernadero & $\mathrm{g} \mathrm{CO} 2 \mathrm{eq} / \mathrm{kWh}$ & \multirow{4}{*}{$\begin{array}{c}\text { Informe de } \\
\text { viabilidad ambiental }\end{array}$} \\
\hline Emisiones precursores de ozono & mg NMVOCs/kWh & \\
\hline Emisiones ácidas & $\mathrm{g}$ ácido-eq/kWh & \\
\hline Emisiones de partículas & mg PM10/kWh & \\
\hline \multicolumn{3}{|l|}{ DIMENSIÓN SOCIAL } \\
\hline Creación de empleo local & Empleos/MWh & \multirow{2}{*}{$\begin{array}{c}\text { Informe de } \\
\text { viabilidad económica }\end{array}$} \\
\hline$\Delta$ Salarios & US\$/MWh & \\
\hline \multicolumn{2}{|l|}{ INDICADORES CUALITATIVOS } & Consulta a expertos \\
\hline
\end{tabular}


En el caso de los indicadores cualitativos, su valor procede de los juicios de valor recogidos en entrevistas o encuestas a expertos en los tópicos pertinentes; 0 a distancia, de forma presencial o a través de Internet.

La justa valoración de las alternativas depende de la calidad con la cual sea efectuada esta etapa del proceso. La asignación de valores a los índices cuantitativos es un procedimiento objetivo a cargo del grupo de analistas y expertos que conforman el grupo de trabajo. El valor de cada indicador cualitativo procede de las opiniones que aportan expertos y representantes de las comunidades afectadas de acuerdo a su conocimiento del problema y a su experiencia en los tópicos consultados. De esta forma, es importante seleccionar el grupo de entrevistados cuidadosamente, entre los más capacitados profesionales y/o agentes de las comunidades afectadas.

La recolección de información debe realizarse de manera sistemática, individualmente o en grupos de opinión, en formularios diseñados al efecto que pueden ser llenados presencialmente o a distancia y enviados a través de las redes de comunicación. El formato presentado en la tabla 5.22, capítulo 5 de este documento, es un ejemplo de un instrumento de esta naturaleza. Si se efectúa un ajuste del modelo original propuesto, el sistema de indicadores debe ser modificado en consecuencia.

\subsubsection{Ordenamiento de las alternativas}

Una vez obtenido el valor de los indicadores citados en el punto anterior, éstos pueden integrarse por alternativa, en un índice o coeficiente de robustez que expresa en forma consolidada el grado de cumplimiento de cada alternativa en relación a los criterios técnicos, ambientales, económicos, sociales, estratégicos y de riesgo propuestos en el modelo de valor; y por tanto, puede utilizarse como medida de la calidad de la alternativa de inversión.

Las ecuación 5.12 en el capítulo 5 de este documento, define el coeficiente de robustez por alternativa para cada entrevistado. La ecuación 5.13 del mismo capítulo consolida en una media geométrica, los coeficientes por entrevistado para cada 
alternativa; y finalmente, el coeficiente consolidado para cada alternativa puede ser expresado en una escala [0-1] mediante la ecuación 5.14 del mismo capítulo. Todos los cálculos pueden efectuarse con ayuda de una hoja de cálculo EXCEL especialmente diseñada al efecto y muestra de la cual se incluye en el anexo 3 al final de este documento. Los coeficientes de robustez obtenidos pueden utilizarse para ordenar las alternativas de inversión bajo evaluación.

De esta forma, el producto de esta etapa es un conjunto ordenado por índice de robustez de las alternativas de inversión. Si las alternativas son excluyentes; esto es, la ejecución de una de ellas implica la no ejecución de las otras; la opción con el mayor índice de robustez será la seleccionada y su ejecución será recomendada a las instancias de decisión. Si no es así, la búsqueda de la mejor combinación posible sujeta a las limitaciones existentes en el país sede del proyecto, exige un próximo paso en el proceso. La materia se trata a continuación.

\subsection{Modelo de programación lineal}

Cuando las alternativas bajo evaluación son independientes; esto es, cuando la ejecución de una de ellas no implica lo no ejecución de las otras; y existen limitaciones en cuanto a la disponibilidad de recursos físicos y/o financieros, y otras restricciones propias del país sede del proyecto; la solución al problema se transforma de un simple ordenamiento de las opciones de inversión bajo estudio a la búsqueda de la mejor combinación posible de ellas, todo sujeto al cumplimiento de las limitantes planteadas. Si además objetivos y restricciones pueden expresarse como una función lineal de las variables críticas del proyecto, resulta muy útil utilizar los resultados obtenidos en la primera parte del proceso como insumo a un modelo de programación lineal cuya resolución permita encontrar la mejor solución al problema, tal como se indica a continuación.

\subsubsection{Planteamiento y solución del modelo}

De acuerdo a lo expuesto en la sección 1.1.1, capítulo 1 de este documento, la construcción de un modelo de programación lineal requiere el planteamiento matemático de: 
- Una función objetivo lineal a maximizar o minimizar. En el sector energético pueden utilizarse las capacidades a instalar de las opciones posibles como las variables del problema y el índice de robustez de la solución como la función a maximizar; ésta última definida como la suma de los productos de tales capacidades por sus respectivos coeficientes de robustez. Otro camino posible es minimizar el costo total de la solución. Las variables del problema deben ser respectivamente mayores o iguales a cero.

- Las restricciones del problema. En general, tales restricciones incluyen limitaciones de orden financiero y/o de naturaleza física como los potenciales desarrollables de los recursos energéticos primarios asociados a las alternativas de inversión bajo estudio. También incluyen la disponibilidad de terrenos, agua y otros servicios necesarios para una buena operación, las capacidades mínimas o máximas a desarrollar de acuerdo a las características de las tecnologías propuestas, a la aceptación o no de las comunidades afectadas, y/o a convenios o compromisos adquiridos por la nación.

Las restricciones se plantean como desigualdades entre las variables sujetas a la limitación y el valor máximo o mínimo exigido. Hace falta un buen conocimiento del problema y de su entorno para la adecuada selección de los valores límites en cada caso y el correcto planteamiento de las restricciones derivadas; de ello dependerá la calidad del resultado obtenido.

Una vez planteado el problema, una solución inicial puede obtenerse con la ayuda de la herramienta Microsoft Excel Solver. Un análisis de sensibilidad de los resultados ante cambios progresivos en las restricciones en las variables críticas del problema resulta de gran ayuda para encontrar la solución final; esto es, la combinación de las alternativas evaluadas que proporcione el mayor beneficio posible a las comunidades afectadas, sujeta a las limitantes planteadas. En general, el problema es muy sensible a tales cambios y la adecuada conducción de este proceso acercará la solución finalmente seleccionada a la realidad del país sede del proyecto; y por tanto, constituirá una mejor propuesta a las instancias con la responsabilidad de tomar la respectiva decisión. 
La lectura del caso de estudio planteado y resuelto en el capítulo anterior puede resultar de ayuda para la ilustración de la metodología combinada [AHP, programación lineal] que se sugiere.

\subsection{Resumen}

En las líneas precedentes se ha explicado cada uno de los pasos que conforman la metodología propuesta para la evaluación integral de opciones de inversión excluyentes o independientes, en el sector energético. La plataforma metodológica que guía todo el procedimiento, es una combinación del método de Jerarquías Analíticas de Saaty [2006a] y de las técnicas de programación lineal ampliamente conocidas en el campo de la investigación de operaciones.

Las figuras 6.1 incluidas al inicio de este capítulo, presentan un diagrama de flujo de la metodología que se propone. A partir de una idea, de la aprobación de su evaluación por parte de las instancias correspondientes y de la asignación de un grupo de analistas para la coordinación de tal tarea, los pasos a seguir son:

- La recuperación, clasificación, complementación y resumen de la información útil para el buen entendimiento y definición del problema.

- La definición preliminar del problema y su entorno.

- La conformación del grupo de expertos que brindarán su apoyo en las diferentes materias relacionadas con el problema y de los representantes de las comunidades afectadas que participarán en su definición y solución final.

- La identificación de los objetivos a cumplir y la formulación legal, técnica, ambiental y económica de las posibles alternativas de acción para el cumplimiento de los mismos.

- La comprobación de la viabilidad legal, técnica, ambiental y económica de cada una de las alternativas de solución planteadas. La verificación de los potenciales beneficios a la sociedad e identificación de las limitaciones existentes para su ejecución, en el país sede del proyecto.

- La selección de las alternativas viables a evaluar, utilizando para ello una matriz de descarte basada en las opiniones de los expertos en las respectivas materias. 
- El ajuste del modelo multicriterio de valor propuesto en el capítulo 4 de este documento a las características de las opciones de inversión a evaluar y de su entorno; y al volumen y calidad de la información disponible.

Alternativamente, los grupos de participantes en el proceso de evaluación pueden crear su propio modelo de valor siguiendo un procedimiento similar al detallado en el capítulo 4 de este documento y que comprende la estructuración y validación de una jerarquía de criterios para la valoración de las alternativas bajo estudio, la determinación de sus importancias relativas con apoyo en la herramienta informática Expert Choice $R_{\text {, y }}$ y el diseño y validación de un sistema de indicadores correspondiente a la jerarquía construida.

- La estimación de los valores de los indicadores respectivamente asociados a cada criterio en el modelo de valor adoptado. La información para el cálculo de los indicadores de carácter cuantitativo procede de los estudios de viabilidad o de cualquier otra fuente complementaria que se considere necesaria. El valor de los indicadores de carácter cualitativo se obtiene de los juicios de valor suministrados por expertos y los representantes de las comunidades afectadas cuidadosamente seleccionados para su participación en el proceso de evaluación.

- El procesamiento de la información, cálculo de los coeficientes de robustez y ordenamiento de las alternativas bajo estudio. Esta etapa puede apoyarse en una hoja de cálculo diseñada a los efectos.

- Si las alternativas en el conjunto ordenado son excluyentes, el paso siguiente es la selección de la opción con el mayor coeficiente de robustez como la mejor solución posible.

- Si las alternativas son independientes, el próximo paso es el planteamiento el modelo de programación lineal que corresponda, incluyendo todas las restricciones existentes para la ejecución de las respectivas alternativas, en el país sede del proyecto; y su resolución con ayuda de la función Solver-Excel, a fin de obtener una primera aproximación a la mejor combinación posible de alternativas, que cumpla con las restricciones impuestas. Un análisis de sensibilidad del resultado obtenido a cambios en las restricciones impuestas fundamentará, si es el caso, sucesivas aproximaciones a la mejor solución posible. 
- La discusión de los resultados obtenidos, la preparación de una propuesta final documentada y razonada, y su sometimiento a la consideración de las instancias con la responsabilidad de tomar la decisión sobre su ejecución o no, concluye el proceso.

La propuesta metodológica para la evaluación integral de proyectos en el sector energético arriba planteada, constituye el objetivo final del trabajo realizado. En el próximo capítulo se clasifica, resume y presenta la discusión final de los resultados obtenidos a lo largo de las etapas cumplidas. 


\section{Capítulo 7 Resultados y su discusión}

El trabajo que se presenta a lo largo de este documento tuvo que ver con la construcción de una metodología para la evaluación integral de proyectos en el sector energético. Atendiendo a la consecución de este objetivo, el trabajo se dividió en seis partes principales que se corresponden respectivamente con los capítulos en los cuales se organizó la información producida, a saber:

- Caracterización de las metodologías de análisis multicriterio

- Caracterización del sector energético

- Selección de la plataforma metodológica para el análisis

- Estructuración del modelo multicriterio de valor

- Aplicación del modelo propuesto.

- Propuesta metodológica para la evaluación

A continuación se presentan los resultados obtenidos en cada tarea y sub-tarea cumplida; así como la discusión final de los mismos vistos en el contexto del documento completo. En general, una discusión más detallada puede encontrarse al final de cada uno de los capítulos incluidos. La exposición sigue el ordenamiento del documento.

La tabla 7.1 muestra la división del trabajo realizado, las fuentes de información utilizadas y el producto obtenido en cada etapa; así como la ubicación en el documento donde se registra cada resultado obtenido. 
Tabla 7.1. División del trabajo realizado y resultados

\begin{tabular}{|c|c|c|c|}
\hline $\begin{array}{l}\text { FUENTE DE } \\
\text { INFORMACIÓN }\end{array}$ & ACTIVIDAD & PRODUCTO & $\begin{array}{l}\text { UBICACIÓN EN } \\
\text { EL DOCUMENTO }\end{array}$ \\
\hline $\begin{array}{l}\text { Bibliografía } \\
\text { especializada }\end{array}$ & $\begin{array}{c}\text { Búsqueda de información } \\
\text { sobre métodos de } \\
\text { análisis multicriterio }\end{array}$ & $\begin{array}{c}\text { Caracterización de } \\
\text { metodologías de análisis } \\
\text { multicriterio }\end{array}$ & $\begin{array}{c}\text { Tablas } 1.2 \text { y } 1.3 \\
\text { Capítulo } 1 .\end{array}$ \\
\hline $\begin{array}{l}\text { Bibliografía } \\
\text { especializada }\end{array}$ & $\begin{array}{l}\text { Búsqueda, clasificación y } \\
\text { resumen de información } \\
\text { sobre el sector energético }\end{array}$ & $\begin{array}{c}\text { Caracterización del sector } \\
\text { energético }\end{array}$ & $\begin{array}{c}\text { Tablas } 3.4 \text { y } 3.5, \\
\text { Capítulo } 3\end{array}$ \\
\hline $\begin{array}{c}\text { Tablas } 1.2 \text { y } 1.3 . \\
\text { Capítulo } 1\end{array}$ & $\begin{array}{l}\text { Selección de plataforma } \\
\text { metodológica básica } \\
\text { para el análisis }\end{array}$ & $\begin{array}{c}\text { Análisis de metodologías } \\
\quad \rightarrow \mathrm{AHP}\end{array}$ & $\begin{array}{l}\text { Sección } 4.1 .1 \\
\text { Capítulo } 4\end{array}$ \\
\hline $\begin{array}{c}\text { Tablas } 3.4 \text { y } 3.5, \\
\text { bibliografía } \\
\text { especializada, } \\
\text { ENCUESTA 1, } \\
\text { análisis } \\
\text { estadístico de } \\
\text { valores y } \\
\text { ENCUESTA } 2\end{array}$ & $\begin{array}{l}\text { Estructuración y } \\
\text { validación del modelo de } \\
\text { valor para la evaluación }\end{array}$ & $\begin{array}{c}\text { Modelo de valor para la } \\
\text { evaluación }\end{array}$ & $\begin{array}{l}\text { Sección } 4.1 .2 \\
\text { Capítulo } 4\end{array}$ \\
\hline $\begin{array}{c}\text { Bibliografía } \\
\text { especializada, } \\
\text { informes } \\
\text { internacionales y } \\
\text { nacionales, } \\
\text { tablas } 1.2 \text { y } 1.3\end{array}$ & $\begin{array}{l}\text { Aplicación del modelo } \\
\text { Caso de estudio: Crisis } \\
\text { eléctrica en Venezuela. }\end{array}$ & $\begin{array}{c}\text { Solución al caso de } \\
\text { estudio }\end{array}$ & Capítulo 5 \\
\hline $\begin{array}{l}\text { Capítulos } 1,3 \\
\quad 4 \text { y } 5\end{array}$ & $\begin{array}{l}\text { Planteamiento de la } \\
\text { propuesta metodológica } \\
\text { para la evaluación }\end{array}$ & $\begin{array}{l}\text { Propuesta metodológica } \\
\text { para la evaluación }\end{array}$ & Capítulo 6 \\
\hline
\end{tabular}

A continuación, un resumen los resultados obtenidos clasificados por actividad realizada y su discusión

\subsection{Caracterización de las metodologías MCDM}

El tema de la decisión multicriterio ha venido adquiriendo relevancia desde las últimas décadas del siglo pasado y es materia de textos, cursos, investigación y un 
número importante de publicaciones en la literatura especializada. Por su clara relación con el tema del trabajo a realizar y a efectos de revisar los avances en el área; se realizó una investigación en artículos especializados sobre el tema, publicados durante el período 2000-2011. El énfasis de la revisión se colocó en las metodologías que individualmente o combinadas podrían servir de plataforma para el análisis multicriterio de proyectos de inversión. El rasgo común de tales métodos es que buscan el ordenamiento de múltiples alternativas de acción, en base a sus respectivos rendimientos frente a múltiples criterios, conflictivos entre si y con diferente importancia para el decisor.

A objeto de organizar la búsqueda y sus resultados, los métodos se clasificaron en cinco grupos, de acuerdo a sus características sobre basamento matemático, tipo de alternativas que manejan y tipo de resultados que ofrecen, información básica necesaria para la definición del modelo que utiliza, e información insumo requerida para el procesamiento. Los grupos y los métodos de análisis incluidos respectivamente en ellos, fueron los siguientes:

- Programación multiobjetivo: programación lineal multiobjetivo

- Programación por metas

- Métodos basados en funciones de valor: función de valor multiatributo (MAVT, por sus siglas en inglés) y función de utilidad multiatributo (MAUT, por sus siglas en inglés).

- Métodos de sobrecalificación: métodos PROMETHEE y métodos ELECTRE

- Métodos basados en jerarquías analíticas y redes analíticas: proceso de jerarquías analíticas (AHP, por sus siglas en inglés) y proceso de redes analíticas (ANP, por sus siglas en inglés).

El resultado de la investigación se resume en los cuadros 1.2.1 y 1.2.2, incluidos en el capítulo 1 de este documento. Se hizo particular énfasis en las características diferenciadoras entre los métodos de análisis estudiados, así como en las ventajas y desventajas de su utilización. También se hizo referencia a los paquetes informáticos que respectivamente respaldan a estas metodologías. 
Los métodos de jerarquías y redes analíticas mostraron ser más fáciles de entender y más sencillos en su aplicación que otros métodos investigados. Adicionalmente, permiten la incorporación de criterios de evaluación de carácter cualitativo y cuantitativo, característica muy importante si se desea incorporar al análisis los juicios que en lenguaje común puedan expresar los afectados por la ejecución del proyecto. Los métodos incorporan relaciones para verificar la consistencia de los juicios emitidos por los participantes en el proceso.

Los métodos de sobrecalificación también permiten el procesamiento de información cualitativa y cuantitativa; sin embargo, la aplicación de los algoritmos que lo definen requiere de la introducción de conceptos complicados para su comprensión por el usuario común; y la asignación por consenso de valores a los parámetros relacionados, hace manipulables los resultados obtenidos. Esta condición también se presenta con los métodos basados en funciones de valor los cuales muestran ser compensatorios dependiendo del manejo que se haga de los pesos de los criterios de evaluación seleccionados.

Por su parte, los métodos de programación multiobjetivo sólo admiten variables cuantificables en el análisis, y sus resultados son sensibles al correcto planteamiento del modelo y al valor de los parámetros asignados a los niveles de satisfacción para cada objetivo. Sin embargo, pueden ser utilizados para introducir en el análisis, las limitaciones propias de cada situación particular.

Los resultados de la investigación bibliográfica realizada, clasificados y organizados de forma que pudiesen compararse las fortalezas y debilidades de cada metodología de análisis estudiada, resultaron un valioso insumo para seleccionar los métodos sobre los cuales se fundamentaría el modelo de valor para la evaluación de alternativas de inversión.

\subsection{Caracterización del sector energético}

El sector energético en el mundo agrupa las actividades y los grupos de individuos, empresas u organismos públicos relacionados con la ubicación, cuantificación, extracción o captación, mejoramiento, transporte y transformación, de los recursos energéticos existentes en el planeta; así como con la distribución y 
comercialización de sus principales productos derivados: calor, electricidad y combustibles, indispensables para el desarrollo económico de los países y el mejoramiento de la calidad de vida de sus pobladores.

Por su relación directa con el objetivo del trabajo a realizar y a fin de actualizar el conocimiento sobre las características de cada tipo de fuente energética existente, su manejo y su importancia en el sector; se realizó una investigación indispensable para proseguir con el trabajo planteado. En esta oportunidad, las fuentes bibliográficas consultadas fueron fundamentalmente textos en el área, artículos publicados en revistas especializadas y recopilados por la base de datos Science Direct e informes preparados para o por organismos gubernamentales, organizaciones internacionales y grandes empresas, generalmente disponibles a través de Internet.

La investigación se dividió en dos partes una, correspondiente a las fuentes de energía no renovable; y la otra, a las fuentes de energía renovable. A su vez, cada sección se dividió en tantas sub-secciones como tipos de recursos energéticos podían cobijarse bajo las respectivas definiciones, a saber,

- Fuentes de energía no renovable: petróleo convencional, arenas asfálticas, petróleo extrapesado y esquistos bituminosos; gas natural convencional, gas natural en arenas compactas, metano en lechos de carbón, gas de esquistos e hidratos de metano; carbón y uranio.

- Fuentes de energía renovable: potencial hidráulico, vientos y radiación solar; mareas, olas y gradiente térmico oceánico; recursos geotérmicos y biomasa.

De esta forma, un total de diecinueve tipos de recursos energéticos fueron investigados. Para cada uno de ellos, se obtuvo información sobre sus atributos más importantes, la ubicación y magnitud de sus reservas o de su potencial energético desarrollable, las tecnologías para su extracción o captación; los procesos para su transformación a potencia eléctrica, calor o combustibles; los medios y técnicas para su transporte y para la distribución de sus productos derivados; los niveles de contaminación que su explotación y uso causan en el medio ambiente, y las modernas tecnologías para la reducción de tales efectos. También se recuperó información sobre los riesgos de su explotación para el ambiente y sus poblaciones; y en casos de interés, sobre la normativa internacional existente para reducirlos. 
La información recabada fue cuidadosamente estudiada; y posteriormente, resumida en las tablas 3.4 para recursos no renovables, y en las tablas 3.5 para recursos renovables, incluidas en el capítulo 3 de este documento. En especial, se destacaron las ventajas y desventajas asociadas al uso de cada fuente energética estudiada; todo en un intento por identificar los aspectos diferenciadores más importantes que pudiesen convertirse en criterios e indicadores para la valoración integral de un proyecto en el sector energético.

En el caso de los recursos fósiles y para cada fuente identificada, se recuperó, validó, clasificó, resumió y graficó información estadística referente a la magnitud, duración estimada y distribución de sus reservas en el mundo; a sus volúmenes de producción, a su participación en el suministro mundial de energía primaria, a la tendencia en sus precios; y finalmente, a la capacidad instalada para su conversión en productos útiles al hombre.

En cuanto a los recursos renovables, se realizó un trabajo similar. Para cada fuente energética identificada, se recuperó, validó, clasificó, resumió y graficó información referente a la magnitud y ubicación de su potencial desarrollable en el mundo; a la capacidad instalada para su conversión en calor, electricidad y biocombustibles y a la participación de estos productos en el consumo mundial de energía.

El estudio del material reunido permitió tener una visión de conjunto del sector energético en el mundo y de su funcionamiento. El medio se caracteriza por la existencia de múltiples fuentes de energías y de múltiples tecnologías para su explotación, la participación de grandes intereses económicos, la desigualdad en la tenencia de las reservas energéticas convencionales y en el acceso a los productos energéticos básicos como la electricidad y los combustibles, el agotamiento a mediano plazo de tales reservas, la alta participación de energías fósiles en un elevado consumo mundial de energía y la contaminación ambiental que su uso causa; la continua investigación y aparición de nuevas tecnologías para el aprovechamiento de las energías renovables y la creciente participación de estas energías 'limpias' en el suministro de energía mundial. A continuación, una breve discusión de las particularidades encontradas; entre ellas: 
- Un consumo mundial de energía muy elevado y con una alta participación de energías fósiles, especialmente por parte de los países altamente industrializados. En efecto, para el año 2009, el suministro mundial de energía primaria alcanzó 12.150 millones de toneladas de petróleo equivalente del cual alrededor de un $81 \%$ correspondió a combustibles fósiles cuya combustión arrojó a la atmósfera unos 29,000 millones de toneladas de CO2 equivalente [IEA, 2011a]. La emisión de gases invernadero a la atmósfera contribuye al calentamiento global del planeta, problema que afecta a todos sus pobladores.

El mundo está consciente de que se debe frenar el exagerado consumo de energía fósil; sin embargo, las acciones en tal sentido no son significativas. Para el año 2035, si se logra establecer un marco de políticas de protección al ambiente que estabilice la concentración de gases invernadero en la atmósfera en 450 ppm, se estima que el suministro mundial de energía primaria será de unos 14.900 millones de toneladas de petróleo equivalente, con una participación de un $62 \%$ de combustibles fósiles. Si no es así, el suministro sobrepasará los 18.000 millones de toneladas de petróleo equivalente. con una participación cercana a un 80\% de combustibles fósiles [IEA, 2011a].

- La distribución geográfica no uniforme de las reservas de petróleo y gas. Las mayores reservas de petróleo se localizan en unos pocos países, algunos de ellos políticamente inestables. La situación crea un problema de dependencia energética de los naciones que no pueden autoabastecerse hacia las naciones que tienen capacidad de exportar sus excedentes de producción. La situación puede convertirse en un problema de seguridad energética de los países importadores, si aparecen amenazas de interrupción física en el suministro y volatilidad en los precios producto de conflictos en las zonas productoras o en las rutas regulares para la distribución. La situación para el gas natural es similar, aunque menos pronunciada.

- El agotamiento de las reservas de petróleo y gas a mediano plazo. A los niveles actuales de producción, la duración promedio de las reservas de estos combustibles se estiman en 46 y 60 años respectivamente (BP, 2011]; de forma que su agotamiento no es un problema a corto plazo. Por el contrario, la 
declinación natural de la tasa de producción de los yacimientos de petróleo una vez que sobrepasan su pico de producción máximo, si lo es; especialmente si no se efectúan cuantiosas inversiones en exploración y desarrollo de nuevos yacimientos, así como en el mantenimiento de los que ya están en funcionamiento.

- Una creciente participación de los países productores en el manejo de sus recursos energéticos. En efecto, desde el siglo pasado países como Irán, Irak y Libia en el Medio Oriente y México, Bolivia, Perú, Ecuador, Brasil y Venezuela en Latinoamérica, con grandes yacimientos de petróleo y/o gas originalmente manejados por grandes consorcios internacionales, han ido recuperando progresivamente el control de sus respectivas industrias. En Venezuela, la industria fue nacionalizada en el año 1975; y en años recientes, las empresas operando en el país han sido objeto de un proceso de expropiación de las instalaciones y proyectos en curso.

Hoy día, los países productores han constituido empresas nacionales que han asumido el manejo del negocio. Con alguna excepción, las condiciones iniciales de funcionamiento de estas empresas ha sido difícil por la falta de las tecnologías, experiencia y capitales necesarios para acometer las labores de exploración, explotación y comercialización de sus recursos. En consecuencia, la producción ha declinado y se ha debido recurrir de nuevo, aunque en condiciones más favorables, a convenios de participación con consorcios internacionales dispuestos a asumir grandes y riesgosas especialmente en las áreas de exploración, desarrollo y explotación de nuevos yacimientos.

- Un desigual acceso a la energía. Aproximadamente un 25\% de personas en el mundo no tienen acceso a la electricidad ni a los modernos combustibles necesarios para mejorar la calidad de sus vidas. Sólo en Latinoamérica, la cifra alcanza unos 31 millones de habitantes. Las poblaciones rurales o más apartadas de los países menos desarrollados deben recurrir a la quema de material orgánico para cubrir sus necesidades esenciales. En los países más pobres, sin recursos petroleros que explotar y sin los recursos financieros para importarlos, la magnitud del consumo anual de electricidad per cápita no llega a dos dígitos 
mientras en algunos de los países más ricos, la cifra supera con creces los 12.000 kWh/cápita [IEA, UNDP y UNIDO, 2010; World Bank, 2012]. Estados Unidos y China consumen la mayor cantidad de energía por país, con más de $3.400 \times 10^{9}$ kWh cada uno, durante el año 2009; consumo muy superior al de cualquier otro país en el mundo.

- El creciente desarrollo de las energías renovables. En efecto, la contribución de las energías renovables al suministro global ha venido creciendo y se continua la búsqueda de tecnologías más eficientes y rentables para su aprovechamiento.

En primer lugar, parece evidente que para preservar el clima y la calidad de vida en el planeta deben sustituirse, al menos parcialmente, los combustibles fósiles por fuentes de energía limpia cuyo uso no contribuya a incrementar la concentración de $\mathrm{CO} 2$ y otros gases invernadero en la atmósfera; y con ello, a agravar el problema del calentamiento global. La comunidad internacional se ha movido en esa dirección; y desde hace algunos años, la casi totalidad de los países del mundo han firmado acuerdos y adquirido compromisos con el objetivo final de resguardar el ambiente en el planeta.

Sin embargo, las metas sólo se han cumplido parcialmente. A pesar de que en algunos países entre los que destacan Estados Unidos, España, Alemania y otros países de la Unión Europea, China, y en Latinoamérica, Brasil y México; se han puesto en marcha desarrollos importantes para el aprovechamiento de las energías renovables. Muchas de las iniciativas tecnológicas en el área no han logrado su paso a escala comercial debido fundamentalmente a las grandes inversiones necesarias que elevan el costo del producto final a precios no competitivos con los de productos similares derivados de los combustibles fósiles.

Por otra parte, los recursos renovables están por doquier y la escala de las instalaciones para su aprovechamiento es muy flexible. Las minicentrales hidroeléctricas y pequeñas instalaciones eólicas o solares pueden contribuir a solucionar el problema de acceso a la electricidad de comunidades rurales o apartadas. 
Finalmente, cuando un país hace uso de las energías renovables está diversificando e incrementando sus fuentes energéticas; si ello se puede lograr a precios que compitan con los precios de los combustibles tradicionales, el país habrá incrementado su independencia energética. Caso patente de ello, es el programa para el desarrollo de los biocombustibles en Brasil el cual además de crear un número importante de puestos de trabajo directos e indirectos, ha impulsado un grupo de actividades económicas que han contribuido, al progreso económico y social de ese país.

- La reciente tendencia al abandono de la energía nuclear. Los eventos catastróficos ocurridos en Fukushima, Japón a mediados del año 2011 consecuencia de un terremoto de 8,5 en la escala Ritcher seguido de un tsunami, se catalogan como el segundo accidente más grave en toda la historia de la generación nuclear, después de Chernóbil, Rusia, en el año 1989. A raíz de los sucesos, organizaciones internacionales defensoras de la conservación del ambiente y las comunidades que se sienten amenazadas ante la expansión de la energía nuclear en el mundo han presionado una y otra vez ante sus respectivos gobiernos para que los programas nucleares sean definitivamente abandonados.

A un año de los acontecimientos, Alemania y Bélgica tienen plazos fijos para el cierre de sus reactores nucleares y elaboran planes que apoyen el desarrollo de las energías renovables; otros países han paralizado los planes de construcción de nuevos reactores hasta tanto no se compruebe la robustez de sus sistemas de seguridad ante eventos extremos e incluso ante ataques terroristas; Japón ha apagado la casi totalidad de sus reactores y se ha ordenado no reabrirlos si no pasan las pruebas que comprueben que pueden operar con seguridad. Estados Unidos, China, India, Rusia, México, Brasil, Argentina y otros países han seguido con sus planes y operaciones previo una revisión de sus sistemas de seguridad. En Asia y Latinoamérica, algunos países entre los que se cuenta Venezuela esgrimen su derecho a utilizar la energía nuclear con fines pacíficos y gestionan la construcción de su primer reactor nuclear.

En general, se cuestiona la validez de incrementar la capacidad de generación nuclear; e incluso, de no cerrar paulatinamente las centrales en operación, 
tomando el riesgo de daños inmensos e irreparables a los pobladores del mundo, por pequeña que sea su probabilidad de ocurrencia; en lugar de trabajar en su sustitución por energías limpias y más seguras.

- La necesidad de grandes inversiones, personal especializado y entrenado, protección al ambiente, mejoramiento de los rendimientos, políticas energéticas y marcos regulatorios adecuados. En efecto, la magnitud y variedad de los volúmenes de materiales y energía que se manejan a lo largo de toda la cadena de operaciones que van desde la ubicación y obtención del recurso energético hasta su conversión en calor, electricidad, combustibles y otros productos indispensables para el buen funcionamiento de las sociedades en el planeta, demandan:

- Grandes inversiones que exigen rendimientos proporcionales al riesgo que asumen; a veces, en desmedro del bien común. En efecto, el negocio está dominado por grandes consorcios poseedores de la tecnología requerida en cada caso. Sin su participación, tareas como la exploración, el desarrollo y explotación de nuevos yacimientos, la conversión de los recursos extraídos o captados, en todas sus modalidades; e incluso la comercialización de los productos finales obtenidos se hace casi imposible.

- Personal con conocimiento, experiencia y responsabilidad en las tareas que le corresponda desempañar sean estas manuales, de alta precisión, logística, administrativa o de gestión y dirección de los proyectos en todas sus etapas desde su concepción, evaluación, diseño y construcción; hasta y muy especialmente, el mantenimiento y la completa operación de sus instalaciones.

Fallas en la selección del personal necesario entrenado para seguir protocolos de operación estrictos en las situaciones más sensibles, ponen en riesgo la efectividad del trabajo realizado, las metas de producción, las instalaciones, el ambiente, y la salud; o en casos más graves, la vida de los trabajadores y de las comunidades cercanas.

- Estrictas medidas para la protección del ambiente y sus poblaciones. La preservación de la fauna, flora, el paisaje y la acústica del ambiente que puede 
verse comprometido durante la construcción y operación de un proyecto para el aprovechamiento de la energía, requiere la regulación y estricto control de las actividades relacionadas.

Fallas en el diseño, operación y mantenimiento de las instalaciones por falta de presupuesto; o simplemente descuido; $y / 0$ errores humanos pueden ocasionar daños importantes al ambiente y a sus habitantes. Para ilustrar la situación basta recordar el gravísimo derrame de petróleo ocurrido el año 2010 que afectó la fauna, flora y paisaje de unos $11.000 \mathrm{~km} 2$ del Golfo de México y parte de las costas sur de los Estados Unidos. En Venezuela, por fallas de mantenimiento, se produjo recientemente el colapso de un tramo de la red de tuberías que transportan crudo en el oriente del país, originando un gran derrame de hidrocarburos en los ríos que surten de agua a la región, con los consiguientes efectos sobre el ambiente y las poblaciones que lo habitan. Otros accidentes gravísimos han sido citados a lo largo del documento.

De importancia son también, los procedimientos y estrictos controles sobre la emisiones gaseosas y disposición de los efluentes sólidos y líquidos de las operaciones del sector; especialmente, de los que revisten mayor peligrosidad como los químicos de alta toxicidad que pueden contaminar las aguas superficiales y subterráneas; y los desechos radiactivos que se producen no sólo en la reacción nuclear sino en el desmantelamiento de las respectivas instalaciones una vez finalizada su vida útil.

- Políticas energéticas y marcos regulatorios adecuados. Mientras que en los países más desarrollados existen políticas energéticas con objetivos, planes y metas; y si es el caso, con incentivos bien definidos; y se cuenta con las acciones y normativa legal que las respalda; sólo existe el deseo de que así sea, en algunos de los países menos desarrollados. Esto es particularmente cierto cuando se habla del desarrollo de energías alternativas, donde con alguna excepción, las decisiones no obedecen a un estudio riguroso de la situación ni a planes previamente definidos sino a la urgencia de los requerimientos energéticos presentes que tienen los países, a oportunidades 
que se presentan y/o a la necesidad de cumplir convenios de internacionales firmados o compromisos de índole política o económica.

- El mejoramiento de los rendimientos. El incremento en el rendimiento de cualquier tarea que se emprenda se traduce en un mejor uso de los recursos disponibles. En el sector energético, la investigación dirigida a la búsqueda de más eficientes tecnologías, técnicas, y procedimientos en todas las actividades relacionadas al aprovechamiento de las fuentes de energía disponibles ha cumplido un papel muy importante; sin embargo, siempre queda un camino que recorrer. Los avances logrados, especialmente en el sector de las energías renovables han abierto el camino para lograr una reducida independencia de los combustibles fósiles; los futuros logros, poco a poco, la consolidarán.

Con la ayuda de un personal entrenado y comprometido a dar lo mejor de sí mismo, el concurso de los recursos financieros requeridos; y en la medida en que se mejoren las tecnologías y se incrementen los rendimientos no sólo en la obtención sino en el uso de los productos energéticos indispensables para una mejor calidad de vida de los pueblos, podrá optarse a cumplir con el suministro demandado con eficiencia y equidad; y con la menor destrucción posible del planeta.

Para finalizar este punto, es importante destacar que la investigación realizada sobre el sector energético permitió conformar una base de información estructurada de mucho valor en la escogencia de los criterios más adecuados para la evaluación y diferenciación de alternativas de inversión en el sector energético, objetivo principal del trabajo realizado.

\subsection{Selección de la plataforma metodológica de análisis}

La elección de un método o de una combinación de métodos como plataforma base para la evaluación multicriterio de proyectos en el sector energético debió tener en cuenta la posibilidad de que se pudiese incorporar al análisis y consolidar de forma adecuada, información que se caracteriza por ser muy variada, discreta, procedente de fuentes diversas y por tanto no homogénea en su formato; y de naturaleza cuantitativa y/o cualitativa. Y viceversa, el modelo de evaluación que se pretenda utilizar, debería adaptarse a los métodos de análisis elegidos; por tanto la 
selección de los últimos, fue el paso inicial de una secuencia de actividades a cumplir, para completar el trabajo planificado.

En base a la información contenida en las tablas 1.2 .1 y 1.2 .2 , capítulo 1 de este documento, fue preliminarmente seleccionado como plataforma base para el análisis multicriterio, el Proceso de Jerarquías Analíticas de Saaty cuya descripción detallada se presenta en la sección 1.1.5.1, del mismo capítulo.

El método requiere la construcción de una estructura jerárquica de criterios con importancias relativas diferentes, en base a la cual se evalúan y ordenan las alternativas de inversión bajo estudio. La elección de los criterios, su estructuración, sus pesos relativos y la valoración de las diferentes opciones se realiza con la participación de expertos en la materia y de los representantes de las comunidades relacionadas con el problema cuya solución se busca. El método incorpora relaciones para verificar la consistencia de los juicios emitidos por los participantes en el proceso y cuenta con el paquete informático Expert Choice $®$ para el procesamiento de la información insumo al análisis.

Los métodos de sobrecalificación ELECTRE y PROMETHEE, y el Proceso de Redes Analíticas (ANP, por sus siglas en é) también ofrecen la posibilidad de procesar información subjetiva. Sin embargo en el primer caso, su uso requiere la aplicación de algoritmos complicados y la asignación de valores a los parámetros relacionados lo que disminuye la objetividad de los resultados entregados.

Por su parte, el proceso de Redes Analíticas (ANP, por sus siglas en inglés) permite incorporar las interrelaciones entre los diferentes factores del problema; ello incrementa el alcance del análisis pero a la vez hace más complicada la interpretación de sus resultados y multiplica por muchas veces el número de los juicios de valor que deben ser recabados para el análisis del problema. La captación y control de la consistencia de tal información requiere un esfuerzo adicional importante en horas-hombre; de esta forma y a criterio del autor, la aplicación del método sólo se justifica si el número de factores a incluir en el análisis no es elevado. 
Así las cosas y para añadir otro tipo de argumentación a la preselección, se realizó una segunda investigación sobre la tendencia de uso de los métodos citados. La búsqueda se realizó en la base de datos Science Direct y se restringió al sector de planificación energética. Específicamente, se contabilizó el número de publicaciones anuales para cada método de análisis multicriterio durante el período 2000-2010, referentes a la evaluación de proyectos y planes relacionados con energías renovables, energía nuclear, gas natural, energía eléctrica, desarrollo sostenible, manejo de residuos, impacto ambiental, localización de recursos, gestión de proyectos, entre otras.

Los resultados obtenidos se detallan en la tabla 4.2 del capítulo 4 de este documento; y confirmaron la amplia preferencia de los usuarios por el Proceso de Jerarquías Analíticas de Saaty como herramienta para el análisis multicriterio de problemas en el sector energético. En efecto, de un total de 1.713 trabajos publicados a partir el año 2000 y hasta inicios del año 2011, más de un 52\% correspondió a aplicaciones del AHP. La cifra se eleva a un 56\% si se refiere sólo al año 2010.

Las consideraciones anteriores fundamentaron la selección del AHP como la plataforma de análisis multicriterio en base a la cual se estructuraría el modelo de valor para la evaluación de proyectos en el sector energético, objetivo principal de este trabajo. Como herramienta de apoyo al análisis, el método puede ser combinado con otros métodos de análisis como las técnicas de programación lineal, si la solución del problema así lo requiere.

\subsection{Estructuración del modelo de valor}

La construcción del modelo para la valoración multicriterio de alternativas de inversión en el sector energético es el objetivo central del trabajo de investigación que presenta este documento; el mismo se realizó en las siguientes etapas:

- Selección y validación de los criterios para la evaluación

- Definición de los indicadores y de las escalas para su medición

- Determinación de los pesos de los criterios y validación del modelo

- Análisis de sensibilidad y propuesta final 
La tabla 7.2 que se incluye a continuación, presenta la secuencia de actividades que se cumplieron hasta lograr el objetivo final, los resultados parciales obtenidos, su ubicación en el documento y las fuentes de información utilizadas en cada caso.

Tabla 7.2. Estructuración del modelo de valor: actividades y resultados

\begin{tabular}{|c|c|c|c|}
\hline $\begin{array}{l}\text { FUENTE DE } \\
\text { INFORMACIÓN }\end{array}$ & ACTIVIDAD & PRODUCTO & $\begin{array}{l}\text { UBICACIÓN EN } \\
\text { EL DOCUMENTO }\end{array}$ \\
\hline $\begin{array}{l}\text { Tablas } 3.4 \text { y } 3.5 \\
\text { Capítulo } 3\end{array}$ & $\begin{array}{l}\text { Selección de aspectos } \\
\text { diferenciadores }\end{array}$ & $\begin{array}{l}76 \text { aspectos } \\
\text { diferenciadores } \\
\text { identificados }\end{array}$ & Anexo 1.1 \\
\hline $\begin{array}{c}\text { Bibliografía } \\
\text { especializada }\end{array}$ & $\begin{array}{l}\text { Tipificación de los } \\
\text { principales problemas y } \\
\text { necesidades en el sector }\end{array}$ & $\begin{array}{l}\text { Jerarquía analítica } \\
\text { preliminar con } 59 \\
\text { criterios }\end{array}$ & Anexo 1.2 \\
\hline \multirow{3}{*}{$\begin{array}{c}\text { Bibliografía } \\
\text { especializada, } \\
\text { consulta expertos } \\
\text { ENCUESTA } 1\end{array}$} & $\begin{array}{l}\text { Validación preliminar de } \\
\text { criterios }\end{array}$ & $\begin{array}{c}\text { Reducción a } 44 \\
\text { aspectos principales }\end{array}$ & $\begin{array}{l}\text { Tabla 4.3, } \\
\text { Capítulo } 4\end{array}$ \\
\hline & $\begin{array}{l}\text { Análisis estadístico y } \\
\text { consolidación información }\end{array}$ & $\begin{array}{c}\text { Reducción a } 24 \\
\text { aspectos principales }\end{array}$ & $\begin{array}{c}\text { Tabla } 4.5 \text { a } 4.7, \\
\text { Figura } 4.4, \\
\text { Capítulo } 4\end{array}$ \\
\hline & Estructuración de criterios & $\begin{array}{c}\text { Estructura jerárquica de } \\
\text { criterios } \sqrt{ }\end{array}$ & $\begin{array}{l}\text { Figura } 4.5 \\
\text { Capítulo } 4\end{array}$ \\
\hline \multirow{2}{*}{$\begin{array}{l}\text { Bibliografía } \\
\text { especializada, } \\
\text { consulta a } \\
\text { expertos }\end{array}$} & \multirow{2}{*}{$\begin{array}{c}\text { Definición de indicadores } \\
\text { y sus escalas }\end{array}$} & Fichas de indicadores & $\begin{array}{l}\text { Secc. } 4.1 .2 .4 .3 \\
\text { Capítulo } 4\end{array}$ \\
\hline & & $\begin{array}{c}\text { Sistema de indicadores } \\
\sqrt{ }\end{array}$ & $\begin{array}{c}\text { Tablas } 4.10, \\
\text { Capítulo } 4\end{array}$ \\
\hline \multirow{2}{*}{ ENCUESTA 2} & $\begin{array}{c}\text { Validación final de } \\
\text { criterios, indicadores y } \\
\text { determinación de pesos }\end{array}$ & $\begin{array}{c}\text { Modelo de valor para } \\
\text { la evaluación } \sqrt{ }\end{array}$ & $\begin{array}{c}\text { Figuras } 4.11, \\
4.12 \text {, Tabla } \\
4.13, \text { Capítulo } 4\end{array}$ \\
\hline & $\begin{array}{l}\text { Análisis de sensibilidad y } \\
\text { propuesta final }\end{array}$ & $\begin{array}{c}\text { Modelo final para la } \\
\text { evaluación } \sqrt{ }\end{array}$ & $\begin{array}{l}\text { Figura 4.12, } \\
\text { Sección 4.1.2.6, } \\
\text { Capítulo } 4\end{array}$ \\
\hline
\end{tabular}

Cada grupo de actividades señalado en la segunda columna de la tabla, se cumplió el número de veces que fue necesario para lograr los resultados citados en la tercera columna. Cada resultado parcial es información insumo a la obtención del 
próximo resultado en la lista. Los resultados marcados con la señal $\sqrt{ }$, constituyen respectivamente el producto final de las etapas listadas anteriormente como componentes de esta fase. A continuación se presenta la discusión de los resultados obtenidos.

\subsubsection{Criterios para la evaluación}

La revisión de las tablas 3.4 y 3.5 en el capítulo 3 de este documento, permitió la identificación inicial de 76 aspectos técnicos, económicos, ambientales, sociales, estratégicos y de riesgo, en base a los cuales se podrían diferenciar las tecnologías de aprovechamiento de una u otra fuente energética; o los efectos de su aplicación. La consulta informal con expertos en las diferentes áreas, la revisión bibliográfica y varios intentos de clasificación de la información disponible, redujeron la lista a 59 atributos diferenciadores que se asociaron al mismo número de criterios; y estos su vez, a siete objetivos en una primera estructura jerárquica que sirvió de base para una encuesta indagatoria sobre la validez de los criterios seleccionados. Los objetivos se plantearon de forma que respondieran a los principales problemas y necesidades previamente tipificados en el sector; ellos fueron:

- Maximizar seguridad energética

- Maximizar apoyo gubernamental

- Minimizar impacto ambiental

- Minimizar el riesgo para la población y el proyecto

- Maximizar bienestar de la comunidad

- Maximizar conveniencia técnica

- Maximizar conveniencia económica

Las entrevistas se realizaron a 53 personas pertenecientes a la Universidad Metropolitana, Caracas, Venezuela. Diez personas fueron entrevistadas individualmente y el resto se organizó en tres grupos de discusión; dos de ellos conformados por estudiantes del último año de Ingeniería relacionados con el tema de estudio; y el tercero, por académicos. Previa la exposición del problema y su discusión, se solicitó contestar la pregunta ¿Cuán pertinente es el criterio sometido a validación para medir el cumplimiento del objetivo al cual está asociado, y cuál su 
importancia? Se solicitó que la respuesta se expresase en una escala del 1 al 5, donde 5 correspondía a la mayor importancia.

La encuesta cumplió su objetivo; en efecto, el análisis de sus resultados mostró que la jerarquía propuesta era muy compleja. En consecuencia y a objeto de simplificar todo el sistema, algunos de los criterios incluidos se eliminaron $\mathrm{y} / \mathrm{o}$ consolidaron; otros, calificados como relevantes en las entrevistas y no incluidos previamente fueron incorporados; y todo el conjunto se reorganizó en seis dimensiones: técnica, económica, ambiental, social, estratégica y riesgo.

Una revisión preliminar de la información redujo la lista a a 44 criterios. Entre ellos, los primeros criterios fueron eliminados en base al análisis estadístico de las medias de los juicios recabados sobre la validez de cada criterio, expresado en una escala [1-5] por cada uno de los entrevistados; sus varianzas y los coeficientes de variación de cada criterio por grupo, de cada criterio para todos los grupos y de todos los criterios en la dimensión.

La eliminación de los criterios cuyas medias resultaron respectivamente inferiores a la media de la dimensión correspondiente, redujo el grupo a treinta y seis criterios; el resto de trató como se indica a continuación.

- Se consideró conveniente asignar a cada dimensión entre dos y cuatro criterios, a menos que otras consideraciones aconsejasen lo contrario.

- Los aspectos limitantes para la ejecución del proyecto no son negociables; y por tanto, se eliminaron de la estructura jerárquica a proponer y su consideración se transfiere a estudios de viabilidad previos.

- Los criterios afines, interdependientes o derivados se consolidaron en un único criterio o se incluyeron en el criterio con la preferencia más alta.

- Se consideró conveniente eliminar algún criterio cuya aplicación requiriese información de difícil acceso.

- Se incorporaron criterios no considerados originalmente cuya presencia en la jerarquía resultaba importante para los expertos en el área. Específicamente se incorporaron algunos subcriterios en la dimensión ambiental y en la dimensión estratégica. 
El proceso permitió la reducción de aproximadamente un $50 \%$ del número de atributos/criterios de la lista modificada que pasó de contener 44 aspectos principales a una jerarquía con 17 criterios principales y 12 criterios subordinados; e incrementó la calidad de los criterios en su conjunto, en cuanto a su simplicidad, facilidad de medición, independencia y cualidades diferenciadoras para la evaluación. El detalle de las actividades realizadas se encuentra en las secciones 4.1.2.2.2 y 4.1.2.2.3, capítulo 4 de este documento; y los resultados obtenidos en las tablas 4.3 a 4.7 y en las figuras 4.4 y 4.5 del mismo capítulo.

\subsubsection{Indicadores para la evaluación y sus escalas}

La próxima etapa del trabajo consistió en la definición de los indicadores y de las respectivas escalas que permitirían medir el potencial desempeño de cada alternativa a evaluar, con relación a cada criterio incluido en la estructura jerárquica construida en la etapa anterior.

A modo de contrastar las ideas surgidas de la reflexión del autor y de alguna consulta efectuada especialmente en el campo ambiental ${ }^{86}$, se realizó una investigación bibliográfica dirigida a la revisión detallada de sistemas de indicadores para la evaluación de planes, programas y proyectos de desarrollo de los países. Los resultados obtenidos de 20 publicaciones en el área durante la última década, se recogen en la tabla 4.8 , capítulo 4 de este documento.

En la información recabada destacó el tema de la energía relacionada con el desarrollo sostenible En tal sentido, es notable el esfuerzo conjunto realizado por la Agencia Internacional de Energía Atómica, el Departamento de Asuntos Económicos y Sociales de las Naciones Unidas, la Agencia Internacional de Energía, la Oficina Europea de Estadística y la Agencia Europea para el Ambiente para desarrolla un sistema de 30 indicadores capaz de suministrar información de apoyo para la evaluación de la sostenibilidad de programas y planes de desarrollo en el sector

86 Jefe del Instituto de Recursos Naturales Renovables, Universidad Simón Bolívar, Venezuela 
energético. El sistema se ha implementado con éxito en algunos países en vías de crecimiento.

Por otra parte, el tema de la sostenibilidad de planes o alternativas de inversión, en uno o más subsectores del sector energético o para un determinado país, fue objeto de gran parte de las publicaciones académicas revisadas. En ellas, una vez demostrada la viabilidad técnica de la alternativa bajo estudio, su sostenibilidad se define como la convergencia de requisitos mínimos en los ámbitos económico, social y ambiental; y en tal sentido, se plantean sistemas de indicadores particulares que midan el cumplimiento de tales requisitos. Las propuestas presentaron una gran variabilidad en contenido y número de indicadores; sin embargo en ninguno de los casos referenciados, el problema de la evaluación de proyectos se trata de forma integral.

En base a todas las consideraciones anteriores y en un todo de acuerdo con la estructura jerárquica de criterios obtenida, se diseñó un sistema de 24 indicadores como instrumentos para estimar el grado de cumplimiento de los objetivos planteados por parte de alternativas de inversión en el sector energético. Se definieron indicadores de índole cuantitativa y cualitativa atendiendo al origen de la información para su estimación; doce de ellos, correspondieron a criterios en el segundo nivel del modelo; y doce, a criterios en el tercer nivel. Para cada indicador se diseñó una escala de medición [1-5] en función de los valores extremos que podía tomar el indicador, si éste era de índole cuantitativa; o de su intensidad, si éste era de índole cualitativa.

En la sección 4.1.2.4.3, capítulo 4 de este documento se presenta la descripción detallada de cada indicador propuesto así como una ficha resumen que contiene: el nombre del indicador y su identificación y ubicación dentro del modelo de evaluación propuesto; su objetivo asociado, una breve definición, las posibles fuentes de información para la obtención de su valor, sus unidades de medida y su escala de medición. Por su parte, las tablas 4.10 .1 a 4.10 .3 en el capítulo 4 de este documento, resumen el sistema de indicadores diseñados.

Todo el proceso de diseño de indicadores interactuó con la estructuración del modelo de valor para la evaluación; esto es, la definición de algunos indicadores UNIVERSIDAD POLITÉCNICA DE VALENCIA. TESIS DOCTORAL. Violeta Parodi 
requirió la adaptación de los criterios respectivos y viceversa, a fin de lograr un modelo de valor consistente en todas sus partes, sencillo de aplicar y que cumpliese con el objetivo final de facilitar la correcta evaluación de alternativas o proyectos de inversión en el sector energético.

\subsubsection{Pesos de los criterios y validación final}

La última etapa a cumplir para la completa definición del modelo de valor buscado fue la determinación de las importancias relativas de los diferentes atributos incluidos en su paulatina estructuración; y la validación final de todo el conjunto de los criterios, los pesos y los indicadores respectivamente asociados.

La información necesaria para el cumplimiento de las actividades antes señaladas, fue recabada en una segunda ronda de entrevistas. La muestra entrevistada fue dividida en la forma siguiente;

- Un grupo de expertos cuidadosamente elegidos, con conocimiento y amplia experiencia en sus respectivas materias que incluyeron energía, ambiente, planificación, finanzas y economía, innovación y emprendimiento; además de formulación, evaluación, y ejecución de proyectos.

- Un grupo de profesionales jóvenes con postgrado y experiencia en sus labores superior a diez años, con una visión y disponibilidad de herramientas modernas en el manejo de proyectos.

- Dos grupos de estudiantes del último año de la carrera de Ingeniería en la Universidad Metropolitana, Caracas, Venezuela.

El grupo de entrevistados totalizó 66 personas, pertenecientes a los sectores público, privado y/o académico de Venezuela y de otros países como Estados Unidos, Panamá, Bélgica y España. La recolección de la información se realizó mediante la interacción con los participantes en entrevistas personales y con dos grupos de opinión, la comunicación telefónica e Internet. El diseño de la muestra y la composición de los grupos de profesionales entrevistados se presentan las tablas 4.11 a 4.13 , capítulo 4 de este documento. 
Utilizando la escala de Saaty, los participantes vertieron su opinión sobre la importancia relativa de los criterios en el modelo bajo consideración, en matrices de juicio reunidas en un formulario diseñado al efecto que se presenta en el anexo 2 de este documento. La información recogida fue revisada, eventualmente completada, y

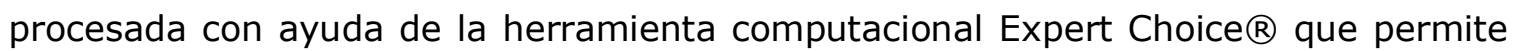
la participación de múltiples actores en el proceso, consolida los resultados y calcula los índices de consistencia a nivel individual y de grupo.

La información fue consolidada por tipo de encuestados y para todo el grupo; y su consistencia controlada a nivel individual y de grupo. La figura 4.11 , capítulo 4 de este documento, muestra la pantalla suministrada por el Expert Choice $₫$ con los resultados obtenidos cuando se consolidaron las opiniones de todo el grupo. La tabla 4.14 del mismo capítulo, lista los pesos locales y globales de los criterios del modelo para diferentes formas de agrupar la información; y el anexo 2 al final del documento, las pantallas respectivamente suministradas por el Expert Choice ${ }^{\circledR}$, en cada caso.

Adicionalmente, a cada entrevistado en los grupos 1 y 2, se le solicitó opinión sobre la calidad del modelo. En general, las opiniones sobre la relevancia, alcance, no redundancia de criterios, simplicidad de uso y/o posibilidad de medición objetiva o subjetiva de los criterios/indicadores en él incluidos, fueron favorables; sin embargo, hubo sugerencias sobre la nomenclatura de algunos de los criterios ambientales, las cuales luego de las consultas de rigor, fueron incorporadas al modelo.

\subsubsection{Análisis de sensibilidad y propuesta final}

Un estudio de sensibilidad mostró la variación los pesos globales de los criterios como consecuencia de diversas formas de consolidar la información para su procesamiento. El análisis mostró, entre otras cosas, que la diferencia entre los resultados obtenidos para el grupo de profesionales y para el grupo de estudiantes, era menor a un $4 \%$ del total, en 22 de los 24 criterios finales incluidos en el modelo. De esta forma, se seleccionó como propuesta final del modelo de valor para la evaluación de proyectos en el sector energético, la resultante de la consolidación de las opiniones de todos los entrevistados. La correspondiente estructura jerárquica de 
criterios y sus respectivos pesos está reflejada en las figuras 4.11 y 4.12 , sección de este documento.

En el modelo propuesto, la mayor importancia $(24,3 \%)$ correspondió a la dimensión riesgo reflejando sin duda el temor a potenciales daños causados por falla de las instalaciones, especialmente si ellas manejan material radioactivo. Lo siguen en importancia las dimensiones ambiental (20,5\%) y económica $(15,3 \%)$ lo que constituye un resultado esperado dada la relevancia que ha adquirido el tema de impacto ambiental; y la que siempre ha tenido el rendimiento económico de las alternativas para su selección. Por su parte, las dimensiones técnica $(13,7 \%)$, estratégica $(13,5 \%)$ y social $(12,2 \%)$ tienen importancias relativas semejantes, siendo ligeramente inferior la correspondiente a los aspectos sociales.

Los pesos globales obtenidos son producto de las opiniones que sobre cada materia expresaron una selección de expertos, sin duda influenciados por las circunstancias presentes que vive Venezuela y el mundo. En consecuencia, su potencial aplicación en la evaluación multicriterio de proyectos en el sector energético debe considerar un ajuste previo del modelo de acuerdo a las condiciones específicas del problema a resolver, su localización geográfica y a las circunstancias del momento.

Para finalizar es conveniente añadir que el modelo propuesto permite valorar alternativas de inversión en el sector energético y ordenarlas de acuerdo a su menor o mayor conveniencia. Sin embargo, si se desea elaborar y evaluar planes donde puedan participar más de un tipo de proyecto, es necesario maximizar o minimizar la función que se considere pertinente, expresada como una combinación de las respectivas participaciones; e incorporar al problema las limitaciones que pueda haber para su ejecución. Si la función a optimizar es lineal; se sugiere utilizar las técnicas de programación lineal explicadas en la sección 1.1.1.1, capítulo 1 de este documento.

\subsection{Aplicación del modelo de valor propuesto}

A fin de probar su aplicabilidad, el modelo de valor propuesto se utilizó en la solución a un caso de estudio: la crisis eléctrica que vive Venezuela desde hace unos 
tres años y que tuvo su máxima expresión en el año 2010 cuando a las repetidas fallas en los equipos de generación se sumó una sequia que afectó los niveles del embase del Guri que surte al principal complejo hidroeléctrico del país.

El capítulo 5 de este documento explica detalladamente la obtención de una posible solución al caso en cuestión. El procedimiento seguido se dividió en tres partes principales, a saber

- Definición del problema y su entorno

- Búsqueda de una solución al problema

- Análisis de sensibilidad y propuesta final

La resolución del caso de estudio citado permitió además ilustrar la posibilidad de aplicar con éxito la combinación de dos métodos de análisis completamente diferentes en su fundamentación y en el tipo de problemas a cuya solución se aplican, a fin de aprovechar las potencialidades de cada uno. Por considerar este punto de importancia, se incluye a continuación la discusión de los resultados obtenidos en cada etapa anteriormente listada.

\subsubsection{Definición del caso de estudio y su entorno}

Venezuela es un país con un considerable potencial energético. En efecto, posee las reservas de petróleo más grandes del mundo, reservas de gas y carbón; yacimientos de uranio; un importante potencial hidroeléctrico; y en zonas seleccionadas del territorio, la posibilidad de aprovechar los vientos, la radiación solar, la energía geotérmica y las mareas que son característicos de cada región.

El potencial energético no renovable total se estima en 36,2 mil millones de toneladas de petróleo equivalente mientras que el potencial energético renovable se ubica en 9 millones de barriles de petróleo/día. Las tablas 5.1 y 5.2 muestran respectivamente la distribución de tales potenciales; y las figuras 5.1 a 5.4 muestran la ubicación geográfica de los mismos.

La industria de petróleo, gas, carbón y energía eléctrica están nacionalizadas. Las actividades de explotación, transformación, distribución y comercialización de petróleo y gas son manejadas por la empresa Petróleos de Venezuela, PDVSA; el 
carbón es extraído por empresas estatales filiales de CORPOZULIA, y recientemente fue creada La Corporación Eléctrica Nacional, CORPOELEC que está a cargo de la generación, transmisión y distribución y comercialización de la energía eléctrica. En el país no hay explotación registrada de uranio.

A pesar del elevado potencial de energías renovables, Venezuela sólo ha incursionado modestamente en el aprovechamiento de las energías renovables, exclusión hecha de los grandes desarrollos hidroeléctricos al sur del país, los cuales para el año 2010 suplían alrededor de un 66\% de la electricidad consumida por el país.

La falta de inversiones oportunas para la ampliación, mejoramiento y mantenimiento de las instalaciones existentes en el sector petrolero, el agotamiento natural de los yacimientos, la excesiva politización en sus actividades, la expropiación de proyectos y operaciones de grandes consorcios internacionales y la poca eficacia en el cumplimiento de las metas, ha afectado notablemente la eficiencia en los resultados del sector de petróleo y gas en el país.

El deterioro en el sector petróleo y gas se ha manifestado en (i) la disminución de la producción petrolera en aproximadamente $1 \times 10^{6}$ barriles/día, si se compara con la producción de finales del año 1998, (ii) la disminución de la producción de gas natural asociado y las importaciones a las que se ha visto forzado el país para suplir su consumo interno y (iii) la disminución de la holgura de la capacidad de refinación con relación a la demanda de productos derivados como la gasolina y el diesel.

En consecuencia, la vulnerabilidad del país se ha visto afectada en cuanto a los ingresos por venta de excedentes petroleros, su principal fuente de sustento. La situación se agrava por la serie de envíos de petróleo que el país debe efectuar a precios y condiciones de pago preferenciales, a algunos países latinoamericanos y del Caribe; y por los compromisos de envío de parte de su producción a China, a precios muy bajos como parte de pago de créditos recibidos por el país.

\subsubsection{Crisis eléctrica venezolana}

Paralelamente, desde mediados del año 2008 se ha venido desarrollando una minusvalía en el suministro eléctrico al país, consecuencia de nuevo del considerable 
retraso en la ejecución de proyectos que soportasen el incremento de la demanda, la falta de inversiones y del mantenimiento adecuado de las instalaciones para la generación y transmisión de la energía eléctrica, la politización de las actividades , la desprofesionalización del sector, la falta de planificación para poder manejar adecuadamente los recursos hídricos disponibles, y la improvisación en la toma de decisiones. La situación se agravó en el año 2010 cuando:

- Se produjo una sequía por varios meses y el nivel del embalse de Guri, la planta hidroeléctrica más grande del país, se acercó peligrosamente a la cota crítica.

- Las plantas termoeléctricas no pudieron incrementar su suministro, debido a la falta de mantenimiento y obsolescencia de algunos de sus equipos instalados hace más de dos décadas.

- La producción de gas se hizo deficitaria frente a las necesidades del país; en consecuencia, muchas de las plantas termoeléctricas que operaban regularmente con gas, debieron operarse con fueloil o diesel, elevándose los costos de mantenimiento.

- A pesar de la instalación de un grupo de plantas termoeléctricas de baja capacidad que funcionan con diesel, la operatividad de las incorporaciones fue sólo del $73 \%$. Las grandes empresas debieron instalar plantas termoeléctricas a diesel para garantizar la continuidad de sus operaciones

- El consumo de diesel se acercó a la máxima capacidad de producción en las refinerías del país. El exceso de diesel consumido se dejó de exportar con la consiguiente baja en los ingresos de la nación y una menor disponibilidad de los fondos necesarios para la adecuación y expansión del sistema eléctrico.

- La falta de agua en Guri y de disponibilidad de una fracción importante de equipos en la planta hidroeléctrica y térmica del país fueron causantes de apagones en todo el territorio nacional y se racionó el suministro eléctrico.

A pesar de las inversiones realizadas por el gobierno nacional para ampliar la capacidad de generación eléctrica del país, aún no se soluciona la situación y continúan los apagones aunque con menor frecuencia. La definición detallada del problema y de su entorno se expone en las secciones 5.1.1 a 5.1.3 de este 
documento. A continuación, algunos comentarios sobre los resultados de la utilización del modelo de valor propuesto en la evaluación de posibles planes de solución al problema.

\subsubsection{Búsqueda de una solución al problema}

Claramente, la solución del problema no ha estado en la toma de medidas puntuales aunque las mismas hagan falta ante la emergencia. Es necesario formular planes y programas que tomen en cuenta la demanda futura de electricidad frente a los recursos energéticos que posee la nación, las mejores tecnologías para su aprovechamiento, las inversiones necesarias para su instalación y operación, el impacto ambiental y social que ello pueda causar y los potenciales riesgos para la población, la capacitación de personal si ello es necesario, las características políticas, sociales y económicas del país; y los compromisos internacionales por él adquiridos, entre otras cosas.

La formulación y ejecución de planes a mediano y largo plazo para ampliar la capacidad de generación eléctrica Venezuela y estabilizar la situación en el sector, requiere como paso previo del diseño de una matriz eléctrica para el país, definida ésta como la mejor combinación de uso de los recursos energéticos que posee la nación para la generación. Con este objetivo en mente, y dada la característica multifactorial del problema, se utilizó una combinación de métodos multicriterio para ilustrar la aplicabilidad del modelo de valor propuesto. Se seleccionó el año 2025 como horizonte de estudio y todo el proceso se dividió en las actividades que se listan a continuación,

- Proyección de la capacidad eléctrica a instalar para el período 2011-2025

- Selección de las opciones de generación eléctrica a evaluar

- Aplicación del modelo de valor a la evaluación de las alternativas seleccionadas

- Ordenamiento de las alternativas y análisis parcial de resultados

- Aplicación de técnicas de programación lineal

- Análisis de resultados y propuesta final

La tabla 7.3 que se presenta en la próxima página muestra la secuencia de las actividades realizadas. 
Tabla 7.3. Búsqueda de una solución al problema

\begin{tabular}{|c|c|c|c|}
\hline $\begin{array}{l}\text { FUENTE DE } \\
\text { INFORMACIÓN Y/O } \\
\text { HERRAMIENTA }\end{array}$ & ACTIVIDAD & RESULTADO & $\begin{array}{l}\text { UBICACIÓN EN } \\
\text { EL DOCUMENTO }\end{array}$ \\
\hline $\begin{array}{c}\text { Estadísticas } \\
\text { nacionales e } \\
\text { internacionales }\end{array}$ & $\begin{array}{l}\text { Proyección de la demanda } \\
\text { eléctrica para tres } \\
\text { escenarios, 2011-2015 }\end{array}$ & $\begin{array}{c}\text { Proyección de la } \\
\text { capacidad eléctrica a } \\
\text { instalar, } 2011-2015 \\
\sqrt{ }\end{array}$ & $\begin{array}{l}\text { Tablas } 5.5 \text { y } \\
\text { Figura } 5.13 \\
\text { S.5.1.3.3.1.4, } \\
\text { Capítulo } 5\end{array}$ \\
\hline $\begin{array}{l}\text { Bibliografía } \\
\text { especializada, } \\
\text { Secciones } 5.1 .1 \\
\text { y } 5.1 .2, \text { Cap.5 }\end{array}$ & \multirow{3}{*}{$\begin{array}{l}\text { Selección de las opciones } \\
\text { de generación a evaluar }\end{array}$} & Alternativas posibles & $\begin{array}{l}\text { Figura } 5.16, \\
\text { Capítulo } 5\end{array}$ \\
\hline \multirow{2}{*}{$\begin{array}{l}\text { Consulta a } \\
\text { expertos }\end{array}$} & & Matriz de descarte & $\begin{array}{l}\text { Tabla 5.7, } \\
\text { Capítulo } 5\end{array}$ \\
\hline & & $\begin{array}{l}\text { Alternativas a evaluar } \\
\qquad \sqrt{ }\end{array}$ & $\begin{array}{l}\text { Tabla 5.8, } \\
\text { Capítulo } 5\end{array}$ \\
\hline $\begin{array}{c}\text { Consulta a expertos, } \\
\text { modelo de valor, } \\
\text { EXPERT CHOICE } ®\end{array}$ & Ajuste del modelo & $\begin{array}{c}\text { Modelo ajustado } \\
\sqrt{ }\end{array}$ & $\begin{array}{l}\text { Figuras } 5.16 \text { y } \\
5.17, \text { sección } \\
5.1 .3 .3 .3 .3 \\
\text { Capítulo } 5\end{array}$ \\
\hline $\begin{array}{l}\text { Organismos } \\
\text { internacionales, } \\
\text { bibliografía } \\
\text { especializada }\end{array}$ & $\begin{array}{c}\text { Estimación del valor de } \\
\text { los indicadores de índole } \\
\text { cuantitativa, por } \\
\text { alternativa }\end{array}$ & \multirow{2}{*}{$\begin{array}{l}\text { Valor de los } \\
\text { indicadores, por } \\
\text { entrevistado }\end{array}$} & $\begin{array}{l}\text { Tablas } 5.11 \text { a } \\
5.20, \text { sección } \\
5.1 .3 .3 .3 .4 \\
\text { Capítulo } 5\end{array}$ \\
\hline ENCUESTA 3 & $\begin{array}{l}\text { Obtención del valor de los } \\
\text { indicadores de índole } \\
\text { cualitativa, por } \\
\text { entrevistado }\end{array}$ & & $\begin{array}{l}\text { Tabla } 5.22 \text { y } \\
\text { anexo } 3.1\end{array}$ \\
\hline \multirow{2}{*}{$\begin{array}{c}\text { Modelo de valor } \\
\text { ajustado, encuesta } \\
\text { 3, hoja de cálculo } \\
\text { EXCEL }\end{array}$} & \multirow{2}{*}{$\begin{array}{l}\text { Ordenamiento de las } \\
\text { alternativas y análisis } \\
\text { parcial de resultados }\end{array}$} & $\begin{array}{l}\text { Coeficientes de } \\
\text { robustez }\end{array}$ & \multirow{2}{*}{$\begin{array}{l}\text { Tablas } \\
5.23 \text { y } 5.24 \\
\text { Capítulo } 5\end{array}$} \\
\hline & & $\begin{array}{l}\text { Conjunto ordenado de } \\
\text { alternativas } \sqrt{ }\end{array}$ & \\
\hline $\begin{array}{l}\text { Limitaciones al } \\
\text { modelo }\end{array}$ & $\begin{array}{c}\text { Planteamiento y solución } \\
\text { de modelo de } \\
\text { programación lineal }\end{array}$ & $\begin{array}{l}\text { Primera aproximación } \\
\text { a la solución } \sqrt{ }\end{array}$ & $\begin{array}{l}\text { Tabla } 5.31 \text { y } \\
\text { figura } 5.19, \\
\text { Capítulo } 5\end{array}$ \\
\hline $\begin{array}{l}\text { Análisis de } \\
\text { resultados }\end{array}$ & $\begin{array}{l}\text { Aproximación a la } \\
\text { solución final }\end{array}$ & $\begin{array}{c}\text { Propuesta de matriz } \\
\text { eléctrica 2013-2035, } \\
\text { Venezuela } \sqrt{ }\end{array}$ & $\begin{array}{c}\text { Tablas } 5.38 \text { a } \\
5.40 \text { y figura } \\
5.24 \text {, Capítulo } 5\end{array}$ \\
\hline
\end{tabular}


En la primera columna de la tabla 6.3 se muestra la fuente de información a la actividad citada en la columna 2; y las columnas 3 y 4 señalan respectivamente, el producto parcial obtenido en cada etapa y su ubicación en el documento. La señal $\sqrt{ }$ indica que el resultado marcado constituye el producto final de la etapa correspondiente. A continuación un breve resumen de los resultados alcanzados en cada etapa listada.

\subsubsection{Proyección de la capacidad eléctrica a instalar, 2011-2025}

Las tablas 5.5 y la figura 5.13 del capítulo 5 de este documento resumen las proyecciones efectuadas respectivamente para el consumo eléctrico, la demanda máxima y la capacidad de generación eléctrica que se estima necesaria para cumplir con los requerimientos del país, durante el período 2011-2025.

Las proyecciones tomaron como referencia los crecimientos históricos de la población, del consumo y de la demanda eléctrica, las prospecciones de crecimiento económico del país y los planes de carácter urgente que el gobierno ya ha comenzado a ejecutar. La data oficial más reciente fue contrastada y/o complementada con información de índole privada divulgada en artículos especializados, conferencias y prensa electrónica; y con data puntual suministrada en ruedas de prensa ofrecidas por las autoridades respectivas. Basados en las estadísticas propias del sector para la última década, se seleccionó un factor de carga igual a 0,8 y un coeficiente de operatividad igual a 0,73 . Los cálculos de capacidad instalada se efectuaron con una holgura del $30 \%$.

De acuerdo a lo anteriormente señalado, la proyección del consumo eléctrico en Venezuela se realizó en base a las siguientes suposiciones:

- Período 2011-2012. A partir de la cifra registrada de consumo (GWh) para el año 2010, se asume un crecimiento del consumo igual a la tasa interanual de crecimiento poblacional (1,4\%, figura 5.9) hasta el año 2012. A lo largo del período, se añade un total de $4.420 \mathrm{MW}$, de acuerdo a los planes de las autoridades gubernamentales en el sector. 
- Período 2013-2025. Para el resto del período, se contemplan tres escenarios de crecimiento del consumo:

ESCENARIO 1. Se asume una tasa interanual de crecimiento del consumo igual a su crecimiento histórico del 4,3\%, y cercano al crecimiento promedio estimado por el Fondo Monetario Internacional para las economías destacadas de América Latina durante el año 2012.

ESCENARIO 2. Se asume un crecimiento moderado del consumo, con una tasa intermedia del 3,6\% interanual, igual a la estimada por el FMI para el país durante el año 2012.

ESCENARIO 3. Se asume un crecimiento bajo del consumo con una tasa igual a $3 \%$ de crecimiento interanual, superior al crecimiento poblacional pero inferior a la cifra estimada por el FMI para el país durante el año 2012.

Para el año 2025, los resultados obtenidos indicaron que el consumo eléctrico del país se ubicará entre 176.000 y 208.00 GWh. El gobierno nacional deberá cumplir con los planes de instalación de 4.420 MW durante el lapso 2010-2012; y para el período 2013-2025 deberán instalarse entre 19.700 y $27.500 \mathrm{MW}$; lo que equivale a un promedio anual de 1,5 y $2,1 \mathrm{GW}$. El cálculo detallado y la justificación de cada cifra utilizada en el mismo, se presenta en la sección 5.1.3.3.1 de este documento.

Las cifras obtenidas fueron comparadas con un estudio realizado en cuatro escenarios para el período 2011-2030, por CORPOELEC, empresa estatal responsable por las operaciones del sector eléctrico en Venezuela. Los resultados de la proyección realizada por el autor para el escenario con mayor crecimiento económico, se acercaron a la proyección realizada por la empresa en el escenario que asume un mayor desarrollo económico sujeto a las limitaciones estipuladas por el Programa de Uso Racional de la Energía que promueve el gobierno nacional.

\subsubsection{Selección de las alternativas a evaluar}

La figura 5.16 del capítulo 5 de este documento, muestra esquemáticamente las posibles alternativas de generación a evaluar. Las opciones se asocian respectivamente a los recursos energéticos con un potencial identificable en el país. 
A objeto de reducir el tamaño del problema y de racionalizar el tiempo de la etapa de análisis, se construyó una matriz de descarte en base a los juicios expresados por un grupo reducido de expertos con amplio conocimiento y experiencia en el sector.

Las tablas 5.7 y 5.8 en el capítulo 5 de este documento muestran respectivamente la matriz de descarte y las alternativas de generación seleccionadas para su evaluación. El análisis de los resultados aconsejó concentrar el esfuerzo de evaluación en las opciones termoeléctricas que utilizan derivados líquidos del petróleo, gas o carbón como combustible; y en las opciones de aprovechamiento de energía hidráulica y energía eólica. Sin embargo, el gobierno nacional estudia la posibilidad de aprovechar energías alternativas como la nuclear, la geotérmica y la utilización de la biomasa para la expansión de su capacidad de energía eléctrica. Por esta razón, también se incluyeron en la lista para la evaluación.

\subsubsection{Aplicación del modelo de valor propuesto}

Una vez seleccionadas las alternativas a evaluar, el próximo paso fue la aplicación del modelo de valor para su evaluación y ordenamiento de acuerdo a su robustez, estimada ésta como un índice ponderado de los desempeños parciales de cada alternativa con respecto a cada criterio incluido en el modelo jerárquico propuesto. Las actividades dirigidas a tal fin, se dividieron en:

- Ajuste del modelo

- Estimación de los indicadores para la evaluación

- Estimación de los coeficientes de robustez por alternativa

- Ordenamiento final de las alternativas

A continuación una breve descripción de los resultados obtenidos en cada etapa listada.

\subsection{Ajuste del modelo}

El objetivo de esta etapa fue el ajuste del modelo de valor propuesto a las características particulares del problema a resolver. La tabla 5.9 del capítulo 5 muestra los cambios efectuados, su causa y su efecto sobre el modelo. Fueron 
suficientes dos cambios para ajustar el modelo; en primer lugar, el indicador ' $\Delta$ Déficit de energía' fue eliminado por no relevancia para la comparación; y en segundo lugar, el indicador 'A Diversidad de la cesta energética" pasó a ser un indicador de índole cualitativa.

Ambos indicadores en su planteamiento original tienen que ver con el tamaño del proyecto para la evaluación, que en el caso bajo estudio se realiza en base a una unidad de energía producida. De esta forma, el primer indicador tomaría el mismo valor para todas las alternativas en estudio, no sería relevante para la comparación y puede eliminarse simplificando el modelo., Naturalmente se tomó la precaución de distribuir su participación entre los indicadores restantes en el mismo nivel; para ello se utilizó la herramienta informática Expert Choice $\Re$. Las figuras 5.16 y 5.17 muestran los ajustes realizados y el modelo ajustado respectivamente. En el caso del segundo indicador, el mismo argumento es válido; sin embargo, se prefirió mantenerlo en el modelo como un indicador de índole cualitativa para tener información sobre tan importante aspecto.

\subsection{Obtención del valor de los indicadores para la evaluación}

Un paso de la mayor importancia en la ruta a la determinación de los coeficientes de robustez con los cuales se calificará cada alternativa bajo estudio, fue la estimación de los valores de los indicadores para la evaluación. El procedimiento se dividió en dos partes, a saber:

- Estimación de los indicadores de naturaleza cuantitativa

- Obtención de los indicadores de naturaleza cualitativa

En total se estimó el valor de cada uno de 24 indicadores de los cuales 10/24 correspondieron a indicadores de naturaleza cuantitativa; el resto fueron indicadores de naturaleza cualitativa. La tabla 5.10 del capítulo 5 de este documento, muestra los indicadores considerados, clasificados por dimensión. El cuadro adicionalmente incluye el carácter del indicador, la fuente de la información para su estimación y las unidades originales de medida, si es el caso. A continuación, un breve resumen de los resultados obtenidos. 


\subsection{Indicadores de naturaleza cuantitativa}

Dada la falta de consistencia en la escasa información nacional disponible, los datos técnicos, económicos y de impacto ambiental sobre las diferentes fuentes de energía primaria consideradas como alternativas para generación eléctrica en Venezuela, fueron obtenidos de publicaciones especializadas e informes de organizaciones internacionales relacionadas. De esta forma, la información insumo al proceso correspondió a promedios globales que pueden diferir entre variantes de la tecnología utilizada y con las características del país sede del proyecto. En todos los casos, la información fue contrastada en diversas fuentes y seleccionada la que a criterio del autor, se adaptase mejor a las condiciones venezolanas.

Las tablas 5.11 a 5.20 en la sección 5.1.3.3.3.4 de este documento muestran respectivamente los valores seleccionados para los indicadores cuantitativos. Los cuadros incluyen la información necesaria para el cálculo de cada valor o directamente el valor, en su unidad original y en una escala [1-5]. La conversión de una a otra escala se realizó de acuerdo a los procedimientos respectivamente sugeridos en las fichas de los indicadores incluidas en el capítulo 4.

\subsection{Indicadores de naturaleza cualitativa}

La estimación de los indicadores de índole cualitativa se realizó con la ayuda de un grupo de 13 expertos venezolanos trabajando en Venezuela, Panamá o Estados Unidos cuidadosamente seleccionados: dos, pertenecientes al sector público; seis, al sector académico; y cinco, al sector privado. En cada caso, se estableció un diálogo personal o telefónico, para aclarar dudas sobre la materia.

La información se recogió en forma sistemática en el formato que se presenta en la tabla 5.22 del capítulo 5, previo el llenado con los valores obtenidos de las celdas correspondientes a los indicadores cuantitativos. Las celdas restantes correspondieron a los indicadores de índole cualitativa; y para su llenado se solicitó a cada entrevistado expresase su opinión en una escala [1-5], sobre el potencial desempeño de cada opción a evaluar, donde 5 representaba el mejor desempeño. La información recabada se presenta en detalle en el anexo 3 al final del documento. 


\subsection{Obtención de los coeficientes de robustez}

El procesamiento de toda la información reunida, se llevó a cabo con ayuda de una hoja de cálculo EXCEL especialmente diseñada al efecto. La utilización de la herramienta automatiza el cálculo del coeficiente de robustez para cada alternativa bajo evaluación, en sus tres versiones:

- Robustez por alternativa y por entrevistado, en escala 1-5, de acuerdo con la ecuación 5.12, capítulo 5 de este documento.

- Robustez consolidada por alternativa, como un promedio geométrico de los coeficientes de robustez por entrevistado, en escala 1-5, de acuerdo con la ecuación 5.13, capítulo 5 de este documento.

- Robustez consolidada normalizada por alternativa, en escala 0-1, de acuerdo con la ecuación 5.14 , capítulo 5 de este documento.

La tabla 5.23 incluye los resultados correspondientes a las dos primeras versiones del coeficiente; y la tabla 5.24 presenta los coeficientes de robustez normalizados que fueron insumo a la última fase del proceso.

\subsubsection{Ordenamiento final de las alternativas}

El coeficiente de robustez consolida los valores que miden el potencial desempeño de una alternativa con relación a los criterios técnicos, ambientales, económicos, sociales, estratégicos y de riesgo propuestos en el modelo de valor. En base a sus valores estimados, se ordenó el conjunto de las nueve opciones de generación consideradas por entrevistado y para la muestra entrevistada. El ordenamiento final obtenido en este último caso, se muestra a continuación:

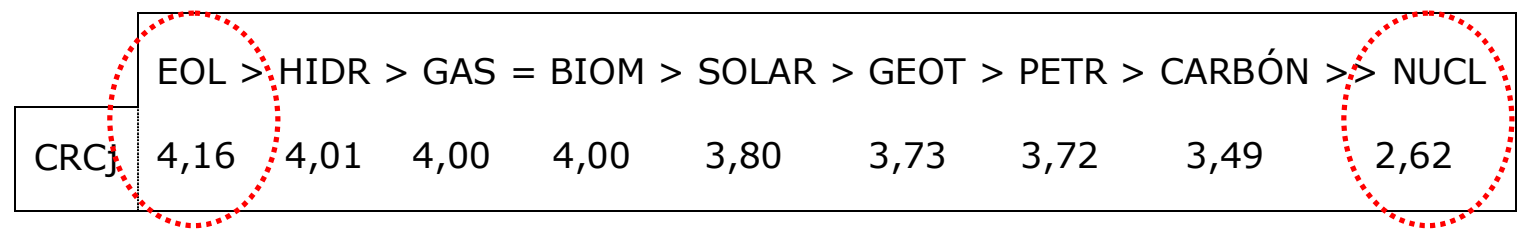

Como puede observarse, los coeficientes de robustez obtenidos se ubicaron entre 2,62 para la opción nuclear y 4,16 para la opción eólica, en una escala [1-5]. La 
lectura del cuadro anterior, permite anotar los siguientes hechos, en orden de importancia:

- La alternativa de generación nuclear obtuvo un coeficiente de robustez muy inferior al resto de las opciones. La percepción de las graves consecuencias que puede ocasionar un accidente nuclear unido a la elevada importancia que dentro del modelo de evaluación tiene la dimensión riesgo, incide en la baja calificación obtenida por esta opción. Venezuela no dispone actualmente del personal entrenado para participar en la instalación, operación y mantenimiento de instalaciones que por su naturaleza deben ser estrictamente controladas y reguladas. Tampoco se dispone de un marco legal que norme tales actuaciones, y la disposición de desechos radioactivos producto de las operaciones.

Por otra parte, está el problema de los insumos al reactor. Aunque Venezuela dispone de reservas de uranio no explotadas, el material debe ser sometido a una serie de operaciones muy especializadas para convertirlo en material apto para el reactor; ello pondría al país en situación de dependencia de los centros que poseen la tecnología, los equipos y la experiencia para realizar tales transformaciones. Adicionalmente, está el costo de inversión que es elevado y el tiempo de construcción y puesta enmarcha que puede ser muy largo.

- Las opciones eólica e hidráulica para generación de electricidad lograron los mejores coeficientes de robustez. El bajo impacto ambiental de estas opciones de generación frente a alternativas como la combustión de carbón o de derivados líquidos del petróleo, ambos altamente contaminantes; la existencia de un alto potencial hidráulico al sur del territorio nacional y de las líneas para la transmisión de la potencial electricidad a generar; la experiencia en la construcción y operación de plantas hidroeléctricas que tiene el país; la percepción de la poca complejidad de equipos, operación y logística de la opción eólica frente a la opción nuclear, geotérmica y bioenergética; y finalmente el menor costo de la alternativa eólica comparada a la alternativa solar incidieron en la buena evaluación obtenida.

- La alternativa de generación eléctrica con gas natural obtuvo una mayor robustez que las opciones que se basan en combustibles fósiles como el petróleo y el carbón que se perciben como menos "limpios" y que requieren una inversión 
inicial más elevada para su aprovechamiento. Sin embargo, antes de su selección como potencial alternativa para generación eléctrica debe tenerse en cuenta el déficit de gas natural que actualmente vive el país detallado en la sección 5.1.3.1 de este documento.

- El aprovechamiento de la biomasa obtuvo un coeficiente de robustez semejante al de la opción de gas natural. Este resultado debe utilizarse con precaución, recordando que el valor obtenido al menos en su porción cuantitativa, es un promedio global de múltiples tecnologías, insumos y experiencias existentes en el área; y que como tal, es una aproximación a la cifra real que aplique para Venezuela.

- Otras opciones se ubicaron entre los dos extremos citados. Entre ellas, las alternativas de generación basadas en la combustión de derivados líquidos de petróleo o de carbón que se perciben como más contaminantes, obtuvieron los peores coeficientes. La alternativa solar, no contaminante, renovable y con un gran potencial en Venezuela, quedó mejor ubicada; sin embargo, fue perjudicada por su elevado costo.

El conjunto final ordenado de las opciones de generación eléctrica sólo informa sobre la mayor o menor robustez de una opción comparada con las otras; y en general, es de utilidad cuando se trata de seleccionar un proyecto sobre otros, si así lo permite el presupuesto destinado a su ejecución.

\subsubsection{Modelo de programación lineal}

En la búsqueda de una solución al problema bajo estudio, no basta con el ordenamiento de las posibles opciones de uso de las fuentes de energía primaria para generación de potencia eléctrica en el país sino que debe encontrarse cuales de ellas califican para su ejecución y en qué proporción intervendrán en la solución al problema, todo sujeto a las limitantes físicas, económicas, ambientales y a las políticas gubernamentales y compromisos internacionales suscritos por la nación. La matriz eléctrica así planteada, si es ejecutada, debe ser capaz de satisfacer la demanda eléctrica estimada para el país, durante el período 2011-2025. 
Los objetivos a cumplir, las limitantes existentes y la disponibilidad de información confiable moldearon el problema que se convirtió en la búsqueda de la mejor combinación de uso de las fuentes de energía primaria para generación de potencia eléctrica en el país, sujeto a las restricciones existentes. A efectos de su solución, se definió como "mejor combinación" aquella que proporciona la máxima robustez al sistema; y ésta a su vez, como una función lineal a maximizar igual a la suma de las capacidades de generación a instalar ponderadas por los respectivos coeficientes de robustez obtenidos en la primera parte del estudio.

En el planteamiento del problema se supuso que el gobierno nacional cumpliría con sus planes de instalación de 4.420 MW para el período 2010-2012, parte de los cuales ya se han ejecutado, con una operatividad de un $73 \%$; de esta forma, la búsqueda de la matriz solución se centró en el período 2013-2025. A estos efectos, el trabajo se ejecutó en tres pasos:

- Identificación de limitaciones y modelo de solución

- Introducción de parámetros al modelo y su resolución

- Análisis de sensibilidad

\subsection{Identificación de limitaciones y modelo de solución}

Un grupo de suposiciones básicas se incorporó inicialmente al modelo en forma de restricciones $[\leq,=, \geq]$; las mismas están detalladamente justificadas $\mathrm{y} / \mathrm{o}$ referenciadas en la sección 5.1.3.3.4.1 de este documento. Entre ellas, las más importantes fueron:

- Para el período 2011-2025, el consumo eléctrico en Venezuela se ajustará a las proyecciones realizadas en la sección 5.1.3.3.1.3 de este documento. De esta forma, la capacidad de generación demanda eléctrica se ubicara entre $(176.241 / 0,8)$ y $(207.241 / 0,8)$ GWh, para el año 2025.

- La capacidad eléctrica a instalar se basará primordialmente en generación termoeléctrica; de esta forma, la participación de la generación hidroeléctrica en la matriz buscada será menor o igual a su participación pera el año 2010. 
- El presupuesto asignado para la incorporación de la capacidad de generación eléctrica necesaria será al menos de 55 mil millones de US\$ distribuidos a lo largo del período 2013-2025. El monto no incluye inversiones en la adaptación, recuperación o instalación de las líneas requeridas para la transmisión y distribución de la electricidad producida.

La cifra es un estimado promedio inicial que incluye como una aproximación, la participación en la matriz eléctrica a obtener un $90 \%$ de energías convencionales y un $10 \%$ de energías alternativas. La cifra fue contrastada con declaraciones hechas por autoridades gubernamentales y por expertos en el sector privado. Su cálculo detallado se presenta en la tabla 5.25, aparte (3), sección 5.1.3.3.4.1 del capítulo 5 de este documento; y debe ser ajustado a la luz de los resultados que se obtengan.

- Para el año 2025, la participación de las energías renovables excluyendo la energía hidráulica se acercará a un $10 \%$ del suministro total de electricidad a la nación. La cifra luce elevada si se compara con los niveles de aprovechamiento de energías renovables alcanzados en los países latinoamericanos; y baja, si la comparación se efectúa con los logros de algunos países europeos.

- Durante el período 2013-2025, el país incorporará al menos 7.400 MW de capacidad de generación eléctrica basada en sus reservas desarrollables de carbón y en la producción estimada de coque de petróleo subproducto de los procesos de refinación del crudo extrapesado procedente de la Faja Petrolífera del Orinoco; y en menor proporción de otras refinerías del país. En tal sentido, el gobierno nacional ya ha firmado algunos convenios de cooperación con China.

- Las capacidades de generación a instalar para cada tipo de energía primaria básica bajo estudio, serán iguales o menores a sus respectivos potenciales desarrollables. Para el carbón y coque de petróleo, el potencial es

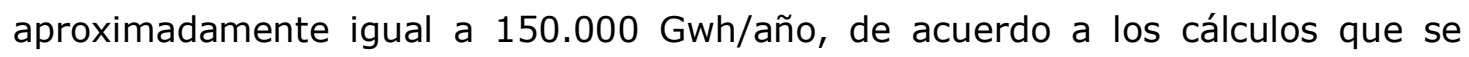
muestran en la tabla 5.30 del capítulo 5 de este documento. Para la energía eólica

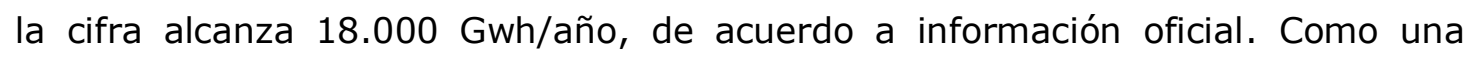
aproximación, el potencial de otras energías renovables se estima como se indica en la tabla 5.30, dada la falta de información al respecto. 
- Los potenciales desarrollables de petróleo y de gas son muy elevados. Durante el período 2013-2025, se ampliará la capacidad de refinación del país y se desarrollarán sus reservas gasíferas; de esta forma, no habrá restricciones en el suministro de gas y de derivados de petróleo necesarios para el funcionamiento de las potenciales plantas termoeléctricas.

- Para el año 2025, la capacidad nuclear instalada para generación eléctrica será al menos de $2.400 \mathrm{MW}$, de acuerdo a convenios de cooperación firmados por el gobierno nacional con Rusia.

- Para el período 2013-2025, la capacidad hidroeléctrica adicional será al menos de 2.931 MW de plantas nuevas ya en construcción.

Las limitaciones citadas acotan las soluciones del problema a un espacio mucho más reducido que el considerado en la sección anterior, donde implícitamente se supone la completa disponibilidad de todos los recursos necesarios. La tabla 5.26 del capítulo 5, muestra el modelo de programación lineal utilizado para su solución. El modelo permite determinar las capacidades de generación de potencia eléctrica basadas en las diferentes fuentes energéticas consideradas, que maximizan una función lineal de dichas capacidades ponderadas con los respectivos coeficientes de robustez obtenidos en la sección anterior; todo sujeto a las restricciones identificadas.

\subsection{Introducción de parámetros al modelo y su resolución}

La completa definición del modelo requiere la introducción de los valores de los parámetros en función de los cuales se enuncia el mismo. Las tablas 5.28 a 5.30, sección 5.1.3.3.4.3 del capítulo 5 de este documento, muestra el detalle de los cálculos efectuados para la cuantificación de los restricciones listadas en la sección anterior; y la tabla 5.31, el modelo a resolver.

Las capacidades de generación de potencia eléctrica a instalar para cada recurso energético bajo estudio, fueron las variables del problema, expresadas en GWh/año y la función a maximizar la suma de los productos obtenidos al multiplicar cada variable por su respectivo coeficiente normalizado de robustez (escala 1-5; tabla 
5.28). Nótese que la única razón para utilizar los coeficientes normalizados fue reducir el orden de magnitud de los números a manejar; de la misma forma y sin diferencia en los resultados, podría haberse utilizado el grupo de coeficientes originales, expresados en la escala [1-5].

El modelo planteado fue resuelto con ayuda de una hoja de cálculo diseñada para la utilización de la herramienta Microsoft Office Excel Solver. Si la función a maximizar es lineal como en el caso bajo estudio, la herramienta utiliza el método Simplex para encontrar la solución. La matriz eléctrica resultado para el período 2013-2025 se muestra en la figura 5.19 del capítulo 5 de este documento . La tabla 7.4 presenta el resultado ampliado para el período 2011-2025.

Tabla 7.4. Capacidad eléctrica a incorporar. Período 2011-2025, con todas las restricciones planteadas en el modelo original.

\begin{tabular}{|l|c|c|}
\hline OPCIÓN DE GENERACIÓN & GWh/año & MWI \\
\hline HASTA EL AÑO 2012 & 23.887 & 4.420 \\
\hline Térmica Petróleo/Gas & 21.809 & 3.920 \\
\hline Hidroeléctrica & 2.078 & 500 \\
\hline \multicolumn{1}{|c|}{ PERÍODO 2013-2025 } & 120.000 & 25.300 \\
\hline Carbón (IGCC) & 40.000 & 7.400 \\
\hline Petróleo (Ciclo Combinado) & 0 & 0 \\
\hline Gas (Ciclo Combinado) & 37.033 & 6.700 \\
\hline Nuclear & 13.800 & 2.400 \\
\hline Hidráulica & 14.420 & 3.500 \\
\hline Eólica & 14.747 & 5.300 \\
\hline Solar Térmica & 0 & 0 \\
\hline Biomasa & 0 & 0 \\
\hline Geotérmica & 0 & 0 \\
\hline ROBUSTEZ DE LA ADICION $2013-2025: 13.202$ \\
\hline
\end{tabular}

MWI: capacidad a instalar, MW

La tabla anterior incluye en sus primeras líneas, la capacidad de generación eléctrica que el gobierno nacional ha planificado ejecutar hasta el año 2012 y parte 
de la cual ya está en construcción; y en su segunda parte, el resultado obtenido para el período 2013-2025, con base en el modelo planteado en la tabla 5.31 y resuelto con la ayuda de la rutina Microsoft Office Excel Solver.

Nótese que la solución recomienda sólo la instalación de las capacidades mínimas de generación exigidas para tecnologías basadas en carbón, reactores nucleares y potencial hidráulico y no incluye generación adicional basada en derivados del petróleo, lo cual luce altamente improbable en un país cuya principal actividad económica es la explotación, refinación y comercialización de petróleo y sus productos derivados. En la sección que sigue se presentan el análisis de sensibilidad realizado para explorar otras posibles soluciones.

\subsection{Análisis de sensibilidad}

El estudio de sensibilidad de la solución ante cambios en los parámetros del modelo planteado permite tener una idea más elaborada de lo que puede ser una aproximación a una matriz energética para la generación de potencia eléctrica en el país. En tal sentido, las secciones 5.1.3.3.4.5 y 5.1.3.3.4.6 de este documento, dan cuenta detallada del análisis realizado que se dividió en tres etapas, a saber:

Etapa 1. En esta etapa se analizó el efecto que sobre la solución tienen cambios en el presupuesto asignado y en la participación mínima de generación con base en carbón y con base nuclear. La tabla 5.32 y la figura 5.20 del capítulo 5, muestran los resultados obtenidos. En resumen puede observarse lo siguiente:

- Un incremento en el presupuesto de inversión sin variar la capacidad de generación total necesaria ni otras restricciones, favorece la opción hidráulica y aumenta la robustez del sistema, hasta alcanzar un máximo de 68 mil millones de US\$, más allá del cual la solución permanece constante.

- La inclusión de mínimos de capacidad de generación carboeléctrica y de generación nuclear sin variar la capacidad total necesaria ni otras restricciones, reduce la robustez del sistema. Para un presupuesto de 55 mil millones de US\$ se variaron paulatinamente tales mínimos desde cero hasta la participación incluida en el caso original obteniéndose coeficientes de robustez entre 14.430 y 13.402 
respectivamente. El resultado no sorprende si se tiene en cuenta que los coeficientes de robustez de estas opciones son los peores de todo el grupo de alternativas estudiado.

Etapa 2. En esta etapa se estudió el efecto que sobre la solución del problema tiene la inclusión de limitaciones en la participación de generación termoeléctrica basada en gas o derivados líquidos de petróleo, de acuerdo a la disponibilidad efectiva del combustible a utilizar. Se estudiaron múltiples combinaciones de participación para diferentes niveles de presupuesto asignado. Otras restricciones se mantuvieron constantes. Las tablas 5.33 y 5.34 del capítulo 5 de este documento resumen algunos de los casos planteados y sus soluciones.

La figura 5.21 del capítulo 5, muestra una selección de cuatro casos que a criterio del autor resultaron interesantes; uno de ellos, sin participación alguna de generación basada en gas o en petróleo. Para los casos restantes, la tabla 5.35 del mismo capítulo, presenta los estimados de diesel y/o gasoil o de gas requeridos. Para las combinaciones estudiadas hará falta la importación de gas y de derivados líquidos de petróleo. Paralelamente será necesario acometer el desarrollo los yacimientos gasíferos del país, los planes de ampliación de la capacidad de refinación y el incremento del nivel de producción de crudo que se dirige a ella. A pesar de ello, es criterio del autor que debe incluirse este tipo de alternativas de generación en la matriz eléctrica adicional 2025 de la nación; no hacerlo resultaría poco realista en un país con grandes reservas de gas y petróleo y cuya principal actividad económica se centra en el aprovechamiento de las mismas.

Etapa 3. En esta etapa se estudió el efecto que sobre la solución de los dos casos con los mejores coeficientes de robustez en la etapa 2, tiene la imposición de una participación mínima de energías renovables, exclusión hecha de la opción hidráulica. La participación se varió entre un $5 \%$ y un $10 \%$ de la energía eléctrica total a producir para el año 2025. La tabla 5.33 del capítulo 5, muestra el detalle de los casos planteados y sus soluciones.

La imposición de una participación mínima de energías renovables en la generación total eléctrica mayor a $18.000 \mathrm{GWh} / a n ̃ o ~(8 \%$ y $10 \%$ ) introduce nuevos tipos de energías renovables en la solución, además de algunos ajustes en la UNIVERSIDAD POLITÉCNICA DE VALENCIA. TESIS DOCTORAL. Violeta Parodi 
participación de otro tipo de energías. La bioenergía es la primera que se hace presente, seguida de la energía geotérmica; y finalmente de la energía solar la cual parece menos atractiva por su alto costo de inversión inicial. La capacidad de generación eléctrica basada en energía eólica alcanza su potencial desarrollable estimado de $18.000 \mathrm{Gwh} /$ año en casi todos los casos estudiados, lo cual muestra su robustez como fuente de energía primaria para generación eléctrica.

Tomando en cuenta los resultados anteriores y la necesidad de minimizar el riesgo de fracasos o de retardos en la implementación de soluciones que incluyan la utilización de energías renovables en la generación de potencia eléctrica; y conocida la poca experiencia y la falta de personal entrenado en la materia en el país, se consideró conveniente incluir solamente la energía eólica como energía básica primaria en los planes de generación eléctrica.

Es conveniente hacer notar que lo dicho en el párrafo anterior, no significa el descarte de las energías renovables diferentes a la eólica y a la hidráulica, de cualquier matriz eléctrica para el país. Por el contrario, el país debe privilegiar la investigación en la materia y la formulación de proyectos que una vez demuestren su valía técnica, económica, ambiental y social puedan implementarse y ponerse en marcha. En tanto, el potencial de recursos energéticos renovables que posee el país puede utilizarse parcialmente como energía primaria básica para la generación de potencia eléctrica a pequeña escala en medios rurales o industriales.

\subsubsection{Análisis de resultados y propuesta final}

El análisis de sensibilidad efectuado sentó las bases para una selección más documentada de la propuesta final, entre las múltiples soluciones surgidas en el análisis. Para un presupuesto de 65 mil millones de US\$ dirigido a incrementar la capacidad de generación eléctrica a lo largo del período 2013-2025, se propusieron cinco combinaciones de recursos para generación eléctrica. Las soluciones se recogen en la figura 5.22 del capítulo 5 de este documento y corresponden a las siguientes situaciones:

- Un caso de referencia, sólo sujeto a las limitaciones de potencial desarrollable de cada fuente de energía, a las capacidades de generación hidráulica ya en 
ejecución y a un porcentaje de participación $[<]$ de energías renovables en el sistema. La solución de este caso, sólo incluye las opciones hidráulica, eólica y la basada en la combustión de gas natural, resultado que se corresponde con los mejores coeficientes de robustez encontrados para estas alternativas y con sus menores costos estimados de inversión.

- El caso 18, con todas las restricciones originales al problema excepto que se limita la participación de gas y de derivados de petróleo en la solución.

- El caso 24 que excluye la participación de la opción nuclear de la solución manteniendo el resto de las restricciones del caso 18 sin alteración.

- El caso 25 que excluye la participación nuclear, rebaja la participación mínima de la opción carbón e incluye mínimos de participación para las opciones petróleo y gas.

- El caso 26 semejante al caso 25, excepto que incluye participación nuclear.

La escasez ya señalada de gas en el país y la cercanía del nivel de consumo a la capacidad de producción de diesel existente en las refinerías del país, hicieron razonable incluir el caso 18 en el análisis para la escogencia de la propuesta final. La existencia de grandes reservas de gas y de petróleo, la posibilidad de ampliar la capacidad de refinación en el país y el bajo coeficiente de robustez de la opción de la generación basada en carbón, justificaron la decisión de incluir el caso 25 en el análisis; Y finalmente, la consideración de los inmensos daños que puede causar el mal manejo de las instalaciones nucleares, la disposición inadecuada de los residuos radioactivos; o simplemente, un accidente nuclear; motivó la inclusión en el análisis final de los casos 24 y 26 , similares a los casos 18 y 25 respectivamente pero que excluyen la participación nuclear en las soluciones.

La figura 5.22 muestra las soluciones a los casos planteados. Su análisis incluyó no sólo la revisión de sus coeficientes de robustez sino la consideración explícita de sus respectivos índices de diversidad, estimados de acuerdo a la fórmula de Herfindhal-Hirschman [Kruyt et al., 2009] expresada en la ecuación 4.5, capítulo 4, de este documento. La tabla 5.37 incluida en el capítulo 5, resume los coeficientes de robustez y los índices de diversidad de cada caso bajo consideración; y en el recuadro inferior derecho de la figura 5.21 del mismo capítulo se grafican dichas 
cifras. La lectura e interpretación de este último grafico permitió seleccionar las soluciones a los casos 25 y 26 como las mejores alternativas de generación eléctrica entre las consideradas para el período 2013-2025. En efecto, ellas presentan respectivamente mejores coeficientes de robustez y mayor diversidad que las soluciones a los casos 18 y 24.

La tabla 5.38 del capítulo 5, muestra para las soluciones a los casos 25 y 26: (i) la estructuración porcentual del potencial suministro adicional de electricidad (GWh/año) para el año 2025 y (ii) la capacidad a instalar (MW) durante el período 2013-2025, todo clasificado por tipo de energía primaria. Para el caso 25, la relación entre las respectivas participaciones de la generación termoeléctrica y la hidroeléctrica es ligeramente inferior a 1, mientras que para el caso 26, la misma relación alcanza el valor de 1,7 . La justificación detallada de la selección final se presenta en la sección 5.1.3.3.4.7 de este documento.

Las matrices solución propuestas para la ampliación del suministro eléctrico al país durante el período 2013-2025, son similares excepto por la participación o no de la energía nuclear en ellas. La implementación y puesta en marcha de una u otra es capaz de añadir 120.000 GWh para el año 2025; y en ambas, la participación de las opciones basadas en carbón (25\%), derivados líquidos de petróleo $(8,3 \%)$, gas natural $(8,3 \%)$ y energía eólica $(15 \%)$ es similar; el resto $(43,4 \%)$ corresponde a energía hidráulica en la solución al caso 26 , o se comparte entre energía nuclear $(11.5 \%)$ y energía hidráulica $(31,9 \%)$ en la solución al caso 25 . Para lograr este nivel de suministro es necesario instalar $27.100 \mathrm{MW}$ a lo largo del período 2013-2025 MW en el caso 26; y dada las diferentes eficacias entre tecnologías, $28.000 \mathrm{MW}$ en el caso 25.

Requerimiento de combustibles. La tabla 5.39 del capítulo 5, presenta los volúmenes adicionales requeridos de gas natural y derivados líquidos de petróleo, una vez que uno u otro plan sea completamente instalado. Las estimaciones señalan que para el año 2025 se requerirán unos 2.100 millones de metros cúbicos estándar de gas natural/año y 34,4 miles bbls/día de gasoil/fueloil. El consumo se crecerá a lo largo del período 2013-2025, a medida de que la capacidad a instalar vaya entrando en operación. Como ya se ha señalado anteriormente, tales volúmenes deberán ser 
importados hasta tanto se desarrolle capacidad adicional de producción en los yacimientos de gas y capacidad adicional de refinación en las refinerías del país.

Localización geográfica. Como un ejercicio del autor, se realizó en forma aproximada, la distribución sobre el territorio nacional de las soluciones sugeridas para el suministro de nueva potencia eléctrica en Venezuela. La figura 5.23 incluida en el capítulo 5, muestra en forma aproximada tal distribución. La materia no es fácil y debe ser resuelta en base a proyectos específicos que suministren no sólo la necesaria información de carácter técnico, económico y de impacto ambiental sino los detalles sobre requerimientos de tierras, agua, accesos y costo de infraestructura requerida para conectar la fuente de energía primaria con las instalaciones de generación de potencia eléctrica; y éstas a su vez con las regiones demandantes, a través de una red distribución eléctrica confiable. Adicionalmente deberá tomarse en cuenta la aceptación que pueda tener cada proyecto, por parte de la comunidad afectada. Cada uno de tales requerimientos pueden resultar limitante en la decisión final.

Cronograma de ejecución. En cuanto al cronograma de ejecución de las soluciones sugeridas para el suministro de potencia eléctrica en Venezuela a lo largo del período 2013-2025; el mismo debe ajustarse a la evolución estimada de la demanda para dicho período, a la urgencia de instalación en cada zona del país, a la disponibilidad de equipos en el mercado, a la inversión requerida frente a los recursos financieros disponibles y a los lapsos de construcción y puesta en marcha de las instalaciones asociadas a cada tipo de tecnología.

Conocida la reciente historia de baja efectividad en la ejecución de proyectos que ha demostrado Venezuela en los últimos años, a criterio del autor es necesario multiplicar al menos por un factor de 1.5, los lapsos de construcción promedio que se presentan en la tabla 5.11 del capítulo 5 de este documento. Si a ello se suman unos dos años para disponer de los proyectos respectivos, se requerirán al menos unos cinco años para contar con las nuevas instalaciones con períodos de construcción más cortos; esto es, aquellas que basan su operación en la combustión de gas natural o derivados líquidos del petróleo, o en la energía eólica. Las instalaciones de generación asociadas a tecnologías basadas en la combustión de 
carbón o coque de petróleo, las plantas hidroeléctricas y las plantas nucleares requerían lapsos más largos. En consecuencia:

- En el plazo inmediato sólo queda recuperar y/o actualizar las instalaciones existentes, la instalación de pequeñas plantas termoeléctricas a petróleo o gas, o eólicas; y paralelamente, la elaboración de un plan estratégico para el desarrollo e incorporación progresiva de centrales a mayor escala que son las que finalmente resolverán el problema del suministro de energía eléctrica.

- A mediano y largo plazo y en la medida de que se disponga de los proyectos y los recursos monetarios para su financiamiento, podrán ponerse en marcha programas más ambiciosos que contemplen el aprovechamiento de las reservas de petróleo, gas y del gran potencial hidráulico que posee el país. Para ello será necesario la activación urgente de planes de desarrollo de sus reservas gasíferas, la expansión de su capacidad de refinación, el incremento de su producción petrolera; y finalmente, las acciones que lleven a la progresiva recuperación de las cuencas hidrológicas al sur del país.

Paralelamente y a criterio del autor, deberá revisarse la decisión de instalar centrales nucleares teniendo en cuenta las circunstancias presentes y futuras del país y la conducta internacional al respecto. Todo requerirá de voluntad política, una fuerte inversión y de la experiencia y constancia de sus mejores profesionales y técnicos en las respectivas áreas de experticia.

Presupuesto. El presupuesto de inversión necesario para la construcción y puesta en marcha de las instalaciones para generación de nueva energía eléctrica sugeridas en las soluciones 25 o 26, suma 65 mil millones US\$. A este monto debe añadirse la inversión requerida para la adecuada distribución de la energía adicional producida. En tal sentido, fueron realizadas consultas a expertos en el sector eléctrico, privado y público del país y todos coincidieron en que dadas las condiciones de falta de mantenimiento que presenta la red existente en Venezuela, la inversión en su adecuación se ubica entre un $50 \%$ a $100 \%$ de la inversión en generación. De esta forma, el monto total de inversión en instalaciones de generación y distribución 
asociado a una u otra de las soluciones sugeridas, oscila entre 100 y 130 mil millones US\$ distribuidos a lo largo del período 2013-2025.

Propuesta de matriz eléctrica 2025. La tabla 5.40 y la figura 5.24 del capítulo 5 de este documento, muestran la conformación de las matrices energéticas que para el sector eléctrico nacional tendría el país para el año 2025, en caso de implementarse una u otra de las soluciones propuestas. Para cada una de ellas, se incluye su coeficiente de robustez y su índice de diversidad. A efectos de comparación, se incluye la situación para los años 2010 y 2012; ésta última estimada en base a los planes que el gobierno viene implementando con urgencia desde el año 2010.

La lectura de las cifras y gráficos presentados permite realizar las siguientes consideraciones:

- Cualquiera de las matrices eléctricas propuestas para el año 2025 tiene menor robustez que la correspondiente a la del año 2012; y ésta es menos robusta que la del año 2010. Tal resultado no puede evitarse si la solución se supedita a participaciones mínimas de generación basada en carbón, derivados de petróleo y de la opción nuclear. Por el contrario, la diversidad del sistema mejora en la medida que se incluye un mayor número de fuentes energéticas en el mismo.

- La relación entre las respectivas participaciones de energía hidroeléctrica y energía termoeléctrica en la matriz eléctrica, se mueve desde 1,9 en el año 2010 hasta 1,3 en el año 2012; y a 1,2 o 0,9 para el año 2025, si se implantasen respectivamente las soluciones a los casos 25 o 26. Ello se corresponde con la política nacional de basar la expansión del sistema eléctrico nacional en generación termoeléctrica y disminuir la importancia de la generación hidroeléctrica.

- La participación de las energías renovables en la matriz energética para el sector eléctrico se mueve desde cero en el año 2010 a una participación estimada de $6,9 \%$ para el año 2025 . Esta meta recomendada por la solución al problema es difícil de obtener dada el modesto conocimiento y poquísima experiencia que en la materia tiene el país; frente a la existencia de una industria petrolera instalada, 
en funcionamiento por muchos años, y de las grandes reservas de crudo y de gas de las cuales dispone el país.

De nuevo, las matrices eléctricas propuestas para el año 2025 son similares excepto por la participación o no de la energía nuclear en ellas. La adopción y total puesta marcha de cualquiera de ellas, producirá unos 260.000 GWh para ese año; y en ambas, la participación de las opciones basadas en carbón (11.5\%), derivados líquidos de petróleo $(20,5 \%)$, gas natural $(10,8 \%)$ y energía eólica $(6,9 \%)$ es similar; el resto $(50,2 \%)$ corresponde a la participación de la energía hidráulica, si se adoptase la solución asociada al caso 26; o se comparte entre energía nuclear (5.3\%) y energía hidráulica (44,9\%), si se adoptase la solución asociada al caso 25. Para lograr este nivel de suministro es necesario incorporar entre 27,100 MW y 28.000 MW durante el período 2013-2025 y 4.420 MW durante el período 2010-2012 correspondientes a planes ya en ejecución del gobierno nacional, para un total de 31.520 MW y 32.420 MW a incorporar para el período 2011-2025. Si estas cifras se añaden a 15.129 MW de instalaciones disponibles para el año 2010, se obtiene el total de capacidad instalada de generación para el año 2025.

Los resultados obtenidos demuestran la aplicabilidad del modelo multicriterio de valor propuesto en el capítulo 4 de este documento, en la solución de un problema complejo no sólo por el número de factores involucrados, mucho de ellos impredecibles sino por su relación con otras materias dentro del sector eléctrico y con otros sectores de la vida del país. La solución completa del ejercicio requirió la construcción de un modelo de programación lineal que permitió acotar la solución del problema con limitaciones físicas, financieras y con las restricciones que originan compromisos y convenios firmados por el país.

La propuesta realizada debe verse como una aproximación al problema del suministro eléctrico en Venezuela. Ante la falta de información completa, confiable y consistente por parte de los organismos oficiales del país, la resolución del caso se basó en promedios publicados por organismos internacionales en el sector y en información suministrada en conferencias y publicaciones de expertos ubicados en universidades y en el sector privado del país. En lo posible, toda la información fue validada en diferentes fuentes. Alguna información, especialmente la referente a planes gubernamentales, fue obtenida de la empresa pública responsable del sector 
eléctrico en el territorio nacional. Información valiosa se recabó en entrevistas realizadas entre expertos en la materia ubicados en el sector académico, público y privado de la nación y de otros países.

Las decisiones finales a tomar por las instancias a las que corresponda hacerlo deben apoyarse en proyectos específicos que suministren información técnica y económica, completa y confiable y que informen sobre el impacto ambiental y los beneficios sociales que pueden tener los proyectos de ejecutarse. Paralelamente, debe considerarse la aceptación que las comunidades afectadas tengan sobre la implantación de los proyectos bajo evaluación y poseer un amplio conocimiento de la realidad nacional. Aún así, la propuesta realizada puede contribuir a orientar los planes que en el sector se efectúan y a concentrar el esfuerzo que implica un mayor detalle en la información, en las alternativas energéticas con la mejor opción para contribuir a fortalecer el sector eléctrico en el país.

\subsection{Propuesta metodológica para la evaluación}

En base al conocimiento y la experiencia adquiridos a través de la realización de este trabajo, se estructuró la propuesta metodológica para la evaluación integral de proyectos en el sector energético que se presenta en el capítulo 6 de este documento.

Las figuras 6.1 y 6.2 muestran el diagrama de flujo del procedimiento propuesto que se extiende desde la concepción y aprobación de la idea hasta la consecución de la mejor solución posible al proyecto; todo ello apoyado en un proceso sistemático de evaluación multicriterio, ordenamiento y selección de una o más alternativas de acción viables previamente identificadas.

La metodología propuesta considera la posibilidad de que las alternativas sean excluyentes en cuyo caso el procedimiento propuesto conduce a la selección de la más 'robusta' entre ellas; o de que las alternativas sean independientes y sujetas a una serie de restricciones físicas, técnicas, ambientales, financieras y otras existentes en el país sede del proyecto; en cuyo caso el procedimiento contempla el planteamiento y resolución de un modelo de programación lineal particularizado a las condiciones identificadas, cuyo insumo son los resultados de la fase de evaluación 
anterior; y cuyo fin, es obtener como resultado no la mejor alternativa sino la mejor combinación de alternativas, que cumpla con las limitantes identificadas.

En el último caso, la aplicación del modelo de valor propuesto en el capítulo 4 de este documento en combinación con técnicas de programación lineal permite aprovechar las ventajas que cada método ofrece para aproximarse a una solución más ajustada a las condiciones en el marco de las cuales debe tomarse la decisión sobre la ejecución de una o más alternativas de inversión, y/o su inclusión en los planes de una nación, región, localidad o empresa.

El procedimiento ofrece la posibilidad de utilizar el modelo de valor propuesto en su forma original o ajustado a las características del problema a resolver y a la calidad de la información disponible; o de crear un modelo de valor propio en cuyo caso se sugiere seguir las pautas incluidas en el capítulo 4 de este documento.

Naturalmente, la calidad de los resultados obtenidos dependerá de las cualidades de la información insumo al proceso que debe ser completa, consistente y confiable; del conocimiento y experiencia en la materia que tengan los ingenieros y expertos a cargo del proceso de formulación y evaluación del proyecto; de la disponibilidad de recursos requeridos para ello; y finalmente, del interés y constancia que pongan todos los participantes en el logro de la mejor propuesta posible. 


\section{Conclusiones y trabajos futuros}

Cada nación debe desarrollar los mejores planes de utilización de sus fuentes energéticas atendiendo a sus necesidades de energía y a la disponibilidad de los presupuestos requeridos para lograrlo. En tal sentido, cualquier esfuerzo que facilite la evaluación formal y sistemática de proyectos, programas o planes en el sector; y de allí, la selección de las mejores opciones para su ejecución, contribuye a una mejor toma de decisiones en el mundo altamente competitivo de hoy día.

El diseño y la propuesta de una metodología para la evaluación integral de proyectos en el sector energético y para la selección de sus mejores alternativas de solución, constituyeron el objetivo central del trabajo de investigación realizado.

Las actividades cumplidas para lograr el objetivo señalado, se organizaron a partir de las hipótesis formuladas en el capítulo introductorio de este documento y alrededor de los objetivos específicos enunciados en el mismo. Las hipótesis formuladas se han comprobado y los objetivos se han cumplido. A continuación las principales conclusiones alcanzadas al respecto y algunas sugerencias sobre posibles líneas de investigación que pueden derivarse del trabajo realizado.

\section{Conclusiones}

A efectos de su exposición, las conclusiones se organizan siguiendo el orden de presentación de las materias en el documento:

- La aplicación de metodologías multicriterio como apoyo a la toma de decisiones con la participación de múltiples actores en el análisis, ubicados o no en la misma localización geográfica, con diferentes intereses y opiniones, ha venido 
sustituyendo al uso de metodologías de optimización de sólo un objetivo que pueden desviarse considerablemente de la forma de tomar decisiones en el mundo de hoy día. El desarrollo de las redes de telecomunicaciones, Internet, la diversidad de aplicaciones informáticas y las velocidades de acceso y procesamiento de la información ha incentivado la inventiva de los analistas y propiciado un enfoque más amplio de los problemas de la vida moderna.

- El tema de análisis multicriterio ha venido adquiriendo especial relevancia desde finales del siglo pasado como lo demuestra el creciente número de publicaciones en revistas especializadas sobre la materia, sus métodos y sus aplicaciones. En el sector energético los métodos se han utilizado especialmente en el estudio de la sostenibilidad de planes y programas de desarrollo con la participación de recursos renovables y no renovables, y en la selección de tecnologías para su aprovechamiento; entre otros tópicos.

- La programación multiobjetivo, la programación por metas y los procedimientos basados en funciones de valor, en relaciones de sobrecalificación; en jerarquías analíticas o en redes analíticas son métodos de análisis multicriterio. Entre ellos, es el Proceso de Jerarquías Analíticas de Saaty el que ha reunido el mayor número de publicaciones en la última década. Su fácil comprensión, su sencillez de uso y su capacidad para incorporar información de índole cuantitativa y cualitativa al análisis, procedente de más de un participante; unido a la existencia de Expert Choice $\AA$, una herramienta computacional que permite verificar la consistencia de la data recabada por participante, consolida la información y proporciona los resultados esperados en pantallas amigables, lo han convertido en uno de los métodos más utilizados para la evaluación multicriterio de alternativas de inversión.

- El Proceso de Jerarquías Analíticas puede utilizarse individualmente o combinado con técnicas de programación lineal, como plataforma metodológica para la evaluación de proyectos en el sector energético y para la selección de la mejor solución entre las posibles alternativas de acción. La combinación de los dos métodos en el análisis del problema no sólo potencia las ventajas que ofrece cada 
uno sino que permite incorporar a la solución. las limitantes propias del país sede del proyecto y obtener resultados más ajustados a la realidad.

- El sector energético tiene que ver con la recuperación y transformación de diferentes tipos de fuentes de energía en calor, electricidad y combustibles, fundamentales para el desarrollo económico de los países y una buena calidad de vida para sus pobladores. El sector se caracteriza por la existencia de múltiples fuentes de energías y de múltiples tecnologías para su explotación, la alta participación de energías fósiles en un elevado consumo mundial de energía y la contaminación ambiental que su uso causa; la desigualdad en la tenencia de las reservas energéticas convencionales y en el acceso a los productos energéticos básicos como la electricidad y los combustibles; el agotamiento a mediano plazo de tales reservas; la participación de grandes intereses económicos en el negocio; la continua investigación y aparición de nuevas tecnologías para el aprovechamiento de las energías renovables y la creciente participación de estas energías 'limpias' en el suministro de energía mundial; entre otras particularidades.

- La participación mayoritaria de los combustibles fósiles en el elevado consumo mundial de energía tiene un efecto directo sobre el calentamiento global del planeta, preocupación principalísima de sus pobladores en los últimos tiempos. En efecto, el procesamiento del petróleo y la combustión de sus derivados líquidos en industrias, plantas eléctricas; y especialmente, en el sector transporte, arroja a la atmósfera grandes cantidades de $\mathrm{CO}_{2}$ y otros gases causantes del efecto invernadero. Adicionalmente. emisiones de gases ácidos, gases orgánicos y partículas deterioran el ambiente y tienen efectos nocivos sobre la salud de la población.

- Las reservas de petróleo en el mundo están en manos de un grupo muy limitado de países en desarrollo, algunos de ellos políticamente inestables y muchos de ellos agrupados en la Organización de Países Exportadores de Petróleo (OPEP) la cual tiene una considerable influencia sobre los volúmenes comercializados y sus precios en el mercado. La situación del gas es similar pero menos crítica. 
Todo ello causa la dependencia energética de los países que no disponen de petróleo o gas en cantidad suficiente para satisfacer sus necesidades, hacia los países con capacidad de exportar excedentes de producción; y configura una situación de amenaza a la seguridad energética de los países importadores ya sea por la probabilidad de una interrupción física del suministro o por la imposibilidad de pagar la cuantiosa factura asociada al mismo.

- A la tasa de consumo actual, la duración de las reservas probadas de petróleo convencional es de unos 46 años mientras que la de gas natural convencional se acerca a unos 60 años, sin incluir los nuevos descubrimientos que puedan ocurrir. De esta forma, su agotamiento a corto plazo no es un problema; por el contrario si lo es, la declinación de la tasa de producción mundial si no se efectúan las inversiones necesarias para el mantenimiento de los yacimientos, especialmente de aquellos explotados por un largo período de tiempo.

- Desde mediados del siglo pasado, los países productores de petróleo y gas han venido recuperando el control de sus respectivas industrias, originalmente en manos de grandes consorcios internacionales. Países como Irán, Irak, Libia, México, Bolivia, Perú, Ecuador, Brasil y Venezuela han constituido empresas nacionales que han asumido el manejo del negocio. En Venezuela, la nacionalización de la industria se produjo en el año 1975; y en años recientes, las empresas operando en el país han sido objeto de un proceso de expropiación de las instalaciones y proyectos en curso. Muy recientemente, Argentina ha procedido de forma similar.

El hecho ha producido con alguna excepción, la declinación de la producción en estos países, por falta de los grandes capitales requeridos especialmente en las áreas de exploración, desarrollo y explotación de nuevos yacimientos; de la disponibilidad de nuevas tecnologías y de la experiencia necesaria para el buen desenvolvimiento de las operaciones.

- Aproximadamente un $25 \%$ de personas en el mundo no tienen acceso a la electricidad ni a los modernos combustibles necesarios para mejorar la calidad de sus vidas. Hoy día, existen en el mundo más de 1.400 millones de personas sin acceso a electricidad y unos 2.700 millones que dependen de la biomasa UNIVERSIDAD POLITÉCNICA DE VALENCIA. TESIS DOCTORAL. Violeta Parodi 
tradicional para la cocción de sus alimentos; mayoritariamente localizados en las zonas rurales de los países menos desarrollados. En Latinoamérica, la cifra alcanza unos 31 millones de habitantes. China y Estados Unidos consumen más energía que cualquier otro país en el mundo.

- Ante los problemas citados, la contribución de las energías renovables al suministro global ha venido creciendo y se continúa la búsqueda de tecnologías más eficientes y rentables para su aprovechamiento. La comunidad internacional se ha movido en esa dirección; y desde hace algunos años, la casi totalidad de los países del mundo han firmado acuerdos y adquirido compromisos con el objetivo final de resguardar el ambiente en el planeta.

Sin embargo, las metas sólo se han cumplido parcialmente. Con excepción de algunos casos notables en la Comunidad Europea, Estados Unidos, China y unos pocos países en Latinoamérica que han puesto en marcha ambiciosos desarrollos eólicos y solares y/o programas de producción de biocombustibles con gran éxito; muchas de las iniciativas tecnológicas en el área no han logrado su paso a escala comercial debido fundamentalmente a las grandes inversiones necesarias que elevan el costo del producto final a precios no competitivos con los de productos similares derivados de los combustibles fósiles. En Venezuela, el desarrollo de las energías renovables a excepción de los grandes complejos hidroeléctricos ubicados al sur del país, es prácticamente nulo.

Adicionalmente, está la crítica de los escépticos, especialmente cuando se habla de biocombustibles procedentes de cultivos dedicados de maíz. En efecto, se han expresado dudas sobre el balance energético para todo su ciclo de vida allí incluido el cultivo de la biomasa requerida, sobre la dedicación de terrenos que de otra forma se dedicarían al cultivo de alimentos y sobre el desplazamiento de las cosechas de maíz a la producción de biocombustibles causando el incremento de los precios regulares que como alimento tiene el cultivo.

- Al menos por ahora y a causa de los graves accidentes ocurridos en instalaciones nucleares existe una tendencia al abandono de la utilización de este tipo de energía. A un año de los acontecimientos de Fukushima, Japón, algunos países en Europa tienen plazos fijos para el cierre de sus reactores nucleares y elaboran UNIVERSIDAD POLITÉCNICA DE VALENCIA. TESIS DOCTORAL. Violeta Parodi 
planes que apoyen el desarrollo de las energías renovables; otros países han paralizado los planes de construcción de nuevos reactores hasta tanto no se compruebe la robustez de sus sistemas de seguridad ante eventos extremos e incluso ante ataques terroristas. Japón ha apagado la totalidad de sus reactores y se ha ordenado no reabrirlos si no pasan las pruebas que comprueben que pueden operar con seguridad. Estados Unidos, China, India, Rusia, México, Brasil, Argentina y otros países han seguido con sus planes y operaciones previo una revisión de sus sistemas de seguridad. En tanto, Irán y Venezuela esgrimen su derecho a utilizar la energía nuclear con fines pacíficos y gestionan la construcción de su primer reactor nuclear.

- El sector energético es un sector muy dinámico e interrelacionado con los otros sectores de la economía. Para el funcionamiento sostenible de sus proyectos se requiere la definición y cumplimiento de políticas energéticas y marcos regulatorios adecuados; el desarrollo de tecnologías más eficientes y menos costosas en el campo de las energías renovables; medidas estrictas para la protección del ambiente y sus poblaciones, especialmente en el caso de desarrollos nucleares; el mejoramiento de los rendimientos a lo largo de la cadena de operaciones que llevan al aprovechamiento de cada fuente energética, y mayores eficiencias en el uso de sus productos derivados; personal capacitado y responsable en las tareas que le toque desempeñar, grandes inversiones; y finalmente, la colaboración de todos en el uso racional de los recursos energéticos disponibles a fin de contribuir a disminuir la brecha entre los que tienen y no tienen acceso a la energía; y de frenar en la medida de lo posible, el deterioro acelerado del clima y del ambiente en el planeta.

- Existe una gran variedad de recursos energéticos en el mundo. Cada tipo de recurso posee características propias en cuanto a su carácter renovable o no, en cuanto a la ubicación y magnitud de sus reservas o de su potencial energético desarrollable, a la madurez y flexibilidad de las tecnologías para su extracción o captación, y para su transformación en potencia eléctrica, calor o combustibles; en cuanto a los rendimientos y costos asociados, la disponibilidad en el mercado de los equipos necesarios para su explotación y el período para la construcción y puesta en marcha de las instalaciones necesarias; en cuanto a las técnicas y 
costos para su transporte y para la distribución de sus productos derivados, las vías de comercialización y sus precios; en cuanto a los niveles de contaminación que su explotación y uso causan, los riesgos de su explotación y transformación para el ambiente y sus poblaciones, la aceptación de su desarrollo por parte de las comunidades aledañas; y en cuanto a la existencia o no, en las regiones de interés de un marco legal que regule y controle las operaciones y la disposición de residuos peligrosos; entre otras cosas.

- Tomando como punto de partida las características antes mencionadas, es posible seleccionar un grupo de atributos diferenciadores entre uno u otro recurso energético, cuando se evalúa su aprovechamiento frente a los objetivos de minimizar los problemas del sector tipificados anteriormente y maximizar los beneficios derivados de ello.

En efecto, la investigación realizada sobre diecinueve tipos de recursos energéticos permitió identificar originalmente un total de 76 aspectos diferenciadores que podían afectar la priorización de proyectos en el área; éstos fueron reducidos progresivamente a 59, 44 y 24 aspectos agrupados de acuerdo a su naturaleza, en seis dimensiones: técnica, económica, ambiental, social, estratégica y de riesgo. La reducción se realizó en base a rondas de consulta a expertos, reflexión y el análisis estadístico de las opiniones recabadas. A cada aspecto se asignó un objetivo y un criterio que guiase la evaluación del grado de cumplimiento del objetivo, por parte del potencial proyecto bajo estudio. Los criterios seleccionados fueron agrupados en una estructura jerárquica de tres niveles y la estructura validada de nuevo por académicos y profesionales. Dada la amplitud de la investigación realizada y el número de validaciones efectuadas, el conjunto de criterios resultante puede considerarse como representativo de los aspectos importantes que pueden afectar la priorización de proyectos en el área.

De esta forma, se comprueba la primera hipótesis del trabajo propuesto que dice textualmente, "Para el sector energético de cada país, es posible identificar y validar un conjunto común de objetivos, atributos y criterios relevantes, significativos, fácilmente entendibles y no redundantes que reflejen los aspectos importantes que pueden afectar la priorización de proyectos en el área". 
- Es posible diseñar un sistema de indicadores de naturaleza cualitativa y/o cuantitativa, que se corresponda con la estructura jerárquica de criterios propuesta para la evaluación de un proyecto de inversión en el sector energético. Los indicadores permiten "medir" el desempeño de una propuesta de inversión con relación a cada criterio en la jerarquía propuesta.

En efecto, fue diseñado un sistema de 24 indicadores, correspondiente a la estructura jerárquica propuesta. La inclusión de cada indicador fue justificada y resumidas sus características en un ficha resumen contentiva de su definición, sus unidades originales de medida, las posibles fuentes de información para su estimación y una escala alternativa [1-5] para su medición. El sistema fue comparado contra la bibliografía especializada existente al respecto y validado con la opinión de expertos en el sector académico, en el sector público o en el sector privado en el país.

De esta forma, se comprueba la segunda hipótesis del trabajo propuesto que dice textualmente, "Para el sector energético de cada país, es posible definir y validar un conjunto común de indicadores que permitan la cuantificación de los atributos previamente identificados y validados".

- La importancia relativa de cada criterio incluido en la estructura jerárquica construida pudo obtenerse a partir de los respectivos juicios de valor de expertos radicados en Venezuela, Estados Unidos, Panamá, Bélgica y España. Todo el conjunto validado de objetivos, criterios, indicadores y pesos puede utilizarse como modelo de valor para la evaluación y ordenamiento de un grupo de alternativas de inversión en el sector energético. La aplicación del modelo permite obtener un coeficiente de robustez para cada alternativa a evaluar que consolida el desempeño de la misma con relación a cada criterio de evaluación; y que por tanto puede utilizarse para caracterizar dicha alternativa en un proceso de selección u ordenamiento de las mismas.

En el modelo jerárquico de criterios para la evaluación obtenido, la mayor importancia $(24,3 \%)$ correspondió a la dimensión riesgo reflejando sin duda el temor a potenciales daños causados por falla de las instalaciones, especialmente si ellas manejan material radioactivo. Lo siguen en importancia las dimensiones 
ambiental $(20,5 \%)$ y económica $(15,3 \%)$ lo que constituye un resultado esperado dada la relevancia que ha adquirido el tema de impacto ambiental; y la que siempre ha tenido el rendimiento económico de las alternativas a efectos de su evaluación. Por su parte, las dimensiones técnica $(13,7 \%)$, estratégica $(13,5 \%)$ y social $(12,2 \%)$ tienen importancias relativas semejantes, siendo ligeramente inferior la correspondiente a los aspectos sociales.

De esta forma, se comprueba la tercera hipótesis propuesta en el trabajo realizado que dice textualmente," Para el sector energético de cada país, es posible formular un modelo de valor de apoyo a las decisiones en el área que incorpore los aspectos económicos, sociales y ambientales que puedan influir en la priorización de proyectos técnica y legalmente viables en el área.

- El modelo de valor propuesto se utilizó con éxito en la evaluación de posibles soluciones al suministro de energía eléctrica en Venezuela, ante la crisis que vive el país y que tuvo su máxima expresión en el año 2010 cuando una sequía prolongada comprometió seriamente los niveles del Guri, embalse que alimenta al principal complejo hidroeléctrico del país. En tal oportunidad, el sistema eléctrico nacional sólo fue capaz de responder parcialmente a la demanda de la nación, produciéndose apagones y racionamientos del fluido eléctrico en todo el territorio nacional.

El objetivo general a cumplir se estableció como el diseño de una matriz eléctrica para Venezuela a ejecutar a lo largo del período 2011-2025, basada en los potenciales desarrollables de cada fuente energética que posee el país y en su demanda estimada; y sujeta a las limitaciones financieras de la nación y a los compromisos y convenios internacionales que la misma ha suscrito. Para su uso como insumo a la resolución del problema, se proyectó la demanda eléctrica del país al período señalado, en tres escenarios: bajo, mediano y elevado crecimiento económico.

- La información de fuentes oficiales requerida para la completa definición del problema y de sus posibles alternativas de solución resultó poco clara, escasa y a veces puntual, no consistente, no completa; y en general, no confiable. 
Constituyó una excepción, alguna información sobre planes en el sector obtenida de CORPOELEC, la empresa estatal a cargo de todas las operaciones en el sector.

De esta forma, gran parte de la data utilizada se obtuvo de publicaciones, conferencias y entrevistas en los medios de comunicación, ofrecidas por expertos en el sector privado. En lo posible, cada cifra fue confirmada en varias fuentes. Información promedio sobre tecnologías de generación eléctrica, sus rendimientos, sus costos, sus niveles de impacto ambiental y similares se obtuvo de publicaciones en revistas especializadas y de informes de agencias internacionales muy reconocidas en sus respectivas áreas de experticia.

- Nueve opciones de generación eléctrica fueron seleccionadas como alternativas a evaluar. Cada una ellas se definió en función a la fuente de energía primaria que propone utilizar para suplir los requerimientos de energía eléctrica del país, y a la tecnología básica necesaria para su transformación. Las fuentes de energía primaria incluidas en el análisis fueron petróleo, gas, carbón, biomasa y las fuentes de energía nuclear, hidráulica, eólica, solar y geotérmica. El modelo de valor propuesto se aplicó exitosamente en su evaluación y posterior ordenamiento.

- Las opciones eólica e hidráulica encabezaron los ordenamientos a nivel individual y grupal. Su naturaleza renovable y su bajo impacto ambiental frente a opciones como la combustión de carbón o de derivados líquidos del petróleo, ambos altamente contaminantes, influyeron sin duda en la selección. La existencia de un alto potencial hidráulico en el sur del país y de potencial eólico desarrollable al norte del mismo; la experiencia acumulada en la construcción y operación de plantas hidroeléctricas, y la disponibilidad de al menos parte de la red de distribución requerida para la transmisión de la electricidad a generar; la percepción de la poca complejidad de equipos, operación y logística de la opción eólica y su bajo costo frente a otras opciones de energía renovable incidieron en la buena calificación obtenida.

- Por el contrario, la alternativa de generación nuclear obtuvo un coeficiente de robustez muy inferior al resto de las opciones. De esta forma, sobre el gran atractivo que significa la enorme cantidad de calor que puede obtenerse de la UNIVERSIDAD POLITÉCNICA DE VALENCIA. TESIS DOCTORAL. Violeta Parodi 
fisión de una pequeña porción de material nuclear, prevaleció la percepción de las terribles consecuencias que puede generar un accidente nuclear como el ocurrido hace poco más de un año en Fukushima, Japón, independientemente de su baja probabilidad de ocurrencia.

En el caso de Venezuela, el país no dispone de la tecnología ni del personal entrenado para participar en la instalación, operación y mantenimiento de instalaciones que por su naturaleza deben ser estrictamente controladas y reguladas. Tampoco se dispone de un marco legal que norme tales actuaciones ni la disposición de desechos radioactivos producto de las operaciones. La percepción de la gente es que el gobierno nacional maneja en forma poco clara, la posibilidad de la instalación de un reactor nuclear con fines pacíficos y tecnología no probada. Por otra parte, aunque Venezuela dispone de reservas de uranio no explotadas, el material debe ser sometido a una serie de operaciones muy especializadas para convertirlo en material apto para el reactor; ello pondría al país en situación de dependencia de los centros que poseen la tecnología, los equipos y la experiencia para realizar tales transformaciones. Todo ello, se reflejó en las opiniones de los expertos para dar a la alternativa nuclear la última opción.

- La alternativa de generación eléctrica con turbinas de gas resultó mejor opción que otras opciones con base en recursos fósiles que se perciben como menos 'limpias' y con inversión inicial más elevada. Por su parte, el aprovechamiento de la biomasa para la generación de energía eléctrica mostró elevada preferencia por parte de algunos de los entrevistados. Otras opciones de generación mostraron puntuaciones intermedias.

- La identificación de la "mejor combinación" de uso de las fuentes de energía primaria para generación eléctrica en el país, sujeta a las limitantes existentes, requirió el planteamiento y resolución de un modelo de programación lineal. A efectos de su solución, se definió como "mejor combinación" aquella que proporciona la máxima robustez al sistema; y ésta a su vez, como una función lineal a maximizar igual a la suma de las capacidades de generación a instalar ponderadas por los respectivos coeficientes de robustez obtenidos de la aplicación del modelo de valor en la evaluación de las alternativas planteadas. 
Restricciones relativas a la capacidad total mínima de generación a instalar, a los potenciales desarrollables de cada recurso energético considerado, al presupuesto asignado, y a las participaciones mínimas de recursos renovables, carbón y coque de petróleo, generación nuclear y generación hidroeléctrico, en el suministro total a generar, acotaron la solución al problema.

Las restricciones colocadas forzaron la participación de las opciones basadas en carbón, energía nuclear y potencial hidráulico en la solución obtenida que también incluyó las opciones a gas y eólica hasta completar un suministro de 120.000 GWh adicionales a instalar a lo largo del período 2013-2025. La solución inicial no incluyó ninguna otra energía renovable ni generación adicional basada en derivados del petróleo.

- Un análisis de sensibilidad de los resultados obtenidos ante cambios en las restricciones planteadas logró mejorar la solución, no ajustada a la realidad de un país cuya principal actividad económica es la explotación, refinación y comercialización de petróleo y sus productos derivados. Cambios en el nivel de presupuesto asignado, y en las participaciones mínimas de las opciones basadas en carbón, energía nuclear, gas, petróleo y energías renovables permitieron obtener una visión más amplia del problema a resolver.

- La evaluación final se realizó en base al coeficiente robustez y al índice de diversidad de cada una de cinco soluciones preseleccionadas; este último como un indicador del incremento en la seguridad energética que proporciona la solución al país, si se incrementan en la proporción adecuada el número de fuentes energéticas incluidas en ella.

Finalmente, dos soluciones fueron propuestas para la ampliación del suministro eléctrico en el país, durante el período 2013-2025; ambas son similares excepto por la participación o no de la energía nuclear en ellas. La implementación y puesta en marcha de una u otra es capaz de añadir $120.000 \mathrm{GWh}$ al suministro para el año 2025; y en ambas, la participación de las opciones basadas en carbón (25\%), derivados líquidos de petróleo (8,3\%), gas natural $(8,3 \%)$ y energía eólica $(15 \%)$ es similar; el resto $(43,4 \%)$ corresponde a energía hidráulica en una de las opciones; o se comparte entre energía nuclear (11.5\%) y energía hidráulica UNIVERSIDAD POLITÉCNICA DE VALENCIA. TESIS DOCTORAL. Violeta Parodi 
$(31,9 \%)$ en la otra. Para lograr este nivel de suministro es necesario instalar 27.100 MW a lo largo del período 2013-2025 MW para una de las opciones; y dada las diferentes eficiencias, $28.000 \mathrm{MW}$ para la otra.

- Las estimaciones señalan que para el año 2025 se requerirán unos 2.100 millones de metros cúbicos estándar de gas natural/año y 34,4 miles bbls/día de gasoil/fueloil adicionales al consumo actual, de implementarse y entrar en operación uno u otro de los planes propuestos. Tales volúmenes deberán ser importados o sustraídos de la exportación, hasta tanto se desarrolle capacidad adicional de producción en los yacimientos de gas y capacidad adicional de refinación en las refinerías del país.

- La distribución en el territorio nacional de las soluciones sugeridas para el suministro de nueva potencia eléctrica en Venezuela debe ser resuelta en base a proyectos específicos que suministren no sólo la necesaria información de carácter técnico, económico y de impacto ambiental sino los detalles sobre requerimientos de tierras, agua, accesos y costo de infraestructura requerida para conectar la fuente de energía primaria con las instalaciones de generación de potencia eléctrica; y éstas a su vez con las regiones demandantes, a través de una red de distribución eléctrica confiable. Adicionalmente deberá tomarse en cuenta la aceptación que pueda tener cada proyecto, por parte de la comunidad afectada. Cada uno de tales requerimientos pueden resultar limitante en la decisión final.

- El cronograma de ejecución de las soluciones sugeridas para la ampliación del suministro de potencia eléctrica en Venezuela a lo largo del período 2013-2025, debe ajustarse a la evolución estimada de la demanda para dicho período, a la urgencia de instalación en cada zona del país, a la disponibilidad de equipos en el mercado, a la inversión requerida frente a los recursos financieros disponibles y a los lapsos de construcción y puesta en marcha de las instalaciones asociadas a cada tipo de tecnología.

- En base a los lapsos de construcción promedio de las instalaciones de las diferentes alternativas de generación, un factor que ajuste tales lapsos a la baja efectividad en la ejecución de proyectos que ha demostrado el país en los últimos 
años y un período prudencial de tiempo para disponer de los respectivos estudios, se requerirán al menos unos cinco años para contar con las instalaciones con períodos de construcción más cortos; esto es, aquellas que basan su operación en la combustión de gas natural o derivados líquidos del petróleo, o en la energía eólica. Las instalaciones de generación asociadas a tecnologías basadas en la combustión de carbón o coque de petróleo, las plantas hidroeléctricas y las plantas nucleares requerirán lapsos más largos.

De esta forma, en el plazo inmediato sólo queda recuperar y/o actualizar las instalaciones existentes, la instalación de pequeñas plantas termoeléctricas a petróleo o gas, o eólicas; y paralelamente, la elaboración de un plan estratégico para el desarrollo e incorporación progresiva de centrales a mayor escala que son las que finalmente resolverán el problema del suministro de energía eléctrica.

A mediano y largo plazo y en la medida de que se disponga de los proyectos y los recursos monetarios para su financiamiento, podrán ponerse en marcha programas más ambiciosos que contemplen el aprovechamiento de las reservas de petróleo, gas, carbón y del gran potencial hidráulico que posee el país. Para ello será necesario la activación urgente de planes de desarrollo de sus reservas gasíferas, la expansión de su capacidad de refinación, el incremento de su producción petrolera; y finalmente, las acciones que lleven a la progresiva recuperación de las cuencas hidrológicas al sur del país.

- El presupuesto de inversión necesario para la construcción y puesta en marcha de las instalaciones para generación de nueva energía eléctrica asociado a una u otra de las soluciones sugeridas alcanza unos 65 mil millones US\$, distribuidos a lo largo del período 2013-2025. El monto oscila entre 100 y 130 mil millones de US\$ si se incluye la inversión para la distribución de la energía adicional producida, dada la condición de falta de mantenimiento que presenta la red hoy existente en el país.

- Las matrices eléctricas que tendría el país para el año 2025 , en caso de implementarse una u otra de las soluciones propuestas son similares excepto por la participación o no de la energía nuclear en ellas. La adopción y total puesta 
marcha de cualquiera de ellas, producirá unos 260.000 GWh para ese año; y en ambas, la participación de las opciones basadas en carbón (11.5\%), derivados líquidos de petróleo $(20,5 \%)$, gas natural $(10,8 \%)$ y energía eólica $(6,9 \%)$ es similar; el resto $(50,2 \%)$ corresponde a la participación de la energía hidráulica en una de las soluciones propuestas; o se comparte entre energía nuclear (5.3\%) y energía hidráulica $(44,9 \%)$, si se adoptase la otra solución. Para lograr este nivel de suministro es necesario incorporar entre 27,100 MW y $28.000 \mathrm{MW}$ durante el período 2013-2025 y 4.420 MW durante el período 2010-2012 correspondientes a planes ya en ejecución del gobierno nacional; para un total que oscila entre 31.520 MW y 32.420 MW a incorporar para el período 2011-2025. Si estas cifras se añaden a 15.129 MW de instalaciones disponibles para el año 2010, se obtiene el total de capacidad de generación para el año 2025.

- Cualquiera de las matrices eléctricas propuestas para el año 2025 tiene menor robustez que la correspondiente al año 2012; y ésta es menos robusta que la del año 2010. Tal resultado no puede evitarse si la solución se supedita a participaciones mínimas de generación basada en carbón, derivados de petróleo y de la opción nuclear. Por el contrario, la diversidad del sistema mejora en la medida que se incluye un mayor número de fuentes energéticas en el mismo.

- La relación entre las respectivas participaciones de energía hidroeléctrica y energía termoeléctrica en las matrices eléctricas 2025, se mueve desde 1,9 en el año 2010 a una relación estimada de 1,2 o 0,9 para el año 2025, para uno u otro caso. Ello se corresponde con la política nacional de basar la expansión del sistema eléctrico nacional en generación termoeléctrica y disminuir la importancia de la generación hidroeléctrica.

- La participación de las energías renovables en la matriz energética para el sector eléctrico se mueve desde cero en el año 2010 a una participación estimada de $6,9 \%$ para el año 2025. Esta meta recomendada por la solución al problema es difícil de obtener dado el modesto conocimiento y poquísima experiencia que en la materia tiene el país; frente a la existencia de una industria petrolera instalada, en funcionamiento por muchos años, y de las grandes reservas de crudo de las cuales dispone la nación. 
- La propuesta realizada debe verse como una aproximación al problema del suministro eléctrico en Venezuela; aún así, puede contribuir a orientar los planes que en el sector se efectúan y a focalizar el estudio en las alternativas energéticas que efectivamente pueden hacer más robusto el sector eléctrico del país.

- La solución de un caso complejo de la realidad venezolana, con participación de las opiniones de profesionales en el sector académico, empresarial y estatal, ubicados en diferentes localidades geográficas mostró la potencialidad de los métodos de análisis multicriterio, especialmente si se combinan para aprovechar las ventajas que ofrece cada uno de ellos.

El trabajo realizado y la experiencia obtenida en la solución del caso de estudio planteado, fueron reflejados en una propuesta metodológica para la evaluación integral de proyectos en el sector energético. La metodología establece una secuencia de actividades a cumplir para obtener la mejor solución entre un grupo de alternativas de acción, institucional, técnica, ambiental y económicamente viables, identificadas para cumplir con los objetivos del proyecto. Para la evaluación y selección de la mejor solución, la metodología propone la aplicación combinada del Proceso de Jerarquías Analíticas (AHP, por sus siglas en inglés) y de técnicas de programación lineal.

Si las alternativas son excluyentes, será suficiente para su evaluación, priorización y selección de la mejor entre ellas, la aplicación de la estructura jerárquica de criterios (AHP) para la valoración de alternativas de inversión en el sector energético desarrollada en este trabajo. Si las alternativas son independientes, será necesario utilizar los resultados de esta primera etapa de la evaluación en el planteamiento de un modelo de programación lineal cuya resolución permita obtener la mejor combinación posible de las alternativas incluidas en el estudio, todo sujeto a las restricciones propias del país sede el proyecto.

De esta forma, se comprueba la última hipótesis planteada en el trabajo realizada, que dice textualmente, "Dado que las decisiones sobre planes y proyectos en el sector energético competen a las autoridades locales, regionales o nacionales de un país, es deseable incorporarlas junto a otros expertos en el área, al proceso de validación de objetivos, atributos, criterios e indicadores previamente 
identificados. Si se cumple este paso, es posible formular una metodología para la evaluación integral de proyectos en el sector, que sea sencilla de aplicar, compatible con la información disponible, que provea el tipo de resultados requerido y que se perciba como confiable por parte del decisor".

\section{Trabajos futuros}

El trabajo realizado puede servir como referencia a una serie de futuras líneas de investigación relacionadas al tema de evaluación integral de proyectos; entre las cuales, se incluyen:

- Diseño de estructuras jerárquicas de criterios para la evaluación, priorización y selección de alternativas de inversión de viabilidad comprobada, en sectores o subsectores seleccionados de la actividad productiva del país.

De acuerdo al sector donde se ubiquen las opciones a evaluar y a la motivación de sus patrocinadores, el objetivo final podría mantenerse como la maximización de la robustez de la solución, expresada ésta como un índice del desempeño global de la misma en las dimensiones técnica. económica ambiental, social, estratégica y de riesgo. O podría reducirse a uno de los siguientes objetivos: maximizar el beneficio social, minimizar el impacto ambiental, maximizar el impacto económico o el número de empleos en la región de influencia del proyecto, maximizar el beneficio económico, minimizar el riesgo para las comunidades o maximizar el grado de satisfacción de los usuarios, todo sujeto a una demanda estimada a cumplir y a las restricciones propias del país sede del proyecto. Nótese que aunque el objetivo final reduzca su alcance, su cumplimiento sigue expresándose como una combinación ponderada del cumplimiento de los objetivos parciales en la estructura jerárquica que corresponda.

Entre los sectores típicamente generadores de proyectos a evaluar se cuentan: el sector de producción primaria relacionado con la explotación minera, petrolera, agropecuaria, pesquera y forestal; el sector industrial en todas sus vertientes y escalas, dedicado a la producción y comercialización de alimentos, bebidas, detergentes y productos de consumo masivo en general, textiles, plásticos, químicos, papel, derivados del petróleo y muchos otros productos; el sector de 
prestación de servicios como el transporte, el suministro eléctrico y de agua potable y las comunicaciones; y el sector de la construcción de vivienda y obras de infraestructura económica, social, cultural y turística.

Mención especial merece el sector académico en su búsqueda de los mejores planes, programas y métodos que potencien la inventiva y capacidad de emprendimiento en el estudiante, lo motive a la investigación y al aprendizaje continuo, y lo capacite para su buen desempeño como profesional y como ciudadano con sensibilidad social y respeto hacia los demás.

- Exploración de métodos combinados para la evaluación integral de proyectos en sectores o subsectores seleccionados de la actividad productiva del país. Así, puede investigarse la potencialidad como instrumento de análisis de metodologías basadas en la utilización de:

- Métodos de análisis conjunto para el diseño de productos y la predicción de sus posibles cuotas de mercado, combinados con el diseño y aplicación de modelos jerárquicos de criterios para la evaluación de los proyectos respectivamente asociados a los productos diseñados. De acuerdo a los objetivos planteados podría seleccionarse para su ejecución el mejor de los proyectos evaluados; o a continuación, plantearse un modelo de programación lineal que permita seleccionar la mejor combinación posible de artículos a producir y comercializar de acuerdo a la valoración obtenida en la etapa anterior. Este tipo de tratamiento puede aplicarse para obtener propuestas que apoyen la toma de decisiones en cuanto al lanzamiento al mercado de alimentos, bebidas, productos de belleza, jabones, pañales y en general todo tipo de productos de consumo masivo.

- Modelos jerárquicos de criterios especialmente diseñados para la evaluación de proyectos en grandes sectores de la vida económica de un país combinados con el planteamiento y resolución de modelos de programación lineal para la obtención de la mejor combinación posible de las alternativas bajo evaluación; y de modelos de transporte que permitan obtener la mejor localización posible para ellos. Este tipo de tratamiento puede utilizarse como apoyo en el diseño de planes de desarrollo de un país, en sectores o subsectores como el cultivo 
de alimentos, el suministro de vivienda, educación, salud, agua potable y de servicios como comunicaciones y turismo; entre otros. Todos ellos, son proyectos de gran envergadura que requerirán del concurso de un grupo de trabajo conformado por ingenieros y expertos en los tópicos que sean necesarios, capaces de buscar o generar la información que haga falta; o de contratar los estudios que la complementen.

Como una ilustración al procedimiento sugerido, puede pensarse en añadir a la metodología seguida para obtener una matriz eléctrica para Venezuela 2025, el planteamiento y resolución de un modelo de transporte, que seleccione la ubicación geográfica de cada alternativa de generación incluida en la solución, de tal forma que se minimice el costo de distribución de la electricidad producida, En base a la demanda 2011-2025 para el país, estimada durante el trabajo realizado y de la ubicación de los recursos energéticos necesarios el planteamiento del modelo puede realizarse por región o para todo el país, La solución al problema requiere información detallada y muy especializada de los componentes del costo de transmisión y distribución de una unidad de energía, allí incluida cualquier inversión adicional que sea necesario efectuar en la actualización de la red eléctrica venezolana.

Más específicamente, con relación al desarrollo de temas de investigación relacionados con la evaluación integral de proyectos en el sector energético, pueden sugerirse:

- El estudio de la potencialidad de la Orimulsión, mezcla emulsionada de $70 \%$ de crudo extrapesado, $30 \%$ de agua y una pequeña cantidad de surfactante, frente a otras alternativas para la generación de electricidad en el país. La orimulsión fue desarrollada y patentada en Venezuela en la década de los años 80, tiene un alto rendimiento de combustión, es menos contaminante que el carbón y más fácil de transportar que el crudo extra pesado. Fue utilizada con éxito como sustituto del carbón en plantas eléctricas hasta que en el año 2003, el gobierno nacional decidió que el negocio no rendía los dividendos suficientes y paralizó su producción y venta. El país tiene grandes reservas de petróleo extra pesado en la Faja del Orinoco, materia prima para la producción del combustible. 
- La selección de los mejores sitios para la instalación de aprovechamientos de energía renovable en el país, en función de la localización de los potenciales aprovechables y de los potenciales mercados a suplir; o el análisis multicriterio de las tecnologías y equipos para su aprovechamiento, en función de su robustez técnica, ambiental y económica,

En tal sentido, reviste especial interés la energía eólica que ha demostrado su mayor competitividad, entre las fuentes de energía renovable en el país. El estudio comparativo de la posibilidades relacionadas con el aprovechamiento de otras fuentes de energía renovable también es importante, como un aporte al escasa experiencia que en la materia se tiene en el país.

- La identificación de las potenciales fuentes bioenergéticas en el país y de las mejores técnicas para su aprovechamiento Hoy día, los residuos forestales, agrícolas y municipales; y los residuos o desechos provenientes de actividades industriales o domésticas constituyen una fuente de energía importante para la generación de calor y electricidad en el mundo. Por su parte, los cultivos ricos en azúcar o almidón como la caña de azúcar y el maíz; y cultivos oleaginosos como la canola, el girasol y la palma africana se utilizan para la producción de biocombustibles líquidos como el bioetanol, el aceite vegetal y el biodiesel. En cuanto a las tecnologías de conversión, pueden diferenciarse procesos termoquímicos y procesos bioquímicos.

El aprovechamiento de la biomasa no aparece como opción para la generación eléctrica en la propuesta de matriz eléctrica a implementar durante el período 2011-2025, obtenida como solución al caso de estudio planteado en páginas anteriores de este documento; sin embargo, el recurso está ampliamente distribuido en la geografía nacional y puede pensarse en su utilización como fuente de energía en ambientes industriales y medios rurales.

- El diseño y construcción progresiva de bancos de información de uso común en la evaluación de proyectos en el sector energético, especifica para Venezuela. Relacionado con este en tema, pueden citarse: 
- La determinación en laboratorio de índices de contaminación atmosférica, resultado de los procesos de combustión y otras operaciones en el sector energético venezolano, clasificado por tecnología y tipo de recurso utilizado.

- La construcción de índices de costos y factores de localización específicos para el sector energético venezolano, en base a información sobre costos de tecnologías llave en mano, equipos, partes, mano de obra y eficiencias de construcción propia del país.

La disponibilidad de un banco de datos consistente y aplicable al entorno sede del proyecto a evaluar acortaría el tiempo que se invierte en la búsqueda de información confiable y mejoraría la calidad de los resultados obtenidos. 


\section{Referencias}

Aguilar J. (2011), El Guri y la Depresión Energética en Venezuela, en

http://www.slideshare.net/plumacandente/entendamos-al-coloso-del-caroni-guri, $07 / 2011$.

Aguilar J. (2010), Las Crisis Energéticas Convergentes y en Colisión, en http://www.slideshare.net/plumacandente/crisis-energeticas-convergentes-y-encolision, $07 / 2011$.

Allen D.H. (1972), A Guide to the Economic Evaluation of Projects, The Institution of Chemical Engineers, ISBN 085295080 2, The Institution of Chemical Engineers, England.

Archer C. y Jacobson M., Stanford University (2005), "Evaluation of Global Wind Power", Journal of Geophysical Research, en http://www.stanford.edu/group/efmh/winds/global_winds.html, 05/2012.

Argonne National Laboratory, Environmental Science Division (2008), Water Issues Associated with Heavy Oil production, ANL/EVS?R-08/4, en http://www.evs.anl.gov/pub/doc/ANL_EVS_2321_heavyoilreport.pdf, 5/2012.

Asociación Integral de Políticas Públicas A.C. (2010), La Crisis Eléctrica en Venezuela. Situación Actual del SEN, AIPOP, Venezuela, en http://www.slideshare.net/plumacandente/situacin-actual-del-sen-09062010, $07 / 2011$.

Baca G. (2005), Evaluación de Proyectos, ISBN970-10-3001-X, Mc Graw Hill. Interamericana Editores S. A, México D.F. 
Bana e Costa C. y Vansnick J.C. (2007), "A critical analysis of the eigenvalue method used to derive priorities in AHP", European Journal of Operational Research, Prueba corregida en prensa, disponible en línea 2/2007.

Bauen A., Berndes G., Junginger M., Londo M., Vuille F., Ball R., Bole T., Chudziak C., Faaij A. y Mozaffarian H. (2010), Bioenergy - A sustainable and reliable energy source. A review of status and prospects, Main Report, IEA Bioenergy Annual Report 2009, IEA Bioenergy ExCo: 2010:01, en http://www.ieabioenergy.com/DocSet.aspx?id=6506\&ret=lib, 6/2012.

Beccali M., Cellura M. y Mistretta M. (2003), "Decision-making in energy planning. Application of the Electre method at regional level for the diffusion of renewable energy technology", Renewable Energy, 28, 2063-2087.

Belton V. y Stewart T. (2003), MultiCriteria Decision Analysis. An Integrated Aproach, ISBN 0-7923-7505-X, Kluwer Academic Publishers, U.K.

Bertani R. (2010), Geothermal Power Generation in the World 2005-2010 Update Report, Proceedings World Geothermal Congress 2010, Bali, Indonesia, en http://geothermie.nl/fileadmin/user_upload/documents/bestanden/IGA/Geotherm al_electricity_in_the_world_2010_report_Ruggero_Bertani.pdf, 5/2012.

Bertani R. (2009), Long Term Projections of Geothermal Electricity Development in the World, GeoTHERM Conference, Offenburg 2009, Alemania, en http://www.ieagia.org/documents/LongTermGeothermElecDEvelopWorldBertanioffenburg23Feb0 8.pdf, 6/2012.

Bierman H., Bonini C. y Hausman W. (1991), Quantitative Analysis for Business Decisions, ISNB 0-25608267-7, Irwin, Boston, Ma, USA.

Björnsson O. B. (2009), Geothermal Energy as Replacement for Oil and Gas. A Proven Option among the Renewables, Verkís, Suðurlandsbraut 4, IS-105, Reykjavík, Iceland, en

http://www.verkis.is/media/frodleikur/Geothermal-Energy-as-Replacement-forOil-and-Gas.pdf, 5/2012.

Bourne J. (2007), "Green Dreams", National Geographic, Oct. 2007, 38-59. 
Brans J.P. y Mareschal B. (2005), "PROMETHE methods". Multiple Criteria Decision Analysis: State of the Art Surveys, editado por Figueira J., Greco S. y Ehrgott M., Springer International Series, ISBN 0-387-23067-X, Springer Science + BusinesS Media, Inc., USA.

Brans J.P., Vincke Ph. y Mareschal B. (1986), "How to select and how to rank projects: The PROMETHEE method", European Journal of Operational Research, 24, 228-238, North Holand.

Britannica Online Encyclopedia (2009), Conventional Gas Reservoirs, en http://www.britannica.com/EBchecked/topic/406163/naturalgas/50602/

Conventional-gas-reservoirs \#ref=ref502429, 5/2012.

British Petroleum (2011), Statistical Review of World Energy June 2010, Statistical, BP p.I.c., London, UK, en

http://www.bp.com/assets/bp_internet/globalbp/globalbp_uk_english/reports_and _publications/statistical_energy_review_2011/STAGING/local_assets/pdf/statistica I_review_of_world_energy_full_report_2011.pdf, 6/2012.

Brito e Melo A. (2009), Ocean Energy Potential, IRENA Workshop on Renewable Energy Potentials, Wave Centre, Paris, Francia, en http://www.wavec.org/client/files/2009_Presentation_IRENA_ABM.pdf, 5/2012.

Buchholz Th, Luzadis V., y Volk T. (2009), "Sustainability criteria for bioenergy systems: results from an expert survey", Journal of Cleaner Production, 17, 586592.

Burton J. y Hubacek K. (2007), "Is small beautiful? A multicriteria assessment of small-scale energy technology applications in local governments", Energy Policy $35,6402-6412$.

Bustamante M., Melillo J., Connor D., Hardy Y., Lambin E., Lotze-Campen H., Ravindranath N., Searchinger T., Tchhirley J. y Watson H. (2009), What are the Final Limits?, Biofuels: Environmental Consequences and Interaction with Changing Land Use, Scientific Committee on Problems on the Environment (SCOPE), p.271-291, R.W. Howard y S. Bringezu (eds), Cornell University, Ithaca NY, U.S.A. (http://cip.cornell.edu/biofuels/), 6/2012 
Cameco (2012), Uranium Prices, en

http://www.cameco.com/investors/uranium_prices_and_spot_price/, 5/2012.

Campbell R. y Krauss C. (2010), Gulf Spill is the Largest of its Kind, Scientists Say, The New York Times, $7 / 2010$, en

http://www.nytimes.com/2010/08/03/us/03spill.html, 6/2012.

Canadian Association of Petroleum Producers (2012), What are oil sands?, en http://www.capp.ca/canadaIndustry/oilSands/Energy-Economy/Pages/what-areoilsands.aspx, 5/2012.

Carrera D., y Mack A. (2010), "Sustainability assessment of energy technologies via social indicators: Results of a survey among European energy experts", Energy Policy, 38, 1030-1039.

Cavallaro F. y Ciraolo L. (2005), "A multicriteria approach to evaluate wind energy plants on an Italian island", Energy Policy, 33, 235-244.

Centro de Desarrollo de la Organización para la Cooperación y el Desarrollo Económico (1972), Análisis Empresarial de Proyectos Industriales en Países en Desarrollo, Centro de Estudios Monetarios Latinoamericanos, México, D.F.

Chatzimouratidis A. y Pilavachi P.(2009), "Technological, economic and sustainability evaluation of power plants using the Analytic Hierarchy Process", Energy Policy, $26,778-787$.

Chatzimouratidis A. y Pilavachi P. (2008), "Multicriteria evaluation of power plants impact on the living standard using the analytic hierarchy process", Energy Policy $36,1074-1089$.

Chatzimouratidis A. y Pilavachi P. (2007), "Objective and subjective evaluation of power plants and their non radioactive emissions using the analytic hierarchy process", Energy Policy, 35, 4027-4038.

China Three Gorges Corporation (2002), "China Three Gorges Project", en http://www.ctgpc.com.cn/en/benefifs/benefifs_a_2.php, 03/2010. 
Cloquell V.A., Cloquell V.A., Monterde R. y Santamarina M.C. (2006), "Indicators validation for the improvement of environmental and social impact quantitative assessment", Environment Impact Assessment Review, 26, 79-105.

CNG, Centro Nacional de Gestión del Sistema Eléctrico (2010), Parque de Generación. Capacidad instalada. Año 2009, Venezuela.

Comité de Profesionales y Técnicos de EDELCA, V2011.1 (2011), Futuro de la Electricidad en Venezuela en http://www.slideshare.net/energia/futuro-de-laelectricidad-en-venezuela, 6/2012.

Congress of the United States, Office of Technology Assessment (1992), Managing Industrial Solid Wastes from Manufacturing, Mining, Oil and Gas Production, and Utility Coal Combustion, OTA-BP-O-82, NTIS order \#PB92-157619, GPO stock \#052-003-01273-1, en http://www.fas.org/ota/reports/9225.pdf, 5/2011.

Corporación Eléctrica Nacional (2010), Plan Maestro Socialista para el Rescate y Desarrollo del Sistema Eléctrico 2010-2030, CORPOELEC, Venezuela, en http://es.scribd.com/doc/53556207/Plan-Maestro-Socialist-A, 8/2011.

Corporación Eléctrica Nacional/ Electrificación del Caroní C.A. (2009), Situación Actual del Sistema Eléctrico Nacional, CORPOELEC/EDELCA, Venezuela, en http://www.slideshare.net/energia/venezuela-situacion-actual-del-sistemaelectrico-nacional, 07/2011.

Czisch G.(2001), Global Renewable Energy Potential. Approaches to its use, Fraunhover-Institute for Wind Energy and Energy Systems Technologies, Kassel, http://www.iset.uni-kassel.de/abt/w3-w/folien/magdeb030901/,04/2010.V

Da Silva J., Ferreira A., Neira A., Matas G., y Brandt M. (2008), "Alternativas de generacion termoeléctrica utilizando el coque de petróleo como fuente de energía", Revista de la Facultad de Ingeniería, Universidad Central, ISSN 07984065, vol. 23, 4, p 81-92, Caracas, Venezuela.

Dernburg Th. Y McDougall D. (1968), Macroeconomics. The Measurement, Analysis and Control of Aggregate Economic Activity, Library Catalog Card Number 6726877 16520, Mc Graw Hill, Book Inc., New York, USA. 
Diakoulaki D. y Karangelis F.,(2009), "Multi-criteria decision analysis and costbenefit analysis of alternative scenarios for the power generation sector in Greece", Renewable and Sustainable Energy Reviews, 11, 716-727.

Dickson M. y Fanelli M. (2004), What is Geothermal Energy?, International Geothermal Association, en

http://www.geothermal-energy.org/314,what_is_geothermal_energy.html 6/2010

Durán V. (2009), Aprovechamiento de las Energías Renovables para la Preservación del Ambiente, Foro: Cuidando El Planeta. Propuestas para el Táchira, Universidad Nacional Experimental del Táchira, Venezuela en

http://postgrado.unet.edu.ve/aniversario/ambiente/v_duran.pdf, 07/2011.

Dusseault M.B (2008), Comparing Venezuelan and Canadian Heavy Oil and Tar Sands, Paper2001-061, Canadian International Petroleum Conference, Calgary, Alberta, Ca, en

http://www.energy.gov.ab.ca/OilSands/pdfs/RPT_Chops_app3.pdf, 5/2012.

Energyboom.com (2010), Sarnia, Ontario welcomes the world's largest photovoltaic solar plant, en http://www.energyboom.com/solar/sarnia-ontario-welcomesworlds-largest-photovoltaic-solar-plant, 5/2012.

European Commission (2012), Eurostat, Sustainable Development Indicators en http://epp.eurostat.ec.europa.eu/portal/page/portal/sdi/indicators, 6/2012.

European Commission (2009), Photovoltaic Solar Energy, Development and Current Research, European Communities, ISBN 978-92-79-10644-6, doi:10.2768/38305 Bélgica, en http://ec.europa.eu/energy/publications/doc/2009_report-solarenergy.pdf, 5/2012.

European Environment Agency (2008), Energy and Environment Report 2008, ISBN 978-92-9167-980-5, ISSN 1725-9177, DOI 10.2800/10548, EEA, Copenhagen, en http://www.eea.europa.eu/publications/eea_report_2008_6,5/2012

European Photovoltaic Industry Association (2012), Global Market Outlook for Photovoltaics until 2016, en 
http://www.epia.org/publications/epiapublications/globalmarketoutlookforphotovolt aicsuntil2016.html, 5/2012.

Erdogmus S., Arasb H. Y, Ekoc E. (2006), "Evaluation of alternative fuels for residential heating in Turkey using analytic network process (ANP) with group decision-making", Renewable and Sustainable Energy Reviews, 10, 269-279.

Faaij A (2006), "Bioenergy in Europe: changing tecnology choices", Energy Policy, $34,322-342$.

Fetter S. (2009), "How long will the world's uranium supplies last?" , en http://www.scientificamerican.com/article.cfm?id=how-long-will-global-uraniumdeposits-last, Febrero 2010.

Figueira J., Mousseau V. y Roy B. (2005), "ELECTRE Methods", Multiple Criteria Decision Analysis: State of the Art Surveys, editado por Figueira J., Greco S. Y Ehrgott M., Springer International Series, ISBN 0-387-23067-X, Springer Science + Business Media, Inc., USA.

Fondo Monetario Internacional (2011), Perspectivas Económicas. Las Américas. Vientos cambiantes, nuevos desafíos, HC94A1R445, International Monetary Fund, Publication Services, Washington D.C, p.91, 2011 en http://www.imf.org/external/spanish/pubs/ft/reo/2011/whd/wreo1011s.pdf, 6/2012.

Gallego D. y Mack A. (2010), "Sustainability assessment of energy technologies via social indicators: Results of a survey among European energy experts" , Energy Policy, 38, 1030-1039

Garner (2011), Research Tecnologies, "Gartner Hype Cycle', en http://www.gartner.com/technology/research/methodologies/hype-cycle.jsp, 5/2012.

Georgsson I. y Fridleifsson I. B. (2010), Geothermal Energy in the World in 2010. from Energy Perspective, United Nations University Geothermal Training Programme, en www.os.is/gogn/unu-gtp-sc/UNU-GTP-SC-11-09.pdf, 5/2012 
Goldstein, B., Hiriart G., Bertani R., Bromley C., Gutierrez-Negrin L., Huenges E., Muraoka H., Ragnarsson A.,Tester J., Zui V. (2011), Geothermal Energy. In IPCC Special Report on Renewable Energy Sources and ClimateChange Mitigation, Chapter 4 [Edenhofer O., Pichs-Madruga R., Sokona Y., Seyboth K., Matschoss P., Kadner S., Zwickel T.,Eickemeier P., Hansen G., Schlomer S., von Stechow C. (eds)], Cambridge University Press, Cambridge, United Kingdom and New York, NY, USA, en http://srren.ipcc-wg3.de/report/IPCC_SRREN_Ch04.pdf, 5/2012

Government of Alberta, Canadá (2012), Energy. About Oil Sands, en http://www.energy.alberta.ca/OilSands/791.asp, 5/2012

Greenberg J. (2009), "Unconventional Gas Potential Examined", Journal of Petroleum Technology, en http://www.spe.org/atce/2009/documents/Wednesday.pdf, $1 / 2010$.

Green World Investor (2011), List of World's Largest Hydroelectricity Plants and Countries- China leading in Building Hydroelectric Stations, en http://www.greenworldinvestor.com/2011/03/29/list-of-worlds-largesthydroelectricity-plants-and-countries-china-leading-in-building-hydroelectricstations/, 5/2012.

Greenpeace, SolarPACES y ESTELA (2009), Concentrated Solar Power. Global Outlook 09. Why Renewable Energy is Hot, en http://www.estelasolar.eu/fileadmin/ESTELAdocs/documents/Greenpeace_Concen trating_Solar_Power_2009.pdf, 5/2012.

Hering G. (2009), "Room for Growth", Photon International, en http://www.protermosolar.com/boletines/22/CSP_gains_steam_-_PHOTON.pdf, $5 / 2012$.

Hermann B., Kroeze C. y Jawjit W. (2007), "Assessing environmental performance by combining life cycle assessment, multi-criteria analysis and environmental performance indicators", Journal of Cleaner Production 15, 1787-1796.

Hernández N. (2011a), Fracturada la Seguridad Energética en Venezuela, en http://www.box.net/shared/rfnhfzn424cev1xpvf5n, 07/2011. 
Hernández N. (2011b), La Crisis Energética en Venezuela, Mesa de Análisis. Política Energética en Venezuela, Observatorio Económico-Legislativo y CEDICE en http://www.cedice.org.ve/fotos/file/(CEDICE)\%20La\%20Crisis\%20Energetica\%20 Venezolana.pdf, 07/2011.

Hernández N. (2010a), La Situación Energética Venezolana, Gerencia y Energía, en http://www.slideshare.net/energia/la-situacin-energetica-venezolana-5348660, 07/2011.

Hernández N., (2010b), Las Energías Alternativas, Diplomado de Prospectivas y Estrategias, Universidad Simón Bolívar en http://www.slideshare.net/energia/energias-alternativas-usb, 07/2011.

Hernández N. (2010c), La Situación del Sector Eléctrico Nacional, Gerencia y Energía, en http://www.slideshare.net/energia/crisis-electrica-en-venezuela-nh, $07 / 2011$.

Hernández N., (2009a), Una Mirada al Potencial Energético de Venezuela, Foro: Presente y Futuro Energético de Venezuela, Colegio de Ingenieros de Venezuela, http://www.slideshare.net/energia/una-mirada-al-potencial-energetico-devenezuela-foro-civ, 07/2011.

Hernández N. (2009b), Crisis Eléctrica en Venezuela, en http://www.analitica.com/va/economia/opinion/8685730.asp, 6/2012.

Hirschberg S., Dones R., Heck T., Burgherr P., Schenler W., Bauer C. (2007), Strengths and Weaknesses of Current Energy Chains in a Sustainable Development Perspective, Energieversogung und Nachhaltigkeit, Villingen, Switserland, en http://www.kernfragen.de/kernenergie/documentpool/Jul/atw2006_07_hirschberg .pdf, 6/2012.

Hirschberg S., Burgherr P., Spiekerman G., Cazzoli E., Vitazek J. y Chen L. (2003), Comparative Assesment of Severe Accidents in the Chinese Energy Sector, China Energy Tecbology Program, ISSN1019-0643, Paul Sherrer Institute, Suiza, en http://gabe.web.psi.ch/pdfs/PSI_Report/CETP_RA_Report.pdf, 6/2012. 
Holgrem P. (FAO, 2006), Global Land use Area Change Matrix, Forest Resources Assessment, Working Paper 134, Input to the Fourth Global Environment Outlook (GEO-4), Forestry Department, Food and Agricultural Organization of the United Nations, Roma, en ftp://ftp.fao.org/docrep/fao/010/ag049e/ag049e00.pdf, 6/2012.

Hoogwijk M., Faaij A., Eickhout B., De Vries B. y Turkenburg W. (2005), "Potential of biomass energy out to 2100, for four IPCC SRES land-use scenarios", Biomass and Bioenergy, 29, 225-257.

Hore-Lacy I. (2009), "Nuclear Power Reactor", The Encyclopedia of Earth, en http://www.eoearth.org/article/Nuclear_power_reactor, 5/2012.

IFP Energies Nouvelles (2008), "Coal: resources, reserves and production", Panorama Technical Reports, en

http://www.ifpenergiesnouvelles.com/publications/notes-de-synthesepanorama/panorama-2008/charbon-ressources-reserves-et-production, 5/2012.

Instituto Latinoamericano de Planificación Económica y Social, ILPES (1974), Guía para la Presentación de Proyectos, Siglo Veintiuno Editores, México, D.F.

Instituto Nacional de Estadística (2011), Proyecciones de Población, Venezuela, en http://www.ine.gov.ve/demografica/distribucion.asp, 5/2012.

Intergovernmental Panel on Climate Change (2008), Cambio Climático 2007, Informe de Síntesis. Contribución de los Grupos de Trabajo I, II y III al Cuarto Informe de Evaluación del Grupo Intergubernamental de Expertos sobre el Cambio Climático, ISBN 92-9169-322-7, Ginebra, Suiza, en http://www.ipcc.ch/pdf/assessment-report/ar4/syr/ar4_syr_sp.pdf, 5/2012.

Intergovernmental Panel on Climate Change (2007), FAQ 1.1 What Factors Determine Earth's Climate, Climate Change 2007: Working Group I: The Physical Science Basis, en http://www.ipcc.ch/publications_and_data/ar4/wg1/en/faq-11.html, 6/2012.

International Atomic Energy Agency (1970), 'Treaty on Non-proliferation of Nuclear Weapons', Information Circular, en 
http://www.iaea.org/Publications/Documents/Infcircs/Others/infcirc140.pdf, $5 / 2012$.

International Atomic Energy Agency, United Nations Department of Economic and Social Affairs, International Energy Agency, Eurostat, European Environment Agency (2005), Energy Indicators for Sustainable Development: Guidelines and Methodologies, IAEA, Viena, Austria, en

http://www-pub.iaea.org/MTCD/publications/PDF/Pub1222_web.pdf, 03/2011.

International Energy Agency (2012a), Technology Road. Bioenergy for Heat and Power, OECD/IEA 2012, en

http://www.iea.org/publications/freepublications/publication/bioenergy.pdf, 6/2012.

International Energy Agency (2012b), Biorefineries: Co-production of fuels, chemicals, power and materials from biomass, IEAbionergy, Task 42, en http://www.ieabioenergy.com/Task.aspx?id=42, 5/2012

International Energy Agency (2011a), Key World Energy Statistics, OECD/IEA 2011, en http://www.iea.org/publications/free_new_desc.asp?pubs_ID=1199, 5/2012.

International Energy Agency (2011b), World Energy Outlook 2011, Executive Summary, OECD/IEA 2011, International Energy Agency, Paris, France, en http://www.iea.org/Textbase/npsum/weo2011sum.pdf , 5/2012

International Energy Agency (2011c), CO2 Emissions from Fuel Combustion, Highlights, IEA Statistics, 2011 Edition, Paris, France, en

http://www.iea.org/co2highlights/co2highlights.pdf, 5/2012

International Energy Agency (2011d), Are we Entering a Golden Age of Gas?, Special Report, World Energy Outlook 2011, OECD/IEA 2011, International Energy Agency, Paris, France, en http://www.iea.org/weo/docs/weo2011/WEO2011_GoldenAgeofGasReport.pdf, 5/2012.

International Energy Agency (2011e), Renewable Energy. Markets and Prospects by Technology, OECD/IEA 2011, International Energy Agency, Paris, France, en http://www.iea.org/publications/free_new_Desc.asp?PUBS_ID=2475, 5/2012. 
International Energy Agency (2011f), Technology Road. Biofuels for Transport, OECD/IEA 2012, en http://www.iea.org/papers/2011/biofuels_roadmap.pdf, 6/2012

International Energy Agency (2010a), Renewable Energy Essentials: Hydropower, OECD/IEA 2010, en http://www.iea.org/papers/2010/Hydropower_Essentials.pdf, $5 / 2012$.

International Energy Agency (2010b), Renewable Energy Essentials: Geothermal, OECD/IEA 2010, en http://www.iea.org/papers/2010/Geothermal_Essentials.pdf, $5 / 2012$.

International Energy Agency (2009a), World Energy Outlook 2009, Executive Summary, OECD/IEA 2009, International Energy Agency, Paris, France, http://www.iea.org/Textbase/npsum/weo2009sum.pdf , 6/2012.

International Energy Agency (2009b), Renewable Energy Essentials: Solar Energy and Cooling, OECD/IEA, en http://www.iea.org/papers/2009/Solar_heating_cooling.pdf, 5/2012.

International Energy Agency (2009c), Renewable Energy Essentials: Concentrating Solar Thermal Power, OECD/IEA, en http://iea.org/papers/2009/csp_Essentials.pdf, 5/2012.

International Energy Agency (2008), World Energy Outlook 2008, Executive Summary, OECD/IEA 2008, International Energy Agency, Paris, France, en http://www.iea.org/textbase/npsum/WEO2008SUM.pdf, 6/2012.

International Energy Agency y otros (2004), Recommendation1: Converting solar thermal collector area into installed capacity $\left(m^{2}\right.$ to $\left.k W_{T}\right)$, en http://www.iea-shc.org/welcome/Technical_note_solar_thermal_capacity.doc, $5 / 2012$.

Intpow, Norwegian Renewable Energy Partners (2010, Hydropower Potential and Development, en http://www.intpow.no/index.php?id=487, 5/2012

Josey J. (2008), Natural Energy Laboratory of Hawaii Authority Returns to Its Energy Roots, U.S. Department of Energy, State Energy Program, Conservation Update, http://www1.eere.energy.gov/wip/update/m/2008-01_nelha_roots.html, 5/2012. 
Junginger M., Bolkesjo T., Douglas Bradley D., Dolzan P., Faaij A., Heinimo J., Hektor B., Leistad O., Erik Ling E., Perry M., Piacente E., Rosillo-Calle F., Ryckmans Y., Schouwenberg P., Solberg B., Tromborg E,, Da Silva Walter A. y De Wit M. (2008), "Developments in international bioenergy trade", Biomass and Bioenergy $32,717-729$.

Kahraman C. y Kaya I. (2010), "A fuzzy multicriteria methodology for selection among energy alternatives", Expert Systems with Applications, 37, 6270-6281.

Kaya T. y Kahraman C. (2010), "Multicriteria decision making in energy planning using a modified fuzzy TOPSIS methodology", Expert Systems with Applications, doi:10.1016/j.eswa.2010.11.081.

Kimble M., Pasdeloup M. y Spencer C. (2008), "Biomass Conversion Tecnologies", Sustainable Bioenergy Development in UEMOA Member Countries, Ch.5, 45-56, The West African Economic and Monetary Union (UEMOA) and The Hub for Rural Development in West and Central Africa, en http://www.unfoundation.org/newsand-media/publications-and-speeches/sustainable-bioenergy-report.html, 6/2012.

King D., Inderwildi R. y Williams A. (2010), The Future of Industrial Biorefineries, World Economic Forum, Ginebra, Suiza, en http://www3.weforum.org, 6/2012.

Klainberg R. (2007), Oil Shales, Working Document \#27 of the NPC Global Oil and Gas Study, en http://www.npc.org/Study_Topic_Papers/27-TTG-Oil-Shales.pdf, 5/2012.

Kristoff S. (2008), "Hydroelectric Power Generation. How the Potential Energy of Water is Used to Generate Electricity", en http://environmentalengineering.suite101.com/article.cfm/hydroelectric_power_generation, 03/2010.

Kruyt B., van Vuuren D.P, Vries H. y Grenenberg H. (2009), "Indicators for energy security", Energy Policy, 37, 2166-2181.

Kumar, A., Schei T., Ahenkorah A., Caceres Rodriguez R., Devernay J. M., Freitas M., Hall D., Killingtveit A., Liu Z. (2011), Hydropower. In IPCC Special Report on Renewable Energy Sources and Climate Change, Chapter 5, [Edenhofer O., PichsMadruga R., Sokona Y., Seyboth K., Matschoss P., Kadner S., Zwickel T.,Eickemeier P., Hansen G., Schlomer S., von Stechow C. (eds)], Cambridge 
University Press, Cambridge, United Mitigation Kingdom and New York, NY, USA, en http://srren.ipcc-

wg3.de/report/IPCC_SRREN_Ch05.pdf/view, 5/2012

Lanadai S. y Vinterback J. (2009), Global Potential of Sustanaible Biomass for Energy, Report 013, ISSN 1654-9406, SLU, Department of Energy and Technology, Suecia, en http://pub.epsilon.slu.se/4523/1/ladanai_et_al_100211.pdf, 6/2012

Lara M., González G., Pirela J., Rousse I., y Poleo Víctor (2010), Crisis Eléctrica. en http://www.soberania.org/Archivos/Crisis_electrica_version_1_abril_2010.pdf, $6 / 2012$.

Lazard Ltd. (2009), Levelized Cost of Energy Analysis. Version 3.0, en http://blog.cleanenergy.org/files/2009/04/lazard2009_levelizedcostofenergy.pdf, $5 / 2012$.

Lebre La Rovere E., Borghetti J., Basto L. y Lauria T. (2009), "Sustainable expansion of electricity sector: Sustainability indicators as an instrument to support decision making", Renewable and Sustainable Energy Reviews, doi:10.1016/j.rser.2009.07.033.

Lewandowski I. y Faaij A. (2006), "Steps towards the development of a certification system for sustainable bio-energy trade ", Biomass and Bioenergy, 30, 83-104.

Loken E. (2007), "Use of multicriteria decision analysis methods for energy planning problems", Renewable and Sustainable Energy Reviews, 11, 1584-1595.

Lu X., McElroy M. y Kiviluoma J., Comunicado por Anderson J., Harvard University (2009), "Global Potencial for wind-generated electricity",

http://www.pnas.org/content/106/27/10933.full.pdf, 04/2010.

Matos M. (2007), "Decision under risk as a multicriteria problem", European Journal of Operational Research, 181, 1516-1529.

Mathews J. (2007), Can renewable energies be turned to a source of advantage by developing countries?, http://cat.inist.fr/?aModele=afficheN\&cpsidt $=18776760$, $5 / 2007$. 
McKendry P. (2002), "Energy production from biomass (part 2): conversion technologies", Bioresource Technology, 83, 47-54.

Meier P., Wilson P., Kulcinski G. y Denholm P. (2007), "US electric industry response to carbon constraint: a life-cycle assessment of supply side alternatives", Energy Policy, 33, 1099-1108.

Ministerio del Poder Popular para la Energía y Petróleo, MENPET (2008), Petróleo y Otros Datos Estadísticos 2007-2008, Sección I. Venezuela, en http://www.menpet.gob.ve/repositorio/imagenes/secciones/pdf_pode/pode_2007 _2008/Venezuela.pdf, 8/2011.

Naciones Unidas (1958), Manual de Proyectos de Desarrollo Económico, Publicación E/CN.12/426/Add.1/Rev.1, TAA/LAT/12/Rev.1, México, D.F.

Naciones Unidas (1972), Pautas para la Evaluación de Proyectos, Publicación IS/SER.H/2, New York, U.S.

Naturalgas.org (2010a), Offshore drilling, en http://www.naturalgas.org/naturalgas/extraction_offshore.asp, 5/2012.

Naturalgas.org (2010b), "Electric generation using natural gas", en http://www.naturalgas.org/overview/uses_eletrical.asp, 1/ 2010.

Naturalgas.org (2010c), "Unconventional natural gas resources", en http://www.naturalgas.org/overview/unconvent_ng_resource.asp, 1/2010.

National Renewable Energy Laboratory, U.S. Department of Energy (2012a), Ocean Thermal Energy Conversion, en http://www.nrel.gov/otec/what.html, 5/2012.

National Renewable Energy Laboratory, (2012b), Geothermal Electricity Production, Learning about Renewable Energy, en http://www.nrel.gov/learning/re_geo_elec_production.html, 5/2012.

National Renewable Energy Laboratory (2012c), Geothermal Heat Pumps, Learning about Renewable Energy, U.S. Department of Energy (2012c), en http://www.nrel.gov/learning/re_geo_heat_pumps.html. 5/2012. 
National Renewable Energy Laboratory, U.S. Department of Energy (2010), Cost and Performance Assumptions for Modeling Electricity Generation Technologies, Tidball R., Bluestein J., Rodriguez N., y Knoke S., ICF International Fairfax, Virginia, Subcontract Report NREL/SR-6A20-48595, Noviembre 2010, en http://www.nrel.gov/docs/fy11osti/48595.pdf, 5/2012.

National Renewable Energy Laboratory (2009a), A Consumer Guide to Solar Electricity for the Home, Energy Efficiency \& Renewable Energy, U.S. Department of Energy, DOE/GO-102009-2656, Energy Efficiency \& Renewable Energy, en http://www.nrel.gov/learning/pdfs/43844.pdf, 5/2012. . $\sqrt{ }$

National Renewable Energy Laboratory (2009b), What is a Biorefinery?, Biomass Research, U.S. Department of Energy, http://www.nrel.gov/biomass/biorefinery.html, 6/2012.

National Petroleum Council (2007), Unconventional Gas, Working Paper \# 29, NPC Global and gas Study, Technology Task Group, NPC Committee on Global Oil and Gas en http://www.npc.org/Study_Topic_Papers/29-TTG-Unconventional-Gas.pdf, $5 / 2012$.

Nuclear Energy Agency/International Atomic Energy Agency (2008), Uranium 2007: Resources, Production and Demand, Organization for Economic Cooperation and Development, ISBN 978-92-64-04766-2, Paris, Francia, en http://books.google.co.ve/books?id=ABKo3wSTvt0C\&printsec=frontcover\&source =gbs_navlinks_s\#v=onepage $\& q=\& f=$ false, $5 / 2012$.

Nuclear Energy Agency (2005), Nuclear Energy Today, OECD Publications, OECD No 530792003, ISBN 92-64-10328-7, Paris, Francia, en http://www.nea.fr/html/pub/nuclearenergytoday/net/nuclear_energy_today.pdf, $5 / 2012$.

Núñez J.(2012), "La crisis eléctrica y su extendida contingencia está vigente", Petrofinanzas, en http://www.petrofinanzas.com/?p=5718, 2/2012.

Ocean Energy Council (2012), Tidal Energy, en http://www.oceanenergycouncil.com/index.php/Tidal-Energy/Tidal-Energy.html, $5 / 2012$. 
Organization for Economic Cooperation and Development, (2008), Key Environmental Indicators, OECD, Paris, Francia, en

http://oecd.org/dataoecd/20/40/37551205.pdf, 6/2012

Ocean Energy Systems, An International Vision for Ocean Energy (2011), OES/IEA, en http://www.ocean-energy

systems.org/documents/14015_brochure_v18_final.pdf/, 5/2012

Organización de las Naciones Unidas para el Desarrollo Industrial, (1987), Manual para la Preparación de Estudios de Viabilidad Industrial, ISBN 92-1-306161-7 01500P, ONUDI, Viena..

Organization of the Petroleum Exporting Countries (2011), Annual Statistical Bulletin 2010/2011, ISSN 0475-0608, Viena, Austria, en

http://www.opec.org/opec_web/static_files_project/media/downloads/publications /ASB2010_2011.pdf, 6/2012.

Papadopoulos A. y Karagiannidis A. (2006), "Application of the multi-criteria analysis method Electre III for the optimization of decentralized energy systems", Omega, Prueba corregida en prensa, disponible en línea, Mayo 2006

Papalexandrou P., Pilavachi P. y Chatzimouratidis A. (2008), "Evaluation of liquid bio-fuels using the Analytic Hierarchy Process", Process Safety and Environment Protection, 86, 360-374.

Parodi de Camargo V., (2007), Análisis de decisión multicriterio. Revisión de metodologías y procedimientos de apoyo a la decisión utilizados en planificación energética, presentado ante la Universidad Politécnica de Valencia, España.

Pérez J., Jimeno J. L. y Mokotoff E. (2004), "Another potencial strong shortcoming of AHP", Papel de trabajo, Universidad de Alcalá, España, recuperado en http://www2.uah.es/docecon/documentos/DT8.pdf, 6/2012

Petróleos de Venezuela S.A. (2010), Informe de Gestión Anual 2009, en http://www.pdvsa.com/interface.sp/database/fichero/free/5889/1049.PDF, $5 / 2012$. 
Phalan B. (2009), "The social and environmental impacts of biofuels in Asia: An overview", Applied Energy, Articulo en prensa.

Pinto L. (2005), El uso de energías alternativas en Venezuela, Soberania.org, en http://www.soberania.org/Articulos/articulo_1651.htm, 6/2012

Pohekar S.D. y Ramachandran M. (2004), "Application of multi-criteria decision making to sustainable energy planning-A review", Renewable and Sustainable Energy Reviews, 8, 365-381.

Presidencia de la República Bolivariana de Venezuela (2007), Proyecto Nacional Simón Bolívar, Desarrollo Social y Económico de la Nación 2007-2013 en http://www.gobiernoenlinea.ve/noticias-view/shareFile/PPSN.pdf, 07/2011. ????

Programa de las Naciones Unidas para el Medio Ambiente, Primera Reunión Extraordinaria del Foro de Ministros de Medio Ambiente de América Latina y el Caribe (2002), Iniciativa Latinoamericana y Caribeña para el Desarrollo Sustentable, Johannesburgo, Sudáfrica en

http://www.pnuma.org/forumofministers/17-panama/ILAC_VersionEsp.pdf, 7/11.

Ravelo O. y Sepúlveda M. (2009), Energía Eólica en Venezuela, V Seminario de Ecoeficiencia, Producción Limpia y Consumo sustentable, Instituto de Energía, Universidad Simón Bolívar, Caracas, Venezuela, en

http://es.scribd.com/doc/54288895/3-Ponencia-La-energia-eolica-en-VenezuelaMiguel-Sepulveda, 7/2011.

Ravindranath N.H., Manuvie R, Fargione J., Canadell J.G., Berndes G., Woods J., Watson H., Sathaye J. (2009,) Greenhouse Gas Implications of Land Use and Land Conversion to Biofuel Crops. In: Biofuels: Environmental Consequences and Interactions with Changing Land Use, Howarth RW, Bringezu S (eds), Scientific Committee on Problems of the Environment (SCOPE), Island Press, New York. en http://cip.cornell.edu/biofuels, 6/2012

REN21, Renewable Energy Policy Network for the 21th Century (2010), Renewables 2010 Global Status Report (Paris: REN21 Secretariat), Deutsche Gesellschaft für Technische Zusammenarbeit (GTZ) $\mathrm{GmbH}$, en 
http://www.ren21.net/Portals/97/documents/GSR/REN21_GSR_2010_full_revised\% 20Sept2010.pdf, 6/2012.

REN21, Renewable Energy Policy Network for the 21th Century (2011), Renewables 2010 Global Status Report, (Paris: REN21 Secretariat), en http://www.ren21.net/Portals/97/documents/GSR/REN21_GSR2011.pdf, 6/2012.

Renewable Energy World (2004), "Solar Thermal Water Heating", en http://www.volker-quaschning.de/articles/fundamentals4/index_e.php, 5/2012.

Romero C. (1996) Análisis de las Decisiones Multicriterio, ISBN 84-89338-14-0, ISDEFE, Madrid, España.

Roselund C. (2010), "Concentrated solar power: Versatile technology with huge potential for clean and affordable energy", The Solarserver, en http://www.solarserver.de/solarmagazin/download/csp_solar_report_0510-e.pdf, $05 / 2012$.

Rousse I., (2010), El Sector Eléctrico Venezolano. Fortalezas Y Debilidades en su Actual Crisis. Causas Y Soluciones, XII Convención Nacional de la Vivienda Y Hábitat, Caracas, Venezuela en http://www.cvc.com.ve/portal/files/docs/215.pdf, 6/2012.

Saaty T.L. (2006a), Fundamentals of Decision Making and Priority Theory with the Analytic Hierarchy Process, Vol.VI of the AHP Series, ISBN 0-9620317, RWS Publications, Pittsburgh, Pa., USA.

Saaty T.L. (2006b), "Rank from comparisons and from ratings in the analytic hierarchy/network processes", European Journal of Operational Research, 168, 557-570.

Saaty T.L. (2005a), Theory and Applicatios of the Analytic Network Process, Decision Making with Benefits, Opportunities, Costs and Risks, ISBN 1-888603-06-2, RWS, Publications, Pittsburgh, Pa., USA.

Saaty T.L. (2005b), "The Analytic Hierarchy and Analytic Network Processes for the measurement of intangible criteria and for decision making", Multiple Criteria 
Decision Analysis: State of the Art Surveys, José Figueira, Salvatore Greco y Matthias Ehrgott (editores), Springer International Series, ISBN 0-387-23067-X, Springer Science + Business Media, Inc., USA.

Saaty T.L. (1994), How to make a decision: the Analytic Hierarchy Process, Interfaces, Vol. 24, 6, 19-43.

Saaty T.L. y Vargas L. (1993), "Experiments on rank preservation and reversal in relative measurements", Mathematical and Computer Modeling, Vol. 1, 4-5,13-8.

Saaty T.L. (1986), Decision Making for Leaders. The Analytical Hierarchy Process for Decisions in a Complex World, RWS Publications, Pittsburgh, Pa., USA.

Sapag N, y Sapag R. (1998), Preparación y Evaluación de Proyectos, ISBN 958-600338-8, Mc Graw Hill Interamericana, Bogotá D.C., Colombia.

Sapag N. (2001), Evaluación de proyectos de Inversión en la Empresa, ISNBN9879460-19-7, Prentice Hall, Buenos Aires, Argentina.

Sawin J. (2004), "National Policy Instruments. Policy Lessons for the Advancement \& Diffusion of Renewable Energy Technologies Around the World", International Conference for Renewable Energies, Bonn, en http://www.renewables2004.de/pdf/tbp/TBP03-policies.pdf, 6/2012.

Schlumberger (2012a), Heavy Oil Recovery Methods, en http://www.slb.com/services/industry_challenges/heavy_oil/recover_methods.asp x 5/2012.

Schlumberger (2012b), Thermal Heavy Oil Production Methods, en http://www.slb.com/services/industry_challenges/heavy_oil/recover_methods/the rmal.aspx, 5/2012.

Shtub A., Bard J. y Globerson S. (1994), Project Management. Engineering, Technology, and Implementation, ISBN 0-13-556458-1, Prentice Hall, Inc., N.J., USA. 
Smeets E., Faaij A., Lewandowski I. y Turkenburg W. (2006), "A bottom-up assessment and review of global bioenergy potentials to 2050", progress in Energy and Combustion Science, 33, 56-106.

Smeets E., Faaij A. y Lewandowski I. (2004), "A quickscan of global bio-energy potentials to 2050. An analysis of the regional availability of biomass resources for export in relation to the underlying factors", Report NWS-E-2004-109, ISBN 90-393-3909-0, Copernicus Institute, Utrecht University, Holanda, en http://www.mendeley.com/research/a-quickscan-of-global-bioenergy-potentialsto-2050-an-analysis-of-the-regional-availability-of-biomass-resources-for-exportin-relation-to-the-underlying-factors-1/\#page-1, 6/2012.

Society of Petroleum Engineers (2009), Petroleum Resources Management System, <http://www.spe.org/industry/reserves/docs/spanish_PRMS_2009.pdf>, 11,2009.

Soerensen H. (2008), Ocean Energy, European Ocean Energy Association Energy, North Sea Region Programme, en http://www.northsearegion.eu/files/user/File/IVB\%20Events/Thematic_Seminars/ 2008_09_Transnational_Cooperation_Seminar_Energy_Aberdeen/Ocean_Energy_ __Soerensen.pdf, 5/2012

Solarpraxis (2012), PV Power Plants 2012, Industrial Guide, en http://www.pvpower-plants.com/index.php?id=973, 5/2012.

Solarserver.com, Solar Collectors: Different Types an Fields of Applications (2011), en http://www.solarserver.com/knowledge/basic-knowledge/solar-collectors.html, $5 / 2012$.

Terrados J., Almonacid G. y Perez P. (2009), "Proposal for a combined methodology for renewable energy planning. Application to a Spanish region", Renewable and Sustainable Energy Reviews, 13, 2022-2030

Terrados J., Almonacid G. y Hontoria L., (2007) "Regional energy planning through SWOT analysis and strategic planning tools. Impact on renewable development", Renewable and Sustainable Energy Reviews, 11, 1275-1287. 
Theodorou S., Florides G. Y Tassou S (2010), "The use of multiple criteria decision making methodologies for the promotion of RES through funding schemes in Cyprus, A review ", Energy Policy, 38, 7783-7792.

The World Bank (2012), Data, Electric Power Consumption (kWh per cápita), en http://data.worldbank.org/indicator/EG.USE.ELEC.KH.PC, 4/2012 $\sqrt{ }$

The World Bank (2009), "Qatar: First Gulf Country Joins World Bank-led Effort to Reduce Greenhouse Emissions from Gas Flaring", Press Release No: 2009/ 208/COPCO, en http://web.worldbank.org/WBSITE/EXTERNAL/NEWS/0, contentMDK:22044056 p agePK:64257043 piPK:437376 theSitePK:4607,00.html?cid=3001_131, 6/2012.

TradeTech (2012), Uranium Prices Overview, en http://www.uranium.info/uranium_prices_overview.php, 5/2012

Tsoutsos T., Drandaki M., Frantzeskaki N., Iosifiais E. y Kiosses I. (2009), "Sustainable energy planning by using multicriteria analysis aplication in the island of Crete", Energy Policy, 37, 1587-1600.

United Nations/WECD (1987), Report of the World Commission on Environment and Development: Our Common Future, Transmitted to the General Assembly as an Annex to document $\mathrm{A} / 42 / 427$ - Development and International Co-operation: Environment, en http://www.un-documents.net/wecd-ocf.htm, 6/2012.

Ulutas B. (2005), "Determination of the appropriate energy policy for Turkey", Energy, 30, 1146-1161.

Uriarte A. (2010), Historia del Clima de la Tierra. Flujos Verticales de Energía, en http://web.me.com/uriarte/Earths_Climate/Appendix_1._Vertical_energy_flows.ht $\mathrm{ml}, 5 / 2012$.

U.S. Department of Energy (2011), Fossil Energy, Gasification Technology R\&D, en http://www.fossil.energy.gov/programs/powersystems/gasification/, 5/2012. $\sqrt{ }$

U.S. Department of Energy (2011a), Absorption Cooling, Energy Efficiency \& Renewable Energy, en http://www.eere.energy.gov/basics/buildings/absorption_cooling.html, 5/2012. 
U.S. Department of Energy (2011b), Solar Water Heaters, Energy Savers, Energy Efficiency \& Renewable Energy, http://www.energysavers.gov/your_home/water_heating/index.cfm/mytopic $=128$ $50,5 / 2012$.

U.S. Department of Energy (2011c), Photovoltaic Cell Materials, Energy Basics, Energy Efficiency \& Renewable Energy, en http://www.eere.energy.gov/basics/renewable_energy/pv_cell_materials.html, 5/2012.

U.S. Department of Energy (2011d), Concentrating Solar Power, Energy Basics, Energy Efficiency \& Renewable Energy, en http://www.eere.energy.gov/basics/renewable_energy/csp.html, 5/2012,

U.S. Department of Energy (2011e), Linear Concentrator Systems for Concentrating Solar Power, Energy Basics, Energy Efficiency \& Renewable Energy, en http://www.eere.energy.gov/basics/renewable_energy/linear_concentrator.html, 5/2012,

U.S. Department of Energy (2011f), Power Tower Systems for Concentrating Solar Power, Energy Basics, Energy Efficiency \& Renewable Energy, en http://www.eere.energy.gov/basics/renewable_energy/power_tower.html, 5/2012,

U.S. Department of Energy (2011g), Dish/Engine for Concentrating Solar Power, Energy Basics, Energy Efficiency \& Renewable Energy, en http://www.eere.energy.gov/basics/renewable_energy/dish_engine.html, 5/2012,

U.S. Department of Energy (2011h), Thermal Storage Systems for Concentrating Solar Power, Energy Basics, Energy Efficiency \& Renewable Energy, en http://www.eere.energy.gov/basics/renewable_energy/thermal_storage.html, 5/2012,

U.S. Energy Information Administration (2012a), Independent Statistics and Analysis, Petroleum \& Other Liquids. Spot Prices, en http://tonto.eia.doe.gov/dnav/pet/hist/LeafHandler.ashx?n=pet\&s=rwtc\&f=d, 5/2012. 
U.S. Energy Information Administration (2012b), Independent Statistics and Analysis, Natural Gas Futures Contract 1 , en

http://tonto.eia.doe.gov/dnav/dnav/ng/hist/rngc1d.htm, 5/2012.

U.S. Energy Information Administration (2012c), Independent Statistics \& Analysis, Levelized Cost of New Generation Resources in the Annual Energy Outlook 2011, http://www.eia.gov/forecasts/aeo/electricity_generation.cfm, 6/2012

U.S. Energy Information Administration (2011) "Country Analysis Briefs, Venezuela", en http://www.eia.gov/cabs/venezuela/oil.html, 6/2012.

U.S. Energy Information Administration (2010), Assumptions to the Annual Energy Outlook 2010, Report \#:DOE/EIA-0554(2010), Electricity Market Module, en http://www.eia.gov/oiaf/aeo/assumption/pdf/electricity_tbls.pdf, 6/2012.

U.S. Energy Information Administration (2009), Assumptions to the Annual Energy Outlook 2009, Report \#:DOE/EIA-0554(2009), Electricity Market Module, en http://www.eia.gov/oiaf/aeo/assumption/pdf/tbl8.2.pdf, 6/2012

U.S. Environment Protection Agency (2011), Spent Nuclear Fuel and High Level Radioactive Waste, en http://www.epa.gov/radiation/docs/radwaste/402-k-94001-snf_hlw.html, 6/2012.

U.S. Environment Protection Agency (2012), Hazardous Waste Land Disposal Units (LDUs), en http://www.epa.gov/osw/hazard/tsd/td/ldu/, 6/2012.

U.S. Environment Protection Agency, Climate Change Division (2006), Global Anthropogenic Non-CO2 Greenhouse Gas Emissions: 1990-2020, en http://www.epa.gov/climatechange/economics/downloads/GlobalAnthroEmissions Report.pdf, 6/2012.

U.S. Environment Protection Agency, Solid Waste and Emergency Response (1999), Land Disposal Restrictions for Hazardous Wastes, EPA530-F-99-043, en http://www.epa.gov/osw/hazard/tsd/ldr/snapshot.pdf, 6/2012.

Ux Consulting Company (2012), UxC Nuclear Fuel Price Indicators, en http://www.uxc.com/review/uxc_Prices.aspx, 5/2012 
Van Dam J., Junginger M., Faaij A., Jurgens I, Best G. y Fritsche U. (2008), "Overview of recent developments in sustainable biomass certification", Biomass and Bioenergy, 32, 749-780.

Vera I. y Langlois L. (2007), "Energy Indicators for sustainable development", Energy 32, 875-882.

Walter A., Rosillo-Calle F., Dolzan P., Piacente E. y Borges da Kunha K. (2008), "Perspectives on fuel ethanol consumption and trade", Biomass and Bioenergy, Vol 32, 8, 730-748.

Wang B., Kocaoglu D., Daim T. y Yang J. (2010), "A decision model for energy resource selection in China", Energy Policy, 38, 7130-7141.

Wang J., Jing Y., Zhang Ch. y Zhao J. (2009), "Review on multi-criteria decision analysis aid in sustainable energy decision-making", Renewable and Sustainable Energy Reviews, 13, 2263-2278.

Wang J., Jing Y., Zhang Ch., Shi G. y Zhang X. (2008), "A fuzzy multi-criteria decision-making model for trigeneration system", Energy Policy, 36, 3823-3832.

Wei M., Patadia Sh. y Kammen D. (2010), "Putting renewable and energy efficiency to work: How many jobs can the clean energy industry generate in the US?", Energy Policy, 38, 919-931.

Weiss W. y Mauthner F. (2011), Solar Heat Worldwide. Markets and Contributions to the Energy Supply 2009, Solar Heating \& Cooling program , International Energy Agency, en http://www.ieashc.org/publications/downloads/Solar_Heat_Worldwide-2011.pdf, 5/2012.

World Coal Association (2012a), Carbon Capture \& Storage Technologies, en http://www.worldcoal.org/coal-the-environment/carbon-capture-storage/ccstechnologies/, 5/2012

World Coal Association (2012b), Carbon to Liquids, en http://www.worldcoal.org/coal/uses-of-coal/coal-to-liquids/, 5/2012. World Coal Institute (2012a), Coal, en http://www.worldcoal.org/coal/, 5/2012 
World Coal Institute (2012b), Coal Market \& Transportation, en

http://www.worldcoal.org/coal/market-amp-transportation/, 5/2012.

World Coal Institute (2012c), Underground Coal Gasification, en

http://www.worldcoal.org/coal/uses-of-coal/underground-coal-gasification/, 2/2012.

World Energy Council (2010), 2010 Survey of Energy Resources, Executive Summary, World Energy Council, ISBN 978-0-946121-021, London, UK, en http://www.worldenergy.org/documents/ser2010exsumsept8.pdf, 5/2012

World Energy Council (2007), 2007 Survey of Energy Resources, World Energy Council, ISBN 0-946121-26-5, London, UK, en http://www.worldenergy.org/documents/ser2007_final_online_version_1.pdf, $5 / 2012$

World Nuclear Association (2012a), World Nuclear Power Reactors \& Uranium Requirements, en http://www.world-nuclear.org/info/reactors.html, 5/2012.

World Nuclear Association (2012b), World Uranium mining, WNA, en http://www.world-nuclear.org/info/inf23.html, 5/2012

World Nuclear Association (2012c), Uranium Enrichment, WNA, en http://www.world-nuclear.org/info/inf28.html, 5/2012.

World Nuclear Association (2012d), Nuclear Power Reactors, WNA, en http://www.world-nuclear.org/info/inf32.html, 5/2012.

World Nuclear Association (2011a), Supply of Uranium, WNA, en http://www.worldnuclear.org/info/inf75.html, 5/2012.

World Nuclear Association (2011b), Uranium Mining, WNA, en http://www.worldnuclear.org/education/mining.htm, 5/2012.

World Nuclear Association (2011c), Research Reactors, WNA, en http://www.worldnuclear.org/info/inf61.html, 5/2012.

World Nuclear Association (2011d), Military Warheads as a Source of Nuclear Fuel, WNA, en http://www.world-nuclear.org/info/inf13.html, 5/2012. 
World Nuclear Association (2011e), Power Reactor Characteristics, 2011 WNA Pocket Guide, en http://www.worldnuclear.org/uploadedFiles/Pocket\%20Guide\%202009\%20Reactors.pdf, 5/2012.

World Nuclear Association (2011f), Processing of Used Nuclear Fuel, WNA, en http://www.world-nuclear.org/info/inf69.html, 5/2012.

World Wind Energy Association (2011), World Wind Energy Report 2010, WWEA, Bonn, Alemania, en http://www.wwindea.org/home/images/stories/pdfs/worldwindenergyreport2010_s.pdf, $5 / 2012$.

World Radiation Data Center (2010), WRDC Data Access, en http://wrdc-mgo.nrel.gov/html/get_data-ap.html , 5/2012.

Zhang Q.,Yoshikawa H., Ishii H., y Shimoda H. (2008), Intercomparison of the long run coefficients between the both prices of LNG and crude oil Japan, EU and USA, Journal of the Japan Institute of Energy, 87, 139-145. .

Zitter W. y Schlinder J. (2007), Crude Oil, The Supply Outlook, Energy Watch Group, EWG Series 3/2007, en http://www.energywatchgroup.org/fileadmin/global/pdf/EWG_Oilreport_10200.pdf, $11 / 2009$. 
Anexos 1

\title{
Encuesta preliminar
}

\author{
1.1. Aspectos importantes para la evaluación \\ 1.2. Formato para recolección de la información \\ 1.3. Hoja de cálculo y resultados
}


Anexo 1.1. Aspectos importantes para la evaluación de proyectos. Sector energía

- Disponibilidad de la fuente energética $(P)$

- Reservas/producción $(T)$

- Fase desarrollo tecnología (T)

- Accesibilidad a tecnología y equipos (E, P)

- Complejidad de la tecnología (T)

- Acceso seguro a la materia prima $(E, P)$ )

- Flexibilidad de la tecnología (T)

- Vida útil de la tecnología (T, E)

- Vida útil del proyecto $(T, E)$

- Tiempo de construcción

- Requerimiento de personal especializado (T. S)

- Seguridad en manejo de insumos y residuos $(A, S)$

- Existencia de protocolos de seguridad $(A, S)$

- Disposición de residuos (A)

- Daños posibles por accidentes de operación $(A, S)$

- Rendimientos $(T)$

- Balance energético (T)

- Subproductos con valor agregado (E)

- Acceso a redes de distribución (T, P)

- Acceso a financiamiento (E, P)

- $\Delta$ Producto Interno Producto/kWh producido (S)

- Inversión/kWh producido (E)

- Costo/kWh producido (E)

- CO2/ cápita $(\mathrm{A}, \mathrm{S})$

- $\mathrm{CO} 2 / \mathrm{kWh}$ producido (A)

- Valor Presente Neto (E)

- Rentabilidad (E)

- Precio de venta/unidad producto (E)

- $\mathrm{CO} 2 / \Delta$ Producto Interno Bruto (A)

- Efecto derrames o vertidos al ambiente (A)

- Contaminación ambiental regular (tierra, aguas, ruido, paisaje) (A)

- Calidad marco político y regulatorio (P)

- Consumo de agua/unidad de producto $(T, A)$

- Volumen de residuos /unidad de producto(T, A)

- Volumen de subproductos peligrosos/unidad de producto $(A)$.

- Riesgo de uso no controlado de materiales radioactivos $(P)$

- Existencia de convenios internacionales (P)
- Superficie inundada (A)

- Población desplazada (S)

- Daños al ecosistema (A)

- Pérdida de activos culturales (S)

- Producción de metano y otros gases tóxicos (A)

- Daños posibles por fractura instalaciones $(A, S)$

- Aporte a desarrollo rural $(E, S)$

- Riesgo por posible sismicidad inducida $(T, S, E)$ )

- Posibilidad de conflicto por uso de áreas comunes (S)

- Conflicto con otras actividades en la zona (S)

- Continuidad de suministro de energía $(T, E, S)$

- Vulnerabilidad de las instalaciones y equipos (E)

- Emisiones radioactivas (A)

- Extensión de terrenos requerida $(A, E)$

- Posible recuperación del terreno $(A, S)$

- Escalabilidad de la tecnología (T, E)

- Operable en forma autónoma a pequeña escala (S).

- Monto de la inversión (E)

- Riesgo de la inversión (E)

- Continuidad y calidad del servicio (S)

- Factor de carga (T, S, E)

- Tecnología de almacenamiento de energía (T)

- Eficiencias de de almacenamiento (T)

- Investigación en el área (T).

- Crecimiento de aplicaciones de las tecnologías(T)

- Efectos sobre el ecosistema (A)

- Otros efectos ambientales (S)

- Interferencia con comunicaciones, rutas aéreas, migración de aves.(S)

- Efecto sobre el ambiente por construcción y desmantelamiento de las instalaciones $(A)$

- Disponibilidad de tierras (alimentos) $(T, S, P)$

- Disponibilidad de aguas (T)

- Rendimiento del cultivo $(T, E)$

- Compatibilidad con planes (E)

- $\Delta$ Seguridad energética

- Cambio de uso de la tierra (A)

- Aceptación de la comunidad (S)

- $\Delta$ Numero de empleos (S, E)

- $\Delta$ Calidad del empleo (S, E)

- Usos múltiples del proyecto (E) 
Anexo 1.2. Formato para recolección de la información. Parte 1 y 2 . Encuesta preliminar

PREGUNTA : ¿Cuán pertinente es el criterio sometido a validación para medir el cumplimiento del objetivo al cual está asociado y cuál su importancia?

ESCALA : [1-5], donde 5 es la mejor puntuación.
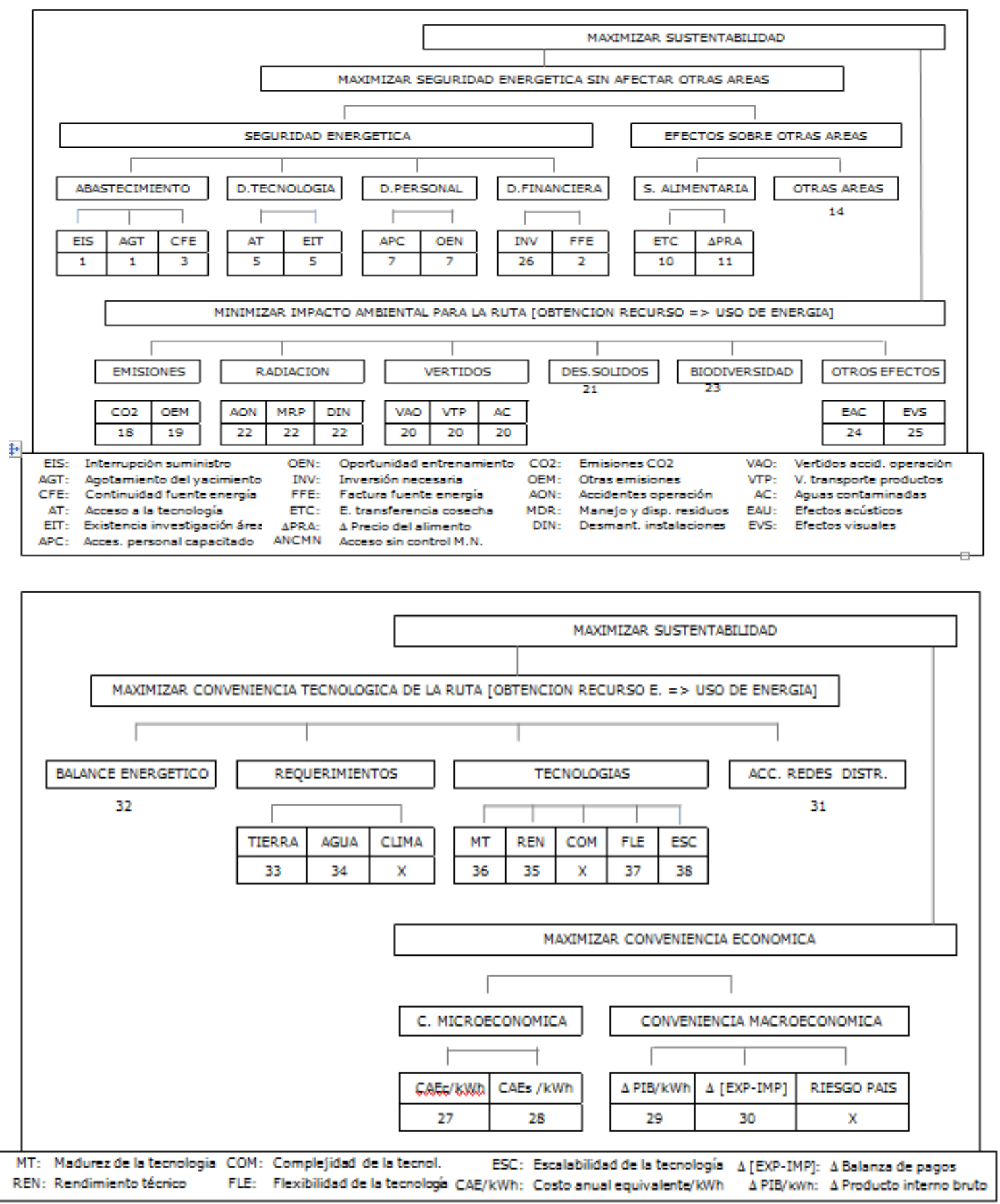
Anexo 1.2. Formato para recolección de la información. Parte 3 Encuesta preliminar

PREGUNTA : ¿Cuán pertinente es el criterio sometido a validación para medir el cumplimiento del objetivo al cual está asociado y cuál su importancia?

ESCALA : [1-5], donde 5 es la mejor puntuación.

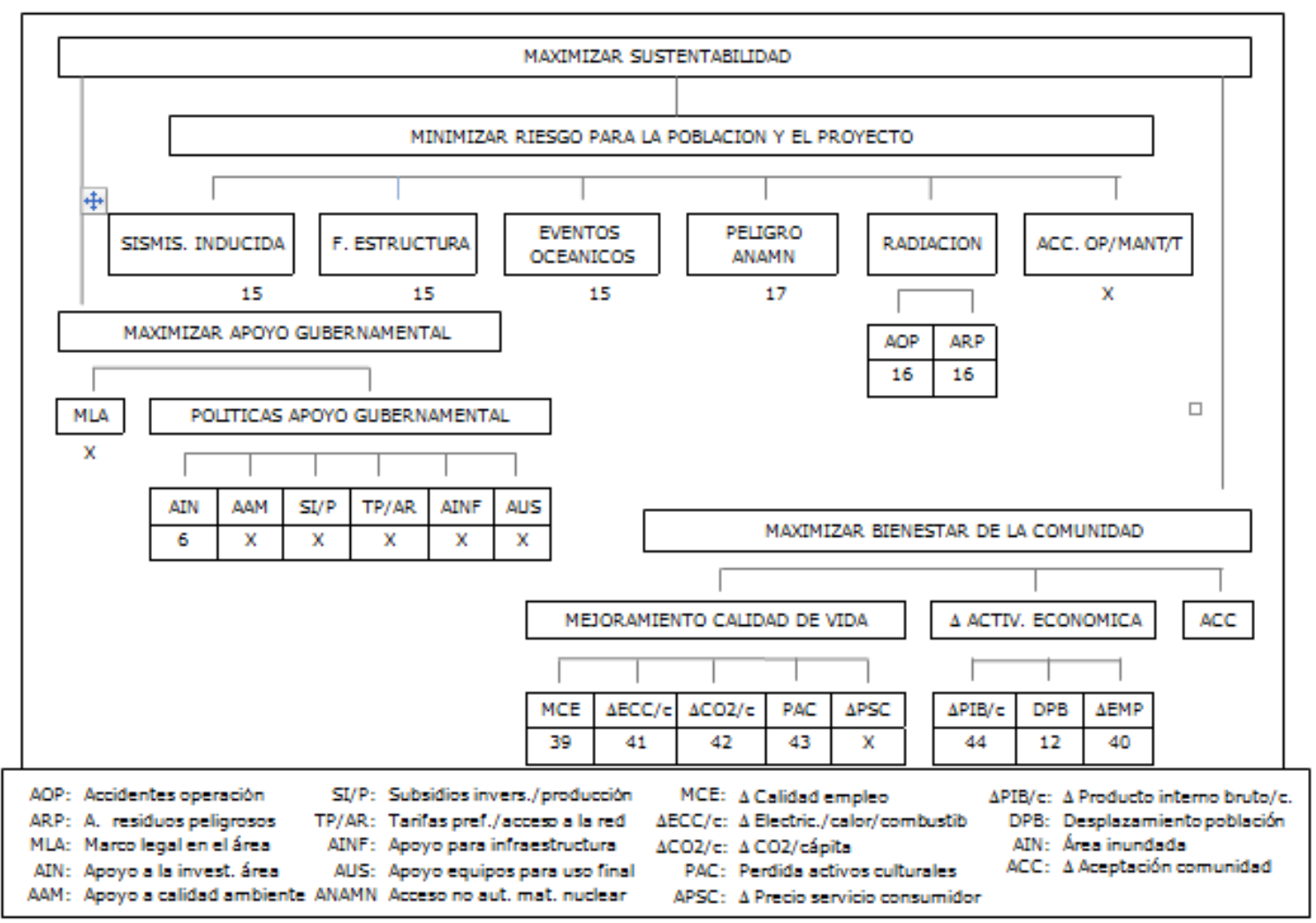


Anexo 1.3. Hoja de cálculo y resultados. Parte 1. Encuesta preliminar

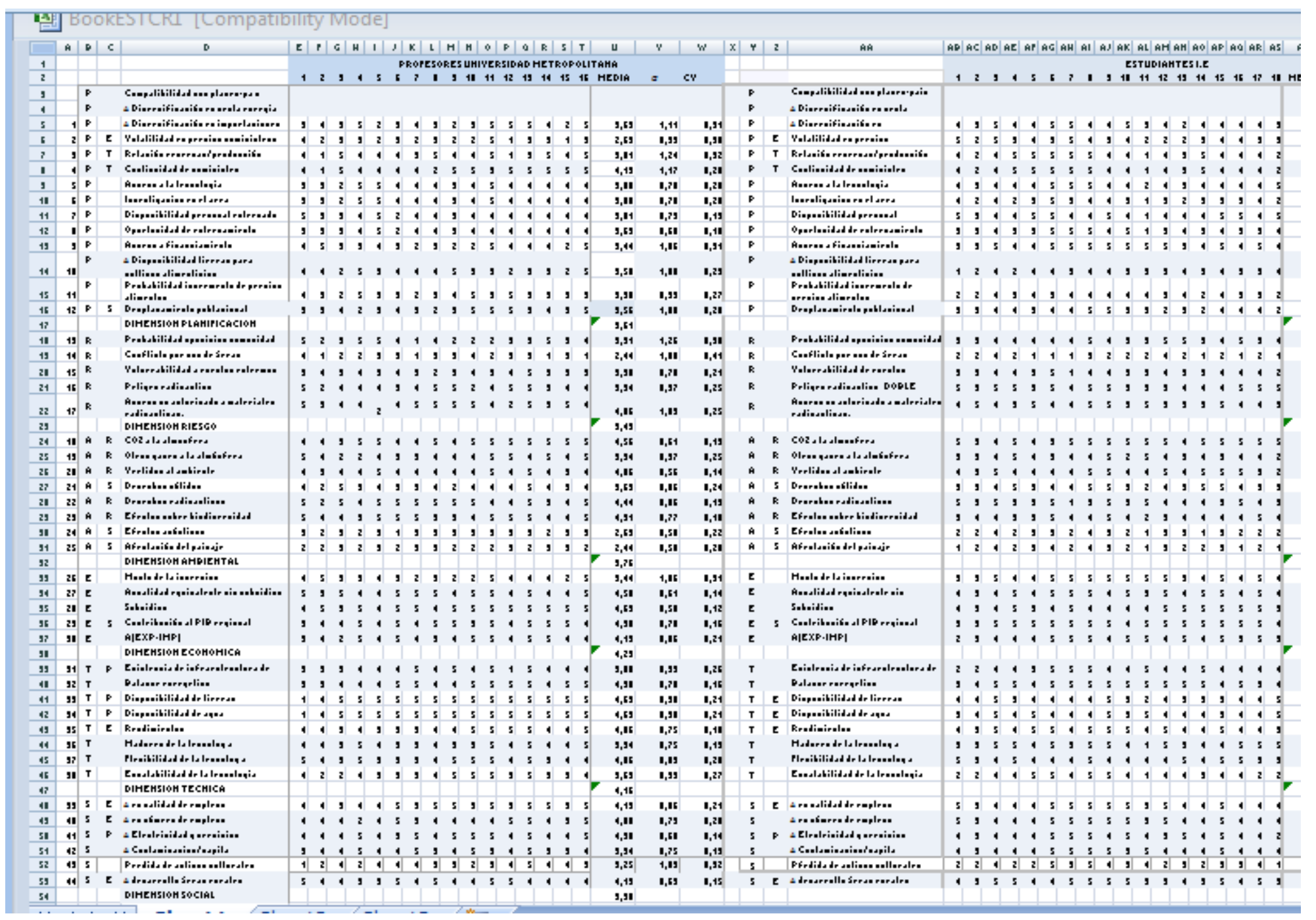


Anexo 1.3. Hoja de cálculo y resultados. Parte 2. Encuesta preliminar

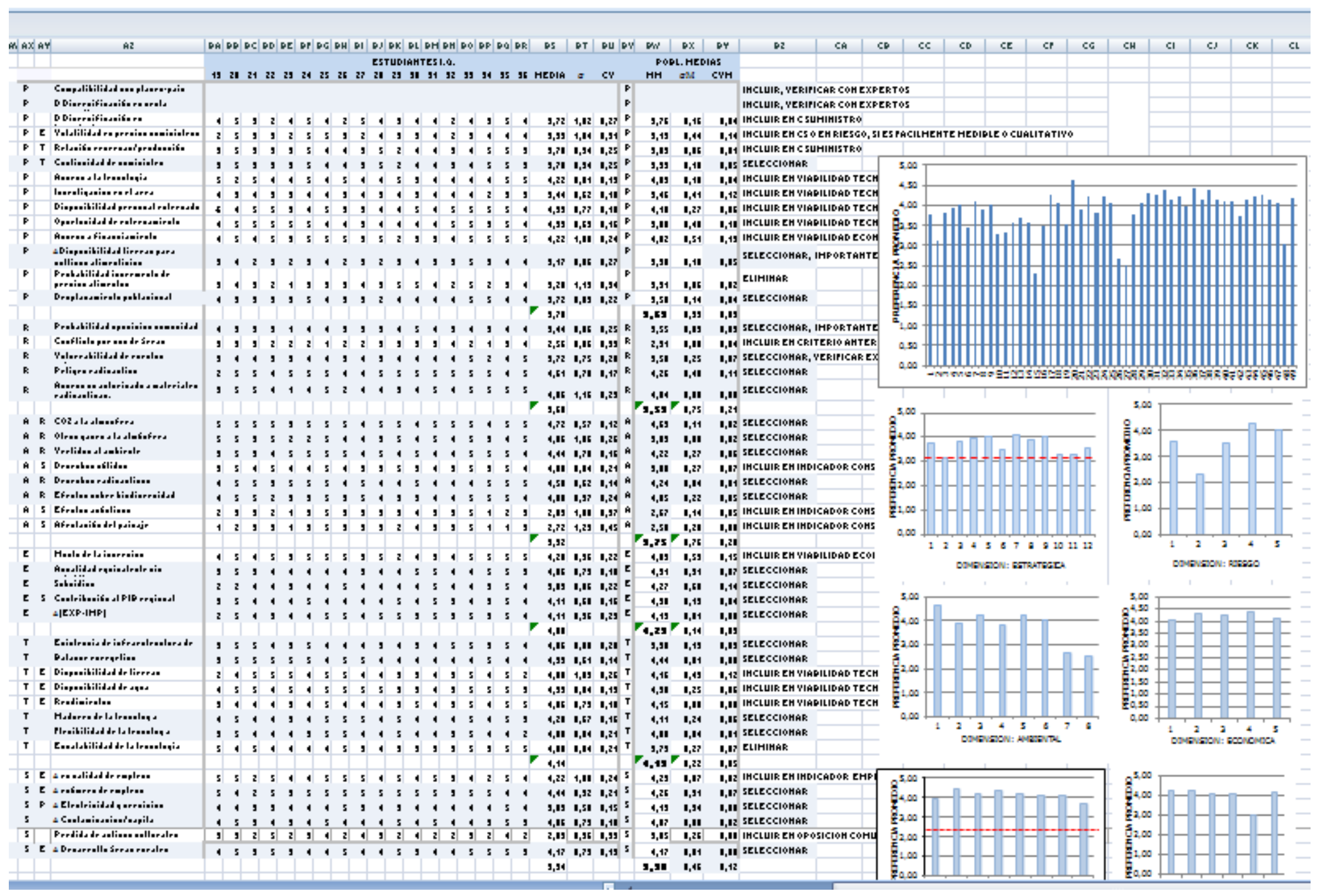




\section{Anexos 2 \\ Encuesta 1. Validación del modelo y peso de los criterios}

2.1. Encuesta 1. Matrices de juicios de los entrevistados

2.2. Pantallas Expert Choice $®$. Grupos1, $[1+2]$ y [3+4] 
Anexo 2.1. Formato para matrices de juicios de los entrevistados.Parte1. Encuesta 1 NOMBRE

Fecha

UBICACIÓN

\section{Encuesta para la determinación de la importancia relativa de los criterios.}

INSTRUCCIONES. En las próximas páginas Ud encontrara una serie de matrices cuyos espacios en blanco se le solicita que utilice para expresar su opinión sobre la importancia relativa de los criterios que se listan a mano izquierda de cada matriz. Los criterios conforman un modelo de valor jerárquico que puede utilizarse para evaluar la conveniencia de un proyecto en el sector energético. El modelo se presenta en la página siguiente.

Cada criterio está identificado por una combinación de una letra y uno o más números de acuerdo al nivel que ocupa en el diagrama. Para registrar su opinión, usted debe comparar cada par de criterios $[\mathrm{i}, \mathrm{j}$ ] del mismo nivel, responder la pregunta: ¿Con relación al criterio inmediatamente superior, cuanto más importante es el criterio i que el criterio $j$ ? , asignar un valor Cij a su respuesta de acuerdo a la escala que se muestra a continuación y copiar tal valor en el espacio en blanco que corresponda a la fila i y a la columna j de la matriz que se indica en cada caso.

ESCALA DE SAATY

\begin{tabular}{|c|c|c|}
\hline $\mathrm{Cij}$ & CONDICIÓN & EJEMPLO \\
\hline 1 & $\begin{array}{l}\text { Ambos criterios se consideran } \\
\text { igualmente importantes. }\end{array}$ & \multirow{6}{*}{$\begin{array}{l}\text { EJEMPLO: Si a su juicio, el } \\
\text { criterio i debe tener un peso } \\
\text { bastante más importante que el } \\
\text { criterio j, entonces el valor Cij } \\
\text { debe ser } \mathbf{5} \text {, pero si por el } \\
\text { contrario, el criterio j debe } \\
\text { tener un peso bastante más } \\
\text { importante que el criterio i, } \\
\text { entonces el valor que toma Cij } \\
\text { es } \mathbf{1} / \mathbf{5} \text {. }\end{array}$} \\
\hline 3 & $\begin{array}{l}\text { El criterio i es ligeramente más } \\
\text { importante que el criterio j. }\end{array}$ & \\
\hline 5 & $\begin{array}{l}\text { El criterio i es bastante más importante } \\
\text { que el criterio j. }\end{array}$ & \\
\hline 7 & $\begin{array}{l}\text { El criterio i es mucho más importante } \\
\text { que el criterio j. }\end{array}$ & \\
\hline 9 & $\begin{array}{l}\text { El criterio i es incuestionablemente } \\
\text { más importante que el criterio j. }\end{array}$ & \\
\hline $2,4,6,8$ & Valores intermedios & \\
\hline
\end{tabular}


PROPUESTA DE MODELO DE VALOR

\begin{tabular}{|c|c|c|}
\hline CRIT. NIVEL 1 & CRITERIOS NIVEL 2 & CRITERIOS NIVEL 3 \\
\hline C1 Técnicos & 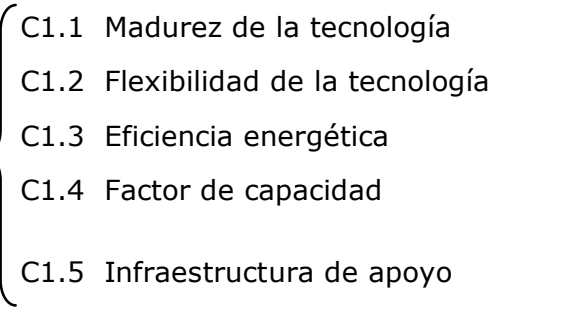 & $\begin{array}{l}\text { C1.5.1 Infraestructura física y logística } \\
\text { C1.5.2 "Saber-como" local }\end{array}$ \\
\hline C2 Económicos & 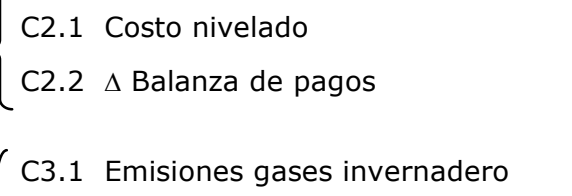 & \\
\hline C3 Ambientales & $\begin{array}{l}\text { C3.2 Emisiones gases no radioactivos } \\
\text { C3.3 Residuos peligrosos } \\
\text { C3.4 Uso de la tierra }\end{array}$ & 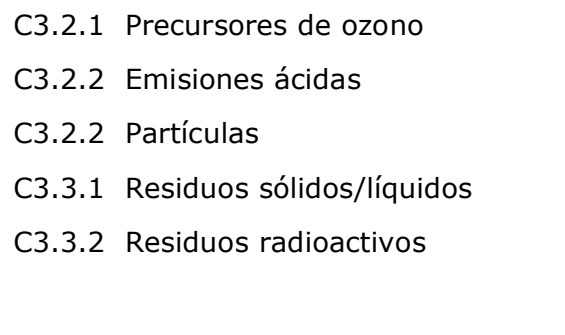 \\
\hline C4 Sociales & $\begin{array}{l}\text { C4.1 Aceptación de la comunidad } \\
\text { C4.2 Calidad de vida }\end{array}$ & $\begin{array}{l}\text { C4.2.1 Creación de empleo local } \\
\text { C4.2.2 } \Delta \text { Salarios } \\
\text { C4.2.3 } \Delta \text { Déficit de energía }\end{array}$ \\
\hline C5 Estratégicos & C5.1 $\Delta$ Seguridad energética & $\begin{array}{l}\text { C5.1.1 } \Delta \text { Diversidad cesta energías } \\
\text { C5.2.1 Seguridad de suministro }\end{array}$ \\
\hline C6 Riesgo & $\begin{array}{l}\text { C6.1 Riesgo ante eventos extremos } \\
\text { C6.2 Uso ilícito de material radioactivo }\end{array}$ & \\
\hline
\end{tabular}


1. Para el grupo CRITERIOS TÉCNICOS (C1), rellene los cuadros en color blanco con el Cij que corresponda.

\begin{tabular}{|c|c|c|c|c|c|c|c|}
\hline \multicolumn{2}{|r|}{ CRITERIOS TÉCNICOS } & $\mathrm{C} 1.1$ & $\mathrm{C} 1.2$ & $\mathrm{C} 1.3$ & $\mathrm{C} 1.4$ & $\mathrm{C} 1.5$ & \multirow{6}{*}{$\begin{array}{c}\text { Responda: } \\
\text { Cuanto más } \\
\text { importante es } \\
\text { C1.1 que C1.2? Y } \\
\text { que C1.3? y así } \\
\text { sucesivamente } \\
\text { hasta completar } \\
\text { los espacios? }\end{array}$} \\
\hline $\mathrm{C} 1.1$ & Madurez de la tecnología & 1 & & & & & \\
\hline $\mathrm{C} 1.2$ & Flexibilidad de tecnología & & 1 & & & & \\
\hline C1.3 & Eficiencia energética & & & 1 & & & \\
\hline $\mathrm{C} 1,4$ & Factor de capacidad & & & & 1 & & \\
\hline $\mathrm{C} 1.5$ & Infraestructura de apoyo & & & & & 1 & \\
\hline
\end{tabular}

2. Para el subgrupo INFRAESTRUCTURA DE APOYO ( $\mathrm{C} 1.4)$, rellene los cuadros en color blanco con el $\mathrm{Ci}, \mathrm{j}$ que corresponda.

\begin{tabular}{|l|l|c|c|c|}
\hline \multicolumn{2}{|c|}{ INFRAESTRUCTURA DE APOYO } & C1.4.1 & C6.1.2 & \multirow{2}{*}{$\begin{array}{c}\text { Responda : Cuanto más importante } \\
\text { es C1.4.1 que C1.4.2? }\end{array}$} \\
\cline { 1 - 3 } C1.5.1 & Infraestructura física y logística & 1 & & 1 \\
\hline
\end{tabular}

3. Para el grupo CRITERIOS ECONómicos (C2), rellene los cuadros en color blanco con el Cij que corresponda.

\begin{tabular}{|c|c|c|c|c|}
\hline \multicolumn{2}{|r|}{ CRITERIOS ECONÓMICOS } & $\mathrm{C} 2.1$ & $\mathrm{C} 2.2$ & \multirow{3}{*}{$\begin{array}{l}\text { Responda : Cuanto más importante es } \\
\text { C2.1 que C2.2? Y que C2.3? C2.2 que } \\
\text { C2.3? }\end{array}$} \\
\hline $\mathrm{C} 2.1$ & Costo nivelado & 1 & & \\
\hline $\mathrm{C} 2.3$ & $\Delta$ Balanza de pagos & & 1 & \\
\hline
\end{tabular}

4. Para el grupo CRITERIOS AMBIENTALES (C3), rellene los cuadros en color blanco con el Cij que corresponda.

\begin{tabular}{|c|c|c|c|c|c|c|}
\hline \multicolumn{2}{|r|}{ CRITERIOS AMBIENTALES } & C3.1 & $\mathrm{C} 3.2$ & C3.3 & C3.4 & \multirow{5}{*}{$\begin{array}{l}\text { Responda: Cuánto más } \\
\text { importante es C3.1 que } \\
\text { C3.2? Y que C3.3? y que } \\
\text { C3.4? C3.2 que C3.3? y } \\
\text { así sucesivamente hasta } \\
\text { completar los espacios? }\end{array}$} \\
\hline C3.1 & Emisiones gases invernadero & 1 & & & & \\
\hline C3.2 & Emisiones otros gases no radioactivos & & 1 & & & \\
\hline C3.3 & Residuos peligrosos & & & 1 & & \\
\hline C3.4 & Uso de la tierra & & & & 1 & \\
\hline
\end{tabular}

5. Para el subgrupo EMISIONES OTROS GASES NO RADIOACTIVOS (C3.2), rellene los cuadros en color blanco con el $\mathrm{Ci}, \mathrm{j}$ que corresponda.

\begin{tabular}{|c|c|c|c|c|c|}
\hline \multicolumn{2}{|c|}{ EMISIONES GASES NO RADIOACTIVOS } & C3.2.1 & C3.2.2 & C3.2.3 & \multirow{4}{*}{$\begin{array}{c}\text { Responda : Cuanto más } \\
\text { importante es C3.2.1 } \\
\text { que C3.2.2? Y que } \\
\text { C3.2.3? 3.2.2 que } \\
\text { C3.2.3? }\end{array}$} \\
\hline C3.2.1 & Propulsores de ozono & 1 & & & \\
\hline C3.2.2 & Emisiones ácidas & & 1 & & \\
\hline C3.2.3 & Partículas & & & 1 & \\
\hline
\end{tabular}

6. Para el subgrupo RESIDUOS PELIGROSOS (C3.3), rellene los cuadros en color blanco con el Ci,j que corresponda.

\begin{tabular}{|c|c|c|c|c|}
\hline \multicolumn{2}{|r|}{ RESIDUOS } & C3.3.1 & C3.3.2 & \multirow{3}{*}{$\begin{array}{c}\text { Responda : Cuanto más importante } \\
\text { es C3.3.1 que C3.3.2? }\end{array}$} \\
\hline C3.3.1 & Residuos sólidos & 1 & & \\
\hline C3.3.2 & Residuos radioactivos & & 1 & \\
\hline
\end{tabular}


7. Para el grupo CRITERIOS SOCIALES (C4), rellene los cuadros en color blanco con el Cij que corresponda.

\begin{tabular}{|c|c|c|c|c|}
\hline \multicolumn{2}{|r|}{ CRITERIOS SOCIALES } & C4.1 & $\mathrm{C} 4.2$ & \multirow{3}{*}{$\begin{array}{l}\text { Responda : Cuanto más importante es } \\
\text { C4.1 que C4.2? }\end{array}$} \\
\hline C4.1 & Aceptación de la comunidad & 1 & & \\
\hline $\mathrm{C} 4.2$ & Calidad de vida & & 1 & \\
\hline
\end{tabular}

8. Para el subgrupo CALIDAD DE VIDA (C4.2), rellene los cuadros en color blanco con el Ci,j que corresponda.

\begin{tabular}{|c|c|c|c|c|c|}
\hline \multicolumn{2}{|r|}{ CALIDAD DE VIDA } & C4.2.1 & C4.2.2 & $\mathrm{C} 4.2 .3$ & \multirow{4}{*}{$\begin{array}{c}\text { Responda : Cuanto más } \\
\text { importante es C4.2.1 } \\
\text { que C4.2.2? Y que } \\
\text { C4.2.3? C4.2.2 que } \\
\text { C4.2.3? }\end{array}$} \\
\hline C4.2.1 & Creación de empleo local & 1 & & & \\
\hline C4.2.2 & $\Delta$ Salarios & & 1 & & \\
\hline C4.2.3 & $\Delta$ Déficit energía & & & 1 & \\
\hline
\end{tabular}

9. Para el grupo de CRITERIOS ESTRATÉGicos (C5), rellene los cuadros en color blanco con el Cij que corresponda.

\begin{tabular}{|c|c|c|c|c|}
\hline \multicolumn{2}{|r|}{ CRITERIOS ESTRATÉGICOS } & C5.1 & C5.2 & \multirow{3}{*}{$\begin{array}{l}\text { Responda : Cuanto más importante es } \\
\text { C5.1 que C5.2? }\end{array}$} \\
\hline C5.1 & Seguridad energética & 1 & & \\
\hline C5.2 & Compatibilidad planes-nación & & 1 & \\
\hline
\end{tabular}

10. Para el subgrupo SEGURIDAD ENERGÉTICA (C5.1), rellene los cuadros en color blanco con el Cij que corresponda.

\begin{tabular}{|c|c|c|c|c|}
\hline \multicolumn{2}{|r|}{ SEGURIDAD ENERGÉTICA } & C5.1.1 & C5.1.2 & \multirow{3}{*}{$\begin{array}{c}\text { Responda : Cuanto más importante } \\
\text { es C5.1.1 que C5.1.2? }\end{array}$} \\
\hline C5.1.1 & Diversidad de cesta energías & 1 & & \\
\hline C5.1.2 & Seguridad de suministro & & 1 & \\
\hline
\end{tabular}

11. Para el grupo CRITERIOS DE RIESGO (C6), rellene los cuadros en color blanco con el Cij que corresponda.

\begin{tabular}{|l|l|c|c|c|}
\hline \multicolumn{2}{|c|}{ CRITERIOS DE RIESGO } & C6.1 & C6.2 & \multirow{2}{*}{$\begin{array}{c}\text { Responda : Cuanto más importante es } \\
\text { C6.1 que C6.2?. }\end{array}$} \\
\cline { 1 - 2 } C6.1 & Riesgo ante eventos extremos & 1 & & 1 \\
\cline { 1 - 2 } C6.2 & Uso ilícito de material radioactivo & & 1 & \\
\hline
\end{tabular}

12. Para cumplir con el OBJETIVO PRINCIPAL, rellene los cuadros en color blanco con el Cij que corresponda.

\begin{tabular}{|c|c|c|c|c|c|c|c|c|}
\hline & OBJETIVO PRINCIPAL & $\mathrm{C} 1$ & $\mathrm{C} 2$ & $\mathrm{C} 3$ & $\mathrm{C} 4$ & C5 & $\mathrm{C} 6$ & \multirow{7}{*}{$\begin{array}{c}\text { Responda: } \\
\text { Cuanto más } \\
\text { importante es C1 } \\
\text { que C2? Y que } \\
\text { C3? Y que C4, C5 } \\
\text { y C6? C2 que C3? } \\
\text { y así } \\
\text { sucesivamente } \\
\text { hasta completar } \\
\text { los espacios? }\end{array}$} \\
\hline $\mathrm{C} 1$ & Criterios técnicos & 1 & & & & & & \\
\hline $\mathrm{C} 2$ & Criterios económicos & & 1 & & & & & \\
\hline $\mathrm{C} 3$ & Criterios ambientales & & & 1 & & & & \\
\hline $\mathrm{C} 4$ & Criterios sociales & & & & 1 & & & \\
\hline $\mathrm{C} 5$ & Criterios estratégicos & & & & & 1 & & \\
\hline C6 & Criterios de riesgo & & & & & & 1 & \\
\hline
\end{tabular}


Anexo 2.2. Pantalla de resultados Expert Choice $®$. Grupo 1. Encuesta 1

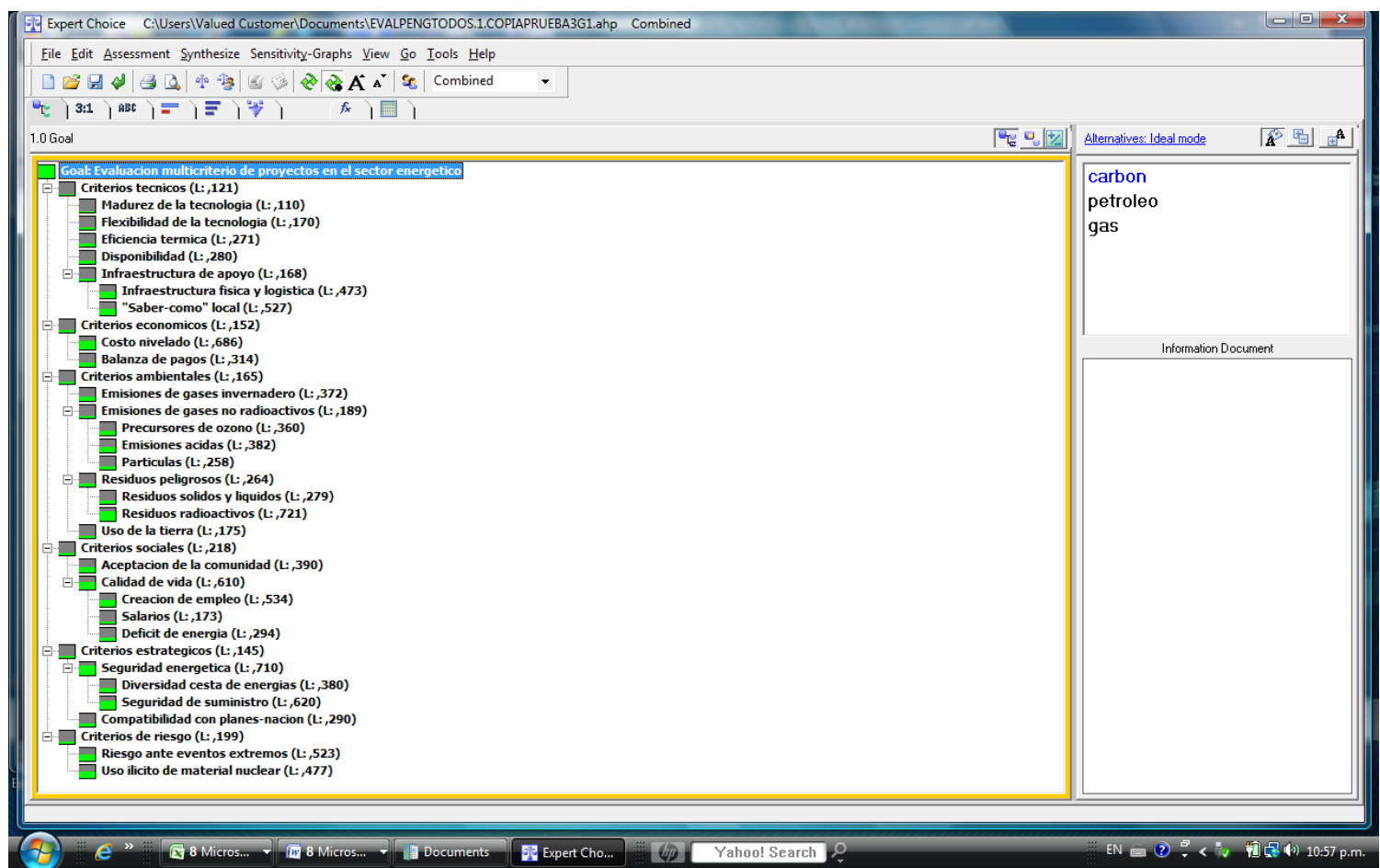

Anexo 2.2. Pantalla de resultados Expert Choice. Grupo [1+2]. Encuesta 1

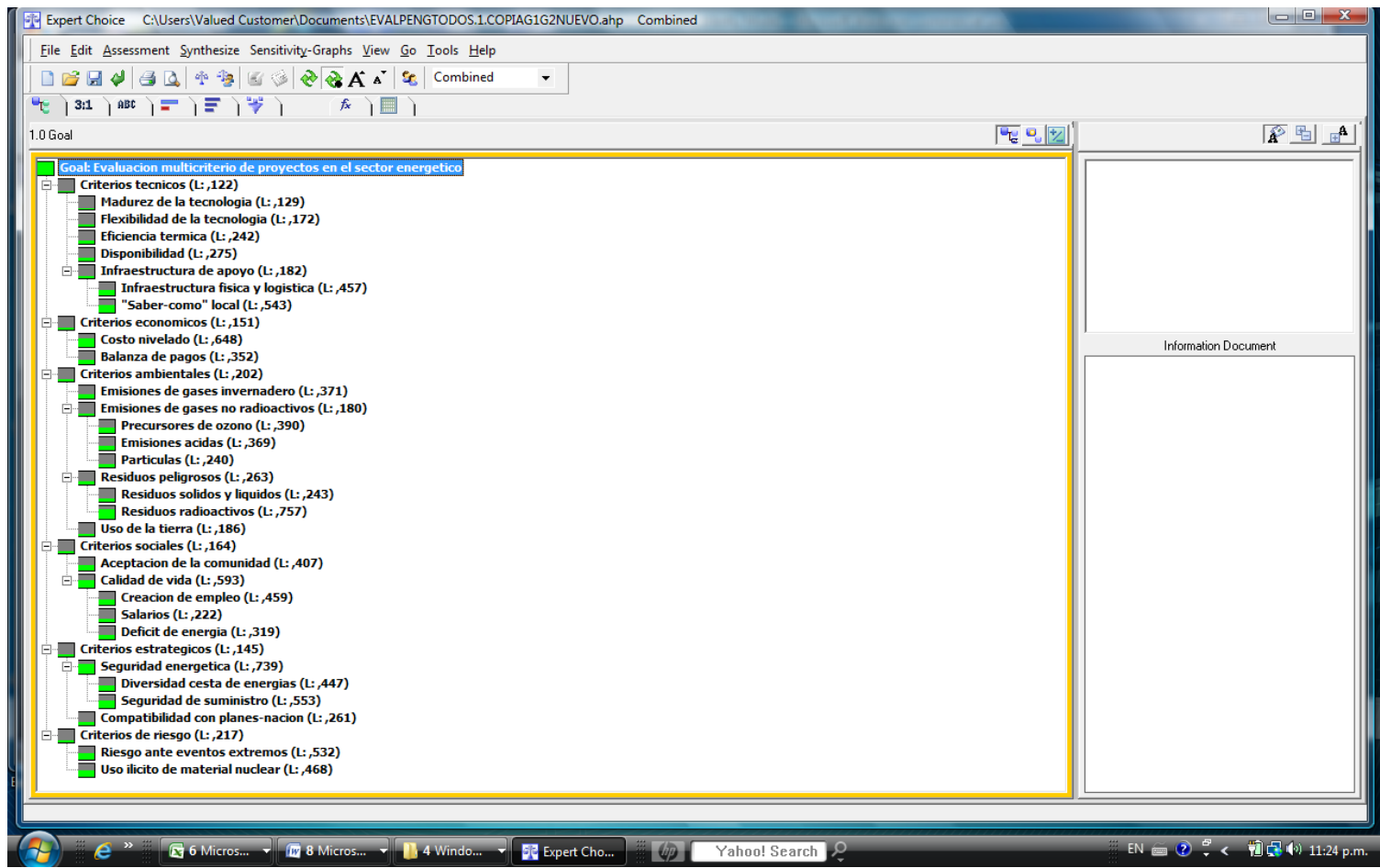


Anexo 2.2. Pantalla de resultados Expert Choice $®$. Grupo [3+4]. Encuesta 1

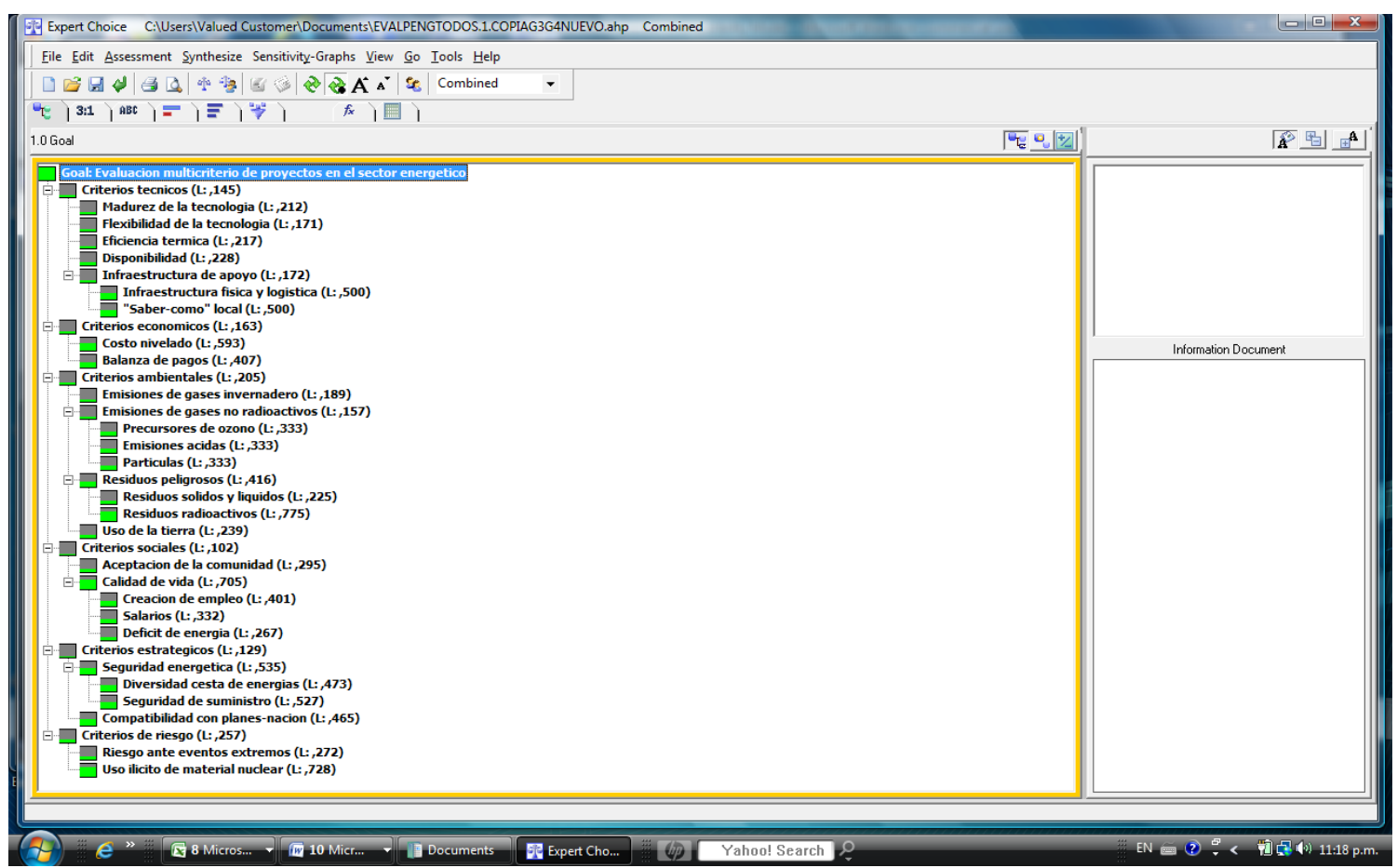

GRUPO 1 (G1). Veinte entrevistas, 16 encuestas llenas. Profesionales y/o académicos de amplia trayectoria en una o más de las siguientes áreas: energía, energía, energías renovables, generación y distribución de energía eléctrica, economía, finanzas, planificación y políticas públicas, ambiente, proyectos y métodos de análisis multicriterio.

GRUPO 2 (G2): Ocho encuestas. Ingenieros venezolanos con postgrado en el sector privado de la economía, radicados en Venezuela o fuera de ella. Experiencia entre 7 años y 12 años en formulación, evaluación multicriterio, control de ejecución, procura y/o gerencia de proyectos.

GRUPO 3 y $4(G 3+G 4)$ : Cuarenta y dos encuestas. Dos grupos de estudiantes cursando el último año de Ingeniera en la Universidad Metropolitana, Caracas, Venezuela relacionados con las áreas de energía y evaluación de proyectos. 


\section{Anexos 3}

\section{Encuesta 2. Aplicación del modelo}

3.1. Hoja para el cálculo de los coeficientes de robustez 3.2. Hoja para consolidación de los coeficientes de robustez

3.3. Hoja de cálculo para SOLVER. Casos 25 y 26

3.4. Hoja de cálculo para SOLVER. Caso base 
Anexo 3.1. Hoja para el cálculo de los coeficientes de robustez por entrevistado y alternativa. Parte1 Encuesta 2
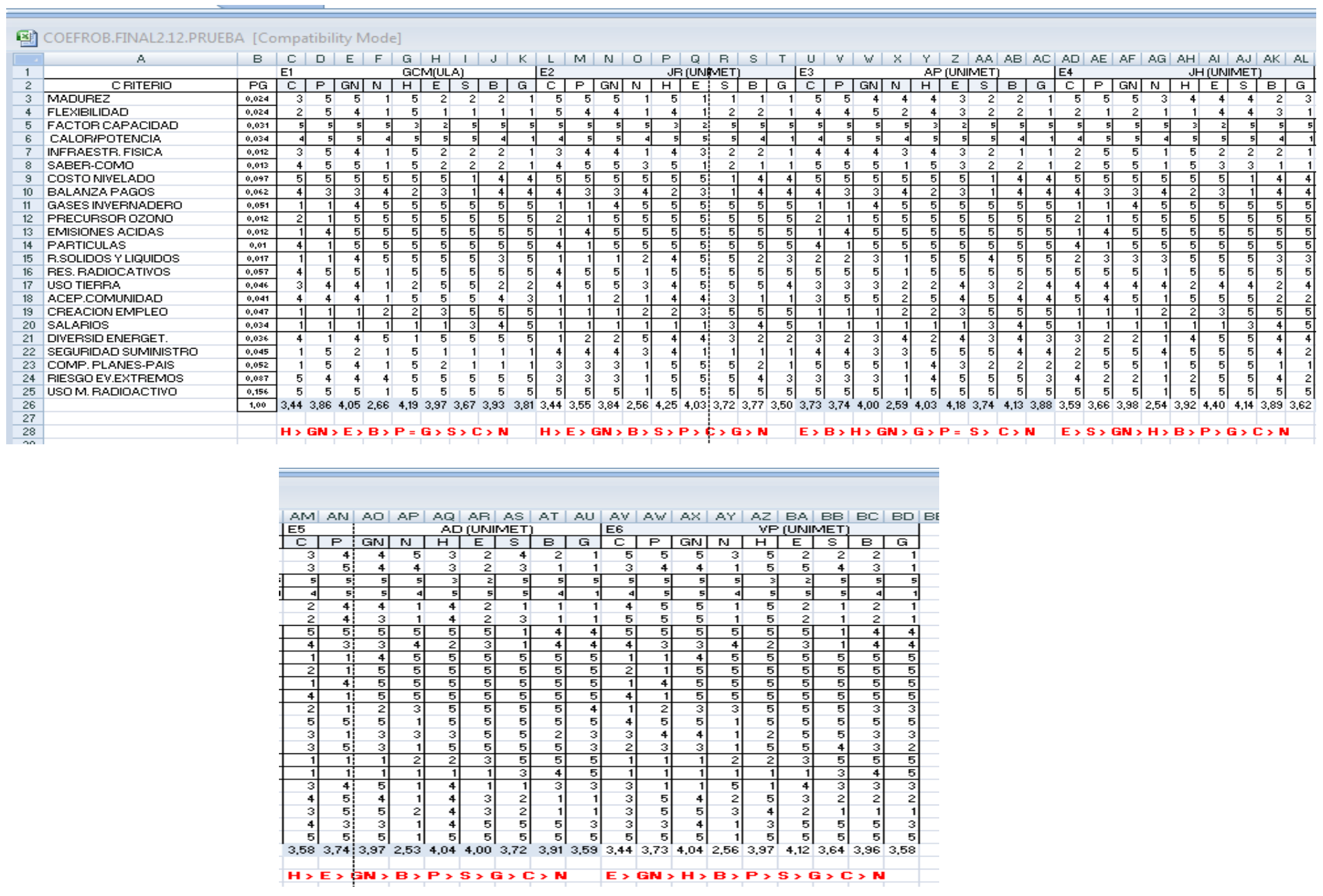

UNIVERSIDAD POLITÉCNICA DE VALENCIA. TESIS DOCTORAL. Violeta Parodi 
Anexo 3.1. Hoja para el cálculo de los coeficientes de robustez por entrevistado y alternativa. Parte 2. Encuesta 2

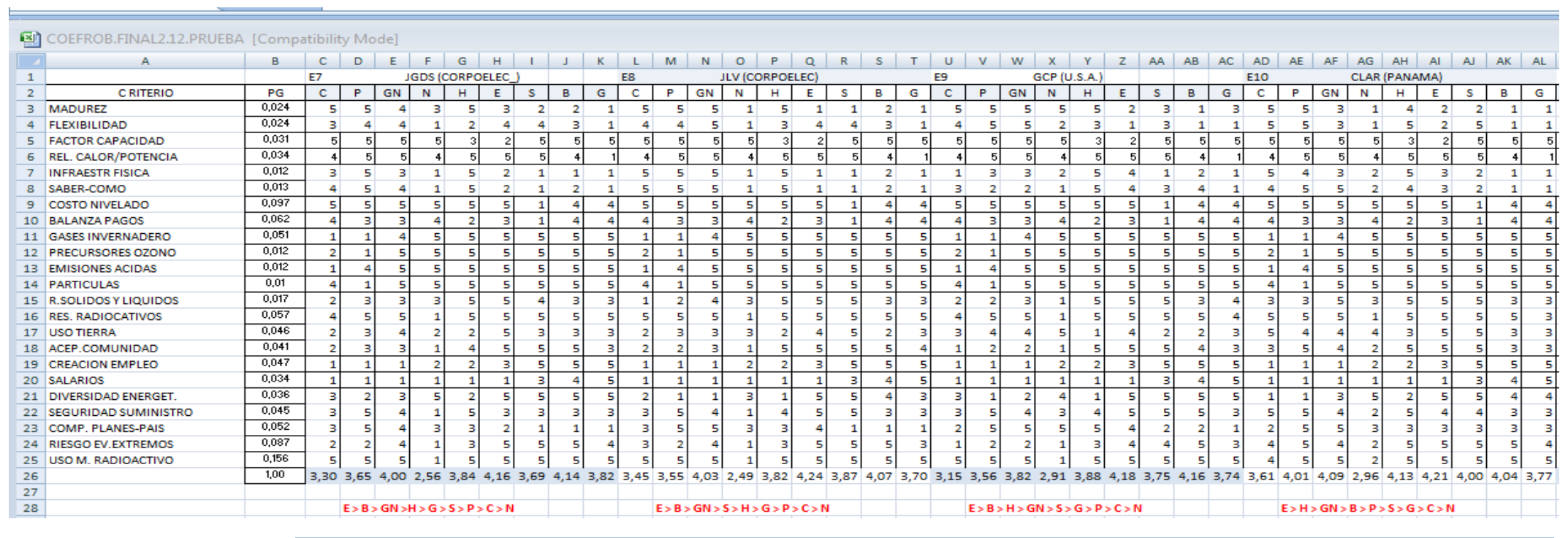

\begin{tabular}{|l|l|l|l|l|l|l|l|l|l|l|l|l|l|l|l|l|l|l|l|l|l|l|l|l|l|l|}
\hline AM & $A N$ & $A O$ & $A P$ & $A Q$ & $A R$ & $A S$ & $A T$ & $A U$ & $A V$ & $A W$ & $A X$ & $A Y$ & $A Z$ & $B A$ & $B B$ & $B C$ & $B D$ & $B E$ & $B F$ & $B G$ & $B H$ & $B I$ & $B J$ & $B K$ & $B L$ & $B M$ \\
\hline
\end{tabular}

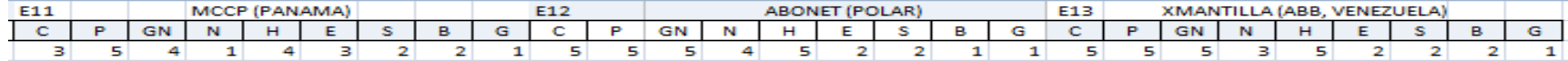

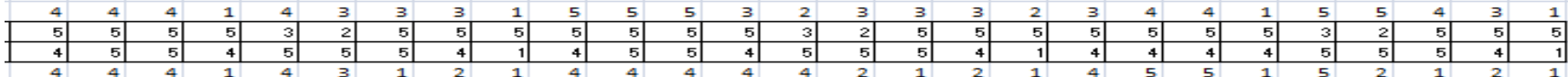

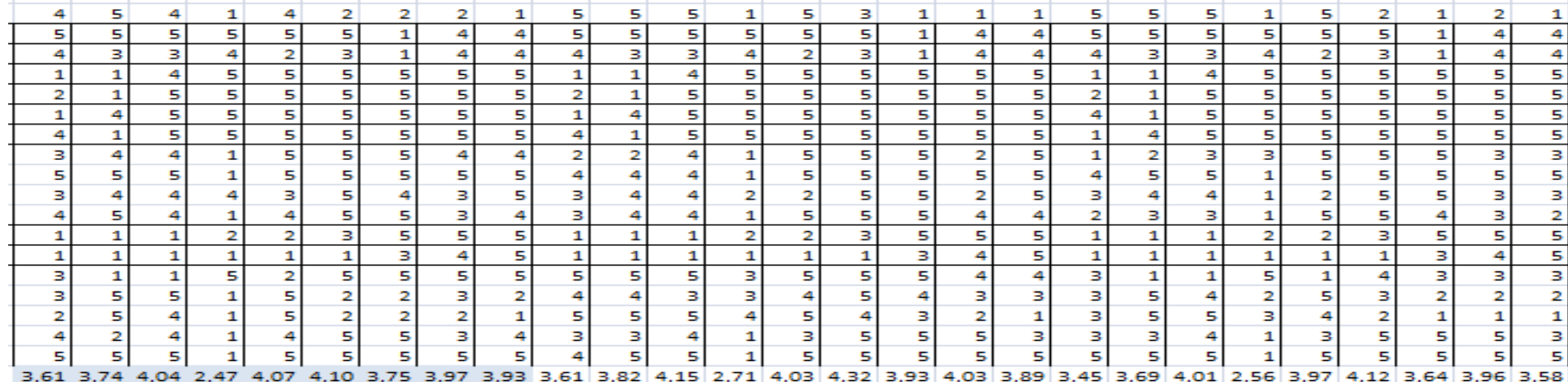


Anexo 3.2. Hoja para consolidación de los coeficientes de robustez por alternativa

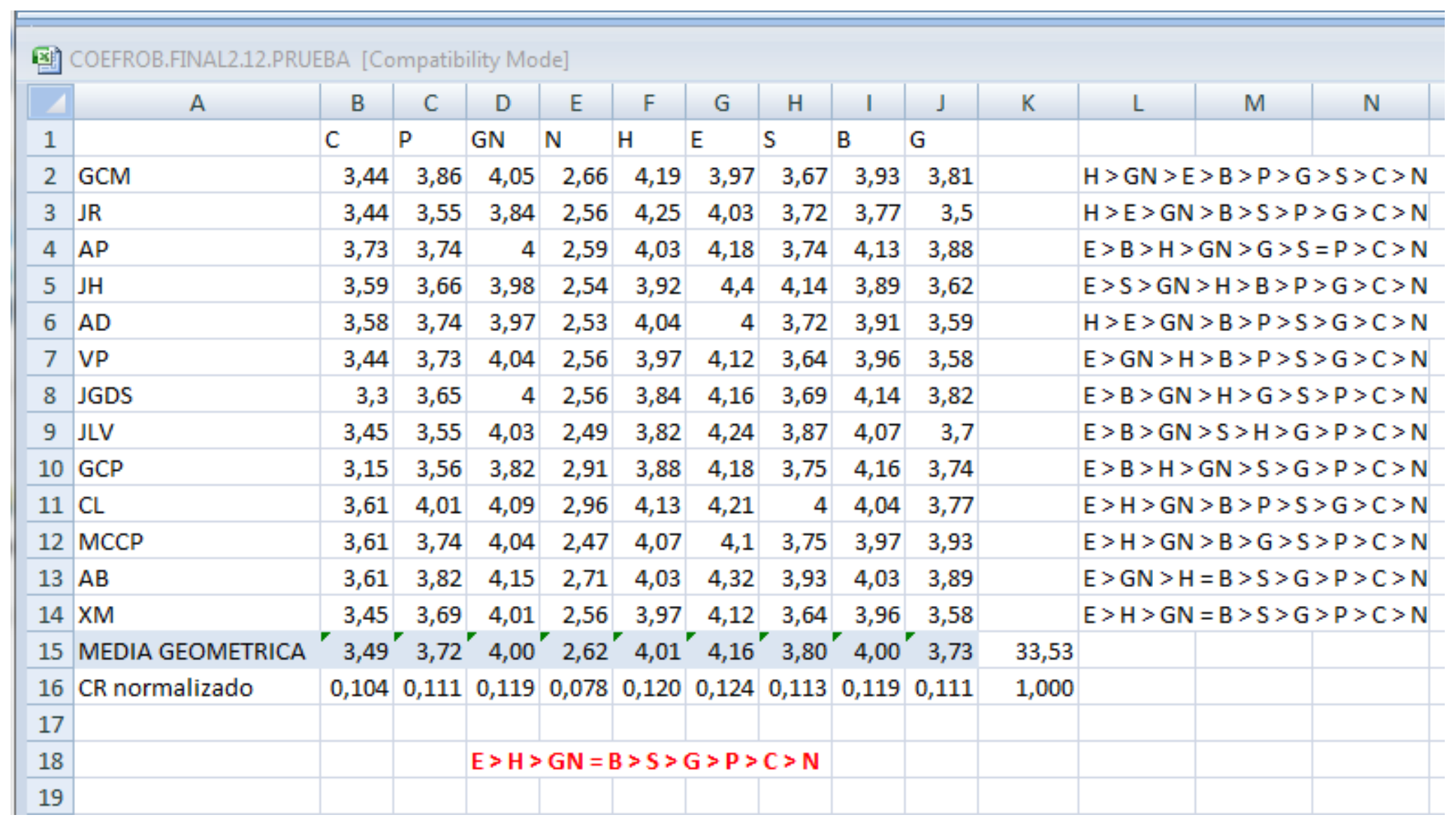




\section{Anexo 3.3. Hoja de cálculo para SOLVER. Caso 25}

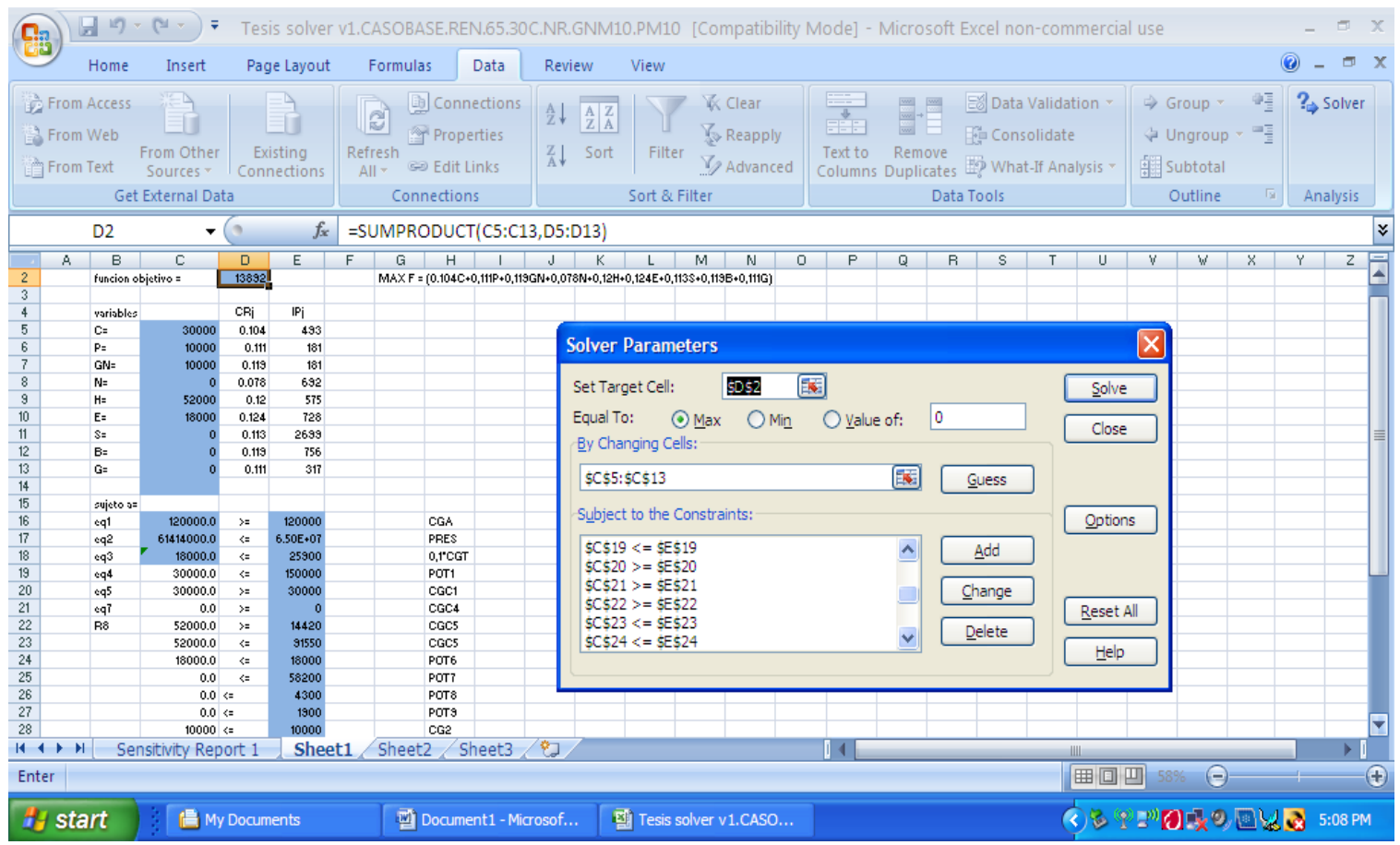

Anexo 3.3. Hoja de calculo para SOLVER. Caso 26

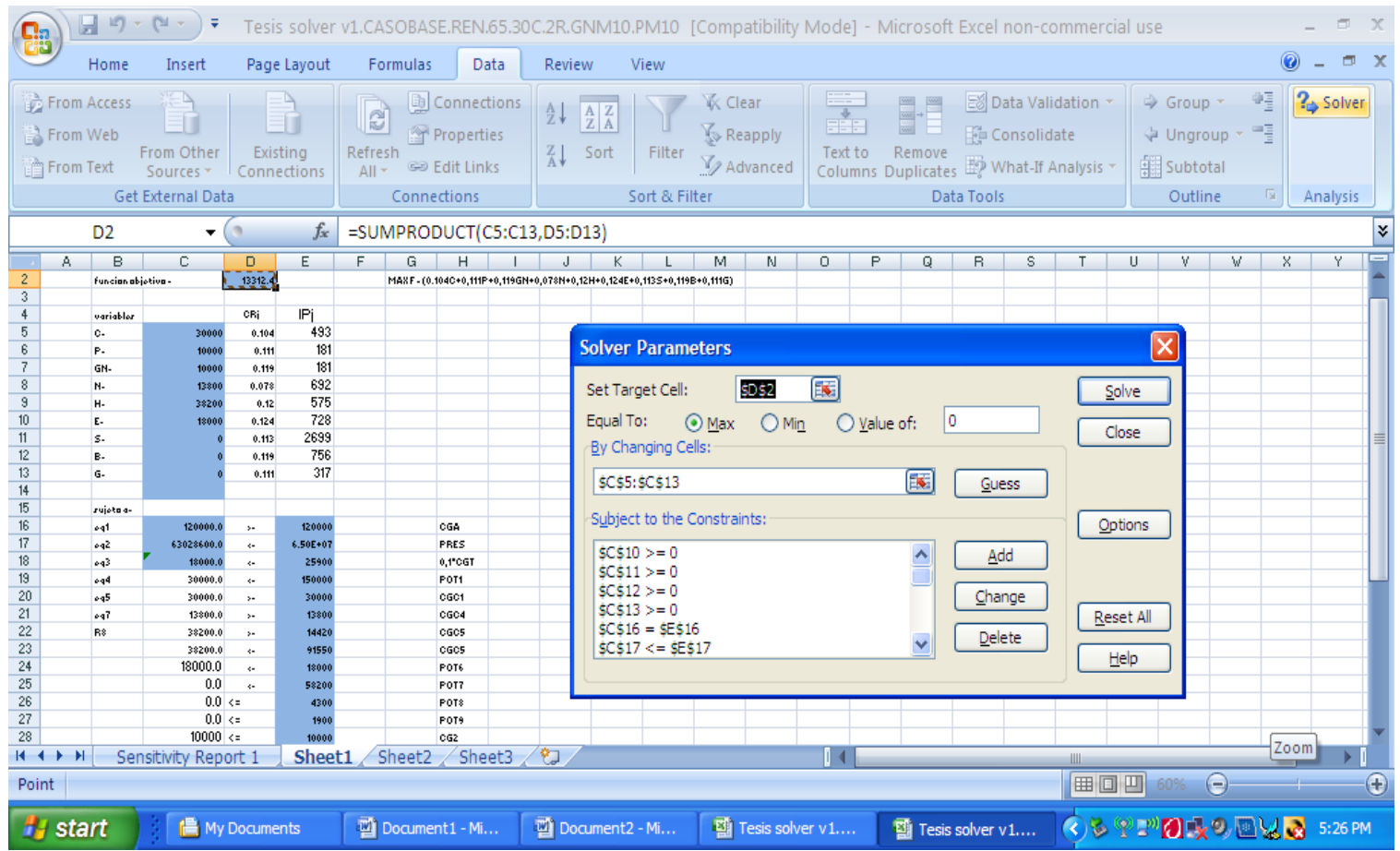


Anexo 3.4. Hoja de cálculo para SOLVER. Caso base

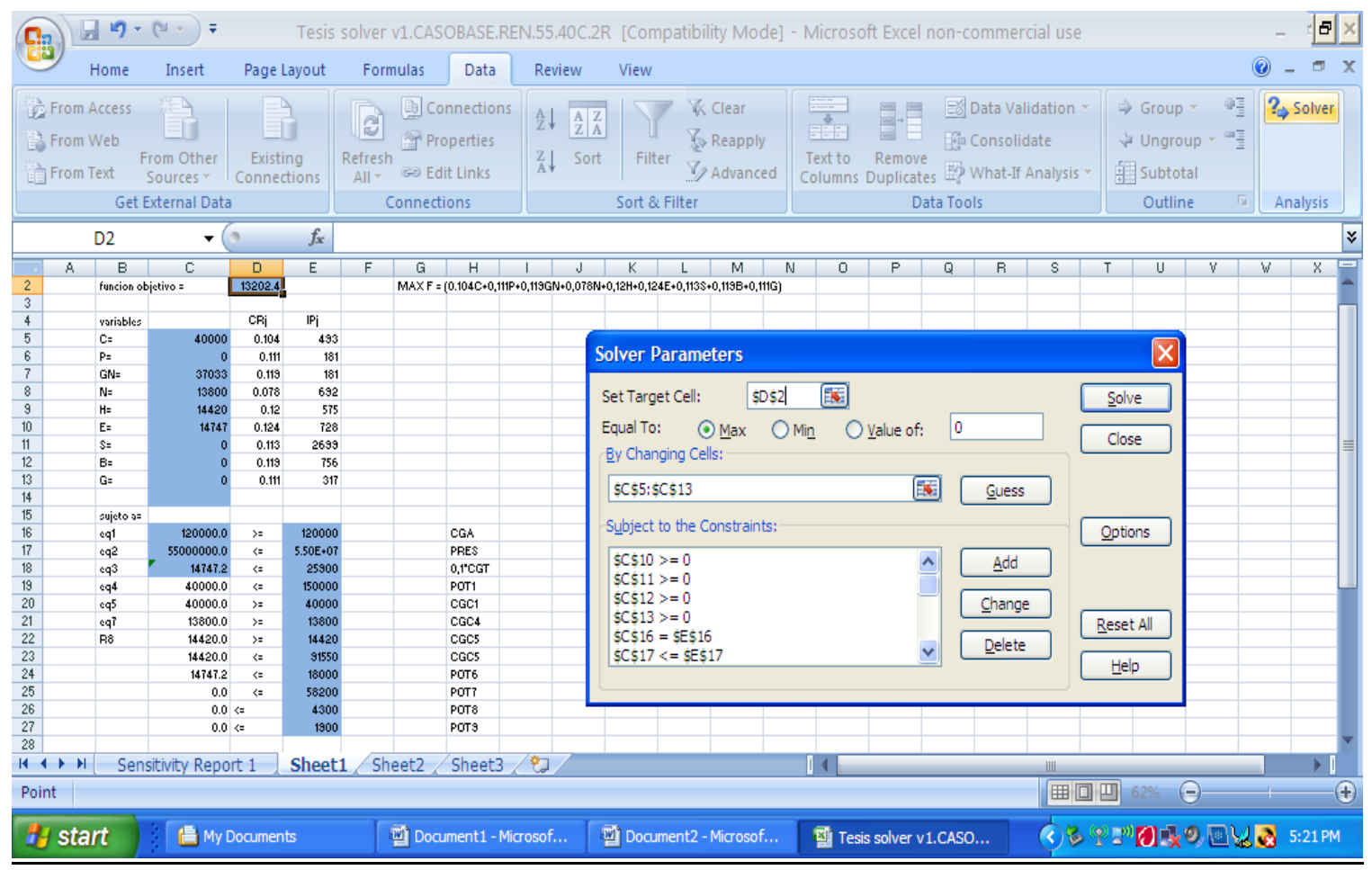

PERIODO: 2013-2025

CASO BASE

CAP. TOTAL A INSTALAR $=120.000 \mathrm{GWh} / /$ año PRESUPUESTO $\leq 55$ mil millones US\$

CAP. BASADA EN CARBÓN $\geq 40.000$ GWh/año

C. GENERACIÓN NUCLEAR $\geq 13.800 \mathrm{GWh} /$ año

C. GENERAC. HIDRÁULICA $\geq 14420 \mathrm{GWh} /$ año

PERIODO: 2013-2025

CASO 25

CAP. TOTAL A INSTALAR $=120.000 \mathrm{GWh} / /$ año PRESUPUESTO $\leq 65$ mil millones US\$

CAP. BASADA EN CARBÓN $\geq 30.000 \mathrm{GWh}$ /año

C. BASADA EN PETRÓLEO $\geq 10.000 \mathrm{GWh} /$ año

CAPAC. BASADA EN GAS $\geq 10.000 \mathrm{GWh}$ /año

C. GENERAC. HIDRÁULICA $\geq 14420 \mathrm{GWh} /$ año

PERIODO: 2013-2025

CASO 26

CAP. TOTAL A INSTALAR $=120.000 \mathrm{GWh} / /$ año

PRESUPUESTO $\leq 65$ mil millones US\$

CAP. BASADA EN CARBÓN $\geq 30.000 \mathrm{GWh} /$ año

C. BASADA EN PETRÓLEO $\geq 10.000 \mathrm{GWh} /$ año

CAPAC. BASADA EN GAS $\geq 10.000 \mathrm{GWh}$ /año

C. GENERACIÓN NUCLEAR $\geq 13.800 \mathrm{GWh}$ /año

C. GENERAC. HIDRÁULICA $\geq 14420 \mathrm{GWh} /$ año 